Göttinger Beiträge zum Alten Orient Band 3

\title{
Dahlia Shehata
}

\section{Musiker und ihr vokales Repertoire}

Untersuchungen zu Inhalt und Organisation von Musikerberufen und Liedgattungen in altbabylonischer Zeit

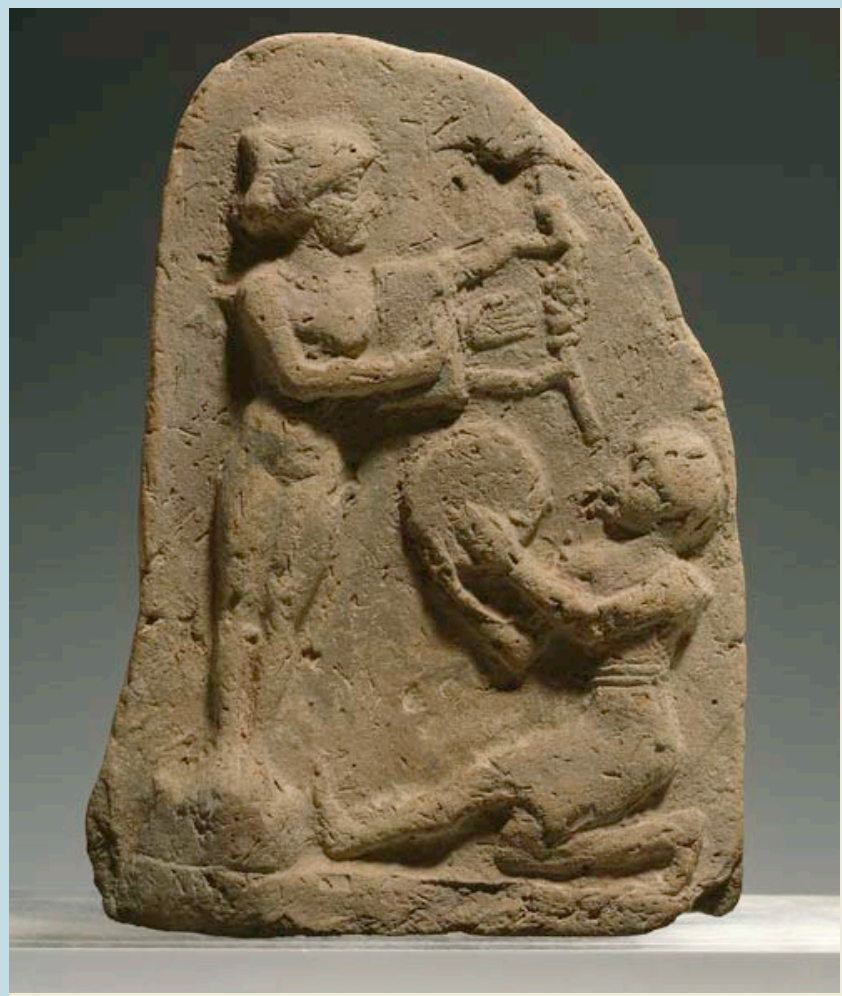





\section{Dahlia Shehata}

Musiker und ihr vokales Repertoire

This work is licensed under the Creative Commons License 2.0 "by-nc-nd", allowing you to download, distribute and print the document in a few copies for private or educational use, given that the document stays unchanged and the creator is mentioned. Commercial use is not covered by the licence.

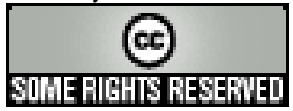


erschienen als Band 3 in der Reihe „Göttinger Beiträge zum Alten Orient“ im Universitätsverlag Göttingen 2009

Früher unter dem Titel : „Göttinger Arbeitshefte zur Altorientalischen Literatur" 
Dahlia Shehata

Musiker und

ihr vokales Repertoire

Untersuchungen zu Inhalt und

Organisation von

Musikerberufen und Liedgattungen

in altbabylonischer Zeit

Göttinger Beiträge

zum Alten Orient

Band 3

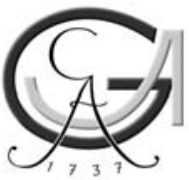

Universitätsverlag Göttingen 2009 
Bibliographische Information der Deutschen Nationalbibliothek

Die Deutsche Nationalbibliothek verzeichnet diese Publikation in der

Deutschen Nationalbibliographie; detaillierte bibliographische Daten sind im Internet über $<$ http://dnb.ddb.de $>$ abrufbar

\author{
Anschrift der Herausgeberin \\ Prof. Dr. Brigitte Groneberg \\ Seminar für Altorientalistik \\ Georg-August-Universität Göttingen \\ Weender Landstr. 2 \\ D-37073 Göttingen \\ Anschrift de $U$ AutoriQ \\ Dahlia Shehata \\ e-mail:dahlia.shehata@orient.uni-freiburg.de
}

Dieses Buch ist nach einer Schutzfrist auch als freie Onlineversion über die Homepage des Verlags sowie über den OPAC der Niedersächsischen Staatsund Universitätsbibliothek (http://www.sub.uni-goettingen.de) erreichbar und darf gelesen, heruntergeladen sowie als Privatkopie ausgedruckt werden. Es gelten die Lizenzbestimmungen der Onlineversion. Es ist nicht gestattet, Kopien oder gedruckte Fassungen der freien Onlineversion zu veräußern.

Satz und Layout: Dahlia Shehata

Umschlaggestaltung: Jutta Pabst

Titelabbildung: Relief mit Musikantenszene

Original: Vorderasiatisches Museum, Staatliche Museen zu Berlin / VA 7224

Foto: Jürgen Liepe

(C) 2009 Universitätsverlag Göttingen

http://univerlag.uni-goettingen.de

ISBN: 978-3-941875-13-5

ISSN: $1866-2595$ 
ich singe das lied aus der tiefe der hölle und rufe alle stummen dieser welt erklärt den gesang zu eurem lied taut die eisigen mauern auf und wehrt euch ausgestoßen zu werden wir wollen eine neue generation der stummen sein eine schar mit gesängen und neuen liedern wie es die redenden noch nicht vernommen haben Birger Sellin 



\section{Vorwort}

Die vorliegende Monographie ist die überarbeitete Fassung meiner im Dezember 2004 an der Georg-August-Universität vorgelegten Dissertation mit dem Titel Musiker und ihr vokales Repertoire im babylonischen Raum des zweiten Jahrtausends (aB Zeit). In dieser Druckfassung bemühe ich mich, auch alle seit dieser Zeit erschienenen Arbeiten zum Thema zu integrieren. Gerade in den letzten Jahren nahm das Interesse an Musik und Musikern im Alten Orient in verstärktem Maße nicht nur innerhalb des Faches zu. Es bleibt zu hoffen, dass mithilfe dieser Arbeit der Diskussion und Beschäftigung mit diesem Randgebiet altorientalischer Forschung neue Anregungen gegeben werden.

Das Thema der Untersuchung geht auf ein persönliches Interesse an der Musik im Alten Orient zurück, das aus meinem Zweitstudium an der Hochschule für Musik und Theater Hamburg resultiert. Besonderen Dank möchte ich an dieser Stelle meiner Doktormutter Prof. Dr. Brigitte Groneberg aussprechen, die mich in der Durchsetzung dieses Vorhabens unterstützte und mir in unermüdlicher Bereitschaft mit konstruktiver Kritik, eingängiger Diskussion aber auch persönlicher Betreuung beratend zur Seite stand. Nicht zuletzt sei Frau Prof. Dr. Brigitte Groneberg auch für die Aufnahme dieses Buches in die Reihe Göttinger Beiträge zum Alten Orient herzlich gedankt.

In gleicher Weise möchte ich meinem Zweitgutachter Prof. Dr. Ricardo Eichmann am Deutschen Archäologischen Institut Berlin herzlich danken. Mit ihm konnte ich vor allem die die Musik betreffenden Aussagen in meiner Arbeit in anregenden Gesprächen diskutieren.

Diese Dissertation wurde dankenswerterweise durch ein Promotionsstipendium nach dem niedersächsischen Gesetz zur Förderung von Nachwuchswissenschaftlern in den Jahren 2002-2003 unterstützt. Auch für die Aufnahme in das seit Beginn des Jahres 2004 laufende Graduiertenkolleg der Theologischen Fakultät Göttingen mit dem Titel „Götterbilder - Gottesbilder - Weltbilder“ für die Dauer eines Jahres sei besonderer Dank ausgesprochen. Dieses Graduiertenkolleg wurde begleitet durch intensive Kolloquiumssitzungen und informationsreiche Symposien, in denen auch meine Thesen und Ergebnisse zur religiösen Funktion der Musik innerhalb des mesopotamischen Weltbildes ausgiebig diskutiert wurden.

An dieser Stelle sind auch die informativen aber vor allem von Musik erfüllten Tage mit den Kollegen der Internationalen Studiengruppe Musikarchäologie (ISGMA) in der Stiftung Kloster Michaelstein und im Ethnologischen Museum Berlin (September 2000/'04/'06/'08) zu nennen. Ganz herzlich sei Prof. Ellen Hickmann (Hannover) gedankt, die mich zu dieser Studiengruppe im Jahre 2001 einlud, womit sie mir die Möglichkeit zur Erforschung antiker Musik weiter eröffnete und mir den Kontakt zu Kolleginnen 
und Kollegen gleicher Forschungsgebiete ermöglichte, vor allem zu Prof. Dr. Anne D. Kilmer und Prof. Dr. Bo Lowergren.

Herzlich gedankt sei in diesem Rahmen auch Kolleginnen und Kollegen, die mir bereitwillig ihre teilweise noch im Druck befindlichen Arbeiten zur Verfügung stellten, darunter Dr. U. Gabbay (Jerusalem), Dr. T. Krispijn (Leiden), Dr. S. Mirelman (London), PD Dr. M. Schuol (Berlin), Prof. Dr. M. Streck (Leipzig), Prof. Dr. N. Wasserman (Jerusalem) und Dr. F.A.M. Wiggermann (Amsterdam). Auch den Kuratoren Dr. C. B. F. Walker und Dr. J. Taylor des British Museum London sowie Dr. A. Marzahn am Vorderasiatischen Museum Berlin sei für die Ermöglichung der Einsichtnahme und Kollation von Tafeln und der Bereitstellung von Fotografien herzlich gedankt.

Für etliche Recherchen und dem Besorgen schwer zugänglicher Literatur, aber auch für ihre aufmunternden und ermutigenden Worte möchte ich mich an dieser Stelle bei meinen Kollegen und Freunden Bojana Jankovic (Wien) Anja Piller (Göttingen), PD Dr. Regine Pruzsinszky (Freiburg i. Br.), PD Dr. Ellen Rehm (Stuttgart), Annabelle Steiger (Freiburg i. Br.), Dr. Frauke Weiershäuser (Heidelberg) und Dr. Kamran Zand (Jena) herzlich bedanken.

Für die Hilfe bei den Korrekturarbeiten gilt mein besonderer Dank Dr. Sabina Franke (Rostock), Franziska J. Meynen (Stade), Ursula Möller (Dörverden) und Markus Timm (Potsdam), die mir hilfreich und unermüdlich zur Seite standen. Mein größter Dank gilt schließlich meiner Mutter, die nicht nur persönlichen Beistand leistete, sondern auch aufgrund ihrer fachlichen Kenntnisse oft erhellende Kommentare lieferte und das Entstehen dieser Arbeit mit ständigem Interesse verfolgte. Gerne erinnere ich mich der oft nächtelangen philosophischen Gespräche zur Bedeutung kulturhistorischer Forschung im Bereich der Musik. Nicht zuletzt wäre auch die Vorbereitung der Arbeit für den Druck kaum ohne ihren geduldigen und unermüdlichen Einsatz vorstellbar gewesen. Allen übrigen Mitgliedern meiner Familie sei in gleicher Weise für ihren Rat und ihre regelmäßige Unterstützung auf das Herzlichste gedankt. 


\section{Inhaltsverzeichnis}

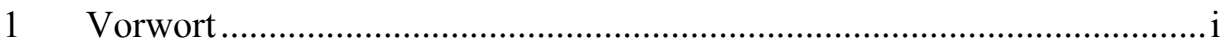

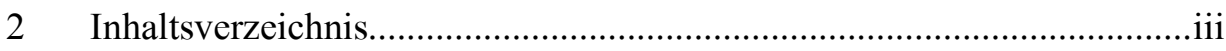

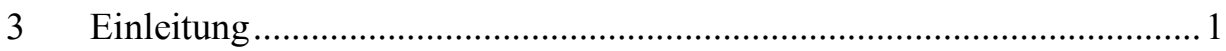

3.1 Bisherige Forschung ........................................................................

3.2 Fragestellung und Abgrenzung des Themas..............................................

3.3 Zum historischen und geographischen Rahmen .........................................

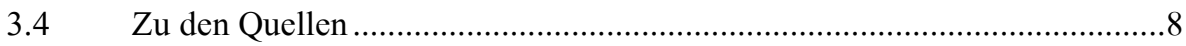

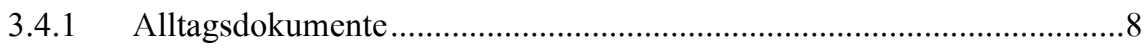

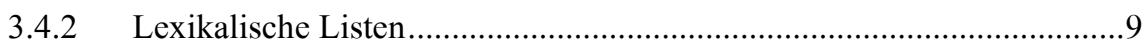

3.4.3 Literarische Texte und Kataloge.........................................................10

3.5 Transliteration und Wiedergabe von Fachtermini ......................................11

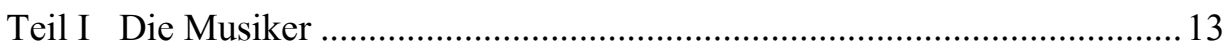

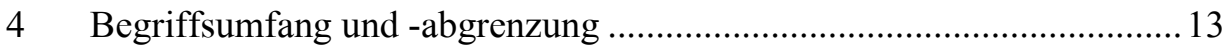

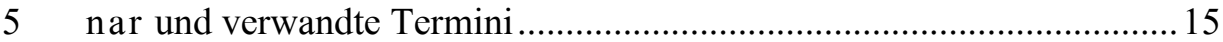

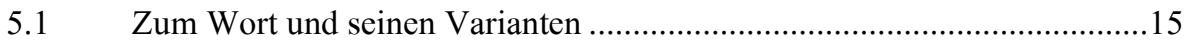

$5.2 \quad$ Organisation und Verteilung ..............................................................19

5.2.1 Palast- und Hofmusiker ........................................................................19

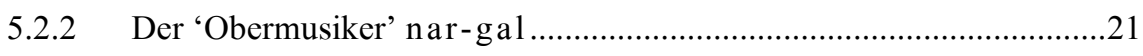

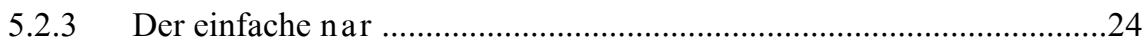

5.2.4 'Kleine' und 'lernende' Musiker: nar-tur und nar hal(-la)-tuš-a ..26

5.2.5 'Musikerhäuser' und Aufseher ...............................................................28

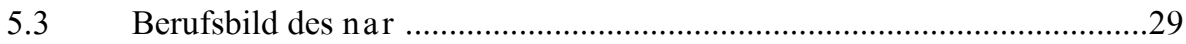

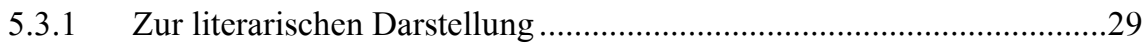

5.3.2 Die sumerischen Sprichwörter.............................................................33

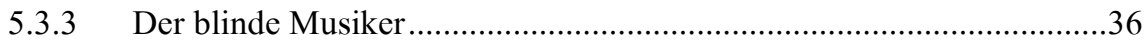

$5.4 \quad$ Instrumentale und vokale Spezialisierungen .............................................39

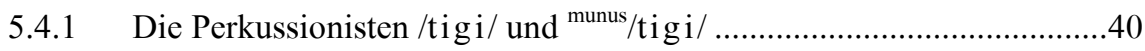

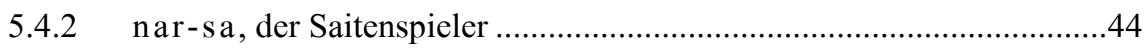

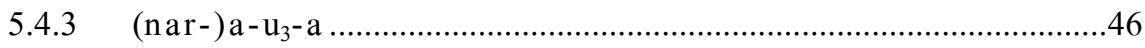


5.5 Künstler und Akrobaten im Umfeld des nar-gal .................................49

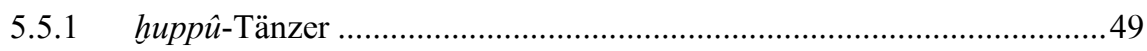

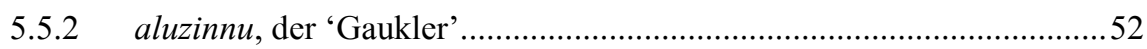

6 Der gala, Klagesänger und Priester..................................................55

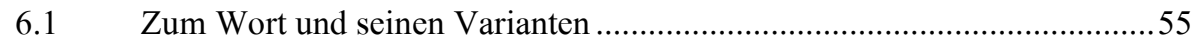

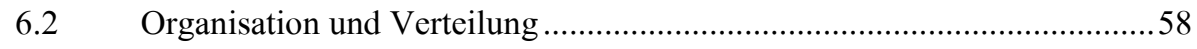

6.2.1 Zur Stellung innerhalb der Administration..........................................5 58

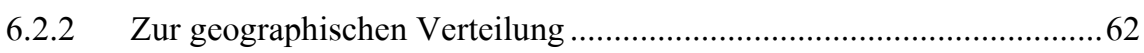

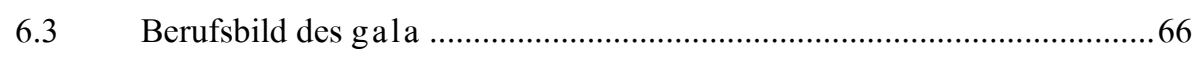

6.3.1 Erschaffung und Wesen des gala nach literarischen Texten ................66

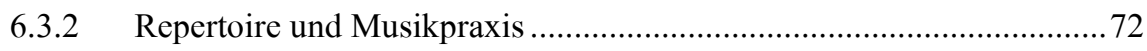

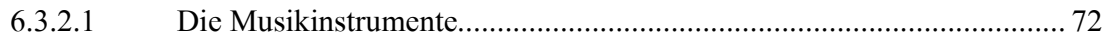

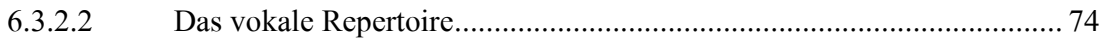

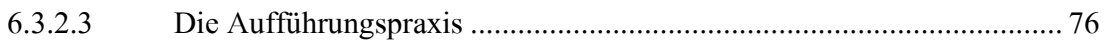

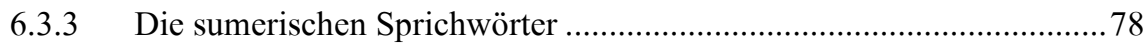

6.3.4 Exkurs I: Geschlecht, Gender und Sprache des gala ...........................82

6.3.5 'Transformation' und 'Übergang': Ein Ausblick zum Ritus des gala ..88

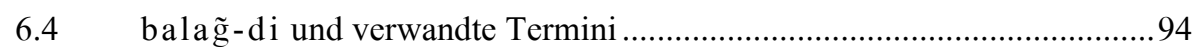

7 Musizierende Frauengruppen........................................................... 99

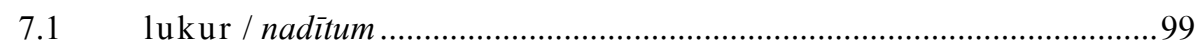

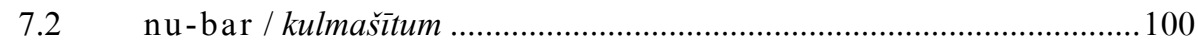

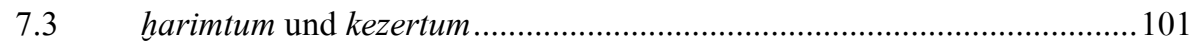

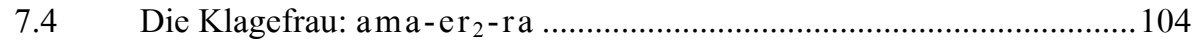

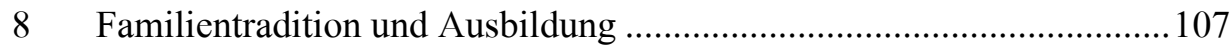

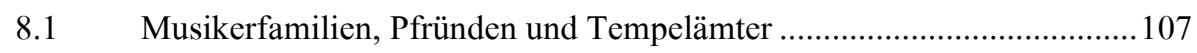

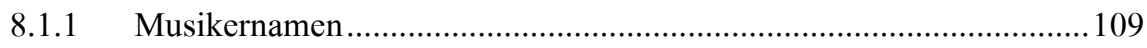

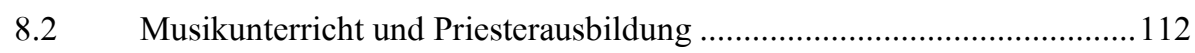

$9 \quad$ Musiker in altbabylonischen Städten ............................................. 117

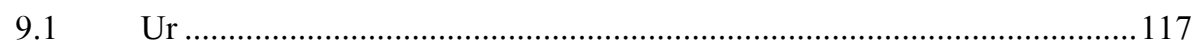

9.1.1 Historischer Hintergrund und Quellenlage ...................................... 117

9.1.2 Die namentlich belegten Musiker von Ur......................................... 119

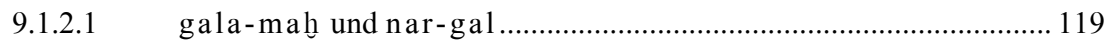


9.1.2.2 gala, nar und seine Varianten ..........................................................121

9.1.3 Ein Fest des Nanna in Ur: Die Rationenliste YOS 5, 163 (WS 5)......124

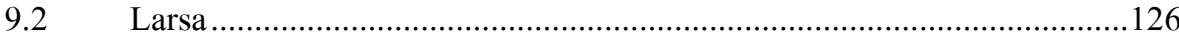

9.2.1 Historischer Hintergrund und Quellenlage .......................................126

9.2.2 Die namentlich belegten Musiker von Larsa ....................................127

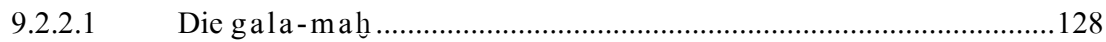

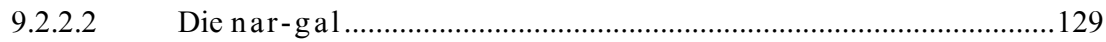

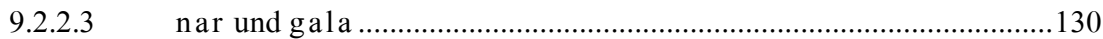

9.2.2.4 Palastmusikerinnen in Larsa_................................................................134

9.2.3 Musik zu einem Opferfestritual von Larsa .......................................136

9.2.3.1 Inhalt und Rekonstruktion des Festverlaufs .........................................136

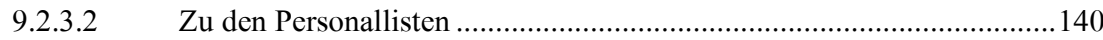

9.2.3.3 Musiker, Tänzer und Akrobaten..............................................................143

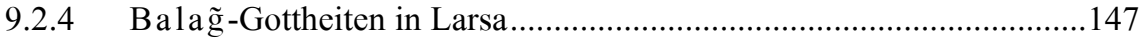

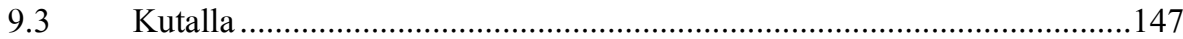

9.3.1 Die Musiker in den Privatarchiven Kutallas........................................148

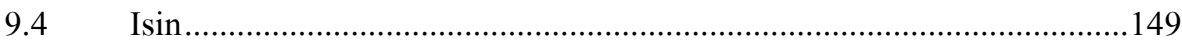

9.4.1 Historischer Hintergrund und Quellenlage ........................................ 149

9.4.2 Die namentlich belegten Musiker Isins .............................................152

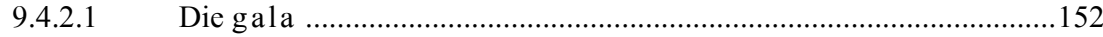

9.4.2.2 Ein Archiv des gala-mah der Ninisina ...............................................153

9.4.2.3 Andere Musiker in Texten der Palastverwaltung ..................................156

9.4.3 Musiker in den Urkunden des Lederarchivs .......................................156

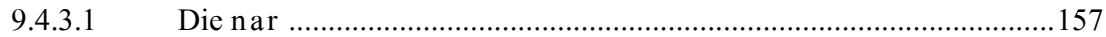

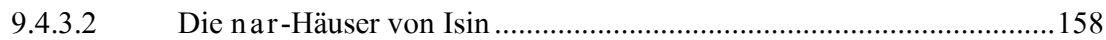

9.4.4 Bala g̃ -Gottheiten in Isin.............................................................161

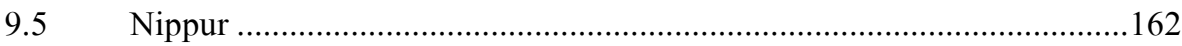

9.5.1 Historischer Hintergrund und Quellenlage .........................................162

9.5.2 Die namentlich belegten Musiker Nippurs .........................................164

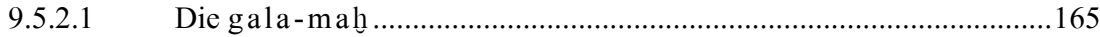

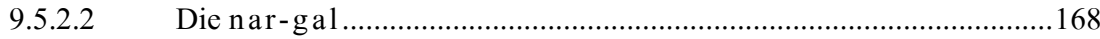

9.5.2.3 Urkundliche Belege zu gala und nar.............................................170 
9.5.2.4 Ein Musikgelehrter am Ešumeša........................................................ 171

9.5.2.5 gala und nar in Tempelrationenlisten........................................... 171

9.5.2.6 Die Musikerfamilie des Lu-Ninurta _...................................................... 172

9.5.3 Die Musikerpfründen Nippurs........................................................ 174

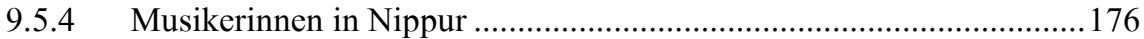

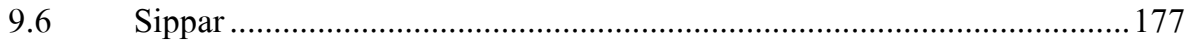

9.6.1 Historischer Hintergrund und Quellenlage ..................................... 177

9.6.2 Die namentlich belegten Musiker Sippars......................................... 180

9.6.2.1 Die gala-mah von Sippar.................................................................. 180

9.6.2.2 Ur-Utu, gala-mah der Annunìtum .................................................. 185

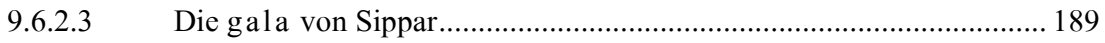

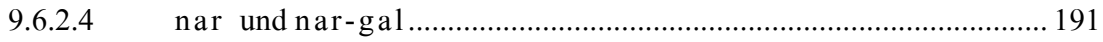

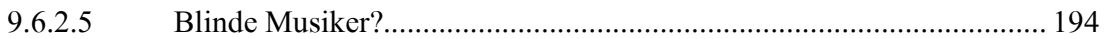

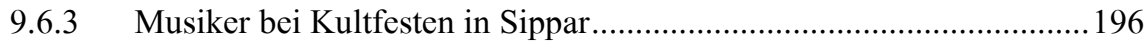

9.6.3.1 Die parșum-Kulthandlungen von Sippar ................................................ 196

9.6.3.2 Klagefeiern für Annunītum und ihren Kreis ....................................... 202

9.6.3.3 Ein Fest zum Eintreten der Annunītum................................................ 204

9.6.3.4 Rituale und Kultprozessionen am Marduk-Tempel .............................. 206

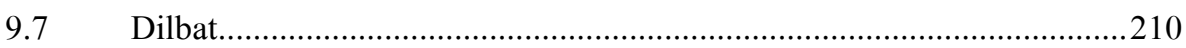

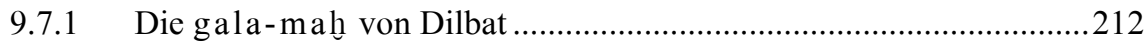

9.7.2 Andere Musiker und Kultakteure .....................................................2214

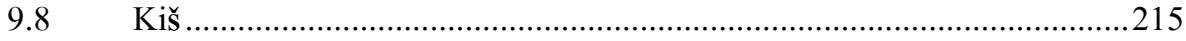

9.8.1 Historischer Hintergrund und Quellenlage .......................................2215

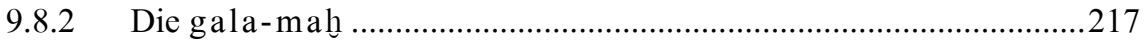

9.8.3 Andere Musiker................................................................................220

9.8.4 Die kezertum-Kultobligationen von Kiš ......................................221

Teil II Das Repertoire .......................................................................223

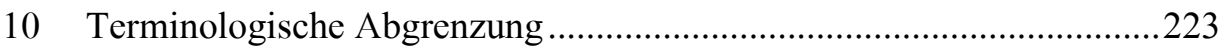

11 Grundbegriffe für den vokalen Vortrag ..........................................227

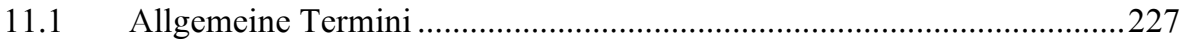

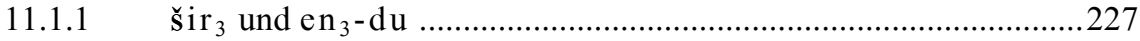

11.1.2 i-lu und verwandte Interjektionen .........................................234 


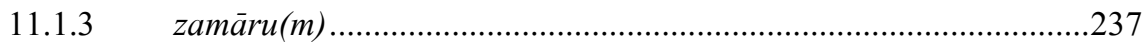

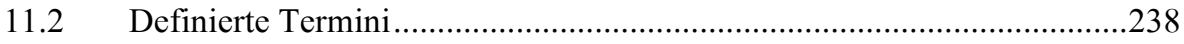

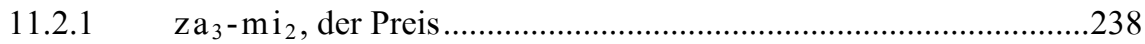

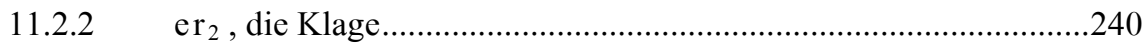

11.2.3 Das Gebet: šud $\mathrm{d}_{3}$ und $i k r i b u(m)$..................................................242

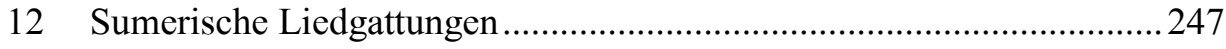

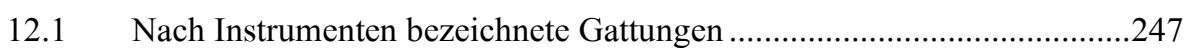

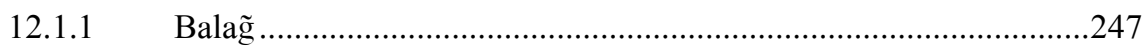

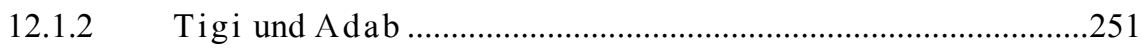

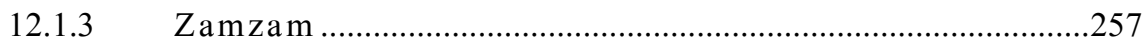

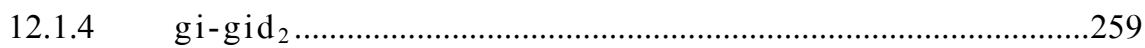

12.2 Mit šir ${ }_{3}$ „Lied“ gebildete Gattungsnamen .................................................262

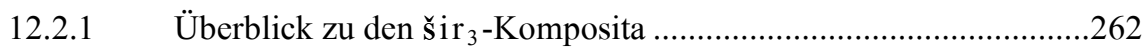

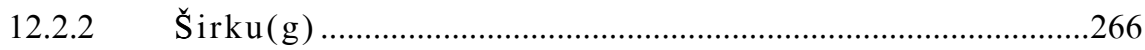

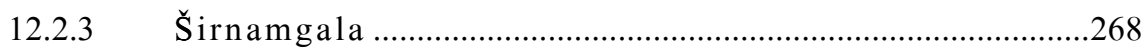

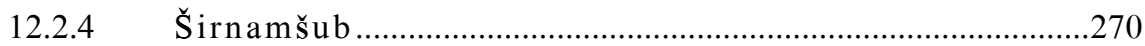

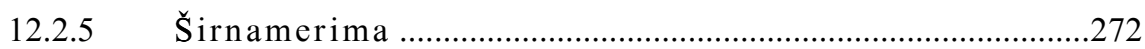

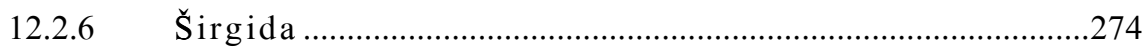

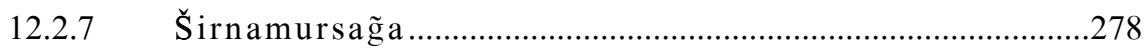

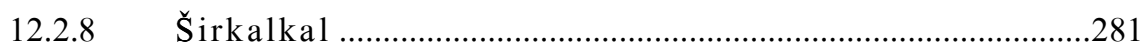

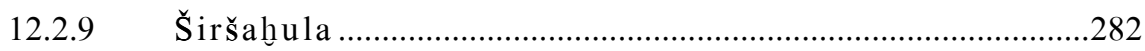

12.3 Mit er ${ }_{2}$ „Klage/Träne“ gebildete Gattungsnamen....................................284

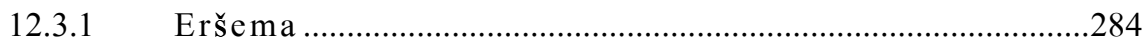

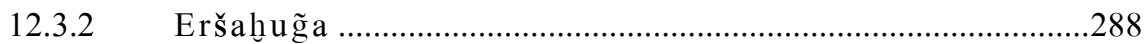

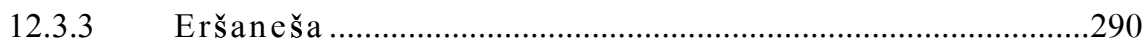

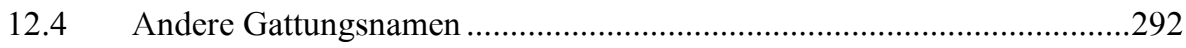

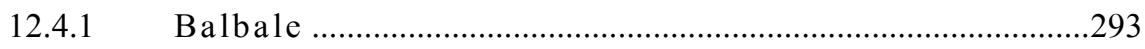

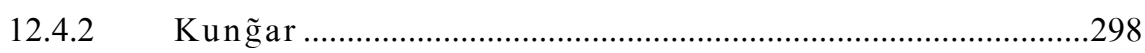

12.4.3 Liedgattungen unbekannten Inhalts ..............................................299

12.4.3.1 Malgatum ...................................................................................29

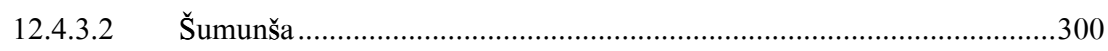

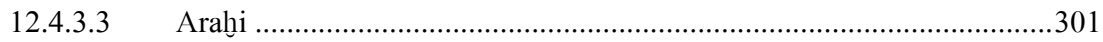




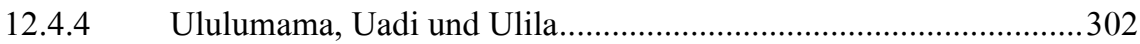

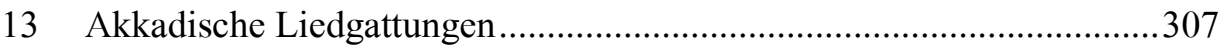

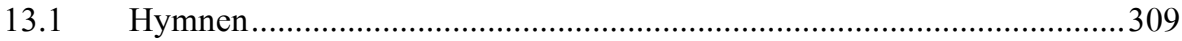

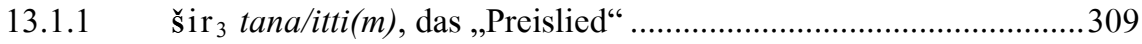

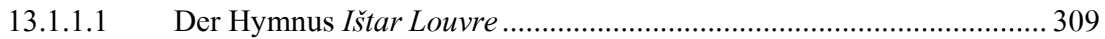

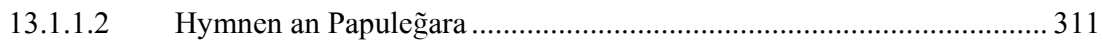

13.1.2 pārum-Hymnen an Ištar und Papuleg̃ara .....................................312

13.1.3 Ein kummu-Lied auf Adad.......................................................... 315

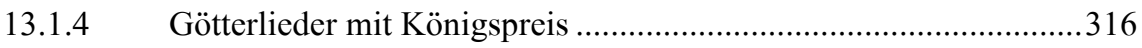

13.1.4.1 Die Götterhymnen des Ammiditana und des Samsuiluna ...................... 317

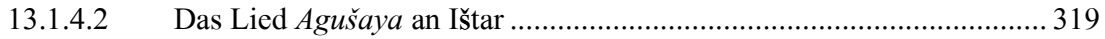

13.1.5 Götter- und Königshymnen ohne Gattungsangaben .......................321

13.1.5.1 Fragmentarische Hymnen an Marduk, Ištar und Nanaja....................... 322

13.1.5.2 Hymnen an die Muttergöttin Mami / Aruru / Bēlet-ilī ............................ 323

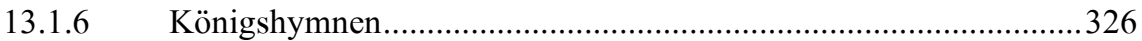

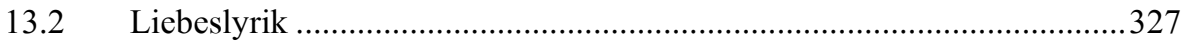

13.2.1 Ein Liebeslied auf Ištar und Dumuzi ........................................... 327

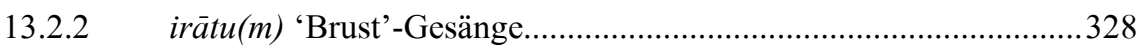

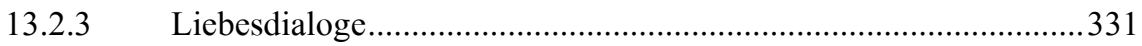

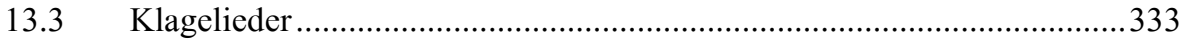

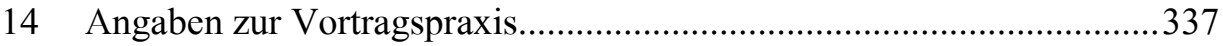

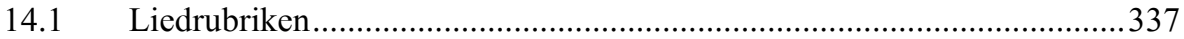

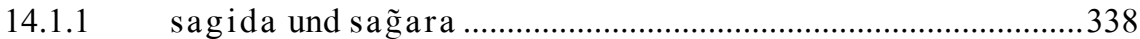

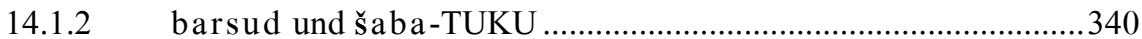

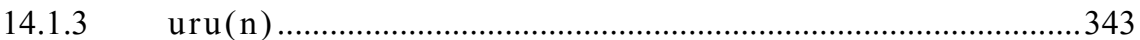

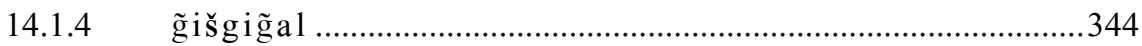

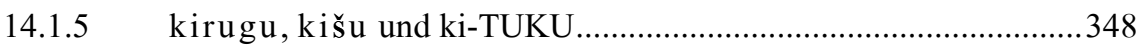

14.2 Termini technici und Anweisungen zum vokalen Vortrag......................351

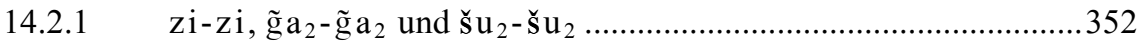

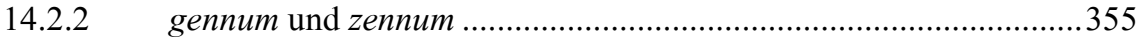

14.2.3 Ein Liebeslied mit Singanweisungen (CT 58, 12) .......................357

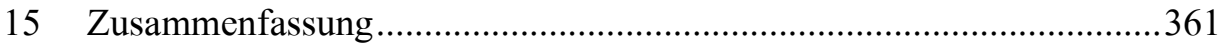




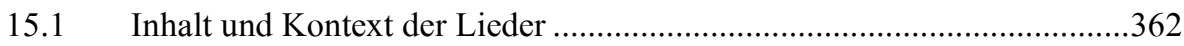

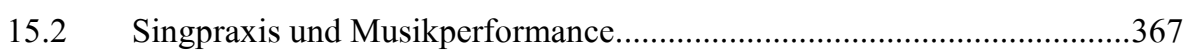

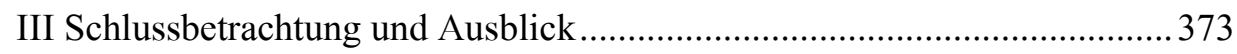

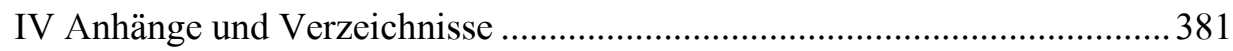

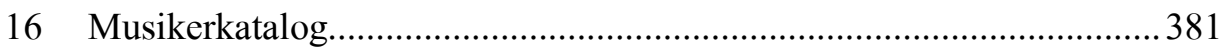

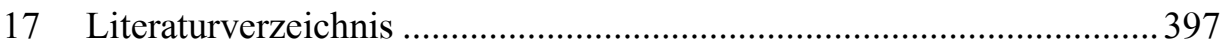

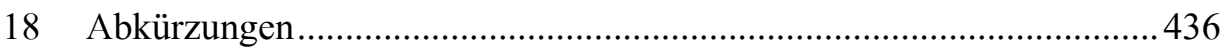

18.1 Allgemeine Abkürzungen / Herrschernamen ......................................436

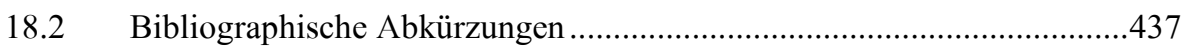

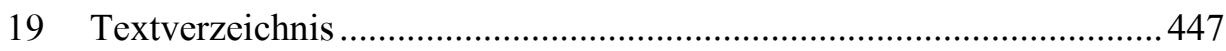

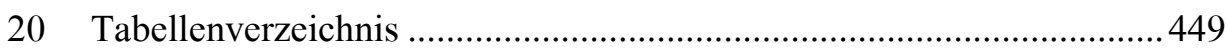

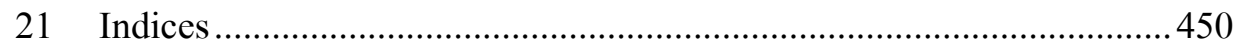





\section{Einleitung}

Musik bildet in ihrer theoretischen Auffassung wie auch in ihrer praktischen Ausübung einen zentralen Aspekt kultureller Errungenschaften und ist als Bestandteil unterschiedlichster Lebensbereiche, vom profanen Alltag über die religiöse Kultpraxis bis hin zur Auffassung des Weltbildes, Trägerin kulturspezifischer Inhalte und Ausdrucksformen.

Auch im Mesopotamien des dritten und zweiten Jahrtausends durchdrang Musik alle Bereiche des babylonischen Lebens. So war die Musikausübung nicht nur auf den rein ästhetischen Bereich der Kunstrezeption beschränkt, sondern sie wirkte vor allem funktional als ein Mittel der Kommunikation, das sowohl in religiösen wie profanen Kontexten die begrenzten Möglichkeiten beispielsweise einfacher Sprache ergänzen und überwinden konnte.

Als ein dem Schrifttum mehr als ebenbürtiges Ausdrucksmittel genoss die Musik auch in der kulturellen Selbstreflektion einen hohen Stellenwert, was in einem altbabylonischen Schuldialog mit dem Titel Der Vater und sein missratener Sohn in einem poetischen Vergleich festgehalten wird. In diesem vor über 4000 Jahren niedergeschriebenen Dialog ermahnt der Vater seinen lernfaulen Sohn mit folgenden Worten:

„Unter den sachkundigen Meistern, die im Lande wohnen,

Die mit Namen benannt sind, hat Enki

Keinen Beruf, der so schwer ist wie das Schreiberhandwerk -

Wohlan er hat ihn genannt! -

Mit Namen benannt, mit Ausnahme von der Musik/Gesangskunst (nam-nar):

So wie bei den Meeresufern das eine von dem anderen weit weg ist,

So fern sind die 'Geheimnisse' der Musik/Gesangskunst (nam-nar).“1

Die sumerische Abstraktabildung nam-nar, ein nicht nur hier sondern auch allgemein in der altorientalischen Literatur angetroffener Terminus für die 'Handwerkskunst' des Musizierens, wird auf unterschiedliche Weise übersetzt und inhaltlich definiert. Wesentlich ist hierfür die Abgrenzung des Begriffs und der Profession nar, welche in unterschiedlichen Kontexten den Sänger, den Instrumentalisten oder allgemein den Musiker bezeichnen kann. Diese verschiedenen Bedeutungsebenen verbunden mit der entsprechenden Musikpraxis gilt es unter anderem in der vorliegenden Arbeit für den angesetzten Untersuchungsrahmen des Babylonien im zweiten Jahrtausend v. Chr. näher darzulegen, auch unter Berücksichtigung anderer ihm komplementär gegenüber

\footnotetext{
${ }^{1}$ Vgl. Sjöberg 1973b, 117; s. a. Wilcke 2002, 22.
} 
Musiker und ihr Repertoire

gestellter Musikerberufe, wie beispielsweise des gala, welcher gängigerweise mit Klagepriester bzw. -sänger wiedergegeben wird. ${ }^{2}$

Im inhaltlichen Zusammenhang des oben zitierten Passus kann nam-nar, der 'Schreibkunst' entgegen gestellt, dennoch allgemein mit 'Musizieren' oder gar 'Musik' wiedergegeben werden, ohne hierbei gleich Gefahr eines Anachronismus laufen zu müssen.

Bemerkenswert ist hier die recht modern wirkende Einschätzung von $\mathrm{Mu}-$ sik, deren Erfassung in schier unerreichbare Ferne gerückt wird. Zusätzlich erstaunt der ihr gleichzeitig damit beigemessene hohe Stellenwert unter allen von Enki dem Menschen gegebenen 'Handwerkskünsten' ( $\tau \varepsilon \chi v \eta)$. Als Kunstund Kommunikationsform werden die Musik und ihr Wirken selbst der Schreibkunst übergeordnet. Allein über diesen hier so herausragend formulierten Sitz, den die Musik im Weltbild des Babyloniers einnimmt, ist die in diesem Buch erstrebte Behandlung und Einordnung von Musik und Musikern als wesentlicher Bestandteil kulturhistorischer Betrachtung mehr als gerechtfertigt. Schließlich ist die Musik, insbesondere der Gesang, ein weit älteres Medium als die Schrift, das in übergeordnetem Maße und nicht nur im altorientalischen Raum dem Erhalt und der Tradierung gesellschafts- und kulturspezifischer Identitäten in Form von Geschichten, Liedern oder Hymnen diente.

\subsection{Bisherige Forschung}

An Arbeiten, die sich ausgiebig mit dem Thema Musik als Teilaspekt der Kulturgeschichte Mesopotamiens beschäftigen, ist zunächst die Studie von Henrike Hartmann von 1960 mit dem Titel Die Musik der Sumerischen Kultur zu nennen. Ihre Arbeit stellt den bisher einzigen Versuch einer umfassenden Studie zur Musik innerhalb eines zeitlich und geographisch abgegrenzten Rahmens dar, unter Einbeziehung sowohl urkundlichen und literarischen Textmaterials wie auch der ikonographischen und archäologischen Quellen. Da seit den 60ern nicht nur das Quellenmaterial, sondern auch die Beiträge in der Erforschung der altorientalischen Musikkultur erheblich zugenommen haben, sind viele ihrer Ergebnisse inzwischen jedoch revisionsbedürftig geworden.

Besonderes Interesse wurde der Musik Mesopotamiens auch von musikwissenschaftlicher Seite durch den Fund einer Stimmungsanweisung für eines der wichtigsten Saiteninstrumente Mesopotamiens, der ${ }^{\tilde{g} i \check{s}} \mathrm{za}_{3}-\mathrm{mi}_{2}$-Leier (akkadisch samm $\hat{u}){ }^{3}$ zur Mitte des letzten Jahrhunderts entgegen gebracht. ${ }^{4}$ Insbe-

\footnotetext{
${ }^{2}$ S. jetzt auch den allgemeinen Überblick von C. Ambos zum Stichwort 'Sänger' im R1A Bd. 11 (2008) S. 499-503.

${ }^{3}$ Zur Diskussion um das ${ }^{\tilde{g} i s ̌} \mathrm{Za}_{3}-\mathrm{mi}_{2}$ als Leier oder Harfe s. Kilmer 1980-83b, 572; Kilmer 1993-97, 463; Lawergren/Gurney 1987, 40-51 und jetzt Michalowski 2009.

${ }^{4}$ Der aus Ur stammende Text UET 7, 74; Erstbearbeitung bei Gurney 1968, 229-233.
} 
sondere, da sich herausstellte, dass die in diesem Text enthaltenen Namen von Saitenpaaren als feststehende Termini von Skalen und Modi zu deuten sind. ${ }^{5}$

Von besonderem Wert für die Erschließbarkeit altorientalischer Musikkulturen war schließlich die Herausgabe eines Bandes zu Mesopotamien in der Reihe Musikgeschichte in Bildern im Jahr 1984 durch den Musikarchäologen Subhi Anwar Rashid, wodurch das hier relevante archäologische Material auch einer breiteren Leserschaft zugänglich wurde. In philologischer Hinsicht leistete vor allem Anne Draffkorn-Kilmer einen wichtigen Beitrag, da sie erstmals die Aufmerksamkeit auf musiktheoretische Texte und das sie beschreibende Tonsystem Mesopotamiens richtete. ${ }^{6}$ Inzwischen sind etliche kleinere Beiträge zu den unterschiedlichsten Aspekten der Musik Mesopotamiens veröffentlicht worden, welche sich nicht nur mit der Identifizierung einzelner Musikinstrumente oder der Musiktheorie beschäftigen, sondern auch Fragen nach Inhalt und Funktion der Musikpraxis im Alten Orient stellen. ${ }^{7}$

Gerade in den letzten Jahren ist das Interesse am Thema Musiker erheblich angewachsen, was sich in der Veranstaltung wissenschaftlicher Kongresse ${ }^{8}$ aber auch in entsprechenden monographischen Veröffentlichungen widerspiegelt. Hier gilt die Studie von Nele Ziegler von 2007 mit dem Titel Les Musiciens et la musique d'après les archives de Mari als herausragend. Gerade die vornehmlich epistolare Literatur aus dem Palastarchiv von Mari zeigt sich hier als besonders ergiebig für die Rekonstruktion des Musiklebens am Königspalast. Es werden verschiedene Musikerprofessionen mit ihren jeweiligen Verantwortungsbereichen unterschieden, sowie ihre Organisation und Stellung am Palast im Detail nachgezeichnet. Durch die lebendige Sprache der Briefe wird ein differenzierter Einblick in den Musikalltag einzelner vor allem auch mit Namen bekannter Personen geboten.

\footnotetext{
${ }^{5} \mathrm{Zu}$ keinem Thema im Bereich der altorientalischen Musik wurden annähernd viele Beiträge geschrieben. Um auf sich unterscheidende Positionen zu verweisen, sind hier die Artikel Krispijn 2002, 465-479 und Shehata 2002, 487-494 zu nennen; zum jüngst in UET 6/3, 388 veröffentlichten Fragment, das den bekannten Stimmungstext ergänzt, erscheint demnächst in der Zeitschrift Iraq ein Beitrag von S. Mirelman und T. Krispijn; zur Einschätzung dieser musiktheoretischen Texte innerhalb der altbabylonischen Schultradition s. jetzt auch Michalowski 2009.

${ }^{6}$ Um nur einige ihrer Publikationen zu nennen: Kilmer 1960, 273-308; 1965, 261-281; 1984, 6980; Kilmer/Civil 1986, 94-98; Kilmer/Tinney 1996, 49-56.

${ }^{7}$ Einen Überblick zum Thema Musik bieten Limet 1993, 231-237 sowie Kilmer im RlA 1993-97 Stichwort 'Musik'. Das monographische Werk von R. Dumbrill 2000 ist in erster Linie als Sammelwerk zu den verschiedenen Bereichen der Musik Mesopotamiens zu werten.

${ }^{8}$ Beispielsweise September 2007 an der Universität Wien Musiker und ihre Rolle bei der Verschriftlichung und Tradierung von literarischen Werken und Juli 2008 am Maison de l'Orient et de la Méditerranée Jean-Pouilloux, Lyon Le statut du musicien dans la Méditerranée ancienne Égypte, Mésopotamie, Grèce, Rome.
} 
Musiker und ihr Repertoire

In gleicher Weise bietet die dem hethitischsprachigen Raum gewidmete Monographie von Monika Schuol (2004) eine reiche und detailliert geführte Studie zur Organisation vornehmlich kultischer Musik, die auf der Auswertung der wichtigsten hethitischen Kultrituale sowie der archäologischen Quellen aus dem gesamtorientalischen Raum und der Ägäis basiert. Hier werden nicht nur Art und Inhalt verschiedener Musikerprofessionen beleuchtet, sondern auch alle im Hethitischen belegten Instrumentennamen sowie verschiedene Formen der Musikpraxis vorgestellt und eingängig diskutiert.

Für das Quellenmaterial aus dem babylonischen Raum galt die Studie von Renger zum Priestertum der altbabylonischen Zeit, welche auch die Musikerberufe nar und gala integrierte, bisher als richtungweisend. ${ }^{9}$ Dieser bedient sich hauptsächlich des urkundlichen Materials, auf Details in literarischen und anderen Textquellen wird jeweils kurz verwiesen. Auch in der demographischen Studie von Rivkah Harris findet sich ein Kapitel zu den Musikern, welche in den urkundlichen Texten der Stadt Sippar belegt sind. ${ }^{10}$ In den letzten Jahrzehnten nahm das urkundliche Quellenmaterial für die altbabylonische Zeit erheblich zu. Hier sind beispielsweise die Archivfunde aus dem Hause des gala-mah Ur-Utu von Sippar zu nennen.

Eine intensivere Beschäftigung kam in den letzten Jahren vor allem dem Klagepriester gala zu, es liegen Arbeiten von Michalowski (2006), Gabbay (2007) und (2008), Shehata (2008) und Löhnert (2008) vor. Diese beschäftigten sich nicht nur mit Fragen zum mythologischen Hintergrund und der physischen Natur dieses Musiker-Priesters, sondern auch mit der Art und der Funktion seiner speziellen Kultliturgie.

Einen umfassenden und richtungweisenden Beitrag zu den Namen von Liedgattungen und Rubriken in altbabylonischer Zeit lieferte Wilcke in der Festschrift Jacobsen von 1975 mit dem Titel „Formale Gesichtspunkte in der sumerischen Literatur". In dieser Studie widmete sich Wilcke insbesondere den sprachlichen sowie formalen Eigenheiten speziell der sumerischen Literatur. ${ }^{11}$

Monographisch aufgearbeitet in Texteditionen auch im Hinblick auf ihren 'Sitz im Leben' sind die liturgischen Texte in sumerischer Sprache, die bekanntermaßen das Kultrepertoire des gala bilden, hierzu gehören die Gattungen Balag̃ (Cohen 2008), Eršema (Cohen 1981, Gabbay 2007) sowie die Eršahung g̃a-Gebete (Maul 1988). ${ }^{12}$

\footnotetext{
${ }^{9}$ Renger 1967, 110-188 und 1969, 104-230.

${ }^{10}$ Harris 1975, 174-175, 182-183.

${ }^{11}$ S. jetzt auch Rubio 2009, 22-25, 62-70 mit einem Überblick zu den Liedgattunsgnamen und Rubriken.

${ }^{12}$ Zum Repertoire des gala s. a. Löhnert 2008 und Shehata 2009.
} 
Auch dem 'Sitz im Leben' anderer Gattungen sumerischer Literatur widmete man sich in monographischen Einzelstudien, neben den Klassikern von Jacobsen The Treasures of Darkness (1970) und The Harps that Once... (1976) sind zur sumerischen Literatur zu nennen Ludwig (1993) und FlückigerHawker (1999) zu den Königshymnen, Sefati (1998) zu den Dumuzi-InanaLiedern oder auch Fritz (2003) zu literarischem Material um Dumuzi.

Weniger umfangreich und dementsprechend diskutiert ist die akkadischsprachige Literatur, wobei ein Großteil der altbabylonischen Texte über entsprechende Einzelpublikationen inzwischen gut zugänglich ist. ${ }^{13}$ Einen wichtigen Beitrag zu ihrer Erschließung leistet jüngst das an den Universitäten Leipzig und Jerusalem eingerichtete Projekt SEAL (Sources of Early Akkadian Literature). ${ }^{14}$

Eine ausgiebige Beschäftigung mit der Musik bleibt aufgrund der zahlreichen neueren Quellenfunde und den aus ihnen resultierenden Fragestellungen äußerst notwendig. Dementgegen lässt sich jedoch eine ausschließlich diesem Thema gewidmete Studie in Anbetracht des inzwischen mehr als reichhaltigen Materials nicht mehr realisieren, wodurch eine Themeneingrenzung unumgänglich wird.

\subsection{Fragestellung und Abgrenzung des Themas}

Der zeitliche sowie geographische Rahmen der vorliegenden Arbeit, welche sich in einer differenzierenden Betrachtung mit den Musikern (Teil I) einerseits und dem vokalen Repertoire (Teil II) andererseits beschäftigt, wird durch das Babylonien des zweiten Jahrtausends v. Chr. bestimmt.

Die Wahl des zeitlichen Rahmens vom Untergang der Ur III-Dynastie bis zum Ende der ersten Dynastie von Babylon begründet sich durch die historische Situation einerseits, die auf einem markanten Epochenwandel und dem damit verbundenen Zusammentreffen unterschiedlicher Traditionen und Musikkulturen beruht. Andererseits wird sie durch die vorliegende Quellenlage begünstigt. So sind für diese Epoche trotz ihrer Masse überschaubare Mengen an Alltagsdokumenten, wie Urkunden und Briefe, auf uns gekommen. Auch der Großteil literarischer Werke mit Informationen zur Einteilung von Liedund Hymnengattungen, ob in sumerischer oder akkadischer Sprache, die auch Aufschluss über ihre mögliche musikpraktische Ausführung geben können, sind erstmals im zweiten Jahrtausend verschriftlicht worden.

\footnotetext{
${ }^{13}$ Vgl. die Einleitung zu Kapitel 13 mit Angabe der Literatur.

${ }^{14} \mathrm{http}: / /$ www.seal.uni-leipzig.de/.
} 
Musiker und ihr Repertoire

Die räumliche Eingrenzung auf den babylonischen Raum ist aus methodologischen Gründen gewählt, um in der Analyse den üppigen und vielfältigen Quellenaussagen gerecht werden zu können und einer detaillierteren Betrachtung von Einzelphänomenen Raum zu geben.

Diese historisch-geographische Eingrenzung des Themas fußt schließlich auf der Arbeitshypothese, dass die für diese Zeit zu beobachtenden Veränderungen in kultureller, politischer und gesellschaftlicher Hinsicht auch die Situation der Musiker sowie das jeweils gängige Repertoire beeinflussen.

In der vorliegenden Arbeit wird daher die Erfassung des gesamten veröffentlichten Materials angestrebt, an die sich im ersten Teil Fragen zur Verteilung und Organisation der Musiker in den einzelnen altbabylonischen Städten anschließen. Hier werden die Texte erneut nach Informationen zu den Bezeichnungen, den Tätigkeitsbereichen sowie der Stellung der verschiedenen Musikerberufe in gesellschaftlicher wie religiöser Hinsicht untersucht.

Untersuchungsrahmen und Quelleneingrenzung für den zweiten Teil „Das vokale Repertoire" bildet die bereits in früheren Studien angesetzte These, dass die in den Texten selbst enthaltenen technischen Termini in Form von Unterund Überschriften sowie Rubriken auch Zeugnis für eine 'orale' Form der entsprechenden literarischen Werke geben. ${ }^{15}$ Über dieses Kriterium sind die zu untersuchenden Texte im zweiten Teil gewählt, wobei gleichermaßen sumerische wie auch akkadische Kompositionen integriert sind. ${ }^{16}$ Über die detaillierte Darstellung und Diskussion dieser Termini soll in dieser Arbeit der Nachweis gegeben werden, dass solche Angaben in den meisten Fällen auf einer real existenten musikalischen Praxis fußen. Neben der Identifizierung des 'gesungenen' Repertoires und dem Versuch seiner Zuordnung werden im zweiten Teil der Arbeit vornehmlich Fragen zur musikpraktischen Aufführung zu beantworten sein. Diese betrifft den möglichen Darbietungsrahmen, die Ausführenden sowie die Form des Vortrags, ob als reiner Gesang, solistisch oder chorisch, oder mit instrmentaler Begleitung. Eine poetische Untersuchung der Texte hinsichtlich ihres eventuellen Metrums oder Rhythmus findet in dieser Arbeit nicht statt. Dieser Bereich ist noch zu wenig erschlossen, um hieraus eventuelle Schlüsse auf die Melodiebildung ziehen zu können. ${ }^{17}$

\footnotetext{
${ }^{15}$ Allgemein Wilcke 1975; aber auch Kilmer 1993-97 und Rubio 2009, 22-24.

${ }^{16}$ S. a. die Einleitung zu Kapitel II. Das vokale Repertoire.

${ }^{17}$ Vgl. D. O. Edzard Stichwort 'Metrik' im RlA Bd. 8 (1993-97) 148-149.
} 


\subsection{Zum historischen und geographischen Rahmen}

Der mesopotamische Raum zeichnet sich durch ein Konglomerat verschiedener Traditionen aus, das durch das stetige Ein- und Auswandern von Kulturvölkern unterschiedlichster Herkunft zustande gekommen ist. ${ }^{18}$

Das ausgehende dritte und beginnende zweite Jahrtausend wird bestimmt durch zwei historisch-politisch bedeutende Dynastien, die Ur III-Dynastie mit ihrem Begründer König Ur-Namma sowie die erste Dynastie von Babylon mit ihrem berühmtesten Vertreter König Hammurabi. ${ }^{19}$ Während die Ur IIIDynastie noch weitestgehend der sumerischen Kultur verpflichtet ist, steht die Hammurabi-Dynastie auch unter dem Einfluss nordwestsyrischer Traditionen. ${ }^{20}$

Mit dem Zerfall der Ur III-Dynastie bilden sich vermehrt neue unabhängige Dynastien und Stadtstaaten heraus, von denen im Süden Mesopotamiens als bedeutendste die Isin- und Larsa-Dynastien zu nennen sind. Im nordbabylonischen Raum bestehen hingegen eigenständige Fürstentümer und Königreiche in den Städten Sippar, Dilbat und Kiš. ${ }^{21}$

Die Vermischung sumerischer und nordwestsyrischer Traditionen lässt sich am überlieferten Liedrepertoire nachvollziehen, wonach erstmals Larsa-zeitlich auch Hymnen in akkadischer Sprache verfasst wurden. ${ }^{22}$

Unter König Hammurabi von Babylon wird schließlich der gesamte mesopotamische Raum, von Uruk in Südbabylonien bis nach Mari in Nordsyrien, zu einem Großreich zusammengeführt. Mit der Entstehung größerer Königreiche, die mehrere Städte in ihren Herrschaftsbereich eingliedern, bildet sich auf der Basis des politisch-wirtschaftlichen auch ein kultureller Zentralismus heraus. Eine entscheidende politische Wende findet bereits unter dem Nachfolger

${ }^{18}$ Der folgende historische Überblick zum babylonischen Raum des zweiten Jahrtausend soll insbesondere der fachfremden Leserschaft als Leitfaden zu den verschiedenen Dynastien und Königen, auf die in der vorliegenden Arbeit verwiesen wird, dienen. Die Angaben der Regierungsjahre für die altbabylonische Zeit basiert auf der sogenannten 'mittleren Chronologie', welche von Brinkmann bei Oppenheim 1977, 336-337 zusammengestellt ist. Für König Hammurabi von Babylon wird hiernach die Regierungszeit 1792-1750 angesetzt.

${ }_{19} \mathrm{Zu}$ welchem Zeitpunkt das Sumerische 'ausstirbt', bleibt eine rege diskutierte Frage. Im Allgemeinen wird der Übergang von der gesprochenen zur geschriebenen Sprache an das Ende der Ur III-Zeit gesetzt; s. hierzu zuletzt Woods $2007^{2}$ und Michalowski $2007^{2}$.

${ }^{20} \mathrm{Zu}$ dieser Übergangszeit sei hier auf Van deMieroop 1992, 45-71 und Charpin 2004, 57-75 verwiesen.

${ }^{21}$ Einen Überblick über die historischen sowie gesellschaftlichen Eigenheiten der altbabylonischen Zeit liefert der Band Mesopotamien. Die altbabylonische Zeit aus der Reihe Orbis Biblicus et Orientalis Bd. 160/4, 2004 mit Beiträgen von D. Charpin, D. O. Edzard und M. Stol.

${ }^{22}$ Frühestes Beispiel für eine akkadischsprachige hymnische Dichtung ist die Hymne des Königs Gungunum von Larsa (1923-1906) TIM 9, 41; s. hier Kapitel 13.1.6. 
Musiker und ihr Repertoire

Hammurabis, König Samsuiluna statt. Dieser findet sich mit zahlreichen Revolten in verschiedenen Gebieten des Landes konfrontiert, von denen die Rebellion des Rīm-Sîn II aus dem südbabylonischen Larsa eine der bestdokumentierten ist. ${ }^{23}$

Der darauf folgende Verlust Südbabyloniens für das Reich der ersten babylonischen Dynastie ist nicht nur politisch begründet. An den archäologischen Befunden lassen sich in den altbabylonischen Besiedlungsschichten der Städte Südbabyloniens Verwüstungen ausmachen, die sich offenbar über das gesamte Gebiet erstreckten. ${ }^{24}$ Schließlich ist auch in wirtschaftlicher Hinsicht bereits unter König Hammurabi ein abnehmendes Interesse an den südlich gelegenen Städten seines Reiches zu beobachten, was mit verschlechterten ökologischen Bedingungen in Zusammenhang gebracht wird. ${ }^{25}$

\subsection{Zu den Quellen}

Das Hauptmaterial der vorliegenden Untersuchung bilden die schriftlichen Quellen, auf archäologische Daten wird lediglich am Rande verwiesen. Es steht außer Frage, dass eine gleichwertige Untersuchung beider, textlicher wie archäologischer Quellenarten im Hinblick auf eine Zeit oder einen Ort unter Berücksichtigung der Fundorte und -umstände zu neuartigen Erkenntnissen führen würde, die auch zur Abgrenzung unterschiedlicher Bereiche des musikalischen Lebens beitragen können. Eine solche Untersuchung muss jedoch anderen weiterführenden Studien vorbehalten bleiben.

Die in dieser Arbeit verwendeten schriftlichen Quellen sind nach drei Gruppen eingeteilt: den Alltagsdokumenten, den lexikalischen Listen sowie den literarischen Texten und Katalogen. ${ }^{26}$ In ihrer Aussagekraft sind diese Textgruppen nach primären und sekundären Quellen zu unterscheiden.

\subsubsection{Alltagsdokumente}

Eine Primärquelle liegt mit der Gruppe der hier bezeichneten 'Alltagsdokumente' vor, welche durch Urkunden und Verträge, Personal- und Opferlisten, Lieferscheine und Quittungen sowie Briefe gebildet werden. Aus diesen Dokumenten werden im Wesentlichen zahlreiche Musiker mit Namen bekannt, die

\footnotetext{
${ }^{23}$ Pientka 1998, 12.

${ }^{24}$ Pientka 1998, 18-20.

${ }^{25}$ Ausführlicher bei Pientka 1998, 11-21; s. a. van Koppen 2004, 19-23.

${ }^{26}$ Bei den Titeln der hier diskutierten sumerischen literarischen Texte richte ich mich im Wesentlichen nach ETCSL (www-etcsl.orient.ox.ac.uk/catalogue.htm), soweit sie dort veröffentlicht sind. Umschriften des Sumerischen sind ETCSL und ePSD (http://psd.museum.upenn.edu./ epsd/) angeglichen.
} 
dann über die prosopographische Studie im besten Fall einzelnen Familien und Institutionen zugeordnet werden können. In Urkunden und Verträgen werden Musiker meist in Zeugenlisten angetroffen, von Bedeutung sind hier nicht nur etwaige Angaben zur Filiation einer Person, sondern auch die Zusammenstellung eines solchen Zeugenkreises, worüber Rückschlüsse auf seine Zugehörigkeit gezogen werden können. Kauf- oder Erbschaftsverträge informieren über Stellung und Vermögen eines Musikers. Auch Besitz und Anteile an einer Tempelpfründe sind von besonderem Interesse, die über die Verteilung auch zeitlich begrenzter Musikerdienste Auskunft geben.

Personen- und Opferlisten enthalten Daten zur Entlohnung von Musikern, andererseits kann hierüber auch die Zusammenstellung von Musikerensembles zu den Festen einzelner Götter nachgezeichnet werden.

Lieferscheine und Quittungen mit Belegen zu Musikern stammen vor allem aus dem so genannten 'Lederarchiv' von Isin, in dem auch Bau und Lieferung von Musikinstrumenten dokumentiert sind. Andererseits können solche Lieferscheine auch Informationen zum allgemeinen Verantwortungsbereich eines Musikers liefern, wie beispielsweise der Verteilung von Opfermaterie an das bei Kultfesten mitwirkende Personal.

Briefe können sowohl einzelne Details aus dem Wirkungsbereich eines $\mathrm{Mu}-$ sikers beschreiben wie auch Hinweise auf seine Besitzverhältnisse und seine Stellung enthalten. Problematisch bleibt bei dieser Textgruppe dennoch, dass die größeren Zusammenhänge zu einem meist knapp und bündig formulierten Ereignis oder Anliegen häufig nicht mehr nachvollziehbar sind.

\subsubsection{Lexikalische Listen}

Ein dem Alten Orient vorbehaltenes Textgenre sind Lexikalische Listen, deren funktionaler Hintergrund in der Tradition der Schreiberausbildung liegt. ${ }^{27}$ Für die Fragestellung dieser Arbeit ist vor allem die in erster Linie thematisch angeordnete altbabylonische Liste Proto- $\mathrm{Lu}_{2}$ (MSL 12, 23-84) von Bedeutung, die die Bezeichnung von Professionen auflistet, darunter auch etliche Musikerberufe und anderes bei Kulten und Götterfesten musizierendes Personal. Zwar lassen sich aus dieser Liste keine Aussagen zu den Tätigkeitsbereichen der Musiker erschließen, doch liegt ihr eine thematische und hierarchische Struktur zugrunde, die mit Daten anderer Textquellen verglichen werden kann.

Dieselbe Liste Proto- $\mathrm{Lu}_{2}$ enthält schließlich auch einen Abschnitt zu den sumerischen Liedgattungsnamen und Rubriken, woran in gleicher Weise eine gewisse Ordnung dieser sonst nur aus den literarischen Texten und Katalogen bekannten Termini nachvollzogen werden kann. Genuin akkadische Gattungsnamen sind in diese Liste nicht integriert, da die altbabylonischen Listen eine

\footnotetext{
${ }^{27}$ Zur besonderen Problematik dieser Textgruppe s. Veldhuis 1997.
} 
Musiker und ihr Repertoire

rein auf das Sumerische ausgerichtete Schreibtradition widerspiegeln. Insgesamt ist die Aussagekraft lexikalischer Listen als sekundär einzuordnen.

\subsubsection{Literarische Texte und Kataloge}

$\mathrm{Zu}$ den literarischen Texten zählen gleichermaßen mythologische und epische Erzählungen, lyrische Lieder und Hymnen, die so genannten Klagelieder, Sprichwortsammlungen sowie Streit- und Schuldialoge. ${ }^{28}$ Der Großteil dieser Texte ist in sumerischer Sprache, dem Emegir oder dem Emesal, gehalten. Im zweiten Jahrtausend, beginnend mit der Larsa-Dynastie und vermehrt seit der Zeit des Hammurabi von Babylon, entstehen schließlich auch die ersten literarischen Kompositionen in akkadischer Sprache.

Aus literarischen Texten lassen sich vornehmlich Informationen zum Kontext der Musikausübung ziehen. In ihnen finden sich meist fragmentarische poetisch in den Text eingebettete Beschreibungen zu Kultfesten oder Ritualen mit Hinweisen auf die Beteiligung von Musikern oder dem Erklingen verschiedener Musikinstrumente. Insgesamt sind die Texte als Sekundärquelle zu behandeln, da die in ihnen beschriebenen Handlungen in ihrem Ablauf nicht eindeutig rekonstruierbar sind und nur schwer auf einen nach Alltagsdokumenten bekannten Kult bezogen werden können.

Bei dem im zweiten Teil dieser Arbeit unternommenen Versuch, die musikalische Aufführungspraxis für einzelne Liedgattungen $\mathrm{zu}$ rekonstruieren, werden gleichermaßen die Gattungsnamen und Rubriken selbst, wie auch etwaige in den Liedern enthaltene Hinweise auf den Kontext und das beteiligte Personal eine wichtige Rolle spielen. Für die Erschließung und Einordnung der einzelnen Liedgattungen sind auch die literarischen Kataloge von großer Bedeutung, die u. a. zur Ergänzung der Liste bekannter Gattungsnamen beitragen. Während die meisten dieser Kataloge in die altbabylonische Zeit datieren, ${ }^{29}$ wird auch auf den Ur III-zeitlichen Katalog Y1 (YBC 3654) ${ }^{30}$ sowie auf den mittelassyrischen Liederkatalog KAR 158 verwiesen. Letzterer ist vor allem für die Erschließung der akkadischen Gattungsnamen von Bedeutung. ${ }^{31}$

\footnotetext{
${ }^{28}$ Zur Unterscheidung 'literarischer Gattungen' und den damit verbundenen Schwierigkeiten s. Vanstiphout 1999, 80-84, 88-94.

${ }^{29}$ Die meisten der hier zitierten altbabylonischen Kataloge sind in ETCSL 0.2 einsehbar; s. ausführlich die Einleitung von Teil II.

${ }^{30}$ Hallo 1963.

${ }^{31}$ S. hierzu Limet 1996 und Groneberg 2003.
} 
Zuletzt sei hier auf die Gattung der Ritualtexte kurz hingewiesen. Diese Textgruppe spielt in der vorliegenden Arbeit eine untergeordnete Rolle, da sie für das zweite Jahrtausend kaum vertreten ist. Am bedeutendsten sind die Vertreter aus Mari, die hier allerdings lediglich zum Vergleich herangezogen werden. ${ }^{32}$

\subsection{Transliteration und Wiedergabe von Fachtermini}

Die Umschrift der sumerischen Zitate richtet sich nach ETCSL. Im Text wird dementgegen die kurze Lautform favorisiert, z. B. ša ${ }_{3}$ anstelle von ša ${ }_{4}$.

Die Angabe verschiedener Lautwerte geschieht hier auch für den zweiten und dritten Wert anhand von Zahlen und nicht von 'Akzenten': $\tilde{\mathrm{g}} \mathrm{a}_{2}=$ gá ; ša ${ }_{3}$ $=$ šà. Dasselbe Umschriftsystem wird für das Akkadische angewendet.

Feststehende Termini, zu denen ich die meisten Gattungsnamen zähle, werden, sofern sie nicht in Zitaten auftreten, im Text als Eigennamen gehandhabt, so steht Tigi für tigi wie auch für tigi $i_{2}$. Rubriknamen werden in gleicher Weise, allerdings in Kleinschreibung wiedergegeben; unsichere Lesungen bleiben hierbei in Großbuchstaben: z. B. ša $a_{3}$-ba-TUKU = šaba-TUKU.

Fachtermini und Begriffe mit durchgängig einheitlicher Schreibung werden in dieser Form beibehalten, z. B. šud ${ }_{3}$ oder šir ${ }_{3}$. Um den Lesefluss zu erleichtern werden hingegen Termini mit mehreren Schreibvarianten in / / gehalten, so gilt z. B. /endu/ für en-du $u_{3}$, en-du, en-du ${ }_{12}$ etc.

\footnotetext{
${ }^{32}$ Durand/Guichard 1997, 19-78; s. außerdem das Ritualfragment aus Uruk in AUWE 23, 64-65 Nr. 122.
} 



\section{TEIL I DIE MUSIKER}

\section{Begriffsumfang und -abgrenzung}

Der Begriff Musiker, welcher auf Griechisch mousikos „(Kunst) der Musen“ zurückzuführen ist, wird ,zur Benennung von Musizierenden oder Musikwerke Setzenden sowie als Amtsbezeichnung verwendet(e)...“.33

Die zwei gängigsten Berufsbezeichnungen professioneller Musiker in Mesopotamien werden über die sumerischen Termini nar und gala angezeigt, die ins Akkadische als $n \bar{a} r u(m)$ und kalu(m) entlehnt werden. ${ }^{34}$ Auf ihnen liegt der Schwerpunkt der folgenden Darstellung, auch da hier die Dokumentationslage im behandelten Material am reichhaltigsten ausfällt. Ausschließlich dem Bereich der Klage sind die Berufe des balag̃-di, wörtlich „der das bala g̃ spricht/spielt", und der der Klagefrau ama' erra zuzuordnen. ${ }^{35}$ Im Gegensatz $\mathrm{zu}$ gala und nar sind diese in Texten der altbabylonischen Zeit sehr selten vertreten. Der $\check{s} a$ em/būbim „Rohrinstrumentenspieler“ ist altbabylonisch nur einmal belegt. ${ }^{36}$ Weitere akkadische Bezeichnungen für Vokalisten und Instrumentalisten, darunter a/eštalû $(m)$, zammeru $(m)$ oder zammāru(m) sind im babylonischen Raum dieser Zeit außerhalb der lexikalischen Listen unbekannt, weshalb sie aus der folgenden Untersuchung ausgeschlossen werden. Viele zudem aussagekräftige Belege finden sich zu diesen Musikern hingegen in Mari. ${ }^{37}$

\footnotetext{
${ }^{33}$ MGG 6 s. v. „Musiker“ 1213.

${ }^{34}$ Vgl. die Wörterbücher CAD K 91 kalû A, CAD N/1 376; AHw 427 kalû(m) III, ibid. 748 nāru(m) II. Zu Musikern im Alten Orient vgl. auch die früheren Studien: Hartmann 1960, 129-183; Renger 1969, 172-199; Henshaw 1994, 88-114; Kilmer 1993-97, 467-469; für Mari Ziegler 2007, 7-37; mA Jacob 2003, 518-521; nA Menzel 1981, 233-237, 254-258; bei den Hethitern Schuol 2004, 157-177.

${ }^{35}$ S. allgemein Kilmer 1993-97, 469; Henshaw 1994, 104-106.

${ }^{36} \mathrm{AbB}$ 6, 144.

${ }^{37}$ Ziegler 2007.
} 
Eine musikalische Betätigung ist nicht nur professionell ausgebildeten Musikern vorbehalten. Die Ausübung von Musik in Mesopotamien ist auch für unterschiedliches Personal am Tempel, im Palast oder auch auf der Straße attestiert. Musikalisch-klangliche Ausdrucksmittel sind in solchen Berufen eher sekundär belegt. Hier sind zunächst die Tänzer, Schausteller und Akrobaten zu nennen, in diese Arbeit werden daher auch aluzinnu(m) und huppu $(m)$ integriert. Nebenberufliches Musizieren ist außerdem für verschiedene Frauengruppen am Tempel oder Palast belegt, darunter die Priesterinnenklassen naditu $(\mathrm{m})$ und kulmašit $t$ (m), aber auch die dem Bereich der erotischen möglicherweise auch kultischen Unterhaltung zugeordneten kezertu $(m)$ und harimtu $(m)$. Zwar sind auch für den Reinigungspriester $\mathrm{gudu}_{4}$ insbesondere in Quellen des dritten Jahrtausends neben gala musikalische Tätigkeiten nachweisbar, für die altbabylonische Zeit ist hier die Beleglage allerdings dürftig, weshalb auf eine ausführliche Behandlung dieses Priesters verzichtet wurde. ${ }^{38}$

In den ersten Kapiteln des folgenden Teils werden jeweils umfassende Darstellungen zu den einzelnen als Musiker attestierten Professionen geführt, wobei gleichermaßen Quellen aller Gattungen einbezogen werden. Die Daten alltäglicher Dokumente, darunter Urkunden und Briefe, sind in den entsprechenden Kapiteln zusammengefasst.

Detaillierte Informationen zu einzelnen auch mit Namen belegten Musikern werden ab Kapitel 5 nach den unterschiedlichen altbabylonischen Städten getrennt dargestellt. Mit Hilfe dieser Aufteilung sollen mögliche lokale und historische Unterschiede in der Organisation der Musiker aufgedeckt werden. Hierbei beschränke ich mich auf das in Veröffentlichungen zugängliche Textmaterial aus den Hauptfundorten des babylonischen Raums: Ur, Larsa, Kutalla, Isin, Nippur sowie Sippar, Dilbat und Kiš in Nordbabylonien. Der jeweils vorangestellte Überblick zur Historischen Situation sowie zur Quellenlage soll insbesondere der fachfremden Leserschaft als Leitfaden zu den lokalen Kulten und den vorherrschenden Dynastien und Königen dienen. Jede der behandelten Städte ist Hauptkultort unterschiedlicher Gottheiten, sodass am Musikerpersonal auch die Musikpraxis in den verschiedenen Götterkulten nachvollziehbar wird. Besonders zu berücksichtigen ist hier jedoch auch die Fund- und Quellensituation, womit unterschiedliche Ergebnisse in der Auswertung zu begründen sind.

\footnotetext{
${ }^{38}$ Hartmann 1960, 122-124; vgl. bei Kultfesten neben Musikern hier Kapitel 9.2.3.2 und zusammen mit gala-Pfründen Kapitel 9.5.3.
} 


\section{5 nar und verwandte Termini}

\subsection{Zum Wort und seinen Varianten}

Das sumerische Wort nar(LUL) ${ }^{39}$ bezeichnet im Allgemeinen eine musizierende Person und wird ins Akkadische als nāru(m) bzw. nārtu(m) entlehnt. ${ }^{40}$ Da das Wort sowohl in seiner sumerischen als auch akkadischen Form weder inhaltlich noch qualitativ näher definiert wird, kann es mit dem gleichfalls allgemeinen deutschen Wort „Musiker“" wiedergegeben werden. ${ }^{41}$ Hierbei gilt $\mathrm{zu}$ berücksichtigen, dass nar in literarischen Texten vermehrt auf Vokalisten bezogen wird, weshalb zuweilen eine Übersetzung mit „Sänger“ zu bevorzugen ist. $^{42}$ Außerdem wurden wohl auch keine Rohrinstrumentspieler als nar bezeichnet, die über den eigenständigen Ausdruck ša em/bbūbim benannt werden. ${ }^{43}$ In der folgenden Arbeit wird dennoch durchgängig mit „Musiker“ übersetzt, sofern das Wort selbst nicht inhaltlich spezifiziert wird. Eine Spezifizierung des Begriffs nar geschieht in aller Regel in Form von Komposita, worüber die musikalische Tätigkeit oder die Rangposition definiert werden.

nar-Komposita sind überwiegend in lexikalischen Listen und Dokumenten attestiert. In der Literatur tritt dagegen neben dem häufig belegten nar nur noch nar-gal ,großer Musiker“ und einmal nar-tur „,kleiner Musiker“ auf.

${ }^{39}$ Die Form des Keilschriftzeichens LUL geht auf das piktographische Abbild eines Fuchskopfes zurück, eine Verbindung zu Musik ist damit über das Zeichen selbst nicht gegeben; Labat 1952, 164-165:355; Green/Nissen 1987, 252: 390; ausführlich zur frühen Entwicklung der Zeichenform Mittermayer 2005, 70-74:5.1) KA .

${ }^{40}$ Vgl. außer den Belegen in den Wörterbüchern UET 5, 663:11 (D.a.) mit syllabischer Schreibung $n a-r u-u_{2}$ und YOS 13, 390:3 (Sd 14) mit ${ }^{\text {munus }}$ na-ar-ti.

${ }^{41}$ So auch CAD N/1 376b „musician“ und AHw 748b nāru(m) II „Musiker“.

${ }^{42}$ Vor allem in den sumerischen Sprichwörtern wird das Hauptaugenmerk auf die Stimme des nar gelegt; s. hier Kapitel 5.3.2.

${ }^{43}$ AbB 6, 144 mit ša ebbūbim, die Inana zugeordnet sind; beachte auch das Sprichwort SP 2.54, wonach ein in Ungnade gefallener bzw. 'schlechter' nar das gi-gid -Rohrinstrument $^{-}$ spielt; Alster 1997, 55-56; s. hier Kapitel 12.1.4. 
Die Liste Proto- $\mathrm{Lu}_{2}$ unterscheidet zu Beginn des Abschnitts zu den musizierenden Personengruppen fünf verschiedene nar-Musiker:

T 1: Proto-Lu $\mathrm{Lu}_{2} 641-645\left(\right.$ MSL 12, $56\left(\right.$ Texte A/B)): $:^{44}$

$\begin{array}{lll}641 \mathrm{~A} / \mathrm{B} & \text { nar } & \text { „Musiker“ } \\ 642 \mathrm{~A} / \mathrm{B} & \text { nar-gal } & \text { „Obermusiker“ } \\ 643 \mathrm{~A} & \text { tigi (NAR.BALAG̃) } & \text { „Perkussionist(?)“ } \\ 644 \mathrm{~A} & \text { nar-sa } & \text { „Saiteninstrumentalist“ } \\ \text { Text B } & \text { nar-tur } & \text { „Kleiner Musiker“ }\end{array}$

Neben nar und nar-gal handelt es sich bei den Begriffen tigi (NAR.BALAG̃) und nar-sa um gängige nar-Komposita, die urkundlich sowie literarisch für die Ur III- und altbabylonische Zeit bezeugt sind und damit eigenständige Berufszweige bezeichnen.

Die Liste setzt sich mit weiteren nar-Komposita fort, von denen einige nur hier bezeugt sind:

T 2: Proto-Lu $\mathrm{Lu}_{2}$ 646-650 (MSL 1256 // Or 70, 216)

\begin{tabular}{|c|c|c|}
\hline $646 \mathrm{~A} / \mathrm{B} / \mathrm{S}$ & nar igi suhur-la & „Musiker vor der kezertum“ \\
\hline $647 \mathrm{~A} / \mathrm{B}$ & nar igi lugal & „Musiker vor dem König““ \\
\hline $648 \mathrm{~A} / \mathrm{Or} 70: 18^{\prime}$ & nar $\mathrm{gu}_{3}$ silim-ma & $\begin{array}{l}\text { „Musiker mit feiner Stimme/ } \\
\text { des Rumpreises“ } 46\end{array}$ \\
\hline $648 \mathrm{a} \mathrm{B} / \mathrm{S}^{\prime}$ & [na]r inim-bal-bal & $\begin{array}{l}\text { „Musiker, der das Wort } \\
\text { wechselt/hin- und herwirft“ }\end{array}$ \\
\hline 648b B/S'/Or 70:17' & $\mathrm{dug}_{3}-\mathrm{ga}$ & „Musiker mit süßer Stimme“ \\
\hline $648 \mathrm{c} \mathrm{B} / \mathrm{S}^{\prime}$ & nar $\mathrm{gu}_{3}{ }^{?} \mathrm{nu}-\mathrm{dug} \mathrm{g}_{3}-\mathrm{ga}$ & $\begin{array}{l}\text { „Musiker mit keiner süßen } \\
\text { Stimme“ }\end{array}$ \\
\hline $648 \mathrm{~d} \mathrm{~B} / \mathrm{S}^{\prime} /$ Or 70:16' & nar $z e_{2}-z a$ & $\begin{array}{l}\text { „Krächzender/Seufzender(?) } \\
\text { Musiker““ }\end{array}$ \\
\hline - Or 70:19' & ${ }^{\mathrm{n}} \mathrm{ar}-\mathrm{a}_{2}{ }^{1}-\mathrm{na} \mathrm{a}_{2} !$ & $\begin{array}{l}\text { „Musiker im } \\
\text { Schlafgemach(?)“47 }\end{array}$ \\
\hline
\end{tabular}

\footnotetext{
${ }^{44}$ Ergänzend die Version der Liste bei Taylor 2001, 210-211, wo tigi und nar-tur fehlen, vgl. im Folgenden.

${ }^{45}$ Der Textvertreter $B_{3}$ (MSL 12, 67) aus Nippur bringt in Kol. ii eine andere Anordnung und fügt den nar-tur hinzu.

${ }^{46}$ Nach Taylor 2001, 223 ,'singer of glorification'“ im Hinblick auf die Gleichung $\left(\mathrm{g} \mathrm{u}_{3}\right)$-silim = tašrihtum „Verherrlichung, Pracht; Ruhmredigkeit“; AHw 1339; CAD T 295-296. Angesichts der gemeinsamen Nennung mit dem Schlafgemach der Götter in $I \check{S} D A(+V)$ Text C:11 (T 4) auch hier wohl eher der „Musiker mit sanfter Stimme“.

${ }^{47}$ Taylor 2001, 216, ,'singer of the (deity's) sleeping chamber“.
} 
649 A/B/S'/Or 70:20'nar hal-1a tuš-a

649a B/Or 70:21' ' ${ }^{\prime}$ nar $^{\top}$ eš $_{3}-\mathrm{a}$

649b S'/Or 70:22' [nar] ' $\mathrm{pad}_{3}{ }^{1}-\mathrm{da}$

$650 \mathrm{~A} / \mathrm{S}^{\prime}$ nar $\breve{S I R}_{3} / \mathrm{KES}_{2}$ ? $-\mathrm{da}$
„Lernender Musiker“

„Musiker im Heiligtum?“

„Berufener Musiker?“

„Musiker ...?"

Der Ausdruck nar igi suhur-la $a_{2}$ „Musiker vor der kezertum“ ist nur hier bezeugt. kezertum-Frauen sind für Mari, Kiš und Larsa am Tempel wie auch am Palast belegt, wo sie an kultischen Festen teilnahmen, in deren Verlauf sie möglicherweise auch selbst musizierten. ${ }^{48}$ Der „Musiker vor der kezertum“ könnte entweder eine Position im Rahmen der Musizierpraxis kennzeichnen, vielleicht einen Anleiter oder Vorsänger, oder sich konkret auf ein Vorsteheramt am Tempel oder im Palast beziehen. ${ }^{49}$ Da der Ausdruck jedoch urkundlich nicht weiter belegt ist, bleibt letztere Annahme zweifelhaft.

Der nar igi lugal ist für das zweite Jahrtausend sonst nur noch in einer Isin-zeitlichen Urkunde bezeugt. ${ }^{50}$ Dem Namen nach bezeichnet der Ausdruck die Position des ersten Hofmusikers vor dem König.

Die Komposita der Zeilen 648-648c sind einmalige Wortverbindungen mit nar, die Stimmqualität und Singart eines Musikers bezeichnen. ${ }^{51}$ Auf den schlechten Sänger von 648c könnte mit nar ze $\mathrm{ze}_{2}$-za in Zeile 648d ein weiterer stimmschwacher Musiker folgen, was in diesem Fall aber auf ein körperliches Hindernis zu beziehen ist, etwa ein Stottern, Jappen oder Nuscheln. ${ }^{52}$

\footnotetext{
${ }^{48}$ S. hier Kapitel 7.3.

${ }^{49}$ Vom ugula suhur-1a 2 (kezertim) zu unterscheiden.

${ }^{50}$ BIN 7, 69 (Di a); s. a. hier Kapitel 5.2.1.
}

51 Ausführlicher in Kapitel 5.3.1. Zum Vokalisten [na]r inim-bal-bal vgl. außerdem inimbal-bal = $m u$ - $t a-m u-u_{2}$ in $\mathrm{Lu}_{2}=\check{s} a$ IV 244 (MSL 12, 136) „Redner/Sprecher“(?); vgl. AHw 91b. Mit diesem Ausdruck könnte auch ein Bezug zur Gattung der bal-bal-e-Lieder vorliegen, deren Kennzeichen ein 'hin- und hergeworfener Gesang', also eventuell eine Form des gesungenen Dialogs ist; anders eme-ur ${ }_{\mathrm{x}}$ (URI.KI)- bal-b [al-1a?...] im Examenstext A 25 akk. [li-ša $a_{2}$-an ak]-ka-di-i e-ni-ta bei Sjöberg 1975b, 142-143 ,"veränderte' akkadische Sprache“ im Sinne einer Übersetzung vgl. Seminara 2002, 246-247; s. a. die Vogelart in imbal-bal ${ }^{\text {mušen }}$ in aB Ur ${ }_{5}$-ra sowie in Nanše B; Veldhuis 2004, 256.

${ }^{52} \mathrm{~S}$. aB Lu $\mathrm{Lu}_{2}$-Azlag B Kol. v 8. $\mathrm{lu}_{2} \mathrm{ze}_{2}-\mathrm{za}=h a-s u-u_{2}$ (MSL 12, 183) zwischen igi-Komposita, zuletzt Z. 7. $1 \mathrm{u}_{2}$ igi-su $\mathrm{su}_{4}-\mathrm{su}_{4}=z a$-ar-ri-qum „Mann mit 'schillerndem' Auge“, und Z. 9. $1 \mathrm{u}_{2} \mathrm{gu}_{3}-\mathrm{de}_{2}-\mathrm{de}_{2}=\check{s} a-a s_{2}-s a_{3}-a-u_{3}$; AHw 1194b šassā'u ,Rufer(in), Schreier(in)“, treffender „,wailer (?)“ nach Taylor 2001, 223. Gegen AHw 331a hassûm, hassājûm „'an Haarausfall leidend?" ist der Ausdruck nach seinem lexikalischen Kontext auf ein körperliches Merkmal, hier die Stimme zu beziehen. Volk 2000, 17 Anm. 80 gibt den Ausdruck daher als „an einem Sprachfehler leidend“"wieder. Auch im Streitgespräch B Zeile 3 (ETCSL 5.4.11) ist der Ausdruck negativ konnotiert. Eine Ableitung von (h)az/sû ,seufzen; jappen“, das aB für Mensch und Tier belegt ist, wäre zu erwägen; AHw 92b; CAD A/2 528b ,to produce unnatural sound". 
Der nar hal-1a tuš-a in Zeile 649 bezeichnet wie auch nar-tur einen Musiker, der sich in Ausbildung befindet. ${ }^{53}$ Auf die Position eines Musikers am Kultschrein, also in direkter Nähe zur Gottheit, scheint der Ausdruck nar eš ${ }_{3}$ a zu verweisen. ${ }^{54}$ Der Ausdruck nar pad ${ }_{3}$-da wird in der kanonisierten Fassung $\mathrm{Lu}_{2}=\check{s} a$ akkadisch amru ,ausersehen“ geglichen, eine entsprechende

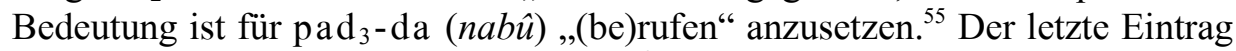
könnte auf einen Solosänger verweisen ${ }^{56}$ oder aber als nar keš ${ }_{2}$-da auf eine Tempelpfründe entsprechend dem gudu $\mathrm{kes}_{2}$-da als Bezeichnung eines Amtes am Tempel des Ninurta. ${ }^{57}$

Die einmaligen Komposita, wie sie in lexikalischen Listen angetroffen werden, müssen kein Alltagsvokabular widergeben. Vielmehr bilden sie eine Zusammenstellung des in literarischen Texten verwendeten Wortschatzes. ${ }^{58}$ So sind einige der aufgeführten Termini in den Zeilen 648-648b der Hymne IšmeDagan $A(+V)$ enthalten, wo sie ähnlich in Form einer Auflistung angegeben werden. ${ }^{59}$

Aus Alltagsdokumenten sind neben den gängigen und hier kurz vorgestellten lexikalischen nar-Komposita noch der ugula nar, der „Musikeraufseher“, sowie in Ur ein nar-a- $\mathrm{u}_{3}-\mathrm{a}$ bekannt, der mit dem lexikalisch attestierten $\mathrm{a}-\mathrm{u}_{3}$ a in Beziehung gesetzt werden kann. ${ }^{60}$ Weiterhin erscheinen zwei jeweils nur einmal belegte Ausdrücke: ein sa g̃-nar namens Ilī-iqī̌sam in Ur und ein nar $\mathrm{ra}_{2}$-gaba, ein „Berittener“ mit Namen Ilī-bāni. ${ }^{61}$ Da der sag̃-nar in einer Zeugenliste genannt wird, könnte das Wort als Amts- oder Berufstitel einzuordnen sein, ausgehend von der Wortbedeutung sag̃ „Haupt, Spitze“ als Anleiter oder Solist ${ }^{62}$ oder aber entsprechend dem ugula nar als Vorsteher der Musiker. Der Ausdruck $\mathrm{ra}_{2}$-gaba bezieht sich nach Renger auf einen Lehensdienst des Musikers. ${ }^{63}$

\footnotetext{
${ }^{53}$ S. hier Kapitel 5.2.4.

${ }^{54}$ S. a. Taylor 2001, 216 ,singer of the shrine“.

${ }^{55} \mathrm{Lu}_{2}=s \breve{a}$ IV (MSL 12, 135) 217; vgl. AHw 44-45 zu amru I; hierzu Taylor 2001, 216, 223 "'selected' singer".

${ }^{56}$ Parallel zu gala-S̆ IR 3 -da nach CAD A/2 385 sub 3c) ,,solo(singer)“ und hier Kapitel 6.1.

${ }^{57}$ ARN 4+PBS 8/1, 2 (BS a) und JCS 3, 185b (o.D.) hier Kapitel 9.5.3 .

${ }^{58}$ Zur Korrelation von lexikalischen Listen und literarischen Texten des aB Schulkurrikulums s. Veldhuis 2004, 95-96 und passim am Beispiel der Hymne Nanše B.

${ }^{59}$ S. hier Kapitel 5.3.1.

${ }^{60} \mathrm{~S}$. hier die Kapitel 5.4.3.

${ }^{61}$ Renger 1969, 174, 179; UET 5, 440:13 (RS 40) und AbB 4, $12: 4$.

${ }^{62} \mathrm{Vgl}$. in $D I J$ 30. šir ${ }_{3}$-e sag̃-bi nu-mu-un-ne-pad 3 -ne ETCSL 4.08 .10 ,they did not declare the beginning of the song to them“; anders Alster 1985, 224:30 „They could not find the beginning of the song".

${ }^{63}$ Renger 1969, 186.
} 


\subsection{Organisation und Verteilung}

\subsubsection{Palast- und Hofmusiker}

Dass am Palast eines Königs auch Musiker vertreten waren, lässt sich für die altbabylonische Zeit am deutlichsten für die syrische Stadt Mari aufzeigen. ${ }^{64}$ Hierbei ist grundsätzlich zwischen der Position eines einzeln amtierenden Hofmusikers, der in unmittelbarer Nähe des Königs agiert, und den unter seiner Obhut sich befindenden Gruppen an Palastmusikern zu unterscheiden. Solche Gruppen sind außer für Mari nur noch für Isin sicher nachweisbar. Neben den zahlreichen Musikerhäusern, die in Texten des Lederarchivs genannt werden und mit großer Wahrscheinlichkeit dem Palast zuzuordnen sind, ${ }^{65}$ werden in drei weiteren Urkunden verschiedene Instrumente aufgelistet, die vor den König (igi lugal) gebracht wurden ${ }^{66}$ wohl um von Musikern am Hofe des Königs zu festlichen Anlässen gespielt zu werden.

Gruppen weiblicher Palastmusikerinnen könnten in drei fragmentarisch erhaltenen Listen aus Larsa genannt sein, ${ }^{67}$ was analog zu den Haremslisten aus Mari zu schließen ist. Andere vereinzelte Belege zu Musikergruppen lassen sich hingegen keinem institutionellen Kontext zuweisen. ${ }^{68}$

Das Amt des Hofmusikers begründet sich auf eine nicht nur im Alten Orient weit verbreitete feste Institution. Dennoch sind altbabylonisch Vertreter einer solchen Position kaum belegt. Einmalig ist der nar igi lugal mit Namen ȘillīAdad in der Isin-zeitlichen Urkunde BIN 7, 69 (Di a). ${ }^{69}$ An ihn wird Bauland des Königs Damiq-ilǐšu ausgegeben. ${ }^{70}$ Ein nar igi lugal ist sonst nur noch lexikalisch in Proto- $\mathrm{Lu}_{2}$ attestiert. ${ }^{71}$ Der Terminus nar-lugal findet dementge-

\footnotetext{
${ }^{64}$ Ziegler 2007.
}

${ }^{65}$ S. hier Kapitel 9.4.3.2; anders Van de Mieroop 1987a, 107, der die Lederarchiv-Musiker dem Tempelpersonal zuordnet. Der Name des nar Išbi-Erra-šâm-balāțim in BIN 9, 415:15 (IšEr 24) verweist allerdings auf eine enge Beziehung zum König.

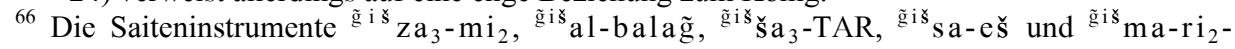
tum; BIN 9, 458:Rd (IšEr 14); BIN 9, 496:6 (IšEr 14); BIN 9, 257:7 (IšEr 14).

${ }^{67}$ S. hier Kapitel 9.2.2.4.

${ }^{68}$ Interessant auch der Brief AbB 6, 174 unbekannter Herkunft, der eine Schuldrückzahlung in Anwesenheit einer Musikerversammlung im Palast(?) betrifft 24-25 mahar nārī kalǐšu watram anaddin ,In Anwesenheit aller Musiker werde ich die zusätzliche Bezahlung verrichten.“; nach Frankena, ibid. Lesung unsicher.

${ }^{69}$ Kraus 1951, 111-112. Der angebliche Beleg für nar igi lugal in der Ur III-zeitlichen Urkunde NG II 110:14 ist gegen Hartmann 1960, 154 unsicher, da [igi] von Falkenstein 1956, 181 ergänzt ist.

${ }^{70}$ Insgesamt ist das Formular der Urkunde ungewöhnlich und der Preis für das Bauland des Königs unrealistisch hoch angesetzt; so Kraus 1951, 112.

${ }^{71}$ S. hier Kapitel 5.1. 
gen ausschließlich in Urkunden der Ur III-Zeit Verwendung. ${ }^{72}$ Im altbabylonischen Mari wird das Amt eines Hofmusikers, dem sowohl musikalische wie auch organisatorische Aufgaben zukamen, vom nar-gal ausgeführt, ${ }^{73}$ ein Titel, der in Babylonien zunächst dem obersten Tempelmusiker zukam. ${ }^{74}$

In Hammurabi-zeitlichen Briefen aus der Šamaš-hāzir-Korrespondenz werden einzelne nar mit Namen genannt, für deren Angelegenheiten bezüglich ihrer Pachtfelder und Ländereien der König selbst konsultiert wird. ${ }^{75}$ Auch nar-sa können nach einer Feldausgabenliste vom König mit Ländereien bedacht werden. ${ }^{76}$ Es bleibt unklar, ob es sich in diesen Fällen um höher situierte Musiker handelt, auch über Lehensverpflichtungen im Dienste des Königs standen.

Ein einziger Beleg, der möglicherweise in die Zeit des Samsuiluna von Babylon datiert, nennt einen Musiker des Kudurmabuk, der Ölrationen erhält. ${ }^{77}$ Da die Tafel auch Ausgaben für Kudurmabuk selbst verbucht, könnte es sich hier um die Ausführung eines Königskults um den längst verschiedenen LarsaDynastiegründer handeln.

Nach der mythologischen Erzählung Enki und Ninmah kam die besondere Position eines Hofmusikers dem von der Muttergöttin Ninmah erschaffenen Blinden zu. ${ }^{78}$ Er erhielt den Titel „Großdrache“ (ušumgal), ein Wort, das als Epitheton zumeist bei Göttern angetroffen wird. ${ }^{79}$ Als ušumgal-kalam-ma „Großdrache des ganzen Landes“ wird der persönliche nar des Gottes Ning̃irsu im Gudea Zylinder B tituliert. ${ }^{80}$

\footnotetext{
${ }^{72} \mathrm{Zu}$ den königlichen nar der Ur III-Zeit s. Pruzsinszky 2007.

${ }^{73}$ Ziegler 2007, 10-11.

${ }^{74}$ S. hier Kapitel 5.2.2.

${ }^{75}$ Die nar Ea-kīma-ilīja in AbB 9, 188:4 und AbB 4, 14:4.16; Ilī-iqī̌sam in AbB 4, $12: 4$ und Utumešaram in $\mathrm{AbB}$ 4, 62:5.

${ }^{76}$ Die nar-sa Etel-pī-Sîn, Sohn des Zar[riqum] und sein Bruder Inana-muzuše-nirg̃al in TCL 11, 146 (Ha 33) 20-23; s. a. hier Kapitel 5.4.2.

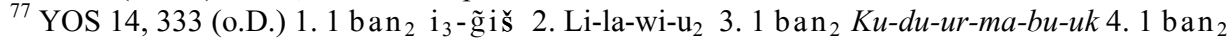

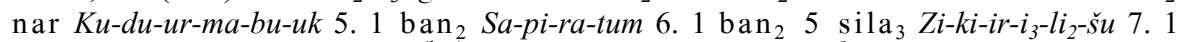

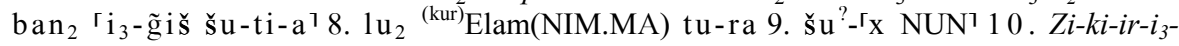
$l i_{2}-\check{s} u$.

${ }^{78}$ S. Kapitel 5.3.3.

${ }^{79}$ Tallquist 1938, 481-482.

${ }^{80}$ Gudea Zyl. B xviii 22. ušumgal-kalam-ma ti-gi $\dot{1}_{4}$-a mu-gub xix $1 . \mathrm{a}_{2}-\mathrm{la}_{2}$ ud-dam $\mathrm{sig}_{4}$ mu-na-ab-gi $i_{4}, /$ tigi/-Trommeln begleiteten Ušumgalkalama, und $\mathrm{a}_{2}-1 \mathrm{a}_{2}$ Trommeln donnerten für ihn wie ein Sturm“; vgl. Wilson 1996, 183; ETCSL 2.1.7. Derselbe Ausdruck ist auch Name des balag̃-Instruments des Ning̃irsu im Gudea Zyl. A vi 24, vii 24 und $B$ xv 21; Wilson 1996, 36, 40, 175.
} 
Aus literarischen Texten wird mit Namen nur noch Lugal-gaba-g̃al ${ }_{2}$, der nar des Gilgamesch bekannt, der einmalig in der Erzählung von Gilgamesch und der Himmelsstier auftritt. ${ }^{81}$ Dieser kündigt seinem König die Ankunft des feindlichen Himmelsstiers an, woraufhin sich Gilgamesch zum Kampf rüstet. ${ }^{82}$ Bemerkenswerterweise ist es ein nar gleichen Namens Lugal-gaba-g̃al 2 , der in der Gudam-Erzählung dem Zerstörung androhenden Wesen Gudam mit einem Lied entgegentritt. ${ }^{83}$

In den Selbstlobhymnen des Šulgi und des Išme-Dagan sind es ausschließlich anonyme nar oder auch nar-gal, die mit ihren Hymnen den Ruhm des Königs besingen und seinen Namen für alle Zeiten erhalten sollen ${ }^{84}$ Bei IšmeDagan sind dieselben Musiker auch für das Dichten und Verfassen der entsprechenden Hymnen zuständig.

Insgesamt lässt sich aus dieser Beleglage für die Position des ersten 'Hofmusikers' feststellen, dass für das entsprechende Amt keine einheitliche Terminologie besteht. Während Isin-zeitlich noch einmalig ein nar igi lugal bezeugt ist, wird die entsprechende Position zur Ur III-Zeit vom nar-lugal und in Mari vom nar-gal eingenommen. Unter Hammurabi von Babylon könnten Musiker gleicher Stellung wiederum über einfaches nar bezeichnet worden sein. Dass das Amt eines Hofmusikers trotz fehlender terminologischer Einheit dennoch $\mathrm{zu}$ allen Zeiten Bestand hatte, ist auch für die jüngeren Epochen grundsätzlich anzunehmen.

\subsubsection{Der 'Obermusiker' nar-gal}

Der Ausdruck nar-gal, wörtlich „großer Musiker“ wird in der bisherigen Literatur meist mit 'Obermusiker' wiedergegeben und ist ein ranghöherer Musiker als der nar. ${ }^{85}$ Der Terminus findet bereits in frühsumerischen Verwaltungstexten Erwähnung, ${ }^{86}$ altbabylonisch ist er in Urkunden und Briefen mehrfach bezeugt, wobei er im Unterschied zum nar ausnahmslos als Einzelperson auftritt. ${ }^{87}$ Vertreter dieser Rangposition sind in den Städten des südlichen und mittleren Mesopotamien ausschließlich männlich. ${ }^{88}$

\footnotetext{
${ }^{81}$ Lugal-gaba-g̃ar in der Meturan-Version. Zuletzt Cavigneaux/Al-Rawi 1993a, 97-136. Der früheste Textvertreter dieser Komposition datiert in die Ur III-Zeit und stammt aus Nippur; Cavigneaux/Al-Rawi 1993a, 101-103 Text Na. Die Zugehörigkeit des um 2600 datierten Textes SC 2652/3 der Schøyen-Sammlung ist nach George 2003, 6 Anm. 14 noch zu verifizieren; hierzu auch Alster 2004, 33-34 Anm. 15.

${ }^{82}$ Cavigneaux/Al-Rawi 1993a, 124; George 2003, 12.

${ }^{83}$ Gadotti 2006, 69-72.

${ }^{84}$ Šulgi A 81; Šulgi B 326-331; Šulgi D 368-370; ك̌ulgi E 63-73; IšD A(+V) 330-339, 384-393.

${ }^{85}$ Hartmann 1960, 147; Renger 1969, 184; AHw 746b; CAD N/1 352a nargallu „chief musician".

${ }^{86}$ Hartmann 1960, 147; nA lu 2 nar-gal/nar - $_{3}$ gal $_{2}$ (nargallu); Menzel 1981, 254-255.

${ }^{87} \mathrm{nA}$ ist allerdings die Beteiligung einer Gruppe $1 \mathrm{u}_{2}$ nar-gal-meš an einem Ritual bezeugt;
} 
Insgesamt sind aus Zeugenlisten, seltener auch Rationenlisten, zehn nar-gal in den Städten Ur, Nippur, Larsa und Sippar namentlich identifizierbar:

Tabelle 1: nar-gal an altbabylonischen Tempeln

\begin{tabular}{|l|l|l|}
\hline Ur & $\begin{array}{l}\text { (Nanna/Ningal - Ekišnugal ?) } \\
\text { Ningal - Ekišnugal }\end{array}$ & $\begin{array}{l}\text { Ir-Nanna (RS 2) } \\
\text { Ir-Ningal (RS 34) }\end{array}$ \\
\hline Nippur & & Lugal-gabari-nutuku (RS 25) \\
& $\begin{array}{l}\text { (Ninurta - Ešumeša ?) } \\
\text { (Ninurta - Ešumeša ?) }\end{array}$ & $\begin{array}{l}\text { Lugal-melam-g̃ir (RS 50-55/Si 2) } \\
\text { Ka-Ninurta (RS 50-55/Si 2) } \\
\text { Sîn-erībam (Si 14) }\end{array}$ \\
\hline Larsa & & $\begin{array}{l}\text { Šu-Amurrum (Ha) } \\
\text { Ilī-iddinam (Si 7) }\end{array}$ \\
\hline Sippar & & Marduk-muballiṭ (Aș 10) \\
\hline Šaduppûm & (Šmaš - Ebabbar) & Sinn-mušallim (D.a.) \\
\hline
\end{tabular}

Von den namentlich bekannten nar-gal können nur die wenigsten eindeutig einem Göttertempel oder Kult zugewiesen werden, der unmissverständliche Ausdruck 'nar-gal des GN' ist nur zweimal belegt:
1. Larsa
Ilī-iddinam nar-gal Šamaš (YOS 12, 227:39 [Si 7])
2. Ur Ir-Ningal nar-gal Ningal (UET 5, 363:14 [RS 34])

Aus der Auflistung in Tabelle 1 wird deutlich, dass das Amt eines nar-gal in aller Regel von einer einzelnen Person innerhalb einer Stadt eingenommen wurde. Lediglich in Nippur sind zeitgleich zwei nar-gal bezeugt, welche möglicherweise an zwei unterschiedlichen Tempeln amtierten.

nar-gal werden in Rationenlisten über regelmäßige oder einmalige Ausgaben genannt, wobei in nur wenigen Texten auch der Anlass der Ausgabe vermerkt wird. So erhielt in Ur ein namentlich nicht genannter nar-gal Rationen zum ezem-mah-Fest des Stadtgottes Nanna. ${ }^{89}$ In Larsa war ein nar-gal an einem mehrtägigen Opferfest beteiligt, wobei er ausschließlich unter dem Personal des Stadtgottes Šamaš aufgeführt wird. ${ }^{90}$ Der für Šaduppûm belegte nar-gal Sîn-mušallim wird in einer Rationenliste neben mehreren nar er-

Menzel 1981, 254 und T 94 Vs I 24'.

${ }^{88}$ Anders in nA Zeit: Henshaw 1994, 100 und Menzel 1981, T 35.37 Rs V 23' munus-nar ${ }_{3}$ gal $_{2}$-(Rasur)-DUG als ,nargallutu-Sängerin“? Die munus-nar-meš gal in Texten des Palastarchivs von Mari sind hiervon zu unterscheiden und bezeichnen wohl eher 'ältere $\mathrm{Mu}$ sikerinnen'; Ziegler 1999, 71 + Anm. 470.

${ }^{89}$ YOS 5, 163 (WS 5); s. hier Kapitel 9.1.3.

90 HUCA 34, 1ff. (RS 2); s. hier Kapitel 9.2.3; zur Datierung des Textes s. Westenholz/Westenholz 2006, 7. 
wähnt, die möglicherweise für ein Fest der Inana von Kuzaja entlohnt wurden. ${ }^{91}$

Für das Amt eines nar-gal kann insbesondere für die frühaltbabylonische Zeit in den Städten Süd- und Mittelbabyloniens Ur, Larsa und Nippur eine hohe Position am Tempel angenommen werden, teilweise gehörten die Inhaber eines solchen Amtes einer einflussreichen Musikerfamilie an. ${ }^{92}$ Eine wichtige Beobachtung aus der im Kapitel 9 geführten prosopographischen Studie kann für die zeitliche Verteilung der Belege zum nar-gal erbracht werden: So fällt auf, dass aus Texten der nordbabylonischen Städte Kiš, Dilbat und Sippar Amnānum (Tell ed-Dēr) insbesondere zur spätaltbabylonischen Zeit keine nargal bekannt werden. Die einzige Ausnahme bildet die Ammișaduqa-zeitliche Urkunde CT 8, 21c aus Sippar, die die igisûm-Steuerabgabe eines nar-gal verzeichnet. Derselbe Musiker war gleichzeitig einem Hauptmann (abi șābim) als Vertreter des Palastes unterstellt.

Die vorgestellte Beleglage zum nar-gal legt verschiedene Schlussfolgerungen zu dieser Position nahe. So könnte sie in spätaltbabylonischer Zeit innerhalb der Tempeladministration an Bedeutung und Einfluss verloren haben. Bis zum Erscheinen neuer Texte ist sogar zu bezweifeln, dass an den Tempeln der nordbabylonischen Städte Kiš und Dilbat überhaupt noch nar-gal tätig waren. Es könnte außerdem angenommen werden, dass analog zur Situation in Mari, wo der nar-gal dem Palastpersonal angehörte, auch in Nordbabylonien das entsprechende Amt auf eine Königsresidenz in Babylon oder auch Sippar beschränkt war. Es bleibt zu hoffen, dass über die Veröffentlichung der Sipparund Babylon-Texte hierzu neue Informationen bekannt werden.

Künstlerisches Personal im Umfeld des nar-gal sind die hupp $\hat{u}(m)$-Tänzer und der aluzinnu(m)-Gaukler. ${ }^{93}$ Während die Tänzer dem nar-gal direkt unterstanden, gehörte der einmalig in diesem Umfeld genannte Gaukler einer Gruppe von Lohnarbeitern an. Aus dieser, wenngleich jeweils nur einmaligen Beleglage, lässt sich schließen, dass der nar-gal als oberste Instanz bei der Organisation künstlerischer Darbietungen auftrat, und also nicht nur die musikalischen Inhalte, sondern auch die verschiedenen damit zusammenhängenden administrativen Schritte beaufsichtigte. Ähnliche Aufgabenbereiche wurden von Ziegler für das Amt des nar-gal im altbabylonischen Mari festgestellt, wo dieser in gleicher Weise für die Organisation des musikalischen Personals und die Auswahl der Musiker und Instrumente zuständig war. ${ }^{94}$

\footnotetext{
${ }^{91}$ YOS 14, 75:10 (o.D.); Simmons 1960, 54 No. 88.

${ }^{92}$ Vgl. die Familie des Lu-Ninurta in Nippur; Kapitel 9.5.2.6.

${ }^{93}$ AbB 9, 193:14-15 aus Larsa; AbB 8, 109:4-10 (H.u.) und hier Kapitel 5.5.

${ }^{94}$ Ziegler 2007, 10, 51-56.
} 
Nur wenige literarische Texte berichten vom musikalischen Repertoire eines nar-gal. Die Hymne Nanše $A$ nennt ihn als Spieler des 'Ibex-Horns' (a tarah) und Sänger eines Širku(g), das er an den Tempel der Nanše in Sirara richtet. ${ }^{95}$ Auch in der Uruk Klage, die dem Išme-Dagan zugeordnet ist, werden zum Ende hin mehrere 'große nar' genannt, die in Uruk ihre Lieder zum Gedenken an die tragischen Geschehnisse um Sumer und Akkad singen. ${ }^{96}$ In der Selbstlobhymne Išme-Dagan A $(+V)$ werden schließlich nar-gal neben den um-mi-a, den „Gelehrten“, als Verfasser von Hymnen zum Preis des Königs angesprochen. ${ }^{97}$ Bei der Analyse der literarischen Belege bleibt allerdings zu bedenken, dass die Wortkombination nar gal nicht zwingend auf das gleichnamige, vornehmlich aus administrativen Texten bekannte Amt verweist, sondern auch einen nar als besonders herausragend auszeichnen kann. In diesem Sinne sieht sich auch Šulgi in seiner Hymne Šulgi E als 'großen Musiker'. ${ }^{98}$

Aus der literarischen Darstellung zum nar-gal wird deutlich, dass er in seinen musikalischen Fertigkeiten weder auf ein Instrumentarium noch auf eine Singart beschränkt war. Schließlich konnte er auch als Dichter und Liedsetzer tätig sein. In der Hymne Nanše A musizierte der nar-gal allein. Dass dieser Musiker zumeist einzeln agierte, wird auch durch die Auswertung der Alltagsdokumente bestätigt. Damit ist der nar-gal als Solist zu identifizieren, der instrumental oder auch vokal musizierte. Wenige Textbelege aus Ur, Larsa und Šaduppûm legen außerdem nahe, dass er größere Musikergruppen, die einen Chor oder auch ein Instrumentalensemble bildeten, anführte, ob als Vorsänger oder Anleiter ist jedoch nicht bekannt. ${ }^{99}$

\subsubsection{Der einfache nar}

Im Gegensatz zum nar-gal sind nar weitaus zahlreicher vor allem in den Städten Süd- und Mittelbabyloniens belegt. ${ }^{100}$ Meist sind es Einzelpersonen, die unter Angabe ihres Namens angetroffen werden, vereinzelt sind auch Gruppen anonymer Musiker bezeugt, die Empfänger von Rationen sind.

\footnotetext{
${ }^{95}$ Nanše A 44-46; Heimpel 1981, 84-85; ETCSL 4.14.1.

${ }^{96}$ Uruk Klage Text H 27 nar gal-zu šir ${ }_{3}$-ra hu-mu-ni-ib-tum ${ }_{2}$-tum ${ }_{2}$,Mögen deine 'großartigen' Musiker dort Lieder singen“; vgl. Green 1984, 276:12.27; ETCSL 2.2.5.

${ }^{97}$ Ludwig 1990, 167-168:18-20, 174, 189-190; s. a. ETCSL 2.5.4.01 Iš $A+V$ 333. um-mi-a nar gal-gal-e-ne 334. ša $a_{3}-b a l_{a}-1 a_{2}$ he $_{2}$-ni-in-gar,„I installed $\ldots$ my scholars and chief singers".

${ }^{98}$ Šulgi E 155 (ETCSL 2.4.2.05).

${ }^{99}$ S. zu den einzelnen Stadtkapiteln; zu Šaduppûm YOS 14, 75:10 (o.D.) bei Simmons 1960, 54 No. 88.

${ }^{100}$ Hier findet sich die Zusammenführung der in Kapitel 9 durchgeführten Einzelstudien.
} 
Insgesamt lassen sich im untersuchten Textkorpus über 60 nar-Musiker namentlich identifizieren. Sie werden überwiegend als Zeugen und in Ausgabenlisten genannt. ${ }^{101}$ Neben Getreide- und Bierrationen sind sie in Larsa, Ur und Uruk auch Empfänger edler Materialien, Bronze und Silber sowie Wolle. ${ }^{102}$ Schließlich sind sie nach Texten aus Isin und Ur auch für zahlreiche Musikinstrumente, vom Spielen bis hin zur Aufsicht über Reparaturen und die Lieferung zuständig. Die Musiker des Handwerkerarchivs von Isin sind vor allem Lieferanten des ${ }_{\text {ğiš }}^{\tilde{z}} / \mathrm{zami} /$, daneben auch der Saiteninstrumente ${ }_{\text {sis }}^{\tilde{s}}$ maritum und ğišš $\mathrm{a}_{3}$-TAR. In Ur empfing ein Tempelmusiker namens Dudu ein ${ }^{\tilde{g} i s ̌}$ al-g̃ar.

Für die frühaltbabylonische Zeit unter Rīm-Sîn, Hammurabi und Samsuiluna sind nar und nar-sa auch als Haus- und Feldbesitzer bekannt. ${ }^{103}$ Vom Palast erhielten sie Pachtfelder und entrichteten einen Teil ihrer Ernte als biltum-Abgabe. ${ }^{104}$ Ein Brief aus dem nahe Kiš gelegenen Lagaba zeigt weiterhin, dass nar selbst über ihre eigenen Felder biltum einnahmen, ob für den Palast oder für den Tempel wird hierbei allerdings nicht klar. ${ }^{105}$

Für die spätaltbabylonische Zeit werden einzelne nar nur noch aus Erntearbeiterlisten aus Sippar bekannt. ${ }^{106}$

Neben den einzeln mit Namen belegten Musikern nennen Texte aus Isin auch Gruppen von nar, die möglicherweise einem Aufseher oder Musiklehrer zugeordnet waren. ${ }^{107}$

${ }^{101}$ Išçāli: OBTI 140:3 (o.D.); Larsa: YOS 5, 216:1-2 (Sid 7) an nar-meš und 'munus-na'r rmeš; TCL 10, 45:8 (RS 16) Silber an den nar Šu-Sîn; Šaduppûm: YOS 14, 75 (o.D.); s. a. HUCA 34, 1 ff. hier Kapitel 9.2.3. Belege zu n ar als Zeugen unter den einzelnen Stadtkapiteln und im Musikerkatalog; s. a. Erībam-Sîn in YOS 14, 46:4 (o.D.[früh-aB]) unbekannter Herkunft.

${ }^{102}$ S. zu den einzelnen Städten; für Uruk BaM 24, 151 Nr. 202:I 29' (o.D.) Silbergeschenk für den $n$ ar Ipqu-Arahtum und BaM 23, 136 Nr. 173 (D.a.) ein nar Šēp-Sîn, Sohn des ${ }^{d}[X]$ als Überbringer von Vlies und Wolle der Kaufleute.

${ }^{103}$ AbB 9, 188 (o.D.) und AbB 4, 14 (o.D.) zum Feld des nar Ea-kīma-ilija; YOS 8, 6:4 (RS 3) mit Nachbarhaus des nar Ipquša; AbB 4, 62 (o.D.) zum Feld des nar Utu-mešaram; AbB 4, 12 (o.D.) zum Feld des Ilī-iqī̌sam; TCL 11, 146:20-23 (Ha 33) Versorgungsfelder für die nar-s a Etel-pī-Sîn und Inana-muzuše-nirg̃al, den Söhnen des Zarriqum.

${ }^{104}$ Zum Pachtland des Palastes und zum komplexen Begriff der biltum-Abgabe s. Stol 2004, 758762.

${ }^{105}$ RA 90, 125 bei Tammuz 1996, 125-126 zum nar Pû-ilī; im Brief verweist der Absender in Vertretung des nar auf das Königsedikt des Samsuiluna Jahr 8, wonach der nar dem ilkuahhum-Status angehörte; zu diesem unklaren Terminus s. Stol 2004, 740 und Anm. 693.

${ }^{106}$ Sippar: Bēlānu CT 6, 23b:8 (Aṣ 17+c); Ir-Sig̃ar in MHET I/1, 53:8 (Aṣ 1), MHET I/1, 60:5 (o.D.), MHET I/1, 54:9' (o.D.), MHET I/1, 56:12 (o.D.) und MHET I/1, 51:4 (o.D.); Dilbat: VS 7, 155 (D.a.[Ad/Aṣ]) Rs IV 55: Tarïbu.

${ }^{107}$ Der Titel der vorstehenden Person, ob Aufseher oder Musiklehrer wird nicht angegeben; zu Mari s. Ziegler 2007, 13-20 und hier Kapitel 9.4.3.2. 
Eine besondere Art der Unter- oder Zuordnung von Musikern findet sich in einem Text aus Šaduppûm. ${ }^{108}$ In dieser Gersterationenliste YOS 14, 75 werden neben dem sukkal der Kuzaja (Z. 2) auch ein Opferschaupriester (Z. 5.16 maš- id $_{2}-g_{i d}$ ) und mehrere Musiker als Empfänger von Rationen aufgelistet. Hierunter zählen der nar-gal Sîn-mušallim (Z. 10), der nar-Vorsteher Sînmuballit (Z. 15 šapir nārî̀) sowie fünf nar-Musiker, die jeweils einer Person zugeordnet sind. ${ }^{109}$ Möglicherweise handelt es sich in diesem speziellen Fall um Musiker, die Einzelhaushalten angehörten und aus Anlass eines Festes für Inana von Kuzaja dem nar-gal, der obersten organisatorischen Instanz, sowie dem Vorsteher für gemeinsames Musizieren unterstellt wurden. ${ }^{110}$ Dass Musiker auch Privathaushalten angehörten, ist sicher anzunehmen. Für die Umgebung von Sippar ist eine Musikerin bekannt, die dem Haushalt einer nadìtum und Prinzessin angeschlossen war. ${ }^{111}$ Zwei weitere Texte unbekannter Herkunft, die dem Archiv eines gewissen Awìl-Ea entstammen, nennen ein Haus der Musikerinnen, das möglicherweise in denselben Kontext zu stellen ist. ${ }^{112}$

Insgesamt zeigen die Belege, dass das Wort nar unabhängig von einer Institution auf den Beruf des Musikers verweist. Einzelne dieser namentlich belegten Musiker konnten der Tempel- wie der Palastadministration, oder auch einem Privathaushalt angehören.

\subsection{4 'Kleine' und 'lernende' Musiker: nar-tur und nar hal(-1a)-tuš-a}

Termini, die auf den Status eines Musikschülers verweisen, könnten mit nartur, „kleiner Musiker“, sowie dem inhaltlich verwandten nar hal(-la)-tuš-a „Musiker, der auf dem 'Schenkel"! sitzt" ${ }^{\star 113}$ vorliegen, die in der kanonisierten Fassung $\mathrm{Lu}_{2}=\check{s} a$ beide dem akkadischen Lehnwort hallatušš $\hat{u}$ gleichgesetzt werden. ${ }^{114}$ In derselben Liste wird hallatušš $\hat{u}$ auch gala-hal-tuš-a und aluzinnu entsprochen. ${ }^{115}$ Das Kompositum nar-tur wird daneben auch schon altbabylonisch ins Akkadische wörtlich als nāru șehru übertragen. ${ }^{116}$ Zwar sind

\footnotetext{
${ }^{108}$ YOS 14, 75 (o.D.) bei Simmons 1960, 54 No. 88.

${ }^{109}$ YOS 14, 75 (o.D.) 3. [x U]S̆ ${ }^{2}$-UR-ni nar Ha-ab-li-ia 6. 5.0.0.0 Ka-ki nar Ta $a_{3}$-ab-ši-i-rum 9. 3.3.0.0 Du-lu-qum nar ${ }^{\mathrm{d}}$ EN.ZU-mu-ba-li $i_{2}-i t$ 12. 6.2.3.0 Zabardabbû(UD.KA.BAR.TAB) nar Mi-ta-ku-ma-ta 14. ' ${ }^{\mathrm{X}}$ E'-ra-「a-r'i nar Warad-Sîn.

${ }^{110}$ Anders der nar $\check{s} a_{2}$ Ku-du-ur-ma-bu-uk in YOS 14, 333 (o.D.).

111 JCS 2, 109 Nr. 18:4 (Ae 28) und hier Kapitel 9.6.2.4.

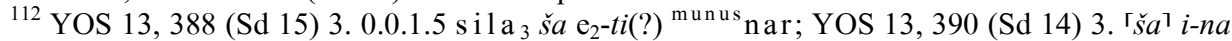
$\mathrm{e}_{2}{ }^{\text {munus }}$ na-ar-ti.

${ }^{113}$ Vgl. Taylor 2001, 223 ,(x) who sits on the crotch“.

${ }^{114}$ CAD H 45a „,apprentice“; AHw 312 „Lehrling“; dementsprechend Renger 1969, 184; $\mathrm{Lu}_{2}=\check{s} a$ IV (MSL 12, 135) 215. nar-tur = hal-la-tu-šu-u 216. nar hal-tuš-a = KI.MIN; aB Lu L $^{-}$ Azlag A (MSL 12, 166) 285. lu $\mathrm{u}_{2}$-hal- ${ }^{\ulcorner} \mathrm{la} \mathrm{a}^{1}-\mathrm{tu} \breve{s}-\mathrm{a}=\check{\text { sa }}$ ha-la-tuš-še-e.

${ }^{115} \mathrm{Lu}_{2}=\check{s} a$ IV (MSL 12, 134) 171. gala-hal-tuš-a = ŠU-u $u_{2}$; (MSL 12, 136) 248. hal-1a-tuš$\mathrm{a}=\operatorname{MIN}(a-l u-z i-n u)$.

${ }^{116}$ Proto-Lu $\mathrm{Lu}_{2}$ aus Boghazköy (MSL 12, 83 Fragment III) 9. [nar-tu]r = lu $\mathrm{u}_{2}-\mathrm{n}$ ar șe-[eh-ru];
} 
beide Termini bereits altbabylonisch lexikalisch bezeugt, doch sind bislang keine Belege aus urkundlichem Material bekannt geworden. ${ }^{117}$ Im zeitgleichen Mari fällt die Beleglage zu nar-tur dementgegen sehr reichhaltig aus. Aus den Palasttexten und Listen des Zimrī-Lîm ist eine Gruppe von 10 bis 14 jungen Musikern bekannt, die dem Königsharem angeschlossen waren. ${ }^{118}$ Demselben Harem gehörte außerdem eine Gruppe von 'sehr jungen Musikerinnen' an, den munus nar-tur-tur. ${ }^{119}$ Gleiche Gruppen sowohl weiblicher als auch männlicher Musiker sind Ur III-zeitlich in Verwaltungstexten aus Ur und G̃irsu auch im Zusammenhang mit dem um-mi-a „Gelehrten“ bezeugt. ${ }^{120}$

In literarischen Texten erscheint nur einmal ein nar-tur in der sumerischsprachigen Komposition Inana und Šukaletuda, wo er im Palast des Königs sein Lied vorträgt. ${ }^{121}$ Das Wort hallatušš $̂$ ist literarisch in einer fragmentarischen Šulgi-Hymne (PBS 1/1, 11) neben $n \bar{a} r u(m)$ bezeugt, wo es Sumerisch nar pa-ah-tuš(-a) „Musiker, der auf dem Bein sitzt(?)“ gleichgesetzt wird. ${ }^{122}$ Weitere Termini für Personen, die sich im Ausbildungsstatus befinden, sind nach Ziegler die hauptsächlich aus Mari bekannten a/eštalu( $(m)$ oder a/eštalìtu $(m) .{ }^{123}$ Auch hierzu lassen sich keine entsprechenden Belege aus dem babylonischen Raum finden.

Insgesamt lässt sich für ḩal(-la)-tuš-a eine auf lexikalische und literarische Texte beschränkte Verwendung feststellen, während für den Terminus nar-tur(-tur) zu vermuten bleibt, dass er zur Bezeichnung eines jungen wohl in Lehre stehenden Musikers im Mesopotamien der altbabylonischen Zeit ungebräuchlich ist.

SK 79 nach CAD N/1 376-377; hierzu auch Volk 1995, 210:298.

${ }^{117}$ Proto-Lu 649 (MSL 12, 56); Text B ${ }_{3}$ Kol. ii 6 (MSL 12, 67).

${ }_{118}$ Ziegler 1999, 73-76 und 132 Nr. 3 ii 24 . nar-tur-meš .

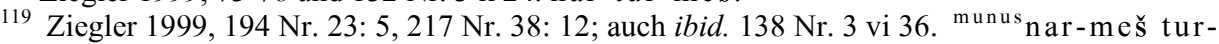
tur(!).

${ }^{120}$ In Ur: UET 3, 1113 (o.D.) 2. nar-tur-tur; UET 3, 63 (0.D.) 3. siskur 2 nar munus turtur; in G̈irsu: SAT 1, 118:Vs 7. nar tur um-mi-a ,junger Musiker des Gelehrten(?)“; hierzu ausführlich Pruzsinszky 2009 zu um-mi-a im Zusammenhang mit Musik s. hier Kapitel 9.5.2.4.

${ }^{121}$ Volk 1995, 114, 210:298

122 Westenholz 2005, 355 (PBS 1/1, 11): 82 er $_{2}\left(<\mathrm{A}>\right.$.IGI)-šem s $_{3}$ nar pa-ah-tuš-a ka *nig̃in-ta // e $\mathrm{e}_{3}-\mathrm{de}_{3}$-me-eš 50. si-pi $i_{2}$-it-tam na-ru hal-la-tuš-a ša pi-i-[šu-nu] up-p[u$u_{2}$ ]; s. a. CAD S 299b sipittu (Koll.); zu /pah/ = puridu „Bein“ s. CAD P 517b; Westenholz 2005, 364-365 versteht die Zeichenfolge pa-ah für pa-pah „Cella“ und übersetzt ,the singers who are sitting in the cella are those giving out of (their) round mouths the eršemma lament".

${ }^{123}$ Ziegler 2007, 18; vgl. AHw 85a ,eine Art 'Musiker'“. 


\subsection{5 'Musikerhäuser' und Aufseher}

Der Ausdruck $\mathrm{e}_{2}\left(\mathrm{lu}_{2}\right)$-nar „Musikerhaus“ ist mehrfach in Texten aus Isin sowie je einmal in Larsa und in Išçāli bezeugt. ${ }^{124}$ Mit ihm wird entweder auf eine Institution oder konkret auf ein Gebäude verwiesen, das eine größere Gruppe von Musikern beherbergte. Aus Isin sind solche Häuser getrennt nach Frauen ( $e_{2}$ nar-munus) und Männern $\left(e_{2}\right.$ nar) belegt. Zudem konnten sie auch auf bestimmte Instrumentalisten beschränkt sein, in dieser Hinsicht ist wohl das $\mathrm{e}_{2}$ nar ${ }^{\tilde{s}} \mathrm{iš} a-a-a b-d u ~ z u$ interpretieren. ${ }^{125}$ An diese Häuser wurden durch Musiker auch Musikinstrumente geliefert, in der Regel die Saiten-

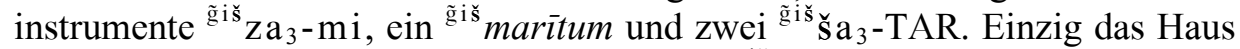
der $\mathrm{e}_{2}$ nar munus zi-ik-rum erhielt ein ${ }^{\tilde{g} i s ̌} \mathrm{dub}_{2}-\mathrm{dub}_{2}$-ba, höchstwahrscheinlich eine Trommel.

In den Texten zum Palastharem von Mari wird mehrfach ein bit tegêtim, „Haus der tegêtim“" genannt, in dem sich überwiegend die jungen Musikerinnen aufhielten, weshalb es von Ziegler als eine Art 'Musikkonservatorium' gedeutet wird. ${ }^{126}$ Des Weiteren wird auch das bit mummim in Mari als Ausbildungsstätte für Musiker identifiziert, die dem obersten Musiker, dem nar-gal am Palast unterstanden. ${ }^{127}$

Auch bei den Isin-Häusern könnte es sich um Ausbildungsstätten handeln. Einige dieser Häuser werden auch Einzelpersonen zugeordnet, die den dort wohnhaften Musikern möglicherweise als Aufseher oder Lehrer vorstanden. ${ }^{128}$ Die Personen Ubarrum, der auch als nar belegt ist, und Zikrum, sind andernorts für die Auslieferung und wohl auch für den Bau von Musikinstrumenten verantwortlich. ${ }^{129}$ Da diesen Personen weder eine Berufsbezeichnung noch ein Titel beigegeben ist, lässt sich nicht eindeutig feststellen, welche Position sie gegenüber den Musikern aus den 'Musikerhäusern' einnahmen.

${ }^{124}$ Isin: BIN 9, $441: 5$ (IšEr 9); BIN 10, 104:12 (IšEr 13); BIN 9, 348:8 (IšEr 18); BIN 9, 350:9 (IšEr 19); BIN 9, 451:9 (IšEr 22); BIN 9, 417:7 (IšEr 24); BIN 9, 352:5 (IšEr 13); BIN 10, 256:6 (IšEr 14); BIN 10, 82: 7 (D.a.); Išçālī: OBTI 182 (o.D.) 1. 1 ban $_{2} a-n a \mathrm{e}_{2}$ nar? (Lesung unsicher); s. a. die zwei Texte unbekannter Herkunft YOS 13, 338:3 (Sd 15) und YOS 13, 390:3 (Sd 14) zum Archiv des Awīl-Ea gehörig (H), wo ‘Öl des Getreides' bzw. 'Öl für die Ernte’ an ein „Haus der Musikerinnen“ ausgeteilt wird; Pientka 1998, 526 Anm. 3; Stol 1973, 226-227. Zu den „Musikerhäusern“ im Detail s. hier Kapitel 9.4.3.2.

${ }^{125}$ BIN 9, 352:5 (IšEr 13); ${ }^{\text {ğ } i \breve{a} a-a-a b-d u ~ i s t ~ m i r ~ a l s ~ N a m e ~ e i n e s ~ M u s i k i n s t r u m e n t s ~ a n s o n s t e n ~}$ unbekannt.

${ }^{126}$ Ziegler 1999, 94 und 2007, 79.

127 Ziegler 2007, 77-78.

${ }^{128}$ BIN 10, 82 (D.a.) 7. e 2 nar ki $u_{4}$-bar-ra; BIN 10, 104 (IšEr 13) 12. e $e_{2}$ nar-munus ki $u$ bar-ra; s. hier Kapitel 9.4.3.2.

${ }^{129}$ Der nar Ubar(rum) empfängt nach BIN 9, 496: 11 (IšEr 14) fünf fertig gestellte Musikinstrumente; Zikrum empfängt nach BIN 9, 444 (Šull 3) Herstellungsmaterialien für zwei ğ ${ }^{\mathrm{z}} \mathrm{Za}_{3}-\mathrm{mi}$. 
Das eigenständige Amt eines 'Musikeraufsehers' wird über den Terminus ugula nar angezeigt und ist bisher in den Städten Nippur, Larsa und Šaduppûm bezeugt, ${ }^{130}$ wobei die Belege aus Larsa die Söhne eines ugula nar nennen. Diese Söhne sind über die Ausführung eines Lehensdienstes (ilkum) in Form einer Reise dokumentiert. ${ }^{131}$ Neben dem ugula nar ist in Texten aus Nippur und Sippar auch der ugula ${ }^{\text {munus }}$ tigi bezeugt. ${ }^{132}$

Tabelle 2: Namentlich belegte 'Musiker-Aufseher'

\begin{tabular}{|l|l|l|l|}
\hline dumu ugula nar & Larsa & $\begin{array}{l}\text { Elmēšum } \\
\text { Ilī-hāzirīi }\end{array}$ & RS 56 \\
\hline ugula nar & Isin & - & IšEr 17a \\
\hline & Nippur & Erib-Sîn & Si 3 \\
\hline & Šaduppûm & Sîn-muballit & - \\
\hline ugula tigi & Nippur & Sîn-erībam & Si 10 \\
\hline & Sippar & Šumum-libši & Aș 10 \\
\hline
\end{tabular}

Die Existenz eines Aufseheramtes gibt Aufschluss über die Organisation der Musiker, die seit Rīm-Sîn von Larsa bis zur spätaltbabylonischen Zeit unter Ammișaduqa Bestand hatte. Wie Renger bereits zu Recht vermutete, lagen die Aufgaben eines Aufsehers wohl nicht im musikalischen, sondern eher im organisatorischen Bereich. ${ }^{133}$ Die unter seiner Aufsicht sich befindenden Musiker lebten wie die meisten Frauen- und Priesterinnengruppen, die ebenfalls Aufsehern unterstellt waren, in abgeschlossenen Wohnkomplexen unter der Obhut der Palast- oder auch Tempeladministration.

\subsection{Berufsbild des nar}

\subsubsection{Zur literarischen Darstellung}

Von allen bekannten Termini, die eine musizierende Person bezeichnen können, ist der Begriff nar inhaltlich am weitesten gefächert. In diesem Sinne wird er vor allem in literarischen Quellen verwendet, wo nur selten nar-Komposita

\footnotetext{
${ }^{130}$ Nippur: BE 6/2, 63:12 (Si 3); ARN 23+PBS 8/2, 169:12 (D.a); Isin: BIN 9, $532: 3$ (IšEr 23); Larsa: TCL 10, 112:23-24 (RS 56); Šaduppûm: YOS 14, 75 (o.D.) 15. In VS 8, 108/109:7 (Ha 4) ist nach Harris 1975, 174+Anm. 120 gegen Renger 1969, 179 keine ugula nar zu lesen.

${ }^{131}$ TCL 10, 112 (RS 56); s. a. Stol 2004, 750.

${ }^{132}$ Nippur: SAOC 44, 95:3 (Si 7); Sippar: CT 8, 21 c:9 (Aṣ 10); zu den tigiātum s. hier Kapitel 5.4.1.

${ }^{133}$ Renger 1969, 184.
} 
Teil I Die Musiker

auftreten. Damit reflektiert diese Textgruppe ein eher allgemeines Bild von den Tätigkeiten und Handlungsbereichen eines nar.

Über das Wort nar werden sowohl Sänger als auch Instrumentalisten angezeigt. Die Lieder, die der nar als Sänger vorträgt, werden mit den allgemeinen Begriffen en ${ }_{3}$-du oder šir ${ }_{3}$ bezeichnet. ${ }^{134} \mathrm{Zu}$ diesen zählen sowohl Götterlieder als auch Königshymnen. Andererseits kann der Vortrag eines nar auch durch einen konkreten Liedgattungsnamen angegeben sein, so wird in der Hymne Iddin-Dagan $A$ in Zeile 209 beschrieben, wie nar-Musiker ein „Herzerfreuungslied“ (šir ${ }_{3}$-ša $\left.a_{3}-h_{h u} l_{2}-1 a\right)$ für die Göttin Inana singen. ${ }^{135}$ Mit $\mathrm{s}_{\mathrm{ir}} \mathrm{r}_{3}-\mathrm{s̆}_{3}$-hul $\mathrm{l}_{2}$-la wird eine bestimmte Gattung von Götterliedern bezeichnet, die im musikalischen Vortrag möglicherweise durch das Spiel eines ${ }^{\tilde{g} i s ̌} \mathrm{Za}_{3}$ $\mathrm{mi}_{2}$-Instruments begleitet wurde. ${ }^{136}$

Als Instrumentalist wird der nar literarisch eher selten herausgestellt. In diesen wenigen Belegen wird ihm jedoch ein vielseitiges Instrumentarium zugeordnet. Im Gudea Zylinder B und in der Keš Tempel-Hymne spielt er zu Opferfesten und zur Freude der Götter das tigi, das ğišal-g̃ar, das mirìtum und das $\mathrm{a}_{2}-1 \mathrm{a}_{2}$, die sowohl als Saiten- als auch als Schlaginstrumente identifiziert werden können. ${ }^{137}$ Der nar bzw. nar-gal beherrschte außerdem das Saiteninstrument ${ }^{\tilde{g}} \mathrm{~s}_{\mathrm{s}} \mathrm{Za}_{3}-\mathrm{mi}_{2}$ sowie das Blasinstrument $\mathrm{a}_{2}$-tarah, das so genannte 'Ibex-Horn', welches er zur Begleitung von Opferhandlungen ertönen ließ. ${ }^{138}$ Über das allgemeine Wort nar wurden somit Musiker mit unterschiedlichsten instrumentalen Fertigkeiten benannt.

nar-Musiker bleiben in den meisten literarischen Belegen anonym. Ausschließlich in der Gudam-Erzählung sowie in Gilgamesch und der Himmelsstier begegnet uns ein Musiker mit Namen Lugal-gaba-gal 2 gagar. In beiden Erzählungen trägt er ein en ${ }_{3}$-du-Lied vor. ${ }^{139}$ Nach Ansicht Alsters und Gadottis gilt sein Vortrag der Vermittlung zwischen den Kontrahenten Gilgamesch bzw. Inana und dem Himmelsstier bzw. Gudam. ${ }^{140}$

${ }^{134} \mathrm{Zu}$ diesen zwei Begriffen s. a. hier Kapitel 11.1.1.

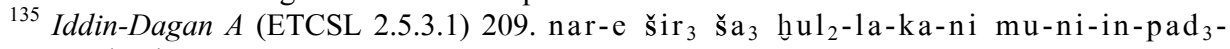
$\operatorname{pad}_{3}-\mathrm{de}_{3}$.

${ }^{136}$ S. Kapitel 12.2.9.

${ }^{137}$ Gudea Zyl. B x 9-15; Keš Tempel-Hymne (ETCSL 4.80.2) 118. nar ${ }^{\mathrm{kuš}} \mathrm{a}_{2}-1 \mathrm{a}_{2}$-e šeg ${ }_{11} \mathrm{mu}$ ni-ib-gi ${ }_{4}$ (Var.: hu-mu-ni-ib-be ${ }_{2}$ ) „Der Musiker 'schreit aus' (Var.: 'deklamiert/rezitiert(?)') zum ledernen ala“; Geller 1996, 77. Die $\mathrm{a}_{2}-1 \mathrm{a}_{2}$-Trommel ist aus Texten jüngerer Epochen auch als Instrument des gala bekannt, s. Kapitel 6.3.2. Zu den genannten Instrumenten s. im Allgemeinen Krispijn 1990, 1-27.

${ }^{138}$ Nanše A 44.

139 Alster 2004, 24.27:15; ETCSL 1.3.4:10-16. Zu PBS 5, 26:9b. sa šu-na bi ${ }_{2}$-in-RU; s. a. Cavigneaux/Al-Rawi 1993a, 110 Anm. 20; Gadotti 2006, 69-70 ,..., he strummed the strings:“" und ETCSL 1.3.4 Text C 9b. ,...string with his hand“" gegen Römer 1991, 366.368.

140 Alster 2004, 38-39; Gadotti 2006, 72; s. a. Römer 1991, 368-378. In der Zuordnung des nar zur Göttin Inana und nicht zu Gudam folge ich der Interpretation von Gadotti 2006, 72 gegen Cavigneaux/Al-Rawi 1993a, 110; Alster 2004, 27.31.38, demzufolge der Sänger an sei- 
nar werden auch als schaffende Musiker, als Liedschreiber und -setzer angesprochen. In den Selbstlobhymnen des Šulgi und des Išme-Dagan treten neben den um-mi-a, den „Gelehrten“, nar und nar-gal als Liedschreiber oder Setzer auf. ${ }^{141}$ Die Hymne Šulgi $E$ enthält weiterhin eine Textpassage, die über die Rolle von Schreibern beim Verfassen von Liedtexten Auskunft gibt:

\section{T 3: Šulgi E 249-251}

„Der Schreiber soll es zum Sänger bringen und ihn schauen lassen;

Es sind Weisheit und Verstand der Nisaba;

Wie von einer Lapislazuli-Tafel soll er es ihm vortragen!“‘142

249. nar-e dub-sar ḩe $e_{2}$-en-ši-tum 2 igi h. $e_{2}$-en-ni-in-bar-re

250. g̃eštug 2 g̃izzal dnisaba-ka-kam

251. dub za-gin $3-\operatorname{gin}_{7} \mathrm{gu}_{3} \mathrm{he}_{2}-\mathrm{na}^{?}-\mathrm{ta}^{?}-\mathrm{de}_{2}-\mathrm{e}$

Der von einem nar zu intonierende Liedtext wurde offenbar zuvor von einem Schreiber verfasst. Eine solche Vorgehensweise kann zumindest für die Königshymnen angenommen werden. Es bleibt außer Frage, dass über diese einmalige literarische Passage keine endgültigen Aussagen zur Rolle von Musikern bei der Verschriftlichung und Tradierung literarischer Texte getroffen werden können. ${ }^{143}$ Dennoch, die hier dargestellte enge Verbindung zwischen den beiden Berufen des Musikers und des Schreibers scheint generell vorgeherrscht $\mathrm{zu}$ haben. Denn diese spiegelt sich auch in den sumerischen Sprichwörtern wider, wo beide Berufsgruppen häufig parallel behandelt werden. $^{144}$

Zusammenfassend lässt sich für den Begriff nar nach literarischen Texten eine Vielfalt an Funktionen und musikalischen Ausrichtungen feststellen. nar musizierten zu den unterschiedlichsten Anlässen. Musikalische Beiträge der nar fanden im Tempel, im Palast, bei Prozessionen, Schiffsreisen oder auch an verschiedenen Orten im Freien außerhalb der Stadt statt. ${ }^{145}$ Musiker traten zum Lob der Götter, aber auch zum Preis und Gedenken von Königen auf, was ebenfalls im Rahmen des Kultes stattfinden konnte. ${ }^{146}$

nen Herrn Gudam über sein Lied eine Nachricht der Inana weiterleitet.

141 Šulgi B 325-329; IšD A(+V) 336-338; Ludwig 1990, 41-42.

${ }^{142}$ ETCSL 2.4.2.05:249ff.; vgl. Ludwig 1990, 43.

${ }^{143}$ Eine umgekehrte Richtung, also eine Art 'mündliches' Diktat des Sängers an den Schreiber stellt Wilcke 2006, 205-206 für die Darstellung in der Keš Tempel-Hymne fest.

${ }^{144}$ Vgl. Kapitel 5.3.2.

${ }^{145}$ Im Tempel: Gudea Zyl. B x 9-13; Nanše A 39-44; DI C 27-28; DI P Fragm. B 6-9; IdD A 206209. Im Freien: Enkis Reise 62-67; Keš Tempel-Hymne 116-119?; in Gudea St. L Vs iv 3-7 am Fluss (Steible1991/1, 226-227:4'.3-7); Šulgi A 79-83 im Palast?; Šulgi D 368-370 zu einer Schiffsreise; Hendursag̃a A 21-22 zu einer Schiffsprozession der Nanše.

${ }^{146}$ Martu A 58-59; Šulgi E 252-257; IšD A(+V) 384-385 und 400-407; Ludwig 1990, 45-46. 
Abschließend sei hier eine bislang einzigartige literarische Textpassage zitiert, in der eine Auflistung verschiedener Sänger und Musiker und ihrer jeweiligen Tätigkeitsfelder enthalten ist. Es handelt sich um ein Textfragment, das der Selbstlobhymne des Išme-Dagan $(I \check{S} D A+V)$ zugeordnet wird:

\section{T 4: Išme-Dagan A(+V) Text C 6-12 147}

„Ein zweites Mal möge es einen 'Obermusiker' geben;

Möge es einen Gelehrten, einen 'Mann der Vortrags(dichtung)' geben; ${ }^{148}$

Möge es das ‘/e n d u/-Liedsetzen' und das '/a d š a /-Singen' geben; ${ }^{149}$

Möge es einen Musiker mit süßer Stimme beim König geben;

Möge es einen beratenden Musiker geben, der das Herz erfreut; ${ }^{150}$

Möge es einen Musiker des Schlafgemachs (der Götter) mit sanfter Stimme geben;

Möge es einen Musiker mit wechselnder/antwortender Stimme (Singweise') geben;

Möge es [einen. .. ] an seiner Seite geben.“
6. ${ }^{r} \min _{3}{ }^{7}-\mathrm{kam}-\mathrm{ma}-\breve{s}_{3}$ nar-gal he $\mathrm{e}_{2}-\mathrm{a}$
7. um-mi-a $l u_{2}-\check{s ̌ r}_{3}$ he $_{2}-\mathrm{a}$
8. en ${ }_{3}-d u$ gar-g̃ar ad-ša $\mathrm{di} \mathrm{he}_{2}-\mathrm{a}$
9. nar $\mathrm{gu}_{3} \mathrm{dug}_{3}$-ga lugal-a he $\mathrm{e}_{2}$-a
10. nar ad $\mathrm{gi}_{4}-\mathrm{gi}_{4} \breve{s a g}_{4}-\mathrm{ba}^{?}-\mathrm{a}{ }^{\Gamma} \mathrm{hul}_{2}{ }^{?}{ }^{7} \mathrm{hbe}_{2}-\mathrm{a}$
11. nar $\mathrm{gu}_{3}$ silim-ma $\mathrm{a}_{2}-\mathrm{nu}_{2}-\mathrm{da}-\mathrm{ka} \mathrm{he} \mathrm{h}_{2}-\mathrm{a}^{151}$
12. 'nar inim-bal'-bal ad-da-a he $e_{2}-a$
13. [... $]^{\ulcorner} \mathrm{zag}^{\text {? }}$-ba he $\mathrm{h}_{2}-\mathrm{a}$
Rest abgebrochen

Die meisten dieser nar-Komposita sind bereits aus der Auflistung in Proto- $\mathrm{Lu}_{2}$ bekannt mit dem Unterschied, dass sie hier einem Kontext zugeordnet werden. ${ }^{152}$ Besondere Beachtung verdient hier außerdem die Aussage der Zeile 7, wonach auch der um-mi-a, der „Gelehrte“, als $\operatorname{lu}_{2}$-šir ${ }_{3}$ „,derjenige der šir ${ }_{3}$ (Vortrags)“" ausgezeichnet ist und unter die nar-Musiker eingereiht wird.

\footnotetext{
${ }^{147}$ Unpubliziertes Fragment zu $I s ̌ D A(+V)$ gehörig (alias $I s ̌ D Z$ ), bei ETCSL 2.5.4.01 als Text C.

${ }^{148}$ Entgegen ETCSL 2.5.4.01, die hier als Aufzählung übersetzen, fasse ich $1 \mathrm{u}_{2}$-šsir ${ }_{3}$ als Apposition zu um-mi-a „Gelehrter" auf mit šir ${ }_{3}$ in der Bedeutung 'vorgetragene Dichtung'.

${ }^{149}$ Auch in anderen Textbelegen tritt die Gesangsform ad-ša ${ }_{4}$ in aller Regel neben en $n_{3}$-du auf; s. hier Kapitel 11.1.1 und 5.3.2.

${ }^{150}$ Anders ETCSL 2.5.4.01. „let there be a joyful-hearted (?) alternating singer“. Für ad $\mathrm{gi}_{4}$ - $\mathrm{gi}_{4}$ bevorzuge ich die Übersetzung „beratend“ nach PSD A/3, 2 sub a d A 2.7.7 „to advice“, „to counsel“" und PSD A/3 18 sub ad-gi ${ }_{4}-\mathrm{gi}_{4}$,advisor", „counselor". Das Beraten ist eine Funktion, die häufig Instrumenten, insbesondere dem bala g̃ zugesprochen wird.

${ }^{151}$ Anders bei Michalowski 1989, $103 \mathrm{a}_{2}-\mathrm{na}_{2}$-da nar gu $\mathrm{u}_{3}$-silim-ma $\mathrm{a}_{2}-\mathrm{na}_{2}$-da-ka he $\mathrm{e}_{2}-\mathrm{a}$; hierzu auch Taylor 2001, 223.

${ }^{152}$ Hier Kapitel 5.1.
} 
Aus dieser Aufzählung lässt sich nur annähernd erahnen, wie vielseitig die Anlässe, aber auch die Singarten und Darbietungsformen der uns erhaltenen Lieder gewesen sein müssen. Ungenannt bleiben in dieser Textpassage die Instrumentalmusiker, doch auch von ihnen wird Virtuosität und Repertoirevielfalt gefordert. Dies drückt sich am deutlichsten in den Selbstlobhymnen des Šulgi $(\breve{S} u l g i A / D)$ aus, in der sich der König rühmt, alle ihm bekannten und auch neue Instrumente virtuos zu beherrschen. ${ }^{153}$

\subsubsection{Die sumerischen Sprichwörter}

In der sumerischen Sprichwortsammlung finden sich auch mehrere Einträge zum nar. Diese folgen direkt auf die Sprichwörter zum Beruf des Schreibers, worin sich die Nähe beider Berufe ausdrückt. Von sieben uns erhaltenen Sprichwörtern behandeln fünf das für den Beruf des nar erforderliche fachliche Können. ${ }^{154}$ Das folgende Sprichwort SP 2.43 setzt auf anschauliche Weise die Berufe des Schreibers und des Musikers einander parallel unter Angabe ihres jeweils wichtigsten Berufskriteriums:

\section{T 5: SP 2.43}

„Ein Schreiber ohne Hand (ist ein) Musiker ohne 'Kehle'.“

$$
\text { dub-sar šu nu-a nar g̃ili }{ }_{3}(\mathrm{KAxLI})^{155} \mathrm{nu}^{156}
$$

Aussagen zur Stimme und ihrer korrekten Beherrschung werden auch in den Sprichwörtern SP 2.41 und SP 2.57 thematisiert. ${ }^{157}$

Im Sprichwort SP 3.87 werden konkrete Angaben zu den Singarten eines nar vorgeführt. Ähnlich wie in dem zuvor zitierten Sprichwort SP 2.43 sind hier verschiedene Handwerke und ihre charakteristischen Berufsmerkmale einander parallel gesetzt:

\footnotetext{
${ }^{153}$ Krispijn 1990, 1-27.

${ }^{154}$ SP 2.39, SP 2.41, SP 2.43, SP 2.57, SP 3.87.

${ }^{155} \mathrm{Zu}$ ğili ${ }_{3}\left(/ \mathrm{mili}_{2}\right)=$ nemlû „Kehle“" s. Gordon 1959, 204; Alster 1997, 53.364 und CAD N/2 $165 \mathrm{a}$.

${ }^{156}$ ETCSL 6.1.02:75.

${ }^{157}$ ETCSL 6.1.02:73: SP 2.41 nar za-pa-a g. nu-dug ${ }_{3}$-ga hu-ru-um nar-e-ne „A singer whose voice is not sweet is a wretch among singers!"; zu Textvarianten s. Alster 1997, 53; ETCSL 6.1.02:99: SP 2.57 nar za-pa-a g ${ }_{2}$ he $_{2}$-en-dug ${ }_{3}$ e-ne-am ${ }_{3}$ nar-am ${ }_{3}$ „When a singer's voice is sweet, he is indeed a singer“; za-pa-a $\tilde{g}_{2}=$ rigmu $(m)$,Stimme; Klang; Geschrei“; CAD R 328; anders Alster 1997, 53, 56, 363-364 (Kom.), der „breathing“ übersetzt mit zi-pa-a $\tilde{g}_{2}=$ napištu(m) „Kehle, Leben“ auch „Atem“; CAD N/1 296.
} 
T 6: SP 3.87

„(dem) Tischler ist es der 'Hobelspan';

(dem) Rohrarbeiter ist es der Korb;

(dem) Schmied ist es, 'kleine ..., ${ }^{158} \mathrm{zu}$ formen;

dem Musiker ist es das /u a / und /a la la/.“

nagar ${ }^{\tilde{g} i s ̌}$ kibir $_{2}-\mathrm{am}_{3}$

ad-KID ma-sa $2-a b-a m_{3}$

simug da tur-tur ak

nar $u_{8} !-u_{x}(P A)-a$ a- $1 a-1 a^{159}$

/ua/ und /alala/ sind zwei Interjektionen, die als konkrete Singarten einem musikalischen Ausdruck zugeordnet werden. ${ }^{160}$ Sie stehen für den Ausdruck der Klage und Trauer oder auch des Jubels und des Preises. Als gängige Interjektionen werden mit ihnen auch sumerische Liedgattungsnamen gebildet. ${ }^{161}$

Auch das Sprichwort SP 2.39 nennt vokale Ausdrucksformen des nar:

\section{T 7: SP 2.39}

„Ein Musiker, möge er ein einziges en $\mathrm{n}_{3}$-du-Lied kennen aber die ad-š $\mathrm{a}_{4}$ Technik gut machen, so ist er wahrhaftig ein Musiker."“162

$$
\begin{aligned}
& \text { nar-re en } n_{3}-d u 1(D I S ̌)-a m_{3} h_{2} e_{2}-e n-z u \text { ad-ša } \\
& \text { e-ne-am }-a m_{3} \text { har-ra }
\end{aligned}
$$

Einzig im Sprichwort SP 2.54 wird auf ein Instrumentalspiel des nar Bezug genommen. Dort heißt es, dass in Ungnade gefallene nar sowie gala nur noch Rohrinstrumente spielen. ${ }^{163}$

Während der Großteil der sumerischen Sprichwörter die Singfähigkeit des nar thematisiert, ist nur ein einziges überliefert, das offenbar auf das alltägliche Umfeld dieses Musikers Bezug nimmt. Dieses Sprichwort SP 3.150 handelt

\footnotetext{
158 Alster 1997, 96 ,,(What characterizes) the smith is the making of 'little sides'“ mit Kommentar S. 386; AHw 470b kibirrum sub 2) „Bolzen“(?).

${ }^{159}$ ETCSL 6.1.03:164-167; Alster 1997, 96.

${ }^{160}$ Edzard 2003, 167, 170; Alster 1997, 386; PSD A/1 100 a-1a-1a A „(an exclamation; a workcry)“.

${ }^{161}$ S. Kapitel 12.4.4.

${ }^{162}$ Renger 1969, 181-182 Anm. 820 und ETCSL 6.1.02:70-71; anders Gordon 1959, 201 und Alster 1997, 53 „When a singer knows every song, when his performance is good, he is indeed a singer!“.

${ }^{163}$ Alster 1997, 55-56, 365; s. a. hier Kapitel 12.1.4.
} 
von einem Affen, der sich im Hause des nar(-gal) von Eridu, der Stadt des Gottes Enki, aufhält:

T 8: SP 3.150

„In Eridu, in Üppigkeit gebaut, sitzt der Affe im Hause des nar(-gal) mit sehnsüchtigem Blick."

eridug $^{\mathrm{ki}} \mathrm{he}_{2}-\tilde{g} \mathrm{al}_{2}-\mathrm{la} \mathrm{du}_{3}-\mathrm{a}-\mathrm{ba}$

${ }^{u g u} u_{g u}$-bi e ${ }_{2}$ nar-ra-ka ${ }^{164}$ igi $1 a_{2}-$ bi $^{165}$ al-tuš ${ }^{166}$

Eine direkte Parallele zu diesem Sprichwort ist der Monkey Letter, ein Text aus der Sammlung literarischer Briefe, der von einem Affen an seine Mutter adressiert wird. ${ }^{167}$ In der Aussage des Affen drücken sich sowohl in diesem Sprichwort als auch im Brief Mittellosigkeit und Hunger aus, die in beiden Texten dem Reichtum und der Üppigkeit der Stadt des Enki, Schutzgott der Musik, gegenüber gestellt werden. ${ }^{168}$ Der Affe sitzt im Hause des nar(-gal), womit er dem Kontext der Musik zugeordnet wird. ${ }^{169}$ Ob der hier beschriebene missliche Zustand, in der sich der Affe im Hause des Musikers befindet, eine Ausnahmesituation ist, oder den Normalzustand darstellt, bleibt allerdings unklar. Insgesamt wirft diese Darstellung ein negatives Bild auf den Beruf des nar und seine finanzielle Situation, der offenbar nicht imstande war, die Mitglieder seines Hauses ausreichend zu versorgen.

Für die hier behandelte Textgruppe lässt sich zusammenfassen, dass in ihr der Schwerpunkt der musikalischen Tätigkeit eines nar auf das Singen und das Beherrschen verschiedener Singarten gelegt wird. Zum Musikinstrumentarium oder den verschiedenen Spieltechniken, die den nar als Instrumentalisten auszeichnen, wird nichts gesagt.

\footnotetext{
164 Textvarianten: $\mathbf{H ~ e}_{2}$ nar-<gal>-la-kam, JJ e 2 nam-nar-ra-ka; Alster 1997, 106.

${ }^{165}$ Zum gleichbedeutenden ig i-tum $\mathrm{m}_{3}-1 \mathrm{a}_{2}$ in Text $\mathbf{H}$ und dem Monkey Letter 7 s. Alster 1997, 391.

${ }^{166}$ Alster 1997, 106, 391; ETCSL 6.1.03:276-277 „In Eridug, built in abundance, the monkey sits with longing eyes in the singer's house“.

${ }^{167}$ Letter Collection B 14:4-7 „Ur ist die herausragende Stadt des Nanna. In Eridu, der üppigen Stadt des Enki, sitze ich da hinter der Haustür des nar-gal, genährt allein durch sehnsüchtige Blicke"; Ali 1964, 120-123; ETCSL 3.3.07; s. a. Alster 1997, 391 und Dunham 1985, 244-245; s. jetzt auch Michalowski 2009.

${ }^{168}$ Alster 1997, 391.

${ }^{169}$ Zur Verbindung von Affen und Musik in bildlichen Quellen vgl. Dunham 1985, 244-246.
} 


\subsubsection{Der blinde Musiker}

In der mythologischen Erzählung Enki und Ninmah findet sich eine bisher einzigartige Textpassage, die angesichts der behandelten Thematik als Ätiologie zum nar, im Speziellen zum blinden Musiker am Hofe des Königs aufgefasst werden kann. Der Mythos setzt mit einer verkürzten Erzählung von den Vorgängen zur Menschenschöpfung ein. Mit Hilfe von Geburtsgöttinnen, unter denen sich auch die Muttergöttin Ninmah befindet, erschafft Enki den Menschen und setzt ihn im Austausch für die niederen Gottheiten ein, um diese von ihren schweren Arbeiten zu entlasten (Z. 1-37). Bei einem anschließenden Fest, in dessen Verlauf die Götter durch größere Mengen Biergenusses in Trunkenheit geraten, fordert Ninmah den Schöpfergott Enki zu einem Wettstreit heraus. Ihrer Ansicht nach werde allein durch ihren Schöpfungsakt, nämlich der Gestaltung des physischen Körpers, dessen Schicksal bestimmt (Z. 44-55). Mit dieser Aussage äußert sie ihre Zweifel an der herausragenden Position des Enki, einzig und allein über das Schicksal eines Geschöpfes bestimmen zu können. Um hierfür den Beweis zu erbringen, schafft die Göttin Ninmah der Reihe nach sechs körperlich missgebildete Wesen und fordert anschließend Enki dazu auf, ihnen allen trotz ihrer physischen Nachteile ein angemessenes Schicksal zu bestimmen (Z. 58ff.). Von besonderem Interesse ist hier vor allem die zweite Schöpfung, für die Ninmah die Blindheit als körperliche Behinderung ansetzt: ${ }^{170}$

\section{T 9: Enki und Ninmah 62-65}

„Zweitens erschuf sie (Ninmah) einen, der das Licht zurückwendet, einen Mann, der 'schaut'.

Enki betrach[tete] denjenigen, der das Licht zurückwendet, den Mann, der 'schaut'.

Er bestimmte sein Schicksal und gab ihm die 'Musik'. Er stellte ihn auf als großen/Ober-[Musiker] Ušumgal ${ }^{171}$ im Angesicht des Königs. “

\footnotetext{
${ }^{170}$ S. jetzt auch Gadotti 2009.

${ }^{171}$ Benito 1970, 39 bezieht das Epitheton ušumgal auf Enki wie auch Bottéro/Kramer 1989, 191; anders Kramer/Maier 1989, 34 ,named him chief [musician] of the ušumgal-lyre before the king“, ähnlich übersetzt Römer 1993, 394 „Großdrachen(-Instrument)“. Die Schwierigkeit dieser Zeile ist auch inhaltlicher Natur, vgl. bei Gudea ušumgal-kalam-ma als Name des nar (Gudea Zyl. B x 14) und des balag̃ des Ning̃irsu (Gudea Zyl. A vii 24 und $B \times 1$ 21); Wilson 1996, 40, 159, 175. Klein 1997, $518+$ Anm. 32 liest die Zeichen ušumgal-la als $\mathrm{za}_{2}$-gu-la „,die große (rechte) Seite“ und übersetzt den gesamten Vers: „And seated it (as) chief-[musician] in a place of honor, before the king".
} 
62. $\mathrm{gi}_{4}$-bi $\tilde{g} i \breve{s}-\mathrm{nu}_{11} \mathrm{gi}_{4}-\mathrm{gi} \mathrm{i}_{4} \quad \mathrm{lu}_{2} \mathrm{u}_{6}-\mathrm{e}^{172} \mathrm{am}_{3}-\mathrm{ma}-\mathrm{ni}-\mathrm{in}-\mathrm{dim}_{2}$

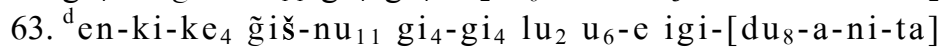

64. nam-bi i-ni-in-tar nam-nar mi-ni-in-ba

65. [nar]-gal ${ }^{173}$ ušumgal-la igi lugal-la-ke ${ }_{4}$ am $_{3}-[\mathrm{ma}]-n i-i n-[g u b]^{174}$

Die Übersetzung des Ausdrucks g̃ $\mathrm{iš}-\mathrm{nu}_{11} \mathrm{gi}_{4}-\mathrm{gi}_{4} \quad \mathrm{lu}_{2} \mathrm{u}_{6}-\mathrm{e}$ ist hier annähernd mit „der das Licht zurückwendet, ein Mann, der 'schaut'"، wiedergegeben. ${ }^{175}$ Dass mit dieser Phrase ein poetischer Ausdruck für die Blindheit vorliegt, wird inzwischen übereinstimmend angenommen. ${ }^{176}$ Der Ausdruck g̃iš-nu $\mathrm{nu}_{11} \mathrm{gi}_{4}$ $\mathrm{gi}_{4}$ „,das Licht zurückwenden“ verbildlicht in einer poetischen Formulierung die Tatsache, dass das Licht nicht in das Auge eindringen kann, sondern zurückgewendet wird. Sumerisch $1 \mathrm{u}_{2} \mathrm{u}_{6}$-e ,ein Mann, der sieht" steht der ersten Aussage gegenüber und ist auf die 'inneren Werte' des Blinden zu beziehen: Trotz seiner Blindheit wird der Mann dennoch als 'sehend' bezeichnet, was meines Erachtens als metaphorische Wertung seiner geistigen Fähigkeiten zu interpretieren ist. ${ }^{177}$ Dem Gott Enki gelingt es also, dem Blinden wie auch allen anderen von Ninmah erschaffenen 'missgebildeten' Geschöpfen ein herausragendes Schicksal zu bestimmen.

Der Topos des blinden Musikers oder Sängers ist in zahlreichen alten sowie neuen Musikkulturen anzutreffen. Auch in Mesopotamien scheint er angesichts der besprochenen Passage in Enki und Ninmah verbreitet gewesen zu sein. ${ }^{178}$ Aus Alltagsdokumenten der altbabylonischen Zeit sind hierzu allerdings nur sehr wenige Belege bekannt. ${ }^{179}$ Auch in der gesamten Ikonographie des Alten Orients können, im Gegensatz zu den zahlreichen altägyptischen Abbildungen, ${ }^{180}$ keine Darstellungen von blinden Musikern erschlossen werden. Der

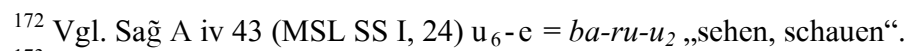

${ }^{173}$ Ich folge mit [nar]-gal der Ergänzung von Kramer/Maier 1989, 34, 213 Anm. 33 sowie Klein 1997, 518 Anm. 31 gegen Benito 1970, 27, der das Zeichen e n ergänzt. Offen dagegen bei Römer 1993, 394 und Jacobsen 1987, 160.

${ }^{174}$ Vgl. ETCSL 1.1.2; Benito 1970, 26-27, 39.

175 Anders Römer 1993, 393 „,der das Licht dem Menschen, der sehen (konnte), > zurückgab<“; ähnlich Jacobsen 1987, 159 ,,the 'One-handing-back-the-lamp-to-the-man-who-can-see'“.

${ }^{176}$ Renger 1969, 184 Anm. 839; Kramer/Maier 1989, 34, 213 Anm. 32; Klein 1997, 518 Anm. 30; Bottéro/Kramer 1989, 191 „aveugle“; Klein 1997, 518 „'deprived of light', a blind(?) man“ gegen Benito 1970, 39 „.. . man who could see (even) with blinking(?) eyes“ und S. 65. Jacobsen 1987, 160 Anm. 16 nimmt auch für die Komposition Enki und Ninmah selbst einen blinden Dichter an; unsicher dagegen Römer 1993, 393 Anm. 62a) und 394 Anm. 64a).

${ }^{177}$ So auch Kramer/Maier 1989, 34, 213 Anm. 32; Klein 1997, 518 Anm. 30 als Euphemismus.

${ }^{178}$ Hierzu allgemein Fincke 2000, 67.

${ }^{179}$ Fincke 2000, 64-65; zur Blindheit im Allgemeinen, der Terminologie und Verbreitung s. ibid. S. 61-68 und die frühere Untersuchung von Farber 1985.

180 Die so genannten „blinden Harfenisten“ der 18. Dynastie; Manniche 1991, 99-101; s. a. 
häufig in diesem Zusammenhang zitierte Brief TJAUB S. 151 aus Kiš nennt eine blinde Frau mit Namen Šinunūtum, die zur Musikerin ausgebildet werden sollte. ${ }^{181}$ Die wenigen Belege für Mari, die einen Zusammenhang zwischen Blinden und Musikern herstellen, wurden von Ziegler zusammengetragen. ${ }^{182}$ Dort könnten Kinder über einen künstlichen Eingriff geblendet worden sein, um ihre Fähigkeiten in der Gesangskunst bewusst zu steigern. ${ }^{183}$ Auch für Sippar könnten wenige Belege auf die Beteiligung von Blinden an Kultfesten zur Ausführung von Musik dokumentiert sein. ${ }^{184}$

Es stellt sich die Frage, welche Gründe der weit verbreiteten Blindheit von Musikern zugrunde liegen. Für das pharaonische Ägypten beobachtete Manniche eine Verbindung von Blindheit und dem Kontakt zum Göttlichen. ${ }^{185}$ So finden sich auf Amarna-zeitlichen Reliefbildern aus Karnak und el-Amarna männliche Kultakteure, darunter auch Musiker abgebildet, die im Kontext kultischer Handlungen Augenbinden tragen. Laut Manniche ist diese Handlungsweise mit der Vorstellung zu begründen, dass der direkte Blick auf die Gottheit zu einer Blendung führen könne. Frauen waren dementgegen von einer solchen Gefahr nicht betroffen. Dass die Blendung oder die Blindheit eines Musikers auch im alten Mesopotamien mit einer religiösen Vorstellung verbunden war, ist aus den uns bekannten Texten nicht zu schließen.

Der Hintergrund zum Topos vom blinden Musiker kann jedoch auch rein profaner Natur sein, so ist für einige moderne afrikanische Kulturen bekannt, dass die Blendung des Hofmusikers dessen mögliches Interesse an den Haremsfrauen des Königs unterbindet. ${ }^{186}$ Ähnliches könnte für die geblendeten Musiker am Hofe des Palastes von Mari angenommen werden, die mit Sicherheit auch in Anwesenheit der zahlreichen Haremsdamen musizierten. Andererseits könnte die Blendung auch ihre mögliche Flucht verhindert haben. ${ }^{187}$ Blendungen wurden schließlich in Mesopotamien vermehrt auch an Kriegsgefangenen und als gesetzliche Bestrafung vorgenommen. ${ }^{188}$

Schlott 1996, 55-60 mit gegenteiliger Meinung.

181 TJAUB pl. xxvi und S. 151(UMM G 40): 3: ${ }^{\mathrm{P} N}$ igi-nu 4. a-na na-ru-tim a-ha-zi-im 5. a-na ma-ah-ri-ia 6. ub-lu-ni-iš „Die blinde ${ }^{\mathrm{f}} \mathrm{PN}$ brachten sie zu mir zum Erlernen der nar-Kunst“; vgl. Renger 1969, 184 Anm. 839.

182 ARM(T) 26/2, 25 No. 297 [M. 9756] Z. 17b. i-na-t[i-šu-nu] 18a. šu-nu-li-im ,ihre Augen 'zum Schlafen bringen'" und weiter in Z. 19-22, was nach Charpin in ARM(T) 26/2, 26 Anm. d) als Euphemismus für das Blenden zu werten ist; hierzu auch Ziegler 2007, 21-23.

${ }^{183}$ ARM(T) 26/2, 27; dazu Ziegler 2007, 22-23. Zu den Ursachen von Blindheit im Allgemeinen s. Fincke 2000, 63.

${ }^{184}$ S. hier Kapitel 9.6.2.5.

${ }^{185}$ Manniche 1991, 99-100.

${ }^{186}$ Gelb 1975, 60.

${ }^{187}$ Fincke 2000, 67.

${ }^{188}$ Fincke 2000, 63-64. 
Bezüglich der physischen Fähigkeiten von Blinden ist auch unserer Tage noch die Vorstellung verbreitet, der Verlust des Augenlichts führe zur Schärfung aller erhaltenen Sinne, des Tastens und Hörens. Moderne Untersuchungen konnten jedoch zwischen Blinden und gleich geschulten Sehenden keine besonderen Unterschiede feststellen. ${ }^{189}$

Der oben behandelte Ausdruck für den Blinden im Mythos Enki und Ninmah „ein Mann, der 'schaut'“ weist m. E. auf besondere geistige Fähigkeiten eines Blinden hin, als ein Schauender könnte er im übertragenen Sinne auch als ein Wissender oder Verständiger erachtet worden sein. Der moderne koptische Sänger wird noch heute als 'arif „Wissender“ bezeichnet und seines unfehlbaren Gedächtnisses wegen gerühmt. ${ }^{190}$ In Kulturen, die primär der oralen Tradition verhaftet sind, kommt dem Gedächtnis eine große Bedeutung bei der Erhaltung von Wissen und Weisheit zu.

Ungeachtet der verschiedenen Vorstellungen, die über Blinde in verschiedenen Kulturen herrschen, so werden sie in erster Linie als Musiker ausgebildet worden sein, da diese Kunst ihren körperlich eingeschränkten Fähigkeiten am ehesten entgegenkam. Zwar wurden in Mesopotamien Blinde auch als Korbflechter, in der Weberei, als Gärtner und Viehmäster eingesetzt, ${ }^{191}$ doch nur als Musiker kann ein Blinder zur höchstmöglichen Position in den persönlichen Kontakt zum König aufsteigen, wie es im Mythos von Enki und Ninmah dargestellt wird.

\subsection{Instrumentale und vokale Spezialisierungen}

Neben den nar-Komposita, die auf eine hierarchische Struktur des Musikerberufs hinweisen, sind vor allem aus Alltagsdokumenten zahlreiche Wortverbindungen mit nar bekannt, die eine musikalische Spezialisierung anzeigen. Im Folgenden werden die drei wichtigsten dieser Berufe behandelt: der /tigi/ und der nar-sa, zwei Instrumentalisten, sowie der nar-a- $u_{3}-a$, womöglich ein Vokalist, der auf eine bestimmte Vortragsart spezialisiert war.

${ }^{189}$ In Versuchen wurde lediglich beobachtet, dass Blinde die Schallquellen in einem Raum besonders präzise orten können; s. Roder, F. et al. „Improved auditory spatial tuning in blind humans", in: Nature 1999 July 8;400(6740):162-166. Dieselbe Fähigkeit wurde nach privater Mitteilung von Prof. H. Altenmüller (Hochschule für Musik und Theater Hannover) allerdings auch bei modernen Dirigenten festgestellt.

${ }^{190}$ Collaer/Elsner 1983, 36.

${ }^{191}$ Fincke 2000, 65. 


\subsubsection{Die Perkussionisten /tigi/ und ${ }^{\text {munus } / \text { tigi/ }}$}

Das Wort /tigi/ bezeichnet nach mehreren Einträgen in lexikalischen Listen einen eigenständigen Musikerberuf, der neben nar und gala $\mathrm{zu}$ stellen ist. Seine Verwandtschaft zum Beruf des nar resultiert aus der Form des Logogramms /tigi/, welches durchgängig mit der Zeichenkombination NAR.BALAG̈ für tigi ${ }_{2}$ und BALAG̃.NAR für tigi geschrieben wird. ${ }^{192}$ Ins Akkadische ist der Ausdruck als tigh für männliche und te/igittum für weibliche Vertreter dieses Berufszweigs entlehnt. ${ }^{193}$

Außer einen Musikerberuf bezeichnet derselbe Terminus ein Musikinstrument sowie eine Liedgattung. ${ }^{194}$ Aufgrund der Bedeutungsvielfalt des Wortes /tigi/ ist anzunehmen, dass über diesen Begriff ein umfassender Bereich innerhalb der altorientalischen Musikpraxis bezeichnet wird, für den aufführungspraktische wie inhaltlich-funktionale Merkmale kennzeichnend sind.

Nach lexikalischen Einträgen werden über/tigi/ gleichermaßen Frauen wie Männer bezeichnet, wobei die männliche Form bislang nur einmal für das späte zweite Jahrtausend in einer Ausgabenliste attestiert ist. ${ }^{195}$

Weibliche /tigi/-Musikerinnen (sumerisch munus/tigi/meš , akkadisch tigiātum oder tegêtum) sind hingegen in lexikalischen Listen, in Alltagsdokumenten sowie bislang in einer einzigen mittelbabylonschen Königsinschrift aus Isin bezeugt. Die frühesten Belege zu ${ }^{\text {munus }} / \mathrm{tigi/}$ in Alltagsdokumenten datieren in die Zeit der Isin-Dynastie. ${ }^{196}$

In Sippar und Nippur sind jeweils einzeln auftretende „Aufseher der /tigi/Frauen" (wakil tigiātim) bezeugt. ${ }^{197}$ Die Existenz dieses Berufs gibt Aufschluss über die Organisationsform der Musikerinnen, die offensichtlich in größeren

192 Borger 2003, 153:565, 156:570. Ebenfalls als /tigi/ liest Sallaberger 1993, 142 Anm. 668 $\mathrm{e}_{2}$.bala $\tilde{\mathrm{g}}=\mathrm{tigi}_{\mathrm{x}}$ in $\breve{S}$ ulgi $D 367$ und nar.e $\mathrm{e}_{2}$. bala $\tilde{g}=$ tigi $_{\mathrm{y}}$ in einer Šu-Suen-Inschrift nach RIME 3/2.1.4.9, S. 318:xii 14. NAR.E. 2 .BALAĞ [ni $\left.{ }_{3}\right]-\mathrm{du}_{10}$-ge 15. si mu-na-ab$\mathrm{sa}_{2}$,For him, the tigi harp, the sweet-toned instrument, was correctly tuned“. Möglicherweise auch in einem $\mathrm{aB}$ Lehrvertrag über Musik nar.bulug̃ für /tigi/; Geller 2003, 109:6, 110.

${ }^{193}$ CAD T 398; AHw 1356b.

${ }^{194}$ S. hier Kapitel 5.4.1; zu tigi als Instrument s. Krispijn 1990, 3.

${ }^{195} \mathrm{Zu}$ aB Proto- $\mathrm{Lu}_{2}$ s. hier Kapitel 5.1 und MSL 12, 67 Text B 3 ii 7.9. Ausführlicher die kanonische Version $\mathrm{Lu}_{2}=\check{s} a$ Taf. III ii 20 (MSL 12, 124) und Taf. IV 226-229 (MSL 12, 136). Die Gleichsetzung nar.bala g̃ $=a$-ši-pu „Beschwörungspriester“ in $\mathrm{Lu}_{2}=\check{s} a$ Excerpt I 205 (MSL $12,102)$ ist sonst unbekannt. Der einzige bislang mir bekannte männliche Vertreter dieses Berufszweigs wird dem Gott Marduk zugeordnet; CAD T 398 sub a).

${ }^{196}$ In Isin sind Enlil-bāni-zeitlich zwei dieser Musikerinnen namentlich belegt; s. hier Kapitel 9.4.2.3. Zum Ur III-zeitlich bezeugten $\mathrm{e}_{2}$. bala $\tilde{g}-\mathrm{gi}_{4} \mathrm{du}_{6}-\mathrm{ku}_{3}$ s. Sallaberger 1993, 139.

${ }^{197}$ In Nippur logographisch: SAOC 44, 95 (Si 7) 2. ki din-i-ri-b[a-am] 3. ugula munus-

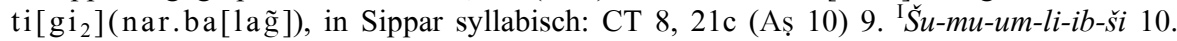
ugula ti-gi-a-ti; gegen Renger 1969, 184 Anm. 838 mit $g i_{4}$ statt gi! 
Gruppen auftraten. Die einzigen zwei namentlich bekannten ${ }^{\text {munus }} /$ tigi/ sind Amerti-Ištar und x-Nanaja, die in zwei Rationenlisten aus Isin über Gersteausgaben des Palastes aufgeführt werden. ${ }^{198}$

In Mari-Texten aus der Regierungszeit des Zimrī-Lîm wird mehrfach ein 'Haus der tegētim' genannt, nach Ziegler möglicherweise ein Musikkonservatorium. ${ }^{199}$

Auskunft über den Einsatz von /tigi/-Musikerinnen gibt auch die mittelbabylonische Inschrift des Königs Takil-ilissu von Malgium aus Isin. ${ }^{200}$ In ihr berichtet der König von Baumaßnahmen und Erneuerungen des Inventars, die er an den Tempeln des Himmelsgottes An, seiner Gemahlin Ulmašitum und ihrem Wesir Ninšubur vornahm:

T 10: RIME 4.11.2.2: 50-57

„Reines Feinmehl, eine kulmāšum-Waffe, zweihundert tigiātum, ein großes Orchester(?) und ein angemessenes Bierfass, das für das Erscheinen ihrer (Ulmašìums) großartigen Göttlichkeit geeignet ist, habe ich wahrhaftig im Tempel/Tor installiert.“

50. $\mathrm{sa}_{3}$-as $-\mathrm{a}$-ka-a-am el-lam 51. ku-ul-ma-ša-am 52. 2 me-at ti-gi-a-tim

53. si-it-ra-am ra-bi-a-am 54. hu-bu-ra-am wa-as 2 -ma-am

55. ša a-na zi-mi i-lu-ti-ša 56. ra-bi-[tim? ${ }^{?}$ šu-lu-ku

57. $i-n a \mathrm{e}_{2} ? / \mathrm{ka}_{2}{ }^{?} \check{s} a-a-t i$ lu $a r-m i^{201}$

${ }^{198}$ IB 1304 Rs 16.' [..] ${ }^{\ulcorner} A^{7}$-me-er-ti-Ištar, munus-tigi, wohl dieselbe von IB 1293 iii 12; IB 1294 i $24 .[. . \mathrm{x}(-\mathrm{x})]^{-} \mathrm{x}^{\mathrm{d}}{ }^{\mathrm{d}}$ na-na-a munus-tig i ${ }^{\text {? }}$; Wilcke 1994, 306-307, 312.

199 Ziegler 1999, 94; sie übersetzt „maison des joueuses de lyre-tigûm“ und folgt damit in der Identifizierung des Instruments /tigi/ Krispijn 1990, 3.

${ }^{200}$ Wilcke/Kutscher 1978, 95-128; Frayne in RIME 4.11.2.2, S. 672-674.

${ }^{201}$ Kompositumschrift nach insgesamt drei Textvertretern in Anlehnung an Kutscher/Wilcke 1978, 115. Kommentar: Z. 51. Zu kulmāšum als Variante zu kulpāšum „eine Götterwaffe“ s. AHw 1569 bub kulmašitu $(m)$ und $\mathrm{CDA}^{2} 166$. Z. 52. Lesung nach CAD Š/3 146 sub šitru 3. 2 me-at tigiātim ,two hundred women drum players“, so auch Westenholz/Westenholz 2006, 76 zu v 60 und Ziegler 2007, 13+Anm. 37; anders Kutscher/Wilcke 1978, 115 als 2 me-ze „Zwei meze-Trommeln“. Es bleibt zu bedenken, dass nach Foto und Kopie des Textzeugen A bei Kutscher/Wilcke 1978, 106-107:ii 8 ein $\mathrm{ZI}_{2}$ zu bevorzugen ist. Z. 53. Zur Wiedergabe von šitrum als „Orchester“ oder „Chor“ s. Durand 1984, 136 Anm. 52; Durand/Guichard 1997, 57:i 11' und Ziegler 2007, 13-14. Inwiefern die einmalig im mA Liederkatalog KAR 158 v 16 und viii 14 belegte Gattung sitru auf das Ensemble zu beziehen ist, bleibt unklar; s. a. CAD Š/3, 146 sub 3 ,,(to perform) great music" für ši-it-ra-am ra-bi-a-am. Z. 57 . Zu ramû „gründen; anlegen“ vgl. Kutscher/Wilcke 1978, 123 und CAD R 133 sub 1 „to set in place, to enboe"; so auch insgesamt die Übersetzung von Frayne in RIME 4.11.2.2, 673-674; Ziegler 2009 . 
Die hohe Anzahl der vom König eingesetzten tigiātum erstaunt zunächst, angesichts der hohen Ausgaben an dieselbe Frauengruppe beim Larsa-Ritual CM 33, 158ff.(=HUCA 34, 1ff) von etwa 300 Litern ist sie durchaus realistisch.

Die von Takil-ilissu eingesetzten Gegenstände sowie das Personal scheinen einem einmaligen Festritual gegolten $\mathrm{zu}$ haben, das dem 'Erscheinen' der Gottheit gewidmet war. In jedem Fall weisen Mehl und Bier auf die Ausführung von Schüttopfern und Libationen hin, die eingesetzten Personengruppen wiederum auf die das Festritual begleitenden Musikensembles.

Dieselben tigiātum sind auch beim mehrtägigen Ritualfest von Larsa zugegen, in dessen Verlauf zahlreiche Opferhandlungen für verschiedene männliche und weibliche Gottheiten im Monat Šēbat ausgeführt wurden. ${ }^{202}$ In diesem Zusammenhang treten sie allerdings nur bei den Göttinnen Inana, Nanaja und Ninegala auf. ${ }^{203}$

Insgesamt lässt sich daher schlussfolgern, dass die Gruppe der tigiātum und ihre Musik grundsätzlich weiblichen Gottheiten zugeordnet war. Es wäre daher zu vermuten, dass auch die tigiātum von Sippar und Nippur, wo jeweils „Aufseher der/tigi/-Frauen“ bezeugt sind, vornehmlich für die dort verehrten weiblichen Gottheiten wie Bēlet-Nippuri, Annunītum oder Șarpanītum musizierten.

Angesichts der Terminologie liegt es nahe, die tigiātum mit dem Musikinstrument und der Liedgattung Tigi in Zusammenhang zu bringen. Leider sind diese Musikerinnen nie als Spielerinnen des Instruments oder gar als Sängerinnen von Tigi-Liedern belegt.

Das Musikinstrument /tigi/ wurde in früheren Untersuchungen bevorzugt als Membranophon gedeutet, ausgehend von der Schreibung des Lautwertes über das Kompositum NAR.BALAG̃ bzw. BALAG̃.NAR, das dem nar-sa, dem Saitenspieler gegenüber gestellt wird. ${ }^{204}$ Für die Liedgattung Tigi und das gleichnamige Instrument wird in literarischen Quellen grundsätzlich ein hymnisch-preisender Charakter angesetzt. Vertreter der Liedgattung Tigi sind unter Gudea (ca. 2100), Ur III-zeitlich (2112-2004) und zur ersten Dynastie von Isin bis Ur-Ninurta (1923-1896) attestiert. ${ }^{205}$ Zwar sind nachaltbabylonisch bislang

\footnotetext{
${ }^{202}$ Kingsbury 1963 (=HUCA 34, 1-28); neu bearbeitet bei Westenholz/Westenholz 2006, 1-81.

${ }^{203}$ Westenholz/Westenholz 2006, 32, 48-49:iv 60 (Inana), 50-51:vi 4 (Nanaja), 54-55:vii 41 (Ninegala).

${ }^{204}$ So schon Renger 1969, 182-183 und Gelb 1975, 57. Vgl. Ugu-mu XI (MSL 7, 153) 194. urudubala g. ${ }^{t i-g i}$ nar $=t i-i g-g u-u_{2}=$ hal-hal-la-tum, letzteres wird auch še $\mathrm{m}_{3}$ bzw. $\mathrm{ub}_{3}$ gleichgesetzt und ist als Perkussionsinstrument zu identifizieren; anders Krispijn 1990, 3; CAD T 398 tigû A ,(a stringed instrument)“.

${ }^{205}$ Die Larsa-zeitliche Hymne Sinn-iqüšam A (1840-1836) trägt keine Unterschrift, sie ist allerdings aufgrund ihrer Rubrikaufteilung und der abschließenden, dem uru(n) entsprechenden Fürbitte als Adab zu identfizieren; s. Kapitel 12.1.2.
} 
keine Vertreter dieser Gattung aufgefunden worden, doch nennt der mittelassyrische Liederkatalog KAR 158 aus Assur insgesamt 23 Titel von TigiLiedern, ${ }^{206}$ womit ihre Überlieferung zeitlich bis in die zweite Hälfte des zweiten Jahrtausends und räumlich bis nach Nordmesopotamien und Syrien dokumentiert ist.

Beim Thema Trommlerin ist an dieser Stelle ein Blick auf die Ikonographie und die zahlreichen altbabylonischen Terrakottareliefs mit Rahmentrommelspielerinnen sinnvoll. Diese werden meist nackt oder nur mit wenigen Schmuckstücken bekleidet dargestellt und halten ihr Instrument vor ihrer Brust. ${ }^{207}$ Es stellt sich die Frage, ob hier die aus den zeitgleichen Texten bekannten tigiātum dargestellt sind. In Anlehnung an literarische Aussagen scheint allerdings die vor die Brust gehaltene Rahmentrommel eher auf das $\mathrm{ub}_{3}$ $\mathrm{zu}$ verweisen, eine Trommel, die vorwiegend dem Kontext der Klage angehört. In einer kurzen Textpassage aus der Ur Klage heißt es hierzu:

\section{T 11: Ur Klage 300}

„Ihre Brust, das heilige $u b_{3}$ ist dort, schlägt sie (Ningal), sie ruft 'Wehe! Meine Stadt! "“

300. gaba-ni ub $b_{3}$ kug-ga-am $i_{3}-\mathrm{sag}_{3}-g$ e a $\mathrm{uru}_{2}-\tilde{g} \mathrm{u}_{10} \mathrm{im}-\mathrm{me}^{208}$

Die Göttin Ningal spielt das $\mathrm{ub}_{3}$ auf ihrer Brust zum Ausdruck der Trauer. Wie von Kilmer bereits hervorgehoben, ist das Schlagen der Brust ein gängiger Klagegestus zur Begleitung von Klagerufen und Gesängen, der vielfach auch aus Texten des ersten Jahrtausends bekannt ist. ${ }^{209}$ Derselbe Gestus ist nach der neuassyrischen Ritualanweisung TuL 27 zur Restaurierung eines Götterbildes von einem kalû zur Begleitung seines Klagegesangs auszuführen:

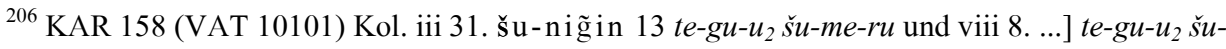
me-ru.

${ }^{207}$ Rashid 1984, 96-97 Abb. 91-96. Die Deutung des vor die Brust gehaltenen Gegenstands als Rahmentrommel ist inzwischen übereinstimmend angenommen. Zum Motiv der nackten Frau bzw. Göttin s. allgemein Wiggermann/Uehlinger 1998-2001, 46-64, bes. 53, wo die Trommlerinnen unter Typ X erscheinen.

${ }^{208}$ ETCSL 2.2.2; Kommentar: zur Lesung ub ${ }_{3}$ s. Römer 1965, 157 gegen ders. 2004, 66 mit $\mathrm{s} \mathrm{em}_{3}$. Parallelen zu diesem Vers finden sich in den Balag̃ -Liedern E Turgin Niginam (aB Version; Cohen 1988, 77, 85:a+42) und Enzu Samarmar (Cohen 1988, 408, 412:g+114) sowie im aB Eršema an Ningirgilu bei Cohen 1981, 64 Nr. 79:34. Die Übersetzung von Jacobsen 1987, 466 ,on her chest, on the silver fly-ornament, she smites and is crying: . ." ist obsolet; s. a. Römer 2004, 147-148.

${ }^{209}$ Kilmer 1977, 133; CAD S 150-151 sapādu; s. a. aB das Eršema an Inana-Dumuzi No. 97 bei Cohen 1981, 71-84, v. a. S. 74:i 16 B g̃uruš uru ${ }_{2}$-na-ka gaba nu-sag ${ }_{3}$-ga-an-na „die jungen Männer seiner (Dumuzis) Stadt, die nicht die Brust für ihn geschlagen haben“; als gängiger Klagegestus ergänzend zu Fritz 2003, 345 und Anm. 1487.
} 
T 12: TuL 27: 8-9a

„Er (der kalû) schlägt seine Brust und sagt das 'Wehe' und singt das (Eršema)

Uru-ašerra“"

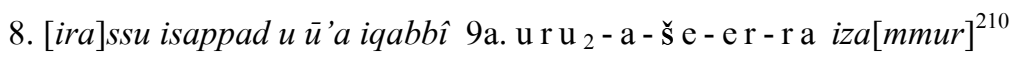

Eine Zuweisung der Rahmentrommelspielerinnen, die ihr Instrument vor die Brust halten und spielen, zum Kontext der Klage erscheint damit sehr wahrscheinlich. Die Frage nach der ikonographischen Identifizierung der tigiātum muss demgegenüber zurückgestellt werden.

\subsection{2 nar-sa, der Saitenspieler}

Der nar-sa ist nach Einträgen der altbabylonischen Liste Proto- $\mathrm{Lu}_{2}$ ebenfalls als eigenständiger Berufszweig innerhalb der Sänger- und Musikerberufe einzuordnen. ${ }^{211}$ Ausgehend von der Bedeutung des Wortes sa = ,Tiersehne/Saite" wird der nar-sa als 'Saiteninstrumentspieler' gedeutet, ${ }^{212}$ wobei eine akkadische Entsprechung bislang nicht bekannt geworden ist. ${ }^{213}$

Dieser Musiker ist ausschließlich in lexikalischen Listen und Alltagsdokumenten bezeugt, in sumerischen literarischen Texten sind keine Belege zum nar-sa enthalten. ${ }^{214}$ Vertreter dieses Berufs sind in allen bekannten Belegen männlich, in Rationenlisten können sie zuweilen neben Frauen, meist Gattinnen hoher Funktionäre und Priester auftreten. ${ }^{215}$ Die frühesten Erwähnungen von nar-sa-Musikern finden sich in Verwaltungstexten der Ur III-Zeit. ${ }^{216}$ Altbabylonisch ist der nar-sa-Musiker in Dokumenten der Städte Ur, Nippur, Larsa und Sippar bezeugt, wobei sich die Belege zu diesem Berufszweig auf insgesamt elf Texte beschränken. ${ }^{217}$ Einmalig ist der in BE 6/2, 86 ( $\mathrm{Si} 30$ )

${ }^{210}$ Walker/Dick 2001, 231-232; Farber 2003, 209; sapādu(m) ist häufig im Zusammenhang mit dem Klagegestus des Brustschlagens belegt; AHw 1024a; CAD S 151 sub 2. Der kalû ist wohl auch im mB Games Text (HS 1893) aus Nippur angesprochen: Kilmer 1991, 10: 15. ana zimri šahunni isappid irta, ,at the song of lament, he beats the breast“.

${ }^{211}$ S. hier Kapitel 5.1.

${ }^{212}$ Renger 1969, 182-183; Gelb 1975, 57.

${ }^{213}$ Ausgehend von der Schreibung nar-sa-tim als Abstraktum in der Erbrechtsurkunde BE 6/2, 86:2 (Si 30) aus Sippar meint Wilcke 1983, 64, dass die akkadische Entsprechung ein einzelnes Wort und kein zusammengesetzter Ausdruck zu sein habe; s. a. Foto bei Wilcke 1983, Abb. 7-8.

${ }^{214}$ Gegen Renger 1969, 182 Anm. 826 liegt mit nar-tur sa...za = nāra șehra mudê pitni in einem aB sowie $n A$ überlieferten Lied auf Nergal (SK 79: bearbeitet von Zimmern 1917/18; Übersetzung bei Falkenstein/von Soden 1953, 83-84 Nr. 15) keine Variante dieses Berufsnamens vor; s. a. zum besagten Vers CAD Ș sub șēhru S. 180a und Volk 1995, 210 „(s)eine(n) jungen Sänger, kundig eines Saiten(instruments)“.

215 Auch in CT 4, 8b:33 (Ad 13) finden sich in Anlehnung an Wilcke 1983, 64 keine weiblichen nar-sa.

${ }^{216}$ Gelb 1975, 67.

${ }^{217}$ Ur: UET 5, 191:50 (RS 54); YOS 5, 163:17 (WS 10); YOS 12, 353:24 (Si 11); Nippur: PBS 
vorliegende Beleg eines nar-sa-Amtes, das an einem der kleineren Göttertempel Sippars eingerichtet war. ${ }^{218}$ Die Angabe 'nar-sa des GN' ist ebenfalls nur einmal in Ur für den Gott Enki belegt. ${ }^{219}$ Häufiger sind Gruppen von nar-saMusikern Empfänger von Tempelrationen, die regelmäßig oder aus Anlass eines Götterfestes ausgegeben wurden. So werden sie aus drei Texten des spätaltbabylonischen Sippar als Teilnehmer an parșum- und anderen Ritualfesten der Göttinnen Annunītum, Șarpanītum und Tašmētum bekannt. ${ }^{220}$ Angesichts dieser Beleglage ist das Amt des nar-sa am Tempel anzusiedeln.

Folgende nar-sa sind in frühaltbabylonischen Texten mit Namen belegt:

Tabelle 3: nar-sa in aB Texten

\begin{tabular}{|l|l|}
\hline Ur & $\begin{array}{l}\text { Sîn-šemi des Enki, V.d. Sîn-gāmil (RS) } \\
\text { Apil-Amurrum (Si) }\end{array}$ \\
\hline Larsa & $\begin{array}{l}\text { Etel-pī-Sîn, S.d. Zarriqum (Ha) } \\
\text { Inana-muzuše-nirg̃al, S.d. Zarriqum (Ha) }\end{array}$ \\
\hline Nippur & Damiq-ilǐš, S.d. Lugal-heg̃al (Si) \\
\hline Sippar & $\begin{array}{l}\text { Būratum (Si) } \\
\text { Sîn-iddinam, S.d. Lu-šaga (Si) } \\
\text { Ali-talīmi, S.d. Nūr-Adad (Si) } \\
\text { Warad-Bunene, S.d. Utu-za'emen (Si) } \\
\text { Šamaš-nī̌su, S.d. Rǐš-ilim (Si) }\end{array}$ \\
\hline
\end{tabular}

Einige der namentlich belegten nar-sa sind Mitglieder von Familien, in denen weitere nar-Ämter vertreten sind. ${ }^{221}$

Der Rang des nar-sa innerhalb der Musiker- und Priesterhierarchie ist nur schwer bestimmbar. Einen Hinweis könnte die Rationenliste YOS 5, 163 (WS 10) aus Ur zu einem Fest des Nanna/Sîn enthalten, derzufolge an einen einzelnen nar-sa dieselbe Menge an Getreide wie an nar-gal und gala-mah ausgegeben wurde. In zwei Dokumenten aus Larsa und Sippar sind wiederum Angaben zum Eigentum von nar-sa-Musikern enthalten, das aus Feldern und Immobilien bestehen konnte. ${ }^{222}$ Schließlich sind unter den namentlich belegten

13, 61+:Rs vi 2 (Ha 35); BE 6/2, 48:40 (Si 18); Larsa: TCL 11, 146 (Ha 33); Sippar: RA 85, 42 Nr. 13:19 (Si 9); BE 6/2, 86:2.Rs 20'-23' (Si 30); OLA 21, 4:7 (Ae 28); CT 4, 8b:33 (Ad 13); CT 45, 84:33-34 (o.D.).

${ }^{218}$ BE 6/2, 86 (Si 30) hier Kapitel 9.6.2.4; s. a. Wilcke 1983, 60-61, 64.

${ }^{219}$ UET 5, 191 (RS 54) 50. Sîn-gāmil du mu Sîn-šemi 51. nar-sa den-ki; bearbeitet bei Charpin 1986, 85-86; s. a. Kapitel 9.1.2.2.

${ }^{220}$ YOS 5, 163:17 (WS 10); PBS 13, 61:Rs vi 2 (Ha 35); OLA 21, 4:7 (Ae 28); CT 4, 8b:33 (Ad 13); CT 45, 84:33-34 (o.D.).

${ }^{221}$ S. Kapitel 8.1.

${ }^{222}$ Larsa: TCL 11, 146 (Ha 33) mit Versorgungsfeldern; Sippar: BE 6/2, 86 (Si 30) mit einem 
nar-sa auch solche mit sumerischen Namen vertreten, was in aller Regel auf eine hohe Position an Tempel oder Palast verweist. Das Amt dieses Musikers ist damit innerhalb der Musikerhierarchie über dem gewöhnlichen nar anzusiedeln, möglicherweise war er sogar dem nar-gal in seiner Rangposition gleichgestellt, wobei sich die Berufsinhalte dieser beiden Musiker grundlegend voneinander unterschieden. Der nar-gal war zu einem großen Teil mit administrativen Aufgaben betraut, der nar-sa scheint hingegen ausschließlich praktizierender Instrumentalist gewesen zu sein.

Wie auch schon zum nar-gal beobachtet, scheint auch der Beruf des narsa zum Ende der altbabylonischen Zeit hin zunehmend an Bedeutung verloren zu haben. Während jedoch der nar-gal in Ritualtexten des ersten Jahrtausends wieder Erwähnung findet, ist das Wort nar-sa in schriftlichen Quellen der nachaltbabylonischen Zeit nicht mehr belegt.

\subsection{3 (nar-) $\mathrm{a}-\mathrm{u}_{3}-\mathrm{a}$}

Auch wenn der nar-a- $\mathrm{u}_{3}-\mathrm{a}$ bislang nur in wenigen Urkunden aus Ur attestiert ist, ${ }^{223}$ so lässt sich dieses seltene nar-Kompositum dennoch mit dem aus lexikalischen Listen und literarischen Texten sowie Alltagsdokumenten bekannten $\mathrm{a}-\mathrm{u}_{3}-\mathrm{a}$ oder $\mathrm{a}-\mathrm{u}_{3}$ identifizieren, welches lexikalisch als Berufsbezeichnung zwischen Musikern, Sängern und Tänzerberufen, darunter verschiedene narKomposita, gala, /tigi/, huppû und eštalû eingereiht wird. ${ }^{224}$ Die Berufsbezeichnung $\mathrm{a}-\mathrm{u}_{3}-\mathrm{a}$ oder auch $\mathrm{a}-\mathrm{u}_{3}$ wird damit dem Bereich der Musik zugeordnet und kann so als verkürzte Form zum nar-a- $\mathrm{u}_{3}-\mathrm{a}$ angesehen werden. Inwiefern sich die Namen oder auch Inhalte dieses Berufs vom gleichnamigen Beruf des „Fährmanns“, welcher ebenfalls über $a-u_{3}-a$ oder $a-u_{5}(-a)$ (auch addir) angezeigt wird, abgrenzt, lässt sich derzeit nicht feststellen. ${ }^{225}$

$\mathrm{a}-\mathrm{u}_{3}-\mathrm{a}$, ein onomatopoetisch gebildetes Wort, ist in der Literatur sonst als Interjektion bekannt, wo es überwiegend im Kontext der Klage auftritt und nur selten auch freudigen Gesang kennzeichnet, etwa den besänftigenden Klang eines Wiegenliedes oder einen jubelnden Ausruf. ${ }^{226}$

Hausgrundstück.

${ }^{223}$ UET 5, 160:17.21 (Sel 6); YOS 5, $163: 21$ (WS 5); UET 5, 95:27a (Ha 33); Charpin 1986, 250 Anm. 3 mit Korrektur der früheren Lesung nar er er $_{2}$ IB-a von Renger 1969, 179-180, 183.

${ }^{224}$ PSD A/I 199a a-u $u_{3}$-a B ,a cult person, probably a musician“; Proto- $\mathrm{Lu}_{2} \mathrm{~A}_{3}$ i 1'-3' $\mathrm{B}_{3}$ ii 7-9 (MSL 12, 67) und aB Proto-Lu $\mathrm{Lu}_{2}$ 484-486 (MSL 12, 54).

${ }^{225}$ PSD A/I 200b a- $\mathrm{u}_{5}$ bzw. $\mathrm{a}-\mathrm{u}_{5}-\mathrm{a}=$ ADDIR ,ferryman“ ( $\mathrm{u}_{5}=$ rakābu ,reiten; fahren“); CAD A/2 523a $a$ ' $\hat{u}$,ferryman“ dagegen AHw 89a $a$ ' $\hat{u}$, ,eine Kultperson“.

${ }^{226}$ Edzard 2003, 168, 170; PSD A/I 199a a-u ${ }_{3}$-a A. 
Vertreter der Profession $\mathrm{a}-\mathrm{u}_{3}-\mathrm{a}$ werden urkundlich mehrfach in Opferrationenlisten (sattukk $\hat{u})$ des Ninurta-Tempels von Nippur, teilweise auch unter Angabe des Namens aufgeführt. ${ }^{227}$ Dort sind sie u. a. den Göttern Nanna/Sîn und Nusku zugeordnet. ${ }^{228}$ Eine Identifizierung dieser $\mathrm{a}-\mathrm{u}_{3}-\mathrm{a}$ als Musiker an den Tempeln Nippurs bleibt dennoch schwierig, da in den Texten keine Hinweise auf einen musikalischen Kontext enthalten sind. ${ }^{229}$

In der Literatur wird die Berufsbezeichnung $\mathrm{a}-\mathrm{u}_{3}-\mathrm{a}$ lediglich in zwei sumerischen Kompositionen erwähnt. In der Ur Klage treten $\mathrm{a}-\mathrm{u}_{3}-\mathrm{a}$ neben anderen Priestern auf, die alle dem Gott Nanna/Sîn zugeordnet werden. Die betreffende Textpassage handelt von der Beklagung der zerstörten Stadt. Die a- $\mathrm{u}_{3}-\mathrm{a}$ verleihen ihrer Trauer Ausdruck, indem sie von ihren üblichen Tätigkeiten, nämlich dem freudigen Spiel ihrer Musikinstrumente, ablassen:

\section{T 13: Ur Klage 355-356}

„Die a- $\mathrm{u}_{3}$-a feiern keine Feste mehr in deinem (Nannas/Sîns) 'Haus der Feste', $\breve{s e} \mathrm{~m}_{3}$ und $\mathrm{a}_{2}-\mathrm{la}_{2}$, die das Herz erfreuen, und(?) das tigi spielen sie nicht mehr für dich."

355. a- $u_{3}-a e_{2}$ ezem-ma-za ezen nu-mu-ni-in-dug $g_{3}-$ ge-eř

356. šem $_{3}{ }^{\text {kuš }} \mathrm{a}_{2}-\mathrm{la}_{2}$-e ni ğ $\check{\mathrm{s}}_{2} \mathrm{~g}_{4}$ hvul $_{2}$-le-da tigi-a nu-mu-ra-an$\mathrm{du}_{12}-\mathrm{us} \check{\mathbf{s}}^{230}$

Zwar bleibt im zweiten Vers ein Subjektwechsel möglich, doch werden die a$\mathrm{u}_{3}$-a hier im Kontext hymnisch-preisender Musik genannt, wodurch ihre Identifizierung als Musiker unterstützt wird. ${ }^{231}$

Der zweite literarische Beleg zu den $\mathrm{a}_{-} \mathrm{u}_{3}-\mathrm{a}$ findet sich in der Komposition Nanna/Sins Reise nach Nippur, wo ihre Tätigkeit allerdings aufgrund des schlechten Erhaltungszustands unbekannt bleibt. ${ }^{232}$

Mit Namen bekannt sind drei nar-a- $\mathrm{u}_{3}-\mathrm{a}$ aus zwei Rechtsurkunden aus Ur: IrNanna, Sohn des Ur-Šulpa'e, Etel-Kūbi und Iddin-Ištar, die alle dem Tempel des Nanna/Sîn zugeordnet werden können. ${ }^{233}$ Die Rationenliste YOS 5, 163

\footnotetext{
${ }^{227}$ Sigrist 1984, 85-88; PSD A/I 199a a-u $\mathrm{u}_{3}$-a B.

${ }^{228}$ Sigrist 1984, 85:No. 146, 101 No. 193 Rs i 15 und S. 169; auffallend auch Sigrist 1984, 85 No. 143 ein $a-u_{3}-a$ des Ekur $\left(a-u_{3}-a e_{2}-[k u r]-k a l a m-m a\right)$ und No. $150 a-u_{3}-a$ [ ] lukur.

${ }^{229}$ Anders Charpin 1986, 250 Anm. 3.

${ }^{230}$ Zuletzt bearbeitet von Römer 2004, s. a. ETCSL 2.2.2. Kommentar: Z. 356. Die Verbindung von šem ${ }_{3}{ }^{k u s ̌} a_{2}-1 a_{2}$-e und tigi-a ist inhaltlich zwar schlüssig aber grammatikalisch unklar; vgl. Römer 2004, 102,158.

231 Gegen Jacobsen 1987, 470, der das Wort Ahua liest und als ein Gebäude oder Bauwerk deutet; Römer 2004, 157-158 zur Diskussion um a-u $\mathrm{u}_{3}$-a, die er damit m. E. abschließt.

${ }^{232}$ Sigrist 1984, 169 ,le nocher“ zu Ferrara 1973, 54: 136-139 und 143.

${ }^{233}$ UET 5, 160 (Sel 6) 17. igi $\mathrm{Ir}_{3}{ }^{\mathrm{d}}{ }^{\mathrm{N}}$ Nanna nar-a-u ${ }_{3}$-a 18. dumu Ur- ${ }^{\mathrm{d}}$ Šul-pa-e 3 und 21. ${ }^{\mathrm{I}} E-t e-$
} 
(WS 10) gibt Aufschluss über die Beteiligung einer Gruppe von 18 nar-a- $\mathrm{u}_{3}-$ a am ezem-mah ('Großes Fest') des Nanna/Sîn. ${ }^{234}$ Demzufolge traten diese Musiker bei größeren religiösen Festen als Gruppe auf. Da ihnen im Vergleich zu den ebenfalls am Fest teilnehmenden nar-gal, nar-sa und gala-mah nur die Hälfte der Rationenmenge zugeteilt wird, sind sie innerhalb der Musikerhierarchie möglicherweise an untergeordneter Stelle anzusiedeln.

Da Belege zum nar-a- $u_{3}-a$ aus jüngeren Texten gänzlich fehlen, ist sein Auftreten zeitlich auf die frühaltbabylonische Zeit beschränkt. Möglicherweise lässt sich eine Verbindung zum Kult des Nanna/Sîn ziehen. Nach Hall ist eine Pflege seines Kultes auch durch die Könige der ersten babylonischen Dynastie nachweisbar. ${ }^{235}$ Für das Verschwinden dieses Musikerberufs könnte daher ein auf politischen und historischen Ereignissen beruhender Traditionswechsel angenommen werden.

Abschließend ist nochmals darauf hinzuweisen, dass die genaue Identifizierung und Abgrenzung der Berufsbezeichnung $\mathrm{a}-\mathrm{u}_{3}-\mathrm{a}$, ob als Musiker oder Fährmann unklar bleiben muss. Denn während dieser in altbabylonischen lexikalischen Listen noch unter Vertretern künstlerischer Berufe genannt wird, findet sich in den kanonischen Listen des ersten Jahrtausends nur noch der a$\mathrm{u}_{5}$ neben addir. ${ }^{236}$ Mögliche Spezialisierungen des Musikers ( nar-) $\mathrm{a}-\mathrm{u}_{3}-\mathrm{a}$ sind nur vereinzelten Belegen zu entnehmen, so scheint er nach Aussage der Passage in der Ur Klage vorwiegend freudige Musik gespielt zu haben. Die Bedeutungsfelder der Interjektion /aua/ legen wiederum den Vortrag von Klagegesängen nahe. ${ }^{237}$ Damit bleibt die Frage offen, welche Inhalte dem Element $\mathrm{a}-\mathrm{u}_{3}-\mathrm{a}$ im Zusammenhang mit nar zugrunde liegen.

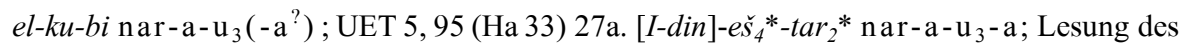
letzten Namens nach Emendation bei Charpin 1986, 137:29.

${ }^{234}$ S. Kapitel 9.1.3.

${ }^{235}$ Hall 1985, 195-199; Van de Mieroop 1992, 70-71. S. a. KH Kol. ii 13-15 und Hammurabi C 8-14, wo sich Hammurabi selbst rühmt, die Kulte des Nanna/Sîn und seiner Gattin Ningal im Ekišnugal durchgeführt und weiterhin gepflegt zu haben; vgl. Richter 2004, 427-428. SpätaB vgl. die Jahresdaten Ae h, n, p, 28 und Sd 10; Pientka 1998, 32-35, 45-47, 134-135. Auch die Pflege des Enitendu-Tempels („Haus der angenehmen Ruhe“) des Sîn im Osten Babylons ist in Jahresdaten belegt: Ad 30, Aș 17+a; Pientka 1998, 80-81, 123; s. a. Horsnell 1999/2 zu den einzelnen Jahresdatenformeln.

${ }^{236}$ MSL 12, 136:230 a-u $\mathrm{u}_{5}=a-u_{2^{-}}\left[u_{2}\right] 231$. addir $=$ MIN.

${ }^{237}$ So Charpin 1986, 250 Anm. 3 ,spécialiste des lamentations“. 


\subsection{Künstler und Akrobaten im Umfeld des nar-gal}

\subsection{1 huppû-Tänzer}

Der huppî wird lexikalisch in Proto-Lu $\mathrm{u}_{2}$ 581-586 (MSL 12, 54) zwischen Akrobaten, Jongleuren und Tierdompteuren (alan/m-zu/zu $/ u_{2}, u_{4}$-da-tuš) sowie Sängern und Musikern $\left(a-u_{3}-a, e \breve{s}_{3}-t a-1 a_{2}\right)$ eingereiht. Über diesen engen Bezug zum musikpraktischen Bereich wird er mit Tanz oder Akrobatik in Verbindung gebracht. ${ }^{238}$

Der Brief AbB 9, 193 (o.D.) aus der Korrespondenz des Šamaš-hāzir nennt eine Gruppe von huppĥ-Tänzern, über die der nar-gal Šu-Amurrum gestellt war:

T 14: AbB 9, 193

Zu Šamaš-hāzir sprich: folgendes (sprach) Hammurabi: „,... .. wenn sich dieses unbearbeitete Feld im Besitz des Palastes befindet, gib es den huppû unter der Aufsicht des nar-gal Šu-Amurrum!‘239

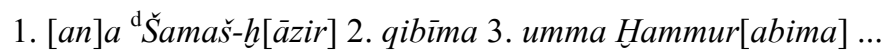

11. šumma eqlum annum 12. nadîma rēš ekallim 13. ukāl

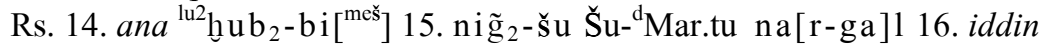

Nach diesem Brief wurde das Palastfeld an die Tänzer zur Selbstversorgung ausgegeben, wobei sich der nar-gal als ihr Aufseher zeigt. Gleicher Art ist das Verhältnis des nar-gal zu den huppĥu von Mari, die von Ziegler im Rahmen der Mari-Dokumentation ausführlich diskutiert wurden. ${ }^{240}$

Reichhaltig belegt sind die hupp $\hat{u}$-Tänzer auch zum Ende des dritten Jahrtausends in Ebla und Nagar, wo sie neben anderen Musikern (nar, NE-di) Empfänger von Textilien und edlen Metallgegenständen des Königspalasts sind. ${ }^{241}$

Dementgegen fällt die Beleglage zum huppû im babylonischen Raum des zweiten Jahrtausends sehr dürftig aus. Empfänger eines Lehensfeldes durch Šamaš-hāzir ist auch der huppû mit Namen Rē'išu-dāmiq im Brief AbB 4,

${ }^{238}$ AHw 356 ḩuppû II „ein Kulttänzer“; CAD H 240 „acrobat“; s. a. Ziegler 2007, 261 „,saltimbanque“; akk. huppû ist dem Zeichen $\mathrm{HUB}_{2}$ entlehnt, das eine Sprung- oder Laufbewegung anzeigt; Catagnoti 1997, 582-584; aB sind die Schreibungen hub $\mathrm{b}_{2}-\mathrm{be}_{2}$, hub $\mathrm{b}_{2}$-bu oder $1 u_{2}-h u b_{2}$ belegt, in Ebla konsequent hub $b_{2}$ oder hub $b_{2}-$ KI. In Mari wird das Wort ausschließlich syllabisch wiedergegeben ${ }^{\mathrm{lu2}} h u-u p-p u-u_{2} / u m$ (Durand/Guichard 1997, 55:iii 2526; Ziegler 2007, 270 No. 67:17, 273 No. 68:8); so auch in Dilbat VS 7, 127:3..hu-up-pu $-u_{2}$. Die ungewöhnliche Schreibung ${ }^{\mathrm{lu} 2} u_{2}-p i_{2}$ (Ziegler 2007, 274 No. 69:14') ist bisher einmalig in Mari belegt.

${ }^{239}$ Anders CAD N/1 77 ,if that field remains fallow it is reserved for the palace“.

${ }^{240}$ Ziegler 2007, 11, 261-275.

${ }^{241}$ Catagnoti 1997, 564-577, 584-585. 
Teil I Die Musiker

45. ${ }^{242}$ Aus Dilbat wird der huppû Sîn-iqī̌am als Empfänger von Getreiderationen bekannt. ${ }^{243}$

Über die kultischen Aktivitäten der huppû im babylonischen Raum gibt die Ritualliste HUCA 34, 1ff. aus Larsa Auskunft. Dort werden sie zum Fest des Enki am zweiten und zum Fest des Šamaš am dritten Tag als Empfänger von Rationen genannt. ${ }^{244}$ Neben diesen traten auch verschiedene Musikergruppen, nar-gal, nar und gala, und der Ekstatiker $1 u_{2}$-gub-ba auf. ${ }^{245}$ Hierzu vergleichbar ist der Auftritt der huppû im Ištar-Ritual von Mari, wo sie zum Klagegesang des kalû mit seiner halhallatum-Trommel neben „Trägern(?)“ (mubabbilum) und Ringkämpfern ( ̌̌a humāa/ūšim) auftraten. ${ }^{246}$

Die Tätigkeit der huppĥ wird über die Verben mēlulum ,spielen, wirbeln“ und dem iterativ-habitativen nabalkutum ,i. w. hin- und herwechseln/hinübergehen /überqueren“ angezeigt. ${ }^{247}$ Die Deutung einer Tanz- oder Hüpfbewegung ist daher nahe liegend.

Die Vorführungen der huppû wurden außerdem durch Musik begleitet. Neben den oben genannten Belegen ist ihre Erwähnung neben nar ša uppîm, den Musikern der uppûm-Trommel, als Empfänger edler Geschenke zur gemeinsamen Festprozession nach Razamā beachtenswert. ${ }^{248}$ Die musikalische Begleitung der huppû könnte damit rein rhythmisch-perkussiv vorzustellen sein.

Die huppû-Tätigkeit ist ausschließlich Männern vorbehalten. ${ }^{249}$ Ihre Tabuisierung für Frauen ist möglicherweise damit zu begründen, dass der in einer schaustellerisch-musikalischen Weise dargestellte huppû-Tanz dem Wirkungsbereich von Männern entlehnt ist, beispielsweise dem Kriegs- oder Jagdge-

${ }^{242} \mathrm{AbB} \mathrm{4,} \mathrm{45:5.}$ bur $_{3} \mathrm{iku}$ a-ša $\mathrm{a}_{3}$-lam i-na āl(uru) ${ }^{\mathrm{ki}} \mathrm{maškenim} \mathrm{6.} \mathrm{a-na} \mathrm{Ré’i(sipa)-šu-da-}$ ${ }^{\ulcorner} m i^{1}-i q$ bub ${ }_{2}$-bi 7. i-di-in; Lesung hub ${ }_{2}$-bi nach van Dijk apud Buccellati 1972, 151-152.

${ }^{243}$ VS 7, 127:3 (Aș 17+a).

${ }^{244}$ Westenholz/Westenholz 2006, 33-34, 40: ii 11, 44: iii 32; für Ebla ist vergleichsweise eine Aktivität der huppû zum Opferfesttag des Enki belegt; s. Catagnoti 1997, 580-582; ausführlich zur Larsa-Opferritualliste hier Kapitel 9.2.3.

${ }^{245}$ Westenholz/Westenholz 2006, 32-33, 44 iii 21-32.

${ }^{246}$ Durand/Guichard 1997, 55:iii 16-27; auch im Ölarchiv werden huppû neben Ringkämpfern genannt, in M 13211 bei Duponchel 1997, 251 No. 103:2-3 aus Anlass des Festes kuššum im xii. Monat, das zur Verabschiedung des Königs Simah-ilānī von Kurdâ stattfand; ibid., 215.

${ }^{247} \mathrm{Zu}$ mélulu(m) (auch in kriegerischem Zusammenhang) AHw 644, CAD M/2, 16-17; zu nabalkutu(m) AHw 696a, 356 sub huppô II ,umherspringen“, CAD N/1, 11a nabalkūtu(m) S. $17 \mathrm{sub} 2 \mathrm{c}$ auch als ,to change sides“; vgl. Ziegler 2007, 262 mit Disk.

${ }^{248}$ ARM(T) 25, 190 No. 624; huppû neben Musikern auch bei Duponchel 1997, 238 No. 74 (xi 18): .. 2. a-na pa-ša-aš hu-up-pu(-)um!-me-ni 3. lu ${ }_{2}$-nar-meš ša si $i_{2}$-hi-ir-ti 4. a-li-im 5. $u_{3}$ Ia-ri-ib- ${ }^{\mathrm{d}} \mathrm{IM} 6$ 6. ${ }^{\mathrm{lu} 2} h u-p i_{2}-i$ 7. $i$-na Di-ir ${ }^{{ }^{\mathrm{ki}}{ }^{1}}$.. ,...für die hupp $\hat{u}$-Meister?; die nar aus dem Umkreis der Stadt und Jarim-Addu der huppû in Dēr ..“; Duponchel 1997, 238 zu Z. 3.-4. „les musiciens qui (font le) tour de la ville...“; anders Ziegler 2007, 266 „les musiciens de l'ensemble de la ville".

${ }^{249}$ Catagnoti 1997, 587; Ziegler 2007, 262. 
schehen. ${ }^{250} \mathrm{Da}$ an die huppô von Mari verschiedentlich Waffen, insbesondere Schwerter ausgegeben wurden, deutete Ziegler ihre Profession in einer Art 'Schwertkampf-Tanz'. ${ }^{251}$

Der Rahmen des huppû-Tanzes war grundsätzlich festlich-kultischer Natur. Sie traten entweder vor einer Gottheit oder vor dem König auf und vollführten ihre Künste auch im Freien. ${ }^{252}$ Ihr Tanz konnte entweder neben anderen akrobatischen und sportlichen Darbietungen eingereiht sein oder als Einzeldarbietung stattfinden. Eine Zuordnung zu einem bestimmten Götterkult ist nicht feststellbar. Anlässe für Auftritte der huppĥ in Mari sind Feste für weibliche Gottheiten, ${ }^{253}$ in Larsa treten sie für Enki und Šamaš auf. Der Tanz der hupp $\hat{u}$ ist höchstwahrscheinlich mit einem konkreten Inhalt verbunden, der auch Bezüge zu Klagekulten aufweisen kann. ${ }^{254}$

Das Zentrum des hupphi-Tanzes setzt Ziegler nach Aussage eines Mari-Briefes in Aleppo an. ${ }^{255}$ Auch hinsichtlich der Beleglage für das dritte Jahrtausend ist die Tradition des hupp $\hat{u}$ in den syrischen Raum zu verorten. ${ }^{256}$ Damit steht er der sumerischen Tradition Südbabyloniens gegenüber. ${ }^{257}$ In Ur, Nippur und Isin

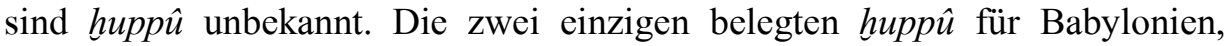
Rē'išu-dāmiq und Sîn-iqī̌sam, weisen dennoch gängige akkadische Namen auf, die keinerlei fremdländische Bezüge zum Westen und Norden vermuten lassen. Weiterreichende Spekulationen zu Ursprung und Tradierung des huppû-Tanzes in Babylonien können an dieser Stelle nicht geführt werden, da hierzu die Beleglage zu dünn ausfällt.

\footnotetext{
${ }^{250}$ Anders Catagnoti 1997, 587, die von einer hemmungslosen Tanzart ausgeht, die für Frauen tabuisiert war; s. a. Ziegler 2007, 262.

${ }^{251}$ Ziegler 2007, 261, mit ikonographischer Identifizierung der huppû ibid., 263-264.

${ }^{252}$ Ziegler 2007, 266-268 mit Belegen; für Ebla ist eine Aktivität der huppĥ im Garten belegt; Catagnoti 1997, 580-582.

${ }^{253}$ Duponchel 1997, 214-215.

${ }^{254}$ Vgl. Catagnoti 1997, 568, 585+Anm. 84 für Ebla; Kilmer 1977, 133 und George 2003, 842.

${ }^{255}$ Ziegler 2007, 265, 270 zu No. 67.

${ }^{256}$ Catagnoti 1997, 586-587; Durand/Guichard 1997, 51.

${ }^{257}$ So auch Ziegler 2007, 265.
} 


\subsection{2 aluzinnu, der 'Gaukler'}

Wie der Inhalt eines altbabylonischen Briefs nahe legt, war der nar-gal auch für die Gruppe der aluzinnu verantwortlich:

\section{T 15: AbB 8, 109:4-13}

„Betreffs der aluzinnū, die zum Frondienst 'aufgestiegen' sind, in Bezug auf mich hat der König Folgendes gesagt: 'Diesen Knaben hier, der bei mir ist, kenne ich, die anderen (aber) kenne ich nicht! Vielleicht werden sie ihm beim ilkum-Dienst gleichkommen!' Folgendes (sprach) der nar-gal: 'Niemand wird/kann ihn anfeinden!' Und Folgendes (hat) der König (gesagt): 'Fünf von ihnen und fünf...d[ie] ich [den] Soldaten zugeteilt habe, [kehr]en nicht zum Frondienst [zurück]!'“

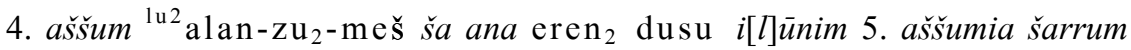
kīam iqbî umma šarrumma 6. șuhāram annammiam ša mahria 7. an[āk $]$ u šăatima lū i $[$ de] 8. u[l]luttini ul ìde 9. midde ana ilkim išannanūšsu 10. umma nar-gal-ma mamman ul igerrîšu 11. u umma šarrumma 5-šunu $u_{3} 5[.$.$] 12. š[ [a$ ana] ag a-uš-meš assuhušun[ūti $]$ 13. ana dusu [...] ul i[târ $] m a^{258}$

Der aluzinnu (alam $\left./ \mathrm{n}-\mathrm{zu}_{2} / \mathrm{zu}\right)$ wird nebst seinen zahlreichen sumerischen Entsprechungen $u_{4}$-da-tuš(-a) „Bärendompteur(?)“ und gu-za-tuš(-a) „Seiltänzer(? ${ }^{، 259}$ als Gaukler oder Schauspieler gedeutet. ${ }^{260}$ Sein Beruf beinhaltete verschiedene Formen der öffentlichen Schaustellerei, ob als Komiker, Dompteur oder Akrobat lässt sich seine Tätigkeit je nach Aussage der Texte unterscheiden.

Im zitierten Brief werden aluzinnu im Zusammenhang mit öffentlichen Arbeiten im Dienste des Königs genannt. Weitere altbabylonische Belege sind aus Sippar, Dilbat, Larsa (/Ur?) sowie Mari, Alalah und Susa bezeugt. ${ }^{261}$ Für den

${ }^{258}$ AbB 8, 109: Kommentar: Z. 8. ulluttini ist Hapax; vgl. AbB 8 S. 73 Anm. 109c); Z. 10 geru $(m)$ eigentl. „befehden; prozessieren (gegen jmd.)“; AHw 286.

${ }^{259} \mathrm{Lu}_{2}=\check{s} a$ IV (MSL 12, 136) 245/a-249a; wörtlich „,der auf der Ziege sitzt“ und ,der auf dem Seil sitzt“; Römer 1974, 47-48; in Igituh 273 neben Schankwirten; Ziegler 2007, 278.

${ }^{260}$ Römer 1974, 43-68 „Spassmacher“; Foster 1974, 69-85 „trickster“; Blocher 1992, 80, 97 zur Ikonographie; Durand in ARM(T) 21 S. 500 Anm. 37 zur 'Mütze' des aluzinnu; AHw 39b „Spaßmacher, Clown“; PSD A/3, 171 ,,jester“; CAD A/1 392 ,a profession“; Stol 2003, 639640, 642 „Schauspieler“; Ziegler 2007, 277 ,amuseur“.

${ }^{261}$ Sippar: CT 47, 80:36. a-lu-zi-in-nu (o.D.); BBVOT 1, 86:6. a-lu-zi-nu-um?; Dilbat: YOS 13, 169:9 1 a-wi-il- ${ }^{\mathrm{d}}$ Mar.tu alan-zu (Aș 13); Larsa: AbB 8, 109:4 ${ }^{\text {lu2 }}$ alan-zu ${ }_{2}-\mathrm{meš}_{\text {s }}$ und TCL 11, 242:3. 0.2 lu2 a-lu-zi-nu (o.D.); Ur/Larsa: Stol 2003, 645(YBC 4936 (Ha 34)):2. 12 alan-zu ${ }_{2}$; s. a. ibid., 642 mit einem weiteren Beleg in BM 97004 iv 10; Susa: MDP 22, 52:19-20 igi Dan-šu-šu-un dumu a-lu-zi-nu (CAD A/1 392b; Römer 1974, 49); zu Mari s. Ziegler 2007, 277-280. Nach Stol 2003, 642 ist die logographische Schreibung mit $\mathrm{zu}_{2}$ früh-, mit zu spätaB. 
babylonischen Raum sind aluzinnu hauptsächlich als Fronarbeiter bekannt. ${ }^{262}$ Belege aus Mari und Alalah bezeugen ihre Teilnahme an Hochzeitsfeierlichkeiten. ${ }^{263}$

Neben aluzinnu ist altbabylonisch nur noch der $\mathrm{u}_{4}$-da-tuš(-a) „Bärendompteur $^{6}$ urkundlich belegt. ${ }^{264}$ Belege $\mathrm{zu}$ dieser Profession datieren sonst überwiegend in die präsargonische und Ur III-Zeit. ${ }^{265}$ Zwei Vertreter dieses Berufsstands sind in Isin zur Zeit des Enlil-bāni Empfänger von Rationen der Königsverwaltung. ${ }^{266}$ Neben ihnen wird auch eine Musikerin munus-tigi genannt.

Der Bezug dieser Schausteller zu Musikern begründet sich literarisch und lexikalisch. In der Liste Proto-Lu $\mathrm{L}_{2}$ wird der aluzinnu neben Tänzern (hub $\mathrm{b}_{2}-\mathrm{bi}$ ) und Musikern $\left(\mathrm{a}-\mathrm{u}_{3}-\mathrm{a}\right.$, ešs $\left.{ }_{3}-\mathrm{ta}-\mathrm{a}_{2}\right)$ eingereiht. ${ }^{267}$ Die satirische Komposition Edubba $B$ nennt einen a-tar-du 3 ,Persifleur“, als Variante zum aluzinnu, ${ }^{268}$ neben einem eštal $\hat{u}$-Musiker, die sich beide tanzend und musizierend auf den Straßen herumtreiben. ${ }^{269}$

Die grundsätzlich männlichen aluzinnu gehörten nicht zum festen Personal eines Tempels oder Palasts, auch weist ihre Tätigkeit keinen konkreten Bezug zu einem religiösen oder kultischen Kontext auf. ${ }^{270}$ Es wäre möglich, dass sie als 'fahrendes Volk' keinen spezifischen Ort ihre Heimat nannten. ${ }^{271}$ Nach Art

${ }^{262}$ Römer 1974, 50; Stol 2003, 639; auch mA als Arbeitskräfte bei Bauunternehmen; Jacob 2003, 465-466.

${ }^{263}$ ARM(T) 25, 225 (Ziegler 2007, 277); Al. 409 (Römer 1974, 50; Blocher 1992, 82).

${ }^{264}$ Römer 1974, 48-51; Henshaw 1994, 114; nach dem Nippur-Sprichwort N 6119 und N 4047 (ETCSL 6.2.1) auch Spaßmacher und Clown.

${ }^{265}$ Sigrist 1992, 221; Gelb 1975, 63; zu Bärenlieferungen auch an gala für die Ausübung der nam-u ${ }_{4}$-da-tuš „Kunst/Profession des Bärendompteurs“ s. Römer 1974, 51; Blocher $1992,80$.

${ }^{266}$ Wilcke 1994, 312: IB 1304 Rs. 14'-15'.

267 aB Proto-Lu 581ff. (MSL 12, 54); aB Lu Fragm. II 8 (MSL 12, 202 ohne Kontext); PSD A/3, 171; Henshaw 1994, 103-104; s. a. Gelb 1975, 63 zur Einordnung von muš-lah ${ }_{4}$ „Schlangenbeschwörer“ und u $\mathrm{u}_{4}$-da-tuš „Bärendompteur“ unter nar.

${ }^{268} \mathrm{Zu}$ a-tar akk. namūtu(m) „Verhöhnung“ s. Römer 1974, 52-53 auch zum Beleg in Inana C (ETCSL 4.07.3) 159; in aB Lu L $_{2}$-Azlag Fragm. II 9 (MSL 12, 202) wird nach Sjöberg 1973b, 130:130 dementsprechend $\left[\mathrm{lu}_{2}\right.$ a-tar]- $\mathrm{du}_{3}$ als Gleichung zu aluzinnu ergänzt; zum Terminus namūtu in diesem Zusammenhang s. a. Groneberg 1997b.

${ }^{269}$ Edubba B 130-132: „Wenn (du) bei/mit den 'Spaßmachern' (a-tar-du ${ }_{3}$ ) und Sängerknaben (aš-ta-lu $\mathrm{u}_{2}$ ) bist, (und) dich bei ihnen herumtreibst, dann ist deine 'Sache' Hüpfen/Springen - das passt dir (wohl so)!“; vgl. Sjöberg 1973b, 113, 118, 130-131; Römer 1974, 52. Zum a/eštalûm als sich in Ausbildung befindlichen Musiker s. Ziegler 2007, 16-17.

${ }^{270}$ Anders der hethitische ${ }^{\text {lu2 }}$ ALAM.ZU 9 ; ausführlich Schuol 2004, 157-158.

${ }^{271}$ Dies legt der Mari-Brief bei Ziegler 2007, 229-231 (FM 9 No. 56 ) nahe, wonach der aluzinnu Urabbâ-ana-Šarrim (Künstlername?), der mit seiner Familie(ergänzt!) nach Ekallātum will, für eine Weile beim Musiklehrer (mušāhizum) Imgur-Šamaš im mummum-Konservatorium unterkommt; anders Ziegler 2007, 277-278. 
der Tagelöhner könnten sie Zeiten finanzieller Not mit Arbeiten bei der Feldbestellung oder Bauunternehmen überbrückt haben. Entsprechend der huppuTänzer gehörte ihre Organisation und die Verwaltung ihrer Bedürfnisse zu den Aufgaben des nar-gal. ${ }^{272}$

${ }^{272}$ Vgl. Stol 2003, 642. 


\section{Der gala, Klagesänger und Priester}

\subsection{Zum Wort und seinen Varianten}

Über das Wort gala wird eine Berufsgruppe bezeichnet, die im Wesentlichen mit der Ausführung eines wichtigen Bereichs der Kultmusik betraut war. Das Logogramm gala wird durch das Zeichenkompositum UŠ.KU gebildet und ins Akkadische als kalu $(m)$ entlehnt. ${ }^{273}$ Die ursprüngliche Bedeutung der Zeichenkombination UŠ.KU konnte bisher nicht zufrieden stellend gelöst werden. Bisherige Deutungsversuche setzen meist eine auf das Geschlecht bezogene Aussage an, da in der Forschung die Meinung vorherrscht, der gala zeichne sich durch ein 'zweideutiges' Geschlecht aus. ${ }^{274}$ In diesem Zusammenhang spielt auch seine enge Beziehung zu Göttinnen und Frauen eine bedeutende Rolle. Die Diskussion um das Geschlecht des gala wird hier im Exkurs I erörtert.

In den altbabylonischen Quellen werden Vertreter dieses Berufs überwiegend logographisch gala (UŠ.KU) angezeigt, syllabische Schreibungen sind für das zweite Jahrtausend äußerst selten und beschränken sich auf Texte aus dem nordbabylonischen und syrischen Raum. ${ }^{275}$ Für den gala-mah (UŠ.KU$\mathrm{mah})^{276}$ sind zwei syllabische Varianten in frühaltbabylonischen Texten bezeugt, die sich im Anlaut unterscheiden: kalamāhu und galamā/(h)hu ${ }^{277}$ Eine weibliche Form des Berufsnamens gala ist bislang nicht bekannt. ${ }^{278}$

${ }^{273}$ Hierzu im Allgemeinen AHw 427b; CAD K 91a. Die Zeichenkombination UŠ.KU wird zuweilen zu KU.UŠ verkehrt, so in der Ausgabenliste IB 1774:8 (Enba f) bei Krebernik 1992, 123; im aB Ištar-Ritual von Mari Kol. iv 16' (Durand/Guichard 1997, 61) und im nA Gebet an einen verfinsterten Gott Z. 23; Ebeling 1948, 418, 420:23. $1 \mathrm{u}_{2}$ [KU].UŠ li-li-is-su li-ri-[im] ,der kalû-Priester möge die Pauke bedecken“.

${ }^{274}$ Gelb 1975, 66-74; Steinkeller/Postgate 1992, 37; Gabbay 2008, 47-54.

275 Tuttul: KTT 86 (Aw) 15. dumu-meš ka-le-e-em; KTT 130 (Ab) 5.-10. $\mathrm{sa}_{2}$-dug $\mathrm{du}_{4}$ ! ( sa g̃ ) u $s i_{2}$-di-it $4{ }^{\mathrm{lu} 2} \mathrm{ka}$-le-e i-nu-ma iš-tu igi lugal a-na ma-ri ${ }^{\mathrm{ki}} i$-ti[-qu $]$, ,regelmäßige Ausgabe und Reiseproviant für vier kalu, als sie (auf dem Weg) nach Mari vor den König traten (wörtl. vorbeikamen!)“; Krebernik 2001, 66-67, 86-87. Bisher einmalig ist die Schreibung GA.LA- $u_{2}-$ tam $_{3}$ in einem Brief aus T. as-Sulaima für ein kalû-Amt, das von einer Frau bekleidet wird; Al-Rawi 1992b, 185: IM 85455 Rs 3; dazu Black 1991, 27.

${ }^{276}$ Beachte in TCL 1, 230:39' (D.a.) die einmalige Schreibung ma h- UŠ.KU.

277 JCS 11, 20 No. 6 (Ha 35) 5. dam ka-la-ma-hu gegen Renger 1969, 195 Anm. 907 ist $k a-$ lamāhu trotz fehlender Flektion kein Eigenname, vgl. gramm. korrekt mit derselben Frau in 


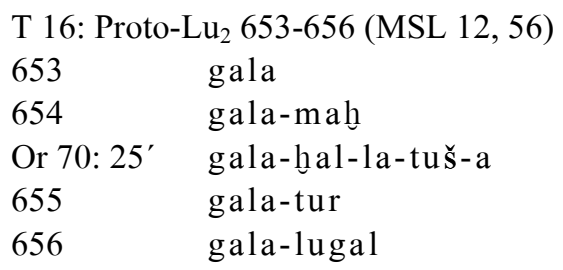

In literarischen Texten werden gala, gala-mah und gala-tur unterschieden, wobei am häufigsten das Wort gala angegeben wird, um dann ähnlich dem Wort nar als Sammelbegriff für alle Spezialisierungen und Hierarchien innerhalb dieser Berufsgruppe zu fungieren. ${ }^{279}$ Der gala-tur(-ra), der „kleine/junge gala" ist nur einmal in Inanas Gang in die Unterwelt belegt. ${ }^{280}$

Auch der gala-mah lugal oder auch gala-lugal, „gala-mah/gala des Königs“" ist urkundlich nur für die Ur III-Zeit in G̈irsu attestiert. ${ }^{281}$ Dort kann er dem Umfeld des Königskultes, im Speziellen des Šulgi zugeordnet werden. An dessen Tempel sind seine Tätigkeiten ebenfalls im religiösen Bereich anzusetzen. $^{282}$

VS 9, 152 (Ha 39) 4. ' A-ha-ti-ma dam ka-la-ma-hi; Harris 1975, 173 Anm. 115; s. a. die Immerum-zeitliche Rechtsurkunde aus Sippar: BM 82437a/b:1.Rd/32. ig i Ku-la-lu-um (kala-ma-hi-im) (Koll.). Schreibungen mit $g$-Anlaut finden sich in den Briefen AbB 10, 124(=OECT 15 Nr. 263) 9. ga-la-ma-hi und AbB 9, 166:6 ga-la-ma-ah-hi; zur Entlehnung von $m$ a h als mahhû s. CAD M/1 89. Vergleichbar ist die Schreibung GA.LA- $u_{2}$-tam 2 (für

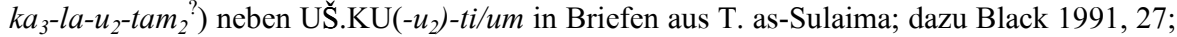
Al-Rawi 1992b, 184-185. In LL und Bilinguen des 1. Jt. gal-ma-hu/hi neben kalû für gala; AHw 273b; Menzel 1981, 233.

${ }^{278}$ Weibliche Vertreter des gala-Berufs sind überwiegend altsumerisch belegt; Hartmann 1960, 132; Selz 1995, 109 und Anm. 397. S. aber auch den Beleg aus T. as-Sulaima bei Al-Rawi 1992b.

${ }^{279}$ Für gala als Oberbegriff auch anderer künstlerischer Berufe in frühsumerischer Zeit s. Hartmann 1960, 133; s. a. Groneberg 1997a, 148-149 + Anm. 232 zu den Zeilen 53-54 in der Balag̃-Klage Uru-ama 'irabi bei Volk 1989, 84, 92, derzufolge das Wort kalû allgemein für Kultdiener der Ištar stehe.

${ }^{280}$ Inanas Gang in die Unterwelt 236ff. und 263ff.; s. Kapitel 6.3.1. In administrativen Texten ist der gala-tur vornehmlich frühdynastisch und aAkk. attestiert (vgl. Selz 1995, 62:131; s. a. beispielhaft für G̃irsu Index zu VS 25, 27 und VS 25, 21 sub Personennamen; bei Marzahn/Neumann 1995, 115:iii 13' wohl PN'); für das 1. Jt. sind mehrere junge, wohl in Lehre stehende kalu aus Kolophonen als Schreiber u. a. zweisprachiger Klagelieder bekannt; Hunger 1968, 58 Nr. 149:3 (SBH 54 Rs. 51) und ibid. 77 Nr. 226:4 (KAR 305 Rs. 7) ${ }^{(\mathrm{lu2})}$ gala$\operatorname{tur}(-\mathrm{ru})$ „Klagepriester-Schüler/Lehrling“. Ebenfalls in Lehre stehende kalû bezeichnen die Ausdrücke ${ }^{\text {lu2 šaman }}{ }_{2}-1 \mathrm{a}_{2}{ }^{(\mathrm{lu} 2)}$ g a la bei Hunger 1968, 126 Nr. 433:4 (CT 46, 52 Rs. 6') und ibid. 48 Nr. 115:3 sowie gala $a$-ga-aš-gu- $u_{2}$ in UET 6, 204:46; vgl. CAD K 93b sub b'; Henshaw 1994, 89. agašgû steht zur Bezeichnung eines Lehrlings oder 'Novizen' auch bei Schreibern und Ärzten (asû); CAD A/1, 149 ,youngest son, youngster, novice“; AHw 16.

${ }^{281}$ TUT 287 (AS 1) 10' gala-lugal-me; HLC 2 (pl. 52) Rs ii 21 (AS 1) zum Personal des Šulgi-Tempels (23. e ${ }_{2}$ '̌́ul-gi-me) gehörig; s. a. Hartmann 1960, 140, 169.

${ }^{282}$ Anders der Status im aB Brief aus T. as-Sulaima, der eine Frau nennt, die gleichzeitig ein 
Während die meisten altbabylonischen lexikalischen Listen nach den Einträgen zum gala Klagefrauen und balag̃-Spieler nennen, wird in einer einzigen Variante die Liste mit Kultakteuren der Inana/Ištar fortgeführt, darunter kur-g̃ar-ra, sa g̃-ur-sag̃ und pi-li-pi-li, die sonst auf die Sektion der Priesterinnen folgen. ${ }^{283}$

Lexikalische Listen führen weitere Komposita mit gala, die auf mögliche Berufsspezialisierungen hinweisen:

T 17: Proto- $\mathrm{Lu}_{2}$ 657-659 (MSL 12, 56)

657 gala-lugal-ra-us 2 -sa

658 gala ma-da-ab-us ${ }_{2}$

T 18: $\mathrm{Lu}_{2}=\check{s} a$ IV 170-173 (MSL 12, 134)

170 gala- $\mathrm{us}_{2}-\mathrm{sa}$

171 gala-bal-tuš-a

$172 \quad$ gala-ze ${ }_{2}-\mathrm{e}_{3}=a-s \underline{u}-u_{2}$

173 gala-ŠSIR ${ }^{2}-\mathrm{da}=$ MIN ki-iș-ri

Der gala-lugal-ra-us ${ }_{2}$-sa „gala, der dem König folgt(?)“ weist entweder auf eine Rangposition oder auf Vorgänge im Ritualzusammenhang hin, ${ }^{284}$ so tritt beispielsweise im altbabylonischen Mari-Ritual ein gala-Priester im Verlaufe einer Kulthandlung in unmittelbarer Nähe zum König auf. ${ }^{285}$ Der gala-us ${ }_{2}$-sa der kanonisierten $\mathrm{Lu}_{2}$-Fassung wird von den Wörterbüchern als gala zweiten Ranges aufgefasst. ${ }^{286}$ Auch der gala ma-da-ab-us ${ }_{2}$ von Zeile 658 könnte auf einen niedrigeren Rang verweisen. Es folgt der gala-hal-tuša zur Bezeichnung des lernenden gala. Der folgende Eintrag mit akkadisch $\bar{a} s \hat{u}$,herausragend“" verweist nach CAD möglicherweise auf den solistisch auftretenden gala im Gegensatz zum darauf folgenden Chor-Klagesänger. ${ }^{287}$

nar- sowie ein gala-Amt am Königspalast bekleidete; Al-Rawi 1992b, 184-185 und hier Exkurs I.

${ }^{283}$ aB Proto- $\mathrm{Lu}_{2} 278 \mathrm{ff}$., 660ff. (MSL 12, 42:56) und Taylor 2001, 216-217:27'-31'.

284 aB Proto- $\mathrm{Lu}_{2} 657$ (MSL 12, 56); Lesung nach Renger 1969, 187 Anm. 855; vgl. auch Variante aus Isin (IB 1318) iii 5. gala-lugal a-ra-x-us $\mathrm{s}_{2}$-sa; Taylor in cdli.

${ }^{285}$ Durand/Guichard 1997, 55-56 Kol. iii 14-18.

${ }^{286}$ AHw 254 „Klagepriester 2. Ranges“; CAD G 14, „kalu-musician of the second rank“; s. a. Henshaw 1994, 89 ,'the one following the kal $\hat{u}$ ' apparently a kalû of secondary rank".

${ }^{287} \mathrm{CAD} \mathrm{A} / 2385$ sub 3c) als gala $\mathrm{S}^{2} \mathrm{R}_{3}$-da , ,kalû-singer of the chorus“; andererseits könnte es als gala keš $\check{2}_{2}-\mathrm{da}$ als ein spezialisiertes Amt zu deuten sein; vgl. gudu ${ }_{4} \mathrm{keš}_{2}-\mathrm{da}$ in T 52, Kapitel 9.5.2.6 und das entsprechende Amt nar kešs $\breve{2}_{2}$ da in Proto-Lu $\mathrm{Lu}_{2} 650$ (T 2) hier Kapitel 5.1 . 
Als Emesalform zum Berufsnamen gala wird in lexikalischen Listen und zweisprachigen Balag̃-Liedern des ersten Jahrtausends das Zeichen sur $_{9}$ geführt. ${ }^{288}$ Ein gleichnamiger Priesterberuf ist nach Veldhuis bereits für das dritte Jahrtausend nachweisbar. Möglicherweise wies dieser Parallelen zum gala auf, weshalb Veldhuis eine sekundäre Gleichsetzung beider Priesterberufe für das ausgehende dritte und beginnende zweite Jahrtausend in Betracht zieht. ${ }^{289}$ Weitaus jünger und erst mittelassyrisch belegt sind die Gleichungen des Wortes kalu mit la-bar und murub $(2)$, die auf einer Vermengung ursprünglich unterschiedlicher Priesterberufe beruhen. ${ }^{290}$

\subsection{Organisation und Verteilung}

\subsubsection{Zur Stellung innerhalb der Administration}

Entgegen den vielfältigen Berufsvarianten des nar, die in den Alltagsdokumenten der altbabylonischen Zeit auftreten, werden in derselben Textgruppe lediglich die gala von den gala-mah, den „großen gala“ unterschieden, in aller Regel als „Oberklagepriester“ wiedergegeben. ${ }^{291}$ Dass die gala den galamah unterstellt waren, ist aufgrund der Wortbedeutung anzunehmen. Der gala-mah wird als Vorsteher der gala-Priester angesehen, der im Gegensatz zum gala ein festes Tempelamt mit Aufgaben im Bereich des Götterkults besetzte. ${ }^{292}$ Diese Hierarchie implizieren auch Angaben in Rationenlisten, in denen der gala-mah immer als Einzelperson gegenüber einer Gruppe von gala-Priestern genannt wird. ${ }^{293}$ Nach Aussage literarischer Texte könnte er ihnen auch in musikalischer Hinsicht als Solosänger und Instrumentalist vorgestanden haben. ${ }^{294}$ Das Amt eines gala-mah war zur altbabylonischen Zeit eine feste Institution an jedem Tempel einer Hauptgottheit. In diesem Sinne finden sich weitaus häufiger gala-mah, die in ihrem Titel einer Gottheit zugeordnet

\footnotetext{
${ }^{288}$ Veldhuis 1997/98, 117.

${ }^{289}$ Veldhuis 1997/98, 118-119.

${ }^{290}$ Vgl. Schretter 1990, 201:206 und MAOG 13/2, 45:16-17, 49:16-18.

${ }^{291}$ So AHw 273; s. a. CAD G 19 „,chief singer of dirges“; Hartmann 1960, 129 „oberste Klagepriester".

292 Renger 1969, 197-198 als „Vorsteher der Klagepriester“ in Anlehnung an Hartmann 1960, 129; Harris 1975, 174. Zum Abhängigkeitsverhältnis von gala-mah und gala s. a. AbB 10, 1 und hier Kapitel 9.6.2.1.

${ }^{293}$ Bspw. OLA 21, 4:5.8 (Ae 28).

${ }^{294}$ So im Fluch über Akkade hier Kapitel 6.3.2.3. Nach der sumerischen Komposition ŠumundaGras 16-19 (ETCSL 1.7.7.) gehörten gala-mah neben „alten Frauen“ (um-ma) und „Vätern“ (ab-ba) zur Gruppe der 'Ältesten', die die Tage der Sintflut überdauerten; vgl. Kramer 1980, 92-93, 96:16-19.
} 
sind als gala-Priester ${ }^{295}$ Der Beruf des gala war demgegenüber in aller Regel über Pfründen organisiert, deren Eigentümer auch anderen Berufen nachgehen konnten. ${ }^{296}$

In südbabylonischen Städten sind gala-Priester überwiegend als Zeugen bei Verträgen verschiedenen Inhalts belegt. Solche Verträge konnten Immobilien und Felder, ${ }^{297}$ Tempelämter und Pfründe ${ }^{298}$ sowie Darlehen und andere Rechtsangelegenheiten beinhalten. ${ }^{299}$ Die Rolle von gala bei der Bezeugung von Rechtseiden findet sich außerdem in drei spätaltbabylonischen Briefen explizit dokumentiert. ${ }^{300}$ Sie nahmen Teil an der Vernehmung bei Rechtsfragen. Im Brief AbB 12, 178, der möglicherweise nach Sippar zu verorten ist, leistet die Absenderin einen Schwur, der den Verbleib eines zappu(m) „Kamm; Bürste“ betraf, das möglicherweise einen Zusammenhang $\mathrm{zu}$ einer parșumKulthandlung aufweist: ${ }^{301}$

T 19: AbB 12, 178:8-11

„Ich schwor zu Bēlet-ālim, zu Šamaš-muballiṭ, dem gala, dass dein zappu für einen Šeqel Silber (oder) für zwei Šeqel Silber sich nicht in meiner Hand befin$\operatorname{det}^{\star 302}$

$u_{3} z a-p u-k i$ a-na $1 \operatorname{gin}_{2} \mathrm{ku}_{3}$-babbar a-na $2 \mathrm{gin}_{2} \mathrm{ku}_{3}$-babbar i-na qa $a_{2}$-ti-ia la $i-b a-a s ̌-s ̌ u-u_{2} a-n a{ }^{\mathrm{d}} \mathrm{Nin}-\mathrm{uru}^{\mathrm{ki}} a-n a{ }^{\mathrm{d}} \mathrm{Utu}-m u-b a-l i i_{2}-i t$ gala $a t-m a$

Die Verbindung des gala zur Bēlet-ālim überrascht hier nicht, da die Institution der gala-Priester einen engen Bezug zu weiblichen Gottheiten aufweist.

\footnotetext{
${ }^{295}$ Ur: YOS 12, 353:23 (Si 11) gala des Ninšubur; TSifr 9/9a:25 (RS 10) gala der Gula; Sippar: Di 1996 (Ae 10) bei Dekiere 1994, 130 gala der Inana (Jahrūrum).

${ }^{296}$ S. Kapitel 8.1.

${ }^{297}$ MHET II, 544:12 (Aṣ 16); MHET II, 545:12 (Aṣ 16); PBS 8/2, 218:12 (Aș 16); Riftin Nr. 20:20 (RS 30); TJDB 84f., 27:20 (Si 8); TSifr 9/9a:25 (RS 10); TSifr 99:15 (RS 25); TSifr 25:23 (RS 35); TSifr 27/27a:36 (RS 57); TSifr 28/28a:25 (RS 37); TSifr 31:26 (D.a.); TSifr 43/43a:30 (Ha 36); TSifr 42:31 (Ha 36).

${ }^{298}$ BIN 7, 65:18 (Di 6); BIN 7, 68:25 (Di a).

${ }^{299}$ MHET I/1, 94:4' (D.a.); PBS 8/1, 11:11 (Zam 1); PBS 8/2, 176:23 (D.a.); VS 7, 122:9 (Aṣ 16); YOS 12, 353:23 (Si 11); AUCT 5, 36:11 (RS 58).

${ }^{300}$ AbB 12, 178; AbB 1, 11; MHET I/1, 69.

${ }^{301}$ Zum zappum, das bei den parșum in CT 45, 84:1-2 (o.D.) Verwendung findet s. Gallery 1980, 336 und Wilcke 1985a, 196 Anm. 17.

302 Anders G. Th. Ferwerda apud Stol in AbB 12, 141+Anm.178.b) „I swore to Bēlet-ālim against Šamaš-muballit the lamentation-priest...".
} 
Auch im Brief AbB 1, 11 werden zwei gala $u_{2}$-nu-tim „gala der Gerätschaften(?)" genannt, die dem Verhör eines Sklaven beiwohnen sollen:

T 20: AbB 1, 11:10-15

„Betreffs (dessen), was du mir geschrieben hast: so du: „Sîn-mušallim, der gala unūtim und Marduk-muballiț, der gala unūtim, und (Leerstelle); ${ }^{303}$ in mein Haus ließ ich sie eintreten, dass sie die Aussage (wörtl. Lippen) des Sklaven hören. ..." 304

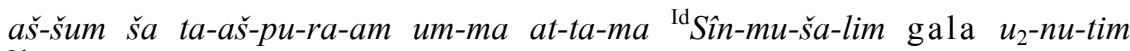
${ }^{\mathrm{Id}}$ Marduk-mu-ba-li $i_{2}$-it gala $u_{2}$-nu-tim $u_{3}$ (Leerstelle) a-na $\mathrm{e}_{2}-i a \quad u_{2}-\check{s} e-r i-i b-\check{s} u$ $n u-t i-m a \check{s} a-a p-t i \mathrm{sa} \tilde{\mathrm{g}} . \mathrm{ir}_{3} e \check{s}^{\prime}-m u-u_{2}^{305}$

Ungeachtet der genauen Bedeutung des Ausdrucks unūtum ${ }^{306}$ wird hier auf die Abnahme eines Eides Bezug genommen, der in Anwesenheit von galaPriestern abzunehmen war. ${ }^{307}$ Dieselbe Situation findet sich im Brief MHET I/1, 69 aus dem Ur-Utu-Archiv, wo die gala-Priester Warad-Ibari und Sînnādin-šumi den Absender zu einer Erbschaftstafel vernehmen sollen.

Die Briefe weisen darauf hin, dass gala bei Eidesbefragungen einbezogen wurden. Bei allen genannten Fällen handelt es sich um Beweiseide, die in aller Regel vor einem Gott oder vor dem König ausgeführt wurden. ${ }^{308}$ Belege zu gala in Prozessurkunden sind eher selten, weitaus häufiger treten dort galamah als Zeugen auf. ${ }^{309}$ Auch die meisten in Kauf- oder Erbschaftsverträgen als Zeugen belegten gala entstammen meist dem Umfeld der verhandelnden Parteien. Welche Rolle die Anwesenheit der gala bei Eidesbekundungen über die einfache Bezeugung des Aktes hinaus einnahm, bleibt ungewiss. Bezeichnend ist dennoch, dass in AbB 12, 178 der gala neben der Göttin Bēlet-ālim genannt wird, möglicherweise um vermittelnde Funktionen einzunehmen.

\footnotetext{
${ }^{303}$ Vgl. Kraus in AbB 1 S. 10-11. Offenbar sollte hier noch ein weiterer Name eingefügt werden.

${ }^{304}$ Auf der Rückseite sind zwei weitere Namen notiert, die offenbar keinen Zusammenhang zum übrigen Text aufweisen. Insgesamt bleibt der Brief unvollendet; Kraus in AbB 12 S. 10 Anm. 11.a).

${ }^{305}$ AbB 1, 11:15 zu emend. nach Kraus in AbB 1, S. 11 Anm. 11.a).

${ }^{306}$ Das Wort unütum „Gerät; Utensilien“ ist aB noch in VS 22, 61:7'-9' (Sd 16?) und VS 22, 62:6-8 (Sd 16?) belegt: Tarībum dumu $\mathrm{e}_{2}-\mathrm{dub}-\mathrm{b}$ a $\check{s} a \mathrm{e}_{2} u_{2}-n u$-tim ,Tarībum, Schreiberschüler des Gerätehauses"; s. Pientka 1998, 307 + Anm. 129. Möglicherweise verweist der Ausdruck hier ähnlich dem титти von Mari auf eine Ausbildungsstätte.

${ }^{307} \mathrm{Zu}$ šaptĩ šemûm s. AHw $1176 \mathrm{~b}$ sub 4a-b).

${ }^{308}$ Dombradi 1996/1, 192-195.

309 gala-mah: UET 5, 248 (RS 16) 4. gala<mah>; RIAA 238 (Si ?); YOS 13, 203 (D.a.); YOS 12, 325 (Si 10); RA 69, 122 Fig. 8 (Si 3); TLB 1, 257 (Ad 14?); gala: TSifr 25 (RS 35); TSifr 42 (Ha 36); TSifr 43/43a (Ha 36); MHET I/1, 94 (o.D.); der bei Dombradi 1996/2, 329 angegebene Beleg in TCL 10, 34:47 (D.a.) für einen gala ist mit CAD M/1 90 als $1 u_{2}$ gub-ba zu lesen.
} 
Von Renger wird der gala der altbabylonischen Zeit neben nar an niedrigster Position innerhalb der Tempeladministration angesiedelt. ${ }^{310}$ Dennoch konnten die Hüter eines gala-Amtes vielfach angesehenen Familien angehören ${ }^{311}$ und über eigenes Vermögen verfügen. Neben den Belegen in Rationenlisten ${ }^{312}$ sind gala häufig auch Haus- und Grundbesitzer. ${ }^{313}$ Schließlich sind gala-Priester mehrfach mit einem Zweitberuf attestiert, in Sippar sind zwei gleichzeitig sag̃ g̃a-Priester, während in Nippur ein Besitzer von gala- und gudu $4_{4}$ Pfründen Schreiber war. ${ }^{314}$

Nach einem Brief aus Sippar leisteten gala igisûm-Abgaben, die an den Palast weitergeführt wurden. ${ }^{315}$ Diese könnten möglicherweise bei der Einteilung von gala zu Feld- und Trägerarbeiten eine Rolle gespielt haben. Eintreiber einer solchen Abgabe konnten auch gala-mah sein, die damit in Vertretung des Palasts handelten. ${ }^{316}$ Des Weiteren erhielten gala auch Versorgungsfelder, ${ }^{317}$ wofür sie wiederum für Lehensdienste (ilkum) eingesetzt wurden. ${ }^{318}$

Im Gegensatz zum gala ist der gala-mah in Zeugenlisten, vor allem frühaltbabylonischer Urkunden, wenig vertreten. In Nippur bezeugt er meist Verträge, die die Weitergabe von gala- und gudu ${ }_{4}$-Tempelämtern oder Pfründen zum Inhalt haben. ${ }^{319}$ In Texten nordbabylonischer Städte ist er auch Zeuge in Kaufurkunden über Immobilien von Tempelangestellten, beispielsweise der lukur-Priesterinnen in Sippar oder der nin-dig̃ir in Kiš. ${ }^{320}$ gala-mahPriester wurden damit bevorzugt bei Angelegenheiten um die Tempelverwaltung als Zeugen eingesetzt. Nur wenige Beispiele sind für gala-mah bei privatrechtlichen Angelegenheiten, wie Scheidungen, Adoptionen oder Erbschaften bekannt. ${ }^{321}$ Insbesondere für die gala-mah der nordbabylonischen

\footnotetext{
${ }^{310}$ Renger 1969, 194-195.

${ }^{311} \mathrm{~S}$. hierzu auch den vielfach zitierten Brief JCS 11, 107 (CUA 57) 16-18: ki-ma ti-du- ${ }_{2}{ }^{\mathrm{I}} I p-$ $q a_{2}$-tum gala pu-ur-šu-um bi-tim „Wie du weißt ist Ipqatum, der gala ein 'Clanoberhaupt'; CAD P 525b puršumu sub 2a), head of the house“; vgl. Renger 1969, 194 Anm. 899.

312 OLA 21, 4:8 (Ae 28); KTT 86:15 (Aw); KTT 130:5 (Ab); YOS 12, 78:21 (Si 3).

${ }^{313}$ BIN 7, 212:5 (o.D.); Cornell 6:12 (Si); Cornell 18:2 (Si 8); MHET II, 544:4 (Aṣ 16); MHET II, 633:3.8 (o.D.); MHET II, 928:2 (Si); OLA 21, 71:17 (Aș 20); PBS 8/1, 89:2 (Ilil 2).

314 Sippar: Inana-mansum, Sohn des Sîn-rēmēni und Nabīum-mālik; Nippur: Inana-mansum; s. hier Kapitel 8.1.

${ }^{315}$ AbB 10, 1; zur igisûm-Abgabe s. Pecha 2001; Stol 2004, 771-773.

${ }^{316}$ Vgl. YOS 13, 471 (Ae 28) ein gala-mah unbekannten Namens.

${ }^{317}$ Vgl. die gal a Warad-ilǐšu in TCL 11, 156:Rs 15 (Ha 36) und Sîn-uballit in AbB 8, 3:12, einem Brief des Lu-Ninurta an Šamaš-hāzir.

${ }^{318}$ So in AbB 10, 1; zum ilkum-Dienst an den Palast Stol 2004, 732-741.

${ }^{319}$ Nippur: ARN 44:19 (RS 55); BE 6/2, 26:iv 17-18 (Si 6); BE 6/2, 42:15 (Si 13); ARN $23+$ PBS 8/2, 169:iv 3 (D.a.). Ur: PBS 8/2, 264:33 (RS 35); YOS 12, 297:22 (Si 8). S. aber auch Sippar: RA 82, 28:25'-26' (D.a.);

${ }^{320}$ Sippar: MHET II, 909:20 (Aș 15); CT 48, 76:5 (Aș 17); CT 45, 62:27 (D.a.); BE 6/1, 119:ii 22 (o.D.); Kiš: YOS 13, 325 Siegel C, D (Ad 5); YOS 13, 94 Siegel A (Ad 13); YOS 13, 90 Siegel A, C (D.a.); auch einmal Ur: TSifr 7/7a:17 (RS 8).

${ }^{321}$ Ur: UET 5, $96: 23$ (o.D.); Larsa: RA 69, 122 Fig. 8:27 (Si 3); Sippar: TCL 1, 145:24 (Si 30).
} 
Städte Sippar und Kiš fällt auf, dass sie eine wichtige Position innerhalb der Verwaltung auch in Verbindung zum Palast einnahmen. Dementsprechend sind auch ihre Siegelinschriften zumindest während ihrer Amtszeit als Huldigungen des jeweils regierenden Königs formuliert. Im spätaltbabylonischen Brief AbB 2, 73 stand ein gala-mah auch in persönlichem Kontakt zum König, um Angelegenheiten um das Tempelpersonal zu regeln. ${ }^{322}$

In Sachen Vermögen ist der gala-mah auch als Kreditgeber sowie Landund Hausbesitzer bezeugt, so in den Städten Dilbat, Nippur, Isin, Kiš und Sippar. ${ }^{323}$ Einige gala-mah verwalteten ein beträchtliches Privatvermögen. ${ }^{324}$ Andererseits ist in Sippar auch die Frau eines unbekannten gala-mah bezeugt, die bei einer lukur einen Kredit in Form von Weizen und Silber aufnahm. ${ }^{325}$ Dies muss allerdings nicht als Verweis auf die Mittellosigkeit des Gatten angesehen werden, vielmehr könnte hiermit ein Privatgeschäft zwischen zwei Frauen von höherem Rang dokumentiert sein. ${ }^{326}$

\subsubsection{Zur geographischen Verteilung}

Mit Ausnahme der Stadt Kutalla sind in allen behandelten babylonischen Städten gala-mah-Ämter bezeugt. Die folgende Tabelle bietet einen Überblick zur Verteilung sowohl der namentlich als auch der ohne Namen belegten gala-mah, sowie ihre Zuordnung und Belegzeit, sofern diese bekannt oder rekonstruierbar sind: $:^{327}$

${ }^{322}$ Der Brief behandelt einen Streitfall, an dem auch ein sa g̃ ga beteiligt war.

${ }^{323}$ Isin: TIM 5, 26:11 (Si 15). Nippur: PBS 8/1, 11:4-5 (Zam 1); PBS 8/1, 89:2 (Ilil 2); ARN 29:Rs 5 (RS 21). Kiš: TJA 55f.:11 (D.a.[Ad 1-10]). Dilbat: YOS 13, 289:12 (Ad 34). Immobilien waren auch im Besitz der Ur-Utu-Familie, s. hier Kapitel 9.6.2.2.

${ }^{324}$ Renger 1969, 199 Anm. 922; PBS 8/1, 89 (Ilil 2); ARN 29:Rs. 5 (RS 21); PBS 8/1, 11:4-5 (Zam 1); VS 9, 39:10 (Ha ?); AbB 11, 101:18 (o.D.). Nach Renger 1969, 199 ist es außerdem wahrscheinlich, dass der gala-mah wie auch andere Priester šukūsum-Felder zugeteilt bekamen, was allerdings bisher nicht belegt ist.

${ }^{325}$ JCS 11, 20:6 (Ha 35); VS 9, 152:4 (Ha 39).

${ }^{326}$ Anders Renger 1969, 199; Harris 1975, 173 Anm. 115. Ob auch der gala-mah Balanihe'inzalag aus dem Sippar-Brief AbB 1, 89 aufgrund privater Geldprobleme mit der Auszahlung des Lohns an den eigens engagierten Steuereintreiber rückständig ist, bleibt unklar; Harris 1975, 173.

${ }^{327}$ In fettem Druck erscheinen die gesicherten Zuweisungen, sekundär hergeleitete in Normaldruck. 
Tabelle 4: gala-mah in aB Städten

\begin{tabular}{|l|l|l|l|}
\hline Ur & Nanna/Sîn & $\begin{array}{l}\text { Nūr-Šamaš } \\
\text { (Sîn-erībam) }\end{array}$ & $\begin{array}{l}\text { WS-RS 35 } \\
\text { Si } 8\end{array}$ \\
\hline
\end{tabular}

\begin{tabular}{|l|l|l|l|}
\hline Larsa & & $\begin{array}{l}\text { Ubār-Šamaš } \\
\text { Nanna-kiag̃, S.d. Imgur-Sîn }\end{array}$ & $\begin{array}{l}\text { RS 2 } \\
\text { RS 39 }\end{array}$ \\
\hline Zabalam? & Inana Zabalam & $\begin{array}{l}\text { Saniq-pī-[GN] / Sanqum, S.d. } \\
\text { Warad-Zugal }\end{array}$ & Si 3-10 \\
\hline Badtibira? & Dumuzi & namenlos & o.D. \\
\hline
\end{tabular}

\begin{tabular}{|l|l|l|l|}
\hline Nippur & Enlil & $\begin{array}{l}\text { namenlos } \\
\text { (Ninurta-mušallim) }\end{array}$ & $\begin{array}{l}\text { Ilil 2 } \\
\text { Si 6-13 }\end{array}$ \\
\hline & Ninurta & $\begin{array}{l}\text { (Nanna-gugal) } \\
\text { (Ir-Enlila) }\end{array}$ & $\begin{array}{l}\text { Sel 28-RS 21 } \\
\text { RS 55-Si 6 }\end{array}$ \\
\hline
\end{tabular}

\begin{tabular}{|l|l|l|l|}
\hline Isin & Ninisina & $\left(\mathrm{Lu}_{2}\right.$-igi-KU $)$ & IšEr 25 \\
& Ur-Nininsina, S.d. Ibni-Amurrum & Si 15 \\
\hline
\end{tabular}

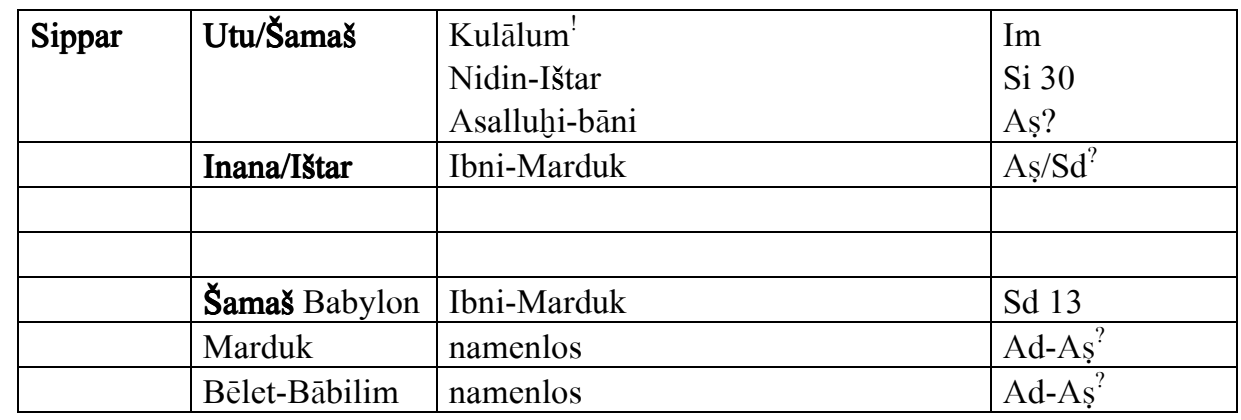

\begin{tabular}{|c|c|c|c|}
\hline Sippar A. & Annunītum & $\begin{array}{l}\text { Sîn-mušallim } \\
\text { Inana-mansum, S.d. Marduk-nāṣir } \\
\text { Ur-Utu }^{328} \text {, S.d. Inana-mansum } \\
\text { Marduk-muballit }\end{array}$ & $\begin{array}{l}\text { Ae } \\
\text { Ad-Aṣ } 4 \\
\text { Aṣ 4-17 } \\
\text { Sd } 4 \\
\end{array}$ \\
\hline & $?$ & $\begin{array}{l}\text { Balani-he'inzalag } \\
\text { Diğir-šaga } \\
\text { Ur-Guanaka } \\
\text { Ur-Sakkud }\end{array}$ & $\begin{array}{l}\text { O.D. } \\
\text { Ad } 15 \\
\text { Aș? } \\
\text { Aș } 15\end{array}$ \\
\hline
\end{tabular}

${ }^{328}$ Zu Bēlānum als Zweitname des Ur-Utu s. Janssen 1992, 47-48. 


\begin{tabular}{|l|l|l|l|}
\hline Dilbat & Ninegala(?) & $\begin{array}{l}\text { Marduk-muballiț } \\
\text { Lugal-zi-mansum, S.d. Ilī-erībam }\end{array}$ & $\begin{array}{l}\text { Ad 30 } \\
\text { Ad 34-Aṣ 11 }\end{array}$ \\
\hline & $?$ & $\begin{array}{l}\text { namenlos } \\
\text { Warad-Ešurrītum }\end{array}$ & $\begin{array}{l}(\text { Aș 17 } \\
\text { Ad 34-Sd 3 }\end{array}$ \\
\hline
\end{tabular}

\begin{tabular}{|l|l|l|l|}
\hline Kiš & Zababa & Ka-Inana & Si $^{?}$ \\
& & Mea'imriag̃u, S.d. Inana-zig̃u & Ad 3-14 \\
& & Nanna-šalasud, S.d. Mea'imriag̃u & Aș 7?-Sd 5 \\
& & Abandasa, S.d. Be-x & nach Sd \\
\hline & Inana Uruk & Eannatum, S.d. Ina-palêšu/Aplatum & Ad 1'-35 \\
& & Ilšu-X, S.d. Samsu[iluna-X & Aṣ 9 \\
& & Rī̌s-Marduk & Sd 2-? \\
\hline & Nanaja & Igmil-Ištar & Ad 31 \\
\hline & $?$ & Sîn-išmeanni, S.d. Ibbi-ilim & Ad 5 \\
& & namenlos & Ae 28 \\
\hline
\end{tabular}

Wie aus dieser Tabelle zu ersehen, liegt eine Beschränkung auf eine einzige Gottheit oder auf den Kreis einer Gottheit für den Beruf des gala-mahPriesters nicht vor.

Bis zur Regierungszeit des Samsuiluna amtierte in den meisten Städten jeweils nur ein gala-mah am Tempel der Hauptgottheit. Eine Ausnahme liegt mit Nippur vor, wo zeitgleich ein gala-mah am Ekur und ein weiterer am Ešumeša des Ninurta amtierte, ${ }^{329}$ wobei die hier rekonstruierte Zuordnung nicht endgültig gesichert ist.

Lückenhaft ist die Beleglage zu den gala-mah von Larsa. Nur Saniq-pī[GN] mit Kurznamen Sanqum lässt sich einem Heiligtum der Inana von Zabalam zuordnen. Der Kult dieser Göttin ist für Larsa seit der Regierung des Königs Nūr-Adad bezeugt. ${ }^{330}$ Da sich jedoch ihr Hauptkultort in der nahe Larsa gelegenen Stadt Zabalam befand, ist es nahe liegend, Saniq-pī-[GN]/Sanqum an das Hauptheiligtum der Inana in Zabalam und nicht nach Larsa zu verorten. Auch für den zweiten in Larsa bezeugten gala-mah des Dumuzi ist dementsprechend ein Amt in der nahe Larsa gelegenen Stadt Badtibira anzunehmen, wo sich der Haupttempel dieses Gottes befand. Die übrigen zwei namentlich in Larsa belegten gala-mah lassen sich keinem Tempel oder Kult eindeutig zuweisen. Der gala-ma Ubār-Šamaš tritt einmalig im Rahmen des siebentägigen Opferfestes auf, wo er unter den Teilnehmern des Nanaja-Festes genannt wird. ${ }^{331} \mathrm{Ob}$ er damit auch am Tempel dieser Göttin oder aber gemäß der Bil-

\footnotetext{
${ }^{329}$ Ninurta-mušallim und Ir-Enlila in BE 6/2, 26:iv 17-18 (Si 6).

${ }^{330}$ Richter 2004, 365-366; anders hingegen Stol 2001, 175.

${ }^{331}$ Westenholz/Westenholz 2006, 52-53, 171 vi 20; s. a. hier Kapitel 9.2.3.3.
} 
dung seines Namens am Tempel des Šamaš anzusiedeln ist, lässt sich ohne weitere Belege nicht festlegen. ${ }^{332}$ Die Zuordnung des gala-mah Nanna-kiag̃, Sohn des Imgur-Sîn in Larsa bleibt ebenfalls unsicher, da dieser bislang nur einmal als Zeuge eines Gartenkaufs belegt ist. ${ }^{333}$ Seltsam bleibt, dass kein gala-mah der Larsa-Texte explizit dem Gott Šamaš zugeordnet wird, was mit der schlechten Beleglage zur Tempeladministration von Larsa begründet werden kann. Dass gala-mah-Ämter für diesen Gott eingerichtet waren, ist für seinen Tempel in Sippar nachgewiesen. ${ }^{334}$

Entgegen der Beleglage für die frühaltbabylonische Zeit sind spätaltbabylonisch in Sippar, Dilbat und Kiš mehrere gala-mah bezeugt, die zur selben Zeit an verschiedenen Tempeln einer Stadt amtierten. In Sippar und Kiš bestanden zunächst Ämter für die jeweilige Stadtgottheit, für Šamaš in Sippar Jahrūrum, für Annunītum in Sippar Amnānum und für Zababa in Kiš. Weitere Ämter wurden in spätaltbabylonischer Zeit für eingeführte Gottheiten eingerichtet, so im Falle der Inana von Uruk und der Nanaja in Kiš.

Die zahlreichen in Sippar-Texten ohne Namen und Zuordnung genannten gala-mah könnten auf das Hauptamt für Šamaš am Ebabbar zu beziehen sein. ${ }^{335}$ Hinsichtlich der gala-mah des Marduk und seiner Gemahlin BēletBābilim stellt sich die Frage, ob diese der Stadt Babylon oder eher Tempeln in Sippar zuzuordnen sind. ${ }^{336}$ Der Kult des Marduk ist für Sippar seit spätaltbabylonischer Zeit bezeugt. ${ }^{337}$ Auf ein Fest des Marduk weist die Tempelrationenliste CT 45, 85 (o.D.) aus Sippar hin, die auch gala und gala-mah-Priester nennt. ${ }^{338}$ Die Erweiterung des Marduk-Kultes auf die Stadt Sippar begründet sich durch die besondere Verehrung, die ihm als Reichsgott durch die Könige der ersten Dynastie von Babylon zukam. Andererseits könnten die bislang in einer einzigen Liste aus Sippar belegten gala-mah des Marduk und der BēletBābilim in Babylon beheimatet und lediglich zu einem Fest in Sippar angereist sein.

Für Dilbat lässt sich nur der gala-mah Lugal-zi-mansum möglicherweise der Ninegala, der Gattin des Uraš zuweisen. In Anlehnung an die allgemein beobachtete Ämterverteilung wäre außerdem ein gala-mah für den Stadtgott

\footnotetext{
${ }^{332}$ Zur Verehrung der Nanaja in Larsa s. Richter 2004, 372-373.

${ }^{333}$ VS 13, 80/80a:Rs 12-13 (RS 39).

${ }^{334}$ Ausführlichere Daten sind erst nach Veröffentlichung des Ebabbar-Textkorpus zu erwarten.

${ }^{335}$ OLA 21, 4:5 (Ae 28); CT 45, 77:6.9.11.15.8' (o.D.); CT 45, 85:3.4.5.11 (o.D.); CT 45, 89:i 2 (o.D.); JCS 11, 38 No. 30:6.3'.7' (o.D.); CT 4, 15c:13 (o.D.); VS 9, 39:10 (Ha ?); s. a. dumu gala-mah in TCL 1, 168:7 (Aș 13); TCL 1, 230:39' (D.a.); dam ka-la-ma-hu/i in JCS 11, 20 No. 6:5 (Ha 35) und VS 9, 152:4 (Ha 39). Unklar bleibt MHET I/1 S. 140:96 (o.D.) und JCS 11, 38 No. 30:6.3'.7' (o.D.) mit Bierrationen an drei gala-mah ohne Namen.

${ }^{336}$ Einmalig belegt in MHET I/1, 65:3.18 (o.D.).

${ }^{337}$ Harris $1975,146-147$.

${ }^{338}$ S. hier Kapitel 9.6.3.4.
} 
Uraš zu erwarten, doch lassen sich in den Dilbat-Texten hierzu keine Hinweise finden. Insgesamt ist die Beleglage zur Tempeladministration von Dilbat als lückenhaft zu bewerten. Auch bleibt die Zuweisung der behandelten Texte zu dieser Stadt unsicher, so werden einige der namentlich belegten Personen auch in Sippar-Texten genannt. ${ }^{339}$ Der in Dilbat belegte gala-mah Marduk-muballit könnte daher mit dem gleichnamigen Priester der Annunītum in Sippar identifiziert werden. ${ }^{340}$ Angesichts der zu geringen Informationen bezüglich seiner Person lassen sich solche Annahmen jedoch nicht weiter erhärten.

Für Kutalla sind keine gala-mah sondern ausschließlich einfache gala bekannt. Möglicherweise war in dieser Stadt kein Kult einer Hauptgottheit beheimatet oder aber die wichtigen administrativen Aufgaben auch hinsichtlich der Ausführung verschiedener Kultfeiern waren dem Zuständigkeitsbereich der nahe gelegenen Stadt Larsa zugeordnet. ${ }^{341}$

Im Gegensatz zum gala-mah sind im behandelten Material nur wenige Belege, in denen ein gala einer Gottheit zugeordnet wird. Für Ur sind dies ein gala der Gula mit Namen Awīl-dāri und ein gala des Ninšubur mit Namen Šamašmuballiț, die als Zeugen, letzterer zusätzlich als Rationenempfänger aufgeführt werden ${ }^{342}$ In Sippar sind es Ur-Inana aus der Familie des Ur-Utu sowie QurdiIštar, die beide der Inana zugeordnet sind. ${ }^{343}$ Diese gala können als Inhaber eines entsprechenden Amtes an den jeweiligen Tempeln angesehen werden. Außer ihnen lassen sich sonst keine gala in den Texten eindeutig einem Tempel oder Gott zuweisen, was zu bestätigen scheint, dass gala primär über Pfründe organisiert waren und in der Regel kein festes Amt innehatten.

\subsection{Berufsbild des gala}

\subsubsection{Erschaffung und Wesen des gala nach literarischen Texten}

Die Erschaffung und Einsetzung des gala ist Thema eines Bala g̃-Liedes an Inana, welches 1981 erstmals von Kramer publiziert wurde. ${ }^{344}$ Das Lied datiert in die altbabylonische Zeit und ist wie für Lieder der Gattung Bala g̃ üblich im Emesal gehalten. Von der beidseitig einkolumnig beschriebenen Tafel ist

\footnotetext{
${ }^{339}$ Vgl. den abi eren 2 („Hauptmann“) Marduk-muballiț; Pientka 1998, 438:305.

${ }^{340}$ Dilbat: VS 7, 58:5 (Ad 30), VS 7, 57:3 (Ad 30); Sippar: CT 48, 45:13-14 (Sd 4), AbB 11, 93:3' $\left(\mathrm{Sd}^{?}\right)$.

${ }^{341}$ Renger 1969, 197.

${ }^{342}$ YOS 12, 353:23 (Si 11); YOS 12, 78 (Si 3); TSifr 9/9a:25 (RS 10).

343 Dekiere 1995, 129-130, 134; OLA 21, 71:17 (Aș 13); die Zuordnung des gala Abum im Siegel von VS 9, 18 (Ha 1) ist nicht rekonstruierbar.

${ }^{344}$ Kramer 1981, 1-11.
} 
lediglich die Vorderseite gut erhalten. Die Unterschrift mit Angaben zur Gattung und Widmung der Komposition ist zerstört. Dass es sich bei der Tafel dennoch um ein Balag̃-Lied handelt, ist dem altbabylonischen KatalogZylinder $H$. Clark zu entnehmen, wo der Titel des Textes zusammen mit anderen Klageliedern als „Balag̃ der Götter“ (balag̃ dig̃ir-re-e-ne) ausgewiesen wird. ${ }^{345}$ Angesichts der einleitenden Verse des Liedes ist die Komposition der Göttin Inana gewidmet. ${ }^{346}$

In den Fragesätzen der einleitenden Litanei wird die Göttin Inana mit den Worten angerufen: „Was bekümmert dein Herz? Himmel und Erde, was sind sie in Sorge?““. ${ }^{347}$ Hauptthema des Liedes ist damit eine bekümmerte Göttin, die die Welt durch ihren Zustand in Sorge versetzt. ${ }^{348}$ Auf die Litanei folgt ein mehrere Zeilen umfassender narrativer Abschnitt, der von der Erschaffung des gala handelt. Schöpfer ist der Gott Enki, der die von der unruhigen Inana ausgehende Gefahr abzuwenden sucht:

T 21: Kramer 1981, 1ff. (BM 29616) 21-28 349

„Er(Enki) erschuf für sie(Inana) den gala, denjenigen(?) der Herz besänftigenden Klagen (er ${ }_{2}-\breve{s ̆}_{3}$-ḩun-e). . .

Das Eršaneša, seine Klage der..., richtete er.

Seine /ub/ und /lilis/-Trommeln, die das 'ach genug!' zum Ausdruck bringen, gab er(Enki) in seine Hand!

Enki sandte ihn, der . . , zur heiligen Inana:

'Meine(?) Herrin, möge dein Herz besänftigt sein, begib dich auf deinen Thron, Der gala möge für dich die Eršaneša-Klage, die das 'ach genug!' zum Ausdruck bringt, eine ...-Nacht darbringen, der Gott [Enki?] . . . der/des. . .

Den Plan der einzigartigen (göttlichen) Kultordnungen hat er für dich bereitet.“

21. gala mu-lu er ${ }_{3}-\breve{s a}_{3}-h$ hun-e da ${ }^{?}-n i^{?}-X-X$ mu-na-an-dim 3

22. er $_{2}-\breve{s ̆}_{3}-n e-\breve{s a}_{4}$ i-si-iš ma-al-la-ni XX [si] bi $i_{2}-i n-s a_{2}$

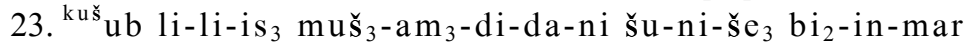

24. ${ }^{\mathrm{d}}$ am-an-ki-ke ${ }_{4} \mathrm{ku}_{3}$ ga-ša-an-na-ra mu-lu da MES ${ }^{?}$ mu-ši-in-gi ${ }_{4}$

${ }^{345}$ Kramer 1981, 1-2; Shaffer 2000, 432:9. $1 \mathrm{ša}_{3}-\mathrm{r}^{\mathrm{zu}}{ }^{1}$ ta-am 3 -me-er „eine (Tafel) 'Was bekümmert dein Herz" " und Z. 19. balag̃ dig̃ir-re-e-ne; Shaffer 2000, 431 zur Datierung.

${ }^{346}$ Vgl. Kramer 1981, 1-2.

${ }^{347}$ Kramer 1981, 2-4:Z. 1-2.17 ša $a_{3}-z u$ ta-am $m_{3}$-er an-ki ta-kuš $\check{\mathbf{s}}_{2}-\mathrm{u}_{3}$.

${ }^{348} \mathrm{kus}_{2}-\mathrm{u}_{3}=$ anāh $u$ auch „belasten, quälen“ im D- und Š-Stamm; AHw 40-41; Thomsen 1984, 310.

${ }^{349}$ Umschrift und Übersetzung in Anlehnung an Kramer 1981, 3,5. 
25. nin-da ${ }^{?} \check{s} a_{3}-z u$ he $e_{2}-e m-h u n-e^{\tilde{g} i s ̌} g u-z a-z a$ tuš- $u_{3}$

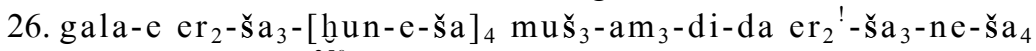

$[\mathrm{hu}-\mathrm{mu}]-\mathrm{ra}-\mathrm{gal}_{2}{ }^{350}$

27. ${ }^{\mathrm{d}} \mathrm{X}-\mathrm{X} 1 \mathrm{u}_{2}-\mathrm{X}-\mathrm{X}-\mathrm{ra}-\mathrm{ke} \mathrm{e}_{4}$

28. g̃iš-hur g̃arza kal ${ }^{?}-\mathrm{kal}^{?}$-la si ha-ra-ni-ib-sa

Im Anschluss an die hier zitierte Textpassage werden weitere Gottheiten genannt, darunter Ninkasi, die Göttin des Bieres, Ninšubur, Minister und Bote der Inana und auch ihr Gatte Ama'ušumgalana, welche sich offenbar ebenfalls um die Besänftigung der bekümmerten Göttin bemühen sollen (Z. 29-37). ${ }^{351}$ Der Fortgang der Erzählung ist aufgrund des schlechten Erhaltungszustands unbekannt. $^{352}$

Aus der oben zitierten Textpassage lassen sich mehrere Aussagen zum Ursprung und zur Funktion des gala ziehen. Zu Beginn des Liedes wird von einer trauernden und beunruhigten Inana berichtet, wobei auf den Ursprung dieses Gemütszustandes nicht näher eingegangen wird. Für die Erschaffung des gala ist ausschließlich die Tatsache von Belang, dass dieser Gemütszustand der Göttin Besorgnis erregend ist und eine Bedrohung für den Erhalt allen Lebens auf Erden darstellt. Dem Gemütszustand der Inana kann offenbar nichts bisher Existentes entgegengesetzt werden, weshalb sich Enki für die Erschaffung eines neuen 'Wesens' entscheidet, den gala. Dieser wird mit besonderen Gaben und Mitteln ausgestattet, die es ihm ermöglichen, der Besorgnis erregenden Situation Herr zu werden. Bei diesen Gaben handelt es sich ausschließlich um musikalische Mittel für den instrumentalen und vokalen Vortrag: Ihm werden die Musikinstrumente /lilis/ und /ub/ ausgehändigt ${ }^{353}$ sowie Klagelieder, die das Herz besänftigen. ${ }^{354}$ Die im Text genannten Bezeichnungen dieser Klagen gelten bereits im zweiten Jahrtausend als Gattungsnamen von Klageliedern. ${ }^{355}$ Ungenannt bleiben allerdings die zwei gängigen Klagegattungen Balag̃ und das Eršema aus dem Repertoire dieses Klagepriesters. Letzteres könnte über das Musikinstrument $\mathrm{ub}_{3},{ }^{356}$ das zur Begleitung dieser Klage gespielt wurde, sekundär bezeichnet sein.

${ }^{350}$ Nach Gadotti 2009 mit Anm. 18.

${ }^{351}$ Kramer 1981, 2-5.

352 Kramer 1981, 3-7. Der auf Z. 37 folgenden durchgezogenen Linie könnte auch eine eigenständige Klage an Dumuzi gefolgt sein.

${ }^{353}$ Zur Identifizierung dieser Instrumente s. Kilmer 1993-97, 465 § 2.3 und dies. 2004, 368-369.

${ }^{354} \mathrm{~m} \mathrm{u} \check{\mathbf{s}}_{2}-\mathrm{a} \mathrm{m}_{3}=$ ahulap eine Interjektion mit der Bedeutung „Ach!/Wehe!/es ist genug!“ als Ausruf zum Ausdruck einer Begnadigungsbitte; vgl. AHw 22b; CAD A/I 213.

${ }^{355} \mathrm{mu}-1 \mathrm{u}$ e $\mathrm{r}_{3}-\breve{s}_{3}-\mathrm{h} \mathrm{u}$ - e ,derjenige der herzbesänftigenden Klagen“ stellvertretend für die Gattung der Erša hu ũa-Gebete; vgl. Maul 1988, 9 Anm. 22.

${ }^{356}$ Die Musikinstrumente $\mathrm{ub}_{3}$ und šem ${ }_{3}$ werden über dasselbe Zeichen LIBIŠ $\left(\mathrm{AB}_{2} \mathrm{x} \breve{\mathrm{S}} \mathrm{A}_{3}\right)=$ $\mathrm{ub}_{3}$ und še $\mathrm{m}_{3}$ angezeigt, was gleichzeitig als ${ }^{\mathrm{dug}} \mathrm{kir}_{2}$ ein großes Gefäß bezeichnet; Borger 2003, 178:677 aber auch $\mathrm{ub}_{3} \quad\left(\mathrm{GA}_{2} \mathrm{xNIR}\right)$ ibid. Nr. 411! Beide Termini könnten daher Na- 
Aus diesem Bala g̃ an Inana lassen sich bereits die wichtigsten Hintergründe und Informationen zum Wesen des gala ziehen. Die Existenz des gala geht auf eine Neuschöpfung des Gottes Enki zurück, die unabhängig von der Erschaffung des Menschen stattfindet. Er wird damit als ein Vater- und Mutterloses Wesen ausgewiesen, das aus einem bestimmten Anlass und mit einer konkreten Funktion erschaffen wurde. Die wichtigste Funktion des gala liegt in der Abwehr des von der unruhigen Göttin Inana ausgehenden Übels und der Besänftigung ihres Herzens, wofür ihm ausschließlich musikalische Mittel zur Verfügung gestellt werden.

Im sumerischsprachigen Mythos von Inanas Gang in die Unterwelt findet sich eine vergleichbare ätiologisch angelegte Textpassage, die allerdings vom Einsatz eines gala-tur(-ra) berichtet. ${ }^{357}$ Die in mehreren Abschriften überlieferte Erzählung handelt vom Bestreben der Göttin, ihren Machtbereich auf die Unterwelt auszudehnen. ${ }^{358} \mathrm{Da}$ die Unterwelt jedoch niemandem zugänglich ist, mit Ausnahme der Unterweltgottheiten und dämonischer Wesen, scheitert das Anliegen der Inana. Sie wird geschwächt und entblößt von Ereškigal, der Herrin der Unterwelt, überwältigt und getötet. Da dieser Zustand der Inana als Göttin der Liebe und Fruchtbarkeit für den Erhalt des Lebens auf Erden unhaltbar ist, initiiert wiederum Enki eine Rettungsaktion. ${ }^{359}$ Aus dem Dreck unter seinen Fingernägeln erschafft er zwei neue Wesen, den gala-tur(-ra), einen „kleinen gala“, und den kur-g̃ar(-ra), einen auch andernorts bekannten Kultdiener der Inana. ${ }^{360} \mathrm{Ihr}$ Auftrag lautet, den in der Unterwelt verweilenden Körper der Inana zum Leben zu erwecken und der Göttin anschließend zur Flucht zu verhelfen. Aus dieser Beschreibung ist zunächst zu ersehen, dass es sich bei gala-tur(-ra) und kur-g̃ar(-ra) um zwei Wesen handelt, die im Gegensatz zu Menschen und Göttern nicht den Gesetzen der Unterwelt unterliegen, sondern die Fähigkeit besitzen, gleich 'Phantomen' und dämonischen

men von ähnlichen, wenn nicht gleichen Membranophonen sein.

${ }^{357}$ Auf die akkadischsprachige Fassung Ištars Höllenfahrt wird hier nicht eingegangen, da sie keinen gala nennt. Zu der mit diesem Text verbundenen Diskussion zu Geschlecht und Gender des gala s. hier Exkurs I.

${ }^{358}$ Inanas Gang in die Unterwelt 4. nin- $\tilde{\mathrm{g}} \mathrm{u}_{10}$ an mu-un-šub ki mu-un-šub kur-ra bae-a-ed $d_{3}$, Meine Herrin verließ (wörtl. ließ fallen!) den Himmel, verließ die Erde und ging hinab in die Unterwelt"; vgl. Sladek 1974, 103, 153.

${ }^{359}$ Inanas Gang in die Unterwelt 65-67 bei Sladek 1974, 111, 158.

${ }^{360}$ Inanas Gang in die Unterwelt 236ff. und 263ff. hierzu auch Fritz 2003, 102-104. Über galatur(-ra) wird in diesem Zusammenang wohl kaum auf einen in Lehre stehenden galaPriester verwiesen. Zutreffender ist wohl eher der September 2007 von Nele Ziegler (Tagungsdiskussion) vorgeschlagene Deutungsvorschlag, der Ausdruck gala-tur(-ra) wäre an dieser und allen übrigen Parallelstellen aus Gründen des Versreims gewählt worden: ECTSL 1.4.1 224. kur-g̃ar-ra $u_{2}$ nam-til ${ }_{3}-1 \mathrm{a}$ ba-an-šum ${ }_{2}$ 225. gala-tur-ra a nam-til ${ }_{3}-1$ a ba-an-šum . $^{2}$ 
Wesen, unbemerkt und ohne Schaden zu nehmen, in die Unterwelt hinab zu steigen. ${ }^{361}$

Die Erzählung bietet weitere bereits bekannte Details zu den Funktionen des gala. Wie bereits andernorts bemerkt, werden hier beide neu erschaffenen Wesen als 'Klageexperten' ausgewiesen. ${ }^{362}$ Sie gewinnen das Vertrauen der Ereškigal, indem sie auf ihr Klagen bestätigend antworten:

$\mathrm{T}$ 22: Inanas Gang in die Unterwelt 236-239

„Auf ihren Ausspruch: 'Oh mein Herz!'

sagt ihr 'Du bist besorgt unsere Herrin; Oh dein Herz!'

Auf ihren Ausspruch: 'Oh mein Inneres!'

sagt ihr 'Du bist besorgt unsere Herrin; Oh dein Inneres!'“

236. u- $u_{8}-a \check{s ̆ a}_{3}-\tilde{g} u_{10} d u g_{4}-g a-n i$

237. kus $\check{s}_{2}-u_{3}-m e-e n$ nin-me a ša $a_{3}-z u\left[d u g_{4}\right]-g a-<z u>-n e-[n e]$

238. [u- $\left.\mathrm{u}_{8}\right]-\mathrm{a}$ bar-g $\mathrm{g} \mathrm{u}_{10} \mathrm{dug}_{4}$-ga-ni

239. kušs $\breve{2}_{2}-u_{3}-m e-e n$ nin-me a bar-zu $\left[\operatorname{dug}_{4}\right]-g a-<z u>-n e-[n e]^{363}$

Parallel zur Erschaffung des gala im Balag̃-Lied an Inana geht auch hier die Existenz des gala-tur(-ra) auf den Gott Enki zurück, der eigens dafür ins Leben gerufen wird, um der Göttin Inana zu Hilfe zu kommen. Durch die Errettung der Göttin soll die Weltordnung wieder hergestellt werden. Seine Klageerwiederungen richten sich hier zwar an Ereškigal, doch mit derselben Absicht, das Vertrauen der Göttin zu gewinnen und sie zu besänftigen. Dieselben Klageerwiederungen werden in Balag̃ - und Eršema-Liedern formuliert. ${ }^{364}$

Der kur-g̃ar(-ra) ist als Ekstatiker zu identifizieren, der sich möglicherweise durch transsexuelle Merkmale auszeichnet. ${ }^{365}$ In seinen Auftritten zeichnet er sich durch den Umgang mit Schwert oder Stilett sowie durch das

${ }^{361}$ Inanas Gang in die Unterwelt 255. gूiš ig nim-gin 7 mu-un-dal-dal 256. za-ra lil $_{2}$ gin $_{7}$ mu-un-gur-gur „Wie Fliegen durchfliegen sie die Tür (zur Unterwelt); Wie Geister 'winden sie sich' durch die Türangel"; ETCSL 1.4.1; Sladek 1974, 135, 173.

${ }^{362}$ Sladek 1974, 97-98; Kilmer 1971, 301, 304-305; Jacobsen 1976, 58-59; Maul 1992, 162-164. In den Zeilen 240ff. (Sladek 1974, 132-133, 171-172) fragt Ereškigal nach der Natur der zwei Wesen, die sie weder als Götter noch als Sterbliche einordnen kann, insbesondere erstaunt sie ihre Fähigkeit der Erwiderung auf ihr innerstes Gemüt, was auf ihre Rolle als Mittler verweist.

${ }^{363}$ Und parallel in den Z. 263-266; ETCSL 1.4.1; Sladek 1974, 132-133, 171 und 135-136, 163.

${ }^{364}$ Renger 1969, 190. „Der gala singt ihr/ihm nicht mehr 'Oh' dein Herz!'“ gala-e a ša ${ }_{3}$-zu nu-mu-ni-ib ${ }_{2}-\mathrm{be}_{2}$; im Bala g̃ Uruhulake an Gula (Cohen 1988, 265:Vs ii 17); Ame Amašana (Cohen 1988, 164:b+234) und Udam kiamus an Enlil (Cohen 1988, 133:d+185); Eturgin Niginnam an Enki (Cohen 1988, 77:a+52); im Gula-Eršema CT 36, 41-42 (Cohen 1981, 104-105) 23. gala-e ša ${ }_{3}-m u$ nu-šed $d_{7}-d_{3}-m u$ „Der gala, der nicht mehr mein Herz besänftigt (wörtl. 'kühlt')".

${ }^{365}$ Maul 1992, 163-164, 168 Anm. 38; Groneberg 1997a, 143. 
Vergießen von Blut aus, was als eine Art Selbstkasteiung oder -mutilation zu deuten ist, durch die der ekstatische Zustand herbeigeführt wird. ${ }^{366} \mathrm{Im}$ Fluch über Akkade werden unter den verschiedenen Handlungen eines Klageritus auch Männer mit geschärften Schwertern und Frauen in einem typischen Klagegestus des Haareraufens beschrieben. ${ }^{367}$ Die Selbstkasteiung der kur-g̃ar(ra) galt damit als Klageritus, was auch seine Rolle neben gala-tur(-ra) verständlich macht. Im ersten Jahrtausend auf einer spätbabylonischen Ritualtafel ist der kurgarrû denn auch explizit als Vortragender von inhu-Klagen und Sänger von Gebeten belegt. ${ }^{368}$

Die neu erschaffenen Wesen verhelfen Inana zur Flucht mithilfe von lebenserweckendem Kraut und Wasser. ${ }^{369}$ Auch dieses Detail kann als Ätiologie zu den Fertigkeiten dieser zwei Kultakteure zu verstehen sein, wonach sie auch im Bereich der Reinigungs- und Beschwörungskunst praktizierten. Die Reinigung durch Wasser und magische Kräuter sowie das Vortragen von Beschwörungen gehört zu den Standards einer rituellen Reinigung bei Bann- oder Löseritualen. ${ }^{370}$ Für den kurgarrû ist ein Mitwirken bei solchen Ritualen für das erste Jahrtausend belegt, auch der kalû ist bei Beschwörungsritualen bekannt, allerdings wird ihr Umgang mit magischen Mitteln nie explizit dargestellt. ${ }^{371}$

Aus den besprochenen Textpassagen lassen sich folgende Aussagen zum gala treffen:

(1) Er wird als eine Neuschöpfung des Gottes Enki betrachtet und damit der übrigen Menschheit gegenüber gestellt. ${ }^{372}$

(2) Er überschreitet Grenzen und kommuniziert mit dem Göttlichen, womit er als 'Mittler' und 'Grenzgänger' eingeordnet werden kann. ${ }^{373}$

${ }^{366}$ Inana und Ebih 173; Uru-ama 'irabi 54, $58-59$ (Volk 1989, 84, 92); Iddin-Dagan A 74-9 (vgl. Groneberg 1997a, 143); ähnlich Maul 1992, 164 auch im Eršema Nr. 97:17 (Cohen 1981, 74) angenommen, und Rubio 2001, 409 allerdings bezogen auf Selbstkastration. Beim hethitischen Ištanūa-Festritual trat ein "úA.ZU (allgemein mit „Arzt“" übersetzt“) auf, spielte das huhupal-Instrument („Laute?“), tanzte und stach sich immer wieder mit zwei Nadeln, um über Tanz, Musik und Selbstkasteiung den Trancezustand zu erreichen; Schuol 2004, $206-$ 207.

${ }^{367}$ Fluch über Akkade 198-206.

${ }^{368}$ Love Lyrics BM 41005 iii 13 bei Lambert 1975, 104-105.

${ }^{369}$ Sladek 1974, 134, 172:252-253.

${ }^{370}$ Vgl. Maul 1994, 41-42, 94-95.

${ }^{371}$ Maul 1992, 164-166; zum gala vgl. SP 2.106, wonach er Beschwörungen vortrug, und die nA Baurituale und Beschwörungen des kalû; Ambos 2004, 10-13, 171-198.

${ }^{372}$ Zum Hintergrund der Menschenschöpfung s. allgemein Pettinato 1971, 21-29.

${ }^{373}$ Maul 1992, 163-164 sieht hier sogar Parallelen zum Schamanismus. Zu „Zwischenwesen“ und „Mittelwesen“ s. allgemein HrwG V 418-419 und IV 146-147; Mayer/Sallaberger 2003, 94-95. 
(3) Er wird Inana zugeordnet und ist für ihren Gemütszustand zuständig. ${ }^{374}$

(4) Er wird mit musikalischen (Musikinstrumente, Klagelieder) und magischen (Wasser und Kraut des Lebens) Mitteln ausgestattet.

\subsubsection{Repertoire und Musikpraxis}

\subsubsection{Die Musikinstrumente}

Bei der Erschaffung des gala wurden ihm durch Enki /ub/ und /lilis/als seine wichtigsten Perkussionsinstrumente ausgehändigt. ${ }^{375}$ Dieselben Instrumente wurden ihm nach der Erzählung von Inana und Ebih von Inana übergeben. ${ }^{376}$ Aufgrund der engen Verbindung dieses Priesters zu Inana wird ihr auch sein Instrumentarium zugeordnet, so auch in Enki und die Weltordnung:

\section{T 23: Enki und die Weltordnung 447-448}

„Du bist es, die vom še $\mathrm{m}_{3}\left(/ \mathrm{ub}_{3}\right)$ der Klage das 'Tuch' (wörtl.') abdeckt, Mädchen Inana, du verschließt tigi und /adab/ in ihre 'Häuser'.“

447. šem ${ }_{3}\left(/ u b_{3}\right)$ a-nir-ra-da tug hye $_{2}$-em-mi-si-ig

448. ki-sikil d Inana tigi a-da-ab e $e_{2}-$ ba he $e_{2}-\mathrm{em}-\mathrm{mi}^{\mathrm{d}} \mathrm{gi}_{4}{ }^{377}$

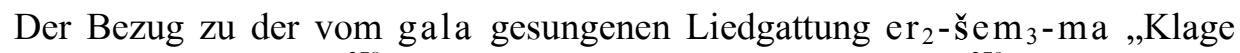
der $\breve{s} \mathrm{em}_{3}$-Trommel “, ${ }^{378}$ ist hier unmissverständlich gegeben. ${ }^{379}$ Das Initiieren

\footnotetext{
${ }^{374}$ Vgl. die SP 2.101, SP 2.100; Alster 1997, 65-66, 371 und hier Kapitel 6.3.3.

${ }^{375}$ Kramer 1981, 5:23; hier Kapitel 6.3.1.

${ }^{376}$ ETCSL 1.3; Attinger 1998, 180-181:173-175.
}

377 ETCSL 1.1.3; Benito 1969, 113, 136:442-443. Kommentar: Z. 447. liest Römer 1993, 420 $\mathrm{ub}_{3} ; \mathrm{zu} \mathrm{AB}_{2} \mathrm{x} \breve{\mathrm{S}} \mathrm{A}_{3}=\mathrm{ub}_{3} / \check{\mathrm{s} e \mathrm{em}_{3}}$ s. Römer 1965, 157, 167 und Borger 2003, 178:677. Z. 448

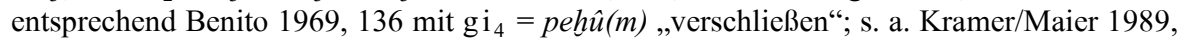
56 und ETCSL 1.1.3; anders Römer 1993, 420:448 „Mädchen Inana, du hast die tigi- und adab(-Lieder) fürwahr aus ihren Tempeln entfernt".

${ }^{378}$ Kramer/Maier 1989, 56, 222 Anm. 134-135. Mit dem Auf- und Zudecken des bei der Klage gespielten Instruments verbindet sich offensichtlich eine liturgische Handlung, die die Aufführung einer Klage einleitet und wieder abschließt. Im nA Gebet an einen verfinsterten Gott findet sich in Z. 23 zuletzt die Anweisung $l_{2}$ [KU].UŠ li-li-is-su li-ri[-im] ,der gala soll die /lilis/ zudecken!“; Ebeling 1948, 418. arämu = si bezeichnet in einem seleukidischen Ritual auch den Akt der Fellbespannung bei einer /lilis/; Thureau-Dangin 1921, 26:7-8 jetzt Linssen 2004, 252:I 1 und nachfolgend die Bearbeitung der verschiedenen Ritualversionen; s. a. katāmu $=\breve{s}_{2}$ in AHw 464a. In diesem Zusammenhang ist auf den Rubriknamen ki$\check{s ̌ u}_{2}$ zu verweisen, der nach Wilcke 1975, 261 als „'...Stelle davon, an der man das Instrument wieder zudeckt'“ das Ende des Liedes anzeigt.

${ }^{379}$ Zur instrumentalen Begleitung des Eršema durch den gala s. das Mari-Ritual A.3165 Kol. iii 16-18 ištèn ina kalê izzazma [i]na halhallatim erse[m]akam ana Enlil izammur; vgl. Durand/Guichard 1997, 55 und hier Kapitel 12.3.1. 
der Klage und das Beenden freudiger Tigi- und Adab-Musik ist hiernach Inanas Willen unterworfen.

Das balag̃ gilt in Anlehnung an die gleichnamige Klageliedgattung nach bisheriger Forschung als wichtigstes Instrument des gala. Textpassagen, die ihn als Spieler dieses Instruments nennen, sind allerdings selten. Der früheste mir bekannte Beleg findet sich auf der Gudea Statue B. ${ }^{380}$ Im Fluch über Akkade spielt es ein gala-mah. ${ }^{381}$ Ein Balag̃-Lied an Utu aus dem ersten Jahrtausend listet schließlich den gala neben all seinen Musikinstrumenten, darunter auch das bala g, auf. ${ }^{382}$ Alltagsdokumente legen nahe, dass diesem auch Wartung und kultische Pflege des balag̃ oblagen. ${ }^{383}$ Neben bala g̃ nennt der Fluch über Akkade noch šem ${ }_{3}, \mathrm{ub}_{3}$ und /lilis/ als Instrumente des gala-mah, die Version des ersten Jahrtausends fügt das me-ze ${ }_{2}$ hinzu.

Nach einem einzigen literarischen Beleg im Balag̃-Lied Uru-ama'irabi des ersten Jahrtausends wird dem gala auch das $\mathrm{a}_{2}-1 \mathrm{a}_{2}$, ein großformatiges Membranophon, ${ }^{384}$ zugeordnet. ${ }^{385}$ Bereits in der altbabylonischen Liste der me aus der Erzählung Inana und Enki wird dieses Instrument der Göttin Inana zugeordnet:

\section{T 24: Inana und Enki Text I 99}

„,Du (Inana) brachtest das heilige tigi, das heilige /lilis/, das $\mathrm{ub}_{3}\left(/ \mathrm{s}_{\mathrm{em}}\right)$, me-ze ${ }_{2}$ und $\mathrm{a}_{2}-1 \mathrm{a}_{2}$ mit dir."

99. Гtigi $\mathrm{ku}_{3} \mathrm{li-li-is_{3 }} \mathrm{ku}_{3} \mathrm{ub}_{3}\left(/ \mathrm{šem}_{3}\right) \mathrm{me}-\mathrm{ze}_{2}{ }^{\mathrm{kuš}} \mathrm{a}_{2}-\mathrm{la}_{2}$ ba $-<\mathrm{e}-\mathrm{de}_{6}>^{386}$

Zum Instrumentarium des gala lässt sich zusammenfassen, dass es sich über seine Verbindung zur Göttin Inana definiert. Seine Instrumente sind $u b_{3}$ und š $\mathrm{m}_{3}$, akkadisch halhallatu(m), das paukenförmige /lilis/, das als Trommel zu identifizierende bala $\tilde{g},{ }^{387}$ im ersten Jahrtausend auch me-ze ${ }_{2}$ und $a_{2}-1 a_{2} \cdot{ }^{388}$

${ }^{380}$ Gudea Statue B Kol. v 3 bei Edzard 1997, 32.

${ }^{381}$ Fluch über Akkade 198-201; hier Kapitel 6.3.2.3.

${ }^{382}$ Balag̃ Utu..Ekura bei Cohen 1988, 420:a+36-a+41.

${ }^{383}$ BIN 9, 445:1-2.7 (IšEr 25).

${ }^{384}$ Nach Kilmer 2003-05, $369 \S 3.3$ ist es mehrdeutig und kann auch eine Harfe bezeichnen. Für seine Identifizierung als großes Membranophon sprechen jedoch eindeutige Belege aus Mari; Durand 1988, 119-120; Villard 1989:92; s. a. Mirelman in: Y. Maurey et al. (Hrsg.), Sounds from the Past. Yuval, vol. 8. Jerusalem: 2010 (im Druck).

${ }^{385}$ Volk 1989, 83, 91:48-50.

${ }^{386}$ ETCSL 1.3.1 Text I; Farber-Flügge 1973, 60-61:24; die Ergänzung des tigi am Anfang der Zeile ist unsicher.

${ }^{387}$ Ausführlich zum bala g̃ und zu seinem Bedeutungswandel vom 3. zum 1. Jt. Gabbay 2007, 57-65; s. a. Michalowski 2009, der es für das 2. Jt. ebenfalls als Membranophon identifiziert.

${ }^{388}$ Vgl. Renger 1969, 191. 
Ihnen wird in mythologischer Hinsicht eine göttliche Herkunft zugeschrieben. In Alltagsdokumenten, Jahresdatenformeln und Inschriften ist mehrfach dokumentiert, dass sie zum Tempelinventar gehörten und einen göttlichen Status annehmen konnten. ${ }^{389}$

Das gala-Instrumentarium bestand damit ausschließlich aus Perkussionsinstrumenten, Membranophonen und möglicherweise auch Idiophonen. ${ }^{390}$ Für die Begleitung der Lieder des gala kann damit eine rein rhythmisch-perkussive Form festgestellt werden.

\subsubsection{Das vokale Repertoire}

Zum Liedrepertoire des gala gehören nach bisheriger Kenntnis die Gattungen Balag̃, Eršema und Eršahug g̃a sowie nach Texten des ersten Jahrtausends das Šu'ila, ein 'Handerhebungsgebet' ${ }^{391}$ Nach der oben besprochenen Ätiologie könnte auch das Eršaneša „Flehklage(?)“ dem gala zuzuordnen sein. ${ }^{392}$ Seine Gesänge sind damit vornehmlich Lieder, die einen Begnadigungs- oder Fürbittegestus zum Ausdruck bringen. ${ }^{393}$

In einer Rationenliste unbekannter Herkunft werden gala für die Entrichtung von 'Fürbittegebeten' (takribtum) entlohnt ${ }^{394}$ Hierbei handelt es sich um eine Bezeichnung der Kultliturgie von gala-Priestern, zu der auch der Vortrag von Eršema und Balag̃ gehörte. ${ }^{395}$

Neben den Klageliedgattungen können dem gala außerdem die Gattungen Širnamšub und Širnamgala zugeordnet werden. ${ }^{396}$ Beide sind größtenteils im sumerischen Hauptdialekt gehalten und formulieren in aller Regel Preislie-

${ }^{389}$ Vgl. Selz 1997, 172-173, 178, 213; Kilmer 2003-05, 368 § 2. Ausführlich Shehata 2010. Zum me-ze ${ }_{2}$ s. a. das aB Eršema an Gula bei Cohen 1981, 104-105:17-20.

${ }^{390}$ Allgemein Kilmer 2003-05, 368-370; $\mathrm{aB}$ noch lexikalisch im Vorläufer zu Ur $\mathrm{U}_{5}$-ra XII aus Nippur (MSL 7, 234) 33. me-ze ${ }_{2}^{\text {zabar }}$; nach Kilmer 2003-05, 369 ein Membranophon, ein Idiophon nach Volk 1989, 101:17 Klangstab(?) und Selz 1997, 192 Anm. 90 ,a sort of sistrum(?)“; für das 1. Jt. sind die gala als Spieler von Sistren sicher belegt; s. hier Anm. 1450; zum Thema Musikinstrumente des gala s. a. Gabbay 2007, 53-54.

${ }^{391}$ Vgl. allgemein auch Cohen 1988, 14-17; zuletzt Black 1991, 23-26; und hier Teil II.

${ }^{392}$ Als Unterschrift der Komposition Ein Mann und sein Gott; ETCSL 5.2.4:144. 「 $\tilde{\mathrm{g}} \mathrm{i} \mathrm{s}^{\mathrm{T}}{ }^{-} \mathrm{gi}_{4}$ $\tilde{g} a l_{2}$ 145. er $r_{2}-\breve{s}_{3}-n e-s ̌ a_{4}$ 146. dig̃ ir $l u_{2}-u l u_{3}-k a m$,g̃išgiğal, ein Eršaneša für den Gott eines Mannes".

${ }^{393}$ Zur Einordnung des Klagens unter den m e Farber-Flügge 1973, 56-57:58; dazu Zgoll 1997, 116 Anm. 486.

${ }^{394}$ TCL 10, 123 (D.a.) 4.15 gur še $a-n a{ }^{\ulcorner} \mathrm{gala}^{\top}$-meš 5. i-nu-ma [ta-a]k-「ri ${ }^{\top}$-ba-tim iš-ta-ka-nu; vgl. CAD T 200. Zur Lesung der von gala vorgetragenen Texte als „Gebete“ (von karäbu) im eigentlichen Sinne s. Gabbay 2007, 106.

${ }^{395}$ Vgl. Walker/Dick 2001, 231:6; Farber 2003, 209:6.

396 Titel von Širnamšub werden im aB Sippar-Katalog (B1) (VS 10, 216) neben Balag̃ und Eršema aufgelistet, weshalb diese Gattung von Krecher 1966, 33 und Black 1991, 24 zum Repertoire des gala gezählt wird. 
der an Götter und Könige. ${ }^{397}$ Dass der gala nicht nur Klagen vortrug, geht auch sekundär aus dem Balbale-Lied Dumuzi-Inana $P$ hervor. Das Lied handelt von Inanas und Dumuzis Hochzeitsvorbereitungen. ${ }^{398}$ Nach Eintritt der Göttin richten gala und nar ihre Gesänge an sie, was in einen Wechselgesang zwischen gala und Göttin übergeht: ${ }^{399}$

\section{T 25: Dumuzi-Inana P Text B 14-15}

„Die junge Herrin hob an, sich selbst zu preisen,

Der gala [antwortete ihr] im Lied.“

14. in-ning-e ni ${ }_{2}$ silim-e-reš ${ }^{\urcorner}$[na-e]

15. gala-e $\breve{s i r}_{3}-r a \mathrm{r}^{\top} \mathrm{mu}-\left[\mathrm{ni}-\mathrm{ib}_{2}-\mathrm{gi}_{4}{ }^{?}-\mathrm{gi}_{4}{ }^{?}\right]^{400}$

Es ist bezeichnend, dass nur der gala hier in direkten Kontakt zur Göttin tritt. Zuletzt sei hier auf ein Balag̃ an Utu aus dem ersten Jahrtausend verwiesen, das den gala als Vorträger von 'Herrschaftsliedern' (sumerisch šir ${ }_{3}$-ra namen-na; akkadisch zamāri/zamār bēlüti) auszeichnet. ${ }^{401}$

Zusätzlich zu den Klagen im Emesal und möglicherweise auch Götterpreisliedern konnten gala auch Beschwörungen rezitieren. Das folgende Sprichwort nimmt Bezug auf dieses Repertoire des Priesters: ${ }^{.02}$

T 26: SP 2.106

„Ein gala, (dessen) Beschwörungen nicht süß klingen, ... (?).“

gala $\mathrm{mu}_{7}-\mathrm{mu}_{7}$ nu-dug ${ }_{3}-\mathrm{ga} \mathrm{BAD}_{3}$ gala-e-ne $\mathrm{e}^{403}$

${ }^{397}$ Unter den Širnamšub ist lediglich Nisaba B als Klage der Göttin gehalten; zu beiden Gattungen s. a. hier ausführlich Kapitel 12.2.3 und 12.2.4.

${ }^{398}$ Zuletzt bei Sefati 1998, 218-235.

${ }^{399}$ Sefati 1998, 224; an dieser Passage zeigt sich die Verbindung zwischen Klage und Hochzeitspreis, die von Cooper 2006b, 43-44 über den gemeinsamen Nenner der Sprache (Emesal) und der Inana aufgezeigt wurde. Hervorzuheben ist hier vor allem die Beteiligung des gala.

${ }^{400}$ ETCSL 4.08.16; Ergänzung nach Sefati 1998, 220, 224 col. ii „The young lady ext[ols] herself, The gala-priest answers her in song".

${ }^{401}$ Bala g̃ Utu..Ekura bei Cohen 1988, 420:a+38.

${ }^{402}$ Vgl. auch nA die Bauritual-Beschwörungen des kalû; Ambos 2004, 10-13, 171-198.

${ }^{403}$ Kommentar: Die Lesung des $\mathrm{BAD}_{3}$ ist unklar. Als un 3 bei Gordon 1959, 254-255 ,a superior(?)“. In Anlehnung an das Sprichwort SP 2.41 zum nar wäre auch hier in der zweiten Vershälfte eine negative Aussage zu erwarten; Alster 1997, 372. Möglich wäre daher auch die Lesung ug ${ }_{5}$ „sterben; Tod“ mit folgendem Sinn: „Ein gala, dessen Beschwörungen nicht süß klingen, 'ein Toter’ gala ist er!“. Gegen e-ne als Pl. (ETCSL 6.1.02:182: „A lamentation priest whose incantations do not sound sweet is highly regarded among lamentation priests!“) besser Pron. 3. Sg. (Gordon 1959, 254; Alster 1997, 67 zu 372). 
Dass für das Rezitieren einer Beschwörung eine spezialisierte Ausbildung erforderlich war, zeigt sich an einem Brief aus Mari, wonach der Obermusiker und Lehrer Ilšu-ibbîšu dem Unterrichten von Beschwörungen täglich im mum$m u(m)$, der 'Musikschule' des Palastes, lauschte. ${ }^{404}$

In unmittelbarer Nähe eines gala-mah-Archivs in Isin wurde außerdem eine mehrsprachige Liebesbeschwörung aufgefunden. ${ }^{405}$ Dass Beschwörungen zum Repertoire des Klagepriesters gehörten lässt sich damit sicher annehmen.

Zur formalen Struktur des gala-Repertoires fällt auf, dass vor allem die Liedgattungen Balag̃, Širnamšub und Širnamgala nach den Rubriken kirugu und kišu unterteilt werden. ${ }^{406}$ Da diese Rubriken in Texten des gala auftreten, ist zu vermuten, dass über sie eine Kulthandlung oder Vortragsform angezeigt wird, die für die Lieder dieses Priesters kennzeichnend ist.

Für das erste Jahrtausend lässt sich schließlich das Repertoire des gala auf die Gattungen Balag̃, Eršema und Šu'ila eingrenzen, worüber spezielle Liederkataloge und Kultkalender des gala Aufschluss geben. ${ }^{407}$

\subsubsection{Die Aufführungspraxis}

Die Ausführung von Klageriten ist literarisch und im Mari-Ritual belegt. Hiernach traten gala und gala-mah meist solistisch auf und begleiteten ihren eigenen Gesang auf einem Perkussionsinstrument. ${ }^{408}$ Andererseits wurden gala auch in größeren Ensembles integriert. Beispielhaft ist hier eine Passage aus dem Fluch über Akkade:

\section{T 27: Fluch über Akkade 198-201}

„Der gala-mah, der diese Jahre überdauert hatte,

für sieben Tage und sieben Nächte lang,

postierte er sieben bala g̃ wie am Horizont aufrecht aufgestellt,

und ließ in ihrer Mitte /ub/,/meze/ und /lilis/ für ihn (Enlil) wie Iškur erklin-

gen.

Die alten Frauen ließen nicht ab von (ihren Ausrufen) 'Oh weh! Meine Stadt!';

die alten Männer ließen nicht ab von (ihren Ausrufen) 'Oh weh! Ihre Leute!';

die gala-Priester ließen nicht ab von (ihren Ausrufen) 'Oh weh! Das Ekur!'“

\footnotetext{
${ }^{404}$ Ziegler 2007, 206, 215 No. 51:19. mu-ša-am $u_{3}[u] r$-[ra-am] 20. [i]-na ${ }^{\ulcorner} m u^{\top}$-mi-im e-en ${ }_{2}$ -

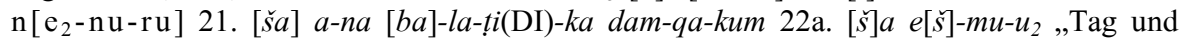
Nacht sind es die enenuru-Beschwörungen, die für dein Leben gut sind, die ich im mummum höre".

${ }^{405}$ IB 1554; Wilcke 1985a, 190-209; zur Einordnung Groneberg 2007, 100-17.

${ }^{406}$ Hierzu ausführlich in den entsprechenden Kapiteln von Teil II.

${ }^{407}$ Allgemein Cohen 1988, 15ff.; s. a. Maul 2000, v. a. 392-393.

${ }^{408}$ Gudea Statue B v 3; Edzard 1997, 32 v 3.
} 
198. gala-mah mu-ta ba-ra-ab-taka 4 -a

199. ud 7 gi $\mathrm{i}_{6} 7$-še $\mathrm{e}_{3}$

200. balag̃ 7 -e an-ur 2 gub-ba-gin 7 ki mu-un-ši-ib-us 2

201. ub $_{3}$ me-ze $_{2}$ li-li-is ${ }_{3}^{\text {d Iškur-gin }}$ ša $_{3}$-ba mu-na-an-du $u_{12}$

202. um-ma a $u r u_{2}-\tilde{g} u_{10} n u-g ̃ a_{2}-\tilde{g} a_{2}$

203. ab-ba a $l u_{2}-b i n u-\tilde{g} a_{2}-\tilde{g} a_{2}$

204. gala-e a $e_{2}$-kur nu-g̃a $a_{2}-\tilde{g} a_{2}{ }^{409}$

Die hier zitierten Zeilen beschreiben die Ausführung eines Klageritus zur Besänftigung des Gottes Enlil, der insgesamt sieben Tage andauerte. ${ }^{410}$ Beim Ensemble bestehend aus mehreren Perkussionsinstrumenten und größeren Chören könnte es sich um eine gängige Aufstellung für die Ausführung von größeren Klagezeremonien handeln. ${ }^{411}$ Dementsprechend könnten die Aufgabenbereiche von gala und gala-mah zu unterscheiden sein, der gala-mah als Solist und erster Instrumentalist und die gala vornehmlich als Chorsänger. Eine ähnliche instrumentale und vokale Aufstellung implizieren Angaben in Rationenlisten, wo einzelne gala-mah neben Gruppen von gala-Priestern stehen. ${ }^{412}$ Im Ištar-Ritual von Mari ist es ein gala, der solistisch das Erš ema an Enlil vorträgt, sich selbst auf einer halhallatum $\left(\mathrm{s}_{\mathrm{e}} \mathrm{m}_{3}\right)$-Trommel begleitet und einem gala-Chor vorsteht. ${ }^{413}$ Welche Lieder vom Chor der gala gesungen wurden, ist nirgends vermerkt. Im zitierten Fluch über Akkade anworten die gala auf den gala-mah lediglich mit dem Ausruf „Oh weh! das Ekur“. In einem altbabylonischen Eršema an Inana folgt auf den Text des Liedes die Anweisung ,(und) sie alle singen (gemeinsam)“ (kalûšunu izammaru). ${ }^{414}$ Der Chor der gala-Priester könnte damit auf den Vortrag des Solisten mit refrainartigen Textpassagen geantwortet haben. Dies lassen auch die Inhalte der Rubrik g̃išgig̃al „Gegengesang“ in Klageliedern vermuten, die wohl den Einsatz eines Chores anzeigt. ${ }^{415}$ Die Form des Wechsel- bzw. des responsorialen Ge-

409 Kommentar: Die hier zitierten Zeilen sind auf bis zu 16 aB Textvertretern erhalten, die größtenteils aus Nippur stammen und nur wenig variieren, vornehmlich jedoch in der Aufzählung der Musikinstrumente: Z. 200 vgl. Attinger 1984b, 105, 118 ,sept balag̃ ont été po-

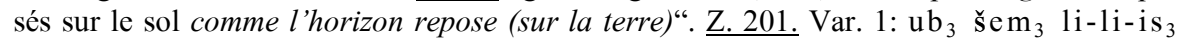
(Texte $\mathrm{O}, \mathrm{S}, \mathrm{W}$ ); Var. 2: $\mathrm{ub}_{3}$ šem $_{3}$ zabar „bronzenes /šem/“ (Text $\mathrm{D}_{4}$ ); Var. 3: ub $\mathrm{b}_{3}$ meze $_{2}$ li-li-is ${ }_{3}$ (Texte $\mathrm{E}_{1}, \mathrm{Q}_{2}, \mathrm{Y}_{2}, \mathrm{G}_{3}$ ); keiner der aB Textvertreter schreibt me-ze 2 , s. Cooper 1983, 188-191, 201. Z. 202-204. vgl. Übersetzung bei Cooper 1983, 59.

${ }^{410}$ Cooper 1983, 251-252.

411 Ausführlich zu dieser Passage jetzt auch Cooper 2006b, 41-42; eine chorische Aufstellung gleicher Musikinstrumente, wie sie hier für die sieben bala g̃ beschrieben wird, ist literarisch nur noch für /tigi/-Trommeln in Šulgi A 81 und Enkis Reise nach Nippur 128 bezeugt; vgl. Cooper 1983, 252.

412 OLA 21, 4:5.8 (Ae 28).

${ }^{413}$ Durand/Guichard 1997, 55:iii 17-18.

${ }^{414}$ PBS 10/2, 15:24; Krecher 1966, 33.

${ }^{415} \mathrm{Zu}$ dieser Rubrik ausführlicher Kapitel 14.1.4. 
sangs wurde auch für die oben zitierte Textpassage aus dem Balbale DumuziInana $P$ vermutet. ${ }^{416}$

Beachtenswert sind auch die Gruppen von Frauen und Männern, die das Ensemble mit Klageschreien unterstützen. Die Zusammenarbeit von galaPriestern und Klagefrauen wird hier an anderer Stelle erörtert. ${ }^{417}$ Dem galamah standen auch nach Ausweis alltäglicher Dokumente zahlreiche Frauengruppen zur Seite, in Sippar die harimātum und auch die kulmašiātum. Ihre Beteiligung an den Klageriten und -gesängen dieses Priesters ist sehr wahrscheinlich.

\subsubsection{Die sumerischen Sprichwörter}

Den gala betreffend ist eine Gruppe von bislang zwölf sumerischen Sprichwörtern überliefert, in denen sein im Alltag herrschendes Bild karikiert wird. ${ }^{418}$ Die größte Gruppe SP 2.97-106 ist eingebettet zwischen Sprichwörtern zu Rindern und Hunden, was insgesamt eine eher negativ konnotierte Einordnung des gala aufzeigt. Auch in den bisherigen Publikationen dieser Textgruppe wurde die Darstellung zum gala von Jacobsen und Alster insofern gedeutet, als dass er als großtuerischer und bequemer Sonderling auftritt, der sich auf naive Weise der göttlichen Intervention überlässt. ${ }^{419}$ Auch wenn dieses Bild hier nicht revidiert werden soll, so wird es anhand einiger Details weiter differenziert. So implizieren die Sprichwörter nicht nur eine Sicherheit in religiöser Hinsicht, die aus der Verbindung des gala zu Inana resultiert, sondern auch eine materielle Absicherung, die möglicherweise auf seine Tempelzugehörigkeit zurückzuführen ist.

Die folgenden zwei Sprichwörter deute ich in diesem Sinne als Verweis auf die materielle und institutionelle Sicherheit des gala:

T 28: SP 2.103

„Auch wenn das Getreideschiff eines gala sinkt, wandelt er dennoch auf trockenem Land. ...“

gala-e ${ }^{\tilde{g} i \check{s}} \mathrm{ma}_{2}$ še-ka-ni ha-ba-da-an-su

bar-rim 4 -ma ba-e-g̃en

$[\ldots] \times \times(\mathrm{x}){ }^{420}$

${ }^{416}$ S. Kapitel 6.3.2.2.

${ }^{417}$ Falkenstein/von Soden 1953, 29; Hartmann 1960, 138; Schretter 1990, 127; Cooper 2006b, 43-44; und hier Kapitel 7.4.

418 SP 2.97-106; SP 21.D 3; SP 2.54; lediglich das Sprichwort SP 2.102 ist stark zerstört.

${ }_{419}$ Alster 1997, 371 zu SP 2.97; Jacobsen apud Gordon 1959, 482-484.

${ }^{420}$ ETCSL 6.1.02:174-176; Alster 1997, 66, 371. Die Textvariante J nennt in stark zerstörtem Kontext den Namen Enki, sodass in einer Variante dieses Sprichwortes möglicherweise Enki als Schutzpatron des gala interveniert. 
T 29: SP 2.97

„Für einen gala liegt das Feld nahe am Haus.“

gala-e $\operatorname{gan}_{2} \mathrm{e}_{2}$-e $\mathrm{us}_{2}$-sa

Getreideschiff und Feld sind Sinnbilder für die tägliche Nahrungsversorgung, die nach diesen zwei Sprichwörtern für den gala als unproblematisch galt.

Im folgenden Sprichwort spiegelt sich die übertriebene Selbstsicherheit des gala in seinem Übermut wider:

\section{T 30: SP 2.99}

„Ein gala schleuderte seinen Sohn ins Wasser (und sagte):

'Die Stadt soll bauen wie ich; das Land soll leben wie ich!'“421

gala-e dumu-ni a ha-ba-an-da-ra-ra ${ }^{422}$ iri $^{\mathrm{ki}} \tilde{g}_{26}-\mathrm{gin}_{7} \mathrm{he}_{2}-\mathrm{du}_{3}$

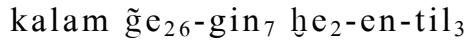

Der gala meint hiernach auf seine eigene Versorgung zu Lebzeiten sowie posthum über die Totenkultpflege durch seine Kinder verzichten zu können. Sein gesamtes Umfeld aufzufordern, ihm Gleiches zu tun, stellt ihn wiederum großtuerisch und übermütig dar. ${ }^{423}$

Dass sich die scheinbar religiöse Sicherheit des gala jedoch nicht auf seine materielle Versorgung auswirkt, könnten die folgenden Sprichwörter anzeigen:

\section{T 31: SP 2.104}

„Das Brot eines gala, (im Umfang) groß, aber (im Gewicht) leicht“

ninda gala-kam lag-ga ab-gu-ul ki-la 2 -bi al-tur ${ }^{424}$

${ }^{421}$ ETCSL 6.1.02:163-164; Alster 1997, 65 „Let the city built like me, let the people live like me!“. Nach Alster 1997, 371 wird hier wie auch in SP 2.100 die übertriebene Selbstüberschätzung des gala dargestellt. $\mathrm{Zu}$ einer gänzlich anderen Interpretation gelangt Jacobsen apud Gordon 1959, 484, demzufolge das 'Ins-Wasser-Werfen' des Sohnes auf den Akt der Masturbation verweise, worin die Unfruchtbarkeit des gala verbildlicht wäre; dazu Diakonoff 1975, 115 Anm. 31; Schretter 1990, 74 Anm. 8 und zuletzt Whittaker 2002, 635-636. Die Annahme von Renger 1969, 191, das Sprichwort beziehe sich auf rituelle Handlungen, ist abzuweisen.

${ }^{422}$ Variante in Text A dumu-na a-a ba-da-ze ${ }_{2}-e \tilde{g}_{3}$; Alster 1997, 65.

${ }^{423}$ Zum 'Wegwerfen' seiner eigenen Kinder als negative Apodosis s. CAD Š/1, 272-273 zu šalû A sub 3.

${ }^{424}$ ETCSL 6.1.02:177; Alster 1997, 66. 
T 32: SP 21.D 3

„Ein gala ging auf das Feld eines Mannes um Gerste zu stehlen.

Als der Feldbesitzer ihn erwischt, (sagt der gala):

'Mein schöner Kopf hat sich verwirrt, ist (vollkommen) auseinander geraten [..].

Lass mich ihn wieder 'richtig stellen'! Lass mich meine Sinne [wieder erhalten]!

Lass mich gehen!"“

$$
\begin{aligned}
& \text { gala-e a-ša } \left.a_{3} l u_{2}-u_{3}-k a \text { še zuh-zuh-d[ } e_{3} i_{3}-\tilde{g} e n\right] \\
& \text { lugal a-ša } a_{3}-g a-k e_{4} \text { ba-an-dab } \\
& \text { sa g̃-an-sag }-g a-\tilde{g} u_{10} b i_{2}-s u b b_{2}-b i r-\left\ulcorner b i{ }^{1}[x]\right. \\
& \text { si ga-ba-an-sa } a_{2} \text { umuš-g } u_{10} \text { ga-ba-da-ab- }{ }^{\top} x^{1} \\
& \text { ga-ba-g̃en-e-[ře }]^{425}
\end{aligned}
$$

Dieselbe Aussage von SP 2.104 zum Brot des gala äußert sein Diener im darauffolgenden Sprichwort SP 2.105 sich gleichzeitig über seine geringe Speiseration (kurum $_{6}$ ) beklagend. ${ }^{426}$ Zusätzlich zur Brotlosigkeit bringt das Sprichwort SP 21.D 3 einen weiteren negativen Zug des gala an. Dieser versucht sich der Verantwortung gegenüber seiner Diebestat zu entziehen, indem er geistige Verwirrung vortäuscht.

Die weniger materielle als vielmehr religiöse Selbstsicherheit des gala wird in den zwei folgenden Sprichwörtern auf seine enge Verbindung zur Göttin Inana bezogen:

\section{T 33: SP 2.101}

„Ein gala begegnete einem Löwen in der Steppe,

(Daraufhin) läuft er wahrhaftig in die Stadt?, zum Tor der Inana,

Wo er den Hund im 'Scherbenloch'? mit einem Stock 'verdrischt' (und sagt):

'Was macht (denn) dein Bruder in der Steppe?'“

$$
\begin{aligned}
& \text { gala-e ur-mah-e edin-na } u_{3} \text {-mu-ni-in-te }
\end{aligned}
$$

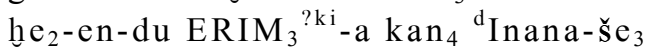

$$
\begin{aligned}
& \text { ur šika-da-ke } e_{4} \tilde{g} i \check{s}-a^{?}-n i-r^{r} a^{\top} \\
& \text { šeš-zu edin-na ta-am } 3 \text { mu-un-ak-e-še } e^{427}
\end{aligned}
$$

${ }^{425}$ ETCSL 6.1.21:3-7; Alster 1997, 259-260, 444.

${ }^{426}$ Erweitert ist das Bild allerdings um den Vergleich der gering-gewichtigen Speise mit einer Lanze ( ${ }^{\tilde{g}}$ iš šukur), die die Stadt 'durchdringt(?)'(te-te), was inhaltlich unklar ist; Alster 1997, 371 deutet den Brotlaib als Metapher für das Wesen des gala selbst.

${ }^{427}$ Kommentar: ERIM ${ }_{3}^{\text {?ki }}$ - a wörtl. ,,in die Stadt (mit Namen) 'Speicher'“ vielleicht als Anspielung auf den Reichtum der Stadt. ETCSL 6.1.02:167-170 und Alster 1997, 371 setzen die direkte Rede beginnend mit der he $\mathrm{e}_{2}$-Form von Z. 2 an, wodurch allerdings die Zuordnung des letzten provokativen Fragesatzes schwierig wird, richtet ihn der gala noch an den Löwen oder jetzt an einen Hund? Die h $\mathrm{e}_{2}$-Form fasse ich hingegen affirmativisch mit Bezug 
Der vom Löwen verängstigte gala bringt sich am Tor seiner Göttin Inana in Sicherheit. Dort gewinnt er seinen Mut zurück und lässt sich an einem Hund aus, sich für seine Angst vor dem Löwen rächend. ${ }^{428}$ Das Sprichwort verbildlicht die Feigheit des gala, sich vor Mächtigen zu ducken und im Gegenzug gegen Schwache zu wenden. Deutlich wird hier auch die Verbindung zur Göttin Inana, auf die im folgenden Sprichwort ebenfalls angespielt wird, allerdings in einem stark ironischen Ton:

\section{T 34: SP 2.100}

„Der gala wischt sein Gesäß ab (und sagt):

'Was meiner Herrin Inana gehört, sollte nicht 'ausgerissen' werden!“

gala-e bid ${ }_{3}-d a-n i$ hya-ba-an-da-ze 2 -er

a ğ 2 ga-ša-an-an-na ga-ša-an-ğ $u_{10}$ ba-ra-zi-zi-de $e_{3}-e n-e-s ̌ e^{429}$

Unübersehbar ist die Karikierung des gala in den Sprichwörtern. Der Schwerpunkt liegt meines Erachtens auf seiner zeitlebens gesicherten Versorgung, die sich über seine besondere Verbindung zur Göttin Inana begründet. Hinsichtlich seiner materiellen Absicherung sind die Sprichwörter doppeldeutig. In seiner Heraushebung als feigen Lügner und Wichtigtuer könnte sich auch ein gesellschaftlicher Neid widerspiegeln, ungeachtet der Frage, ob hier möglicherweise auch auf eine 'sexuelle' Abart Bezug genommen wird. ${ }^{430}$ Auch die durchgängige Verwendung des Emesal für seine direkte Rede verstärkt das Bild vom religiös abgehobenen Sonderling. ${ }^{431}$

zum gala auf.

${ }^{428}$ Fast gleichlautend aber wohl inhaltlich anders ausgerichtet ist SP 22.11.280-283 (ETCSL 6.1.22), wobei hier noch in einer Lücke $\mathrm{gudu}_{4}$-Priester genannt werden: 280 . ${ }^{\top} \mathrm{gala}^{\top} \mathrm{-e}$ ur-mah-e 「edin ${ }^{\top}-n a \mathrm{ni}_{2}$ mu-ni-ib-tešs-še ${ }_{26}$ 281. ${ }^{\ulcorner} \mathrm{kan}_{4}{ }^{\top}{ }^{\mathrm{d}}$ Inana-ta X-be ${ }_{2}-n e$ 282. ${ }^{\circ g u d u}{ }_{4}$ ? $^{7}$-ge-ne ba-e-DU 283. [šeš]-zu edin-na [ta-am ${ }_{3}$ mu-un-na-ake-š e ,A lamentation priest became afraid of a lion in the desert, and said: 'From Inana's gate ... ... The purification priests come to you, asking: 'What is your brother doing in the desert?'“; vgl. Alster 1997, 268 viii 31-38.

${ }^{429}$ ETCSL 6.1.02:165-166; s. a. Alster 1997, 65, 371 „'I must not stir up that which belongs to the Queen of Heaven (i.e. Inana), my lady.'“.

${ }^{430}$ Krecher 1966, 36; Al-Rawi 1992b, 183-184; zuletzt Whittaker 2002, 636; zum Thema s. hier Exkurs I.

${ }^{431}$ Gegen Zgoll 1997, 441 ist das hier verwendete Emesal wohl nicht als Alltagssprache des gala zu deuten, da den Sprichwörtern meist ein zynischer und ironischer Ton zugrunde liegt. 
Lediglich im folgenden Sprichwort könnte eine Andeutung auf die eigentliche religiöse Funktion des gala vorliegen.

\section{T 35: SP 2.98}

„Ein ga la ist die (Schutz)abdeckung(?) des Schiffes.“

gala $\mathrm{TUN}_{3}{ }_{\text {ği }}^{\tilde{\mathrm{S}}} \mathrm{ma}_{2}-\mathrm{kam}^{432}$

Unsicher ist hier die Bedeutung des Wortes $\mathrm{TUN}_{3}$. Mit B. Alster nehme ich an, dass es sich um einen Teil des Bootes handeln muss, ${ }^{433}$ der allerdings für seine Sicherheit zuständig ist. Als akkadisch takaltu(m) „Tasche, Futteral, Magen/Innereien" könnte an die innere Abdichtung des Schiffes zu denken sein. ${ }^{434}$ Mit $\mathrm{DUN}_{3}$ als katāmu(m) „abdecken“ (Lesung /dul/) wohl in $\mathrm{ma}_{2}-\mathrm{T} / \mathrm{DUN}_{3}$ „Asphalteur" oder „Kalfaterer“435 weist die Bedeutung in Richtung einer Schutzabdeckung. Hierin liegt deutlich die Verbindung zu den religiösen Aufgaben des gala, nämlich drohendes Übel prophylaktisch abzuweisen.

\subsubsection{Exkurs I: Geschlecht, Gender und Sprache des gala}

Besonderes Interesse in der bisherigen Forschung um den priesterlichen Beruf des gala erfuhr die Frage nach seinem Geschlecht. Eine ausführliche Zusammenfassung der hierzu bereits seit Jahrzehnten andauernden Diskussion wurde zuletzt von Schretter vorgelegt. ${ }^{436}$ Erst jüngst wurde das Thema mit neuen Argumenten von Gabbay aufgegriffen, der sich für eine hermaphrodite Natur des gala aussprach. Aufgrund der inzwischen an Umfang und Komplexität zugenommenen Theorien zu diesem Thema werden die verschiedenen Ansätze im Folgenden erneut vorgestellt und vor dem Hintergrund der in dieser Arbeit vollzogenen Quellenanalyse erörtert.

\footnotetext{
${ }^{432}$ ETCSL 6.1.02:162; Alster 1997, 65.

${ }^{433}$ Alster 1997, 371 mit T U N 3 = šaptu(m) ,(Gefäß)-Lippe; -Rand“" auf ein Boot bezogen.

434 CAD T 61b; akk. auch mākaltu $(m)$,(Holz)Schale“ möglich; CAD M/1 122b. Ein g̃iš/urudu $\operatorname{tun}_{3}=p \bar{a} s ̌ s$ „Beil“" ergibt hier wenig Sinn.

${ }^{435}$ Edzard in $A f O$ 19, 18 zu VI' 17-18; gleiches als $\mathrm{ma}_{2}$ - g in $_{2}$ bei Bauer in $A f O 36-37,82$ zu 12 I 1.

${ }^{436}$ Schretter 1990, 128-133.
} 
Die Ansichten zu einem besonderen oder 'dritten' Geschlecht des gala fußen auf drei wesentlichen Beobachtungen: (1) Der Kultsprache des gala, (2) seiner mythologischen Darstellung als Grenzgänger und (3) seiner Einordnung unter Personen mit besonderen physischen Merkmalen auch im Zusammenhang zur eigentlichen Bedeutung des Wortes gala bzw. akkadisch kalu ${ }^{437}$ Bisherige Arbeiten deuteten diesen Priester in allen erdenklichen Veränderungen des Geschlechts oder Genders als Eunuch, als Kastrat, als Homosexuellen, als Transvestit, als zwitterähnliches Wesen bzw. Hermaphrodit. ${ }^{438}$

(1) Kultsprache des gala

Ausgangspunkt der Diskussion in den Fünfziger Jahren des letzten Jahrhunderts ist die Interpretation des Emesal, der Kultsprache des gala als 'Frauensprache'. ${ }^{439}$ Die Verwendung des Emesal ist frühestens seit der altbabylonischen Zeit belegt, um die Mitte des zweiten Jahrtausends, und ist auf literarische Texte beschränkt. Dort ist es vermehrt in der direkten Rede von Göttinnen und sterblichen Frauen, seltener auch von männlichen Gottheiten wie Dumuzi und Ninšubur, von den gallû-Dämonen, einigen Tieren und schließlich auch vom gala anzutreffen. ${ }^{440}$ Im Emesal verfasst sind die Gattungen Bala g̃, Eršema und das Eršahuug̃a, die erst seit der Mitte des zweiten Jahrtausends in schriftlicher Form überliefert sind und zum Repertoire des gala-Priesters zählen. ${ }^{441}$

Die Interpretation des Emesal als 'Frauensprache' ist inzwischen revidiert, das Namenselement sal(MUNUS) ist in diesem Zusammenhang als 'fein' im Sinne einer 'feinen Sprache' und nicht als Verweis auf die 'Frau'(munus) aufzufassen. ${ }^{442}$

Zwar lässt sich die Verbindung des gala zum Emesal auch über besondere Fähigkeiten in der Überwindung von Grenzen festmachen, so findet es sich auch in der direkten Rede von Dämonen und Fliegen ${ }^{443}$ doch ist es, wie bereits in früheren Publikationen vorgeschlagen, als eine besondere Vortragssprache

\footnotetext{
${ }^{437}$ Einen solchen Ansatz verfolgen Steinkeller/Postgate 1992, 37, sie lesen die Zeichen UŠ.KU = gala als GIŠ $\breve{S}_{3}$.DUR 2 ,Penis+After“ und deuten sie damit als Bezeichnung für Homosexualität; ihnen folgt allerdings mit einiger Zurückhaltung Cohen 2005, 54. Gerade bei sexuellen Praktiken sollte von zu eiligen Schlüssen Abstand genommen werden, so wird Analverkehr auch von Heterosexuellen praktiziert. Eine solche nach Cohen 2005, 54 'visuelle Etymologie', wie sie von Steinkeller und Postgate geboten wird, bietet daher kein klares Argument für die Homosexualität des gala.

${ }^{438}$ Zusammenfassung bei Schretter 1990, 6-7; Cohen 2005, 52-58; Gabbay 2008, 52-53.

${ }^{439}$ Vgl. Whittaker 2002, 635.

440 Zur Verwendung des Emesal ausführlich Schretter 1990, 71-103; zusammenfassend bei Whittaker 2002.

441 Überblick bei Black 1991.

${ }^{442}$ Schretter 1990, 123; zuletzt Whittaker 2002, 634-635. 641.

${ }^{443}$ Whittaker 2002, 637-638.
} 
oder Intonation des Sumerischen zu deuten. ${ }^{44}$ So können im Emesal auch andere Sänger ihre Lieder vortragen, beispielsweise der nar-Sänger des Gilgamesch $^{445}$ oder ein zammerum mit Namen Bēlī-Tukultī in Mari. ${ }^{446}$ Im Emesal klagen schließlich auch die 'Klageweiber' im Fluch über Akkade, die Verbindung von Klagen und Frauen ist hier wiederum deutlich. ${ }^{447}$

Zwar legen vereinzelte Einträge in lexikalischen Listen die Vermutung nahe, dass das Emesal besonders hoch intoniert worden sei, ${ }^{448}$ was auch dem Klang von Klageschreien und Gesängen durchaus entsprechen mag. ${ }^{449}$ Eindeutig belegen lässt sich diese Annahme bislang aber nicht. In diesem Zusammenhang ist auf neue Deutungen der noch gänzlich unverstandenen Glossen in späteren Versionen der bala g̃-Lieder zu hoffen. Als Melismen interpretiert könnten sie Aufschluss über die Vortragsweise und Intonation der Lieder geben. ${ }^{450}$

(2) Der gala als Grenzgänger

Noch in den Fünfzigern und weiterführend in den siebziger Jahren lenkten Oppenheim und Diakonoff das Augenmerk auf die Rolle des gala im Mythos Inanas Gang in die Unterwelt. Alle übrigen neben dem gala-tur genannten Akteure, die in die Unterwelt zur Errettung der Inana reisen, werden andernorts als Geschlechtswechsler, Zwitter oder Transvestiten dargestellt: Die sumerische Version nennt den kur-g̃ar(-ra), die akkadischen Fassungen desselben Mythos assinnu(m) (sumerisch /pilipili/) bzw. kulu'u. ${ }^{451}$ In Inanas Gang in die Unterwelt wird berichtet, wie diese von Enki neu erschaffenen Wesen wie

${ }^{444}$ Haupt 1917/18, 243-244 als Litaneidialekt ausgehend vom Inhalt der im Emesal verfassten Lieder; zu ähnlichen Ansätzen bei anderen Autoren s. Zusammenfassung bei Schretter 1990, 6. Alster 1982, 5-6 spricht die Möglichkeit an, dass das Emesal auf die UD.GAL.NUNTexte zurückzuführen sei.

${ }^{445}$ Gadotti 2006, 71 Anm. 15.

${ }^{446}$ Ziegler 2007, 16-17, 175; da unter demselben Personennamen sowohl eine Frau als auch ein Mann belegt sind, könnte es sich nach Ziegler um einen Eunuchen gehandelt haben.

${ }^{447}$ Vgl. Cooper 2006b, 44.

${ }^{448}$ Al-Rawi 1992a; vgl. MSL 12, 229:14' $1 \mathrm{u}_{2}$ eme-sal = lu-ru- $u$; AHw 656 „Mann mit Fistelstimme“; auch MSL 4, 73:222. [em] e-mušen-[n] a „Vogelsprache(?)“ = lu-ru-um. Möglicherweise ist hier an einen Gesang oder Vortrag im Falsett bzw. mit Kopfstimme zu denken.

449 Vgl. in diesem Zusammenhang bereits Hallo 1968, 80 zum Emesal „.. . .more properly described as a kind of whining or wailing tone used by women or goddesses neither exclusively nor universally, but by them only in certain contexts, and also by certain men, notably the singers called gala (kalu) and in the context of lamentation“.

${ }^{450}$ Bielitz 1970; Katalog bei Mirelman 2009.

${ }^{451}$ Der kurgarrû $(m)$ schminkt sich wie Frauen, der assinnu(m) legt bevorzugt Frauenkleider an, vom kulu'u wird gesagt, dass er nicht eindeutig männlich sei; vgl. Oppenheim 1950, 135 Anm. 1; Groneberg 1986, 33-39; Maul 1992, 163; Groneberg 1997a, 131-132; so auch Henshaw 1994, 89 + Anm. 27 und 29; anders CAD K 557b kurgarrû sub 1) S. 558b; zuletzt Gabbay 2008, 50; CAD K 529 kulu'u. 
Fliegen und Dämonen unbeschadet in die Unterwelt hinabsteigen. ${ }^{452}$ Allen gemein ist damit die Fähigkeit, Grenzen zu anderen Welten zu überschreiten. Analog zu anderen Kulturen wird hier die Überwindung von Lebens- oder Weltengrenzen Wesen von unbestimmbarem Geschlecht zugeordnet, zu denen dann auch der genannte gala-tur(-ra) gezählt wurde. ${ }^{453}$

$\mathrm{Zu}$ demselben Schluss kommt in den Siebzigern des letzten Jahrhunderts auch Diakonoff über die Interpretation des Emesal als 'Botensprache'. ${ }^{454} \mathrm{Ihm}$ fällt auf, dass nicht nur Göttinnen und Frauen, sondern auch die Botengottheit Ninšubur, welche sowohl einen männlichen wie auch weiblichen Aspekt aufweist, im Emesal spricht. Wichtige Parallelen zwischen dieser Gottheit und dem gala, allerdings unter musikalisch-kultischem Aspekt, wurden auch von Gabbay aufgezeigt. ${ }^{455}$ Ninšubur wird in literarischen Texten auch als die Gottheit angesprochen, die die Götterherzen besänftigt und schließlich auch die Klagezeremonien für Inana bei ihrem Gang in die Unterwelt vollzieht. Hier finden sich auch die für den gala typischen Handlungen wie das Spiel der šem ${ }_{3}$-Trommel oder die Umrundung und Beopferung von Stadt und Tempeln wieder. ${ }^{456}$ Dass Ninšubur und gala mehrere Gemeinsamkeiten teilen, unterstützt nach Gabbay die Annahme eines zweideutigen Geschlechts für diesen Priester.

(3) Ein physisches Merkmal des gala

Ein verändertes Geschlecht des gala wird auch über die ursprüngliche Bedeutung des Wortes selbst und seine mögliche Etymologie diskutiert. Bereits Gelb führte an, dass in präsargonischen Listen der Begriff gala parallel zu igi-nu-

${ }^{452}$ Inanas Gang in die Unterwelt 227-229 nach ETCSL 1.4.1. „Go and direct your steps to the underworld. Flit past the door like flies. Slip through the door pivots like phantoms." 227. šen-na-an-ze 2 -en g̃iri $i_{3}$ kur-še ${ }_{3}$ nu $_{2}$-ba-an-ze ${ }_{2}$-en 228. g̃išig nim-gin ${ }_{7}$ daldal-e-de ${ }_{3}$-en-ze $e_{2}$-en 229. za-ra lil 2-gin $_{7}$ gur-gur-re-de ${ }_{3}$-en-ze $e_{2}$-en; vgl. Sladek 1974, 171.

${ }^{453}$ Nach Oppenheim 1950, 133-136 ist besonders hervorzuheben, dass gala-tur(-ra) und kurgar(-ra) nicht 'geboren' wurden, und weiter S. 134-135 ,The Sumerian texts speak of two such beings, called kur.gar.ra and gala.tur. All these terms denote kindred if not identical types of 'priests' who where made sexually impotent.."; s. a. Kilmer 1971, $304+$ Anm. 23; Groneberg 1986, 37; Maul 1992, 161-162. Beachte allerdings, dass HrwG V 418-421 „Zwischenwesen“ und HrwG IV 146-147 „Mittelwesen“ keine Anmerkungen zum Geschlecht oder Gender von Mittlerwesen enthalten.

${ }^{454}$ Diakonoff 1975, 115. Ihm zufolge könne über die Interpretation des gala als Eunuchen auch dessen vermeintlich niedrige soziale Stellung in frühdynastischen Wirtschaftstexten zu erklären sein; hierzu Schretter 1990, 130-131. Die von Diakonoff angesetzte Doppelgeschlechtlichkeit von Boten ist ausschließlich für Ninšubur bezeugt.

${ }^{455}$ Gabbay 2008, 51-52.

${ }^{456}$ Inanas Gang in die Unterwelt 32-39, 176-181 und die Hymne Ninšubur A Fragment B 1-8 (ETCSL 4.25.1; Zólyomy 2005, 398); hierzu Gabbay 2008, 51-52 auch zu möglichen lexikalischen Belegen. 
$\mathrm{du}_{8}$,blind“ und tul ${ }_{2}$-ta- $\mathrm{pad}_{3}$-da „Findling“ gebraucht wird. Hieraus schließt er auch für den Begriff gala oder kalû die Kennzeichnung einer Randgruppe und deutet solche Personen daher als Homosexuelle. ${ }^{457}$ Al-Rawi vermutet im Wort gala eine ursprünglich akkadische Entlehnung und nimmt für das Akkadische kalû wie auch für kulu'u einen gemeinsamen Ursprung an. ${ }^{458}$ Diesem Ansatz folgt auch Gabbay und setzt eine Herleitung beider Wörter von der gemeinsemitischen Wurzel $k l$ ”, ,beide(s)“ an, worin das zweideutige Geschlecht dieser Individuen verdeutlicht sei. ${ }^{459}$

Eine besondere Physis des gala könnte altbabylonisch lediglich in einer Opferrationenliste aus Sippar angedeutet sein, wo Blinde neben dem Ausdruck kalûtum auftreten. ${ }^{460}$ Ein gemeinsamer etymologischer Ursprung von kalû und dem Kastraten oder Eunuchen kulu'u bleibt allerdings fragwürdig. Letzterer ist bereits für die altakkadische Zeit belegt und auch im ersten Jahrtausend deutlich vom kalû unterschieden. ${ }^{461}$

Als besondere physische Beschaffenheit des gala vermutet Al-Rawi eine auffallend hohe Stimme, ${ }^{462}$ womit er sich von der Frage nach dem Geschlecht abwendet. Hierin berücksichtigt er die Theorie Falkensteins, dass Klagelieder ursprünglich von Frauen vorgetragen worden seien. ${ }^{463}$ Die hohe Stimme sei möglicherweise das entscheidende Merkmal für den Beruf des gala-Priesters gewesen, weshalb er im dritten Jahrtausend sowohl von Frauen als auch von Männern ausgeübt wurde.

Eine zunächst klare Aussage zum Geschlecht von gala-Priestern bieten Verwaltungstexte und Briefe. Hiernach übten im dritten Jahrtausend auch Frauen diesen Beruf aus. ${ }^{464}$ Explizit sind zwei Briefe aus dem Diyala-Gebiet, deren Datierung wohl um den Beginn des zweiten Jahrtausends anzusetzen ist. ${ }^{465}$ Sie

${ }^{457}$ Gelb 1975, 69-74; dazu Al-Rawi 1992b, 183; kritisch hingegen Schretter 1990, 131-132.

${ }^{458}$ Al-Rawi 1992b, 183 Anm. 22.

${ }^{459}$ Gabbay 2008, 49-51.

${ }^{460}$ CT 45, 85:7 (o.D.) und hier Kapitel 9.6.2.5.

${ }^{461} \mathrm{CAD}$ K 529. Auffällig sind auch die $\mathrm{aB}$ Schreibungen mit g-Anlaut in galamāhum und GA.LA- $u_{2}$-tam 2 s. hier Kapitel 6.1.

${ }^{462}$ Al-Rawi 1992b, 183 ,..., the castrato voice explaining how men and women could hold the same office"; s. a. Edzard 2003, 171.

${ }^{463}$ Falkenstein/von Soden 1953, 29.

${ }^{464}$ Gegen Gelb 1975, 68. Hartmann 1960, 132, 165 zur gala-Priesterin Nin-e 2 -bala $\tilde{g}-i_{3}-$ $\mathrm{du}_{10}$, die zu den „Schweinemästern“ gezählt wird; Schretter 1990, 132 gegen Gelb 1975, 70-71; Al-Rawi 1992b, 183; Selz 1994, 205-206 unter dem Tempelpersonal der Nanše; Henshaw 1994, 89-90.

${ }^{465}$ Al-Rawi 1992b, 185. Nach Angabe von Al-Rawi 1992b, 181 lagen die zwei Briefe in einem etwa $13 \mathrm{~cm}$ hohen Keramikkrug, der in Schicht II geborgen wurde. Auch wenn nach AlRawi 1992b, 180-181 die Schichten I-V der altbabylonischen Zeit angehören, favorisiert dieser eine Datierung in die späte Akkadzeit; vgl. Al-Rawi 1992b, 181 Fig. 5. Nach Black 1991, 
berichten von einer Frau, die zugleich ein gala- wie auch ein nar-Amt innehatte. Mit Ausnahme dieser Briefe sprechen sonst alle in dieser Arbeit behandelten Texte aus dem babylonischen Raum desselben Jahrtausends den gala als männlich an.

Dass die Lieder dieses Priesters ursprünglich von Frauen vorgetragen wurden, wie von Falkenstein und später Cooper angenommen, ${ }^{466}$ könnte am deutlichsten in der Erhebung der Inana beschrieben sein. Um das Herz ihrer Göttin Inana zu besänftigen, führt Enḩeduana neben Räucherungen und Reinigungsriten auch den Vortrag ihres Liedes an: ${ }^{467}$

T 36: Erhebung der Inana (Inana B) 138-142

„Was dir zur Mitternacht gesagt wurde, soll der gala dir zur Mittagszeit wiederholen:

'Wegen deines gepackten Gatten, wegen deines gepackten Schützlings

ist dein Zorn groß geworden, hat sich dein Herz nicht beruhigt.'“

139. ni $\tilde{g}_{2} \quad \tilde{g} i_{6}-u_{3}-n a m a-r a(-a n)-d u g_{4}-g a-a m_{3}$

140. gala-e an-bar $7-k$ a šu hu-mu-ra-ab-gi $i_{4}-g i_{4}$

141. dam dab $b_{5}-b a-z a-k e_{4}-e s ̌ ~ d u m u ~ d a b_{5}-b a-z a-k e_{4}-e \breve{s}$

142. $\mathrm{ib}_{2}-\mathrm{ba}-\mathrm{zu} i \mathrm{~b}_{2}-\mathrm{gu}-\mathrm{ul} \mathrm{s̆a}_{3}-\mathrm{zu}$ nu-te-en-te-en ${ }^{468}$

Hiernach sollte die als Klage formulierte Dichtung der Enheduana täglich von einem gala wiederholt werden.

Dass die Gattung der Klage allerdings nicht gänzlich an den gala abgegeben wurde, zeigen die altbabylonisch überlieferten Texte der amerakütum „Kunst der Klagefrau“. Es ist anzunehmen, dass die Wirkungsbereiche dieser zwei Vokalisten deutlich unterschieden wurden, möglicherweise über die Vortragsform oder den Kontext.

Keine Zweifel bestehen an der Existenz von Hermaphroditen im Alten Orient überhaupt, ${ }^{469}$ und auch Kastraten und Eunuchen werden wohl als Musiker am Palast eingesetzt worden sein. ${ }^{470}$ Was allerdings die Zeugungsunfähigkeit von gala und gala-mah betrifft, so wurde für die altbabylonische Zeit bereits

26 Anm. 32 sind beide Texte jedoch aufgrund orthographischer Kriterien an den Beginn des

2. Jt. zu datieren; so auch Sallaberger 1994, 541.

${ }^{466}$ Cooper 2006b, 41-45 mit ausführlicher Diskussion zahlreicher Belege.

${ }^{467}$ Zgoll 1997, 430:140, 441, ibid. 115-117 mit 116 Anm. 486.

${ }^{468}$ Zgoll 1997, 14-15; s. a. ETCSL 4.07.2.

${ }^{469}$ Hermaphroditen sind ein weitaus häufiger auftretendes Phänomen als allgemein angenommen; allein in Deutschland sind für das Jahr 2007 8000-10000 Fälle bekannt; s. B. Brandt und B. Supp „Und Gott schuf das dritte Geschlecht“, Spiegel Heft 47 (2007) 108-114.

${ }^{470}$ Vgl. die Diskussion um die Figur des Ur-Nanše aus Mari zuletzt bei Cohen 2005, 54-55; s. a. Ziegler 2007, 16-17, 175. 
mehrfach darauf hingewiesen, dass diese Priester häufig verheiratet und auch Väter zahlreicher Kinder waren. ${ }^{471}$ Zwar legen einige Belege nahe, dass sie ihre Zöglinge zuweilen in ihrem Haus aufnahmen und möglicherweise auch adoptierten, um sie in ihrem Priesterberuf zu unterweisen, ${ }^{472}$ doch beruhen wohl kaum alle gala-Familien dieser Zeit auf Adoptionen. ${ }^{473}$

Abschließend ist festzuhalten, dass die besonderen Merkmale des gala in der altbabylonischen Literatur ausschließlich über sein musikalisches Repertoire und seine Verbindung zur Göttin Inana definiert werden. Hier sticht vor allem seine Rolle als Grenzgänger und Mittler hervor. Diese Fähigkeiten stehen in engem Zusammenhang zu seinem Gesang im Emesal, einer möglicherweise bevorzugt bei der Hinwendung zum Göttlichen gewählten Vortragssprache, die eventuell auch besonders hoch intoniert wurde. Es bleibt ganz im Tenor früherer Darlegungen des Themas nochmals zu betonen, dass das Bild vom Wesen des gala und die Inhalte des gleichnamigen Amtes über die Jahrtausende altorientalischer Geschichte ständigen Veränderungen unterlagen, die sich sicherlich auch in der Bedeutung des Wortes selbst niederschlugen. Für den untersuchten Zeitraum lässt sich jedoch keine Bestätigung der Annahme eines veränderten Geschlechts oder Genders des gala feststellen.

\subsection{5 'Transformation' und 'Übergang': Ein Ausblick zum Ritus des gala}

Das folgende Kapitel dient in erster Linie dazu, die zum Handlungsbereich des gala aus literarischen Texten und Alltagsdokumenten erbrachten Daten zusammenzuführen. Auf diesem Hintergrund wird der Versuch einer Ausdeutung seiner wesentlichen Funktion im Ritus unternommen. Hierbei wird auch auf Ergebnisse zurückgegriffen, die aus der Untersuchung von Teil II resultieren.

In mythologischer Hinsicht ist die Verbindung des gala zur Göttin Inana markant, die aus literarischen Texten, einem Bala g̃-Lied zu seiner Erschaffung und Sprichwörtern ersichtlich wird. ${ }^{474}$ Die Dichtung Inana und Ebih zählt ihn neben anderen Kultstatisten auf, dem kur-g̃ar-ra und pi-li-pi-li, ${ }^{475}$ die sich alle durch die Überwindung von Grenzen und die Kommunikation mit dem

\footnotetext{
${ }^{471}$ Krecher 1966, 36 + Anm. 99; Renger 1969, 192-193; Schretter 1990, 133-134; Henshaw 1994, 88, 126 Anm. 22; s. a. Van Lerberghe/Voet 1997, 150 zur Familie des Ur-Utu.

${ }^{472}$ So der Brief aus dem Archiv des Ur-Nininsina IB 1541 (Wilcke 1985a, 189-190) und Aussagen über die Söhne des gala-mah Inana-mansum in Sippar Amnānum; hierzu Gabbay 2008, 53-54.

${ }^{473}$ Al-Rawi 1992b, 183 deutet seinem Argument zur hohen Stimme nachgehend diese Berufsvertreter als Countertenöre im Gegensatz zu den kinderlosen Kastraten.

${ }^{474}$ S. Kapitel 6.3.1 und 6.3.3.

${ }^{475}$ Inana und Ebih 173-175 (ETCSL 1.3.2); Attinger 1998, 180-181; ähnlich im Bala g̃-Lied Uru-ama 'irabi 16/17-17/19; Volk 1989, 29.
} 
Göttlichen auszeichnen. ${ }^{476}$ Während das Kommunikationsmittel von kurgarrû und assinnu(/pilipili/) die Ekstase ist, ob durch Selbstmutilation oder wilden Tanz, sind es beim gala seine Instrumente und die dazugehörige Musik.

Die mythologische Zuordnung dieser Kultspezialisten zur Inana lässt sich auf ihre Rolle als Göttin der Verwandlung, der Gegensätze und Grenzüberschreitungen zurückführen. ${ }^{477}$ Sie vertritt Hochzeit, Tod und Wiedergeburt als Göttin der Liebe, Fruchtbarkeit und Zerstörung. ${ }^{478}$ In Inana und Enki wird diese ihre Fähigkeit zur Umwandlung von Freude zu Trauer mit dem Klang von Musikinstrumenten assoziiert. Hier wird das šem $\mathrm{s}_{3}$ der Klage dem hymnischen Kontext von Tigi und Adab gegenübergestellt. Dementspechend sind auch die ihr zugeordneten, im Mythos sogar von ihr eingesetzten Kultakteure auf verschiedene Arten der Transformation spezialisiert, seien diese über den Zustand der Ekstase und Grenzüberschreitung oder über ihr äußeres Erscheinungsbild realisiert. ${ }^{479}$

Die wichtigste Funktion des gala, wie sie in der Literatur dargestellt wird, liegt in der Besänftigung der Götterherzen, um drohendes Übel abzuwenden. Hierbei half ihm der Gesang seiner Klagen, mit dem er auf die Gemüter der Götter Einfluss nehmen konnte. Der Schwerpunkt seines Wirkungsbereichs wird damit auf die Kommunikation gelegt, in deren Verlauf er die Grenze zum Göttlichen überschreitet. Er nimmt damit primär die Rolle eines Mittlers ein. ${ }^{480}$ Seinem Gesang unter Begleitung von perkussiven Klängen wird eine 'therapeutische' Wirkung beigemessen, die in Form einer 'Umschmeichelung' oder 'Mitleidsbekundung' eine Besänftigung erzielt. Am trefflichsten wird dies für Ereškigal in Inanas Gang in die Unterwelt dargestellt. ${ }^{481}$

Für den gala lässt sich ein Handeln im offiziellen wie auch im privaten Ritus ausmachen. Hier bleibt sein Wirken nicht auf den Dienst an Inana beschränkt. Alltagsdokumente belegen bekanntlich für ihn Aktivitäten an Tempeln männlicher wie auch weiblicher Gottheiten.

Anlässe im offiziellen Kultgeschehen sind nach Ur III-zeitlichen und altbabylonischen Daten zusammenfassend als Götterreisen oder Umzüge zu definieren. ${ }^{482}$ Hierbei kann es sich um Stadtumrundungen handeln, in deren Verlauf mehrere Tempeltore angelaufen wurden. Daneben begleiteten gala auch den 'Eintritt' einer Gottheit, wobei der Zielort nicht immer klar ersichtlich ist. In

\footnotetext{
${ }^{476}$ Maul 1992, 159-171; Groneberg 1997a, 152-154.

${ }^{477}$ So Pientka-Hinz 2009 zu Inanas Gang in die Unterwelt (private Kommunikation).

${ }^{478}$ Vgl. Cooper 2006b, 43-44 zum Bezug zwischen Hochzeit und Totenkult.

${ }^{479}$ Vgl. Maul 1992 ausführlich zu den Travestien von kurgarrû und assinnu.

${ }^{480}$ Ausführlich Shehata 2008.

${ }^{481}$ Hier Kapitel 6.3.1.

${ }^{482}$ Sallaberger 1993, 149-150 und hier Kapitel 9.6.3.3 und 9.6.3.4.
} 
diesem Zusammenhang sind auch die wohl regelmäßig stattfindenden Umzüge von Balag̃-Gottheiten zu nennen, die vom gala-mah begleitet wurden. ${ }^{483}$ Diese in seine Fürsorge übergebenen Gottheiten können letzten Endes als Personifizierung des religiösen Konzepts angesehen werden, über musikalische Mittel den Göttern beratend und besänftigend zur Seite zu stehen. ${ }^{484}$ Es bleibt die Frage bestehen, ob es sich bei diesen Objekten um vergöttlichte Musikinstrumente oder um anthropomorphe Götterbilder handelt. Rituale des ersten Jahrtausends bezeugen den liturgischen Vortrag der gala zu Bautätigkeiten, sei es eine Tempel- oder Kultbildrestaurierung, zu Mondfinsternissen, zu rituellen Reinigungen und zu Königsritualen auch zur Abwehr von Feinden. ${ }^{485}$

Dass auch zur altbabylonischen Zeit die rituellen Pflichten eines gala im offiziellen Kult den König integrierten, lässt sich über die Inhalte der ihm zugeordneten Liedgattungen rekonstruieren. So handeln die Širnamgala vornehmlich von der Erhöhung des Königs und seine Einführung vor eine meist weibliche Gottheit. ${ }^{486}$ In Širnamšub werden auch Baderiten für die Götter angesprochen. ${ }^{487}$

Wie schon von Ambos für die Baurituale des gala aus dem ersten Jahrtausend postuliert, ${ }^{488}$ so sind auch alle übrigen Anlässe, an denen dieser Priester zum Einsatz kam, 'Übegangsriten', bei denen eine rituelle 'Transformation' stattfand. ${ }^{489}$ Die Teilnahme des gala begründet sich in seiner besonderen Fähigkeit, in diesen instabilen und Gefahr androhenden Situationen den Schutz der Beteiligten und die Besänftigung der Götter zu sichern.

Dass sich seine kultische Tätigkeit hierbei nicht auf den Vortrag von Gesängen beschränkte, geht vornehmlich aus Alltagsdokumenten hervor. So nennt die Opferrationenliste CM 33, 158ff.(=HUCA 34, 1ff.) aus Larsa gala, die Räucherungen durchführten. Die Ausführung ritueller Schlachtungen, insbesondere für die kultische Pflege des bala g̃-Instruments ist vornehmlich Ur IIIzeitlich belegt. ${ }^{490}$ Für das altbabylonische Kiš sind Tierlieferungen bezeugt, die möglicherweise auf entsprechende Opferhandlungen des gala-mah hinwei-

\footnotetext{
${ }^{483}$ Sallaberger 1993, 297-298; Heimpel 1998. Dass der gala-mah eine wichtige Position in der Versorgung dieser Gottheiten einnahm, ist auch altbabylonisch belegt; s. hier Kapitel 9.4.4.

${ }^{484}$ S. Shehata 2010.

${ }^{485} \mathrm{Zu}$ den Ritualen des gala in seleukidischer Zeit s. Linssen 2004, 16-18, 96-117; zu den nA Bauritualen Ambos 2003, 50-61; zum Sitz der Eršahug g̃a Maul 1988, 25-56; s. zusammenfassend zu den Kultanlässen des gala Löhnert 2008, 427.

${ }^{486}$ Auch in der akkadischsprachigen Bēlet-ilī-Hymne HS 1884 könnte eine Einführung beschrieben sein; s. hier Kapitel 13.1.5.2.

${ }^{487}$ S. hier Kapitel 12.2.4.

${ }^{488}$ Ambos 2003, 45-61.

${ }^{489} \mathrm{Im}$ Überblick Lang 1998 zu Gennep $2005^{3}$ und Wallace 1966.

${ }^{490}$ Sallaberger 1993, 220, 297-298.
} 
sen. ${ }^{491}$ Auch Libationen wurden unter der Aufsicht oder im Beisein von gala ausgeführt, was möglicherweise im Širnamšub Utu $E$ angedeutet wird.

Dass die Fähigkeiten dieses Priesters auch im privaten Bereich gefragt waren, belegen zunächst Alltagsdokumente. Am besten bezeugt ist dies für Bestattungszeremonien. Reichhaltig ist hier die Beleglage früherer Epochen, wonach gala auch häufig neben der Klagefrau (ama-er ${ }_{2}-\mathrm{ra}$ ) auftraten. ${ }^{492}$ Die Ausführung von 'Fürbittegebeten' (takribtum) durch gala für eine Privatperson könnte altbabylonisch in einer Ausgabenliste dokumentiert sein. ${ }^{493}$ In einer altbabylonischem Hymne an Utu/Šamaš, die nicht eindeutig dem Kontext einer staatlichen oder privaten Bestattungszeremonie zugeordnet werden kann, ${ }^{494}$ wird der Übergang des Toten vom Diesseits ins Jenseits mit einem Vortrag des gala begleitet, der sich wohl aus Gründen der Besänftigung an den Richterund Sonnengott Utu/Šamaš richtet. Unter den aus Sippar bekannten parșum, die im Verantwortungsbereich des gala-mah lagen, ist auch eine Kulthandlung mit Namen muqabbirūtum belegt, die auf einen Dienst bei Totenzeremonien bezogen werden kann.

Über diese parșum liegt schließlich der Nachweis vor, dass der gala-mah auch Rituale begleitete, die religiöse Aufgaben oder Positionen einer Privatperson betrafen und die von ihnen einmalig in ihrem Leben ausgeführt bzw. eingenommen wurden. Sie könnten als 'Lebenszyklus' oder auch 'Inaugurationsrituale' zu identifizieren sein, die aber offensichtlich einem engen Kreis der Elite vorbehalten waren. Auch wenn der Inhalt dieser Rituale nicht rekonstruierbar ist, so reichen sie weit über die bisher für diesen Priesterberuf zusammengetragenen Handlungsbereiche hinaus.

Auffällig in Alltagsdokumenten ist außerdem seine Verbindung zu verschiedenen Frauengruppen und Priesterinnen, der harimtum, der kezertum, der kulmašitum aber auch der nadìtum und qadištum. ${ }^{495}$ Insbesondere die harimtum und kezertum genossen den besonderen Schutz der Inana/Ištar und ihrer Manifestationen, worin sich ihre Mitwirkung an Kulthandlungen für diese Göttin

${ }^{491}$ Ähnliches könnte für die zwei Bullen für den gala-mah Marduk-muballiṭ von Sippar in AbB 11,93 vermutet werden.

${ }^{492}$ S. hierzu Kapitel 7.4.

${ }^{493}$ TCL 10, 123: 4-5 (D.a.); vielleicht auch im Brief AbB 9, 51 mit der Entlohnung von gala im Zusammenhang mit taqrïbatum. Es bleibt allerdings unklar, ob die gala selbst oder die im Brief angesprochene Gruppe von Frauen diese auszuführen hatte. taq/kribtum sind altbabylonisch vor allem für Mari zwar zahlreich belegt, dort jedoch meist als allgemeiner Verweis auf die Ausführung von Opferhandlungen zu werten; vgl. Belege in CAD T 200 sub 2'; so wohl auch AbB 6, 22, wo die Absenderin über ein Gewand der Adressatin Bēltani ein Fürbitteopfer auszuführen ankündigt.

${ }^{494}$ Cohen 1977, 10, 12:65. gala di-ku ${ }_{5}$-dig̃ir-re-e-ne-ke ${ }_{4}$ gu $_{3}$ mu-un- ${ }^{\ulcorner n a-d e}{ }_{2}{ }^{7}$ „Der gala ruft den Richter der Götter (Utu) an“.

${ }^{495}$ Cooper 2006b, 45 zum gala-mah Inana-mansum, der mit der qadištum Ilša-hyeg̃alli verheiratet war und frühdynastisch Visicato 1995, 105-107 mit qadištum-Frauen in der Obhut des gala-mah. Zu den Aufgaben der qadištum s. Stol 2000, 173, 186-188. 
begründet. Gruppen von qadištum, die altbabylonisch für Ammen- und Hebammendienste belegt sind, beteiligten sich im ersten Jahrtausend auch an Götterprozessionen, in deren Verlauf sie an verschiedenen Stationen inhuGesänge vortrugen. ${ }^{496}$ Literarisch sticht in diesem Zusammenhang auch das Klagen der Kreißenden im Geburtsvorgang hervor. ${ }^{497}$

Weiterführend könnte insgesamt für den gala aufgrund seiner Nähe zu weiblichen Göttinnen und Frauen eine Rolle bei 'Frauenriten' angenommen werden. So beschreibt das Liebeslied Dumuzi-Inana $P{ }^{498}$ wie ein gala seine Göttin Inana bei ihren Hochzeitsvorbereitungen, also ihrer 'Verwandlung' zur Braut und Gattin, begleitet. ${ }^{499}$ Der Fund einer Liebesbeschwörung im Umfeld eines gala-mah-Archivs in Isin weist unmissverständlich auf eine rituelle Praxis in diesem Bereich hin, die sich in diesem Fall allerdings auf die Abwehr und den Bann einer 'feindseligen' Liebe konzentriert. ${ }^{500} \mathrm{Ob}$ die harimtum unter der Aufsicht des gala-mah oder auch die Kulthandlung harimūtum, die vornehmlich von Männern ausgeführt wurde, einem sexuellen Kontext zuzuordnen sind, etwa in Form einer Initiation oder Reifewerdung, lässt sich aufgrund der spärlichen Quellenaussagen nicht entscheiden. Insgesamt bleibt aber das Wirken dieses Priesters bei Frauen spezifischen Akten markant. Zwar wäre es zu weit spekuliert und zudem unbelegbar, den gala angesichts seiner Nähe zur qadištum auch dem Kontext der Geburt zuzuordnen, ${ }^{501}$ dennoch lässt sich meines Erachtens auch in privatem Rahmen auf der Basis der hier vorgestellten Einzelphänomene für ihn eine wichtige Rolle bei Riten aus Anlass einer 'Transformation' oder eines 'Übergangs' feststellen, bei denen er in erster Linie auch im magischen Sinne für die Abwehr möglicher Gefahren sorgte.

Seine in der Mythologie beschriebene Fähigkeit, Grenzen zu überschreiten und mit den Göttern zu kommunizieren definiert seine Aufgaben nicht nur im Bereich von Götterkulten, sondern auch im Rahmen individueller Rituale für Einzelpersonen. Dem Wesen seiner Göttin der Verwandlung zur Seite gestellt war er dafür prädestiniert, 'Übergangsriten' unterschiedlicher Art zu begleiten,

\footnotetext{
${ }^{496}$ KAR 154 bei Menzel 1981/II, T 2-4.

${ }^{497}$ Die Gefahren einer Geburt sind im nA Klagelied BA 2, 634 einer Gebärenden, die dem Tode nahe ist, verbildlicht; vgl. Hecker 1989, 780-781. Klageschreie der Kreißenden begleiten schließlich den Vorgang der Geburt selbst; vgl. Enki und Ninhursag̃ 186 (ETCSL 1.1.1) zur gebärenden Uttu und dazu Stol 2000 136-137; gleich einer Gebärenden klagt auch Ereškigal in Inanas Gang in die Unterwelt 231-239/258-266 (ETCSL 1.4.1; Sladek 1974, 171-173), worauf ihr gala-tur(-ra) und kur-g̃ar(-ra) besänftigend antworten.

${ }^{498}$ S. hier Kapitel 6.3.2.2.

${ }^{499}$ Vgl. in diesem Zusammenhang Wilcke 1985b, 267-284 zu Hochzeit und begleitenden rituellen Akten; vom Beisein eines gala ist allerdings nirgends die Rede.

${ }^{500}$ Wilcke 1985a, 188-209; dazu auch Groneberg 2007.

501 Der im Brief AbB 9, 166 genannte 'Lehmklumpen', der in die Hand eines gala-mah gegeben wurde, bezieht sich wohl auf einen Vertragsabschluss und nicht auf Geburtsriten.
} 
ob diese nun Götter oder Menschen betrafen. Kultbildrestaurierung, Baderitus oder Bestattung, möglicherweise auch Amtseinführungen und Initiation des Einzelnen, stellen den Wechsel eines Zustandes in den nächsten dar und sind damit Anlässe, in denen ein besonderer Schutz erforderlich ist. Diesen sicherte der gala mithilfe seiner besonderen Fähigkeiten, die bei der Ausführung von Opfern vor allem im Vortrag von Gebeten, Beschwörungen und Fürbitteklagen zur Geltung kamen. ${ }^{502}$

Das Handlungsspektrum des gala, wie es in Alltagsdokumenten und literarischen Texten der altbabylonischen Zeit zum Ausdruck kommt, deutet auf eine Vielfalt an rituellen Kontexten hin, als es bislang angenommen wurde. Zwar bleibt die hierzu erbrachte Beleglage noch sehr dürftig, hier könnten jedoch eingängige diachrone Untersuchungen $\mathrm{zu}$ diesem Priesterstand auch unter Berücksichtigung seiner Ritualphänomenologie interessante und weiterführende Daten liefern.

${ }^{502}$ Unklar bleiben beispielsweise die im Brief AbB 10, 124 (H.u.) 5-12 genannten Vögel des gala-mah im Austausch gegen Vögel aus dem Tempel der Ištar von Lagaba, die möglicherweise für Riten verwendet wurden; zu Vogelriten s. Groneberg 1997a, 147-148 mit weiteren Belegen. 


\section{4 balag̃-di und verwandte Termini}

Das Kompositum balag̃-di kann wie zahlreiche Termini aus dem Bereich der Musik mehrere Bedeutungen annehmen. Während es in den frühen Epochen im dritten und zweiten Jahrtausend den Sänger und Instrumentalisten balag̃-di, wörtlich ,,(der) das balag̃ 'spricht'/'spielt'(?)“', bezeichnet, ${ }^{503}$ wird es in lexikalischen Listen und Bilinguen des ersten Jahrtausends auch als Name eines Musikinstruments geführt und akkadisch timbuttum „Harfe(?)“ oder telìtum entsprochen. ${ }^{504}$ Schließlich wird es als akkadisch sirh $u$ auch als allgemeine Bezeichnung für „Klage“ oder „Gesang“ aufgefasst. ${ }^{505}$

Das vorliegende Kapitel beschränkt sich auf den Musiker balag̃-di, der allerdings entgegen der reichhaltigen Beleglage zu nar und gala für die altbabylonische Zeit ausschließlich aus literarischen Texten und lexikalischen Listen bekannt ist. In Alltagsdokumenten, Urkunden und Rationenlisten ist er bislang lediglich im dritten Jahrtausend attestiert. ${ }^{506}$ Für die Zeit der Sargoniden sowie der nachfolgenden Ur III-Könige sind es vor allem Frauen, die als Vertreter dieses Berufszweigs auftreten, einmalig ist in einer Urkunde mit Ausgaben verschiedener Art von einem „Haus der balag̃-di-Frauen“ die Rede. ${ }^{507}$

${ }^{503}$ PSD B 79b sub balag-di B „lyre player“, „lamentation singer“, und „mourner“; s. a. Krecher 1966, 162 „'Klagesänger' von Haus aus wohl allgemein 'Harfenmusikant'“; dementsprechend Attinger 1993, 451-453, ,joueur de 'b.'“. In zweisprachigen Bala g̃ -Liedern des 1. Jt. akk. ša șirhi „,derjenige des Klagegesangs“; Cohen 1988, 54:85; s. a. Henshaw 1994, $105-$ 106.

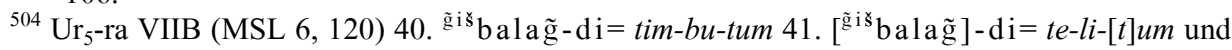
im Examenstext A 28 (Sjöberg 1974, 144); dementsprechend aB Lu 2 -Azlag A (MSL 12, 165) 250. $1 \mathrm{u}_{2}$ bala $\tilde{g}-\mathrm{di}-\mathrm{da}=\check{s} a t[$ imbuttim $]$,derjenige des timbuttum-Instruments“; s. a. aB $\mathrm{Lu}_{2}$-Azlag A (MSL 12, 165) 251. dub $\mathrm{b}_{2}-\mathrm{dub}_{2}-\mathrm{di}=\check{\text { sa }}$ [telitim? $]$; vgl. Attinger 1993, 452. In ${ }_{\mathrm{gi}} \mathrm{i}-\mathrm{lu}$-bala $\tilde{\mathrm{g}}-\mathrm{di}=$ kiss/tur(r)atu als Rohrinstrument; s. Izi V 48 (MSL 13, 162); CAD K 433; CAD T 329, 417.

505 CAD S 205-206; vornehmlich in Balag̃-Liedern; Cohen 1988, 224:a+11, 429:a+2, 570:c+277 mit șirhu $u^{\tilde{g} i s ̌ b}$ bala g̃ als „Klage des balag̃-Instruments(?)“; s. a. hier Anm. 447. Die Gleichsetzung von bala g̃ -di mit șirhu „Klagegesang“ wird als sekundär angesehen; Volk 1989, 109:38; Attinger 1993, 453 §306; vgl. aber in diesem Zusammenhang auch in einem aB Mari-Ritual bei Durand/Guichard 1997, 71:3 [a-na $\left.{ }^{\mathrm{d}} \mathrm{Ut}\right] \mathrm{u} e-n u$ bala g̃ $+\mathrm{di} i-z a-m u-$ [ur] „,c'est le grand prêtre qui chante la lamentation pour Šamaš“.

${ }^{506}$ Fara-zeitliche, sargonische und Ur III-zeitliche Belege in PSD B 79b und bei Attinger 1993, 452; s. a. Hartmann 1960, 124 Anm. 4.

${ }^{507}$ Westenholz 1974/77, 110 Anm. 32 in AnOr 7:372 ii 2'-4' (nach Koll.) und 9'; s. a. MAD 1, 336:17. 
Bedeutendste Vertreterin dieses Musikerberufes ist die Prinzessin Lipuš-Jā'um, Enkelin des Naram-Suen von Akkade, die auf einer königlichen Inschrift aus G̃irsu als balag̃-di des Gottes Sîn tituliert wird. ${ }^{508}$ Demzufolge konnten bala g̃-di-Musiker wie auch gala und nar im Dienste einer Gottheit stehen.

In literarischen Texten der altbabylonischen Zeit treten schließlich auch männliche balag̃-di in Erscheinung. Ähnlich dem gala liegt ihre Aufgabe hauptsächlich im Vortrag von Klagegesängen, die in aller Regel zerstörten Tempeln und sich abwendenden Göttern gelten. ${ }^{509}$

Eine besondere Form der musikalischen Interaktion zwischen einem bala g̃ di und einer Gottheit findet sich in einer bereits altbabylonisch überlieferten Inana-Klage beschrieben. ${ }^{510}$ In dieser Komposition tritt der bala g̃-di auf, an den sich die Göttin Inana zu Beginn des Liedes in verzweifeltem Zustand wendet: Sie beklagt den Einfall eines unbekannten Feindes und ihre hierauf folgende Flucht aus ihren Tempeln und ihrer Stadt. Auf diese Klage der Göttin antwortet ihr der zu Beginn des Liedes angerufene bala $\tilde{g}$-di in gleichermaßen anklagendem Ton:

\section{T 37: Klage Inanas von Unug 41-46 \\ „(balag̃ -di): So hast du ihn zerstört, so hast du ihn gänzlich zerstört, so hast du selbst ihn gedemütigt; \\ Herrin, so hast du deinen Kultraum (gänzlich) zerstört, so hast du selbst ihn ge- demütigt, so hast du selbst ihn dem Feinde ausgeliefert. \\ Herrin, so <hast du ihn $>$ dem Feinde < ausgeliefert $>$ !'; \\ (Inana): 'Ich habe ihn nicht selbst gedemütigt, mein Vater hat ihn gedemütigt, der Herr, der große An, hat ihn gedemütigt, mein Vater $<$ hat ihn gedemütigt $>$ ...6511}

Eine derartige Interaktion zwischen bala g̃ -di und Inana in einem Klagelied ist in dieser Form nicht nur einmalig, sie positioniert den Musiker gleichzeitig als einen der Göttin gleichgestellten Kommunikationspartner. Am ehesten vergleichbar ist eine Passage im Liebeslied Dumuzi-Inana $P$, wo ein gala auf den Gesang der Göttin im Lied antwortet. ${ }^{512}$

\footnotetext{
${ }^{508}$ Frayne 1993, 159-160 = RIME 2.1.4.54:6. li-pu-uš-ia $a_{3}-a-u m$ 7. balag̃-di 8. ${ }^{\mathrm{d}}$ EN.ZU 9. dumu-munus-su ,Līpuš-iä'um, the lyre player of the god Sîn (is) his daughter“; schon bei Hartmann 1960, 124.

${ }^{509}$ Nippur Klage 40-41 (ETCSL 2.2.4); Ur-Namma A 194 (ETCSL 2.4.1.1); s. a. Krecher 1966, 56, 68: III 25ff. und Attinger 1993, 451-452 (\$304).

${ }^{510}$ Bearbeitet bei Römer 1983, 566-592.

511 Übersetzung nach Römer 1983, 574; die direkte Rede des balag̃-di wird im Text nicht angezeigt, erschließt sich jedoch aus der Ansprache der Göttin nach ihrer vorausgehenden und nachfolgenden Rede.

${ }^{512}$ S. hier Kapitel 6.3.2.2.
} 
Die im Gesang vorgetragene Klage eines balag̃-di an die Gottheit kann auch menschliches, sehr persönliches Leid beinhalten. In diesem Sinne tritt in der Klage Ein Mann und sein Gott die Schwester für ihren klagenden Bruder ein, um das von ihm Erlebte seinem persönlichen Gott mitzuteilen:

\section{T 38: Ein Mann und sein Gott 65-66}

„Möge meine Schwester, fürwahr eine bala g̃ -di mit süßer Stimme, das, was mich ruinierte, dir (meinem Gott) in einer Klage mitteilen.“

65. $\operatorname{nin}_{9}-\tilde{g}_{10}$ balag̃ di ad dug na- $^{\top}$ nam? ${ }^{1}$

66. ni $\tilde{g}_{2}$ ak šu hul dug $g_{4}-g a-\tilde{g} u_{10}$ er $_{2}-r a$ ha-ra-ni-ib-be ${ }_{2}^{513}$

In den einleitenden Zeilen derselben Dichtung wird die balag̃-di konkret aufgefordert, die Herzen zu besänftigen, worin eine Parallele zu den Funktionen des gala vorliegt. ${ }^{514}$ Die Komposition weist nach einer g̃išgig̃al-Rubrik die Unterschrift er $_{2}$-ša $a_{3}-n e-s ̌ a_{4}$ dig̃ir $1 u_{2}-u l u_{3}-k a m$ „Fürbitteklage für den Gott eines Mannes“" auf. ${ }^{515}$ In der oben behandelten Erschaffung des gala werden mit dem Ausdruck er ${ }_{2}-\check{s ̆}_{3}-n e-\check{s}_{4}$ die Klagen dieses Priesters bezeichnet. ${ }^{516}$

Insgesamt wird deutlich, dass sich die Wirkungsbereiche von balag̃-di und gala in vielerlei Hinsicht überschneiden. Dies veranlasste Krecher im Wort balag̃-di eine Anredeform für den Sänger in Emesalliedern zu vermuten. ${ }^{517}$ Die Beleglage für das dritte Jahrtausend zeigt dennoch, dass hier zwei eigenständige Musikerberufe bestehen, wobei der Berufszweig eines balag̃-di im Gegensatz zum Priesterstand eines gala wohl vermehrt von Frauen ausgeübt wurde. Unterschiede könnten möglicherweise in der musikalischen Auffüh-

\footnotetext{
${ }^{513} \mathrm{Vgl}$. ETCSL 5.2.4.
}

${ }^{514}$ Ein Mann und sein Gott (ETCSL 5.2.4) 4-5 „May the bala g singer assuage the spirit of his neighbour and friend. May it soothe their (?) hearts,.. ." 4. ${ }^{\tilde{g} i s ̌ s} \mathrm{balag}$ di ušar gu $\mathrm{gu}_{5}-\mathrm{li}-\mathrm{ni}$

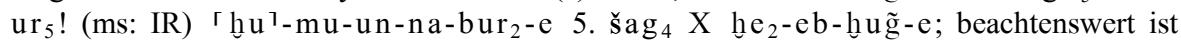
hier die Schreibung mit Determinativ g̃ iš, womit auf das Spiel des bala g̃ Bezug genommen wird. S. a. im Balag̃ -Lied Uru-ama 'irabi 38. eine nicht zum Text gehörige Anweisung zum Vortrag eines Liedes durch den balag̃-di: (zusammengesetzte Umschrift nach Textzeugen A und $\mathrm{H})$ 38. bala g̃-di $\check{s i r}_{3}-\mathrm{kad}_{4}-\mathrm{da}$ al- $\mathrm{x}-\mathrm{x} / /$ ina șir-hi ${ }^{\tilde{g} \mathrm{iš}} \mathrm{balag} \tilde{g} \Gamma_{z a-m a-r i\urcorner}: r i-k i-i s$ $z a-m a-r i$,Der Klagesänger (singe(?) das) Širkadda (mit dem Refrain): <'Das wegen . . . bedrückt ist'.>"; Volk 1989, 82, 91 Anm. 21, 109. Wie Volk ibid. bereits bemerkte, findet sich hier keine direkte Entsprechung des Sumerischen im Akkadischen. Das šir ${ }_{3}-\mathrm{kad}_{4}-\mathrm{da}$ ist seinem Namen nach mit $\mathrm{kad}_{4}=$ kașāru ,knoten, fügen, sammeln“ (AHw 457a; CAD K 257) wohl als 'Bann-Lied' im rituell-magischen Sinne aufzufassen; in denselben Zusammenhang könnte auch der nur lexikalisch belegte gala-keš $\check{2}_{2}$-da in nA $\mathrm{Lu}_{2}=\check{s} a$ IV 173 (MSL 12, 134) zu stellen sein; hier Kapitel 6.1.

${ }^{515}$ Ein Mann und sein Gott 145-146 (ETCSL 5.2.4).

${ }^{516}$ Kramer 1981, 3, 5:22 und hier Kapitel 6.3.1.

${ }^{517}$ Krecher 1966, 38, 162. 
rungspraxis bestanden haben. So fällt für das zweite Jahrtausend auf, dass der gala auf das Spiel von Perkussiva spezialisiert war, während für den bala g̃-di mit Ausnahme des Instruments bala g̃ kein Zusammenhang zu anderen Musikinstrumenten beobachtet werden kann. Nach Ausweis literarischer Texte trat ein balag̃-di-Musiker grundsätzlich solistisch auf. gala-Musiker konnten dementgegen auch in größeren musikalischen Ensembles agieren. Der gala übte schließlich neben seiner Tätigkeit als Musiker andere priesterliche Funktionen im Rahmen größerer Götterfeste aus, wie etwa die Darbringung von Rauchopfern oder Libationen. Zu den beruflichen Tätigkeiten des bala g̃-di kann aus Mangel an Belegen keine konkrete Aussage getroffen werden.

Der balag̃-di als Berufsbezeichnung oder Titel ist den altbabylonischen Alltagsdokumenten unbekannt. Er ist einer altsumerischen und altakkadischen Tradition des Klagegesangs verhaftet, die im Zuge des ausgehenden dritten Jahrtausends einem Wandel unterlag. Seine Aufgabenbereiche im Vortrag ritueller Klagen zur Besänftigung der Götter gehen auf den gala über. Innerhalb der Klageliturgie und in lexikalischen Listen bleibt der Ausdruck gleichbedeutend mit gala bestehen, verweist hier aber auch, neue Bedeutungsfelder annehmend, auf ein Musikinstrument. Beim bala g̃-di könnte wiederum das Argument Falkensteins zum Tragen kommen, wonach die Klagen des gala ursprünglich vermehrt von Frauen vorgetragen wurden. ${ }^{518}$ Hierzu wären tiefer gehende Untersuchungen des älteren Textmaterials notwendig.

Neben balag̃ -di ist unter die Klagespezialisten noch der $\breve{s i r}_{3}$-sag̃ einzureihen, der aus wenigen literarischen Textbelegen und lexikalischen Listen bekannt ist. $^{519}$ Die altbabylonische Liste $\mathrm{Lu}_{2}$ nennt den $1 \mathrm{u}_{2}$-šir ${ }_{3}$-sa g im Anschluss an den $1 u_{2}$-balag̃ ,Mann des bala $\tilde{g}^{\prime}$ und weitere Komposita desselben Wortes, wo er ebenfalls akkadisch ša șirhi gleichgesetzt wird ${ }^{520} \mathrm{Da}$ dieser Ausdruck im Gegensatz zum bala g̃ -di nicht urkundlich belegt ist, wird er nicht als Berufsname oder Titel verwendet worden sein. Beachtenswert ist der Eingang beider Termini in die altbabylonische Götterliste TCL 15, 10, wo sie zum Kreis des Enlil gezählt werden:

\footnotetext{
${ }^{518}$ Falkenstein/von Soden 1953, 29; s. a. hier Exkurs I 6.3.4.

519 Belege bei Henshaw 1994, 108. Zu Komposita mit i-lu, die ebenfalls auf das 'Klagen' verweisen, s. hier Kapitel 11.1.2.

${ }^{520}$ MSL 12, 165: 249-253. lu $\mathrm{u}_{2}$ bala $\tilde{g} \ldots, 254.1 \mathrm{u}_{2} \mathrm{hub}_{2} 255.1 \mathrm{u}_{2} \mathrm{šir}_{3}-\mathrm{sa} \tilde{\mathrm{g}}=\check{s}[a] \check{s} e-e r-[s ̌ a-$ $n[i m]$ 256. $\operatorname{lu}_{2}$ šir $_{3}$-sa $\tilde{g}=\check{s} a$ și-ir-hii-[im]; zu šeršănum ein „Klage-/Kultlied“ s. AHw 1218a und CAD Š/2, 320b; s. a. Krecher 1966, 162.
} 
T 39: TCL 15, $10 \mathrm{i}^{521}$

38 den-lil 2

39 dnu-nam-nir

$40{ }^{\mathrm{d}}$ kur-gal

$41 \mathrm{~d}^{\mathrm{es}} \check{\mathrm{s}}_{3}$

42 d ̌sir $_{3}-\mathrm{sa} \tilde{g}$

$43{ }^{\mathrm{d}}$ bala $\tilde{g}-\mathrm{di}$

Die Aufnahme der zwei auf das Klagen spezialisierten Vokalisten bala g̃-di und $\breve{s i r}_{3}-s a \tilde{g}$ unter die Erscheinungsformen des Enlil könnte als ein Verweis auf die Verbindung des Enlil zu Klageriten zu deuten sein. ${ }^{522}$

${ }^{521}$ So die Lesung auch bei Krecher 1966, 162 ausgehend von der Gegenüberstellung von šir ${ }_{3}$ sa g̃ und bala g̃-di in LL und Bilinguen; anders Litke 1998, 39:162 als ${ }^{\text {E}} E Z E N-$ sag̃ ; so auch Richter 2004, 56-57.

${ }^{522}$ Zum aB belegten Fest der 'großen Klagen' er $_{2}$-gu-la von Nippur ohne Monatsangabe s. Richter 2004, 167. Ur III-zeitlich sind Klageriten für Nippur für den xi. Monat belegt, an denen auch gala-Priester beteiligt waren; Sallaberger 1993, 149-150. 


\section{Musizierende Frauengruppen}

\section{1 lukur / naditum}

Sumerisch lukur bezeichnet als akkadisch naditum ${ }^{523}$ eine Klasse von meist unverheirateten Frauen, die ausnahmslos männlichen Gottheiten geweiht waren und gemeinsam mit Verwandten und Bediensteten eigene Bezirke innerhalb des Tempelkomplexes ihres jeweiligen Gottes bewohnten. ${ }^{524}$ Sie sind im behandelten Korpus für Sippar, Nippur, Larsa, Dilbat und Kiš belegt, wo sie meist angesehenen höher gestellten Familien angehörten und über ein eigenes Vermögen in Form von Land und Immobilien verfügten. ${ }^{525}$

Eine Verbindung der nadìtum zur Ausübung von Musik lässt sich an einem einzigen Beleg aus Nippur aufzeigen, in dem ein bala g̃-lukur-ra, ,ein bala gू der lukur" genannt wird. ${ }^{526}$ Dieses balag̃ wurde im Ninurta-Tempel mit Getreideopfern versorgt, eine entsprechende kultische Verehrung ist altbabylonisch auch für Ur belegt. ${ }^{527}$ Da ein solches Instrument sonst von gala oder gala-mah-Priestern gespielt wurde, bleibt unklar, ob hier ein von lukur gespieltes oder lediglich bei ihnen verwahrtes und kultisch gepflegtes Instrument vorliegt. Grundsätzlich ist hier von einem kultischen Zusammenhang auszugehen, da das bala g̃ Opferausgaben erhielt. Die nadiātum sind sonst nicht als Musikerinnen attestiert.

${ }^{523}$ CAD N/1 63 aB meist über lukur angezeigt.

${ }^{524}$ Ausführlich bei Renger 1967, 149-176; vgl. Friedl 2000, 66-69. Zum gaĝि(m) meist mit „Kloster“ übersetzt s. AHw 273a dagegen neutral CAD G 10. Ausschließlich in Nippur ist für dieselbe Institution der Name ki-lukur „Ort der lukur“ überliefert; Renger 1967, 170.

${ }^{525}$ Renger 1967, 149-170; s. a. Stone 1982.

${ }^{526}$ Taf. 307 (RS 28) Rs 2; Sigrist 1984, 25, 118, 163 „harpe en lamentation (chantée par) des lukur“. Die Verbindung der lukur zum balag ist hier nicht einmalig; s. a. Ur III-zeitlich aus Umma Ausgaben des Šara-Tempels über Lederwaren und Leim/Farbe für ein großes balag̃ der lukur: UTI 4, 2849 (ŠS 2) 6.2 kuš $u_{2}$-ḩab $b_{2}$ 1/3 ma-na še-gin 3 bala g̃ lukur gal si-ga.

${ }^{527}$ In Ur: UET 3, 282 [D.a.] 21. ni $\tilde{g}_{2}-\mathrm{dab}_{5}$ bala g za[bar]); zu einzelnen namentlich belegten balag̃-Gottheiten s. a. hier Kapitel 9.2.4 und 9.4.4. 


\section{2 nu-bar / kulmašitum}

Am 'Eintrittsfest'(erib bìtim) der Annunītum von Sippar Amnānum waren nach Ausweis der Liste OLA 21, 4 (Ae 28) neben gala-mah, Gruppen von gala, nar-sa auch kulmašiātum beteiligt, was durch die Nennung eines wakil kulmašiātim (ugula nu-bar) „Aufseher der kulmašiātum“ an zweiter Stelle nach dem gala-mah zu schließen ist. ${ }^{528}$

Über die Verbindung dieser Frauengruppe zur Musik gibt bislang nur eine neuassyrische Hymne an die Stadt Arba'îl Auskunft. Sie nennt kulmašiātumFrauen, die neben instrumental musizierenden kurgarrû und assinnu inhuGesänge vortragen. ${ }^{529}$ Das Akkadische inhu „(Lied des) Seufzens“ verweist im mittelassyrischen Liederkatalog KAR 158 auf eine bestimmte Gattung von Liedern und wurde nach neuassyrischen Bauritualen von nar auch neben klagenden kalû vorgetragen, aber auch von anderem Personal der Ištar, wie assinnu und kurgarru. ${ }^{530}$

Die mit dem Wort kulmašìtum bezeichnete Frauengruppe ist für die altbabylonische Zeit nur in Sippar bezeugt. ${ }^{531}$ Solche Frauen gehörten meist angesehenen Familien an, einige unter ihnen sind gleichzeitig als nadìtum des Marduk belegt. ${ }^{532}$ Im altbabylonischen Sippar fällt ihre Nähe zur Göttin Annunītum auf. $^{53}$

Neben harimtum wird die kulmašitum aufgrund von Belegen des ersten Jahrtausends häufig mit Prostitutionsdiensten in Zusammenhang gebracht, für die altbabylonische Zeit ist ihr Wirken im kultischen Bereich anzusetzen ${ }^{534}$ Ein einziger literarischer Beleg legt außerdem eine Verbindung zum Ammentum nahe. ${ }^{535}$

Das Auftreten dieser Frauengruppe beim Eintrittsfest der Annunitum von Sippar in OLA 21, 4 (Ae 28), an dem auch ein gala-mah, eine Gruppe von gala und nar-sa teilnahmen, legt die Vermutung nahe, auch für die kulmašiātum eine musikalische Tätigkeit anzunehmen. Angesichts der Beleglage für das erste Jahrtausend könnten sie auch hier als Klagefrauen aufgetreten sein, ihre Tätigkeiten im Kult sind allerdings insgesamt unbekannt.

${ }^{528}$ OLA 21, 4 (Ae 28) Zeile 6 und hier Kapitel 9.6.3.3.

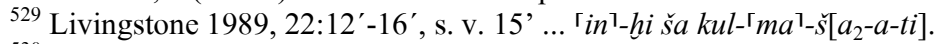

${ }^{530}$ KAR 158 iv 24; AHw 382; Groneberg 2003, 63-64; Ambos 2004, 43-44.

531 aB meist logographisch nu-bar; CAD K 526a und Henshaw 1994, 201-203 mit Belegen. Zur kulmašitum in Sippar Harris 1975, 324-328; allgemein Renger 1967, 185-187.

${ }_{532}$ Renger 1967, 186-187; Harris 1975, 324-326.

${ }^{533}$ Harris 1975, 324.

${ }^{534}$ Renger 1967, 187 mit „Bezug zum Sexuellen“; zur selben Thematik s. a. Henshaw 1994, 201 202. Zur Interpretation von Lambert 1960, 102:72-80 s. Assante 1998, 53-54 Anm. 142.

535 Sammlung sumerischer Tempelhymnen: ETCSL 4.80.1: 390. nu-bar-ra ubur 7 si $\mathrm{sa}_{2}$ $\mathrm{sa}_{2}$-e „Du (Ninisina) lässt die sieben Brüste für die nu-bar fließen“; s. a. Renger 1967, 187. 


\section{3 harimtum und kezertum}

Sowohl die harimātum als auch die kezrētum wurden in der bisherigen Forschungsliteratur als Prostituierte gedeutet oder zumindest mit Prostitutionsdiensten in Zusammenhang gebracht. ${ }^{536}$ Aus altbabylonischen Urkunden, Briefen und Listen der Städte Sippar, Kiš und Mari wird dementgegen vor allem bekannt, dass diese Frauen bei Götterfesten, insbesondere weiblicher Gottheiten mitwirkten.

Die Personenliste CT 4, 15c (o.D.) aus Sippar nennt eine Gruppe von harimtum-Frauen, die dem gala-mah unterstellt (ni $\tilde{g}_{2}$-šu) war. ${ }^{537}$ Die Liste führt insgesamt elf Frauennamen auf, darunter auch Töchter, denen jeweils eine bis zu drei harimtum-Frauen zugeteilt sind. Insgesamt werden 21 harimtum-Frauen auf die elf namentlich genannten Frauen verteilt.

In Sippar ist weiterhin ein parșum-Ritual mit Namen ${ }^{\text {lu2 }}$ harimūtum belegt, das auf die gleichnamige Frauengruppe bezogen wird. ${ }^{538}$ Bezeichnend ist allerdings, dass dieses parșum in der Regel von Männern ausgeführt wurde, die Annahme einer institutionellen Form der rituellen Prostitution ist in diesem Zusammenhang jedoch zu bezweifeln. ${ }^{539}$ Sollte dieses parșum und die oben genannte Liste in einen Zusammenhang gehören, so müssten auch Frauen, verheiratete und unverheiratete, eine Rolle bei dieser Kulthandlung gespielt haben. In beiden Fällen zeigt sich der gala-mah verantwortlich. Hierzu wurde vermutet, dass harimtum-Frauen unter der Anleitung dieses Priesters Gesänge, möglicherweise auch Emesallieder vorgetragen haben könnten. ${ }^{540}$ Belege des dritten Jahrtausends weisen diese Frauen als nar aus. ${ }^{541}$ In der Standardversion des Gilgamesch-Epos aus dem ersten Jahrtausend gehören sie dem Kultpersonal der Ištar an und sollen Klagen um den getöteten Himmelsstier ausführen. ${ }^{542}$ Dass sie in der Liste CT 4, 15c einzelnen Frauen zugeordnet werden, könnte darauf hinweisen, dass sie diesen womöglich individuelle Dienste leisteten, die aber leider ungenannt bleiben. In welcher Weise die das harimütum ausführenden Männer mit diesen in Zusammenhang stehen, bleibt unbekannt. Abgesehen davon, dass es sich hier um Kulte für Ištar gehandelt haben könnte, lässt die derzeitige Beleglage keine konkrete Ausdeutung dieser Rituale und der Tätigkeit der harimtum zu.

\footnotetext{
${ }^{536}$ Allgemein Cooper 2006a, 12-21; kritisch dagegen Assante 1998, 39-43.

${ }^{537}$ Vgl. Stol apud Yoffee 1998, 328 Anm. 55.

${ }^{538}$ MHET I/1, 65:10'.14'.17'.24'; MHET I/1, 66:19; MHET I/1, 78:9.15 als ni $\tilde{g}_{2}$ ha-ri-im-ti.

539 Tanret/Van Lerberghe 1993, 441; vgl. Cooper 2006a; 18, der für die beteiligten Männer auch einen Kleidertauschritus für möglich hält.

${ }^{540}$ Harris 1975, 173; Assante 1998, 63.

${ }^{541}$ Pomponio 1986, 66 mit Fara-zeitlichen Belegen zu geme ${ }_{2}$ kar-kid ${ }_{3}$; dazu Cooper 2006a, 16-17.

${ }^{542}$ George 2003, 628-629:158-159 und Variante KAR 115+ v 11' bei CAD B 225 sub c).
} 
Das Wort kezertum oder kezretum ( ${ }^{(\mathrm{munus})}$ suhur- $\left.\mathrm{la}_{2}\right)$ leitet sich vom Adjektiv kezrum ab, das eine bestimmte Beschaffenheit des Haares bezeichnet, die im Allgemeinen als "gelockt" wiedergegeben wird. ${ }^{543}$ Von kașāru(m) „binden; knoten" abgeleitet könnte es auch auf geknotete Haare oder Zöpfe verweisen. ${ }^{544}$ Zusätzlich zur Deutung der kezertum als Prostituierte wurde für sie daher auch eine Tätigkeit im Bereich der Haarpflege und Kosmetik postuliert. ${ }^{545}$ Für den hethitischen Raum liegen Belege vor, wonach kezrētum im Geleit der Göttin Ištar Reinigungstätigkeiten nachgingen und für die kosmetische Pflege der Göttin im Rahmen kultischer Feste zuständig waren. ${ }^{546}$

Auch altbabylonisch liegt für Kiš und Babylon der Nachweis vor, dass diese Frauen Göttinnen auf Reisen geleiteten. Die Briefe AbB 2, 34 und AbB 5, 135 aus der Korrespondenz des Königssekretärs Sîn-iddinam betreffen jeweils Hinund Rücktransport einer Gruppe namentlich nicht genannter Göttinnen aus dem nahe Larsa gelegenen Jamutbal nach Babylon. ${ }^{547}$ Beim Hintransport folgten nach Anweisung des Königs den Göttinnen auch kezertum-Frauen. Auch mehrere Dokumente zu einer Kulthandlung der kezrētum in Kiš weisen einen Bezug zu Götterreisen auf. ${ }^{58}$ Der diese Handlungen leitende Aufseher der kezrētum (ugula munus suhur- $\mathrm{la}_{2}$ ) ist mehrfach als Pächter eines Kanals, möglicherweise für eine Götterreise, attestiert. ${ }^{549}$

In Larsa sind kezrētum an den Opferfesten für Inana und Nanaja beteiligt. ${ }^{550}$ Bei allen übrigen im Verlaufe des Festrituals bedachten Gottheiten, ob männliche oder weibliche, nahmen sie nicht teil. Diese Verbindung ist einmalig auch in einem Siegel dokumentiert, das eine kezertum als Dienerin der Inana und der

${ }^{543}$ AHw 468b; CAD K 314b.

${ }^{544}$ Civil bei Westenholz/Westenholz 2006, 32 Anm. 34.

${ }^{545}$ CAD K 314b kezertu A ,prostitute (lit. woman with curled hair, a hair-do characteristic of a special status)“; Finkelstein in YOS 13 S. 10; Blocher 1987, 229; s. a. Cooper 2006a, 19 zu kezrētum als Haarpflegerinnen nach nA Beschwörungen.

${ }^{546}$ Güterbock 1983, 159 übersetzt „attendant woman“, „lady attendant“ im Sinne von Deutsch „Zofe“.

${ }^{547}$ S. a. Finet 1981, 3-4.

${ }^{548}$ S. hier Kapitel 9.8.4; Yoffee 1998, 310-343 mit Belegen und Diskussion.

${ }^{549}$ Yoffee 1998, 322-329; Pientka 1998, 392-393.

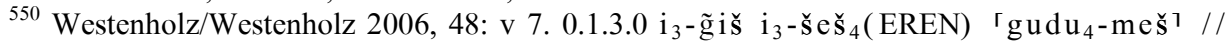

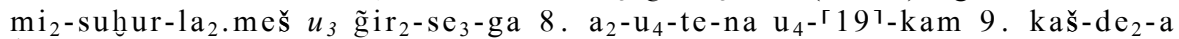
dInana „one bariga and 3 ban $_{2}$ of oil for the anointing of the gudu $u_{4}$-priests, the suhur-la ${ }_{2}-$ women, and the temple-collegium. Evening of the 19th day. Feast-(day) (of) Inana“; dementsprechend beim Fest der Nanaja in Kol. vi 30 zu ergänzen; Westenholz/Westenholz 2006, 32-33, 48, 52 . 
Nanaja ausweist. ${ }^{551}$ Im ersten Jahrtausend gehörten kezrētum dem Personal des Inana/Ištar-Tempels an. ${ }^{552}$

In Mari sind kezrētum der königlichen Familie zugeordnet, in Texten des Palastharems werden sie auch neben Musikerinnen (munus-nar) genannt. ${ }^{553}$ Dort unterstanden sie auch dem mušăhizum, dem 'Musiklehrer' Ilšu-ibbîšu, der sie wohl in das praktische Musizieren einwies. ${ }^{554}$

Literarisch ist bislang nur ein einziger Text bekannt, der auf die Handlungen einer kezertum Bezug nimmt. Die altbabylonische Komposition The Slave and the Scoundrel aus Nippur erzählt vom Gebaren eines jungen Mädchens, das nach Art der kezertum tut, die tigidlu-Laute spielt, süße Lieder singt und sich dem Tanz vor einem 'Mann' hingibt. ${ }^{555}$ Die Aussage weist unmissverständlich auf den Bereich der musikalisch-erotischen Unterhaltung hin.

Insgesamt zeigt die altbabylonische Beleglage auf, dass kezrētum unterschiedliche Status inne hatten, die verheirateten kezrētum in Kiš stehen den von der königlichen Familie und dem Palast von Mari abhängigen Frauen gegenüber. Die Organisation dieser Frauengruppe und ihre kultischen Aufgaben unterliegen damit lokalen Unterschieden.

Abschließend ist für die in diesem Kapitel erörterten Frauen festzuhalten, dass ihre Eingrenzung auf Prostitution dem tatsächlichen Umfang ihrer Tätigkeiten nicht gerecht wird. ${ }^{556}$ Beide Frauengruppen nahmen an Kulthandlungen teil. Hinsichtlich ihrer Verbindung zum gala-mah könnten harimātum auch unterstützend bei Klagefesten mitgewirkt haben. Die Dienste der kezrētum als Musikerinnen, vielleicht auch als 'Schönheitspflegerinnnen' und Unterhalterinnen, könnten sowohl im Kult für die Götter, am Hofe des Königs wie auch im privaten Bereich in Anspruch genommen worden sein. Schließlich sind beide Frauengruppen für das erste Jahrtausend auch als Klagesängerinnen attestiert. ${ }^{57}$

\footnotetext{
${ }^{551}$ S. Verweis Stol apud Yoffee 1998, 329 Anm. 62 zu W. P. Fogg 1875 Arabistan. (Hartford: Dustin, Gilman and Co.).

${ }_{552}$ Menzel 1981, 29-30; Cooper 2006a, 19.

${ }^{553}$ Ziegler 1999, 87-88; Ziegler 2007, 40 zum Brief ARM 10, 140.

${ }^{554}$ Ziegler 2007, 50.

${ }^{555}$ Ausführlich Shehata 2007, 523-525.

${ }_{557}^{55}$ S. a. Assante 1998, 83-86.

${ }^{557}$ George 2003, 628: Gilg. VI 158-159 und Variante in KAR 115+ v 11' k[e]zrēt $[i]$ u harimèti $i[n a] m[u h h i$ imit $] t i$ ša ale $b[i k i t]]$ iškunu ,kezrētu und harimētu führten ein Wehklagen über der Schulter des Stieres aus“; vgl. CAD B 225 sub c); zur kezertu auch George 2003, 453454.
} 


\subsection{Die Klagefrau: ama-er 2 -ra}

Die mehrfach lexikalisch als ama-er ${ }_{2}-$ ra „Mutter der Klage/des Weinens“, in frühsumerischen Texten auch über um-ma er $_{2}$-ra bezeichnete Klagefrau bleibt altbabylonischen Dokumenten bislang unbekannt. ${ }^{558}$ Auch das akkadische Äquivalent bakkītu ist nur im altbabylonischen Mari, wo eine Gruppe solcher Klagefrauen möglicherweise bei kultischen Totenklagen um den Hirtengott Dumuzi mitwirkte, ${ }^{559}$ sowie in wenigen Texten des ersten Jahrtausends belegt. ${ }^{560}$

Im Gegensatz zu dieser dürftigen Beleglage in Alltagsdokumenten sind anderweitig wesentlich mehr Informationen zum vokalen Repertoire dieser Musikerinnengruppe bekannt. Hierüber informieren ein literarischer Katalog und eine vollständig erhaltene literarische Komposition in akkadischer Sprache der Gattung amerakūtum, die beide in die altbabylonische Zeit datieren. ${ }^{561}$ Der Gattungsname ist dem sumerischen ama-er ${ }_{2}$-ra entlehnt und kann damit als Sammelbezeichnung für das Liedrepertoire von Klagefrauen angesehen werden. Sowohl die Lieder des Katalogs BM 85563 als auch das vollständig erhaltene akkadische Lied derselben Gattung sind der Göttin Mami bzw. Bēlet-ilī gewidmet. ${ }^{52}$ Ähnlich den sumerischsprachigen Klagen des gala-Priesters handelt es von der Zerstörung des Tempels der besungenen und selbst klagenden Gottheit, in diesem Falle der Mami. ${ }^{563}$

Klagefrauen begegnen im Kontext von Bestattungszeremonien meist gemeinsam mit dem gala. Häufig zitiert wird in diesem Zusammenhang eine Passage aus der Gudea Statue B:

${ }^{558}$ Krecher 1966, 173; Henshaw 1994, 110 zu den lex. Belegen; aB Proto-Lu 2 (MSL 12, 56) nur

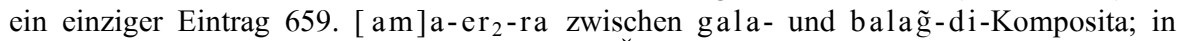
$\mathrm{Lu}_{2}=\check{s} a$ IV (MSL 12, 134) 181. a ma er ${ }_{2}-\mathrm{ra}=\breve{S} U-u$ zwischen kur-g̃ar-ra und pi-il-pi1i. Zu u m-ma noch als männlicher Klagender s. Hartmann 1960, 125.

${ }^{559}$ ARM 9, 175:9 ( ${ }^{\text {munus.meš }}$ ba-ki-tim); entlohnt wurden die Frauen mit einer ungeheuren Menge Getreide, weshalb von einer größeren Gruppe ausgegangen werden kann; Kutscher 1990, 40; dazu Fritz 2003, 235-236; s. a. Charpin 1984, 89-90:40 mit Ölausgaben zum Anlass der 'Beweinung' des Königs (i-nu-ma ba-ku-tim ša lugal).

${ }^{560}$ AHw 97a; CAD B 35a.

561 Katalog BM 85563 ursprünglich an einem Tafelkorb befestigt; Shaffer 1993, 209-210; außerdem zwei Textzeugen eines bisher unpublizierten Vertreters der Gattung amerakūtum im British Museum; Angabe von Prof. B .Groneberg; s. a. hier Kapitel 13.3.

${ }^{562}$ So in den letzten Zeilen des Katalogs vermerkt, BM 85563: 10.37 im-gid ${ }_{2}$-da 11. ama-er $2^{-}$ ra-ku-tim 12. ša dig̃ ir-mah ,37 one-column tablets of 'The Art of Wailing' (in the cult) of Bêlet-ili"“; Shaffer 1993, 209.

${ }^{563}$ Mitteilung Prof. B. Gronebergs 2004. 
T 40: Gudea Statue B Kol. v 1-4 $4^{564}$

„Im Friedhof der Stadt wurde die Hacke nicht angesetzt,

Kein Leichnam wurde bestattet,

Der gala brachte nicht das bala g̃ brachte darüber keine Klage hervor.

Die Klagefrau sprach keine Klage.“

1. ki-mah iri-ka al nu-gar

2. adda(LU $\mathrm{L}_{2}-$ g. - ̌̌.xBAD) ki nu-tum 2

3. gala-e bala g nu-tum ${ }_{2}$ er $_{2}$ nu-ta-e 3

4. ama-er $r_{2}-\mathrm{ke}_{4} \mathrm{er}_{2} \mathrm{nu}-\mathrm{bi} \mathrm{i}_{2}-\mathrm{du}_{11}$

Bereits in den Reformtexten des Uru-inimgina werden neben dem Klagepriester gala alte Klagefrauen und -männer genannt, deren Entlohnung für die Teilnahme an Bestattungszeremonien geregelt wurde. ${ }^{565}$ Vergleichbar ist die Gruppe musizierender Personen aus dem Fluch über Akkade, wonach ein einzelner gala-mah Musikinstrumente spielte, während ihn die Klagerufe alter Frauen (um-ma), alter Männer (ab-ba) und gala-Priester begleiteten. ${ }^{566}$ Die Ur III-zeitliche Urkunde NATN 853 aus Nippur verbucht die Vergütung an die Beteiligten einer privaten Bestattungszeremonie, unter ihnen erscheinen gala und ama-er ${ }_{2}$-ra in direkter Nachfolge. ${ }^{567}$

Eine Gruppe von Klagefrauen, wie sie in literarischen Textpassagen auftritt, wurde in Alltagsdokumenten der altbabylonischen Zeit als solche nicht gekennzeichnet. In mehreren Opferrationenlisten aus Larsa und vor allem Sippar treten vermehrt Frauen aus höher gestellten Familien neben gala-mah aus Anlass verschiedener Klagerituale auf. ${ }^{568}$ Andererseits werden auch kulmašiātum im Kontext kultischer Klagegesänge erwähnt. Möglich wäre, dass solche Frauengruppen die Tätigkeiten der ursprünglich über ama-er a $_{2}$-ra bezeichneten Klageweiber übernahmen. Insgesamt wäre zu überlegen, ob unabhängige Frauen zu solchen Anlässen mit einem eigenen, angesichts der

\footnotetext{
${ }^{564}$ Steible 1991/1, 160-163; Edzard 1997, 32.

${ }^{565}$ Steible 1982/1, 304-307: 31-37; dazu Schretter 1990, 126; zu ABxA $\check{S}_{2}$.IGI als „Klageweiber“ und nicht „Klagemänner“ s. Selz 1995, 206 Anm. 957.

${ }^{566}$ Fluch über Akkade 196-204 und hier Kapitel 6.3.2.3.

${ }^{567}$ NATN 853:Rs 6-7; Wilcke 2000, 43-45.

${ }^{568}$ S. hier Kapitel 9.6.3.2.
} 
Gattung amerakūtum möglicherweise auch in schriftlicher Form überlieferten Klageliedrepertoire auftraten. Die Beleglage fällt hierzu allerdings sehr dürftig aus. 


\section{Familientradition und Ausbildung}

\subsection{Musikerfamilien, Pfründen und Tempelämter}

In allen babylonischen Städten kann beobachtet werden, dass die Berufe des gala und des gala-mah-Priesters an die Familientradition gebunden waren. ${ }^{569}$ Auch für den Beruf des nar bestand eine starke Familienbindung. Hierzu liegen Beispiele aus den Städten Sippar, Kutalla und Nippur vor.

Bestens dokumentiert ist die Familie des gala-mah Ur-Utu aus Sippar Amnānum, von der sieben Generationen bekannt sind. ${ }^{570}$ Zahlreiche Mitglieder der Ur-Utu-Familie waren gala-Priester, einige besetzten auch gala-mahÄmter am Tempel der Annunitum in Sippar Amnānum. Für den Beruf des nar liegt mit der Familie des Lu-Ninurta von Nippur das aussagekräftigste Beispiel vor. ${ }^{571}$ Von dieser Familie sind vier, je nach Deutung vielleicht auch eine fünfte oder sechste Generation bekannt. ${ }^{572}$ Zahlreiche ihrer Mitglieder waren professionelle Musiker, die über den Berufstitel nar ausgewiesen werden. Derselben Familie könnten auch mehrere nar-gal angehört haben. Seit dem ältesten bekannten Mitglied Lu-Ninurta, der zur Zeit des Königs Ur-Ninurta (19231896) von Isin lebte, stand diese Familie im Dienste des Gottes Ninurta von Nippur. Eine weitere Musikerfamilie in Nippur gruppiert sich um den Eigentümer einer nar-Pfründe Ur-Pabilsag̃, Sohn des Ubarrum. In seiner Familie waren sowohl nar als auch nar-sa vertreten ${ }^{573}$ Aus Kutalla werden vier Musiker und Söhne eines Nūr-Ninšubur aus der Zeit des Hammurabi und des Samsuiluna bekannt, die alle den Beruf des nar ausübten. ${ }^{574}$ Die namensgebende

\footnotetext{
${ }^{569}$ So schon Hartmann 1960, 141 für die Ur III-Zeit; dementsprechend auch Renger 1969, 193.

${ }^{570}$ Dekiere 1995, 125-141 mit Stammbaum S. 139; Kalla 2002, 136-137, 154; s. a. hier Kapitel 9.6.2.2.

${ }^{571}$ Zuletzt Kalla 2002, 133-134, 149; hier Kapitel 9.5.2.6.

572 Möglicherweise gehören die nar-gal Lugal-melam-g̃ir und Ka-Ninurta in PBS 8/2, 116/116a:24-25 (RS 50), ARN 44:17-18 (RS 55) und PBS 8/2, 142/a:20 (Si 2) derselben Familie an.

${ }^{573}$ Stone/Owen 1991, 11-19.

${ }^{574}$ TSifr 40/40a:26/25' (Ha 36); TSifr 41/41a:26.33 (Ha 36); TSifr 49/49a:22 (Ha 41); TSifr 50a:25 (Ha 41); TSifr 51a:26 (Ha 41); TSifr 56/56a:30 (Ha 42); TSifr 65:28,29,30 (Si 4); TSifr 66/66a:20 (Si 4); s. a. Kapitel 9.3.1.
} 
Gottheit Ninšubur ist nach Ausweis eines erhaltenen Siegels auch Familiengottheit. ${ }^{575}$

In Familien mit zahlreichen gala-Priestern sind generell auch unter den weiblichen Mitgliedern Priesterberufe vertreten. Mehrere Frauen der Ur-UtuFamilie waren entweder nadiātum des Šamaš oder des Marduk. ${ }^{576}$ Die Mutter des Ur-Utu war wiederum qadištum-Priesterin und ursprünglich in Babylon beheimatet. ${ }^{577}$ Insgesamt sind Frauen und Söhne von gala-mah weitaus häufiger belegt, da sie wie aus Sippar-Texten zu ersehen auch in den Opferrationenlisten des Tempels geführt wurden. ${ }^{578}$

Einzelne Familien zeichneten sich damit durch die traditionelle Ausübung von Musiker- und Priesterämtern aus. Für Nippur und Sippar ist bekannt, dass die Verbindung einer Familie zu einem Musikerberuf auch mit dem Besitz einer Pfründe zusammentraf. ${ }^{579}$ Eine Pfründe konnte Dienste an einem oder verschiedenen Tempeln für eine festgelegte Zeit innerhalb eines Jahres beinhalten. ${ }^{580}$

Die im Rahmen eines Amtes oder einer Pfründe versorgten Gottheiten müssen allerdings nicht mit der Familiengottheit übereinstimmen. ${ }^{581}$ Über mehrere Generationen hinweg konnten 'Dienststellen' auch wechseln, wie es im Falle der Ur-Utu-Familie zu beobachten war, deren Mitglieder zunächst am Inana/Ištar-Tempel von Sippar, später am Tempel der Annunitum von Sippar Amnānum tätig waren. ${ }^{582}$

Der Wert einer Pfründe hing von der Größe und Bedeutung des jeweiligen Tempels ab. Das Eigentum einer Tempelpfründe wurde mit einem ökonomischen und gesellschaftlichen Wert verbunden. Für die altbabylonische Zeit sind gala, nar sowie nar-sa-Pfründe in Texten aus Nippur, Isin, Sippar und Kiš bezeugt. Der Besitz einer gala-Pfründe in Sippar beinhaltete eine igi-sa $a_{2}$ Abgabe, die der ausübende gala an einen vorstehenden Priester, aller Wahrscheinlichkeit nach dem gala-mah zu entrichten hatte. ${ }^{583}$ Für die Besitzer

\footnotetext{
${ }^{575}$ TSifr 40/40a (Ha 36).

${ }^{576}$ Von Waqartum (3. Generation) bis Lamassāni (7. Generation); Dekiere 1995, 126-127, 131 $133,137,139$.

577 Dekiere 1995, 134-135.

${ }^{578}$ MHET I/1, 63 (Ad 2); MHET I/1, 52 (Ad 31/34?); MHET I/1, 42 (Aṣ 5); Ehegattinnen von gala-mah sind bereits präsargonisch als Empfängerinnen von Geschenken und Opfern belegt; Hartmann 1960, 137; Selz 1995, 206 Anm. 962.

${ }^{579} \mathrm{Zu}$ Pfründen im Allgemeinen s. van Driel 2003-5, 518-524.

${ }^{580}$ Ur: TSifr 23 (RS 30-25?); Sippar: der Text RA 82, 28 (D.a.[Aṣ]) zu einer gala-Pfründe in verschiedenen Tempeln von Sippar Jahrūrum; Charpin 1988, 29-31.

${ }^{581}$ Hierzu Kalla 2002, 131-132, 145-146.

${ }^{582}$ Ur-Inana (2. Generation) war gala der Inana von Sippar Jahrūrum, während Inana-mansum (6. Generation) als erster aus der Familie im Dienste der Annunītum von Sippar Amnānum belegt ist; Dekiere 1995, 129-130, 134.

${ }^{583}$ So nach AbB 10, 1; dazu Charpin 1988, 31 .
} 
einer gala-Pfründe sind außerdem Zweitberufe bezeugt, so beim Schreiber Inana-mansum oder dem nu-eš ${ }_{3}$-Priester Nannatum. ${ }^{584}$

Die Ämter von gala-mah und nar-gal waren nicht in das System der Tempelpfründe integriert. Hier stellt sich die Frage nach der Nachfolge innerhalb eines Amtes, die sicherlich auch mit der jeweiligen Familientradition zusammenhing. In Mari hing die Einsetzung eines nar-gal von der Gunst höherer Beamter und des regierenden Königs $a b .{ }^{585}$ Aus dem babylonischen Raum wird hierzu nichts bekannt. Es fällt dennoch auf, dass in keinem Beleg Vater und Sohn als aufeinander folgende Vertreter des nar-gal-Amtes belegt sind. Dementgegen konnte das Amt des gala-mah in spätaltbabylonischer Zeit vom Vater an den Sohn weitergegeben werden, wie es für Sippar oder Kiš bezeugt ist. ${ }^{586}$

Beim Ausdruck dumu gala-mah ist zu mutmaßen, dass er nicht zwingend einen leiblichen Sohn sondern auch allgemein den Amtsnachfolger bezeichnet. Nach welchen Kriterien seine Wahl getroffen wurde, ist nicht bekannt, die Befragung von Omina könnte hierbei eine Rolle gespielt haben. Der Isin-Brief IB 1541 beschreibt eine enge Lehrer - Schüler Liaison, die zwischen dem gala-mah Ur-Nininsina und möglicherweise einem Adoptivsohn bestand. ${ }^{587}$ Nach Beendigung der Ausbildung könnte der gala-mah unter seinen Schülern, oder auch unter bereits ihren Beruf ausübenden gala-Priestern, einen Nachfolger auserwählt haben. Zu den Vorgängen einer eventuellen Priesterweihe sagen die altbabylonischen Texte leider nichts aus. ${ }^{588}$

\subsubsection{Musikernamen}

Namen von Musikern werden in aller Regel aus Alltagsdokumenten bekannt. Häufiges Kompositelement bei Namensbildungen ist die jeweilige Familiengottheit, die sich nach lokalen und religiösen Ursprüngen einer Familie richtet. $^{589}$ Eine Vorliebe zum Sonnengott Utu/Šamaš als Namenselement kann

\footnotetext{
${ }^{584}$ Der Schreiber Inana-mansum in BE 6/2, 26 ( $\mathrm{Si}$ 6) und der nu-eš $\check{s}_{3}$ in BE 6/2, 42 (Si 13), letzterer hütete zwei Jahre lang die gala-Pfründe für den rechtmäßigen Erben. In Nippur sind Söhne eines nu-eš $\breve{3}_{3}$-Priesters auch als nar-gal belegt; BE 6/2, 44: 24-25 (Si 14). Die Verbindung dieses Priesterberufs zu Musikerberufen könnte daher recht eng gewesen sein.

${ }^{585}$ Ziegler 2007, 7-8.

${ }^{586}$ Vgl. Ur-Utu, Sohn des Inana-mansum in Sippar und Nanna-šalasud, Sohn des Mea'imriag̃u in Kiš.

${ }^{587}$ Wilcke 1985a, 189-190: IB 1541; so gesehen sind weder der Name des Absenders (Zeichenrest Ur- ${ }^{\mathrm{d}}[\ldots .$.$) noch des Empfängers erhalten; s. a. hier Kapitel 9.4.2.2; der gala-mah küm-$ merte sich nicht nur um den Lehrling selbst, sondern auch um seinen unbekannten Vater.

${ }^{588}$ Inwiefern der Ur III-zeitliche Ausdruck $u_{4}$ nam-gala-š $e_{3}$ in-ku $u_{4}$-ra „Tag, zum Eintritt in das gala-tum" darauf hinweist, ist noch unklar; Gelb 1975, 67; zuletzt Gabbay 2008, 53 Anm. 56 als möglicher Verweis auf den Akt der Kastration.

${ }^{589}$ Kalla 2002, 131-142; s. a. schon Renger 1969, 198 zum Bezug der Namen auf die jeweilige Tradition.
} 
beispielsweise auf einen Familienursprung in Larsa oder Sippar hinweisen. Zusätzlich wurden innerhalb einer Familie bevorzugt dieselben Namen vergeben. Der gala-mah Ur-Utu aus Sippar Amnānum war beispielsweise nach einem Großonkel benannt. ${ }^{590}$ Auch innerhalb der nar-Musikerfamilie des LuNinurta wurden häufig dieselben Namen vergeben. ${ }^{591}$ Ein Umkehrschluss aus dieser Beobachtung für den Nachweis möglicher Verwandtschaftsbeziehungen ist jedoch unzulässig, da auch in Mesopotamien das Phänomen der Modenamen für einzelne Epochen oder Regionen bekannt ist. ${ }^{592}$

Für die spätaltbabylonische Zeit ist in Nordbabylonien eine besondere Namenswahl bei Priesterberufen zu beobachten. Auf eine Vorliebe für ungewöhnliche sumerische Namen in spätaltbabylonischer Zeit bei gala-mah hat bereits Pientka-Hinz hingewiesen. ${ }^{593}$ Beachtenswert sind Namen wie Balani-he'inzalag (wörtlich: „Sein 'Amt' möge aufleuchten!“). Trotz dieser Tendenzen sind akkadische Namen auch in Nordbabylonien in gleicher Anzahl belegt. Über die Textarten im Bezug zu den dort jeweils belegten Namen, worüber möglicherweise auf Amts- oder Zweitnamen geschlossen werden könnte, sind keine Auffälligkeiten zu beobachten: Sumerische und akkadische Namen tauchen gleichermaßen in Zeugenlisten, in Ausgabenlisten sowie in Rechtsverträgen und Kaufurkunden auf.

Bei gala- Priestern sind sumerische Namen seltener anzutreffen. Die wenigen Belege verteilen sich über die gesamte altbabylonische Zeit und sind meist an die Namenstradition innerhalb der Familie gebunden. Auch Kurz-, Zärtlichkeits- oder Merkmalsnamen werden häufig vergeben, wie Huzālum „Gazelle“ oder Zarriqum „schillernden (Auges?)“. In aller Regel tragen gala-Priester gängige akkadische Namen, die häufig auch als Kurznamen erscheinen. Diesen Beruf zeichnet damit keine besondere Namensgebung aus.

Unter den nar-Musikern sind, wie auch beim einfachen gala-Priester, sumerische Namen eher selten vertreten. In den Belegen zum nar und seinen Berufsvarianten nar-sa, nar-gal und nar-a- $\mathrm{u}_{3}-\mathrm{a}$ sind sumerische Namen ausschließlich für die frühaltbabylonische Zeit belegt, vor allem unter den Mitgliedern der Lu-Ninurta-Familie, aber auch bei Musikern aus der Zeit der Isin- und Larsa-Könige in Ur, Nippur und Isin vertreten.

Daneben werden auch besondere akkadische Namen bekannt, wie Išbi-Errašâm-balāțim „Išbi-Erra ist Bestimmer des Lebens“, worin sich eine besondere Nähe zum König ausdrückt. ${ }^{594}$ In gleicher Weise können auch sumerische Namen von nar gebildet sein, wie bei Lugal-melam(-g̃ir), Lugal-gabari-nutuku

\footnotetext{
${ }^{590}$ Dekiere 1994, 125-127, 139; Kalla 2002, 142-145, bes. 144 zur Ur-Utu-Familie.

${ }^{591}$ Kalla 2002, 133-134, 144; Edzard 1998, 99 § 6.3.

${ }^{592}$ Edzard 1998, 99, 110.

${ }^{593}$ Pientka 1998, 205.

${ }^{594}$ BIN 9, 415:15 (IšEr 24).
} 
oder dem in der Literatur belegten Musiker des Gilgamesch Lugal-gaba-g̃al ${ }_{2}$ „der König ist mächtig“. 595

Die noch heute in vielen Ländern des semitischsprachigen Raums verbreiteten Kurznamen, die von den längeren häufig als Satz gebildeten vollständigen Namen abgeleitet sind, ${ }^{596}$ stellen vor allem für die prosopographische Einordnung von Einzelpersonen eine besondere Schwierigkeit dar. So wird oft nicht bekannt, welche Personen über einen Lang- und auch einen Kurznamen verfügten und ob diese auch schriftlich fixiert wurden. Zudem können von einem einzigen Langnamen mehrere Kurznamen gebildet werden. Kurznamen sind häufiger unter nar und gala belegt, wie Gimillum, Ubarrum, ${ }^{597}$ Ilūni, Aplum, Bēlānum oder Mummatum. Altbabylonisch ist bisher nur ein einziger galamah-Priester belegt, dessen zwei Namensformen auf einer einzigen Tafel notiert sind. Dieser gala-mah der Inana von Zabalam (Sugallìtum) aus Larsa namens Saniq-pī-[GN] trug den Kurznamen Sanqum. ${ }^{598}$ Name und Titulatur dieses gala-mah sind in seinem Siegel erhalten. In der Zeugenliste wird er hingegen unter seinem Kurznamen Sanqum angegeben.

Für die Inhaber dieser Priesterämter insbesondere in spätaltbabylonischer Zeit ist letztlich bekannt, dass sie zu ihrem Amtsantritt zusätzlich einen sumerischen Namen annehmen konnten. ${ }^{599}$ Dies wird für zwei Mitglieder der Ur-UtuFamilie angenommen: den gala Zarriqum mit späterem Namen Nannašalasud $^{600}$ und für Ur-Utu, gala-mah der Annunītum von Sippar Amnānum, der vor seinem Amtsantritt den Namen Bēlānum trug. Auch beim literarisch belegten Namen des nar des Ning̃irsu in den Gudea-Zylindern „Großdrache des ganzen Landes“" (ušumgal-kalam-ma) wird es sich um einen Amts- oder Ehrentitel handeln. ${ }^{601}$ Ungewöhnlich ist auch der in der Unterschrift einer Eršema-Klage angegebene Name eines dumu gala-mah Udug-ga, der dem Namen eines Dämon entlehnt ist. ${ }^{602}$

Angesichts dieser mehrschichtigen Namengebung liegt der Schluss nahe, dass von den belegten akkadischen und sumerischen Namen mehrere auch einer einzigen Person zuzuordnen sind.

\footnotetext{
${ }^{595}$ Gadotti 2006, 71.

${ }^{596}$ Arabische Satznamen sind mit dem GN Allah oder einem seiner weiteren 99 Namen gebildet, bsp.: 'Abd-el-Fattāh > Fathī; akkadisch bsp. Igmil-GN > Igmillum; Gimillum; Edzard 1998, 106; Stamm 1939, 111-117.

${ }^{597}$ Ubarrum „Fremder; Fremdling“ kann Vollname oder verkürzter Name sein; Stamm 1939, 251.

${ }^{598}$ RA 69, 122 Fig. 8; zu Sugallitum s. a. George 1993, 161:1248; Stol 2001, 174-175.

${ }^{599}$ Pientka 1998, 205-206; Janssen 1992, 47-48; vgl. die Namenspraktiken in Mari, die sich nach Stand und Beruf richten; Durand 1984, 127-128.

${ }^{600}$ Dekiere 1994, 128-129.

${ }^{601}$ Gudea Zyl. B x 14. nar ki-a g̃ GAL.UŠUM kalam-ma; vgl. Edzard 1997, 94.

${ }^{602}$ Bruschweiler 1990, 120:29, 122; Gabbay 2007, 155.
} 


\subsection{Musikunterricht und Priesterausbildung}

Über Inhalt und Organisation des Musikunterrichts geben altbabylonische Texte nur wenig Auskunft. Insgesamt sind lediglich zwei altbabylonische Lehrverträge über Musik überliefert, bei denen es sich allerdings nicht um reale Dokumente, sondern um Schultexte handelt, die im Schulmilieu als Schreibund Formulierungsübung verfasst wurden. ${ }^{603}$

Der erste dieser Texte unbekannter Herkunft entstammt der SchøyenSammlung (MS 2951) und wurde erstmals von M. Geller publiziert. ${ }^{604}$ Auf der Rückseite der Tafel findet sich der Name des um-mi-a, des 'Meisters', angegeben, weshalb sie unmissverständlich als Schulübung identifiziert werden kann:

T 41: Geller 2003, $111^{605}$

„Hebe-Eridu, Sohn des Adad-lamassī saß bei Il-șiri, um die Musikkunst zu erlernen. Für diese Zeit, um die Musik des tigidlû, den Jubel(gesang) von Tigi und Adab sieben Male zu erlernen, zahlt Adad-lamassī an Il-ṣīi 5 Schekel Silber."

Tag (...) Ilī-ippalsanni, der (Schreib-)Gelehrte ${ }^{, 606}$

$$
\begin{aligned}
& \text { Vs } 1{ }^{\mathrm{I}} \mathrm{He}_{2}-\mathrm{be}_{2}-\mathrm{eridu}^{\mathrm{ki}}-\mathrm{ga} \\
& \text { dumu }{ }^{\mathrm{d}} \mathrm{IM}-\mathrm{la}-m a-s i_{2} \\
& \text { nam-nar zu-zu-de }
\end{aligned}
$$

${ }^{603}$ Geller 2003, 111 und IB 1515+IB 1534 iii' 1-19 aus Isin; Wilcke 1987, 104-106; s. jetzt zu diesem Thema auch mit Diskussion der hier vorgestellten Texte Michalowski 2009.

${ }^{604}$ Geller 2003, 109-111.

${ }^{605}$ Vgl. Geller 2003, 109-110.

${ }^{606}$ Kommentar: Z. 5. Entgegen der Übersetzung von Geller 2003, 109 fasse ich nar hier nicht als allgemeinen Terminus für „Gesangskunst“ oder „Musik“ auf, was entsprechend der Z. 3 nam-nar wäre, sondern als Teil einer vom Folgenden abhängigen Gen.-Verbindung. Die Schreibung $\breve{\text { S }} A_{3}$.MIN für das bei Civil 1987, 27 identifizierte Musikinstrument /tigidlu/ ist sonst nicht belegt, weshalb Geller 2003, 109 zu Š $\mathrm{A}_{3} . \mathrm{MIN}<$ DI $>$ emendiert. Bisher belegt sind die Varianten $\breve{S} A_{3}$.TAR, DI.TAR, $\breve{S} A_{3}$.MIN.DI, $\breve{S} A_{3}$.MIN.TAR und $\breve{S} A_{3}$.MIN.KASKAL; Ziegler 1996, 483-484; Veldhuis 1997/98, 123-124. Z. 6. Diese Zeile fasse ich parallel zur vorherigen als Gen.-Verbindung auf mit asila(1) ${ }_{3}$ in der Bedeutung „Jubel; Freude“ (akk. rī̌stum, rišătum); s. a. Jaques 2006, 496. Gegen Geller 2003, 109 übersetze ich daher auch tigi $i_{x}$ und a-da-ba(k) hier nicht als Instrumentennamen, sondern als die gleichnamigen Liedgattungen. Die Schreibung nar.bulug̃ für den Lautwert /tigi/ ist hier einmalig, dazu bereits Geller 2003, 110. Zu den Formen des Zeichens asila(1) 3 (so gegen Geller 2003, 109) s. Mittermayer 2006, 62-63 Nr. 158-159 und älter Römer 1965, 258-259. Geller 2003, 109 sieht hier in asila(1) $)_{3}$ das gleichnamige Musikinstrument ,the asila, tigi instrument, and the $a d a b$ instrument seven times". Die Identifizierung des Wortes als Musikinstrument geht auf Schreibungen mit Det. g̃iš zurück; Hartmann 1960, 114 und Krispijn 1990, 4-5 mit Belegen und Disk. PSD A/2 81 übersetzt die Zeichenvariante si-EZEN mit „trumpet“; Krispijn 1990, 4-5 will es dementgegen als die Bünde der Laute identifizieren; vgl. auch Michalowski 2009. 
ki $\mathrm{Il}_{2}-s i-r i$ ba-tus

5

ud-a nar g̃ištigidlû( ${ }^{\mathrm{S}} \mathrm{A}_{3}$. MIN)

asilal $_{3}$ tigi $_{\mathrm{x}}$ (NAR.BULUĞ) a-da-ba

a-ra 2 7-kam zu-zu-de 3

$5 \operatorname{gin}_{2} \mathrm{ku}_{3}$-babbar

10

$\mathrm{a}_{2} \mathrm{Il}_{3}-\mathrm{si}-\mathrm{ri}$

${ }^{\mathrm{Id}} \mathrm{IM}-\mathrm{la}-\mathrm{ma}-\mathrm{Si} \mathrm{i}_{2}$

in-na-an-sum

Rs $\quad \mathrm{u}_{4}$

$$
\begin{aligned}
& \left.{ }^{\mathrm{I}}\right]^{\ulcorner} I_{3}{ }^{\top}-l i_{2}-i p-p a-a l-s a_{3}-n i \\
& \left\ulcorner l \mathrm{u}_{2}{ }^{\top}\right. \text { um-mi-a }
\end{aligned}
$$

Der in dieser Schulübung angesprochene private Musikunterricht umfasste das Erlernen des /tigidlu/ und des Gesangs von Tigi- und Adab-Hymnen. Das Saiteninstrument/tigidlu/ kann als Laute identifiziert werden. ${ }^{607}$ Tigi und Adab sind dementgegen Götterhymnen, die auch Gebete für einen König einschließen können. ${ }^{608}$

Unklar bleibt die Bedeutung der Angabe 'sieben Mal' (a-ra 2 7-kam), die nach Geller wohl am treffendsten als Verweis auf die Anzahl der erteilten Unterrichtseinheiten zu deuten ist. ${ }^{609}$ Insgesamt wird hierfür ein verhältnismäßig hoher Preis von fünf Silberschekeln berechnet, die vom Vater des Schülers zu zahlen waren. ${ }^{610}$

Der Text zeigt zunächst auf, dass Musiker Instrumente und Liedgattungen zugleich erlernten und damit in ihrem musikalischen Repertoire vielseitig ausgerichtet waren. Auffällig ist weiterhin der Anwendungskontext der zu erlernenden Musik. Das Instrument/tigidlu/ lässt sich dem Bereich der Musikunterhaltung zuordnen. ${ }^{611}$ Das Erlernen der hymnisch-preisenden Tigi- und Adab-Götterlieder könnte dagegen auf einen Dienst am Tempel abzielen. Der Musikschüler Hebe-Eridu, dessen Name deutlich eine Hommage an die Stadt des Enki ausdrückt, konnte damit seine Künste zu unterschiedlichen Anlässen zu Gehör bringen. Beachtenswert ist dennoch, dass der gesamte Bereich der Klagemusik ausgeschlossen bleibt.

Der zweite altbabylonisch überlieferte Lehrvertrag über Musik findet sich auf einer zwölfkolumnigen Sammeltafel aus Isin mit mehreren juristischen Schultexten in Urkundenformular. ${ }^{612}$ Gegenstand des Vertrags ist allgemein namnar, die Musik- bzw. Gesangskunst. Nähere Angaben zu ihrem Inhalt werden

\footnotetext{
${ }^{607}$ Shehata 2007, 524 mit Literatur.

${ }^{608}$ S. hier Kapitel 12.1.2.

${ }^{609}$ Geller 2003, 109.

${ }^{610}$ Fünf Silberschekel entsprechen zur aB Zeit etwa dem Preis eines Sklaven.

${ }^{611}$ Shehata 2007, 524.

${ }^{612}$ IB 1515+IB 1534 iii’ 1-19; Wilcke 1987, 104-105.
} 
nicht gemacht ${ }^{613}$ Schüler war wohl ein gewisser Ea-rēṣušu, wörtlich „Ea ist sein Helfer ${ }^{\text {“6 }}{ }^{614}$ Gezahlt wurden 2/3 Schekel Silber, was deutlich unter dem Preis des zuvor zitierten Lehrvertrags liegt. ${ }^{615}$

Über die Musiklehrer wird aus dem untersuchten altbabylonischen Material nur wenig bekannt. In Nippur ist einmalig in einer Rationenliste aus dem Tempelarchiv des Ešumeša ein nar um-mi-a bezeugt, ein Ausdruck, der wohl als 'Musikgelehrter' wiederzugeben ist. ${ }^{616}$ Welchen musikalischen Gebieten seine Gelehrsamkeit gewidmet war, ist unbekannt. Er könnte zusätzlich zum Vortrag auch mit dem Setzen und Zusammenstellen von Liedern und Hymnen vertraut gewesen sein. Die Selbstlobhymnen der Könige Šulgi und Išme-Dagan sprechen um-mi-a und nar-gal als 'Setzer' verschiedener Liedgattungen und Hymnen an. ${ }^{617}$ Angesichts der besonderen Stellung der Stadt Nippur als herausragendes Zentrum des Gelehrtentums könnte der nar um-mi-a auch dem Umfeld des Tafelhauses (edubba'a) zuzuordnen sein. Der einmalige Beleg lässt keine Rückschlüsse auf seinen institutionellen Hintergrund zu.

Für Mari sind Informationen zur Organisation des Musikunterrichts reichhaltig. Zwar gehörte das Unterrichten am Palast in erster Linie zu den Aufgaben des nar-gal, doch konnten ihm hierbei auch mehrere Musiklehrer (mušăhizum) assistieren. ${ }^{618} \mathrm{Im}$ Harem des Palastes gab es zusätzlich auch Musiklehrerinnen (mušăhizātum). ${ }^{619}$

Musiklehrer konnten demnach einer hohen Institution, dem Palast oder Tempel, angeschlossen sein oder aber für privaten Musikunterricht von den Schülern oder ihren Angehörigen direkt entlohnt werden. ${ }^{620}$ Die hohe Entlohnung im oben zitierten Lehrvertrag lässt auf einen gewissen Wohlstand des Lehrers schließen, was allerdings der Aussage von Sprichwörtern und Anekdoten zur Armut eines Musikers widerspricht. ${ }^{621}$

$\mathrm{Zu}$ den Inhalten einer gala-Ausbildung, die im Gegensatz zur allgemeinen musikalischen Bildung eines nar auch priesterliches Fachwissen enthalten musste, sind keine Informationen bekannt. Ausgehend von den Berufsinhalten

\footnotetext{
${ }^{613}$ Auf die abgebrochenen Anfangszeilen folgt eine Art Versicherungsklausel: 6. tukumb [i (x)]

7. ${ }^{\mathrm{I}} E_{2}-a-r e-s u_{2}-\check{s} u$.. 10. DA.KALAG̃ nam-nar-r[a] $11 . \mathrm{nu}-\mathrm{mu}-\mathrm{na}-\mathrm{an}-\mathrm{du} \mathrm{u}_{3}$ ?

${ }^{614}$ Der Text bleibt insgesamt schwer verständlich; s. Umschrift bei Wilcke 1987, 106.

${ }^{615}$ Wilcke 1987, 106:iii' 12.

${ }^{616}$ Sigrist 1984, 137:Nr. 415 mit Umschrift und S. 162 übersetzt als „maître chantre“.

${ }^{617}$ Ludwig 1990, 41-42, 189-190.

${ }^{618}$ Ziegler 2007, 85 (Rišija), 166 (Warad-ilī̌šu), 206 (Ilšu-ibbîšu).

${ }^{619}$ Ziegler 1999, 82-83.

${ }^{620}$ So auch im Edubba-Brief 3.3.18 (van Dijk 1989, 451-452:22), wonach der Schreiblehrer Gold und Silber für den Unterricht berechnet.

${ }^{621}$ Monkey Letter und SP 3.150; Ali 1964, 120-123 und hier Kapitel 5.3.2 mit Literatur.
} 
dieses Priesteramtes lassen sich lediglich allgemeine Lehrbereiche skizzieren. So beinhaltete die musikalische Ausbildung einen vokalen wie auch instrumentalen Bereich. Für die Klagelieder im Emesal sowie für Beschwörungen und Gebete war das Erlernen einer bestimmten Vortragstechnik notwendig. ${ }^{622}$ Für die instrumentale Begleitung musste der gala die Anschlagtechniken von mehreren Perkussionsinstrumenten und ihre Rhythmen beherrschen. Er musste außerdem in eine spezielle Ritualpraxis eingewiesen werden, um auch Opferhandlungen durchführen zu können. ${ }^{623}$ Anzunehmen ist außerdem, dass galaPriester bis zu einem bestimmten Grad Lesen und Schreiben beherrschten. Ob sie jedoch in dieser Kunst so versiert ausgebildet wurden, dass sie auch als Schreiber ihrer eigenen Kultliturgie in Frage kommen, lässt sich bislang nicht eindeutig nachweisen. ${ }^{624}$

Als Lehrer fungierten die obersten Priester selbst, die gala-mah, was über den Isin-Brief IB 1541 zum Ausdruck kommt. ${ }^{625}$ Auch in Mari wurden junge Musiker einem amtierenden gala-Priester unterstellt, um unter ihm die Inhalte dieses Priestertums zu erlernen. ${ }^{626}$

Insgesamt gilt es an dieser Stelle festzuhalten, dass auch im Alten Orient das Spiel von Musikinstrumenten sowie die kontrollierte Beherrschung der Gesangsstimme als hohe Kunst galten, deren Erlernen eine gezielte und intensive Ausbildung benötigte. Die wenigen hierzu erhaltenen Belege zeigen auf, dass Musikunterricht organisiert und in Einzelfällen über Verträge zwischen Lehrenden und Lernenden geregelt wurde. Das Fachwissen über Bereiche des Priestertums und der Musik konnte auch vom Vater auf den (Adoptiv-)Sohn übergehen und fand damit privat innerhalb der Familie statt. Andererseits konnten die Lehrenden auch einer Institution angebunden sein, einem Palast oder Tempel, möglicherweise auch dem $\mathrm{e}_{2}-\mathrm{dub}-\mathrm{ba}(-\mathrm{a})$, dem 'Tafelhaus'. Es sind zwei Lehrmethoden, die des Einzel- und des Gruppenunterrichts belegt. ${ }^{627}$

\footnotetext{
${ }^{622}$ Vgl. SP 2.100, das auf einen gala Bezug nimmt, der Beschwörungen korrekt anzustimmen und zu rezitieren weiß. Auch das Emesal könnte auf eine besondere Singart zu beziehen sein.

${ }^{623}$ So schon Rashid 1984, 19-20.

${ }^{624}$ Renger 1969, 198 „Die Aufgaben des gala-mab im Kult und in der Verwaltung machten es erforderlich, daß er lesen und schreiben konnte“; Tanret 2002, 8, 171; vgl. Bruschweiler 1990, 119-120:29 (=RA 84, 119ff.), wo nach der Unterschrift der Text des Eršema durch einen dumu gala-mah diktiert wurde; s. zu dieser Fragestellung auch Löhnert 2008 und Shehata 2009.

${ }^{625}$ Wilcke 1985a, 189-190; s. a. hier Kapitel 9.4.2.2.

${ }^{626}$ Ziegler 2007, 105-106(=FM 9, 15):15. $10 \mathrm{lu}_{2}$-tur-meš ana ka-l[u-tim e-pe ${ }_{2}$-šim] 16. a-na qa-at A-mur-gi-mil- ${ }^{\mathrm{d}}[\mathrm{utu} i n-n a-a d]-{ }^{\mathrm{r}} d i^{1}-n u-m a$,Zehn junge Musiker werden Amur-gimil[Šamaš unterst]ellt, um das kalû-Priestertum auszüben“. In Mari waren dennoch alle Musiker, auch die kalû-Priester, dem obersten nar-gal am Palast unterstellt; Ziegler 2007, 65.

${ }^{627} \mathrm{Zu}$ Gruppenunterricht s. die Beispiele bei Ziegler 2007, 15-17 und hier zu den Musikerhäusern in Kapitel 5.2.5.
} 
Je nach Inhalt und Ziel des Unterrichts wurde unterschiedliches theoretisches und praktisches Wissen vermittelt. Auch Umfang und Dauer einer Musikerausbildung sind von den Lehrinhalten und Berufszielen abhängig und können je nach Amts- und Berufsanforderung unterschiedlich spezialisiert ausfallen. Die Organisation der Ausbildung war damit relativ frei und wohl häufig auch von lokalen Begebenheiten abhängig. 


\section{Musiker in altbabylonischen Städten}

Die Daten aus Alltagsdokumenten zu Musikern, ihrer Beleglage, Organisation und Verteilung werden in den folgenden Kapiteln nach einzelnen Städten getrennt dargestellt. Mit Hilfe dieser Aufteilung sollen mögliche lokale oder historische Unterschiede aufgedeckt werden. Hierbei beschränke ich mich auf Textmaterial aus den Hauptfundorten des babylonischen Raums: Ur, Larsa, Kutalla, Isin, Nippur sowie Sippar, Dilbat und Kiš in Nordbabylonien. Jede dieser Städte ist Hauptkultort unterschiedlicher Gottheiten, sodass am Musikerpersonal eventuell auch die Musikpraxis der jeweiligen Götterkulte aufgezeigt werden kann.

Nur ein geringer Teil dieses Textmaterials ist bei regulären Ausgrabungen zutage gekommen. Der größte Teil wurde im Kunsthandel erworben und wird nach prosopographischen Kriterien geographisch zugeordnet. Besonders zu berücksichtigen ist hier die unterschiedliche Fund- und Quellensituation zu jeder einzelnen der behandelten Städte, weshalb auch Lücken in der Beleglage zu erwarten sind.

\section{$9.1 \mathrm{Ur}$}

\subsubsection{Historischer Hintergrund und Quellenlage}

Die Stadt Ur, ehemalige Hauptstadt der Ur III-Dynastie (heute: Tell Muqayyir), rückte seit ihrer Zerstörung durch die aus dem Osten vordringenden Elamer Ende des dritten Jahrtausends politisch und wirtschaftlich immer mehr in eine Nebenrolle. Unter der Herrschaft der Kudurmabuk-Dynastie, den Königen Warad-Sîn und Rīm-Sîn von Larsa, erlebt die Stadt für kurze Zeit einen wirtschaftlichen und religiösen Aufschwung. ${ }^{628}$ Ihre Eingliederung in das babylonische Reich durch König Hammurabi von Babylon führte $\mathrm{zu}$ ihrem wirtschaftlichen Abstieg, da sich das Interesse dieses Herrschers vermehrt auf Nordbabylonien konzentrierte. Nur kurze Zeit nach der Zerstörung der Stadtmauern durch Samsuiluna bei seinem Versuch, der Invasion seines südlichen Rivalen Rīm-Sîn II entgegen zu treten (Jahr Si 11), wird die Stadt aufgegeben.

${ }^{628}$ Van de Mieroop 1992, 61-64. 
Der letzte altbabylonische Text aus Ur trägt das Datum Samsuiluna $12 .{ }^{629}$ Die Stadt wurde allerdings in spätaltbabylonischer Zeit bis zur Neubesiedlung durch die Kassiten im 14. und 13. Jahrhundert nicht vollkommen aufgegeben. Funde von Keramikresten deuten darauf hin, dass eine kleinere Besiedlung bestehen blieb, die jedoch keine schriftlichen Zeugnisse hinterließ. ${ }^{630}$

Die Stadt Ur war Hauptkultort des Mondgottes Nanna/Sîn und dessen Tempel Ekišnugal. Zum Bezirk dieses Tempels gehörte das Gipar, das gleichzeitig Heiligtum seiner Gattin Ningal sowie Residenz der en-Priesterin des Nanna/Sîn war. Die von Sargon von Akkade im 24. Jahrhundert eingeführte Tradition, eine weibliche Verwandte des Königs als en-Priesterin diesem Gott zu weihen, wurde auch nach der Eroberung von Ur durch die Könige der Isin- und Larsa-Dynastien fortgeführt. ${ }^{631}$ Zum Tempelkomplex des Ekišnugal gehörte weiterhin das Ganunmah, eine wichtige Verwaltungsstelle für Opfermaterie. ${ }^{632}$ Von den übrigen Göttertempeln im Stadtgebiet von Ur ist für die folgende Darstellung noch das Heiligtum des Gottes Enki von Eridu zu nennen, das sich im Tempelkomplex des Nanna/Sîn befand. Die mögliche Einführung dieses ursprünglich in Eridu beheimateten Gottes nach Ur durch seine exilierte Priesterschaft wurde von Charpin erstmals aufgezeigt, ${ }^{633}$ wobei gegen diese Theorie inzwischen berechtigte Einwände vorgebracht wurden. ${ }^{634}$

Der größte Teil der Ur-Texte stammt aus regulären Ausgrabungen auf dem Siedlungshügel Tell Muqayyir, die durch Woolley in den Jahren 1926 und 1931 durchgeführt wurden. ${ }^{635}$ Die Texte aus diesen Grabungskampagnen wurden in zwei größeren Wohnkomplexen geborgen. Sie umfassen ein Gesamtkorpus von etwa 2500 Tafeln, die größtenteils in älteren Publikationen zugänglich sind. ${ }^{636}$

${ }^{629}$ UET 5, 868 nach Kraus 1955, 524; Pientka 1998, $11+$ Anm. 27; zur Geschichte vgl. Van de Mieroop 1992, 45-71.

${ }^{630}$ Gasche 1989, 130-131; Van de Mieroop 1992, 70. Die administrativen Textquellen sind zur Isin- und frühen Larsa-Dynastie reichhaltig, ab der Mitte der Regierung Rīm-Sîns und unter Hammurabi ist jedoch das Gegenteil der Fall. Zum Ende der Regierungszeit Samsuilunas nimmt die Anzahl der Texte wieder zu. Nach einer zeitlichen Lücke datieren die ersten Verwaltungstexte wieder in das späte 13. und 12. Jh.

${ }^{631}$ Unter Išme-Dagan bspw. bei Frayne RIME 4.1.4.3-4, S. 29-31, unter Sumu’ēl Jahr 23 (Sigrist 1990, 20) und Warad-Sîn Jahr 8 (Sigrist 1990, 33-34); dazu ausführlicher Van de Mieroop 1992, 53f., 57f., 62f.; Richter 2004, 419-420, 422, 425.

${ }^{632}$ Zusammenfassend Richter 2004, 435-438. Möglicherweise werden in den Texten auch zwei Ganunmah, des Nanna und der Ningal unterschieden; Van de Mieroop 1992, 38-43, 78; s. a. Richter 2004, 429+Anm. 1825.

${ }^{633}$ Charpin 1986, 393-402.

${ }^{634}$ Van de Mieroop 1989b, 246; Richter 2004, 458-459. Beider Kritik begründet sich auf die bereits Ur III-zeitlich intensiven Beziehungen im Kult zwischen beiden Städten.

${ }^{635}$ Woolley 1934.

${ }^{636}$ UET 5 und UET 3; Charpin 1986 und Van de Mieroop 1992; zu Publikationen weiterer Texte 


\subsubsection{Die namentlich belegten Musiker von Ur}

Trotz des überreichen schriftlichen Materials aus Ur sind in lediglich 23 Dokumenten Angaben zu Musikern enthalten. ${ }^{637}$ Die Texte, in denen gala-Priester und nar-Musiker mit Namen belegt sind, stammen größtenteils aus Privathäusern und behandeln Verträge und Rechtsprozesse. nar und gala werden in diesen Texten hauptsächlich als Zeugen genannt. Sechs Texte können der Tempeladministration zugeordnet werden. Sie listen Naturalien oder Objekte auf, die an das Tempelpersonal, darunter auch Musiker, ausgeteilt wurden.

\subsubsection{1 gala-mah und nar-gal}

Zwei nar-gal sind namentlich in Ur-Texten belegt: Ir-Nanna und Ir-Ningal als nar-gal der Göttin Ningal. ${ }^{638}$ Ir-Ningal ist letzter Zeuge auf einer Darlehensurkunde des Nanna-Tempels. In der Zeugenliste gehen ihm zwei Tempelpförtner $\left(\mathrm{i}_{3}-\mathrm{du}_{8}\right)$ voraus. Aufgrund der Urkundendaten ist anzunehmen, dass sowohl IrNingal als auch Ir-Nanna zur Regierungszeit des Rīm-Sîn am EkišnugalTempel tätig waren. Ungeklärt bleibt allerdings, ob sie gleichzeitig oder zeitlich aufeinander folgend am Haupttempel der Stadt amtierten, da beide nargal jeweils nur einmal belegt sind.

Für das Amt des gala-mah sind für Ur ebenfalls nur zwei Personen namentlich belegt: Nūr-Šamaš aus der Zeit des Königs Rīm-Sîn sowie Sîn-erībam in einer Urkunde aus dem Jahre Samsuiluna $8{ }^{639}$ Beide gala-mah waren am Ekišnugal tätig.

Der insgesamt viermal belegte Nūr-Šamaš wird nach seinem Siegel in PBS 8/2, 264 (RS 35) als ,gala-mah des Nanna, Diener des Šamaš und der/des Ninšubur“ bezeichnet. ${ }^{640}$ Der Ausdruck „Diener des GN“ gibt den persönlichen Familien- und Schutzgott an ${ }^{641}$ Der auch in seinem Namen enthaltene Bezug zum Sonnengott Šamaš ist für Ur außergewöhnlich, da der Kult des Šamaš in dieser Stadt relativ unbedeutend war. ${ }^{642}$ Die Familie des Nūr-Šamaš könnte womöglich ursprünglich in einer anderen Stadt, am wahrscheinlichsten in Larsa, Hauptkultort des Šamaš, beheimatet sein. Ur befand sich mehrere Jahrzehnte lang unter der Herrschaft der Larsa-Könige. Besondere Aufmerksamkeit wurde dem Kult des Sonnengottes in Ur durch die Kudurmabuk-Dynastie

aus Ur s. Bibliographie bei Charpin 1986, 158-192 und ders. 2004, 407-408.

${ }^{637}$ S. Musikerkatalog Kapitel 16.

${ }^{638}$ TSifr 93:18 (RS 2); UET 5, 363:14 (RS 34).

${ }^{639}$ TSifr 7/7a:18 (RS 8); PBS 8/2, 264:33 (RS 35); UET 5, 96:23 (o.D.); YOS 12, $297: 22$ (Si 8); in UET 5, 248:4 (RS 16) wird auf ihn lediglich als gala verwiesen, obwohl er Jahre früher bereits gala-mah ist; Charpin 1986, 161, 250.

${ }^{640}$ PBS 8/2, 264 (RS 35) Siegel B. Nu- $u\left[r_{2}{ }^{-}\right]$Utu gala-mah ${ }^{\mathrm{d}}$ Nanna $i r_{3}{ }^{\mathrm{d}} \mathrm{Utu} u_{3}{ }^{\mathrm{d}}$ Nin-šubur; Charpin 1986, 170.

${ }^{641}$ Kalla 2002, 130.

${ }^{642}$ Richter 2004, 493-496. 
zuteil. Ein Abwandern des gala-mah-Priesters und seiner Familie von Larsa nach Ur im Zuge der Eroberungen durch Rìm-Sîn wäre zu vermuten. Das Siegel des Nūr-Šamaš gibt außerdem die Botengottheit Ninšubur an. Für diese Gottheit aus dem Kreise der Inana, die sowohl einen weiblichen wie auch einen männlichen Aspekt aufweist, ließ Rīm-Sîn mehrere Heiligtümer in Ur errichten. ${ }^{643}$

Der gala-mah Sîn-erïbam ist nur einmal als letzter Zeuge auf einer Kaufurkunde über ein gudu ${ }_{4}$-Amt bezeugt. ${ }^{644}$ Das Amt mit einem Dienstumfang von zwei Monaten innerhalb eines Jahres für die Göttin Nin-e'igara ging an den zabardabbu $(m)$ Sîn-šemi ${ }^{645}$ die beiden Verkäufer entstammen der Familie des Waqar-abūšs. ${ }^{646}$ Alle genannten Zeugen bekleiden höhere Ämter im Umfeld des Ekišnugal, ${ }^{647}$ weshalb auch der gala-mah Sîn-erībam als Angehöriger desselben Tempels identifiziert werden kann. Bezeichnend ist dennoch, dass entgegen sonst üblicher Zeugenanordnung der gala-mah an letzter Stelle genannt wird. Hier zeigt sicht wiederum, wie auch häufiger in Nippur, dass die Bezeugung von Transaktionen um $\mathrm{gudu}_{4}$-Pfründe für gala-mah offenbar obligatorisch war.

In Ur hat damit immer nur ein gala-mah am Haupttempel des Nanna amtiert. Dass die Belege zu den zwei gala-mah Nūr-Šamaš und Sîn-erībam zeitlich weit auseinander liegen, lässt sich nur über die Annahme einer Überlieferungslücke begründen.

\footnotetext{
${ }^{643}$ Richter 2004, 474-475.

${ }^{644}$ YOS 12, 297 (Si 8) 22. igi d EN.ZU-e-ri-ba-am gala-mah.

${ }^{645}$ Ausführlich besprochen bei Charpin 1986, 160-161.

${ }^{646}$ Die Transaktionen des Personenkreises um Waqar-abūšu sind aus Texten des Sîn-išmēniArchivs teilweise einsehbar; hierzu Charpin 1986, 162. Derselben Textgruppe gehört die Adoptionsurkunde des Sîn-išmēni BIN 2, 75 (Si 7) an, die einen nar Halija als Zeugen nennt. Zur selten bezeugten Göttin Nin-e'igara Gattin des Ningublaga im aB Ur s. Richter 2004, 444 und allgemein Cavigneaux/Krebernik 1998-2001a, 348.

${ }^{647}$ YOS 12, 297:18-21 (Si 8), darunter ein $\operatorname{ababd\hat {u}}(\mathrm{m})$ und gudu ${ }_{4}$-Priester der Ningal und des Dublamah des Nanna/Sîn; s. Charpin 1986, 161.
} 


\subsubsection{2 gala, nar und seine Varianten}

Für Ur werden vier gala gegen 13 nar und seine Varianten namentlich bekannt, die meist nur einmalig belegt sind. ${ }^{648}$ Beide Berufsgruppen werden auch gemeinsam $^{649}$ als Zeugen in Erbschafts-, Kaufverträgen und Quittungen genannt. Nur selten sind sie auch Empfänger von Nahrungsrationen oder anderen Gütern. Es fällt auf, dass insbesondere die $\mathrm{n}$ ar auch edlere Materialien, Wolle und Silber erhalten. ${ }^{650}$

Einzelne Musiker erscheinen als Zeugen in Urkunden, die Pfründe der Tempel des Nanna, der Ningal, der Gula und des Ninšubur betreffen. ${ }^{651}$ Die Urkunde YOS 12, 353 aus dem Jahr Samsuiluna 11 enthält den Verkauf eines Amtes am Tempel der Gottheit Ninšubur. In der Zeugenliste werden nacheinander der gala Šamaš-muballiț, der nar-sa Apil-Amurrum ${ }^{652}$ sowie ein Barbier ( $\breve{u}$-i) und ein Hirte (sipa) der Gottheit Ninšubur zugeordnet. Unter den zahlreichen belegten Heiligtümern des Ninšubur in Ur könnte sich auch eines am Tempelkomplex des Ekišnugal befunden haben. ${ }^{63}$ Es bleibt allerdings unklar, welchem Tempel dieser Gottheit die in YOS 12, 353 (Si 11) aufgeführten Musiker zuzuordnen sind.

Ein gala der Gula mit Namen Awīl-dāri ist Zeuge der Kaufurkunde TSifr 9/9a (RS 10). Abgesehen von den oben genannten Pfründen ist der Kult dieser Heilgöttin bereits Ur III-zeitlich und auch altbabylonisch an einem eigenen Tempel belegt. ${ }^{654}$ Unter Warad-Sîn ist außerdem ein Heiligtum der Heilgöttin

${ }^{648}$ gala: Awīl-dāri TSifr 9/9a:25 (RS 10); Sîn- $u_{2}$-WI-li? TSifr 25:23 (RS 35); Šamaš -muballị YOS 12, 78:21 (Si 3), YOS 12, 353:23 (Si 11); Andul-Sîn Nisaba 19, 296:1.Rd.2 (D.a.); nar: Dudu UET 5, 550:5 (AbS 6) und UET 5, 672:23 (o.D.); Arašuta TSifr 4:20 (RS 6) nach

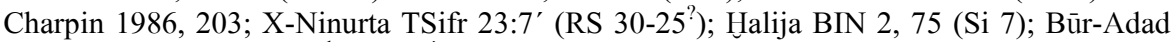
UET 5, 453:9 (o.D.); Ur- ${ }^{\mathrm{d} P A P-n u !-s ̌ e ~ U E T ~ 5, ~ 561: i ~} 15$ (o.D.); Nanna-g̃eštubi UET 5, 663:11 (D.a.); Ankuta Nisaba 19, 296:1.Rd.1. (D.a.); nar-sa: Sîn-gāmil Sohn des Sîn-šemi UET 5, 191:50 (RS 54); Apil-Amurrum YOS 12, 353:24 (Si 11); $\mathbf{n}$ ar-a- $\mathbf{u}_{\mathbf{3}}$-a: $:$ Ir-Nanna Sohn des Ur-Šulpa'e und Etel-Kūbi UET 5, 160:17.21 (Sel 6); Iddin-Ištar UET 5, 95/95a:25a (Ha 33); größtenteils schon bei Renger 1969, 188-189, 196-197.

${ }^{649}$ Nisaba 19, 296 (D.a.) eine Kaufurkunde mit nar und gala als erste Zeugen.

${ }^{650}$ Empfänger von Getreiderationen YOS 12, 78:21 (Si 3) gala Šamaš-muballiț; sonst nar in UET 5, $672: 23$ (o.D.); UET 5, 663:11 (D.a.); YOS 5, 163 (WS 10). Der n ar Būr-Adad in UET 5, 453:9 (o.D.) empfängt Wolle, Ur- ${ }^{\mathrm{d}}$ PAP-nu! -še in UET 5, 561:i 15 (o.D.) Silber; Dudu in UET 5, 550 (AbS 6) ein al-g̃ar-Instrument.

${ }^{651}$ Sîn- $u_{2}$-WI-li, gala in TSifr 25:23 (RS 35); $\left[\mathrm{x}^{-\mathrm{d}} \mathrm{Nin}-\mathrm{ur}\right]$ ta $\mathrm{nar}$ in TSifr 23:7 (RS 30-25?); Šamaš-muballiț, ga la Ninšubur und Apil-Amurrum, nar-sa in YOS 12, 353:23-24 (Si 11).

${ }^{652}$ Richter 2004, 475 korrigiert für YOS 12, 353 (Si 11) 24 die Lesung $\mathrm{zu}^{\top} \mathrm{nar}^{\top}{ }^{-\mathrm{s} a}$ gegen Renger 1969, 179 nar-gal. Derselbe gala Šamaš-muballit ist in der Rationenliste YOS 12, 78:21 (Si 3) Empfänger von Getreide.

${ }^{653}$ Richter 2004, 473-476 mit Belegen für mindestens vier Heiligtümer im Stadtgebiet von Ur; zu

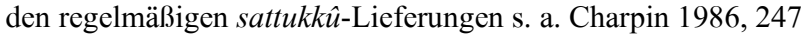

${ }^{654}$ Sallaberger 1993, 159; Richter 2004, 465-467. 
Ninisina in einer fragmentarischen Inschrift bezeugt. ${ }^{655}$ Für die altbabylonische Zeit ist die spätere Gleichsetzung beider Heilgöttinnen jedoch nicht sicher. ${ }^{656}$

Der Kult des Gottes Enki ist in Ur seit der präsargonischen Zeit belegt. Enge Beziehungen zwischen Ur und der im Süden gelegenen Stadt Eridu, Hauptkultort des Enki, bestanden bereits zur Ur III-Zeit ${ }^{657}$ In seiner Studie zum Tempelpersonal von Ur legte Charpin über die Untersuchung von Personennamen und Titulaturen den Beleg vor, wonach die Priesterschaft des Enki von Eridu zum Ende der III. Dynastie von Ur mit der Zerstörung der Stadt Eridu nach Ur exilierte, wo sie eine Neuetablierung des Enki/Ea-Kultes im Ekišnugal des Nanna veranlasste. ${ }^{658}$ Trotz ihrer Plausibilität bleibt diese Theorie diskussionswürdig. ${ }^{659}$

Der nar-sa Sîn-šemi, Vater des Sîn-gāmil, wird in der Zeugenliste der Urkunde UET 5, 191 (RS 54) dem Gott Enki zugeordnet. ${ }^{660}$ Diese Zeugenliste nennt außerdem Angehörige der Priesterschaft des Enki von Eridu. ${ }^{661}$ Die Namen Sîn-šemi und seines Sohnes Sîn-gāmil weisen keinerlich Verbindung zur Eridu-Priesterschaft auf. Ihre Familienursprünge deuten vielmehr auf Ur, wo ihre Angehörigen möglicherweise im bereits Ur III-zeitlich belegten Heiligtum des Enki Dienst taten.

An Musikern, die im Dienste einer Gottheit stehen, ist noch der nar Ankuta zu nennen, der in einer Kaufurkunde unbekannten Inhalts der Getreidegottheit Ezinu( ( ${ }^{2}$ ŠE-TIR) zugeordnet wird. ${ }^{62}$ Bemerkenswert ist hierbei, dass es sich um eine kleine, recht unbedeutende Gottheit handelt, die dem Kreis des Enlil angehört. ${ }^{63}$ Es könnte vermutet werden, auch angesichts des ungewöhnlichen Personennamens, dass es sich um einen aus Nippur oder Uruk zugezogenen Musiker handelt. In der Zeugenliste wird er gefolgt vom gala Andul-Sîn, dem ebenfalls ein Göttername beigestellt ist, der allerdings abgebrochen ist. Insgesamt zeigt sich hier, dass einzelne Musiker auch auf den Dienst kleiner Gott-

\footnotetext{
${ }^{655}$ Frayne in RIME 4.2.13.2, S. 205-205, wonach Warad-Sîn in seinem ersten Regierungsjahr einen Tempel für diese Göttin errichtete, allerdings ist die Zuordnung der Inschrift zu diesem König unsicher; dazu Frayne 1998, 204; Edzard 2000, 387-388. Die Identifizierung dieses Tempels mit den in UET 5, 592:9.20 (o.D.) genannten Gebäuden $\mathrm{e}_{2}{ }^{\mathrm{d}} \mathrm{gu}$-la und $\mathrm{e}_{2}$-SAR ${ }^{\mathrm{d}} \mathrm{gu}-1 \mathrm{a}$ ist nach Richter 2004, 466 aufgrund der unsicheren Datierung nicht möglich.

${ }^{656}$ Richter 2004, 466

${ }^{657}$ Richter 2004, 459; Sallaberger 1993, 223-224.

${ }^{658}$ Charpin 1986, 343-418.

${ }^{659}$ Hierzu Van de Mieroop 1989b, 246; Richter 2004, 459.

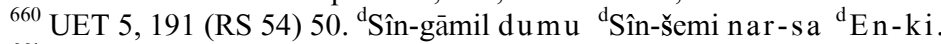

${ }^{661}$ Charpin 1986, 396-402.

${ }^{662}$ Nisaba 19, 296:1.Rd.1. (D.a.).

${ }^{663}$ Allgemein Ebeling 1938, 489-490.
} 
heiten beschränkt sein konnten, was möglicherweise auch mit dem Besitz von entsprechenden Tempelpfründen in Zusammenhang steht.

Bisher einmalig ist die Aussage der Urkunde UET 5, 550 (AbS 6), wonach ein $\mathrm{n}$ a r als Angehöriger des Ningal-Tempels ein Musikinstrument erhielt: ${ }^{664}$

\section{T 42: UET 5, 550 (AbS 6)}

„Ein ledernes al-g̃ar, Weihgeschenk des Abum-țābum für das Heiligtum der Ningal.

Der nar Dudu hat es empfangen."

Vs 1. $1^{\text {kušal-g̃ar 2. a-ru-a 3. }{ }^{\ulcorner} A-b^{\urcorner} u-u m-\mathrm{dug}_{3}-b u-u m}$

4. zag-u ${ }^{\mathrm{d}} \mathrm{Nin-gal-šs}{ }_{3}$

5. Du-du nar 6. šu-ba-an-ti

Die Urkunde entstammt dem Ganunmah, dem Schatzhaus des Nanna und Ningal-Tempels. Die Übergabe dieses Weihgeschenks seitens des Abum-tābum unterstand einem Reinigungspriester $\left(\mathrm{gudu}_{4}\right)$ der Göttin Nanaja, dessen Siegel ebenfalls auf der Tafel erhalten ist. ${ }^{665}$ Das ${ }^{\text {kuš }}$ al-g̃ar könnte demnach auch in der Kapelle der Nanaja platziert worden sein, die sich ebenfalls im Tempelbezirk des Nanna befand. ${ }^{666}$ Der Empfang und die Übergabe der Weihgeschenke an das Tempelpersonal fand in Ur entweder in Anwesenheit eines Reinigungspriesters oder eines Siegelschneiders (bur-sa g̃) statt. ${ }^{667}$ Das besagte Instrument wurde an den nar Dudu übergeben. ${ }^{668}$ Aus den Inhalten dieser Urkunde ist zu ersehen, dass nar als Tempelmusiker auch Musikinstrumente spielten, die als Weihgeschenke geliefert wurden.

\footnotetext{
${ }^{664}$ Van de Mieroop 1989a, 398.

${ }^{665}$ UET 5, 550:7 (AbS 6) und Siegel: Ni $\tilde{g}_{2}-$ ga- $^{\mathrm{d}}$ Nanna, gudu ${ }_{4}{ }^{\mathrm{d}} \mathrm{Na}$-na-a, dumu En-[nu-1]i-bur.

${ }^{666}$ Van de Mieroop 1989a, 398b. Ihm zufolge wurden Weihgeschenke, die anderen Gottheiten außer Nanna oder Ningal galten, meist von einem gudu $u_{4}$-Priester in Empfang genommen. Zur Kapelle der Nanaja am Nanna-Tempel von Ur s. Charpin 1986, 306 und Richter 2004, 471.

${ }^{667}$ PSD B 187b sub 1; Van de Mieroop 1989a, 398a.

${ }^{668}$ Derselbe Musiker Dudu könnte ein weiteres Mal in UET 5, $672: 23$ (o.D.) als Empfänger von Emmerbier (ulušin ${ }_{x}$ ) und Rohrkörben (gi-gur) genannt sein. Die Identifizierung des kušs/gišs al-g̃ar ist umstritten; als Harfe bei Krispijn 1990, 70; anders Veldhuis 1997/98, 119120, der eine Identifizierung als Trommel favorisiert, ähnlich Kilmer 2003-05, 369.
} 


\subsubsection{Ein Fest des Nanna in Ur: Die Rationenliste YOS 5, 163 (WS 5)}

Die aus Ur stammende Ausgabenliste YOS 5, 163 aus dem Jahr fünf des Warad-Sîn notiert Bierausgaben an verschiedenes Personal des EkišnugalTempels. ${ }^{669}$ Neben hohen Funktionären aber auch allgemeinen Bediensteten des Tempels ${ }^{670}$ sind auf der Tafelrückseite auch Ausgaben an einen nar-gal, einen nar-sa, einen gala-mah sowie eine Gruppe von nar-a- $u_{3}-a$ angegeben, deren Namen allerdings ungenannt bleiben:

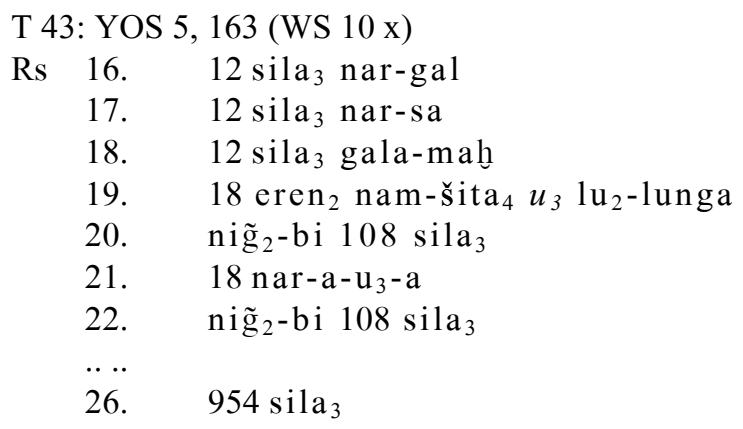

Die drei einzelnen Musiker erhalten jeweils dieselbe Rationenmenge über 12 Liter Bier, während an die Gruppe von 18 nar-a- $\mathrm{u}_{3}-\mathrm{a}$ pro Person nur 6 Liter ausgeteilt werden.

Der Anlass der Ausgabe findet sich im Kopf der Tafel (Zeile 3) angegeben. Der Ergänzung Charpins mit $\mathrm{u}_{4}$-[sakar]-gibil-mah folgend handelt es sich hier um ein großes Fest anlässlich des Neulichts, dem ersten Erscheinen der Mondsichel. ${ }^{671}$

Was die Identifizierung der angegebenen Musiker anbetrifft, so könnte es sich ausgehend vom Datum der Urkunde beim gala-mah um den bereits bekannten Nür-Šamaš handeln. Dieser ist für die Zeit der Könige Warad-Sîn und Rīm-Sîn am Ekišnugal beschäftigt. ${ }^{672}$

Beim nar-gal könnte es sich um Ir-Nanna handeln, der in der etwa zehn Jahre jüngeren Urkunde TSifr 93 (RS 2) Zeuge eines Hausgrundstückskaufs ist.

Ein nar-sa ist in Ur einmalig in der Adoptionsurkunde UET 5, 191 aus dem Jahre Rīm-Sîn 54 mit Namen Sîn-gāmil belegt. Schon aufgrund des späten Datums kann es sich nicht um den hier aufgeführten nar-sa handeln.

\footnotetext{
${ }^{669}$ Bearbeitet bei Charpin 1986, 234-251.

${ }^{670}$ Zum genannten Personal s. ausführlich Charpin 1986, 235-250.

${ }^{671}$ Charpin 1986, 234-235.

${ }^{672}$ Charpin 1986, 250; Gasche 1989, 4 Anm. 7.
} 
Abgesehen von der Identifizierung der genannten Musiker lässt sich an der Liste auch ablesen, welche Musikergruppen beim monatlich stattfindenden Neulichtfest beteiligt sein konnten. ${ }^{673}$ Die Beteiligung von Musikern, auch größeren Ensembles, an diesem Fest ist bereits Ur III-zeitlich belegt und findet sich auch in literarischen Texten dokumentiert. ${ }^{674}$

Nach der Liste YOS 5, 163 stehen die solistisch auftretenden Musiker nargal, gala-mah und nar-sa einer Gruppe von 18 nar-a- $u_{3}-a$ gegenüber. Diese Variante zum Beruf des nar findet sich ausnahmslos in Dokumenten aus Ur bezeugt. ${ }^{675}$

Zur musikalischen Aufführungspraxis ließe sich folgendes mutmaßen: Sofern es sich bei den nar-a- $u_{3}-a$ um spezialisierte Vokalisten handelt, könnte die musikalische Darbietung aus einem oder zwei Vorsängern, einem Instrumentalisten sowie einem Chor mit ausschließlich männlichen Stimmen bestanden haben. Die Form der dargebrachten Musik bleibt uns unbekannt. Da der Anlass des Festes positiver Natur ist, werden wohl vornehmlich Hymnen und Preislieder an den Gott Nanna vorgetragen worden sein, wie sie uns als literarische Werke überliefert sind. ${ }^{676}$ Die Anwesenheit eines gala-mah lässt des Weiteren darauf schließen, dass auch Klagelieder unter der Begleitung von Perkussionsinstrumenten und eventuell auch des bala g̃ vorgetragen wurden. ${ }^{677}$ Das Fest und die dazugehörige musikalische Umrahmung wird demzufolge in mehreren auch zeitlich voneinander getrennten 'Abteilungen' stattgefunden haben. Wie auch die Ritualtafel aus Larsa HUCA 34, 1ff. deutlich aufzeigt,

${ }^{673}$ Insgesamt bleibt die Ergänzung und Interpretation unsicher, auch da der Zusatz mah darauf hinzuweisen scheint, dass es sich um ein einmaliges, möglicherweise auch ein jährliches Fest gehandelt haben könnte; vgl. Sallaberger 1993, 39, 71-72 zur Terminologie. $\mathrm{u}_{4}$-s akar gibil ist vielfach literarisch belegt, beispielsweise bei Gudea Zyl. A xxiv 10.23. Möglich wäre auch, in der Lücke von Zeile 3 ezem zu ergänzen; das ezem-mah des Nanna ist aB mehrfach belegt (s. Richter 2004, 501) und wurde jährlich im 10. Monat gefeiert, in den auch die hier behandelte Tafel YOS 5, 163 datiert. Die Schreibung wäre dennoch ungewöhnlich; vgl. Cohen 1993, 232 zu einer möglichen Variante zum Festnamen mit $\mathrm{u}_{4}$-ezem? mah. Zum ezem-mah des Nanna zur Ur III-Zeit s. Sallaberger 1993, 191-194.

${ }^{674}$ Vgl. Sallaberger 1993, 68 zu TRU 41 mit zehn Sängerinnen! und weiteren Belegen in den Šlgi-Hymnen $A$ und $X$. Zur Pflege dieses Festes durch das Personal des Ekišnugal zur Zeit der Larsa-Könige vgl. das Gebet des Rīm-Sîn an Nanna (Rimm-Sîn F) 34-38, zulezt bei Brisch 2007, 228-231; s. a. Gungunum B Fragment C.

${ }^{675}$ In den Zeugenlisten zweier privater Verträge werden weitere Vertreter dieses Musikerberufs mit Namen aufgeführt: UET 5, 160:17.21 (Sel 6) und UET 5, 95:27a (Ha 33); zusammenfassend Kapitel 5.4.3.

${ }^{676}$ Vgl. beispielsweise die Hymne Nanna E, das Širnamgala Nanna L 18-21 oder das Adab an Nanna des Išme-Dagan (Išme-Dagan M) 27-30.

${ }^{677}$ Zur Verbindung von Neulicht und dem Spiel des balag̃ s. literarisch Šulgi $N$ 39ff. v. a. 45 „dass der Mungo für dich das bala g̃ schlägt“ inmitten einer Tierkapelle? Möglicherweise auch lautmalerisch gemeint nach Cavigneaux/Al-Rawi 2000, 76 ,que la mangouste fasse boumboum pour toi!“. 
konnten zum Fest einer Gottheit im Verlaufe eines Tages mehrere Opferhandlungen, begleitet von jeweils anderen Musikdarbietungen ausgeführt werden.

\subsection{Larsa}

\subsubsection{Historischer Hintergrund und Quellenlage}

Die Stadt Larsa (heute: Senkereh) ist bereits frühdynastisch als Kultort des Sonnengottes Utu/Šamaš belegt. ${ }^{678}$ Besondere Zuwendung erfuhr der Kult des Sonnengottes im zweiten Jahrtausend zur Zeit der Larsa-Dynastie, deren Könige zahlreiche Bauarbeiten an seinem Tempel Ebabbar durchführen ließen. ${ }^{679}$ Auch nach der Eroberung der Stadt durch Hammurabi und dem damit einhergehenden Untergang der Larsa-Dynastie wurde der Kult des Sonnengottes im Ebabbar weiterhin gepflegt. In dieser Zeit wurde Šamaš zu einem der wichtigsten Götter des Reiches und zum persönlichen Gott des Königs erhoben.

Für eine kurze Zeit gelang es Rīm-Sîn II. von Larsa im Zuge der südbabylonischen Revolte sich der Vorherrschaft Babylons zu widersetzen (Si 8-11), bis er dem babylonischen König Samsuiluna endgültig um 1739 unterlag. Larsa selbst wurde zerstört und schließlich aufgegeben, der letzte Text datiert in das Jahr Samsuiluna 11. Eine Wiederbesiedlung des Ortes ist erst wieder für das 14.-13. Jahrhundert nachweisbar. ${ }^{680}$

Neben dem Sonnengott Utu/Šamaš erweist sich auch der Kult der Inana/Ištar als einer der ältesten in Larsa ${ }^{681}$ An ihrem Tempel bauten vor allem die Larsa-Könige Gungunum, Sumu'ēl und Rìm-Sîn I. Zu demselben Tempel gehörte außerdem eine unter letzterem König angelegte Kultstätte für die seit Sîn-iddinam in Larsa verehrte Nanaja ${ }^{682}$ Ebenfalls in Larsa war der Kult der Inana von Zabalam (heute: Tell Ibzayh) angesiedelt. Der früheste Beleg für diese auch Sugallìtum genannte Gottheit datiert in die Regierungszeit des NūrAdad (1865-1850) von Larsa. ${ }^{63}$

Ein Großteil der Dokumente Larsas wurde im Kunsthandel erworben, weshalb die Zuordnung der Texte zu diesem Fundort hauptsächlich auf inhaltlichen Kriterien beruht. ${ }^{644}$ Mit einiger Wahrscheinlichkeit entstammen einige von

\footnotetext{
${ }^{678}$ Richter 2004, 337.

${ }^{679}$ Richter 2004, 338-343.

${ }^{680}$ Zur politischen Geschichte s. Margueron/Huot 1980-83, 497-498; Charpin 2004, 101-108, 116-127, 340-341.

${ }^{681}$ Richter 2004, 363.

${ }^{682}$ Richter 2004, 372-373.

${ }^{683}$ Richter 2004, 365-366. Zu Sugallitum s. Stol 2001, 174-175.

${ }^{684}$ Die Texte sind in TCL 10 und 11; YOS 5, 8 und 14 und anderen Publikationen veröffentlicht; Margueron/Huot 1980-83, 496-497; Charpin 2004, 411-414.
} 
ihnen kleineren auch noch unbekannten Ortschaften in der näheren Umgebung Larsas.

Larsa-Dokumente lassen sich größtenteils aufgrund prosopographischer Daten zu Einzelarchiven zusammenführen. So dokumentieren die Texte des so genannten Ölarchivs die Manufaktur und Ausgabe von Sesamöl für den privaten und öffentlichen Bereich. ${ }^{65}$ Diese Einzelarchive werden als verschiedene Einheiten eines größeren Amtsarchivs identifiziert, das die staatliche Produktion und ihre Verwaltung dokumentiert. ${ }^{686}$

Die meisten Texte sowohl älterer als auch der jüngsten französischen Ausgrabungen in Larsa sind bisher nicht in Veröffentlichungen zugänglich. ${ }^{687}$ Texte dieser Grabungen stammen aus den öffentlichen Baukomplexen der Stadt, aus dem Ebabbar-Tempel, dem Palast des Nūr-Adad, des Sîn-iddinam und schließlich auch aus kleineren Wohn- oder Sakralbauten. ${ }^{688}$ Bemerkenswert ist beispielsweise der Fund zahlreicher Emesal-Texte der Gattungen Bala g̃ und Eršema in einem Privathaus, worin die Bibliotheksreste oder Schreibübungen eines gala oder gala-mah vermutet werden. ${ }^{69}$ Weiterhin sind Daten zu den nar-Musikern des Königspalasts von Larsa zu erwarten.

\subsubsection{Die namentlich belegten Musiker von Larsa}

Für die Stadt Larsa sind mir insgesamt 41 Urkunden und Verwaltungstexte sowie neun Briefe mit Belegen zu den Musikern gala und nar bekannt geworden. Sie datieren in die Regierungszeit der Könige Sîn-iddinam (1849-1843) bis Samsuiluna (1749-1712) und dokumentieren damit einen Zeitraum von etwa 100 Jahren. Unter den Briefen befinden sich fünf aus der Korrespondenz des Šamaš-hāzir, dem Stadtverwalter Larsas unter König Hammurabi von Babylon.

Unter den Urkunden, die den größten Teil der Texte bilden, finden sich Schuld- und Familienrechts- sowie Kaufurkunden zu Transaktionen von Grundstücken, Ländereien und Immobilien. Zu den Verwaltungstexten zählen wenige Rationenlisten sowie Quittungen über Ausgaben von Getreide oder auch Metallen.

\footnotetext{
${ }^{685}$ Etwa 148 Texte; YOS 14 S. 12-15; Charpin 1979, 191-193.

${ }^{686}$ Dyckhoff 2002 mit Bibliographie.

${ }^{687}$ S. zuletzt Hout 2003.

${ }^{688}$ Beschreibung der Texte bei Arnaud 1976, 41-76; Arnaud 1981, 46-99; Arnaud 1994; Charpin 2003, 313-315.

${ }^{689}$ Im Haus B 59 Raum 12: Die Tafeln lagen auf einem älteren Fußboden verstreut, der in die Regierungszeit des Rìm-Sîn datiert; Charpin 2003, 314-315 und Calvet 2003, 172-173, 188189, 195, 231 Fig. 40.
} 
Etwa ein Viertel der Texte entstammen dem Privatarchiv eines gewissen Balg̃unambe, ${ }^{690}$ welcher zuletzt von Dyckhoff als Hauptverwalter des EnkiTempels von Larsa identifiziert wurde. ${ }^{61}$ Die Familie dieses Balg̃unambe stammt wohl ursprünglich aus Eridu, weshalb Beziehungen zum dortigen EnkiTempel bestanden haben könnten. ${ }^{692}$ Die Texte seines Verwaltungsarchivs bestehen größtenteils aus Sklavenkauf- oder Freilassungsverträgen sowie Immobilienkaufurkunden und Schuldscheinen. ${ }^{693}$ Darüber hinaus werden seinem Archiv auch Gebete und Königshymnen, Beschwörungen aber auch die Opferrationenliste HUCA 34, 1ff. zugeordnet. ${ }^{694}$ Dyckhoff vermutet am Tempel des Enki eine wichtige zentrale Bibliothek zur Zeit des Rīm-Sîn und nachfolgender babylonischer Könige.

\subsubsection{Die gala-mah}

In den Texten aus Larsa werden drei gala-mah namentlich erwähnt: UbārŠamaš, Nanna-kiag̃ und Saniq-pī-[GN] (mit Kurznamen Sanqum). ${ }^{695}$ Ein weiterer gala-mah des Dumuzi, dessen Name nicht angegeben wird, ist im Brief BBVOT 3, 64/65 (o.D.) belegt.

Der gala-mah Ubār-Šamaš wird einmalig in der Larsa-Ritualliste genannt, wo er für den vierten Tag, dem 19. des elften Monats zum Fest der Göttin Nanaja als Empfänger eines /bardul/-Gewands aufgeführt wird ${ }^{696}$ Ansonsten werden bei diesem Opferfestritual keine weiteren Vertreter dieses Berufs erwähnt. Dies verwundert insofern, als dass an allen übrigen Festtagen, mit Ausnahme des Enki-Festes, grundsätzlich auch gala-Priester teilnahmen. ${ }^{697}$ Der einmalig erwähnte gala-mah Ubār-Šamaš wird der Göttin Nanaja zugewiesen, an deren Kultanlage er möglicherweise seinen Dienst pflegte. ${ }^{698}$

Auch der gala-mah Nanna-kiag̃, Sohn des Imgur-Sîn, ist nur einmal belegt, und zwar als Zeuge einer Urkunde aus dem Archiv des Qǐšti-Erra. ${ }^{699}$ Diese Urkunde enthält den Kauf von Gartengrundstücken, die in der Nähe eines Nanna/Sîn-Gartens lagen. Zum Kult des Nanna/Sîn und seiner Gemahlin

\footnotetext{
${ }^{690}$ Dyckhoff 1999/I-II; zu den Familienstrukturen s. Kalla 2002, 148.

${ }^{691}$ Van de Mieroop 1987b, 1-29; Dyckhoff 1998, 117-123; Dyckhoff 1999/I, 119-120.

${ }^{692}$ Kalla 2002, 133, 148.

${ }^{693}$ Vgl. Dyckhoff 1999/I, 27-28.

${ }^{694}$ Darunter der Liebesdialog des Rìm-Sîn (YOS 11, 24) und die sumerischsprachigen Gebete Hammurabi B (TCL 16, 61) Samsuiluna B (TCL 16, 43); Dyckhoff 1999/I, 108-113; Westenholz/Westenholz 2006, 7-8.

${ }^{695}$ Westenholz/Westenholz 2006, 52:vi 20; VS 13, 80:Rs 12 (RS 39); RA 69, 122 Fig. 8:27 + Siegel (Si 3); YOS 12, 325:25 (Si 10).

${ }^{696}$ Westenholz/Westenholz 2006, 52:vi 20. [1] ${ }^{\top} \operatorname{tug}_{2} \cdot$ bar-dul $_{8}{ }^{7}$ U-bar- ${ }^{\mathrm{d}}$ Utu gala-mah und hier Kapitel 9.2.3.3.

${ }^{697}$ Westenholz/Westenholz 2006, 32 mit Angabe der Textstellen.

${ }^{698}$ Renger 1969, 191, 196.

${ }^{699}$ VS 13, 80:12 (RS 39).
} 
Ningal in Larsa liefern die Texte nur wenig Belege, dennoch vermutet Richter, dass sich an diesem Tempel eine größere Verwaltungseinheit befunden habe. ${ }^{700}$ Die Namensgebung des gala-mah ist ein weiteres Indiz für seine Zuordnung zu einem Nanna/Sîn-Tempeldienst.

Einzig der dritte gala-mah Saniq-pī-[GN], kurz Sanqum, ist nach zwei Texten bekannt, in denen er ebenfalls als Zeuge auftritt. Beide Rechtsurkunden datieren in die Regierungszeit des Samsuiluna, wobei die erste, der Scheidungsvertrag RA 69, 122 Fig. 8 das Siegel des Sanqum erhalten hat:

T 44: RA 69, 122 Fig. 8 (Si 3) Siegel f:

Saniq-pī-[GN] Sohn des Warad-Zugal, Diener der Inana von Zabalam.

$S a_{3}-n i-i q-p i(\mathrm{KA})-{ }^{\mathrm{d}}[\mathrm{x}]^{701}$ dumu $\operatorname{Ir}_{3}-{ }^{\mathrm{d}} \mathrm{Zu}-{ }^{-} \mathrm{gal}^{7} \mathrm{ir}_{3}{ }^{\mathrm{d}}$ Inana $\mathrm{zabalam}^{\mathrm{ki}}$

In den Zeugenlisten beider Urkunden wird der gala-mah unter seinem Kurznamen Sanqum angeführt: ${ }^{\mathrm{I}} \mathrm{Sa}_{3}$-an-qum gala-mah ${ }^{\mathrm{d}} \mathrm{Su}_{2}$-ga-li-tum. Wie bereits erwähnt, ist der Kult der Inana Zabalam in Larsa seit Nūr-Adad dokumentiert. ${ }^{702}$ In Sippar ist für dieselbe Göttin die Stiftung einer Kesselpauke (lilis) durch den lokalen König Itēr-pīša attestiert. ${ }^{703}$ Einem sumerischen Klagelied zufolge entstammen der Stadt Zabalam spezialisierte Sängergruppen, die am Vortrag von Klagen für Dumuzi unter der Anleitung seiner Schwester G̃eštinana beteiligt sind. ${ }^{704}$ Mit der Stadt Zabalam und dem Kult seiner Hauptgöttin Sugallìtum scheint damit ein traditionsreiches Zentrum für die musikalische Gestaltung der kultischen Klage vorzuliegen.

Zuletzt sei auf den einmalig ohne Namen belegten gala-mah des Dumuzi im Brief BBVOT 3, 64/65 hingewiesen, der wohl der nahe Larsa gelegenen Stadt Badtibira, dem Hauptkultort dieses Gottes, zuzuordnen ist. ${ }^{705}$

\subsubsection{Die nar-gal}

Für Larsa ist lediglich ein nar-gal des Šamaš mit Namen Ilī-iddinam belegt. Im Kaufvertrag YOS 12, 227 (Si 7) über ein Baugelände aus dem Archiv des Šamaš-hāziri ${ }^{706}$ tritt dieser als letzter Zeuge einer vergleichsweise langen Zeu-

\footnotetext{
${ }^{700}$ Richter 2004, 391.

${ }^{701}$ Möglicherweise ist der GN Inana zu rekonstruieren, in deren Diensten der Priester stand.

${ }^{702}$ Kultreisen für Sugallītum (alias Supalītum) finden sich im Balg̃unamhe-Archiv dokumentiert: YBC 7262 (RS 4) und YOS 5, 172 (RS 7) Schiffsreisen u. a. nach Uruk; Dyckhoff 1999/I, 69 und 1999/II, 56-57.

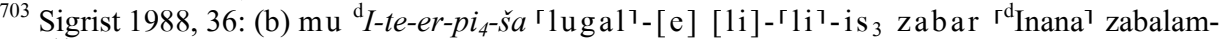
ki-ra mu-na-dim 2 ,Jahr: Itēr-pišsa der König hat eine bronzene lilis-Trommel für Inana von Zabalam gebaut".

${ }^{704}$ Dumuzi-Inana J; Alster 1985; s. a. hier Kapitel 12.3.1 und 14.2.1.

${ }^{705}$ Für Larsa ist ein Kult des Dumuzi nur durch eine einzige Urkunde bezeugt; Richter 2004, 376.

${ }^{706}$ Zuordnung aufgrund des Zeugen Aplum, der Versammlungsleiter $\left(\mathrm{a}_{2}-\tilde{g} \mathrm{al}_{2}\right)$ von YOS 12,
} 
genliste (insgesamt 17 Zeugen) auf. ${ }^{707}$ Weiterhin nennt die Opferrationenliste HUCA 34, 1ff. (RS 22) in Kolumne iii 23 einen nar-gal ohne Namen zum Fest des Šamaš. ${ }^{708}$ Dieser ist möglicherweise dem Tempel desselben Gottes zuzuordnen. Ein letzter nar-gal namens Šu-Amurrum wird im Brief AbB 9, 193 aus der Šamaš -hāzir-Korrespondenz genannt, dort allerdings keinem Gott zugeordnet. ${ }^{709}$ Dieser Brief des Hammurabi betrifft ein Lehensfeld im Eigentum des Palastes, das an eine Gruppe von hupph-Tänzern zu vergeben war. Nach Angabe des Briefes waren die huppû-Tänzer dem nar-gal unterstellt. Derselbe nar-gal könnte wiederum im Brief AbB 8, 109 genannt sein und einer Gruppe von aluzinnu vorstehen. ${ }^{710}$

Insgesamt sind für Larsa seit der Zeit der Larsa-Könige nur nar-gal am Ebabbar des Šamaš nachweisbar, im Falle des Šu-Amurrum bleibt die Zuordnung unklar. ${ }^{711}$ An der engen Verbindung zu Šamaš-hāzir zeigt sich dennoch eine gewisse Verantwortung des nar-gal gegenüber dem Palast, auch in der Aufsicht über künstlerisches Personal, in diesem Falle die hupp $\hat{u}$-Tänzer.

\subsubsection{3 nar und gala}

In Verwaltungstexten und Urkunden der Stadt Larsa finden sich insgesamt 12 Namen von einfachen nar-Musikern. ${ }^{72}$ Nur zwei gala sind demgegenüber namentlich belegt: Sîn-ēriš und Warad-ilī̌su. Sîn-ēriš ist Zeuge in der Gartenkaufurkunde Riftin 20 (RS 30), die keinem bekannten Archiv zugeordnet werden kann. Der zweite gala Warad-ilǐšu wird in TCL 11, 156 (Ha 36) neben Palastangestellten und Funktionären des Ebabbar-Tempels als Empfänger eines Lehensfeldes genannt.

227:33, der auch in TCL 11, 148:7 und TCL 11, 162a:21 aus dem Achiv des Šamaš-hāzir belegt ist; Charpin 1981, 539 zu Nr. 227.

${ }^{707}$ Renger 1967, 174 verzeichnet diese Urkunde fälschlicherweise sowohl unter Ur als auch unter Larsa.

${ }^{708}$ Westenholz/Westenholz 2006, 44.

${ }^{709}$ Für den namensgebenden Gott Martu/Amurrum dieses nar-gal ist in Larsa nur ein unbedeutender Kult nachweisbar; Richter 2004, 381-382, 461.

${ }^{710}$ S. hier Kapitel 5.5.2.

${ }^{711}$ Ein weiterer Beleg zu einem nar-gal könnte in Bab. 7, 46:5 (RS 3) vorliegen, wo die Ausgabe von Sesamöl aus Anlass des NE.NE-g̃ar-Festes des Enki verbucht wird. Als Empfänger steht in Z. 5 ein Sîn-ēriš $1 u_{2}-n a r-{ }^{\top} g a{ }^{1}$, die Lesung bleibt allerdings ohne erneute Kollation unsicher; vgl. Richter 2004, 355 + Anm. 1509.

${ }^{712}$ S. Musikerkatalog Kapitel 16. 
Zusätzlich zu einfachen nar-Musikern sind zwei nar-sa, ${ }^{713}$ zwei dumu ugula nar, ${ }^{714}$ ein dumu (munus-)nar ${ }^{715}$ und ein nar $\mathrm{ra}_{2}$-gaba ${ }^{716}$ mit Namen bezeugt. Außerdem werden Gruppen männlicher wie auch weiblicher nar genannt. ${ }^{717}$

Die Texte aus der Regierungszeit der Könige Warad-Sîn und Rìm-Sîn von Larsa gehören hauptsächlich dem Archiv des bekannten Balg̃unamhe, Sohn des Sîn-nūr-mātim an. Nach Ansicht Dyckhoffs besetzte dieser die höchste Verwaltungsinstanz am Enki-Tempel. ${ }^{718}$ Die in diesen Texten genannten nar könnten demnach dem Personal des Enki-Tempels angehören. ${ }^{719}$ Häufig belegt ist aus der Zeit der Könige Warad-Sîn und Rīm-Sîn ein nar mit Namen Sîn-māgir. ${ }^{720}$ Ein weiterer Musiker mit Namen Sîn-māgir wird nach TCL 10, 39 (RS 14), wo er erster Empfänger einer Silberausgabe ist, dem Ort Maškan-šāpir zugewiesen, möglicherweise ein Reisender. ${ }^{721}$ Der Anlass seiner Bezahlung wird allerdings nicht bekannt.

Mit Sîn-ilī wird ein weiterer nar aus den Archivtexten des Balg̃unambue bekannt. In der Ausgabenquittung YOS 5, 191 (RS 9) ist er neben einem Koch und einem Tischler Empfänger von Gerste. ${ }^{722}$ Derselbe nar wird in der Ritualliste HUCA 34, 1ff. unter den Beteiligten am Enki-Fest genannt, wonach er ein /bardul/-Gewand erhielt. ${ }^{723}$ Dieselbe Person könnte nach zwei weiteren Texten Bronze empfangen haben. ${ }^{724}$ Die Sonderausgaben an diesen Musiker vor allem im Zuge des Enki-Festes zeugen von seiner hohen Stellung. Ob die Bronze, wie

${ }^{713}$ Die Brüder Etel-pī-Sîn und Inana-muzuše-nirg̃al, Söhne des Zarriqum in TCL 11, 146:20-23 (Ha 33).

${ }^{714}$ Ilī-hāzirī und Elmēšum, Zeugen in TCL 10, 112:23-24 (RS 56).

${ }^{715}$ Amurrum-tillassu in RA 85, 38 Nr. 2:6.14 (RS 49); YOS 8, 153:13 (RS 55).

${ }^{716}$ Ilī-iqišsam im Brief AbB 4, 12:4.

${ }^{717}$ ARRIM 4, 14:48 (o.D.); YOS 5, 216 (Sid 7); JCS 4, $111 \mathrm{a} / \mathrm{b}-112$ (Sid 5).

${ }^{718}$ Dyckhoff 1998, 122-123; in der derzeit laufenden Forschung wird diese Deutung erneut unter Diskussion gestellt.

${ }^{719}$ YOS 8, 6:4.29 (RS 3) Ipquša; YOS 8, 48/48a:10/8 (RS 34) Lalûm; YOS 8, 47:25 (RS 6) Nūrkabta; YOS 8, 20:27 (RS 8) Pušuja; YOS 8, 36:9 (RS 22) und YOS 8, 15:21 (RS 23) Utuzig̃u; YOS 8, 41:22 (RS 23) und YOS 8, 13:22 mit Siegel (Koll. Van de Mieroop 1987b, 28) Enlil-mansum.

${ }^{720}$ Zum Zeugenkreis des Balg̃unamhe gehörig in YOS 5, 128:11 (WS 10); YOS 8, 31:21 (RS 21); YOS 8, 36:14 (RS 22); YOS 8, 25:17 (RS 23); Bab. 7, 45:13 (RS 23); YOS 8, 45:19 (RS 25); YOS 8, 72:19 (RS 25); YOS 8, 19:16 (RS 31); vgl. Dyckhoff 1999/II, 145-146 sub Sîn-māgir. Wohl nicht derselbe aus YOS 14, 348:22 (SiEr 1), der Empfänger einer Silberschenkung. Auch nicht identisch mit dem gleichnamigen Bruder des Balg̃unamhe; Dyckhoff 1999/I, 69-70.

${ }^{721}$ TCL 10, 39:4 (RS 14) mit Silberausgaben verschiedener Bestimmung; Dyckhoff 1999/II, 3943.

${ }^{722}$ Gerste aus dem Lagerhaus des Tarỉbum; Dyckhoff 1999/I, 54 und II, 75-76.

${ }^{723}$ Westenholz/Westenholz 2006, 35, 40-41.

${ }^{724}$ In YOS 5, 235:3 (RS 13) und YBC 6207 (RS 10) ohne Berufsangabe; vgl. Dyckhoff 1999/I, 103 und II 51, 93-94. 
Dyckhoff an gleicher Stelle mutmaßt, für den Bau von Musikinstrumenten aufgewendet werden sollte, ist nicht nachzuweisen.

Insgesamt fällt die hohe Anzahl an Musikern auf, die aus dem Personenumfeld des Balg̃unambe bekannt werden. Dies hängt höchstwahrscheinlich mit der Verbindung zum Enki-Tempel zusammen, der bekanntlich als Schutzpatron der Musiker galt. Als Empfänger von Silberbeträgen sind zwei weitere Musiker bezeugt, die nicht diesem Personenkreis angehörten: Sîn-māgir aus Maškanšāpir und Šu-Sîn, der möglicherweise dem Nanna-Tempel zugeordnet ist. ${ }^{725}$

Eine Person, die in Texten aus den Jahren Rīm-Sîn und Samsuiluna hervorsticht, ist ein gewisser Amurrum-tillassu, der als dumu nar oder dumu munus nar ausgezeichnet wird. ${ }^{726}$ Der Ausdruck dumu (munus) nar „Sohn des nar-Musikers/der nar-Musikerin" muss hier nicht im Sinne eines eigenständigen Berufstitels aufgefasst werden, sondern lediglich als Zuordnung zu einer Berufsgruppe innerhalb eines Familienkreises im Sinne einer 'Gilde' oder eines 'Clans'. Amurrum-tillassu erhielt Geschenke in Form von Ländereien und Immobilien des Königs. Dieses ihm von Rìm-Sîn geschenkte Land wurde noch unter Samsuiluna von ihm selbst verwaltet:

T 45: YOS 12, 307 (Si 8)

„(Betreff des) [...] sar 15 še Baulands, [das] der König Rīm-Sîn Amurrumtillassu gegeben hat; Šamaš-tillatī, Kurrûm, Sohn des Šamaš-ummati und Unnubtum seine Mutter, sowie Țāb-qabâša!, Tochter des Timgu und Narubtum ihre Mutter; 5 Šekel Silber haben sie nach Vereinbarung des Šamaš-Tempels von Amurrum-tillatī erhalten. Ihre Herzen sind befriedigt. (Abschlussformel und Zeugen).“

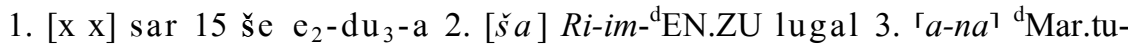
kaskal.kur-su 2 i-di-nu 4. ${ }^{\text {Id } U t u-k a s k a l . k u r-t i ~} *$ Rasur* 5 . ${ }^{\mathrm{I}} \mathrm{Ku-ru-um} \mathrm{dumu}$ ${ }^{\mathrm{d}} \mathrm{Utu}-u m-<m a>-t i \quad 6 . \quad u_{3} \quad U n-n u-u b-t u m$ ama-ni 7. ${ }^{\mathrm{I}} T a_{3}-a b-q a_{2}-\mathrm{AS} \breve{S}^{\prime}-b a-\check{s} a$ dumu-<munus $>$ Ti-im-gu 8. $u_{3}$ Na-ru-ub-tum ama-ni

9. $5 \operatorname{gin}_{2} \mathrm{ku}_{3}$-babbar $\check{s} a$ mi-it-gu-[ur-ti $\left.{ }^{2}\right] \quad 10 . \mathrm{e}_{2}{ }^{\mathrm{d}} \mathrm{Utu} i-n a a_{2}-t i{ }^{\mathrm{d}}$ Mar.tukaskal.kur- $t i^{727}$

11. il-qu $u_{2}-u_{2} l i-b a-\check{s} u-n u$ 12. ța $a_{3}-a b$

13. la i-tu-ru la $i-z[i-z u] 14 . \mathrm{mu}{ }^{\mathrm{d}} \mathrm{Utu} u_{3} S a-a m-s u-<i>-l u-n a$ lug al

15. in- pad $_{3}-$ meš

16. igi E-tel-KA-ša ab-ab-du ${ }_{7} \quad 17 .{ }^{\mathrm{I}} I_{3}-l i_{2}-u_{3}{ }^{\mathrm{d}}{ }^{\mathrm{d}} \mathrm{Utu} \quad 18 .{ }^{\mathrm{I}} \check{S}_{20} e_{20}-e p-{ }^{\mathrm{d}} \mathrm{EN} . Z U$

19. ${ }^{\mathrm{I}} A$-hi-ia nu-banda 3 20. ${ }^{\mathrm{I}} I-d i n-{ }^{\mathrm{d}} \mathrm{EN} . Z \mathrm{U} \quad 21 .{ }^{\mathrm{I}} I_{3}-l i i_{2}-i p-p a-a l-s a_{3}-a m$

22. ${ }^{\mathrm{I}}$ A-na-E $E_{2}-a-t a k_{2}-l a-k u \quad 23 .{ }^{\mathrm{Id}} \mathrm{Utu}-\mathrm{s} a-h i-r i \quad 24 .{ }^{\mathrm{I}} \mathrm{I}_{3}-l_{2}-i-r i-b a-a m$. (Datum).

\footnotetext{
${ }^{725}$ TCL 10, 39:4 (RS 14) Sîn-māgir; TCL 10, 45:8 (RS 16) Šu-Sîn.

${ }^{726}$ RA 85, 38 Nr. 2:6.14 (RS 49); YOS 8, 153:13 (RS 55); derselbe in YOS 12, 307:3.10 (Si 8); als Sklavenkäufer in YOS 12, 225:6 (Si 7); die meisten Texte dieses Archivs sind nach Anbar/Stol 1991, 15 Anm. zu L. 6 unveröffentlicht.

${ }^{727}$ Wohl Verschreibung für denselben Amurrum-tillassu.
} 
In welchem Verhältnis die genannten Personen zu Amurrum-tillassu standen, ist unbekannt, zumindest wurden sie an den Erträgen seines Landes aus unbekannten Gründen beteiligt.

In Anbetracht des Landbesitzes dieses Amurrum-tillassu und seiner Stellung zu Palast und Tempel muss er einer einflussreichen Familie von Musikern entstammen, die bereits unter Rìm-Sîn von Larsa hohes Ansehen genoss und hierin den politischen Machtwechsel zur Herrschaft der babylonischen Dynastie überdauerte.

Weitere Belege zu nar-Musikern sind in Briefen der Šamaš-hāzir-Korrespondenz enthalten. ${ }^{728}$ Hauptthema dieser Briefe des Hammurabi an seinen Stadtverwalter sind Lehensfelder von nar-Musikern, die im Dienste des Palastes standen. Beim nar $\mathrm{ra}_{2}$-gaba Ilī-iqī̌sam, dem „Berittenen“ im Brief AbB 4, 12 könnte es sich nach Renger um einen Lehensdienst handeln. ${ }^{729}$ Möglicherweise handelt es sich hier um einen Musiker mit überregionalen künstlerischen Verpflichtungen. Lehensfelder des Königs erhielten auch die zwei namentlich belegten nar-sa Etel-pī-Sîn, Sohn des Zarriqum, sowie dessen Bruder Inanamuzuše-nirg̃al nach der Liste TCL 11, 146 aus dem Jahr Hammurabi 33.

Aus der Zeit des Hammurabi ist schließlich auch ein nar des Gottes Amurrum mit Namen Idijātum belegt. ${ }^{730}$ Der Kult dieses Gottes ist in Larsa zwar relativ unbedeutend, er wurde dennoch regelmäßig seit der Zeit der frühen Larsa-Könige gepflegt. ${ }^{731}$

Nur in wenigen Texten sind nar als Empfänger von Naturalien, wie Getreide, Öl oder Bier verzeichnet. ${ }^{732}$ Abgesehen von der Ritualliste HUCA 34, 1ff. und den Listen JCS 4, 111a/b-112 (Sid 5b), die in den folgenden Kapiteln behandelt werden, sind Musiker noch in der folgenden Ausgabenquittung über Bierrationen belegt:

\footnotetext{
${ }^{728} \mathrm{AbB} 4,12 ; \mathrm{AbB} 4,14 ; \mathrm{AbB} 4,62 ; \mathrm{AbB} 9,188$.

${ }^{729}$ Renger 1969, 186; s. a. Dombradi 1996, § 342-344.

${ }^{730}$ TCL 11, 174:33' (Ha 34) Zeuge neben einem weiteren nar Ibbi-ilim, Vater des Ilšu-nāṣir, welcher bereits unter Rìm-Sîn in TCL 11, 224:63 (RS 51) genannt wird.

${ }^{731}$ Richter 2004, 381-383.

${ }^{732}$ HUCA 34, 1ff., dazu hier Kapitel 8.2.3, und YOS 5, 216 (Sid 7). Der Beleg in TCL 10, 97:7 mit nar.hi. a bei Renger 1969, 175 ist obsolet; s. CAD E 140 ANŠE.HI.A ša ana še'im ša GN e-me-di-im iguru „of the donkeys which they have hired in order to load barley for GN“.
} 
T 46: YOS 5, $216(\operatorname{Sid} 7)$

1. $0.1 .1 .0^{\Gamma \mathrm{n}\urcorner} \mathrm{ar}-\mathrm{me} \breve{s}$

0.0.1.0 ${ }^{\ulcorner}$munus-nar ${ }^{7}-$ meš

0.0.4.0 $\left.{ }^{\ulcorner} \mathrm{ma}-a q-q i_{2}-t u m\right\urcorner$

「0.0.4.0? Ku-du-ur-ma-bu-uk

5. $\left.0.2 \cdot{ }^{\ulcorner} 4^{?}\right\urcorner .0 \mathrm{kaš}-\mathrm{x}$ ?

gi-na (Datum)

Bezeichnend sind hier zunächst die unterschiedlich ausfallenden Rationenmengen an die männlichen (70 Liter) gegenüber den weiblichen (10 Liter) nar. Weiterhin werden 40 Liter für eine Libation sowie für Kudurmabuk, den Begründer der Larsa-Dynastie, ausgegeben. ${ }^{733}$ Die Tafel gehört einem Palastarchiv an, ${ }^{734}$ wodurch auch die Bierrationen dieser Institution zuzuordnen sind. $\mathrm{Ob}$ die aufgeführten Ausgaben alle demselben Anlass zugute kamen, beispielsweise einer Festhandlung mit Opferungen und Musikdarbietungen, muss allerdings unbeantwortet bleiben.

\subsubsection{Palastmusikerinnen in Larsa}

$\mathrm{Zu}$ Musikerinnen-Gruppen werden Informationen aus drei Listen über Ölzuteilungen bekannt, die möglicherweise einem Palastarchiv angehörten. In JCS 4, $111 \mathrm{a}, 111 \mathrm{~b}$ sowie $112 \mathrm{~b}^{735}$ sind einzelne nar-Musikerinnen unter Angabe ihres Namens als Empfängerinnen genannt. In den ersten zwei dieser drei Listen sind insgesamt 18 nar-Musikerinnen mit Namen aufgeführt, die bis auf wenige Ausnahmen miteinander identisch sind. Lediglich die Reihenfolge der Namen variiert in ihrer Aufzählung: ${ }^{.76}$

${ }^{733}$ Kommentar: Z. 3. maqqītum „Libation; Opfer“s. CAD M/1 253 mit Zitat; Z. 4. Es handelt sich hier um den einzigen Beleg für Kudurmabuk zur Zeit des Sîn-iddinam; Charpin 2004, 116-117. 5. Das letzte Zeichen ist unleserlich, es bleibt damit unklar, um welche Art Bier es sich handelt.

${ }^{734}$ Stol 1976, 10 Anm. 3-4.

${ }^{735}$ Trotz des schlechten Erhaltungszustandes von JCS 4, 112b ist auch diese Liste der Ansicht Goetzes 1950, 98 zufolge den anderen zwei zuzuordnen.

${ }^{736}$ Die Kopien in JCS 4 sind überprüfungsbedürftig. Kommentar: In JCS 4, 111a ist für alle Musikerinnen dieselbe Menge Öl notiert, insgesamt 18 Liter. JCS 4, 111b und 112b geben pro Person unterschiedliche Ölmengen an. In JCS 4, $111 \mathrm{~b}$ findet sich keine Summierung der Ausgaben. Dennoch ist aus den einzelnen Mengenangaben ersichtlich, dass diese zwischen 0,5 und 1,5 Litern variierten. JCS 4, 112 bibt als Summe 33 Liter an. 
Tabelle 5: Larsa-Musikerinnen

\begin{tabular}{|c|c|}
\hline JCS 4, 111a & $\mathrm{JCS} 4,111 \mathrm{~b}$ \\
\hline 1. 1 sil $\left[a_{3} i_{3}\right]$-g̃ iš Nu-țu $\mathbf{u}_{3}$-up-tum & 1.-2.1 sila $_{3} \mathrm{i}_{3}$ - g̃iš ${ }^{\mathrm{d}}$ EN.ZU-nu-ri \\
\hline 2. 1 sila $_{3} \mathrm{i}_{3}-\tilde{g}$ iš Ištar-la-ma-si ${ }_{2}$ & 3. 1.1. Ištar-la-ma-si ${ }_{2}$ \\
\hline 3. 1 sila $_{3}$ Ši-ba-pi--「̌̌a $\mathbf{r}$ & 4. 1.2 Ha-bi! - iș-tum $^{737}$ \\
\hline 4. 1 sila $_{3}$ Ha-bi'-iș-tum ${ }^{737}$ & 5. 1.1 Ištar-šar-rat \\
\hline 5. 1 sila $_{3}$ Da-bi-tum & 6. $1.2 \mathrm{Si}^{*}$-bi*-a-pi $\mathbf{i}_{2}$-ša \\
\hline 6. 1 sila $_{3}$ Ia-šu-ha-tum & 7. $1.1 \mathrm{~A}-\mathrm{ma}-\mathrm{at}-\mathrm{ku}-\mathrm{bi}$ \\
\hline 7. 1 sila $_{3}{ }^{\mathrm{d}}$ EN.ZU-nu-ri & 8. $1.1 \mathrm{~A}$-ra-bu-tum \\
\hline 8. 1 sila $_{3}$ Ka-al-ba-tum & 9. $0.1 \mathrm{~A}-\mathrm{ha}_{\mathrm{a}}-\mathrm{su}_{2}-\mathrm{nu}$ \\
\hline 9. 1 sila $_{3}$ E-ri-iš-A.ZU & 10. $0.1 \breve{S a}^{738}-[\ldots .]$. \\
\hline 10. 1 sila $_{3}$ Ištar-šar-r[at] & $11.0 .1[. . .]$. \\
\hline 11. 1 sila $_{3}$ Iš-ta-[..] & 12. Rd. šu.[nig̃ in? .... \\
\hline Rs & \\
\hline 12. $1^{\ulcorner} \mathrm{sila}_{3}{ }^{\top}$ Ši-mi-[..] & 13. A-ha-ti-še-ma-at \\
\hline 13. $1^{\ulcorner} \mathrm{sila}_{3}{ }^{7} \mathrm{Du}-u m-\mathrm{mu}-[\mathrm{uq}-\mathrm{tum}]$ & 14. $\mathrm{Nu}$-țu $\mathbf{u}_{2}$-up-tum ${ }^{739}$ \\
\hline 14. $1^{\ulcorner}$sila $_{3}{ }^{\top}$ A-ha-ti-[šeme’at] & 15. 1.2 Da-bi-tum \\
\hline 15. $1^{\Gamma}$ sila $_{3}{ }^{7}$ Ša-at- ${ }^{\Gamma} I_{\text {štar }}{ }^{\top}$ & 16. 1.2 Eriš-A.ZU \\
\hline 16. $1^{\Gamma} \mathrm{sila}_{3}$ A-ra-bu-tum ${ }^{\top}$ & 17. Ia-šu-ha-tum \\
\hline 17. $1^{\ulcorner} \mathrm{sila}_{3}{ }^{\top} \mathrm{A}-\mathrm{ma}-{ }^{\ulcorner} \mathrm{at}^{\top}-\mathrm{ku}-\mathrm{bi}$ & 18. [x] Sa-la-tum \\
\hline 18. $1^{\ulcorner} \mathrm{Sila}_{3} \mathrm{Sa} \mathrm{Sa}^{\top}$-tum & 19. $1.1 \mathrm{Ka}-a l-b a-t u m$ \\
\hline 19. [šu.ni] g̃ in $1.8 \mathrm{i}_{3}-\tilde{g}$ is & 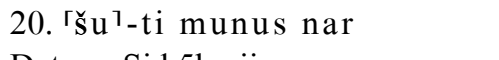 \\
\hline Datum: Sid 5b xi & Datum: Sid 5b xii \\
\hline
\end{tabular}

Aus den Texten JCS 4, 111a und b lassen sich folgende Namen rekonstruieren: ${ }^{740}$ Ahassunu, Ahāti-šeme'at, Amat-Kūbi, Arrabūtum, Dabītum, Dumm[uqtum], Eriš-A.ZU, Habiștum, Ištar-lamassī, Ištar-šarrat, Iš-ta-[..], Jašuhatum, Kalbatum, Nutțuptum, Sallatum, Sîn-nūrī, Šāt-Ištar, Šibia/â-pīša, ${ }^{741}$ Šìmi-[..].

\footnotetext{
${ }^{737}$ Wörtl. „die Üppige“ nach Emendation von JCS 4, 111a:4. Ha-AK/AL-iṣ-tum und JCS 4, $111 \mathrm{~b}: 4$. Ha-AŠ́-iș-tum.

${ }^{738}$ Nach der Kopie in JCS 4, 111b könnte hier ein NA oder ŠA stehen, möglicherweise ist hier der Name von JCS 4, 111a:15. Ša-[at-Ištar...] zu ergänzen.

${ }^{739}$ Die Namen in Zeile 13-14 sind eingerückt ohne vorangestellte Mengenangabe.

${ }^{740}$ Vgl. Renger 1969, 173-175.

${ }^{741}$ Mit unterschiedlichen Schreibungen: JCS 4, 111a:3 (Sid 5b), JCS 4; 111b:6 (Sid 5b). Die unterschiedlichen Namensversionen sind m. E. hier Zeugnis dafür, dass die Namenslisten diktiert wurden.
} 
Die dritte Liste JCS 4, 112b (Sid 5b) ist stark zerstört, vollständige Namen sind dort nicht erhalten. ${ }^{742}$ Dennoch ist nur in dieser dritten Liste als ausgebende Position ein gewisser Sîn-muballiṭ angegeben. ${ }^{743}$

Keine der drei Rationenlisten enthält Angaben zum Anlass der Ausgabe. Demzufolge könnten hier regelmäßige monatliche Ölzuteilungen vorliegen, wie sie auch für die Musikerinnen von Mari bekannt sind ${ }^{744}$ Dementsprechend könnten die Larsa-Musikerinnen dem Palastharem des Königs Sîn-iddinam angehören. Mit Ausnahme dieser drei Listen sind für die altbabylonische Zeit keine vergleichbaren Ausgaben an Palastmusikerinnen bekannt.

\subsubsection{Musik zu einem Opferfestritual von Larsa}

\subsubsection{Inhalt und Rekonstruktion des Festverlaufs}

$\mathrm{Zu}$ den wenigen altbabylonischen Verwaltungstafeln, die Informationen zur Beteiligung von Musikern an Götterfesten enthalten, zählt die mehrkolumnige Tafel HUCA 34, 1ff., die jetzt in CM 33 neu publiziert wurde. ${ }^{745}$ Diese bisher einmalige Opferrationenliste ${ }^{746}$ verzeichnet über insgesamt neun Kolumnen und etwa 450 Zeilen Opfer- und Materialausgaben, die für die Ausführungen eines achttägigen Ritualfestes für insgesamt acht Gottheiten und ihre jeweiligen Familienkreise aufgewendet wurden. ${ }^{747}$ Das Fest dauerte vom 15. bis zum 23. des elften Monats (Šabāțu) insgesamt acht Tage an, in deren Verlauf Opfer an die Götter und Geschenke an beteiligtes Personal dargereicht wurden, die u. a. kultische und künstlerische Handlungen ausführten. Jede dieser acht 'Bewirtungen' wird als kaš- $\mathrm{de}_{2}-\mathrm{a}$, wörtlich der „Bierausschank“ geführt, einem gängigen Ausdruck für das 'Gastmahl' oder 'Bankett' im Beisein der Götter. ${ }^{748}$

Für die Rekonstruktion des Handlungsverlaufs ist von besonderem Interesse, dass die Liste nicht nur Ausgabenmengen und beteiligte Personen nennt, sondern auch die jeweilige Tageszeit und den Anlass. Ein jedes der kaš-de ${ }_{2}-\mathrm{a}$ beginnt am Abend, nach altorientalischer Zeitrechnung der Anfang eines Tages, und endet am darauffolgenden Abend zum Beginn des nächsten Tages. $^{749}$

\footnotetext{
${ }^{742} \mathrm{JCS} 4,112 \mathrm{~b}$ (Sid 5b) 3. vielleicht $N u-t\left[u_{2}-u p\right.$-tum $]$ zu ergänzen.

743 JCS 4, 112b (Sid 5b) 2'. ki ' EN.ZU-mu-ba-li-it 3'. ba-zi 4.' x x. 5'. Datum.

${ }^{744}$ Ziegler 1999, 69-82.

745 Erstveröffentlichung durch Kingsbury 1963, jetzt in einer ausführlichen Neuedition bei Westenholz/ Westenholz 2006, 3-81.

${ }^{746} \mathrm{Zu}$ vergleichbaren Texten s. Westenholz/Westenholz 2006, 4-7.

${ }^{747}$ Ausführlich Westenholz/Westenholz 2006, 3-8 besonders 4+Anm. 2 gegen Kingsbury 1963, 26-27, der ein siebentägiges Fest ansetzt.

748 Sallaberger 1993, 35-36; Westenholz/Westenholz 2006, 20-21 mit Literatur und aB Belegen.

${ }^{749}$ Westenholz/Westenholz 2006, 19.
} 
Die acht Festtage und ihre Ausgaben waren den Göttern Ninsiana, Enki, Utu, Inana, Nanaja und Nergal, Ninegala, Dig̃irmah und ihren jeweiligen Familienkreisen, sowie abschließend dem vergöttlichten König Sîn-iddinam am 23. Šabātu gewidmet. Am letzten Tag, dem 24. des Monats folgten weitere Opferhandlungen, die nicht näher spezifiziert sind. ${ }^{750}$

Mit Ausnahme der ersten, sehr kurz gehaltenen Opferdarbietungen an Ninsiana, die auf dem Dach stattfanden, ${ }^{751}$ verliefen die Opferfeste aller übrigen Gottheiten relativ gleich. ${ }^{752} \mathrm{Am}$ Abend fand zunächst das pit bìtim statt, die „Tempelöffnung“. Auch wenn der Ausdruck in dieser Form auf diesen Text beschränkt bleibt, lässt er sich mit der andernorts belegten „Öffnung des Tores“ (pit bābim) in Verbindung bringen. ${ }^{753}$ Diese Zeremonie beinhaltete Schlachtund verschiedene Schüttopfer, die im Tempel selbst ausgeführt wurden.

Nach Ausführung weiterer Opfermahlzeiten, die hauptsächlich aus Getreideprodukten bestanden (nindabbum), wurden anschließend bei allen Gottheiten mit Ausnahme der Ninsiana tassistum-Klagen veranstaltet. ${ }^{754} \mathrm{Zu}$ dieser Zeremonie wurden ausschließlich pflanzliche Produkte aufgewendet, darunter verschiedene Öle, Mehl und Räuchermittel. ${ }^{755}$ Von Bedeutung ist hier vor allem die Tatsache, dass der Ausdruck tassistum auch in Kombination mit einer Gruppe von nar-Musikern gebraucht wird. Mögliche Parallelen zu den Ur IIIzeitlich belegten gerrānum-Klagen, die ausschließlich weiblichen Gottheiten

${ }^{750}$ Westenholz/Westenholz 2006,9-19, 38:i 11-12 (Ninsiana), 40:i 42-56, ii 24-25 (Enki und Asalluhi), 44:iii 49-50 (Utu), 48:v 8-9 (Inana), 52:vi 31-33 (Nanaja und Nergal), 54:vii 5052 (Ninegala), 58:viii 44'-45' (Dig̃irmah (Rek!)), 60:ix 50-51 (Sîn-iddinam) und 52-58 (abschließende Opferhandlung am 24.). Die Niederschrift der Tafel geschah nach Datumsangabe am selben Tag des Ritualabschlusses, dem 24. Šabātu.

${ }^{751}$ Westenholz/Westenholz 2006, 9, 38-39:1 1-12; Richter 2004, 371-372 zu Ninsiana in Larsa.

752 Insgesamt nimmt die Auflistung für Ninsiana nur 13 Zeilen ein. Beachtenswert sind dennoch

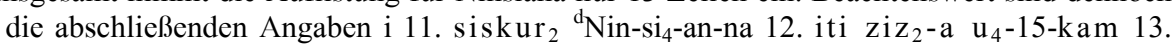
$\mathrm{u}_{4}-u m$ ni $\tilde{\mathrm{g}}_{2}-\mathrm{ab}_{2}$. Der letzte Ausdruck ni $\tilde{\mathrm{g}}_{2}-\mathrm{ab}_{2}$ verweist hier unmissverständlich auf ein Membranophon (vgl. Westenholz/Westenholz 2006, 65 mit Kommentar), das ähnlich dem bala g̃ und der/lilis/-Trommel eine Rolle im Kult spielte. S. bspw. Nanše A 39-41 „Gudea, ensi von Lagaš; stellte die 'Kuh des Überflusses'( $\left(\mathrm{b}_{2}\right.$-hii-nun) zu den /tigi/; stellte das heilige balag̃ an ihre Seite“. Für die Kulte um die „Kuh der Klage“ $\left(* a b_{2}-e r_{2} \cdot a(k)\right)$ in Ur III-Texten s. Heimpel 1998, 14-15 und OBTR 92 mit gala-mah Utu-bar-ra als Überbringer $\left(\tilde{g} \mathrm{ir}_{3}\right.$ ) der Opfermaterie (Sallaberger 1993, 298). Für die aB Zeit s. die LL aus dem Hause des Ur-Utu Tanret 2002, 83: 21. $\mathrm{ab}_{2}$ 22. li-li-su; Belege für das 1. Jt. bei Gabbay 2007, 71 und ergänzend in Bìt mēseri II 118 mašak rìmti șirti „Fell der erhabenen Wildkuh" (GMeier 1941-4, 146-147). Der 15. eines jeden Monats ist der Vollmondtag, an dem Ur III-zeitlich ebenfalls gerrānum-Klagen ausgeführt wurden; Sallaberger 1993, 46-47. Es liegt nahe, hier Klagegesänge unter Begleitung des Instruments ni $\tilde{g}_{2}-\mathrm{ab}_{2}$ (nach Heimpel 1998, 15 möglicherweise identisch mit der š $\mathrm{em}_{3}$-Trommel) zu vermuten.

${ }^{753}$ Westenholz/Westenholz 2006, 22-23.

${ }^{754}$ Westenholz/Westenholz 2006, 23-24, 66:27; CAD T 283b; ein weiterer Beleg mit derselben Schreibung findet sich im aB Marduk-Ritual bei Wasserman 2006, 201-202:18.

755 Beispielsweise Westenholz/Westenholz 2006, 38: i 24-27, zum Fest des Enki oder entsprechend Westenholz/Westenholz 2006, 42: ii 36-39 zum Fest des Šamaš. 


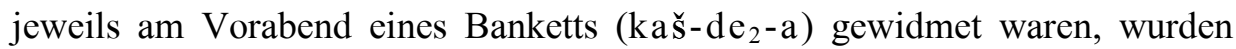
von W. Sallaberger und nachfolgend von A. und J.-G. Westenholz aufgezeigt. $^{756}$

Nach Ausführung der Klagen folgen weitere Zeremonien, die allerdings nicht bei allen Gottheiten stattfanden. Auf das Fest der Nanaja beschränkt ist die Station eš $\check{3}_{3}-\tilde{g} i_{6}$-zal „Im Heiligtum die Nacht verbringen“, die möglicherweise im Zusammenhang mit dem Ritus der 'Heiligen Hochzeit' steht. ${ }^{757}$

Die nach anderen Quellen gut belegte Räucherung im Kohlebecken kinūnum wird unter Verwendung von Ölen, Mehl und aromatischen Hölzern hier lediglich für Šamaš, Inana und Ninegala durchgeführt. ${ }^{758}$

Noch vor Eintritt der Nachtwache wird ein Opfertisch vorbereitet und ein weiteres 'Brandopfer' bei allen beteiligten Gottheiten ausgeführt. Nach Aufzählung der hierfür benötigten Materialien, darunter Sirup, Feinmehl und Datteln, wird der Ausdruck ana pettim „(wörtl.) für die (Holz-)Kohle“ angegeben, der in einer solchen Verwendung ebenfalls auf diesen Text beschränkt bleibt. ${ }^{75}$

Eine der wichtigsten Aktionen, die noch am Abend stattfand, war das 'Eintreten' der Gottheit (ina erēbiša/šu). ${ }^{760}$ Ein solches 'Eintreten' ist vielfach dokumentiert. Ungeachtet der unterschiedlichen Schreibungen für diesen Terminus bleibt häufig die Frage nach dem 'Ort des Eintretens' unklar. ${ }^{761}$ Anhand von Parallelen könnte vermutet werden, dass der eigene Tempel verlassen wurde zum Zwecke des Gastmahls in einem gesonderten Festhaus oder dem Königspalast. ${ }^{762}$ Hierdurch werden die zuvor ausgeführten Klagen ver-

${ }^{756}$ Westenholz/Westenholz 2006, 23; Sallaberger 1993, 47, 200; s. a. Cohen 1993, 472-474.

${ }^{757}$ Vgl. Westenholz/Westenholz 2006, 15 zu den Statuen der Könige Sîn-iqǐšam und Warad-Sîn im Tempel der Nanaja; Ur III-zeitlich ist derselbe Ausdruck in Verbindung mit einem Fest der „himmlischen Schiffsbarke“ belegt; Westenholz/Westenholz 2006, 24. Vergleichbar ist außerdem das Aufstellen des Bettes im Mari-Ritual an Ištar; zuletzt bei Ziegler 2007, 57:i 2'4'. In einen ähnlichen Zusammenhang ist die Quittung bei Charpin 1984, 87:22(=MARI 3, 87) zu stellen über Ölausgaben an die Göttinnen Derītum und Ninekallim aus Anlass des 'Eintretens des Königs' (erēb lugal).

${ }^{758}$ Kol. ii 57 (Utu), iv 26 (Inana) und wohl vii 7ff. bei Ninegala zu ergänzen; vgl. Westenholz/Westenholz 2006, 25, 73:57.

${ }^{759}$ Westenholz/Westenholz 2006, 24. Vgl. die ähnlichen Aufstellungen in verschiedenen Ritualen des 1. Jt.

${ }^{760}$ Kol. i 41, iii 5, iv 31, v 40, vii 21, viii 5', ix 28; Westenholz/Westenholz 2006, 40-61.

${ }^{761}$ S. Westenholz/Westenholz 2006, 67-68 mit zahlreichen Belegen und hier Kapitel 9.6.3.3 und 9.6.3.4 für entsprechende Feste in Sippar.

${ }^{762}$ Vgl. ARM 9, 90 mit Ausgaben anlässlich des Eintretens der Ištar in den Palast; auch in unserem Text folgen auf das Eintreten Opfer des Königs (Westenholz/Westenholz 2006, 6869). Umgekehrt verweist erēb lugal (Charpin 1984, 87:22) wohl auf das Eintreten des Königs in den Tempel; Westenholz/Westenholz 2006, 67-68 sehen hier das Eintreten der Gottheit in ihren Tempel (wofür sie auch mehrere Belege liefern), sie gehen aber auf die damit verbundene Problematik hinsichtlich des Festablaufs nicht weiter ein. 
ständlich. Die Gottheit wurde über den Vortrag solcher Klagen besänftigt, da sie ihren regulären Sitz verlie $\beta^{763}$

Der folgende Morgen wurde mit weiteren fleischlichen wie pflanzlichen Opfern für die Götter eröffnet. Brot und Bierrationen bilden zwei weitere Mahlzeiten (iptin(n)um, nindabbum) des Tages. Hierauf folgten in aller Regel Rationen- und Geschenkausteilungen an alle Beteiligten, ${ }^{764}$ wobei in der Liste die menschlichen Teilnehmer von den göttlichen getrennt aufgeführt werden. Die Ausgaben an die menschlichen Teilnehmer enden mit einem Schlachtopfer über zwei Schafe aus Anlass des 'Aufrichtens der Gottheit' (ina rabîšu/-ša). ${ }^{765}$ Es folgen die Listen über Opferausgaben und edle Geschenke an alle göttlichen Beteiligten, die Hauptgottheiten, ihre jeweiligen Kreise sowie ihr Tempelinventar, wie beispielsweise die Waffe des Enki oder der Thron des Šamaš. ${ }^{766}$ Nicht zuletzt wurden in dieser Auflistung auch die goldenen Statuen des Sîn-iqī̌am und des Warad-Sîn zu den Festen des Šamaš und der Nanaja mit Geschenken in Form von Gewändern bedacht. ${ }^{767}$

Zusammenfassend lässt sich der Ablauf des Festes damit wie folgt rekonstruieren: Nach einem kleineren Opfer an Ninsiana, das ihr wohl im Hinblick auf ihren astralen Aspekt auf dem Dach ihres Tempels dargeboten wurde, möglicherweise auch der Ausführung von Kultgesängen zum Membranophon ni $\tilde{\mathrm{g}}_{2}-$ $\mathrm{ab}_{2},{ }^{768}$ folgt eine achttägige Prozession, deren verschiedene Stationen die Heiligtümer der in ausgiebigen Ritualhandlungen 'verköstigten' wichtigsten Gottheiten von Larsa darstellen. Auf das Opfer an Ninsiana folgt der Besuch der Heiligtümer des Enki $^{769}$ und Asalluhi, des Šamaš, der Inana/Ištar, der Nanaja, der Ninegala, der Dig̃irmah und des Panig̃ara sowie des Sîn-iddinam. ${ }^{770}$ Ein jedes dieser als Bankett (kaš- $\left.\mathrm{de}_{2}-\mathrm{a}\right)$ gekennzeichneten Feste nimmt seinen Anfang bei der Tempelöffnung. Nach etlichen Schlacht- und Schüttopfern folgen tassistum-Klagen, die die Gottheit möglicherweise aus Anlass ihres bevorstehenden Austritts zu besänftigen suchen. Am Abend folgt dann ihr 'Erscheinen'. Dieser Vorgang sowie der weitere Verlauf der Nachtwache

\footnotetext{
${ }^{763}$ Auch das Ur III-zeitlich gefeierte erubbātum für Annunitum war mit dem kaš-de ${ }_{2}$-a eng verbunden, bei dem auch Klagen ausgeführt wurden; Sallaberger 1993, 201.

${ }^{764}$ Westenholz/Westenholz 2006, 25-26.

${ }^{765}$ Kol. ii 16, iii 39, iv 66, vi 21, vii 45, viii 31', ix 42; Westenholz/Westenholz 2006, 40, 70:16 übersetzen „2 sheep as siskur-offering in her/his setting“.

${ }^{766}$ Kol. ii $17 \mathrm{ff}$. (Enki und Asalluhi), iii 40ff. (Šamaš), v 1ff. (Inana), vi 22ff. (Nanaja), vii 46ff. (Ninegala), viii 32'ff. (Dig̃irmah), ix 43ff. (Sîn-iddinam); dazu Westenholz/Westenholz 2006, 25-26.

${ }^{767}$ Kol. iii 46-47 und vi 28-29; Westenholz/Westenholz 2006, 15, 44-45, 52-53.

${ }^{768}$ S. oben Anm. 752.

${ }^{769}$ Nach Dyckhoff 1999/I, 103 wird Enki hier am ersten Tag aufgeführt, da die Opferritualliste dem Verwaltungsarchiv des Enki-Tempels entstammt.

${ }^{770} \mathrm{Zu}$ Tempeln und Kult der einzelnen Gottheiten s. ausführlich Westenholz/Westenholz 2006, 9-19.
} 
werden durch reinigende Räucherungen und Brandopfer begleitet. Am Morgen des darauf folgenden Tages finden wiederum mehrere Mahlzeiten zur Bewirtung der Gottheiten statt. Ausgehend von den hierauf folgenden Personallisten könnten hierzu begleitend musikalische und künstlerische Darbietungen stattgefunden haben. Im Text folgt dann die Auflistung der Ausgaben und Geschenke an das Tempelpersonal, was in Abhängigkeit von der jeweiligen Tempelgröße in Anzahl und Funktion unterschiedlich ausfällt. Nach Aufstellen der Gottheit wird sie schließlich selbst sowie die in ihrem Kreis und Inventar sich befindenden Gottheiten mit Gewändern und weiteren Utensilien ausgestattet. An diesem Punkt endet die Auflistung, ob die Götter in ihre Tempel zurückgeführt wurden oder an einem anderen Ort exponiert aufgestellt blieben, wo sie in Vorbereitung auf noch folgende Festhandlungen zunächst verweilten, ist nicht bekannt. Insgesamt bleibt auch der Anlass zu diesen ausgiebigen Ritualhandlungen an acht wichtige Gottheiten des Pantheons von Larsa unbekannt, sodass sich die recht detaillierten Informationen zum kultischen Ablauf keinem der für die altbabylonische Zeit bekannten Feste zuordnen lassen.

\subsubsection{Zu den Personallisten}

Trotz der Ähnlichkeiten im Ablauf der Festhandlungen bestehen bei den verschiedenen Stationen des insgesamt achttägigen Götterfestes Unterschiede sowohl in den aufgewendeten Opfergaben und Geschenken als auch beim beteiligten oder empfangenden Personal. Ein Überblick hierzu wird in den folgenden Tabellen geboten.

Deutlich hervorgehoben ist das Fest des Šamaš, das die längste Personalliste aufweist. ${ }^{771} \mathrm{Zu}$ den beteiligten Priestern fällt auf, dass šita-e š ${ }_{3}$-Priester auf die Šamaš-Liste beschränkt bleiben. ${ }^{772}$ gudu $_{4}$-Priester werden hingegen bei allen Göttern zur Nachtwache, als Empfänger von Salbölen oder auch edlen Geschenken genannt. ${ }^{773}$ Ein Mundschenk (KAŠ.LUL) ist lediglich bei Inana und Sîn-iddinam beteiligt. ${ }^{774}$

\footnotetext{
${ }^{771}$ Kol. ii 17-38; Westenholz/Westenholz 2006, 11-12, 44-45.

${ }^{772}$ Kol. iii 29-30:38 mit Namen Bītum-rabi; Westenholz/Westenholz 2006, 31, 44-45.

${ }^{773}$ Westenholz/Westenholz 2006, 29, 31. Sowohl gudu ${ }_{4}$ als auch šita-eš $\breve{s}_{3}$ werden als Reinigungspriester aufgefasst, detailliertere Untersuchungen zu ihren genauen Aufgabenbereichen fehlen jedoch bislang; Renger 1969, 143-172, 194.

${ }^{774}$ Kol. iv 54 (Inana) und ix 30 (Sîn-iddinam); Westenholz/Westenholz 2006, 46-47, 60-61; nach ibid., 54 vii 37 möglicherweise auch bei Ninegala und Nanaja am Ende von Kol. v zu ergänzen.
} 
Tabelle 6: Šamaš-Personal in CM 33, 44-45(=HUCA 34, 1ff.)

Kol. iii

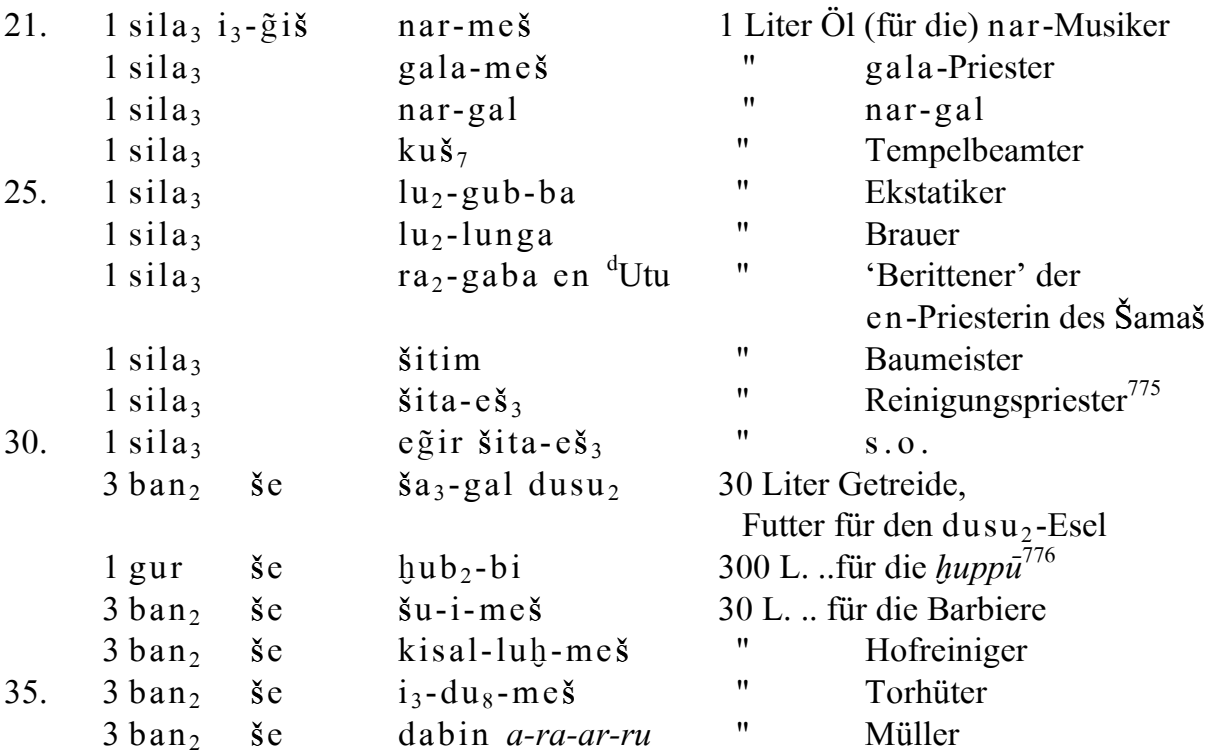

Am Ende einer jeden Ausgabenliste wird Öl für die Salbung der gudu - $^{-}$ Priester und anderes Tempelpersonal ( $\left.\tilde{g} \mathrm{ir}_{3}-\mathrm{se}_{3}-\mathrm{ga}\right)$ notiert, nur bei Inana und Nanaja auch für die beteiligten kezrētum. ${ }^{777}$

\footnotetext{
775 Die Aufgaben dieses Funktionärs sind bislang ungeklärt; Renger 1969, 129-132 und Westenholz/Westenholz 2006, 31 auch zum folgenden e g̃ir šita-e š ${ }_{3}$,assistant purification priest“. ${ }^{776}$ S. hier Kapitel 5.5.1.

${ }^{777}$ Kol. ii 23 (Enki); iii 48 (Utu); v 7 (Inana); vi 30 (Nanaja); vii 49 (Ninegala); viii 43' (Dig̃irmah/Panig̃ara); ix 49 (Sîn-iddinam).
} 
Tabelle 7: Personal der Gottheiten ${ }^{778}$ in CM 33, 1-81(=HUCA 34, 1ff.)

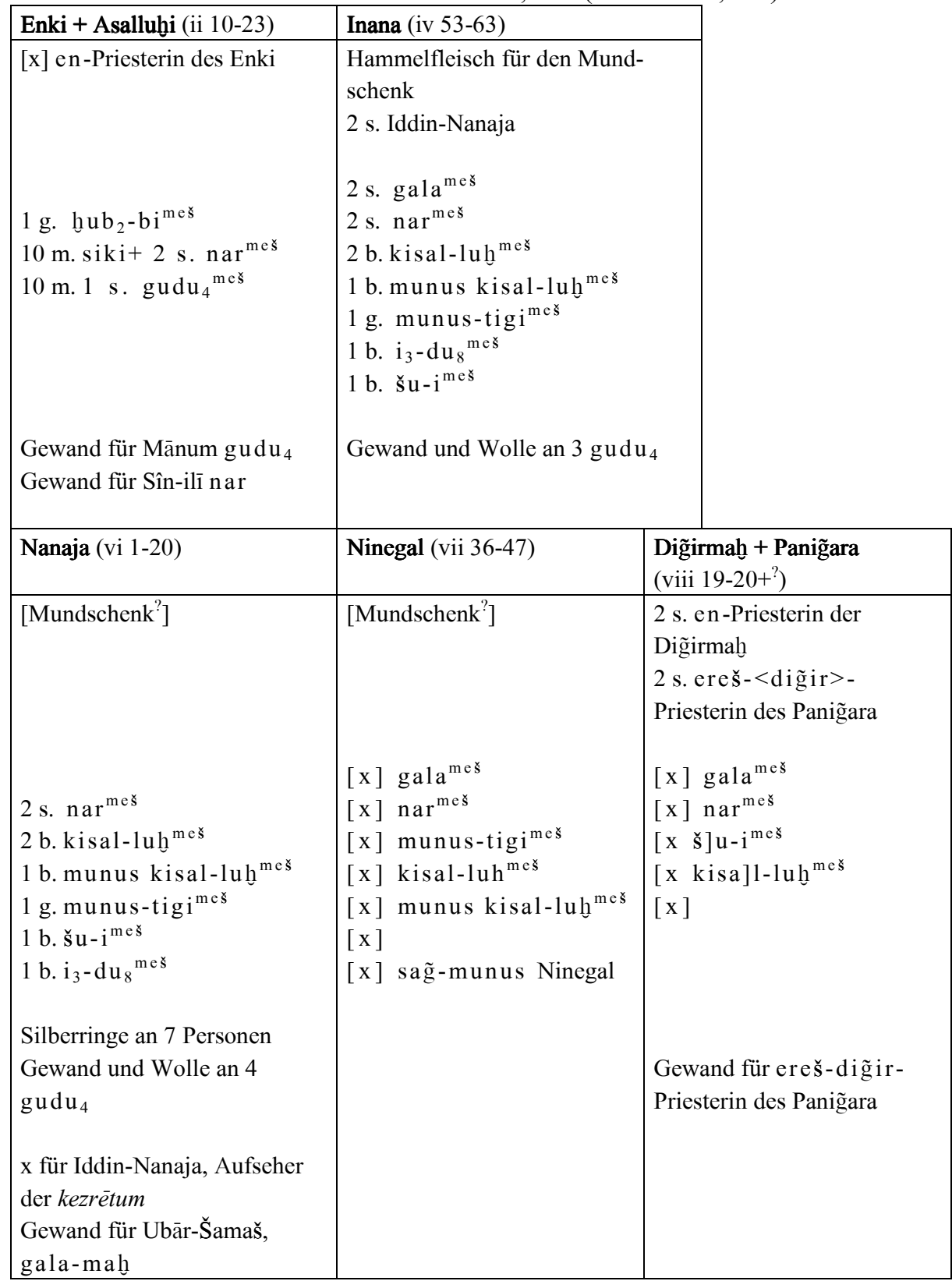

${ }^{778}$ Maßeinheiten werden wie folgt abgekürzt: b. $=\mathrm{ban}_{(2)} / \mathrm{b}$ ariga; g. $=$ gur; m. = ma-na; s. $=$ sila $_{3}$. 


\subsubsection{Musiker, Tänzer und Akrobaten}

Insgesamt lässt sich an den Tabellen 6-7 ablesen, dass sowohl nar als auch gala-Priester zu den ersten aktiven Teilnehmern an den Opferhandlungen des Ritualfestes von Larsa zählen. Gleich zu Beginn der Handlungen, kurz nach Öffnung des Tempels, führte eine Gruppe von nar-Musikern tassistum-Klagen auf:

T 47: CM 33, 38 i 28-30 passim

„10 Liter Bier, vierzehn Brotrationen;

Ausgabe an die nar der tassistum(-Klage)“

$0.0 .1 .0 \mathrm{kaš}-\mathrm{gin} 14 \mathrm{ninda}$

šu-ti-a nar-meš ša ta-as-si $i_{2}-i s_{2}-t u m^{779}$

Als nar tassistum sind die hier Auftretenden von allen nachfolgenden narGruppen der Opferrationenliste zu unterscheiden. Es ist dennoch nicht anzunehmen, dass hier ein eigenständiger Berufsstand angezeigt wird, sondern eine auf das Klagen spezialisierte Vokalistengruppe. nar-Musiker, die neben galaPriestern einen besonderen Klagegesang (inhu vortrugen, sind auch aus neuassyrischen Bauritualen bekannt. ${ }^{780}$

Noch am selben Abend werden ausschließlich bei Šamaš, Inana und Ninegala von gala-Priestern Räucherungen durchgeführt:

T 48: CM 33, 42 iii 3-4 passim

„Ausgabe für die gala-Priester, für das 'Räuchern' des Zedern(harzes).“

šu-ti-a gala-meš $i$-na $q u_{2}-t u r_{4}$ šim ${ }^{\tilde{g} i \check{s}} \operatorname{eren}^{781}$

Altbabylonisch ist damit nachgewiesen, dass gala im Rahmen von Kultritualen auch nicht-musikalischen Tätigkeiten nachgingen. Für ihre Dienste erhielten die gala unterschiedliche Mehl- und Brotsorten. ${ }^{782} \mathrm{Ob}$ sie zu den Räucherhandlungen auch Gesänge ausführten, bleibt unbekannt. ${ }^{783}$

\footnotetext{
${ }^{779}$ Nach insgesamt sechs Textstellen: Westenholz/Westenholz 2006, 38: i 28-30, 42: ii 40-42, 48: v 24-26, 52: vii 1-3, 56: viii 1-3, 58: ix 15-17 (einzig vollständig erhalten). Die Angaben zu den Klagen für Inana sind Anfang der Kol. iv abgebrochen s. ibid., 76.

${ }^{780}$ Groneberg 2003, 63-64 „,song of sighs“; Ambos 2004, 43-44 „Seufzlied“.

${ }^{781}$ Kol. iii 3-4, iv 29, vii 19-20; Westenholz/Westenholz 2006, 42-43, 46-47, 54-55, übersetzen ina qutur "for" und ,in the smoke“; zur ungewöhnlichen Schreibung qu $u_{2}$-tur ${ }_{4}$ s. ibid., 73:57.

${ }^{782}$ Die entsprechenden Zeilen sind an keiner der drei Textstellen vollständig erhalten.

${ }^{783}$ S. nA allerdings mit Westenholz/Westenholz 2006, 30 die Ritualanweisung BM 50503 zum Vortrag von Klageliedern, in deren Verlauf ein kalamāhu mit Räucherbecken in der Hand ein Lied? 'ruft'(řasû); Maul 1999, 292-293: Rs. 3-4.
} 
nar-Musikergruppen werden mit Ausnahme der Feste der Ninsiana und des Sîn-iddinam bei allen übrigen Götterfesten genannt, wo jeweils eine Ausgabe von ein bis zwei Litern Öl für sie notiert wird. ${ }^{784}$ Ausschließlich beim Fest des Enki findet sich der bereits behandelte mit Namen aufgeführte nar Sîn-ilī als Empfänger eines /bardul/-Gewands. ${ }^{785}$ Diese Ausgabe lässt auf eine hohe Position desselben innerhalb der Tempelhierarchie schließen.

Der einzige nar-gal des Festrituals wird unter den Beteiligten des ŠamašFestes erwähnt. ${ }^{786}$ Als Einzelperson erhielt er dieselbe Ölrationenmenge wie die Gruppe der nar-Musiker.

Gruppen von gala-Priestern sind wie auch nar-Musiker an allen Götterfesten beteiligt, unerwähnt bleiben sie lediglich in den Personallisten des Enki und Asalluhi ${ }^{787}$ An ihrer Stelle treten dort gudu ${ }_{4}$-Priester auf, die sonst bei keinem anderen Götterfest erscheinen. ${ }^{788}$

Unterschiede bestehen weiterhin bei den jeweiligen Festausgaben. So erhielten die nar des Enki zusätzlich zur üblichen Ölration eine Mine Wolle ${ }^{789}$. Die an den Festen der Inana und Nanaja beteiligten nar- und gala-Gruppen erhielten doppelt soviel Öl wie die Beteiligten am Šamaš-Fest. Solche Unterschiede in der Mengenausgabe erlauben Rückschlüsse auf die Anzahl der Beteiligten. Die musikalischen Darbietungen bei Inana und Nanaja wären damit umfangreicher als die der übrigen Götter ausgefallen. Die zusätzliche Wollration an die Musiker des Enki könnte dementgegen auf einen höheren Status dieser spezifischen Truppe verweisen.

\footnotetext{
${ }^{784}$ Kol. ii 12 , iii 21, iv 57, vi 1, vii 39, viii 22' bei Westenholz/Westenholz 2006, 40-42, 44-47, 50-51, 54-57.

${ }^{785}$ Kol. ii 15; Westenholz/Westenholz 2006, 40-41 und 70:14 zu ${ }^{\text {tug2 }}$ bar-du1 $1_{8}$; zu Sîn-ilī hier Kapitel 9.2.2.3.

${ }^{786}$ Kol. iii 23; Westenholz/Westenholz 2006, 44-45.

${ }^{787}$ Aufgrund der Parallelität kann die Gruppe von gala-Priestern auch bei Nanaja am Ende der Kolumne v ergänzt werden.

${ }^{788}$ Eine Beziehung zwischen diesen beiden Priesterberufen hinsichtlich der Pfründenverteilung konnte für Nippur aufgezeigt werden, s. hier Kapitel 9.5.3.

${ }^{789}$ Kol. ii 12; Westenholz/Westenholz 2006, 40. Zu weiteren Wollrationen an nar s. die Quittung UET 5, 453 (o.D.) mit Ausgaben an den Musiker Būr-Adad; vgl. auch BaM 23, $136 \mathrm{Nr}$. 173:7' (D.a.) mit Šēp-Sîn als Überbringer von Wolle.
} 
Nur bei den weiblichen Gottheiten Inana, Nanaja und Ninegala treten /tigi/Frauen auf, die reichlich mit Getreide bedacht werden ${ }^{790}$ Insgesamt weisen die Personallisten dieser drei Göttinnen auf eine stärkere Beteiligung von Frauen hin. ${ }^{791}$ Neben den /tigi/-Musikerinnen treten hier auch Hofreinigerinnen ( ${ }^{\mathrm{munus}}$ kisal-luh) zusätzlich zu den schon andernorts genannten männlichen Hofreinigern (kisal-luh) auf. In der Ausgabenliste zum Fest der Nanaja werden außerdem zahlreiche Silberringe verbucht, die an mehrere mit Namen genannte Frauen von hohem Rang, darunter auch eine Königstochter, ausgegeben wurden. ${ }^{792}$ Nicht zuletzt waren bei Inana und möglicherweise auch bei Nanaja kezrêtum-Frauen beteiligt. ${ }^{793}$ Diese werden allerdings nicht in den regulären Personallisten aufgeführt, sondern an letzter Stelle neben einer Gruppe von gudu ${ }_{4}$-Priestern sowie anderem nicht näher definierten Tempelpersonal. ${ }^{794}$ Der Aufseher der kezrētum mit Namen Iddin-Nanaja wurde ebenfalls entlohnt. ${ }^{795}$ Die Briefe AbB 2, 34 und AbB 5, 135 dokumentieren kezrētum, die Göttinnen aus dem nahe Larsa gelegenen Jamutbal nach Babylon begleiteten. Auch wenn die Aufgaben dieser Frauen im Rahmen des Festes nicht bekannt sind, so wird hier nochmals bestätigt, dass diese meist im Kult weiblicher Gottheiten mitwirkten. ${ }^{796}$

Das seinem Personal nach wohl am aufwendigsten veranstaltete Fest war dem Stadtgott Šamaš gewidmet. Aus Anlass dieser Feier wurden neben den üblichen Musikern und Priestern noch ein Diener $\left(k u \check{s}_{7}\right),{ }^{797}$ ein Ekstatiker (lu $u_{2}$-gub-ba), ein Brauer ( $\left(\mathrm{u}_{2}\right.$-lunga), ein Baumeister (šitim), der 'Bote' der e n-Priesterin des Šamaš, eine Gruppe von huppû-Tänzern, sowie die Müller beschäftigt. ${ }^{798}$ Von allen Genannten traten wohl die hupp $\hat{u}$-Tänzer unter Musikbegleitung auf. Dieselbe Gruppe von Tänzern war auch am Enki-Fest betei-

\footnotetext{
${ }^{790}$ Kol. iv 60 (Inana), vi 4 (Nanaja), vii 41 (Ninegala); die ursprüngliche Lesung ${ }^{\text {munus }}$ narlukur-meš von Kingsbury 1963, 12-13 und Renger 1969, 181 ist mit Westenholz/Westenholz 2006, 32 obsolet.

${ }^{791}$ Kingsbury 1963, 14; Westenholz/Westenholz 2006, 15.

${ }^{792}$ Kol. vi 7-13; Westenholz/Westenholz 2006, 50-53; zu Pișētum als Königstochter s. ibid., 35.

${ }^{793}$ Kol. v 7 (Inana) und wohl zu ergänzen in vi 30 (Nanaja); Westenholz/Westenholz 2006, 32$33,48-49,52-53$.

${ }^{794} \mathrm{Da}$ an sie Salböl ausgegeben wurde, vermuten Westenholz/Westenholz 2006, 32-33, 78:7, dass sie insofern nicht zum regulären Tempelpersonal zählten, da Salböl zur rituellen Reinigung vor dem Eintritt in den Tempel verwendet wurde.

${ }^{795}$ Kol. iv 55 (Inana) und vi 18-19 (Nanaja); Westenholz/Westenholz 2006, 46-47, 52-53. IddinNanaja wird bei Inana ohne Berufsangabe genannt, dennoch wird es sich um dieselbe Person handeln schon aufgrund der Beteiligung der kezrētum an den Festen dieser beiden Göttinnen; vgl. ibid., 34, 79:18.

${ }^{796}$ S. hier Kapitel 7.3.

${ }^{797} \mathrm{Zu} \mathrm{kuš}$ akk. kizûm als Tempelbeamter in spätaB Zeit s. a. Pientka 1998, 380.

${ }^{798}$ Kol. iii 21-36; Westenholz/Westenholz 2006, 44-45.
} 
ligt. ${ }^{799}$ Auch der Ekstatiker könnte sich mithilfe musikalischer Klänge in den Ekstasezustand versetzt haben. ${ }^{800}$

Nicht zuletzt sei hier noch auf den einzig beim Personal der Nanaja genannten gala-mah Ubār-Šamaš hingewiesen, auf den bereits in Kapitel 9.2.2.1 eingegangen wurde. Die Dienste dieses Priesters wurden nur beim Opferfest der Nanaja in Anspruch genommen.

Eine Rekonstruktion der musikalischen Darbietungen zum achttägigen Ritualfest von Larsa wird aufgrund der spärlichen Informationslage hier nicht möglich sein, dennoch sind einzelne Beobachtungen zusammenzufassen. An allen Abenden wurden Klagegesänge von nar veranstaltet. Die Beteiligung von gala lässt weiterhin vermuten, dass Emesal-Liturgien zum Vortrag kamen. Aus dem Ištar-Ritual von Mari ist bekannt, dass der Vortrag eines Balag̃-Liedes mit seinen unterschiedlichen kirugu-Abschnitten über den gesamten Verlauf eines Kultfestes andauern konnte. ${ }^{801} \mathrm{Zu}$ diesem Ritual weist die Larsa-Liste zahlreiche Parallelen in der personellen Beteiligung auf. ${ }^{802}$ Dort treten ebenfalls hupp $\hat{u}$-Tänzer neben Ekstatikern auf und zwar zum solistischen Vortrag eines gala-Priesters, der eine Eršema-Klage darbringt. Unglücklicherweise lassen sich ansonsten im Hinblick auf die gefeierten Gottheiten oder die Festinhalte keine Ähnlichkeiten zwischen diesen beiden bislang einzigartigen Texten feststellen.

Die meisten Musiker der Larsa-Ritualliste waren an den Festen der Göttinnen Inana, Nanaja und Ninegala beteiligt. Zusätzlich zu den gängigen Gruppen traten einzig hier auch /tigi/-Frauen sowie die kezrētum auf.

Im Gegensatz zu den Klagen am Abend wird die Musik des Tages wohl als Preis- oder Hymnengesang zu identifizieren sein. Tänzergruppen sind wiederum nur bei Enki und Šamaš belegt. Die Feiern des Tages, am deutlichsten bei Šamaš, fanden wohl im Beisein einer nicht zu verachtenden Menschenmenge mit klangstarker vokaler sowie instrumentaler Musikbegleitung statt. Bei weiblichen Gottheiten nahmen wieder große Gruppen musizierender, wohl trommelnder Frauen teil. Weiterhin ist anzunehmen, dass die einzelnen Feststationen nicht nur durch Klagen oder Preisgesänge begleitet wurden, sondern auch zu den vollzogenen Opferhandlungen von den Priestern Beschwörungen und Gebete begleitend rezitiert wurden.

\footnotetext{
${ }^{799}$ Kol. ii 11; Westenholz/Westenholz 2006, 40-41, 69:11.

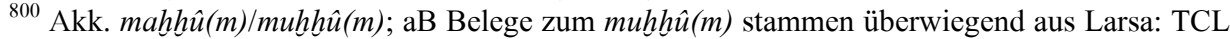
10, 39 (RS 14) 11. der Inana Zabalam; TCL 10, 34:47 (D.a.); TCL 10, 69:4 (RS 27) und Mari, u. a. bei Ziegler 2007, 58:ii 22', 61, 64; s. a. CAD M/1 90a. Ekstatiker konnten Männer oder Frauen sein; Renger 1969, 219-220; Westenholz/Westenholz 2006, 33, 73. Zur Verbindung von Ekstase und Musik s. Schuol 2004, 206-207.

${ }^{801}$ Cavigneaux 1998, 46; und zuletzt Ziegler 2007, 58-60.

${ }^{802}$ Durand/Guichard 1997, 46-58.
} 


\subsubsection{Balag̃-Gottheiten in Larsa}

In einer einzigen Urkunde aus dem so genannten Ölarchiv werden Ausgaben an Ninigizibara verzeichnet, der bekanntesten bala g̃-Gottheit der Inana. ${ }^{803}$ Nach Richter könnte Anlass der Ausgabe ein in derselben Liste später aufgeführtes NE.NE-g̃ar-Fest sein. ${ }^{804}$ Für Spiel und Pflege von balag̃-Instrumenten sind grundsätzlich gala-mah zuständig. Im Kontext des vielfach belegten NE.NEgar-Festes ist bislang jedoch keine Beteiligung von gala-mah geschweige denn gala-Priestern bekannt geworden ${ }^{805}$ Denkbar wäre daher eher, dass die Opfer aus Anlass einer kultischen Klage oder eines anderen Kultfestes um Inana stattfanden. Vergleichbare Opferausgaben und Rituale, an denen auch gala und gala-mah beteiligt waren sind für Isin, Sippar und Mari attestiert. ${ }^{806}$

Eine weitere im Kult von Larsa belegte Bala g̃-Gottheit ist Ninezen, die dem Kreis des Enki angehört. Es werden ihr ein eigener Tempel mit Bediensteten und ein Tor zugeordnet. ${ }^{807}$ Bezeichnend ist außerdem, dass auf sie Eide geleistet wurden, womit sie auch eine Rolle bei Rechtssprüchen einnimmt.

\subsection{Kutalla}

Die kleinere altbabylonische Siedlung Kutalla (heute: Tell Sifr) gehörte zum Einflussbereich der etwa $14 \mathrm{~km}$ nordwestlich gelegenen Stadt Larsa. Die Stadt stellte in religiöser Hinsicht kein bedeutendes Zentrum irgendeines Götterkultes dar. Als Stadtgott von Kutalla galt Lugalkisuna, wobei auch ein Tempel der Amanna bzw. Geštinana, der Schwester des Hirtengottes Dumuzi, erwähnt wird. ${ }^{808}$ Die Verwaltung Kutallas und seiner umliegenden Regionen war der Stadt Larsa unterstellt. Von dort aus wurde auch königliches Bauland aus der Gegend um Kutalla verwaltet, das in Form von Lehensfeldern an Angestellte der Palast- oder Tempeladministration zur Eigenversorgung übergeben wurde. Die Stadt war außerdem ein wichtiges Handelszentrum, in dem Produkte aus Larsa abgesetzt wurden. Die Texte reflektieren hauptsächlich die Beziehungen dort ansässiger Privatpersonen zur königlichen Länder- und Handelsverwaltung von Larsa. ${ }^{809}$

\footnotetext{
${ }^{803}$ YOS 14, 246:1-2 (Sel 13); Ninigizibara wird in den jüngeren Götterlisten der mA und nA Zeit zu den $\mathrm{gu}_{4}$-bala g̃ „Stier-b.“ der Inana/Ištar gezählt; s. allgemein zu dieser InstrumentenGottheit Heimpel 1998-2001a, 382-384.

${ }^{804}$ Richter 2004, 374. Das NE.NE-g̃ar ist ein Feuer- bzw. Lichtfest; s. Sallaberger 1993, 125; im aB Larsa ist das Fest für den 8. und 9. Monat belegt; Richter 2004, 403-404.

${ }^{805}$ Nur in Bab. 7, 46 (Rs 3), wo Ausgaben für ein NE.NE- g̃ar-Fest für Enki notiert sind, erscheint möglicherweise auch ein $1 \mathrm{u}_{2}$-nar-gal; vgl. Richter 2004, 355 + Anm. 1509.

${ }^{806}$ Für Mari s. Durand/Guichard 1997 und Ziegler 2007, 55-64.

${ }^{807}$ Richter 2004, 357-358.

${ }^{808}$ Charpin 1980, 183, 347; Lambert 1987-90, 146.

${ }^{809}$ Charpin 1980, 126-131, 187-194.
} 
Kutalla gehörte zum Reich der ersten babylonischen Dynastie, bis es sich der Revolte des Rìm-Sîn II (1822-1763) gegen die Herrschaft Samsuilunas anschloss. ${ }^{810}$ Der letzte Text aus Kutalla datiert in das Jahr Samsuiluna 10, danach wurde die Stadt zerstört und aufgegeben. ${ }^{811}$

Nur etwa 100 Texte wurden in Kutalla selbst durch den Ausgräber W. K. Loftus in situ gefunden ${ }^{812}$ Zusammen mit weiteren im Kunsthandel erworbenen Texten, die ihrem Inhalt nach zum selben Textkorpus gehören, wurden sie von Charpin in einer ausführlichen Studie herausgegeben. ${ }^{813}$ Diese Texte sind mehreren Archiven von Privatfamilien zuzuordnen. Sie dokumentieren Transaktionen von Immobilien zwischen Angehörigen mehrerer Familien. $\mathrm{Zu}$ Tempeln und Götterkulten geben die Texte daher kaum Auskunft. Die wenigen namentlich erwähnten Tempelfunktionäre und Priester können keinem bestimmten Tempel oder Kult in Kutalla zugeordnet werden.

\subsubsection{Die Musiker in den Privatarchiven Kutallas}

In 17 Urkunden aus Kutalla, die alle ausschließlich Käufe und Rechtsfragen um Baugelände und Felder zum Inhalt haben, werden insgesamt 12 Musiker erwähnt. Die Texte gehören zum Privatarchiv des Kaufmanns Șillī-Ištar und seiner Familie. ${ }^{814}$ Insgesamt werden nur zehn nar und zwei gala ausschließlich aus Zeugenlisten namentlich bekannt. ${ }^{815}$ Dort besetzen sie meist die letzten Positionen neben dem Schreiber oder anderem gleichrangigen Tempelpersonal wie Gärtner (nu- $\left.{ }^{\tilde{g} i s ̌ s}{ }^{2}{ }_{i r i}{ }_{6}\right)$ oder Barbier (šu-i). Nur in der Urkunde TSifr 30 (RS 47) aus der Zeit des Rīm-Sîn von Larsa wird ein nar mit Namen Šu-ilī̌su als erster Zeuge aufgeführt, da er mit dem in der Urkunde genannten Käufer Sîn-ușellī verwandt war. Beide Personen, sowohl Šu-ilišsu als auch Sîn-uṣellī, sind Söhne des Kaufmanns Șillī-Ištar. ${ }^{816}$

Für die Zeit der ersten babylonischen Dynastie enthalten die Texte Angaben zur Familie des Nūr-Ninšubur. Die Angehörigen dieser Familie übten alle den Beruf des nar aus. Vier Söhne des Nūr-Ninšubur mit Namen Šēp-Sîn, Apililīšu, Nanna-g̃eštug und Anum-pī-Ninšubur treten in acht Urkunden als narMusiker auf. ${ }^{817}$ Sie sind die einzigen für Kutalla namentlich bezeugten nar aus

\footnotetext{
${ }^{810}$ Pientka 1998, 19; zur Geschichte Charpin 1980, 182-185, 194-195.

${ }^{811}$ Gasche 1989, 130; Pientka 1998, 11 Anm. 27.

${ }^{812}$ Zur Ausgrabungsgeschichte Charpin 1980, 1-4.

${ }^{813}$ Charpin 1980.

${ }^{814}$ Charpin 1980, 119-131; ders. 2003, 319-320.

${ }^{815}$ n ar unter Rìm-Sîn von Larsa: Ilī-awìlī Sohn des Ka- ${ }^{\mathrm{d}}$ Dudu TSifr 10/10a:21 (RS 11); Inī-Ea TSifr 12/12a:29 (RS 12); Gimillum TSifr 99:15 (RS 25); Šēp-Sîn TSifr 28/28a:25 (RS 37); x-iqī̌am TSifr 31:26 (D.a.); zu den übrigen s. im Folgenden.

${ }^{816}$ TSifr 30/30a:13 (RS 47); Charpin 1980, 115, 219-220. Nicht identisch mit gala Șillī-Ištar.

${ }^{817}$ TSifr 40/40a:26/25' (Ha 36); TSifr 41/41a:26.33 (Ha 36); TSifr 49/49a:22 (Ha 41); TSifr 50a:25 (Ha 41); TSifr 51a:26 (Ha 41); TSifr 56/56a:30 (Ha 42); TSifr 65:28,29,30 (Si 4); TSifr 66/66a:20 (Si 4); Renger 1969, 184.
} 
der Zeit der ersten babylonischen Dynastie. Von diesen vier Brüdern wird der nar namens Šêp-Sîn am häufigsten und in den Zeugenlisten immer vor den anderen genannt. Seine Titulatur ist in der Siegellegende der Urkunde TSifr 40 (Ha 36) erhalten: „Šēp-Sîn, Sohn des Nūr-Ninšubur, Diener des Ninšubur““ 818 Sowohl die Siegellegende als auch die Namen von Šèp-Sîns Vater NūrNinšubur und Bruder Anum-pī-Ninšubur sprechen für eine enge Verbindung der Familie zur Gottheit Ninšubur, und zwar in ihrer Rolle als Wesir und Botengott des Himmelsgottes Anum. Die Familie des Nūr-Ninšubur liefert ein Beispiel dafür, dass der Beruf des nar innerhalb einer Familie ausgeübt und weitertradiert wurde. Ihre Präsenz in Kutalla könnte mit der Vergabe von königlichem Pachtland zu erklären sein. Von Landvergabe an Musiker ist vielfach in Briefen aus der Šamaš-hāzir-Korrespondenz die Rede. ${ }^{819}$

Nur zwei gala sind in Kutalla-Texten mit Namen belegt: Șillī-Ištar (Ha 36) ist Zeuge zweier Rechtsurkunden, während Lipit-Eštar (RS 57) in der Zeugenliste eines Geländekaufvertrags auftritt. ${ }^{820} \mathrm{Im}$ Allgemeinen sind unter den Angehörigen der in Kutalla residierenden Privatfamilien nur wenige Priester oder Tempelfunktionäre bezeugt. Texte aus der Regierungszeit des Hammurabi und seines Nachfolgers Samsuiluna nennen vermehrt höher gestellte Beamte, die dem König und der Palastadministration angehörten. ${ }^{821}$ Die einzigen in Kutalla-Texten belegten Tempelbediensteten sind ein Priester (sag̃ga), ein

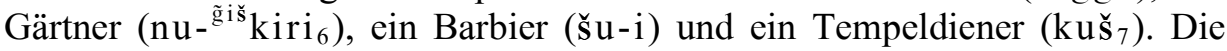
Präsenz der königlichen Verwaltung tritt in den Texten Kutallas stärker hervor als die irgendeiner Tempeladministration. Die zwei in Kutalla belegten gala waren möglicherweise am Tempel des Stadtgottes Lugalkisuna tätig, doch ist ein solcher Tempel in den Texten bisher nicht belegt.

\subsection{Isin}

\subsubsection{Historischer Hintergrund und Quellenlage}

Die Stadt Isin (heute: Išān Bahrīyāt) wird Ende des dritten Jahrtausends zum Zentrum einer Herrschaftsdynastie, die von Išbi-Erra (2017-1985), dem ehemaligen Stadtverwalter Isins unter Ibbi-Suen von Ur, begründet wurde. ${ }^{822}$ Išbi-

\footnotetext{
${ }^{818}$ TSifr 40/40a (Ha 36) Siegel 4: $\check{S}_{20}-e p$ - ${ }^{\mathrm{d}} \mathrm{EN} . Z U ;$ dumu Nu-ur ${ }^{-}{ }^{\mathrm{d}} \mathrm{Nin}-\mathrm{šubur} ; \mathrm{ir}_{3}{ }^{\mathrm{d}} \mathrm{Nin}-\mathrm{šubur}$; Charpin 1980, 228.

${ }^{819} \mathrm{AbB} 4$ 4, 12; AbB 4, 14; AbB 4, 62; AbB 9, 188 und hier Kapitel 9.2.2.3.

${ }^{820}$ TSifr 27/27a:36 (RS 57); TSifr 42:31 (Ha 36); TSifr 43/43a:30 (Ha 36).

${ }^{821}$ Ein Bürgermeister (rabiānum), ein Leutnant (nu-banda $a_{3}$ ), ein Aufseher der Bogenschützen

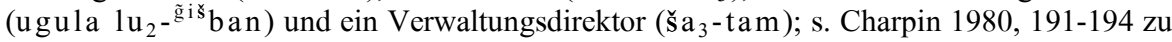
rabiānum und $\mathrm{nu}_{3}$-banda.

${ }^{822}$ Zur Geschichte Isins allgemein Charpin 2004, 60-64.
} 
Erra gelang es, sich von der Herrschaft des geschwächten Ur III-Reiches loszulösen, womit für die Stadt Isin eine politische und kulturelle Glanzzeit beginnt, die insgesamt zwei Jahrhunderte andauern sollte. Den Königen Isins gelingt es zuweilen, politisch und religiös bedeutende Städte Süd- und Mittelbabyloniens, wie Uruk, Ur und Nippur, in ihren Herrschaftsbereich einzugliedern.

Doch mit dem Sieg des Königs Rīm-Sîn von Larsa (1822-1763) über Damiq-ilī̌su von Isin (1816-1794) wird die Herrschaft der Isin-Könige beendet. Drei Jahrzehnte später erliegt Rīm-Sîn den Eroberungen des Hammurabi von Babylon, womit die Stadt Isin in den Herrschaftsbereich der ersten Dynastie von Babylon gelangt.

Das Ende Isins wird durch Samsuiluna, dem Nachfolger Hammurabis, herbeigeführt, bald darauf wird die Stadt von der Bevölkerung aufgegeben. Der letzte datierbare Isin-Text trägt das Datum Samsuiluna 29. ${ }^{823}$ Die archäologischen Überreste dieser Zeit weisen eine Brandschicht auf, die von einer dicken Verwitterungsschicht überlagert wird.

Eine Wiederbesiedlung Isins ist erst wieder im 14. und 13. Jahrhundert zur Zeit der kassitischen Herrschaft über Teile Babyloniens nachweisbar, wobei sich ihre Besiedlungsspuren auf den Bereich des Gula-Tempels beschränken.

Isin ist Hauptkultort der Heilgöttin Gula bzw. Ninisina „Herrin von Isin““ ${ }^{824} \mathrm{Im}$ südöstlichen Teil der Stadt, unweit des Gula-Tempels, weisen Reste eines größeren Gebäudes auf einen Palast des Enlil-bāni von Isin (1860-1837) hin. ${ }^{825}$ Diesem südöstlichen Grabungsgelände entstammen 137 inventarisierte Texte verschiedenster Gattungen: Königsinschriften, Hymnen, Schul- und Verwaltungstexte. ${ }^{826}$ Bei Grabungen im nordöstlichen Stadtbereich wurden weitere Schultexte gefunden, die auf den Standort einer schulähnlichen Institution schließen lassen. ${ }^{827}$

Der größte Teil der altbabylonischen Isin-Dokumente, insgesamt etwa 1000 Tafeln, wurde im Kunsthandel erworben. ${ }^{828}$ Von diesen bilden mehr als 900 Tafeln ein zusammenhängendes Textkorpus, das so genannte Lederarchiv. ${ }^{829}$ Dieses Archiv besteht aus Verwaltungstexten, die die Organisation eines handwerklichen Betriebs unter der Aufsicht des Palastes dokumentieren. Die Texte umfassen einen Zeitraum von etwa 30 Jahren. Sie datieren in den Beginn der Isin-Dynastie, in die Regierungszeit der Könige Išbi-Erra (2017-1985) und

\footnotetext{
${ }^{823}$ Gasche 1989, 126; Pientka 1998, 11 Anm. 28 und S. 19; Sommerfeld 1992, 150.

${ }^{824}$ Zum Verhältnis der Namen Gula und Ninisina s. Richter 2004, 193.

${ }^{825}$ Wilcke 1994, 303-306 ausführlich zu den Ausgabenlisten an das Palastpersonal.

${ }^{826}$ Textfunde der 9. Grabungskampagne; Krebernik 1992, 102.

${ }^{827}$ Wilcke 1987, 83 auch zur Schwierigkeit bei der Identifizierung solcher 'Schulgebäude'.

${ }^{828}$ Zur Quellenlage vgl. allgemein den Überblick bei Richter 2004, 175-177 und Charpin 2004, 423 mit Bibliographie.

${ }^{829}$ Vgl. Richter 2004, 175-176; publiziert in BIN 9, BIN 10 u. a.; Van de Mieroop 1987a, 2-5.
} 
Šu-ilišsu (1984-1975). In diesem Korpus sind die meisten Belege zu narMusikern der Stadt Isin enthalten. Von besonderem Interesse sind auch die in den Texten genannten Musikinstrumente, deren Herstellungsmaterial und Verbleib dokumentiert sind.

Die Texte des Lederarchivs werden nach Van de Mieroop ihrem Inhalt nach in zwei Gruppen aufgeteilt. ${ }^{830}$ Die erste Gruppe bilden Lieferscheine und Quittungen, welche wiederum in fünf Subkategorien unterteilt werden. Sie umfassen alle Vorgänge von der Anlieferung der Rohmaterialien an die Werkstätten bis hin zur Auslieferung der fertig gestellten Produkte an ihren jeweiligen Bestimmungsort. Als Bestimmungsort der in den Handwerkstätten gefertigten Produkte werden Institutionen am Palast oder am Haupttempel der Ninisina angegeben. Aber auch Tempel und Haushalte außerhalb der Stadt Isin werden mit Produkten derselben Werkstätte beliefert, so nennen die Texte die Städte Ur, Nippur, Larsa und andere kleinere Ortschaften. ${ }^{831}$ Die zweite Gruppe der Lederarchivtexte besteht aus Namenslisten. Diese Listen enthalten einerseits die Namen der jeweiligen Vorsteher und Arbeiter der einzelnen Werkstätten, andererseits führen sie auch Informationen zur Arbeitszeit, zur An- und Abwesenheit sowie zum Arbeitsplatz auf. Insgesamt sind in den Texten die Handwerker von vier Werkstattabteilungen vertreten, Tischler, Leder-, Rohr- und Textilarbeiter. ${ }^{832}$

Neben den Texten des Lederarchivs können andere im Kunsthandel erworbene Archive von Privatpersonen dem Umfeld der Isin-Tempel zugeordnet werden. Diese Texte enthalten vornehmlich Transaktionen über Immobilien und Tempelämter. In ihnen sind bisher nur gala-Priester attestiert.

Die bereits erwähnten Ausgrabungen in Isin unter der Leitung Hroudas brachten weitere 300 altbabylonische Texte zutage. ${ }^{833}$ Etwa 90 Tafeln dieses Fundes gehören einer Verwaltungseinheit an, die Ein- und Ausgänge von Mehl und anderen Getreideprodukten verbucht. ${ }^{834}$ Dieses so genannte 'Mehlarchiv' sowie eine weitere in sich abgeschlossene Gruppe über 20 Tafeln, darunter Schul- und Verwaltungstexte, werden dem Palast des Enlil-bāni im Südosten der Stadt zugeordnet. Unter diesen Texten der Palastverwaltung befanden sich auch Opferrationenlisten und Zuteilungen für Götter, die wohl dem nahe gelegenen Gula-Tempel galten. ${ }^{835} \mathrm{Da}$ aus Isin keine Tempelrationenlisten mit der Nennung von Musikern bekannt geworden sind, lässt sich über die Teilnahme

\footnotetext{
${ }^{830}$ Van de Mieroop 1987a, 9-18.

${ }^{831}$ Van de Mieroop 1987a, 105-116.

${ }^{832}$ Zur Organisation dieser Teams s. Van de Mieroop 1987a, 58-78, 81-89.

${ }^{833}$ Veröffentlicht in Hrouda (Hrsg.) 1977, 83-89; Hrouda (Hrsg.) 1981, 91-96; Hrouda (Hrsg.) 1987, 83-120; Hrouda (Hrsg.) 1992.

${ }^{834}$ Krebernik 1992, 102, 117-138; Wilcke 1994, 303-306.

${ }^{835}$ IB 1292, IB 1295; Wilcke 1994, 303-304; Krebernik 1992, 114-116 Abb. 15-16: IB 1700, IB 1829.
} 
des musikalischen Personals an Götterfesten in Isin zurzeit nichts Konkretes aussagen.

Unter den literarischen Texten fand sich auch eine Emesal-Komposition, möglicherweise der Gattung Eršema ${ }^{836}$ Sie ist in diesem Fall dem Kontext einer Palastschreiberschule zugeordnet. ${ }^{837}$

Insgesamt datieren die Texte von Ur-Ninurta (1923-1896) bis zum 26. Regierungsjahr des Samsuiluna von Babylon (1749-1712), sie decken damit einen Zeitraum von etwa 100 Jahren ab.

Unter den im nordöstlichen Bereich der Stadt gefundenen Schultexten befindet sich auch eine Sammelurkunde mit juristischen Modellverträgen, wie sie üblicherweise zum Lehrstoff eines Schreiberlehrlings gehörte. ${ }^{838}$ Die Sammelurkunde enthält auch einen Lehrvertrag über die „Sängerkunst“ ${ }^{839}$

\subsubsection{Die namentlich belegten Musiker Isins}

\subsubsection{Die gala}

Drei Kaufurkunden aus der Regierungszeit des Königs Damiq-ilīšu nennen einen gala mit Namen Šallūrum, Sohn des Warad-Damu. ${ }^{840}$ Laut seinem in BIN 7, 212 (o.D.) erhaltenen Siegel ist er „Diener des Martu/Amurrum und der Ninisina“ ${ }^{841}$ Im Gegensatz zur Göttin Ninisina, deren Haupttempel Egalmah sich in Isin befand, ist ein Kult des Martu/Amurrum in Isin nicht bezeugt. Die Erwähnung dieses Gottes im Siegel des Šallūrum könnte darauf hinweisen, dass die Familie Šallūrums Beziehungen nach Uruk oder Larsa pflegte, wo Martu/Amurrum auch in einem eigenen Heiligtum verehrt wurde. ${ }^{842}$ Die Wahl der Ninisina als zweite Familiengottheit spiegelt sich im Namen des Vaters wider, der als Namenselement den Gott Damu enthält, den Sohn der Ninisina.

Der gala Šallūrum ist zweimal Zeuge beim Kauf eines Tempelamtes: In BIN 7, 65 (Di 6) ist ein Sohn dieses gala, dessen Name nicht erhalten ist, Käufer eines Brauer-Wechselamtes am Tempel der Ninisina. ${ }^{843}$ Šallūrum ist

${ }^{836}$ Krebernik 1992, 104-105, Abb. 10: Die Unterschrift der einkolumnigen, nicht länger als insgesamt 11-12 Zeilen umfassenden Tafel wird als ${ }^{\top} \mathrm{er}_{2}{ }^{! ?}-\mathrm{se}^{\mathrm{e}} \mathrm{m}_{3}{ }^{7}-[\mathrm{ma} \ldots]$ gedeutet (Volk apud Krebernik 1992, 104).

${ }^{837}$ Ein weiteres Beispiel für Klagepriesterrepertoire unter Schultexten liegt mit UET 6/2, 403 vor, der akkadischen Übersetzung eines Ausschnitts aus dem Bala g̃ Uru-ama'irabi; Wasserman/Gababy 2006.

${ }^{838}$ IB 1515+IB 1534; Wilcke 1987, 104-105.

${ }^{839}$ Die erste Hälfte des Vertrags ist abgebrochen, in der zweiten wird die Unterrichtsbezahlung als eine Summe von $2 / 3$ gin $_{2}$ Silber (III' 12) notiert, die wahrscheinlich monatlich zu entrichten war; ausführlich hier Kapitel 8.2.

${ }^{840}$ BIN 7, 212:5.7 (o.D.); BIN 7, 65 (Di 6); BIN 7, 68 (Di a).

${ }^{841}$ BIN 7, 212 (o.D.) Siegel: Ša-lu-ru-um dumu $\operatorname{Ir}_{3}-{ }^{\mathrm{d}} \mathrm{Da}-\mathrm{mu}$ ir ${ }_{3}{ }^{\mathrm{d}} \mathrm{Mar} . t u u_{3}{ }^{\mathrm{d}}$ Nin-in-si-na.

${ }^{842}$ Richter 2004, 381-383, 462; Kalla 2002, 130.

${ }^{843}$ BIN 7, 65 (Di 6) 1. bala nam-lu ${ }_{2}-$ lunga 2. e ${ }_{2}^{\text {d }}$ Nin-in-si-na-ka 3. mu-a u $u_{4}$ 7-kam und 7. 
hier erster Zeuge ${ }^{844}$ Unter den weiteren sechs Zeugen befindet sich noch ein Bruder des Šallūrum mit Namen Kala-Ajja ${ }^{845}$ Die zweite Kaufurkunde BIN 7, 68 (Di a) betrifft eine Pfründe am Tempel des Ning̃išzida, dessen Inhalt allerdings nicht erhalten ist, Šallūrum tritt hier als letzter Zeuge auf. ${ }^{846} \mathrm{Im}$ Jahr des Regierungsantritts des Itēr-pīša gingen ein Brauer-Wechselamt sowie eine $\mathrm{gudu}_{4}$-Pfründe desselben Tempels in den Besitz einer weiteren Person mit Namen Šallūrum, Sohn des Ane-babdu, über ${ }^{847}$ die allerdings mit dem gala Šallūrum aus der Regierungszeit des Damiq-ilī̌su nicht identisch ist. Ungeachtet des verhältnismäßig sehr niedrigen Preises für diese Ämter ${ }^{848}$ könnten dennoch beide Šallūrum demselben Personen- oder Familienkreis angehört haben. Es besteht zumindest eine personelle Verbindung zwischen den genannten Ämtern am Ninisina- und am Ning̃išzida-Tempel, was darauf hinweisen könnte, dass beide Kultorte gemeinsam verwaltet wurden, oder auch die betreffenden Ämter im Besitz einer einzigen Familie waren.

Mit Ausnahme des einzelnen gala mit Namen Šallūrum ist auf einer Urkunde des Mehlarchivs aus der Zeit des Enlil-bāni nur noch eine Gruppe von gala-Priestern als Empfänger von Gersterationen neben Ausgaben an Müller(innen) und für Mastfutter belegt. ${ }^{849}$ Die Ausgabe des Palastes könnte mit einer Teilnahme der Priester an kultischen Festhandlungen zusammenhängen, was sich allerdings nicht nachweisen lässt.

\subsubsection{Ein Archiv des gala-mah der Ninisina}

Der bereits eingangs erwähnte zusammenhängende Textfund, der nahe der nördlichen Umfassungsmauer der Stadt zutage kam, gehörte nach Wilcke zum Privatarchiv eines gewissen gala-mah Ur-Nininsina. ${ }^{850}$ Zusammenhängend wurden drei Briefe, ${ }^{851}$ zwei Urkundenfragmente unbekannten Datums ${ }^{852}$ sowie eine Schultafel mit Abschriften sumerischer und akkadischer Königsinschriften $^{853}$ geborgen. Da in einem der Briefe besagter gala-mah Ur-Nininsina genannt wird, können auch alle übrigen Briefe als ihm zugeordnet identifiziert werden. ${ }^{854}$ Dieser gala-mah ist als Sohn des Ibni-Amurrum bereits aus einer

\footnotetext{
[x x] $\left.{ }^{\ulcorner} \times \mathrm{x} \mathrm{x}^{?}\right\urcorner$ 8. [x dum]u $\left.{ }^{\ulcorner} \check{S} a-l u-r\right\urcorner u-u m-\mathrm{ke}_{4}$.

${ }^{844}$ BIN 7, 65 (Di 6) 18'. igi Ša-lu-ru-um gala dumu $\operatorname{Ir}_{3}{ }^{\mathrm{d}}{ }^{\mathrm{d}} \mathrm{Da}-\mathrm{mu}-\check{s}_{3}$.

${ }^{845}$ BIN 7, 65 (Di 6) 23'. igi Ka-la-a-a dumu $\operatorname{Ir}_{3}-{ }^{\mathrm{d}} \mathrm{Da}-\mathrm{mu}-\mathrm{še}_{3}$.

${ }^{846}$ BIN 7, 68 (Di a) 1. bala nam [...] und 25'. igi Ša-lu-ru-um gala.

${ }^{847}$ YOS 14, 326:3-4 (ItPī 1).

${ }^{848}$ Richter 2004, $250+$ Anm. 1045.

${ }^{849}$ IB 1774 (Enba f) 8. x še gala(KU.UŠ)-meš; Krebernik 1992, 123, Abb. 22.

${ }^{850} \mathrm{Vgl}$. Wilcke 1985a, 188-190.

${ }^{851}$ IB 1536, 1538 und 1541; Wilcke 1985a, 189-190.

${ }^{852}$ IB 1539-40; Wilcke 1985a, 189.

${ }^{853}$ Wilcke 1985a, 188-189 zu IB 1537 mit Königsinschriften der Könige Ur-Namma und IšmeDagan.

${ }^{854}$ IB 1536:11; Wilcke 1985a, 189.
} 
im Kunsthandel erworbenen Kaufurkunde aus dem Jahr Samsuiluna 15 bekannt (TIM 5, 26), weshalb auch alle übrigen Texte desselben Fundes in dieselbe Zeit datiert werden. ${ }^{855}$

Aus unmittelbarer Nähe dieses Tontafelfundes stammt weiterhin ein bauchiges, mit einem Deckel versehenes Tongefä $\beta$, das die Bruchstücke einer teils sumerisch- teils akkadischsprachigen Liebesbeschwörung enthielt. ${ }^{856}$ Der Ausgrabungsbefund lässt deutlich erkennen, dass die Tafel bereits antik zerbrochen und im Gefäß unterhalb einer Ziegelsteinsetzung vergraben wurde. ${ }^{857}$

Aus den Briefen werden Hinweise zu den persönlichen Kontakten des gala-mah bekannt, so teilt ein von Ur-Nininsina nach Babylon entsendeter Unbekannter im Brief IB 1536 diesem mit, wie er sich in seinem Namen an den gala-mah von Babylon ${ }^{858}$ wendete. ${ }^{859}$ Hieraus wird deutlich, dass auch überregional ein reger Austausch unter den gala-mah-Priestern dieser Zeit bestand.

Besondere Beachtung verdient weiterhin der Brief IB 1541, der von einem unbekannten Schüler an den gala-mah Ur-Nininsina als sein Gönner und Erzieher gerichtet ist. ${ }^{800}$ Der Brief ist als eine Antwort auf einen offenbar vorhergehenden Vorwurf - möglicherweise wegen mangelnder Respektsbekundungen - seitens des Gönners zu verstehen:

T 49: ZA 75, 189-190 861

„Bezüglich dessen, was [du mir] auf einer Tafel so [geschrieben hast]: so du: 'Ich habe dich zur Welt [gebracht], und ich habe dich großgezogen; auch habe ich deinen Vater [unterhalten]!' Dass ic[h nicht wüsste], dass du mich zur Welt gebracht hast und [dass] du auch [mich großgezogen hast] und dass du auch meinen Vater unterhalten hast - so schreibst du mir! Ja, du hast mich großgezogen [...]; du hast mich das gala-Priestertum gelehrt! Seit ich klein war, bi[s...]“

${ }^{855}$ So auch Wilcke 1985a, 190; dieselbe Person könnte noch in IB 1669:2 (o.D.) genannt sein.

${ }^{856}$ IB 1554; Wilcke 1985a, 190-209; Groneberg 2007.

${ }^{857}$ Wilcke 1985a, 188, 190.

${ }^{858}$ Wie von Wilcke 1985a, 189 Anm. 6 zurecht angenommen, amtierte zu dieser Zeit wohl immer nur jeweils ein gala-ma h in einer Stadt; s. a. Kapitel 0. Unglücklicherweise sind für Babylon keine gala-mah namentlich bekannt.

${ }^{859}$ IB 1536:Rs. 7-13: ištu libbi Isin kìma ana Babilim erubam itti gala-mah annammer

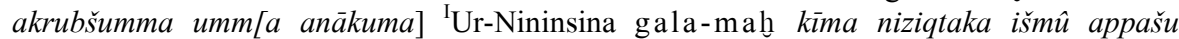
$i q[d u d]$,Als ich von Isin (kommend) nach Babylon hereinkam, bin ich beim gala-mahPriester erschienen, habe ihn gegrüßt und s[o (gesprochen)]: 'Der gala-mah Ur-Nininsina war sehr betrübt, als er von deinem Kummer erfuhr [...]'“; Wilcke 1985a, 189.

${ }^{860}$ Vom Namen des Absenders ist lediglich der Rest ${ }^{\mathrm{d}}$ Ur-[... erhalten, der Empfänger ist hingegen gänzlich abgebrochen. Dennoch meine ich, dass dieser Brief an Ur-Nininsina gerichtet war; anders Wilcke 1985a, 189, der sich einer Zuordnung enthält.

${ }^{861}$ IB 1541: 5'-13'; Umschrift und Übersetzung nach Wilcke 1985a, 189-190. 
aššum ina tuppim kīa[m...] umma attāma anā $[k]$ u uwallidakka urabbīka $u$ abak[a ataššì kima tuwallidanni u t[ura(b)bianni] u abì tataššu an[āku ul ìde] kīam tašappara $[m(. .)$.$] attāma tarabbianni [...] kalûtam tušāhiza[nni(...)] ištu$ sehrēku ad[i...]

Aus diesem Brief wird ersichtlich, dass der gala-mah als Lehrer agierte und einen Familienfremden in den Beruf des gala einwies. Der Absender hatte offenbar den Status eines Adoptivsohnes inne. Er wurde im Hause des galamah aufgenommen, aufgezogen und für das gala-Priestertum vorbereitet. Da zum Tontafelfund auch ein Schultext mit Abschriften von Königsinschriften gehörte, könnte der g a la-Schüler auch allgemein in der Schreibkunst unterrichtet worden sein. ${ }^{862}$

Die in unmittelbarer Nähe gefundene bereits antik zerbrochene und vergrabene Tafel mit akkadischen und sumerischen Liebesbeschwörungen, darunter auch eine im Emesal, ${ }^{863}$ ist nach Wilcke ebenfalls dem Textfund des galamah-Archivs zuzuordnen. ${ }^{864}$ Der Fundzusammenhang lässt auf eine konkrete rituelle Situation schließen, in deren Verlauf die Tafel auf dem Hintergrund eines Löse- oder Bannritus zerbrochen und vergraben wurde. ${ }^{865} \mathrm{Da}$ die Beschwörung konkrete Personen mit ihren Namen angibt, scheint sie dem Beziehungsleben real existierender Indiviuen zu einer einmaligen Situation gegolten zu haben. Da der Text zusätzlich teilweise in Dialogform gehalten ist, könnte nach Wilcke die Beschwörung, nach einleitenden Worten des gala-mah, auch szenisch aufgeführt worden sein. ${ }^{866}$ Dass gala- und gala-mah-Priester auch für die Ausführung von Beschwörungen zuständig waren, ist altbabylonisch vor allem literarisch bezeugt. ${ }^{867}$ Ausgehend von der Schulübung, die demselben Tafelfund angehörte, kann darauf geschlossen werden, dass der gala-mah die Texte auch selbst konzipierte und niederschrieb.

${ }^{862}$ Möglicherweise wird im Brief AbB 14, 50 (=VAB 6, 246) ein ähnliches Lehrverhältnis beschrieben: 3. umma Sîn-išmeanni .. .. 10. kima tidû šubarû gala 11. ištu šattim 8-kam ittīja [wāš̀ib ša?] 12. ištālima i'lam 13. ana e'élim ul addinšu „So Sîn-išmeanni: .. .. Wie du weißt, ist bei mir seit acht Monaten ein Subaräer, ein Klagepriester [wohnhaft, der?] mich 'wiederholt fragt'(?). Vertraglich habe ich ihn nicht gebunden. (Rest unverständlich); s. a. Übersetzung Veenhofs in AbB 14 mit Šubarû als PN; ištāli verkürzt für ištālanni „, fragte mich“. Die Identifizierung des Absenders als gala-mah, der den im Brief genannten gala ohne Vertrag(?) unterweist, bleibt zweifelhaft. Der weitere Briefinhalt, der von der Ausführung von Ritualen aus Anlass des Neumonds handelt, ist allerdings ein deutlicher Hinweis auf den Wirkungsbereich eines solchen Priesters.

${ }^{863}$ Wilcke 1985a, 198-199.

${ }^{864}$ Ausführlich zur Fundsituation Wilcke 1985a, 190-197.

${ }^{865}$ Groneberg 2007, 100-107.

${ }^{866}$ So Wilcke 1985a, 194.

${ }^{867}$ Nach dem Inhalt von SP 2.106; zum Repertoire s. a. hier Kapitel 6.3.2.2. 


\subsubsection{Andere Musiker in Texten der Palastverwaltung}

In den von Wilcke 1994 veröffentlichten Verwaltungstexten, die er dem Palast des Enlil-bāni im Südosten der Stadt zuordnet, sind zwei tigiātum namentlich belegt: Amerti-Ištar (IB 1304:16') und x-Nanaja (IB 1293). Die Musikerinnen sind Empfängerinnen von Gersterationen. Die Rationenlisten aus dieser Textgruppe nennen hauptsächlich weibliches Palastpersonal und deren Kinder, seltener auch männliche Angestellte des Palastes. Auch zwei Bärendompteure $\left(u_{4}\right.$-da-tuš $)$ werden in dieser Textgruppe erwähnt. Ihre jeweiligen Namen sind jedoch nicht mehr erhalten. ${ }^{868}$

Auf einer einzigen weiteren Urkunde, deren Archivzugehörigkeit unbekannt ist, wird ein nar igi lugal „nar vor dem König“ genannt. Die Urkunde BIN 7, 69 (Di a) ${ }^{869}$ enthält einen Kaufvertrag über Bauland, das vom König Damiqilīšu an besagten Musiker Șillī-Adad, Sohn des Bēlī-ašarēd für eine halbe Mine Silber verkauft wurde. Der Vorgang ist ungewöhnlich, da der Preis im Verhältnis zur Grundstücksgröße sehr hoch angesetzt wird. Zumindest ist hier ein Hinweis auf das private Vermögen eines solchen Königsmusikers enthalten.

\subsubsection{Musiker in den Urkunden des Lederarchivs}

In Texten des Lederarchivs sind mit einer Ausnahme nur nar-Musiker belegt. Sie werden als Einzelpersonen mit Namen oder als Gruppe genannt. Darüber hinaus sind mehrere Namen von Musikerhäusern „Haus (der) nar (nn)“ bezeugt, die im Folgenden näher erörtert werden. Die verschiedenen Handwerksstätten, die in den Texten des Lederarchivs dokumentiert sind, waren für den Palast tätig. Auch die in den Texten genannten Einzelpersonen können, je nachdem, ob sie in den Arbeiterlisten dieser Werkstätten angeführt werden, dem Palast zugeordnet werden. Andererseits nennen die Texte zuweilen auch Priester, die den Tempeln der Stadt Isin angehörten.

gala bleiben in den Archivtexten ungenannt, da sie offenbar weder mit den vertretenen Handwerken noch mit dem Bau oder gar dem Spiel der hier beleg-

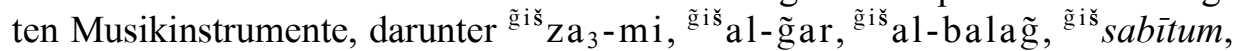

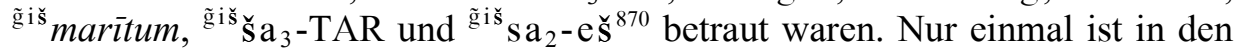

\footnotetext{
${ }^{868}$ Wilcke 1994, 305, 312.

${ }^{869}$ Kraus 1951, 111-112; zum Datum s. Liebermann 1982, 107.

${ }^{870}$ BIN 10, 87:1. 1 g̃ išal-g̃ar (IšEr 6/i); BIN 9, 353:1 (IšEr 12/x); BIN 10, 104:1-2 (IšEr 13/ii); BIN 9, 352:2 (IšEr 13/viii); MCS 5, 115 Nr. 1:6 (IšEr 13/x); BIN 9, 354:1 (IšEr 13/xi); BIN 9, 334:2.7.11 (IšEr 13/14?); BIN 9, 458:7-8 (IšEr 14/ii/12); BIN 9, 253:34 (IšEr 14/ii/24); BIN 9, 496:1-5 (IšEr 14/iii); BIN 9, $257: 7$ (IšEr 14/iv); BIN 9, 185:7 (IšEr 23a/xii); BIN 10, 82:5-6 (D.a.); BIN 9, 444:1 (Šull 3/iii); die häufigsten Instrumente sind der Reihe nach

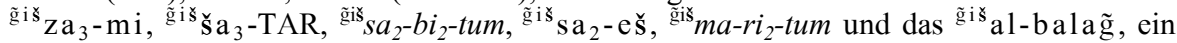
bislang nicht belegter Instrumentenname, vielleicht daher eher als 'Plektrum' bzw. 'Trommelschlägel' des bala g̃ zu deuten. Bezeichnenderweise werden alle diese Instrumente, vor
} 
Archivtexten ein gala-mah mit Namen $\mathrm{Lu}_{2}$-igi-KU belegt, der ein bala g der Inana und des Išbi-Erra und seine Materialien, darunter eine rote Rinderhaut für seine Membran in Empfang nimmt. ${ }^{871}$ Möglicherweise war es Aufgabe des gala-mah, das Instrument im Rahmen eines Rituals neu zu bespannen und auszubessern. Wie seine Aufgaben auch immer ausgesehen haben mochten, aus diesem Beleg wird ersichtlich, dass nur der ranghöchste Klagepriester, nämlich der gala-mah, für das gleichfalls ranghöchste und auch vergöttlichte Instrument bala ̃̃ zuständig war.

\subsubsection{Die nar}

Mit Namen werden nar-Musiker grundsätzlich nur in der ersten Gruppe von Texten über Lieferscheine und Quittungen erwähnt. Dort sind sie meist in der $\tilde{g}_{1}{ }_{3}$-Position anzutreffen, welche die ,für die Übergabe/den Transport verantwortliche“ Person angibt. ${ }^{872}$ Insgesamt werden vier Musiker mit Namen bekannt, die alle zur Zeit des Išbi-Erra agierten: ${ }^{.73}$ Ipiq-Lulu, Lu-Baba, Išbi-Errašâm-balātim und Ubar(rum). Da sie in keiner der Arbeiterlisten des Archivs genannt werden, müssen sie als Vertreter der Empfangsstelle gelten. Sie gehörten somit nicht den Werkstätten an. ${ }^{874}$

In fünf der sechs Belege sind diese nar verantwortlich für die Übergabe von Musikinstrumenten und ihre Materialien. ${ }^{875}$ Die empfangende Institution wird allerdings nur selten angegeben. Abgesehen von der Grundbedeutung der g gir ${ }_{3}-$ Position ist dennoch davon auszugehen, dass die zuständigen nar die Musikinstrumente auch selbst spielten. ${ }^{876}$

allem die ${ }^{\tilde{g} i \mathrm{~s}} \mathrm{Za}_{3}-\mathrm{mi}$, zwischen Ende des Jahres IšEr 12 und IšEr 14 geliefert. Ob sich dahinter der Aufbau eines Saiteninstrumentenensembles verbirgt, lässt sich nur mutmaßen.

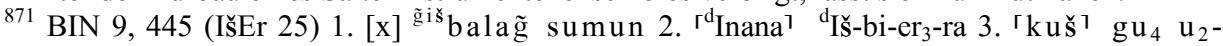
$\mathrm{hab}_{2}$-bi 1/3 4. ba-a-si; zur Lesung vgl. PSD B 75a sub 1.1.2.

${ }^{872}$ Krebernik 2001, 251; zur g̃ ir ${ }_{3}$-Funktion s. Sallaberger 1993, 24.

${ }^{873}$ BIN 9, 496 (IšEr 14) 11. nar U-bar; BIN 9, 334 (IšEr 13/14?) 11. Ipiq-Lulu; BIN 9, 353:4 (IšEr 12) und BIN 9, 354 (IšEr 13) 4. Lu-Baba; BIN 9, 415 (IšEr 24) 15. nar Išbi-Erra-šâmbalāțim (ohne g̃ ir ${ }_{3}$ ) erhält ein Paar Sandalen; BIN 9, 491 (IšEr r8 ${ }^{\text {?l }}$ ) 14. [x] kein g̃ ir ${ }_{3}$ erhalten. Die Auslieferung der Gegenstände wurde von Arbeitern der Lederabteilung ausgeführt; Van de Mieroop 1987a, 58-59, 65-71.

${ }^{874}$ Nach Van de Mieroop 1987a, 107 gehörten die im Lederarchiv genannten Musiker alle dem Tempelpersonal an.

${ }^{875}$ Ipiq-Lulu in BIN 9, 334:14 (IšEr 13/14²); Lu-Baba in BIN 9, $353: 4$ (IšEr 12), BIN 9, 352:6 (IšEr 13/viii) und 354:4 (IšEr 13/xi); nar U-bar in BIN 9, 496:11 (IšEr 14).

${ }^{876}$ Einmalig ist bei Ferwerda 1985, 40 Nr. 24:10 (LiEš a) ein nar unbekannten Namens als Bierempfänger belegt, der wohl dem Palast zuzuordnen ist. Diese Liste ist m. E. einem anderen Archivzusammenhang zuzuordnen. 


\subsubsection{Die nar-Häuser von Isin}

In neun Texten des Lederarchivs sind insgesamt vier verschiedene Bezeichnungen von Musikerhäusern ( $e_{2}$ nar) belegt: ${ }^{877}$

1. $\mathrm{e}_{2}$ nar-munus / $\mathrm{e}_{2}$ nar

2. $\mathrm{e}_{2}$ nar-munus $z i-i k-r u(-u m)$

3. $\mathrm{e}_{2}$ nar-(munus) ki ubar(r)a

4. $e_{2}$ nar ${ }^{\text {siš }} \mathrm{a}-\mathrm{a}-\mathrm{ab}-\mathrm{du}$

Mit einer einzigen Ausnahme, der Arbeiterliste BIN 10, 256 (IšEr 14), sind alle Musikerhäuser Empfänger von Produkten der Werkstätten. Ausgeliefert wurden verschiedene Alltagsgegenstände wie Betten, Matten, Behälter und Türen sowie in mehreren Fällen auch Musikinstrumente und ihre Materialien.

\subsubsection{1 $\mathrm{e}_{2}$ nar}

Der Beleg zum 'Haus der Musiker' findet sich in einer Arbeiterliste. Neben den Informationen zu Arbeitszeit und Anwesenheit wurde in den Arbeiterlisten auch angegeben, an welchem Ort ein Handwerker seinen Aufgaben nachging. ${ }^{878}$ Die folgende Liste nennt einen im Haus der Musiker arbeitenden Tischler:

T 50: BIN 10, 256 (IšEr 14)

1. $1 \mathrm{Ur}-{ }^{\mathrm{d}} \mathrm{Li}_{3}-\mathrm{si}_{4} 2.1 \mathrm{En}-\mathrm{um}-\mathrm{e}_{2}$-a 3. $1 \mathrm{Lugal}-\mathrm{ku}_{3}-\mathrm{zu}$ 4. 1 Mu-na-nu-um

5. ša $\mathrm{a}_{3} \tilde{\mathrm{g} i \mathrm{~s}} \mathrm{~s}-\mathrm{kig} \tilde{g}_{2}-\mathrm{ti}$

6. 1 Zitta(HA.LA)-ša $\mathrm{e}_{2}$ nar

7. nagar-me

8. $1 \mathrm{Lu}_{2}{ }^{-}$Inana 9.1 Šu- ${ }^{\mathrm{d}} \mathrm{Nin}-\mathrm{s} u b u r 10.1 A-h u-a-t a \bar{b} b\left(\mathrm{DUG}_{3}\right)$

${ }^{877}$ BIN 9, 441:5 (IšEr 9); BIN 10, 104:12 (IšEr 13); BIN 9, 348:8 (IšEr 18); BIN 9, 350:12 (IšEr 19); BIN 9, $451: 9$ (IšEr 22); BIN 9, 417:7 (IšEr 24); BIN 9, 352:5 (IšEr 7); BIN 10, 256:6 (IšEr 14); BIN 10, 82: 7 (D.a.) und in BIN 9, 352:5 (IšEr 7). Der Beleg über eine Gruppe von nar des Palastes in BIN 9, 445 (IšEr 25) nennt wohl eher wasserdichte Schafshäute (und Decken $\left.{ }^{3}\right)$ als Scheuklappen für die Palastesel auf einer Schiffsreise (9. 2 kuš udu a-lum e$\mathrm{ri}_{2}$-na 10. kuš ešs $\mathrm{ma}_{2}$-kaskal-ta gur-ra 11. igi-tab anše!-e-ne-še ${ }_{3}$ 12. ša $\mathrm{a}_{3} \mathrm{e}_{2}-$ gal-š $\left.\mathrm{e}_{3}\right)$.

${ }^{878}$ Van de Mieroop 1987a 53-54. Der Beleg in BIN 9, 522 (IšEr 8) ist unsicher. 
Rs

11. ašgab-me

12. 1 dig̃ir-šu-e-er 13. $1 \mathrm{Ur}-\mathrm{du}_{6}-\mathrm{ku}_{3}-\mathrm{ga}$

14. ad-kup - $_{4}$ e

15. 1 Ur- ${ }^{\mathrm{d}}$ lugal-ban ${ }_{3}$-da 16. 1 Zitta(HA.LA)-̌̌a 17. 1 Di g̃ir-ba-ni

18. $\operatorname{tug}_{3}-\mathrm{du}_{8}-\mathrm{me}$

19.-20. Datum: IšEr 14 vi

1.Rd. 13 g̃uruš $u_{4}\left\ulcorner 17^{?}\right\urcorner-\mathrm{kam}$

In dieser Urkunde sind die Namen von insgesamt 13 Vorarbeitern der vier Handwerkerabteilungen aufgelistet: Tischler (Z. 7. nagar-me), Lederarbeiter (Z. 11. ašgab-me), Rohrflechter (Z. 15. ad-kup a $_{4}$-me) und Textilarbeiter ( $Z$. 18. tug $\left._{2}-\mathrm{du}_{8}-\mathrm{me}\right){ }^{879}$ Vier Personen aus der Gruppe der Tischler in den Zeilen

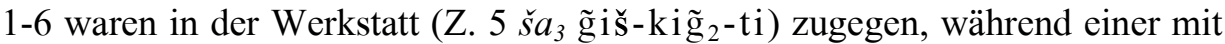
Namen Zittaša dem 'Haus der nar-Musiker' (Z. 6 e ${ }_{2}$ nar) zugeteilt war. ${ }^{880}$

\subsubsection{2 $\mathrm{e}_{2}$ nar-munus}

Das 'Haus der Musikerinnen' ist in den Lederarchivtexten dreimal belegt. ${ }^{881}$ Neben der Versorgung mit Matten und Holzgegenständen wurde an dieses Haus nach der Urkunde BIN 9, 441:1 (IšEr 9) auch ein ${ }^{\tilde{g} i s ̌ ~} \mathrm{dub}_{2}-\mathrm{dub} \mathrm{b}_{2}$-baInstrument geliefert. Hierbei könnte es sich um eine Schreibvariante zum bekannten ${ }^{\tilde{g} i s ̌ s}$ bala $\tilde{g}\left(\mathrm{DUB}_{2}\right)$ - bala $\tilde{g}\left(\mathrm{DUB}_{2}\right)$-di handeln. ${ }^{882}$

\subsubsection{3 $\mathrm{e}_{2}$ nar-munus $z i-i k$-ru(-um)}

Die mehrdeutige Schreibung dieses Musikerhauses erschwert seine Identifizierung. ${ }^{883}$ Naheliegend ist für ${ }^{\text {munus }} z i-i k-r u(m)$ die Deutung sekretum anzusetzen,

\footnotetext{
${ }^{879}$ Van de Mieroop 1987a, 58-61, 83-86 + Anm. 74.

${ }^{880}$ Van de Mieroop 1987a, 60 Anm. 43.

${ }^{881} \mathrm{e}_{2}$ nar-munus in BIN 9, 441:5 (IšEr 9); $\mathrm{e}_{2}$ nar-munus-e-ne in BIN 9, $451: 9$ (IšEr 22) und BIN 9, 417:7 (IšEr 24). Beachtenswert ist die durchgängige Schreibung mit nachgestelltem munus.

${ }^{882}$ PSD B 79a balag̃-bala $\tilde{g}-d i$ A und bala g̃-di A. Zur Lesung des Instrumentennamens s. Attinger 1993, $453 \S 307$ mit bulu $\tilde{g}_{5}$-bala $\tilde{g}$-di, dagegen Nabnītu 32 iii 14 (MSL 16, 252) $\mathrm{DUB}_{2}-\mathrm{DUB}_{2}$-di mit Glosse $b u-d u-b u-{ }^{\top} u_{2}{ }^{1}$, die allerdings auf einen anderen Eintrag zu beziehen sein könnte. In der nA Hymne an Ištar von Arbela bei Livingstone 1989, 22:16': $a$ rim dub-dub-bi ${ }^{\Gamma} \mathrm{X}^{\top}$-hal-la ša li-li-[sa]- ${ }^{\Gamma} a^{\top}-[t i]$, "bedeckt ${ }^{2}$ ' ist das dubdubbu, das $\mathrm{x}$ der lilisPauken“ anders Livingstone, ibid., der arāmu mit ,tuned“" wiedergibt. Das Instrument wird von Kilmer 2003-05, 369 als Trommel aufgefasst. Andere Perkussionsinstrumente wie Klappern oder Rasseln, angesichts der Stelle bei Livingstone, ibid. vielleicht sogar Trommelschlägel, kämen ebenso gut in Frage.

${ }^{883}$ BIN 9, 348 (IšEr 18) 8. e 2 nar munus zi-ik-ru-um-ma-še ${ }_{3}$; BIN 9, 350 (IšEr 19) 9. ka $\mathrm{a}_{2}$ ša $_{3}$ $\mathrm{e}_{2}$ nar munus $z i$-E!-ik-ru-um-š $\mathrm{e}_{3}$.
} 
eine Priesterin im Kult der Inana/Ištar oder eine 'Palastdame' ${ }^{884}$ Eine ausführliche Untersuchung zu den Funktionen dieser Frauen steht noch aus.

Andererseits ist $z i-i k-r u(m)$ auch die Kurzform eines männlichen Personennamens der Bildung zikir-GN „Wort/Ausspruch des GN“. ${ }^{885}$ In sechs Lieferscheinen des Lederarchivs ist eine Person mit diesem Kurznamen belegt. ${ }^{886}$ Die Urkunde BIN 9, 444 (Šull 3) nennt zudem einen Zikrum als Empfänger von Herstellungsmaterialien für zwei ${ }^{\tilde{~} i \mathrm{~s}} \mathrm{za}_{3}$-mi-Instrumente, was die Identifizierung des Musikerhauses als „Haus der Musikerinnen (des) Zikrum“ nahe legt ${ }^{887}$ Ein Haus der sekrētum-Frauen ist in den Texten des Lederarchivs auch unabhängig von nar belegt. ${ }^{888}$ Es bleibt daher unklar, ob hier die Musikerinnen des Zikrum, Musiker der sekrētum oder aber eine Gruppe von musizierenden sekrētum gemeint sein könnten. Als Musikerinnen ist mir diese Frauengruppe bislang aus keiner anderen Quelle bekannt.

\subsubsection{4 $\mathrm{e}_{2}$ nar-(munus) ki ubar(r)a}

Dieses Musikerhaus wird in den Lederarchivtexten zweimal erwähnt mit jeweils unterschiedlichen Schreibungen: $e_{2}$ nar ki $u_{4}$-bar-ra in BIN 10, 82:7 (D.a.) und $e_{2}$ nar-munus ki Ubārum in BIN 10, 104:12 (IšEr 13). Van de Mieroop übersetzt den Namen des Musikerhauses mit „House of the (female) singers from Ubarrum/Ubarra" und fasst Ubarrum/Ubarra damit als den Namen einer sonst unbekannten Ortschaft auf. ${ }^{889}$ Kilmer sieht hier dementgegen einen Personennamen und übersetzt „House of male/female singers, with Ubarum“. 890 Eine Person mit Namen Ubārum ist in BIN 10, 186:6 (o.D.) Empfänger verschiedener Hölzer. ${ }^{891}$ Die Urkunde BIN 9, 496: 11 (IšEr 14) nennt weiterhin einen nar Ubār, der fünf fertig gestellte Saiteninstrumente erhält: zwei ${ }^{\text {ğiš }} \mathrm{za}_{3}$ $\mathrm{mi}$, ein ${ }^{\tilde{g} \text { iš }}$ maritum und zwei ${ }^{\text {ğiš } ̌ \text { ša }}{ }_{3}-\mathrm{TAR}^{892}$

${ }^{884}$ Die Grundbedeutung des Namens sekretum „Abgeschlossene“ könnte auf die Lebenssituation dieser Frauen hinweisen; CAD S 215a; AHw 1036a; Groneberg 1986, 27-28. Zu sekrētum in Mari s. Ziegler 1999, 83-86.

${ }^{885}$ AHw 1526b zikrum I sub A 5); Stamm 1939, 111-117.

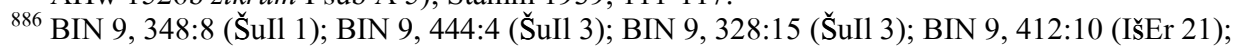
BIN 9, 485:10 (IšEr 22); JAOS 98, 256:14:6 (D.a.). Da das Determinativ munus nie angegeben ist, muss m. E. gegen Van de Mieroop 1987a, 107 sekrū „devotees“ und 149 (Index) der Kurzname Zikrum gemeint sein.

${ }^{887}$ Ungewöhnlich aber nicht unbedingt unüblich wäre in einem solchen Kontext die Terminativendung am PN Zikrum; s. hier Anm. 883.

${ }^{888}$ Belege zusammengestellt in CAD S 215 sub 1a).

${ }^{889}$ BIN 10 S. 29 sub e 2 nar; im Namenindex S. 23 allerdings als PN verzeichnet.

${ }^{890}$ Kilmer 1993-97, 469; AHw 1399b sub 1) in PN oder als Kurzform zu Ubār-GN; Stamm 1939, 251.

${ }^{891}$ BIN 10, 186 (o.D.) 6. U-bar-um $u_{3}$ Še-x-x ?; im Index von BIN 10, S. 23 als Personenname Ubarrum verzeichnet; beachte dieselbe gebrochene Schreibung wie in BIN 10, 104:12 (IšEr 13).

${ }^{892}$ BIN 9, 496 (IšEr 14) 11. ki nar u-bar; möglicherweise hier als „ortsfremder nar“ zu deuten, 
Auch an beide Musikerhäuser, sowohl das der Männer wie auch das der Frauen, werden Materialien für die Instrumente ${ }^{\tilde{g} i s ̌} \mathrm{Za}_{3}-\mathrm{mi}$ und ${ }^{\tilde{g} i \mathrm{~s}} \mathrm{Š}_{3}-\mathrm{TAR}$ geliefert. ${ }^{893}$

Schließlich bezeichnet das Wort ubārum in seiner Grundbedeutung auch eine ortsfremde Person, ${ }^{894}$ womit eine dritte Deutung dieser Institution möglich wäre, als Haus der ortsfremden/auswärtigen Musiker/innen.

Insgesamt halte ich dennoch die Deutung Kilmers am wahrscheinlichsten auch angesichts der Beleglage zur Person des Ubarrum im Zusammenhang mit Musikinstrumenten. ki „Ort; bei/von“ kann dann als 'seitens des' wiedergegeben werden. Die Person namens Ubarrum könnte einem Musiker(innen)haus vorgestanden haben. Darüber hinaus könnten dieser Ubarrum oder die narMusiker unter seiner Aufsicht auch für den Bau von Musikinstrumenten zuständig gewesen sein.

\subsubsection{5 $\mathrm{e}_{2}$ nar ${ }^{\tilde{g} i \mathrm{~s}} \mathrm{a}-\mathrm{a}-\mathrm{ab}-\mathrm{du}$}

An das in den Texten des Lederarchivs einmal belegte e ${ }_{2}$ nar g̃iša-a-ab-du wurden nach der Urkunde BIN 9, 352 (IšEr 13) zwei ${ }^{\tilde{g} i s ̌ s} \mathrm{Za}_{3}$-mi-Instrumente durch den nar Lu-pada ausgehändigt. Da dieser nar nicht als Arbeiter der Werkstätten bekannt ist, muss er für dieses Musikerhaus tätig gewesen sein. Ausgehend vom Determinativ g̃i ̌̌ „Holz“ könnte der Name des Musikerhauses auf ein Instrument oder eine Instrumentengattung verweisen. Bislang ist mir ein solcher Name für ein Musikinstrument allerdings unbekannt. ${ }^{895}$

\subsubsection{Bala $\tilde{g}-$ Gottheiten in Isin}

Aus dem Bereich des Gula-Tempels stammt eine fünfkolumnige Opferliste frühaltbabylonischer Datierung (IB 1006a), die neben Opferausgaben für die Hauptgottheiten Isins auch Ausgaben für Ninhinuna und Ninigizibara im Kreise der Gula verbucht. Die selbstständige Gottheit Ninhinuna gilt nach Ausweis der mittelassyrischen Götterliste An=Anum als Stier-bala g der Gula. ${ }^{896}$ Ninigizibara ist hingegen die am häufigsten belegte (Stier-)bala g̃ Gottheit, die in aller Regel Inana zugeordnet ist. ${ }^{897}$ Dass sie in der genannten

da die Berufsbezeichnung vorausgeht.

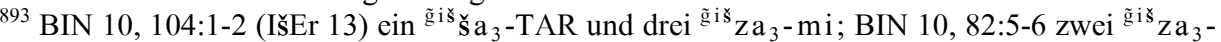
mi til und zwei ${ }^{g}{ }^{2} \breve{s}_{\breve{s}} a_{3}$-TAR; die Instrumentenanzahl muss nicht der Anzahl der Hausbewohner entsprechen.

${ }^{894}$ AHw 1399b ubāru(m) „Ortsfremder, Beisasse; Schutzbürger“. Die Schreibvariante mit $\mathrm{u}_{4}$ wäre damit allerdings nicht zu klären.

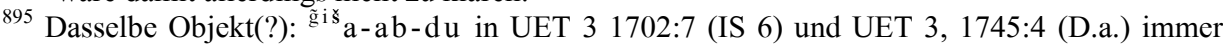
neben ${ }^{\text {tug } 2}$ bar-siki $=$ parš/sigu $(m)$ „Turban, Kopfbinde“; AHw 836a. S. a. ababdû mit Variante TUR.a.a.ab.du in $\mathrm{aB}$ Proto-Lu $\mathrm{Lu}_{2}$,ein Funktionär“; CAD A/1 2a. Es könnte sich um Musiker mit einer besonderen Kopfbedeckung handeln.

${ }^{896}$ S. allgemein Cavigneaux/Krebernik 1998-2001b, 378.

${ }^{897}$ Walker/Wilcke 1981, 96; dazu Richter 2004, 212-213. Belege zu Ninigizibara u. a. im 
Opferliste aus Isin dem Kreise der Gula zugewiesen wird, könnte nach Richter auf Ur III-zeitliche Synkretismen zurückgehen. ${ }^{898}$

Ninhinuna ist schließlich noch in zwei weiteren Texten des Handwerkerarchivs aus der Zeit des Išbi-Erra belegt. ${ }^{899}$ Nach diesen Texten wurden ihr einmal 'goldene Lamellen' (ni $\tilde{g}_{2}-\mathrm{su}_{3}-\mathrm{a} \mathrm{ku}_{3}-\mathrm{sig}_{17}$ ) und ein andermal ein 'Schild(?)' ( $\left.{ }^{\tilde{g} i \check{s}} \mathrm{ga}-\mathrm{bu}\right)$ gefertigt. ${ }^{900}$ Leider lässt sich nicht klären, ob diese Objekte Teile des Musikinstruments bala g̃ sind, das in seiner Personifizierung als Gottheit Ninhinuna kultisch verehrt wurde. Nichtsdestotrotz geben diese wenigen Belege Auskunft über die Verwahrung vergöttlichter balag̃ Instrumente im Gula-Tempel sowie ihre Einbeziehung in Kultfeste oder Reisen der Götter.

Die Wartung und kultische Pflege dieser balag̃-Instrumente lag angesichts der oben vorgestellten Urkunde BIN 9, 445 (IšEr 25) im Zuständigkeitsbereich eines gala-mah.

\subsection{Nippur}

\subsubsection{Historischer Hintergrund und Quellenlage}

Die Stadt Nippur (heute: Nuffar) war zu keiner Zeit Zentrum einer herrschenden Dynastie oder Hauptsitz eines regierenden Königs. ${ }^{901}$ Trotzdem nahm Nippur gegenüber anderen Städten Babyloniens bereits seit frühdynastischer Zeit eine herausragende Stellung ein, vor allem aufgrund seiner religiösen Bedeutung. Nippur ist Hauptkultort des sumerischen Götteroberhauptes Enlil mit seinem Haupttempel Ekur. In der Zeit der Sargoniden geht die Rolle des Stadtgottes von Enlil auf seinen und Ninlils Sohn ${ }^{902}$ Ninurta über. Ninurta wurde schon früh in seinem eigenen Tempel verehrt, dem Ešumeša ${ }^{903}$ Für seine Gemahlin Ninnibru, „Herrin von Nippur“, akkadisch Bēlet Nippurim, die erst seit Beginn der Ur III-Zeit in Texten fassbar wird, sind nur sehr wenige altbabylonische Belege überliefert. ${ }^{904}$ Bislang unbekannt ist, ob sie über ein

Jahresdatum Ibbi-Suen 21 sowie in den Mari-Ritualen (Ziegler 2007, 57:i 5'ff., 60, 63-64); allgemein Heimpel 1998-2001a.

${ }^{898}$ Ur III-zeitlich gehört sie dem Gefolge der Gula von Umma an und begleitet diese auf ihrer Reise nach Zabalam; Richter 2004, 213.

${ }^{899}$ BIN 10, 75:7 (IšEr 14); BIN 9, 433:24 (IšEr 25).

${ }^{900}$ Hierzu Richter 2004, 212.

${ }^{901}$ Klein/Stol/Streck 1998, 532ff., 539ff.; Sallaberger 1997, 148-164.

902 Zur Genealogie des Ninurta s. Richter 2004, 171-172.

${ }^{903} \mathrm{Klein} /$ Stol/Streck 1998, 533, 541; George 1993, 147 Nr. 1065.

${ }^{904} \mathrm{e}_{2}{ }^{\mathrm{d}}{ }^{\mathrm{n}}$ nin-nibru ${ }^{\mathrm{ki}}$; Bernhardt/Kramer 1975, 98:16; George 1993, 106 Nr. 544: $\mathrm{e}_{2}$-ka-ašbar; Richter 2004, 71-72; Biggs 1998, 476. 
eigenständiges Heiligtum verfügte oder eher in einem kleineren Kultschrein als Teil eines größeren Tempelkomplexes verehrt wurde.

Wie dem Gott Šamaš in Sippar oder Marduk in Babylon wurden auch Ninurta lukur-Priesterinnen (akkadisch ugbabtum) geweiht, die ein eigenes abgeschlossenes Wohnviertel, das ki-lukur „Ort der lukur" bewohnten. ${ }^{905}$

Die politische Herrschaft über Nippur wechselte seit dem späten dritten Jahrtausend zwischen den in Südbabylonien herrschenden Dynastien von Isin und Larsa. ${ }^{906}$ Die Stadt Nippur blieb trotz dieser häufigen Machtwechsel vor Zerstörungen verschont. ${ }^{907}$

In der Ideologie der Isin-Könige wurde Nippur als wichtigstes Zentrum der sumerischen Kultur, seiner Tradition und Sprache verehrt. Auch die Einwohner Nippurs erhielten unter der Herrschaft der Isin-Könige einen Sonderstatus. Die auffällig hohe Anzahl an Tempelpfründen, die in den Texten Nippurs genannt werden, ist auf diesen Sonderstatus der Stadt und seiner Einwohner zurückzuführen. Ein Großteil der ranghohen Bevölkerung war für Tempeldienste eingeteilt, die auch Musik und Gesang beinhalten konnten.

Mit der Eroberung Südbabyloniens durch Hammurabi von Babylon verliert Nippur mit seinem Haupttempel des Enlil seine herausragende religiöse Stellung. ${ }^{908} \mathrm{Im}$ Jahr Samsuiluna 11 kommt es zusätzlich zu einer schweren ökonomischen Krise. Größere Anteile der Bevölkerung verlassen Nippur und ziehen in nördliche Regionen. Die letzten Samsuiluna-zeitlichen Texte datieren in dessen 30. Regierungsjahr. ${ }^{909}$ Nippur geht dem babylonischen Reich verloren und gerät für kurze Zeit in den Herrschaftsbereich des Meerland-Königs Ilumailum. ${ }^{910}$ Eine Flussbettverlagerung führt wahrscheinlich zu weiteren Emigrationen. ${ }^{911}$ Eine kleinere Besiedlung könnte um den Tempelbezirk des Ekur bis in die Zeit des babylonischen Königs Ammișaduqa bestanden und den Enlil-Kult weiterhin gepflegt haben. ${ }^{912}$ Die Hauptkulte des Enlil und des Ninurta wurden hingegen in den Landestempel Enamtil von Babylon verlegt, ein Gedenken des Ninurta lässt sich darüber hinaus in Kiš nachweisen. ${ }^{913}$ Erst im späten 14. Jahrhundert zur Zeit der kassitischen Herrschaft über Babylonien lässt sich in Nippur eine neue Besiedlungsschicht und die Kultpflege am Ekur wieder nachweisen. ${ }^{914}$

\footnotetext{
${ }^{905}$ Allgemein Stol 1998, 542.

${ }^{906}$ Sigrist 1977b, 363-374; Tinney 1996, 2-6.

${ }^{907}$ Sallaberger 1997, 160.

${ }^{908}$ Sallaberger 1997, 161-163.

${ }^{909}$ Stone 1987, 26-27; dazu Postgate 1990, 230-234; Pientka 1998, 13-14, 20.

${ }^{910}$ Brinkmann 1993-95, 6; Gasche 1989, 124-126.

911 Pientka 1998, 20.

${ }^{912}$ Pientka 1998, 193-194.

${ }^{913}$ Zur Pflege des Enlil und Ninurta-Kultes in spätaB Zeit Pientka 1998, 190-195; Sallaberger 1997, 163.

${ }^{914}$ Klein/Stol/Streck 1998, 544.
} 
Das urkundliche Material Nippurs stammt sowohl aus Privatarchiven als auch aus der Tempeladministration. In den Privaturkunden, die bereits früh publiziert und ausgiebig dokumentiert wurden ${ }^{915}$ finden sich zahlreiche Belege zu nar und gala. Herausragend sind insbesondere die Erwähnungen von Tempelpfründen in Kauf- und Erbschaftsverträgen, die über die Organisation von Musikerämtern am Ekur und dem Ešumeša des Ninurta Aufschluss geben. ${ }^{916}$

Die Texte zur Tempeladministration sind bisher nur teilweise veröffentlicht. Eine erste Gruppe von etwa 450 Urkunden, die in die Zeit der Isin und LarsaKönige datiert, dokumentiert die Organisation von Opferlieferungen und Personalausgaben des Ninurta-Tempels. ${ }^{917}$ Die Texte informieren hauptsächlich über Lieferungen von Agrarprodukten, die verschiedenen Göttern geopfert und anschließend an das Tempelpersonal Nippurs verteilt wurden. ${ }^{918}$ Die Veröffentlichung einer zweiten Gruppe von etwa 500 Urkunden, die höchstwahrscheinlich dem Ekur entstammt, steht noch aus. ${ }^{919}$ Diese Textgruppe, die in die Zeit des Rìm-Sîn von Larsa datiert, beinhaltet die Verteilung von Opferrationen und Vieh. $^{920}$

\subsubsection{Die namentlich belegten Musiker Nippurs}

Aufgrund der noch ausstehenden Publikation von Texten zur Tempeladministration können nur 33 Texte, die überwiegend aus Privatarchiven stammen, für die Untersuchung der Musikerberufe in Nippur herangezogen werden. Für die Texte des Ešumeša wird im Folgenden auf die Angaben bei Sigrist (1984) verwiesen.

\footnotetext{
915 Klein/Stol/Streck 1998, 543; Charpin 2004, 418-420 mit Bibliographie.

${ }^{916}$ Klein/Stol/Streck 1998, 541-542; nach Renger 1969, 194 sind daher nur aus dieser Stadt gala-Pfründen im Privateigentum überliefert.

${ }^{917}$ Sigrist 1984 und dazu Rezension bei Kraus 1985.

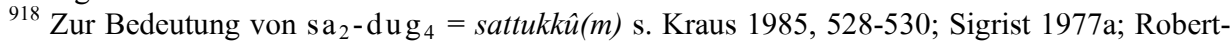
son 1992, 179-182.

${ }^{919}$ Dokumentiert bei Robertson 1992, 182-183; Robertson 1984, 145-190; Texte z. T. in PBS 8/1-2 publiziert; s. a. Kraus 1959, 136-167; Kraus 1985, 534.

${ }^{920}$ Sigrist 1984, 156; Robertson 1984, 153-155; Robertson 1992, 181-182, 185-188; allgemein Stol 1998, 542-543.
} 


\subsubsection{Die gala-mah}

In den administrativen Texten aus Nippur sind ausschließlich für die frühaltbabylonische Zeit insgesamt vier, möglicherweise auch fünf gala-mah bezeugt. Namentlich sind Nanna-gugal, Ir-Enlila und Ninurta-mušallim bekannt. ${ }^{921}$ Ohne Namen ist ein weiterer gala-mah des Enlil belegt. ${ }^{922}$

Der gala-mah mit Namen Nanna-gugal wird insgesamt in drei Urkunden genannt. Im Vertrag ARN 23+ aus der Zeit Sumu'ēls, welcher die Erbschaft einer bekannten Familie Nippurs regelt, neben anderem eine gudu ${ }_{4}$-Pfründe am Heiligtum der Ninlil, ${ }^{923}$ ist der gala-mah Nanna-gugal Zeuge. ${ }^{924}$ Die zweite Kaufurkunde ARN 29 (RS 21) nennt einen gala-mah Nanna-gugal als Eigentümer eines Feldes, das neben dem Landbesitz einer einflussreichen Familie Nippurs gelegen war. ${ }^{925}$ Ein dritter Beleg zum gala-mah Nanna-gugal findet sich in der Schuldurkunde PBS 8/1, 11 (Zam 1), wo er als Gläubiger auftritt. Unter den Zeugen ist auch ein gala mit Namen Lu-Ninlila. ${ }^{926}$

Die drei hier vorgestellten Belege umfassen insgesamt einen Zeitraum von über 65 Jahren (Zam 1 - Sel 28?). Es ist daher zu vermuten, dass mehrere gala-mah unter diesem Namen zu identifizieren sind. Filiationen werden in den Texten nicht angegeben, auch lassen sich keine Rückschlüsse auf eine Familienzugehörigkeit ziehen. Die Unterscheidung und Identifizierung dieses bzw. dieser gala-mah muss daher ungeklärt bleiben.

Der zweite in Nippur belegte gala-mah Ir-Enlila ist als Zeuge zweier Urkunden belegt, die Erbschaften über gudu ${ }_{4}$ - und gala- Pfründe betreffen ${ }^{927}$ In der auffällig langen Zeugenliste der Urkunde ARN 44 (RS 55) werden neben IrEnlila weitere Tempelangestellte genannt, wobei der Tempelaufseher an erster Position genannt wird:

\footnotetext{
${ }^{921}$ Nanna-gugal 1: ARN 23+PBS 8/2, 169:iv 3 (D.a.[Sel 28?]); Nanna-gugal 2: ARN 29:Rs. 5 (RS 21); PBS 8/1, 11:4-5 (Zam 1); Ir-Enlila: ARN 44:19 (RS 55) und BE 6/2, 26:iv 17 (Si 6); Ninurta-mušallim: BE 6/2, 26:iv 18 ( $\mathrm{Si}$ 6) und BE 6/2, 42:15 (Si 13); vgl. Renger 1969, 196.

${ }^{922}$ PBS 8/1, 89:2 (Ilil 2).

${ }^{923}$ Familie des Ninlil-zig̃u; Stone 1987, 41-54 Fig. 2; Kalla 2002, 134-135, 151 Familie 4.

${ }^{924}$ ARN 23+PBS 8/2, 169 :iv 3 (D.a. [Sel 28?]); Stone 1987, 45 zur Rekonstruktion des Urkundendatums.

${ }^{925}$ Unter den Angehörigen dieser Familie sind auch zahlreiche lukur des Ninurta; vgl. Stone $1982,57-59$

${ }_{926}$ PBS 8/1, 11:11 (Zam 1).

${ }^{927}$ ARN 44: 19 (RS 55); BE 6/2, 26:iv 17 (Si 6).
} 
T 51: ARN 44 (RS 55) Rs 16-28

16. igi ${ }^{d}$ Nin-urta-me-gub ugula $e_{2}{ }^{d}$ Nin-urta

17. igi Lugal-me-lam 2 - gir $_{3}{ }^{\text {? }}$ nar-gal

18. igi $\mathrm{Ka}-{ }^{\mathrm{d}} \mathrm{Nin}-\mathrm{urta}$ nar-gal

19. igi $\mathrm{Ir}_{3}-{ }^{\mathrm{d}} \mathrm{En}-1 \mathrm{il}_{2}-1 \mathrm{a}_{2}$ gala-mah

20. igi ${ }^{d} \mathrm{Nin}-u r t a-g a-m i l ~ i_{3}-d u_{8}$

21. igi $\mathrm{E}_{2}-m u-b a-l i_{2}-i t \mathrm{i}_{3}-\mathrm{du}_{8}$

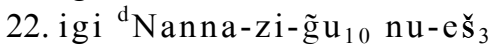

23. igi $A$-pil- $i_{3}-l i_{2}-\check{s} u$ šà ’ilu(ensi)

24. igi $I$-din- ${ }^{\mathrm{d}} I-$ šum bur-gul

25. igi $A$-pil- ${ }^{\mathrm{d}}$ Sîn dub-sar

26. igi Gir ${ }_{3-}^{-{ }^{d} a_{3}-a l-s i g} 6$ dub-sar

27. igi d Nanna-ibila-ma-an-sum aga-uš šandabakku(g̃a $\left.{ }_{2}-\mathrm{dub}-\mathrm{ba}\right)$

28. igi Ku-nu-tum lukur ${ }^{\mathrm{d}} \mathrm{Nin}-$ urta dumu- $<$ munus $>{ }^{\mathrm{d}} \mathrm{Utu}$-illat

29. - 31. Weitere PN ohne Berufsangabe

Die Urkunde regelt die Erbschaft einer gudu ${ }_{4}$-Pfründe, die sich am Heiligtum der Ninsiana befand. Ausgehend von den Angaben der Ešumeša-Texte sowie der hier zitierten Zeugen wurde dieses gudu ${ }_{4}$-Amt durch den Ninurta-Tempel verwaltet, ${ }^{928}$ weshalb die in der Zeugenliste genannten gala-mah und nar-gal ebenfalls diesem Tempel zuzuordnen sind.

Der zweite Beleg zum gala-mah Ir-Enlila in der jüngeren Urkunde BE 6/2, 26 aus dem Jahr Samsuiluna 6 beinhaltet die Erbschaftsteilung von gala- und $\mathrm{gudu}_{4}$-Pfründen am Tempel der Dig̃irmah sowie an einem Tempel der Ninsun. Der Kult der Muttergöttin Dig̃irmah spielte Ur III-zeitlich auch am Ekur in Nippur eine bedeutende Rolle, altbabylonisch ist er jedoch kaum bezeugt. ${ }^{929}$ Ein Heiligtum der Ninsun in Nippur ist nur in der vorliegenden Urkunde belegt, die Mutter des vergöttlichten Gilgamesch wird sonst nach den sattukk $\hat{u}$ Listen mit Opferlieferungen bedacht. ${ }^{930}$ Der in der Urkunde BE 6/2, 26 genannte Erblasser über gala- und gudu ${ }_{4}$-Pfründe mit Namen Inana-mansum ist im Hauptberuf Schreiber. ${ }^{931}$

Neben Ir-Enlila nennt dieselbe Erbschaftsurkunde BE 6/2, 26 (Si 6) den gala-mah Ninurta-mušallim als Zeugen, der in der Auflistung dem Erstgenannten folgt. Ninurta-mušallim ist weiterhin Zeuge der Erbschaftsübergabe BE 6/2, 42:15 (Si 13), die ebenfalls ein gala-Amt zum Inhalt hat. Die Zeugen dieser Übergabe sind alle unterschiedlichen Göttern zugeordnet, darunter ApilSîn, ein Aufseher (ugula $e_{2}$ ) des Heiligtums der Dig̃irmaḩ, Awiātum, ein

\footnotetext{
${ }^{928}$ So Richter 2004, 131-132 + Anm. 580.

${ }^{929}$ Sallaberger 1993, 100-102, 111 als Ninhursag̃; Richter 2004, 144 zu Dig̃irmah.

${ }_{930}$ Richter 2004, 153; Sigrist 1984, 140, 146.

${ }^{931} \mathrm{BE}$ 6/2, 26 (Si 6) iv 13. ibila dnana-ma-an-sum dub-sar.
} 
Brauer $\left(1 u_{2}\right.$-lunga) des Enlil und Nūratum, ein gudu $u_{4}$-Priester der Ninlil. ${ }^{932}$ Für Ninlil und Dig̃irmah bestanden in Nippur sowohl eigene Tempel als auch kleinere Heiligtümer am Ekur des Enlil. ${ }^{933}$ Da die Pfründen selbst von einem nu-e $\breve{s}_{3}$-Priester des Ekur gehalten wurde, ist in diesem Fall anzunehmen, dass die genannten Personen dem Enlil-Tempel angehörten.

Ein letzter gala-mah ist im Kaufvertrag PBS 8/1, 89 mit dem Datum des Meerland-Königs Iluma-ilum Jahr 2 als Nachbar eines zu veräußernden Grundstücks bezeugt. Da kein Name, sondern lediglich der Titel gala-mah ${ }^{\mathrm{d}} \mathrm{En}-\mathrm{lil}_{2}$ angegeben wird, ${ }^{934}$ ist anzunehmen, dass er der einzige gala-mah des Enlil zu seiner Zeit in Nippur war.

In den sattukk $\hat{u}$-Listen des Ešumeša finden sich zahlreiche Belege zu galamah als Rationenempfänger, allerdings grundsätzlich ohne Namensangabe. ${ }^{935}$ Unter den Isin-Königen erhielten die gala-mah Rationenmengen von 2-3 Litern Getreide. ${ }^{936}$ Für die Regierungsjahre des Larsa-Königs Sîn-iqī̌am steigt die Ration auf 8 (Siq 2) und 10 Liter (Siq 3). ${ }^{937}$ Nach Sigrist könnte die erhöhte Rationenmenge auf eine Zunahme der empfangenden Personen hinweisen. ${ }^{938}$ Die sattukk $\hat{u}$-Listen notieren allerdings auch weitaus höhere Ausgaben an Einzelpersonen. ${ }^{939}$ Rückschlüsse solcher Art sind irreführend, da die jeweilige Ration auch vom Status, der Häufigkeit der Ausgabe sowie dem zu versorgenden Privathaushalt abhängen kann. Eine eindeutige Aussage zur Anzahl der genannten gala-mah ist daher nicht möglich. Auch lassen sich auf der Basis der zeitlichen Verteilung der Belege keine Verbindungen zu den namentlich bekannten gala-mah von Nippur ziehen. ${ }^{940}$

Mehrere Beobachtungen lassen sich zu den gala-mah von Nippur zusammenfassen. Die gala-mah Nanna-gugal und Ir-Enlila sind dem Tempel des Ninurta zuzuordnen, auch da ihr Landbesitz in der Umgebung des ki-lukur gelegen

\footnotetext{
${ }^{932} \mathrm{BE} \mathrm{6/2,} \mathrm{42:16-18} \mathrm{(Si} \mathrm{13).}$

933 George 1993, 96 Nr. 425 e 2 -gu-la.

${ }^{934}$ PBS 8/1, 89:2 (Ilil 2).

${ }^{935}$ Zusammenfassend Sigrist 1984, 158, 161, 165.

${ }^{936}$ Bspw. Taf. 62 (IrIm da), Taf. 66 (Enba h), Taf. 165 (Enba ?), Taf. 313 (Dail ?); dazu Sigrist 1984, 63-65, 70, 92, 119.

${ }^{937}$ Sigrist 1984, 105-106.

938 Sigrist 1984,161; Charpin 1986, 235, 251. Für die Urkunden aus Uruk geht Sanati-Müller 1988, 477 Anm. 11 von 3 sila $_{3}$ Getreide pro Person aus. Für Nippur liegt mit der Urkunde BE 6/2, 26 ( $\mathrm{Si} \mathrm{6)}$ tatsächlich der seltene Fall vor, dass frühaltbabylonisch zwei gala-mah gleichzeitig belegt sind.

${ }^{939}$ Bspw. Sigrist 1984, 129 Tafel 322 ii mit bis zu 120 Litern an eine Einzelperson.

${ }^{940}$ Höchstens der/die gala-mah mit Namen Nanna-gugal von PBS 8/1, 11 (Zam 1) und ARN 23+PBS 8/2, 169 (o. D.[Sel]) könnte/n auf die Belege zur Zeit der Isin-Könige bezogen werden.
} 
war. Der zeitgleich mit Ir-Enlila belegte gala-mah Ninurta-mušallim kann hingegen keinem Tempel Nippurs, weder dem Ekur noch dem Ešumeša, eindeutig zugewiesen werden. Das gleichzeitige Auftreten von zwei gala-mah in einer einzigen Urkunde ist für die frühaltbabylonische Zeit ungewöhnlich. Dies könnte als eine nur kurzzeitige Überschneidung der Amtsinhaber zu werten sein, in der Ir-Enlila seinen Nachfolger Ninurta-mušallim in sein Amt einwies. Andererseits könnte hier auch eine veränderte Ämterverteilung bedingt durch die gesonderte Stellung Nippurs vorliegen. Da insbesondere die Rolle des Stadtgottes erst in späterer Zeit auf Ninurta übertragen wird, könnten in dieser Stadt entgegen der bisher beobachteten Norm zeitweise auch zwei gala-mah jeweils an den zwei Haupttempeln der Stadt gleichzeitig amtiert haben. Bezeichnenderweise ist für die Zeit des Meerland-Königs wiederum nur ein galamah des Enlil bezeugt. Eine endgültige Aussage zur Verteilung der gala-mah in Nippur kann bis zur Veröffentlichung der Texte des Ekur nicht getroffen werden.

\subsubsection{Die nar-gal}

Für Nippur sind vier nar-gal namentlich belegt, die einen Zeitraum seit Beginn der Regierungszeit des Rīm-Sîn von Larsa bis Samsuiluna von Babylon abdecken: Lugal-gabari-nutuku II, Lugal-melam-g̃ir III und Ka-Ninurta II sowie Sîn-erībam. ${ }^{941}$

Lugal-gabari-nutuku II ist zweimal Zeuge bei Baugrundstückskäufen $\left(\mathrm{e}_{2}-\mathrm{du}_{3}\right.$ a), die zwischen zwei lukur-Priesterinnen des Ninurta stattfanden. ${ }^{942}$ Beide Zeugenlisten sind bis auf die letzten zwei Zeuginnen miteinander identisch. Der nar-gal Lugal-gabari-nutuku II folgt in beiden Zeugenlisten dem Tempelaufseher (ugula $\mathrm{e}_{2}$ ) und dem Tempelpförtner $\left(\mathrm{i}_{3}-\mathrm{du}_{8}\right)$.

Die zwei nar-gal Lugal-melam-g̃ir III und Ka-Ninurta II treten immer gemeinsam in drei Urkunden als Zeugen auf. ${ }^{943}$ Da sie in den Zeugenlisten teilweise miteinander die Position wechseln, scheint offensichtlich kein Rangunterschied zwischen ihnen bestanden zu haben. Zwei der drei Urkunden behandeln Angelegenheiten um die Besitztümer von lukur-Priesterinnen des Ninurta. ${ }^{944}$ Die Reihenfolge der Zeugen ist auch hier meist konstant. Es werden

${ }^{941}$ TIM 4, 10:17 (RS 25); JCS 20, 45:24 (RS 25); PBS 8/2, 116/116a:24-25 (RS 50); ARN 44:17-18 (RS 55); PBS 8/2, 142:20-21 (Si 2); BE 6/2, 44:24 (Si 14); anders als Renger 1969, 178 steht laut Kopie in BE 6/2, 44 (Si 14) 25. igi Ka- ${ }^{\mathrm{d}}$ Nanna igi Šeš-ki nar-L A ${ }^{\text {? }}\left(/ \mathrm{gal}^{\text {? }}\right.$ ) 25b. dumu-me Ad-da-du 10 -ga.

${ }^{942}$ TIM 4, 10:17 (RS 25); JCS 20, 45 Nr. 7:24 (RS 25).

943 PBS 8/2, 116/116a:24-25 (RS 50); ARN 44:17-18 (RS 55); PBS 8/2, 142:20-21 (Si 2). Obwohl in der letzten Urkunde beide wiederum gemeinsam genannt werden und zwischen den Urkunden nur etwa 25 Jahre liegen, meine ich gegen Renger 1967, 178, dass es sich in diesem Fall um dieselben nar-gal handelt.

${ }^{944}$ PBS 8/2, 116/116a (RS 50) Zeugenliste ab Z. 24ff. und PBS 8/2, 142 (Si 2) Zeugenliste ab Z. 
zunächst Tempelaufseher (ugula $\mathrm{e}_{2}$ ), die zwei nar-gal sowie der Tempelpförtner $\left(i_{3}-d_{u_{8}}\right)$ genannt. Schließlich folgen nu-e $\check{s}_{3}$-Priester, nar-Musiker oder lukur des Ninurta. Lediglich die Erbschaftsurkunde ARN 44 (RS 55), die Angelegenheiten um eine $\mathrm{gudu}_{4}$ - Pfründe der Ninsiana behandelt, nennt zusätzlich einen gala-mah, und zwar den bereits bekannten Ir-Enlila. ${ }^{945}$ Sowohl die Zeugenlisten als auch die Inhalte der Urkundenbelege zu den nar-gal Lugal-gabari-nutuku II sowie Lugal-melam-g̃ir III und Ka-Ninurta II lassen vermuten, dass alle drei in das Umfeld des Ninurta-Tempels anzusiedeln sind. ${ }^{946}$ Darüber hinaus ist zu vermuten, dass sie derselben Familie angehörten, worauf ihre Namensgebung im Zusammenhang mit verschiedenen Erbschaftsurkunden aus dem Umfeld des bekannten Lu-Ninurta, nar des Ninurta, hindeutet. $^{947}$

$\mathrm{Zu}$ einem anderen Personenkreis ist der nar-gal Sîn-erībam zu zählen. ${ }^{948} \mathrm{Er}$ ist Zeuge einer Erbteilungsurkunde neben zahlreichen nu-eš $\breve{3}_{3}$-Priestern, auch ein Nachbar der vererbten Hausgüter ist ein solcher Priester. ${ }^{949}$ nu-e š ${ }_{3}$-Priester sind mit wenigen Ausnahmen nur in Nippur bezeugt, wo sie ausschließlich im Kult des Enlil auftreten. ${ }^{950}$ Obwohl in der Hymne Enlil $A$ die Priesterberufe nu-eš $\breve{s}_{3}$ und gudu ${ }_{4}$ als gemeinsame Kultakteure am Tempel Ekur genannt werden, sind nach administrativen Texten diese beiden Priesterberufe nie am selben Tempel bezeugt. ${ }^{951}$ Der Beruf des nu-eš ${ }_{3}$-Priesters wurde häufig von den Mitgliedern einer Familie ausgeübt. ${ }^{952}$ Da der nar-gal Sîn-erībam neben mehreren Vertretern dieses Priesterberufs als Zeuge auftritt, kann er demselben Tempel Ekur zugeordnet werden.

In den sattukk $\hat{u}$-Listen des Ninurta-Tempels sind nar-gal weitaus seltener belegt als gala-mah. ${ }^{953}$ Während ihre Rationenmenge bei 2-3 Litern Getreide lag, erhält zur Zeit des Isin-Königs Enlil-bāni wohl ein einzelner nar-gal mit 10 Litern pro Ration mehr als die dreifache Menge eines gala-mah. ${ }^{954}$ Dies könnte auf einen höheren Status dieses Musikers unter Enlil-bāni hinweisen.

\section{$19 \mathrm{ff}$.}

${ }^{945}$ ARN 44:19 (RS 55) und hier Kapitel 9.5.3.

${ }^{946}$ Die Zeugenreihen enthalten überwiegend die gleichen Personen.

${ }^{947}$ S. hier Kapitel 9.5.2.6.

${ }^{948} \mathrm{BE} 6 / 2,44: 24$ (Si 14).

${ }^{949}$ BE 6/2, 44:4.17-20 (Si 14). Anders als Renger 1969, 178, 185 ist Ka-Nanna selbst kein Musiker, sondern sein Bruder Šeš-ki, der in BE 6/2, 44:25 (Si 14) als nar-LA!(/g al $\left.{ }^{2}\right)$ ausgewiesen wird. Ihr gemeinsamer Vater Adda-duga könnte mit einem gleichnamigen nues ${ }_{3}$-Priester identisch sein; so Renger 1969, 139, 142.

${ }^{950}$ Renger 1969, 139-140; Westenholz 1992, 299-300; Sallaberger/Huber Vulliet 2005, 630.

${ }^{951}$ Römer 2001, 145:58-59; Renger 1969, 141.

${ }^{952}$ Renger 1969, 142-143.

${ }^{953}$ Zusammenfassend Sigrist 1984, 162, 165.

${ }^{954}$ In den Jahren Enba h, i und Taf. 392 (o. D.); Sigrist 1984, 70, 76-77, 136. 
Die Identität der Musiker bleibt unbekannt, da namentlich bekannte nar-gal alle erst zu einer späteren Zeit (RS/Si) belegt sind.

\subsubsection{Urkundliche Belege zu gala und nar}

In privaten Urkunden Nippurs sind insgesamt elf gala sowie elf nar und ein nar-sa namentlich belegt. ${ }^{955}$

Beide Berufe werden überwiegend in Zeugenlisten von Erbschafts- und Kaufverträgen genannt. Ihre Funktion als Zeugen begründet sich entweder über die Verwandtschaft zu den vertretenen Parteien oder durch den Vertragsinhalt. Die Erbschaftsurkunde BE 6/2, 26 ( $\mathrm{Si} \mathrm{6)}$ über die Verteilung von gala- und gudu $_{4}$-Pfründen nennt neben den bereits bekannten gala-mah Ir-Enlila und Ninurta-mušallim zwei weitere gala und einen nar als Zeugen. ${ }^{956}$

Sechs der in Nippur namentlich belegten nar-Musiker gehörten dem Personenkreis des Ur-Pabilsag̃, Sohn des Ubarrum an, der aus mehreren Erbschafts- und Kaufverträgen bekannt ist. ${ }^{957}$ Er selbst war nach ARN 35 (RS 37) im Besitz einer nar-Pfründe am Tempel des Lugal-abta und des Martu/Amurrum. Sein Bruder Lugal-heg̃al war nar, dessen Sohn Damiq-ilišu nar-sa. ${ }^{958}$

Bei den namentlich belegten gala können keine vergleichbaren Familienstrukturen beobachtet werden, was auch mit der Fundsituation der Privatarchive zusammenhängen mag.

Vier gala-Priester erscheinen allerdings in der Personenliste PBS 8/1, 94 (o.D.), die insgesamt 74 Personen für einen Lehensdienst in Form einer Reise, möglicherweise auch einer Militärkampagne auflistet. ${ }^{959}$ Von zwei der fünf $\operatorname{eren}_{2}$ gala-me sind die Namen erhalten: Apiljatum, Sohn des Sîn-iqišam und Mummatum, Sohn des Šurbūtum. ${ }^{960}$ Dieselbe Tafel listet zusätzlich zu den 74

${ }^{955}$ gala: Lu-Ninlila, Enlil-galzu, Aplum, Apiljatum Sohn des Sîn-iqī̌sam, Mummatum Sohn des

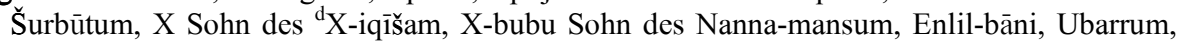
Mumu-hegub und Warad-Ištar; nar: Lu-Ninurta I, Lugal-ibila Sohn des Dudu-kalla, Lugalmelam Sohn des Niğ ${ }_{2}$-DU.DU, Utu-Enlilla, Lugal-heg̃al Sohn des Ubarrum, Iddin-mēšar; Ilūnim, Sîn-mūdi, Lugal-hegaal Vater des Damiq-ilǐšs, Apil-ilǐ̌̌u, Sîn-X Sohn des Šumumlibši und Damiq-ilī̌su nar-sa Sohn des Lugal-heg̃al.

${ }^{956}$ gala Mumu-hegub und Warad-Ištar, nar Sîn-x Sohn des Šumum-libši; BE 6/2, 26:19.23.iv 26 (Si 6).

${ }^{957}$ Utu-Enlilla, Ilūnim, Sîn-mūdi und Apil-ilī̌šu sind Zeugen; Stone/Owen 1991, 11-19; Oelsner 1993, 501-504.

${ }_{958}$ PBS 8/1, 81:5 (Ha 31); BE 6/2, 48:40 (Si 18).

959 PBS 8/1, 94 (o.D.) iv 16. eren 2 kaskal-a; zu eren 2 allgemein „Personen, Arbeiter, Truppe“ CAD Ș 54b; Stol 2004, 777; zu kaskal als Lehensdienst Stol 2004, 747-749.

${ }^{960}$ PBS 8/1, 94 (o.D.) iv 1. [ [ ..]-al 2. [. . .] 3. [ [ ...-i-qi ${ }_{2}^{\mathrm{I}}$ ]-ša-am 4. [ [ ..]-bu-bu 5. [dumu] Nannama-an-sum 6. ${ }^{\mathrm{I}} A^{7}$-pil ${ }_{2}$-ia-tum 7. dumu ${ }^{\mathrm{d}} \mathrm{EN} \mathrm{ZU}_{2}-i$-qi $i_{2}$-ša-am 8. ${ }^{\mathrm{I}} M u$-ma-tum 9. dumu $\breve{S} u r b \hat{u}\left(b_{\text {bulu }} \tilde{g}_{3}\right.$ )-tum. Die Namen Apiljatum und Mummatum sind ungewöhnliche Kurz- und Zärtlichkeitsnamen. 
männlichen Teilnehmern vier Frauen auf, die als Ehegattinnen bzw. Töchter ausgewiesen werden. ${ }^{961}$

Für Nippur sind auch Musikeraufseher (ugula nar) belegt, die Tür eines solchen wird im Erbteilungsvertrag ARN 23+ genannt. ${ }^{962}$

\subsubsection{Ein Musikgelehrter am Ešumeša}

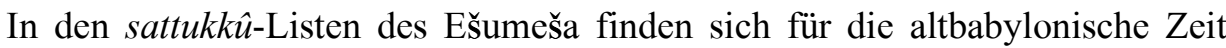
einmalige Belege für einen nar um-mi-a, einen „Musikgelehrten“, dessen Name allerdings unbekannt bleibt. ${ }^{963}$ Dieser erscheint zweimal in Texten des Isin-Königs Irra-imitti und erhält neben einem gala-mah dieselbe Menge an 2 bzw. 4 Litern Getreide. ${ }^{964}$ In Hymnen der Ur III- und Isin-Könige werden ummi-a neben nar-gal vielfach auch als Liedsetzer angesprochen. ${ }^{965}$ Ur IIIzeitlich ist ein solcher Gelehrter ebenfalls aus Verwaltungstexten bekannt, wonach ihm auch Musikschüler (nar dumu um-mi-a) angeschlossen waren. ${ }^{966}$ Die Nennung dieses nar um-mi-a neben einem gala-mah in einer Tempelrationenliste des Ešumeša zeigt auf, dass er auch im Dienste des Tempels stand und dort von gleichem Rang mit dem obersten Klagepriester war.

\subsubsection{5 gala und nar in Tempelrationenlisten}

In den sattukk $\hat{u}$-Listen des Ešumeša werden grundsätzlich keine gala genannt, da sie offenbar nicht zu dem über diese Opferausgaben versorgten Personal gehörten. Ausnahmen bilden ein gala des Enlil und ein gala des Damu. ${ }^{967}$ Der Kult des Damu, dem Sohn der Heilgöttin Ninisina, ist in Nippur unbedeutend, ein eigenes Heiligtum ist für ihn nicht belegt, allerhöchstens ein Kultschrein. ${ }^{968}$

${ }^{961}$ PBS 8/1, 94 iv 11-15: Narubtum dam Aplum, Lušlim dam Šumum-libši, Sal-kalla dam Aha-nīrši, Ali-ahī du mu-munu s Tarībum. Die 74 männlichen Teilnehmer teilen sich auf in 65 kräftige (?) Arbeiter (PBS 8/1, 94:iii 26. eren $_{2}$ KALA- $^{\top} u$ ), 4 ?-Arbeiter (PBS 8/1, 94 iii 32.4 eren $_{2}$ GIIN $_{2}$ IGI? $^{2}$.[ . .; Werkzeug/Waffe? ) und die 5 eren ${ }_{2}$ gala.

962 ARN 23+PBS 8/2, 169:iv12 (D.a.); der von Renger 1969, 178 angeführte Beleg in BE 6/2, 63:12 (Si 3) für einen Erīb-Sîn ist unsicher, vielleicht eher Erīb-Sîn-lu-mur' nach Poebel in BE 6/1 Index S. 129.

${ }^{963}$ Sigrist 1984, 162.

${ }^{964}$ Taf. 415 Rs i und ergänzt in Taf. 62 bei Sigrist 1984, 63, 137.

${ }^{965}$ S. hier Kapitel 8.2.

${ }^{966}$ Ur III-zeitlich meist gefolgt von einem gala; Umma: Ontario 2, 326 Vs 3. ... nar um-mi-a $u_{3}$ dumu um-mi-a; SA 142 Vs 20. $\mathrm{sa}_{2}-\mathrm{du}_{11}$ nar dumu um-mi-a und G̈irsu: SAT 1, 118:Vs 7. nar dumu um-mi-a; ausführlich Pruzsinszky 2009.

967 Taf. 211 ([IrIm]) und Taf. 196 (Sib 1); Sigrist 1984, 69 Anm. 43, 104 Anm. 78, 161.

${ }^{968}$ Richter 2004, 117-119 auch zur Genealogie des Damu. Derselbe Gott wird in den sattukk $\hat{u}$ Listen bedacht; Sigrist 1984, 178-180. 
nar-Musiker werden in den Ešumeša-Listen nicht genannt. Auch diese Berufsgruppe gehörte in Nippur wohl nicht zu dem vom Tempel zu entlohnenden Personal. Eine Ausnahme bildet der oben genannte nar um-mi-a und eine Gruppe von nar-Musikerinnen. ${ }^{969}$

Eine Gruppe von nar-sa-Musikern ist auf einer Opferausgabenliste des Nusku-Tempels verzeichnet. ${ }^{970}$ Der Tempel des Nusku bestand in Nippur aus einer größeren Anlage, die auch Kultstätten anderer Gottheiten umfasste. ${ }^{971}$ Die achtkolumnige Rationenliste des Nusku-Tempels enthält die Tempelausgaben eines gesamten Jahres, die an Götterfesten sowie zum Opferkult an das Tempelpersonal ausgegeben wurden. Unter den aufgelisteten Personengruppen befinden sich nar-sa, fünf gudu $u_{4}$ - Priester, zwei Tempelpförtner $\left(i_{3}-d_{u_{8}}\right)$, ein Schlangenbeschwörer $\left(m u s ̌-l a h_{4}\right)$, sechs nin-dig̃ir-Priesterinnen und die Tochter eines $1 \mathrm{u}_{2}$-dig̃ ir-ra. ${ }^{972}$ Höher gestellte Priester und Tempelfunktionäre wie en, lagab oder auch gala-mah sind in dieser Auflistung nicht enthalten.

Weitaus häufiger als die gängigen Musiker nar und gala nennen die sattukk $\hat{u}$ Listen den $\mathrm{a}-\mathrm{u}_{3}-\mathrm{a}$ als regelmäßigen Empfänger von Rationen. ${ }^{973}$ Dieser ist meist dem Nusku zugeordnet, seltener auch dem Nanna. Darüber hinaus ist ein $\mathrm{a}-\mathrm{u}_{3}-\mathrm{a}$ des Ekur-Tempels sowie ein $\mathrm{a}-\mathrm{u}_{3}$-a der lukur bezeugt. ${ }^{974} \mathrm{Im}$ Allgemeinen wird das Wort a- $\mathrm{u}_{3}-\mathrm{a}$ als „Fährmann“ wiedergegeben, der die Prozessionsschiffe der Götter führt. Derselbe Begriff wird außerdem als Bezeichnung eines Musikers oder Sängers verwendet. ${ }^{975}$

\subsubsection{Die Musikerfamilie des Lu-Ninurta}

Von der Familie des Lu-Ninurta I konnten anhand der aus Privaturkunden erhältlichen Daten bis zu vier Generationen rekonstruiert werden ${ }^{976}$ Ein besonderes Interesse kommt hier dieser Familie zu, da mehrere ihrer Mitglieder dem Beruf des nar nachgingen.

Lu-Ninurta I, das älteste bisher bekannte Mitglied dieser Familie, war nar des Ninurta zur Zeit des Herrschers Ur-Ninurta von Isin. ${ }^{977}$ Weitere 15 männliche Personen lassen sich derselben Familie zuordnen. Die vier Generationen lebten verteilt über einen Zeitraum von Ur-Ninurta (1923-1896) bis Enlil-bāni von Isin (1860-1837).

\footnotetext{
${ }^{969}$ Sigrist 1984, 128; hier Kapitel 9.5.4.

${ }^{970}$ PBS 13, 61+CBS 8550:vi 2 (Ha 35) bearbeitet bei Sigrist 1977a.

${ }^{971}$ Bernhardt/Kramer 1975, 98:21; George 1993, 121-122 Nr. 763. 767; Sigrist 1977a.

${ }^{972}$ Sigrist 1977a, 178-180.

${ }^{973}$ Auch mit Namen belegt; Sigrist 1984, 85, 169.

${ }^{974}$ PSD B 199a sub a-u ${ }_{3}$-a B; Sigrist 1984, 169.

${ }^{975}$ S. hier Kapitel 5.4.3.

${ }^{976}$ Kraus 1951, 184-209 zur Geschichte der Prozesse; Edzard 1998, 99; Kalla 2002, 149 Nippur: Familie 1.

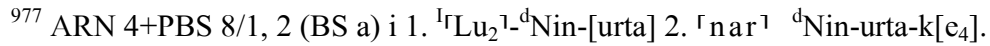


Die Familienmitglieder aus vier Generationen sind aus mehreren Erbschaftsprozessurkunden über den Nachlass des Lu-Ninurta I bekannt. ${ }^{978}$ Über diesen gerieten seine Nachkommen insgesamt zweimal in Konflikt. Der Nachlass enthielt unter anderem folgende Tempelpfründen:

T 52: ARN 4+PBS 8/1, 2 (BS a) und JCS 3, 185b (o.D.)

,(die) nar-Pfründen der Ninnibru und des Tempels der Inana, die gudu ${ }_{4}$ keš $_{2}$-da des Ninurta (sind) sein Halbanteil.“

6. nam-nar ${ }^{\mathrm{d}} \mathrm{Nin-nibru}{ }^{\mathrm{ki}}$ 7. $u_{3} \mathrm{e}_{2}{ }^{\mathrm{d}}$ Inana 8. gudu $\mathrm{u}_{4}$ kešs-da ${ }_{2}^{\mathrm{d}} \mathrm{Nin-urta}$ 9. šu-ri-a-bi ${ }^{979}$

Der Kultplatz für Ninnibru, Gemahlin des Ninurta, war im Tempel Ešumeša gelegen, ein eigenes Heiligtum ist für diese Göttin in Nippur nicht eindeutig nachweisbar. ${ }^{980}$ Für Inana sind sowohl am Ekur als auch am Ešumeša des Ninurta Kultplätze bezeugt. ${ }^{981} \mathrm{Ihr}$ eigener Ur III-zeitlich ausgebauter Tempel wird in Texten der altbabylonischen Zeit sowie späteren Epochen kaum erwähnt.

Neben diesen Hauptprozessurkunden zur Erbschaft des Lu-Ninurta I werden in drei weiteren Tempelämterlisten die genauen Inhalte dieser Pfründen und ihre Aufteilung notiert. ${ }^{982}$ Die vererbten Pfründen bestanden aus nar-Diensten für Enki und Asalluhi, für Lugalbanda sowie für zahlreiche weitere Götter, deren Kulte am Ekur, am Ešumeša oder an eigenen Heiligtümern nachweisbar sind. ${ }^{983}$ Die Kulte Enkis und Asalluhis sind Ur III-zeitlich mehrfach bezeugt, altbabylonisch ist ihre Verehrung jedoch nur in den hier genannten Erbschaftslisten sowie in einer Siegelinschrift nachgewiesen. ${ }^{984}$ Ein Kultplatz des Enki befand

${ }^{978}$ Kraus 1951, 184-185.

${ }^{979}$ So auch in ARN 4+PBS 8/1, 2:10-13 zu ergänzen.

980 Bernhardt/Kramer 1975, 98:16; George 1993, 106 Nr. 544: e 2 -ka-aš-bar; Richter 2004, 71 72; Biggs 1998, 476.

981 Zettler 1992, 43-49. S. a. Lambert 1982, 173-218 zur akk. Šarrat Nippuri-Hymne aus dem 1. Jt.; Beaulieu 1995, 205; Biggs 1998, 476-477. Mit Šarrat Nippuri liegt eine örtliche Manifestation der Inana vor, die möglicherweise auf eine 'Vermischung' ihrer Aspekte mit denen der Ninnibru zurückzuführen ist, der eigentlichen als Gattin des Ninurta im Ešumeša verehrten „Herrin von Nippur“; ausführlicher bei Richter 2004, 122-124.

982 In ARN 58 und JCS 3, 185a werden diese Pfründen in drei Erbschaftsteile geteilt; Kraus 1951, 198-203.

983 ARN 57, ARN 5 sowie JCS 3, 185a: Išum/Hendursag̃a, Ninisina, Ninsiana, Ninamaškuga, Gu(a)nungia, Lugaltilla, Gibil, Igišagšag, NinPA, Gula, Irda, Martu, Šulpa'e und Šulpa'edara; Kraus 1951, 198-203; Richter 2004, 79 (Gu(a)nungia), 83 (NinPA), 79-80 (Lugaltilla), 95 (Irda), 100 (Ninamaškuga), 112-114 (Gula), 113 (Ninisina), 131-132 (Ninsiana), 141-143 (Martu), 147-148 (Šulpa'e/Šulpa'edara), 155-56 (Hendursag̃a/Išum), 157 (Gibil), 157-158 (Igišagšag).

${ }^{984}$ Richter 2004, 102-104 + Anm. 458-459; die Siegelabrollung findet sich auf der Tafel PBS 
sich im Ešumeša des Ninurta, für Asalluhi existieren hingegen keine Hinweise auf eine solche Einrichtung. Dagegen hatte Lugalbanda, vergöttlichter Vater des Gilgamesch, in Nippur eine eigene Kapelle, und auch die Verehrung seiner Mutter Ninsun ist in Nippur bezeugt. ${ }^{985}$ Zum Nachlass des Lu-Ninurta I gehörte schließlich auch eine gudu ${ }_{4}$-Pfründe.

Der Besitzer all dieser Pfründen wurde demnach nicht nur durch den Tempel des Ninurta, sondern auch durch den Ekur sowie durch andere verschiedene kleinere Heiligtümer in Tempeln Nippurs vergütet. Es verwundert nicht, dass die Nachkommen des Lu-Ninurta I über dessen Nachlass mehrfach in Streit gerieten.

Da alle in Nippur bezeugten nar-gal, Lugal-gabari-nutuku sowie die immer gemeinsam auftretenden Ka-Ninurta und Lugal-melam-g̃ir Namen der Familienmitglieder des Lu-Ninurta I tragen, ist anzunehmen, dass sie die fünfte und sechste Generation derselben Familie stellen. Hierüber ließe sich begründen, dass die drei nar-gal grundsätzlich im Umfeld des Ešumeša des Ninurta und des ki-lukur genannt werden. Ihr Dienst als Musiker und 'Musikmanager' am Tempel des Gottes Ninurta geht auf eine Familientradition zurück, die erstmals für die Zeit des Lu-Ninurta I nachweisbar ist. Die Söhne des Lu-Ninurta I, Dudu-kalla und Lugal-gabari-nutuku I, erbten als erste die oben genannte narPfründe am Ešumeša des Ninurta. Von den Söhnen des Dudu-kalla ist wiederum Lugal-ibila als nar belegt. ${ }^{986} \mathrm{Um}$ wessen Enkel oder Urenkel es sich bei den in der Regierungszeit des Rīm-Sîn sowie des Samsuiluna belegten nar-gal handeln könnte, bleibt unklar. Sowohl die in der Familie übliche Namensgebung, welche meist aus dem Namen des Stadtgottes Ninurta verbunden mit dem Element $1 u_{2}$ „Mensch“ oder lugal „König“ besteht, als auch die Ausübung des nar- oder nar-gal-Berufs am Tempel des Ninurta weist auf eine alte Tradition dieser Familie in Nippur sowie am Kult ihres Stadtgottes hin. ${ }^{987}$

\subsubsection{Die Musikerpfründen Nippurs}

Weitere nar-Pfründen befanden sich im Besitz der Familie des Ur-Pabilsag̃. ${ }^{988}$ Diese beinhalteten Dienste am Tempel des Lugalaba und des Martu/Amurrum. ${ }^{989}$ Die nar-Pfründe wurden von Ur-Pabilsa $\tilde{g}$, dem Sohn des Ubarrum im Jahre Rīm-Sîn 37 von G̃irni’isa, dem Sohn des Sîn-išmēni erworben. ${ }^{990}$ Dass

\footnotetext{
8/1, 37 (o.D.) mit Erwähnung von Enki, Damgalnuna und Asalluhi.

985 Richter 2004, 152-153; Sigrist 1984, 140, 146.

${ }^{986}$ ARN 4 (BS a); JCS 3, 185a/b (o.D.).

${ }^{987}$ Kalla 2002, 133-134.

${ }^{988}$ Kraus 1951, 143-148; Stone/Owen 1991, 11-19; Oelsner 1993, 501-504.

${ }^{989}$ ARN 35 (RS 37); ARN 41 (RS 53); PBS 8/1, 81 (Ha 31).

990 ARN 35 (RS 37). Gegen Richter 2004, 143 besaß der Bruder des Ur-Pabilsag̃ namens Lugalzig̃u wohl keine nar-Pfründe; s. Stone/Owen 1991, 14.
} 
die Heiligtümer der zwei Gottheiten Lugalaba und Martu/Amurrum in Nippur miteinander verknüpft waren, geht aus verschiedenen Texten hervor, doch müssen im Vergleich zu anderen Tempelpfründen die Kultstätten dieser zwei Gottheiten relativ klein ausgefallen sein. ${ }^{91}$ Schon der ältere Bruder des UrPabilsag̃ namens Lugal-hegãal war nar, sein Sohn Damiq-ilǐšu nar-sa. ${ }^{992}$ Die Ausübung des nar-Berufs beruhte auch hier wieder auf einer Familientradition.

Auch gala-Pfründen sind in zwei Nippur-Texten bezeugt, wo sie jeweils Teil einer Erbschaft bilden. Erblasser der ersten Pfründe war der Schreiber Inanamansum in BE 6/2, 26 (Si 6) ${ }^{993}$ Dieser vererbte seine gala-Pfründe zusammen mit einer gudu $_{4}$-Pfründe der Göttin Ninsun an seine vier Söhne, darunter Nanna-ara-mungen, Ur-Šulpa'e und Ur-dukuga. ${ }^{94}$ Dieselbe Urkunde enthält den einzigen Beleg für den Tempel der Ninsun, der Mutter des vergöttlichten Gilgamesch, in Nippur. ${ }^{995}$

Die zweite gala-Pfründe, die zum Eigentum eines Sîn-abūšu gehörte, wird im Aushändigungsvertrag BE 6/2, 42 (Si 13) genannt. Dieser dokumentiert die Übergabe der Pfründe an den rechtmäßigen Erben Aba-Enlilgin durch einen nu-eš ${ }_{3}$-Priester:

\section{T 53: BE 6/2, $42\left(\right.$ Si 13) ${ }^{996}$}

„Sîn-abūšu, Sohn des Nanna-luti, hatte die Besitztümer (wörtl. gesiegelten Urkunden) über die gala-Pfründe und seinen Erbanteil an Nannatum, den nu-eš ${ }_{3}$-Priester übergeben. (Jetzt) nach Ablauf von zwei Jahren, nachdem Sînabūšu gestorben war, hat Aba-Enlilgin die Besitztümer (wörtl. gesiegelten Urkunden) des Sîn-abūšu von Nannatum erhalten."

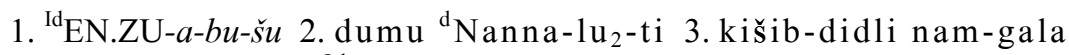

4. $u_{3}$ ha-la-ba-ni 5. Id Nanna-tum nu-ešs $\breve{s}_{3}-\check{\mathrm{e}}_{3}$ 6. šu-na ba-an-sum-ma

7. mu 2-kam du-u 3 -bi 8. e g̃ir ${ }^{\text {Id EN.ZU- } a-b u-s ̌ u}$ ba-til-a-ta

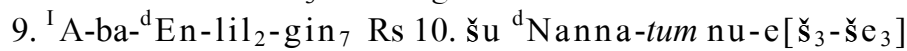

11. kišib-didli ${ }^{\text {Id EN.ZU-a-bu-šu 12. ba-an-de }} 6$

\footnotetext{
${ }^{991}$ Richter 2004, 142-143 + Anm. 626.

992 PBS 8/1, 81:5 (Ha 31); BE 6/2, 48:40 (Si 18).

${ }^{993}$ S. hier Kapitel 9.5.2.1.

${ }^{994} \mathrm{BE} 6 / 2,26$ (Si 6) i 13. šab-ta nam-gala $u_{3}$ nam-gudu $\mathrm{e}_{2} \mathrm{D}$ [ig̃ir-mah... und ii 13/iii $14 /$ iv 3.

995 Richter 2004, 153+Anm. 679 wertet gegen Sigrist 1984, 145 den Eintrag der Urkunde nicht als Hinweis auf einen eigenen Tempel der Göttin.

${ }^{996}$ BE 6/2, 42 (Si 13); vgl. Poebel in BE 6/2, S. 45-46.
} 
Die gala-Pfründe wurde zwei Jahre lang nach dem Tod des Erblassers durch Nannatum bewahrt, da möglicherweise der rechtmäßige Erbe aufgrund seines Alters oder einer Abwesenheit den mit ihr verbundenen Diensten nicht nachgehen konnte. Da nu-e $\check{s}_{3}$-Priester ausschließlich für den Kult des Enlil im Ekur bezeugt sind ${ }^{997}$ könnte sich auch die besagte gala-Pfründe an eben diesem Tempel befunden haben.

In beiden zitierten Erbschaftsverträgen sind unter den Zeugen auch galamah-Priester aufgeführt. Die Urkunde des Schreibers Inana-mansum nennt sogar zwei gala-mah, zwei gala und einen nar. ${ }^{998}$ Aus dieser Regelmäßigkeit in der Zeugenliste schließe ich, dass für die Verteilung und Organisation von gala- wie auch gudu ${ }_{4}$-Pfründen am Tempel die Bezeugung durch gala-mah erforderlich war.

\subsubsection{Musikerinnen in Nippur}

Einmalig wird in denselben sattukk $\hat{u}$-Listen des Ešumeša auch eine Gruppe weiblicher nar genannt, die dem Ekur des Enlil zugeordnet wird. Hierbei muss es sich um eine einmalige Entlohnung möglicherweise aus Anlass eines Göttermahls (kaš- $\mathrm{de}_{2}$-a) handeln. ${ }^{999}$

Für Nippur sind weiterhin /tigi/-Spielerinnen bezeugt. Die Samsuilunazeitliche Urkunde SAOC 44, 95 nennt einen 'Aufseher der tigiātim' namens Sîn-irībam als Gläubigen eines Schuldverhältnisses. ${ }^{1000}$ Gruppen von /tigi/Spielerinnen sowie ihre Aufseher sind für die altbabylonische Zeit noch in Sippar, Isin und Mari bezeugt. ${ }^{1001}$ Diese Frauengruppe wurde, wie auch für Mari und Isin nachgewiesen, wohl durch den königlichen Palast versorgt. ${ }^{1002}$

\footnotetext{
${ }^{997}$ Sallaberger/Huber Vulliet 2005, 630.

${ }^{998}$ BE 6/2, 26:17-19, 23, 26 (Si 6).

${ }^{999}$ Taf. 318 Kol. ii; Sigrist 1984, 128 nar(?)-munus mu-g̃ar-ra; e ${ }_{2}^{d}{ }^{d}$ nlil $_{2}-\mathrm{la}_{2}-\mathrm{še}_{3} ; 175$ sila $_{3}$ kaš-de $_{2}-[\mathrm{da}]$. Der Ausdruck nar(?)-munus mu-g̃ar-ra „Musikerinnen, die den Namen 'setzen"“ könnte möglicherweise auf den Inhalt ihrer Gesänge als Preis- und Lobgesang verweisen.

${ }^{1000}$ SAOC 44, 95:2. ki d EN.ZU-i-ri-b[a-am] 3. ugula munus-ti[gi].

${ }^{1001} \mathrm{~S}$. zusammenfassend Kapitel 5.4.1.

${ }^{1002}$ Ziegler 1999, 94-96.
} 


\subsection{Sippar}

\subsubsection{Historischer Hintergrund und Quellenlage}

Mit Namen Sippar wurden in altbabylonischer Zeit vornehmlich zwei benachbarte Städtekomplexe bezeichnet: Sippar Jahrūrum (T. Abu Habbah) und Sippar Amnānum (T. ed-Dēr). ${ }^{1003}$ Sippar Jahrūrum war Hauptkultort des Sonnengottes Šamaš und seiner Gattin Aja im Tempelkomplex Ebabbar, dem ein so genanntes 'Kloster' ${ }^{1004}$ (gagûm) der lukur-Priesterinnen (akkadisch nadiàtum) angeschlossen war. nadiātum des Šamaš genossen gesamtbabylonisch ein hohes Ansehen, so sind auch Prinzessinnen als naditum des Šamaš belegt. Der Wohnkomplex dieser Priesterinnengruppe bildete eines der wichtigsten ökonomischen Zentren Sippars.

In Sippar befand sich des Weiteren das Eanna, der Tempel der Inana/Ištar, der seit Immerum, einem lokalen Herrscher Sippars, belegt ist. ${ }^{1005}$

Der Stadtkomplex Sippar Amnānum (Tell ed-Dēr) beherbergte den Haupttempel E'ulmaš der Annunītum, einer eigenständigen Göttin aus dem Kreis der Inana/Ištar. ${ }^{1006}$ Die Stellung dieser Göttin innerhalb des Sippar-Pantheons nahm seit der Regierungszeit des Samsuiluna an Bedeutung zu. Sowohl Inana/Ištar als auch Annunītum in Sippar Amnānum wurden als „Herrin/Königin von Sippar" tituliert. ${ }^{1007}$ Ein kleinerer Tempel des Šamaš mit Namen Edikuda war wohl in der Nähe des Annunītum-Tempels gelegen. ${ }^{1008}$

Vor der Übernahme durch die Könige der ersten babylonischen Dynastie war Sippar Sitz mehrerer Lokalherrscher, von denen jedoch nur wenige Jahresdaten bislang bekannt sind. ${ }^{1009}$ Die Jahresdaten des Immerum zeugen von seinem Bemühen um den Götterkult in Sippar, er baute am Tempel der Inana, am gagûm des Šamaš und stiftete letzterem zwei /lilis/-Pauken für seinen Tempel. $^{1010}$

${ }^{1003}$ Eine ausführliche Studie zur Stadt Sippar in aB Zeit liegt mit Harris 1975 vor. Zu den zwei Städtekomplexen und anderen Sippar-Namen s. Charpin 1988 und Gasche 1989, 112-116 und Charpin 1992; allgemein Charpin 2004, 91-94.

${ }^{1004}$ Die Anwendung des Terminus 'Kloster' auf einen im 2. Jt. v.Chr. hauptsächlich von Gott geweihten Frauen bewohnten Wohnkomplex ist anachronistisch, wird jedoch in der Literatur größtenteils beibehalten.

1005 Immerum b (PBS 8/2, 195) mu e $_{2}-{ }^{\mathrm{d}}$ Inana im-me-ru-um i-pu-šu „Jahr: den Tempel der Inana, (den) Immerum erbaut hat"; Harris 1975, 3.

${ }^{1006}$ George 1993, 155:1169.

1007 bēlet/šarrat zimbir i ${ }^{\mathrm{ki}}$; Harris 1975, 150-151.

${ }^{1008}$ Janssen/Gasche/Tanret 1994, 93.

${ }^{1009}$ Charpin 2004, 91-92.

${ }^{1010}$ Harris 1975, 2-3; das Jahr CT 4, 50a Rs 32-33 mu balag̃-li-li-is 3 min!-a-bi ${ }^{d}$ Utu-ra 
Unter König Sumula'ēl wird Sippar in den Herrschaftsbereich der babylonischen Dynastie eingegliedert, doch im Zuge der Eroberungen eindringender amurritischer und kassitischer Stämme zur Zeit Samsuditanas wird die Stadt Sippar vollkommen zerstört und anschließend aufgegeben. Der letzte bekannte Text aus Sippar trägt das Datum des letzten babylonischen Königs Samsuditana 22. ${ }^{1011}$ Für die Stadt Sippar Amnānum zeigt die archäologische Beleglage aus dem Haus des Ur-Utu gala-mah der Annunītum einen Brand an, der bereits Ammișaduqa-zeitlich das gesamte Gebäude zerstörte. Es bleibt jedoch unklar, ob diese Feuersbrunst nur das Haus oder den gesamten Stadtkomplex traf und seine Bewohner zur Flucht zwang. ${ }^{1012}$ Schließlich ist für das Jahr Samsuditana 4 noch ein gala-mah der Annunitum mit Namen Marduk-muballit in einem Sippar-Text belegt, offensichtlich der Nachfolger des Ur-Utu in Sippar Amnānum. ${ }^{1013}$ Der letzte Text aus dieser Stadt datiert in das Jahr Samsuditana $6 .^{1014}$

Die meisten Texte Sippars stammen aus Raubgrabungen und wurden Ende des vorletzten Jahrhunderts durch das British Museum erworben. Luc Dekiere publizierte 1994-1997 in sechs Bänden etwa 950 ausgewählte Texte dieses Korpus. ${ }^{1015}$ Andere Sammlungen von Sippar-Texten liegen verteilt in zahlreichen amerikanischen und europäischen Museen. ${ }^{1016}$ Die im Kunsthandel erworbenen Texte können nur schwer einer der zwei Sippar-Städte zugeordnet werden, was in erster Linie nach prosopographischen Kriterien erfolgt. Hierbei gilt es zu bedenken, dass zahlreiche Texte auch kleineren Städten in der Umgebung Sippars entstammen können.

Zur Mitte des letzten Jahrhunderts wurden reguläre Ausgrabungen sowohl in Tell Abu Habbah (Sippar) als auch in Tell ed-Dēr (Sippar Amnānum) durchgeführt, bei denen eine große Anzahl an urkundlichen und wenigen literarischen Texten zutage kam. ${ }^{1017}$ Von großem Nutzen ist in diesem Fall das Wissen um die Fundumstände der Tafeln, da mithilfe dieser Informationen detaillierte Untersuchungen zur Zusammenstellung von Familienarchiven geführt werden können. Von herausragender Bedeutung, auch für die Fragestellungen dieser

mu-na-an-dim 2 „Jahr: Er hat balag̃-/lilis/, zwei von ihnen, für Utu angefertigt“ wird von Horsnell 1999/2, 63 Sumula’ēl zugeordnet; zu Jahresdaten mit zwei Königsverweisen s. Charpin 2004, 93 mit Literatur.

1011 Gasche 1989, 113.

1012 Gasche 1989, 44, 114. Durch neue Ausgrabungen im Ort Sippar Amnānum wird zu klären sein, ob sich die Brandreste tatsächlich über den gesamten Ort erstrecken oder sich auf das Haus des Ur-Utu beschränken.

${ }^{1013}$ CT 48, 45 (Sd 4); Gasche 1989, 114 Anm. 287.

1014 Gasche 1989, 114.

1015 In der Reihe Mesopotamian History and Environment, Series 3. Texts (=MHET II/1-6) Ghent: 1994-97.

${ }^{1016}$ Kalla 1999 und Charpin 2004, 433-435 mit Bibliograpie zu den Texten Sippars.

${ }^{1017}$ In den Serien Tell ed Dèr 1-4 und MHET I/1-2. 
Arbeit, ist der Archivfund aus dem Hause des Ur-Utu, gala-mah der Annunītum in Tell ed-Dēr. ${ }^{1018}$ Mit seinen insgesamt etwa 2000 Texten liegt mit diesem Fund das bisher größte in situ aufgefundene Privatarchiv vor, das für die altbabylonische Zeit überliefert ist. Die Zusammenstellung sowie die Inhalte dieser Texte erschließen uns den privaten und offiziellen Wirkungsbereich des gala-mah. Zudem können aus den Inhalten der Texte erstmals Informationen zur Organisation kultischer Dienste rekonstruiert werden, den so genannten $\operatorname{parsu}(m)$-Ritualen, von deren Existenz bis dato nur wenige Texte Kenntnis gaben. ${ }^{1019}$

Etwa 58 der hier untersuchten Texte können mit Sicherheit dem Fundort Tell Abu Habbah zugewiesen werden, hinzu kommen etwa 30 publizierte Tell edDēr-Texte aus dem Hause des gala-mah Ur-Utu. Der größte Teil dieser Texte mit Erwähnungen von gala- oder nar-Berufen datiert in die Zeit der ersten babylonischen Dynastie. In ihnen sind alle verschiedenen Textkategorien urkundlichen Materials vertreten: Verträge, Verwaltungstexte und Briefe. Neben den privatrechtlichen Verträgen über Immobilien aus bedeutenden Familienarchiven sind auch zahlreiche Verwaltungstexte überliefert, die ihrem Inhalt nach einer größeren öffentlichen Institution zugeordnet werden können und $\mathrm{zu}$ denen Schuldscheine sowie Lieferscheine und Rationenlisten unterschiedlicher Art zählen. Die Identifizierung dieser übergeordneten administrativen Institution bleibt allerdings schwierig, da die Texte $\mathrm{zu}$ einem gewissen Teil im Kunsthandel erworben wurden und auch hier wiederum keine Zuordnung zu einem Archivfund möglich ist. Informationen bezüglich der Zugehörigkeit dieser Verwaltungstexte sind in den noch unveröffentlichten Texten Sippars zu erwarten.

Es fällt beispielsweise auf, dass die in Sippar aufgefundenen Briefe alle in die spätaltbabylonische Zeit datieren und sehr viele Belege zu gala-mah enthalten. ${ }^{1020}$

In der folgenden Darstellung werden die Musikerberufe der beiden Städtekomplexe von Sippar Jahrūrum und Amnānum in gemeinsamen Kapiteln erörtert, wobei die jeweilige Herkunft eines Textes, sofern diese bekannt oder erschließbar ist, angegeben wird. Eine gemeinsame Betrachtung der Texte der beiden Sippar-Städte ist deshalb sinnvoll und notwendig, da sich in ihnen häufig zusammenhängende Informationen zu einzelnen Aktionen oder Personen finden. Ein Großteil der mit Namen bekannten Musiker ist in Textbelegen aus beiden Städtekomplexen belegt.

\footnotetext{
1018 Van Lerberghe/Voet 1991 (=MHET I/1) zu den Verwaltungstexten und Tanret 2002 (=MHET I/2) zu den Schultexten.

1019 Tanret/Van Lerberghe 1993; Gallery 1980.

${ }^{1020}$ AbB 2, 73; 89; AbB 6, 29; 61; AbB 10, 1; AbB 11, 93; 107; 101; MHET I/1, 82.
} 


\subsubsection{Die namentlich belegten Musiker Sippars}

Die von Harris zusammengetragenen Daten zu den Musikern von Sippar ${ }^{1021}$ können inzwischen bedeutend ergänzt werden. In den neuen Textbelegen der Stadt Sippar sind überwiegend gala-mah und ihre Familienangehörigen bezeugt, die in Privaturkunden und Tempelrationenlisten genannt werden. Insgesamt sind 14 gala-mah namentlich zusammen aus beiden Städten belegt. Die nar von Sippar sind zumeist aus Rationenlisten bekannt und im Gegensatz zu den Belegen aus den südbabylonischen Städten Ur, Nippur und Larsa nur selten als Zeugen anzutreffen.

Die meisten gala-mah und gala der Tell ed-Dēr-Texte können als Angehörige der Familie des Ur-Utu identifiziert werden. ${ }^{1022}$ Ein Großteil dieser Texte ist jedoch noch unpubliziert, weshalb im Folgenden auf die Ergebnisse bisheriger Arbeiten verwiesen wird. ${ }^{1023}$

\subsubsection{Die gala-mah von Sippar}

Der früheste in Sippar bezeugte gala-mah trägt den Namen Kulālum und ist auf einer unveröffentlichten Rechtsurkunde betreffs eines Feldes als Zeuge vermerkt. ${ }^{1024}$ Die Urkunde datiert in die Regierungszeit des lokalen Herrschers Immerum. Beachtenswert ist hier zunächst die syllabische Schreibung seines Titels. Da dieser Kulālum einen Rechtsspruch im Tempel des Šamaš bezeugte, scheint es wahrscheinlich, dass auch sein Amt am Ebabbar eingerichtet war. ${ }^{1025}$ Die meisten Dokumente aus der Regierungszeit Immerums und Iluma-ilums sind verschiedenen Privatarchiven zugeordnet, die mit Ausnahme des galamah Kulālum keine weiteren Musiker bezeugen. ${ }^{1026}$

Alle übrigen 13 gala-mah der beiden Städte von Sippar Jahrūrum und Amnānum sind ausschließlich in Textbelegen aus der Zeit der ersten babylonischen Dynastie belegt. In die Regierungszeit des Hammurabi datieren drei Belege zu gala-mah-Priestern, deren Namen jedoch nicht angegeben werden. Zwei der Texte notieren ein Schuldverhältnis zwischen der Gattin eines galamah zu einer nadītum des Šamaš, ${ }^{1027}$ während die dritte Urkunde einen galamah als Gläubiger über Getreide nennt. ${ }^{1028}$ Keiner dieser unbekannten galamah aus der Zeit des Hammurabi wird einer Gottheit zugeordnet.

\footnotetext{
${ }^{1021}$ Harris 1975, 173-174.

${ }^{1022}$ Zur Rekonstruktion seines Familienstammbaums s. Dekiere 1994, 139.

${ }^{1023}$ Janssen 1992; Dekiere 1994; Van Lerberghe/Voet 1991.

1024 Text BM 82437a/b:1.Rd/32. igi ku-la-lu-um (ka-la-ma-hi-im) (Koll.); gegen Lalûm bei Renger 1969, 196 und Harris 1975, 172-173.

${ }^{1025}$ Vgl. Harris 1975, 172.

${ }^{1026}$ Vgl. Goddeeris 2002, 41.

1027 JCS 11, 20 Nr. 6:Vs. 5 (Ha 35); VS 9, 152:4 (Ha 39).

${ }^{1028}$ VS 9, 39:10 (Ha ?).
} 
In den spätaltbabylonischen Texten sind für Sippar Jahrūrum selbst galamah-Ämter für den Stadtgott Šamaš sowie für die weiblichen Gottheiten Inana/Ištar und Annunitum belegt. Zusätzlich zu diesen sind drei weitere galamah-Ämter bezeugt, die an kleineren Tempeln der Stadt bestanden bzw. auswärtigen Gottheiten dienten: Es sind jeweils ein gala-mah des Marduk, der Bēlet-ilī und des Šamaš von Babylon.

Der einmalig in einer Darlehensurkunde aus Sippar Jahrūrum genannte gala-mah des Šamaš von Babylon trägt den Namen Ibni-Marduk. ${ }^{1029}$ In der besagten Urkunde VS 29, 84 aus dem Jahr Samsuditana 13 tritt er als Darlehensgeber auf, der seiner Tochter Amat-Šamaš, einer nadītum des Šamaš sechs Kor Gerste aushändigen lässt. Dieser gala-mah aus Babylon wird offenbar aus rein privaten Gründen in einer Sippar-Urkunde genannt und weist damit keinerlei Bezüge zu den Kulten von Sippar auf. Seine Tochter residierte in Sippar als nadìtum des Šamaš, während er selbst bei derselben Gottheit von Babylon in Diensten stand. Es werden insgesamt vier Zeugen aufgeführt, von denen drei ihre Ämter am Šamaš-Tempel von Sippar innehatten. ${ }^{1030}$ Die Urkunde trägt das Siegel des Warad-kinūni, dem Aufseher des Ebabbar des Šamaš (ugula $e_{2}$-babbar ${ }^{\mathrm{d}} \mathrm{Utu}$ ). ${ }^{1031}$

Auf einem einzigen Text aus Tell ed-Dēr, einer parșum-Ritualliste aus dem Ur-Utu-Archiv, sind der gala-mah des Marduk und der gala-mah der BēletBābilim ohne Namensangabe verzeichnet. ${ }^{1032}$ Sie treten als Garanten über ein harimūtum und ein rédûtum auf. ${ }^{1033}$ Dieselbe Ritualabrechnung nennt den Sohn eines gala-mah ohne Gotteszuweisung, dessen Name allerdings abgebrochen ist. ${ }^{1034}$ Ein Kult des Marduk ist in Sippar zwar früh auch mit einem eigenen Tempel belegt, ihm kommt jedoch im Vergleich zu den Hauptgottheiten Samaš und Inana/Ištar keine größere Bedeutung zu, seine Gemahlin Bēlet-Bābilim wird sogar noch viel seltener genannt. ${ }^{1035}$

\footnotetext{
${ }^{1029}$ VS 29, 84:3.12 (Sd 13).

${ }^{1030}$ VS 29, 84:15-17 (Sd 13) zwei Aufseher des Ebabbar und ein Aufseher der naditum des Šamaš.

${ }^{1031}$ VS 29 S. 27 zu 84.

${ }^{1032}$ MHET I/1, 65:3.18 (o.D.).

${ }^{1033} \mathrm{Zu}$ diesen parșum-Ritualen s. hier Kapitel 9.6.3.1.

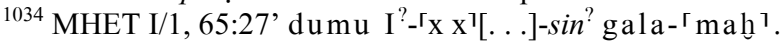

${ }^{1035}$ Harris 1975, 146-147 und Kommentar MHET I/1 S. 97.
} 
Tabelle 8: Namentlich belegte gala-mah in Sippar

\begin{tabular}{|c|c|c|c|c|}
\hline & Šamaš & Inana/Ištar & Annunītum & unbekannt \\
\hline $\mathrm{Im}$ & Kulālum! & & & \\
\hline $\mathrm{Si}$ & Nidin-Ištar & & & \\
\hline $\mathrm{Ae}$ & & & Sîn-mušallim & \\
\hline Ad & & & Inana-mansum & Dig̃ir-šaga \\
\hline Aș & Asalluhi-bāni? & Ibni-Marduk? & $\begin{array}{l}\text { Ur-Utu } \\
\text { [Bēlānum] }\end{array}$ & $\begin{array}{l}\text { Ur-Sakkud } \\
\text { Ur-Guanaka }\end{array}$ \\
\hline $\mathrm{Sd}$ & $\begin{array}{l}\text { Ibni-Marduk, } \\
\text { Šamaš Babylon }\end{array}$ & $"$ & Marduk-muballit & \\
\hline o.D. & & & & Balani-he'inzalag \\
\hline
\end{tabular}

Die gala-mah des Šamaš Nidin-Ištar und Asalluhi-bāni sind jeweils als Zeugen zu Erbteilungsverträgen belegt. ${ }^{1036}$ Letzterer übte sein Amt zeitgleich mit dem berühmten gala-maḩ der Annunītum Ur-Utu aus Sippar Amnānum aus. Die von ihm im Ebabbar bezeugten Erbteilungen betrafen zum einen eine gala-Pfründe und zum anderen verschiedene Güter, die ursprünglich als Geschenke zu einem ausgeführten parșum galten. ${ }^{1037}$ Die gala-Pfründe betraf 5 1/2 Tage am Tempel des Šamaš, am Tor des Manungal, am Tempel der Inana und anderer Gottheiten in Sippar Jahrūrum. ${ }^{1038}$ Unter den weiteren Zeugen befanden sich jeweils ein sag̃ g̃a-Priester des Šamaš und der Aja. ${ }^{1039}$ In zwei Getreideausgabelisten des Šamaš-Tempels aus dem Jahr Ammișaduqa 13 wird der Sohn eines gala-mah mit Namen Sîn-šemi als Getreidefeldbesitzer notiert. ${ }^{1040} \mathrm{Da}$ die Abrechnungen dem Umfeld des naditum-'Klosters' entstammen, ist sein Vater möglicherweise mit Asalluhi-bāni zu identifizieren.

\footnotetext{
${ }^{1036}$ TCL 1, 145:24 (Si 30); RA 82, 28:25' (D.a.[Aṣ]); Di 1804 (Janssen 1992, 42-43, 50 appendice II).

${ }^{1037}$ Di 1804 (Aṣ 5) bei Janssen 1992, 32-33, 42-43.

${ }^{1038}$ RA 82, 28 (D.a.[Aș]): $1^{\prime}-3^{\prime} / 17^{\prime}-19^{\prime}$ (ana) u ${ }_{4} 51 / 2 \mathrm{kam}$ isiq gala-tim ša $\mathrm{e}_{2}{ }^{\mathrm{d}}$ Utu ka ${ }_{2}^{\mathrm{d}} \mathrm{Ma}-$ nun-gal $e_{2}{ }^{\mathrm{d}}$ Inana $u_{3}$ dig̃ir-didli zimbir ${ }^{\mathrm{ki}}$ iahrürum. Die Urkunde datiert nach Charpin 1988, 29-31+Anm. 68 und Pientka 1998, 482:192 etwa Aș 5-17+e.

${ }^{1039}$ RA 82, 28:23'-24' (D.a.[Aș]).

${ }^{1040}$ TCL 1, 168:6-7 (Aṣ 13); TCL 1, 230:39' ([Aṣ 13]).
} 
Ibni-Marduk gala-mah der Inana ist ebenfalls nur einmal belegt, und zwar als Überbringer eines Schuldscheins. ${ }^{1041}$ Aus dem Inhalt des Briefes wird jedoch nicht ersichtlich, ob dieser gala-mah hier als Vertreter eines öffentlichen Amtes oder in privatem Interesse auftritt. ${ }^{1042}$

Das gala-mah-Amt am Tempel der Annunītum von Tell ed-Dēr wird auch in Texten der Stadt Sippar erwähnt. Die Namen der gala-mah Ur-Utu sowie seines Vaters Inana-mansum, Sohn des Marduk-nāṣir, sind in Texten der Regierungszeit des Ammiditana und des Ammișaduqa belegt. ${ }^{1043}$ Doch während Inana-mansum nur einmalig als Käufer eines Feldes in Sippar bezeugt ist (MHET II, 626 [o.D.]), sind die Immobiliengeschäfte des Ur-Utu reichhaltiger dokumentiert. ${ }^{1044}$

Vor der Übernahme des gala-mah-Amtes der Annunītum durch die Familie des Ur-Utu, also zur Zeit des Königs Abi'ēšuh, hatte Sîn-mušallim das Amt inne. Dieser wird in einem Brief an den König erwähnt, der die Klärung der Eigentumsverhältnisse an einem Feld zum Inhalt hat, und ist außerdem Zeuge in einer Kaufurkunde über nadìtum-Besitz. ${ }^{1045}$ In einer Opferausgabenliste für ein Fest der Annunitum wird ein weiterer gala-mah ohne Namen genannt, der aufgrund des Datums mit Sîn-mušallim zu identifizieren ist. ${ }^{1046}$ Auf welche Weise das gala-mah-Amt der Annunītum von Sîn-mušallim an Inanamansum überging, ist nicht bekannt. ${ }^{1047}$ Eine Verwandtschaft zwischen beiden Personen kann zurzeit nicht nachgewiesen werden.

Letzter in Sippar amtierender gala-mah der Annunitum war Mardukmuballit, der aus insgesamt zwei Texten bekannt ist, einem Brief sowie einer parșum-Abrechnung, die beide in die Regierungszeit des Samsuditana datiert werden. ${ }^{1048}$ Der Brief behandelt die Übergabe von zwei Stieren durch die Tempelverwaltung an den gala-mah, die möglicherweise für kultische Zwecke benötigt wurden. ${ }^{1049}$ Marduk-muballit kann damit als direkter Nachfolger

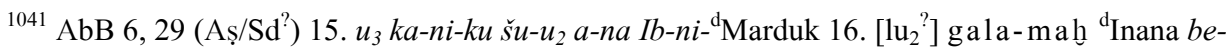
$l i_{2}$ 17. [l]i-ša-bi-lam „Und die betreffende gesiegelte Urkunde soll mein Herr an IbniMarduk, den gala-mah der Inana, meinem Herren, bringen lassen“. Da der Brief einen höheren Beamten mit Namen Ammișaduqa-ilūni nennt, könnte er in die Zeit des gleichnamigen Königs oder seines Nachfolgers Samsuditana zu datieren sein.

1042 S. a. Renger 1969, 198 Anm. 915.

${ }^{1043}$ Ur-Utu: CT 45, 62:27 (D.a.); MHET II, 898:9 (Aṣ 6); CT 48, 76:5 (Aṣ 17); RA 82, 28:26' (D.a.[Aș]) und wohl als Zeuge in MHET I/1, 95:3' (Aṣ 1-27?); Inana-mansum: MHET II, 626:11.4' (o.D.).

${ }^{1044}$ CT 48, 76 (Aṣ 17); CT 45, 62 (D. a.); MHET II, 898 (Aṣ 6).

${ }^{1045} \mathrm{AbB}$ 2, 73:5.5'; BE 6/1, 119: (o.D.) ii 22. igi d EN.ZU-mu-ša-lim [ga]la-mah An-nu-nitum.

${ }^{1046}$ OLA 21, 4:5 (Ae 28).

1047 Janssen 1992, 43 Anm. 61.

1048 AbB 11, 93:3'; CT 48, 45:13-14 (Sd 4).

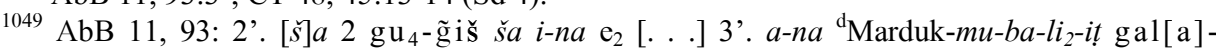


des Ur-Utu in Tell ed-Dēr identifiziert werden. Hierdurch ist bestätigt, dass das gala-mah-Amt der Annunītum auch nach der Zerstörung von Ur-Utus Haus noch bis zum Jahr Samsuditana 4 besetzt war. ${ }^{1050}$ Die Filiation des gala-mah Marduk-muballit ist nicht bekannt. Beachtenswert ist dennoch, dass in der bereits genannten parșum-Abrechnung CT 48, 45 (Sd 4) neben Mardukmuballit der Bruder des Ur-Utu mit Namen Huzālum als Garant über das parșum-Ritual genannt ist. Zwischen diesem Huzālum und Ur-Utu hatte wenige Jahre zuvor ein Erbschaftsstreit bestanden. In welchem Zusammenhang diese Beobachtungen zur Abfolge der Amtsübergabe von Ur-Utu an Mardukmuballit stehen, ist bis zur Veröffentlichung weiterer Sippar-Texte nicht zu klären.

Von den fünf weiteren in Sippar-Texten ohne Gotteszuweisung belegten galamah können Dig̃ir-šaga, ${ }^{1051}$ Ur-Sakkud ${ }^{1052}$ und Ur-Guanaka ${ }^{1053}$ den Haupttempeln von Sippar Jahrürum zugeordnet werden. Dig̃ir-šaga erscheint außer in einer Sammelurkunde über Pachtland einer nadìtum noch als Absender eines Briefes an den Landesvorsteher. ${ }^{1054}$ Bei diesem beschwert er sich wegen der Rekrutierung des gala-Priesters Nabīum-mālik aus Habbuz zu Trägerdiensten, obwohl dieser ihm selbst unterstehe, Lehensdienste leiste und regelmäßig seine igisûm-Abgaben für das gala- und sag̃g̃a-Priesteramt in Sippar Jahrūrum an ihn entrichte. ${ }^{1055}$ Aufgrund der Beleglage könnten die gala-mah Dig̃ir-šaga und Ur-Sakkud am Ebabbar amtiert haben.

Dem gala-mah mit dem außergewöhnlichen sumerischen Namen Balanihe'inzalag ${ }^{1056}$ im Brief AbB 2, 89 wird eine Schuldlast auferlegt, die er an einen Schuldeintreiber zu entrichten hatte. ${ }^{1057}$

[mah] 4'. li-id-di-in-m[a] 5'. la i-da-ab-bu-u[b] „Wegen der zwei Stiere, die im Tempel/Haus . . .er soll sie dem gala-mah Marduk-muballit geben, (dass) er sich nicht beklagt“. Kubburum spricht im Brief Di 620 an seinen Bruder Ur-Utu ebenfalls von zwei Stieren, die er nicht aus dem Hause seines Vaters genommen haben will; Janssen 1992, 48.

${ }^{1050}$ Gasche 1989, 114 + Anm. 287.

${ }^{1051}$ YOS 13, 12:Vs 16 (Ad 15) Sammeltafel über Pachtfelder einer naditum des Šamaš.

${ }^{1052}$ MHET II, 909:20 (Aṣ 15) Mietvertrag über Pachtfelder einer nadìtum des Šamaš. Der galamah Ur-Sakkud erscheint als zweiter Zeuge nach einem sa g̃ g a.

${ }^{1053}$ AbB 6, 61:7 (Aș) mit einer Verordnung des Königs den gala-mah Ur-Guanaka von Sippar Jahrūrum betreffend.

${ }^{1054}$ Brief AbB 10, 1:4; auch wenn Dig̃ir-šaga ohne Titel genannt wird, kann es sich m. E. nur um den gleichnamigen gala-mah handeln.

${ }^{1055} \mathrm{AbB} 10,1: 25$. awìlum awìl qãtia 26. ul nakar 27. 5 ilkì illak 28. $u_{3}$ igi-sa $\mathrm{a}_{2}$ sag̃ g̃a-tim $u_{3}$ gala-tim 29. išaqqala; s. a. Stol 2004, 771.

1056 Bal-a-ni-he $e_{2}$-in-zalag wörtlich, ,sein 'Amt' möge erstrahlen“. Zur Zuordnung des Textes nach Sippar s. Harris 1975, 173.

${ }^{1057}$ So Übersetzung in AbB 2 S. 61; anders Renger 1969, 199 Anm. 924. 
Nennenswert ist weiterhin ein kleines Tafelfragment aus dem Archiv des Ur-Utu, das insgesamt fünfmal den Titel gala-mah und weitere Personennamen auflistet, von denen jedoch aufgrund des schlechten Erhaltungszustands kein einziger mehr lesbar ist. ${ }^{1058}$ Die Tafel könnte alle zu einer Zeit amtierenden gala-mah von Sippar in Form einer Tempelpersonalliste verzeichnet haben. Leider lässt der Erhaltungszustand der Tafel keine konkreten Rückschlüsse auf ihren Inhalt zu.

\subsubsection{Ur-Utu, gala-mah der Annunitum}

Die Ausgrabungen im Hause des gala-mah Ur-Utu von Tell ed-Dēr brachten insgesamt über 2000 Texte zu Tage, die auf vier unterschiedliche Räume verteilt waren. ${ }^{1059}$ Der größte Teil dieser Texte wurde zerstreut auf dem Fußboden vorgefunden, was auf eine eilige Flucht der Hausbewohner hindeuten könnte. Die Überreste waren zudem von einer Brandschicht überlagert. $\mathrm{Ob}$ dieses für das Haus des Ur-Utu dokumentierte Feuer auch andere Wohnbezirke in Sippar Amnānum heimsuchte, ist jedoch bislang archäologisch nicht nachgewiesen. ${ }^{1060}$ Die jüngste Tafel des Ur-Utu-Archivs datiert in das Jahr Ammișaduqa 17+e. Auf den Nachfolger des Ur-Utu mit Namen Marduk-muballit in Samsuditana-zeitlichen Texten wurde bereits hingewiesen, sodass die Besetzung des gala-mah-Amtes der Annunītum auch nach Zerstörung des Ur-UtuHauses noch belegt ist.

Der Tafelfund aus dem Privatarchiv des Ur-Utu eröffnet sowohl Informationen zur Person des Ur-Utu und seiner Familie als auch zu seinen kultischen und administrativen Aufgaben innerhalb der Tempelverwaltung.

Anhand der privaten Urkunden und Briefe des Ur-Utu rekonstruierte Dekiere einen Familienstammbaum von sieben Generationen und 30 Personen. ${ }^{1061}$ Die Ergebnisse seiner Studie werden hier referiert, um einen Eindruck von der Familientradition dieses Priesterberufs zu geben.

Der Beruf des gala-Priesters ist bereits früh innerhalb der Familie des UrUtu nachweisbar, erster Vertreter dieses Berufsstandes ist Utu-mansum, Sohn des Ur-Utu I. ${ }^{1062}$ Für seine Vorväter sind keine Priesterämter in Texten belegt. Innerhalb der folgenden vierten Generation ist ein gewisser Zarriqum, Sohn des Ekigibi, als gala und Erbe einer gala-Pfründe belegt. ${ }^{1063}$ Nach Dekiere könnte dieser Zarriqum auch den sumerischen Namen Nanna-šalasud getragen ha-

\footnotetext{
1058 MHET I/1, 96 (o.D.).

1059 Zu den Fundumständen und Archiven s. Van Lerberghe 1982; Gasche 1989, 9-44; zur zeitlichen Verteilung der Texte ibid., 107.

1060 Gasche 1989, 44, 114.

1061 Dekiere 1994; Kalla 2002, 136-137, 154 zur Namenstradition der Familie.

1062 CT 45, 15:20 (Sm 17); Dekiere 1994, 127-128.

${ }^{1063}$ In Di 2015 (Ha 38); Janssen 1992, 19 Anm. 3.
} 
ben. ${ }^{1064}$ Drei der vier bekannten Söhne des Zarriqum, Ur-Inana, Marduk-nāṣir und Awīlija, waren möglicherweise ebenfalls gala. Im Gegensatz zu späteren Generationen standen sie jedoch im Dienst des Tempels der Inana von Sippar Jahrūrum. ${ }^{1065}$ Die weiblichen Familienmitglieder dieser und früherer Generationen sind ebenfalls alle als nadiātum des Šamaš am Haupttempel des Šamaš in Sippar Jahrūrum zu verorten. ${ }^{1066}$ Damit konzentrieren sich die religiösen und kultischen Verpflichtungen dieses Familienzweigs auf die zwei Haupttempel der Stadt Sippar Jahrūrum.

Erster Inhaber eines gala-mah-Amtes ist der Sohn des Marduk-nāșir mit Namen Inana-mansum aus der sechsten Generation. Entgegen der bisherigen Familientradition wird dieser Inana-mansum gala-mah der Göttin Annunītum und verlagert damit seinen Tätigkeitsbereich nach Sippar Amnānum. Die Amtswürde übernimmt er im Jahr der Inthronisation des Königs Ammiditana von seinem Vorgänger Sîn-mušallim ${ }^{1067}$ und übergibt sie noch zu seinen Lebzeiten im Jahr Ammișaduqa 4 seinem Sohn Ur-Utu (II), den bekannten galamah von Tell ed-Dēr. ${ }^{1068}$ Insgesamt war damit Inana-mansum über 40 Jahre im Amt. Die Verlagerung der Ämter vom Tempel der Inana in Sippar auf den Tempel der Annunītum in Sippar Amnānum könnte mit dem Kauf von Pfründen oder Immobilien zu begründen sein. ${ }^{1069}$ Möglicherweise hing diese religiöse Umorientierung auch mit der Frau des Inana-mansum zusammen, einer qadištum aus Babylon, deren Tochter Lamassāni der mütterlichen Tradition folgend als lukur dem Gott Marduk von Babylon geweiht war. ${ }^{1070}$ Neben UrUtu (II) ist in dieser Generation nur noch sein Bruder Huzālum als gala belegt. ${ }^{1071}$

Anhand einer zusammengehörigen Gruppe von Privatdokumenten rekonstruierte Janssen (1992) einen Familienstreit, der sich in der Generation des UrUtu ereignete. ${ }^{1072}$ Der Streit betraf die Erbschaft des Inana-mansum und wurde zwischen seinen vier Söhnen ausgetragen. Die zwei Streitparteien wurden von den drei Söhnen Kubburum, Huzālum und Ilī-iqī̌sam auf der einen und Ur-Utu

\footnotetext{
${ }^{1064} \mathrm{Zu}$ den unpublizierten Texten s. Dekiere 1994, 128-129; außerdem in VS 18, 8a/b: 13/16.1.Rd. (Si 8); TCL 1, 130/131:25/27 (Si 10).

1065 Dekiere 1994, 129-131 mit einem einzigen Beleg zu einem Ur-Inana gala Inana Jahrūrum; Awīlija ist als Käufer einer gala-Pfründe in Di 1499 (Si 28) belegt(?); Dekiere 1994, 131.

${ }^{1066}$ Dekiere 1994, 139 mit Stammbaum.

${ }^{1067}$ Di 1897; Janssen 1992, 19.

1068 Janssen 1992, 43-44.

1069 Janssen/Gasche/Tanret 1994, 91-92. Ein anderer Zweig derselben Generation, die Söhne seines Onkels Awīlija mit Namen Ibni-Marduk und Išme-Adad waren offenbar dem Tempel des Ea/Enki verpflichtet; Janssen/Gasche/Tanret 1994, 114+Anm. 79.

${ }^{1070}$ Dekiere 1994, 137; Janssen 1992, 40-41 zu ihrem Erbanteil.

${ }^{1071}$ Dekiere 1994, 136.

${ }^{1072}$ Zusammengefasst bei Janssen 1992, 39-47.
} 
auf der anderen Seite gebildet. ${ }^{1073}$ Ausgangspunkt dieser Streitigkeiten ist die Enterbung der drei Söhne durch Inana-mansum und die Einsetzung des Ur-Utu als Alleinerben. Der Streit um die Erbschaft dauerte nach dem Tode Inanamansums insgesamt sieben Jahre an und konzentrierte sich auf ein Haus desselben in Sippar. Rechtlich wurde er zunächst von den Richtern beider SipparStädte beurteilt und später an die Richter von Babylon übergeben, die eine höhere Instanz bilden. Offenbar war die Enterbung der drei Söhne durch Inanamansum nicht rechtskräftig, weshalb sieben Jahre nach dessen Tod schließlich die Aufteilung der Erbschaft auf alle vier Söhne erfolgte. Die Position des UrUtu hinsichtlich dieser Aufteilung bleibt unbekannt. Sechs Jahre nach dieser Erbschaftsregelung fällt schließlich sein Haus in Tell ed-Dēr einem Brand zum Opfer. Über den weiteren Verbleib des Ur-Utu geben die Texte keine Auskunft, was nur mit dem Tod desselben zu erklären ist. Sein Amt ging an einen Marduk-muballit über, dessen Genealogie bisher unbekannt ist. Da seine Namensgebung nicht mit der Familientradition des Ur-Utu übereinstimmt, kann er nicht derselben Familie entstammen. In der parșum-Abrechnung CT 48, 45 (Sd 4) tritt dieser Marduk-muballiṭ neben dem Bruder des Ur-Utu namens Huzālum auf, welcher selbst den Priesterberuf des gala ausübte. Wie diese Verbindung angesichts der Familienstreitigkeiten zu interpretieren ist, bleibt unklar.

Die Siegel beider gala-mah der Annunītum aus der Familie des Ur-Utu sind überliefert. Das Siegel des Inana-mansum ist aus mehreren Immobilienverträgen bekannt und enthält die üblichen Angaben zu Filiation und Dienerschaft: „Inana-mansum, gala-mah̆ der Annunītum, Sohn des Marduk-nāșir, Diener des Ammiditana“. ${ }^{1074}$ Vom Sohn und Nachfolger Ur-Utu wird dieses Siegel noch zu Beginn seiner Amtszeit weiterverwendet, ${ }^{1075}$ bis er sich ein eigenes anfertigen lässt, das - jüngeren Traditionen folgend - ein Gebet an Šamaš enthält. ${ }^{1076}$

Das Ur-Utu-Archiv setzt sich aus unterschiedlichen Textgruppen zusammen. ${ }^{1077}$ Den größten Teil bilden Verwaltungsurkunden, wie Rationenlisten, Lieferscheine und Quittungen, anhand derer die an den Opferkulten beteiligten Personen, Familien- und Tempelhaushalte um den gala-mah und den Tempel der Annunītum rekonstruiert werden können. Da bisher jedoch nur ein geringer Teil des Archivs veröffentlicht wurde, kann eine genaue Analyse der kultischen

${ }^{1073}$ Der in den Texten belegte fünfte Sohn des Inana-mansum mit Namen Bēlānum (Dekiere 1994, 137) wird mit Ur-Utu identifiziert, der seinen sumerischen Namen mit seinem Amtsantritt annahm (Janssen 1992, 47-48). Beachte dennoch, dass der Brief AbB 11, 107:11 [As] und die Urkunde Di 2189 (Aṣ 5) Bēlānum nach dem Amtsantritt Ur-Utus als gala-mah der Annunītum auszeichnen; Janssen 1992, 47-48.

1074 So zu ergänzen; vgl. zur Ungewissheit Pientka 1998, 198 Anm. 114 und Charpin 1988, 30.

${ }^{1075}$ Charpin 1988, 31-32.

${ }^{1076}$ MHET I/1 S. 158 und pl. 79; zu diesen Siegelinschriften s. Pientka 1998, 206-207.

1077 Einführend Van Lerberghe 1982; in MHET I/1 Publikation der Texte aus locus 17. 
Zugehörigkeit dieser Texte nicht stattfinden. Es werden daher lediglich die Inhalte der in MHET I veröffentlichten Tafeln zusammengefasst.

Die meisten Texte behandeln Informationen zur Verwaltung von Getreidefeldern. Es werden verschiedene Schritte von der Aussaat über die Ernte bis hin zur Verteilung und Weiterverarbeitung der Erträge beschrieben. ${ }^{1078}$ Als Empfänger sind häufig auch die Tiermäster $\left(1 u_{2}-\mathrm{ku}_{7}-\mathrm{meš}\right)$ genannt, was als Landpachtabgabe (biltum) des Inana-mansum unter der Aufsicht eines Palastschreibers notiert wird. ${ }^{1079}$ Das vom gala-mah als Pacht verwaltete Anbauland war damit größtenteils Eigentum des Palastes. In 15 Texten sind monatliche Bierlieferungen über einen Zeitraum von zwei Jahren (Aṣ 14-15) dokumentiert. ${ }^{1080}$ Ein Verwendungszweck für das Bier wird leider nicht angegeben, doch werden als letzte Empfänger einzelne Personen angeführt. ${ }^{1081}$ Es wird wohl an das Tempelpersonal verteilt oder auch für Libationen verwendet worden sein. ${ }^{1082}$ Nur wenige Texte notieren die Ausgabe von Silber und anderer Wertgegenstände an Angestellte des Tempels und des Militärs. ${ }^{1083}$ Unter den Tempelangestellten befindet sich auch der gala Inana-mansum, Sohn des Sînrēmēni. Wichtige administrative Aufgaben des Ur-Utu innerhalb des kultischen Bereichs zeigen schließlich die parșum-Texte auf, die hier im Kapitel 9.6.3.1 behandelt werden.

Eine zweite Gruppe von Texten bilden die privaten Dokumente, bestehend aus Verträgen, Erbschafts- und Besitzurkunden sowie Briefen. In Briefen wird neben Angelegenheiten der parșum-Rituale ${ }^{1084}$ auch einmal ein Fest der Annunītum genannt, für das im siebten Monat eine Brotlieferung einging. ${ }^{1085}$

Die dritte Gruppe aus dem Archiv des Ur-Utu besteht größtenteils aus Schultexten und wenigen literarischen Texten. ${ }^{1086}$ Dieses Korpus ist insofern von Interesse, da es über das Schreibvermögen und das literarische und liturgische Repertoire eines gala-mah-Priesters der Annunitum Aufschluss zu geben verspricht. Zwei von insgesamt drei identifizierten Opferschaugebeten

${ }^{1078}$ Erntearbeiterlisten: MHET I/1, 53-56; Verteilung und Weiterverarbeitung: MHET I/1, 34-42; Verteilung an Tempelinstitutionen und Haushalte höherer Tempelbeamter: MHET I/1, 3942. Die Liste MHET I/1, 40:16 (o.D.) nennt das $\mathrm{e}_{2}-\tilde{\mathrm{g}} \mathrm{a}_{2}-\mathrm{gi}_{4}$-a ,Verwaltungshaus des Klosters von Sippar“ als Empfangsstelle; MHET I/1 35:6 nennt den Tempel der Ištar.

${ }^{1079}$ MHET I/1, 13 (Aṣ 1); zu biltum s. Ellis 1976, 56-60; Stol 2004, 757-762.

${ }^{1080}$ MHET I/1, 17-31.

${ }^{1081}$ MHET I/1, 20-23 (Aș 15); MHET I/1, 27-28 (Aș 14).

${ }^{1082}$ S. den Brief MHET I/1, 74 mit der Zahlungsaufforderung für eine Bierlibationsmenge, die von einer qadištum auszuführen war. Die Stadt Sippar Amnānum könnte nach Gasche 1989, 114 zum Brief AbB 2, 67 bekannt für seine Bierproduktion gewesen sein.

${ }^{1083}$ MHET I/1, 43-49.

${ }^{1084}$ MHET I/1, 74?, 78 .

${ }^{1085}$ MHET I/1, 92.

${ }^{1086}$ Tanret 2002 zu Schultexten; De Meyer 1989, 41-43 ein Gottesbrief an Annunitum; De Meyer 1982a, 271-278 zwei ikribu-Gebete. 
$(i k r i b u(m))$ an Ninsiana und Annunitum wurden bisher veröffentlicht, in denen Ur-Utu persönlich als Bittsteller auftritt. ${ }^{1087}$ Sie gehören zum Gebetsrepertoire eines Opferschaupriesters $($ barû $(m))$, es bleibt daher unklar, ob Ur-Utu die Opferschauen selber durchführte oder diese durch einen Opferschauer für private Anliegen ausführen ließ. Eine enge Beziehung zwischen Opferschauer und gala-mah findet sich in der Quittung YOS 13, 329 (Sd 3) aus Dilbat dokumentiert, die die Übergabe eines Silberbetrags vom barûm an den galamah notiert. ${ }^{1088}$ Schließlich wurden Opferschauen auch durchgeführt, um den Träger oder Ausführenden eines parṣum zu bestimmen, was ebenfalls im selben Archiv dokumentiert ist. ${ }^{1089}$

Ein wichtiger Fund liegt mit der Tafel Di 113 vor, bei der es sich um das Fragment einer Bala g̃-Klage handelt. ${ }^{1090}$ Der Text ist keine Schreibübung, da er in sehr feiner Schrift gehalten ist. Ausgehend von Tanrets Schlussfolgerungen, wonach der gala-mah selbst keine hohen Schreibkünste beherrscht habe, ${ }^{1091}$ kann die Tafel nicht von ihm stammen. Er vermutet daher, dass für die Niederschrift des Klageliedrepertoires andere Personen als die Priester selbst in Frage kommen. Dass es sich hierbei um den einzigen Vertreter eines EmesalTextes aus dem Hause des Ur-Utu handelt, lässt außerdem vermuten, dass das Wissen um und die Wiedergabe dieses Repertoires in erster Linie in oraler Form stattfand. ${ }^{1092}$

\subsubsection{Die gala von Sippar}

Die namentlich belegten gala Sippars sind überwiegend aus Zeugenlisten bekannt. Nur wenige werden in Rationenlisten und Erntearbeitsverträgen erwähnt. In Tell ed-Dēr können sie meist der Familie des Ur-Utu zugeordnet werden. ${ }^{1093}$ Einmalig ist außerhalb dieser Familie in Sippar Amnānum auch ein gala der Inana namens Qurdi-Ištar bezeugt. ${ }^{1094}$ Dieser war Nachbar zweier Cousins des gala-mah Inana-mansum, die nach anderen Texten als Diener des Gottes Enki/Ea ausgezeichnet werden. ${ }^{1095}$ Ihre Häuser lagen zudem nahe der Tempel des Enki und des Sîn, deren beide Kulte in Sippar recht unbedeutend waren. ${ }^{1096}$ Der Tempel des Enki/Ea wurde zudem von Funktionären des

\footnotetext{
${ }^{1087}$ De Meyer 1982a, 271-278. Zur Gattung der ikribu s. hier Kapitel 11.2.3.

${ }^{1088}$ Hier Kapitel 9.7.1.

1089 Tanret/Van Lerberghe 1993, 440 und der Brief MHET I/1, 74.

1090 Tanret 2002, 8.

1091 Tanret 2002, 171 zusammengefasst.

${ }^{1092}$ So Tanret 2002, 171.

${ }^{1093}$ Dekiere 1994 auch mit unpublizierten Belegen.

${ }^{1094}$ Im Erbteilungsvertrag OLA 21, 71:17 (Aṣ 13); dazu Janssen/Gasche/Tanret 1994, 114 Anm. 79. Unter den Zeugen sind die Söhne des Awìlija, Onkel des Inana-mansum.

${ }^{1095}$ Es handelt sich um die Söhne des Awīlija mit Namen Ibni-Marduk und Išme-Adad; OLA 21, 71 (Aṣ 13); Di 2231 und Di 1801; dazu Janssen/Gasche/Tanret 1994, 114.

1096 OLA 21, 71:7.18.30 (Aș 13). Zu den Kulten und Tempeln von Enki/Ea und Sîn in Sippar s.
} 
Annunītum-Tempels verwaltet. ${ }^{1097}$ Ähnlich dem gala Ur-Inana I, einem Mitglied der Ur-Utu Familie, ${ }^{1098}$ wird der Arbeitsplatz dieses gala Qurdi-Ištar am Inana-Tempel von Sippar Jahrūrum gewesen sein.

Hammurabi-zeitlich ist möglicherweise ein gala des Nanna/Sîn mit abgebrochenem Namen Abum-x belegt. Auf seinem Siegel, das sich auf einer Eingangsquittung über Gerste für den Sîn-Tempel befindet, wird er als gala UD.NI/DU ${ }_{3}-\left[\mathrm{x}^{?}\right]$ ausgezeichnet. ${ }^{1099}$

Die fünf namentlich belegten gala Nabi-Šamaš, Ilum-pī-Ištar, Ilūni, Gimillum und Utu-mansum in Texten aus Tell Abu Habbah waren wohl an den Haupttempeln der Stadt tätig. ${ }^{1100}$ Unter ihnen lässt sich lediglich Utu-mansum der Familie des Ur-Utu zuordnen. ${ }^{1101}$

Mit Ausnahme der in Kapitel 9.6.2.1 genannten Erbteilungsurkunde zu einer gala-Pfründe an verschiedenen Tempeln Sippars werden aus den veröffentlichten Texten keine weiteren Daten zu solchen Pfründen bekannt. ${ }^{1102}$

Nach dem Brief AbB 10, 1 hatten gala eine igisûm-Abgabe zu leisten. Nach Aussage des Briefes könnte die Abgabe den gala vor Trägerdiensten bewahrt haben. ${ }^{1103}$ Der dort genannte gala Nabium-mālik leistete außerdem eine igisûm-Abgabe für ein sag̃ g̃a-Amt. Dieselben Tätigkeitsbereiche übte ein weiterer gala aus Sippar mit Namen Inana-mansum aus. Dieser Sohn des Sînrēmēni ist sowohl als gala als auch als sag̃ g̃a am Tempel des Šamaš belegt. ${ }^{1104}$ Er bewohnte ein Mietshaus im Besitz einer naditum-Priesterin namens Tarībatum. ${ }^{1105}$ Im Jahr 16 des Ammișaduqa bezeugte er drei Mietverträge über Immobilien, über die dieselbe nadìtum Tarībatum als Eigentümerin verfügte. ${ }^{1106}$ Darüber hinaus mietete er einen Stall von einem gewissen Usātum. ${ }^{1107}$

Harris 1975, 145, 148.

${ }^{1097}$ Harris $1975,179$.

${ }^{1098}$ Dekiere 1994, 130

1099 VS 9, 18 (Ha 1) Siegel: A-「bu-um?-[x x]; dumu ${ }^{\mathrm{d}} \mathrm{EN} .\left[\mathrm{ZU} / \mathrm{Hil}_{2}\right]-\mathrm{rku}^{?}{ }^{2}-[\mathrm{x}] ;$ gala UD.DU NII $^{\text {? }}$, vgl. Harris 1975, 184.

${ }^{1100}$ Ilum-pī-Ištar: BM 81591 Rs 5 (Ad 24?); Ilūni: MHET I/1, 94:4 und BM 80371:5 (Aṣ 5); LuNinurta: TJDB 84f., 27:20 (Si 8) mit Harris 1975, 174 und Renger 1969, 189 zu Sippar gehörig gegen Szlechter in TJDB S. ix; Nabi-Šamaš: MHET II, 928 (Si ?); Gimillum: MHET II, 544:12 (Aș 16), ein gala Gimillum wird auch im fragmentarischen Brief AbB 7, 153 genannt, seine Identifizierung bleibt unsicher.

${ }^{1101}$ CT 45, 15:20 (Sm 17); Dekiere 1994, 127-128 und hier Kapitel 9.6.2.2.

1102 RA 82, 28 ([Aș]); Reichhaltigere Informationen wurden dagegen für das Ur-Utu-Achiv von Dekiere 1994 angekündigt.

${ }^{1103}$ Mit babbilūtum hier als „Trägerdienst“; Stol 2004, 771; vgl. Pecha 2001, 6-7; nach Charpin 1988, 31 könnte die Abgabe im Zusammenhang mit dem Anteil (isqum) an einer galaPfründe stehen (RA 82, 28 ([As]])).

${ }^{1104}$ Gegen Harris 1975, 174 nicht als Berufswechsel zu werten.

${ }^{1105}$ MHET II, 544:4 (Aș 16).

${ }^{1106}$ Als gala in MHET II, 545:12 (Aṣ 16); als sag̃ g̃a in PBS 8/2, 218:12 (Aṣ 16) und PBS 8/2, 224:11-12 (Aṣ 16). 
Derselbe Inana-mansum ist nach einem Text aus dem Ur-Utu-Archiv Garant über einen Silberbetrag. ${ }^{108}$ Mit diesem identisch sein könnte ein weiterer gala gleichen Namens in Gersterationenlisten desselben Archivs, der allerdings ohne Filiation angegeben wird. ${ }^{1109}$

gala-Priester in Sippar und Sippar Amnānum bewohnten nicht nur Mietshäuser, sondern waren auch selbst Eigentümer von Immobilien. Mehrere Beispiele sind für die Mitglieder der Ur-Utu-Familie bekannt. ${ }^{110}$ Darüber hinaus verzeichnet die Immobilienliste MHET II, 633 (D.a.) den gala Ipquša sowie den Sohn des Sîn-rē'̄', ebenfalls ein gala-Priester, als Besitzer von Häusern, die in der Nähe des nadìtum-Klosters sowie Privathäusern von sa g̃ ga-Priestern gelegen waren. ${ }^{1111}$

Verschiedene Listen über Gersterationen und Silberbeträge aus dem Hause des Ur-Utu nennen mehrfach zwei gala gemeinsam mit Namen Utu-mansum und Inana-mansum. ${ }^{112}$ Letzterer könnte wie gesagt mit dem gleichnamigen Sohn des Sîn-rēmēni identisch sein.

\subsubsection{4 nar und nar-gal}

In den veröffentlichten Texten aus Sippar ist bislang nur ein einziger nar-gal mit Namen Marduk-muballit bezeugt. Dieser war laut der Quittung CT 8, 21c einem Hauptmann (abi șābi) mit Namen Ilī-iqīšam zugewiesen und leistete einen als igisûm-Abgabe gekennzeichneten Silberbetrag. Die Abgabe überbrachte dem Text zufolge der Aufseher der tigiātum mit Namen Šumum-libši an zwei Beamte des Palastes. ${ }^{113}$ Dass der nar-gal dem Hauptmann zugewiesen war, könnte nach Harris bedeuten, dass er zu militärischen Unternehmungen herangezogen werden konnte. ${ }^{1114}$ In dieser Urkunde findet sich zugleich der erste Beleg für die Verbindung zwischen dem nar-gal und dem Aufseher der tigiātum. Die Gruppe der tigĥu-Spielerinnen gehörte nach Ausweis verschiedener Dokumente aus Mari und Isin dem Palast an und war den dort ansässigen

${ }^{1107}$ CT 48, 54 (Aṣ 12); Usātum, Sohn des Ilšu-ibni in MHET II, 536 (Aṣ 14).

${ }^{1108}$ MHET I/1, 43 (o.D.) 3. ${ }^{11}{ }^{1}$ gin $_{2}$ ana qabê ${ }^{\mathrm{d}}$ Inana-ma-[an-sum] 4. dumu ${ }^{\mathrm{d}} \mathrm{EN} . \mathrm{ZU}-$ rēmèni.

${ }^{1109}$ MHET I/1, $51: 7$ (o.D.); MHET I/1, 53:2 (Aṣ 1); MHET I/1, 56:3 (o.D.); MHET I/1, 60:4 (o.D.).

${ }^{1110}$ Als Hausbesitzer sind belegt die gala Zarriqum (Ha-Si), Ur-Inana I (Ha-Ae), Marduk-nāṣir (Si-Ae) und Huzālum (Aș); Dekiere 1994, 128, 130, 136; Janssen/Gasche/Tanret 1994, 92.

${ }^{1111}$ MHET II, 633:3.8 (o.D.).

${ }^{1112}$ MHET I/1, 44:7 (D.a.); MHET I/1, 53:1-2 (Aș 1); MHET I/1, 60:3-4 (o.D.).

${ }^{1113} \mathrm{CT} 8,21 \mathrm{c}$ (Aș 10) 5. igi-sa ${ }_{2}^{\mathrm{d}}$ Marduk-mu-ba-li ${ }_{2}-i t$ nar-gal 6. ša a-na $I_{3}-l i_{2}-i-q i_{2}-\check{s} a-a m a-$ $b i$ eren $_{2}$ 7. es $s_{3}$-hu 8. mu-DU 9. Í Šu-mu-um-li-ib-ši 10. ugula ti-gi-a-ti 11. nam-har-ti 12. ${ }^{\mathrm{Id}}$ Marduk-mu-ba-li $2_{2}-i t$ 13. $u_{3}{ }^{\mathrm{d}} \mathrm{EN} . Z \mathrm{ZU}-n a-s ̦ i-i r$ 14. de-ki-i; ,igisûm-Abgabe des Mardukmuballit, des nar-gal, der dem Hauptmann Ilī-iqī̌sam zugewiesen ist. Eingang. Šumumlibši, der Aufseher der tigiāti, hat (die) Einnahme Marduk-muballiṭ und Sîn-nāșir gebracht"; vgl. Pecha 2001, 7.

${ }^{1114}$ Harris 1975, 174. 
Haremsdamen angeschlossen. Der nar-gal gehörte entsprechend der Belege zum babylonischen Raum dem Tempelpersonal an, der wie auch sag̃ g̃a und gala seine Abgaben an den Palast leistete. Dass der Aufseher der tigiātum als Überbringer der Abgabe fungiert, zeigt eine wichtige personelle Schnittstelle zwischen Palast und Tempel auf.

Im Gegensatz zum Amt eines nar-gal findet der Beruf des nar-sa in SipparTexten mehrfach Erwähnung. In den entsprechenden Textbelegen sind nar-saMusiker entweder als Gruppe oder auch als Einzelperson unter Angabe ihres Namens attestiert. Besondere Beachtung verdient eine bisher einmalig bezeugte nar-sa-Pfründe, die Teil einer Erbschaft in der folgenden Rechtsurkunde ist:

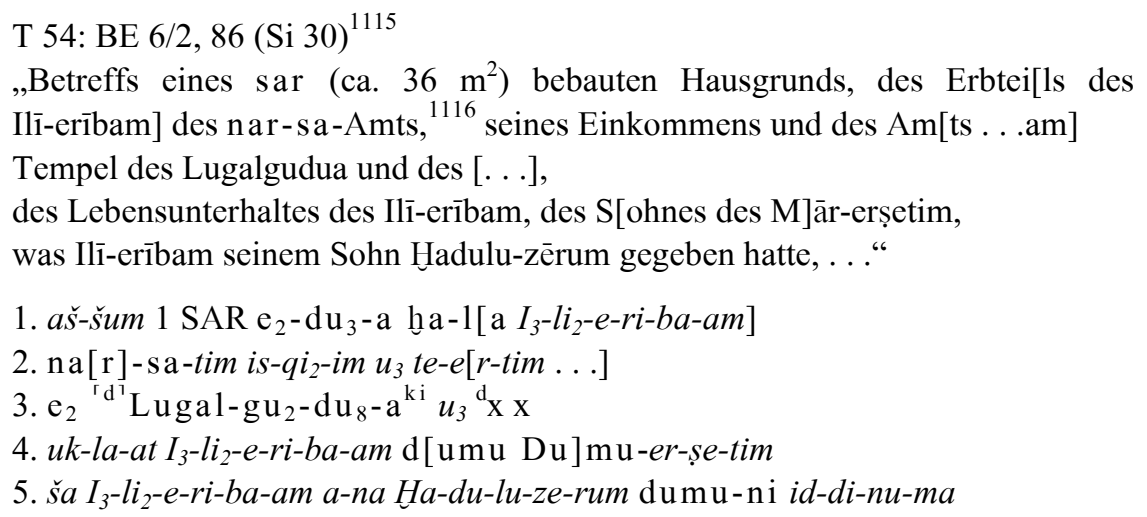

In der Zeugenliste werden nach einem sag̃g̃a des Šamaš, fünf Richtern, einem gudu $_{4}$-abzu zuletzt vier Personen aufgeführt, die als nar-sa-meš ausgezeichnet werden: Sîn-iddinam, Ali-talīmi, Warad-Bunene und Šamaš-nǐšu. ${ }^{1117}$ Über diese Urkunde wird deutlich, dass nar-sa-Ämter in Sippar am Tempel eingerichtet waren. Dieser Gruppe von spezialisierten Musikern und Instrumentalisten gehörten nach Angabe der Tafel zunächst die im Vertrag angegebenen Pfründeninhaber Ilī-erībam und Hadulu-zērum sowie die vier zuletzt genannten Zeugen an. Die Urkunde nennt ein nar-sa-Amt am Tempel des Lugalgudua und einer zweiten nicht mehr lesbaren Gottheit als Erbe des Hadulu-zērum. Ob die in der Zeugenliste genannten nar-sa auch dem Tempel des Lugalgudua zuzuordnen sind oder an anderen Tempeln der Stadt tätig waren, lässt sich aufgrund mangelnder prosopographischer Daten nicht feststellen. Lediglich der Name des Warad-Bunene könnte noch am Ende der Rationenliste CT 45, 84 zu verschiedenen parșum-Ritualen an Șarpanītum zu rekonstruieren

\footnotetext{
${ }^{1115}$ Vgl. Wilcke 1983, 60-61.

${ }^{1116}$ Wilcke 1983, 61 ,des Saitenspieler-Standes“.

${ }^{1117}$ BE 6/2, 86:Rs 12'-23' (Si 30).
} 
sein. Der Tempel des Lugalgudua, eine Erscheinungsform des Nergal, ist frühaltbabylonisch aus Isin und Sippar bekannt, sein Kult ist in Sippar allerdings recht unbedeutend. ${ }^{1118}$

Die hohe Anzahl der nar-sa-Musiker in der Zeugenliste fällt besonders auf, auch dass sie alle unterschiedliche Väter aufweisen und damit wohl auch unterschiedlichen Familien angehörten.

Ein weiterer Vertreter des Musikerberufs nar-sa wird als Zeuge in einem Hauskaufvertrag zwischen zwei nadiātum des Šamaš geführt. ${ }^{1119}$ Dieser nar-sa mit Namen Būratum kann damit dem Umfeld des Šamaš-Personals zugeordnet werden, über seine Familienzugehörigkeit wird jedoch nichts bekannt.

Weitere nar-sa auch mit Namensnennung werden als Empfänger von Getreide und Bier in Ausgabenlisten genannt, die die Ausführung von parșumRitualen für Tašmētum und Șarpanìtum betreffen. ${ }^{1120}$ In der Liste CT 4, 8b (Ad 13) werden die angegebenen Brot- und Biermengen zuletzt als Ausgabe an eine Gruppe von nar-sa und eine Mundschenkin (šaqìtum) verzeichnet. ${ }^{1121}$ Zwei mit Namen angegebene nar-sa finden sich wiederum am Ende der Ausgabenliste CT 45, 84. ${ }^{1122}$ Instrumentalisten scheinen damit als eine feste Institution bei der Ausführung von parșum-Ritualen für weibliche Gottheiten gegolten zu haben.

Drei nar-Musiker sind in vor-Hammurabi-zeitlichen Urkunden als Zeugen in Immobilienverträgen oder Nachbarn einer zu veräußernden Immobilie belegt. ${ }^{1123}$ Von diesen könnten zwei dem Umfeld des Ebabbar angehören. Der nar mit Namen Imgur-Sîn ist Zeuge in einer Urkunde über den Kauf eines Dattelpalmgartens, der von einer nadītum des Šamaš erworben wird. ${ }^{1124}$ In der Zeugenliste folgt er dem sag̃g̃a des Šamaš. Der zweite nar mit Namen Ikūnpī-Ea ist als Nachbar eines Hausgrundstücks bezeugt, das sich in der Nähe der Tempel des Hanašar und der Ninsiana befand. Die Zeugenliste der betreffenden Urkunde nennt auch nadiātum des Šamaš. ${ }^{1125}$

\footnotetext{
${ }^{1118}$ Harris 1975, 187; Pientka 1998, 305 zu einem sa g̃ g̃a dieser Gottheit in Sippar; Sîn-muballit von Babylon stiftete diesem Gott im Regierungsjahr 16 einen Kultsockel; Horsnell 1999/2, 99-100.

${ }^{1119}$ RA 85, 42 Nr. 13:19 (Si 9) und Bearbeitung S. 23-24; neu umschrieben in MHET II, 458.

${ }^{1120}$ Beide Belege bei CAD N/1 378 sub b).

${ }^{1121} \mathrm{CT} 4,8 \mathrm{~b}$ (Ad 13) 33. 0.0.4.0 ninda 0.1.2.0 kašs šu-ti-a nar-sa-me 34. 6 sila $\check{s}_{3} \check{s} a-q i_{2}-$ tim.

${ }^{1122} \mathrm{CT} 45,84$ (o.D.) 33. 0.0.1.2[+. .]x-GA? nar-sa 34. 0.0.1.2[+. .]x- ${ }^{\mathrm{d}} \mathrm{Bu}-\mathrm{ne}-\mathrm{ne}$ nar-sa. Letzterer ist möglicherweise mit dem nar-sa Warad-Bunene aus der Urkunde BE 6/2, 86 (Si 30) zu identifizieren; s. hier Kapitel 5.4.2.

${ }^{1123}$ Sîn-rīmēni: MHET II, 595:18 (o.D.); Imgur-Sîn: CT 4, 50a:27 (Im/S1 ?); Ikūn-pī-Ea: MHET II, 40:7.31 (Sa 5).

${ }^{1124} \mathrm{CT}$ 4, 50a (Im/S1 ?); zur einflussreichen Familie des Verkäufers s. Goddeeris 2002, 60-63.

${ }^{1125}$ MHET II, 40:25.36 (Sa 5).
} 
Neben diesen drei sind nach-Samsuiluna-zeitlich für Sippar weitere vier nar aus Rationen- und Erntearbeiterlisten bekannt. ${ }^{1126}$ In einer dieser Listen wird der Diener (șuhārum, wörtl. „Knabe, 'Kleiner'“) eines nar neben einem anderen als Arbeiter eingeteilten Musiker genannt. ${ }^{1127}$ In Texten des Ur-Utu-Archivs erscheint häufig der nar Ir-Sig̃ar neben den bereits bekannten gala Inanamansum und Utu-mansum.

Nur der nar Iddin-Marduk erscheint in einer Rationenliste über Bierausgaben, die im zehnten Monat aus Anlass der „Vorzeichnung? für das Haus des Bēliātum und des Iddin-Marduk“" verteilt wurden. ${ }^{128}$ Die über 70 Empfänger sind Angehörige unterschiedlichster Berufsgruppen, darunter Handwerker, Köche und Diener, aber auch Kaufleute, Richter, Seemänner und nur wenige Tempelpriester, wie ein érib bìtim und ein gudu ${ }_{4}$-Priester. ${ }^{1129}$ Möglicherweise handelt es sich um Ausgaben aus Anlass eines Weihfests. Der Musiker wird zwischen Brauern genannt.

In einem Archiv, das von Pientka-Hinz an einen kleineren Ort zwischen Sippar und Babylon verortet wird, ist einmalig eine Musikerin mit Namen Šamšì-libūr belegt. ${ }^{1130}$ Sie ist Empfängerin von Getreide, das aus Anlass eines šagigur(r)ûm-Opfers ausgegeben wurde. ${ }^{1131}$ Sollte dieses Archiv tatsächlich der Königstochter und naditum-Priesterin Iltani zuzuordnen sein, so könnte diese Musikerin ihrem Privathausalt angehört haben. ${ }^{1132} \mathrm{Ob}$ Šamšì-libūr für eine musikalische Darbietung begleitend zum Opfer entlohnt wurde, bleibt ungewiss.

\subsubsection{Blinde Musiker?}

Dass Blinde wie in Kapitel 5.3.3 gezeigt auch als Musiker oder Sänger tätig sein konnten, ist bisher nur aus wenigen altbabylonischen Texten aus Mari und Kiš bekannt. In zwei Ausgabenlisten aus Sippar, die Bier und Brotausgaben aus

\footnotetext{
${ }^{1126}$ Warad-Sîn: CT 8, 41b:13 (o.D.); Bēlānu: CT 6, 23 b (Aṣ 5); Usātum und Sîn-māgir: BA 5, 491:19-20 (Si 9); Ir-Sig̃ar: MHET I/1, 51:4 (o.D.); 53:8 (Aṣ 1?), 54:9' ([Aș]); 60:12 (o.D.); vgl. Harris $1975,175$.

${ }^{1127}$ BA 5, 491:20 (Si 9).

${ }^{1128}$ OLA 21, 67:29 (Aș 17+a) 1. qa $a_{2}$-ti kaš $u_{2}$-șu $u_{2}$-ur-tim ša e $_{2} B e_{2}-l i_{2}-a$-tum $u_{3}$ I-din- ${ }^{\mathrm{d}}$ Marduk 2. $\check{s} a$ iti a[b!-ba- $] e_{3} u_{4} 29-k a m$ mu-bi-im; anders OLA 21 S. 10 rekonstruieren den 9. Monat.

${ }^{1129}$ Beachte in OLA 21, 67 (Aṣ 17+a) 47. Ta-ri-bu lu 2 g̃iš-hur -ḥi.a „Mann der Zeichnungen"!

1130 JCS 2, 109 Nr. 18:4 (Ae 28); ibid. S. 90-91; Pientka 1998, 317-327.

${ }^{1131}$ So wohl zu emendieren in JCS 2, 109 Nr. 18 (Ae 28) 3. 2 gur $a-n a \check{s ̆ a}_{3}-<$ gi $_{4}>-$ guru $_{6}$ 4. gir $_{3}{ }^{\mathrm{d}} \mathrm{UTU}-\bar{s} \mathrm{i}$-li-bur munus-nar; dasselbe „freiwillige Opfer“ wird in weiteren Texten dieser Textgruppe erwähnt; Pientka 1998, 318-321.

1132 Pientka 1998, 317-318, 325-327; s. a. Harris 1975, 175, die die Musikerin dementsprechend dem Palast zuordnet.
} 
Anlass von Kultfesten verzeichnen, könnten solche Blinde belegt sein. Die parșum-Liste CT 45, 84 nennt in den letzten Zeilen 33-35 zunächst zwei narsa, auf die als letzte Empfängerin eine Blinde mit Namen Ea-nadinša folgt. ${ }^{1133}$ Im Vergleich $\mathrm{zu}$ allen übrigen Teilnehmern erhielt sie mit zwei Litern die geringste Menge an ausgegebenem Bier.

Die zweite Liste CT 45, 85 verzeichnet Ausgaben über Naturalien an Tempelpersonal zum Anlass verschiedener Ritualhandlungen bei einer MardukProzession. ${ }^{1134}$ Unter den Empfängern finden sich mehrere gala-mah und gala. Auffällig ist der Eintrag in Zeile 7, wo eine geringe Menge an Brot- und Bierrationen für $\mathrm{lu}_{2}$ igi-bal $u_{3} \mathrm{ka}$-lu-tum notiert wird. Der Ausdruck $\left(\mathrm{lu}_{2}\right)$ igi-bal bezeichnet einen Sehbehinderten, wörtlich eine „Person mit 'verdrehten Augen'". ${ }^{1135}$ Das Wort kalûtum wird in Übereinstimmung mit den Wörterbüchern als „Klagepriestertum“ wiedergegeben. ${ }^{1136}$ An anderer Stelle derselben Tafel wird jedoch auf diesen Berufstsand grundsätzlich in logographischer Schreibung mit UŠ.KU(-mah) verwiesen (Z. 3.5.13). Ebenfalls in logographischer Schreibung erscheint das Abstraktum gala-tum in zwei Sippar-Texten, wo es die Pfründe oder das Amt des gala-Priestertums bezeichnet. ${ }^{1137} \mathrm{Die}$ syllabische Schreibung ka-lu-tum muss kein Anlass für eine andere Übersetzung des Wortes geben, dennoch fällt auf, dass der Ausdruck neben $\mathrm{lu}_{2}$ igibal erscheint. Hier kommt die Annahme Gelbs zum Tragen, demzufolge gala $/ k a l \hat{u}$ in seiner ursprünglichen Bedeutung ebenfalls auf ein physisches Merkmal zu beziehen ist. ${ }^{1138}$ Damit wären hier zwei Zustände einer körperlichen Behinderung nebeneinander gestellt, im Zusammenhang mit dem kalu wird diese Behinderung oder 'Missbildung' auf sein Geschlecht bezogen. ${ }^{1139}$ Andererseits könnte hier auch einfach nur eine Verbindung zwischen Sehbehinderten und einem Musikerberuf bestehen. Die Deutung dieser Textzeile bleibt schwierig. ${ }^{1140}$

${ }^{1133} \mathrm{CT} 45,84$ (o.D.) 35. 0.0.0.2 [ . . ] ${ }^{\mathrm{d}} \mathrm{E}_{2}$-a-nadin(MU)-̌̌a ig i-nu-AH/IM?(koll.). Der Name ist als Hommage an den Gott Ea/Enki gebildet, der nach Enki und Ninmah dem Blinden sein Schicksal als Musiker bestimmt; hierzu vergleichbar sind die Namen von zwei Blinden aus Mari: Ea-ilī und Ea-rabī in M.5577+ nach Ziegler 2007, 21 Anm. 101.

${ }^{1134}$ Ausführlich in Kapitel 9.6.3.4.

${ }^{1135}$ In seiner sumerischen Form bisher nur lexikalisch belegt: MSL 12, 166:287. $1 \mathrm{u}_{2}$ igi-bal = mu[tēe ìnim]; AHw 1332b târu(m) sub 15c) S. 1335a „Augen verdrehen“; s. a. Fincke 2000, 172.

${ }^{1136}$ AHw 429b; CAD K 107 sub kalûtu „,collegium of lamentation-priests“.

${ }^{1137}$ AbB 10, 1:28; RA 82, 28:17' (D.a.[Aș]).

${ }^{1138}$ Gelb 1975, 69-70; erneut Gabbay 2008; s. a. hier Exkurs I.

1139 Zuletzt Gabbay 2008.

1140 Nach Fincke 2000, 172 ist unklar, ob mutēr inim „der das Auge zurückwendet“ einen „krankhaften Zustand (Augen verdrehen) oder eine Fähigkeit“ bezeichnet. Andererseits könnte es vielleicht auch auf diejenige Person verweisen, die wörtl. einer anderen Person „die Augen verdreht“, also eine Blendung vollzieht. Ist angesichts der Diskussion um das Geschlecht des gala kalûtum hier parallel zu lu ${ }_{2}$-igi-bal als „Kastration“ zu verstehen? 
Insgesamt muss offen bleiben, ob diese wenigen Textstellen als Belege zu blinden Musikern in Sippar zu werten sind. ${ }^{1141}$

\subsubsection{Musiker bei Kultfesten in Sippar}

\subsubsection{Die parșum-Kulthandlungen von Sippar}

Die über den Begriff parșum bezeichneten Kulthandlungen sind vornehmlich in Alltagsdokumenten der Städte Sippar und Kiš belegt. ${ }^{1142}$ Nach Aussage dieser Texte fanden parșum unter der Aufsicht hoher Tempelbeamter statt. In dieser Position tritt in Sippar der g a l a - m a h -Priester auf.

Erste Untersuchungen zu parșum als Bezeichnung einer Kultobligation wurden von Gallery geführt. ${ }^{1143}$ Den zahlreichen Texten mit Bezug zu parșumRitualen aus dem Archiv des Ur-Utu widmeten sich vor allem Tanret und Van Lerberghe. ${ }^{1144}$ Die zur gleichen Gruppe von Kultritualen gehörende Gruppe der kezrētum-Texte aus Kiš wurde von Yoffee diskutiert. ${ }^{1145}$

Da viele Texte, die ihrem Inhalt nach zum Korpus der parșum gehören, noch unveröffentlicht sind, werden in der folgenden Darstellung bisherige Arbeiten referiert und bezüglich der Aufgabenbereiche des gala-mah und anderer Musikergruppen ausgewertet.

\subsection{Die Texte}

Texte mit Informationen zu den parșum können in drei Gruppen eingeteilt werden: ${ }^{1146}$ den Listen, den Zahlungsquittungen und den Briefen und Privaturkunden.

Zur ersten Gruppe gehören sowohl die von Gallery 1980 behandelten zwei Texte CT 4, 8b (Ad 13) und CT 45, 84 (o.D.) als auch die aus dem Ur-UtuArchiv stammenden Tafeln MHET I, 64-66. Diese beiden Listengruppen repräsentieren zwei unterschiedliche Dokumentationsstufen innerhalb der parșum-Verwaltung. Die zwei Listen CT 4, 8b (Ad 13) und CT 45, 84 sind

\footnotetext{
Zur bislang unbeantworteten Frage nach Kastration bei Musikern s. a. Ziegler 2007, 23-24.

1141 Ein Blinder, der in Sippar residierte, könnte nach einem Mari-Text bei einem dortigen Musiker in Lehre gestanden haben; hierzu Ziegler 2007, 21-22+Anm. 106.

$1142 \mathrm{Zu}$ parșum auch im Sinne eines Amtes s. CAD P 195 und 198 sub c); Farber 1987-90, 613; vgl. a. das nA Königsritual KAR 146 Rs linke Kol. 10. zammeru parșê-šu ${ }_{2}$ e-pa-ă̌ „,Der Sänger führte seine parșū aus“; Ebeling 1952, 144. Die Pflege und korrekte Ausführung der parșum-Kultordnungen lag nach Ausweis literarischer Texte im Zuständigkeitsbereich des Königs: KH ii 63. mu-uš-te-e'-bi 64. pa-ar-și, ra-bu- $u_{2}$-tim 65. ša ${ }^{\mathrm{d}} I \check{s} t a r,,(H a m m u r a b i)$, der die parșum der Ištar planmäßig ausführt".

1143 Gallery 1980, 333-338.

1144 Tanret/Van Lerberghe 1993.

1145 Yoffee 1998, 312-343.

${ }^{1146}$ Vgl. Tanret/Van Lerberghe 1993, 438-440.
} 
zusammenhängende Rationenlisten, in denen Ausgaben über Bier für die Durchführung vier verschiedener parșum-Handlungen verzeichnet sind. ${ }^{1147}$ Die dort angegebenen parșum galten den Göttinnen Șarpanītum, der Gattin des Marduk, sowie der Tašmētum und könnten im Tempel des Marduk stattgefunden haben. ${ }^{1148}$ Empfänger der Rationen sind zunächst der sa g̃ ga des Marduk und seine Familie. Hierauf folgt die Auflistung von etwa 25 verheirateten und unverheirateten Frauen. In beiden Listen werden zuletzt Ausgaben an nar-sa notiert. ${ }^{1149}$

Bei den Texten MHET I, 64-66 ${ }^{1150}$ aus dem Archiv des Ur-Utu handelt es sich dementgegen um Sammellisten über Abrechnungen verschiedener parșum-Handlungen. Diese werden unter Angabe eines Silberbetrags verschiedenen Personen zugeordnet. Wahrscheinlich handelt es sich hier um die Personen, die an den parșum entweder als Garanten oder als Ausführende teilnahmen.

Die zweite Gruppe der parṣum-Texte bilden die Abrechnungen und Zahlungsquittungen. Diese in Form von Bürgschaften oder Schuldscheinen gehaltenen Texte sind auch aus Kiš im Zusammenhang mit den kezrētumHandlungen belegt. In aller Regel wird dort eine Summe über Restsilber für die parșum verzeichnet. ${ }^{1151}$

Aus Briefen und Urkunden werden weitere Informationen zu den Inhalten und zur Ausführung von parșum-Kulthandlungen bekannt. So erhielt beispielsweise Ilša-ḩeg̃alli die Gattin des gala-mah Inana-mansum reichhaltige Geschenke von ihrem Gatten zur Ausführung eines unbekannten parșum. ${ }^{1152}$

\subsection{Namen und Organisation der parșum}

Aus den etwa 100 Texten mit Hinweisen zu den parșum von Sippar konnten insgesamt acht verschiedene Bezeichnungen dieser Kulthandlungen zusammengetragen werden. Sie sind entweder als Abstrakta von Berufsbezeichnungen gebildet oder Namen von Objekten: ${ }^{153}$

\footnotetext{
${ }^{1147}$ Hierzu auch Wilcke 1985a, 196-197 Anm. 17.

${ }^{1148}$ Vgl. CAD R 252 rēdûtu sub 2; Gallery 1980, 333-334.

${ }^{1149}$ CT 4, 8b:33 (Ad 13); CT 45, 84:33-34 (o.D.).

${ }^{1150}$ Nach Van Lerberghe in MHET I/1 S. 91 könnte auch die stark zerstörte Tafel MHET I/1, 98 zur selben Gruppe gehören.

1151 nēbēh/kasap kezērim; Yoffee 1998, 321-322.

${ }^{1152}$ Urkunde Di 1804 (Aș 5) bei Janssen 1992, 32-33, 42. Ilša-hegagalli erhielt ein Feld, ein Haus, zwei Sklaven und Mobiliar. Weitere sind AbB 1, 72; AbB 7, 17; AbB 11, 71; AbB 11, 167; AbB 12, 178; CT 48, 45 (Sd 4); s. a. Tanret/Van Lerberghe 1993, 439-440 mit unveröffentlichten Texten. Rechtsurkunden um parșum in Kiš sind YOS 13, 202 (Sd 5) und YOS 13, $326+236(\mathrm{Sd} 5)$.

${ }^{1153}$ Gallery 1980, 333-337; Tanret/Van Lerberghe 1993, 440-442.
} 
Tabelle 9: Die parșum von Sippar

\begin{tabular}{|c|c|}
\hline Sippar Jahrūrum & Sippar Amnānum \\
\hline 1. rēdûtum & ${ }^{(\mathrm{sal})}$ rēdûtum \\
\hline 2. harimūtum & ${ }^{\text {lu2 }}$ harimūtum \\
\hline 3. & ${ }^{(\mathrm{sal})}$ muGaBBirūtum \\
\hline 4. mubabbilūtum & mubabbilūtum \\
\hline 5. ru'ūtum & \\
\hline 6. qulmû (za-ha-da) zabar & qulmû (za-ha-da) zabar \\
\hline 7. kunukkum $\left({ }^{\mathrm{na} 4} \mathrm{kišib}\right)$ & kunukkum $\left({ }^{\mathrm{na} 4} \mathrm{kišib} / \mathrm{kišib}{ }^{\mathrm{na} 4}\right)$ \\
\hline 8 . & $\mathrm{na}_{4}-\mathrm{gal}^{\mathrm{d}} \mathrm{Utu}$ \\
\hline
\end{tabular}

Diese Bezeichnungen von parșum-Handlungen sind bisher ausschließlich in Texten aus Sippar bezeugt. ${ }^{1154}$ Dementsprechend sind die kezertumKulthandlungen auf die Stadt Kiš beschränkt. Des Weiteren lassen sich beide Kultformen nur in Texten der spätaltbabylonischen Zeit vor allem der drei letzten Könige Ammiditana, Ammișaduqa und Samsuditana nachweisen. ${ }^{1155}$ Von diesen Begriffen werden neben dem Wort parșum selbst auch die Worte rēdûtum, muGaBBirūtum und qulmû mit kaspum „Silber“ zusammengesetzt als 'kasap nn' „Silber der nn-Kulthandlung“. In gleicher Weise ist in den KišTexten vom Silber der kezertum-Kulthandlung (kasap kezéri) die Rede. Zu den einzelnen parșum-Kategorien sind an dieser Stelle einige Anmerkungen zu machen:

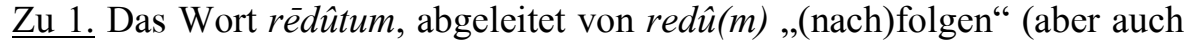
„leiten“ bzw. anführen“), ist auch in sumerischer Schreibung uku-uš attestiert. ${ }^{156}$ Es wird nur im Zusammenhang mit den Ehefrauen hoher Tempelbeamter genannt. Gallery rekonstruiert hierfür einen Dienst dieser Frauen bei militärischen Camps. ${ }^{1157}$ Im Zusammenhang mit Kulten an weiblichen Göttinnen wäre auch an einen 'Begleitdienst' zu denken, der von Frauen ausgeführt wurde. Möglicherweise betraf dieser Dienst die Pflege der Götterbilder, denn im Text CT 45, 84 mit verschiedenen parșum für die Göttin Șarpanītum, die von der Ehefrau eines sag̃ g̃a ausgeführt wurden, geht das Wort rēdûtum verschiedenen Toilettenartikeln voraus. ${ }^{158}$ Die Veranstaltung dieser Kulthand-

\footnotetext{
${ }^{1154}$ Der angebliche Nippur-Beleg in ARN 172 Rs 4 nach CAD R 252 rēdûtu sub 2. nennt m. E. Gefolgsleute.

${ }^{1155}$ Yoffee 1998, 318.

${ }^{1156}$ CT 4, 8b:3 (Ad 13); CT 45, 84:1 (o.D.); MHET I/1, 64:Rs 21 (D.a.) dazu ibid. S. 93-94; CT 48, 45:3 (Sd 4); MHET I/1, 65:12 (o.D.); hierzu Tanret/Van Lerberghe 1993, 442 Anm. 16 und CAD R 251-252.

1157 Tanret/Van Lerberghe 1993, 441 gegen Gallery 1980, 335 „camp follower“.

${ }^{1158}$ CT 45, 84:1-2 (o.D.); Gallery 1980, 336-337; Wilcke 1985a, 196 Anm. 17 ZA-ap-pi $i_{2}$ mu-ere-tim „Kamm der Leiterin“ und nädin mê ana qātim „Wasserspender für die Hände“. Die
} 
lungen müssen sehr umfangreich gewesen sein, da die Liste der an den Ausgaben beteiligten Personen sehr lang ausfällt. Eine Entsprechung zum rēdûtum von Sippar könnte mit den Kultobligationen der kezertu $(m)$ von Kiš vorliegen, für die entsprechende Aufgaben bei der Begleitung von Göttinnen auf Kultreisen angenommen wurden. ${ }^{1159}$

Zu 2. harimūtum ist als Abstraktum von harimtum, der Bezeichnung einer Frauengruppe, gebildet. In den Texten aus Tell ed-Dēr erhält es grundsätzlich das Determinativ $\mathrm{lu}_{2}$ und wird als parșum-Kulthandlung im Gegensatz $\mathrm{zu}$ rēdûtum ausschließlich im Zusammenhang mit männlichen Personen genannt. ${ }^{1160}$ Cooper zieht hier einen Kleidertauschritus in Erwägung. ${ }^{1161} \mathrm{Im}$ Text CT 48, 45 (Sd 4) aus Sippar Jahrūrum wird es dementgegen neben rédûtum einer Frau zugeordnet. ${ }^{1162}$

Die Vergabe eines nig $\tilde{g}_{2}$ harimti an den Schwiegersohn eines hohen Tempelbeamten, was ein kurzzeitiges Amt oder eine Verpflichtung im Zusammenhang mit der Kulthandlung des harimütum zu bezeichnen scheint, ist Thema des Briefs MHET I/1, 78. Weiterhin könnte auch die Personenliste CT 4, 15c (o.D.) in denselben Kontext gehören. Diese listet insgesamt 21 harimtumFrauen unter der Aufsicht des gala-mah auf, die elf Frauen zugeordnet werden. ${ }^{1163}$ In welcher Beziehung harimtum bei Frauen unter der Aufsicht des gala-mah zur Kultobligation harimūtum stehen könnten, ist unklar. Es wäre auch möglich, dass der gala-mah kurzzeitig die harimütum-Kultverpflichtung inne hatte und in diesem Zuge über die Verteilung von harimtum-Frauen waltete. Worin ihre kultischen Tätigkeiten betanden, bleibt allerdings unbekannt.

$\mathrm{Zu}$ 3. Die Lesung des dritten Begriffs ${ }^{(\mathrm{sal})} \mathrm{muK} / \mathrm{GaBBiru}$ tum ist aufgrund der verschiedenen Schreibungen in den Texten von Tell ed-Dēr unsicher. ${ }^{1164}$ Tanret und Van Lerberghe leiten muqabbirum als Partizip im D-Stamm von qebēru $(m)$ „begraben, bestatten“ ab und nehmen einen Bezug zu Begräbnisfeiern an. ${ }^{1165}$

Bedeutungsfelder des zugrundeliegenden Verbs redû $(m)$ sind zu vielseitig, als dass an dieser Stelle eine endgültige Deutung dieser Kultobligation möglich wäre; CAD R 226.

${ }^{1159}$ S. hier Kapitel 7.3.

${ }^{1160}$ Tanret/Van Lerberghe 1993, 441-442. In MHET I/1, 65:14.17.26 und MHET I/1, 66:19 sind dreimal Köche Ausführende.

${ }^{1161}$ Cooper 2006a, 18.

${ }^{1162}$ CT 48, 45:3-5; Gallery 1980, 334.

1163 S. Kapitel 7.3.

${ }^{1164}$ MHET I/1, 64:7.19,Rs 5.9.17 (D.a.) mu-GA-BI-ru-ti, MHET I/1, 66:12 (D.a.) und Di 310:21 ${ }^{\text {sal }} m u$-ka-AB-BI-ru; es könnte sich auch um zwei unterschiedliche Kulthandlungen handeln, insbesondere, da das erste Abstraktum ist und dem zweiten das Determinativ SAL vorangeht; Van Lerberghe las in MHET I/1 S. 98 noch ${ }^{\text {sal }} m u$-ka-ap-pi ${ }_{2}-r u$ von kapāru „kultisch reinigen; abwischen“ oder kabāru „dick sein, werden“; s. a. CAD M/2 181 mukabbiru „boaster, braggart" nur lexikalisch.

1165 Tanret/Van Lerberghe 1993, 437. 
Für das dritte und zweite Jahrtausend ist bekannt, dass der Vortrag von Klagen bei Bestattungsritualen zu den Aufgaben eines gala zählte. ${ }^{1166}$

$\mathrm{Zu}$ 4. Auch das mubabbilütum ist wie das ${ }^{1 \mathrm{l} 2}$ harimūtum einzig im Zusammenhang mit männlichen Personennamen belegt. ${ }^{1167}$ Das Wort bildet möglicherweise ein Abstraktum zu mubabbilum, einem Kultstatisten, der im IštarRitual von Mari zum Emesal-Gesang eines kalû auftrat. ${ }^{1168}$ Als Partizip zu wabālu $(m)$ könnte es als „Träger/-dienst“ zu übersetzen sein. P. Villard setzt mit einer Ableitung von bubbulum als „paradieren, marschieren“ für mubabbilum im Zusammenhang mit Militärparaden die Bedeutung „Schild-/Bannerträger" an. ${ }^{1169}$ Hierin könnte auch der Dienst eines Mannes liegen, der für die Kultobligation mubabbilūtum bestimmt wurde.

$\mathrm{Zu}$ 5. Das Wort ru'ūtum bleibt auf zwei Texte aus Sippar Jahrūrum beschränkt und wird daher von Tanret und Van Lerberghe nicht zu den parșum von Tell ed-Dēr gezählt. ${ }^{1170}$ Gallery stellt diesen Begriff aufgrund seiner Grundbedeutung „Freundschaft, Partnerschaft“ in das gleiche Bedeutungsfeld wie rédûtum und harimūtum. ${ }^{1171}$ Auf welche kultische 'Bindung' zweier Parteien es im Kontext eines Ritus verweisen könnte, ist nicht zu klären, von einem Bezug zu kultischen Prostitutionsdiensten ist allerdings abzusehen. $\mathrm{Zu}$ bemerken ist, dass es in beiden Texten von verheirateten Frauen ausgeführt wurde.

$\mathrm{Zu}$ 6-8. Die letzten drei Worte qulmû (za-ha-da) zabar, kunukkum $\left({ }^{\mathrm{na}}{ }^{4} \mathrm{kišib}\right)$ und na ${ }_{4}$-gal ${ }^{\mathrm{d}}$ Utu bezeichnen alle Objekte. Sie könnten Symbole oder Kultobjekte derjenigen Götter sein, für die die Rituale ausgeführt wurden und die von den Ausführenden verwahrt werden mussten. ${ }^{1172}$

Die Axt qulmû ist in den Texten wie auch rédûtum ausschließlich im Zusammenhang mit Frauen attestiert. ${ }^{1173}$ Auf ein ähnliches Objekt könnte die einmalig in Sippar Jahrūrum belegte „Picke?“ (akkullu(m); ni $\tilde{g}_{2}$-gul) zu beziehen sein. ${ }^{1174}$

Das Siegel kunukkum wird in Texten aus Tell ed-Dēr gleichrangig neben harimūtum, rēdûtum und qulmûu verwendet. ${ }^{1175}$ Der Brief MHET I, 74 nennt ein kunukkum-Amt der Inana 'Königin von Sippar', das sich in der Hand der

\footnotetext{
${ }^{1166}$ S. hier Kapitel 6.3.5.

${ }^{1167}$ De Meyer 1982b, 31-36 und CT 48, 45:6 (Sd 4); Tanret/Van Lerberghe 1993, 441-442.

${ }^{1168}$ Durand/Guichard 1997, 55:iii 21; zuletzt Ziegler 2007, 59, 62.

1169 Villard 1992, 147-148; hierzu auch Ziegler 2007, 62, wobei ich mit Stol 2004, 771 den Dienst babbilūtum im Brief AbB 10, 1, der einem gala auferlegt werden sollte, nicht zu den hier behandelten Kultdiensten zähle, sondern eher als einen niederen Trägerdienst auffasse.

${ }^{1170}$ CT 4, 8b:3 und CT 45, 84:1; nicht in der Liste bei Tanret/Van Lerberghe 1993, 441.

1171 Gallery 1980, 335; s. a. CAD R 441b sub 2 ,(a temple service obligation of kezertuwomen)“.

${ }^{1172}$ Vgl. Gallery 1980, 336; Yoffee 1998, 330-331 zu CT 48, 45.

1173 Tanret/Van Lerberghe 1993, 441-442.

${ }^{1174}$ Einmalig in CT 45, 84:1 (o.D.); hierzu Gallery 1980, 336; AHw 30a „Dechsel, Picke“.

${ }^{1175}$ MHET I/1, 64 (D.a.) und 65 (o.D.); Tanret/Van Lerberghe 1993, 442.
} 
qadištum Ețirtum befand. Diese war für die Ausführung von Libationen zuständig. Andererseits ist das Siegel kunukkum auch im Zusammenhang mit Männern belegt. ${ }^{1176}$ Eine Zuordnung zu einer Gottheit, wie sie im besagten Brief angegeben wird, ist sonst nicht belegt. ${ }^{1177}$

Der ,große Stein des Šamaš“ $\left(\mathrm{na}_{4}-\mathrm{gal}{ }^{\mathrm{d}} \mathrm{Utu}\right)$ ist nur zweimal in Tell edDēr bezeugt und kann andernorts in den Kontext von Rechtseiden gestellt werden. ${ }^{1178}$ Eine entsprechende Verwendung dieses Objekts ist auch im $\mathrm{Zu}-$ sammenhang mit den parșum von Sippar zu erwägen. Bezeichnend ist hier, dass die Vergabe dieses Objekts im Verantwortungsbereich des gala-mah der Annunītum lag. Abgesehen von der Verbindung zu Rechtssprüchen könnte hier auch ein Bezug zur Rolle des Sonnengottes Šamaš im Totenkult hergestellt werden. ${ }^{1179}$

Nach der Rekonstruktion von Tanret und Van Lerberghe waren an der Organisation der parșum insgesamt drei Parteien beteiligt, denen der gala-mah der Annunītum als oberste Verwaltungsinstanz vorstand. ${ }^{1180}$ Diese wurden von der oder dem Ausführenden, vom Garanten und von einem Protektor gebildet. Da die Ausführenden jeweils nur einmalig belegt sind, wird vermutet, dass sie die parșum nur einmal ausführten. ${ }^{1181}$ Meist sind es Ehefrauen oder Schwestern hoher Beamter, seltener auch Männer. Auch Ilša-ḩeg̃alli, die Frau des galamah Inana-mansum führte ein parșum aus, wofür sie von ihrem Ehemann reich beschenkt wurde. ${ }^{182}$ Die übrigen Parteien sind meist Priester oder Palastangestellte von hohem Rang. Die Ausführenden hatten eine Summe an Silber für die im Ritual verwendeten Opfermaterialien zu zahlen. Der Garant stand für die Zahlung eines Restsilbers in Form einer Steuer zur Verfügung. Diese Zahlung wurde als Schuldverhältnis an die verantwortliche Instanz verstanden und in Form der oben beschriebenen parsum-Abrechnungen notiert. Über das empfangene Silber verfügte die Tempeladministration. Das gezahlte Silber galt als Steuer, die von hohen Beamten des Königs verwaltet wurde. ${ }^{1183}$

Zusammenfassend lässt sich für die parșum von Sippar unter der Oberaufsicht des gala-mah feststellen, dass sie verschiedene Ämter oder Verpflichtungen im Kult betrafen, die den Ausführenden einen besonderen Status zuwiesen. So

\footnotetext{
1176 Tanret/Van Lerberghe 1993, 441.

${ }^{1177}$ Möglich, dass in allen Fällen das Siegel der Inana gemeint ist, im Gegensatz zum na a $_{4}$-gal des Šamaš.

1178 Richter 2004, 346; Tanret/Van Lerberghe 1993, 441.

${ }^{1179}$ Eine solche Verbindung liegt in der altbabylonischen Šamaš-Hymne bei Cohen 1977 vor.

${ }^{1180}$ Tanret/Van Lerberghe 1993, 443-449.

${ }^{1181}$ Zur Auswahl der Ausführenden möglicherweise durch die Götter in Form von Opferschauen, s. Tanret/Van Lerberghe 1993, 440; vgl. a. den Brief MHET I/1, 74.

${ }^{1182}$ Di 1804 (Aș 5) bei Janssen 1992, 32-33, 42-43.

${ }^{1183}$ Tanret/Van Lerberghe 1993, 447-449; Yoffee 1998, 322-323.
} 
können Frauen wie Männer als Begleiterinnen von Götterreisen, Prozessionen und Bestattungen, oder auch Träger und Verwahrer verschiedener Kultobjekte für eine gewisse Zeit im Dienst einer Gottheit eine bedeutende religiöse Position erlangen. Um diesen Rang zu erlangen, wurden sie von der organisierenden Instanz erwählt und hatten dann eine Abgabe an ihre Institution zu leisten. $\mathrm{Ob}$ einige der parșum möglicherweise auch auf private Rituale aus dem Alltag eines Einzelnen zu beziehen sind, lässt sich aufgrund der noch zu wenig verständlichen Bedeutungen der einzelnen Termini nicht feststellen.

\subsection{Musiker bei parșum-Kulten}

Die Organisation und Durchführung der parșum von Sippar integrierte sehr häufig Musiker, vor allem Vertreter des gala-Priesterstands aber auch wie bereits oben vermerkt nar-sa, die Saiteninstrumentalisten. Die Aufsicht über diese Rituale am Tempel der Annunītum hatte der gala-mah inne. Darüber hinaus sind gala-mah auch anderer Tempel sowie gala mehrfach Garanten für parșum-Rituale. Es fällt auf, dass sie häufig im Zusammenhang von rēdûtum und harimūtum genannt werden. ${ }^{1184}$ Die Beteiligung der Priester beschränkt sich in diesen Fällen allerdings auf den organisatorischen Bereich.

Anders verhält es sich mit den nar-sa, die zur Teilnahme an verschiedenen parșum der Göttinnen Șarpanītum und Tašmētum entlohnt wurden. Die parșum mit Namen ru'ūtum, rédûtum und diejenigen zu den Objekten qulmû und kunukkum wurden demnach auf Saiteninstrumenten begleitet.

\subsubsection{Klagefeiern für Annunitum und ihren Kreis}

Die Tafel MHET I/1, 63 (Ad 2) aus dem Archiv des Ur-Utu verbucht Getreide, das von zwei hohen Staats- bzw. Tempelbeamten (zabardabbî und galukkin-na) zur weiteren Verteilung an die Götter und das Personal des Annunitum-Tempels ausgegeben wurde: ${ }^{1185}$

„Liste des zabardab- und des [galukkina-]Funktionärs,

welche Lalûtum, die Frau von Utu-man[sum], das Getreide empfangen ließen.“"186

Die Liste bezieht sich auf ein Opferfest der Annunītum und ihren Kreis. Zur Person der Lalûtum, Gattin des Utu-mansum, sind sonst keine Daten bekannt.

Besonderes Interesse verdienen die Namen der Hauptgötter im Kreise der Annunitum, die in den ersten Zeilen vor den Tempelbeamten angegeben werden:

\footnotetext{
${ }^{1184}$ MHET I/1, 65:2-3.17-18.26-27 gala-mah des Marduk und der Bēlet Bābilim und im Brief CT 48, 45 der Bruder des Utu-mansum Huzālum.

$1185 \mathrm{Zu}$ beiden Funktionären s. Charpin 1986, 235-240; zum gal-ukkin-na/mu'irru(m) als Verwalter der Palastwirtschaft s. a. Dombradi 1996, 251-252.

${ }^{1186}$ MHET I/1, 63:1-3 (Ad 2).
} 
T 55: MHET I/1, 63:5-14

5. Verköstigung der Annunītum

Inana Ulmašìtum

Inana

Ninigizibara

gala-mah der Annunītum

10. sa g̃ ga der Annunītum

Söhne des gala-mah

Brüder des gala-mah

Aufseher des zabar-dab 5 und des gal-ukken-na-Funktionärs

Ehefrau des gala-mah

Neben der Hauptgöttin des Tempels von Sippar Amnānum werden unter den empfangenden Gottheiten weitere Erscheinungsformen der Inana einbezogen. Der Kult der Ulmašìtum, die im Tempel E'ulmaš neben Annunītum von Sippar verehrt wurde, ist bereits Ur III-zeitlich dokumentiert. ${ }^{1187}$ An vierter Stelle erscheint Ninigizibara, das bekannte Stier-balag̃ $\left(\mathrm{gu}_{4}\right.$-balag̃ $)$ der Inana. Der schließlich in Zeile neun ohne Namen genannte gala-mah der Annunītum ist aufgrund des Datums der Tafel mit Inana-mansum, dem Vater des Ur-Utu, zu identifizieren. Bezeichnend ist auch, dass die gesamte Familie des gala-mah an den Ausgaben beteiligt wird.

Im Anschluss folgt die Auflistung von über 65 verheirateten Frauen und Töchtern und nur wenigen Männern, die alle namentlich genannt werden. ${ }^{1188}$ In Zeile 33 wird eine weitere Ehefrau eines unbekannten gala-mah angegeben, der möglicherweise an einem anderen Tempel Sippars amtierte. ${ }^{1189}$

Die Inhalte der Tafel lassen keine Rückschlüsse auf eines der bekannten jährlichen Annunītum-Feste zu. Die Liste datiert zum 30. des Monats xi. Der 30. Tag eines Monats gilt, wie Van Lerberghe bemerkte, als Festtag des Mondgottes Nanna/Sîn. ${ }^{1190}$ Dieser so genannte 'Schwarzmondtag', der Tag vor dem Erscheinen des Neulichts, galt als Unglückstag. Nach Ur III-zeitlichen Belegen wurde an diesem Tag monatlich einem vergöttlichten bala g̃ geopfert, wofür auch ein gala-mah zuständig war. ${ }^{1191}$ Aus selbigem Anlass wurden auch vermehrt Klageriten ausgeführt, an denen gala teilnahmen. ${ }^{1192}$ Beim empfangenden Personal der Sippar-Liste MHET I/1, 63 fällt zudem auf, dass mit Ausnahme des sag̃g ga, des gala-mah und weniger Männer am Ende vornehm-

\footnotetext{
${ }^{1187}$ Sallaberger 1993, 198.

${ }^{1188}$ Vgl. MHET I/1 S. 87-89.

${ }^{1189}$ Der einzige mir bekannte gala-mah in Sippar, der zur Zeit des Ammiditana aktiv war, ist Dig̃ir-šaga.

${ }^{1190}$ MHET I/1 S. 90.

${ }^{1191}$ Sallaberger 1993, 297-298.

${ }^{1192}$ Heimpel 1998, 13-16 auch zu den balag̃-Klageriten mit Stadtumrundung.
} 
lich Frauennamen notiert sind. Ähnlich setzen sich die Beteiligten in den parșum-Rituallisten CT 4, 8b an Tašmētum und CT 45, 84 an Șarpanìtum zusammen. ${ }^{1193}$ Dort folgen jedoch auf die Ausgaben an die jeweilige Göttin nur der sag̃ g̃a des Marduk und seine Familie. ${ }^{1194}$

Die Einbeziehung der bala g̃ -Gottheit Ninigizibara in Ritualfeste der Inana ist für die altbabylonische Zeit mehrfach bezeugt. ${ }^{1195}$ Ur III-zeitlich wurde ihr vornehmlich bei Klagefeiern geopfert. ${ }^{1196}$ Es könnte daher zu vermuten sein, dass der Hintergrund der hier notierten Ausgaben an Annunitum und ihren Kreis ein Klageritus unter der Aufsicht des gala-mah war. Gerade bei Kulten um weibliche Gottheiten sowie aus Anlass von Klagen ist auch andernorts eine starke Beteiligung von Frauen zu beobachten. ${ }^{1197}$

\subsubsection{Ein Fest zum Eintreten der Annunitum}

Die Opferrationenliste OLA 21, 4 (Ae 28) führt Ausgaben zu einem Fest der Annunitum, dessen Anlass in der Kopfzeile wie folgt angegeben wird:

T 56: OLA 21, 4 (Ae 28) 1-3

„Nachtwache der 'Opferschau-Weisungen',1198, die beim 'Eintreten der Göttin' an die $\mathrm{gudu}_{4}$-Priester und die érib bïtim-Funktionäre des Annunītum-Tempels ausgegeben wurden. Das, was Sîn-imguranni, Sohn des Ibni-Amurrum, gegeben hat." 1199

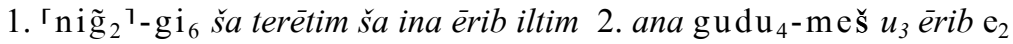
Annunitum innaddinu 3. ša Sîn-imguranni dumu Ibni- ${ }^{\mathrm{d}} \mathrm{M}$ a r-t u iddinu

Die in der Liste aufgeführten Rationen wurden von Sîn-imguranni für die Veranstaltung des Annunītum-Festes aus Anlass des 'Eintretens der Göttin' ausgegeben. Sîn-imguranni, Sohn des Ibni-Amurrum war in Sippar wohl eine einflussreiche Persönlichkeit im Besitz von Immobilien in der Nähe des Annunītum-Tempels. ${ }^{1200}$ Über den Ausdruck des „Eintretens“ wird ein konkreter kultischer Akt auch im Rahmen größerer Festrituale bezeichnet, der für An-

${ }^{1193}$ Eine weitere Rationenliste, die allerdings ausschließlich Frauen nennt, ist MHET I/1, 52. Es handelt sich um Ausgaben des $a b a b d \hat{u}$, es wird kein Anlass bekannt.

${ }^{1194}$ CT 4, 8b:5-9 (Ad 13); CT 45, 84:4-8 (o.D.).

${ }^{1195}$ Zum Ištar-Ritual von Mari s. Durand/Guichard 1997; vgl. Heimpel 1998-2001a, 382-384.

${ }^{1196}$ Sallaberger 1993, 88, 220-221.

${ }^{1197}$ S. hier die Larsa-Ritualliste Kapitel 9.2.3.

${ }^{1198}$ So nach AHw 1350a sub B und Westenholz/Westenholz 2006, 67:41 „Night vigil disbursements for the oracles ....". Anders Sallaberger 1993, 204 Teritum-Fest nach einem bisher nur

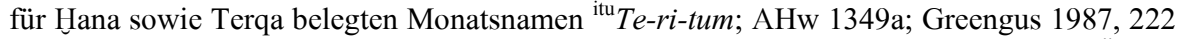
Anm. 54; s. a. Wilcke apud Sallaberger 1993, 204 Anm. 971 „Nachtgabe für Ämter (têrêtim). ." nach AHw 1350a sub A 2d).

1199 Vgl. Sallaberger 1993, 204.

${ }^{1200}$ In MHET II, 895 (Ad 34) ist er Hausbesitzer und Zeuge. 
nunītum Ur III-zeitlich in Ur, altbabylonisch auch für andere Götter in Mari, in Larsa sowie in einem Marduk-Ritual unbekannter Herkunft bezeugt ist. ${ }^{1201}$ Das in Ur unter Königin Šulgi-simtī für die Annunītum und Ulmašītum veranstaltete 'Fest des Eintretens' stand mit dem jährlichen Elūnum-Fest im zweiten und dritten Monat in Zusammenhang. ${ }^{1202}$ In den dritten Monat datiert auch die hier besprochene Rationenliste, sodass der Text möglicherweise auf dieselbe Zeremonie zu beziehen ist. ${ }^{1203}$ Das Fest fand als Nachtopfer statt, worin sich wiederum Parallelen zu den Ritualfesten aus Larsa zeigen. ${ }^{1204}$

An diesem Fest nahmen auch Musiker teil. Erster Rationenempfänger ist ein gala-mah, dessen Name allerdings nicht angegeben wird. Ihm folgen ein 'Aufseher der kulmašitum-Frauen', eine Gruppe von nar-sa-Musikern sowie eine Gruppe von gala-Priestern. Da die Tafel in die Regierungszeit des Abi'ēšuh datiert, könnte der gala-mah mit Sîn-mušallim, dem Vorgänger des Inana-mansum am Tempel der Annunitum zu identifizieren sein.

Im Vergleich zur Larsa-Ritualliste sind weitere Beobachtungen zu machen. Der Eintritt der Gottheit fand nach beiden Texten am Abend zur Nachtwache statt. Aus diesem Anlass wurden in Larsa von nar-Musikern Klagen vorgetragen. Dass auch zum 'Eintreten der Annunitum' Klagen stattfanden, ist aufgrund der beteiligten gala und gala-mah nahe liegend. Dieselben Priester könnten auch Räucherungen ausgeführt haben, wie es bei den Larsa-Festen der Götter Utu, Inana und Ninegala der Fall war.

Im Unterschied zu Larsa nahmen hier nar-sa teil, ihre Musik war im Gegensatz zu den nar der tassistum-Klagen instrumental. Auch die beteiligten Frauengruppen sind unterschiedlich. Anstelle der bei Inana und Nanaja anzutreffenden /tigi/-Frauen oder kezrētum, waren beim Fest der Annunìtum kulmašiātum beteiligt. Die kultischen Aufgaben dieser Frauengruppe sind bislang unbekannt. Im Kontext von Klageriten könnte zu erwägen sein, ob sie möglicherweise im Beisein des gala-mah und der gala einen Chor der 'Klageweiber' gestellt haben.

\footnotetext{
${ }^{1201}$ S. Diskussion und Belege hier Kapitel 9.2.3.1.

${ }^{1202}$ Sallaberger 1993, 203-204.

${ }^{1203}$ Sallaberger 1993, 201-204 unerscheidet zwei Feste des Eintretens bzw. Einzugs, anders Cohen 1993, 138-139. In Mari ist auch ein Fest des Auszugs (wașûm) der Annunītum belegt; Charpin 1984, 87:23, 91:48.

${ }^{1204}$ Westenholz/Westenholz 2006, 24-25 mit Belegen zu ni $\tilde{\mathrm{g}}_{2}-\mathrm{gi}_{6}$ „Nachtwache“; Van Lerberghe 1986, 2 nimmt weiterhin an, dass dieser Text im Zusammenhang mit einer Götterreise steht, doch deutet im Text nichts darauf hin.
} 


\subsubsection{Rituale und Kultprozessionen am Marduk-Tempel}

Wertvolle Daten zur Beteiligung von Musikern und der konkreten Ausführung von Musikdarbietungen zu Kultfesten am Tempel des Marduk sind zum einen der Opferrationenliste CT 45, 85 (o.D.) sowie der von Wasserman 2006 publizierten Ritualliste BM 29638 zu entnehmen. ${ }^{1205}$ Die Opferrationenliste CT 45, 85 (o.D.) verweist auf ein Festritual mit begleitender Prozession, die für Marduk in Sippar stattfanden. ${ }^{1206}$

1205 Eine einheitliche Gruppe bilden weiterhin drei undatierte Sippar-Listen, die mehrfach namenlose gala-mah nennen, die Bierrationen erhalten: CT 45, 77:i 6.9.11.13.15.ii 8 (o.D.); CT 45, 89:2 (o.D.); JCS 2, 38 Nr. 30:6.3'.7 (o.D.); es bleibt allerdings unklar, zu welchem Zweck diese Ausgaben stattfanden.

${ }^{1206}$ Die Tafel wird im Allgemeinen in die aB Zeit datiert, s. allerdings CAD T 312 sub teb̂ $3 \mathrm{~d}$ ) MB? im Gegensatz zu ibid. 429 tìru A sub c) OB. 
CT 45, 85 (o.D.): Kommentar:

Zeile 6: tìru: nach CAD T 429 tìru A ,courtier, attendant“; nach George 1997 auch Eunuch.

Zeile 7: Lesung nach CAD K 107 sub kalûtu; ausführlich dazu hier Kapitel 9.6.2.5.

Zeile 9: tereș qātim als „Handausstrecken“ (vgl. AHw 1349; CAD T 427 sub b) verweist hier auf die Ausführung eines Gebets. Auch wenn man versucht ist, an die Šu'ila aus dem Repertoire des gala zu denken, liegt hier kein Hinweis auf die Gebetsgattung vor; belegt ist sie möglicherweise über sekundäre literarische Textpassagen bereits seit der Larsa-Dynastie, s. Sjöberg 1960, 178 Anm. 1.

Zeile 10: Emendiert nach CAD T 217 tarāšim ,when bread was to be made into loaves“; Grundbedeutung von qarāšu ist ,zerschneiden“(von Fleisch) oder ,zersplittern“(von Holz); s. AHw 903. Im Zusammenhang mit Brot ähnlich ,zerteilen“; vielleicht ein rituelles Mahl im Sinne des 'Brotbrechens'(?).

Zeile 14: Sind hier Tore unterschiedlicher Göttertempel gemeint?

Zeile 17: Die Ausgabe findet sicher zum Anlass eines Schütt- oder Brandopfers (sirqu) statt, angesichts des für ein ${ }^{\text {zid3 }}$ ma-ad-g̃ a 2 akk. mașhatum bestimmten Mehls; gegen CAD S 317 sirqu B (or zirqu) mng unkn. ist $\mathrm{ZI}_{2}$ hier als si/ $\mathrm{e}_{20}$ zu lesen (Borger 2003, 306:259 für Belege in aB Briefen).

Zeile 19-20: nach CAD T 312 sub tebû 3d), for those who carry 'weapons' and have been transferred (?), on the day of the departure". nukkuru als Stat. Pl. von nakāru(m) meint auch ,verändern“ oder „verkleiden?"; bei Waffenträgern wäre an kultisches Personal zu denken, es kommen huppî(m)-Tänzer (s. hier Kapitel 5.5.1) oder kurgarrû(m) (hier Kapitel 6.3.1) in Frage; mit 'Veränderter' oder 'Verkleideter' könnte ein Gaukler gemeint sein, im Beisein von kurgarrû(m) wäre an den assinnu zu denken; für Sippar ist lediglich in CT 47, 80:36 ein aluzinnu belegt. 


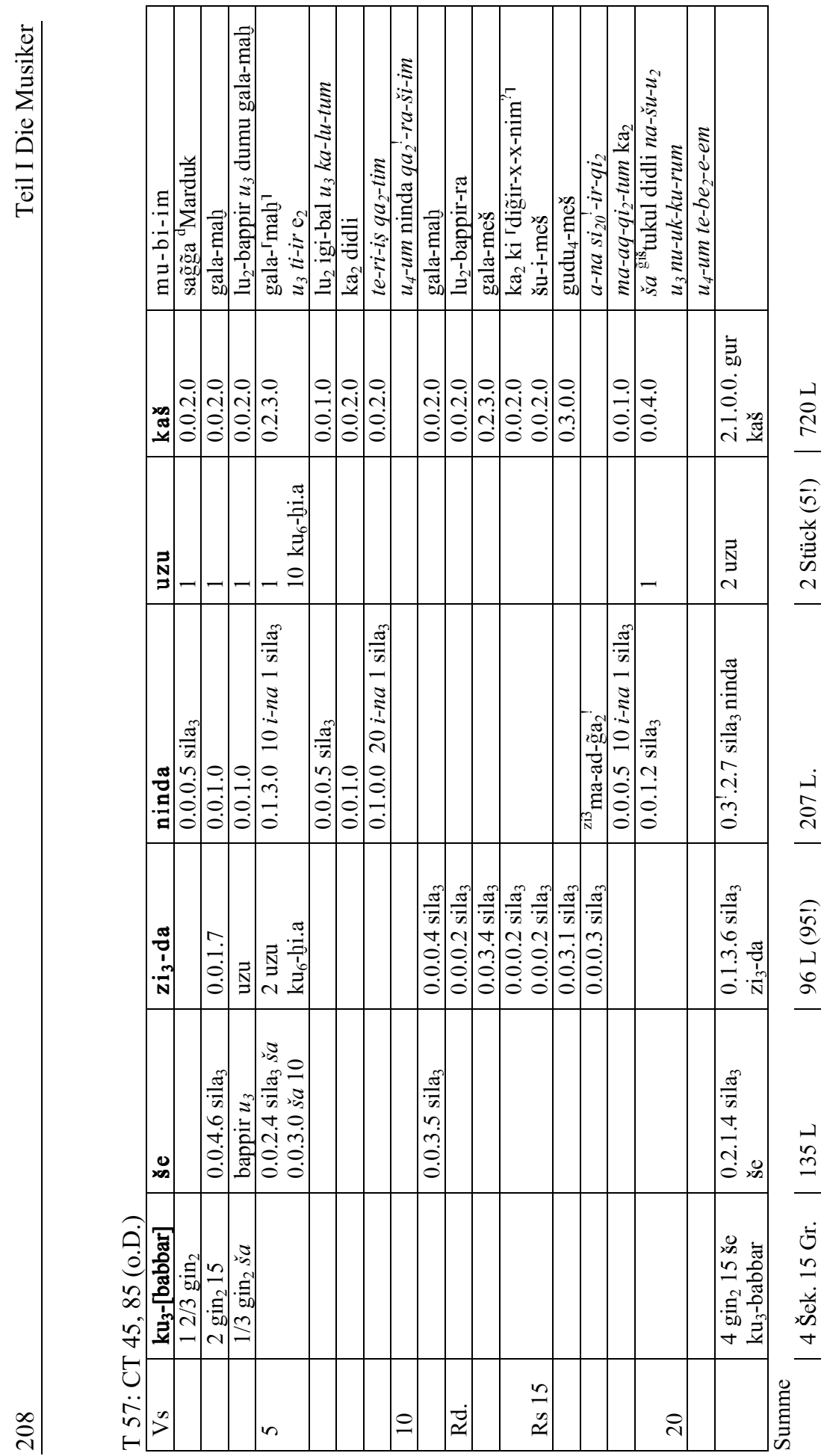


Die Liste verbucht Ausgaben über Silber $\left(\mathrm{ku}_{3}\right.$-babbar), Getreide ( $\left(\mathrm{zi}_{3}-\mathrm{da}\right)$, Brot (ninda), Fleisch (uzu) bzw. Fisch $\left(\mathrm{ku}_{6}\right)$ und Bier (kaš), die entweder an teilnehmendes Personal ausgegeben wurden oder für einzelne rituelle Handlungen bestimmt waren. Die Ausgaben galten zwei Tagen, die im Text vermerkt sind als „Tag des Brotbrechens(?)“ (Z. 10) und „Tag des Aufbruchs" (Z. 21). An diesen zwei Tagen fanden Gebetshandlungen und Schüttopfer statt, die unter anderem an nicht näher definierten Toren von Tempeln und der Stadt ausgeführt wurden. Unter den Beteiligten wird mehrfach ein gala-mah, der Sohn eines solchen sowie eine weitere Gruppe von galaPriestern genannt. Namen werden nicht angegeben. Erster Empfänger ist ein sag̃ g̃a des Marduk, die Kulthandlungen sind damit an den Tempel des Marduk $\mathrm{zu}$ verorten. Weitere bekannte Teilnehmer sind die Barbiere und $\mathrm{gudu}_{4}$ Priester. Ungewöhnlich ist hingegen der Eunuch (tïr bittim), der neben einem gala-mah genannt wird. Welche Personen sich hinter den Ausdrücken Waf-

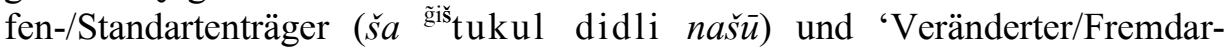
tiger?' (nukkurum) verbergen, lässt sich nur mutmaßen. Da es sich hier offensichtlich um ein religiöses Fest mit Prozession handelt, wären hier Tänzer und Gaukler wie huppî und aluzinnu oder anderes Kultpersonal wie kurgarrû oder assinnu zu vermuten.

Für den ersten Tag sind Brotgaben zu einer Gebetshandlung sowie Libationen (Z. 7) an mehreren Toren verzeichnet, die sich möglicherweise alle im Komplex des Marduk-Tempels befanden. Der zweite Tag des 'Aufbruchs' meint wohl eine Kultprozession, in deren Verlauf die Tore verschiedener Göttertempel besucht wurden $\left(\mathrm{ka}_{2}\right.$ ki di g̃ir x x[unklar']).

Da gala-mah und gala beteiligt sind, vermute ich für den Anlass der Ausgaben die Ausführung eines Klageritus mit Stadtumzug. ${ }^{1207}$ Unklar bleibt allerdings, für welche Gottheiten des Marduk-Tempels der Umzug veranstaltet und an welchen Tempeltoren Station gemacht wurde. Alle genannten Priester, aber auch die möglicherweise beteiligten Kulttänzer oder Gaukler sind, mit Ausnahme von kurgarrû und assinnu, keiner spezifischen Gottheit zugeordnet.

Der bisher einzigartige von Wasserman 2006 publizierte Ritualtext BM 29638 beschreibt Kulthandlungen, die am 'Tag, an dem Marduk eintritt' (ina ümim ša Marduk irrubu) ausgeführt wurden. ${ }^{1208}$ Dieser 28-zeilige Text bleibt allerdings schwer zu deuten, da er keinem bisher bekannten Formular für Ritualausgaben oder -handlungen entspricht. Die Herkunft des Textes ist unbekannt. ${ }^{1209}$ Da das

\footnotetext{
${ }^{1207} \mathrm{Zu}$ Klagekultumzügen (z. B. $e_{2}$ uru $^{\mathrm{ki}}$ nig̃in-na) unter Beteiligung von balag̃-Instrumenten und gala-Priestern s. hier Kapitel 11.2.2 und zu den Ur III-zeitlichen Belegen Heimpel 1998.

${ }^{1208}$ Wasserman 2006, 201:1.

${ }^{1209}$ Wasserman 2006, 207-208 vermutet eine Herkunft aus Babylon allerdings mit südbabyloni-
} 
Ritual dem Gott Marduk galt, soll er dennoch in diesem Zusammenhang kurz vorgestellt werden.

Der Text nennt zwar explizit keine Musiker, in ihm finden sich jedoch konkrete Anweisungen zum Vortrag von Gesängen. Die beschriebenen Handlungen fanden insgesamt an drei Tagen statt, am letzten Tag wurden auf dem Dach ein Tempelpreislied (zamār alälim ša bìtätim) und eine tassistum-Klage vorgetragen. ${ }^{1210}$ Hier sind mehrere Parallelen zur Larsa-Ritualliste zu beobachten. Auch dort werden von den tigiätum möglicherweise Preislieder gesungen und rhythmisch begleitet, neben den nar tassistum, die ihre Klagen vortrugen. Das Ritual beinhaltete wohl auch eine Kultreise, da mehrere Schiffer und das Boot für den Transport des Gottes genannt werden. Es stellt sich allerdings wiederum die Frage, ob der Gott in seinen eigenen Tempel eintritt oder einem anderen Göttertempel oder Palast einen Besuch abstattet. Zudem bleibt der Anlass des Rituals unbekannt. ${ }^{1211}$

\subsection{Dilbat}

Der altbabylonische Ort Dilbat wird mit dem heutigen Tell ad-Deylam identifiziert, welcher etwa $30 \mathrm{~km}$ südlich der Stadt Babylon zwischen den Euphratarmen Hilla und Hindiya gelegen ist. Seine Identifizierung basiert hauptsächlich auf schriftlichen Quellen, unterstützt wird sie zudem durch einen aus Tell adDeylam stammenden Schatzfund aus spätaltbabylonischer Zeit. ${ }^{1212}$

Von den etwa 400 altbabylonischen Dilbat-Texten kam nur ein geringer Teil in der Siedlung selbst zutage. Der größere Teil wurde im Kunsthandel erworben und kann aufgrund inhaltlicher Kriterien diesem Ort zugeordnet werden. Die Texte sind größtenteils in Veröffentlichungen zugänglich, eine detaillierte Zusammenstellung des Textmaterials aus Dilbat liegt bisher nur für die spätaltbabylonischen Urkunden und Briefe vor. Basierend auf Inhalt und Prosopographie kann dieses Textkorpus in mehrere Archive gruppiert werden. ${ }^{1213}$ Bekannt ist Dilbat vor allem auch aufgrund des Archivs einer Tochter des Ammișaduqa, das Informationen zur Dattelpalmwirtschaft und Vergabe von Opfern in Dilbat und Umgebung enthält. ${ }^{1214}$

\footnotetext{
schen Ursprüngen.

${ }^{1210}$ Wasserman 2006, 201:15-18; gegen ibid. interpretiere ich zamar alālim als Preislied.

${ }^{1211}$ Vgl. Wasserman 2006, 208-210.

${ }^{1212}$ S. a. Pientka 1998, 409-410.

${ }^{1213}$ Veröffentlichung der meisten Dilbat-Texte in VS 7 und YOS 13. Zu Archivzusammenhängen s. Klengel 1976, 67-84 und Stol 1973, 224-228.

${ }^{1214}$ Pientka 1998, 311-312, 409; Charpin 2004, 431-432 mit Bibliographie.
} 
Die Dilbat-Texte datieren in die Zeit der ersten Dynastie von Babylon und umfassen damit einen Zeitraum von etwa 260 Jahren. Der Hauptteil dieser Texte stammt aus der Zeit der Könige Hammurabi und Ammișaduqa. Über Bauarbeiten in Dilbat wird in Jahresdatenformeln der frühen babylonischen Könige berichtet. ${ }^{1215}$ Erst zur Zeit der ersten babylonischen Dynastie nimmt die Bedeutung dieser Siedlung aufgrund ihrer landwirtschaftlich günstigen Lage $\mathrm{zu}$.

Der letzte Text aus Dilbat trägt das Datum des Jahres Samsuditana 6, ${ }^{1216}$ doch ist das historische Ende dieser Siedlung bisher unbekannt. Die jüngsten Ausgrabungen in Tell ad-Deylam wurden 1989 geführt, hierbei kamen jedoch keine weiteren textlichen Funde für die altbabylonische Zeit zutage. ${ }^{1217}$

Stadtgott von Dilbat ist Uraš, eine Kriegergottheit, die in jüngeren Epochen auch dem Ninurta gleichgesetzt wird. ${ }^{1218}$ Bereits in altbabylonischen Texten, doch vornehmlich im ersten Jahrtausend, wird dem Uraš Ninegala als seine Gattin zur Seite gestellt. Der Gott Uraš entstammt nordbabylonischen Traditionen, in Mittel- und Südbabylonien wird er kaum verehrt. ${ }^{219}$ Sein Tempel mit Namen E'ibbiānum „Haus, von Anum berufen“ ist in altbabylonischen Urkunden indirekt über das Tempelpersonal belegt. ${ }^{1220}$ Von seiner Restaurierung berichtet die Jahresdatenformel Sabium 9, ansonsten sind zu diesem Tempel in altbabylonischer Zeit keine Daten bekannt. ${ }^{1221}$

Weitere Tempel in Dilbat und seiner Umgebung sind für die Gottheiten Šamaš, Adad, Inana/Ištar, auch unter ihrer Erscheinungsform Urkitum (Inana von Uruk), Nanaja und möglicherweise auch für Marduk nachweisbar. ${ }^{1222}$ Der Tempel des Šamaš steht vielfach im Zusammenhang mit Darlehensvergabe und Angelegenheiten der Palastwirtschaft.

In politischer Hinsicht spielte Dilbat zur altbabylonischen Zeit eine eher untergeordnete Rolle. Bereits in den Anfängen der ersten babylonischen Dynastie wird sie in deren Herrschaftsbereich eingegliedert. Für die Landwirtschaft nimmt die Siedlung Dilbat und das umliegende Land dennoch eine wichtige Position ein. Nach den Inhalten der Dilbat-Texte war das Gebiet um diese Stadt Hauptproduzent und -lieferant von Agrarprodukten für den gesamten babyloni-

\footnotetext{
${ }^{1215}$ Horsnell 1999/2, 46 (Sa 9), 70 (Sb 9); die früheste politische babylonische Kontrolle fand nicht vor S1 12 statt.

${ }^{1216}$ Gasche 1989, 124.

1217 Armstrong 1992, 220-221.

1218 Black/Green 1992, 182.

${ }^{1219}$ Richter 2004, 368-369, 401 auch zu Uraš in Larsa.

${ }^{1220}$ George 1993, 102:493; Pientka 1998, 459 zum sag̃ g̃a des Uraš.

${ }^{1221}$ Sabium 9: mu e $e_{2}-i-b i-a-n u-u m$ mu-un-gibil „Jahr: Er erneuerte das Eibbiānum“; Horsnell 1999/2, 70:59.

1222 Pientka 1998, 460-461.
} 
schen Raum. ${ }^{1223}$ Die Organisation dieser Agrarproduktionslandschaft oblag einem staatlichen Beamtenapparat. Ein Teil der in der Stadt Dilbat und ihrer Nachbarorte gelegenen Ländereien und Felder war an Personen aus dem militärischen Bereich vergeben, welche hauptsächlich in Privaturkunden erwähnt werden.

Hinweise zu einer Tempelverwaltung sind in den Dilbat-Texten nicht enthalten. Bis auf wenige Darlehensurkunden von Tempelangestellten sowie Belegen zu Priesterberufen in Zeugenlisten enthalten die Texte keine Aussagen zur Organisation des Tempelpersonals.

In 12 Texten aus Dilbat werden Vertreter der Musikerberufe gala und nar genannt. Trotz dieser geringen Anzahl an Textbelegen sind in ihnen insgesamt drei gala-mah namentlich vertreten. ${ }^{1224}$

\subsubsection{Die gala-mah von Dilbat}

Alle drei für Dilbat belegten gala-mah mit Namen Marduk-muballiț, Lugalzi-mansum und Warad-Ešurrītum stammen aus Texten der spätaltbabylonischen Zeit.

Der gala-mah Marduk-muballit ist Empfänger von Arbeitern und Zeuge auf einem Darlehensvertrag. ${ }^{1225}$ Beide Urkunden datieren in das Jahr Ammiditana 30. Die in VS 7, 57 verzeichneten Personen wurden bei Erntearbeiten eingesetzt. Auch der Schuldschein VS 7, 58 (Ad 30) betrifft Arbeiter, über die ein gewisser Warad-Kūbi aus Suhûm eine Schuld aufweist. ${ }^{1226}$

Der zweite namentlich belegte gala-mah Lugal-zi-mansum ist für die Jahre Ammiditana 34 und Ammișaduqa 11 bezeugt. Er ist Zeuge zweier Darlehensurkunden, die Getreideausgaben des Palastes notieren. ${ }^{1227}$ Die ältere dieser zwei Urkunden YOS 13, 289 gibt ihn als Sohn des Ilī-erībam jedoch ohne Priestertitel an. ${ }^{1228}$ Die zweite Urkunde VS 7, 94 (Aṣ 11) notiert eine Getreidevorauszahlung an seinen Sohn Awīl-Sîn, die dieser zur Erntezeit zurückzuzahlen hatte. Das Siegel des Lugal-zi-mansum ist auf beiden Urkunden erhalten, seine vollständige Titulatur findet sich auf der Tafel VS 7, 94 (Aṣ 11): „Lugalzi-ma[nsum], Sohn des Ilī-erī[bam], Diener der Nin[egala?]““. ${ }^{1229}$ Dass diese beiden Urkunden denselben Lugal-zi-mansum nennen, ist aufgrund der Filiati-

\footnotetext{
${ }^{1223}$ Pientka 1998, 449-450.

${ }^{1224}$ Alle hier vorgestellten Belege wurden bereits von Pientka 1998, 461-462 zusammengetragen.

${ }^{1225}$ VS 7, 58:5 (Ad 30); VS 7, 57:3 (Ad 30).

${ }^{1226}$ Pientka 1998, 266.

${ }^{1227}$ Zur Person der ausgebenden Institution vertreten durch Marduk-muballit abi șābim s. Yoffee 1977, 66-68.

${ }^{1228}$ YOS 13, 289:12 (Ad 34); s. a. Yoffee 1977, 63-64.

1229 VS 7, 94 (Aș 11) Siegel A: 1. Lugal-zi-ma-[an-sum] 2. dumu $I_{3}-l i_{2}-e-r i-[b a-a m] 3$. ir $_{3}$ ${ }^{d}$ Nin-[e $e_{2}-$ gal(-1a)]; s. a. YOS 13 S. 89:29. Die Ergänzung des GN lehnt sich an das Pantheon von Dilbat an. Mit Ausnahme der Ninegala sind für Dilbat keine Gottesnamen mit NIN attestiert; zum Inhalt der Urkunde s. a. Klengel 1976, 87.
} 
on anzunehmen. ${ }^{1230}$ Ein Tempel der Göttin Ninegala ist altbabylonisch in Dilbat zwar nicht attestiert. ${ }^{1231}$ Dennoch wird sie in einer umfangreichen Opferrationenliste aus Dilbat unter dem Namen Šarrat Dilbat „Königin von Dilbat“ mit Opferrationen bedacht, wodurch ihr Kult bereits altbabylonisch in Dilbat nachgewiesen ist. ${ }^{1232}$ Der Sohn dieses gala-mah mit Namen Awīl-Sîn wird in einer weiteren Darlehensurkunde aus derselben Textgruppe als gala ausgezeichnet. ${ }^{1233}$ Auch hier zeigt sich wiederum, dass der Beruf des gala-Priesters innerhalb der Familie weitertradiert wurde.

Der dritte für Dilbat belegte gala-mah Warad-Ešurrītum ist mit vollständigem Titel nur einmal auf einer Samsuditana-zeitlichen Urkunde bezeugt. Diese Urkunde YOS 13, 329 (Sd 3) quittiert den Empfang von Silber durch den gala-mah, welches ihm der Opferschauer (barû $(m))$ ausgibt. ${ }^{1234}$ Die Ausgabe gilt der Bestärkung einer Zusage des Opferschauers, deren Inhalt unbekannt bleibt. ${ }^{1235}$ Nach Belegen aus Sippar pflegten gala-mah ein enges Verhältnis zu Opferschauern, die zum wichtigsten Personal eines Tempels gehörten. Für den Stadtgott Uraš ist in Dilbat die Ausführung zweier Opferschauen belegt. ${ }^{1236}$ Das Siegel des gala-mah Warad-Ešurrītum ist schlecht erhalten und lässt lediglich den Priestertitel erkennen: ,Warad-Ešurrītum, gala-mah, Sohn des . . .“.1237 Mit Ausnahme der namentlichen Verbindung zur hauptsächlich in Nordbabylonien verehrten Ištar-Erscheinung Ešurrītum kann dieser gala-mah keiner Gottheit oder einem Tempel von Dilbat zugeordnet werden. Ohne Priestertitel ist er auf zwei weiteren Empfangsquittungen über Getreide- und Silberbeträge belegt. ${ }^{1238}$ Die Texte datieren in die Jahre Ammiditana 34 und Ammișaduqa $17+\mathrm{b}$ und liegen damit zeitlich parallel zu den Belegen zum gala-mah Lugalzi-mansum (Ad 34-Aṣ 11).

Ein gala-mah ohne Namen ist schließlich Empfänger in der Ausgabenliste YOS 13, 168 (o.D. [ca. Aș17+a/+b]) über Getreide- und Silberbeträge. ${ }^{1239}$ Eine Identifizierung dieses Priesters ist auf der Basis der vorgeführten Beleglage nicht möglich.

\footnotetext{
${ }^{1230}$ Anders Pientka 1998, 201:70 + Anm. 125 .

${ }^{1231}$ Richter 2004, 368.

${ }^{1232}$ VS 7, 185 :iv 2-3 (o.D.[ca. Aṣ 17+a]); Pientka 1998, 459.

${ }^{1233}$ VS 7, 122:9 (Aṣ 16).

1234 YOS 13, 329 (Sd 3) 4. aš-šum La-pi-iš-tum mašs-šu-gid ${ }_{2}-$ gid $_{2}$ 5. qa $a_{2}$-ba-am iš-ku-nu 6. mu-DU 7. ${ }^{\mathrm{I}}$ La-pi-iš-tum $\mathrm{mašs}_{2}-\check{s ̌ u}_{-}-\mathrm{gid}_{2}-\mathrm{gid}_{2}$ 8. nam-har-ti 9. ${ }^{\mathrm{I}} \mathrm{Ir}_{3}-{ }^{\mathrm{d}} E-$ šur-ri-tum $^{-}$ 10. gala-mah „Betreff Lapištum, des Opferschauers, der zugesagt hat. Ausgabe des Lapištum, des Opferschauers. Einnahme des gala-mah Warad-Ešurritum“.

${ }^{1235}$ CAD Q 19 sub 3 qabâm šakānu.

${ }^{1236}$ Pientka 1998, 459; und Kapitel 9.6.2.2 zu den $i k r i b u(m)$ aus dem Ur-Utu-Archiv.

${ }^{1237}$ YOS 13, 329 (Sd 3) Siegel A: $\operatorname{Ir}_{3^{-}}{ }^{\mathrm{d}} E_{2}$-šur[-ri-tum] [g a]la-[mab] [du mu] ${ }^{\mathrm{d}} \mathrm{Na}-[\ldots]$

1238 YOS 13, 37:7 (Aș 17+b); BBVOT 1, 91:6.8 (Ad 34); vgl. Pientka 1998, 410:1, 440:321; letztere Urkunde dokumentiert eine kiššătum-Ablöse für Warad-Ešurrītum; AHw 492b); zu Schuldverhältnissen in Dilbat-Texten s. Klengel 1976, 84-96.

${ }^{1239}$ YOS 13, 168:15 (o.D. [ca. Aș+a+b]); Pientka 1998, 431:247.
} 
Mit Ausnahme des Lugal-zi-mansum, welcher möglicherweise der Göttin Ninegala diente, lassen sich für die übrigen gala-mah in den Dilbat-Texten keine Zuordnungen feststellen. Nach den Datierungen der Urkundenbelege amtierten einige der belegten gala-mah möglicherweise auch zeitgleich, so zumindest Warad-Ešurrìtum und Lugal-zi-mansum. Im Gegensatz zu den südbabylonischen Städten der frühaltbabylonischen Zeit können spätaltbabylonisch mehrere gala-mah-Ämter im Dienste verschiedener Hauptgötter einer einzigen Stadt stehen, wie am Beispiel Sippars zu ersehen war. Die gala-mah von Dilbat sind vornehmlich im Zusammenhang mit Angelegenheiten der Tempelwirtschaft, der Vergabe von Darlehen und der Aufsicht über Erntearbeiter belegt.

\subsubsection{Andere Musiker und Kultakteure}

Neben den drei gala-mah von Dilbat werden weiterhin zwei nar sowie zwei gala bekannt. Hammurabi-zeitlich ist nur ein einziger gala mit Namen Ninurta-mansum belegt. ${ }^{1240}$ Alle übrigen Künstler und Musiker sind auf spätaltbabylonischen Dokumenten aus der Regierungszeit des Ammișaduqa bezeugt. Die zwei nar mit Namen Warad-Kūbi und Tarïbum werden im Zusammenhang mit Erntearbeiten genannt, ${ }^{1241}$ letzterer erhielt seine Rationen möglicherweise für landwirtschaftliche Tätigkeiten. Auf den gala Awīl-Sîn, den Sohn des galamah Lugal-zi-mansum, wurde bereits hingewiesen. ${ }^{1242}$

Der unter Hammurabi belegte gala Ninurta-mansum begegnet einmalig auf der Rechtsurkunde VS 7, 149 betreffs der Schuldeinlösung seiner eigenen Person. ${ }^{1243}$ Die Urkunde, die in Anwesenheit der Versammlung von Dilbat besiegelt wurde, ist Zeugnis einer hohen Verschuldung des gala.

Neben den gängigen Musikerberufen ist in Dilbat auch anderes künstlerisches Personal attestiert. Ein hupp $\hat{u}(m)$-Tänzer mit Namen Sîn-iqī̌sam wird in einer Ausgabenliste über insgesamt 600 Liter Getreide aufgelistet. Die Hälfte der Ausgabe ging an eine Truppe (illatum) unbekannter Zuordnung. ${ }^{1244}$ Der hupp $\hat{u}(m)$ wurde am Getreide, das von einem nicht näher definierten Dachspeicher stammt, mit 60 Litern beteiligt. ${ }^{1245}$ Der Anlass der Ausgabe ist nicht be-

\footnotetext{
${ }^{1240}$ VS 7, 149:13-14 (D.a. [Ha]).

${ }^{1241}$ VS 7, 155:55 (D.a.[Ad/Aș]); TJA 94:12 (Aṣ 10); Renger 1969, 172; Pientka 1998, 462.

${ }^{1242}$ VS 7, 122:9 (As 16); s. a. Kapitel 9.7.1.

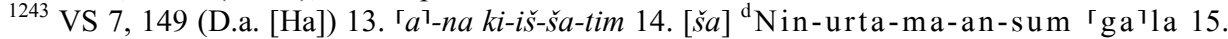
$i z$-zi-iz; der Inhalt der Tafel ist schwer verständlich; CAD K 460 1b). Zur Datierung Renger $1969,188$.

${ }^{1244} \mathrm{Zu}$ illatum „Gruppe, Truppe, Sippe, Karawane“ s. CAD I/J 82; AHw 372.

${ }^{1245}$ VS 7, 127 (Aș 17+a) 1. 1.0.0.0 še-gur il-la-tum 2. 0.2.0.0 ${ }^{\mathrm{d}} \mathrm{Nu}$-ni-tum-um-mi 3. 0.1.0.0

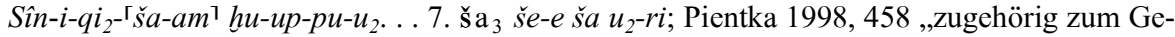
treide des Daches“.
} 
kannt. Dass es sich allerdings nicht um einen Erntearbeitsdienst handelte, zeigt das Fehlen weiterer männlicher Personen auf dieser Liste.

Auch ein aluzinnu namens Awīl-Amurrum ist unter 27 Arbeitern der Liste YOS 13, 169:9 (Aṣ 13) bezeugt. Der aluzinnu wurde hiernach zu Erntearbeiten eingezogen.

\subsection{Kiš}

\subsubsection{Historischer Hintergrund und Quellenlage}

Kiš (heute: Tell Uhaimir) ist etwa $15 \mathrm{~km}$ östlich von Babylon gelegen und wird von mehreren Ruinenhügeln umgeben, unter denen sich auch das antike Hursag̃kalama (Inġarra) befindet. ${ }^{246}$ Im Hügel von Hursag̃kalama, der das Hauptheiligtum der Ištar von Kiš beherbergte, wurde ein Großteil der für diesen Ort überlieferten administrativen Texte geborgen. Das Hauptheiligtum des Stadtgottes von Kiš, des Kriegs- und Heldengottes Zababa, war auf dem Tell Uhaimir selbst gelegen.

Vor der Einnahme und Zerstörung der Stadt Kiš durch den babylonischen König Sumula'ēl befand sich die Stadt abwechselnd im Herrschaftsbereich rivalisierender Könige Nord- und Südbabyloniens. ${ }^{1247}$ Mehrfach wurde Kiš von den südbabylonischen Dynastien in Isin und Larsa umkämpft, aber auch zahlreiche lokale Herrscher sowie Könige nordbabylonischer Dynastien hatten teilweise die Herrschaft über Kiš inne. Die Kämpfe um den Süden Babyloniens unter Samsuiluna erreichten auch die Stadt Kiš, wo es diesem babylonischen König schließlich gelang, seinen südbabylonischen Rivalen Rīm-Sîn II zu besiegen.

Der letzte Text aus Kiš datiert in das Jahr Samsuditana 13. ${ }^{1248}$ Über die Zeit nach der ersten babylonischen Dynastie berichten nur wenige Quellen, dennoch lässt sich an diesen rekonstruieren, dass die Stadt bis in die neuassyrische Zeit besiedelt blieb.

Entsprechend der Städte Nippur und Sippar mit ihren jeweiligen männlichen Stadtgöttern Ninurta und Šamaš, wurden auch dem Stadtgott Zababa nadiātumPriesterinnen geweiht, die ein $\operatorname{gag} \hat{u}(m)$ „Kloster“ bewohnten. Die Verehrung des Zababa, einer Kriegsgottheit, die spätaltbabylonisch mit Ning̃irsu und Ninurta identifiziert wird, ist bereits frühdynastisch in Kiš belegt. Als Ehegattin des Zababa galt die Göttin Inana (von Kiš), die eine bedeutende Rolle inner-

\footnotetext{
${ }^{1246}$ Edzard/Gibson 1976-80, 613-614. 618-619; Gibson 1972.

1247 Überblick zur Geschichte bei Edzard/Gibson 1976-80, 611-612; Donbaz/Yoffee 1986, 3-15; Charpin 2004, 88-89.

${ }^{1248}$ Gasche 1989, 122.
} 
halb des Kultes dieser Stadt einnahm. Haupttempel des Zababa in Kiš war das Emete-ursag̃ „Haus, einem Helden würdig“. ${ }^{1249}$ Bereits die frühesten Könige der ersten babylonischen Dynastie zeigten sich um diesen Tempel und seine Kulte besonders bemüht, Wiederaufbau und Restaurierung dieses Tempels werden in Jahresdaten der Könige Sumula'ēl (30) sowie in Inschriften des Hammurabi thematisiert. Besondere Beachtung erfährt der Kult in dieser Stadt auch durch die spätaltbabylonischen Könige. ${ }^{1250}$

Seit der Zerstörung der Stadt Uruk im Süden Mesopotamiens ist in Kiš auch der Kult der Inana von Uruk (= An-Inana) beheimatet. ${ }^{1251}$ Ein Abwandern der Priesterschaft dieser Göttin von Uruk nach Kiš konnte Charpin für das Ende der Regierungszeit des Samsuiluna nachweisen. ${ }^{1252}$ Derselben Priesterschaft gehörten auch gala-mah an, die in den spätaltbabylonischen Urkunden aus Kiš mehrfach mit Namen erwähnt werden. Der in Kiš neu erbaute Tempel dieser Göttin wird allerdings nur einmal in einer Empfangsquittung über Opferlämmer genannt. ${ }^{1253}$ Dem ursprünglichen Tempel der Inana gleichen Namens Eturkalama „Haus, Viehhürde des gesamten Landes“ sind zwei Balag̃ Kompositionen der Inana gewidmet, die auch in altbabylonischen Vertretern überliefert sind. ${ }^{1254}$ Zusammen mit Inana von Uruk wurden auch die Göttinnen Nanaja und Kanisurra, Tochter der Nanaja, nach dem Untergang Uruks in Kiš aufgenommen und kultisch etabliert. Die Einrichtung des Kultes dieser Göttinnen-Triade Inana, Nanaja und Kanisurra fällt zwischen die Jahre Samsuiluna 10 bis Abi'ēšuh $1 .{ }^{1255}$

In den Ruinenhügeln von Kiš wurden zwei reguläre Ausgrabungen durchgeführt, die über 1500 Tafeln unterschiedlichster Textgattungen zutage brachten. ${ }^{1256}$ Der größte Teil dieser Texte wurde aus einem Gelände in der Nähe der Zikkurat von Kiš geborgen und beinhaltete Briefe und Urkunden sowie verschiedene Texte des literarischen Genres. Weitere etwa 300 Tafeln, die im Kunsthandel erworben wurden, können ihrem Inhalt nach ebenfalls der Stadt Kiš zugeordnet werden. ${ }^{1257}$

\footnotetext{
1249 George 1993, 125:785; Black/Green 1992, 187 allgemein zu Zababa.

${ }^{1250}$ Sl 30, Ad 34.29, Aṣ 15; s. Horsnell 1999/2, 59.311.316.344; Frayne in RIME 4.3.6.8-9, S. 342-344.

${ }^{1251}$ Charpin 1994/39.

${ }^{1252}$ Charpin 1986, 403-418.

${ }^{1253}$ In YOS 13, 435 (Sd 13); hierzu Charpin 1986, 404; Pientka 1998, 179.

${ }^{1254}$ Uruhulake und Ašergita; Cohen 1988, 650, 704.

1255 Pientka 1998, 182-183; Charpin 1986, 411-415.

${ }^{1256}$ Genouillac 1924 und 1925; Langdon 1924, 1930 und 1934.

${ }^{1257}$ Bibliographie bei Charpin 2004, 429-430; s. a. Donbaz/Yoffee 1986, 2-3.
} 


\subsubsection{Die gala-mah}

Trotz der verhältnismäßig hohen Anzahl an Texten, die in Kiš geborgen wurden, finden sich in ihnen mit Ausnahme eines nar nur Belege zu gala-mahPriestern. Von diesen datiert nur ein einziger Beleg in die Zeit des Samsuiluna, alle übrigen gala-mah sind ausschließlich in Texten der spätaltbabylonischen Zeit belegt.

In Kiš lassen sich insgesamt drei gala-mah-Ämter nachweisen: für den Hauptgott Zababa, für Inana von Uruk (An-Inana) sowie ein Amt für die Göttin Nanaja.

Tabelle 10 gala-mah von Kiš

\begin{tabular}{|c|c|c|}
\hline Zababa & Inana Uruk & Nanaja \\
\hline \multicolumn{3}{|l|}{ Ka-Inana ${ }^{1258}(\mathrm{Si}$ ?) } \\
\hline $\begin{array}{l}\text { Mea'imriag̃u, S.d. Inana-zig̃u } \\
(\text { Ad 3-14? })^{1259}\end{array}$ & $\begin{array}{l}\text { Eannatum, S.d. Ina-palêšu/ } \\
\text { Aplatum (Ad 1-35) }\end{array}$ & $\begin{array}{l}\text { [Sîn-išmeanni, S.d. Ibbi-ilim } \\
(\text { Ad 5) }]^{1261} \\
\text { Igmil-Ištar (Ad 31) })^{1262}\end{array}$ \\
\hline $\begin{array}{l}\text { Nanna-šalasud, S.d. } \\
\text { Mea'imriag̃u } \\
(\text { Aṣ } 7-\mathrm{Sd} 5)^{1263} \\
\end{array}$ & $\begin{array}{l}\text { Ilšu-X, S.d. Samsui[luna-X] } \\
\text { (Aṣ 9) }\end{array}$ & \\
\hline $\begin{array}{l}\text { Abandasa, S.d. Be-x } \\
(\text { nach Sd 5) }\end{array}$ & $\begin{array}{l}\text { Rī̌s-Marduk S.d. E-x } \\
(\mathrm{Sd} 2 \text {-?) }\end{array}$ & \\
\hline
\end{tabular}

Jedes der in dieser Tabelle aufgeführten gala-mah-Ämter war den Textbelegen nach nur jeweils von einer einzigen Person besetzt. Das Amt am Tempel des Zababa wurde von zwei Generationen einer Familie vertreten, ob Inanazig̃u, der Vater des Mea'imriag̃u, ein gala-mah-Amt innehatte, ist nicht dokumentiert. In gleicher Weise herrscht Unkenntnis über die Familienzugehörigkeit des Abandasa, der nur einmal als Zeuge belegt ist. Sein stark zerstörtes Siegel gibt ihn als Diener des Zababa und einer weiteren nicht mehr rekon-

\footnotetext{
${ }^{1258}$ RIAA 238:21 (Si ?).

${ }^{1259}$ YOS 13, 33:4 (Ad 3) ohne Titel; YOS 13, 325 (Ad 5) Siegel C; YOS 13, 94 (Ad 13) Siegel A; TLB 1, 257 (Ad 14?) Rs 2'.

1260 TJA 55f. pl 25:11 (D.a.[Ad 1-10]); YOS 13, 24:4 (Ad 35); ohne Amt in YOS 13, 174:12 (Ad 21); TJA 48ff. pl 38:31 (Ad 21).

${ }^{1261}$ YOS 13, 325 (Ad 5) Siegel D.

${ }^{1262}$ YOS 13, 348 (Ad 31) 24. igi Ig-mil-Ištar gala-mah ${ }^{\mathrm{d}} N a-n a-a$.

1263 YOS 13, 232:6-7 (Aṣ 9); YOS 13, 77:6-7 (Aṣ 9); YOS 13, 217:3-4 (Aṣ 17+b); YOS 13, 324:3-4 (Sd 1); YOS 13, 268:4-5 (Sd 1); YOS 13, 224:7-8 (Sd 4); YOS 13, 216:4-5 (Sd 5); YOS 13, 203 (D.a.) Rs 22 und Siegel J; als lu lu $_{2}$ kurun $_{2}$-na in YOS 13, 88:6 (Aṣ 9); YOS 13, 266:4-5 (Aș 8).

${ }^{1264}$ YOS 13, 90 :Rs 9 (D.a.) und Siegel.

${ }^{1265}$ YOS 13, 262:18 (Sd 2); YOS 13, 90 (D.a.) Siegel C.
} 
struierbaren Gottheit an. ${ }^{1266}$ In einer Urkunde aus der Zeit des Königs Abi’ ěšuh wird ein gala-mah ohne Namen angegeben, der eine igisûm-Abgabe in Empfang nimmt. ${ }^{1267}$ Dieser könnte dem Zababa-Tempel zuzuordnen und mit dem Vorgänger des Mea'imriag̃u zu identifizieren sein. In der Mitgiftsurkunde YOS 13, 325 aus dem Jahr Ammiditana 5 wird neben Mea'imriag̃u ein weiterer gala-mah mit Namen als Zeuge genannt. Sein Siegel (D) ist ebenfalls erhalten: „Sîn-išmeanni gala-mah, Sohn des Ibbi-ilim“. ${ }^{1268}$ Dieser könnte dem Tempel der Nanaja zugeordnet werden. ${ }^{1269}$

Am häufigsten belegt ist der gala-mah des Zababa Nanna-šalasud, der seinem Vater im Amt folgte. Für ihn sind zwei Siegel belegt, die eine jeweils unterschiedliche Dienerschaft angeben, zum Gott Nergal (o.D.) und zum König Ammi[șaduqa] (Sd 1). ${ }^{1270} \mathrm{Im}$ jüngeren der beiden Siegel würdigt er den König seiner ersten Amtsjahre, während er im älteren Siegel mit einer Dienerschaft zum Nergal zwar mit Filiation aber noch ohne Titel angegeben wird. Der Gott Nergal wurde unter seinem Namen Lugal-Marada in der etwa $50 \mathrm{~km}$ südlich von Kiš gelegenen Stadt Marad verehrt, möglicherweise liegen hier die Ursprünge dieser Priesterfamilie. ${ }^{1271}$

Bei den Amtsinhabern der gala-mah für Inana von Uruk lassen sich keinerlei Verwandtschaften feststellen. Die Vertreter dieses Amtes sind möglicherweise auch unterschiedlicher Herkunft. Während der erste gala-mah dieser Göttin Eannatum einen sumerischen Namen in der Tradition der Priesterschaft von Uruk trägt, hat der letzte bekannte Amtsträger Rīš-Marduk einen akkadischen Namen mit Huldigung des Reichsgottes. Aus der Familie des Eannatum ist lediglich ein Sohn mit Namen Tarībatum bekannt, der als Garant über eine Silberschuld auftritt. ${ }^{1272}$ Rī̌s-Marduk wird in seinem Siegel als Diener des Königs Samsuditana bezeichnet, der Name seines Vaters ist allerdings nicht erhalten. ${ }^{1273}$

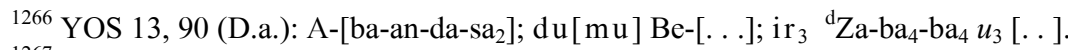

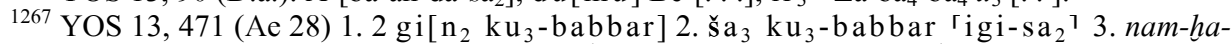
ar-ti gala-m[ah] 4. ${ }^{\Gamma} \mathrm{mu}^{7}$-DU 5. Iš-me- ${ }^{\mathrm{d}} \mathrm{EN} . Z \mathrm{ZU}$ 6. nam-ha-ar-ti 7. ${ }^{\mathrm{Id}}$ Marduk-mu-ba-li ${ }_{2}$-it.

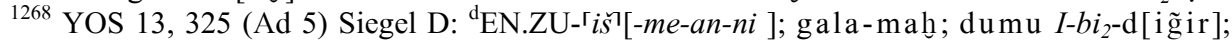
vgl. Pientka 1998, 378. Nach der Kopie in YOS 13 muss auf dig̃ir kein Zeichen mehr folgen.

1269 Absender des Briefes AbB 14, 50 (=VAB 6, 246) unbekannter Herkunft ist wohl derselbe Sîn-išmeanni, da er einen subaräischen gala bei sich unterkommen ließ.

${ }^{1270}$ YOS 13, 203 (D.a.) Siegel F: ${ }^{d}$ Nanna-ša ${ }_{3}-l_{2}$-sud; dumu Me-a-im-ri-a-g̃u $u_{10} ; i_{3}{ }^{d} \mathrm{Ne}_{3}-$ iri $_{11}$ -

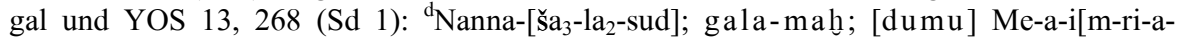
$\left.\tilde{\mathrm{g}} \mathrm{u}_{10}\right] ; \mathrm{ir}_{3} A m-m i-\left[s a-d u-q a_{2}\right]$.

1271 Wiggermann 1998-2001, 222.

${ }^{1272}$ YOS 13, 24:4 (Ad 34); Pientka 1998, 340:75.

${ }^{1273}$ YOS 13, 90 (D.a.) Siegel C: Ri-iš-d [Marduk]; gala-mah; dumu E-[. . .]; ir ${ }_{3}$ Sa-am-[su-dita-na]. 
Zwar wird der gala-mah Ilšu-X, Sohn des Samsui[luna-X] im einzigen für ihn bekannten Beleg keiner Gottheit zugewiesen. ${ }^{1274} \mathrm{Da}$ er allerdings eine Bürgschaft über kezérum-Silber besiegelt, kann er dem Tempel der Inana von Uruk zugeordnet werden.

Der einzige für die Stadt Kiš sicher belegte gala-mah der Nanaja Igmil-Ištar ist nach einer einzigen Tafel über Depositum von Vieh bezeugt. ${ }^{1275}$ Auch andere Priesterämter dieser Göttin sind ausschließlich aus der Regierungszeit des Ammiditana bekannt, für ihre Tochter Kanisurra auch sag̃ g̃a-Priester. ${ }^{1276}$ Trotz der lückenhaften Belegsituation für die Göttinnen Nanaja und Kanisurra ist anzunehmen, dass für die Ausführung ihres Kultes bis zum Ende der babylonischen Dynastie hin verschiedene, wenn nicht die wichtigsten Priesterämter eingerichtet waren.

Der bislang einzige aus einer frühaltbabylonischen Sklavenkaufurkunde als Zeuge belegte gala-mah Ka-Inana dürfte dem Tempel des Zababa zuzuordnen sein, auch wenn die Kultpflege für Inana von Uruk oder Nanaja in Kiš bereits im Jahr Samsuiluna 10 nachweisbar ist. ${ }^{1277}$ Aus seiner Familie wird lediglich sein Sohn Iddin-Ištar bekannt, der neben ihm als Zeuge genannt wird.

Zusätzlich zur Verteilung der Ämter und ihrer Besetzung lassen sich auch Informationen zu den Wirkungsbereichen der gala-mah von Kiš erschließen. In vier Urkunden werden sie im Zusammenhang mit Viehlieferungen genannt. ${ }^{1278}$ Die Darlehensurkunde YOS 13, 268 (Sd 1) nennt ein Milchkalb, das vom Palast als Leihgabe geliefert und als nabrûm-Opfertier für den ersten Tag des Monats vii bestimmt war. ${ }^{1279}$ Der in der Position des Entleihers genannte gala-mah des Zababa Nanna-šalasud führte in diesem Fall wohl die Opferung des Tieres aus. Das nabrûm-Opfer ist altbabylonisch häufig belegt, zur Ur IIIZeit wurde es vornehmlich den Göttinnen Ulmašìtum und Annunītum dargebracht. ${ }^{1280}$

\footnotetext{
${ }^{1274}$ YOS 13, 314 (Aṣ 9) Siegel B: Dig̃ ir-šu-[. .]; dumu Sa-am-su-i-[lu-na-. . ]; [ga]la-mabn; $\operatorname{ir}_{3}[.$.$] .$

${ }^{1275}$ YOS 13, 348:24 (Ad 31).

${ }^{1276}$ Pientka 1998, 384; Charpin 1986, 411.

${ }^{1277}$ Charpin 1986, 414.

1278 TJA 48ff. (Ad 21); YOS 13, 348 (Ad 31); YOS 13, 268 (Ad 1); YOS 13, 262 (Sd 2).

${ }^{1279}$ YOS 13, 268: 1.1 ama-ga 2. ša $Q i_{3}{ }^{\prime}-i \check{s}-{ }^{\mathrm{d}}$ Marduk 3. dumu Warad-i $i_{3}-l i_{2}-\check{s} u$ 4. a-na ${ }^{\mathrm{d}}$ Nanna$\mathrm{ša}_{3}-\mathrm{la}_{2}$-sud 5. gala-mah ${ }^{\mathrm{d}} \mathrm{Za}-\mathrm{ba}_{4}-\mathrm{ba}_{4}$ 6. bu-bu-tu 7. a-na itu du $\mathrm{du}_{6}-\mathrm{kug} \mathrm{u}_{4}$ 1-kam 8. 1 ama-ga 9. a-na siskur ${ }_{2} n a-a b-{ }^{-} r^{1}-i$ 10. $u_{2}-u l$ ub-ba-la-ma 11. pi $2_{2}$-ha-tam 12. e ${ }_{2}$-gal $i$-ippa-al; vgl. Pientka 1998, 387.

${ }^{1280}$ CAD N/1 30; zur Ur III-Zeit s. Cohen 1993, 394-395; Sallaberger 1993, 205.
} 
Beachtenswert ist auch Text TJA 48ff. mit einer Viehlieferung, die als „Auflage“ (nēmettum) gekennzeichnet ist. Ein Teil dieser „Auflage“ für den Tempel der Inana von Uruk und das Tor des Šamaš galt zugleich als igisûmAbgabe an den Aufseher der kezrētum. ${ }^{1281}$ Zeugen dieser Zahlung sind der gala-mah Eannatum der Inana von Uruk und ein sag̃g ga der Nanaja.

Für den gala-mah Nanna-šalasud des Zababa ist belegt, dass er ähnlich den gala-mah der Annunitum von Sippar Bierlieferungen und Silberzahlungen verwaltete. Derselbe Nanna-šalasud ist auf zwei Urkunden aus den Jahren Ammișaduqa 8-9 auch selbst als Brauer belegt und für monatliche Bierlieferungen zuständig. ${ }^{1282}$ Nanna-šalasud ist schließlich auch einmal als Einzahler eines parșum-Restsilberbetrags für eine Person aus Dilbat belegt. Da der Schuldner in diesem Falle männlich war, muss eine andere Kulthandlung als die in Kiš mehrfach belegten kezerrum-Handlungen gemeint sein.

Insgesamt zeigt sich, dass die gala-mah eng an den königlichen Palast gebunden waren. Hierauf deutet ihre Rolle als Überwacher und Empfänger von igisûm-Abgaben sowie der Verwaltung von Darlehen des Palastes hin. In den Siegeln der amtierenden gala-mah findet sich dementsprechend seit spätaltbabylonischer Zeit eine Dienerschaft zum regierenden König ausgedrückt. ${ }^{1283}$ Der gala-mah des Zababa Nanna-šalasud ließ sich nach seinem Amtsantritt sogar ein zweites Siegel anfertigen, in dem er sich als Diener seines Königs Ammișaduqa bezeichnet. ${ }^{1284}$

\subsubsection{Andere Musiker}

Außer den gala-mah-Priestern ist für Kiš nur noch ein nar-Musiker mit Namen Warad-Nabium belegt. Dieser ist auf einer Lieferungsquittung als Empfänger von Getreide aus dem Speicher verzeichnet, die unter den ersten Empfängern auch einen Sohn des Königs nennt. ${ }^{1285}$

Das Fehlen von Belegen zu Musikern wie nar, gala oder nar-gal in Kiš lässt sich über die derzeitige Quellenlage begründen. Texte der Palastadministration einerseits und Opferrationenlisten aus der Tempelverwaltung andererseits, die möglicherweise über die Beteiligung von Musikern an Festhandlungen Auskunft geben könnten, sind bislang nicht bekannt geworden.

\footnotetext{
${ }^{1281}$ TJA 48ff. (Ad 21); s. a. Stol 2004, 766-767, 771.

${ }^{1282} \mathrm{Als} \mathrm{lu}_{2}-\mathrm{kurun}_{2}$-na in YOS 13, 266:4-5 (Aș 8 v); YOS 13, 88:6 (Aṣ 9 i); als gala-mah in YOS 13, 232:6-7 (Aș 9 ii); YOS 13, 77:6-7 (Aș 9 iii).

${ }^{1283}$ YOS 13, 90 (D.a.) Siegel C des Rīš-Marduk; YOS 13, 203 (D.a.) Siegel F und YOS 13, 268 (Sd 1) jeweils Siegel des Nanna-šalasud; vgl. auch den Vater des gala-mah Ilšu-X, der mit seinem Namen dem König Samsuiluna huldigt; YOS 13, 314 (Aș 9) Siegel B.

1284 S. hier Anm. 1270.

${ }^{1285}$ YOS 13, 43:13 (Sd 12).
} 


\subsubsection{Die kezertum-Kultobligationen von Kiš}

Entsprechend der parșum von Sippar findet sich für Kiš eine Gruppe von Texten, die Kulthandlungen der kezrētum dokumentiert. ${ }^{1286}$ Hier handelt es sich überwiegend um Zahlungsquittungen über Silberrestbeträge, die konkret als kezerr(t)um oder auch allgemein parșum bezeichnet werden. Die kezer(t)umSilberabgabe (kasap/nēbeh kezrēe(t)im) wurde verheirateten und unverheirateten Frauen abgenommen, wobei die Silberzahlung an den Aufseher der kezrētumFrauen erfolgte. Dieser gehörte dem Tempelpersonal der Inana von Uruk an und hatte ähnlich dem gala-mah der Annunītum von Sippar Amnānum die Verantwortung über die korrekte Ausführung der Kultobligation. Einmalig ist das Siegel eines gala-mah auf einer solchen Restsilberzahlung erhalten, sodass vermutet werden kann, dass er als Vertreter des Tempels der Inana von Uruk in die Vorgänge einbezogen war. ${ }^{1287}$ Garanten über die Zahlung der Silber(rest)beträge sind männliche Personen von höherem Rang in der Palastoder Tempeladministration. Das Silber galt als Steuer, die an den Palast abgetreten wurde. ${ }^{1288}$

Die Liste YOS 13, 111 nennt acht Frauen, Töchter und Schwiegertöchter von Männern in hoher Position, die in der Summierung als kezrētum-Frauen ausgewiesen werden. Sie entstammen unterschiedlichen Ortschaften in der Umgebung von Kiš, wie Babylon, Ilip oder dem bei Dilbat gelegenen Ort Šapattānu. ${ }^{1289}$

Für die Ausführung der Kultobligationen selbst wurden nach drei Texten vom Aufseher der kezrētum verschiedene Kanäle für eine Reise (harrānum) aus Anlass der Kulte gepachtet. ${ }^{1290}$ In diesem Zusammenhang sind auch die Hammurabi-zeitlichen Briefe AbB 2, 34 und AbB 5, 135 aus der Korrespondenz des Stadtverwalters Sîn-iddinam zu nennen, die die Teilnahme von kezrētum an der Reise nicht genannter Göttinnen vom nahe Larsa gelegenen Jamutbal nach Babylon dokumentieren. ${ }^{1291}$

Hieraus könnte zu schließen sein, dass die für die kezertum-Kultobligation bestimmten Frauen Götterbilder und -symbole auf ihren Reisen außerhalb der Stadt begleiteten. ${ }^{1292}$ Um diese kultische Position einzunehmen und den hierzu

\footnotetext{
${ }^{1286}$ Zusammengestellt und diskutiert von Yoffee 1998; s. a. Spaey 1990 und Pientka 1998, 379380.

${ }^{1287}$ Ilšu-X, Sohn des Samsui[luna-X] in YOS 13, 314 (Aṣ 9) Siegel B.

${ }^{1288}$ Yoffee 1998, 332-333 mit einem Überblick zur Organisation.

${ }^{1289}$ Yoffee 1998, 328-329 auch zu vergleichbaren Texten; Pientka 1998, 379-380.

${ }^{1290}$ TJA 83f. pl 25 (Aṣ 17+b); YOS 13, 401 (Aṣ 17+b) und YOS 13, 297 (Sd 5); Pientka 1998, 392-393; Yoffee 1998, 323-328, 332-337; vgl. auch YOS 13, 202 (Sd 5) 5. ina kidim ūi $\bar{u}$ libbi älim „Im Feld oder innerhallb der Stadt“ als Orte dieser Kulthandlung; Yoffee 1998, 326-327, 337.

${ }^{1291}$ Dazu Finet 1981, 3-4.

${ }^{1292}$ So auch die Beleglage im hethitischen Raum; Güterbock 1983, 159.
} 
erforderlichen Kult auszuführen, kamen die Frauen offenbar aus unterschiedlichen Orten in diesem Falle nach Kiš. Dass für die Teilnahme an Kulthandlungen von nicht-geweihten Frauen eine Steuer zu zahlen war, zeigt möglicherweise auch die Urkunde YOS 13, 375 (Ad 34), die eine Abgabe für den Dienst der 'Hofreinigerin' für die Göttin Baba nennt (nēbeh ${ }^{\text {munus }}$ kisal-luh ša ${ }^{\mathrm{d}} \mathrm{Ba}$ $\left.\mathrm{ba}_{6}\right) .{ }^{1293}$ Diese Abgabe wurde vom sag̃ g̃a des Zababa eingenommen. Es wäre zu überlegen, ob möglicherweise solche Dienste der Hofreinigerinnen oder auch die der kezertum-Kultobligationen gegen eine Silberzahlung an den Tempel im Sinne einer ehrenvollen Aufgabe entrichtet wurden. Solche Überlegungen sind schwer nachweisbar, auch da ${ }^{\text {munus }}$ kisal-luh „Hofreinigerinnen“ andernorts vom Tempel entlohnt wurden. ${ }^{1294}$

Die Kulte der kezrētum galten der Göttin Inana von Uruk. Dass sie hier erst in spätaltbabylonischen Texten auftreten, hängt nach Ansicht Yoffees mit dem Verlust der südbabylonischen Kultzentren und der Überführung der Inana- und Nanaja-Kulte von Uruk nach Kiš zusammen. ${ }^{1295}$ Worin die genauen Aufgaben dieser Frauen neben der Begleitung der Götter bestand, ist nicht bekannt, entgegen der Meinung Yoffees können allerdings 'sexuelle' Dienste ausgeschlossen werden, da hierzu in den Texten nichts ausgesagt wird. ${ }^{1296}$ Vielmehr zeigen verschiedene Belege außerhalb der Stadt Kiš, dass kezrētum auch als Musikerinnen auftreten konnten. ${ }^{1297}$

\footnotetext{
${ }^{1293}$ Pientka 1998, 357:197, 380.

${ }^{1294}$ Vgl. die Larsa-Ritualliste hier Kapitel 9.2.3.2.

1295 Yoffee 1998, 334.

${ }^{1296}$ Yoffee 1998, 335-336 auch zur Verbindung zu den Kulten weiblicher Gottheiten.

1297 S. Kapitel 7.3.
} 


\section{TEIL II DAS REPERTOIRE}

\section{Terminologische Abgrenzung}

Über den Ausdruck 'vokales Repertoire' ist im Rahmen der folgenden Studie ein Arbeitsbegriff geschaffen, der alle literarischen Kompositionen umfasst, die über ihre Unterschriften und Rubriken als vokal vorgetragene und möglicherweise auch instrumental begleitete Liedkompositionen identifiziert werden können. ${ }^{1298}$ Hierbei werden sumerische wie akkadische Texte gleichermaßen einbezogen.

Inwiefern die uns überlieferten literarischen Kompositionen, darunter Hymnen, Preislieder aber auch Klagen und Gebete, von Musikern oder spezialisierten Priestern in einer musikalischen Form vorgetragen wurden, ist in der altorientalischen Literaturforschung vielfach behandelt und diskutiert worden. Grundlegend ist hier die Arbeit von Henrike Hartmann von 1960 zu nennen, die erstmals die literarischen Kompositionen als das Repertoire von Musikern diskutierte. Es folgten ausführliche Studien von Wilcke 1975 sowie allgemeine Überblicke bei Kilmer 1993-97 und Rubio 2009.

Erst jüngst wurde zum möglichen 'Sitz im Leben' insbesondere der sumerischen Literatur eine entgegengesetzte Position ausgesprochen. Bereits Veldhuis wies darauf hin, dass die meisten dieser Texte vornehmlich in den Schreiberschulen zum Zwecke der Übung niedergeschrieben wurden und nicht dem Vortrag bei festlichen Handlungen galten. ${ }^{1299}$ In gleicher Weise vertreten Michalowski 2009 und Brisch 2009 die Meinung, dass auch alle mit Gattungen und Rubriken versehenen Lieder und Hymnen auf eine ausschließlich schriftliche Existenz zurückzuführen sind und nie in oraler oder gar musikalischer Form dargebracht oder tradiert wurden.

In dieser Arbeit wird dementgegen die These weiterverfolgt, dass diese Termini zu irgendeiner Zeit einen realen aufführungspraktischen Hintergrund aufgewiesen haben, sei dieser musikalischer oder auch liturgischer Natur. ${ }^{1300}$ Der einzigartige Text CT 58, 12 mit seinen Vokalreihungen legt meines Erach-

\footnotetext{
1298 Vgl. Hartmann 1960, 192-196; Wilcke 1975, 253; allgemein Kilmer 1993-97, 470-471;

Rubio 2009, 22-24, 55-57; zu den akkadischen Gattungsnamen s. Groneberg 2003.

${ }^{1299}$ Veldhuis 2004, 58-59.

${ }^{1300}$ Vgl. Vanstiphout 1999, 91-92.
} 
tens ein deutliches Zeugnis dafür ab, dass die auch altbabylonisch verschriftlichten sumerischen Texte gesungen wurden. ${ }^{1301}$

Eine inhaltliche Unterteilung von Genren sumerischsprachiger Literatur setzen Veldhuis und Rubio an. ${ }^{1302}$ Die folgende Studie richtet sich dementgegen in der Gruppierung der zu behandelnden Texte nach der antiken Terminologie, den sumerischen und akkadischen Gattungsnamen. Damit können gleichermaBen Hymnen wie auch Klagelieder in einer Gruppe auftreten. ${ }^{1303}$

Als Liedunterschrift oder Liedgattung werden per Definition sumerische oder akkadische Termini bezeichnet, die in sumerischen Texten am Ende, in akkadischen auch zu Beginn des eigentlichen Liedtextes als Überschriften angegeben werden. ${ }^{1304}$ Den der modernen Literaturwissenschaft entnommenen Begriffen „Gattung" oder „Genre“ kommen sie insofern nahe, als sie Dichtungsarten in Gruppen zusammenschließen, die über inhaltlich-formale, funktionale oder kontextuelle Kriterien definiert sind. Die meisten Liedunterschriften bzw. Gattungsnamen sind aus den Kolophonen und Titeln der originalen Texte selbst bekannt. Weitere solcher Termini finden sich in literarischen Katalogen, ${ }^{1305}$ lexikalischen Listen $^{1306}$ und sekundären Textpassagen, insbesondere in den Selbstlobhymnen Ur III- und Isin-zeitlicher Könige. Auch sie werden in die folgende Darstellung integriert, auch wenn sie aufgrund jeglichen Fehlens vollständiger Textvertreter nur schwer zu fassen sind.

\footnotetext{
${ }^{1301}$ S. hier Kapitel 14.2.3.

${ }^{1302}$ Veldhuis 2004, 67-68; Rubio 2009, 46-70.

${ }^{1303}$ Von einer Erörterung der Diskussion um altorientalische Gattungen wird hier abgesehen; vgl. hierzu zuletzt speziell zu den Hymnen der Larsa-Könige Brisch 2007, 9-33 und Brisch 2009 mit einem Überblick zu den sumerischen Liedgattungen und Rubriken.

${ }^{1304}$ Einen allgemeinen Überblick zu den sumerischen Liedgattungsnamen bietet jetzt auch Rubio 2009, 62-69.

${ }^{1305}$ Ein Großteil der aB und auch Ur III-zeitlichen literarischen Kataloge ist inzwischen über ETCSL in der Kategorie 0 zugänglich, darunter TMH NF 3, 54 (N1) Bernhardt/Kramer 1956-57, 389-391; TCL 15, 28 (L) Kramer 1942; VS 10, 216 (B1) Krecher 1966, 33; UET 6, 123 (U2); UET 6, 196 (U3) Shaffer 2000, 432-433; BASOR 8, 12 (N12) und YBC 3654 (Y1) Hallo 1963; zusätzlich sind hier von Relevanz aus aB Zeit ein Katalog zu den akk. irātu(m) 'Brust'(-Gesängen) bei Finkel 1988; ein Katalog zu den Texten der amerakūtu(m) 'Kunst der Klagefrau' bei Shaffer 1993; Kataloge über Balag̃-Lieder bei Kramer 1982 sowie Shaffer 2000; außerdem der von Wilcke 1975, 263 mB datierte Katalog TMH NF 3, 53 (HS 1477) bei Bernhardt/Kramer 1956/57, 391-393 sowie der mA Liederkatalog KAR 158, zuletzt besprochen von Groneberg 2003; zur literarischen Einordnung von Katalogen s. allgemein Vanstiphout 1999, 81-82.

1306 Vornehmlich die Listen Proto- $\mathrm{Lu}_{2}$ und $\mathrm{Lu}_{2}=\check{s} a$ (MSL 12); Proto-Kagal (MSL 13, 61-88); Proto-Izi (MSL 13, 5-59) sowie Nabnītu (MSL 16).
} 
Im Gegensatz zu den Liedunterschriften stehen die Termini, die in der altorientalischen Forschung als 'Rubrik' bezeichnet werden, nicht am Ende oder zu Beginn einer literarischen Komposition, sondern an unterschiedlichen Stellen innerhalb des Textes. Solche Termini bilden nicht Teil des eigentlichen Liedtextes, vielmehr markieren sie einzelne Textabschnitte, um sie einem aufführungspraktischen Kontext zuzuordnen. Im Allgemeinen werden diese Termini als Anweisungen zur musikalischen Praxis gedeutet, so kann die Angabe solcher Rubriken auf die Form des Vortrags, auf die instrumentale Begleitung oder auch auf die tonale Struktur des Liedes bezogen werden. Andererseits werden einige der Rubriken auch als Anweisungen zur Kultpraxis verstanden, als Angaben zu liturgischen Handlungen. ${ }^{1307}$

Aus der folgenden Darstellung ausgeschlossen bleiben damit alle solche Texte, die keinerlei technische Termini enthalten und auch keiner bekannten Liedgattung aufgrund formaler oder sprachlicher Kriterien zugeordnet werden können. Dies betrifft die meisten Königshymnen, insbesondere die Selbstlobhymnen des Šulgi und des Išme-Dagan, sowie manch narrative Literatur, darunter Heldenlegenden und Göttermythen. ${ }^{1308}$ Bezeichnenderweise bilden ebendiese Texte das literarische Kompendium, dass zu einer fortgeschrittenen Stufe in Schreiberschulen gelehrt und weitertradiert wurde, ${ }^{1309}$ während die meisten erhaltenen Lieder beispielsweise der gängigen Gattungen Tigi und Adab als Einzelkompositionen nur in wenigen Abschriften überliefert sind. Nichtsdestotrotz wird im Falle der Ersteren nicht ausgeschlossen, dass sie ebenfalls von Sängern im Rahmen von Königspreisungen oder Götterfesten vorgetragen wurden.

Die hier im folgenden zweiten Teil der Arbeit zusammengetragenen Informationen zu Liedunterschriften, Rubriken und anderen Termini dienen in erster Linie als Überblick zu den technischen Begriffen in literarischen Kompositionen des ausgehenden dritten und beginnenden zweiten Jahrtausends, die auf einen vokalen Vortrag auch mit instrumentaler Begleitung zu beziehen sind. Hierbei wurde eine Vollständigkeit in der Bestandsaufnahme angestrebt, wobei

${ }^{1307}$ Die bisher einzige grundlegende Studie zu den Rubriken sumerischer Texte lieferte Wilcke 1975, 252-292; s. außerdem Ludwig 1990, 29-32.

${ }^{1308}$ Zur Unterscheidung und Einordnung solcher Texte s. a. schon Wilcke 1975, 248-249 und Ludwig 1990, 33-34, 38-40.

1309 Vgl. Tinney 1999, 159-172 zur Zusammenstellung der in aB Schulen geübten Kompositionen, rekonstruiert als Tetrade und Decade. 
auf unpubliziertes und unkommentiertes Material verzichtet werden musste. Vorangestellt sei in Kapitel 11 ein Überblick zu den wichtigsten sumerischen und akkadischen Termini, die als Ober- oder Sammelbegriffe für vokal vorgetragene Texte identifiziert werden können. 


\section{Grundbegriffe für den vokalen Vortrag}

\subsection{Allgemeine Termini}

\subsection{1 šir $_{3}$ und en $\mathrm{n}_{3}-\mathrm{du}$}

Beide hier behandelten Begriffe $\mathrm{s} \mathrm{ir}_{3}$ und $\mathrm{en}_{3}-\mathrm{du}$ werden dem akkadischen zamāru(m) „Lied, Gesangsstück“ gleichgesetzt, ${ }^{1310} \breve{s i r}_{3}$ kann darüber hinaus ins Akkadische als šèru(m) entlehnt sein.

Die altbabylonische Liste Proto- $\mathrm{Lu}_{2}$ führt šir ${ }_{3}, \mathrm{en}_{3}-\mathrm{du}$ und ihre jeweiligen Komposita in direkter Nachfolge auf. ${ }^{1312}$ Die meisten der in Proto- $\mathrm{Lu}_{2}$ aufgeführten $\breve{s i r}_{3}$-Komposita können nach Einträgen in Liedunterschriften und literarischen Katalogen als Liedgattungsnamen identifiziert werden. ${ }^{1313}$ Nur einmalig belegt ist die akkadische Gleichsetzung von šêru $(m)$ mit dem Rubriknamen ki-ru-gu $2 .{ }^{1314}$ In der Saitenpaarliste CBS 10996 steht šéru(m) wiederum für den Doppelgriff der siebten und dritten Saite, der als große Terz gedeutet wird. ${ }^{1315}$ Es bleibt offen, inwieweit die verschiedenen Bedeutungen desselben Wortes auch in musikpraktischer Hinsicht ineinander greifen.

Im Gegensatz zu šir ${ }_{3}$ sind mit dem Wort en ${ }_{3}-\mathrm{du}$ keine Liedgattungsnamen gebildet.

\footnotetext{
${ }^{1310}$ AHw 1508a; zuletzt von Westenholz 2005, 344-351 besprochen.

1311 AHw 1219b šéru(m) III „Gesang“; ob šir ${ }_{3}$ Akkadisch auch șarāhu(m) „klagen; singen; schreien“ und sitru(m) „Ensemble(?)" geglichen wird, bleibt aufgrund der unsicheren Rekonstruktionen der aB Liste Aa 757:1,4 umstritten; vgl. Attinger 1993, 692 § 790; Nabnītu IX(=X) (MSL 16, 118); Tinney 1996, 139-140 Kom. zu Z. 45. Zu KAR 158 zamār šēri „Lieder des Morgens“ s. CAD Z 35b sub c).

${ }^{1312}$ Für Nippur hauptsächlich Textzeugen A und S'; Isin: IB 1318 Rs und IB 1514 Rs bei Wilcke 1987, 98-100 verläuft parallel, die Version unbekannter Herkunft bei Taylor 2001, 215-216 weicht mehrfach ab.

${ }^{1313}$ S. ausführlich Kapitel 12.2.

${ }^{1314}$ KAR 100 Kol. ii 5; s. a. hier Kapitel 14.1.5.

${ }^{1315}$ Kilmer 1960, 258-283.
} 
T 58: Proto- $\mathrm{Lu}_{2}$ 600-603 (MSL 12, 54)

600. $\mathrm{en}_{3}-\mathrm{du}$

601. en $n_{3}-d u$ an-na

602. $\mathrm{en}_{3}-\mathrm{du}$ gar-g̃ar

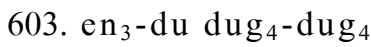

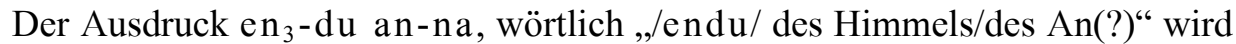
in Nabnītu akkadisch elītu ša zamāri „Oberes/Hohes, vom Singen“ gleichgesetzt, weshalb Taylor eine Übersetzung des Sumerischen mit „high-pitched singing“ vorschlägt. ${ }^{1316}$ Die Einträge in den Zeilen 602-603 bezeichnen Tätigkeitsfelder oder Personengruppen: $e_{3}-d u$ gar-gar ist in literarischen Texten gängiger Ausdruck für den Vorgang des „Liedsetzens“ und bezeichnet auch den „Liedsetzer“. ${ }^{1317}$ Eine entsprechende Bedeutung weist das Kompositum šr $_{3}$ gar-g̃ar auf. Der Ausdruck en ${ }_{3}-\mathrm{du} \mathrm{dug}_{4}-\mathrm{dug}_{4}$ ist außer in der hier zitierten Liste Proto- $\mathrm{Lu}_{2}$ mit Bezug auf einen Musiker ${ }^{1318}$ oder einen Liedvor$\operatorname{trag}^{1319}$ nur noch in Texten des ersten Jahrtausends bezeugt. ${ }^{1320}$

Sumerisch /endu/ ist in unterschiedlichen Schreibungen attestiert. Altbabylonisch wird vorwiegend $\mathrm{en}_{3}-\mathrm{du}$ oder auch syllabisch en-du geschrieben, während Ur III-zeitlich seltener auch $\mathrm{en}_{8}$-du bezeugt ist. ${ }^{1321}$ Im ersten Jahrtausend finden sich etymologisierende Formen wie $\mathrm{en}_{3}-\mathrm{du}_{12}$ und $\mathrm{en}_{3}-\mathrm{du}_{11}$, die das Wort auf die Verben $\mathrm{dug}_{4}$,(aus)sprechen; sagen“ und $\mathrm{du}_{12}$, ,singen; musizieren“"zurückführen. ${ }^{1322}$ Die ursprüngliche Bedeutung des Wortes ist unbekannt.

1316 Taylor 2001, 216, 222; vgl. im aB Dumuzi-Eršema Nr. 88:9 mu-lu šir ${ }_{3}$-an-na-m[u] „My singer of heaven“; Cohen 1981, 84, 86.

${ }^{1317}$ Išme-Dagan A(+V) Text C 6-12 (T 4); Šulgi B 325; Ludwig 1990, 189-195. Anstelle dieses Kompositums werden in Parallelstellen auch die Ausdrücke S̆IR ${ }_{3}$.NAR oder NIG̈IN.RI ein-

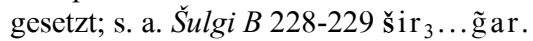

${ }^{1318}$ So in Nabnìtu (MSL 16, 118) IX(=X) 8. mit akk. za-am-me-ru „Sänger; Musiker“ geglichen; hierzu parallel zu setzen ist šir ${ }_{3} \mathrm{dug}_{4}-\mathrm{dug}_{4}$ für die Chorsänger im Lied $D I J 25$ (Alster 1985, 223-224).

1319 So im Balag̃-Lied Ame Baranara; vgl. Attinger 1993, $488 \S 391$ b); Cohen 1988, 330: $\mathrm{f}+229$.

${ }^{1320}$ S. a. Attinger 1993, 488-489 § 391 mit allen Belegen; im Textzeugen IB 1318, einer Version der Proto- $\mathrm{Lu}_{2}$-Liste aus Isin, findet sich nach cdli und ePSD ein zusätzlicher Eintrag 601a. $\mathrm{en}_{3}-\mathrm{du}-{ }^{\ulcorner} \mathrm{ka}-1 \mathrm{a} 1_{3}{ }^{\top}$, „Lied von süßem Mund (?)“ oder „Honigmund-Lied(!)“.

${ }^{1321}$ Hallo 1963, 170.

${ }^{1322}$ Attinger 1993, 489 § $392+$ Anm. 1352. 
Die meisten literarischen Belege $\mathrm{zu} \mathrm{sir}_{3}$ und $\mathrm{en}_{3}-\mathrm{du}$ sind in den Selbstlobhymnen der Könige Šulgi und Išme-Dagan enthalten. ${ }^{1323}$ Dort bezeichnen sie gleichermaßen die Preis- und Lobhymnen, die der Namenserhaltung des gepriesenen Königs dienen. ${ }^{1324}$ Solche Hymnen wurden bekanntlich nach Belegen von Gudea bis Hammurabi auf narû „Stelen“ oder „Statuen“ für die Nachwelt erhalten. ${ }^{1325}$ Diesbezüglich heißt es in der Hymne Išme-Dagan $A(+V)$ :

T 59: Išme-Dagan A(+V) 381-382

„Alles, was in meinen /endu/-Gesängen vorhanden ist, was auf meiner Stele geschrieben [ist], ist bestimmt nicht fal[sch], sondern $\mathrm{w}[\mathrm{ahr} !]^{\text {“ }}$

381. ni $\tilde{g}_{2}$ en $n_{3}-d u-\tilde{g} a_{2}$ a-na a[b-g̃ $] a_{2}-l a$

382. na-ru $2-a-\tilde{g} a_{2}$ a-na ab-sar[-ra] lu[1] ba-ra-na he $e_{2}-g e[-e n]^{1326}$

Die folgende literarische Textpassage aus der Hymne Šulgi $X$ deutet darauf hin, dass das en ${ }_{3}-\mathrm{du}$ dem sir $_{3}$ untergeordnet wurde:

T 60: Šulgi $X 11-13$

„Inana staunte auf; und begann mit einem $\mathrm{sir}_{3}$ (-Vortrag),

den sie als /endu/(-Lied) darbrachte.“

11. ${ }^{\mathrm{d}}$ Inana-ke $\mathrm{u}_{6} \mathrm{mu}-\mathrm{ni}-\mathrm{du} \mathrm{u}_{11}$

12. ni $_{2}$-te-ni-še ${ }_{3} \breve{s i r}_{3}$ ba-ši-ni-ra

13. en $_{3}-\mathrm{du}-\mathrm{še}_{3}$ ! $^{\mathrm{im}-\mathrm{e}^{1327}}$

Der šir ${ }_{3}$-Gesang wird hier als ein en $\mathrm{n}_{3}-\mathrm{du}$-Vortrag gekennzeichnet.

${ }^{1323}$ Šulgi D 370; Šulgi E 53; Šulgi B 309, 318, 328-331; IšD A(+V) 339; s. a. Westenholz 2005, 344, 348-351.

${ }^{1324}$ Entsprechend auch bei Gudea: Gudea St. $B$ viii 21. en ${ }_{3}$-du KA-keš $\check{2}_{2}-\mathrm{ra}_{2}$ - $\tilde{\mathrm{g}} \mathrm{u}_{10}$ 22. mu$\tilde{\mathrm{g}} \mathrm{u}_{10} \mathrm{u}_{3}$-ta- $\tilde{\mathrm{g} a r}$,,der von meinen gesammelten en $\mathrm{n}_{3}$-du-Liedern meinen Namen absetzt,“; Steible 1991/1, 174-175; Edzard 1997, 37; auch mythische Personen werden in /endu/besungen; Volk 1995, 209 zu Inana und Šukaletuda 298 (ETCSL 1.3.3.); s. a. Westenholz 2005, 348-350.

${ }^{1325}$ Gudea St. B viii 21-23; Hammurabi A; IšD Z 5-10; dazu Ludwig 1990, 62-63; s. a. FlückigerHawker 1996, 106 wie schon Ludwig 1990, 73-74 zu den Selbstlobhymnen der Könige Šulgi

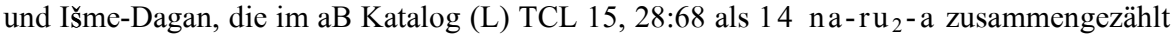
werden; hierzu auch Westenholz 2005, 346-348; für Mari s. Charpin 2006, 153-154.

${ }^{1326}$ Ludwig 1990, 168, 174, 202-203; ETCSL 2.5.4.01.

${ }^{1327}$ Klein 1981, 136-137. 
šir $_{3}$ steht literarisch zunächst für preisende sowie instrumental begleitete Lieder an Götter oder Könige. ${ }^{1328}$ Darüber hinaus können mit šir ${ }_{3}$ auch Alltagslieder bezeichnet sein, so beispielsweise die e-el-lu-Arbeitsgesänge der Rinderhirten nach der Sumer und Ur Klage. ${ }^{1329}$ Unter dem Sammelbegriff $\mathrm{šir}_{3}$ ist auch $\mathrm{za}_{3}-\mathrm{mi}_{2}$ der „Lobpreis“ bzw. das „Preis(lied)“ angeführt. ${ }^{1330}$ Der 'Lobpreis' gilt damit als ein untergeordneter inhaltlich definierter Vortrag. Ob für ihn möglicherweise auch aufführungspraktische Kriterien kennzeichnend sind, nämlich das Spiel des ${ }^{\tilde{g} i s ̌ s} \mathrm{Za}_{3}-\mathrm{mi}_{(2)}$-Instruments, ist vorerst aufgrund unterschiedlicher etymolischer Ableitungen beider Wörter in Frage zu stellen. ${ }^{1331}$ Über den Begriff šir ${ }_{3}$ kann in Klageliedern der Gattungen Eršema und Balag̃ neben er ${ }_{2}$ „Klage (wörtl. Träne)“ auch der Klagegesang bezeichnet sein. ${ }^{1332}$

$\breve{s i r}_{3}$ unterliegt damit keiner inhaltlichen Eingrenzung und kann gleichermaßen für Preis oder Klage stehen. Des Weiteren scheint ihm auch keine aufführungspraktische Definition immanent zu sein, es bezeichnet einen vorgetragenen Text, ganz gleich ob in gesungener oder rezitierter Form. Der Terminus $\breve{s i r}_{3}$ wurde damit auf alle dichterisch-poetischen Kompositionen angewendet, die in erster Linie im Vortrag ihre Funktion erfüllen und damit primär der oralen Tradition verhaftet sind. ${ }^{1333}$

Im Gegensatz zu šir ${ }_{3}$ ist der Terminus en ${ }_{3}-d u$ inhaltlich enger gefasst, was vornehmlich literarischen Textstellen zu entnehmen ist. Als Sammelbegriff für 'Gesungenes' umfasst er dort verschiedene, auch mit šir ${ }_{3}$ gebildete Liedgattungen, die alle als Götterlieder oder -hymnen einzuordnen sind. ${ }^{1334}$ Hierzu

${ }^{1328}$ Nusku B 6. lugal-g̃u $u_{10}$ šir $_{3}$-re-eš 2 ga-am -dug $_{4}$ „Mein König(Nusku), ich will dich im Lied preisen!"; Enkis Reise 71; Šulgi A 81; Šulgi B 4; Šulgi $C$ Refrain in Fragm. A 20, 34, 52, 84, 114, 145 und B 74; IšD A(+V) 376-377; Nergal C 51; das Tigi-Lied Ibbi-Suen A an Nanna 25-29; Winter und Sommer 236; Rìm-Sin B an Haja 9; Asalluhi XA 28; Ning̃išzida $C$ 13, 22, 30, 39; Šara A 32; Nusku B 6 und 12-13; Inana und Bilulu 74-75 šir ${ }_{3}$ der Inana für Dumuzi; unklar sind Inana C 89 neben i-lu sowie Nanše A 132.

${ }^{1329}$ S. hier T 66: Sumer und Ur Klage 43.

1330 S. a. Nabnitu 32 (MSL 16, 253) Kol. iii 30. mit šir ${ }_{3}-z_{3}-m_{2}-d u_{11}-g a$ im Sinne eines vorgetragenen Preisgesangs.

${ }^{1331}$ Ludwig 1990, 34-35, 168, 174; anders Michalowski 2009 Appendix.

${ }^{1332}$ Bala g̃ an Enki Abzu Pe'ellam 85; Cohen 1988, 54, 60; Cohen 1981, 88 No. 88:19; Nippur Klage 34; T 89: Dumuzi-Inana J 30-32, wo der Vortrag des Eršema als šir ${ }_{3}$ bezeichnet wird; Uruk Klage kirugu 12:24-27 (Tinney 1996, 23), wonach Išme-Dagan die Klage $\left(\mathrm{er}_{2}\right)$ als Opfer (siskur) dem Enlil darbringt, die von nar in šir ${ }_{3}$-Liedern vorzutragen ist; hierin liegt möglicherweise ein Verweis zu den in Nippur gefeierten er $_{2}$-siskur ${ }_{2}(-$ ra $)$ „Opferklageriten"; Sallaberger 1993, 149-150.

${ }^{1333} \mathrm{lu}_{2}$ - $\mathrm{sir}_{3}$-ra ist dementsprechend ,(derjenige) Mann der 'Vortragsstücke'“; s. Rìm-Sîn B 5455. Dasselbe Attribut erhält der um-mi-a in Išme-Dagan A(+V) Text C 6-12 (T 4).

${ }^{1334}$ Ausführlich Westenholz 2005, 244-251. 
zählen die Gattungen Adab, Tigi, Malgatum, Širgida, ar ${ }_{2}$-nam-lugal, Šumunša, Kung̃ar, Balbale, gi-gid ${ }_{2}$ und Zamzam. ${ }^{1335}$

Als en ${ }_{8}$-du lugal „Königs-/endu/“" werden im Ur III-zeitlichen Katalog Y1 (YBC 3654) 32 Titel aufgelistet, von denen bisher nur die wenigsten identifiziert sind, darunter die Königshymne Šulgi $A$ sowie das Adab-Lied des Königs Luma an die Göttin Baba. ${ }^{1336}$ Der Begriff /endu/ und auch /endu/ lugal bezeichnet damit sowohl Götter- wie auch Königshymnen. In Abgrenzung von $\mathrm{sir}_{3}$ werden unter $\mathrm{en}_{3}$-du jedoch keine Klagelieder oder Trauergesänge geführt. en $n_{3}-d u$ nimmt ausschließlich auf den Preis und Lobgesang Bezug, weshalb vielfach eine Übersetzung mit „Hymne“ angebracht ist. ${ }^{1337}$

Literarische Textpassagen weisen den mit /endu/ bezeichneten Hymnen außerdem eine konkrete Vortragsweise zu. Hierbei handelt es sich um den gesangstechnischen Begriff ad-ša ${ }_{4}$, über den eine bestimmte Klangmodulation bezeichnet wird, die im Bezug auf die menschliche Stimme meist als ein Tremolieren oder Vibrieren gedeutet wird. ${ }^{1338}$ Die Proto-Lu 2 -Einträge $\mathrm{zu}$ ad-ša folgen direkt auf/endu/ und seine Komposita:

T 61: Proto-Lu $\mathrm{Lu}_{2}$ 604-605 (MSL 12, 54)

604. ad-ša $\mathrm{a}_{4}$

605. ad-ša $\mathrm{a}_{4}-\check{\mathrm{s}} \mathrm{a}_{4}{ }^{1339}$

Laut dem sumerischen Sprichwort SP 2.39 hatte ein guter nar die /endu/Hymnen mit ihrem speziellen ad-ša ${ }_{4}$-Klang zu beherrschen. ${ }^{1340}$ Die Hymne Šulgi $C$ gibt ad-ša ${ }_{4}$ ebenfalls als besondere Vortragstechnik zahlreicher unter dem Begriff/endu/zusammengefasster Liedgattungen an. ${ }^{1341}$

1335 Šulgi E 53; Šulgi B 270-280; IšD A(+V) 339; Wilcke 1975, 257; Šulgi D 368-370; dazu Volk 1995, 209.

${ }^{1336}$ Katalog Y1 (YBC 3654) (ETCSL 0.1.2.) 33. šu-nig̃ in ${ }_{2} 32$ en ${ }_{8}$-du lugal und 44. šunig̃in $10 \mathrm{en}_{8}$-du igi-še ${ }_{3}-\mathrm{am}_{3}$; Hallo 1963, 170:32a. Zu den unsicheren Identifizierungen bei Hallo 1963, 173 von No. 8, No. 22, No. 32 und No. 41 vgl. Ludwig 1990, 40; Tinney

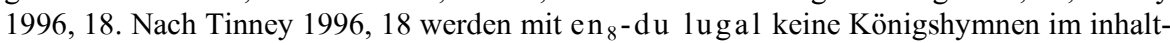
lichen Sinne definiert, sondern Kultlieder, die auch unter Anwesenheit des Königs vorgetragen wurden. Sicher identifiziert sind No. 30 als Šulgi $A 1$. lugal-me ša ${ }_{3}$-ta ur-sag̃-meen und No. 42 dumu an-na das Adab an Baba: 1. dumu an-na an gal ki gal-ta.

${ }^{1337}$ Limet 1993, 233-234, wobei dieser nur kultische Hymnen einschließt.

${ }^{1338}$ Sjöberg 1975a, 169+Anm. 37; Krispijn 1990, 14-15; Ludwig 1990, 190 Anm. 466 übersetzt ad-ša 4 di mit „Tremolosänger“; Attinger 1993, $427 \S 252$. Anders Volk 1994, 187, der es als eine Form der „Vokalimprovisation“ deutet; s. a. PSD A/3 24-25.

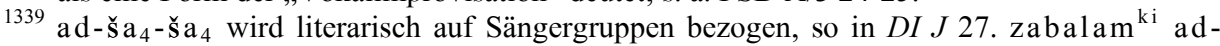
$\breve{\text { śa }}$-ša $_{4} 50$ me-eš und Šulgi $C$ 87. [X] X DI AGA nar-e ad-ša $\mathbf{a}_{4}-$ ša $_{4}$.

${ }^{1340}$ S. Kapitel 11.1.1; dazu Cohen 1988, 322: Bala g̃ Ame Baranara a+20-21.

${ }^{1341}$ Šulgi C Fragm. B 76, „Tigi, Adab und die groß(artigen) Malgatum-Lieder, ihren adša $_{4}$-Gesang beherrsche ich“; vgl. Enkitalu und Enkiheg̃al Vs ii 10-15 bei Sjöberg 1975a, 
Unabhängig von /endu/ kann ad-ša ${ }_{4}$ allerdings auch für den Klang des Klagens und Jammerns stehen. ${ }^{1342}$ Es liegt nahe, diesen vokalen Ausdruck als einen Vibratoklang möglicherweise sogar als Melisma zu deuten. Bezeichnend bleibt außerdem, dass ad-ša ${ }_{4}$ im Zusammenhang mit šir ${ }_{3}$ nur selten attestiert ist. ${ }^{1343}$ Die unter $\breve{S i r}_{3}$ zusammengefassten Lieder könnten daher eher frei von melismatischen bzw. tremolierenden Klangmodulationen vorzustellen sein.

Abschließend ist hier für den Terminus /e $\mathrm{ndu} /$ festzustellen, dass er zunächst inhaltlich auf lobpreisende Lieder an Götter oder Könige beschränkt ist. Aufführungspraktisch ist für diese eine melodiös oder melismatisch ausgeschmückte Vortragsweise charakteristisch.

Ergänzend zur möglichen Aufführungspraxis von /endu/-Gesang sei hier zuletzt auf das Fragment eines altbabylonischen Baurituals aus Uruk verwiesen, das ein Liedzitat als en ${ }_{3}$-du aufführt: ${ }^{1344}$

T 62: AUWE 23, 63-64 Nr. 122

„(Liedzitat:) 'Ziegel, es möge ein gutes Schicksal bestimmt werden, möge der Gott dir hold sein. Ziegel, errichte Herzensfreude, Ziegel, errichte Herzenszufriedenheit!', lässt er sie als Gesang/Lied vorsingen“".

Rs ii 5' sig $_{4}$ nam $<<U N>>$ he $_{2}$-tar dig̃ ir he $e_{2}-$ me-da-sa 6

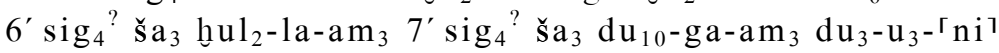

$8^{\prime}$ en $_{3}-d u-s e_{3}$ mu-ni-ib-[du $\left.u_{12}-d_{12}{ }^{?}\right]$

Das zitierte Lied wurde in der folgenden Ritualbeschreibung von einem mehrstimmigen Chor vorgetragen. Damit umfasst der Begriff nicht nur solistisch, sondern auch chorisch vorgetragene Gesänge.

Neben den bereits erbrachten Unterschieden zu Inhalt und Abgrenzung der beiden Sammelbegriffe e $n_{3}$-du und $\check{s i r}_{3}$ sind im Folgenden weitere kleinere, aber nicht zwingend definitionsgebende Beobachtungen hinsichtlich ihrer literarischen Darstellung anzubringen.

169.

1342 PSD A/3 24a; anders in der Tempelhymne an Nisaba Sjöberg/Bergmann/Gragg 1969, 49 No. 42:539. Im Kontext der Klage ist ad-ša ${ }_{4}$ meist Akkadisch nasāsu(m) gleichgesetzt; AHw 753b; CAD N/2 23b; seltener nissatu(m) AHw 795b; CAD N/2 274a tazzimtum und AHw $1341 \mathrm{~b}$.

${ }^{1343}$ Krecher 1966, 223. Aber ŠIR 3 .NAR ad-ša ${ }_{4}$ in $I \check{S} D A(+V)$ 12; Ludwig 1990, 190-191.

${ }^{1344}$ AUWE 23, 63 Anm. 114; s. a. Ambos 2004, 5+Anm. 34. 
Als Kennerin des /e n d u /-Gesangs gilt in mythologischer Hinsicht die Göttin G̃eštinana, Schwester des Hirtengottes Dumuzi. ${ }^{1345}$ Auch die Selbstlobhymnen des Königs Šulgi nennen um-mi-a „Gelehrte“ und nar-Musiker, die unter Anleitung der Ğeštinana als Liedsetzer und Sänger auftreten. ${ }^{1346}$ Bezeichnend ist hierbei, dass von $\breve{s i r}_{3}$ im Umfeld dieser Göttin nie die Rede ist, obwohl sie selbst auch die Klage um ihren toten Bruder Dumuzi intoniert. ${ }^{1347}$

Eine personelle Differenzierung von $\mathrm{s}^{\mathrm{i}} \mathrm{r}_{3}$ und $\mathrm{en}_{3}-\mathrm{du}$ wird über eine Passage in einem Balbale an Inana und Dumuzi nahe gelegt:

T 63: Dumuzi-Inana $P$ ii (Fragm. B) 6-7 $7^{1348}$

„,Der gala [...] dort ein šr $_{3}$-Lied,

der nar [erhebt] dort seinen /endu/-Gesang."

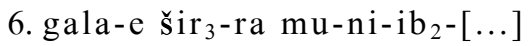

7. nar-e en ${ }_{3}-d u-a$ mu-ni-ib $-\left[b_{2}\right]$

Als Sänger der en ${ }_{3}$-du werden die nar den gala-Priestern mit ihren $\breve{s i r}_{3}$ Liedern gegenübergestellt. Diese Zuordnung bleibt hier einmalig, andernorts werden nar selbstverständlich auch als Vorträger von $\breve{s i r}_{3}$-Liedern angesprochen. ${ }^{1349}$ Umgekehrt wird $\mathrm{en}_{3}$-du nie zur Bezeichnung des gala-Repertoires verwendet, da der Terminus nicht den Bereich der Klage umfasst. ${ }^{1350}$ Auch in Bala g̃ und Eršema wird en ${ }_{3}$-du als Freudengesang dem Klang von Trauerund Klagegesang gegenüber gestellt. ${ }^{1351}$

Die oben dargestellten unterschiedlichen Bedeutungsebenen und Anwendungsbereiche von $\mathrm{šir}_{3}$ und $\mathrm{en}_{3}$-du werden unter Berücksichtigung früherer Diskussionen an dieser Stelle nochmals kurz zusammengeführt. Ludwig setzt für šir ${ }_{3}$ die Übersetzung „Lied“, für /endu/ „Gesang“ an. ${ }^{1352}$ Gegen eine solche konkrete Übersetzung wendet Volk zu Recht ein, dass die einem epo-

${ }^{1345}$ Vgl. Dumuzis Traum 19-24 (ETCSL 1.4.3); Alster 1972, 54-55 sowie ihre leitende Funktion in $D I J$; s. hier Kapitel 12.3.1.

1346 Šulgi B 325-329; vgl. Kapitel 8.2.

${ }^{1347}$ S. Kapitel 12.3.1 und 14.1.4 zu DIJ.

1348 Sefati 1998, 220, 224, 231.

${ }^{1349}$ Vgl. Šulgi B 328-329; Uruk Klage kirugu 12:24-27.

${ }^{1350}$ Die Ur III-zeitliche Urkunde Delaporte 1911, 192 Nr. 14:4-5 (AS 8) (dazu Sigrist 1992, 404) nennt den Sohn des berühmten gala Dada, der für den Vortrag eines en $\mathrm{n}_{3}$-du in Nippur mit Silber entlohnt wurde; insgesamt war diese Familie musikalisch sehr aktiv; Michalowski 2006 zum gala Dada.

1351 Cohen 1988, 322, 330: Bala g̃ des Enlil Ame Baranara a+20-21 und f+229; ibid. 376: Balag̃ des Enlil Aabba huluha a+6; ibid. 617-618: Balag̃ der Ninisina (?) Immal Gudede $\mathrm{c}+234-\mathrm{c}+235$. Deutlich spricht SK 182:9. en-du-g̃u $\mathrm{u}_{10} \quad \mathrm{er}_{2}-\mathrm{ra}$ mu-ni-in- ${ }^{\ulcorner} \mathrm{ku}_{4}{ }^{\top}$ „,Man hat mein 'Lied' in eine Klage verwandelt"; Volk 1995, 210; anders im aB Dumuzi-Eršema No. 60 bei Cohen 1981, 91:41.

${ }^{1352}$ Ludwig 1990, 34 Anm. 45; so auch Sefati 1998, 224: ii 7-8 „song“ (/šir/) und „chant“ (/endu/). 
chalen Wandel unterworfenen Bedeutungsebenen dieser Termini für eine Wiedergabe des Sumerischen nicht ausreichend fassbar seien. ${ }^{1353}$ Nichtsdestotrotz kann hier festgestellt werden, dass die von Ludwig angesetzten Übersetzungen für die Verwendung beider Begriff in altbabylonischen literarischen Texten größtenteils zutreffen. Beide Wörter sind Sammelbegriffe, die sich jedoch auf verschiedene inhaltliche und aufführungspraktische Gegebenheiten beziehen. Je nach Betrachtung kann der eine Begriff dem anderen untergeordnet sein. Im engeren Sinne ist šir ${ }_{3}$ das „Lied/Vortragsstück“, über das jedwede vokal vorgetragene Literarkomposition und Dichtung im offiziellen Kultgeschehen sowie im inoffiziellen Arbeitsalltag bezeichnet wird. /endu/ ist hingegen ein „Freudengesang“, der inhaltlich das Klagen ausschließt und musikpraktisch von einer 'gesungenen' Vortragsform bestimmt wird, für den auch die ad-ša ${ }_{4}$-Technik kennzeichnend ist.

\subsection{2 i-lu und verwandte Interjektionen}

Auch Interjektionen zeigen einen vokalen Vortrag an, so das Wort i-lu, welches allgemein mit „Lied“ übersetzt wird und je nach inhaltlichem Kontext den Ausdruck sowohl jubelnder wie auch klagender Gesänge anzeigt. ${ }^{1354}$ Als Sammelbegriff aller Formen des einfachen vokalen Vortrags, wie Rufen, Schreien oder Singen, wird es akkadisch verschiedenen Wörtern gleichgesetzt, darunter

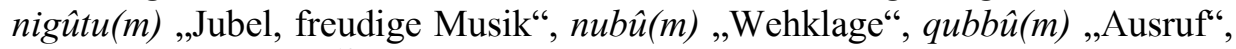
zamāru(m) „singen““. ${ }^{1355}$ Auf den Klang von Klagerufen und -schreien verweist i-lu vornehmlich in Klageliedern, wo es auch parallel zu bala g̃ verwendet wird. ${ }^{1356}$ Als Ausdruck der Freude oder des Jubels wird es in Verbindung mit den Attributen 'süß' oder als 'Lied des Herzens' vornehmlich in Nanna und Dumuzi-Inana-Liedern gebraucht. ${ }^{1357}$ Es bezeichnet Lieder der Rinder- und Schafhirten, aber auch Freudenlieder zum Preis einer Gottheit oder zur Umwerbung der Inana:

\footnotetext{
${ }^{1353}$ Volk 1995, 209 Anm. 1004.

${ }^{1354}$ Edzard 2003, 167-168; Attinger 1993, 555-563 mit Bibliographie; Krecher 1966, 148-149 + Anm. 433; i-lu-di „,der /ilu/ sagt“ oder lu ${ }_{2}-\mathrm{i}-1 \mathrm{lu}$, ,(derjenige) Mann des /ilu/“; Nabnītu 32 Kol. iii 31 šir $_{3}$-i-lu-di; Proto-Izi II 279-282 (MSL 13, 49). S. a. (gi-)i-lu-balag̃-di =

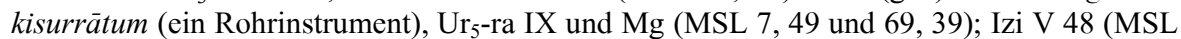
$13,162)$.

${ }^{1355}$ CAD N/2 217b; CAD N/2 309a; CAD Q 291b; AHw 788a, 800a, 925b, 1508a.

${ }^{1356}$ Cohen 1981, 64 Nr. 79:24-26; Ur Klage 86-87; Nippur-Klage 39-40; Ur-Namma A 194; Inana B 33; sehr häufig in Inana und Bilulu; s. a. Elegie an Nawirtum 18-19 i-lu ša ${ }_{3}-\mathrm{ne}$ $\check{s}_{4}$, entsprechend dem er $_{2}-\check{s}_{3}-n e-s a_{4}$, dem positiv konnotierten šir-sa g̃ gegenübergestellt.

${ }^{1357}$ Vgl. Lipit-Eštar B 51, Nanna A 34; Nanna B 59; Nanna-Hymne N 1542:24 (ETCSL 4.13.a; Hall 1985, 849:12).
} 
T 64: Išme-Dagan J 11-12

„Der rechte Hirte, derjenige des süßen i-lu, verehrt dich(Inana) mit 'lauten' /ilu/-Liedern.“

11. sipad zid lu $\mathrm{u}_{2} \mathrm{i}-\mathrm{lu} \mathrm{dug}_{3}-\mathrm{ga}-\mathrm{ke}_{4}$

12. $\mathrm{ur}_{5}-\mathrm{s̆a}_{4}$ i-lu ša-ra-an-ib-be 2

Weitere Interjektionen, die als Ableitungen von i-lu gelten und entsprechend verwendet werden, sind (e-)el-1u, e-la-la, i-lu-1am-ma und a-la-la. ${ }^{1358}$

Literarisch können solche Interjektionen auch einander parallel gesetzt sein, so in Enki und Ninhursag, wo der klang- und gesanglose Zustand vor der Erschaffung der Welt wie folgt umschrieben wird: ${ }^{1359}$

T 65: Enki und Ninhursa g 27-28

„Der nar trägt dort (noch) kein /elulam/ vor; außerhalb der Stadt trägt (noch) keiner ein /ilu/ vor.“

27. nar-e e-lu-lam nu-mu-ni-be 2

28. zag iri-ka i-lu nu-mu-ni-be ${ }_{2}$

Über die kontextuelle Parallelsetzung sind in dieser Passage beide Interjektionen auch inhaltlich voneinander unterschieden. Mit dem e-lu-lam des nar wird auf seine professionelle Singart verwiesen, die überwiegend über a-la-la angezeigt wird. ${ }^{1360}$ Das i-lu des Hirten ist demgegenüber wohl ein volkstümlicher Arbeitsgesang.

Als zur Wortklasse der Interjektionen gehörig ist $\mathrm{i}-\mathrm{lu}$ von $\mathrm{s}_{\mathrm{ir}}$ und $\mathrm{en}_{3}-\mathrm{du}$ unterschieden. Da es auf vokalen Vortrag verweist, kann es selbst sowie andere mit ihm verwandte Ausdrücke dennoch unter dem Oberbegriff šir 3 geführt werden: ${ }^{1361}$

T 66: Sumer und Ur Klage 43

„Dass das /ellu/, Gesang der Rinderhirten, nicht mehr in der Steppe erklingt.“

43. e-el-lu šir $\check{\text { gud }}_{3} \mathrm{sub}_{2}-\mathrm{sub}_{2}$-ba edin-na nu-di-de ${ }_{3}$

${ }^{1358}$ Krecher 1966, 148 Anm. 433; Civil 1976, 90; Attinger 1993, 555; Edzard 2003, 167-168.

1359 Attinger 1984a, 9, 11 Anm. 17-18; Römer 1993, 367:29-30. Anders Jacobsen 1987, 186; Bottéro/Kramer 1989, 153 übersetzen 'Elegie'.

${ }^{1360}$ Vgl. hier Kapitel 5.3.2 und SP 3.87 (T 6).

${ }^{1361}$ Vgl. Inana C 89. i-lu šir ${ }_{3}-\mathrm{ra}_{-\mathrm{am}_{3}} \mathrm{RI}$ ? a zu? bar NE [...] unklar. 
Mit i-lu ist weiterhin das literarisch mehrfach belegte i-lu-lam-ma verwandt. Dieses erscheint überwiegend im Kontext des Rinderhirtentums und bezeichnet Lieder, die von Hirten zum Klang des Buttertrogs gesungen werden: ${ }^{1362}$

\section{T 67: Sumer und Ur Klage 45-46}

„Dass der Hirte nicht die heilige Schafhürde mit einem Zaun umgibt,

Dass das Lied des Butterns nicht im Rinderstall erklingt."

45. sipa-de 3 gi-šukur-ra amaš kug-ga šu-nu-ni ${ }_{10}-\mathrm{ni}_{10}-\mathrm{de}_{3}$

46. i-lu-lam-ma dun ${ }_{5}-$ dun $_{5}{ }^{\text {dug }}{ }_{\text {šakir }}$-ra amaš-a nu-di-de ${ }_{3}$

Für das i-lu-lam-ma kann damit ein konkreter Bezug zum Rinder- und Schafhirtentum hergestellt werden, wo es möglicherweise das Arbeitslied bezeichnet. ${ }^{1363}$ Als Name einer Liedgattung ist es nicht bezeugt. Hier steht für denselben inhaltlichen Kontext um Schaf- und Rinderhirtentum der mit i-lulam-ma verwandte Terminus Ululumama, der als Liedgattungsname bezeugt ist. ${ }^{1364}$ Vertreter dieser Gattung werden einem konkreten Sitz bei kultischen Festhandlungen um Fruchtbarkeit des Landes vornehmlich im Kontext des Rinderhirtentums zugeordnet, in dem auch ein Preis an die Götter formuliert wird.

Weitere Ausrufe und Interjektionen, die zur Bezeichnung von Gesangsformen oder Vokalisten verwendet werden, sind /ua/ und /alala/. ${ }^{1365}$ Diese beiden Ausrufe werden in literarischen Texten häufig als ein komplementäres Begriffspaar gehandhabt. Im sumerischen Sprichwort SP 3.87 stehen sie für die wichtigsten Vortragsformen oder Gesangsarten eines nar-Musikers. ${ }^{1366}$ Der Ausruf /u a / ist in verschiedenen Schreibungen belegt und überwiegend im Kontext von Klagerufen anzutreffen im Sinne des deutschen „Ach!“ oder „Wehe!“. Andererseits bezeichnet er auch inhaltlich neutrale Ausrufe des

${ }^{1362}$ Enki und die Weltordnung 29-30; Šulgi C 92(?); anders in Inana und Ebih 21-22.

${ }^{1363}$ Auch das e-lu-1am wird zu i-lu-lam-ma gestellt und als Bezeichnung von Arbeitsliedern gedeutet; Jacobsen 1987, 186. Anders die akkadische Übersetzung in Izi V 40-41 (MSL 13, 161) qub̂u uššsūutu „ausgiebige Klage“" und šallurānum „Klagelaute?“; AHw 1149a šallurānu(m) und 925b qub̂ि I; CAD Š/I 253b šallurānu „lamentation“.

${ }^{1364}$ S. hier Kapitel 12.4.4.

${ }^{1365}$ Edzard 2003, 167, 170.

${ }^{1366}$ S. hier Kapitel 5.3.2 gegen PSD A/1 100; nebeneinander wohl inhaltlich komplementär verwendet auch in SP Coll. 7.77 „He said: 'Woe!' and the boat sank with him. He said: 'Alas!' and the rudder broke. The young man said: 'Ah god!' and the boat reached its destination" 17. $\mathrm{u}_{\mathrm{x}}(\mathrm{PA})-\mathrm{a} \mathrm{bi}_{2}-\mathrm{in}-\mathrm{dug}_{4} \mathrm{ma}_{2}$ ba-rda-an?-[su] 18. a-la-la bi $\mathrm{i}_{2}$-in-dug

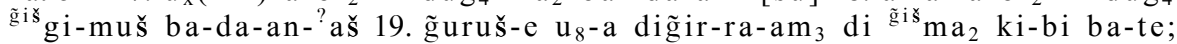
und verkürzte Parallele in SP 2.D 15; gegen Alster 1978, 104, 106, 110 meine ich, dass hier der sicherste Weg in Klagen an die Gottheit gesehen wird; akkadische Version bei Lambert 1960, 274 BE; Diskussion in PSD A/1 100 auch zur Variante mit g̃iš-a-la-la, die dort als Schreibfehler angesehen wird. 
'Erstaunens' („Oh/Ah!“) oder aber Besänftigungslaute, wie sie beispielsweise

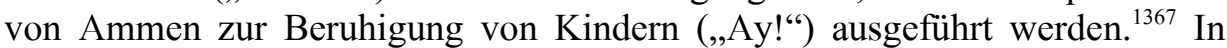
diesem Sinne dient /ua/ allgemein der Wiedergabe verschiedener rein vokaler sowie emotionaler Ausrufe und ist damit keinem konkreten Inhalt zugeordnet.

Im Gegensatz dazu steht die Interjektion /alala/ für den Jubelruf oder -gesang, kann aber außerdem auch eine konkrete Form des auffordernden Arbeitsrufs meinen. ${ }^{1368}$

Auch von den beiden Interjektionen /ua/ und /alala/ werden Gattungsnamen literarischer Kompositionen abgeleitet, das Uadi und möglicherweise das Ulila, welche in einem späteren Kapitel näher erörtert werden ${ }^{1369} \mathrm{Im}$ mittelassyrischen Liederkatalog KAR 158 viii 20 wird a-la-li schließlich als Name einer eigenständigen Gattung geführt: „Elf akkadische alali-Lieder“ (11. zama-ar a-la-li uri $\left.{ }^{\mathrm{ki}}\right) .{ }^{1370}$

\subsection{3 zamāru(m)}

zamāru $(m)$ wird lexikalisch als akkadische Entsprechung zu den zuvor besprochenen Termini š i $\mathrm{r}_{3}, \mathrm{en}_{3}$-du sowie i-lu geführt und steht damit allgemein für das 'Lied', den 'Vortrag' oder das 'Singen' an sich. ${ }^{1371}$ Als gesungen $(\operatorname{zama} r u(m))$ werden zahlreiche akkadischsprachige Literaturwerke, darunter mythologische Texte wie auch Hymnen, entweder innerhalb des Textes selbst, oder auch in einer Einleitungs- bzw. Schlussformel ausgezeichnet. ${ }^{1372}$ Hieraus lässt sich schlussfolgern, dass diese Texte, unabhängig von ihrer Länge, Struktur und ihrem Sprachstil in einer vokalen Form, rezitiert oder gesungen, vorgetragen wurden. Als Liedunterschrift entsprechend der sumerischen und akkadischen Liedgattungsnamen wird das Wort nicht gebraucht. ${ }^{1373}$

Eine besondere Verwendung des Wortes als Sammelbegriff gilt es an dieser Stelle dennoch näher zu beleuchten. Ähnlich den sumerischen Begriffen $\breve{s i r}_{3}$ und $\mathrm{en}_{3}-\mathrm{du}$ werden auch unter zamäru $(m)$ etliche Gattungsnamen zusammengefasst. Dies ist insbesondere im mittelassyrischen Liederkatalog KAR 158 aus Assur der Fall. ${ }^{1374}$ Die unter zamāru $(m)$ aufgeführten Lieder werden dort außerdem der Gruppe der irātu(m) „Brustgesänge“ gegenüber gestellt. Mit

\footnotetext{
${ }^{1367}$ Erzard 2003, 170; Attinger 1993, 49.

${ }^{1368}$ Edzard 2003, 167; PSD A/100-101; CAD A/1, 328-329. Beachte den Ur III-zeitlichen Beleg in NYPL 47:7 zu A-la-la-a als Name eines nar.

${ }^{1369}$ S. hier Kapitel 12.4.4.

${ }^{1370}$ Vgl. CAD A/1, 328 sub b); Groneberg 2003, 62 „field songs“.

${ }^{1371}$ AHw 1508a; MSL 14, 495, 498; MSL 13, 161, 184, 160; s. a. Westenholz 2005, 344-351.

1372 aB bspw. Atramhasīs III vii 14-16; Anzû I 1; Erra I 1; hierzu Wilcke 1977.

1373 Häufig auch in Kolophonen jüngerer Epochen; Hunger 1968, 47:112 ein Balag̃-Lied, 66:188, oder auch logographisch mit šir ${ }_{3}$ und $\mathrm{du}_{12}(\mathrm{TUK})=$ zamāru angegeben; vgl. Hunger 1968,181 Index sub zamāru.

${ }^{1374}$ KAR 158 ii 48, vii 11, 19, 20, 23, 24.
} 
irātu $(m)$ liegt der Name einer akkadischsprachigen Liedgattung vor, die in mehreren Textvertretern fragmentarisch überliefert ist. ${ }^{1375}$ Nur den irātu $(m)$ Liedern, die im Katalog KAR 158 Kol. viii an letzter Stelle angeführt werden, sind Angaben hinsichtlich ihrer Tonalität in Form von Saitenpaarnamen bzw. Skalen beigefügt. ${ }^{1376}$ Demgegenüber erhält keines der zuvor genannten und unter zamāru $(m)$ zusammengefassten Lieder eine entsprechende Angabe zu seiner Tonalität. Aus den auch vollständig überlieferten Liedern, deren Liedtitel dort geführt werden, kann inhaltlich zu den irātu(m)-Liedern kein wesentlicher Unterschied festgestallt werden, sie sind gleichermaßen dem Kontext des Schafhirtentums und der Liebeswerbung gewidmet. ${ }^{1377}$ Eine solche Gegenüberstellung von zamāru $(m)$ und $i r \bar{a} t u(m)$ scheint daher zunächst eine Ungleichheit bezüglich des jeweiligen Begriffsumfangs der zwei Termini aufzuweisen. Da die angegebenen Skalen ausschließlich auf die Instrumentalpraxis Bezug nehmen, könnte in diesem Fall die kategorische Trennung von zamāru $(m)$ und irātu $(m)$ auf die Aufführungspraxis zurückzuführen sein: zamāru(m) wären damit rein vokal vorgetragene Kompositionen, oder zumindest ohne Begleitung eines Saiteninstruments. ${ }^{1378}$ Demgegenüber werden irātu $(m)$-Lieder durch ein Saiteninstrument, aller Wahrscheinlichkeit nach dem ${ }^{\tilde{g}}{ }^{\mathrm{i}} \mathrm{za}_{3}-\mathrm{mi}_{2}$ begleitet.

$\mathrm{Zu}$ den inhaltlichen Bedeutungsfeldern des Wortes zamāru $(\mathrm{m})$ ist ferner festzustellen, dass es auch Klagegesänge bezeichnen kann, so gelten beispielsweise auch die im Ištar-Ritual von Mari vom gala vorgetragenen Klagen als zamāru $(\mathrm{m})$. Der Begriff ist damit insgesamt sehr weit gefasst und wird lediglich in spezifischen Kontexten näher definiert.

\subsection{Definierte Termini}

\subsection{1 $\mathrm{za}_{3}-\mathrm{mi}_{2}$, der Preis}

In zahlreichen literarischen Werken aber auch anderen Textgattungen der altbabylonischen Zeit findet sich am Ende des Textes eine Formel, in der ein Lobpreis für eine Gottheit oder einen König formuliert wird. Hierbei handelt es sich um die so genannte $\mathrm{za}_{3}-\mathrm{mi}_{2}$-Formel, deren Form und Bedeutung zuletzt von Wilcke diskutiert wurden. ${ }^{1379}$ Als den Text abschließende Preisformel ist

\footnotetext{
${ }^{1375}$ Groneberg 1999.

${ }^{1376}$ KAR 158 viii $45-52$.

${ }^{1377}$ Hierzu Black 1983, 25-30 und Anm. 10.

1378 Black 1983, 29 setzt für zamāru in diesem Zusammenhang den m. E. sehr passenden Begriff 'Ballade' an.

1379 Hartmann 1960, 214; Wilcke 1975, 246-247; Conti 1993; Attinger 1993, 755-761 mit Bibliographie; auch wenn die von Wilcke gewählte Wiedergabe dieser abschließenden Verse als 'Doxologie' durchaus mit ihren Inhalten übereinstimmt, so wurde in dieser Arbeit der neutrale Terminus 'Formel' bevorzugt.
} 
sie nicht nur auf literarische Texte beschränkt, sondern kann beispielsweise auch den Schluss lexikalischer Listen bilden, wo häufig ein Preis an die Schreibergöttin Nisaba formuliert wird. Bezeichnenderweise findet sich in Klageliedern der Gattungen Balag̃ und Eršema nie eine solche Preisformel, was ganz offenbar damit zu begründen ist, dass die Angabe im Widerspruch zu den Inhalten und der religiösen Funktion des Klageliedes stände.

Die $\mathrm{za}_{3}-\mathrm{mi}_{2}$-Formel ist keine Liedgattung, die für eine konkrete Form, einen einheitlichen Inhalt oder eine kultische Funktion reserviert ist. Dementsprechend kann eine $\mathrm{za}_{3}-\mathrm{mi}_{2}$-Formel auch in Liedunterschriften vermerkt sein, die zusätzlich eine Gattungsangabe enthalten. $\mathrm{za}_{3}-\mathrm{mi}_{2}$-Formeln sind daher auch in Balbale, Širgida, Širku(g) und in einem einzigen Ululumama-Lied bezeugt. ${ }^{1380}$ Trotz dieser Beleglage ist die $\mathrm{za}_{3}-\mathrm{mi}_{2}$-Formel häufiger in Kompositionen ohne Liedunterschriften anzutreffen. Zudem sind in solchen Texten nur selten Rubriken enthalten.

Der „Preis“ $\left(\mathrm{za}_{3}-\mathrm{mi}_{2}\right)$ von Göttern oder Königen wird nach Aussage literarischer Texte als šir ${ }_{3}$, also als gesungener oder rezitierter Vortrag aufgefasst. ${ }^{1381}$ Zum gleichnamigen Musikinstrument ${ }^{\tilde{g}}{ }^{\mathrm{s}} \mathrm{za}_{3}-\mathrm{mi}_{2}$ muss diese Formel keinen Bezug aufweisen, da mit P. Michalowski sein Name etymologisch nicht verwandt ist. ${ }^{1382}$

Die ursprüngliche These T. Jacobsens, Preishymnen seien grundsätzlich und ausschließlich von nar vorgetragen worden, ${ }^{1383}$ kann inzwischen revidiert werden. Neben den nar tassistum aus der Larsa-Ritualliste CM 33, 158ff. (=HUCA 34, 1ff.) kann hier beispielhaft auch auf das Lied Ninmešara (Inana $B$ ) verwiesen werden, dessen Schluss eine $\mathrm{za}_{3}-\mathrm{mi}_{2}$-Formel aufweist, aber in seinen letzten Zeilen dem gala zugeordnet wird. ${ }^{1384}$ Die Angabe der Preisformel $\mathrm{za}_{3}-\mathrm{mi}_{2}$ am Ende von Literaturwerken lässt damit keine eindeutigen Schlüsse auf den Vortragenden zu.

Abschließend ist hier festzuhalten, dass die $\mathrm{za}_{3}-\mathrm{mi}_{2}$-Formel weder als Gattungsangabe noch als eine Anweisung zu einer musikalischen Aufführungspraxis fungiert.

\footnotetext{
${ }^{1380}$ Ludwig 1990, 33-35.

${ }^{1381}$ S. hier Kapitel 11.1.1.

1382 Michalowski 2009 Appendix.

${ }^{1383}$ Jacobsen 1976, 15.

1384 Zgoll 1997, 441 und T 36: Erhebung der Inana (Inana B) 138-142. Hierin ist gegen Zgoll keine Diskrepanz zu sehen.
} 


\subsection{2 $\mathrm{er}_{2}$, die Klage}

Das Zeichen $\mathrm{er}_{2}$, das nach seiner Bildung wörtlich die „Träne“ bezeichnet, steht in allgemeiner Bedeutung für die Klage oder das Klagegebet. ${ }^{1385}$ In die-

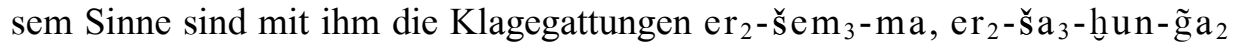
aus dem Repertoire des gala, und auch das $e_{2}-\check{s}_{2} a_{3}-n e-s a_{4}$ gebildet. Lexikalische Listen des ersten Jahrtausends führen ihren Vorträger den kalû dementsprechend als $1 u_{2}$ er er $_{2}$-ra „Mann der Klage“ bzw. $1 u_{2}$ er ${ }_{2}-$ pad $_{3}$ „Mann, der die Klage ruft/singt“". ${ }^{1386}$

Weitere Komposita mit $\mathrm{er}_{2}$, die einen deutlichen Zusammenhang zur Musikpraxis aufweisen, führt die altbabylonische Liste Proto-Kagal: ${ }^{1387}$

T 68: Proto-Kagal 361-365 (MSL 13, 77)

361. $\mathrm{er}_{2}$-bala g̃ $-\tilde{g} \mathrm{a}_{2}$

362. $\mathrm{er}_{2}-\mathrm{ub} \mathrm{b}_{3}-\mathrm{a}$

363. er $_{2}-\mathrm{šem}_{3}-\mathrm{ma}$

364. er $_{2}-\mathrm{gi}-\mathrm{di}$

365. er 2 -hul

Einen Bezug zu den Klagegattungen des gala weisen die ersten drei Einträge auf, wobei $\mathrm{ub}_{3}$ und $\mathrm{s}^{\mathrm{em}} \mathrm{m}_{3}$ hier möglicherweise Namensvarianten gleicher Perkussiva sind. Hier zeigt sich außerdem der enge Bezug der Klage zu Rohrinstrumenten (gi-di ,tönendes Rohr"6), die neben Perkussiva ein wichtiges Begleitinstrument darstellten. ${ }^{1388}$ Einzig der Ausdruck er $_{2}$-hul ,böse Klage?(/der Bedrängnis? )“ steht in keinem musikpraktischen Zusammenhang.

Aus den nach Urkunden rekonstruierten Ur III-zeitlichen und altbabylonischen Kultkalendern werden regelmäßige Opferfeste aus Anlass von Klagen bekannt, an denen auch gala beteiligt waren: er $_{2}$-sud-a, er $_{2}$-siskur s $_{2}$-ra oder auch $\mathrm{er}_{2}$-gu-la. ${ }^{1389}$ Aus der Bezeichnung $\mathrm{er}_{2}$ uru $^{\mathrm{ki}}$ ni g̃in-na lässt sich weiterhin

\footnotetext{
${ }^{1385}$ Belege und Diskussionen bei Attinger 1993, 501-507; Jaques 2006, 163-184.

${ }^{1386} \mathrm{Lu}_{2}=\check{s} a$ 165-166 (MSL 12, 134); s. a. Nabnitu IX 239 (MSL 16, 122) $\mathrm{er}_{2}=\mathrm{MIN}($ kalu $)$ e mesal.

${ }^{1387}$ Vgl. Kilmer 1977, 133.

${ }^{1388}$ Vgl. MSL 4, 120:10 er 2 gi-di-da = ta-ak-ri-ib-ti e-bu-bi-im; CAD T 200 sub lex; s. a. hier Kapitel 12.1.4 sowie den bei einer Ur III-zeitlichen Bestattunszeremonie in Nippur neben gala und ama-er $r_{2}-r a$ mitwirkenden $\mathrm{lu}_{2}-\mathrm{gi}-\mathrm{di}_{3}{ }^{!}-\mathrm{da}$ „Rohrinstrumentenspieler“ (NATN 853: Rs 2); Wilcke 2000, 43-45.

$1389 \mathrm{er}_{2}$-sud-a ist Ur III-zeitlich als Teil des ezem-mah des Nanna in Ur belegt; gegen Sigrist 1992, 174 bezweifle ich in sud „lang; ausgedehnt“ einen Verweis auf die Stimmung des begleitenden Instruments und vermute eher einen zeitlichen oder inhaltlichen Bezug als ,ausgedehnte Klage“. An den Klageopferfesten $\mathrm{er}_{2}$-sikur ${ }_{2}$-ra in Nippur beteiligten sich auch gala; Sigrist 1992, 173-176; Sallaberger 1993, 149-150, 191-193. Altbabylonisch er 2 gu-
} 
ablesen, dass solche Klagefeste auch als eine Stadtumrundung bzw. als Prozession veranstaltet wurden. ${ }^{1390}$

Neben $\mathrm{er}_{2}$ tritt literarisch häufig a-nir „Seufzen; Klage; Mühsal“ auf, im Emesal a-še-er. ${ }^{1391}$ Beide Termini sind nur zum Teil kongruent, da sie in ihrer Grundbedeutung auf zwei unterschiedliche Ausdrucksformen der Klage verweisen, die „Träne“ bzw. das „Weinen“ und das „Seufzen/Wehklagen“ und damit auf visuelle wie akustische Phänomene Bezug nehmen. ${ }^{1392}$ In letzterem Sinne ist in Klageliedern häufig vom bala g̃ a-nir-ra die Rede, ${ }^{1393}$ was die Verbindung zwischen dem Begleitinstrument und dem vokalen Ausdruck der Klage herstellt. Der Klang des Klagens kann außerdem über i-si-iš angezeigt sein, allerdings bleibt dieser Terminus im Gegensatz zu den vorherigen nicht auf das Klagen beschränkt und kann auch für freudige Ausrufe und den Jubelgesang stehen. ${ }^{1394}$

Akkadische Entsprechungen zu den sumerischen Termini der Klage sind zahlreich und auf unterschiedliche Bedeutungsebenen bezogen. Neben der wörtlichen Übertragung des visuellen Aspekts als bakîu(m)/bikitu(m) „Weinen (Verb und Substantiv)“ oder $\operatorname{dimtu}(m)$ „Träne“" werden auch die akustischen Elemente über Gleichsetzungen mit tānīhu(m), nissatu(m) oder gerrānu(m) „Jammern, Klagen“ wiedergegeben. Mit unninu(m) „Flehen, Gebet“ oder taq/kribtu(m) „Fürbitteklage/-gebet“ ist schließlich der Bezug zur rituellen Ausführung der $\mathrm{er}_{2}$ Klage im Gebet und bei der Hinwendung zum Göttlichen hergestellt. ${ }^{1395}$

Eine Klage wird meist gesprochen, wahrscheinlich rezitiert oder ausgerufen (sumerisch $\left.\mathrm{dug}_{4}, \mathrm{pad}_{3}\right)^{1396}$ In Verbindung mit gaar / šakānu(m), wörtlich "setzen; legen“" wird konkret auf den Akt der Ausführung solcher Klageriten Bezug genommen. ${ }^{1397}$ Singtechnisch kann auch von einem „Anheben der Klage“ ( er $_{2}$ zi-zi) die Rede sein. Da auch das ad-ša ${ }_{4}$ in Verbindung mit Klagen bezeugt ist, kann für ihren Vortrag ein schnell ansteigender Melodieverlauf sowie eine vibratoreiche Singtechnik vermutet werden.

1a (uru ${ }^{\mathrm{ki}}$ nig̃in-na) oder siskur ${ }_{2} \mathrm{er}_{2} \mathrm{gu}-\mathrm{la}$ in den süd- und mittelbabylonischen Zentren belegt; Richter 2004 s. $v$.

${ }^{1390}$ Vgl. Heimpel 1998; Richter 2004, 501 für Ur.

${ }^{1391}$ Krecher 1966, 88-89, 91-92; Jaques 2006, 171-177; s. a. PSD A/1 127a a-nir.

${ }^{1392}$ Krecher 1966, 92.

1393 Jaques 2006, 174-175.

1394 Attinger 1993, 563-564; Jaques 2006, 165-173. Nur in lexikalischen Listen wird es Akkadisch sihtu(m), sĭhu(m) „Lachen; Gelächter“ - auch mit sexuellem Bezug - gleichgesetzt; AHw 1100a und b; zuletzt Groneberg 1999, 185-187.

${ }^{1395}$ Gabbay 2007, 106-107.

${ }^{1396}$ Attinger 1993, 501-505.

1397 Jaques 2006, 166-167, 171-172. 


\subsubsection{Das Gebet: šud 3 und $i k r i b u(m)$}

Sowohl das sumerische šud ${ }_{3}$ als auch seine akkadische Entsprechung ikri$b u(m)$ treten in mehr oder weniger verschieden differenzierten Bedeutungsebenen auf. Sie bezeichnen zunächst allgemein das Gebet und damit vokal vorgetragene Texte, die gezielt zum Umgang mit und zur Einflussnahme auf das Göttliche eingesetzt werden. ${ }^{1398} \mathrm{Ihr}$ Sitz ist damit im Kult verankert. Gebete begleiten Opferhandlungen, die vom König oder von einem Priester an eine Gottheit gerichtet werden. ${ }^{1399}$ Ihrem Inhalt nach werden zahlreiche Textpassagen aus Königshymnen und Weihinschriften frühester Epochen als Gebete eingeordnet, die allerdings nicht über die hier behandelten Termini als solche gekennzeichnet werden. Schließlich werden šud ${ }_{3}$ und $i k r i b u(m)$ auch in Unterschriften angegeben. In diesem Fall ist das akkadische ikribu $(m)$ nicht ohne Einschränkungen dem Sumerischen šud ${ }_{3}$ gleichzusetzen.

Als šud ${ }_{3}$ „Gebet“ werden in Unterschriften bereits altbabylonisch Vertreter der Klagegattung Balag̃ ausgezeichnet. ${ }^{1400}$ Entsprechend der Funktion von Gebeten wurden Bala g̃-Lieder gezielt zur Einflussnahme auf eine Gottheit vor allem zum Zwecke ihrer Besänftigung und zur Abwehr drohenden Übels eingesetzt.

Eine offenbar eigenständige Gattung sumerischsprachiger Gebete wird durch neun Kompositionen gebildet, die durch eine einheitliche Schlussformel gekennzeichnet werden: ${ }^{1401}$,(Oh KN), <du bist> mein König“ (KN lugal$\mathrm{mu}$ ). Ein einziger Vertreter dieser Textgruppe, das Gebet Rim-Sin $C$, enthält in einer weiteren Schlusszeile die Angabe: „28 (sind) seine Zeilen. Ein Gebet an An“ (28 mu-ni šud ${ }_{3}-d_{2}$ an). ${ }^{1402}$ Mögen entsprechende Unterschriften bei allen anderen Textvertretern fehlen, so sind sie dennoch aufgrund gemeinsamer formaler, sprachlicher sowie inhaltlicher Kriterien einer gemeinsamen Gruppe von Gebetskompositionen $\left(\breve{s u d}_{3}\right)$ zuzuordnen. Dieser gehören an: vier weitere Gebete an Rìm-Sîn $(D-G)$, Hammurabi $B$ sowie Samsuiluna $B, C$ und $E$, wovon sich die zwei ersteren auf einer Tafel befinden. ${ }^{1403}$ Die Verbreitung dieser Gebetsgattung beschränkt sich damit auf das 18. Jahrhundert, beginnend mit dem letzten großen Herrscher der Larsa-Dynastie bis zum babylonischen König

\footnotetext{
${ }^{1398}$ HrwG II 456.

${ }^{1399}$ S. allgemein Falkenstein und von Soden 1957-71.

${ }^{1400}$ S. hier Kapitel 12.1.1.

${ }^{1401}$ Van Dijk 1966-67; Charpin 1986, 273-275.

1402 Rim-Sin C 9; zuletzt Brisch 2007, 61-63, 200-202 Bearbeitung und Diskussion.

${ }^{1403}$ Bearbeitungen der Rìm-Sîn-Gebete bei Steible 1975, Charpin 1986, 273-275 und neu bei Brisch 2007, 58-67, 200-240; zu Hammurabi B s. van Dijk 1966-67, zu Samsuiluna $B$ und $C$ Falkenstein 1949, Samsuiluna E Sjöberg 1973a. Nach inhaltlichen und sprachlichen Kriterien, die von Segenswünschen und der Bestimmung eines guten Schicksals für den König geprägt werden, könnte Hammurabi D (ETCSL 2.8.24; Sjöberg 1972) derselben Gruppe zuzuordnen sein. Zum schwierigen Gebet Rìm-Sin A, das möglicherweise von einem Priester an den König gerichtet ist, s. zuletzt Brisch 2007, 57-58.
} 
Samsuiluna, in dessen Regierungzeit der Verlust der südbabylonischen Städte stattfand. Bezeichnenderweise stammen die meisten Vertreter dieser Gebete aus Ur (Rìm-Sin C-G) oder Nippur (Rìm-Sìn E; Samsuiluna E).

Ihrem Inhalt nach richten sich die Gebete entweder an eine einzige Gottheit oder an eine Gruppe von Haupt- oder auch Schutzgottheiten. Zentrales Thema sind Opferhandlungen, die in Tempeln durchgeführt werden, und eine abschließende Bitte um ihre Annahme. Neben der Anrufung der Gottheit wird auch gleichzeitig der König in seiner Aufgabe als Opferbringer und Erhalter der rechten Kultordnung bestätigt. Die Sprache der Gebete ist von Segenswünschen und einer rechten Schicksalsbestimmung für den König geprägt. Auch die gemeinsame Unterschrift „Oh KN, mein König!“ zeigt auf, dass zentrales Anliegen der Gebete eine Erhöhung des Königs und die Festigung seiner Herrschaft ist.

Mit Ausnahme des Gebets Rìm-Sìn E, das nach zwei Tafeln aus Ur und Nippur bekannt ist, ${ }^{1404}$ sind alle Textvertreter dieser Gattung in einer einzigen Abschrift erhalten. D. Charpin deutete hieraus, dass die Gebete zu einmaligen Anlässen verfasst wurden. ${ }^{1405}$ Ein konkreter Anlass wird nur einmal in Rim-Sin D angegeben, das in Zeile 49 wie folgt schließt: ,,[Gebet an die wohlwollenden Götter] beim Eintritt durch das große Tor" ${ }^{1406}$ Nicht den konkreten Akt der Inthronisation, sondern die Legitimierung des Königs in den verschiedenen Städten Mesopotamiens über das Darreichen von Opfern und die Begrüßung durch die lokale Priesterschaft kann als Anlass für die Komposition der Gebete angesetzt werden. ${ }^{1407}$ Für die Gebete des Rīm-Sîn vermutet D. Charpin konkret den Huldigungsakt des Königs für die Hauptgötter Nanna und Ningal und damit die Erfüllung seiner religiösen Pflichten in Ur. ${ }^{1408}$

Persönlich führt der König Reisen in die südbabylonischen Kultzentren durch, um ihren jeweiligen Göttern zu opfern und ihre Zusicherung für ein langes Leben zu erhalten. Das sehr kurze Gebet Hammurabi $B$ richtet sich beispielsweise an Enki von Eridu. In Samsuiluna $B$ und $E$ wird deutlich die Legitimation des Königs und seiner Regentschaft in Babylon durch Enlil und seinen Kreis in Nippur einerseits, sowie durch die Schöpfergötter Enki und Damgalnuna in Eridu andererseits erbeten.

\footnotetext{
${ }^{1404}$ UET 6/1, 104 und N 3089; s. Brisch 2007, 64, 212-219.

${ }^{1405}$ Charpin 1986, 302.

${ }^{1406}$ Rim-Sin $D$ 49. [šud ${ }_{3}-\mathrm{de}_{3}$ dig̃ ir silim]-ma abul mah $\mathrm{ku}_{4}$-ra-kam nach Kramer in UET 6/1 S. 10b in Anlehnung an die Unterschrift von Rim-Sin $C$ und der Angabe dig̃ irsilim in Rìm-Sin D 18 ergänzt; Charpin 1986, 285; s. dagegen kritisch Brisch 2007, 63 Anm. 65.

${ }^{1407}$ Vgl. Charpin 1986, 301-302; ergänzend zu Steible 1975, 88-89.

${ }^{1408}$ Charpin 1986, 301-302; hierzu auch Brisch 2007, 62-63.
} 
Beachtenswert ist schließlich die Unterschriftennotitz des Gebets Rìm-Sin E: „Summe: 85 sind seine Zeilen. Geprüft (durch den) König“ (šu-nigin 85 muni igi-du ${ }_{8}$-a lugal). ${ }^{1409}$ Anders als alle bisherigen Deutungsversuche dieser Zeile lehne ich meine Übersetzung an die durch D. Charpin rekonstruierten Vorgänge für die Neudichtung von Königsinschriften in Mari an. ${ }^{1410} \mathrm{Ihm}$ zufolge wählte der König persönlich aus mehreren ihm vorgelegten Kompositionen die gefälligste aus, um sie dann endgültig durch Handwerker auf Stein in Stelenform übertragen zu lassen. Auch zu den hier behandelten Gebeten wäre zu mutmaßen, ob sie möglicherweise als Votivgaben, ob in Ton oder auf Stein, in den jeweiligen Tempeln aufgestellt wurden, um die Beständigkeit der Königslegitimierung durch die Götter zu sichern. Unglücklicherweise sind die genauen Fundumstände der Tafeln nicht mehr bekannt.

Literarisch wird bestätigt, dass Gebete von professionellen Sängern, den nar vorgetragen wurden. ${ }^{1411}$ Königshymnen der Ur III- und Isin-Dynastie beschreiben zudem, wie Instrumentalmusik und Gesang die durch den König ausgeführten Opferhandlungen begleiteten. ${ }^{1412}$ Zur musikalischen Inszenierung der hier kurz vorgestellten Gebete können dennoch aufgrund der mangelnden Hinweise in den Texten selbst keine konkreten Aussagen getroffen werden.

Auch das akkadische ikribu(m) steht nicht nur allgemein für das Gebet, sondern auch konkret für die Bezeichnung der akkadischsprachigen Opferschaugebete, hier von karābu(m) „Gebet; Segen“" abzuleiten, welches sumerisch siskur ${ }_{2}$ „Opfer; Gebet“ entsprochen wird. ${ }^{1413} i k r i b u(m)$-Gebete wurden an die Gottheit gerichtet, um das Gelingen einer Opferschau zu erbitten. Anders als die sumerischsprachigen šud ${ }_{3}$-Gebete können sie einem konkreten kultischen Sitz auch in privatem Kontext zugewiesen werden.

Die Gattung der ikribu(m) bildet mit Ausnahme der meist einfach gehaltenen Götterbriefe die bisher einzig bekannte akkadischsprachige Gebetsform, die bereits altbabylonisch attestiert ist. Eine einheitliche Unterschriftenformel, wie bei sumerischsprachigen literarischen Kompositionen üblich, ist diesen Texten jedoch nicht gegeben. Vertreter der Gruppe lassen sich größtenteils aufgrund inhaltlicher Kriterien und sprachlicher Formulierungen identifizieren. 13 Vertreter sind aus altbabylonischer Zeit bekannt, von denen allerdings nur fünf in Bearbeitungen vorliegen. ${ }^{1414}$ Entgegen der neuassyrischen $i k r i b u(m)$,

\footnotetext{
${ }^{1409}$ UET 6/1, 104; zuletzt Brisch 2007, 64, 219 mit Diskussion.

${ }^{1410}$ Charpin 2006, 153-154.

${ }^{1411}$ Šulgi E 14-15; Šulgi B 311-313; Ludwig 1990, Ludwig 1990, 34-45.

${ }^{1412}$ Vorwiegend durch das Instrumentenensemble tigi $-\breve{s e m}_{3}$ und $\mathrm{a}_{2}-1 \mathrm{a}_{2}$, hierzu ausführlich Shehata 2010

${ }^{1413}$ Von Soden 1957-71, 163-165 § 8; Starr 1983, 25, 44-46.

${ }^{1414}$ Mayer 1976, 32 Anm. 63; bisher veröffentlicht sind eines der „Nachtgebete“ (ikribū mušìtim) aus der Eremitage neu ediert bei Horowitz 2000; übersetzt bei Hecker 1989, 718-719; ein weiteres Nachtgebet (CBS 574) neu ediert bei Horowitz/Wasserman 1996; ein ikribu(m) an
} 
welche sich ausschließlich an die Götter Šamaš und Adad richten, besteht bei den bislang bekannten altbabylonischen Textvertretern eine Vorliebe für die 'Götter der Nacht' sowie für weibliche Göttinnen.

Grundsätzlich gehören diese Gebete und Omina zum Repertoire des $\operatorname{bar} \hat{u}(m)$, des „Opferschauers“, da sie im Verlauf von Opferschauritualen vorgetragen wurden. ${ }^{1415}$ Drei der altbabylonisch erhaltenen Texte entstammen dem Archiv des gala-mah Ur-Utu von Sippar Amnānum. ${ }^{1416}$ Ob diese Gebete vom Opferschauer oder von Ur-Utu selbst mit einer persönlichen Anfrage an die Göttinnen gerichtet wurden, ist nicht bekannt.

$i k r i b u(m)$-Gebete werden in aller Regel gesprochen oder rezitiert, was über

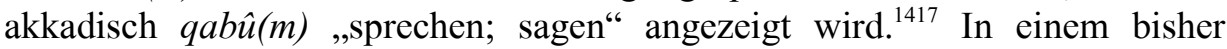
einzigartigen neuassyrischen Text aus Sippar finden sich mögliche Hinweise auf instrumentale Begleitung solcher Gebete. ${ }^{1418}$ Besagter Text BM $65217+66616$ nennt in der ersten Hälfte die Namen der ersten fünf Saiten der $\tilde{g}{ }^{\tilde{s}} \mathrm{za}_{3}-\mathrm{mi}_{2}$-Leier und ordnet sie jeweils den Titeln von fünf nicht identifizierten ikribu(m) zu. ${ }^{1419}$ Unglücklicherweise ist der Text stark zerstört. Des Weiteren bleibt unklar, ob die Saitennamen in diesem Zusammenhang auf den Anfangston für den jeweiligen Gebetvortrag oder wie von Kilmer vermutet auf eine ganze Skala Bezug nehmen, entsprechend der bekannten Saitenpaarnamen. ${ }^{1420}$ Der erste Abschnitt des Textes wird schließlich unterschrieben mit der Angabe: „Dies sind Gebete des nar für...“.”21 Angesichts dieser Zuordnung kann von einem musikalisch-professionellen Vortrag der Gebete ausgegangen werden. Es bleibt allerdings unklar, ob der Terminus $i k r i b \bar{u}$ hier konkret oder eher allgemein verwendet wird. Es müssen hier nicht zwingend Opferschaugebete bezeichnet sein, sondern möglicherweise Texte anderer Gattungen, die im Rahmen größerer Götterfeste mit Hymnen oder Preisliedern in der Funktion eines Gebets an die Gottheit gerichtet wurden. ${ }^{1422}$

Die Begriffe $\check{s u d}_{3}$ und $i k r i b u(m)$ werden zusammengefasst als allgemeine Termini verwendet. Zur Bezeichnung konkreter Textarten mit einheitlichen formalen und inhaltlichen Kriterien können sie ebenfalls auftreten, allerdings wohl weniger im Sinne eines Gattungsnamens als vielmehr einer funktionalen

Šamaš und Adad bei Goetze 1968, 25-29 (YOS 11, 22); Hecker 1989, 719-721; sowie zwei $i k r i b u(m)$ an Ninisina und Annunitum aus dem Ur-Utu-Archiv in Sippar Amnānum bei De Meyer 1982a, 271-278.

${ }^{1415}$ Eine ausführliche Studie hierzu liefert Starr 1983.

${ }^{1416}$ De Meyer 1982a, 271-278 + Anm. 7: Di 261, Di 262 und Di 306.

${ }^{1417}$ AHw 369b nur mit qab̂े.

${ }^{1418}$ Kilmer 1984, 69-80.

${ }^{1419}$ Kilmer 1984, 72-73: BM 65217+66616 Vs 1-11.

${ }^{1420}$ Diskussion bei Kilmer 1984, 74-76.

${ }^{1421}$ Kilmer 1984, 73: Rs 12. an-nu-ti ik-ri-bi $[\check{s}] a \mathrm{lu}_{2}$-nar $a-n a{ }^{\ulcorner} \mathrm{X}^{\top}[\ldots]$.

${ }^{1422}$ Starr 1983, 45-46. 
Einordnung folgend. Gebete im Rahmen größerer Opferfeste, wie sie aus den sumerischsprachigen Dichtungen bekannt sind, wurden mit einem Perkussionsensemble begleitet, für die neuassyrischen Gebete $(i k r i b \bar{u})$ des nar ist auch eine Begleitung mit einem Saiteninstrument belegt, Opferschaugebete im privaten Bereich könnten hingegen auch rein vokal vorgetragen worden sein. Die Darbietungsformen von Gebeten werden damit im Wesentlichen durch den Kontext bestimmt. 


\section{Sumerische Liedgattungen}

\subsection{Nach Instrumenten bezeichnete Gattungen}

\subsubsection{Bala $\tilde{g}$}

Mit dem Wort Balag̃ wird eine eigenständige Gattung von Klageliedern bezeichnet, die zu den wenigen sumerischsprachigen Gebetsgattungen gehört, die bis in die seleukidische Zeit tradiert wurde. ${ }^{1423}$ Balag̃-Lieder sind in der Forschung bereits mehrfach ausführlich behandelt worden, eine wichtige Grundlage zu ihrer Erschließung bilden der bibliographische Artikel von J. Black von 1981 sowie das zweibändige Werk von M. E. Cohen von 1988. An dieser Stelle soll ein Überblick insbesondere zur altbabylonischen Überlieferung geboten und die Aufführungspraxis dieser Texte erörtert werden.

Die Klageliedgattung bala g ist nach dem gleichnamigen Musikinstrument benannt. Ein fragmentarisch erhaltener Katalog aus altbabylonischer Zeit überliefert die Titel von ${ }^{k u s ̌}$ bala g̃ und er-šem ${ }_{3}$-ma-Liedern neben Vertretern der sumerischen Gattung šir ${ }_{3}$-nam-šub. ${ }^{1424}$ Das Determinativ kuš „Tierhaut“ beim Namen der Liedgattung Balag̃ ist hier einmalig und weist auf den instrumentalpraktischen Zusammenhang zwischen Instrument und Gebetstext hin. Die Klagen wurden durch das Spiel eines balag̃-Instruments begleitet, welches meines Erachtens angesichts des rein perkussiven gala-Instrumentariums für diese Zeit als Membranophon zu identifizieren ist. ${ }^{1425}$

Balag̃-Lieder gelten nach antiker Terminologie als Gebete $\left(\check{s}^{\prime} d_{3}\right),{ }^{1426}$ die an die Hauptgottheiten des sumerisch-akkadischen Pantheons gerichtet sind. In ihrer Unterschrift findet sich der Name der jeweils angerufenen Gottheit über die Formel „Bala g̃ des/der GN“ notiert. ${ }^{1427}$

\footnotetext{
${ }^{1423}$ Black 1987; Cohen 1988.

${ }^{1424}$ Katalog B1 (VS 10, 216) aus Sippar; Krecher 1966, 33; ETCSL 0.2.07.

${ }^{1425} \mathrm{~S}$. zum Instrumentarium des gala hier Kapitel 6.3.2.1.

${ }^{1426}$ Cohen 1988, 29-30; s. a. Krecher 1966, 30-31; in Šulgi $C$ Fragm. 90 wird šud ${ }_{3}$ neben bala g̃ genannt.

${ }^{1427}$ Vgl. Black 1987, 36-37; zu den Varianten aB Unterschriftenformeln s. Cohen 1988, 29-31.
} 
Inhaltlich sind die Kompositionen als Klagen formuliert, die zuweilen aber auch narrative Elemente enthalten. Weibliche Gottheiten betrauern die Zerstörung ihrer Tempel und Städte sowie ihre hieraus resultierende Heimatlosigkeit. Männliche Gottheiten werden als Helden gepriesen, wobei ihre zerstörerische und vernichtende Kraft, insbesondere die des Enlil, in den Vordergrund gerückt wird. In wenigen Vertretern sind narrative Textpassagen enthalten, die aus der Mythologie bekannte Themen um Inana und den Verlust ihres Gatten Dumuzi behandeln. Formal sind die Lieder von längeren Litaneien geprägt, die Tempel oder Epitheta der angerufenen Gottheit auflisten.

Die Funktion dieser Klagelieder liegt darin, das Herz der angesprochenen Gottheit zu besänftigen. ${ }^{1428}$ Diesem Sinn und Zweck der Lieder liegt die altorientalische Vorstellung zugrunde, dass eine unruhige, heimatlose und von Wut und Trauer erfüllte Gottheit eine Gefahr für den Erhalt der weltlichen Ordnung darstellt. Für die neuassyrische und seleukidische Zeit ist bekannt, dass Bala g auch in Namburbi-Ritualen zur Abwehr drohenden Übels vorgetragen wurden. ${ }^{1429}$

Balag̃-Lieder oder Gebetsklagen, die nach kirugu-Rubriken ${ }^{1430}$ unterteilt sind, datieren frühestens in die Zeit der Larsa-Könige. ${ }^{1431}$ Die für die altbabylonische Zeit belegten Texte verteilen sich in ihrer Herkunft über den gesamten babylonischen Raum. ${ }^{1432}$ Soweit bekannt sind Bala g̃-Lieder in Ur, Larsa, Nippur, Sippar, Kiš, in Susa, der Hauptstadt des elamischen Herrschaftsgebietes, sowie in Meturān aufgefunden worden. ${ }^{1433}$ Altbabylonisch sind außerdem fünf Kataloge überliefert, die Titel von Bala g̃-Liedern auflisten. ${ }^{1434}$ Mit Beginn der neuassyrischen Zeit werden die Kompositionen kanonisiert, wobei nicht alle altbabylonisch verbreiteten Texte in den Kanon des ersten Jahrtau-

${ }^{1428}$ In 5R 52,1 und 4R 28, 2: „Die (tiefe) Weisheit des Ea, kalû(-Texte), die den Weisen vorbehalten sind, geeignet, das Herz der großen Götter zu besänftigen“" nēmeq ${ }^{d}$ Ea kalûtu nișirti apkalli ša ana nūh libbi ilāni šūluku; Krecher 1966, 26.

${ }^{1429}$ Cohen 1988, 20-21; Black 1991, 29.

${ }^{1430}$ Ausführlich besprochen in Kapitel 14.1.5.

${ }^{1431}$ Vgl. die zwei Balag̃ Nr. 43 (Dumuzi?) und 53 (Ning̃išzida: wohl in zwei Versionen: TCL 15, 8 und CT 15, 26f. mit CT 15, 30) Black 1987, 53-55 die Könige der Ur III- und IsinDynastie nennen, was als Zeitpunkt post quem für die Textkomposition anzusehen ist; s. a. Cohen 1988, 201-202 und Fritz 2003, 183-186.

${ }^{1432}$ Vgl. Liste bei Wilcke 1975, 285-286; Katalog bei Black 1981 sowie jeweils unter den einzelnen Titeln Cohen 1988.

${ }^{1433}$ Balag̃ Nr. 1 Abzu pe'ellam (Nippur, Sippar?, Babylon?); Bala g̃ Nr. 4 Utugin eta (Kiš, Nippur, Sippar?); Nr. 16 Aba Huluhha (Nippur?, Kiš?, Sippar?; Kutscher 1975); Bala g̃ Nr. 36 Uru-ama 'irabi (Susa, Kiš, [Darbietung in Mari]);

${ }^{1434}$ Drei aB Katalogzylinder bei Kramer 1982 BM 23612, 85564 und 23249, neu publiziert bei Shaffer 2000 zusammen mit dem H. Clark Cylinder, alle mit Balag der Inana und anderer Götter; außerdem der bereits genannte Katalog B1 aus Sippar (VS 10, 216) ETCSL 0.2.07 mit Balag̃, Eršema und Širnamšub. 
sends aufgenommen werden. Dass es zur Gattung der Bala g̃-Gebete Vorgänger gab, die möglicherweise bis in die Akkadzeit zurückreichen, ist am Beispiel des Fluch über Akkade oder dem Lied Ninmešara nachweisbar, wo am Schluss der Komposition das gesamte Lied der Liturgie des gala angeschlossen wird. ${ }^{1435}$ Diese Kompositionen weisen sowohl in ihrer Thematik, einer Klage um Zerstörungswut und Trauer einer Gottheit, als auch in ihrer Funktion der Besänftigung einen engen Bezug zum bekannten Repertoire des gala-Priesters auf. $^{1436}$

Balag̃-Lieder sind fester Bestandteil des gala-Repertoires, deren Aufführung im Kult mit dem Vortrag von Eršema-Liedern verknüpft war. Die Kombination beider Klageliedgattungen im Rahmen ritueller Handlungen ist frühestens altbabylonisch im Ištar-Ritual von Mari belegt, wo auf den Vortrag des Bala g̃ der Inana Uru-ama'irabi ein Eršema an Enlil folgt. ${ }^{1437}$ Dieses wird durch einen einzelnen gala unter Begleitung einer halhallatum-Trommel vorgetragen. Über die Verbindung und kultische Zuordnung dieser Lieder im ersten Jahrtausend gibt im Wesentlichen der neuassyrische Katalog 4R2 53 Auskunft. ${ }^{1438}$

Balag̃ und Eršema sind hauptsächlich im Emesal verfasst, das möglicherweise bereits zur altbabylonischen Zeit als liturgische Vortragssprache dieser Texte galt. Noch in dieser Zeit werden außerdem einzelnen Vertretern akkadische Übersetzungen beigefügt. ${ }^{1439}$ Bezeichnend und bisher einmalig ist die Tafel UET 6/2, 403 aus Ur, die eine wortwörtliche akkadische Übersetzung einer Passage aus Uru-ama'irabi enthält. ${ }^{1440}$ Vertreter aus seleukidischer Zeit weisen zusätzlich zum Text Glossen und Melismen auf, die als Anweisungen zur vokalen sowie instrumentalen Aufführungspraxis der Lieder gelten. ${ }^{141}$ Hier werden zusätzlich zur Aneinanderreihung verschiedener Vokale, die möglicherweise eine Singart, ein Melisma oder eine 'Vokalfärbung' anzeigen, auch Anweisungen zum Spiel der Instrumente des gala, dem meze und der šem ${ }_{3}$ -

\footnotetext{
${ }^{1435}$ ETCSL 4.07.2 138-142 und hier T 27: Fluch über Akkade 198-201.

${ }^{1436}$ Vgl. Cooper 2006b, 41-42 zum Fluch über Akkade; zur Diskussion um die 'Vorläufer' von Balag̃-Gebeten s. vor allem Cohen 1988, 33- 39; anders Black 1985, 13, ders. 1991, 31 und Cooper 2006b.

${ }^{1437}$ Zuletzt Ziegler 2007, 55-64.

${ }^{1438}$ Cohen 1988, 15-16; Black 1987, 33; Black 1991, 25.

${ }^{1439}$ Cohen 1988, 20: TCL 16, 69 zu Uru-ama'irabi gehörig; außerdem aus Larsa das Bala g̃ Aba Huluhha mit der Stichzeile zum Bala g̃ Enemani ilu ilu; Charpin 2003, 314.

${ }^{1440}$ Gabbay/Wasserman 2006.

${ }^{1441}$ Bielitz 1970; Lambert 1971; Volk 1994, 187-190; Mirelman 2009 mit ausführlichem Kata$\log$.
} 
Trommel angegeben. ${ }^{1442}$ Für die altbabylonische Zeit sind Glossen, die als vokaltechnische Angaben verstanden werden können, bislang nur in einem Dumuzi-Inana-Lied aus Sippar bezeugt. ${ }^{1443}$

Ein wichtiges formales Merkmal von Bala g̃-Liedern, das gleichzeitig über ihre Aufführungspraxis Auskunft gibt, ist ihre Einteilung nach mehreren nummerierten ki-ru-gu $\mathrm{g}_{2}$-Rubriken, die nach ihrer wörtlichen Bedeutung den „Ort des Gegenübertretens" markieren. ${ }^{1444}$ Der jeweils letzte Abschnitt eines Bala g̃ ist durch die Rubrik ki-šu $\mathrm{u}_{2}$-bi(-im) „Sein Ort des Abdeckens“ gekennzeich-

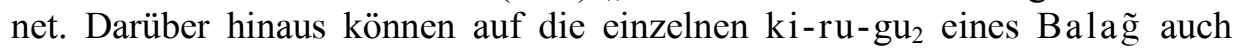
g̃ $i$ š-gi ${ }_{4}$-g̃al ${ }_{2}$-Einheiten, der „Gegengesang“ folgen. ${ }^{1445}$

Über die in Balag̃-Texten enthaltenen Rubriknamen sowie Informationen zu den Kulthandlungen des gala aus Alltagsdokumenten, die frühestens in die Ur III-Zeit datieren, lässt sich rekonstruieren, dass der Vortrag dieser Lieder begleitend $\mathrm{zu}$ einer Festprozession, beispielsweise einer Stadtumrundung stattfand. ${ }^{1446}$ Der Festzug machte bei verschiedenen Stadttoren oder auch an Kultschreinen von Göttern halt, wo dann einzelne kirugu-Liedabschnitte zum Vortrag kamen. Die letzte Rubrik kišu markiert den Abschluss und damit das Abdecken des begleitend gespielten Membranophons. ${ }^{1447}$ Der jeweilige Vortrag des Liedabschnitts konnte auch durch das Darbringen von Opfern begleitet werden. ${ }^{1448}$ Solche Klageumzüge galten der Sicherung der Stadt und ihrer Bewohner. Tore wie auch Türen sind Grenzübergänge, an denen die Abwehr übler Mächte und Feinde aller Art besonders wichtig ist, beispielsweise auch über die Postierung von Schutzfiguren. Ur III-zeitliche Texte sowie Kultkalender des ersten Jahrtausends informieren über die regelmäßige Ausführung solcher Kultrituale, deren Anlass verschiedene Gefahrenzustände sein konnten, beispielsweise auch der Schwarzmondtag. Aus Ritualtexten des ersten Jahrtausends ist schließlich bekannt, dass Bala g̃ und Eršema vom kalû auch begleitend $\mathrm{zu}$ Tempelgrundsteinlegungen und Kultbildrestaurierungen gesungen

${ }^{1442}$ Bspw. meze $1 \mathrm{a}_{2}$, ,das meze halten(?)“ in SBH 8 (r. 8), SBH 66 (r. 49), SBH 1443 und Conv. (r. 4, 27); oder šem 3 gin „die šem ${ }_{3}$-Trommel aufstellen(?)“ in Conv. (r. 5, Г287); als Anleitungen zur Handhabe der begleitenden Musikinstrumente steht auch šu ${ }_{2}$ in verschiedenen Kombinationen für das „Abdecken“ des Instruments und šub für das „Niederlegen“; vgl. Mirelman 2009.

${ }^{1443}$ Volk 1994, 188-190 zu CT 58, 12 und hier Kapitel 14.2.3.

${ }^{1444} \mathrm{Zu}$ dieser Rubrik s. ausführlich Kapitel 14.1.5.

${ }^{1445} \mathrm{Im}$ aB Bala g̃ an Dumuzi CT 42, 15 Vs ii 6 belegt; vgl. Cohen 1988, 31; einen für mich nicht nachvollziehbaren engen Zusammenhang zwischen beiden genannten Rubriken postuliert Rubio 2009, 23-24.

${ }^{1446}$ Für die Ur III-Zeit s. Sallaberger 1993, 149-150, 297-298; Heimpel 1998; für die aB Zeit s. CT 45, 84 hier Kapitel 9.6.3.1.3.

${ }^{1447}$ S. hier Kapitel 14.1.5.

${ }^{1448}$ Vgl. Cohen 1988, 26. 
wurden. ${ }^{1449}$ Bei jedem dieser Ereignisse wurde eine Gottheit von einer alten 'Wohnung', ob Tempel oder Kultbild, in eine neue überführt. Im entstehenden Zwischenzustand, der so genannten 'twilight-zone' lauerten unzählige Gefahren, deren Übergriffe auf die Menschenwelt durch den Priester zu verhindern waren.

Insgesamt ist sowohl für die altbabylonischen wie auch späteren Vertreter dieser Gattung der Nachweis gegeben, dass sie in einer besonderen Vortragssprache, dem Emesal, einer besonderen Singart, angezeigt durch melismenartige Glossen, sowie unter instrumentaler, ausschließlich perkussiver Begleitung zum Vortrag kamen. Aufgrund der Begleitung ist an einen rhythmischen Vortrag zu denken, angesichts der späten Melismen scheinen die Texte jedoch vielfach auch in einem freien Gesang vorgetragen worden zu sein. Da für die Begleitung auch Idiophone in Frage kommen, könnten die Instrumente mehr zur Pointierung einzelner Gesangspassagen und nicht zwingend zur Untermalung eines streng-metrischen Vortrags eingesetzt worden sein. ${ }^{1450}$ Grundsätzlich steht fest, dass die Gebete gesungen und nicht rezitiert wurden, was die Angabe des Verbs zamār(um) ,singen“ im Ištar-Ritual von Mari sowie in neuassyrischen und seleukidischen Kolophonen nahe legt. ${ }^{1451}$

\subsubsection{Tigi und Adab}

Die sumerischen Termini Tigi, Adab, und in dieselbe Gruppe ist auch das Zamzam $^{1452}$ zu zählen, sind zugleich als Namen von Liedgattungen sowie von Musikinstrumenten belegt. ${ }^{1453}$ Lediglich vom Wort Tigi wird darüber hinaus die Bezeichnung eines Musikerberufs abgeleitet. ${ }^{1454}$ Im Gegensatz zum Bala g sind diese Gattungsnamen ausschließlich Hymnen unterschrieben.

1449 Ambos 2004, 10-13, 52-61; Linssen 2004, 253, 257:II 14; Farber 2003, 208-213. Auf die dem gala spezifische Handlungsweise könnte nach Durand/Guichard 1997, 62-63 zu iv 16' Anm. c) ein Verb *kâlu im Ištar-Ritual von Mari verweisen.

${ }^{1450}$ gala bzw. kalû begleiteten im 1. Jt. ihre Kultgesänge auch auf dem Sistrum; Wallenfels (1994: 19, $20 \mathrm{Nr}$. 53); vergleichbar ist diese Aufführungsart mit syrisch-orthodoxen sowie äthiopischen Gottesdiensten, wo das Rezitieren der Gebete auf Zimbeln bzw. Sistren begleitet wird.

${ }^{1451}$ Zuletzt Black 1991, $26+$ Anm. 24. Zu beachten ist allerdings die uneindeutige Definition von 'Singen' in verschiedenen Kulturen, so wird die Qur'ān-Rezitation nach westlichem Sinne als 'Gesang' verstanden, in der arabisch-sprachigen Kultur allerdings als tartīl 'Rezitieren' bzw. 'Psalmodieren' und nicht als ginā' „Gesang“ aufgefasst.

${ }^{1452}$ Nach Wilcke 1975, 257 auch die Gattung Kun g̃ar.

${ }^{1453}$ Die Unterscheidung der jeweiligen Bedeutung ist nicht immer einfach; im Text The Slave and the Scoundrel 26-28 handelt es sich beispielsweise m. E. gegen die Übersetzung von Roth 1983, 276:26-28, ,(Meanwhile,) Nanna-ildu 2 -mu spent all day every day [playing] the tigi and zamzam instruments" (so auch Alster 1992, 200) wohl eher um die gleichnamigen Liedgattungen Tigi und Zamzam; s. Shehata 2007.

1454 S. Kapitel 5.4.1; auch a-da-ba steht präsargonisch in Lagaš-Texten des Baba-Tempels zur Bezeichnung einer Person, möglicherweise auch als Verweis auf den gleichnamigen Ort; 
Tigi und Adab sind im Vergleich zu den meisten mit šir ${ }_{3}$ gebildeten Liedgattungen eher kürzere Preislieder oder Hymnen, die an eine einzelne Gottheit gerichtet sind und zusätzlich einen Preis an den König enthalten können. ${ }^{1455}$ Entsprechend der üblichen Gattungsangabe findet sich in der Unterschrift die Widmung an die jeweilige Gottheit über die formelhafte Wendung „Tigi bzw. Adab des GN" angegeben, an die sich dann in aller Regel auch der im Lied formulierte Preis richtet. Sofern eine Erwähnung des Königs enthalten ist, wird diese in Form einer Fürbitte oder Erhöhung formuliert, die sein besonderes Verhältnis zur Gottheit darstellt. Preis und Erhöhung des Königs können entweder das gesamte Lied parallel zum Gottespreis durchziehen oder lediglich in der Rubrik g̃išgi g̃al enthalten sein. ${ }^{1456}$

Während sich die meisten Tigi- und Adab-Lieder auf den Preis der Gottheit unter Aufzählung von Attributen und Epitheta beschränken, sind in einigen Texten auch Bezüge zu mythologischen und auch realen bzw. historischen Ereignissen formuliert. Das als Dialog gehaltene Tigi Dumuzi-Inana $H$ thematisiert beispielsweise die Liebeswerbung des Dumuzi um Inana. Im Tigi IšmeDagan I wird der Bau eines Wagens für Enlil beschrieben, ${ }^{1457}$ während in der Komposition Ur-Namma B an Enlil der Bau und die Restaurierung des Ekur geschildert werden. ${ }^{1458}$ Das Adab Šulgi $G$ könnte wiederum aus Anlass der Inthronisation in Nippur komponiert worden sein. ${ }^{1459}$

In sekundären literarischen Textpassagen sowie im literarischen Katalog KAR 158 werden Tigi und Adab stets nebeneinander genannt, wodurch ihre strukturelle und möglicherweise auch funktionale Verwandtschaft deutlich wird: ${ }^{1460}$

T 69: Šulgi B 157

„Tigi- und Adab-Lieder, vollendete 'Musikkunst', ihre Tiefe und Weite kenne ich. ${ }^{\text {"1461 }}$

157. tigi a-da-ab nam-nar šu du $u_{7}-a$ buru 3 dag̃al-bi mu-zu

Selz 1989, 107; aB ist eine solche Bedeutung allerdings nicht belegt.

${ }^{1455}$ Wilcke 1975, 262; Krispijn 1990, 3; Ludwig 1990, 28-32 als 'Götterlieder'.

${ }^{1456}$ S. Kapitel 14.1.4.

${ }^{1457}$ Dementsprechend könnte auch Šulgi $R$ mit dem Bau des Bootes der Ninlil ein Tigi-Lied sein; Wilcke 1975, 290-291; Wilcke 1973, 18; Sallaberger 1993, 141.

${ }^{1458}$ Flückiger-Hawker 1999, 183-203.

${ }^{1459}$ Klein 1991, 297-299.

${ }^{1460}$ Enki und die Weltordnung 448 (T 23); Šulgi C 76; S̆ulgi E 22; Ur-Namma A 187; Enkitalu und Enkihegal (TMH NF 3, 42) Vs ii 29; Sjöberg 1975a, 169.

${ }^{1461}$ Krispijn 1990, 1. 
Der Terminus Tigi wird in Unterschriften meist über das Zeichen tigi angezeigt, seltener hingegen über tigi ${ }_{2}{ }^{1462}$ In syllabischer Schreibung als te-ge-e oder te-gu-u $u_{2}$ ist der Gattungsname sicher nur im mittelassyrischen Katalog KAR 158 bezeugt. ${ }^{1463}$ Adab-Lieder werden in aller Regel syllabisch a-da-ab wiedergegeben, die Schreibung a-dab $b_{2}$ ist einmalig in Ur-Ninurta D 42 bezeugt.

Über ihre Unterschriften sind derzeit $15 \mathrm{Tigi}^{1464}$ und $34 \mathrm{Adab}^{1465}$ bekannt. Weitere 17 Liedkompositionen ohne Unterschrift können aufgrund formaler und inhaltlicher Kriterien sowie Angaben in Liederkatalogen denselben Gattungen zugeordnet werden. ${ }^{1466}$

Nur vier der vollständig erhaltenen Tigi-Lieder werden im altbabylonischen literarischen Katalog N3 (TMH NF 3, 54) genannt. ${ }^{1467}$ Weitere nicht identifizierte Tigi werden im Katalog TMH NF 3, 53 sowie neben Adab-Liedern im mittelassyrischen Katalog KAR 158 aufgelistet. ${ }^{1468}$ Von den bekannten AdabLiedern können demgegenüber bis zu acht Kompositionen mit Einträgen in literarischen Katalogen identifiziert werden. ${ }^{1469}$ Nur sehr wenige der überlieferten Textvertreter dieser zwei Liedgattungen sind in mehr als zwei Abschriften

${ }^{1462}$ Inana $E$ 55. tigi $_{2}{ }^{\mathrm{d}}$ Inana-kam; Ninurta $E$ (TCL 16, 84) Rs 4. tigi ${ }_{2}{ }^{\mathrm{d}} \mathrm{Nin}$-urta-ka$\mathrm{kam}$.

${ }^{1463}$ KAR 158 iii 9./17./29. te-ge-e šu-me-ra am-nu, iii 31. šu-nig̃ in 23 te-gu-u

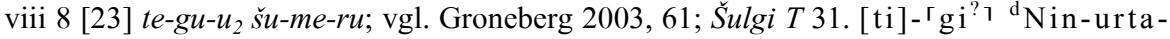
$\mathrm{ka}-\mathrm{kam}$.

${ }^{1464}$ Gudea A; Ur-Namma B; Šlgi T; Ur-Ninurta B; Išbi-Erra C; Išme-Dagan I und Y; Ibbi-Suen $A$; Inana E; DI H; Nanna I; Nergal C; Ninurta D und E; Nintu A.

${ }^{1465}$ Iškur A; Nergal E; Išme-Dagan B, F, G, H, L, M, N, U; Luma A; Šu-Suen E; Ibbi-Suen C; Šulgi $G, H, M$; $\breve{S} u$-ilǐ̌su A-C; Iddin-Dagan C; Lipit-Eštar C, D, G; Ur-Ninurta $C, D, G$; BūrSîn A-B; Gungunum A; Rìm-Sìn H; Utu A; Nanna H; Ninisina E; Ninlil A.

${ }^{1466} \mathrm{Tigi} / \mathrm{Adab}$ ?: Ninurta $M$; Šulgi R; Išme-Dagan C; Sin-iqǐšam $A$ und möglicherweise DI $X$ aufgrund einer sagida-Rubrik; Sefati 2005, 278-280:Rs 19'. Inana-Hymne TMH NF 4, 89 (Tigi); Šu-Suen D (Tigi); Šulgi L (Tigi); Šulgi A (Adab?); Išme-Dagan $O$ (Adab in zwei Textversionen; Zólyomi 2001, 139-147); Išme-Dagan P-Q (Adab); Šu-Suen F (Adab); Šlgi $Q$ (Adab); Ur-Ninurta F (Adab); Rìm-Sin B (Adab); BE 31 Nr. 4 (Adab an Ninlil); Wilcke 1975, 266-271, 290-292.

${ }^{1467}$ Ninurta $D$ (TMH NF 3, 54:30. g̃iš ga-šub-šu); Ibbi-Suen $A$ an Nanna (TMH NF 3, 54:20. en-me-sag 2 nu-di); Ur-Ninurta $B$ an Enki (TMH NF 3, 54:7 en-me-rgalam $\left.{ }^{7}-\mathrm{ma}\right)$; $\check{S} u$-Suen $D$ (TMH NF 3, 54:33 ur-sag̃ ud gal-1「e-e ${ }^{7} \check{\text { š }}$.

1468 TMH NF 3, 53:62; KAR 158 iii 9, 17, 29, 31, 38; als šumera gekennzeichnet, was nach Black 1983, 25 Anm. 6 keine Angabe zur Sprache, sondern parallel zu ištarüta und akkadìta als eine Angabe zur Vortragsweise oder Aufführungspraxis gelten könnte.

$1469 \breve{S} u$-ilǐšu A an Nergal (TMH NF 3, 53:70?); Lipit-Eštar D an Ninurta (UET 6, 196; TMH NF 3, 53:67); Ur-Ninurta $E$ an An (N3=TMH NF 3, 54:11; KAR 158 iii 11); Nanna $H$ (TMH NF 3, 53:62); Ninisina E (TMH NF 3, 53:75); Ninlil A (TMH NF 3, 53:80); Ur-Ninurta F an Iškur (U3=UET 6, 196:7); Šu-Suen $F$ an Nanna (Y1=Hallo 1963, 171-172:6?); vgl. Wilcke 1975, 268-270. 
oder Textversionen erhalten. ${ }^{1470}$ Hieraus könnte zu mutmaßen sein, dass sie zu einem einmaligen festlichen Anlass verfasst und vorgetragen wurden. Abschriften von Tigi- und Adab-Lieder datieren alle in die altbabylonische Zeit, gewidmet sind sie vermehrt Königen der Ur III- und Isin-Dynastien, nur wenige Vertreter sind bislang für die Könige der Larsa-Dynastie bekannt geworden.

Eine weit zurückreichende Tradition wird den Liedern Tigi und Zamzam in der Hymne Šulgi B zugeschrieben. ${ }^{1471}$ Hier rühmt sich der König, sich um den Erhalt dieser offensichtlich alten Liedgattungen und ihre wortgerechte Tradierung verdient gemacht zu haben. Er sorgte außerdem für die Aufnahme dieser Lieder in das gängige Liedrepertoire seiner Sänger:

T 70: Šulgi B 278-279

„(Und) damit sie niemals in 'falsche Hände' geraten,

ließ ich sie dem 'Gesangsrepertoire' hinzufügen. “'1472

278. ni $\tilde{g}_{2}$-šu-ta ba-ra-šub-bu-da-[bi]

279. šu nam-nar-ra-ke ${ }_{4} \mathrm{he}_{2}-\mathrm{bi}_{2}-\mathrm{la}_{2}-\mathrm{la}_{2}$

Zum Zeitpunkt ihrer Verschriftlichung hatten Tigi und Adab damit keinen realen Bezug zu aktuellen Festanlässen mehr, sie könnten allerhöchstens noch dem Gedenken vergangener Könige gedient haben. Die Liederkataloge KAR 158 und TMH NF 3, 53 bezeugen dennoch eine Tradierung dieser Gattungen bis in die zweite Hälfte des zweiten Jahrtausends. ${ }^{1473}$

Die Länge von Tigi- und Adab-Liedern variiert zwischen 25 und 100 Zeilen. ${ }^{1474}$ Ihrem Aufbau nach weisen sie grundsätzlich zwei Teile auf, welche mit den Rubriken sagida und sag̃ara markiert werden. ${ }^{1475}$ Auf die zwei Liedteile sagida und sag̃ara können jeweils zwei- bis dreizeilige g̃išgig̃al-Abschnitte folgen. Sie sind somit als musikalisch verwandte Liedformen anzusehen.

Zwischen Tigi und Adab bestehen zwar geringfügige aber dennoch beachtenswerte formale Unterschiede. Ein erster wesentlicher Unterschied liegt in der Verteilung des g̃išgig̃al, des 'Gegengesangs'. ${ }^{1476}$ Während Tigi-Lieder über lediglich ein g̃išgi g̃al verfügen, das dem sagida folgt und die Mitte des Liedes kennzeichnet, enthalten Adab-Lieder immer zwei g̃išgig̃al, die jeweils dem sagida und sag̃ara nachstehen. Ein zweiter bedeutender Unter-

\footnotetext{
${ }^{1470}$ Ur-Namma B Tigi an Enlil; Šulgi R Tigi ${ }^{?}$ an Ninlil; Šu-ilï̌̌u A Adab an Nergal; Lipit-Eštar $D$ Ad a b an Ninurta; $I s ̌ D Q$ Tigi oder Adab an Nusku.

${ }^{1471}$ ETCSL 2.4.2.02:270-280; s. a. Ludwig 1990, 38 Anm. 52.

1472 šu nam-nar-ra-ke 4 ...la $a_{2}$ wörtl. ,an die Kunst der Musik binden“; Castellino 1972, 213.

${ }^{1473}$ Wilcke 1975, 264.

${ }^{1474}$ Vgl. Šulgi T mit 27 Zeilen und Išme-Dagan I mit 96 Zeilen.

${ }^{1475}$ S. Kapitel 14.1.1.

${ }^{1476}$ Ausführlich hier Kapitel 14.1.4.
} 
schied zwischen beiden Liedformen findet sich am Schluss der Kompositionen. Tigi-Lieder enden grundsätzlich mit dem sag̃ara, Adab-Lieder schließen hingegen mit der Rubrik uru(n), ${ }^{1477}$ das damit als sicheres Kennzeichen dieser Lieder gelten kann. ${ }^{1478}$

Tabelle 11: Struktur der Liedgattungen Tigi und Adab

\begin{tabular}{|c|c|}
\hline Tigi & Adab \\
\hline $\begin{array}{c}\text { sa-gid }{ }_{2}-d a \\
\tilde{g} i \check{s}-g i_{4}-\tilde{g} a l_{2} \\
\text { sa-g̃ar-ra }\end{array}$ & 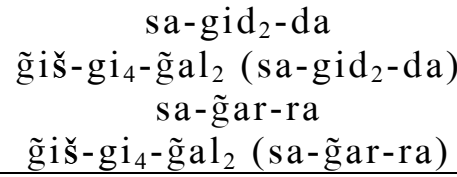 \\
\hline & $/ \operatorname{uru}(\mathrm{n}) /$ \\
\hline Tigi GN & Adab GN \\
\hline
\end{tabular}

Die in Tabelle 11 dargestellten Liedschemata gelten für fünf aller bekannten Tigi- sowie 20 Adab-Lieder und können damit als Grundformen dieser Liedgattungen angesetzt werden. Die hier erschlossene Grundform kann dennoch zusätzlich über weitere Liedrubriken erweitert sein. Das sagida wird beispielsweise in acht Adab-Liedern ${ }^{1479}$ sowie in einem Tigi ${ }^{1480}$ in die Unterrubriken bar-sud und ša ${ }_{3}$-ba-TUKU unterteilt. Diese Rubriken sind in vier weiteren Götterliedern ohne Liedunterschrift enthalten und damit nicht ausschließlich auf die hier behandelten Hymnen beschränkt. ${ }^{1481}$ Die größtenteils sehr einheitlich gehaltene Struktur von Tigi und Adab kann zudem variieren. In der Hymne $\breve{S u-S u e n ~} E$ an den Himmelsgott An, einem Vertreter der Gattung Adab, folgt beispielsweise auf das sagida und seinem g̃išgig̃al sogleich die abschließende Rubrik uru(n). ${ }^{1482}$ Ob diese seltenen Variationen mit inhaltlichen oder musikpraktischen Aspekten zusammenhängen, lässt sich bedauerlicherweise nicht feststellen.

${ }^{1477}$ S. Kapitel 14.1.3.

1478 Wilcke 1994, 257; die Ergänzung [uru ${ }_{\mathrm{x}}$-EN]-bi-im in Nanna L 52 von Sjöberg 1973d, 33 ist nach Wilcke 1975, $288 \mathrm{zu}$ [ki-šu]-bi-im zu korrigieren.

$1479 \breve{S} u$-ilǐšu $A$ an Nergal; Iddin-Dagan C an Ningublaga (Römer 1996); Lipit-Eštar C an An; Lipit-Eštar D an Ninurta; Ur-Ninurta $C$ an Ninurta; Ur-Ninurta $E$ an An; Gungunum $A$ an Nanna; Rìm-Sìn $H$ an Inana; zusätzlich Ur-Ninurta $F$ an Iškur und $\check{S} u$-Suen $F$ an Nanna [ohne Unterschrift, aber mit Rubrik uru(n)].

${ }^{1480}$ Išbi-Erra $C$ an Nanaja.

${ }^{1481}$ Šulgi $U$; $\breve{S} u$-Suen $D$ und $F$; Ur-Ninurta F. Ob die Angabe dieser Rubriken als Unterteile des sagida fakultativ war und daher in vielen Tigi-Liedern fehlt, wie Wilcke 1975, 254 annimmt, ist zu bezweifeln. Das sagida dieser Tigi-Lieder weist zu den übrigen Vertretern derselben Gattung Abweichungen in Satzform und Struktur auf; s. hier Kapitel 14.1.2.

${ }^{1482}$ ETCSL 2.4.4.5 Fragment B 6-9. 
Die Sprache der Tigi- und Adab-Lieder ist meist hymnisch. Eine einheitliche Erzählperspektive lässt sich für sie nicht feststellen. Grundsätzlich sind die Lieder im sumerischen Hauptdialekt gehalten, doch können kürzere Abschnitte im Emesal verfasst sein, das meist auf die direkte Rede oder auf Epitheta einer weiblichen Gottheit beschränkt bleibt. ${ }^{1483}$

Ein beachtenswerter Eintrag zur Hymnengattung Adab findet sich im mittelassyrischen Liederkatalog KAR 158, wo in der Zusammenzählung von Kolumne viii sumerische wie auch akkadische Titel der Gattung aufgelistet werden. ${ }^{1484}$ Diesem Eintrag zufolge wurden Adab offenbar auch in akkadischer Sprache verfasst. Ein solcher Textvertreter, der dies zu bestätigen vermag, ist bisher allerdings nicht bekannt geworden.

Eine kurze Aussage zur musikalischen Aufführungspraxis von Tigi, das in diesem Fall zusammen mit Zamzam genannt wird, findet sich in einer Selbstlobhymne des Šulgi:

\section{T 71: Šulgi E 34}

„Dass ich(Šulgi) die Stelle/den Ort kenne zum Anheben und Senken der Tigi und Zamzam-Lieder“

34. zi-zi šu $\breve{s}_{2}-\breve{s ̆}_{2}$ tigi za-am-za-am-ma-ka ki bi $i_{2}-z u-z u-a^{1485}$

Das oppositionelle Begriffspaar zi-zi „,anheben“ und šu $\mathrm{u}_{2}-\breve{s ̆}_{2}$ „niederlegen, abdecken“, wobei zuweilen auch $\tilde{\mathrm{g}} \mathrm{a}_{2}$ - $\tilde{\mathrm{g}} \mathrm{a}_{2}$, ,hinsetzen/niederlegen“ anstelle des $\breve{s} \mathrm{u}_{2}$-š $\mathrm{u}_{2}$ treten kann, bezieht sich auf die instrumentale und vokale Aufführungspraxis. Wie bereits mehrfach vermutet, ${ }^{1486}$ stehen beide Termini aufführungstechnisch in Zusammenhang mit den Liedrubriken sa-gid ${ }_{2}$-da ,lange(r)/ gestreckte(r) Saite (Modus)“ und sa-g̃ar-ra „niedergelegte(r)/ruhende(r) Saite (Modus)“. Die zitierte Textpassage bezieht sich damit wohl konkret auf die zwei Teile dieser Lieder, den sagida und sag̃ara, sowie ihre musikalische Aufführungspraxis. ${ }^{1487}$

\footnotetext{
${ }^{1483}$ Schretter 1990, 87.

${ }^{1484}$ KAR 158 viii 9. $[\mathrm{x}+10]+1 \check{s} u-m e-r u-m e s ̌ ~ 10 . ~ \mathrm{x}+2 a k-k a-d u-u_{2} 11$. [ šu-nigin $\left.{ }_{2}\right] \mathrm{x}+3 z a-m a-$ ru a-da-pu-meš .

${ }^{1485}$ Ludwig 1990, 35-37; Krispijn 1990, 6 „,...daß ich die Stellen weiß, wo ich auf- und niederstimmen soll im Tigi und Zamzam-Lied“.

${ }^{1486} \mathrm{~S}$. Kapitel 14.2.1.

1487 gid $_{2}$ „lang sein/machen; (an)ziehen“, gaar „,ruhen; hinsetzen“; Wilcke 1975, 259-260; Ludwig 1990, 30; hier Kapitel 14.1.1 und 14.2.1.
} 
Weitere literarische Textbelege deuten für den vokalen Vortrag der Lieder auf eine spezifische Gesangstechnik hin:

T 72: Enkitalu und Enkiheg̃al Vs ii $29^{1488}$

„Wenn er vor den 'Meistern' sitzt, kann er weder Tigi noch Adab vorgetragen."

29. igi um-mi-ia-ke $e_{4}-n e-\check{s ̌}_{3} u_{3}$-ba-tuš tigi a-da-ab nu-ub-be ${ }_{2}$

\section{T 73: Šulgi $C 76$}

„Tigi, Adab und die groß(artig)en Malgatum-Lieder, ihre ad-ša ${ }_{4}$-Technik kenne ich.“

76. tigi a-da-ab ma-al-ga-tum gal-gal-la ad ša ${ }_{4}-b i$ mu-zu

Der Vortrag von Tigi und Adab wird zunächst über das Verb dug ${ }_{4}$,sprechen, sagen, rezitieren“" angezeigt, andererseits ist für sie aber auch eine tremolierende bzw. vibrierende Singart charakteristisch.

Instrumental begleitet wurden Tigi-Hymnen aller Wahrscheinlichkeit nach mit dem gleichnamigen Musikinstrument. Neben der gängigen Kombination tigi šem $_{3 / 5}-a_{2}-a_{2}$ werden literarisch auch 'sieben Tigi-Instrumente' genannt. ${ }^{1489}$ Wird von einer Identifizierung der Instrumente Tigi und Adab als Membranophone ausgegangen, ${ }^{1490}$ liegt die Annahme auch einer chorisch-perkussiven Begleitperformance sehr nahe. Inwiefern die Aufführung der Lieder mit den altbabylonisch belegten tigiätum-Frauen in Zusammenhang steht, bleibt unbekannt. Es ist dennoch vorstellbar, dass diese Musikerinnen beim Preis von Göttern und Königen mitwirkten, auch wenn die Gattungen Tigi und auch das Adab für babylonische Könige bislang fehlen. An ihre Stelle könnten andere sumerischsprachige und auch akkadischsprachige Hymnen getreten sein.

\subsubsection{Zamzam}

Außer als Bezeichnung einer Liedgattung und eines Musikinstruments ist Zamzam auch als Name einer Vogelart bezeugt. Die Bildung des Namens ist onomatopoetisch zu deuten. ${ }^{1491}$ Im lexikalischen Kommentar Murgud wird das Instrument zamzam neben tigi und adab genannt, wo es akkadisch dem

\footnotetext{
${ }^{1488}$ Sjöberg 1975a, 169.

${ }^{1489}$ Enki und die Weltordnung 67, 125; Šulgi A 81.

${ }^{1490}$ Sefati 1998, 25-26.

${ }^{1491}$ CAD S 121a samsammu.
} 
lilissu, der Kesselpauke, entsprochen wird. ${ }^{1492}$ Damit kann das Zamzam zu den Membranophonen gezählt werden.

Als Liedgattungsname ist Zamzam in lexikalischen wie literarischen Texten belegt. In den meisten dieser Textbelege wird es neben Tigi und Adab genannt, ${ }^{1493}$ selten auch neben anderen Liedgattungsnamen, beispielsweise dem gi- $\operatorname{gid}_{2}$ :

\section{T 74: Ur-Namma A 187}

„Meine Tigi, Adab, gi-gid 2 und Zamzam-Lieder sind wegen mir (Ur-Namma) zu Klageliedern geworden.“

187. tigi a- ${ }^{\Gamma} d^{\top}{ }^{\top}-a b$ gi-gid 2 za-am-za-am- $\tilde{g} u_{10}$ a- ${ }^{\Gamma}$ nir $^{?}{ }^{7}-r a$ mu-da-an- urr $_{9}{ }^{1494}$

Diese Aufreihung neben Tigi und Adab legt nahe, dass auch über Zamzam Hymnen und Preislieder bezeichnet werden. Vollständige Vertreter sind bislang allerdings nicht bekannt geworden. Lediglich ein kleineres Fragment aus Nippur legt den Nachweis für die Existenz und auch den Aufbau von sumerischsprachigen Zamzam-Liedern vor. ${ }^{1495}$ Das Fragment ist aus der Mitte einer größeren Sammeltafel, die wohl mehrere Lieder mit Rubriken enthielt. In Kolumne ii 6-7 finden sich Angaben zu einem Zamzam an Enlil:

${ }^{1492}$ Mg A II 191 (MSL 7, 153); anders Dijk 1953, 46-47:14’ „lyre?“; Hartmann 1960, 95; Kilmer 1980-83, 574 und hier Kapitel 12.1.2.

${ }^{1493}$ Uruk Klage 17; Fluch über Akkade 36; Šulgi E 34; Šulgi B 273 und 276; Winter und Sommer 237.

${ }^{1494}$ Flückiger-Hawker 1999, 133 übersetzt hier Musikinstrumente; ähnlich die Auflistung in $I s ̌ D$ $A(+V)$ 335-337.

${ }^{1495}$ Tinney 1995, 12-13, 25 Fig. 1. 
T 75: N $1045(\text { OLZ 90, 25) })^{1496}$

Kol. i

Kol. ii

1.

5.

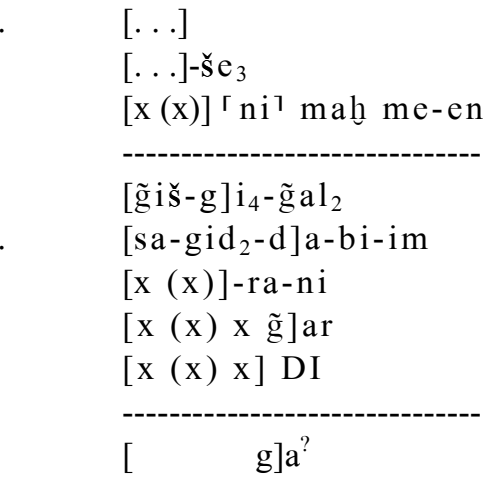

10.
1.

$$
\begin{aligned}
& \text { bala dug }{ }_{3}{ }^{\top} \mathrm{x}^{\top}[ \\
& \mathrm{u}_{4} \text { ha-ba- }[\mathrm{ni}] \\
& -\mathrm{su}_{3}-\mathrm{s}\left[\mathrm{u}_{3}\right]
\end{aligned}
$$

5.

$$
\begin{aligned}
& \tilde{g} i \mathrm{~s}-g i_{4}-\tilde{g} \mathrm{a}\left[1_{2}\right] \\
& \text { sa-gar-ra-bi-i[m] } \\
& \text { za-am-za-am } \\
& \text { den-lil }{ }_{2}-1 a_{2}-k a m
\end{aligned}
$$$$
\mathrm{nin} \text { an } \mathrm{za}-\mathrm{gi}\left[\mathrm{n}_{3}\right.
$$$$
\text { dalla }\left\ulcorner\mathrm{e}_{3}\right\urcorner[
$$

10. ${ }^{\mathrm{d}} \mathrm{Uraš}[$

$\mathrm{x} \times[$

Trotz des fragmentarischen Zustands der Tafel lässt sich für den Aufbau des Za m zam-Liedes rekonstruieren, dass es über ein sagida, ein sag̃ara und ihre jeweiligen g̃išgi gal verfügte, womit es einen ähnlichen Aufbau wie das Adab aufweist.

In Šulgi E Zeile 34 ist von der korrekten Vortragsweise sowohl von Tigi wie auch von Zamzam die Rede, die über ein 'Anheben'(zi-zi) und 'Senken' $\left(\check{\mathbf{s}} \mathrm{u}_{2}-\mathrm{s}_{\mathrm{s}} \mathrm{u}_{2}\right)$ intoniert werden. ${ }^{1497}$ Der Verwandtschaft des Zamzam zu Tigi und Adab könnte daher neben Inhalt und Aufbau auch eine ähnliche Aufführungspraxis zugrunde liegen.

\subsection{4 gi-gid 2}

Außer als Name eines Musikinstruments ist gi-gid 2 , wörtlich „langes Rohr“ nach literarischen Textbelegen auch als Name einer Liedgattung zu identifizieren, die literarisch beispielsweise neben Zamzam, Tigi und Adab aufgelistet wird. ${ }^{1498}$ Im Hinblick auf den inhaltlichen Kontext der entsprechenden Textbelege können alle diese Gattungen als Hymnen und Preislieder sowohl im Bezug auf Götter als auch auf Könige identifiziert werden.

In Liedunterschriften ist gi-gid $\mathrm{g}_{2}$ bisher nicht belegt. Allerdings konnte Kilmer eine akkadisch-syllabische Entlehnung des Gattungsnamens im Liederkatalog KAR 158 identifizieren. ${ }^{1499}$ In der Zusammenzählung von Kolumne viii

\footnotetext{
${ }^{1496}$ Umschrift in Anlehnung an Tinney 1995, 12 und 25 Fig. 1.

${ }^{1497}$ T 71: Šulgi E 34.

1498 Šulgi E 38; Ur-Namma A 187; Fluch über Akkade 36.

${ }^{1499}$ Kilmer 1993-97, 465a.
} 
wird in Zeile 29 ein einziger Vertreter dieser Liedgattung über die Angabe $q a_{2^{-}}$ an git-țu-meš KI.MIN $\left(a k-k a-d u-u_{2}\right)$ genannt. Der Ausdruck qān gitțu ist gleichzeitig Übersetzung wie syllabische Entlehnung des Sumerischen gi$\operatorname{gid}_{2}$. Die Sprache dieses Liedes war nach Angabe des Katalogs akkadisch. Da von dieser Liedgattung nur ein einziges genannt wird, könnte ihm allgemein im musikpraktischen Alltag keine größere Bedeutung beigemessen worden sein. Konkrete Angaben zum Kontext und der Form seines Vortrags sind nicht bekannt. Angesichts seiner Benennung nach einem Musikinstrument könnte lediglich eine Begleitung durch ein Rohrinstrument angenommen werden.

Gängige Bezeichnung eines Rohrinstruments ist das akkadische em/bbübu $(\mathrm{m})$. Dieses ist zugleich Name eines Saitenpaares oder Modus, altbabylonisch attestiert in der berühmten Stimmungsanweisung für das ${ }^{g \tilde{i} i \check{z}} \mathrm{za}_{3}-\mathrm{mi}_{2}{ }^{1500}$ em/bbübu(m) bezeichnet hier den Abstand zwischen der dritten und siebten Saite, welcher nach übereinstimmender Meinung das Intervall einer Quinte bildet. ${ }^{1501}$ Nach Krispijn könnte die Benennung des Intervalls auf das Rohrinstrument zurückzuführen sein und folgert, dass em/bbübu(m) ein Doppelrohrinstrument bezeichnet, für dessen beide Rohre in ihrer Stimmung der Abstand einer Quinte anzusetzen sei. ${ }^{1502}$ Im Modus mit Namen em/bbübu(m) wurden nach Angabe des Liederkatalogs KAR 158 die meisten der akkadischsprachigen Liedgattungen sitru 'Chor-/Orchester-' und irtu 'Brust'(-Lieder) gespielt. $^{1503}$

Rohrinstrumente gehören gewöhnlich dem Kontext des Hirtentums an, nach Inanas Gang in die Unterwelt Zeile 353 sind sowohl gi-gid ${ }_{2}$ wie auch gi-di(da) dem Dumuzi zugeordnet. ${ }^{1504}$ Das Lied Dumuzi-Inana $X$ schildert, wie sich derselbe Gott sein Instrument gi-di aus dem Schilfrohr schneidet. ${ }^{1505}$ Über die mythologischen Erzählungen um den Tod des Dumuzi begründet sich die Verbindung von Rohrinstrumenten zum Kontext der Klage. Im altbabylonischen Eršema an Dumuzi CT 15, 18 wird das gi-di(-da) des nun toten Gottes vom Wind geblasen. ${ }^{1506}$ In Bala g̃-Liedern ist mehrfach der Ausdruck

\footnotetext{
${ }^{1500}$ Zuletzt Krispijn 2002; s. a. Mirelman/Krispijn 2009.

${ }^{1501}$ Kilmer 1960, 281 (CBS 10996): Kol. Vs i 15'.

${ }^{1502}$ Krispijn 1990, 15; Krispijn 2002, 471.

${ }^{1503}$ KAR 158 viii 14. 1]3 ši-it-ru ša eb-bu-bi uri ${ }^{\mathrm{ki}} 15.2 \mathrm{ki}-\mathrm{min} \check{s} a$ pi-i-te und 47.24 gabameš $\check{s} a$ eb-bu-bi.

${ }^{1504}$ Inanas Gang in die Unterwelt 353. sipad-de ${ }_{3}$ gi-gid ${ }_{2}$ gi-di-da igi-ni šu $\mathrm{rnu}^{7}-\mathrm{mu}-$ un-tag-ge-ne „Sie (die Dämonen) ließen den Hirten (Dumuzi) nicht gi-gid ${ }_{2}$ und gi-dida für sie (Inana) spielen?“; ETCSL 1.4.1; anders Sladek 1974, 147, 179; s. a. Sefati 2005, 267 mit weiteren Belegen zur Verbindung von Rohrinstrumenten und Hirtentum; anders Kilmer 1973-97, 475 zur Bedeutung von šițru als „'later’ written music?“" von šațāru(m).

${ }^{1505}$ DI $X$ Text A bei Sefati 2005, 257-258, 262.

${ }^{1506}$ Cohen 1981, 90, 92 Nr. 60:40 „The wind plays his reed pipe“.
} 
gi-er 2 -ra „Rohr der Klage“ attestiert, welches dann ebenfalls dem Hirten zugeordnet wird. ${ }^{1507}$ Die lexikalische Liste Proto-Kagal 364 (MSL 13, 77) nennt schließlich unter mehreren Komposita mit er $_{2}$ auch das er $\mathrm{r}_{2}-\mathrm{gi}$ - di, was sich in diesem Zusammenhang neben $\mathrm{er}_{2}-\mathrm{s}_{\mathrm{e}} \mathrm{m}_{3}-\mathrm{ma}$ und $\mathrm{er}_{2}-\mathrm{ub}_{3}-\mathrm{a}$ wohl auch konkret auf das Musikinstrument bezieht. ${ }^{1508}$ Ur III-zeitlich ist belegt, dass Spieler des /gidida/neben gala und Klagefrauen bei privaten Bestattungsfeiern mitwirkten. ${ }^{1509}$

Das Spiel von Rohrinstrumenten wurde nach Aussage eines sumerischen Sprichworts professionell ausgebildeten Musikern, dem nar oder gala kaum zugemutet:

\section{T 76: SP 2.54}

„Ein heruntergekommener Schreiber wird Beschwörungspriester;

Ein heruntergekommener nar wird gi-di-da-Spieler;

Ein heruntergekommener gala wird gi-gid ${ }_{2}$-Spieler.“" ${ }^{\text {‘510 }}$

dub-sar pe-el-la $\mathrm{a}_{2}-\mathrm{u}_{2}-\mathrm{mu}_{7}-\mathrm{mu}_{7}-\mathrm{ma}-\mathrm{kam}$

nar pe-el-la $1 \mathrm{u}_{2}-\mathrm{gi}-\mathrm{di}-\mathrm{da}-\mathrm{kam}$

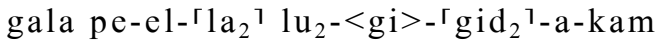

Hier wird zunächst deutlich, dass zwei Formen von Rohrinstrumenten unterschieden werden, wovon keines dem Instrumentarium der gängigen Musiker nar oder gala angehörte. Es gilt grundsätzlich zu bedenken, dass Rohrinstrumentenspieler nicht über den Terminus nar, trotz seiner allgemeinen Grundbedeutung für den Musizierenden, bezeichnet werden. Spieler von Rohrinstrumenten sind immer auch als solche bezeichnet. Die altbabylonische $\mathrm{Lu}_{2}$-Liste unterscheidet $1 \mathrm{u}_{2}$ gi- $\left\ulcorner\mathrm{di}-\mathrm{da}^{\top}, 1 \mathrm{u}_{2}\right.$ gi-gid $\mathrm{g}_{2}$ und $1 \mathrm{u}_{2}$ gi-di mit den akkadischen Entsprechungen $\check{s} a$ malīli $(m), \check{s} a$ ebbūbi(m) und $\check{s} a$ šulpi(m), die alle (Schilf?-/) Rohrinstrumente bezeichnen. ${ }^{1511}$ Auch der altbabylonische Brief AbB 6, 144 nennt ša ebbūbim ,diejenigen des ebbūbum“, die im Schutze der Inana/Ištar stehen. In ihrer Stellung kommen sie möglicherweise niederen Künstler- und Gauklerberufen wie dem aluzinnu gleich.

\footnotetext{
${ }^{1507}$ Utugin eta $\mathrm{a}+214$ (Cohen 1988, 104); Udam kiamus $\mathrm{d}+183$ (Cohen 1988, 132) oder Elum gusun $\mathrm{e}+157$ (Cohen 1988, 279).

${ }^{1508}$ Hier Kapitel 11.2.2.

${ }^{1509}$ NATN 853: Rs 2. ${ }^{1 \mathrm{lu}_{2}} \mathrm{gi}^{1}$ - $\mathrm{di}_{3}-\mathrm{da}$; Wilcke 2000, 43-45.

${ }^{1510}$ Vgl. Alster 1997, 55-56 mit allen Textvertretern und Varianten.

$1511 \mathrm{aB} \mathrm{Lu}_{2}$-Azlag A 242-244 (MSL 12, 165); s. a. die jeweiligen Einträge in CAD und AHw.
} 
Zur Aufführung eines Liedes der Gattung gi-gid ${ }_{2}$ oder zum Spiel des gleichnamigen Instruments wird nichts bekannt. Dementgegen kann aus literarischen Textpassagen einiges zum gi-di(-da) rekonstruiert werden. In einem altbabylonischen Eršema an Gula wird sein Klang mit „laut grollend/tönend“ ( $\operatorname{ur}_{5} \ldots \check{s} \mathrm{a}_{4}$ ) umschrieben. ${ }^{1512}$ In der Dichtung Auszug des Ninurta wird ein Bild von Musikern bzw. Sängern (nar) gegeben, die einem gi-di-da, gemeint ist wohl der Instrumentenspieler, folgen. Nach Unterwerfung der feindseligen Steine des Berglandes bestimmt der Gott Ninurta für den Durul-Stein ein gutes Schicksal: „Die 'Berge' sollen dir (Durul-Stein) wie nar-Musiker dem gi-dida-Rohr(spieler) folgen!“‘ ${ }^{1513}$ Angesichts dieser Beschreibungen, nämlich die durchdringende Lautstärke sowie der die nar-Sängergruppe anführende Bläser, könnte das gi-di-da als Rohrblattinstrument zu identifizieren sein, ${ }^{1514}$ wie es heute noch im Orient einem Festumzug voranschreitend gespielt wird. Das gigid $_{2}$ könnte demgegenüber dann vielleicht eine 'Langflöte' sein.

\subsection{Mit šir ${ }_{3}$ „Lied“ gebildete Gattungsnamen}

\subsection{1 Überblick zu den šir ${ }_{3}$-Komposita}

šir ${ }_{3}$-Komposita werden lexikalisch in den Listen Proto- $\mathrm{Lu}_{2}$, Proto-Izi II und Nabnìtu 32 (1. Jt.) genannt, ${ }^{1515}$ wobei sich die längste Auflistung in Proto-Lu ${ }_{2}$ findet:

T 77: Proto-Lu $\mathrm{Lu}_{2}$ 587-599+ (MSL 12, 54-55 // Or 70, 215-216)

$\begin{array}{lll}587 & \text { sir }_{3} & \text { „Lied“" } \\ 588 & \text { sir }_{3} \text {-kug } & \text { "heiliges/reines Lied“" } \\ 589 & \text { sir }_{3} \text {-ha-mun } & \text { "harmonisches’ Lied“ } \\ 590 & \text { sir }_{3} \text {-nam-nar } & \text { "Lied der } \text { nar-Kunst“ } \\ 591 & \text { sir }_{3} \text {-nam-gala } & \text { „Lied des gala-tums“ }\end{array}$

1512 aB Eršema an Gula CT 36 pl. 41-42:21. gi-di-da-mu ur ${ }_{5}$ nu-ša $a_{4}$ ḩur-mu „My reed pipe which does not thunder forth!"; Cohen 1981, 104-105 Nr. 159.

1513 Auszug des Ninurta 617. kur-kur-re nar-gin 7 gi-di-da he $_{2}$-em-mu-e(Var. mi-in)sar-re-ne; vgl. ETCSL 1.6.2; anders übersetzt van Dijk 1983, 165, 133:620. „que (des habitants des) Montagnes jouant de la flûte comme des musiciens t'invitent à la danse!“"

${ }^{1514}$ Vgl. den ägyptischen mizmār baladī, eine Art Oboe, die bei Festumzügen heterophon unter Trommelbegleitung gespielt wird; Collaer/Elsner 1983, 48-49.

${ }^{1515}$ Proto-Izi II 421-423 (MSL 13, 52); Wilcke 1987, 101:IB 1600 Rs III 20-23; Nabnītu 32 Kol. iii 24-31 (MSL 16, 253). 


\begin{tabular}{|c|c|}
\hline Or 70:7' & {$[\check{s} i] r_{3}-\left\ulcorner n a m^{\top}-\tilde{g}\right.$ ešbun } \\
\hline 592 & šir $_{3}$-nam-šub \\
\hline 593 & sir $_{3}$-nam-erim $2-m a$ \\
\hline Or 70:9' & {$[\check{\mathbf{s}} \mathrm{i}] \mathrm{r}_{3}-{ }^{\Gamma} \mathrm{nam}^{\top}-\mathrm{ke} \check{s}_{2}-\mathrm{da}$} \\
\hline 594 & šir $_{3}-g i d_{2}-d a$ \\
\hline 595 & $\check{s} \mathrm{ir}_{3}-\mathrm{sa} \tilde{\mathrm{g}}$ \\
\hline 596 & $\mathrm{~s} i \mathrm{r}_{3}-\mathrm{RI}-\mathrm{gu} \mathrm{u}_{4}$ \\
\hline 597 & $\operatorname{sir}_{3}-\left[\mathrm{ban}_{3}\right]-\mathrm{da}$ \\
\hline 598 & $\mathrm{~s} \mathrm{rr}_{3}$-ama-[g]an \\
\hline 599 & 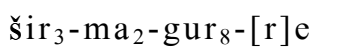 \\
\hline Or 70:11' & {$[\check{s} \mathrm{i}] \mathrm{r}_{3}-\mathrm{s}_{3} \mathrm{a}_{3}-\mathrm{hu} \mathrm{l}_{2}-\mathrm{la}$} \\
\hline Or $70: 12^{\prime}$ & {$[\check{s} \mathrm{i}] \mathrm{r}_{3}-\tilde{g} \mathrm{uruš}-\mathrm{dab}$} \\
\hline
\end{tabular}

„Lied der kultischen Mahlzeit ${ }^{\text {‘1516 }}$

„Beschwörungslied“

„Feind(schafts)lied“

„Bannlied(?)““

„Lied des 'Langen'،

„Anfangs-/Eingangslied"،

„Lied . . .? 1517

„Restitutionslied(?)، ${ }^{\text {(1518 }}$

„Lied der Trächtigen/

Kreißenden(?)،1519

„'Lied des Prozessionsschiffes ‘“1520

„Lied der Herzensfreude“

„, Gefangenenlied(?)،1521

Zusätzlich zu den Komposita der Liste Proto-Lu $\mathrm{Lu}_{2}$ werden in Proto-Izi II 422 šir ${ }_{3}$-gal und sir $_{3}-$ mah, das ,große“ und das „mächtige Lied“ genannt (MSL 13, 52:422-423). ${ }^{1522}$ Weitere Komposita, die offenbar auf das „Lied“ oder die „Musik“ konkreter Musikinstrumente verweisen, sind in Nabnītu 32 iii 27-28

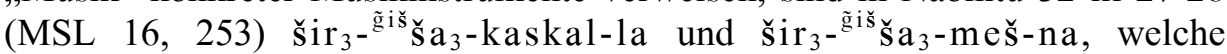
möglicherweise als 'Lautenlieder' zu identifizieren sind. ${ }^{1523}$

Von den insgesamt 21 lexikalisch belegten $\check{s} \mathrm{ir}_{3}$-Komposita werden lediglich fünf als Gattungsnamen in Unterschriften sumerischsprachiger Kompositionen angetroffen:

${ }^{1516}$ Mit g̃ ešbun = akk. tākultu(m) „kultisches Mahl“; vgl. Taylor 2001, 221; Ludwig 1990, 205206.

${ }^{1517}$ Lesung nach J. Taylor zu Text A (CBS 2241+) bei cdli; vgl. Falkenstein 1950, 86; Rubio 2009, 67 liest $\mathrm{sir}_{3}-\mathrm{de}_{5}-\mathrm{gu}_{4}$,song to gather cattle“.

${ }^{1518} \mathrm{Mit} \mathrm{ban}_{3}-\mathrm{da}=$ akk. tākšìru(m) „Wiederherstellung, Restitution“.

1519 PSD A/3, 211b; literarisch wird a ma-gan zumeist als Epitheton von Göttinnen verwendet. Es könnte Hymnen an 'Muttergottheiten' bezeichnen.

${ }^{1520}$ Der Ausdruck verweist wohl auf Hymnen und Preislieder, die auf Schiffsprozessionen der Götter und Könige vorgetragen wurden; in diesem Zusammenhang ist das Musikinstrument g̃išs $\operatorname{dim}_{3} l_{u_{2}} \mathrm{ma}_{2}$ gur $_{8}$-ra „Laute des 'Prozessionsschiffers"“ zu nennen aus Šulgi B 166; Krispijn 1990, 12. In LL des 1. Jt. ist ${ }^{\tilde{g}} \mathrm{i}$ š $\operatorname{dim}_{3}$ dem Fährmann addir zugeordnet; $\mathrm{Ur}_{5}$-ra VIIB 48 und Mg B II (MSL 6, 143) 191. ğ ${ }^{\tilde{i}} \mathrm{di}_{3}-\mathrm{me}$ addir $=s a-g u m$ mar-gu-u $=a r_{2}-k i l-$ la-a „ein Tier(?)“; Krispijn 1990, 12; AHw 1003a sagummargû „ein Musikinstrument“. S. a.

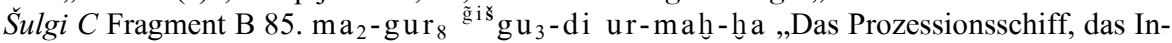
strument des Löwen(?)“; der Kontext zu dieser Zeile ist zerstört.

${ }^{1521}$ Vgl. J. Taylor in cdli sub OrNS 70, 210-211, „song of the captured workers“.

${ }^{1522}$ Die Übersetzung als Musiker oder Liedgattung ist Kontext abhängig; Krecher 1966, 56, 162 163.

1523 Vgl. ğišš ${ }_{3}-T A R / M I N-k a s k a l$ als Namensvariante zu tig̃idlû, möglicherweise eine Laute; Emar VI/1 279:406'. min( $\check{s ̆}_{3}$-tar) kaskal = [. . .]; Diri III, 54ff. (MSL 6, 119) 56. [. .] $]^{\tilde{\text { gi }} \mathrm{s} \breve{s} a_{3} . M I N-k a s k a l}=t i-g i d_{2}-l u-u_{2}$; Veldhuis 1997/98, 122-124 und Shehata 2007. 
1. $\check{s i r}_{3}-\mathrm{kug}$

2. $\breve{s}_{\text {i }} \mathrm{r}_{3}-\mathrm{nam}-\mathrm{gala}$

3. $\breve{s} i r_{3}-n a m-s ̌ b$

4. si $_{3}-n$ am-erim $2-m a$

5. $\quad \check{s}_{i} r_{3}-g i d_{2}-d a$

Hinzu kommen zwei weitere šir $_{3}$-Gattungsnamen, die in lexikalischen Listen unerwähnt bleiben, jedoch aus Unterschriften literarischer Texte bekannt sind:
6. $\breve{s i r}_{3}$-nam-ur-sa $\tilde{g}-\tilde{g} a_{2}$
„Lied des 'Heldentums"“
7. šir $_{3}-k a l-k a l$
„Lied . . ?“

Weitere zwei Komposita sind aus literarischen Katalogen bekannt und könnten damit ebenfalls als Gattungsnamen zu werten sein:
8. šir $_{3}$-dig̃ir-gal-la
„Lied der großen Götter“
9. sir $_{3}$-nam-sipa-da
„Lied des Hirtentums“

Im mittelassyrischen Katalog KAR 158 sind als šir ${ }_{3}$-dig̃ir-gal-la-še ${ }_{3}$ „Zu/von den Liedern der großen Götter“ mehrere unbekannte Titel in der Zusammenzählung von Kolumne viii Zeile 13 vermerkt. Hierbei muss nicht zwingend eine eigenständige Gattung bezeichnet sein, sondern lediglich eine Gruppe von Preisliedern, die sich an die großen Götter des Pantheons richten.

Titel der Gattung šir $_{3}$-nam-sipa-da ${ }^{\mathrm{d}}$ Inana-me enthält der mittelbabylonische Katalog TMH NF 3, 53 zwischen šir ${ }_{3}$-nam-gala auf der Vorderseite und Tigi-Liedern auf der Tafelrückseite. ${ }^{1524}$ Die Namengebung sowie die Liedtitel selbst lassen auf eine Verortung in den Inana-Dumuzi- oder auch Nanna-Kult schließen. ${ }^{1525}$

Dass nicht alle in lexikalischen Listen genannten sir $_{3}$-Komposita als Liedgattungsnamen auftreten, beruht nicht auf einer Überlieferungslücke. Die hier versammelten Ausdrücke sind nicht nach inhaltlichen Kriterien, sondern nach Wortbildungen gewählt. Sie wurden von damaligen Schreibern für ihre Dichtungen gebraucht und können daher in literarischen Texten angetroffen werden. Im Falle der šir ${ }_{3}-K_{0}$ omposita betrifft dies a) šir ${ }_{3}$ ha-mun, b) šir ${ }_{3}$ nam-nar und c) šir ${ }_{3}$ sa g. . ${ }^{1526}$

\footnotetext{
${ }^{1524}$ Bernhardt/Kramer 1956/57, 392:48; Wilcke 1975, 259.

1525 Bernhardt/Kramer 1956/57, 392:44. e-nun-a-tu-da $1 u_{2}$ eridu ${ }^{\mathrm{ki}}$-tu-da „Der Herr, welcher von dem Fürsten abstammt - er, welcher in Eridu geboren wurde" und 47. mu-tin mu-lu ...(Emesal) „Der Bräutigam, welcher. ..“; vgl. Wilcke 1975, 259.

${ }^{1526} \mathrm{Zu}$ den im Examenstext $A$ Zeile 24 genannten $\check{S}^{2} r_{3}$-Komposita s. CAD Š/2 316-317; der dortige Ausdruck šir ${ }_{3}-n a m-u r u-n a / /\left[\check{s e r}_{3}-n a m\right]-u_{2}-r u-n a-k e$ könnte auf die Rubrik /uru(n)/-bi in Adab-Liedern zu beziehen sein; Sjöberg 1975b, 160:24. Zum [ši] $\mathrm{r}_{3}$-namen-na nicht „Lied der en-Priesterschaft“ sondern „Lied der Herrschaft/Herrschaftslied“ s.
} 
a) $\breve{s i r}{ }_{3}$ ha-mun

Das Namenselement ha-mun wird akkadisch mithurtu(m) geglichen, im Sinne eines 'Gegen- oder Miteinanders zweier Parteien'. ${ }^{1527}$ Für seine Übersetzung wird häufig die Bedeutung ,harmonisches Lied“ angesetzt. ${ }^{1528}$ Über die akkadische Gleichsetzung mithurtu(m), die auch für die Rubrik g̃iš-gi ${ }_{4}-$ ga $1_{2}$ belegt ist, wird außerdem eine Wiedergabe mit „Lied verschiedener Stimmen“ oder „Wechselgesang“ wahrscheinlich. ${ }^{1529}$ Andererseits ist für Sumerisch ha-mun auch die Gleichsetzung mit lallar $(t) u(m)$ attestiert, das zur Bezeichnung eines Klagesängers und einer Vogelart dient. ${ }^{1530}$ Dass über šir ${ }_{3}$-h̆a-mun eine eigenständige Gattung bezeichnet wird, ist $\mathrm{zu}$ bezweifeln, allerdings könnte der Ausdruck auf eine Singart Bezug nehmen, die möglicherweise auch professionell praktiziert wurde und dem Klang einer bestimmten Vogelart ähnelt.

b) $\check{\text { sir }} 3$ nam-nar

Der Ausdruck ist außer in Proto-Lu $\mathrm{Lu}_{2}$ literarisch nur noch in der Elegie um Nannayas Tod belegt, wo er sich auf die Ausführung von Klagen bezieht. ${ }^{1531}$ Ein eigenständiger Gattungsname liegt hier wohl nicht vor, vielmehr die Bezeichnung einer melodiös ausgestalteten Vortragsweise für Klagegesänge.

c) šir $_{3}$ sa g

Der Ausdruck šir ${ }_{3}$ sa g ist literarisch häufig neben bala g̃-di belegt. Beide Ausdrücke dienen auch zur Bezeichnung von Klagemusikern und Sängern. ${ }^{1532}$ Lexikalisch wird šir ${ }_{3}$ sag̃ in jüngeren Listen akkadisch dem Verb sarăhu(m) „singen/schreien/klagen“ gleichgesetzt. ${ }^{1533}$ Literarisch ist der Ausdruck in der

Balag̃ Utu..Ekura bei Cohen 1988, 420:a+38. mit šir ${ }_{3}$-ra nam-en-na // zamāri/zamār bèlüti; [šir ${ }_{3}$-nam]-gi-na // [šer $\left.{ }_{3}\right]$-nam-gi-na-ke $e_{4}$ das „Lied der regelmäßigen Opferhandlung“ ist eventuell dem šir ${ }_{3}-n a m-g ̃$ ešbun „Lied der kultischen Mahlzeit“ (s. o.) gegenüber zu stellen. Zum m. E. nicht feststehend gebrauchten Ausdruck šir ${ }_{3} \mathrm{kad}_{4}(-\mathrm{da}) \mathrm{s}$. Volk 1989, 110 „Litanei“ und Rubio 2009, 66-67 „song-cycle“.

${ }^{1527}$ CAD M/2 137b „,conflict; opposition“ und „,correspondence“; AHw 662b „Zusammentreffen; Harmonie“. Ausführliche Besprechung mit Bibliographie bei Sjöberg/Bergmann/Gragg 1969, 83-84:153.

${ }^{1528}$ Gudea Zyl. A xxvii 12 bei Edzard RIME 3/1.1.7, S. 86 „harmonious hymns“; Nanše A 42 bei Heimpel 1981, 84-85 „harmonious song“; Eridu Klage (Green 1978) 60 (3.10) šir ${ }_{3}-\mathrm{ku}_{3}$ šir $_{3}$-h ha-mu[n...] „Holy songs, songs of all kinds“(?). Beachte dha-mun als Name einer Gottheit im Kreise des An neben ${ }^{\mathrm{d}} \mathrm{ad}_{-}-\mathrm{gi}_{4}-\mathrm{gi}_{4}$ in $\mathrm{An}=$ Anum III 166-167; Litke 1998, $134-$ 135.

${ }^{1529}$ Sjöberg/Bergmann/Gragg 1969, 84a; Jacobsen 1987, 129; zu g̃ iš-gi i $_{4}$-g̃al ${ }_{2}$ „Gegengesang; Antiphon“" s. hier Kapitel 14.1.4; s. a. zu bal-bal-e Kapitel 12.4.1.

${ }^{1530}$ Belege in CAD L 48 und AHw 530.

${ }^{1531}$ Nannayas Tod 19. dumu er ${ }_{2}$ in-pad ${ }_{3}$ sahar-ta ma-ra-da-šub šir ${ }_{3}$ nam-nar muun-na-ab-e „Der Sohn begann zu klagen, warf sich auf den Boden(?) und brachte ihm (Nannaya) einen 'Gesang' dar“; ETCSL 5.5.2 und Sjöberg 1983, 319.

1532 S. Kapitel 6.4.

${ }^{1533}$ MSL 16, 118; CAD Ș 99b. 
Elegie an Nawirtum sowie in einer Balag̃-Klage an Enlil belegt. ${ }^{1534}$ Die zweisprachige jüngere Version der Klage gibt für šir ${ }_{3}$ sa g̃ die akkadische Übersetzung șirhi rēssti an, wörtlich ,erste(r)/vorderste(r) Gesang/Geschrei/Klage“, sodass hier auch an den gleichnamigen Klageschreier $\mathrm{lu}_{2}$-šir ${ }_{3}$-sa g zu denken wäre. ${ }^{1535}$ Während im Bala g̃ an Enlil der Ausdruck in Bezug auf Klagegesänge gebraucht wird, steht er in der Elegie an Nawirtum möglicherweise diesen gegenüber, weshalb Kramer im Sinne eines 'ersten' oder 'besten Liedes' übersetzt. ${ }^{1536}$ Über den Begriff könnte eine Form von Introduktionsliedern bezeichnet sein. Insgesamt scheint mir der Terminus allerdings nicht gattungsspezifisch definiert zu sein. ${ }^{1537}$

\subsection{2 Širku(g)}

Ins Akkadische wird ši $\mathrm{r}_{3}$-kug als šerkugû: entlehnt, das in syllabischer Schreibung $\check{s}^{2} r_{3}-k u-g u-u_{2}$ einzig im mittelassyrischen Liederkatalog KAR 158 belegt ist. ${ }^{1538}$

In einer Unterschrift ist Širku(g) bislang nur in der Komposition Enlil und Sud attestiert, der mythologischen Erzählung von der Werbung und Vermählung des Götterkönigs Enlil mit Ninlil bzw. Sud: ${ }^{1539}$

\section{T 78: Enlil und Sud 30-31}

„Wenn die Gaben/Opfer im Heiligtum Nippurs dargebracht werden, ein Širku(g), ein 'Fürsorgewort ${ }^{1540}$ wird dann rezitiert.

Enlil, König des Landes. ..“

30. 「eš $_{3}{ }^{7}$ nibru $^{\mathrm{ki}}$ sah-e-eš rig ${ }_{7}-\mathrm{ga}-\mathrm{ba}$

31. šir ${ }_{3}-\mathrm{ku}_{3} \mathrm{mi}_{2} \mathrm{dug}_{4}-\mathrm{ga} \mathrm{dug}_{4}-\mathrm{ge}-\mathrm{re}^{\mathrm{r}} \mathrm{d}$ en-lil $\mathrm{l}_{2}$ lugal kur-ra-ke $[\ldots]^{1541}$

${ }^{1534}$ Elegie an Nawirtum 18 (PBS 10/2:2 (UM 10/2, 2:8); ETCSL 5.5.3) und Kramer 1960, 55:130; Bala g̃ Ame Bara'anara (Cohen 1988, 319:a+3, 321:a+8).

${ }^{1535}$ Cohen 1988, 321:a+8; vgl. Krecher 1966, 162 mit kurzer Diskussion; s. a. Rubio 2009, 67.

${ }^{1536}$ Kramer 1960, 55, 62:130 „The best(?) songs“.

${ }^{1537}$ Nicht in diesen Zusammenhang gehört m. E. das im Inana-Dumuzi-Lied $D I J$ genannte šir ${ }_{3}$ e sag̃-bi, das wohl auf den „Anfangston des Liedes“ verweist; s. hier Kapitel 12.3.1; anders Alster 1985, 224; Kilmer 1992, 106.

${ }^{1538}$ KAR 158 vi 5 und viii 27; CAD Š/2, 316b zur Schreibung von ši/er ${ }_{3}-\mathrm{ku}_{3}$ mit phonetischem Komplement -gi/-gu-u $/$-ga.

${ }^{1539}$ Civil 1983; ETCSL 1.2.2.

${ }^{1540} \mathrm{Zu} \mathrm{mi}_{2} \ldots \mathrm{dug}_{4}$, akk. kunn̂े auch mit der Bedeutung ,sich kümmern; bemühen; schmeicheln"s. Thomsen 1984, 301.

${ }^{1541}$ Das Fragment S2 weist zur letzten Zeile eine Variante auf: ${ }^{\ulcorner} \mathrm{šir}_{3}{ }^{7}-\mathrm{ku}_{3} \mathrm{mi}_{2} \mathrm{dug}_{4}$-ga [...] ${ }^{d}$ en-lil ${ }_{2}{ }^{\text {nin-lil }}$-bi-[da] [X X]; Civil 1983, 58. 
In diesen Zeilen werden Anweisungen zu den auf den Vortrag der Dichtung Enlil und Sud folgenden Handlungen gegeben. Die Angabe von šir ${ }_{3}-\mathrm{kug}$ ist hier daher nicht auf die Gattung der Komposition selbst zu beziehen, sondern auf ein 'heiliges/reines' Lied, das zu den darauffolgenden Opferhandlungen im Haupttempel des Enlil rezitiert werden sollte.

Sekundär in literarischen Texten wird Širku(g) meist einer Gottheit oder einem Heiligtum zugeordnet, um als Gesangsdarbietung Kultfeste und Rituale zu begleiten. ${ }^{1542}$ Nur im Selbspreis von Šulgi $A$ werden hierüber auch Königshymnen bezeichnet. ${ }^{1543}$ Mehrfach wird es neben nam-šub „Schicksal/Beschwörung" erwähnt. ${ }^{1544} \mathrm{Im}$ altbabylonischen Vorläufer zur Beschwörungsserie Udug-h̆ul ist Geštinana Vorträgerin eines solchen Beschwörungsliedes ( $\check{s}_{1} \mathbf{r}_{3}$ kug nam-šub). ${ }^{1545}$ Diese Göttin ist sonst Sängerin von en n $_{3}$ du-Liedern und gilt als Hüterin des korrekten Liedvortrags. ${ }^{1546}$ Der Vortrag des Liedes wird über das Verb šid ,zählen; rezitieren“" angegeben. ${ }^{1547}$

Wohl als Name einer Liedgattung wird das akkadische šerkugĥ im mittelassyrischen Liederkatalog KAR 158 gebraucht. Der Katalog nennt elf Titel dieser Gattung, von denen jedoch kein einziges als vollständige Liedkomposition überliefert ist. Aus der Zusammenzählung in Kolumne vi 5 und viii 27 ist zu ersehen, dass die Lieder sowohl in sumerischer wie auch in akkadischer Sprache verfasst sein konnten. ${ }^{1548}$

Zum Vortrag und musikalischen Kontext sind in literarischen Texten ansonsten verschiedene Informationen enthalten. Die Lieder wurden meist gesprochen $\left(\mathrm{dug}_{4}\right),{ }^{1549}$ selten in einem gesamtmusikalischen Kontext inszeniert $\left(\mathrm{du}_{12}\right){ }^{1550}$

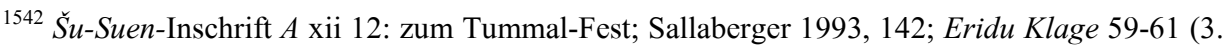
kirugu): Nanna C 23, 42: zu Reinigungsriten der Enheduana; Nanše A 43, 46: zur Tempelweihe durch Gudea; Martu A 58; IšD W 17; Enkis Reise 126; Tempel-Hymnen 298; Alster/Jeyes 1990, 1-2:5-6.

${ }^{1543}$ Bsp. Śulgi A 92-93: ETCSL 2.4.2.01:92. an ub-da 4 ug $\tilde{g}_{3}$ sa g $\operatorname{sig}_{10}-\mathrm{ga}-\mathrm{a}-\mathrm{ba} \mathrm{mu}-\tilde{g} \mathrm{u}_{10}$ $\mathrm{he}_{2}$-em-mi-sa ${ }_{4}$ 93. šir ${ }_{3}$ kug-g̃a $a_{2}$ hu-mu-un-e-ne „Möge mein Name unter den Getreuen aller vier Himmelsrichtungen ausgerufen werden! Mögen sie ihn in heiligen Liedern über mich aussprechen!“.

1544 Z. B. Enki und die Weltordnung 107; Heimpel 1993-97, 552; Flückiger-Hawker 1999, 261 gegen Cohen 1975, 594-595; Zgoll 1997, 365:63, 410: 99 „schicksalbestimmendes Lied“ oder ,performatives Lied“; für das 1. Jt. vgl. Borger 1967, 8:78.

${ }^{1545}$ Geller 1985, 22-23:48.

${ }^{1546}$ S. hier Kapitel 11.1.1.

${ }^{1547} \mathrm{Zu}$ šid/šid ${ }_{3}=$ manû „zählen; rezitieren“ s. CAD M/1 221a manû sub 3; anders Kilmer 1992, 102, die das sumerische šid/šid 3 akk. enû ,ändern, wechseln“ gleichsetzt in Anlehnung an den Examenstext $A 24$ bei Sjöberg 1975b, 142; s. a. Çerný 1994, 17-18

${ }^{1548}$ KAR 158 vi 4. šu-nig̃ in 28 šumeru $3 a k k a \overline{d u} 5$. šu-nig̃ in ${ }_{2}-$ ma 11 šer ${ }_{3}-k u-g u-u_{2}$; von den Titeln in Kol. vi sind lediglich die ersten Zeichen erhalten.

1549 Enlil und Sud 30-31; Inana B 63; Martu A 58; Sumer und Ur Klage 437; Tempel-Hymnen 298. 
Vortragende waren - wenn überhaupt genannt - nar-Musiker, ein Fährmann (addir) oder eine Göttin. ${ }^{1551}$ Instrumental begleitet wurden Širku(g) den meisten Textbelegen zufolge mit dem Perkussionsensemble tigi - šem - $_{3}$ $\mathrm{a}_{2}-\mathrm{a}_{2}$. Die Hymne Nanše A nennt ein Ibex-Horn $\left(\mathrm{a}_{2}\right.$-tarah), das zur Einleitung einer Opferhandlung und dem Vortrag eines Širku(g) ertönte:

\section{T 79: Nanše A 44-46}

„Der nar-gal spielte für sie das Ibex-Horn. (Das Lied) 'Die dem Tempel durch den $A b z u$ geweihten me', das Širku(g) des Tempels von Sirara von den fürstlichen me, wurde vorgetragen."

44. $a_{2}$-tarah nar-gal-e šu mu-na-ab-tag-ge

45. $e_{2}$ abzu-ta me nam-ta-ba

46. $e_{2}$ sirara $^{\mathrm{ki}}-\mathrm{ka} \breve{s ̌ i r}_{3}-\mathrm{kug}-\mathrm{ba}$ me nun-ba mu-un-du ${ }_{12}$

Insgesamt bleibt strittig, ob mit Širku(g) der Name einer Liedgattung vorliegt. Die sekundären Texte beschreiben eher eine allgemeine Bezeichnung für Preislieder, die im Tempel oder bei Götterreisen vorgetragen wurden. ${ }^{1552}$ Auf seinen funktionalen Hintergrund könnten Belege im Kontext von Beschwörungsrezitationen verweisen.

\subsection{3 Širnamgala}

Die Liedgattung šir $_{3}$-nam-gala „Lied des gala-tums“(1553 steht seinem Namen nach in Opposition zum šir ${ }_{3}$-nam-nar „Lied der nar-Musikkunst“. Im Gegensatz zu Letzterem sind jedoch vier Textvertreter der Širnamgala vollständig überliefert. ${ }^{1554}$ Sechs weitere Titel dieser Gattung werden im mittelbabylonischen Katalog TMH NF 3, 53 genannt, von denen bisher nur eine Hymne an den König Šu-Suen identifiziert wurde, die der Katalog als ein Širnamgala des Mondgottes Nanna verzeichnet. ${ }^{1555}$

\footnotetext{
${ }^{1550}$ Emerkar und Aratta 134-135; Šu-Suen-Inschrift $A$ xii 12; Nanše A 42.46.

${ }^{1551}$ Martu A 58; Šulgi R 54; Gudea Zyl. B iv 6.

${ }^{1552}$ Heimpel 1993-97, 552; s. a. Zgoll 1997, 410 zu Zeile 99.

${ }^{1553}$ Wilcke 1975, 259 „kalû-Priester-Lied“; zu nam-gala = kalûtum „Klagepriestertum oder -amt"s. CAD K 107b.

${ }^{1554}$ Nanna L; Ibbi-Suen B; Lipit-Eštar E sowie Šu-Suen Hymne BM 100042 (ETCSL 2.4.4.a) identifiziert nach dem Katalog TMH NF 3, 53:35; vgl. Wilcke 1975, 288; Flückiger-Hawker 1999, 262 Anm. 27. Aufgrund formaler Kriterien ergänzt Wilcke 1975, 288 für Ur-Ninurta $A$ (ETCSL 2.5.6.1) die Unterschrift [šir ${ }_{3}$-n am-gala] ${ }^{\mathrm{d}}$ Inana-kam; Sjöberg 1977a, 192; anders Römer 1989, 659, der es als Bala g̃ identifiziert; s. a. Schretter 1990, 90 Anm. 39.

${ }^{1555}$ Bernhardt/Kramer 1956/57, 392:35; Kramer 1989, 303-316; der einleitende Preis der erhaltenen $\check{S} u$-Suen-Hymne BM 100042 (ETCSL 2.4.4) ist Nanna gewidmet.
} 
Die Länge der überlieferten Vertreter der Liedgattung Širnamgala fällt sehr unterschiedlich aus. Was ihre formale Struktur betrifft, so sind in allen Textvertretern die Rubriken kirugu und g̃išgig̃al enthalten, während IbbiSuen $B$ und ergänzt auch Nanna L entsprechend den Balag̃ und Širnamšub mit einem kišu abschließen. ${ }^{1556}$ Eine Ausnahme bildet die Hymne Lipit-Eštar $E$, die mit zwei Versen als Rubrik ša ${ }_{3}$-ba-TUKU einsetzt.

Formal wird das Širnamgala aufgrund der in ihm vertretenen Rubriken kirugu und kišu mit den verwandten Gattungen Širnamšub und Balag̃ in Verbindung gebracht, ${ }^{1557}$ auch wenn $\mathrm{zu}$ diesen Liedgattungen bedeutende sprachliche und inhaltliche Unterschiede bestehen. So sind ŠirnamgalaLieder größtenteils im sumerischen Hauptdialekt, dem Emegir verfasst, während das Emesal auf die direkte Rede von Göttinnen beschränkt bleibt. ${ }^{1558}$ Ihrem Inhalt nach widmen sich Širnamgala der Erwählung und Erhebung des Königs, der im Lied formulierte Preis kann sich hier allerdings stärker der angerufenen Gottheit zuwenden. ${ }^{1559}$ In Lipit-Eštar E, Ur-Ninurta A und ansatzweise in der Hymne des Šu-Suen (BM 100042) wird die Verbindung des Königs zu einer weiblichen Gottheit (Ninisina und Inana) thematisiert, was mit der Erhebung des Königs durch den Götterkönig Enlil einhergeht. Zwar ist das Širnamgala Nanna $L$ ausschließlich dem Gott Nanna ohne Nennung eines Königs gewidmet, doch liegt in ihm das Hauptthema auf der Manifestation seiner Königsherrschaft im Ekišnugal. Es steht daher außer Frage, dass auch diese Hymne auf das Königtum und seine Erhebung Bezug nimmt. Eine gänzlich andere Thematik weist hingegen das Širnamgala Ibbi-Suen B auf, das einen Preis der Gottheiten Lugal-irra und Meslamta'ea formuliert, die Erhebung des Königs bleibt hierbei auf den Gegengesang des g̃išgi g̃al beschränkt.

Ausgehend von der Thematik der meisten Širnamgala ist ihre Anwendung im Bereich des Königtums anzusetzen. Im Gegensatz zu anderen Liedgattungen ähnlicher Struktur und Form, wie Širnamšub und Balag̃, handeln Š́irnamgala-Lieder ausschließlich von der herausragenden Position des Königs und seine Legitimierung durch die Götter. Sie könnten aus Anlass einer Inthronisation oder einer jährlichen Erneuerung des Königtums verfasst und vorgetragen worden sein. Die als 'Vermählung' angesprochene Verbindung zwischen König und Göttin erhält hier außerdem Anklänge an die Thematik der 'Heiligen Hochzeit', also den Erhalt von Fruchtbarkeit und Wachstum. Der Preis der Zwillingsgottheiten Lugal-irra und Meslamta'ea erinnert wiederum an

${ }^{1556}$ Die Ergänzung [uru ${ }_{x}$-EN]-bi-im in Nanna L 52 von Sjöberg 1973d, 33 ist nach Wilcke 1975, 288 zu [ki-šu]-bi-im zu korrigieren, da diese Rubrik immer abschließend auf die Auflistung von kirugu folgt.

${ }^{1557}$ Flückiger-Hawker 1999, 262.

${ }^{1558}$ Lipit-Eštar E; Ur-Ninurta A; Schretter 1990, 91.

1559 Schretter 1990, 91 spricht bei einigen Vertretern dieser Gattung von 'Königshymnen'; s. a. Ludwig 1990, 32-33. 
Eršema-Lieder, die dem Wettergott Iškur und seiner Zerstörungskraft gewidmet sind.

Ein Širnamgala kann in bis zu zehn kirugu-Rubriken unterteilt sein (Ibbi-Suen B). Das Širnamgala Lipit-Eštar E verfügt nur über ein drittes und ein viertes kirugu, die fehlenden ersten zwei kirugu könnten Teil einer weiteren eigenständigen Komposition gebildet haben.

An ihrer statt sind zwei einleitende Verse als šaba-TUKU-Rubrik notiert, die die Aufforderung an die Göttin Ninisina formulieren, sie solle Lipit-Eštar erwählen und ihn als ihren Versorger einsetzen. Da der folgende Liedtext die Bitte der Ninisina und schließlich die Rede des Enlils enthält, könnten die einleitenden zwei Verse der Rubrik šaba-TUKU von einem Priester in Vertretung des Königs gesprochen worden sein. Über die Angabe der Rubrik wird hier für die einleitenden Verse mit Aufforderung der Gottheit eine andere 'Begleitung' oder Vortragsform angegeben als für den Rest des Liedes, womit sie gleichzeitig von den folgenden direkten Reden der Götter Ninisina und Enlil abgesetzt werden.

Ähnlich der für Balag̃ rekonstruierten Aufführungspraxis könnten aufgrund der Rubriken kirugu und kišu auch Širnamgala an mehreren Kultstationen vorgetragen worden sein. Das nur einmal in Lipit-Eštar E belegte šaba-TUKU lässt angesichts der Interpretation dieser Rubrik für die einleitenden Verse des Priesters außerdem ein Instrumentalspiel vermuten. ${ }^{1560}$

Über die Bildung des Gattungsnamens als auch der enthaltenen Rubriken ist diese Textgruppe eindeutig dem Repertoire des gala zugewiesen. Bezeichnend ist außerdem, dass Širnamgala entgegen des gängigen gala-Repertoires des ersten Jahrtausends ausschließlich hymnisch-preisend mit einem Schwerpunkt auf der Erneuerung des Königtums verfasst sind. Hier könnte wiederum die Rolle des gala bei Übergangsriten Bestätigung finden, der den König bei seiner Einführung vor die Gottheit begleitete.

\subsection{4 Širnamšub}

Von der Liedgattung šir ${ }_{3}$-nam-šub „Lied der Beschwörung“ sind bislang zwölf Textvertreter bekannt geworden, die bis auf eine Ausnahme alle in die altbabylonische Zeit datieren. ${ }^{1561}$ Die Schreibung des Gattungsnamens ist in

\footnotetext{
${ }^{1560}$ S. hierzu Kapitel 14.1.2.

${ }^{1561}$ Inana $G(\mathrm{CT} 42,13)$ und $I$ (CT 42, 22); $D I M$ (UM 29-15-242) und DI $F_{l}$ (A: ISET 1, 61; B: CT 58, 13 (BM 88318)) mit Unterschrift Rs 52. 52 šir $_{3}-n a m-\check{s}{ }^{d}$ Inana-k[am]; Sefati 1998; 320-323; Fritz 2003, 81-82); Nanna K (VS 2, 68); Ninisina B (JCS 16, 79) und $C$ (aB CBS 15132); Ninurta G (SLTN 61); Nisaba B (PRAK C 39; 97; VS 2, 65); Utu $E$ und $F$ (Kramer 1985b) sowie Ur-Namma EF (ISET 1166 f.; CT 44, 16); nur Ninisina $C$ ist auch mA belegt; Cohen 1975, 592-596 'incantation-hymn'; Flückiger-Hawker 1999, 261-262 und Römer 1999, 213. Weitere mögliche Vertreter sind UM 29-15-570 (Sjöberg 1977b, 8-13,
} 
zwei Versionen überliefert, neben dem gängigen šir $_{3}$-nam-šub ist im Katalog B1 (VS 10, 216) sowie im Lied Nisaba B 34 die syllabische Variante $\check{s}^{2}{ }_{3}$ nam-šu-ub attestiert. Mit Ausnahme des Namenselements nam-šub, akkadisch šiptu „Beschwörung“ bestehen zu den gängigen Beschwörungstexten weder inhaltliche noch formale Gemeinsamkeiten. ${ }^{1562}$ Ausgehend von der Grundbedeutung des Verbs šub „(das Schicksal) werfen/hinlegen“ legen Attinger und Flückiger-Hawker eine Übersetzung des Gattungsnamens mit „Bestimmungs-“ oder „Schicksalslied“ an. ${ }^{1563}$ Es wäre dennoch zu vermuten, dass die Lieder begleitend zu Beschwörungen im Rahmen eines größeren Festzusammenhangs vorgetragen wurden. ${ }^{1564}$ Schließlich thematisiert das Sprichwort SP 2.106 (T 26) den gala als Vorträger von Beschwörungen.

Die Lieder sind grundsätzlich einer einzigen Gottheit gewidmet. ${ }^{1565}$ Inhalt und formaler Aufbau der Širnamšub fallen jedoch unterschiedlich aus. Von einer Götterreise oder einem heldenhaften Auszug berichten die Lieder Inana G/I, Ninisina $C$, Ur-Namma EF sowie Ninurta $G$. Eine rituelle Reinigung thematisieren Ninisina $B$ und die Hymne Nanna $K$, die auf Ur III-zeitlich attestierte Baderiten bezogen werden kann. ${ }^{1566}$ Das Lied Utu $E$ ist einem Gastmahl oder einer Bierlibation gewidmet, während Utu $F$ in einer Rede der Inana der Zweisamkeit auch in sexueller Hinsicht huldigt, über die der Sonnengott wacht. ${ }^{1567}$ Ausschließlich im Širnamšub an Nisaba (Nisaba B) wird ein Klagetext formuliert, in dem die Göttin die Zerstörung ihres eigenen Tempels beweint. ${ }^{1568}$

Ein König wird nur im möglicherweise frühesten Vertreter dieser Gattung, der Hymne Ur-Namma EF erwähnt, wo er als Günstling und Auserwählter des im Text gepriesenen Nanna auftritt. Ansonsten verweisen Širnamšub meist nur anonym auf einen König. ${ }^{1569}$

Nicht nur die Inhalte sondern auch die Länge der Texte fällt sehr unterschiedlich aus, so zählt das Širnamšub Utu E 111 Zeilen, ${ }^{1570}$ während Ninisina $B$ lediglich 24 Zeilen aufweist. Die Texte sind überwiegend im Emegir gehalten, nur selten finden sich auch einzelne Wörter oder längere Textpassa-

37:Nr. 3; dazu Flückiger-Hawker 1999, 261 Anm. 13), Alster/Jeyes 1990, 1-3, 12 (jetzt CT 58, 23: Rs 11. [...] d Utu-kam) und die Hymne Cohen 1977, die allerdings dem Kontext einer Bestattung angehört.

${ }^{1562}$ Schretter $1990,90$.

${ }^{1563}$ So schon Sjöberg 1960, 87 „Los-Lied“; Goetze 1965, 57b „,fate fixing song(s). . ““; Attinger 1993, 625 Anm. 1790; Flückiger-Hawker 1999, 261.

${ }^{1564}$ So auch Sefati 1998, 209.

${ }^{1565}$ Wohl auch das fragmentarische Širnamšub Dumuzi-Inana M; Sefati 1998, 208-209.

${ }^{1566}$ Sallaberger 1993, 191-192.

${ }^{1567}$ Kramer 1985b, 118-119.

${ }^{1568}$ Cohen 1975, 602-604; Michalowski 2001, 577.

${ }^{1569}$ Inana I; eventull auch Inana $G$; Utu E und $F$; vgl. Flückiger-Hawker 1999, 262.

${ }^{1570}$ Das Širnamšub Ninurta $G$ mit 184 Zeilen ist nach Halbversen aufgeteilt. 
gen im Emesal, wobei diese nicht an die direkte Rede weiblicher Gottheiten gebunden sind. ${ }^{1571}$ Auffallend sind die lyrische Sprache sowie die zahlreichen Wiederholungen einzelner Verse innerhalb der Lieder. Markant ist das Širnamšub Utu E, dessen erste zwei kirugu mehrere sich wiederholende Interjektionen zum Ausdruck des Freudengesangs enthalten: e-la-lu, $a-u_{3}(-$ $\mathrm{am}_{3}-\mathrm{ma}$ ) und $\mathrm{u}_{3}-\mathrm{li}-\mathrm{li}$.

Die Gattung der Širnamšub ist aus mehreren Gründen mit Balag̃ und Eršema verwandt und wird daher auch dem Repertoire des gala zugeordnet. ${ }^{1572}$ So listet der altbabylonische Katalog B1 (VS 10, 216) aus Sippar die Vertreter dieser Lieder neben Titeln von Bala g̃ und Eršema auf. ${ }^{1573}$ Zwei Textvertreter der Gattung sind nach kirugu-Rubriken unterteilt (Nanna K, Utu $E$ ), das Lied Ninurta $G$ markiert zudem eine einzige kišu-Einheit. Die Einteilung in einzelne Abschnitte wird in einigen Vertretern mithilfe durchgezogener Linien im Text angezeigt. ${ }^{1574}$ Schließlich werden aus Širnamšub so genannte 'Versatzstücke' in Bala g̃-Klagen wiederverwendet. ${ }^{1575}$ Nur einmal wird im Lied Utu E 75-79 ein gala in Aktion genannt, der über die Bierlibation für seinen Gott wacht. Eine in der Verwaltung bestehende Verbindung zwischen diesem Priester und der Verantwortung über Bierausgaben und Libationen konnte für die gala-mah von Sippar und Kiš festgestellt werden.

Insgesamt weisen die Inhalte der Širnamšub auf eine vielseitige Verwendungsmöglichkeit im Kult hin. Die stark variierende Länge sowie die sporadische Einteilung nach Rubriken lassen außerdem auf unterschiedliche Aufführungspraktiken schließen. Grundsätzlich sind es Götterhymnen, die unter Beteiligung des Königs aus Anlass größerer Kultfeste, ob Baderiten, Götterreisen oder Bierausschank in Göttertempeln, möglicherweise auch zu Beschwörungen vom gala vorgesungen wurden. ${ }^{1576}$

\subsection{5 Širnamerima}

Aufgrund der Bildung des Gattungsnamens šir ${ }_{3}$-nam-erim ${ }_{2}-\mathrm{ma}^{1577}$ mit nam-erim 2 , akkadisch māmìtu(m) „Eid, Bann“, ${ }^{1578}$ vermutet Ludwig hier ein Lied mit drängender oder beschwörender Aufforderung und übersetzt es als „Lied der Beschwörung“ oder „Lied der dringenden Bitte““ ${ }^{1579}$ Angesichts der Inhalte der zwei Gattungsvertreter ist meines Erachtens eine Ableitung von

\footnotetext{
${ }^{1571}$ Schretter 1990, 90.

1572 Black 1991, 24; Flückiger-Hawker 1999, 262.

${ }^{1573}$ VS 10, 216; Krecher 1966, 33; Flückiger-Hawker 1990, 261-262.

${ }^{1574}$ Inana G; Inana I markiert den Refrain; Wilcke 1975, 288 zu (a).

1575 Cohen 1975/76, 24.

${ }^{1576}$ Flückiger-Hawker 1999, 263.

${ }^{1577}$ Proto-Lu ${ }_{2} 593$ s. hier Kapitel 12.2.1.

${ }_{1578}$ AHw 599b; CAD M/1 189b „1. oath; 2. curse“.

${ }^{1579}$ Ludwig 1990, 29; s. a. Klein 1981, 41 Anm. 78 „execration“.
} 
$\operatorname{erim}_{2}$ als akkadisch $\operatorname{raggu}(m)$ oder $\operatorname{ajj} \bar{a} b u(m)$ zutreffender, im Sinne eines „Feind(schafts)lieds“، ${ }^{1580}$

Als Gattungsname ist Širnamerima bisher aus einer einzigen Liedunterschrift bekannt, der Königshymne Šulgi $S$, die aus mehreren altbabylonischen Fragmenten aus Ur und möglicherweise Nippur rekonstruiert wird: ${ }^{1581}$

T 80: Šulgi $S$ 23-25

„Es ist sein kišu. Ein $\check{s ̌ r}_{3}$-nam-erim 2 -ma [ . . ]

Vollständig. Es ist die zweite einkolumnige Tafel.“

23. ki-šu $u_{2}$-bi-im $\check{s} r_{3}-n a m-e r i m_{2}-m[a \quad \ldots]$

24. al-t $[\mathrm{il}]$

25 .

$$
\mathrm{im-gid} 2-\mathrm{da} I I-k[\mathrm{am}-\mathrm{ma}]^{1582}
$$

Ein weiterer Vertreter derselben Gattung liegt mit der Komposition IddinDagan $D$ vor, die nach bisheriger Kenntnis lediglich auf zwei altbabylonischen Tafeln erhalten ist. ${ }^{1583}$

Formales Charakteristikum für beide Kompositionen ist ihre Einteilung nach mehreren Gebeten, die an jeweils unterschiedliche Götter des sumerischen Pantheons gerichtet sind und mit der Formel „Oh, dein Name, GN/fGN, Oh dein Name!" (a mu-zu GN/fGN a mu-zu)" abschließen.

Iddin-Dagan $D$ richtet sich nach einer längeren preisenden Anrufung Ninisinas, mit Schwerpunkt auf ihre zerstörerische und kriegerische Kraft, an die Götter An, Enlil, Ninlil und Aruru, wobei jeweils Fürbitten für den König Iddin-Dagan integriert werden. Da das Ende der Komposition abgebrochen ist, bleibt unbekannt, wie viele entsprechende Gebete an weitere Götter des Pantheons folgten. Zudem ist die Liedunterschrift nicht erhalten. ${ }^{1584}$ Auch Šulgi $S$ ist an mehrere Götter gerichtet, wobei vorwiegend kriegerische Gottheiten, darunter Ninurta, Nergal aber auch Ninisina adressiert werden. ${ }^{1585}$

Die Formel a mu-zu GN/fGN a mu-zu wird teilweise über durchgezogene Linien vom übrigen Text abgesetzt, eine entsprechende Markierung ist auch für die Rubrik kirugu in Balag̃ und Širnamšub belegt. Die Hymne Šulgi $S$ endet schließlich auch mit einem kišu, der üblichen Abschlussrubrik von kirugu-Texten.

\footnotetext{
${ }^{1580}$ UET 6/3 S. 15 zu Nr. 521 „hostile song“; s. AHw 23 ajjābu(m) „feindlich; Feind“ und 942 raggu(m) „böse, schlecht“; CAD R 67.

${ }^{1581}$ Klein 1981, 41-42 Anm. 78 mit den Textvertretern und UET 6/3, 521.

${ }^{1582}$ HAV pl. 1 Nr. 1.

${ }^{1583}$ ETCSL 2.5.3.4 und Gurney/Kramer 1976, 19-26 mit Bearbeitung in OECT 5, 19-26 Nr. 8.

${ }^{1584}$ ETCSL 2.5.3.4 und OECT 5, 2-3 mit Anm. 10.

${ }^{1585}$ UET 6/1 S. 9 zu 93-94 mit Nin-EZEN in UET 6/1, 94:8.
} 
Sowohl Šulgi $S$ als auch Iddin-Dagan D sind primär als Hymnen verfasst, ihr Hauptthema liegt allerdings auf dem Abwenden von Feinden durch die jeweils angerufenen Kriegs- und Heldengötter. ${ }^{1586}$ Ihrem Inhalt nach ist daher mit J. Klein für die Gattung Širnamerima eine Funktion innerhalb von Königsritualen zur Abwehr von Feinden anzunehmen. ${ }^{1587}$ An diesen Ritualen waren höchstwahrscheinlich der König selbst und weiteres spezialisiertes priesterliches Personal beteiligt. Angesichts ihres Aufbaus ist anzunehmen, dass die jeweiligen Gebete an unterschiedlichen Orten, Tempeln oder Schreinen vorgetragen wurden. Die Rubrik kišu könnte wiederum darauf hinweisen, dass ein Membranophon zur Begleitung der Gebete gespielt wurde. Aufgrund der Funktion der Texte sowie der enthaltenen Rubriken könnten sie dem gala zuzuordnen sein.

\subsection{6 Širgida}

Die Liedgattung šir $_{3}-$ gidd $_{2}$-da, wörtlich „Lied des 'Langen”“ oder „langes Lied" " ${ }^{1588}$ wurde in der bisherigen Forschung bereits mehrfach diskutiert, ${ }^{1589}$ weshalb in der folgenden Darstellung im Wesentlichen auf frühere Erörterungen verwiesen wird. Diesen werden zusätzliche Bemerkungen hinsichtlich der Form und musikalischen Ausführung hinzugefügt.

An Širgida-Liedern sind derzeit neun größtenteils vollständig erhaltene Textvertreter bekannt. ${ }^{1590}$ Mit Ausnahme der Komposition Ninurtas Rückkehr (=Angimdimma) sind alle übrigen Vertreter auf einer einzigen, höchstens zwei altbabylonischen Tafeln überliefert. Soweit bekannt, stammen die meisten dieser Tafeln aus Nippur. Ninurtas Rückkehr wurde hingegen über den gesamten babylonischen und assyrischen Raum tradiert, die jüngsten Vertreter aus neuassyrischer und neubabylonischer Zeit weisen außerdem interlineare akka-

${ }^{1586}$ UET 6/3 S. 15 zu Nr. 521.

1587 Klein 1981, 41 Anm. 78 „execration“; entsprechende Königs- und Kriegsrituale, an denen auch kalû beteiligt waren, sind ausschließlich für das 1. Jt. bekannt; vgl. Maul 1988, 30-31.

${ }^{1588}$ CAD Š/2 314b „long song“; Falkenstein 1950, 86; Wilcke 1975, 257 „lang gemachtes Lied“.

1589 Zuletzt Ludwig 1990, 38-40.

${ }^{1590}$ Lulal-Hymne (HAV 431 No. 5); Martu A (SRT 8; ETCSL 4.12.1); Ninisina A (SRT 6 und 7; ETCSL 4.22.1); Ninurta A (TCL 15, 7; ISET 1, 87; ETCSL 4.27.01); Ninurta B (STVC 34; ETCSL 4.27.02), Ninurta J (TMH NF 4, 49+88 Rs i'(iii) 1-5); Ninurtas Rückkehr (Cooper 1978; ETCSL 1.6.1); Nusku A (JCS 4, 138f.; ETCSL 4.29.1), Nusku B (STVC 37; ETCSL 4.29.2); Ludwig 1990, 39; Cooper 1978, 3 Anm. 14; ein weiteres Širgida an Ninurta könnte nach Wilcke 1975, 287 auf der Sammeltafel TMH NF 4, 49+88 Rs i 6-? auf das Širgida Ninurta $J$ folgen; in Ninšubur A (BL 195; ETCSL 4.25.1; Zólyomi 2005) wird die Unterschrift zu šir ${ }_{3}-[\mathrm{g}] \mathrm{id}_{2}-[\mathrm{da}]$ ergänzt, angesichts des Inhalts ist eine solche Identifizierung allerdings zu bezweifeln, da hier keine Heldenrolle der in diesem Fall weiblichen Ninšubur thematisiert wird. Der Schluss der Komposition mit der Herzbesänftigung der Inana erinnert vielmehr an den Kontext der gala-Kultliturgie; möglicherweise liegt hier auch ein Irrtum des Schreibers vor; s. Zólyomi 2005, 408 „The signs are difficult to read because apparently someone attemted to wipe them away while the clay was still wet". 
dische Übersetzungen auf. ${ }^{1591}$ Einzig diese Komposition wird außerdem bereits altbabylonisch in literarischen Katalogen zitiert. ${ }^{1592}$ Die Angabe des Gattungsnamens ist dennoch nur in altbabylonischen Texten enthalten. ${ }^{1593}$

Titel der Liedgattung Širgida waren usrprünglich im mittelassyrischen Katalog KAR 158 in Kolumne iv aufgelistet, doch sind sie sowie ihre Anzahl in der Zusammenzählung von Kolumne viii des Katalogs nicht erhalten.

Ihrem Inhalt nach sind Širgida-Lieder grundsätzlich dem Preis von Göttern gewidmet. Allerdings enthalten einige der Texte auch Verweise auf einen anonymen König, der in die Gunst des angepriesenen Gottes einbezogen wird. ${ }^{1594}$ Deutlich wird dies in Ninurtas Rückkehr, wo den Abschluss des Textes die Gattin Ninnibru mit einem Segen an den namentlich nicht genannten König bildet. Insgesamt werden daher die Vertreter dieser Gattung der Königsideologie zugewiesen. ${ }^{1595}$

Der Preis der Gottheit konzentriert sich auf die Gestalt des kriegerischen, jugendhaften Helden und seine göttliche Sohn- oder auch Tochterschaft. Aus diesem Grund könnten Širgida meist männlichen Gottheiten gewidmet worden sein, doch wird auch in Ninisina $A$ die Göttin nicht nur als Heilerin und Dämonenjägerin angesprochen, sondern auch als kriegerische Heldin im Auftrag des Göttervaters Enlil gegen die Fremdländer.

Während die Texte überwiegend lyrisch gestaltet sind, enthalten Ninurta B und Ninurtas Rückkehr längere narrative Passagen, in denen von der Reise des Gottes nach Eridu bzw. von seiner Rückkehr in seinen Heimattempel von Nippur berichtet wird. Mit Ausnahme der Komposition Ninurta B weisen alle Širgida eine abschließende $\mathrm{za}_{3}-\mathrm{mi}_{2}$-Formel auf. ${ }^{1596}$

Auch die längere Ninurta-Dichtung Lugale berichtet vom kriegerischen Auszug des Gottes und seinem Kampf gegen den Asag-Dämonen. Die Unter-

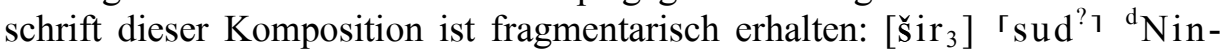
urta-ka. ${ }^{1597}$ Das Wort sud „lang“ könnte auf eine Verwandtschaft zum Gattungsnamen $\check{s i r}_{3}-g \mathrm{gd}_{2}$-da hinweisen, die Rekonstruktion des anfänglichen $\breve{s i r}_{3}$ ist allerdings nicht gesichert.

\footnotetext{
${ }^{1591}$ Mit Ausnahme des nB Fragments x; Cooper 1978, 32-36.

${ }^{1592}$ Im Louvre-Katalog (L) TCL 15, 28:43 und im Ur-Katalog (U2) UET 6, 123:42.

${ }^{1593}$ Cooper 1978, 102; beachte, dass derselbe Schreiberschüler Marduk-balāssu-ēreš, Sohn des Königsschreibers Ninurta-uballițsu, auch das Širnamšub Ninisina $C$ in mA Zeit kopierte; Hunger 1968: 30 Nr. 44.

${ }^{1594}$ Ninurtas Rückkehr 198; Martu A 21ff., 49ff.

${ }^{1595}$ Cooper 1978, 4.

${ }^{1596}$ In Nusku B 77-78 ist der Preis an Nisaba, die Schreibergöttin, gerichtet. Man könnte daher annehmen, dass die /zami/-Formel nicht zum ursprünglichen Text der Hymne gehörte und vom Schreiber im Kontext der Tätigkeit im Tafelhaus hinzugefügt wurde.

${ }^{1597}$ Dijk 1983, 147:729; ETCSL 1.6.2.
} 
Die Länge von Širgida fällt insgesamt sehr unterschiedlich aus. Während die Hymne Martu A 59 Zeilen enthält, weist Ninurtas Rückkehr mit 207 Zeilen mehr als seine dreifache Länge auf. Aufgrund dieser Beobachtung ist die wörtliche Bedeutung des Kompositums šir ${ }_{3}-g \mathrm{dd}_{2}$-da weniger auf die Länge der Lieder, als vielmehr auf inhaltliche, funktionale oder auch musiktechnische Aspekte zu beziehen. Römer und Cooper schlagen eine Wiedergabe des Gattungsnamens mit „Auszugs-“ oder „Prozessionslied“ vor. ${ }^{1598}$ In musiktechnischer Hinsicht klingt der Name an die Rubrik sa-gid ${ }_{2}-\mathrm{da}$ an, ein Praxis bezogener Bezug beider Termini kann allerdings nicht rekonstruiert werden. ${ }^{1599}$

Der Inhalt von Širgida ist hymnisch, wobei die Erzählperspektive auch innerhalb einer Komposition wechseln kann. Einen Selbstpreis in der ersten Person enthalten Ninisina A und Ninurtas Rückkehr. In keinem der bekannten Širgida sind Rubriken oder andere vergleichbare Abschnittsmarker enthalten.

Nach sekundären Textbelegen in den Selbstlobhymnen der Könige Šulgi und Išme-Dagan werden Širgida als Kompositionen eingeordnet, die dem Preis des Königs und seiner heldenhaften Taten dienen:

T 81: Šulgi $E$ 23-30 1600

„Darüber, dass ich ... (Aufzählung der Taten des Königs),

haben sie (die um-mi-a) für mich dort Širgida, Königspreislieder, ${ }^{1601}$

(und) jene Šumunša-, Kung̃ar- und Balbale-Lieder gesetzt.“

23. ... $\ldots--\tilde{\mathrm{g}} \mathrm{a}_{2}$

29. $\check{s i r}_{3}-g^{-d_{2}}-d a a_{2}$ nam-lugal-la

30. šumun-ša $a_{4}$ kun-g̃ar bal-bal-e-bi mu-ši-in-g̃ar-g̃ar-re-eš

Eine entsprechende Aussage findet sich in der Selbstlobhymne des IšmeDagan:

T 82: Išme-Dagan A(+V) 335-339

„Adab, Tigi, Šumunša, Malgatum, Širgida, meine Königspreislieder vollkommenen Inhalts, Arahi, Balbale, Zamzam und Kung ga r-Lieder, die die 'kenntnisreichen' Musiker (nar) für mich verfasst haben.

Dort wo die Hymnen $\left(\mathrm{en}_{3}-\mathrm{du}\right)$ gesungen werden, erhöhen sie meinen Namen“"1602

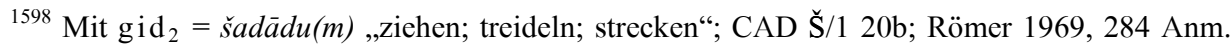
67 „Auszugslied“; Cooper 1978, 3 ,processional song“.

${ }^{1599}$ Falkenstein 1950, 86; Cooper 1978, 3.

${ }^{1600}$ Ludwig 1990, 35-36.

${ }^{1601} \mathrm{ar}_{2}$ nam-lugal-1a in Šulgi $B 29$ und 54 wechselt mit $<\mathrm{za}_{3}->\mathrm{mi}_{2}$ nam-lugal-la in $I S ̌ D$ $A(+V)$ 336, es ist daher wohl nicht als Gattungsname zu identifizieren; dazu Ludwig 1990, 36 Anm. 50.

1602 Vgl. ETCSL 2.4.5.01:335-338 „The skilful singers composed for me adab, tigi, šumunša, 
335. a-da-ab tigi $i_{2}$ šumun-ša ${ }_{4}$ ma-al-ga-tum

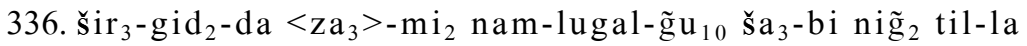

337. a-ra-hi bal-bal-e za-am-za-am kun-g̃ar-bi

338. nar gal-an-zu-ne ma-an-g̃ar-re-eš-a

339. $\mathrm{en}_{3}$-du ki du $\mathrm{d}_{12}$-ba mu-g̃u $\mathrm{u}_{10}$ mi-ni-gal-eš-a

Die meisten der hier zitierten Liedgattungen, Tigi, Adab, Balbale und Kung̃ar, können eindeutig als Götterhymnen identifiziert werden, die gelegentlich auch einen Preis des Königs enthalten. Das Širgida preist vor allem kriegerische Aspekte der adressierten Gottheit, der Bezug zum Königtum und dessen Preis wird trotz fehlender Namen impliziert. ${ }^{1603}$

Außer der stellvertretenden Erhöhung des Königs ist über die Funktion der Lieder im Kult wenig bekannt. Da Textabschnitte der Komposition Ninurtas Rückkehr in einem Eršema an Iškur wiederverwendet werden, wurde angenommen, Širgida könnten ebenfalls als Apothropaion zur Abwehr drohenden Übels eingesetzt worden sein. ${ }^{1604}$ Die Übernahme einer hymnischen Litanei mit Preis des Gottes muss jedoch nicht zwingend auch auf eine Übernahme der in anderem Kontext zugrundeliegenden Funktion verweisen.

Verschiedene Aufführungsorte der Lieder werden in den Selbstlobhymnen des Šulgi genannt. Die Hymne Šulgi E 53-60 setzt den Vortrag der Širgida an nicht näher definierte 'Kultplätze' (kišu(k)) an. Nach Šulgi B könnten sie im Tempel des Königs selbst vorgetragen worden sein:

T 83: Šulgi B $277^{1605}$

„Jene Širgida habe ich in meinem eigenen guten Haus/Tempel herrlich gemacht."

277. sir $_{3}-$ gidd $_{2}$-da-bi e dug $_{3}-g a-g a_{2}$ pa $e_{3}$ ha-ni-ak

Der Abschnitt, dem dieser Vers entnommen ist, bezieht sich auf den Erhalt auch älterer Lieder, den Tigi und Zamzam, um deren Pflege und Aufführung sich der König selbst bemühte. Sie erklangen vornehmlich in Tempeln und an Kultplätzen.

Auf die Aufführungspraxis von Širgida bezieht sich ein Vers aus dem Edubba-Dialog Enkitalu und Enkiheg̃al, der letztlich als Gespräch zwischen zwei 'Musikschülern' gedeutet wird: ${ }^{1606}$

malgatum, šir-gida, royal praise poems perfect in content, arahi, balbale, zamzam and kung̃ar compositions. They magnify my name in the places where odes are performed".

${ }^{1603}$ Ludwig 1990, 38-40; s. a. die Auszeichnung von Ninurtas Rückkehr im Katalog aus Ur UET 6, 123:43 (U2) als lugal; Charpin 1986, 457 ,inscriptions royales“ oder „hymnes royaux“.

${ }^{1604}$ Cooper 1978, 6; Römer 2001, 160.

${ }^{1605}$ Vgl. Ludwig 1990, 48, 51. 
T 84: Enkitalu und Enkiheg̃al Vs ii $28^{1607}$

„(Auch) wenn er seinen 'Arm öffnet', kann er kein Širgida sprechen.“

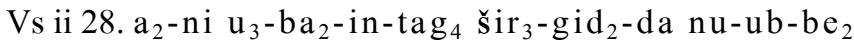

Das angesetzte Verb „sprechen/sagen“ verweist auf einen rezitativen Vortrag der Lieder. Das Öffnen der Arme könnte als eine Form der musikalischen Agogik zu interpretieren sein, die der Unterstützung des rezitierten Vortrags diente.

Zusammenfassend sind Širgida Götterhymnen, die dem Königskult im Tempel dienten, wo sie möglicherweise in Form eines Sprechgesangs vorgetragen wurden. Angaben zu einer instrumentalen Begleitung werden nicht bekannt. Ihre Anwendung in diesem Sinne bleibt auf die altbabylonische Zeit beschränkt. Die Überlieferung von Ninurtas Rückkehr in das erste Jahrtausend begründet sich über das zunehmende Interesse an der Erhöhung des Ninurta innerhalb der Königsideologie im ausgehenden zweiten und beginnenden ersten Jahrtausend. Die Tradierung des Textes ist hier unabhängig vom ursprünglichen Sitz der Gattung Širgida. Auch für die im Katalog KAR 158 aufgelisteten Titel ist ein literarhistorisches Interesse am Schriftum vergangener Epochen und weniger ein Praxis bezogener religiös-kultischer Hintergrund anzusetzen.

\subsection{7 Širnamursag̃a}

Einziger Vertreter der Gattung šir ${ }_{3}-n a m-u r-s a \tilde{g}-\tilde{g} a_{2}$, wörtlich ,Lied des Heldentums“ oder „Heldenlied“ ist die berühmte Hymne an Inana mit Preis des Königs Iddin-Dagan (Iddin-Dagan A). ${ }^{1608}$ Die vollständig erhaltene Komposition ist in mehreren Textzeugen erhalten, die allesamt der Stadt Nippur zugeordnet werden, wobei die Widmung an die Göttin Ninisina, als Erscheinung der Inana in Isin, lediglich in zwei Vertretern erhalten ist. ${ }^{1609}$ Der Titel der Komposition wird außerdem im altbabylonischen Katalog (L) TCL 15, 28:44 aus Ur genannt. Ihre insgesamt 230 Zeilen sind nach zehn kirugu-Gesängen unterteilt. Lediglich dem ersten, achten und zehnten dieser Gesänge folgt ein g̃išgi ga al, ein Gegengesang. Jacobsen rekonstruiert dennoch für den Ablauf des Liedvortrags, dass das erstgenannte g̃išgi g̃al auch nach allen darauf

\footnotetext{
1606 Michalowski 2009.

1607 Sjöberg1975a, 169.

1608 Römer 1965, 128-208; Reisman 1973; ETCSL 2.5.3.1; Jacobsen 1997, 559 ,a song of valor pertaining to Ninsiana".

${ }^{1609}$ In C (HAV 2) und F (CBS 11391; HAV pl. IV); Römer 1965, 128.
} 
folgenden kirugu gesungen wurde, bis dieser im achten kirugu durch einen neuen ersetzt wird. ${ }^{1610}$

Dem zweiten der g̃išgig̃al ist ein šaba-TUKU angefügt, ein möglicherweise instrumental begleiteter Liedabschnitt. Dieser Rubrikname wird jedoch nicht in allen Textzeugen angegeben. ${ }^{1611}$ Der Textabschnitt, dem das šabaTUKU unterschrieben ist, entspricht wörtlich dem dritten und letzten g̃išgi g̃al der Komposition:

T 85: Iddin-Dagan A 133/227-228

„Sie ist mächtig, sie ist heldenhaft, sie ist hoch aufgerichtet, sie ist erhaben und groß, sie ist überragend an Jugendhaftigkeit.“'1612

133. kalag-ga-am 3 nir-g̃al $2-a m_{3}$ bulug̃ $\tilde{g}_{3}-\tilde{g}_{2}-a m_{3}$ mah gal-la-am nam-šul-am ${ }_{3}$ dirig-ga-am 3

/1

227. kalag-ga-am 3 nir-g̃al $2-a m_{3}$ bula $\tilde{g}_{3}-\tilde{g} a_{2}-a m_{3}$ mah gal-la-am 228. nam-šul-la dirig-ga-am 3

Ob der letzte gleichlautende Gegengesang entsprechend dem šaba-TUKU instrumental begleitet wurde, bleibt ungewiss.

Formal weist die Hymne Iddin-Dagan A Ähnlichkeiten zu den Gattungen Širnamgala, Širnamšub und den Balag̃ auf, die ebenfalls nach kiruguEinheiten unterteilt werden. Bezeichnend bleibt dennoch, dass auf die kirugu kein abschließendes kišu folgt. Es könnte daher zu erwägen sein, ob das Lied möglicherweise Teil einer längeren vokalen Darbietung war, auf die weitere kirugu-Rubriken folgten, und die mit einem einzigen gemeinsamen kišu beendet wurde.

Thematisch behandelt die Komposition zwei unterschiedliche Kultfeste, ein monatliches Neulichtfest, an dem Prozessionen und Opfer ausgeführt wurden, und schließlich das Neujahrsfest mit dem Höhepunkt der Vereinigung Inanas und Iddin-Dagans im Königspalast. ${ }^{1613}$ In seiner Thematik weist das Lied hierin wiederum Parallelen zum einzig bekannten Širšahula Damgalnuna A auf. ${ }^{1614}$ Doch auch in Širnamšub wird die enge Verbindung zwischen weiblichen Gottheiten und dem König aufgezeigt, wobei diese Texte einen stärker hymnischen Charakter aufweisen.

In den drei g̃išgi g̃al-Rubriken der Hymne Iddin-Dagan A wird Inana in ihrer Rolle als jugendlicher Held und Krieger gepriesen, wobei der erste Gegengesang mit einem einzigen Satz ungewöhnlich kurz ausfällt: „Ihr Auszug ist

\footnotetext{
${ }^{1610}$ Jacobsen 1997, 554 Anm. 4

${ }^{1611}$ Römer 1989, 667 Anm. 132a).

1612 Römer 1989, 672.

1613 Römer 1989, 659.

${ }^{1614}$ S. Kapitel 12.2.9.
} 
der eines Helden“ ( $\mathrm{e}_{3}-\mathrm{a}-\mathrm{ni}$ ur-sag̃-am $\left.{ }_{3}\right) .{ }^{1615}$ Die Gesamtdarstellung der Göttin im Text entspricht der über die Liedunterschrift šir ${ }_{3}$-nam-ur-sa $\tilde{g}-\tilde{g} a_{2}$ „Heldenlied“ angezeigten Thematik.

In jedem der insgesamt zehn kirugu, nach denen die Hymne eingeteilt ist, werden hymnisch-narrativ die Abläufe verschiedener Zeremonien und Festhandlungen mit dem dazugehörigen Kultpersonal geschildert. Solche genauen Beschreibungen von Festabläufen, die den Anweisungen in Ritualtexten sehr nahe kommen, sind für die Hymnen der Göttin Inana bezeichnend. ${ }^{1616}$

Der Ausdruck Širnamursag̃a ist sonst unbekannt, er ist weder aus weiteren Liedunterschriften noch in sekundären Textbelegen wie Listen, literarischen Katalogen oder Kompositionen bezeugt. In der lexikalischen Liste Nabnitu 32 findet sich dennoch der verwandte Ausdruck $\mathrm{a}_{2}$-nam-ur-sa g̃ $\tilde{g} \mathrm{a}_{2}$ „Heldenhafte(r) (Arm)/Kraft/Waffe (?)“ zwischen šir ${ }_{3}$ - Komposita und anderen Liedgattungsnamen geführt. ${ }^{1617}$ Dieser Terminus wird in literarischen Texten mehrfach als Attribut heldenhafter Götter verwendet, in mehreren Širgida aber auch Adab-Hymnen an Ninurta, Martu, Nusku oder Suen, nur selten allerdings zur Glorifizierung des Königs. ${ }^{1618}$ Die Einordnung der jungen lexikalischen Liste Nabnītu lässt darauf schließen, dass das Thema 'Heldentum' für den Schreiber der Kategorie 'Vortrag/Gesang' (šir ${ }_{3}$ ) angehörte. ${ }^{1619}$

Am ehesten vergleichbar mit dem Terminus Širnamursag̃a als abschließende Gattungsangabe, was in diesem speziellen Fall wohl eher als Angabe zur Funktion des Liedes zu werten ist, sind die letzten Verse der Gudam-Erzählung:

T 86: Gudam-Erzählung 36-37 1620

Inana, von $<$ deinem $>$ Heldentum will ich berichten/sprechen!

Dein Preis ist süß!

36. Inana nam-ur-sag̃ $<-z u>g a-a_{3}-d_{u g}$

37. $\mathrm{za}_{3}-\mathrm{mi}_{2}-\mathrm{zu} \mathrm{dug}_{3}-\mathrm{ga}-\mathrm{am}_{3}$

Die gesamte Erzählung Gudam ist hiermit dem Preis von Inanas Heldentum gewidmet. In diesem Sinne könnte auch die Unterschrift von Iddin-Dagan A aufzufassen sein.

\footnotetext{
${ }^{1615}$ Iddin-Dagan A 18 vgl. ETCSL 2.5.3.1, anders als Römer 1989, 661; ausführlicher sind die zwei weiteren g̃išgi g̃al in den Zeilen 128-131 und 227-228.

${ }^{1616}$ Groneberg 1997a, 137-154.

${ }^{1617}$ Nabnītu 32 iii 34; PSD A/2 87b sub Lexical.

${ }^{1618}$ Z. B. Ninurta B 14; Ninurtas Rückehr 15; Nusku A 6; Martu A 9; Šulgi B 286-287.

${ }^{1619}$ Beachte allerdings in Gudea Zyl. B xiv 3. $\mathrm{a}_{2}$ nam-ur-sa g̃-g̃ $\mathrm{a}_{2}$ als Name einer Waffe des Ning̃irsu; Edzard 1997, 96.

${ }^{1620}$ ETCSL 1.3.4; Alster 2004, 26:45-46.
} 
Die Hymne Iddin-Dagan A wurde offensichtlich aus Anlass des Neujahrsfestes unter König Iddin-Dagan verfasst und vorgetragen. $\mathrm{Zu}$ den Inhalten dieses Festes gehören auch die Erhebung und Erneuerung des Königs, welcher in diesem Zusammenhang dann als jugendlicher Liebhaber der Göttin Inana auftritt.

Parallelen in der Thematik von Helden- und Kriegertum bestehen zu den Širgida, die allerdings meist auf einen anonymen König verweisen. Zudem enthalten diese Texte nur selten narrative Passagen. Eine Ausnahme bildet Ninurtas Rückkehr, das auch im literarischen Katalog L (TCL 15, 28) aus Ur direkt vor Iddin-Dagan A genannt wird. Dies lässt allerdings eher Rückschlüsse auf die Bedeutung dieses Werkes innerhalb der Schrifttradition zu.

Angesichts seiner Struktur kann das einzige erhaltene Širnamursag̃a als eine Gebetshymne eingeordnet werden, worauf die zahlreichen kirugu verweisen. Die g̃išgig̃al-Rubriken legen nahe, dass der Vortrag des Liedes in einem Wechselgesang zwischen Vorsänger und Chor stattfand. Das šaba-TUKU könnte zusätzlich auf ein instrumental begleitetes 'Intermezzo' hinweisen. Über die Vortragenden der Hymne ist nichts Genaueres bekannt, dass zahlreiche nar-Musiker daran beteiligt waren, ist mit Sicherheit anzunehmen. Zusätzlich ist die Beteiligung von gala-Priestern zu vermuten, sofern die verwendete Rubrik kirugu als gängiges Kennzeichen seines Repertoires gelten kann.

\subsection{8 Širkalkal}

Das $\check{s ̌ i}_{3}-k a l-k a l$ ist wie das Širnamursag̃a und das Širšahula bisher nur einmal als Gattungsname bezeugt, und zwar in der Liedunterschrift der Komposition Dumuzis Traum. ${ }^{1621}$ Dort wird es allerdings in einer für Gattungsangaben unüblichen Formulierung angegeben:

\section{T 87: Dumuzis Traum 261}

„Dem toten Dumuzi ist es ein Širkalkal“

261. ${ }^{\mathrm{d}}$ Dumu-zid ug ${ }_{5}$-ga šir ${ }_{3}-\mathrm{kal}^{\top}{ }^{-} \mathrm{kal}^{1}-\left[\mathrm{am}_{3}\right]$

Die literarische Komposition Dumuzis Traum ist eine längere epische Dichtung, ${ }^{1622}$ die von mythologischen Themen um Flucht und Tod des Dumuzi handelt. Sie ist auf über 60 Tafeln und Fragmenten, darunter zahlreichen aus Nippur und Ur überliefert, zudem wird der Titel der Komposition in drei altbabylonischen Katalogen zitiert, die denselben Städten entstammen. ${ }^{1623}$

\footnotetext{
${ }^{1621}$ Alster 1972; ETCSL 1.4.3.

${ }^{1622}$ Wilcke 1975, 261; Fritz 2003, 99.

${ }^{1623}$ BASOR 8 12:19 (N2); TCL 15, 28:13 (L); UET 6, 123:26 (U2).
} 
Im Text sind keine Rubriken oder andere Abschnittsmarkierungen enthalten. Die ständigen Wiederholungen von langen narrativen Textpassagen prägen den epischen Charakter des Textes.

Die wörtliche Bedeutung von šir ${ }_{3}-k a l-k a l$,herausragendes/wertvolles Lied“"1624 lässt keine Rückschlüsse auf Anlass oder Funktion des Textes zu. Die Grundbedeutung des Namenselements kal „rar/kostbar sein/werden“, akkadisch $a q \bar{a} r u(m)$, könnte möglicherweise den zentralen Ausdruck dieses Liedes $\mathrm{zu}$ formulieren suchen, der im Wesentlichen von der Abwesenheit und dem Verlust des Gottes Dumuzi handelt.

Da Sprache und Formulierungen des Textes epische Züge aufweisen, könnte der vokale Vortrag des Liedes eher rezitativ oder sprechend stattgefunden haben. Angesichts der Hauptthematik der Komposition müssen Klageriten oder ähnliche Feiern um den Tod des Dumuzi den Anlass für den Vortrag des Liedes gegeben haben. Da jedoch nur ein einziger Beleg zum Širkalkal überliefert ist, kann nicht sicher davon ausgegangen werden, dass der Text überhaupt für den Vortrag im Rahmen eines kultischen Festes bestimmt war.

\subsection{9 Širšahula}

Der einzige bisher bekannte Vertreter mit der Unterschrift Širšahula, wörtlich „Lied der Herzensfreude“, ist die Hymne Damgalnuna A: šir ${ }_{3}-\mathrm{s̆a}_{3}-\mathrm{hul}_{2}-1 \mathrm{a}$ ${ }^{\mathrm{d}}$ Dam-gal-「nun ${ }^{7}-[\mathrm{na}-\mathrm{kam}] .{ }^{1625}$ Mit dieser Komposition liegt gleichzeitig die einzige bisher bekannte Hymne an die Göttin Damgalnuna vor.

Vom Liedtext selbst sind nur kürzere Abschnitte auf vier zusammengehörigen Tafelfragmenten aus Nippur erhalten (SLTN 65). Der im Lied enthaltene Preis richtet sich neben Damgalnuna auch an die Hauptgötter des sumerischen Pantheons An, Enki und Enlil. Die Göttin wird außerdem als Mutter und Kennerin der Geburtsvorgänge angesprochen, was auf festliche Handlungen in diesem Kontext bezogen werden könnte. Motive aus der Mythologie sind nicht enthalten, auch wird kein König genannt. ${ }^{126}$ Fragmentarisch ist von Erstlingsopfern und begleitenden Libationen die Rede, weshalb das Preislied wohl in den Rahmen des Neujahrsfestes zu verorten ist.

Ur III-zeitlich sind Opfer an Enki und Damgalnuna am Tempeltor des Enlil belegt, sie wurden aus Anlass einer neu errichteten Statue für die Königsnebenfrau Kubātum ausgeführt. ${ }^{1627}$ Angesichts der Thematik des Širšahula mit Verweis auf Schwanger- und Mutterschaft der Göttin wäre zu überlegen, ob die Hymne möglicherweise Ergebnis einer besonderen Zuwendung ist, die eine weibliche Angehörige des Königshauses der Fruchtbarkeit und Nachwuchs

\footnotetext{
${ }^{1624} \mathrm{kal}-\mathrm{kal}=$ šūqurum „kostbar; wertvoll s./w.“; AHw 1282b; CAD Š/3 337b.

${ }^{1625}$ Fragment D Zeile 6; ETCSL 4.03.1.

${ }^{1626}$ Nur der Himmelsgott An wird als König tituliert; Fragment B Zeile 1.

${ }^{1627}$ Sallaberger 1993, 99.
} 
schenkenden Göttin am Ekur zukommen ließ. Für das altbabylonische Nippur sind Opfer am gemeinsamen Tempel des Enki und der Damgalnuna selten attestiert, nur wenige Urkunden belegen auch Pfründen an ihrem Tempel. ${ }^{1628}$

In der šir $_{3}$-Liste von Proto-Lu ${ }_{2}$ bleibt das Širšahula ungenannt, in Proto-Izi II 424 wird es wiederum geführt. ${ }^{1629}$ Sekundär ist von einem 'Lied der Herzensfreude' in Iddin-Dagan A die Rede, dem einzig bisher bekannten Text eines Širnamursag̃a. ${ }^{1630}$ Es wird im zehnten kirugu genannt, der von den Vorbereitungen zur Vereinigung der Inana und des Königs Iddin-Dagan handelt. Hierzu wurden Opferhandlungen und Libationen durchgeführt, die musikalisch begleitet werden:

T 88: Iddin-Dagan A 206-209

„Das 'lauttönende Holz(Musikinstrument/Laute?)', das den Südsturm übertönt;

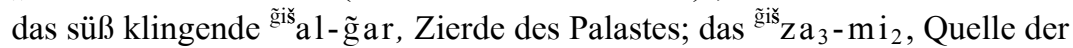
Freude der Menschen; (wozu) Musiker ein Lied der Herzensfreude ausrufen.“

206. g̃ $\mathrm{g} \breve{s}-\mathrm{gu}_{3}$-di ulu $\mathrm{u}_{3}$-ta eme g̃ar-ra

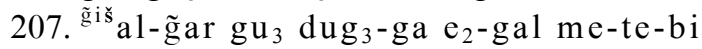

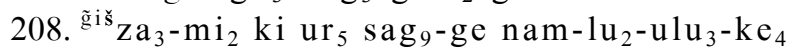

209. nar-e šir ${ }_{3} \breve{s a}_{3}$ hul $_{2}-1 \mathrm{la}-\mathrm{ka}-\mathrm{ni}$ mu-ni-in-pad $3-\mathrm{pad}_{3}-\mathrm{de}_{3}{ }^{1631}$

Den Vortrag des Širšahula begleiteten mehrere Musikinstrumente, darunter g̃išsal-ğar und ${ }^{\tilde{g} i s ̌ s} \mathrm{za}_{3}-\mathrm{mi}_{2}$, also ein Saiteninstrument in Kombination mit einem Rhythmusinstrument. Das Verb pad ${ }_{3}$ „,nennen, ausrufen“ weist auf einen deklamierenden eventuell auch rufenden Gesang hin. ${ }^{1632}$ Die gesamte musikalische Darbietung fand im Königspalast des Iddin-Dagan bei der Darbringung des Morgenopfers statt.

Auf welche Liedinhalte die Angabe des Gattungsnamens $\check{s i r}_{3}-\check{s ̆}_{3}-h \mathrm{~h}_{2}-1 \mathrm{a}$ „Lied der Herzensfreude“ zurückzuführen ist, bleibt unbekannt. Angesichts des sekundären Belegs könnten entweder Kulthandlungen um das Neujahrsfest oder aber Opferhandlungen zu einem 'Königinnenkult' den Anlass zum Vortrag gegeben haben. Die wenigen Belege zum Širšahula, ob als Originaltext oder in sekundärem Kontext, weisen die Lieder weiblichen Göttern zu,

\footnotetext{
${ }^{1628}$ Richter 2004, 102-103.

${ }^{1629}$ MSL 13, 52; s. Kapitel 12.2.1.

${ }^{1630}$ S. Kapitel 12.2.7.

${ }^{1631}$ Römer 1965, 134, 142; ETCSL 2.5.3.1; zu nar Pl. oder Sg. vgl. Castellino 1972, 163, 177. Zur Übersetzung s. a. Römer 1989, 672 „Lied der Herzensfreude“; Jacobsen 1997, 558 "song of joy of heart".

$1632 \mathrm{pad}_{3}$ ist selten mit der Ausführung von nar-Musik belegt; Thomsen 1984, 312; Castellino 1972, 211:274; s. dagegen $\mathrm{er}_{2} \ldots \mathrm{pad}_{3}$ „Klage darbringen“; Attinger 1993, 504-505 $\$ 411$.
} 
Inana/Ninsiana und Damgalnuna. Möglicherweise wurden sie von nar zur Musik eines größeren Instrumentenensembles vorgetragen.

\subsection{Mit er 2 „Klage/Träne“ gebildete Gattungsnamen}

\subsubsection{Eršema}

Der Name der Gattung Eršema, wörtlich die „Klage der šem ${ }_{3}$-Trommel“, schreibt sich altbabylonisch durchgängig mit dem Zeichen šem ${ }_{5}$ $\left(\mathrm{AB}_{2} \mathrm{xGANA} \mathrm{A}_{2}\right)$, in literarischen Texten derselben Zeit wird demgegenüber der Instrumentenname vermehrt mit šem ${ }_{3}$ wiedergegeben. ${ }^{1633}$ Für die Erschließung dieser Gattung gilt die Arbeit von M. E. Cohen von 1981 als grundlegend. ${ }^{1634}$ Die jüngste Studie zu dieser Textgruppe bildet die Dissertation von U. Gabbay von 2007, die zusätzlich zu einem ausführlichen Katalog und der Neuedition zahlreicher Texte sich auch ihrer religiös-kultischen Verortung widmet.

Von den altbabylonisch überlieferten Kompositionen entstammen insgesamt weniger als ein Viertel der Stadt Nippur, dem traditionellen Zentrum des sumerischen Schrifttums. ${ }^{1635}$ Die meisten Eršema wurden in Städten Nordbabyloniens, vornehmlich Sippar aber auch Kiš aufgefunden, ein Hort an bislang unpublizierten Emesal-Texten wurde in einem Privathaus von Larsa geborgen. ${ }^{1636}$ Nur wenige der altbabylonischen Vertreter wurden auch in das erste Jahrtausend tradiert. ${ }^{1637}$

Entsprechend den Balag̃ - Klagen sind auch Eršema fast durchgängig im Emesal gehalten, den jüngeren Texten sind akkadische Übersetzungen beigefügt. Ihre Länge reicht von 30 bis zu 120 Zeilen. Über die gängige Unterschriftenformel „,er ${ }_{2}$-še $\mathrm{e}_{5}$-ma des/r (f)GN (und (f)GN)“ werden Gattung und Widmung des jeweiligen Textes angegeben, nur äußerst selten sind hier auch die Namen zweier Gottheiten verzeichnet. ${ }^{1638}$

Ähnlich dem Balag̃ prägen auch das Eršema längere Litaneien. Die Texte zeichnen sich in ihrer Einleitung durch Auflistungen von Epitheta, Städten oder Tempeln einer Gottheit aus. Einzelne Abschnitte vor allem jüngerer Texte, so genannte 'Versatzstücke', können zudem vollständige kirugu-Einheiten von

\footnotetext{
${ }^{1633} \mathrm{Vgl}$. Inana und Enki 245; Eridu Klage 61 oder das Širnamursa g̃a an Ninisina für IddinDagan 81 (Iddin-Sagan A); so auch in Unterschriften des ersten Jahrtausends; seleukidisch vornehmlich in Texten aus Uruk hingegen šem 4 (MEZE) bspw. in TCL 6, 56 Rs 4; Cohen 1981, 18 Anm. 120; Thureau-Dangin 1921, 48 Anm. 6.

${ }^{1634}$ S. a. Wilcke $1975,282-283$.

${ }^{1635}$ Michalowski 1987, 41 Anm. 21.

${ }^{1636}$ Charpin 2003, 314-315; Eršema: L.89.88 an eine männliche (Vs) und weibliche (Rs) Gottheit; L.89.90 an Inana Mugig ana; L.89.91 an Ninurta? , L.89.94 an Inana.

${ }^{1637}$ Liste bei Cohen 1981, 18-19; s. a. Gabbay 2007, 19-20.

${ }^{1638}$ Cohen 1981 Nr. 97 und 88.
} 
Balag̃-Kompositionen bilden. ${ }^{1639}$ Im Gegensatz zum Balag̃ wird das Eršema jedoch nicht in einzelne Rubriken unterteilt. Die altbabylonischen und auch jüngeren Vertreter dieser Gattung sind als eine zusammenhängende Texteinheit verfasst. ${ }^{1640}$

Einige wenige Unterschriften altbabylonischer Eršema enthalten die Namen von Personen, die als ihre Schreiber oder Verfasser identifiziert werden können. Bezeichnend ist die Unterschrift eines Eršema an Dumuzi mit der zusätzlichen Angabe „Wort (des) Udug-ga, Sohn des gala-mah““ ${ }^{1641}$ Weitere Personennamen, die aus altbabylonischen Eršema-Kolophonen bekannt werden, sind Dig̃ir-addag̃u und Ur-Igizibara. ${ }^{1642}$ Auch wenn weder Beruf noch Filiation dieser Personen angegeben werden, so sind sie aufgrund ihrer sumerischen Namen dennoch als Priester zu identifizieren.

Neben dem gängigen Ton der Klage sind in Eršema auch narrative Passagen enthalten, die Themen aus der Mythologie behandeln. ${ }^{1643}$ Hier sind es vor allem Erzählmomente um den Tod des Dumuzi, sowie die Rolle der ihn umgebenden Göttinnen Inana, G̈eštinana und Bilulu. Eršema, die sich an den Wettergott Iškur richten, sind primär hymnisch formuliert. ${ }^{1644}$ Auch wenn in ihnen keinerlei Bezüge zu Tod und Trauer enthalten sind, so wird in ihnen dennoch ein Schwerpunkt auf die Zerstörungskraft des Gottes und seinen Ansturm auf Fremdländer gelegt.

Die altbabylonisch überlieferten Eršema können mindestens 17 unterschiedlichen Gottheiten zugeordnet werden. Eine Festlegung auf einen konkreten mythologischen Kontext oder den Kreis einer Gottheit lässt sich für diese Gattung nicht ausmachen.

Zur Vortragspraxis von Eršema in altbabylonischer Zeit geben nur vereinzelte Belege Auskunft. Im altbabylonischen Ištar-Ritual von Mari ist die Aufführung dieser Lieder durch gala-Priester in den Ritualverlauf eingebunden. Dort ist es ein einzelner gala-Priester, der sich vor dem König aufstellt, und eine solche Klage an Enlil unter Begleitung des halhallatu(m), einem Perkussionsinstrument, zu dieser Epoche wohl ein Membranophon, vorträgt. ${ }^{1645}$ Im Verlauf

\footnotetext{
${ }^{1639}$ Alster 1985, $220+$ Anm. 3; Cohen 1981, 37 Anm. 167.

${ }^{1640}$ Cohen 1981, 21.

${ }^{1641}$ Bruschweiler 1990, 119-124: $\mathrm{er}_{3}-\check{s ̌}^{\mathrm{e}} \mathrm{m}_{5}{ }^{!}-\mathrm{ma}{ }^{\mathrm{d}}$ Dumu-zi KA ${ }^{\mathrm{d}}$ Udug-ga dumu galamah; hierzu jetzt auch Löhnert 2008, 430-431 und Shehata 2009.

${ }^{1642}$ CT 15, pl. 20-21:Rs 21 und CT 15 pl. 22:Rs 11 [KA?] Dig̃ir-ad-da-ğgu $\mathrm{K}_{10}$; Limet 2000, 4-8, 19:Rs 17. $\mathrm{g} \mathrm{ir}_{3}$ Ur- $^{\mathrm{d}}$ Igi-zi-bar-ra; vgl. Löhnert 2008 und Shehata 2009. Unsicher ist der Text Limet 2000, 8-14, 20:O 53; nach Gabbay 2007, 299 wohl aB, aber nicht eindeutig als Eršema zu identifizieren.

${ }^{1643}$ Bspw. Cohen 1981, Nr. 97; s. a. Wilcke 1975, 261.

1644 Cohen 1981, Nr. 23, 168, 184-5; Römer 2001, 159-171; Schwemer 2001, 183-188 zum 'Auszugsmotiv' in den Iškur-Eršema.

${ }^{1645}$ Durand/Guichard 1997, 55 Nr. 2 (A.3165) iii 16-18 sowie im zweiten Mari-Ritual an Ištar
} 
desselben Rituals wurden auch das Bala g̃ Uru-ama'irabi und andere, bisher nicht identifizierbare sumerische Kompositionen gesungen. ${ }^{1646}$ Auch nach Ritualen des ersten Jahrtausends wurde das Eršema grundsätzlich solistisch unter Begleitung dieser Trommel gesungen. ${ }^{1647}$ Diese solistisch-perkussive Darbietungsform scheint seit dem zweiten Jahrtausend einer gängigen Tradition entsprochen zu haben. Die Bezeichnung der Klagegattung leitet sich schließlich von seiner instrumentalen Begleitung ab.

Belegt ist allerdings auch die Beteiligung eines Chores beim Vortrag eines Eršema. Im altbabylonischen Eršema an Inana PBS 10/2, 15:24 ist die Singanweisung ,(und) sie alle singen (gemeinsam)“ (kalûšunu izammarū) enthalten. ${ }^{1648}$ Es bleibt allerdings unklar, ob der Chor auf den solistischen Vortrag des Eršema antwortete oder aber Teile des Liedes sang. Der Vermerk ist auf dem Hintergrund zweier literarischer Textpassagen zu erörtern, die den Vortrag von Eršema betreffen. Die erste stammt aus dem Lied Dumuzi-Inana $J$ und wird als Ätiologie zur Vortragsweise dieser Lieder verstanden. ${ }^{1649}$ Die letzten Zeilen dieser Komposition sind abgebrochen, weshalb auch die eigentliche Gattung des Liedes unbekannt bleibt. Das Lied erzählt von der Göttin Ğeštinana, die angesichts der Nachricht über ihren verstorbenen Bruder Vorbereitungen zum Vortrag einer Klage trifft. Es wird zunächst von der Zusammenstellung eines Chores berichtet, der aus sieben Sängern aus Uruk und 50 aus Zabalam besteht. Die zusammengeführten Sänger werden als 'Wissende' oder 'Kundige' bezeichnet. ${ }^{1650}$ Hiernach werden im Text verschiedene termini technici aufgeführt, nach denen die Klage in einer wohl festgelegten Weise musikalisch inszeniert wurde: ${ }^{1651}$

von Irradan Durand/Guichard 1997, 59-63 Nr. 3 (A.1249b+) iii 10'-13', in 10' wahrscheinlich eher gala-Priester zu ergänzen.

${ }^{1646}$ Hierzu Cavigneaux 1998/43; Ziegler 2007, 61-63.

${ }^{1647}$ Cohen 1981, 42; Thureau-Dangin 1921, 14:14 und 34:6; Farber 2003, 209: 7-9. Das hier vorgetragene Eršema an Enlil ist bereits altbabylonisch bezeugt; Cohen 1981, 117-121 No. 35 .

1648 Krecher 1966, 33.

${ }^{1649}$ Alster 1985.

${ }^{1650}$ Alster 1985, $221+$ Anm. 5 auch zu den Zeilen 24-27.

${ }^{1651}$ Auch verschiedene Belege des ersten Jahrtausends legen nahe, dass Balag̃ und Eršema gesungen wurden (zamāru), im Gegensatz zum Eršahug g̃a, das rezitiert wurde; Maul 1988, 25 Anm. 81; Black 1989/90, 125+Anm. 2. 
T 89: Dumuzi-Inana J 30-32

„Sie hoben den Gesang an, sie senkten den Gesang,

Das Lied, sein 'Anfangston' war ihnen nicht 'angegeben' worden.

Die Ältesten, am 'Standort' hatten sie sich (noch) nicht niedergesetzt."

30. e-ne-ne šir ${ }_{3}$ im-zi-zi-ne šir ${ }_{3}$ im-g̃a $a_{2}-\tilde{g} a_{2}-n e$

31. sir $_{3}$-e sag̃-bi nu-mu-un-ne-pad ${ }_{3}-n e$

32. ad-da ki-gub-ba nu-mu-un-g̃a $a_{2}-\tilde{g} a_{2}-m e-e \check{s}^{1652}$

Älteste sind auch im Fluch über Akkade am Vortrag eines Klagegesangs beteiligt. Ob hier mit ki-gub-ba, akkadisch mazzäzum, von einem konkreten 'Kultplatz' die Rede ist oder nur allgemein auf die Aufstellung der Beteiligten Bezug genommen wird, bleibt unklar. Nach Ausweis der hierauf folgenden Textpassagen sollte die hier erstmals ausgeführte Gesangsdarbietung aus Anlass des verstorbenen Dumuzi monatlich wiederholt werden, was die Deutung der Komposition als Ätiologie zum Eršema begründet. ${ }^{1653}$ Für die Aufführungspraxis läge hier der Nachweis vor, dass diese Klagen nicht nur rein solistisch, sondern möglicherweise in einem Wechselgesang unter Beteiligung eines Chores aufgeführt wurden. Bezeichnend sind schließlich auch die Herkunftsorte der beiden Sängergruppen Uruk und Zabalam. Beide Städte sind wichtige und traditionsreiche Kultzentren der Inana.

Die zweite Textpassage mit Hinweisen zum Vortrag eines Eršema ist im Fragment einer zweisprachigen Šulgi-Hymne enthalten (PBS 1/1, 11), die möglicherweise für eine Steleninschrift bestimmt war. ${ }^{1654}$ Auch in dieser Hymne tritt Geštinana als Schutzgöttin des Gesangs auf, wobei hier sowohl von einem rühmenden bzw. preisenden Vortrag ( šir $_{3}$ silim / tašrihtum) wie auch von Klagegesängen $\left(\mathrm{er}_{2}-\breve{s}_{\mathrm{em}} / \operatorname{sipittu}(\mathrm{m})\right)$ die Rede ist. Vortragende der Klage sind narū hal-la-tušs-a bzw. nar pa-ah-tuš -a, und damit junge oder in Ausbildung stehende Sänger, die hier allem Anschein nach wegen ihrer hohen Stimmlage gewählt wurden. ${ }^{1655}$ Sie fügen ihren Gesang zu einer Einheit

1652 Die Deutung dieser Zeile ist schwierig: Alster 1985, 224:31. „The elders were such as had not yet been assigned to their standing places.“; Jacobsen apud Alster 1985, 228:31. „They settle not down at the resting place of the wail“" mit a d . ( a ) für rigmu(m) „Geschrei, Klage“; zu dieser Passage auch Kilmer 1992, 106 und hier Kapitel 14.2.1.

${ }^{1653}$ Alster 1985, 220-221; Fritz 2003, 119 Anm. 435, 346-351 auch zum zeitlichen Zyklus von Dumuzi-Klagen.

${ }^{1654}$ Westenholz 2005. Mir scheint der Text eher eine niveauvolle Schreiberübung gewesen zu sein, da hier zahlreiche Termini aus den LL Proto- $\mathrm{Lu}_{2}$ und Proto-Izi eingearbeitet sind, die der Schreiberschüler offenbar in Anlehnung an größere Šulgi-Hymnen in einen zusammenhängenden und gleichzeitig zweisprachigen Text einzuarbeiten suchte.

1655 Wird das Argument zur höheren Stimmlage eines gala beim Vortrag von Klagen von AlRawi 1992b, 183 bedacht (s. dazu Exkurs I 6.3.4), könnte hier ein weiterer Hinweis zu einer solchen Singart für Eršema und dementspechend wohl auch für Bala g̃ vorliegen. Zu einer 
zusammen (te $\check{s}_{2} . . \operatorname{sig}_{10} / /$ išténiš šutešmū), sodass ihre Klage 'ausbalanciert' wird (ki-la $\mathrm{a}_{2}$. tag // zimmatzunu šaqlat). Auch wenn sich die sumerische und akkadische Fassung nicht immer eindeutig entsprechen, so wird hier für die Aufführungspraxis dennoch deutlich, dass eine solche Klage unter Beteiligung einer größeren Sängergruppe zum Vortrag kam, bei der zum einen die Stimmlage, zum anderen das Ausbalancieren und Intonieren eines harmonischen Klangs eine wichtige Rolle spielte.

\subsubsection{Eršahug̃a}

Auch die Gattung der er ${ }_{2}$-ša $\mathrm{a}_{3}$-h̆un-g̃a $\mathrm{a}_{2}$-Gebete gehörte nach Ritualtexten des ersten Jahrtausends zum Repertoire des gala-Priesters. ${ }^{1656}$ Grundlegend zu ihrer Erschließung ist die Studie von S. Maul 1988, die sich auf Textvertreter des ersten Jahrtausends konzentriert.

Altbabylonisch können von dieser Gattung neun Kompositionen identifiziert werden, wobei nur bei einem dieser Texte eine Unterschrift mit Angabe der Gattung erhalten ist. ${ }^{1657}$ Mehrere dieser Kompositionen können der nordbabylonischen Stadt Sippar zugeordnet werden, denen häufig auch akkadische Übersetzungen hinzugefügt sind. ${ }^{1658}$ Zwei Vertreter entstammen möglicherweise größeren Emesal-Archiven aus Larsa ${ }^{1659}$ Weitere Texte wurden außerdem in Meturān (Tell Ḥaddād) aufgefunden, hier allerdings mit variierendem Gattungsnamen $\mathrm{er}_{2}$-ra ša $\mathrm{S}_{3}$-huun-g̃a ${ }_{2} .{ }^{1660}$

Die Lieder sind größtenteils im Emesal gehalten, wobei in ihnen zuweilen auch Wörter im Standarddialekt Emegir auftreten können. ${ }^{1661}$

Die Schreiber bzw. Besitzer zweier dieser Texte, die möglicherweise aus Larsa stammen, sind aus Kolophonen mit Namen bekannt: Es sind Šamaš-muballit (ISET I 223) und Šamaš-nāșir (JCS 39, 44), ${ }^{162}$ die allerdings mit keinem der altbabylonisch attestierten Musiker identifiziert werden können.

anderen Deutung von nar pa-ah-tuš-a als „singers who are sitting in the cella“ s. Westenholz 2005, 364-365 und hier Anm. 122.

${ }^{1656}$ Maul 1988, 25-28 und Anm. 90; s. a. Black 1991, 23-24.

${ }^{1657}$ Vgl. die Listen bei Michalowski 1987, $41-43$ und Maul 1988, 9-10; ergänzend CT 58, 70 an Enki (Wasserman 2003 Katalog Nr. 70), Geller 1992 datiert es allerdings mB; Black 1989/90, 124 Anm. 1. Die Gattungsangabe findet sich nur in Michalowski 1987, 46 (BM 29632 (JCS 39, 37ff)) Rs 42. er - $^{-\mathrm{sa}_{3}}$-hu un-g̃ a $\mathrm{x}$ [. . 43. AN?

${ }^{1658}$ Vgl. Michalowski 1987, 42-43; Bilinguen sind CT 44, 24; CT 58, 70; VS 10, 179; VS 17, 35.

${ }^{1659}$ Löhnert 2008, 341 zur Verortung der Texte BM 29632 (Michalowski 1987) und ISET I 223 nach Larsa gegen Michalowski 1987, 42-43.

${ }^{1660}$ Cavigneaux/Al-Rawi 1993b, 94-95.

${ }^{1661}$ Maul 1988, 2+Anm. 4 und S. 4-8.

1662 BM 29632 bei Michalowski 1987, 44 mit im-gid ${ }_{2}$-da d Utu-na-si-ir, wodurch zunächst der Besitz an der Tafel angezeigt wird; ausführlicher Löhnert 2008, 430-432. 
Im Gegensatz zu den Eršema enthalten Eršahug g̃a keinerlei narrative Elemente oder Bezüge zu mythologischen Themen. Stilistisch sind sie als Gebete gehalten. Aufbau, Inhalt und Formulierungen der meisten etwa 20-60 Zeilen umfassenden Textvertreter sind gleichförmig. ${ }^{1663}$ Die Identifizierung dieser Klagegattung wird trotz des eventuellen Fehlens der Unterschrift durch diese einheitliche Struktur ermöglicht.

Die Gebete können an unterschiedliche Götter gerichtet sein, jüngere Texte enthalten auch neutrale Formulierungen, wie „Gott eines Menschen“ (dig̃ir$1 u_{2}-u_{18}-1 u$ ) oder ,,jeder beliebige Gott" (di g̃ir-du $\left.u_{3}-a-b i\right) .{ }^{1664}$ Damit ist die Gattung auf keine spezifische Gottheit festgelegt. Auf die litaneiartige, teilweise auch preisend formulierte Anrufung folgt die eigentliche Klage $\left(\mathrm{er}_{2}\right)$. Im Gegensatz zu Bala g̃ und Eršema werden hier jedoch nur individuelle Leiden in der ersten oder dritten Person formuliert, weshalb diese Gebetsgattung auch als 'Individualklage' angesehen wird. ${ }^{1665}$ Der Text schließt mit einer Bitte um Einhalt des zuvor dargestellten Leids sowie um Zuwendung oder Annahme des Gebets durch die adressierte Gottheit. In zahlreichen Vertretern des ersten Jahrtausends ist dieser Abschnitt von Wiederholungen des Ausrufs 'Es ist genug!' (ahulap) geprägt, ${ }^{1666}$ worauf die Fürbittelitanei folgt. Den Schluss eines Eršahuug̃a bildet eine einheitliche 'Herzbesänftigungsformel' ${ }^{1667}$

Auch wenn Sprache und Inhalt auf Gebete des privaten Bereichs hinweisen, wurden die Eršahug̃a ausschließlich im offiziellen Kultbetrieb rezitiert, häufig neben Bala g̃ und Eršema durch einen kalû-Priester oder auch durch den König selbst. ${ }^{1668}$ In ihrer Funktion kommen sie den übrigen bekannten Klagegattungen gleich. Sie dienen zur Abwehr drohenden Übels und werden bei verschiedenen apothropäischen Ritualen, bei Reinigungs-, Kriegs- oder Bauritualen, sowie bei Götterprozessionen auch zum Schutz des Königs vorgetragen. ${ }^{1669}$

Eršahugga-Gebete weisen inhaltliche wie formale Parallelen zu den sumerischsprachigen Götterbriefen sowie zum einzigen bekannten Fürbittegebet $\left(e r_{2}-\breve{s a}_{3}-n e-s ̌ a_{4}\right)$ auf. ${ }^{1670}$ Des Weiteren lassen sie sich mit den bereits altbabylonisch belegten Beschwörungen des Typs Dig̃ir ša $a_{3}-d i b-b a$ in Beziehung setzen, die ebenfalls der Besänftigung der Götter dienen, allerdings vornehmlich zum Repertoire des Beschwörungspriesters (āšipu) gezählt werden. ${ }^{1671}$

\footnotetext{
1663 Ausführlich Maul 1988, 17-25; ergänzend Black 1989/90, 124-125.

${ }^{1664}$ Maul 1988, 3.

${ }^{1665}$ Maul 1988, 21, 28-29.

${ }^{1666} \mathrm{Vgl}$. das Bala g̃ zur Erschaffung des gala hier Kapitel 6.3.1.

${ }^{1667}$ Maul 1988, 24-25.

${ }^{1668}$ Maul 1988, 27-29; zum Vortrag durch den König anders Black 1991, 23 Anm. 4.

${ }^{1669}$ Maul 1988, 27-56 zu den Ritualen.

${ }^{1670}$ Hallo 1968, 75-82; Klein 1982, 299-300; s. a. Klein 2003.

${ }^{1671}$ Lambert 1974; Geller 1992, 528; s. jetzt auch die unpublizierte Habilitationsschrift von M.
} 
Nach Angabe von Ritualtexten des ersten Jahrtausends wurden Eršahug̃aGebete rezitiert und nicht gesungen. ${ }^{1672}$ Sie konnten außerdem instrumental auf dem /lilis/ begleitet werden. ${ }^{1673}$ Hier zeigt sich, dass die Kesselpauke sowohl zur Begleitung von gesungenen (Bala g) wie auch rezitierten Gebeten eingesetzt wurde, was sich dann höchstwahrscheinlich in Rhythmus und Tempo niederschlug. Weiterhin zeigt sich, dass die Anfangs- und Abschlusslitaneien, wie sie auch in Bala g̃ und Eršema enthalten sind, ebenfalls nicht an eine festgelegte Form des vokalen Vortrags gebunden waren. So wurden sie je nach rituellem Kontext in Balag̃ und Eršema gesungen, in den Eršahugga hingegen wohl rezitiert.

Hinweise zum Sitz von Eršahug̃a im musikalisch-kultischen Geschehen des zweiten Jahrtausends sind nicht bekannt. Nach Maul könnten ihre individuellen Inhalte auf eine ursprüngliche Anwendung im privaten Bereich hinweisen. ${ }^{1674}$ Für die altbabylonische Zeit ist es sehr wahrscheinlich, dass ähnlich den Beschwörungen, Götterbriefen oder Omenanfragen auch Gebete durch spezialisierte Priester für private Anliegen vorgetragen wurden.

\subsubsection{Eršaneša}

Die einzige bekannte literarische Komposition in sumerischer Sprache, die den Ausdruck er $_{2}-\breve{s ̆}_{3}-$ ne-ša $a_{4}$,Fürbitteklage“1675 in ihrer Unterschrift trägt, ist die unter dem modernen Titel bekannte Klage Ein Mann und sein Gott. Der Text ist auf mehreren Tafeln vornehmlich aus Nippur und Ur überliefert, anhand derer eine Gesamtlänge von insgesamt 145 Zeilen rekonstruiert wird. ${ }^{1676} \mathrm{Im}$ Gegensatz zu den übrigen Gattungen der Klageliteratur, Balag̃, Eršema und Eršahug̃a ist dieser Text nicht im Emesal verfasst. Die vollständige Unterschrift des Textes lautet nach einer durchgezogenen Linie: „Es ist ein Eršaneša für den Gott eines Mannes“" (145. er er $_{2}$ ša $_{3}-n e-$ ša $_{4}$ 146. dig̃ir lu $u_{2}$ $\left.\mathrm{ulu}_{3}-\mathrm{kam}\right)$.

Jaques mit dem Titel "My God, what have I done?" Sumerian and Akkadian sha-dib-ba Prayers, vorgelegt 2009 an der Theologischen Fakultät der Universität Zürich.

1672 Maul 1988, 81.

${ }^{1673}$ Maul 1988, 26; Menzel 1981, T. 56:36’; Ergänzung nach CAD L 186a sub b). Wurde im Gegensatz dazu möglicherweise die lediglich aus Ritualen bekannte Gattung $\mathrm{er}_{2}$-šem $\mathrm{e}_{3}$ ša $\mathrm{a}_{3}$-hun- $\tilde{\mathrm{g}} \mathrm{a}_{2}$ auf dem šem ${ }_{3}$ begleitet? S. a. Maul 1988, 25 Anm. 76; anders Black 1991, 25 Anm. 15 als Variante von eršahungû nach AHw 246.

${ }^{1674}$ Maul 1988, 28-29 entsprechend der Götterbiefe; Hallo 1968, 76-80; s. a. Gabbay 2007, 1920.

${ }^{1675} \mathrm{Zu}$ ša $\mathrm{a}_{3}$-ne-ša $\mathrm{a}_{4}=$ unnīnu(m), „Flehen, Gebet“ AHw 1421a.

1676 Übersetzung bei Römer 1990; s. a. ETCSL 5.2.4; ausführliche Diskussion bei Klein 1982 und 2003; zusätzliche Textzeugen UET 6/3, 621-622. 
Der Text beinhaltet eine Individualklage und weist inhaltliche und formale Parallelen zu sumerischen Götterbriefen und den Eršahug g̃a-Gebeten auf. ${ }^{1677}$ Die Bala g̃-Klage zur Erschaffung des gala weist solche Fürbitteklagen $\left(\mathrm{er}_{2}\right.$ -

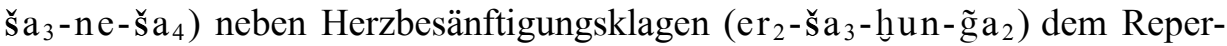
toire dieses Priesters zu. ${ }^{1678}$

Die Einleitung enthält die Anrufung der Gottheit und fordert zur Ausführung der Fürbitte auf, auf dass das Herz der Gottheit besänftigt werde (Zeilen 1-9). Es folgt die Klage und anschließend die Bitte um Erlösung vom Leid, die der Betroffene in der ersten Person an seine Gottheit richtet. Ursache des Leids ist die Abwendung des Gottes von seinem Günstling, deren Gründe dem Beter unbekannt bleiben. In den Zeilen 120-136 wird dann geschildert, wie sich das Herz der Gottheit besänftigt und sich dem Beter zurückwendet, ihn von seinem Leid zu erlösen. Vor der endgültigen Unterschrift folgen wiederum sieben Zeilen, die in der ersten Person gehalten sind und als Gegengesang ( $\mathrm{g} i \mathrm{s̆}_{-}-\mathrm{gi} \mathrm{i}_{4}$ $\mathrm{gal}_{2}$ ) markiert sind. Hieraus ist zu entnehmen, dass am Vortrag der Komposition mehrere Parteien beteiligt waren. Als Ausführende der Klage werden im Text der Einleitung sowie der persönlichen Fürbitte mehrere weibliche Klagende genannt, Mutter, Gattin und Schwester des Bittstellers, letztere wird als bala g̃-di angesprochen. ${ }^{1679}$ Auch ein Sänger, ein Kenner des Gesangs (nar $\breve{s i r}_{3}-\mathrm{zu}$ ), wird neben ihnen genannt, was nochmals bestätigt, dass die Komposition höchstwahrscheinlich gesanglich von mehreren auch professionellen Vorträgern bei einer kultischen Handlung zur Aufführung kam. ${ }^{1680}$ Angesichts der angesprochenen weiblichen Parteien liegt eine Verortung des Textes in einen Dumuzi- oder auch Bestattungskult nahe. Als Ort der Ausführung könnte mit dem im Text genannten Stadttor, an dem der Betroffene seine Klagen und Gebete ausspricht, ein wichtiger Hinweis vorliegen. Stadttore gehörten bekanntlich zu den Stationen, an denen gala-Priester ihre Übel abwehrenden Klagegebete vortrugen, da sie als Grenzübergänge besonderen Schutz erforderten. Zwar werden diese Priester im Text nirgends erwähnt, Inhalt und Sprachwahl des Textes sind dennoch eng mit den späteren Gebeten des gala verwandt, sodass von ähnlichen Hintergründen ausgegangen werden kann.

\footnotetext{
1677 Hallo 1968, 75-82, beachte, dass der Klagende im Gottesbrief $H$ eine Fürbitteklage (er ${ }_{2}$ $\check{s ̌ a}_{3}-n e-s ̌ a_{4}$ ) an seinen Gott vorbringt (Hallo 1968, 84:45); Klein 1982, 299-300.

${ }^{1678}$ Kramer 1981, 6-7 und hier Kapitel 6.3.1. Weitere auch lexikalische Belege zu er ${ }_{2}$-ša ${ }_{3}$-ne$\check{s ̌ a}_{4}$ bei Attinger 1993, 501-503; AHw 1324a; CAD I/J 183b sub e/iršannišakku; in der Ur Klage 343. er ${ }_{2}-\breve{s}_{3}-$-ne-ša $a_{4}$ nu-tuku-am ${ }_{3}$ kur-kur im-ma-an-us ,indem es keinen Fürbitteritus(?) hat, bewohnt es die Bergländer(?)!“ bezogen auf die Stadt Ur; Römer 2004, 101 und ETCSL 2.2.2

${ }^{1679}$ Ein Mann und sein Gott 1-9 und 64-68.

${ }^{1680}$ So auch Klein 2003, 138.
} 
Der Text wird schließlich in einem altbabylonischen Katalog neben anderen bedeutenden Kompositionen des Schulkurrikulums genannt. ${ }^{1681}$ Dass er außerdem altbabylonisch lediglich über Kopien aus Nippur und Ur belegt ist, legt nahe, ihn für diese Zeit dem Schreiberschulmilieu zuzuordnen. Seine Inhalte weisen dennoch auf eine ursprüngliche Anwendung im Kult hin, die mit $\mathrm{J}$. Klein möglicherweise auf die Akkadzeit zurückgeht, was sich auch über die im Text erwähnte bala g̃-di begründen lässt. ${ }^{1682}$

\subsection{Andere Gattungsnamen}

Neben den mit šir ${ }_{3}$ gebildeten Komposita sind aus lexikalischen Listen, Liedunterschriften und literarischen Texten weitere sumerische Gattungsnamen bekannt, von denen die meisten in Proto- $\mathrm{Lu}_{2}$ innerhalb des Abschnitts zu den musiktechnischen Termini aufgelistet werden:

T 90: Proto-Lu $\mathrm{Lu}_{2}$ 612a-619 (MSL 12, 55)

\begin{tabular}{|c|c|}
\hline $612 \mathrm{a}$. & {$[a-d a-a] b$} \\
\hline 613. & BAD-「ga? 1 \\
\hline 614. & $\mathrm{BAD}^{\mathrm{te} ?-\mathrm{el-im}} \mathrm{DU}$ \\
\hline 615. & ma-al-ga-tum \\
\hline 616. & $a-r a_{2}-h i$ \\
\hline 617. & bal-bal-e \\
\hline 618. & kun-g̃ar \\
\hline 619 & $z a-a m-z a-a m$ \\
\hline
\end{tabular}

Der zitierte Abschnitt folgt auf die Auflistung der Liedrubriken, die in den Kapiteln 12.1 und folgende behandelt werden. Von den hier genannten Termini sind Adab, sofern die Rekonstruktion in Zeile 612a zutrifft, Balbale, Kung̃ar und Zamzam als Liedunterschriften sumerischer Texte bezeugt. Malgatum und Arahi sind hingegen nur aus sekundären Angaben in literarischen Texten sowie aus Katalogen bekannt. Ob sich hinter den Schreibungen mit BAD Varianten des Gattungsnamens Šumunša verbergen, ist wegen der in Zeile 614 angegebenen Glosse, die eine Lesung des BAD mit tel angibt, unwahrscheinlich. Ungenannt bleibt hier das Tigi, was in Anbetracht seiner Verbreitung und Verwandtschaft zum Adab verwunderlich erscheint. Einem anderen Kontext gehören die ebenfalls hier fehlenden und selten bezeugten Liedgattungen Ululumama, Uadi und Ulila an.

\footnotetext{
1681 TCL 15, $28: 42$ (L) bei Kramer 1942; ETCSL 02.02.

${ }^{1682}$ Klein 1982, 302 und Klein 2003, 139.
} 
Die Bedeutung dieser Liedgattungsnamen ist bislang ungeklärt, lediglich Adab, Zamzam und Malgatum werden als instrumentale Gattungsnamen eingeordnet, was im Einzelnen noch zu diskutieren sein wird.

Die meisten dieser Lieder werden in literarischen Textpassagen als en $n_{3}-\mathrm{du}$ aufgefasst, also als hymnische Kompositionen, die vorrangig einen Götterpreis formulieren. ${ }^{1683}$

\subsubsection{Balbale}

Mit der Unterschrift bal-bal-e ist ein Großteil der Lieder versehen, die zur Gruppe der sumerischen Liebeslyrik um das Götterpaar Dumuzi und Inana zählen. In diese Gruppe, die nach inhaltlichen und nicht gattungsspezifischen Kriterien definiert ist, werden alle bekannten Textkompositionen zusammengefasst, die sich thematisch mit der Liebeswerbung und Hochzeit des Götterpaares beschäftigen. ${ }^{1684}$ Eine ausführliche Studie $\mathrm{zu}$ den sumerischen Liebesliedern, zu denen vorwiegend Vertreter der Gattung Balbale gehören, wurde 1998 von Y. Sefati vorgelegt.

Von der Gattung Balbale sind insgesamt 32 Textvertreter anhand ihrer Liedunterschriften identifiziert. ${ }^{1685}$ Zwei weitere Dichtungen ohne Unterschrift werden aufgrund formaler und inhaltlicher Kriterien derselben Gruppe zugeordnet. ${ }^{1686}$ Die Tradierung dieser Lieder ist bis in die mittelassyrische Zeit belegt, Vertreter der Gattung werden im Liederkatalog KAR 158 genannt. ${ }^{1687}$ Die Sprache der Lieder ist lyrisch und von zahlreichen Wiederholungen geprägt, wie sie auch Tigi- und Adab-Hymnen kennzeichnet. Auch in ihrer durchschnittlichen Länge von 35 Zeilen sind Balbale mit letzteren vergleichbar. ${ }^{1688}$ Das Streitgedicht Dumuzi und Enkimdu ist mit etwa 89 Zeilen der längste Vertreter der Gattung und unterscheidet sich auch in seiner zusätzlichen Unterschrift 'Streitgespräch zwischen Hirte und Landwirt' (sipad engar-da

\footnotetext{
${ }^{1683}$ S. hier Kapitel 11.1.1.

${ }^{1684}$ Sefati 1998, 22-25.

${ }^{1685}$ Liste bei Sefati 1998, 383-385.

1686 Šulgi $Z$ weist das für die sumerische Liebeslyrik typische sprachliche Formular auf. Auch wenn kein Göttername erhalten ist, meint Kramer 1969, 18 dennoch, dass es sich um einen Liebesdialog zwischen Šulgi und Inana handelt. S. außerdem Šu-Suen $H$ und dazu Wilcke 1975, 274-280; Flückiger-Hawker 1999, 290. Das Balbale Ninurta F (SLTN 62+JRL 925(27)) ist bei Al-Rawi/Black 2000, 31-39 veröffentlicht.

1687 Civil 1967, 209 Anm. 28 identifiziert das Balbale Dumuzi-Inana E in KAR 158 ii 52; Wilcke 1975, 278 Anm. h identifizierte das Balbale Dumuzi-Inana $G$ in KAR 158 ii 49; s. a. Sefati 1998, 167-168, 181. Die fünf Ende der Kol. ii 49-53 aufgelisteten Titel werden in Kol. viii 7 nach der Rekonstruktion von PSD B 63-64 sub Lexical als sumerische Balbale zusammengezählt ba-am-bal-e-ti $i_{2} \check{s} u$-me-ru.

${ }^{1688}$ Sefati 1998, 28-29.
} 
a-da-min dug $_{4}$-ga) von den übrigen Balbale. ${ }^{1689}$ Das kürzeste Balbale ist das Lied Dumuzi-Inana $E$ mit nur zehn Zeilen. ${ }^{1690}$

Auch Balbale-Lieder sind wie die meisten sumerischsprachigen hymnischen Kompositionen einer Gottheit gewidmet, was über die übliche Unterschriftenformel angegeben wird: „Balbale der Gottheit NN“ (bal-bal-e $\mathrm{GN}-\mathrm{ka}(\mathrm{m})$ ). Eine Ausnahme zu dieser Regel bildet die bereits genannte lyrische Komposition Dumuzi und Enkimdu, die am Textende als 'Streitgespräch' ausgewiesen wird und mit einem Preis der Inana schließt. ${ }^{1691}$ Zuletzt wird noch die Unterschrift Balbale angegeben, allerdings ohne Nennung einer Gottheit. ${ }^{1692}$

Insgesamt ist die Hälfte aller überlieferten Balbale-Lieder der Göttin Inana gewidmet. ${ }^{1693}$ Die übrigen Balbale verteilen sich auf unterschiedliche Gottheiten: Nanna/Suen, Šara, Ning̃išzida, Ninurta, Ninazu, Enlil, Enki, Baba, Nanše und Ninkasi. In nur sechs der überlieferten Balbale-Lieder wird ein König namentlich genannt, der dann je nach Liedthematik unterschiedliche Rollen einnimmt: ${ }^{1694}$ In den Balbale an Inana ist er stellvertretend für den Gott Dumuzi Liebhaber und Gatte. ${ }^{1695}$ Die Hymne Ur-Namma $G$ an Enlil stellt den König als Landwirt und Feldbesteller unter der Aufsicht des Enlil dar, während Išme-Dagan $E$ an Enki lediglich eine Fürbitte für den König in einer g̃išgig̃alRubrik formuliert.

Von besonderem Interesse ist schließlich auch die Erwähnung hochrangiger Frauen aus der königlichen Familie in zwei Vertretern dieser Gattung. Das Lied Nanna $C$ nennt mehrfach Enheduana, Tochter des Sargon von Akkade und enPriesterin des Mondgottes Nanna in Ur. ${ }^{1696}$ Enheduana wird in der altbabylonischen literarischen Tradition als Autorin mehrerer Dichtungen an Inana aufgefasst. ${ }^{1697}$ Im vorliegenden Balbale wird sie zusammen mit Ningal, der Gemahlin des Nanna, adressiert.

${ }^{1689}$ Hierzu Sefati 1998, 27-28; Bearbeitung bei Sefati 1998, 324-343; s. a. ETCSL 4.08.33.

${ }^{1690}$ Zweittitel Der Honigmann; Sefati 1998, 165-170 und ETCSL 4.08.05.

1691 Dumuzi und Enkimdu 88-89; hierzu Sefati 1998, 27-28. Auch wenn die Komposition als Streitgedicht ausgewiesen wird, so unterscheidet sie sich dennoch in wichtigen Punkten von den übrigen altorientalischen Vertretern dieser Gattung. So findet beispielsweise der Streit zwischen zwei Personen statt, auch wird am Textende kein Sieger des Streits festgestellt; ausführlicher Vanstiphout 1990, 275-276.

1692 Gegen PSD B 63-64 sub Lexical, die in der Angabe bal-bal-e-dam keinen Gattungnamen sehen, wird hierüber $m$. E. dennoch auf dieselbe Aufführungspraxis von Balbale-Liedern verwiesen; dazu Sefati 1998, 23 Anm. 39.

${ }^{1693} D I A, B, C, D, E, E 1, F, G$ und $O$; Inana $A, F$ und $H$; Šu-Suen $B, C$ und $H$; Išme-Dagan $J$.

${ }^{1694} U r$-Namma $G$; $\breve{S} u$-Suen $A, B$ und $C$; IŠD E und $J$; s. a. Šulgi $Z$ und $\breve{S} u$-Suen $H$ ohne Liedunterschrift.

${ }^{1695} \breve{S} u$-Suen $A, B, C$ sowie Šulgi Z; nur $I \check{S} D J$ enthält eine Fürbitte für den König.

${ }^{1696}$ Nanna C Fragment A Zeile 15, 36, 41; Fragment B Zeile 14; s. a. Westenholz 1989b, 550552.

${ }^{1697}$ Hierzu zuletzt Black 2002. 
Im Balbale $\check{S}$-Suen A, das seiner Unterschrift nach der Göttin Baba geweiht ist, werden die Mutter und die Gemahlin des Königs Abī-simtī und Kubātum genannt. Der Text ist zwar schwer verständlich, formuliert wird allerdings insgesamt ein Preis des Königs, der auch sein enges, von Liebe erfülltes Verhältnis zu seiner Gattin Kubātum integriert. ${ }^{1698}$

Die meisten Balbale formulieren Themen um Fruchtbarkeit und Sexualität mit unterschiedlichen Partizipienten und an unterschiedlichen Handlungsorten. Die Liebeswerbung zweier Gottheiten oder auch zwischen Gottheit und König findet häufig im Idyll von Rinder- und Schafhirtentum statt. Auffallend ist in diesem Zusammenhang auch die metaphorische Sprache der Lieder. Für die Beschreibung sexuellen Verlangens oder auch des Liebesaktes selbst stehen Bilder wie wachsender Lauch oder Flachs. ${ }^{1699}$

In literarischen Textbelegen werden Balbale selten und wenn, dann in einer Reihe mit anderen Liedgattungsnamen wie Kung̃ar, Malgatum, Šumunša, gi-gid ${ }_{2}$ und Zamzam aufgelistet. ${ }^{1700}$ Nur in drei Vertretern wird ein „Gegengesang“, das g̃išgig̃al markiert. ${ }^{1701}$ Ansonsten sind in den Texten keine weiteren Rubriken enthalten.

Die Bedeutung des Gattungsnamens bal-bal(-e) und sein möglicher Bezug zu Form oder Inhalt der Lieder wurde vielfach diskutiert. ${ }^{1702}$ In seiner Grundbedeutung bezeichnet das Element bal ein Umwenden/-drehen oder Wechseln. ${ }^{1703}$ Als mögliches gemeinsames Merkmal von Balbale-Liedern setzte Sefati die häufig verwendete direkte oder zitierte Rede an. ${ }^{1704} \mathrm{Ihm}$ zufolge könnte der Gattungsname auf eine besondere Form der Deklamation verweisen. Hierauf seien seiner Meinung nach auch die Verben inim...bal „sprechen“ und inim...bal-bal ,sich unterhalten“ zu beziehen.

Beachtenswert ist hierzu die bereits behandelte Passage aus der Selbstlobhymne des Išme-Dagan $(I \check{s} D A(+V))$, die verschiedene Spezialisierungen des nar-Sängers auflistet. ${ }^{1705}$ Unter diesen befindet sich auch ein ,nar, der antwor-

${ }^{1698}$ Sefati 1998, 344-352; s .a. Weiershäuser 2008, 277.

${ }^{1699}$ Sefati 1998, 89-94; als Beispiel DI E, DI A, und DI P. Zum bislang falsch gedeuteten Bild des Feldpflügens s. Sefati 1998, 202.

1700 Šulgi E 30, 55; IšD A(+V) 337; JCS 34, 76 Rs 12'; PSD B 63b.

${ }^{1701}$ In $D I C$ folgt das zweizeilige g̃ išgig̃al in 50-51 auf die Gattungsangabe Balbale; Nanna $C$ enthält keine klare Eingrenzung des g̃išgig̃al in Fragment B Zeile 18. Das zweizeilige g̃išgi g̃al von Išme-Dagan E, eine Preishymne an Enki, steht vor der Liedgattungsangabe in Fragment D Zeile 6-7 und formuliert eine Fürbitte für den König; als von einem Sängerchor vorgetragen könnten nach Jacobsen 1953, 47 auch die letzten Zeilen der Dichtung Šu-Suen A zu identifizieren sein.

${ }^{1702}$ Vgl. Sefati 1998, 23 Anm. 39.

${ }^{1703}$ PSD B 48.

${ }^{1704}$ Sefati 1998, 23-25.

${ }^{1705}$ Išme-Dagan $A(+V)$ Text C 6-12 (T 4); s. a. ETCSL 2.5.4.01 Fragment C 12. „let there be a 
tet/erwidert" (nar $\mathrm{gu}_{3} /$ inim-bal-bal). Diese offensichtlich spezialisierte Form der Singpraxis kann meines Erachtens auf die Gattung der Balbale bezogen werden. Mit ihr wird eine besondere Art der Darbietung bezeichnet, an der mehrere Solosänger und Chöre beteiligt waren. Dies lässt auch das bislang einzige altbabylonische Liebeslied CT 58, 12 mit Anweisungen zur Singpraxis vermuten. Nach seinem Inhalt, seiner Sprache und Struktur ist es derselben Gruppe an Balbale-Liedern zuzuordnen, auch wenn keine Gattungsangabe erhalten blieb. ${ }^{1706} \mathrm{Im}$ Lied wird jede Vershälfte als Gegengesang (g̃išgig̃al) markiert, der wohl auf den solistisch vorgetragenen Versanfang erwidert wurde. Der Gattungsname würde damit auf die Vortragspraxis der Lieder Bezug nehmen und den für sie charakteristischen schnellen Wechsel der Stimmen.

Anders ist die Darbietung des gesonderten Balbale Dumuzi und Enkimdu vorzustellen, das gleichzeitig als 'Streitgedicht' ausgewiesen wird. Dieses wurde möglicherweise von mehreren Sprechern mit verteilten Rollen dargeboten. Eine entsprechende Form des Vortrags und des öffentlich veranstalteten spielerischen Disputs wurde von Groneberg auch für den akkadischsprachigen Faithful Lover (Der 'Treue Liebhaber') angenommen. ${ }^{1707}$ Belege, die auf Rollenspiele im Rahmen von Götterfesten und Gesangsdarbietungen auch zum Preis des Königs hinweisen, sind bislang allerdings nicht bekannt geworden.

Abgesehen von der vokalen Aufführungsform der Lieder findet sich lediglich in einer einzigen Textpassage der Selbstlobhymne Šulgi $C$ ein möglicher Hinweis auf ihre instrumentale Begleitung. Dort ist im Bezug auf das Balbale von einem Rohrinstrument die Rede:

T 91: Šulgi C Fragment B 76-82

„Tigi, Adab und die großen Malgatum, ihren ad-ša ${ }_{4}$-Gesang kenne ich.

Beim Richten des . . .? $?^{1708}$ und der großen Šukar-Laute,

kenne ich sein 'Anheben' und 'Senken'.

Umfassend an Kenntnis, im Spiel der sieben Instrumente/Lauten bin ich perfekt.

Balbale, das 'lange Rohr/die Flöte'(gi sud). . ihre/seine offenen/leeren Sai-

ten. . die sa-eš-Laute"

\footnotetext{
singer with answering voice".

${ }^{1706}$ Ausführlich Kapitel 14.2.3.

${ }^{1707}$ Groneberg 2002 und hier Kapitel 13.2.3.

${ }^{1708} \mathrm{Zu}$ si-EZEN s. Anm. 606.

${ }^{1709}$ Nach ETCSL 2.4.2.03.
} 
76. tigi a-da-ab ma-al-ga-tum gal-gal-la ad ša ${ }_{4}$-bi mu-zu

77. si-EZEN g̃ šš $^{\text {šu-kar }} 2$ gal-gal du $u_{7}-d_{7}-d a m$

78. zi-zi-i šu $\breve{s}_{2}-\check{s ̆}_{2}-$ bi in-ga-zu

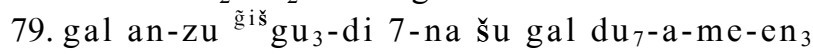

80. bal-bal-e gi SUD X [...]

81. sa-bi bad-bad si [...]

82. sa-ěs [...]

Zwar wird das Balbale im Zusammenhang mit dem Wort „Rohr“ gi angesprochen, doch scheint sich der Gesamtkontext auf das Spiel von Saiteninstrumenten, primär die Lauten ( $\left.{ }^{\tilde{g} i s ̌ s} \mathrm{gu}_{3}-\mathrm{di}\right) \mathrm{zu}$ beziehen. ${ }^{1710}$ Ähnlich dem si-EZEN könnte auch das „lange Rohr“ in diesem Zusammenhang auf den Teil einer Laute, möglicherweise den Hals und seine offenen bzw. leeren Saiten verweisen. ${ }^{1711}$ Andererseits könnte es auch als Variante zum bekannten gi-gid aufzufassen sein. Eine sichere Deutung der Passage bleibt angesichts der Lücken schwierig.

Dass die Gattung der Balbale-Lieder einem konkreten kultischen Anlass diente, ist sicher anzunehmen. ${ }^{1712}$ Angesichts seiner Hauptthematik wird für sie ein Sitz bei Zeremonien der 'Heiligen Hochzeit', den Neujahrsfestlichkeiten oder auch zur Inthronisation des Königs angesetzt. ${ }^{1713}$ Alster hält für den kultischen Rahmen auch Hochzeitszeremonien für wahrscheinlich. ${ }^{1714}$ Die auffällige Erwähnung von Frauen des Königshauses ließ Cooper außerdem einen Sitz bei 'Frauenfesten' vermuten, die sich von weiblicher Perspektive mit Themen um Fruchtbarkeit und Sexualität befassen. ${ }^{1715}$

Über die mögliche Darbietung der Balbale in Form eines theatralischen Rollenvortrags oder in einer deklamatorischen Sprechweise lässt sich nur spekulieren. Auch zur instrumentalen Begleitung sind mit Ausnahme der oben zitierten Passage aus der Hymne Šulgi $C$ keine eindeutigen Aussagen möglich. $^{1716}$

${ }^{1710}$ Zum ${ }^{\tilde{g} i \check{s}}$ gu-di als Laute s. Kilmer 1980-83a; und Krispijn 1990.

${ }^{1711} \mathrm{Vgl}$. allerdings gi sud in $D I X 30$ neben gi-di(-da) ohne Hinweis auf Saiteninstrumente; Sefati 2005, 258; zu si-EZEN als Lautenbünde s. Krispijn 1990, 4-5.

${ }^{1712}$ Lexikalische Belege PSD B 63b lex.; Sefati 1998, 23-25; Wilcke 1975, 249.

${ }^{1713}$ Sefati 1998, 48-49.

1714 Alster 1993, 16-19.

1715 Cooper 1997, 88-97.

${ }^{1716}$ Das Gesamtbild dieser Lieder scheint m. E. am treffendsten im aB Terrakottarelief Rashid 1984, 75 Abb. 58 aus Larsa visualisiert zu sein, das ein mit Laute und Trommel musizierendes Paar darstellt, das sich gleichzeitig im sexuellen Akt befindet; zur sexuellen Konnotation des Lautenspiels s. a. das Sprichwort SP 5.124; Alster 1997, 143 nach der korrigierten Lesung bei Michalowski 2009. 


\subsubsection{Kung̃ar}

Als Vertreter der Gattung kun-g̃ar sind bisher nur zwei Lieder bekannt geworden: Dumuzi-Inana T und Dumuzi-Inana I. ${ }^{1717}$ Beide sind der Göttin Inana gewidmet, was in ihrer jeweiligen Liedunterschrift angegeben wird. ${ }^{1718}$ Thematisch behandeln beide kun-g̃ar das Liebesverhältnis zwischen Dumuzi und Inana. ${ }^{1719}$

Inhaltlich können beide Lieder in zwei Teile unterteilt werden, wobei nur in Dumuzi-Inana $T$ der erste Teil als sagida gekennzeichnet wird. In diesem sagida wird das Ankleiden der Inana mit edlen Schmuckteilen, Steinen und Gewändern geschildert. Im zweiten Teil desselben Liedes wird dann das $\mathrm{Zu}$ sammentreffen beider Liebenden im Eanna von Uruk beschrieben. Aufgrund der konkreten Angaben nimmt Sefati für das kun-g̃ar Dumuzi-Inana T einen kultischen Sitz und Anlass im Tempel der Inana von Uruk an.

Der zweite Textvertreter der Gattung kun-g̃ar Dumuzi-Inana I ist in Form eines Dialogs zwischen Inana und Ama'ušumgalana (Dumuzi) gehalten. Im ersten Teil dieses Liedes findet ein harmloser Disput zwischen beiden Liebenden statt, was in den abschließenden Zeilen sehr treffend als ein 'Liebesnecken' umschrieben wird. ${ }^{1720}$

Die Lieder sind formal in mehrere Strophen unterteilt, die durch Verswiederholungen geprägt sind. Ihre lyrische Sprache legt eine gesungene Vortragsweise nahe. Das Lied Dumuzi-Inana I könnte nach Sefati angesichts der wechselnden Sprecherperspektive von mehreren Solisten und einem Frauenchor vorgetragen worden sein. ${ }^{1721}$ Parallelen weisen die Lieder einerseits zu den Liedgattungen Tigi und Adab auf, was ihre Form und Sprache betrifft, andererseits sind sie inhaltlich den Balbale sehr verwandt. Die nur einmal belegte sagida-Rubrik bestätigt außerdem eine aufführungspraktische Nähe zu Tigi, Adab und Zamzam.

Die wörtliche Bedeutung des Liednamens kann mit „das Endteil setzen“ annähernd wiedergegeben werden. Entgegen der Ansicht Wilckes, das Kung̃ar parallel zu den Termini Tigi und Adab gleichfalls als Name eines Rhythmusinstruments zu deuten, ${ }^{1722}$ vermute ich im Terminus eher einen Verweis auf den aufführungspraktischen 'Sitz' der Komposition. Möglicherweise kennzeichnet Kung̃ar kürzere Liedkompositionen, die das Ende einer längeren musikali-

\footnotetext{
${ }^{1717}$ Zuletzt bei Sefai 1989, 194-205, 247-256; s. a. ETCSL 4.08.09 und 4.08.20.

${ }^{1718}$ DI T 48 und DI I 46 jeweils kun-g̃ar ${ }^{\mathrm{d}}$ In ana-kam „Es ist ein Kung̃ar der Göttin Inana“.

${ }^{1719}$ Sefati 1998, 26.

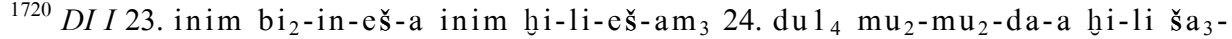
ga-na-ke 4 „Die Worte, die sie sprechen, sind Worte der Liebe; den Streit, den sie beginnen, ist die Liebeswonne ihres (Inanas) Herzens“; Sefati 1998, 195, 197, 201-202.

${ }^{1721}$ Sefati 1998, 200.

1722 Wilcke 1975, 257; so auch Sefati 1998, 26 Anm. 58; der Terminus ist bislang jedoch nie in Auflistungen von Musikinstrumenten attestiert.
} 
schen Darbietung bildeten. Angesichts der Inhalte der bisherigen Textvertreter scheinen den Rahmen einer solchen Darbietung Hochzeits- oder Fruchtbarkeitskulte bestimmt zu haben.

\subsubsection{Liedgattungen unbekannten Inhalts}

\subsubsection{Malgatum}

Als Liedunterschrift ist der Gattungsname ma-al-ga-tum bisher nicht bezeugt, zur Form und Sprache der Lieder kann daher nichts ausgesagt werden. In Proto- $\mathrm{Lu}_{2} 615$ wird die Liedgattung Malgatum neben anderen sumerischen Gattungsnamen wie Balbale und Kung̃ar aufgelistet. ${ }^{1723}$ Sekundär wird es nur aus wenigen literarischen Passagen bekannt. Zwei Selbstlobhymnen des Šulgi und eine Hymne des Išme-Dagan nennen es neben den Liedgattungen Tigi, Adab und Šumunša. ${ }^{1724}$ Auch Malgatum-Lieder wurden hiernach von professionellen Musikern im Auftrag des Königs gedichtet und als Gesangsstücke verfasst. Die Textpassage in der Hymne Šulgi $E$ legt zudem nahe, dass alle aufgelisteten Lieder nicht nur zum Preis des Königs, sondern auch für den Götterkönig Enlil in seinem Tempel Ekur gesungen wurden und Opferhandlungen anlässlich der eššsěšum-Feiern begleiteten. ${ }^{1725}$ In einer dritten Textpassage der Selbstlobhymne Šulgi $C$ rühmt sich der König, die Vokaltechnik ad-ša ${ }_{4}$ und ihre korrekte Ausführung für die Lieder Tigi, Adab und Malgatum zu beherrschen. ${ }^{1726}$

Malgatum ist eine akkadische Entlehnung, die ausschließlich in sumerischen Texten Verwendung findet. Sie basiert auf einer geographischen Angabe, die auf das Land oder Königreich Malgium in der Diyala-Region verweist, wörtlich ,(dasjenige) aus Malgium“. ${ }^{1727}$ Ausgehend von der Parallelbildung zu den ebenfalls nach geographischen Regionen benannten Termini sabìtum „aus Sabium“ und ma/iritum ,aus Mari“ deuteten Falkenstein und Hartmann auch Malgatum als Name eines Musikinstruments. ${ }^{1728}$ Bislang ist das Wort aller-

${ }^{1723}$ S. Kapitel 12.1 mit T 90: Proto- $\mathrm{Lu}_{2}$ 612a-619 (MSL 12, 55); dass es sich um einen eigenständigen Gattungsnamen handelt und gegen Falkenstein 1950, 85 und Ludwig 1990, 206 Anm. 487 nicht als Klassifizierung des Tigi gilt, geht auch aus den literarischen Belegen in Šulgi $C$ und $I s ̌ D A(+V) 335$ hervor, wo es neben Adab und Šumunša genannt wird.

${ }_{1724}$ Šulgi $C$ Fragment B 75; Šulgi $E 22$ und 53; T 82: Išme-Dagan $A(+V)$ 335-339.

1725 Šulgi E 59-62; vgl. Ludwig 1990, 206-207. eššêšum-Feste fanden anlässlich verschiedener Mondfeiertage statt, in deren Verlauf an unterschiedliche Götter und ihre Kultobjekte im Ekur von Nippur Opfer dargebracht wurden; Sallaberger 1993, 56-57.

${ }^{1726}$ S. T 73: Šulgi $C 76$.

${ }^{1727} \mathrm{Zu}$ Malgium s. allgemein Kutscher 1987-90, 300-301.

${ }^{1728}$ Falkenstein 1950, 85; Hartmann 1960, 115; s. a. Wilcke 1975, 255-257 und Kutscher 198790, 304 . 
dings nur aus Auflistungen von Liedgattungsnamen bezeugt, weshalb die von Falkenstein angenommene Zweitbedeutung fragwürdig bleibt. ${ }^{1729}$ Die Einordnung von sabìtum und ma/iritum in der lexikalischen Liste $\mathrm{Ur}_{5}$-ra unter den Musikinstrumenten und Belege in den Handwerksarchiven von Isin machen hingegen ihre Identifizierung eindeutig. ${ }^{1730}$

Bezeichnend ist dennoch, dass das Malgatum trotz seines etymologischen Ursprungs außerhalb der sumerischen Dichtungen und auch sonst nicht nachaltbabylonisch attestiert ist.

Für die Inhalte der Lieder kann aus der Auflistung neben Tigi und Adab ein Preis von König und Gottheit angenommen werden. Auch eine besondere Singtechnik könnte für sie kennzeichnend sein. Ob der Terminus tatsächlich in Liedunterschriften angegeben wurde und nicht vielleicht doch auf eine Schreibertradition zurückgeht, die sich in lexikalischen und literarischen Texten manifestiert, wird mit dem Auftauchen entsprechender Dichtungen zu klären sein.

\subsubsection{2 Šumunša}

In Liedunterschriften ist der Gattungsname šumun-ša ${ }_{4}$ bisher nicht attestiert. Der Terminus ist vielmehr aus Auflistungen in den Selbstlobhymnen des Šulgi und des Išme-Dagan neben anderen Liedgattungsnamen bekannt. ${ }^{1731}$ Der Terminus Šumunša könnte außerdem in den Zeilen 613-614 der Liste Proto-Lu ${ }_{2}$ neben anderen bekannten Liedgattungsnamen zu vermuten sein. ${ }^{1732}$

Beachtenswert ist eine Aussage zur Vortragsweise dieser Lieder, die sich in der Selbstlobhymne Šulgi B findet:

T 92: Šulgi B 173-174 1733

„Ein Šumunša 'rufen' oder einen Klagegesang anstimmen,

kann ich wie einer, der es regelmäßig tut."

173. šumun-ša $\mathrm{ur}_{5}$ ša $a_{4}$-e i-si-iš g ga $a_{2}-\tilde{g} a_{2}$

174. $\check{s a}_{3}$ gen $_{6}$ sa g us -bi-gin $_{7} i_{3}-z u$

\footnotetext{
${ }^{1729}$ So auch CAD M/1 162 „A type of literary composition“.

1730 Veldhuis 1997, 165:603-604; BIN 9, 253:3-4 (IšEr 14); BIN 9, 496:3.9 (IšEr 14); BIN 9, 334:2.7 (IšEr 13/14?).

1731 Šulgi B 173; Šulgi E 30 (T 81), 55; Išme-Dagan A(+V) 335. Klein 1980, xxiii-xxvi deutet es als Musikinstrument; Krispijn 1990, 16.

1732 Beachte die Glosse B AD ${ }^{\text {te?-el im }}$ DU in Proto-Lu 614 (MSL 12, 55), sofern diese die Lesung der Zeichen angibt, kann der Eintrag nicht mit der Gattung Šu munša in Verbindung stehen.

${ }^{1733}$ Vgl. Krispijn 1990, 2, 15-16.
} 
König Šulgi rühmt sich hier, den vokalen Vortrag von Šumunša-Liedern und Klagegesängen wie ein Professioneller zu beherrschen. Der Terminus ur ${ }_{5}-\breve{s}_{4}$ bezeichnet sonst ein durchdringendes und lautes Donnern oder auch Gebrüll. ${ }^{1734}$ Der gängige Ausdruck i-si-iš g ga $a_{2}$-ga $a_{2}$ steht für das Anstimmen eines 'Klagerufs'. ${ }^{1735}$ Das Šumunša wird in dieser Passage auf seine besondere vokale Darbietungsform hin angesprochen, was wohl einem lauten Schreien oder Rufen entsprochen haben könnte. Mit ša ${ }_{4}$ gebildete Komposita bezeichnen allgemein Klänge oder Geräusche. ${ }^{1736}$ Eine Deutung des Gattungsnamens Šumunša bleibt dennoch schwierig, auch da der inhaltliche Bezug zum ersten Namenselement š/sumun ,alt"“ unbekannt ist. ${ }^{1737}$

Als mögliche instrumentale Begleitung für das Šumunša sieht Krispijn das Rohrinstrument gi-di(-da) vor, da dieses in Šulgi $B$ in der vorhergehenden Zeile genannt wird. Über diese mutmaßliche musikalische Einordnung hinaus kann zur Gattung Šumunša sonst nichts weiter festgestellt werden.

\subsubsection{Arahi}

Die Liedgattung mit Namen a-ra/ra $-\mathrm{h}_{2}$ ist zwar selten, aber dennoch in Texten unterschiedlicher Gattungen bezeugt. Bislang bekannt sind neben zwei literarischen Textbelegen ein lexikalischer Eintrag in Proto- $\mathrm{Lu}_{2}$ sowie ein Katalogeintrag im Liederkatalog KAR 158. ${ }^{1738}$ Aus Liedunterschriften ist das Arahi bislang nicht bekannt. Die zwei literarischen Belege finden sich in der bereits abschnittweise zitierten Selbstlobhymne Išme-Dagan A(+V) (T 82) sowie in der Uruk Klage:

T 93: Uruk Klage Fragment H 17

„Tigi-, Ara ḩ i und Zamzam-Lieder möge er (Išme-Dagan) für dich (Inana) spielen." 1739

17.tigi a-ra-hi za-am-za-am huu-mu-ra-ab-du $u_{12}$

${ }^{1734}$ Römer 1982, 310.

1735 Thomsen 1984, 306; Krispijn 1990, 16 mit literarischen Belegen; s. a. Jaques 2006, 171-173.

${ }^{1736} \mathrm{Vgl}$. ad-ša 4 hier Kapitel 11.1.1.

${ }^{1737}$ Vgl. Rubio 2009, 68 für šumun „old wood“; ich denke vielmehr, dass das Komposit eine besondere Klangfarbe beim Vortrag bezeichnet.

${ }^{1738}$ PSD A/1 136a. Hier Kapitel 12.1; nach CAD A/1, 328 sub b) eventuell in abgebrochenem Kontext in TCL 3, 207 (Sargon II-Inschrift). Hiernach könnte es sich um ein Lied mit kriegerischem Kontext handeln. Der Eintrag in Proto-Kagal 302. a-ra $\mathrm{r}_{2}$-hi (MSL 13, 75), zweisprachig $\left[\mathrm{a}-\mathrm{ra}_{2}\right]-\mathrm{hi}=a-r a-h u-u_{4}-u m$ (MSL 13, 84) und dementsprechend in IB $1514 \mathrm{Rs}$ XII 7 (Wilcke 1987, 100 Abb. 14) gehört nach CAD A/2 221 araĥे als mathematischer Terminus nicht hierher.

${ }^{1739}$ Ich folge hier der Lesung von PSD A/1 136 gegen ETCSL 2.2.5 Text H 17. tigi a-ra-dug ${ }_{3}$ za-am-za-am hu-mu-ra-ab-du 12 ,May the tigi sound sweetly for you, and may the zamzam play for you“. 
Bemerkenswert ist außerdem die Aufnahme dieser Liedgattung Arahi in den mittelassyrischen Liederkatalog KAR $158 .{ }^{1740}$ In der Zusammenzählung von Kolumne viii findet sich neben anderen Gattungsnamen der Eintrag: „Ein sumerisches $a r a h h u^{\prime \prime}$. Bedauerlicherweise ist der Titel dieses einzigen Liedes, der sich gegen Ende der Kolumne vi befunden haben muss, aufgrund mehrerer Tafelbruchstellen nicht erhalten. Interessant ist hier vor allem die syllabische Wiedergabe des Gattungsnamens über die Schreibung $a-r a-a h$ - $h u$. Die Angabe im Katalog KAR 158 legt im Wesentlichen nahe, dass die Tradierung dieser Liedgattung wie auch Tigi und Adab bis ins späte zweite Jahrtausend reichte. $\mathrm{Da}$ der Terminus Arahi in den zwei einzigen bisher bekannten literarischen Textbelegen neben Tigi, Zamzam und Balbale aufgelistet wird, ist zu vermuten, dass es sich ebenfalls um eine eigenständige Gattung von Götterliedern oder -hymnen handelt, möglicherweise auch mit integriertem Königspreis. Die genaue Bedeutung des Liednamens sowie der Inhalt oder die Struktur der Lieder bleiben allerdings unbekannt. ${ }^{1741}$

Das Ara h i-Lied im Katalog KAR 158 wird als sumerischsprachig ausgewiesen. Dies muss jedoch kein Indiz dafür sein, dass auch alle Vertreter dieser Gattung grundsätzlich im Sumerischen gehalten waren, so werden im Katalog unter ein und derselben Gattung sowohl akkadische wie auch sumerische Lieder zusammengefasst. ${ }^{1742} \mathrm{Da}$ im Katalog KAR 158 lediglich ein einziges Arahi-Lied genannt wird, könnte zu vermuten sein, dass die Gattung im Vergleich zu Tigi, Adab oder auch Balbale zumindest seit der Ur III-Zeit eine geringere Verbreitung genoss und auch in jüngere Epochen nur sehr wenige Textvertreter überliefert wurden.

\subsubsection{Ululumama, Uadi und Ulila}

Aus Liedunterschriften sumerischer Kompositionen sind drei weitere Gattungsnamen bekannt, die weder in Proto- $\mathrm{Lu}_{2}$ noch in sekundären literarischen Textpassagen genannt werden. Die Namen dieser Lieder, $\mathrm{u}_{3} / \mathrm{u}_{2}-\mathrm{lu}-\mathrm{lu}-\mathrm{ma}-$ $\mathrm{ma}, \mathrm{u}_{3}-1 \mathrm{il}_{2}-\mathrm{la}_{2}$ und $\mathrm{u}_{3}-\mathrm{a}-\mathrm{di}$, sind alle nach sumerischen Interjektionen gebil$\operatorname{det}^{1743}$

\footnotetext{
${ }^{1740} \mathrm{KAR} 158$ viii 35. 1 a-ra-ah-hu šu-me-ru; CAD A/2 220b arahhu B; AHw 63a arahhu II.

${ }^{1741}$ CAD A/2 221a „Perhaps a harvest song, to be connected with arahhu A“ und Groneberg 2003, 65 als Arbeitslied.

${ }^{1742}$ So in KAR 158 viii 9-11 zamār adapu (=Ad a b ), 17-19 zamār šēri, 21-23 zamār Ning̃išzida und 25-27 šerkugû (= Š erku(g)); vgl. Groneberg 2003, 62.

${ }^{1743}$ Edzard 2003, 167, 170; zu den Interjektionen $\mathrm{u}_{3}-1 \mathrm{i}-1 \mathrm{i}$ bzw. e-la-lu und ihren akk. Entsprechungen s. a. Maul in CTMMA 2, S. 37.
} 
Als Ululumama werden vier sumerische Kompositionen in der für Liedunterschriften üblichen Formel „Ululumama des GN“ gekennzeichnet: Nanna J, Ningublaga A, Ibbi-Suen D und das Lied vom Ochsen für Ninurta. ${ }^{1744}$ Die Vertreter dieser Liedgattung sind mit 16-30 Zeilen meist kurz gehalten, nur das Lied vom Ochsen weist etwa 95 erhaltene Textzeilen auf. Die Lieder können inhaltlich sowohl als Götter- als auch als Königshymnen eingeordnet werden. Die Hymne Ibbi-Suen D richtet sich an den König als Erwählten des Gottes Nanna/Suen und schließt mit dem Preis des Königs in einer $\mathrm{za}_{3}-\mathrm{mi}_{2}$-Formel. Namen von Rubriken sind in keinem der Textvertreter enthalten.

Wie Civil bereits bemerkte, weisen diese Kompositionen keine Gemeinsamkeiten in Form oder Struktur auf, Parallelen sind lediglich auf inhaltlicher Ebene festzumachen. Sie alle behandeln Themen um Schaf- und Rinderhirtentum, weshalb Civil eine Wiedergabe mit „cowherd's song“ ansetzt. ${ }^{1745}$ Der Name Ululumama ist eine onomatopoetische Bildung. Auf den offensichtlichen vornehmlich inhaltlichen Bezug zum i-lu-lam-ma, das aus literarischen Texten als Bezeichnung einer Liedform bekannt ist, wurde bereits in Kapitel 11.1.2 hingewiesen. ${ }^{1746}$

Für das Ululumama an Ninurta Lied vom Ochsen setzt Civil als konkreten kultischen Sitz das $\mathrm{gu}_{4}$-si-su-Fest von Nippur an, das Ur III-zeitlich im zweiten Monat gefeiert wurde und als Hauptfest des Stadtgottes Ninurta galt. ${ }^{1747}$ Auch die übrigen Ululumama-Lieder könnten im Kontext kultischer Feste zum Rinderhirtentum auch unter Teilnahme des Königs vorgetragen worden sein.

Die Gattung $\mathrm{u}_{3}$-a-di ist in zwei Textvertretern belegt, der Inana-Hymne LipitEštar $H$ und ergänzt in der Hymne Martu $B .{ }^{1748}$ Beide Texte sind fragmentarisch erhalten, Lipit-Eštar $H$ kann dennoch seinem Inhalt nach als Liebeslied identifiziert werden, in dem König Lipit-Eštar als Gatte der Inana auftritt. Das Lied verfügt über lediglich eine g̃išgi g̃al-Einheit, in der eine Fürbitte für den König formuliert wird. Martu $B$ beinhaltet einen Preis des Gottes in seiner Rolle als Held und Krieger. Die letzten Zeilen formulieren einen Segens-

${ }^{1744}$ ETCSL 4.13.10 (Nanna J), 2.4.5.4 (Ibbi-Suen D), 5.5.5 (Lied vom Ochsen); Ningublaga A ist noch unpubliziert (Civil 1976, 84:4 und Cavigneaux/Krebernik 1998-2001c, 375). In dieselbe Gattungsgruppe zählt Civil 1976, 84 Nanna F, das sich auf derselben Tafel wie Ningublaga $A$ befindet (CBS 11363+(STVC 124+)), doch enthält Nanna $F$ keine Unterschrift oder Gattungsangabe, sondern lediglich eine $\mathrm{za}_{3}-\mathrm{mi}_{2}$-Formel; Hall 1986, 152 Anm. 4.

1745 Civil 1976, 84.

${ }^{1746}$ Falkenstein 1964, 51-52; Krecher 1966, 148 Anm. 433; anders Civil 1976, 84.

${ }^{1747} \mathrm{gu}_{4}$-si-su für Ninurta in Nippur; so Civil 1976, 84-85; Sallaberger 1993, 114-122.

1748 ETCSL 2.5.5.8 (Lipit-Eštar H); Alster 1998, 351; ETCSL 4.12.2 (Martu B); Sjöberg 1977b, 6-8; Ergänzung nach Sjöberg 1998, 345-346. 
wunsch für die Stadt, ihre Frauen und Kinder und für den König, dessen Name allerdings nicht erhalten ist. ${ }^{1749}$

Die Liedbezeichnung $\mathrm{u}_{3}$-a-di „, u a-sagen“ ist mit der Interjektion /ua/ gebildet, welche meist vokale und emotional gefärbte Ausdruckformen der Klage oder auch des Erstaunens anzeigt. ${ }^{1750}$ Im Sprichwort zum nar SP 3.87 (T 6) werden /ua/ und /alala/ als Kennzeichen verschiedener vokaler Ausdrucksformen oder Gesangsarten des Musikers geführt. Dass die Liedunterschrift $\mathrm{u}_{3}$ a-di ,/ua/-sagen“ keine Klage kennzeichnet, geht deutlich aus den Inhalten der zwei Textvertreter hervor. Die Hymnen heben die Position des Königs zu seiner jeweiligen Gottheit hervor. Da solche Themen vielen Königs- und Götterhymnen gemein sind, ist das spezifische Gattungsmerkmal eines Uadi sicher weniger im Inhaltlichen als vielmehr in der Aufführungspraxis zu suchen. So könnte der Gattungsname auf eine bestimmte Singart oder Technik des vokalen Vortrags Bezug nehmen. ${ }^{1751}$

Die Unterschrift $\mathrm{u}_{3}-1 \mathrm{il}_{2}-1 \mathrm{a}_{2}{ }^{\mathrm{d}}$ Inana-kam der Komposition Inana und Bilulu ist bisher nur einmal belegt. ${ }^{1752}$ Ihrem Inhalt nach berichtet sie zunächst von den Vorgängen um den Tod des Dumuzi und formuliert abschließend einen Preis an Inana. Die überwiegend narrative Komposition erzählt den Racheakt der Inana an Bilulu, die für den Tod des Geliebten Dumuzi verantwortlich gezeigt wird. Der Schluss enthält eine Ätiologie zu Libationen und Mehlopfern, die dem in der Unterwelt verweilenden Dumuzi darzubringen waren, wohl um den Toten wieder in Erscheinung treten zu lassen.

Die wenigen lyrischen Passagen enthalten meist die direkte Rede einer Göttin, entweder der Inana oder der Ğeštinana, und sind als vorgetragenes und wörtlich zitiertes Preis- oder Klagelied mit zahlreichen Versrepetitionen gehalten. Die wenigen in diesem Text enthaltenen Emesal-Formen sind auf Namen und Titel des Dumuzi oder der Bilulu beschränkt. Im Text sind keine Angaben zu Rubriken enthalten, sodass keine formale oder musikalische Struktur ersichtlich wird.

Die Bedeutung und Ableitung des Gattungsnamens ist unklar. Von Jacobsen und Kramer wurde eine Verbindung zu e- $1 \mathrm{il}_{2}-\mathrm{la}_{2}$, akkadisch mekû ,eine Singart" postuliert, zugleich verweisen sie auf $\mathrm{u}_{3}-\mathrm{lil}_{2}-\mathrm{la}_{2}$ als Bestandteil eines

\footnotetext{
1749 Sjöberg 1977b, 6-7.

${ }^{1750}$ Edzard 2003, 170; Krecher 1966, 114-115; s. a. in der jungen Version von Nabnītu Tafel B 296-297 Gleichungen von $\mathrm{u}_{3}$-a-di mit tazzimtu und nuzzumu „Klage; Beschwerde“, was wohl nicht in den Kontext der hier besprochenen Hymnen gehört; hierzu auch Attinger 1993, 736-737.

${ }^{1751}$ Attinger 1993, 737 verweist in diesem Zusammenhang auf ĞIŠGAL-di, eine Profession, die frühdynastisch und Ur III-zeitlich neben gala und um-ma genannt sein kann; vielleicht ein spezialisierter Vokalist? S. a. hier zur Rubrik uru(n) Kapitel 14.1.3.

1752 Jacobsen/Kramer 1953; ETCSL 1.4.4; Kommentar bei Fritz 2003, 127-129; s. a. Jacobsen/Moran 1970, 53.
} 
Insektennamens. ${ }^{1753}$ Angesichts seiner Nähe zu Singarten könnte auch ein Bezug zur sumerischen Interjektion $\mathrm{u}_{3}-1 \mathrm{i}-\mathrm{li}$ bestehen. ${ }^{1754}$ In Bala $\tilde{g}-$ Kompositionen steht diese für den Schrei oder Ruf der Klage. ${ }^{1755}$ Andererseits zeigt sie in einem Širnamšub an Utu (Utu E 25-26) auch den Ausdruck des Jubels bei der Ausführung von Bierlibationen an. ${ }^{1756}$ Dieselbe Dichtung nennt in den schlecht erhaltenen Zeilen 75-79 auch einen gala-Priester, der über die Opferhandlungen waltete.

Mit der möglichen Bedeutung des Gattungsnamens als „Wehe des Windhauchs/Geistes!“ $\left(\mathrm{u}_{3}-1 \mathrm{li}_{2}-1 \mathrm{a}_{2}\right)$ könnte auch ein Bezug zum kultischfunktionalen Hintergrund der Dichtung vorliegen, nämlich die Ausführung von Wehklagen begleitet von Libationen und Schüttopfern, die den Geist des Verstorbenen zu erheben suchen!

Hinsichtlich seiner Inhalte wurde von Jacobsen und Kramer bereits eine Nähe zu den Klagegattungen des gala aufgezeigt, wobei der abschließende Preis und damit die Erhebung des Racheaktes der Inana eine inhaltliche Wende darstellen. ${ }^{1757}$ Sicher ist, dass es sich hier um ein liturgisches Lied aus dem Repertoire professioneller Klagesänger handelt, ob des gala oder der Klagefrau amerakūtum ${ }^{1758}$ bleibt allerdings unklar.

${ }^{1753}$ Jacobsen/Kramer 1953, 161 Anm. 4; Izi D iv 28 (MSL 13, 184) zwischen Interjektionen und Gesängen wie e-lil ${ }_{2}=e$-li-lu und e-te-lum $=z a$-ma-rum; CAD M/2, 8; s. a. Proto-Izi I 65 (MSL 13, 19) in ähnlichem Zusammenhang; in Ur $\mathrm{Ur}_{5}$-ra XIV (MSL 8/2, 64) 262. $\mathrm{u}_{3}-1 \mathrm{il}_{2}-1 \mathrm{a}_{2}$ en-na $=a-p u-u$ zwischen Insekten und Käfern.

1754 Aufgrund der unterschiedlichen Schreibungen von Jacobsen/Kramer 1953, 161 Anm. 4 abgelehnt; zur Interjektion s. Edzard 2003, 170, der auf den Eintrag in $\mathrm{Lu}_{2}=\check{s} a$ Taf. III ii (MSL 12, 124) verweist 16. munus $\mathrm{u}_{3}-1 \mathrm{i}-1 \mathrm{i}=z a$-am-me-er-tu; $\mathrm{s}$. a. ibid. 17. munus $\mathrm{u}_{3}$ $\check{\mathrm{se}}_{3}-1 \mathrm{a}_{2}=z a$-am-me-er-tu möglicherweise zu munus $\mathrm{u}_{3}-1 \mathrm{il}_{2}{ }^{?}-\mathrm{l}_{2} \mathrm{zu}$ emendieren?

${ }^{1755}$ Cohen 1988, 521:a+32.

${ }^{1756}$ Utu E 24-25; Kramer 1985b, 120-124: 23-24.

1757 Jacobsen/Kramer 1953, 161-162.

${ }^{1758}$ Vgl. $\mathrm{u}_{3}-1 \mathrm{i}-1 \mathrm{a}$ als Bestandteil eines Klageliedtitels im aB Katalog der amerakūtum „Kunst der Klagefrau“" an Bēlet-ilī bei Shaffer 1993, 209:11 und hier Kapitel 13.3. 
Alle hier behandelten Gattungsnamen sind nach Interjektionen und den Bezeichnungen von Singarten gebildet. Sie könnten daher als rein vokal vorgetragene Lieder $\mathrm{zu}$ identifizieren sein. Angaben $\mathrm{zu}$ einer instrumentalen Begleitung, die über verschiedene Rubriknamen angezeigt werden könnten, sind in ihnen nicht enthalten.

Ihrem Inhalt nach unterscheiden sich die Gattungen Ululumama und Uadi vom Ulila, da sie ausschließlich Aussagen zu Fruchtbarkeit und Sexualität behandeln, sowohl in Bezug auf das Rinderhirtentum, welches auf verschiedene männliche Götter übertragen wird, als auch in Bezug auf die Hochzeitszeremonien um Inana und ihren Geliebten Dumuzi, wobei stellvertretend hier der König auftreten kann. Im Gegensatz dazu liegt der Liedgattung U1ila an Inana der Kontext der Klage zugrunde. 


\section{Akkadische Liedgattungen}

Aus Gründen der Eingrenzung berücksichtigt die folgende Darstellung zunächst alle solchen Texte, die mit dem Namen einer Liedgattung versehen sind und schließlich nach ihrer Sprache der Gruppe der hymnisch-lyrischen Kompositionen zugeordnet werden. ${ }^{1759}$ Das überlieferte Material akkadischsprachiger Literatur wird nach narrativ-epischen und hymnisch-lyrischen Kompositionen unterschieden. Sowohl episch-narrative Dichtungen, zu denen beispielsweise der Sintflutmythos Atramhasis oder das Gilgamesch-Epos zählen, wie auch die hymnisch-lyrischen Texte werden unter den allgemeinen Begriffen šir ${ }_{3}$ bzw. zamāru(m) ,Lied“" geführt. ${ }^{1760}$

Nicht immer sind diese Lieder genuin akkadischsprachig. Solche im Kontext des Schulmilieus angefertigten Übersetzungen sumerischer Dichtungen werden nicht als primär für den Vortrag im Akkadischen verfasste Texte gewertet und bleiben daher aus der folgenden Darstellung ausgeschlossen. ${ }^{1761}$ Die hymnisch-lyrische akkadische Literatur wird primär über inhaltliche und formale Gesichtspunkte nach verschiedenen Textgruppen unterteilt. Aus diesen werden in die folgende Darstellung Hymnen, Liebeslyrik, darunter auch poetische Dialoge, sowie Klagen einbezogen. Ebenfalls unberücksichtigt bleiben hier Beschwörungen in akkadischer Sprache.

Zur Angabe von Liedgattungsnamen in akkadischsprachigen Texten ist zu bemerken, dass sie im Gegensatz zur sumerischen Konvention nicht in einer kurz gehaltenen Unterschrift, sondern auch oder ausschließlich in Überschriften notiert werden. ${ }^{1762}$ An akkadischen Gattungsnamen sind bisher aus den Texten selbst die Ausdrücke $i k r i b u(m),{ }^{1763} i \operatorname{rtu}(m)$, pāru $(m), \check{s i r}_{3}$ tana/ittim, šir $_{3}$ kummi und möglicherweise inhu(m) identifiziert. Neben solchen Gat-

1759 Kennzeichnend sind entweder Über- bzw. Unterschriften oder Formulierungen im Text selbst, vor allem die Aufforderung zum Gesang in den einleitenden Versen. Die rein narrative Dichtung Sîn und Išum (CT 15, 5-6; Römer 1966), die von Wasserman 2003, 194:60 dennoch als Hymne eingeordnet wird, bleibt hier unberücksichtigt.

${ }^{1760}$ S. hier Kapitel 11.1.3.

${ }^{1761}$ Bspw. die Enlil Hymne VS 2, 89, die Ištar Hymne TIM 9, 20-26+CT 58, 53 und die Nisaba Hymne UET 6/2, 388-389+; dazu Edzard/Röllig 1987-90, 54-55 und Katalog bei Wasserman 2003, 187-224.

1762 Wilcke 1977, 179 Anm. 50. So die Papuleg̃ara-Hymnen, das šir ${ }_{3}$ kummi an Adad, Ištar Louvre sowie Agušaya A.

${ }^{1763}$ S. Kapitel 11.2.3 als allgemeiner Begriff „Gebet“ besprochen. 
tungsnamen werden akkadische Lieder häufig auch in Serien zusammengefasst (sumerisch eš $\check{s}_{2}-$ gar $_{3}$; akkadisch iškarum Pl. iškarātu), ${ }^{1764}$ die meist als Satz formuliert über den Inhalt der Liedgruppe Auskunft geben. Eine über einen einzigen Textvertreter identifizierte Serie, die der mittelassyrische Liederkatalog KAR 158 in die Gruppe der zamārum „Lieder" einordnet, wird unter dem Titel māruma rā'imni „Oh Jüngling, der mich liebt!“ geführt. ${ }^{1765}$ Weitere akkadischsprachige Liedgattungsnamen und Serien werden im eben genannten Liederkatalog genannt, von denen bisher allerdings nur sehr wenige identifiziert werden konnten. ${ }^{1766}$

Anhand der hier gebotenen Auswahl an Texten sollen zunächst beispielhaft Unterschiede und Parallelen zum sumerischsprachigen Korpus aufgezeigt werden. Vereinzelt wird auch der Versuch einer musikpraktischen Deutung unternommen.

Insgesamt fällt das akkadische Material im Vergleich zum sumerischen recht dürftig aus. Auch sind alle diese Dichtungen meist nur in einer einzigen Version überliefert. Der größte Teil der hier integrierten Texte datiert in die Zeit der ersten babylonischen Dynastie beginnend mit Hammurabi von Babylon. Für frühere Könige der altbabylonischen Zeit sind nur sehr wenige literarische Dichtungen bekannt geworden, hierzu zählen etwa die Larsa-zeitlichen Hymnen des Gungunum an Nanna? (TIM 9, 43), des Rīm-Sîn an Amurrum (OECT 11, 1) sowie der Liebesdialog desselben YOS 11, 24. Sie sind ein Zeugnis für den Beginn der Verschriftlichung oder Neukomposition genuin akkadischsprachiger Dichtungen.

Leider stellt sich noch immer die Situation um die Erschließbarkeit der Texte als schwierig dar. So sind zahlreiche Vertreter altbabylonischer Literatur bisher nur unzureichend publiziert, was teilweise auch auf ihren schlechten Erhaltungszustand zurückzuführen ist. Erschwerend für die Behandlung und Einordnung akkadischer Hymnen und Lieder ist auch die Vielfalt ihrer Formen und Inhalte. Wesentlich zu ihrer Zugänglichkeit hat N. Wasserman mit seinem Katalog zu den literarischen Werken der altbabylonischen Zeit beigetragen. ${ }^{1767}$ Des Weiteren arbeitet das Literaturprojekt SEAL (Sources of Early Akkadian Literature) der Universitäten Leipzig und Jerusalem an einer online Datenbank zu den akkadischsprachigen literarischen Kompositionen des zweiten Jahrtausends. ${ }^{1768}$ Dies verspricht eine leichtere Zugänglichkeit der Texte, die für zu-

\footnotetext{
${ }^{1764}$ AHw 396 sub iškaru(m); CAD I/J 249b sub b).

${ }^{1765}$ Black 1983.

${ }^{1766}$ Zuletzt Groneberg 2003.

${ }^{1767}$ Wasserman 2003, 187-224.

${ }^{1768} \mathrm{http}: / /$ www.seal.uni-leipzig.de/.
} 
künftige Forschungsarbeiten auf diesem Gebiet von großem Nutzen sein wird. Der folgenden Zusammenstellung wird im Wesentlichen der Katalog von Wasserman 2003 zugrunde gelegt. ${ }^{1769}$

\subsection{Hymnen}

\subsection{1 $\breve{s i r}_{3}$ tana/itti(m), das „Preislied“}

Die Angabe šir ${ }_{3}$ tana/itti ( $m$ „Preislied“"1770 ist bisher für drei akkadischsprachige Götterhymnen bekannt, den längeren Hymnus Ištar Louvre ${ }^{1771}$ sowie zwei kurze Hymnen an Papuleg̃ara. ${ }^{172}$

\subsubsection{Der Hymnus Ištar Louvre}

Der Hymnus Ištar Louvre setzt mit der für akkadische Dichtungen üblichen Gattungsangabe in der Überschrift ein: „Ein Preis[lied] der Ištar“. ${ }^{1773}$ Auf diese Überschrift folgt eine kurze Einleitung, in der ein nicht genannter Sprecher oder Sänger zum Lobpreis der Göttin aufruft und von einem Beschwörungspriester sowie einer weiteren nicht näher definierten Zuhörerschaft aufmerksames Gehör verlangt. ${ }^{1774}$ Hierauf folgt der eigentliche Preisgesang an die Göttin, in dem zahlreiche ihrer Wesensaspekte und Attribute aufgelistet werden. ${ }^{1775}$ Die Auflistung wird von einem Refrain oder Kehrreim mit den Worten „Das ist dein, Ištar!“ (kumma Ištar) begleitet, ${ }^{1776}$ der auf jeden Doppelvers folgt. Angesichts dieses Kehrreims und der im Folgenden beschriebenen Aktivitäten verschiedener Kultakteure ist die Hymne in großen Zügen der sumerischsprachigen Dichtung Inana $C$ angelehnt. ${ }^{1777}$

\footnotetext{
1769 S. außerdem die Zusammenstellung bei Edzard/Röllig 1987-90, 54-57, 66; bei Groneberg 2003, 57-58 sowie Streck 2007, 169 zu den altbabylonischen Hymnen.

${ }^{1770}$ AHw 1319 b tanittum „Ruhm; Lobpreis“.

${ }^{1771}$ Groneberg 1997a, 21-54.

${ }^{1772}$ Erstbearbeitung Pinches 1924; neu bei SEAL und Streck/Wasserman 2008.

${ }^{1773}$ Unsicher ergänzt Groneberg 1997a, 3-4, 39 [ši s $_{3}$ ] ta-na-ti Ištar, ,[Lied]: Ruhm der Ištar“.

${ }^{1774}$ Groneberg 1997a, 22-23:1-10, 16. Die direkte Aufforderung des āšipu „Beschwörungspriester" zum Zuhören könnte nach Groneberg 1997a, 15-16 damit zusammenhängen, dass dieser durch den Lobpreis der Göttin zur Ausführung eines Löserituals aufgefordert wird. Die Ausführung des Rituals und die begleitende Festprozession werden in Kol. II beschrieben; Groneberg 1997a, 16-17, 26-29.

${ }^{1775}$ Groneberg 1997a, 16, 22-25.

${ }^{1776}$ Kol. I 15-52 und weiter in II 28, 32; Groneberg 1997a, 22-29; zur Aufteilung des Textes nach Doppelversen s. a. Lambert 1999/2000, 277.

${ }^{1777}$ Groneberg 1997a, 10-22; Sjöberg 1975c, 162-163.
} 
Aufgrund der Einleitung und der weiteren Form des Textes ist sicher davon auszugehen, dass die Komposition einem öffentlichen Vortrag galt und angesichts ihrer Länge von verschiedenen professionellen Solisten und Gruppen zu einem bestimmten Festanlass gesungen wurde. ${ }^{1778}$ Der insgesamt sechs Kolumnen umfassende Text enthält weiterhin die Beschreibung eines Festrituals mit Prozessionsumzug, an dem sich unterschiedliches Kultpersonal der Ištar beteiligte. ${ }^{1779}$ Hervorzuheben sind der āšipu(m) zu Beginn des Hymnus und der assinnu, deren Rollen nach der Prozession zur Einleitung einer Omenanfrage mit anschließendem Opfer zum Tragen kommt, und schließlich ein Beter unbekannter Identität (Priester oder König), der sich klagend an die Göttin wendet (Kol. II 31ff. und III). Da der Text vom Ende der Kolumne II bis zur Kolumne IV stark zerstört ist, sind die Inhalte dieser Klagen nicht rekonstruierbar. Bemerkenswert sind wiederum die letzten erhaltenen Zeilen der Kolumne $\mathrm{V}$, in denen von einem Mauer- oder Gebäudesims die Rede ist. ${ }^{1780}$ Aus diesen Angaben kann geschlossen werden, dass zumindest dieser Abschnitt der Hymne aus Anlass eines konkreten Bauvorhabens oder einer Restaurierung an Teilen des Ištar-Tempels vorgetragen wurde. ${ }^{1781}$ Hierfür sprechen auch die zuvor formulierten Klagen. Wie bekannt, kamen auch die sumerischen Klagelieder Balag̃ und Eršema aus Anlass unterschiedlicher Bauvorhaben an Tempeln oder Kultstatuen zum Vortrag. Die Klagelieder dienten dem Zweck, die erzürnten und durch den Umbau irritierten Gottheiten zu besänftigen. ${ }^{1782}$

Die Hymne Ištar Louvre ist insofern von besonderem Interesse, da sie wie oben angezeigt Hinweise zum Vortragsanlass, dem Festverlauf und seinem Hintergrund enthält. Im Vergleich zu den erörterten sumerischen Texten ist die Aneinanderfügung von mehreren Abschnitten mit unterschiedlichen Inhalten auffällig. ${ }^{1783}$ Der die Komposition einleitende Lobgesang wird über die Beschreibung einer Festprozession bis hin zu Klagegesängen fortgeführt. Angesichts dieser unterschiedlichen Inhalte ist anzunehmen, dass die verschiedenen Textabschnitte auch von unterschiedlichen Musikern, Priestern, Sängern und Chören, vorgetragen wurden. Sie bildeten dennoch ein in sich geschlossenes und zusammenhängendes Festritual, das mehrere Stunden, vielleicht auch Tage, andauerte und wohl entsprechend viele Kultstationen anlief. Ein entsprechender Ablauf ist altbabylonisch über die Ritualliste von Larsa dokumentiert. ${ }^{1784}$ Der in der ersten Kolumne immer wiederkehrende Refrain „Das ist dein, Ištar!“ könnte als Gegengesang oder ‘Antiphon’ zu deuten sein. Aus dem

\footnotetext{
${ }^{1778}$ Kol. I 7 wird der Text als zamāru(m) „Lied; Gesang“ ausgezeichnet; Groneberg 1997a, 2223, 40:14.

${ }^{1779}$ Groneberg 1997a, 17-18.

${ }^{1780}$ Groneberg 1997a, 18-19, 37 Z. 38'-43.

${ }^{1781}$ Groneberg 1997a, 18-19.

${ }^{1782}$ S. Kapitel 12.1.1.

${ }^{1783}$ Groneberg 1997a, 18.

${ }^{1784}$ Kapitel 9.2.3.
} 
sumerischen Inana-Dumuzi-Lied CT 58, 12 wird deutlich, dass auch einzelne Vershälften als Gegengesänge (g̃ išgiğal) von einem mehrstimmigen Chor vorgetragen wurden. ${ }^{1785}$ Gleiches kann für die Aufführung der Kehrreime angenommen werden.

\subsubsection{Hymnen an Papuleg̃ara}

Dem relativ unbekannten Gott Papuleg̃ara sind auf einer größeren Sammeltafel unbekannter Herkunft drei hymnische Kompositionen gewidmet, die alle als $\breve{s i r}_{3}{ }^{\mathrm{d}}$ Pap-ul-e-g̃ar-ra (vi 37') ausgewiesen sind. ${ }^{1786}$ Die erste Hymne gehört der Gattung $\operatorname{parru}(m)$ an, die zwei letzteren werden als šir ${ }_{3}$ tana/itti $(m)$ eingeordnet. Die Gattungszugehörigkeit wird sowohl in der Über- wie auch Unterschrift notiert: ${ }^{1787}$

T 94: Pinches 1924:i 1-3//vi 34'-37'

\section{1 pārum an Papuleg̃ara}

2 šir $_{3}$ tanittim an Papuleg̃ara

(insgesamt) 3 šir $_{3}$-Lieder des Papuleg̃ara“

(i 1.)/vi 34' 1 pa-ru-um (a-na ${ }^{\mathrm{d}}$ Pap-ul-e-g̃ar-ra)

(i 2.)/vi 35' 2 šir ${ }_{3}$ ta-ni-it-tim (a-na ${ }^{\text {d Pap-ul-e-g̃ar-ra) }}$

vi $36^{\prime}$

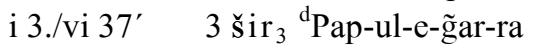

Die zwei šir ${ }_{3}$ tanittim nahmen womöglich gemeinsam die Rückseite der Tafel ein beginnend mit Kolumne iv bis vi. Die Unterschrift des ersten dieser Preislieder könnte in Kolumne iv $3^{\prime}-4^{\prime}$ erhalten sein. ${ }^{1788}$ Der Inhalt der Lieder ist zunächst vom Preis des Gottes geprägt, dessen zerstörerische Kraft, die sich im Kampf gegen Feinde richtet, in den Mittelpunkt gerückt wird. Hierin ähneln die Lieder altbabylonischen Eršema an den Wettergott Iškur sowie den sumerischen Širgida, die vergleichbare Formulierungen aufweisen. Am Ende des zweiten Liedes, das die gesamte Rückseite der Tafel einnimmt, ist vom Aufstellen des Throns des Papuleg̃ara im Tempel von Keš die Rede. Konkret wird dann in Kolumne vi 17' das eššěšum-Fest genannt. Es werden weitere Bauvorhaben über Kultstationen verschiedener Götter, darunter Ištarān, Dig̃irmah und Sugallītum, erwähnt, wobei im Mittelpunkt immer wieder der Tempel von Keš steht. Hier könnte vermutet werden, dass real ausgeführte Bautätigkeiten,

\footnotetext{
${ }^{1785}$ S. hier Kapitel 14.2.3.

${ }^{1786}$ Erstpublikation bei Pinches 1924; neue Umschrift und Übersetzung online bei SEAL und bei Streck/Wasserman 2008; nach Angabe Wassermans ist die Tafel sehr sorgfältig und kunstvoll gestaltet, sodass sie wohl einer längeren Aufbewahrung zugedacht war.

${ }^{1787}$ Pinches 1924, 67:i 1-3, 74:vi 34-37; CAD P 209-210.

1788 Pinches 1924, 69: iv 3' al-ti i-l[a-am ...] 4' šir ${ }_{3}$ ta-ni-it-tim [ana Papuleg̃ara] „,vollendet 'Den Go[tt. . .]"; s. a. Streck/Wasserman 2008, 339, 347-348.
} 
möglicherweise auch das Aufstellen eines Throns für den besungenen Gott durch den König, Anlass zur Komposition und zum Vortrag des Liedes gegeben haben. eššěšum-Feiern fanden überwiegend zu den Mondfeiertagen statt, dem 7., 15. und 25. eines Monats. ${ }^{1789}$ Außer dass an diesen Tagen Opferriten ausgeführt wurden, ist über den Inhalt der Anlässe wenig bekannt.

Papuleg̃ara ist ein sonst unbekannter Gott, der nach diesen Hymnen als Krieger- und Heldengestalt der Stadt Keš zugeordnet wird. ${ }^{1790}$ Im Vergleich zu Istar Louvre sind seine Hymnen sehr kurz gehalten und weisen keine besonderen strukturellen Eigenheiten auf, wie beispielsweise einen Refrain oder Kehrreim.

Gemeinsame sprachliche oder formale Merkmale können für die drei einzigen bekannten Vertreter der Preislieder $\check{s ̌ i r}_{3}$ tana/itti $(m)$ nicht festgestellt werden. Die Hymnen variieren zudem erheblich in ihrer Länge. Lediglich ihrem Inhalt nach scheinen zwei von ihnen auf Bautätigkeiten zu verweisen. Es bleibt damit unklar, ob der Ausdruck šir ${ }_{3}$ tana/itti(m) „Preislied“ entsprechend den sumerischen Gattungsnamen verwendet wurde, oder lediglich ein Sammelbegriff für Preislieder in akkadischer Sprache ist, die aus Anlass einer Tempel- oder Kultobjektsweihe komponiert wurden.

\subsection{2 pārum-Hymnen an Ištar und Papuleg̃ara}

Das akkadische Wort pārum ist als Über- und Unterschrift zweier Textzeugen belegt und damit als Name einer eigenständigen Liedgattung identifizierbar. ${ }^{1791}$ Der erste Beleg findet sich als Angabe zu einer sehr kurzen Komposition von nicht mehr als 20 Zeilen, die der Göttin Ištar gewidmet ist und ihr 'übermenschliches' Liebesbegehren feiert. ${ }^{1792}$ Die Tafel selbst stammt möglicherweise aus Nippur, ${ }^{1793}$ nähere Informationen zum archäologischen Kontext sind nicht bekannt. Die Gattung des Textes ist am Ende der Komposition notiert: „Summe: 20 (Zeilen), pārum der Ištar“. ${ }^{1794}$ Der Kolophon verzeichnet außerdem Datum und Namen des Schreibers: „Jahr Hammurabi ist König; Šeššekbēlū-rēṣūšsu, Sohn des Šumum-libši hat es geschrieben“. ${ }^{1795}$ Die Namen des

\footnotetext{
${ }^{1789}$ Sallaberger 1993, 41; Westenholz/Westenholz 2006, 6-7.

${ }^{1790}$ Krebernik 2003-2005; s. a. Black 2005, 44-45.

${ }^{1791}$ Die Ergänzung Gronebergs 1981, $180[p a]-r u-u_{2}$ für die Unterschriftennotitz der Vorderseite des Nanaja-Hymnus (VS 10, 215) Zeile 29 ist unsicher. Das erste Zeichen gleicht eher einem SI.

${ }^{1792}$ HS 1879 bearbeitet bei von Soden/Oelsner 1991, 339-343; s. a. Hurowitz 1995; Meyer 2003 und SEAL.

${ }^{1793}$ Von Soden/Oelsner 1991, 339.

${ }^{1794}$ Von Soden/Oelsner 1991, 341: 21a naphar(PAP) 20 pa-rum ša Iš-tar. CAD P 210 übersetzt in der Annahme eines Pl. pa-ru, „20 p.-songs for Ištar“.

1795 Von Soden/Oelsner 1991, 340-341: 21b mu lugal Ha-mu-ra-bi-im // lugal-e 22.

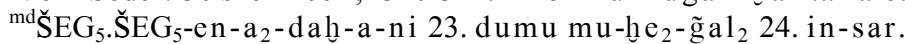


Schreibers sowie seines Vaters sind mit altbabylonisch unüblichen Logogrammen wiedergegeben, auch kann nur Šumum-libši als gängiger Personenname der spätaltbabylonischen Zeit identifiziert werden. ${ }^{1796}$ Für Nippur ist Samsuiluna-zeitlich ein Šumum-libši als Vater eines nar mit Namen Sîn-X belegt, der einem größeren Kreis von Musikern am Ekur angehörte. ${ }^{1797}$ Eine Identifizierung der genannten Personen ist angesichts des ungewöhnlichen Schreibernamens allerdings nicht möglich. Trotz angegebenen Datums setzen außerdem von Soden und Oelsner für die Komposition des Textes die spätaltbabylonische bis frühe mittelbabylonische Zeit an. ${ }^{1798}$

Der erste Vers der Dichtung ist gleichzeitig ein Kehrreim, der auf alle darauf folgenden Zeilen folgt: ,Jauchzen ist das Fundament für die Stadt!“ ${ }^{1799}$ Ähnlich kurze Kehrreime sind auch in Ištar Louvre sowie in der sumerischsprachigen Hymne Inana $C$ enthalten, ${ }^{1800}$ weshalb mit von Soden durchaus ein sumerischer Einfluss auf die Komposition angenommen werden kann. Die Kehrreime wurden möglicherweise von einem Chor auf die ihnen vorausgehenden Verse des Solosängers erwidert.

Seinem Vokabular nach kann der Text der Liebeslyrik zugeordnet werden. Der Hymnus preist eine sexuell unersättliche Göttin, deren Freier, die sie in direkter Rede ansprechen, sich und die Göttin in dunklen Ecken an Hauswänden zu befriedigen suchen. ${ }^{1801}$ Aufgrund der fast pornographisch anmutenden Beschreibungen ${ }^{1802}$ sowie der Schlichtheit von Form und Inhalt setze ich für den Text einen volkstümlichen Hintergrund an. Da das sexuell provokative Lied zudem die Überlegenheit der Göttin gegenüber unzähligen Männern herausstellt, scheint es den sexuellen Verkehr insgesamt preisen zu wollen. Doch entgegen der Meinung von Hurowitz, der hier einen feministischen Unterton vermutet, ${ }^{1803}$ ist es wohl eher aus einer männlichen Perspektive erwachsen, die das Bild der sexuell unersättlichen Ištar in ihrer Rolle als Prostituierte rühmt. Ein offizieller kultischer Rahmen für die Anwendung des Liedes lässt sich daher nur schwer nachvollziehen, am ehesten wäre hier an den Kontext von Liebes- und Potenzbeschwörungen in einem privaten Umfeld zu denken.

\footnotetext{
${ }^{1796}$ Von Soden/Oelsner 1991, 339; Pientka 1998, 618. Ein Göttername d Šeššeg/k ist mir unbekannt; zur gleichnamigen Vogelart s. Veldhuis 2004, 284.

${ }^{1797}$ S. hier Kapitel 9.5.2.3 und Musikerkatalog im Anhang Kapitel 16.

${ }^{1798}$ Von Soden/Oelsner 1991, 339-340 in die frühe Zeit der ersten Meerlanddynastie.

1799 rišătu(m)ma išdum ana ălim(uru ${ }^{\mathrm{ki}}$ ); vgl. Hurowitz 1995, 546 ,Joy is a foundation for the city!"; ähnlich von Soden/Oelsner 1991, 340-341.

${ }^{1800}$ Groneberg 1997a, 10; Inana C 115-173? (ETCSL 4.07.3; Sjöberg 1975c, 163, 188-197).

${ }^{1801}$ Ausführlich Hurowitz 1995.

${ }^{1802}$ Hurowitz 1995, 550-558.

${ }^{1803}$ Hurowitz $1995,558, \ldots$. . our author should be hailed as one of the world's first known feminists!“. Ob in Zeile 4 der Vorderseite mit von Soden/Oelsner 1991, 340-341 tatsächlich $k u-u[l-m a-s ̌ i-t u m]$ zu ergänzen ist, bleibt m. E. fragwürdig.
} 
Der zweite erhaltene Textvertreter der Gattung pāru(m) ist wiederum eine Hymne auf den Gott Papuleg̃ara, die sich auf derselben der im vorherigen Kapitel 13.1.1 behandelten Sammeltafel befindet. ${ }^{1804}$ Vom pāru(m)-Lied des Papuleg̃ara, das sich aller Wahrscheinlichkeit nach über die Kolumnen i bis iii erstreckte, ist nur wenig erhalten. Im ersten Vers wird wie in den meisten akkadischen Hymnen üblich zum Gesang aufgefordert: „Vornehmster, Erstgeborener des Enlil: Deine Kraft wollen wir besingen!““ ${ }^{1805}$ Der hierauf folgende Preis des Gottes hebt seine Rolle als Krieger und Held hervor, der Stürme kontrolliert und Feinde vertreibt. ${ }^{1806}$ In Kolumne ii verlagert sich die Thematik auf die Erwählung eines unbekannten Königs und seine Schicksalsbestimmung durch den zuvor gepriesenen Gott. ${ }^{1807}$ In der stark zerstörten Kolumne iii wird der Fokus auf die Erwählung und Erhöhung des Papuleg̃ara(?) unter anderen Gottheiten gelegt, darunter Anum und Ištar sowie Enki und sein Wesir Usumu. Ein Name des Erwählten ist allerdings nicht erhalten, es könnte sich daher auch um den zuvor genannten unbekannten König handeln. ${ }^{1808}$ In jedem Fall ist hier eine Stellvertreterrolle des zu erhöhenden Königs durch den Gott Papuleg̃ara anzunehmen. Seine Huldigung durch Gottheiten anderer Kultzentren, hier Uruk und Eridu, verstärkt seine regional weit reichende Herrschaftslegitimation. Die ersten Zeilen der Kolumne iv enthalten die Unterschrift mit Gattungsangabe. ${ }^{1809}$

Beide überlieferten Textvertreter der Gattung pāru(m) sind inhaltlich Götterhymnen. Eine Königserhöhung ist lediglich im Papuleg̃ara-Hymnus enthalten, worin Parallelen zu den sumerischsprachigen Tigi- und Adab-Liedern bestehen.

Die Gattung pāru(m) wird auch im mittelassyrischen Liederkatalog KAR 158 genannt, der in Kolumne viii 16 die Summe von fünf pārū akkadī zusammenzählt. Unglücklicherweise ist kein Titel dieser Lieder, welche sich ursprünglich in Kolumne v befanden, erhalten. Auch lässt sich nicht mehr feststellen, ob die zwei einzigen erhaltenen Textvertreter in diesem Katalog aufgenommen waren.

Worauf der Gattungsname pāru(m) in seiner wörtlichen Bedeutung verweist, ist bislang unbekannt. ${ }^{1810}$ Angesichts der sich unterscheidenden Inhalte der zwei einzigen bekannten Liedvertreter scheint der Name keine einheitliche

\footnotetext{
${ }^{1804}$ Erstbearbeitung Pinches 1924, 63-86; Übersetzung bei Hecker 1989, 728-731; Foster 1993, 72-73; jetzt neu bearbeitet durch Streck/Wasserman 2008.

${ }^{1805}$ Pinches 1924, 67: i 4-5 ašarēd bukur Enlil danānka i nuzammer; Streck/Wasserman 2008, 338.

${ }^{1806}$ In i 8 qardum „Held“, i 9 rākisum hulli „,der den 'dröhnenden' Sturm bindet“; Pinches 1924, 67; anders Streck/Wasserman 2008, 342 „Who binds the storms, the swol[lon] clouds“.

${ }^{1807}$ Pinches 1924, 68: ii 1-4; Streck/Wasserman 2008, 338, 342.

${ }^{1808}$ Pinches 1924, 69.

${ }^{1809}$ Streck/Wasserman 2008, 348 zu iv 3'-4' gegen Pinches 1924, 69.

${ }^{1810}$ CAD P 209-210.
} 
Struktur oder Sprache zu implizieren, wie es etwa bei den sumerischsprachigen Tigi- und Adab-Liedern der Fall ist. In den allgemeinen Götterpreis konnte auch der König einbezogen werden. Neben der Einsetzung des Königs spielt auch die Sicherung von Ordnung und Fruchtbarkeit des Landes eine wichtige Rolle für den Erhalt des Königtums. Auf diese Thematik konzentriert sich das pāru(m) an Ištar. Mit Ausnahme des Inhalts und der möglichen religiösen Bezüge sind sonst keine Daten zu musikalischen Aufführungspraktiken der Lieder rekonstruierbar.

\subsubsection{Ein kummu-Lied auf Adad}

Das Wort kummu, wörtlich „Heiligtum“, ist als Angabe zu einem Lied bisher ausschließlich in der Überschrift einer Hymne an Adad bezeugt. ${ }^{1811}$ Die Überschrift enthält außerdem Daten zu seiner Gattungszugehörigkeit: ${ }^{1812}$

\section{T 95: CT 15, 3-4:1-3 (kummu-Lied an Adad)}

„Seuf[zlied]: ‘Den, der Gebete erhört, will ich preisen'!

Vollständig 'Den, der Gebete erhört, will ich preisen'!

Ein Lied des 'Heiligtums' (kummu) für Adad.“

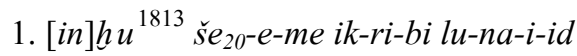

2. al-ti $\check{s e}_{20}-e-m e$ ik-ri-bi lu-na-i-id

3. šir ${ }_{3} k u-u m-m i a-n a{ }^{\mathrm{d}} \mathrm{IM}$

Der hierauf folgende Text des kummu-Liedes ist wohl Schlussteil eines längeren $i n h u$-Liedes mit dem Titel „Den, der Gebete erhört, will ich preisen!““. ${ }^{1814}$

Die Sprache des Textes ist vorwiegend narrativ, wie sie meist in mythischen und epischen Texten verwendet wird, auch mit der hierfür typischen Einleitungsformel der direkten Rede. ${ }^{1815}$ Über die Angabe des Wortes šir $_{3}$ wird der Text für den Vortrag gekennzeichnet. Auch die zum Preis der Gottheit auffordernde Einleitung verstärkt den Eindruck, dass die Komposition für das Singen bestimmt war.

Thema des Liedes ist das ziellose Wüten des Wettergottes Adad über Stadt und Land, dem die Götterversammlung mit Enlil an ihrer Spitze mit besänftigenden Maßnahmen entgegentritt. ${ }^{1816}$ Außer der Unterteilung von Doppel- und

\footnotetext{
${ }^{1811}$ CT 15, 3-4; Römer 1967, 185-199; Schwemer 2001, 420-421.

1812 Vgl. Streck/Wasserman 2008, 348.

${ }^{1813}$ Ergänzung mit Groneberg 2003, 59; so auch Streck/Wasserman 2008, 348+Anm. 5 gegen Schwemer 2001, 420 [GABA ${ }^{?}$.RI.

${ }^{1814}$ Schwemer 2001, 420-421.

${ }^{1815}$ CT 15, 3-4:8-9 Enlil an die Versammlung der Götter und 14-15 Bēlet-ilī an Enlil; Schwemer $2001,420$.

${ }^{1816}$ Schwemer 2001, 421-422.
} 
Einzelversen mithilfe durchgezogener Linien sowie zwei weiteren Doppellinien, die den Text in drei Abschnitte unterteilen, werden keine strukturellen Markierungen oder Rubriken angegeben.

Das Wüten einer Gottheit, die es zu besänftigen gilt, entspricht der Hauptthematik sumerischer Klagelieder der Gattungen Balag̃ und Eršema. Diese steht auch im Zentrum sumerischer Stadtklagen, den Klageliedern des gala sowie des akkadischen Hymnus Ištar Louvre. ${ }^{1817}$ Die von Groneberg vorgeschlagene Ergänzung des inhu als übergeordneter Gattungsname zu diesem Abschnitt des Liedes begründet sich damit auch über die inhaltliche und damit kultisch-funktionale Einordnung der Dichtung. Die „Seufz(-Lieder)“ inh̆u werden als Gattung auch im mittelbabylonischen Liederkatalog KAR 158 vi 22-23 geführt. Für das erste Jahrtausend ist belegt, dass diese Lieder von verschiedenen Kultakteuren um Inana/Ištar zur Abwehr drohenden Übels von Stadt oder Tempel ausgeführt wurden. ${ }^{1818}$ Auch im altbabylonischen Ištar Louvre mit apotropäischem Hintergrund wird beschrieben, wie der assinnu seinen inhu-Gesang ausführt. ${ }^{1819}$ Im kummu-Lied an Adad treten allerdings keine Menschen, ob König oder Priester, sondern vielmehr die Götter selbst auf, um den wütenden Wettergott zu besänftigen.

Die Angabe šir ${ }_{3}$ kummi „Lied des Heiligtums“ ist eine parallel zu šir ${ }_{3} t a$ na/ittim gebildete Gattungsangabe, die in diesem Fall aber wohl als Hinweis auf den Aufführungsort oder Rahmen zu werten ist. ${ }^{1820}$ Es bleibt außerdem unklar, ob diese Angabe als Gattung dem inhu untergeordnet ist, oder lediglich als Zusatznotiz anzusehen ist. Für den Vortrag lässt sich rekonstruieren, dass dieser Teil eines längeren Kultfestes bildete, das aus Anlass einer Tempelrestaurierung oder einer anderen den apotropäischen Ritus benötigenden Handlung ausgeführt wurde. Der Terminus kennzeichnet damit einen Liedvortrag, der im Rahmen eines mehrere Abschnitte umfassenden inhu-Gesangs im Heiligtum stattfand. Weiterhin könnte zu mutmaßen sein, dass es von einem Kultakteur der Inana/Ištar vorgetragen wurde, ob assinnu, gala-Priester oder einfach nar-Musiker lässt sich mit Sicherheit allerdings nicht festlegen. Mit Ausnahme dieses einzigen Liedes ist das šir ${ }_{3}$ kummi oder auch nur kummu in einem entsprechenden Zusammenhang bisher nicht belegt.

\subsubsection{Götterlieder mit Königspreis}

Als hymnische Kompositionen mit integriertem Königspreis sind hier drei herausragende Beispiele zu nennen: Das Lied Agušaya B mit Fürbitte an den

\footnotetext{
${ }^{1817}$ Hier Kapitel 13.1.1.1.

${ }^{1818}$ Groneberg 2003, 63-64; Ambos 2004, 43-44.

${ }^{1819}$ Groneberg 1997a, 28 ii 31; Groneberg 2003, 64.

${ }^{1820}$ Groneberg 2003, 59 ,song of the holy chamber“; Streck/Wasserman 2008, $348 \mathrm{zu}$ iv $3^{\prime}-4^{\prime}$ „song of the shrine“.
} 
König Hammurabi, ${ }^{1821}$ der gut erhaltene Ištar Hymnus des Ammiditana ${ }^{1822}$ sowie der Nanaja Hymnus des Samsuiluna. ${ }^{1823}$ In dieselbe Gruppe sind auch die Hymnen der Larsa-Könige Rīm-Sîn an Amurrum OECT 11, 1 sowie des Gungunum an Nanna(?) TIM 9, 41 einzuordnen, die beide aufgrund ihrer sprachlichen und formalen Eigenheiten eine Sonderstellung einnehmen. ${ }^{1824}$ Die Hymne des Gungunum wird mit der Aufforderung zum Preis der adressierten Gottheit eingeleitet, wie es für akkadische Götterhymnen üblich ist: „Deinen Ruhm will ich wiederholt preisen". ${ }^{1825}$ Am Ende der Amurrum-Hymne des Rīm-Sîn (OECT 11, 1) findet sich eine Unterschrift, in der möglicherweise ein Gattungsname angegeben ist. ${ }^{1826}$ Ansonsten sind in diesen Hymnen keinerlei Hinweise zur Aufführunsgpraxis enthalten.

\subsubsection{Die Götterhymnen des Ammiditana und des Samsuiluna}

Formal und inhaltlich ähnlich gehalten sind der Ištar Hymnus des Ammiditana (RA 22, 170-171) sowie der Nanaja Hymnus des Samsuiluna (VS 10, 215). Der Name des jeweiligen Königs erscheint in beiden Dichtungen zu Beginn des letzten Drittels der Komposition, wo dieser dann als der Geliebte der gepriesenen Göttin eingeführt wird. ${ }^{1827}$ Wie in zahlreichen akkadischsprachigen hymnischen Dichtungen wird auch in der Einleitung des Ištar Hymnus zum Preis der Gottheit aufgefordert: „Besingt die Göttin! Schrecken aller Göttinnen! Sie sei gepriesen, Herrin der Menschen, größte der Igigi!““. ${ }^{1828}$ Am Tafelrand des Nanaja Hymnus findet sich weiterhin eine einzigartige Notiz zum möglichen kultischen Sitz oder zum Titel der Komposition, welche lautet: „Erhöhung der Göttin ... “" (šušqût iltim [. . ]). ${ }^{1829}$

Beide Hymnen weisen eine auffallend regelmäßige Sprachstruktur und Form auf. Ihre durchgängige Aufteilung nach vierzeiligen Strophen erinnert an den strengen Aufbau der sumerischsprachigen Hymnengattungen Tigi und

\footnotetext{
${ }^{1821}$ Groneberg 1997a, 84-93.

1822 Thureau-Dangin 1925, 170-171.

${ }^{1823}$ VS 10, 215; von Soden 1938, 30-41.

${ }^{1824}$ Zur Hymne des Rīm-Sîn an Amurrum s. Erstbearbeitung bei Gurney in OECT 11, S. 15-19; von Soden 1981. Zur Hymne des Gungunum s. Groneberg/Hunger 1978, 522 und von Soden 1989-90, 118.

${ }^{1825}$ Groneberg/Hunger 1978, 522 No. 41:2 tanattaka luštašni.

${ }^{1826}$ Vgl. Gurney in OECT 11, S. 19, der zu Beginn der Zeile 46 ein g̃iš-gi ${ }_{4}$-g̃al ${ }_{2}$ vermutet. Möglich wäre auch die Angabe einer Liedgattung, vielleicht mit $\left\ulcorner^{\top} t i^{\top}-k i !-a m_{3}\right.$ „Es ist ein Tigi!"“ zu rekonstruieren. Eine solche Gattungszuordnung würde auch inhaltlich und formal auf das Lied mit seiner abschließenden Königserhöhung zutreffen. Damit könnte hier eine Übertragung der Gattung Tigi ins Akkadische vorliegen.

1827 Thureau-Dangin 1925, 171: Rs 3. Strophe (= 11. Strophe), 173, 175; von Soden 1938, 3435:34, 51; hierzu Groneberg 1999, 169-171.

${ }^{1828}$ RA 22, 170: 1. [i]l-「ta ${ }^{\top}$-am zu-um-ra-a ra-šu-ub-ti i-la-tim 2. li-it-ta-i-id be-le-et ni-ši ra-bi-it I-gi-gi.

${ }^{1829}$ Nanaja Hymnus (VS 10, 215) Rd 57.
} 
Adab. ${ }^{1830}$ Zusätzlich zu ihrer Form bestehen zu diesen Liedern auch Parallelen im Inhalt. Auch sie enthalten häufig eine Fürbitte für den König, die auf die besondere Beziehung zur angerufenen Gottheit bezogen wird. Nicht selten ist der genannte König auch dort der Erwählte oder Geliebte der gepriesenen Göttin. ${ }^{1831}$ Auch einzelne Formulierungen sind vergleichbar, vor allem im Nanaja Hymnus des Samsuiluna zum Tigi Išbi-Erra C an Nanaja ${ }^{1832}$ oder dem Adab-Lied Ur-Ninurta D an Inana.

Die akkadischsprachigen Götterhymnen der babylonischen Könige Samsuiluna und Ammiditana lehnen sich damit in Form, Sprache und Inhalt direkt an die sumerischsprachigen Gattungen Tigi und Adab an. Es bleibt allerdings zu bemerken, dass trotz dieser Parallelen in ihnen nicht die kennzeichnenden Rubriken sagida, sag̃ara und /uru(n)/ enthalten sind. In den akkadischen Hymnen folgt lediglich dem Ende des Liedtextes jeweils der Vermerk: „Sein g̃iš-gi ${ }_{4}$-g̃al (ist es)". ${ }^{1833}$ Die Angabe des 'Gegengesangs' bezieht sich in beiden Preisliedern auf die wohl letzte der über eine durchgezogene Linie angezeigten Strophen, in der jeweils die Erwählung des Königs oder die Bestimmung seines langen Lebens ausgerufen werden. ${ }^{1834}$ Vor allem die letzten Zeilen des Ištar-Hymnus des Ammiditana entsprechen hier beinahe wortwörtlich der /uru(n)/-Rubrik des Adab Ur-Ninurta D an Inana.

Eine weitere Rubrikangabe ist am Ende der Vorderseite des Nanaja Hymnus notiert. Auch wenn ihre Identifizierung fragwürdig bleibt, so wird über sie dennoch für die gesamte Komposition eine Zweiteilung angezeigt. ${ }^{1835}$ Besondere Beachtung verdient in diesem Zusammenhang der Eintrag im Liederkatalog KAR 158 zu Adab-Liedern in akkadischer Sprache:

${ }^{1830}$ Hier Kapitel 12.1.2.

${ }^{1831}$ Unter den Tigi Gudea A und Išbi-Erra C; unter den Adab Luma A; Ur-Ninurta D, IšmeDagan B und Rim-Sin $H$.

${ }^{1832}$ Vgl. auch die Darstellung der Göttin als leuchtender Stern im Nanaja-Hymnus (VS 10, 215) 1, 24, 51-52 mit Išbi-Erra C 1, 7-8, 29-41.

1833 Thureau-Dangin 1925, 171:60; im Nanaya-Hymnus ergänzt durch von Soden 1938, 34 35:56a; anders Hecker 1989, 726 Anm. zu 56a).

1834 RA 22, 171: 57-59 Ištar ana Ammiditana šarri ra’imīki ; arkam dāriam balātam šurki ; liblut „Ištar, dem dich liebenden König Ammiditana, schenke langes und ewig währendes Leben! Er möge leben!"; die Rasurspuren am Anfang der letzten Zeile zeigen an, dass der Schreiber den letzten Aufruf liblut bewusst einschob. VS 10, 215:53-56 qībitušša mi[gru]š

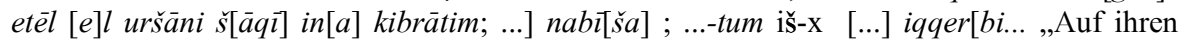
Ausspruch hin ist ihr Erwählter Herrscher, über (alle) Helden ist er in den Weltgegenden erhaben, ... .der von ihr ernannt. .inmitten . ."; vgl. von Soden 1938, 34-35.

1835 Von Soden 1938, 32 erkennt noch x $[r] u$ - $u_{2}$, Groneberg 1981, 180 rekonstruiert anhand der von ihm kopierten Zeichenreste [pa]-ru- $u_{2}$; allerdings bleiben die Ergänzung des Gattungsnamens pāru $(m)$ zur Kompositionsmitte hin sowie die Lesung des Zeichens fragwürdig. Aufgrund der Zeichenreste und Lückengröße halte ich eine Ergänzung mit ši $[t-r] u-u_{2}$ für sehr wahrscheinlich, an dieser Stelle wohl kein Gattungsname, aber möglicherweise ein Verweis auf den Einsatz eines bestimmten Instrumentenensembles! 
T 96: KAR 158 viii 9-11

9. $[\mathrm{x}+10]+1 \check{s u}$-me-ru ${ }^{\mathrm{mes}}$

10. $\mathrm{x}+2 a k-k a-d u-u_{2}$

11. [šu-nigin 2 ] $\mathrm{x}+3$ za-ma-ru $a-d a-p u^{\mathrm{meš}}$

Auch wenn die Liedunterschrift Adab bislang nur aus sumerischsprachigen Kompositionen bekannt ist, so könnten möglicherweise auch akkadischsprachige Lieder gleicher Form und gleichen Inhalts, wie beispielsweise die beiden hier vorgestellten Hymnen, derselben Gattung zugeordnet worden sein. Ohne konkrete Gattungsangabe lässt sich diese Annahme jedoch nicht nachweisen.

Für die vokale Aufführung der akkadischen Hymnen des Samsuiluna und des Ammiditana lässt sich rekonstruieren, dass sie von mindestens zwei Parteien vorgetragen wurden. ${ }^{1836}$ In Anlehnung an bisherige Erkenntnisse zum Aufbau von Vokalensembles könnten ein professioneller Solosänger und mindestens ein Chor am Vortrag der Hymnen beteiligt gewesen sein. Auch wenn das g̃išgig̃al lediglich am Ende der Komposition angegeben ist, so kann der 'Gegengesang' auch nach jedem Doppelvers oder auch jeder Strophe erwidert worden sein. Den Anlass zur Aufführung könnten Stiftungen und Votivgaben der Könige an die jeweils adressierten Götter gegeben haben, was die angegebene „Erhöhung der Göttin“ bezweckte und auch für die Komposition von Tigi und Adab üblich war.

\subsubsection{Das Lied Agušaya an Ištar}

Der Text des längeren Hymnus Agušaya an die Göttin Ištar ist auf zwei Tafeln unbekannter Herkunft überliefert. ${ }^{1837}$ Der moderne Titel der Komposition ist nach einer Notiz am Ende von Tafel B gewählt „Zur Tafel Agušaya (gehörig)“ ${ }^{1838}$ der sie damit der Dichtung aus Tafel A zuweist. Ähnlich den zuvor besprochenen Hymnen wird auch hier eine Königswidmung formuliert. Allerdings weicht die Komposition Agušaya erheblich von den vorherigen in Form und Inhalt ab, sodass für sie eine gesonderte Position innerhalb akkadischsprachiger Preislieder anzusetzen ist. Zusätzlich zu den lyrischen Abschnitten, wie sie in den übrigen akkadischsprachigen Preisliedern anzutreffen sind, verfügt das Lied über längere narrative Passagen, die eine eigene, in sich geschlossene mythische Erzählung bilden. ${ }^{1839}$ Ihr Thema, bisher ohne bekannte literarische Parallelen, ist die Erschaffung einer Ersatzgöttin für Ištar mit hauptsächlich

\footnotetext{
${ }^{1836}$ Hier Kapitel 14.1.4 zur Rubrik g̃išgi g̃al.

${ }^{1837}$ Zum Anschluss von Text B (RA 15, 174ff) an Text A (VS 10, 214); s. Groneberg 1997a, 57.

${ }_{1838}$ Agušaya B 26. tuppiš Agušaja; Groneberg 1997a, 87, 93 Anm. 91.

${ }^{1839}$ Groneberg 1997a, 55-93.
} 
kriegerischen Aspekten, die den Namen Șaltu trägt. Die zweite Tafel Agušaya $B$ enthält die Widmung an den König Hammurabi: ${ }^{1840}$

T 97: Agušaya B V 23-29

„Und der König, der dieses Lied, das Zeichen deines Heldentums,

deinen Lobpreis, hörte; Hammurabi, diesen Gesang,

(der) in seiner Regierungszeit als dein Lobpreis angefertigt wurde; ${ }^{1841}$

Ihm sei für alle Ewigkeit das Leben zueigen gemacht.“

23. $u_{3} \check{s}$ ar-rum $\check{s} a$ an-ni-a-am za-ma-ra- $a[m]$

24. $i-d a-a t q u_{2}-u r-d i-k i$

25. ta-ni-it-ta-ki iš-mu-ni

26. Ha-am-mu-ra-bi an-ni-a-am za-ma-[ra-am]

27. i-na pa-li ${ }^{\text {}}-\check{s} u$ ta-ni-it-ki 28. in-ne 2 -ep-šu

29. lu šu-ut-lu-um-šu ad-da-ar ba-la-t $\left[u_{2}\right]$

In diesen Zeilen wird die gesamte Komposition über zamārum und tanittum als lobpreisendes Singstück(/-spiel?) ausgezeichnet, das dem Heldentum der Göttin Ištar gewidmet ist. Gleichzeitig wird hier der Text als eine Neudichtung aus der Regierungszeit des Hammurabi postuliert. Die abschließende Fürbitte um ewiges Leben für den König ist in sumerisch- wie akkadischsprachigen Götterhymnen mit Nennung eines Königs ein gängiger Topos.

Nicht nur thematisch und inhaltlich, sondern auch ihrem Aufbau nach weist diese Dichtung beachtenswerte Parallelen zur Hymne Iddin-Dagan A an Inana auf, welche ein Širnamursa g̃a „Heldenlied“ ist. ${ }^{1842}$ Unter allen bisher behandelten akkadischsprachigen Liedern und Hymnen ist einzig der Ištar-Hymnus Agušaya auch nach kirugu-Rubriken unterteilt. Insgesamt weist er zehn dieser Einheiten auf, wobei Text $A$ mit dem sechsten schließt und Text $B$ mit dem siebten kirugu einsetzt. ${ }^{1843}$ Auf jede dieser kirugu-Einheiten folgt mit Ausnahme des sechsten ein Gegengesang (g̃ išgig̃al), der insgesamt nicht mehr als zwei bis vier Verse umfasst.

Mit diesen Rubriken ähnelt das Lied Agušaya in seinem Aufbau nicht nur der Hymne Iddin-Dagan A, sondern auch anderen sumerischsprachigen Gattungen, darunter Balag̃ , Širnamšub, Širnamgala sowie den Stadtklagen. ${ }^{1844}$ Die Aufteilung nach kirugu-Einheiten mit folgendem g̃išgig̃al lässt auf eine

\footnotetext{
${ }^{1840}$ Groneberg 1997a, 87.

${ }^{1841}$ Hier wäre parallel zu den Z. 23-25 und dem ebenfalls akkusativischen anniam zamāram ein Št von epěšu(m) „,(der) diesen Gesang. . .anfertigen ließ““ zu erwarten; Groneberg 1997a, 93 Anm. 88.

${ }^{1842} \mathrm{Zu}$ einem ausführlichen Vergleich s. Groneberg 1997a, 59-60.

1843 Agušaya A VIII 33 und Agušaya B II 6; Groneberg 1997a, 83-85.

${ }^{1844}$ Hier Kapitel 14.1.5.
} 
gleiche Aufführungspraxis der verschiedenen Kompositionen im Rahmen kultischer Feste schließen.

Von besonderer Aussagekraft für den möglichen kultischen Sitz des Liedes ist die in Agušaya A befindliche Überschrift uttâr MUŠ „Zurückgewendet wurde die Schlange“. ${ }^{1845}$ Nach B. Groneberg könnte diese Angabe auf eine apotropäische Funktion des Liedes hindeuten. Eine entsprechende Funktion wurde auch mit den formal verwandten sumerischen Liedgattungen Bala ga, Širnamšub und Širnamgala erzielt. Die meisten der nach kirugu unterteilten sumerischsprachigen Liedgattungen können dem Repertoire des gala zugeordnet werden. Dass dieser nicht ausschließlich auf sumerische Dichtungen spezialisiert war, sondern auch akkadische Gebete vortrug, ist für das erste Jahrtausend sicher nachgewiesen. ${ }^{1846}$ Die letzten Zeilen von Agušaya B formulieren schließlich den Ausgang der Geschehnisse: „Es beruhigte, besänftigte sich ihr (Ištars) Herz" (inūh ipšah libbiša). ${ }^{1847}$ Auch diese Aussage zur 'Herzbesänftigung' trifft die gängige Funktion der vom gala vorgetragenen Klagegebete Balag̃ und Eršema.

Die Neuschöpfung der vorliegenden Dichtung aus der Regierungszeit des Hammurabi ist insofern einzigartig, da sie möglicherweise eine individuelle Dichtung darstellt, die sich sumerischen Kompositionsformen anzulehnen sucht. Für einen offensichtlich gleichen Aufführungsrahmen wird eine neue Vortragssprache gewählt, das Akkadische. Damit wird auch deutlich, dass die Aufführungspraxis, die über die Rubrik kirugu angezeigt wird, an keine spezifische Sprache, sondern eher an den Rahmen und seinen Kontext gebunden ist.

\subsubsection{Götter- und Königshymnen ohne Gattungsangaben}

Altbabylonische Hymnen und Preislieder, die ausschließlich einer Gottheit gewidmet sind und keine Gattungsangaben enthalten, sind weitaus zahlreicher als die zuvor behandelten mit Über- oder Unterschriften versehenen Dichtungen. An einsprachigen genuin akkadischen Götterhymnen sind Lieder an Marduk (RA 86, 81), Ištar (VS 10, 213), Nanaja (UET 6, 404+889 $)$, ${ }^{1848}$ Mami/Aruru ${ }^{1849}$ sowie ein Lied an dieselbe Göttin unter ihrem Namen Bēlet-ilī (CT 15, 1-2) bekannt. Sie alle sind ihrem Inhalt nach als Preislieder an eine Gottheit verfasst, enthalten jedoch keinerlei identifizierbare Angaben zu Gattung oder Rubriken.

\footnotetext{
${ }^{1845}$ Groneberg 1997a, 59.

${ }^{1846}$ S. a. Gabbay/Wasserman 2005, 75.

${ }^{1847}$ Groneberg 1997a, 87: vi 23.

1848 Zur möglichen Zusammengehörigkeit beider Fragmente s. Katalog in UET 6/3. Die Eingangszeilen der Hymne in UET 6/2, 404:3-4 Nanaja...luzmur enthalten die für akkadische Dichtungen übliche Aufforderung zum Besingen der Göttin.

${ }^{1849}$ Bearbeitet Krebernik 2003/04; s. a. Black 2005, 54 No. 13.
} 


\subsubsection{Fragmentarische Hymnen an Marduk, Ištar und Nanaja}

Bei den Hymnen an Marduk aus Sippar (RA 86, 81), an Nanaja (UET 6, 404+889?) sowie der Selbstlobhymne der Ištar (VS 10, 213) handelt es sich um sehr kurze und fragmentarisch erhaltene Kompositionen, deren Länge insgesamt wohl keine 30 Zeilen überschritten haben dürfte. Während die MardukHymne für sich auf einer einkolumnigen Tafel erhalten ist, sind die Hymnen der Göttinnen auf mehrkolumnigen, möglicherweise auch Sammeltafeln gehalten.

In den einleitenden Versen des Nanaja-Hymnus wie auch des MardukHymnus wird wie bei den meisten akkadischsprachigen Hymnen der Gesang und Preis der Gottheit angekündigt: „Den Fürsten der Anunnāki, Marduk, will ich besingen". 1850

Die Selbstlobhymne der Ištar VS 10, 213 weist inhaltlich zahlreiche Parallelen zum Lied Agušaya A/B auf, in dem die heldenhafte und kriegerische Göttin gepriesen wird. ${ }^{1851}$ Möglicherweise werden in Zeile 9 tigiātum-Musikerinnen genannt, womit ein Hinweis auf die Vortragenden und die instrumentale Begleitung vorliegen könnte. ${ }^{1852}$

Der Nanaja-Hymnus ist, soweit ihm das Textfragment UET 6, 889 angehört, möglicherweise dem Bereich der Liebeslyrik zuzuordnen, da in ihm von einem Bett und einem namentlich nicht genannten König die Rede ist (Kol. ii 5, 13).

Insgesamt lassen sich für diese fragmentarischen und kurzen Kompositionen sonst keine Aussagen zu ihrer Aufführungspraxis oder dem möglichen Anlass ihres Vortrags treffen.

\footnotetext{
${ }^{1850}$ Al-Rawi 1992a, 79:2 etel enunnaki Marduk lu'izmur. Bemerkenswert ist der synkretistisch anmutende Vers 9. ina ellim apsī Asalluhi eliš ina šamâ An šumšu „Im reinen Apsû ist Asalluhi sein Name, oben im Himmel ist es An"; Al-Rawi 1992a, 79, 81; entsprechende Gesangsankündigung im Nanaja-Hymnus UET 6, 404:4.

${ }^{1851}$ Zimmern 1916, 43; Übersetzung bei Foster 1993, 74.

${ }^{1852}$ Koll. nach Groneberg in CAD T 398 sub tigû B.
} 


\subsubsection{Hymnen an die Muttergöttin Mami / Aruru / Bēlet-ilì}

Altbabylonische akkadische Dichtungen an die Muttergöttin, ob Klagen oder Hymnen, sind bemerkenswert zahlreich. ${ }^{1853}$ Die früheste bekannte Hymne CT 15, 1-2 ist eine längere Komposition, die sich über eine sechskolumnige Tafel erstreckt und bereits 1967-68 von Römer publiziert wurde. Ebenfalls lange bekannt war eine vergleichbar große Tafel der Jenaer Hilprecht-Sammlung (HS 1884), die allerdings mehrere Hymnen an diese Göttin birgt und erstmals von Krebernik 2003/04 in Bearbeitung vorgelegt wurde.

Das Bēlet-ilī-Lied CT 15, 1-2 verdient besonderes Interesse, da es in Aufbau und Inhalt Parallelen sowohl zu sumerischen wie auch akkadischen Dichtungen aufweist. In den einleitenden zwei Versen wird es wie üblich als vorzutragendes Lied angekündigt:

T 98: CT 15, 1-2:1-2 (Bēlet-ilī-Lied) ${ }^{1854}$

„Das Lied der Bēlet-ilī will ich singen!

Freunde, hört aufmerksam zu! Helden, hört her!“

1. [z]a-ma-ar ${ }^{\mathrm{d}} \mathrm{Be}_{2}-l e-e t-i_{3}-l i_{2} a-z a-m a-a r$

2. ib-ru uṣ-și-ra qu $-r a-d u$ ši-me-a

Der größte Teil der Hymne ist stark zerstört, dennoch lassen die Textreste erkennen, dass sie Wort- und Versrepetitionen enthält und größtenteils nach Doppelversen angeordnet ist. ${ }^{1855}$ Nach Einleitung des Preisliedes an Mami folgt eine Aufzählung ihrer Geburten und Söhne, aus dem Folgenden lässt sich unter ihnen allerdings lediglich Lillum identifizieren. ${ }^{1856}$ Nach einem größeren Bruch ab Kolumne vii bis viii finden sich dann narrative Elemente, die auf eine Orakelanfrage des Lillum sowie auf Kriegshandlungen Babyloniens gegen die Subaräer Bezug nehmen, an denen auch die Göttin Ištar aktiv mitwirkte. Für die Komposition des Liedes rekonstruiert Römer daher einen konkreten Bezug zu einem historischen Ereignis unter König Hammurabi von Babylon ${ }^{1857}$ Der einleitende Aufruf der 'Helden' lässt Römer weiterhin mutmaßen, dass es sich um ein zum Kampf aufmunterndes Lied gehandelt haben könnte, dass direkt im Feld vorgetragen wurde.

Nach Angabe einer kurzen Notiz am Schluss der Komposition wurde der Liedtext bereits antik nach einer nur in einem unvollständigen Zustand erhaltenen Textversion kopiert, in der bereits das Ende der Komposition fehlte. ${ }^{1858}$

\footnotetext{
${ }^{1853} \mathrm{Zu}$ den Klagen s. hier Kapitel 13.3.

${ }^{1854}$ Römer 1967-68, 12-13.

${ }^{1855}$ CT 15, 1-2 vornehmlich Kol. i; Römer 1967-68, 12-14.

${ }^{1856} \mathrm{Zu}$ diesem Sohn der Bēlet-ilī s. allgemein Krebernik 1987-1990, 19-20.

${ }^{1857}$ Römer 1967-68, 20-21.

${ }^{1858}$ Römer 1967-68, 13, 15: 11' nu-ti.
} 
Dies belegt, dass auch akkadische Texte mehrfach kopiert und studiert wurden, auch wenn sie nur über einzelne Abschriften überliefert sind.

Im letzten Vers wird der Bedrohung babylonischer Städte durch eindringende Feinde aus dem Norden ein konkretes Bild gegeben: „Die Götter gingen fort. In ihren Städten saßen sie vergessen in ihren Wohnstätten(?)“ “. ${ }^{1859}$ Diese Formulierung erinnert an den Haupttenor der sumerischen Klageliedgattungen Balag̃ und Eršema, in denen die verlassenen Tempel und Städte von Göttern beklagt werden. Entgegen der Annahme Römers könnten ähnlich wie bei diesen sumerischen Klagegebeten oder beim akkadischen Lied Ištar Louvre auch hier Restaurierungsarbeiten an Tempeln Babyloniens den Anlass zur Komposition gegeben haben. Der Hymnus Ištar Louvre weist zudem einen ähnlichen inhaltlichen Verlauf auf, so gehen der anfängliche Preis und die Erzählungen um die kriegerische Ištar in eine Klage über. ${ }^{1860} \mathrm{Im}$ vorliegenden Lied der Bēlet-ilì/Mami werden darüber hinaus die Zerstörungen an den Tempeln in einen politisch-historischen Rahmen gebettet. Schließlich sei hier auch an die Inhalte eines Bala g̃ an Aruru erinnert, wo die Göttin auch die Abwesenheit ihres Sohnes sowie ihre verlassenen Städte und Tempel beweint. ${ }^{1861}$ Dieses Balag̃ galt nach Ausweis seiner Unterschrift (Rs 29) der Restaurierung ihres Tempels von Keš.

Der anfängliche Aufruf der 'Helden' (qurādū) und 'Kameraden' (ibrūu lässt dennoch für den Anfang der Dichtung an zumindest szenische oder im Tanz ausgeführte Kampfhandlungen denken. Beispielhaft kann hier das Ištar-Ritual von Mari angeführt werden, in dem zum Vortrag von Klagegebeten auch Kulttänzer (huppû) auftraten. Die Ausführung von szenischen Vorführungen und Tänzen könnte daher grundsätzlich zu einer solchen Zeremonie gehört haben. Am Inhalt des Liedes konkretisieren lassen sich die hier geäußerten Rekonstruktionen für seinen möglichen Kontext allerdings nicht.

Abschließend kann hier noch auf die akkadische Gattung der qurdu „Heldenlieder(?)“ im Liederkatalog KAR 158 hingewiesen werden. Diese nur noch in der Zusammenzählung von Kolumne viii erhaltene Gattung konnte sowohl in sumerischer wie auch akkadischer Sprache verfasst sein. ${ }^{1862} \mathrm{Da}$ allerdings nicht einmal die Titel dieser Lieder bekannt sind, kann keine konkrete Verbindung zur vorliegenden Dichtung an Bēlet-ilī hergestellt werden.

\footnotetext{
${ }^{1859}$ Bēlet-ilī CT 15 pl. 2:viii 18-19 ilū izzibūma alīšunu šubtīšunu mašî̌s ušbū; Römer 1967-68, $13,15: 10^{\prime}$.

${ }^{1860}$ Groneberg 1997a, 15-19 zum Inhalt.

${ }^{1861}$ Scheil 1920; s. a. Black 2005, 50 Nr. 2.

1862 KAR 158 viii 40. $2 \check{s} u-m e-r u 41.3 a k-k a-d u-u_{2}$ 42. šu-nig̃in $5 q u_{2}-u r-d u$; vgl. Groneberg 2003, 63 .
} 
Die zweite Tafel HS 1884 mit Hymnen an dieselbe Göttin enthält bemerkenswerte Hinweise hinsichtlich des Aufführungskontextes. Insgesamt erhalten ist der Text zweier Hymnen, wobei die erste mit einer leider nicht mehr erhaltenen Unterschrift versehen war: „. . .-Lied der Bēl]et-ilī‘“ ${ }^{1863}$ Diese setzt in Kolumne ii der Vorderseite zunächst mit einem generellen Aufruf des gala sowie des Schreibers ein, möglicherweise als die zwei Zuständigen für Vortrag und Verschriftlichung ihrer Gebete. ${ }^{1864}$ Betende sind neben dem später genannten König vor allem Frauen: „Jegliche Bitte derer(Frauen), die rufen, erhört sie...“. ${ }^{1865}$ Es folgt eine Einführungsszene des Königs vor die Göttin durch seinen persönlichen Gott, der als Stier (rimu) ausgezeichnet wird. Der weitere Text der Hymne preist die Muttergöttin als Hüterin der Quellwasser in Verbindung zu den ebenfalls Wasser und Regen führenden Gottheiten An und Adad. Zentrales Thema ist die Sicherung der Fruchtbarkeit für den erwählten König und seine Länder.

Der zweite auf der Rückseite beginnende Hymnus weist in seinem zweizeiligen Aufbau das auch für sumerische Hymnen typische Muster der 'ornamentalen Wiederholung' für Epitheta und Gottesnamen auf. ${ }^{1866}$ Eingeleitet wird die Hymne über den voluntativen Aufruf tanittaš luzmur ,Ihren Lobpreis will ich singen!“. Thema der Hymne ist zwar auch hier Fruchtbarkeit, doch in diesem Fall bezogen auf den Akt der Schöpfung und Geburt, in der Mami die Rolle der Hebamme einnimmt. Die Aufeinanderfolge dieser zwei Hymnen könnte daher auch inhaltlich manifestiert sein: Auf den Akt der Befruchtung durch die flieBenden Wasser folgt der Akt der 'Fleischwerdung' und Geburt. Ob sich hinter dieser inhaltlichen Abfolge auch entsprechende rituelle Handlungen verbergen, ist nicht mehr feststellbar. Sicher ist, dass die Hymne unter Beteiligung mehrere Partizipienten vorgetragen wurde, zuallererst der König, dann größere Frauenchöre (Klagefrauen?) und schließlich spezialisiertes priesterliches Personal, genannt wird möglicherweise ein Klagepriester. Die Teilnahme des gala an Festhandlungen zu Fruchtbarkeits- und Erneuerungsriten lässt sich möglicherweise über seine Funktion als Hüter der Grenzübergänge und der Wandlungen begründen. Die Einführung des Königs erinnert an die Inhalte der sumerischsprachigen Širnamgala, die in gleicher Weise die Erhöhung des Herrschers durch Enlil geführt von einer meist weiblichen Gottheit thematisieren. Meines Erachtens könnten die einleitenden Zeilen der ersten Hymne mit Einführung des Königs auch eine konkrete rituelle Aufstellung fordern. Näheres zum Vortragsrahmen und -ort lässt sich aus den Inhalten der Hymnen allerdings nicht mehr rekonstruieren.

\footnotetext{
${ }^{1863}$ Krebernik 2003/04, 12, 16.

${ }^{1864}$ Krebernik 2003/04, 15-18, wobei die Lesung des UŠ.KU unsicher ist.

${ }^{1865}$ Krebernik 2003/04, 15-18: 4' mimma sūpu ša išassiānim 5' tešemmêmi šuāt uwașșar iššu; ibid. auch zur schwierigen Deutung der letzten zwei Worte.

${ }^{1866}$ Wilcke 1975, 214; Krebernik 2003/04, 12.
} 


\subsubsection{Königshymnen}

Altbabylonische Hymnen, die sich ausschließlich einem König widmen, sind meist als Bilinguen gehalten. ${ }^{1867}$ Das Akkadische ist hierbei meist direkte Übersetzung des Sumerischen, wobei für einige Hymnen Varianten auftreten oder eine vom Akkadischen ausgerichtete Form der Komposition festgestellt werden können. Die Königshymnen Samsuiluna G und Samsuiluna H, beide unbekannter Herkunft, ${ }^{1868}$ sind beispielsweise zwar zweisprachig verfasst, an zahlreichen Stellen ist das Akkadische allerdings keine direkte Übersetzung des Sumerischen. Auch das verwendete Sumerisch weist ungewöhnliche Eigentümlichkeiten auf. ${ }^{1869}$ Die Hymne Samsuiluna $H$ schließt mit einer Preisformel an den König, die sumerisch gehalten ist: „Oh Samsuiluna, süß ist dein Preis ${ }^{\text {‘1870 }}$ und ist damit den sumerischsprachigen Hymnen angelehnt. Angesichts der einleitenden Verse bildete den Anlass der Komposition eine Opferhandlung des Königs zu seinem 'Eintreten' in das Ekur. ${ }^{1871}$

Rein akkadische Hymnen sind die altbabylonisch überlieferte Dichtung Sargon der Löwe aus Nippur ${ }^{1872}$ sowie der Prolog des Gesetzeskodex des Hammurabi. Keine dieser Preishymnen an einen König weist Unterschriften oder Rubriken auf, wie es bei den entsprechenden sumerischen Königshymnen der Fall ist. Die Anlässe zur Komposition der Hymnen sind unterschiedlich und stehen mit Taten des Königs und seinem Gedenken in Verbindung.

Auch die erst altbabylonisch verfassten akkadischen Heldenerzählungen um die Akkad-zeitlichen Könige Sargon und Naram-Suen sowie die sumerischsprachigen Selbstlobhymnen der Könige der Ur III- und Isin-Dynastien waren dem Gedächtnis früherer Könige und ihrer Heldentaten gewidmet und wurden als Stelen und Statueninschriften gehalten. ${ }^{1873}$ Solche Berichte über frühere Könige und Herrscher wurden auf Tontafeln oder Stelen niedergeschrieben, um anschließend von nar-Musikern öffentlich vorgetragen zu werden, die so für ihre Verbreitung im ganzen Lande sorgten. ${ }^{1874}$

${ }^{1867}$ Laut Katalog bei Wasserman 2003, 187-224 sind es für Babylonien Nr. 182 Hymne an IddinDagan (UET 6/1, 84); Nr. 118 an Hammurabi (Sjöberg 1974-75, 161); Nr. 61 an Hammurabi (CT 21, 40-42 bei Wasserman 1992); Nr. 180 ein Selbstpreis des Hammurabi (UET 1, 156 // VS 24, 41 bei Sjöberg 1961); Nr. 120 an einen unbekannten König? (PBS 1/1, 11).

${ }^{1868}$ Bearbeitet bei Alster/Walker 1989.

${ }^{1869}$ Alster/Walker 1989, 11, 14-18.

${ }^{1870}$ Samsuiluna $H$ 19. [Sa]-am-su-i-lu-na $\mathrm{za}_{3}$-am-zu dug $\mathrm{g}_{3}$-ga mit $\mathrm{za}_{3}$-am-zu hier für $\mathrm{za}_{3}$ $\mathrm{mi}_{2}$-zu; Alster/Walker 1989, 17.

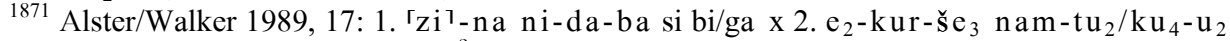
„,...Opfer...; Eintreten zum Ekur?“.

1872 Westenholz 1997, 94-101, 387.

${ }^{1873}$ Ludwig 1990, 71-74 und Westenholz 1997, 16-24; s. a. für Mari Charpin 2006, 153-154, wo es sich allerdings um Entwürfe für Steleninschriften handelt.

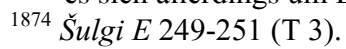


Auch die zweisprachige Königshymne des Hammurabi CT 21, 40-42 ist dementsprechend als Statueninschrift erhalten und wird von Wasserman mit einem historischen Ereignis in Verbindung gebracht, und zwar mit dem Sieg des Hammurabi über Rīm-Sîn von Larsa. ${ }^{1875}$

\subsection{Liebeslyrik}

Das Thema Liebe und Liebeswerbung, ob zwischen zwei Göttern, zwischen Gottheit und König oder auch zwischen zwei unbekannten Personen, ist in den akkadischsprachigen hymnischen Kompositionen häufig anzutreffen. Eine zentrale Rolle nehmen hier das Götterpaar Dumuzi und Ištar ein, in Verbindung zu einem König häufig auch Nanaja.

\subsubsection{Ein Liebeslied auf Ištar und Dumuzi}

Das einzige bislang vollständig überlieferte Dumuzi-Ištar-Lied in akkadischer Sprache datiert in die mittelbabylonische Zeit und trägt seiner Unterschrift zufolge den Titel „Den mutigen Hirten will ich besingen!“ (uršānam rē'â azammur). ${ }^{1876}$ Inhaltlich ist dieses Lied über 39 Zeilen den bekannten sumerischsprachigen Dumuzi-Inana-Liedern der Gattungen Balbale und Kung̃ar angelehnt. ${ }^{1877}$ Auch der mehrfache Wechsel von der Rede der Göttin zur dritten Person erinnert an den gängigen Sprecherwechsel sumerischer Liebeslieder.

Der Titel des Liedes wird im mittelassyrischen Katalog KAR 158 aufgeführt, wo er zur Serie mit Namen „Oh Jüngling, der mich liebt“ (māruma rā'imni) gezählt wird. ${ }^{1878}$ Derselben Serie werden dort drei weitere Liedtitel zugeordnet, die alle ihrer Formulierung nach als Liebeslieder dem Kontext des Hirtentums zugeordnet sind. ${ }^{1879}$ Da diese Titel in der Zusammenzählung des Katalogs als 'Lieder', akkadisch zamāru(m), gekennzeichnet werden, ist sicher davon auszugehen, dass sie auch gesungenen wurden. Der Text ist insgesamt wie andere akkadische Hymnen nach Halbversen unterteilt. Gesangspraktische Anweisungen sind nicht enthalten, weshalb auch zur vokalen Darbietungsform, außer einem möglichen Schwerpunkt zur Versmitte, nichts feststellbar ist.

Im Kolophon ist der Tafelhalter mit Namen Taqī̌sum, Sohn des MemeEnlile angegeben und als Aufseher oder Vorsteher (ugula) des Ištar-Tempels ausgewiesen. ${ }^{1880}$ Auch die verwendete Schriftform weist der Komposition einen

\footnotetext{
${ }^{1875}$ Wasserman 1992, 17.

${ }^{1876}$ Tafel BM 47507 publiziert bei Black 1983.

${ }^{1877}$ Black 1983, 25.

1878 KAR 158 i 7.

1879 Black 1983, 28; anders Edzard/Röllig 1987-90, 66 unter 'Kultische Liebeslyrik' .

${ }^{1880}$ Black 1983, 31
} 
offiziellen Kontext $\mathrm{zu}$, weshalb das Lied wohl weniger im volkstümlichen Umfeld als vielmehr in den Königskult zu verorten ist.

\subsection{2 irātu(m) 'Brust'-Gesänge}

Eine eigenständige Gruppe von Liebesliedern, in denen die Beziehung der Göttin Ištar zu einem auch namentlich genannten König thematisiert wird, bildet die Gattung der so genannten 'Brust'(-Gesänge), akkadisch irtu(m). ${ }^{1881}$ Die bruchstückhafte Sammeltafel Genf 16056 unbekannter Herkunft enthält nach Angabe des Kolophons insgesamt vier Vertreter dieser Gattung, von denen jedoch aufgrund des schlechten Erhaltungszustands kein einziges vollständig erhalten ist. ${ }^{1882}$ Zwar ist die genaue Länge der Lieder nicht mehr feststellbar, dennoch kann aus der Größe der Tafel geschlossen werden, dass es kürzere Lieder von maximal 30 Zeilen sind. Das erste der Lieder wird über durchgezogene Linien in fünfzeilige Strophen unterteilt. ${ }^{1883}$ Am Ende des vierten Liedes findet sich die Angabe „sein g̃išgig̃al“" ${ }^{1884}$ wobei hier allerdings unklar bleibt, welche und wie viele Verse hier den 'Gegengesang' bilden sollen. Möglicherweise war eine entsprechende Angabe auch unter allen vorhergehenden Liedern notiert. Nur beim letzten ist eine Widmung an Ammiditana enthalten. ${ }^{1885}$ Im Kolophon der Sammeltafel ist der Serienname angegeben, dem diese Lieder angehören „Serie: Wohin ist mein Geliebter, er ist kostbar!“ (ê̌s rāmī šūqur), der gleichzeitig den Titel des ersten Liedes bildet. ${ }^{1886} \mathrm{~B}$. Groneberg rekonstruiert eine nordbabylonische Herkunft der Tafel, die ihrer Ansicht nach möglicherweise in Kiš verfasst wurde. ${ }^{1887}$

Der Gattungsname $\operatorname{irtu}(\mathrm{m})$ ist weiterhin in zwei Liederkatalogen belegt. Der erste dieser Belege entstammt der bruchstückhaften Tafel BM 59484 aus Sippar, auf dem die Titel von insgesamt sechs Liedern, darunter fünf 'Brust'(Gesänge) verzeichnet sind. ${ }^{1888}$ I. L. Finkel datiert die Tafel in die Kassitenzeit. Die Lieder selbst stammen aus spätaltbabylonischer Zeit, da ein Titel des dritten Liedes den Königsnamen Ammișaduqa enthält. Auch alle anderen erhaltenen Liedtitel bestätigen den inhaltlichen Tenor dieser Gattung, die der Liebesbeziehung zwischen einer Göttin und dem König gewidmet ist. ${ }^{1899}$ Die Rückseite der Tafel enthält zwei abgesetzte Textzeilen, die als mehrum gekennzeichnet sind, der akkadischen Entsprechung zum sumerischen g̃išgig̃al,

\footnotetext{
${ }^{1881}$ Groneberg 1999 und Groneberg 2003, 66-71.

${ }^{1882}$ Publiziert bei Groneberg 1999, 176-181.

${ }^{1883}$ Groneberg 1999, 177-179.

${ }^{1884}$ Genf 16056: Rs vi 14'; Groneberg 1999, 181.

${ }^{1885}$ Groneberg 1999, 180-181.

${ }^{1886}$ Genf 16056: Vs i 1, Rs iv 17'-18'; Groneberg 1999, 177-181.

${ }^{1887}$ Groneberg 1999, 172.

${ }^{1888}$ Finkel 1988, 17-18.

${ }^{1889}$ S. ausführlich Groneberg 2003, 66-69.
} 
dem 'Gegengesang'. ${ }^{1890}$ Möglicherweise bildeten diese zwei Verse den Gegengesang zu allen zuvor aufgelisteten $\operatorname{irtu}(m)$-Liedern. Es folgen wiederum zwei Textzeilen, deren Gattungs- oder Rubrikzuordnung nicht erhalten ist.

Für die Gattung der 'Brust'-Gesänge lässt sich feststellen, dass sie angesichts der Angabe eines Gegengesangs von mehreren Parteien, bestehend aus einem Solisten und einem Chor oder auch aus zwei und mehr Chören, vorgetragen wurden.

Von größerer Aussagekraft hinsichtlich ihrer musikalischen Aufführungspraxis sind weiterhin Eintragungen im Liederkatalog KAR 158. Hier werden die 'Brust'-Gesänge nach verschiedenen Skalen unterteilt:: ${ }^{1891}$

T 99: KAR 158 viii $45-52$

\begin{tabular}{|c|c|c|}
\hline 45. & 23 & irātu(gaba-me š) ša e-šer 3 -te akkadi \\
\hline 46. & 17 & irātu ša ki-it-me \\
\hline 47. & 24 & irātu ša eb-bu-bi \\
\hline$[\ldots]$ & 4 & irātu ša pi-i-te \\
\hline 49. & $\mathrm{x}+1$ & irātu ša ni-id qablim (murub $\left.{ }_{4}\right)$ \\
\hline 50. & {$[\ldots]$} & irātu ša ni-iš tuh-ri ${ }^{1892}$ \\
\hline 1. & {$[\ldots]$} & irātu ša qabli-te \\
\hline 2. & {$[\ldots]$} & $a k-k a-d]$ \\
\hline
\end{tabular}

Unglücklicherweise sind die Titel der ursprünglich in Kolumne vii enthaltenen irātu(m)-Lieder nicht mehr erhalten. Bemerkenswert an ihrer Zusammenzählung in der hier zitierten Kolumne viii ist vor allem die Tatsache, dass sie in allen sieben bislang für den Alten Orient identifizierten Tonskalen intoniert wurden ${ }^{1893}$ Ganz ungeachtet, ob es neben diesen Skalen noch andere Tonsysteme gab, so wurden diese Lieder offenbar ausschließlich in einem heptatonischen und diatonischen Tonraum vorgetragen. Es scheint außerdem, dass ihr inhaltlicher Ausdruck an keine spezifische Skala oder Modus gebunden war und damit in unterschiedlichen musikalischen Stimmungen dargeboten wurde. Die erhaltenen Zahlenangaben zeigen allerdings eine Bevorzugung von $i s ̌ a r t u(m)$ und ebbübu(m), die in ihrer Tonabfolge den Kirchentonarten Ionisch und Dorisch entsprechen. Angaben zur Tonalität von Liedern sind sonst nur noch im selben Liederkatalog KAR 158 für die bisher unbekannte akkadische Gattung šitru vermerkt ${ }^{1894}$ sowie in den Kolophonen der in etwa zeitgleichen hurritischen Lieder aus Ugarit. ${ }^{1895}$ Die šitru wurden lediglich in den zwei Ska-

\footnotetext{
${ }^{1890}$ S. Kapitel 14.1.4.

${ }^{1891} \mathrm{Zu}$ den Liedtiteln und ihre Einordnung s. Groneberg 2003, 66-69.

${ }^{1892}$ Neue Lesung für gaba nach UET 6/3, 899 s. Mirelman/Krispijn 2009.

${ }^{1893} \mathrm{Zu}$ den diatonischen heptatonischen Skalen s. zuletzt Krispijn 2002, 465-479.

${ }^{1894}$ KAR 158 viii $14-15$.

${ }^{1895}$ Ugaritica V 462-496.
} 
len ebbūbum und pìtum gespielt oder gesungen. Es sind die zwei einzigen diatonischen heptatonischen Skalen im System, die mit einem ganzen gefolgt von einem halben Tonschritt einsetzen. Hierüber definiert sich ihr gemeinsamer musikalischer Charakter. ebbübum und pitum entsprechen den Kirchentonarten Dorisch und Äolisch. Bei den hurritischen Liedern wird hingegen eine Bevorzugung der Skala nìd qabli beobachtet, was dem Phrygischen entspricht. ${ }^{1896}$

irātu $(m)$ sind mit B. Groneberg eine genuin akkadischsprachige Liedform, die offenbar erstmals unter König Ammiditana verschriftlicht wurde. ${ }^{1897}$ Abgesehen von ihrer Vortragsweise, wonach Haupt- und Gegengesang unterschieden werden, könnte auch ihre Tonalität, die sich auf die sieben Skalen der babylonischen Musiktheorie beschränkt, auf eine ursprünglich akkadische, besser babylonische Musiktradition zurückzuführen sein. Das System der sieben Tonskalen, die jeweils nach einem Saitenpaar des Instruments ${ }^{\tilde{g} i \check{s}} \mathrm{za}_{3}-\mathrm{mi}_{2}$ benannt sind, ist frühestens seit Beginn der altbabylonischen Zeit belegt. ${ }^{1898}$ Möglicherweise wurden auch die $\operatorname{irtätu}(m)$ auf einem solchen Saiteninstrument begleitet.

Andererseits kann über den Gattungsnamen $\operatorname{irtu}(m)$ „Brust“ ein Bezug zu Rohrinstrumenten nachvollzogen werden. Insbesondere in der jüngeren Literatur wird diese Verbindung vielfach verbildlicht, so in der Bilingue ASKT S. 122 (= OECT 6 pl. 19): 10. „In seiner Brust, die wie eine Flöte Klagen 'seufzt'“" ${ }^{1899}$ Der Kontext dieser Textpassage ist der einer Klage. Dieselbe Verbindung 'Brust' - 'Flöte' findet sich beispielsweise auch in Ludlul: „Er macht seine Brust wohltuend, wie eine Flöte lässt er sie erklingen“. ${ }^{1900}$ Das hier verwendete Wort malīlu(m) „Rohr, Flöte“ konnotiert gleichzeitig die Zweitbedeutung „Atemröhre“, wofür an anderer Stelle auch ebbūbu(m) stehen kann. ${ }^{1901}$ Rohrinstrumente sind dem Hirtengott Dumuzi zugeordnet und könnten schon aus diesem Grund im Zusammenhang der Liebeswerbung um die Göttin Ištar bei den $\operatorname{irātu}(m)$ eine Rolle spielen. Ob irtu(m) als Name der Gattung auf die vokale Vortragsweise, eine bestimmte Singart ${ }^{1902}$ oder die instrumentale Begleitung Bezug nimmt, muss allerdings vorerst unklar bleiben.

\footnotetext{
${ }^{1896}$ Als na-at/ni-it kib-li in h. 6, 7, 12, 26 und y; Ugaritica V 463-479; zum Hymnus 6 s. zuletzt Krispijn 2002, 472-475.

${ }^{1897}$ Groneberg 1999, 175

1898 S. zuletzt Krispijn 2002.

${ }^{1899}$ [gaba-a]-ni gi-gid 2 i-lu ze ze $_{2}$-b-bi-da-gin ${ }_{7} \|$ ina irtišu ša kìma malīli qubì ihallalu. Zum Wort halālu II s. AHw 309b „pfeifen; plätschern“ beim Klang von Flöten; s. a. LKA 70 i 18 (TuL S. 50) gi-gid ${ }_{2}$ ha-li-lu ša rigimšu tâabu; auch mit malīlu ,eine Flöte“ verwendet, dem Gurren von Tauben und dem Plätschern von Wasser; CAD M/1 164b.

${ }^{1900}$ Ludlul q 31. uštibma irātuša malīiliš uhta[llil] ša; Lambert 1960, 54:31, 298.

${ }^{1901}$ CAD E 137b embūbu sub 2; AHw $180 \mathrm{~b}$ ebbübu $(m)$ sub 3.

1902 Der Gedanke liegt nahe, an eine unserer heutigen Unterscheidung entsprechenden Trennung nach 'Brust'- und 'Kopfstimme' zu denken, allerdings sind den altorientalischen Quellen
} 


\subsubsection{Liebesdialoge}

Zur kultischen Liebeslyrik werden zunächst die zwei relativ kurzen und schwer verständlichen Dialoge YOS 11, 24 mit Fürbitte für König Rīm-Sîn sowie Nanaja und Muati (MIO 12, 52f.) mit einer Fürbitte für den König Abi'ěšuh gezählt. ${ }^{1903}$ In beiden Kompositionen wird die Liebeswerbung zwischen zwei Kontrahenten, Göttern oder Menschen thematisiert, was allerdings im Falle des Rìm-Sîn-Liebesdialogs nicht eindeutig zu unterscheiden ist. Der schlechte Erhaltungszustand des Dialogs Nanaja und Muati aus Babylon erschwert selbst die eindeutige Bestimmung von Vorder- und Rückseite der Tafel. ${ }^{1904}$ Der Text enthält sowohl beschreibende Abschnitte wie auch die jeweiligen Reden des göttlichen Liebespaares Nanaja und Muati. Die Aufforderung an die Göttin, dem König Abi'ěšuh ein langes Leben zu bestimmen, ähnelt den abschließenden Fürbitten in den Hymnen des Samsuiluna und des Ammiditana. ${ }^{1905}$ Dementsprechend könnte diese Fürbitte als g̃išgi g̃al „Gegengesang“ fungiert haben. In seiner sprachlichen Gestaltung lehnt sich der Dialog an die sumerische Hymnendichtung mit ihren Versrepetitionen an. ${ }^{1906}$

Weitaus schwieriger ist die Identifizierung der Sprecher des möglicherweise aus Larsa stammenden Rīm-Sîn-Dialogs, was zwangsweise zu unterschiedlichen Interpretationen führt. Mit Hecker meine ich, dass die Person der Liebenden anonym bleibt, wie es auch für den Faithful Lover (Der 'Treue Liebhaber') und dem fragmentarischen Liebesdialog aus Kiš (Ki 1063) der Fall ist. ${ }^{1907}$ Gewisse Textabschnitte, die nicht eindeutig als Reden einer der zwei Parteien identifizierbar sind, können mit Foster einem Chor zugewiesen werden. ${ }^{1908}$ Beachtenswert ist die inhaltliche Wende in der zweiten Kolumne, die mit den Worten beginnt: „Ich will inbrünstig flehen für meinen Herren!“ ${ }^{1909}$ Nach einer einzeiligen Rasur nimmt der stark zerstörte Text mit den Aussagen „Sie ist sehr erzürnt...“ und „Du streitest...“1910 einen anderen Tenor an. Der Anfang von Kolumne ii könnte daher als der Beginn einer neuen Komposition, vielleicht einer Individualklage zu identifizieren sein.

hierzu keinerlei Daten zu entnehmen.

${ }^{1903}$ S. Übersetzungen bei Hecker 1989, 741-743, 747-750 und Foster 1993, 96-99.

${ }^{1904}$ Foster 1993, 97 setzt die Fürbitte für Abi'ěšuh an das Ende der Komposition.

${ }^{1905}$ MIO 12, 52f.: 14. šar-rum lu da-ri i+na qa $a_{2}-b e_{2}-e-k i$ A-bi-e-šu- $\left\ulcorner u h\right.$ lu ${ }^{1}$ da-r[i ina qabêki] „Der König möge ewig währen auf deinen Befehl hin; Abi'ěšub möge ewig währen auf deinen Befehl hin!“; s. hier Kapitel 13.1.4.1.

${ }^{1906}$ Groneberg 1999, 190.

${ }^{1907}$ Hecker 1989, 747; Nanaja in Z. 27 wäre dementsprechend Patronin und Fürsprecherin der Liebenden. Zum Liebesdialog aus Kiš s. Westenholz 1987.

${ }^{1908}$ Foster 1993, 98-99.

${ }^{1909}$ YOS 11, 24 Kol. II 1. lu-uš-te-mi-iq šum-ma-an 2. a-na be-li-ia; vgl. Hecker 1989, 749.

${ }^{1910}$ So Hecker 1989, 794. 
Der Liebesdialog der ersten Kolumne galt dem im Text selbst genannten Neujahrsfest, zu dessen Anlass vom König Opferhandlungen (Libationen?) ausgeführt und der göttliche Segen empfangen wurde. Da der Text zahlreiche Verschreibungen aufweist und in der zweiten Kolumne zur Mitte eines Wortes einfach abbricht, könnte es sich um eine Schülertafel handeln.

Hintergrund beider Liebesdialoge des Rīm-Sîn und Abi'ěšuh ist das Wiedererwachen von Liebe und Fruchtbarkeit, wie sie im Zentrum von Neujahrsfest und 'Heiliger Hochzeit' stehen. ${ }^{1911} \mathrm{Ob}$ sie tatsächlich aus diesem Anlass im Verlauf öffentlicher Feste vorgetragen oder gesungen wurden, ist nicht feststellbar.

Mit diesen Kompositionen vergleichbar ist der kurze und nur fragmentarisch erhaltene Liebesdialog Ki $1063 .{ }^{1912}$ Die jeweiligen Parts der zwei anonymen Sprecher werden gleichfalls nicht voneinander unterschieden. Auch handelt der Inhalt zunächst von dem gegenseitigen sexuellen Begehren der zwei Liebenden, was in Kolumne ii auf das sehnsuchtsvolle Erwarten einer Nachricht des fernen Geliebten übergeht. ${ }^{1913}$ In dieser Hinsicht könnte die Dichtung mit den sumerischen wie akkadischen Dumuzi-Inana/Ištar-Liedern zu vergleichen sein, die auch verschiedene Sprecher aufweisen. Gottesnamen oder Königsnamen sind in den wenigen Zeilen dieser Komposition nicht enthalten.

Eine eigenständige literarische Form weist der Liebesdialog mit modernem Titel The Faithful Lover (Der 'Treue Liebhaber') auf, der auf einer einzigen Tafel aus Sippar erhalten ist. ${ }^{1914}$ Im Gegensatz zu den zwei vorherigen Liebesdialogen identifiziert Groneberg diese Dichtung als einen 'spielerischen' Dia$\log$ zwischen zwei anonymen Kontrahenten, einer drängenden und verführenden Frau und dem ablehnenden und sie zurückweisenden Mann. ${ }^{1915}$ Da im Text die Göttinnen Nanaja und Ištar als Fürsprecherinnen der Liebe suchenden Frau auftreten und König Hammurabi in einem Schwurspruch des Mannes genannt wird, kann auch von einem offiziellen Rahmen der Darbietung ausgegangen werden. ${ }^{1916}$ Der Aufbau des Textes in 18 Strophen mit den jeweils

\footnotetext{
${ }^{1911}$ Vgl. YOS 11 S. 28 und Foster 1993, 98.

1912 Publiziert bei Westenholz 1987.

${ }^{1913} \mathrm{Ki}$ 1063:9' šipruk lillikamm[a. . .] 10’ lušmè šulmaka ana[ku...] „Deine Botschaft möge mich erreichen...Ich will von Deinem Wohlbefinden hören; Ich...“; vgl. Westenholz 1987, 422423.

${ }^{1914}$ Von Soden 1950, 151-194; Held 1961, 1-26; Groneberg 2002, 175-182.

1915 Groneberg 2002, 172-173. Die Annahme Wilckes 1985a, 195, es handle sich um einen Ehescheidungstext, ist zu revidieren. Auch ist gegen Wilcke 1985a, 194-195 trotz der vergleichbaren Thematik einer ungleichen Liebe die Isin-Beschwörung eindeutig dem religiösmagischen Kontext zugeordnet und steht wohl eher in der Tradition der altakkadischen Liebesbeschwörung MAD V 8; vgl. Groneberg 2001, 109.

${ }^{1916}$ Groneberg 2002, 173.
} 
abwechselnden Reden von Frau und Mann ist regelmäßig und erinnert an die sumerischen oder auch akkadischen Streitgespräche. ${ }^{1917}$ Die letzte Strophe weist deutlich darauf hin, dass dieses 'Dialogspiel' (mēlulum) dem Preis der Göttin Ištar galt. ${ }^{1918}$ Die letzte noch erhaltene Randnotiz „, $[$ g]ut antwortest Du! “1919 könnte als Vermerk für die archivarische Einordnung des Textes als Dialog gedient haben.

Auch wenn in allen hier besprochenen akkadischen Dialogen keine technischen Angaben zur Darbietungsform enthalten sind, so kann dennoch grundsätzlich angenommen werden, dass sie für den vokalen Vortrag bestimmt waren. Sie sind sicherlich auch in einer szenisch-theatralischen Form zur Aufführung gekommen, möglicherweise in einem offiziellen Kontext, der der Unterhaltung oder Erhöhung des Königs galt. ${ }^{1920}$ Andererseits ist denkbar, dass in Dialogen gehaltene 'Liebesspiele' auch bei kultischen Festen für Ištar oder Nanaja veranstaltet wurden.

\subsection{Klagelieder}

Unter den wenigen Klagen in akkadischer Sprache treten die Gebetsklagen eines Einzelnen an eine Gottheit besonders hervor. Auch wenn teilweise Unterschiede in Sprache, Form und Länge bestehen, so können in diese Gruppe Der leidende Gerechte, die Klage Ištar Baghdad, sowie das Gebet an Anüna zusammengeführt werden. ${ }^{1921}$ Alle drei Klagen sind des Weiteren mit der sumerischen Komposition Ein Mann und sein Gott vergleichbar, die in ihrer Unterschrift als ein Eršaneša gekennzeichnet ist. ${ }^{1922}$ Im Zentrum steht die Klage eines Unbekannten, die er mit Unterstützung seiner Familien- oder Schutzgottheit an eine höhere Gottheit richtet. Während der Name dieser Gottheit in Der leidende Gerechte ungenannt bleibt, ist es in den anderen Kompositionen Ištar bzw. Anūna. ${ }^{1923}$ Lediglich Der leidende Gerechte ist über

${ }^{1917} \mathrm{Zu}$ den akkadischen Streitgesprächen, denen allerdings unsere Dichtung nicht zuzuordnen ist, s. zuletzt Vanstiphout 1990, 276-278.

${ }^{1918}$ So Groneberg 2002, 178 und 182: 28' [ta-]ni-tum me $e_{2}-l u^{?}-l i^{?}$ mu-ut-ta-ni? 29' ma-ha-ar Ǐs$\operatorname{tar}_{2}$, ,[Lobpre] is ist mein? Spielen vor uns, vor Ištar...". Anders SEAL! Die 'Verführungsspiele' einer Frau zählt wohl auch der mB Games Text unter die der Göttin geweihten Frauenspiele auf; s. Kilmer 1991, 11:25. [ ] [ ${ }^{\mathrm{X}} \mathrm{x}{ }^{\top}$ nu-ga-ti e-le-ni-ti ša man-ni „,..., frenzy, enchantress of someone(?)“.

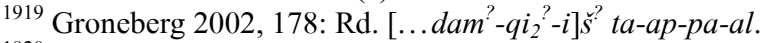

${ }^{1920}$ Groneberg 2002, 172-173.

${ }^{1921}$ Der leidende Gerechte: Lambert 1987; Ištar Baghdad: Groneberg 1997a, 95-120; Streck 2003; Gebet an Anüna: Lambert 1989; auch mit Vergleichen der unterschiedlichen Dichtungen.

1922 Vgl. Klein 2003.

${ }^{1923}$ Lambert 1989, 323-324. 
durchgezogene Linien nach Strophen unterteilt, deren Einteilung jedoch nicht immer inhaltlich nachvollziehbar ist. ${ }^{1924}$ Allen drei Kompositionen ist ein gemeinsames Vokabular eigen, wie lallārum „Klage/Klagender“, inhu/niāhu „Seufzen/Klagen“ oder bikitum „Weinen/Klagen“ und dimtum „Träne“. Über seine Klage erbittet der Leidende die Hilfe der Gottheit, die ihm jeweils am Ende der Komposition zugesprochen wird. Nur in Der leidende Gerechte wird die Erlösung in einer direkten Rede der Gottheit selbst formuliert.

Ähnlich dem sumerischen Ein Mann und sein Gott wird auch in Ištar Baghdad Zeile 5 der Ort der Klage am Tor möglicherweise des Göttertempels verortet. Für die anderen Klagen ist kein eindeutiger Ort des Gebetsvortrags zu erschließen. Auffällig ist außerdem, dass die Klage Ištar Baghdad außer wenigen kurzen Zitaten der Göttin ausschließlich aus der Rede des Leidenden besteht. Im Gebet an Anüna sowie in Der leidende Gerechte werden Betroffener und adressierte Gottheit zuweilen in der dritten Person angesprochen. Die abschließenden zwei Zeilen 68-69 in Der leidende Gerechte mit Bitte um Erlösung könnten daher auch von einer dritten Person gesprochen worden sein, möglicherweise einem vorstehenden Priester.

Es ist anzunehmen, dass der Vortrag dieser Klagegebete in einem rituellen Kontext zur Erlösung von konkretem (in Ištar Baghdad: Fruchtbarkeit) oder allgemeinem Leid auch in apotropäischer Funktion zum Vortrag kamen. Sowohl die Klage Ištar Baghdad als auch das Gebet an Anūna wurden in Nippur aufgefunden, sie könnten konkreten sumerischen Vorbildern angelehnt sein. Der leidende Gerechte entstammt demselben unbekannten Ort möglicherweise auch Archiv, dem auch die Hymne des Ammiditana an Ištar angehörte. ${ }^{1925}$ Bemerkenswert ist folgende Aussage in der letzten Strophe, der abschließenden Rede der Gottheit:

\section{T 100 Der leidende Gerechte 66-67}

„Geöffnet ist für dich das Tor zu Gesundheit und Leben;

In das титти, seiner Mitte sollst du ein- und ausgehen;

mögest du wohlauf sein!“

66 pa-ti-ie-et-ku a-bu-ul šu-ul-mi-im $u_{3}$ ba-la-ti-im

67 mu-um-ma qe $e_{2}-e r-b u-u s ̌ ~ e-r u-u b ~ s ̦ i-i ~ l u ~ s ̌ a-a l-m a-\left\ulcorner a t^{\top}\right.$

Mit dem титти könnte hier das von Ziegler für Mari identifizierte 'Konservatorium' bezeichnet sein, in dem vornehmlich Musiker und Sänger ihrer Kunst nachgingen. ${ }^{1926}$ Sumerisch entspricht es dem ki umun ${ }_{2}$, welches in ŠulgiHymnen neben dem Tafelhaus (edubba'a), dem Zentrum der Schreiber ge-

\footnotetext{
${ }^{1924}$ Vgl. Lambert 1987, 188-189.

${ }^{1925}$ Lambert 1987, 187.

${ }^{1926}$ Ziegler 2007, 77-78.
} 
nannt wird. ${ }^{1927}$ Der am Ende unseres Textes notierte Personenname Kalbānum könnte daher als Schreiber wie auch als Sänger oder Dichter zu identifizieren sein, in jedem Fall ist er einer der Musikkunst gewidmeten Institution zuzuordnen. ${ }^{1928}$

Einem gänzlich anderen Kontext gehören die akkadischsprachigen Klagen der Gattung amerakūtum „Kunst der Klagefrau“ an, die grundsätzlich der Göttin Bēlet-ilī gewidmet sind. Lediglich ein einziger Vertreter dieser Gattung, die Stadtklage der Mami von Keš, ist in zwei Textabschriften vollständig erhalten. ${ }^{1929}$ In der Schlusszeile von Textvertreter A wird zusammengefasst: „53 (Zeilen). 'Kunst der Klagefrau'“(53 a-me-ra-ku-tum). Insgesamt acht Titel derselben Gattung werden auf einer Inventartafel unbekannter Herkunft notiert, die ursprünglich an einem Korb mit den entsprechenden vollständigen Tafeln befestigt war. ${ }^{1930}$ Die Titel werden wie folgt zusammengefasst:

T 101: BM 85563:10-12 (Shaffer 1993)

„2 Tafeln (DUB) 37 einkolumnige Tafeln der 'Kunst der Klagefrau', der Bēlet-ilìi““

10. 2 dub 37 im-gid ${ }_{2}$-da 11. ama-er ${ }_{2}$-ra-ku-tim 12. ša dig̃ir-mah

Der dem sumerischen ama-er ${ }_{2}$-ra „Klagefrau“ entlehnte Gattungsname weist unmissverständlich auf diese wohl auch professionell ausgeübte Tätigkeit hin. Andererseits liegt mit der Bezeichnung dieser Klagen an die Göttin Dig̃irmah bzw. Aruru auch ein Verweis auf ihre eigene Rolle als 'Klagefrau' vor, mit der sie in einem sumerischsprachigen Bala g tituliert wird. ${ }^{1931}$

Unter den Liedtiteln des Katalogs sind zwei in sumerischer Sprache. Lediglich der erste Titel scheint auf zwei mehrkolumnigen Tafeln gehalten zu sein, während alle übrigen auf insgesamt 37 einkolumnigen Tafeln (im-gid ${ }_{2}$-da) niedergeschrieben waren. Aus den aufgelisteten Titeln lässt sich ersehen, dass diese Gattung vermehrt von Stadt- und Tempelklagen bestimmt war. ${ }^{1932}$

Die Stadtklage der Mami von Keš weist eine lyrische Sprache und zahlreiche Wort- und Versrepetitionen auf. Die einleitenden vier- oder fünffach wiederholten Verse bestimmen die Thematik des Textes: „Das zerstreute [Haus], das

\footnotetext{
${ }^{1927}$ Pruzsinszky 2009 und Michalowski 2009.

${ }^{1928}$ Nach Lambert 1987, 187 wurde der Name nachträglich abgerieben.

${ }^{1929}$ An dieser Stelle möchte ich Frau Prof. Dr. Groneberg danken, die mir ihre privaten Unterlagen zur Mami-Klage freundlicherweise zur Verfügung stellte.

1930 Shaffer 1993, 209-210.

${ }^{1931}$ Scheil 1920, 46:Rs 15.

1932 Beispielsweise $u$ 'u bìssa „Wehe; ihr Tempel!“, dulli bìtim „Mühsal des Tempels“ und aštâl àlam „Ich befragte die Stadt“; Shaffer 1993, 209:3.6-7.
} 
vergessene Heiligtum“ ([bìtam] suppūham parakkam mašâ). ${ }^{1933}$ Inhaltlich klingt die Dichtung an die sumerischsprachigen Stadtklagen und Balag̃-Lieder an. ${ }^{1934}$ Hauptthema ist die Zerstörung und das Verlassen einer Stadt, wobei die betroffene Gottheit, belegt ist bisher nur Bēlet-ilī, in der ersten Person ihre Klage vorträgt.

Der Gattungsname amerakūtum 'Kunst der Klagefrau' weist darauf hin, dass dieser Berufsgruppe ein eigenes Liedrepertoire zugeordnet ist. Diese Feststellung ist schließlich auch für das Berufsbild des gala von besonderer Bedeutung. Die Abgrenzung des jeweiligen Repertoires könnte über die Sprache und den Kontext bestimmt worden sein. Die Lieder des gala weisen vornehmlich apotropäische und Übel abweisende Funktionen auf. Für welche rituellen Zwecke das Liedrepertoire der Klagefrau eingesetzt wurde, ist zurzeit nicht feststellbar.

${ }^{1933}$ Die Zeilen Text A $35^{\prime}-36^{\prime}$ und 45' enthalten zudem Aussagen zum Spiel von Musikinstrumenten.

${ }^{1934}$ Vgl. Metzler 2002, 863. 


\section{Angaben zur Vortragspraxis}

Termini, die sich auf die musikalische Darbietung beziehen, sind uns in unterschiedlichsten Texten überliefert und können nach ihrer jeweiligen Belegsituation und Form in verschiedene Gruppen unterteilt werden. ${ }^{1935}$ Die wichtigste Gruppe an musiktechnischen Termini bilden die Liedrubriken, die überwiegend in den vorzutragenden Liedern selbst belegt sind. Eine zweite Gruppe bilden die aus musiktheoretischen Texten sowie sekundärer Literatur bekannten termini technici, die die Intonation oder Stimmung des Gesangs oder eines Instruments anzeigen. Eine dritte Form schriftlich fixierter musikpraktischer Anweisungen, die von den technischen Termini sowie Liedrubriken zu unterscheiden sind, liegt in Form von Glossen vor. Mit Ausnahme eines einzigen sumerischen Liedes aus altbabylonischer Zeit, sind die möglicherweise als Melismen zu interpretierenden Glossen bisher ausschließlich aus Balag̃ Liedern des ersten Jahrtausends bekannt. ${ }^{1936}$

In der folgenden Darstellung werden vorwiegend bisherige Erkenntnisse zu den einzelnen Termini zusammengeführt, die vereinzelt um neue Deutungsversuche ergänzt werden, um so die unterschiedlichen Formen vortragspraktischer 'Notierungen' der altbabylonischen vornehmlich der im Kult vorgetragenen Lieder vorzustellen.

\subsection{Liedrubriken}

Eine vollständige Liste aller aus sumerischen literarischen Texten bekannten Rubriknamen findet sich in der altbabylonischen lexikalischen Liste Proto- $\mathrm{Lu}_{2}$ :

T 102: Proto- $\mathrm{Lu}_{2}$ 606-612 (MSL 12, 54-55)

606. $\quad$ sa-gid $2-d a$

607. sa-g̃ar

608. $\quad \check{\text { sa }}{ }_{3}-\mathrm{b} a-T U K U$

609 bar-sud

610. $\mathrm{u}_{18}-\mathrm{ru}_{12}$

611. $\left[\mathrm{u}_{18}{ }^{?}\right]-\mathrm{ru}_{12}$

612. $\tilde{\mathrm{g} i \mathrm{~s}}-\mathrm{g} \mathrm{i}_{4}-\tilde{\mathrm{g} a l_{2}}$

${ }^{1935}$ Vgl. allgemein auch Kilmer 1993-97, 470-472.

${ }^{1936}$ Hierzu jetzt Mirelman 2009. 
Grundsätzlich kann davon ausgegangen werden, dass die Überlieferung dieser Termini vollständig ist.

\subsection{1 sagida und sa gara}

Die zwei Ausdrücke sa-gid ${ }_{2}$-da „lange(r)/gezogene(r) Saite (Modus)“ und sa-g̃ar-ra „gesetzte(r) Saite (Modus)" sind in der Regel parallel verwendete Rubriknamen, die die zwei Hauptteile der Gattungen Tigi und Adab kennzeichnen. Darüberhinaus sind sie in Vertretern der Gattung Kung̃ar sowie in wenigen ihrer Gattung nach nicht eindeutig identifizierbaren Kultliedern bezeugt. ${ }^{1937}$ Beide Rubriken zeigen damit eine Aufführungspraxis an, die sich auf den Vortrag von Tigi, Adab und Kung̃ar konzentriert. ${ }^{1938}$ Eine interessante Ausnahme bildet die von Kramer publizierte Ekur Hymne, die zwar keine Unterschrift enthält, den Text allerdings jeweils nach einer sagida, einer sag̃ara- und einer kirugu-Einheit aufteilt. ${ }^{1939}$

Eine Entlehnung der sumerischen Namen ins Akkadische als sagarrûm und sagiddûm ist lediglich lexikalisch in der altbabylonischen Liste Nig̃g̃a attestiert. $^{1940}$

Die mit sagida und sag̃ara gekennzeichneten Liedteile weisen in der Regel eine gleichmäßige und symmetrische Form auf mit einer Länge von bis zu vier Strophen, die jeweils wiederum aus vier $(2+2)$ bis zu zwölf $(6+6)$ Zeilen gebildet sind. Diese regelmäßige Struktur ist häufiger beim sag̃ara anzutreffen, worin auch der wesentliche Unterschied zwischen beiden Rubriken besteht. ${ }^{1941}$ Das sagida kann schließlich noch in weitere Abschnitte unterteilt sein, an Rubriken sind hier ausschließlich bar-sud und ša ${ }_{3}$-ba-TUKU bezeugt. ${ }^{1942}$

${ }^{1937}$ Das Kung̃ar DI R ist in Zeile 19' des Fragments C nach einer durchgezogenen Linie bis auf das Zeichen šir $_{3}$ abgebrochen; Sefati 1998, 238-239, pl. XI CBS 8534 Rs. In Version A desselben Liedes ist in der Parallelzeile 29 anstelle des šir ${ }_{3}$ ein sagida angegeben; Sefati 1998, 237. Das šir 3 von Fragment C ist möglicherweise eine Schreibvariante; s. a. DI X ein Teilfragment TMH NF 4, 89 mit einem sagida; Sefati 2005, 278-280:19'.

${ }^{1938}$ Išme-Dagan C endet mit der Angabe eines sa-gid ${ }_{2}$-da und könnte daher erster Abschnitt eines Tigi oder Adab sein. Die Hymne ist auf der Sammeltafel Ni 2485 zusammen mit Išme-Dagan K, einem Liebeslied, erhalten und wird von Römer 1988, 26 einerseits dem Schulbetrieb andererseits einer in Nippur veranstalteten Heiligen Hochzeit des Königs zugeordnet.

${ }^{1939}$ Kramer 1957, 95-102. Zur ungewöhnlichen Schreibweise des Rubriknamens kirugu s. hier Kapitel 14.1.5.

${ }^{1940}$ Ergänzt in MSL 13, 123:294-995; AHw 1002 und CAD S 22 und 24.

${ }^{1941}$ Nintu A; Gudea B; Inana E; Nergal C; DI H; Š-Suen D; Ur-Namma B; Nanna I; Ibbi-Suen $A$; Ninurta $D(?)$.

1942 Vgl. Wilcke 1975, 254. 
In Anbetracht der Namensbildung von sagida und sag̃ara, in denen das Element s a „Saite“ oder „Modus“ enthalten ist, können beide Rubriken als Anweisungen zur instrumentalen Aufführungspraxis gedeutet werden. Eine solche Deutung legt auch die folgende Angabe in der Hymne Ninurta D nahe, die eine zusätzliche Notiz zum sag̃ara angibt:

\section{T 103: Ninurta D 33}

„Es ist das sag̃ara. Mit der Hand [ist] das Spielen.“

33. sa-gar-ra-am 3 šu-ta e-ne-di-[dam]

Sumerisch e-ne-dug 4 /di meint im Allgemeinen „Spiel(en)“ oder „Tanz“ und ist sonst nicht mit Musikinstrumenten bezeugt. ${ }^{1943}$ Die hier von Wilcke teilweise ergänzte Anweisung verweist offenbar auf eine besondere Spieltechnik für ein Saiteninstrument, vielleicht an dieser Stelle die Hand anstelle des Plektrums(?) zu verwenden. ${ }^{1944}$

Nach seiner wörtlichen Bedeutung könnte sich sagida „lange/lang gemachte Saite“ auf das 'Anspannen' und also 'Höherstimmen' einer Saite, während über das sag̃ara „niedergelegte/hingesetzte Seite“ das 'Entspannen' markiert wird, also der Liedabschnitt von Tigi und Adab-Liedern, an dem ein 'Niederstimmen' der Saite vollzogen wird. ${ }^{1945}$ Andererseits kann das Namenselement sa auch ein Saitenpaar, eine Tonskala oder einen Modus bezeichnen. Möglich wäre daher auch, dass sich die Rubriken sagida und sag̃ara nicht auf das Stimmen einer einzigen Saite, sondern auf den Wechsel einer Tonskala, einer Modulation über das Umstimmen von Saiten, oder auch lediglich auf einen markanten Wendepunkt innerhalb der Melodieführung beziehen. ${ }^{1946} \mathrm{Ob}$ der Verlauf dieser Lieder sich in dem Sinne rekonstruieren lässt, dass sie mit einem 'Anheben' der Stimmung oder der Melodie ihren Anfang nahmen, um dann mit einem 'Absenken' oder 'Niederlegen' des tonalen Verlaufs zu schließen, lässt sich nicht feststellen, hierzu bietet der Ausdruck sa „Saite“ einen zu großen Übersetzungsspielraum. Ein inhaltlicher, in gewissem Sinne auch praktischer Bezug der zwei Rubriken sagida und sag̃ara liegt zudem zu den musiktechnischen Termini zi-zi ,anheben; addieren; anspannen“ und g $a_{2}-\tilde{g} a_{2}$,nieder-

\footnotetext{
${ }^{1943}$ Vgl. Brisch 2009.

${ }^{1944}$ Nach Wilcke 1975, 260 könnte es auch auf ein begleitendes Schlaginstrument verweisen.

${ }^{1945} \mathrm{Vgl}$. in der nA Bilingue (C: Sm 526; B: SK 79) des auch aB belegten Nergal-Gebets (A: CBS 11344+; s. cdli-Katalog) mit der Gleichsetzung ki sa gar-ra-ba na-an-ni-ku $u_{4}-\mathrm{ku}_{4}-$ $\mathrm{de}_{3} / /$ a-šar pit-nu šak-nu la ter-ru-ub „Wo die Saiten '(fest)gesetzt' werden, dorthin tritt nicht ein!“; Zimmern 1917/18, 116:22; dazu auch Kilmer 1993-97, 471 „(place) where the musical string/mode is played/set"; m. E. aber wohl nicht auf die hier besprochene Rubrik zu beziehen.

${ }^{1946}$ Vgl. Kilmer 1993-97, 471.
} 
setzen/-legen; entspannen“" vor. ${ }^{1947}$ Auch sie werden nach Ausweis des Liedes Dumuzi-Inana $J$ von G̃eštinana der göttlichen Kennerin des Gesangs eingeführt, um das 'Anheben' und 'Senken' des Liedvortrags anzuzeigen. ${ }^{1948}$ Was diese beiden technischen Begriffe tatsächlich meinen, lässt sich ebenfalls nicht eindeutig klären. Von Çerný wird eine Trennung beider Teile oder Techniken hinsichtlich ihrer Singart angesetzt, so unterscheidet er einen psalmodischen von einem melodiösen Gesang. ${ }^{1949}$

Im Wesentlichen gilt, dass über die Rubriken sagida und sag̃ara zwei in ihrer Tonalität, möglicherweise auch in ihrer Melodieentwicklung sich unterscheidende Abschnitte von Tigi, Adab, Kung̃ar und wenigen anderen Liedern angezeigt werden. Diese Ton- oder Melodiestruktur ist damit für diese Liedgattungen kennzeichnend.

\subsection{2 barsud und šaba-TUKU}

Die zwei ebenfalls meist parallel auftretenden Begriffe bar-sud und ša ${ }_{3}$-ba(a-)TUKU sind entweder eigenständige Rubriknamen innerhalb literarischer Kompositionen oder aber, was die Regel ist, Unterteile der sagida-Rubrik in Tigi- und Adab-Liedern. Zur Schreibweise der beiden Rubriknamen sind keine Auffälligkeiten zu beobachten. In den meisten Texten ist diese gleichbleibend mit Ausnahme eines einzigen Belegs in der Hymne Išbi-Erra C Zeile 23, wo šaba-TUKU in syllabischer Schreibung ša-ba-du-ga wiedergegeben wird. Dieser Schreibvariante angelehnt könnte die Lesung des TUKU mit du 12 „(ein Musikinstrument) spielen“ angesetzt werden, das nominalisiert eine lange Form /dug/ annimmt. ${ }^{1950}$ Sowohl die Rubrik barsud als auch das šaba-TUKU werden als Anweisungen zu einer gesanglichen oder instrumentalen Aufführungspraxis gedeutet. ${ }^{1951}$

šaba-TUKU-Einheiten können in Götterliedern unterschiedlichster Gattungen auftreten, in Adab, Tigi, Širnamgala, Širnamursag̃a sowie äußerst selten auch in Klageliedern. ${ }^{1952}$ Außerhalb der Hymnengattungen Tigi und Adab markiert diese Rubrik meist nur einen einzigen Vers des Liedes. Die Rubrik barsud bleibt dementgegen auf Adab- und Tigi-Lieder beschränkt. ${ }^{1953}$

\footnotetext{
1947 S. schon Kilmer 1965, 263 mit Belegen; Kilmer 1992, 105-106.

1948 T 89: Dumuzi-Inana J 30-32.

1949 Çerný 1994, 25-26, was er an der unterschiedlichen Sprachstruktur von sagida und sag̃ara begründet.

${ }^{1950}$ Borger 2003, 211:827, 431:827.

${ }^{1951}$ Wilcke 1975, 260.

1952 CT 36, $43-44$ Klage an Nippur und Isin, Koll. Kramer 1974, 36, 101; von Wilcke 1975, 285 als Balag̃ identifiziert.

${ }^{1953}$ Wilcke $1975,258$.
} 
In den Hymnengattungen Adab und Tigi markieren die Rubriken šabaTUKU und barsud ausschließlich Unterabschnitte des sagida. ${ }^{1954}$ Ein solcher sagida-Abschnitt kann in bis zu drei barsud und zwei šaba-TUKU unterteilt sein, die dann durchgängig nummeriert werden. In den meisten Fällen folgen hier barsud und šaba-TUKU im Wechsel aufeinander, wobei in aller Regel mit dem barsud begonnen wird. Von dieser meist einheitlich durchgehaltenen Anordnung der beiden Rubriken in einem sagida-Teil wird lediglich in zwei Hymnen abgewichen. In Lipit-Eštar $C$ findet sich die Abfolge: barsud I šaba-TUKU - šaba-TUKU - barsud II. Die Hymne Sîn-iqǐšam A lässt wiederum die Rubrik barsud gänzlich aus und weist lediglich zwei nummerierte šaba-TUKU-Einheiten auf. Am Aufbau des Liedtextes selbst oder seiner Länge fallen in diesen beiden Fällen keine Besonderheiten auf, die eine mögliche Begründung dieser Strukturvarianten bieten könnten. Es ist daher anzunehmen, dass sie auf bestimmte musikpraktische Eigenheiten zurückgehen, die für uns über den erhaltenen Keilschrifttext selbst nicht mehr nachvollziehbar sind.

Eine wesentliche Beobachtung, die auch zur Erschließung der musiktechnischen Hintergründe zu diesen zwei Rubriken beitragen könnte, liegt in der Beschränkung des barsud auf Tigi- und Adab-Lieder. Diese bedingt sich durch den engen Bezug des barsud zum sagida, was an insgesamt vier Textbelegen, in denen Schreibvarianten auftreten, deutlich wird. Der erste dieser Belege findet sich in der Hymne Lipit-Eštar $C$, einem Adab an An, wo in Zeile 29 anstelle des erwarteten sagida der Ausdruck sa-bar-gid ${ }_{2}$-da ,äußere? gelängte Saite" steht. Die Hymne Sin-iqī̌am A enthält wiederum in Zeile 33 die Textvariante $\mathrm{sa}^{-} \mathrm{su}_{3}-\mathrm{ud}-\mathrm{da}$ g̃ $\mathrm{iš}-\mathrm{gi}_{4}-\tilde{g} \mathrm{al} \mathrm{l}_{2}$ anstelle des üblichen sagida g̃išgig̃al. Die Schreibung $\mathrm{su}_{3}$-ud für /sud/ „lang/weit sein/machen“ ist hier offensichtlich Synonym für gid ${ }_{2}$,lang sein/machen“. In der Hymne $\breve{S} u$-Sin $F$ steht wieder anstelle des erwarteten sagida in Zeile 37 der Ausdruck [sa] bar-sud-da-am 3 . Eine ähnliche Variante ist in $\check{S} u-i l i \check{s} u A$ enthalten, wo in Zeile 36 lediglich bar-sud anstelle des sagida steht. All diese Varianten der Rubriknamen barsud und sagida sowie ihre teilweise Durchmengung lassen zwischen ihnen einen engen Bezug vermuten. Möglicherweise bezieht sich auch barsud auf die Tonalität des Liedes, auf die Saitenstimmung oder auf einen Moduswechsel. Mit den Namenselementen sud „fern/weit sein/machen“ und $\operatorname{gid}_{2}$ „lang sein“ könnten ähnliche musiktechnische Vorgänge bezeichnet sein. Die Deutung des Namenselements bar in barsud ist dementgegen unsicher. Es kann unterschiedliche Bedeutungen wiedergeben, das „Äußere“, andererseits auch „Inneres/Gemüt“ oder die „Stimmung“. ${ }^{1955}$ C. Wilcke schließt, dass das Namenselement bar das „Äußere“ eines Schlaginstruments bezeichnet, welches dann in Opposition zum ša ${ }_{3}$ „Inneres; Herz“ von ša ${ }_{3}$-ba-

${ }^{1954}$ Ihre Angabe ist allerdings optional; s. Wilcke 1975, 254.

${ }^{1955}$ PSD B 93a bar A und 107a bar B. Ähnlich schon Falkenstein 1950, 92-93. 
$\mathrm{du}_{12}$ (TUKU) stehe. Diesen Rubriknamen gibt er dementsprechend mit ,ist in seiner Mitte gespielt" wieder. ${ }^{1956}$ Angesichts der hier vorgelegten Beobachtungen zur Rubrik barsud, die in einem engen Verhältnis zum sagida steht, könnte ihr auch ein Bezug zur Tonalität oder zum Melodieverlauf und weniger zur Anschlagtechnik eines Musikinstruments zugrunde liegen. Wird das TUKU in ša $\mathrm{a}_{3}$-ba-TUKU als du $\mathrm{u}_{12}$ gelesen, wäre hiermit ein instrumentales Zwischenspiel oder zumindest der Einsatz von Musikinstrumenten wahrscheinlich. ${ }^{1957}$ Ein weiterer Hinweis zur Bedeutung der Rubrik könnte im Fluch über Akkade (T 27) gegeben sein: 200. „und er (gala-mah) ließ in ihrer (der 7 bala g̃) Mitte $\left(\breve{\mathrm{s}} \mathrm{a}_{3}-\mathrm{ba}\right) / \mathrm{ub} /, / \mathrm{meze} / \mathrm{und} / \mathrm{lilis} /$ für ihn (Enlil) wie Iškur erklingen $\left(\mathrm{du}_{12}\right)^{\text {“. }}$. Über diese Rubrik könnte damit nicht nur die Instrumentalpraxis selbst, sondern auch eine bestimmte Aufstellung der begleitenden Instrumente für die Darbietung im Rahmen der Festhandlungen bezeichnet worden sein. Das šaba-TUKU ist zudem unabhängig von den Inhalten der Lieder, es könnte daher ganz gleich in welchem rituellen Kontext einen Textabschnitt markieren, der in einer neuen Aufstellung der Musiker mit ihren Instrumenten ausgeführt wurde.

Ein oppositionelles Begriffspaar sind schließlich beide Rubriken auch aufgrund ihrer literarisch häufigen Gegenüberstellung mit bar als „Äußeres/Mitte/ Leber“ und ša ${ }_{3}$ als „Inneres/Herz“. Im Zusammenhang mit Klagegesängen steht die Besänftigung des inneren Gemüts (bar) und des Herzen ( $\left.\check{s}_{3}\right)$ der Götter im Zentrum des Interesses:

T 104: Enemani ilu ilu (Balag̃) b+60-62

„Sein (Enlils) Herz will ich besänftigen, sein Inner[es will ich kühlen!]

An sein Herz und sein Inneres will ich [(meine) Worte wenden]!“

$$
\begin{aligned}
& \check{s ̆}_{3}-g a-n i \text { ga-am } \\
& \text { šaun ba } a_{3}-g e \text { bar-ra-ni ga-an-šed } \\
& 7
\end{aligned}
$$

Auch Ereškigal klagt in Inanas Gang in die Unterwelt über den Zustand ihres Herzen und ihres inneren Gemüts. ${ }^{1959}$

\footnotetext{
${ }^{1956}$ Wilcke 1975, 260.

${ }^{1957}$ S. Kapitel 12.2.3.

${ }_{1958}$ Cohen 1988, 195, 199.

1959 T 22: Inanas Gang in die Unterwelt 236-239. In gleichem Kontext in den Balag -Liedern Ašergita (Cohen 1988, 718) b+273. a ša ${ }_{3}$-ba-ni $\mathrm{u}_{5}$ [bar-ra-ni] ,Oh ihr Herz; Oh ihr Inneres!"; A Urume ime a+38 (Cohen 1988, 645) und ausgedehnter in Dingir paea a+71-76 (Cohen 1988, 733-734).
} 
Es bleibt zu bedenken, dass einerseits in diesen Textpassagen kein Hinweis auf das Spiel von Musikinstrumenten vorliegt, andererseits auch weder in Tiginoch in Adab-Liedern der Kontext einer Klage enthalten ist. Bekannt ist allerdings, dass Klagegesänge perkussiv begleitet wurden, über das Schlagen der Brust oder aber einer Trommel, die vor die Brust gehalten wurde. Dass hierin auch ein Bezug zum Herzschlag vorliegt, wurde bereits in Kapitel 5.4.1 dargestellt. ${ }^{1960}$ Aufgrund solcher Verbindungen könnte vermutet werden, dass musikpraktische Techniken oder liturgische Handlungen über die Rubriken barsud und šaba-TUKU auch inhaltlich konnotiert waren. Außer dass ihnen wohl ein musikpraktischer Hintergrund zugrunde liegt, eine Anschlagtechnik, vielleicht auch ein standardisiertes Rhythmuspattern, Angaben zur Tonalität oder einfach Hinweise zur Ausftellung der Musizierenden, sind die genauen Funktionen dieser Rubriken nicht ohne sekundäre Belege in Erfahrung zu bringen.

\subsection{3 $\operatorname{uru}(\mathrm{n})$}

Die Liedrubrik uru(n) ist bislang ausschließlich in Adab-Liedern bezeugt, ${ }^{1961}$ wo sich am häufigsten die Schreibung $\mathrm{u}_{18}-\mathrm{ru}_{12}$ findet, ${ }^{1962}$ daneben aber auch $\mathrm{u}_{19}-\mathrm{ru}_{12} /{ }^{\mathrm{uru}} \mathrm{uru}_{16}{ }^{1963}$ und $\mathrm{uru}_{2}{ }^{\mathrm{ru}} .{ }^{1964}$ Angesichts des Belegs $\mathrm{u}_{18}-\mathrm{ru}_{12}$-NI-biim in Š́lgi $G$ Zeile 69 ist ein Wortauslaut mit $/ \mathrm{n} /$ anzunehmen. ${ }^{1965}$ Für das erste Jahrtausend findet sich dementsprechend die Gleichung [uru-EN] $=\left[u_{2}\right]-$ ${ }^{\ulcorner} r u^{\top}$-en-nu in Nabnìtu 32. ${ }^{1966}$ Im zweisprachigen Examenstext $A$ wird in ähnlicher Weise der Terminus über šir ${ }_{3}$-nam-uru-na, akkadisch [šir $\left.{ }_{3}-n a m\right]-u_{2}-r u-$

${ }^{1960} \mathrm{Zu}$ einer positiven Konnotation des Herzschlags s. das Kiš-Liebeslied bei Westenholz 1987, 422:2': [turuk] $\ulcorner l i\urcorner b b i k a$ nigî $[$ tu/ta/ti. . .] ,the beating of your heart is joyful music“".

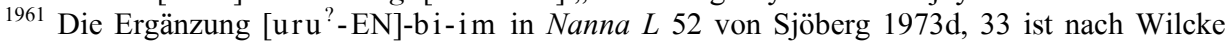
1975, $288 \mathrm{zu}$ [ki-šu]-bi-im zu korrigieren. kišu und kirugu-Rubriken sind in den Gattungen Širnamgala und Širnamšub häufig anzutreffen, dementgegen nie die Rubriken sagida, sag̃ara und uru(n). Zudem weisen die letzten vier Zeilen des Širnamgala Nanna $L$ nicht die für uru(n) übliche Form A.A'.B mit Fürbitte für den König auf. Die einzige mir bekannte Ausnahme ist die Hymne Rìm-Sin B an Haja ohne Gattungsbezeichnung, die eine uru(n)-Rubrik in klassischem A.A'.B aufweist, wobei der letzte Vers dieser Struktur als g̃ išgi g̃al ausgewiesen wird. Da die Hymne zweiteilig aufgebaut ist sowie Gebete für den König integriert, könnte sie als ein Adab zu identifizieren sein, wobei der Liedschreiber in diesem Fall wohl die klassische Form variierte; ausführlicher Brisch 2007, 58-60.

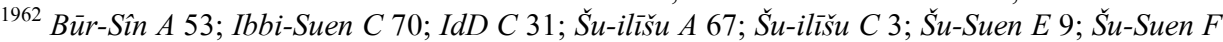
69; Nanna H 14; Ninisina E 13; Ninlil A 33; Ur-Ninurta D 41; Ur-Ninurta E 49; Ur-Ninurta F 17; Ludwig 1990, 32 Anm. 32 und Falkenstein 1957, 71-72.

1963 Išme-Dagan B 65; Lipit-Eštar C 59; Lipit-Eštar D 50.

${ }^{1964}$ Ur-Ninurta C 54.

1965 Klein 1991, 293 Anm. 9, 304:69; s. a. Kilmer 1993-97, 471.

${ }^{1966}$ Nabnìtu 32 iv 6' (MSL 16, 254). 
$n a-k i$ wiedergegeben. ${ }^{1967}$ Über diese Angabe mit šir ${ }_{3}$ wird gleichzeitig der enge Bezug der Rubrik zu einem vokalen Vortrag angezeigt.

Insgesamt ist die Rubrik uru(n) in 17 Adab-Liedern enthalten, wo sie grundsätzlich die letzten drei bis vier Zeilen des Liedtextes markiert. Die Struktur dieser wenigen Zeilen weist inhaltlich meist die Form A.A'.B auf. ${ }^{1968}$ In ihnen wird häufig eine Fürbitte für den König formuliert. ${ }^{1969}$

Die Bedeutung des Wortes bleibt schwer erschließbar. Ob ein Zusammenhang zu uru(n) im literarischen Kontext mit den Bedeutungsfeldern ,gewaltig; hoch hinausragend“, vielleicht auch „Pfeiler“ oder „Säule“ besteht, bleibt unklar. ${ }^{1970}$ Möglich wäre auch eine Verbindung zum präsargonisch und Ur IIIzeitlich belegten Vokalisten $\mathrm{u}_{18} / \mathrm{ulu}_{3}$ ( (ŨS̆GAL)-di. ${ }^{1971}$

Fürbitten für einen König können in zahlreichen literarischen Kompositionen und Liedern enthalten sein, ohne über die Rubrik uru(n) markiert zu sein. Seine Angabe könnte daher einen abschließenden Gesang anzeigen, der an einem bestimmten Kultplatz, möglicherweise einem 'erhabenen' Standort, stattfand. Demgegenüber könnte uru(n) aber auch auf eine betimmte Vortragsform verweisen, oder entsprechend den Rubriken sagida und sag̃ara eine abschließende tonale Wendung markieren, die für Adab-Lieder charakteristisch ist. Wesentlich ist hier vor allem die Feststellung, dass der wichtigste Unterschied zwischen den sonst eng miteinander verwandten Liedgattungen Adab und Tigi eben in dieser letzten Rubrik uru(n) liegt, die inhaltlich der Erhöhung des Königs galt. ${ }^{1972}$

\subsection{4 g̃išgig̃al}

Das bedeutendste Merkmal der Rubrik g̃išgig̃al ist zunächst ihr häufiges Auftreten, denn im Gegensatz zu den übrigen bekannten Rubriken kann sie in nahezu allen hymnischen Liedern sowie Klagen ob in sumerischer oder akkadischer Sprache auch ohne Angabe von Liedunterschriften enthalten sein. Sie ist in Tigi, Adab, Balbale, Širnamšub, Širnamgala, Širnamursag̃a, Uadi, in den sumerischen Stadtklagen, in akkadischen Götterhymnen sowie in Balag̃-Klagen bezeugt. Dort ist sie meist einzelnen Versen oder kurzen Textabschnitten als g̃išgi g̃al-bi(m),,(es) ist sein g̃išgig̃al“ unterschrieben, oder

\footnotetext{
${ }^{1967}$ Examenstext A 24; Ludwig 1990, 107; Sjöberg 1975b, 160; CAD ऽ̌/2 317a.

${ }^{1968}$ Wilcke 1975, 257.

1969 Falkenstein 1957, 71 mit „seine (be)zwingenden (Worte)“; dazu Wilcke 1975, 269 und Ludwig 1990, 32.

${ }^{1970}$ Civil 1989, 55 zu den verschiedenen Bedeutungen; s. a. Ludwig 1990, 107-113 mit „Zentrumspfeiler".

${ }^{1971} \mathrm{Zu}$ den Belegen Attinger 1993, 736-737 auch mit $\mathrm{u}_{3}$-a-di verbunden; die einmalige Schreibung mit uru ${ }_{2}{ }^{\mathrm{ru}}$ in Ur-Ninurta $C 54$ ist aus lautlichen, nicht inaltlichen Gründen gewählt.

1972 Wilcke 1975, 257.
} 
auch mit den Rubriken kirugu, sagida oder sag̃ara verbunden. ${ }^{1973}$ Meist wird der Ausdruck über die Zeichenkombination g̃iš-gi $i_{4}-\tilde{g} a l_{2}$ angegeben, daneben sind auch die Varianten $\tilde{g} i \breve{s}-g i_{5}(\mathrm{KI})$ - $g a l_{2}$ und g̃ $i \breve{s}-g i-\tilde{g} a l_{2}$ attestiert. ${ }^{1974}$

Ein noch ungelöstes Problem bildet die eigentliche Bedeutung dieses Rubriknamens. Grundsätzlich wird der Ausdruck als Verweis auf eine spieltechnische Anweisung verstanden, die auf das begleitende Instrument bezogen wird. In diesem Sinne übersetzt Wilcke den Terminus wörtlich mit „'Holz zurückkehren(?) (oder: zur[?] Erde[?]) lassen'“, und zieht hierfür eine Unterbrechung des Instrumentalspiels in Betracht. ${ }^{1975}$ Die Rubrik könnte also eine Liedpassage kennzeichnen, die ohne instrumentale Begleitung rein vokal zum Vortrag kam. Welche Grundbedeutung dem sumerischen Rubriknamen zugrunde liegt, bleibt fraglich, außer dass etwas 'zurückgekehrt' oder 'zurückgewendet' wird. Das Namenselement g̃iš „Holz“ kann letzten Endes direkt oder auch in übertragenem Sinn auf eine Handlung verweisen, die den Gesang begleitete und für uns aufgrund der fehlenden Kontexte nicht mehr rekonstruierbar ist.

Das sumerische g̃išgig̃al wird lexikalisch dem akkadischen mehrum gleichgesetzt, was mit „Entsprechung“, „Antwort“ oder auch „Gegenüber“ wiedergegeben wird, ${ }^{1976}$ weshalb sich in der bisherigen Forschungsliteratur und den Wörterbüchern der Terminus „Antiphon“ für diese Rubrik auch in vokalpraktischer Hinsicht durchgesetzt hat. ${ }^{1977}$ Beachtenswert ist der altbabylonische Katalog über 'Brust'(-Gesänge), wo zusätzlich zu den Titeln der irtu(m)-Lieder zuletzt mehrere Verszeilen als mehrum zusammengefasst werden. ${ }^{1978}$ mehrum entspricht hier dem sumerischen g̃išgig̃al und zeigt dieselbe Rubrik allerdings in akkadischer Übersetzung an. Akkadisch mehrum ist damit nicht nur rein lexikalische Übersetzung sondern als dem Sumerischen g̃išgig̃al gleichbedeutender und adäquater Rubrikname verwendet.

${ }^{1973}$ Als g̃išgi g̃al sa-gid 2 -da-bi-im/sa-g̃ar-ra-bi-im; bspw. im Adab Nanna H 10 oder Lipit-Eštar D 45 und g̃ $\mathrm{iš}_{-} \mathrm{gi}_{4}$-g̃al ki-ru-gu ${ }_{2}$-da-kam in der Sumer und Ur Klage 114; s. a. das ungewöhnliche $\mathrm{sa} \mathrm{su}_{3}-\mathrm{ud}-\mathrm{da}$ g̃iš-gi $\mathrm{i}_{4}-\mathrm{gal}_{2}$ in Sin-iqǚ̆am A 33; Dupret 1974, $331: 27$.

1974 Als g̃iš-gi-g̃al ${ }_{2}$-bi-im bspw. in der Ur Klage 330, in Ur-Ninurta A 29 oder Abi'ěšuh A

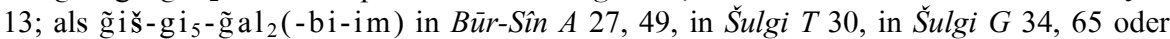
Šlgi $Q 25,49$; s. zu den Belegen ePSD.

1975 Wilcke 1975, 260; ihm angelehnt Ludwig 1990, 30 „,das Wende-Holz vorhanden sein lassen, anlegen?".

${ }^{1976}$ CAD Z 35b lexikalisch auch meher zamāri oder mehrum ša zamāri etwa „Antwort-Gesang“; Wilcke 1975, 260 „Gegenstück zum Gesang“.

1977 AHw 640b sub 3; CAD M/2 54b lex. und sub d); Hartmann 1960, 239; Wilcke 1975, 255.

${ }^{1978}$ Finkel 1988, 17-18:12-14 und hier Kapitel 13.2.2. 
Da das g̃išgig̃al meist eine inhaltliche Zusammenfassung der vorhergehenden Zeilen formuliert, kann diese Rubrik auch als eine Art 'Quintessenz' oder 'Motto' aufgefasst werden. ${ }^{1979}$ Das im g̃išgi g̃al formulierte Motto kann sich sowohl auf den Inhalt des vorhergehenden Abschnitts, bei kürzeren Liedern aber auch auf das Thema der gesamten Komposition beziehen.

Die Rubrik legt den Nachweis vor, dass ein großer Teil der sumerischen und akkadischen Kultlieder durch Vokalensembles bestehend aus mindestens zwei Parteien vorgetragen wurden, ob aus zwei Chören oder auch einem Solosänger und einem Chor. Bemerkenswert sind diesbezüglich zunächst konkrete, auch über Glossen angezeigte Gesangsanweisungen in dem bislang unbearbeiteten sumerischen Dumuzi-Inana-Lied CT 58, $12 .{ }^{1980}$ Zusätzlich zum Text des Liedes werden Vokal- und Silbenreihungen notiert und abschließend über die Rubrik g̃išgig̃al gekennzeichnet. Aus der graphischen Notation dieser Gesangsanweisungen kann eindeutig auf die Darstellung von zwei (oder auch drei) voneinander unabhängigen Melodiefloskeln oder auch 'Stimmen' geschlossen werden. Unklar bleibt dennoch, ob diese verschiedenen 'Stimmen' beim Vortrag zeitlich aufeinander folgten oder gleichzeitig erklangen. Da außerdem jede zweite Vershälfte mit g̃išgig̃al „Gegengesang“ unterschrieben ist, wird deutlich, dass als Gegengesänge nicht nur längere Textabschnitte, sondern auch kurze Sätze und auch Vershälften vorgetragen wurden.

Informationen zur Zusammenstellung eines Chores enthält eine altbabylonische Ritualanweisung aus Uruk. ${ }^{1981}$ Dort findet sich die Beschreibung eines Vokalensembles, das für die Ausführung des Baurituals zusammengestellt wurde:

T 105: AUWE 23, 63-64 Nr. 122 ii 4'

„(nimmt er) sieben Knaben oder Mädchen, aber keine erwachsenen Männer, und sieben 'junge' Männer.“

Spalte ii $4^{\prime}$. imin nita munus nu-g̃uruš imin nita munus zu ${ }^{1982}$

Der Chor wird hier aus sieben hohen (Knaben oder Mädchen) und sieben tiefen (geschlechtsreifen Männern) Stimmen gebildet. Auch der jeweilige Stimmumfang der Sänger oder Sängergruppe spielte damit wohl eine wichtige Rolle bei der Liedaufführung.

${ }^{1979}$ Groneberg 1999, 171 Anm. 7, wonach diese Rubrik „Sinn und Zweck des Hymnus wie eine Unterschrift kurz und bündig" kundtut.

${ }^{1980}$ S. hier Kapitel 14.2.3 zu T 110: CT 58, 12; hierzu auch Fritz 2003, 157-158.

${ }^{1981}$ S. T 62: AUWE 23, 63-64 Nr. 122.

1982 Cavigneaux in AUWE 23, 64 übersetzt „geschlechtsreife Männer“ für nita munus zu, wörtlich „Männer, die Frauen kennen“. 
Eine weitere Beschreibung zur Zusammensetzung eines Vokalensembles findet sich im sumerischen Lied Dumuzi-Inana $J$, das auch als Ätiologie zum Vortrag von Eršema gedeutet wird. ${ }^{1983}$ In diesem Lied wird der Chor aus sieben šir $_{3} \mathrm{dug}_{4}-\mathrm{dug}_{4}$ aus Uruk, wörtlich 'Liedsprechern', und fünfzig ad$\check{s ̌ a}_{4}$-ša $\mathrm{s}_{4}$ aus Zabalam, etwa 'Tremolo/Melismen-Sängern', zusammengestellt. ${ }^{1984}$ Eine solche Unterscheidung der zwei Sängergruppen nimmt Bezug auf die Singart und nicht auf die Stimmlage. Hiermit könnte rezitativisches oder psalmodisches von melismatischem Singen unterschieden sein. Im Text wird anschließend beschrieben, wie die Göttin G̃eštinana die anwesenden Sänger nach hohen und tiefen Stimmen einteilt, in gleicher Weise, wie es für das oben genannte Bauritual aus Uruk geschieht. ${ }^{1985}$

Die Existenz von Gegen- und Wechselgesang gilt für die Aufführung unterschiedlichster Liedgattungen als gesichert. Grundsätzlich kann angenommen werden, dass der Haupttext des Liedes von einem Solosänger vorgetragen wurde, während ein Chor, bestehend aus unterschiedlichen Stimmen, die im g̃išgig̃al formulierte 'Quintessenz' oder das 'Motto' des Liedes auf den Solovortrag erwiderte. Ein solcher Gegengesang konnte auch von zwei oder mehr Chören ausgeführt werden.

Das g̃išgig̃al wird in der Regel am Ende oder auch nach einzelnen längeren Textabschnitten und Rubrikangaben innerhalb des Liedes notiert. Da im oben genannten Dumuzi-Inana-Lied mit Silben- und Vokalreihungen die Rubrik g̃išgig̃al nach jeder einzelnen Liedzeile notiert wird, scheint wohl auch auf jeden solistisch gesungenen Liedvers jeweils ein Gegengesang gefolgt zu sein. ${ }^{1986}$ Hieraus könnte zu schließen sein, dass auch die lediglich einmal notierten g̃išgig̃al-Abschnitte nicht nur zum Ende des Liedes oder einer Rubrik hin, sondern auch zwischen einzelnen Strophen oder auch Versen des Liedes auf den Sologesang erwidert wurden. Eine solche Rekonstruktion der Aufführungspraxis bleibt jedoch vorerst hypothetisch, da sie sich am bestehenden Schriftbild des Keilschrifttextes nicht nachvollziehen lässt.

Die gängige Übersetzung der Rubrik g̃išgig̃al mit „Antiphon“ im weitesten Sinne ist damit zutreffend, sie sollte aber nicht zu voreiligen Gleichsetzungen mit den gregorianisch liturgischen Antiphonen führen, die als selbstständige kurze Lieder den Psalmengesang ein- und ausleiten. Da die g̃išgiğal-Rubriken von unterschiedlicher Länge und unterschiedlichem Inhalt sind, zudem die eigentlichen Vorträger, ob Solisten, ein oder zwei Chöre, Professionelle oder Laien, unbekannt sind, bleiben auch verschiedene Möglichkeiten für ihre Wiedergabe abhängig vom jeweiligen Textkontext bestehen.

\footnotetext{
${ }^{1983}$ Hier Kapitel 12.3.1.

${ }^{1984}$ Alster 1985, 220-221 zu den Zeilen Dumuzi-Inana J 24-37.

1985 Alster 1985, 224:33.

${ }^{1986}$ Hier Kapitel 14.2.3.
} 


\subsection{5 kirugu, kišu und ki-TUKU}

Die drei in diesem Kapitel zu behandelnden Rubriknamen werden in der Liste Proto- $\mathrm{Lu}_{2}$ als eine eigenständige Gruppe behandelt, die auf die Auflistung der Liedgattungsnamen folgt:

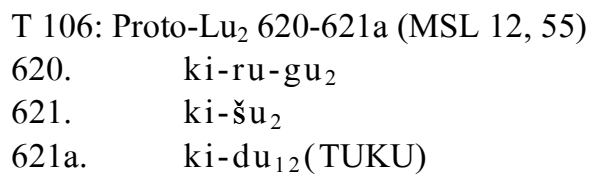

Allen drei Termini ist das Namenselement ki „Ort; Stelle“ gemein. Es bezieht sich auf den Ort, an dem eine bestimmte Handlung ausgeführt wurde. ${ }^{1987}$ Der Ausdruck ki-du ${ }_{12}$ (TUKU) „Ort des Musizierens“ ist bislang nicht als Rubrikname belegt und scheint in einer solchen Funktion auch nicht verwendet worden zu sein. ${ }^{1988}$ Seine Aufnahme in diese Liste resultiert lediglich aus dem gemeinsamen Namenselement ki.

Der Terminus kirugu wird ins Akkadische als kirugu entlehnt oder über das Wort šerru „Lied“ wiedergegeben. ${ }^{1989}$ Als Rubrik ist er in den sumerischen Gattungen Balag̃ , Širnamšub, Širnamgala und Širnamursag̃a, in sumerischen Stadtklagen, in einer Hymne an den Ekur-Tempel, in einem DumuziInana-Lied (DI BI), in der Hymne Abi'éšuh A sowie im akkadischen AgušayaHymnus an Ištar bezeugt. Die Rubrik ist damit auf keinen konkreten Inhalt beschränkt und kann gleichermaßen in Gebetsklagen, Hymnen wie auch Liebes- bzw. Fruchtbarkeitsliedern angetroffen werden. ${ }^{1990}$ Auch in sprachlicher Hinsicht besteht keine Einschränkung, kirugu teilt sumerische wie akkadische Dichtungen ein. Die jeweiligen Abschnitte innerhalb einer Komposition sind

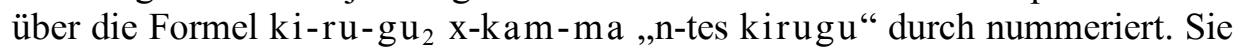
bilden meist inhaltlich in sich geschlossene Sinneinheiten, nur selten geht der Inhalt über die Angabe der Rubrik hinaus. Die Anzahl an kirugu-Einheiten, aus denen eine Komposition gebildet wird, fällt sehr unterschiedlich aus, so sind Bala g̃-Lieder des ersten Jahrtausends in bis zu 60 und mehr kirugu unterteilt. ${ }^{1991}$ Während Balag̃ sowie längere Hymnen mit mehreren kirugu eine

\footnotetext{
${ }^{1987}$ Zuletzt ausführlich besprochen bei Ludwig 1990, 30-32; Wilcke 1975, 254-255, 260-261.

${ }^{1988}$ Literarisch in $I \check{S} D A(+V) 339$ (T 82) als Ort, an dem die Hymnen des Königs vorgetragen werden; anders Krispijn 1990, 6 mit der Übersetzung „Stelle wo (nur) Instrumente spielen“.

${ }^{1989}$ Nabnitu 32 iv 7' (MSL 16, 254) als [ki]-「ru?-gu entlehnt; zur Gleichung mit šerru s. CAD Š/2 335 šèru B sub b).

1990 Das hierfür einzige Beispiel Dumuzi-Inana B1 (Kramer 1973) ist schwierig einzuordnen; entgegen der Meinung Alsters 1972, 89 Anm. 10 und mit Fritz 2003, 154 meine ich, dass es wohl keine ironische oder humoristische Dichtung ist. Da etliche Balag̃ und Eršema die Erzürnung der Inana zum Inhalt haben, könnte auch der beschriebene geplante Inzest des Dumuzi mit seiner Schwester Ğeštinana Grundlage eines späteren Wütens der Göttin sein.

1991 Black 1985, 11; bspw. BM 86535 Kramer 1985a, 115-135.
} 
einzige Gottheit adressieren, können einzelne solcher Abschnitte innerhalb einer Komposition auch unterschiedlichen Göttern oder Tempeln gewidmet sein, beispielsweise in der Eridu und der Ur Klage. Auf die Angabe des kirugu folgt häufig ein kurzes g̃išgig̃al, ein Gegengesang, der wahrscheinlich auf den vorausgehenden Liedvortrag von einem oder auch zwei Chören erwidert wurde.

Wörtlich übersetzt bezeichnet die Rubrik kirugu den „Ort des Gegenübertretens“. ${ }^{1992}$ Bemerkenswert ist die einmalige Schreibung ki $\mathrm{u}_{4}$-ru-gu $\mathrm{u}_{2}$-dam in der von Kramer publizierten Ekur Hymne UM 29-16-51, ${ }^{1993}$ die womöglich gleichzeitig auf ein temporal festgelegtes Ritualgeschehen verweist. Auch sonst weicht diese Hymne von gängigen Strukturen $a b$, da sie jeweils nur ein sagi$\mathrm{da}$, ein sag̃ara und das besagte ki $\mathrm{u}_{4}-\mathrm{ru}-\mathrm{gu}_{2}$-dam aufweist, worauf Gegengesänge (奋išgig̃al) folgen. Diese Rubriken sind sonst sehr selten in ein und derselben Komposition attestiert.

Der Rubrikname ki-š $\mathrm{u}_{2}$ markiert in der Regel den letzten Textabschnitt einer nach kirugu-Einheiten unterteilten Dichtung. Ähnlich der Rubrik uru(n) ist das kišu damit die abschließende Einheit einer solchen Liedkomposition, ${ }^{1994}$ auch wenn sie zuweilen fehlen kann, etwa im akkadischen Agušaya-Lied. In seiner wörtlichen Bedeutung meint der Rubrikname den „Ort des Zudeckens“ ${ }^{1995}$ Ins Akkadische wird kišu als kal $\hat{u}$ „Fest-/Zurückhalten“ wiedergegeben. ${ }^{1996}$

Bisherige Deutungen der zwei Rubriken kirugu und kišu weisen sie entweder einem kultischen oder einem musikalischen Geschehen zu. Falkenstein wie Ludwig schließen aus der wörtlichen Bedeutung von ki-ru-gu $\mathrm{u}_{2}$ einen Verweis auf eine kultische bzw. rituelle Handlung. ${ }^{1997}$ Es zeigt den Ort, den Zeitpunkt oder die Stationen eines Götterfestes oder einer Prozession an, an denen eine

\footnotetext{
${ }^{1992} \mathrm{ru}-\mathrm{gu}_{2}=$ mahāru(m), ,gegenübertreten“.

${ }^{1993}$ Kramer 1957, 97:42; ETCSL 4.80.4.

${ }^{1994}$ Die formale Verwandtschaft zwischen kišu und uru(n) könnte weiterhin in Nabnìtu 32 (MSL 16, 249-254) impliziert sein, wo in Kol. iv beide Rubriken nebeneinander genannt sind.

$1995 \breve{s}_{2}=$ katāmu ,bedecken“".

${ }^{1996}$ AHw 476a; Thureau-Dangin 1921, 55, 75; Hartmann 1960, 234 Anm. 4; Ludwig 1990, 32; Shaffer 1981, 83+Anm. 20 als 'Finale' einer Komposition auch in Bezug auf die termini technici $\check{\mathrm{su}}_{2}-\breve{\mathrm{s}}_{2}$ und sihpum. Im Examenstext $A 24$ steht als akkadische Entsprechung für ki-la das sumerische gul-1a, was auch dem akkadischen abātu $(m)$ „zerstören, vernichten“ entspricht; AHw 5a.

1997 Falkenstein 1950, 105; Ludwig 1990, 31 „Stelle, an der man (zum Gebet einer Gottheit) gegenübertreten muss". Sie sieht hierin eine Parallele zur Aufteilung der bereits früh belegten Keš Tempel-Hymne nach 'Häusern', e ${ }_{2}$ x-kam-ma „n-tes Haus“; Sjöberg/Bergmann/ Gragg 1969, 158-159; s. hingegen Jacobsen 1997, 554-559 „place of countering“; ganz anders Vanstiphout 1999, 89 Anm. 59 „,place for changing turn (for speaker or singer)“.
} 
Verbeugung, ein Niederknien ausgeführt wurde, oder allgemein aus Anlass einer Opferhandlung der Priester der adressierten Gottheit gegenübertrat.

Wilcke und Krispijn setzen für diese Rubriken wiederum einen musikalischen Hintergrund an. ${ }^{1998}$ Letzterer bezieht sie auf den tonalen Verlauf einer Liedkomposition und übersetzt ki-ru-gu ${ }_{2}$ mit ,Stelle, wo man (Harfe/Leier) (nach)stimmt“ und ki-šu ${ }_{2}$ mit „Stelle der Modulation“. 1999 Dementgegen vermutet Wilcke für beide Rubriken eine Anleitung zur instrumentalen Begleitung. Den Ausdruck ki-š $\mathrm{u}_{2}$-bi-im gibt er in Anlehnung an seine Grundbedeutung mit „,ist die Stelle davon, an der man das Instrument wieder zudeckt“ wieder. ${ }^{2000}$

Hinsichtlich der Bedeutung der Rubriken kirugu und kišu ist zu beachten, dass sie vermehrt in Texten des gala-Repertoires enthalten sind. Die kultischen oder musikpraktischen Handlungen, die sie markieren, könnten daher im Verlauf des Vortrags auch vom gala-Priester selbst ausgeführt worden sein. ${ }^{2001}$ In diesem Zusammenhang sei auf ein akkadisches Gebet aus neuassyrischer Zeit verwiesen, das weitere Klärung verspricht. Das Gebet an einen verfinsterten Gott enthält in den letzten Zeilen die rituelle Anweisung: „Der gala soll die lilis-Pauke bedecken!““. ${ }^{2002}$ Mit dem Akt des 'Zudeckens' wird hier eine besondere kultische Handlung verbunden, die den abschließenden Akt eines Klageliedvortrags an eine Gottheit markiert. ${ }^{2003}$ Entsprechend der Annahme Wilckes zeigt die Rubrik kišu ganz offensichtlich diese letzte abschließende Handlung eines religiösen Aktes an, bei der ein gala oder auch ein anderer Priester das zur Begleitung verwendete heilige Musikinstrument wieder zudeckt. Damit wäre diese Rubrik als eine liturgische Handlung einzuordnen, die gleichzeitig den Umgang mit dem zu spielenden Musikinstrument regelt.

Für die Rubrik kirugu ist Entsprechendes anzunehmen. Seine akkadische Wiedergabe mit šeru „Lied“ zeigt an, dass es Textabschnitte für den gesungenen Vortrag markiert. Die sumerische Bedeutung des Rubriknamens verweist ebenfalls unmissverständlich, wie von Falkenstein und Ludwig bereits aufge-

${ }_{1998}$ Wilcke 1975, 260-261; Krispijn 1990, 6; ihm folgend Kilmer 1993-97, 471.

1999 Ähnlich Shaffer 1981, 83, der den Rubriknamen kišu zu šu $_{2}$-šu ${ }_{2}$ und sihpum in Beziehung setzt; s. a. hier Kapitel 14.2.1.

${ }^{2000}$ Wilcke 1975, 261 auch wörtlich ,ist das Deckelstück (= der Schluss) davon“.

${ }^{2001}$ In Nabnītu 32 iv (MSL 16, 254) folgen beide Rubriknamen auf Klageliedgattungen, er $r_{2}-\check{s} a_{2}$ $n e-\check{s} a-k u m$ oder [e]r-ki-tu-ša-kum; vgl. AHw 242b erkitušû „Wohnungsklagelied“ und 246a; dagegen wohl eher „Klage des Orts des Hinsetzens“( $\left(\mathrm{er}_{2}-\mathrm{ki}\right.$-tuš-a) im Verlauf eines Rituals.

2002 Ebeling 1948, 418, 420:23. lu 2 [KU].UŠ li-li-is-su li-ri-[im] „der kalû-Priester möge die Pauke bedecken“.

${ }^{2003}$ In wenigen Emesal-Liedern des 1. Jts. werden am linken Rand Anweisungen zum begleitenden Instrument in Form von Glossen notiert, darunter auch šu ${ }_{2}(-e)$,,abdecken“? und šu ${ }_{2}$ meze-dab ,abgedeckte Meze-Trommel ...“; Mirelman 2009. Da sich die Angaben innerhalb des Textes befinden, muss es eine andere spieltechnische Anweisung sein als die abschließende rituelle Abdeckung des Instruments, die über kišu angezeigt wird. 
zeigt, auf einen Ort oder einen Zeitpunkt im Verlauf der Kulthandlung, an dem eine 'Gegenüberstellung' oder auch eine Form der 'Begegnung' stattfand. Das kirugu markiert damit einzelne Liedabschnitte einer längeren liturgischen Komposition, die an verschiedenen Stationen eines Festaktes an eine Gottheit gerichtet wurden. Die jeweiligen Gesänge sind entweder verschiedenen Gottheiten oder einer einzigen an verschiedenen Kultstationen gewidmet. Eine solche Rekonstruktion für die Aufführungspraxis deckt sich mit den aus Urkunden bekannten Informationen zu Stadtumrundungen und Prozessionen von Bala g̃-Instrumenten, die an Stadttoren und verschiedenen Schreinen der Gottheit halt machten. ${ }^{2004}$

Ich erachte kirugu-Gesänge als ein Spezifikum des gala-Repertoires. Auch am Vortrag des Agušaya-Hymnus oder zumindest an seiner instrumentalen Begleitung könnte daher ein gala beteiligt gewesen sein. Wie am Gebet an einen verfinsterten Gott zu ersehen, beschränkt sich das Repertoire dieses Priesters nicht auf Gebete oder Gesänge in sumerischer Sprache.

Das Repertoire des gala-Priesters lässt sich damit nicht nur nach sprachlichen und funktionalen, sondern auch nach strukturellen, gleichfalls aufführungspraktischen Kriterien abgrenzen. Kennzeichnend sind bestimmte liturgische und musikpraktische Handlungen, die in den Texten des gala über die Rubriken kirugu und kišu angezeigt werden. Hierüber wird außerdem deutlich, dass musik- und instrumentalpraktische Aktionen während eines religiösen Festaktes der Liturgie angehörten.

\subsection{Termini technici und Anweisungen zum vokalen Vortrag}

Die in der Liste Proto- $\mathrm{Lu}_{2}$ auf die Rubriknamen folgenden Ausdrücke können alle als termini technici zur musikalischen Aufführungspraxis identifiziert werden: ${ }^{2005}$

T 107: Proto- $\mathrm{Lu}_{2}$ 622-627 (MSL 12, 55)

622. $\quad \operatorname{gid}_{2}-\mathrm{i}$

623. tu-lu

624. gi-en-gi-en

$625 . \quad \mathrm{zi}-\mathrm{zi}-\mathrm{i}$

626. (B) $\tilde{g} a_{2}-\tilde{g} a_{2}$

627. $\quad \check{\mathrm{s}} \mathrm{u}_{2}-\check{s}_{2}$

${ }^{2004}$ S. für die Ur III-Zeit Heimpel 1998; auf eine Prozession oder Stadtumrundung bezieht sich auch die aB Ausgabenliste T 57: CT 45, 85 (o.D.).

${ }^{2005} \mathrm{Zu}$ diesen musiktechnischen Termini s. Krispijn 1990, 1-27; Krispijn 2002, 465-479 und allgemein Kilmer 1993-97, 469-477. 
Für alle sechs hier zitierten Einträge werden musiktechnische Hintergründe vermutet, die den tonalen oder auch melodiösen Verlauf einer Musikdarbietung kennzeichnen. Von Krispijn und Kilmer werden sie auf das Stimmen der verschiedenen Tonskalen meist eines Saiteninstruments bezogen. ${ }^{2006}$ Dieselben sechs Termini werden in einem Abschnitt der Hymne Šulgi B zu den musikalischen Fertigkeiten des Königs gezählt:

T 108: Šulgi B $160 / 171$

160. zi-zi-i $\breve{s} u_{2}-\breve{s u}_{2}$-ba g̃iš mu-e-hur-hur

„Für das 'Anheben' und 'Senken' habe ich die Regeln festgesetzt.“

171. ad-pad ${ }_{3}-$ de $_{3}$ gid $_{2}-\mathrm{i}$ tu-lu gi-na/gen 6 -na šu-g̃a $a_{2}$ la-ba-ra-e 3

„Beim 'Einstimmen' (der Stimme?) gehen gid g $_{2}-\mathrm{i}$, tu-lu und /gen/ nicht aus meiner Hand (?). ‘2007

Das auch zu Beginn der Liste Proto- $\mathrm{Lu}_{2}$ genannte Begriffspaar gid $\mathrm{g}_{2}-\mathrm{i}$, akkadisch $n a s \bar{a} h u(m)$,entnehmen, abziehen“ und tu-lu, akkadisch $n e$ ' $\hat{u}(m)$ „lösen, entspannen“2008 wird als Anspannen und Entspannen einer Saite gedeutet. ${ }^{2009}$ Dies sind Stimmvorgänge, die auch im Stimmungstext UET 7, 74 aus Ur am $\tilde{g}_{\text {giš }} \mathrm{za}_{3}-\mathrm{mi}_{2}$ ausgeführt werden. Aufgrund des Ausdrucks ad- $\mathrm{pad}_{3}$ im zitierten Vers 171 können gid $_{2}-\mathrm{i}$, tu-lu und gen ${ }_{6} /$ gi-en-gi-en aber auch auf den vokalen Vortrag bezogen werden. Welche Stimmtechniken oder Singarten mit ihnen bezeichnet sein könnten, bleibt unbekannt.

Das Begriffspaar zi-zi und $\breve{s} \mathrm{u}_{2}-\breve{s}_{2}$ ist in der Šulgi-Hymne auf die Instrumentalpraxis zu beziehen. In Dumuzi-Inana $J$ wird zi-zi neben $\tilde{g} a_{2}-\tilde{g} a_{2}$ wiederum auf den Vortrag eines Liedes angewendet.

\subsection{1 zi-zi, $\tilde{g} a_{2}-\tilde{g} a_{2}$ und $\check{s} u_{2}-\check{s} u_{2}$}

Die Ausdrücke g̃ $a_{2}-\tilde{g} a_{2}$ und $\check{s} u_{2}-\breve{s ̆}_{2}$ bilden jeweils mit zi-zi ein oppositionelles Begriffspaar, das auf eine auf- und absteigende Bewegung verweist, auf ein $\mathrm{Zu}$ - und Abnehmen, in mathematischem Kontext auch Addieren und Subtrahieren. ${ }^{2010}$ In der Musikpraxis beziehen sie sich in den Hymnen Šulgi B und Šulgi $C$ laut Krispijn auf das Auf- und Niederstimmen der ${ }^{\tilde{s}} \mathrm{iš} \breve{s} \mathrm{~s}-\mathrm{kara}_{2}-$ Laute. ${ }^{2011}$

\footnotetext{
${ }^{2006}$ Krispijn 1990, 5-7, 17; Kilmer 1993-97, 471.

${ }^{2007}$ Anders Krispijn 1990, 2 „Wenn ich beim Stimmen (die Saiten) anspanne, entspanne oder festsetze, entglitten sie (die Saiten) mir nicht aus der Hand“".

${ }^{2008}$ Nabnītu 32 iii 20-21 (MSL 16, 253); Sjöberg 1970, 85-87; CAD N/2 1a und 198a.

${ }^{2009}$ Krispijn 2002, 472.

${ }^{2010}$ Alster 1985, 226-227; Krispijn 1990, 5-6.

2011 Šulgi B 158-160; Šulgi C 77-78; Krispijn 1990, 5-6; Shaffer 1981, 83.
} 
Das Begriffspaar zi-zi und $\tilde{g} a_{2}-\tilde{g} a_{2}$ bleibt jedoch nicht auf den instrumentaltechnischen Bereich beschränkt. Im Lied Dumuzi-Inana $J$ beziehen sich beide Ausdrücke auf den vokalen Vortrag. ${ }^{2012}$ In diesem Lied ist unter anderem von der Zusammenstellung eines Doppelchores die Rede, der aus zwei Sängergruppen unterschiedlicher Herkunft sowie unterschiedlicher Stimmlagen und Singarten besteht. ${ }^{2013}$ Die erste Gruppe aus Uruk führt einen gesprochenen, möglicherweise rezitativen oder psalmodischen Vortrag aus ( $\left.\check{s i r}_{3} \mathrm{dug}_{4}-\mathrm{dug}_{4}\right)$, während die zweite Gruppe aus Zabalam auf eine Art tremolierenden oder melismatischen Gesang (ad-ša ${ }_{4}$-ša $\left.a_{4}\right)$ spezialisiert war. ${ }^{2014}$ Als Anweiserin und möglicherweise auch als Vorsängerin tritt die Göttin G̃eštinana auf, die die anwesenden Sänger nach großen und kleinen, also hohen und tiefen Stimmen einteilt. ${ }^{2015}$ Als der Vortrag des eigentlichen Liedes beginnen soll, wird im Text beschrieben, dass die Anwesenden im 'Anheben' (zi-zi) und 'Setzen' ( $\tilde{g} a_{2}-$ $\tilde{\mathrm{g}} \mathrm{a}_{2}$ ) eines Liedes zwar bewandert waren, die Göttin ihnen aber den Liedanfang, wörtlich den 'Kopf des Liedes' anzeigen musste. ${ }^{2016}$ Hinter diesem nur hier belegten Ausdruck šir ${ }_{3}$ sag̃-bi ist wohl der Anfangston oder auch der 'Hauptton' des Liedes zu vermuten, der vor Beginn des Vortrags von der Vorsängerin angegeben wird, um Anfang und Ende einer $\mathrm{zu}$ verwendenden Skala zu bestimmen. ${ }^{2017}$ Hierauf folgt von der Göttin eine zweite konkrete Anweisung zum Verlauf des Liedvortrags selbst: „Wenn wir das Lied/den Gesang 'anheben' (zi-zi), werdet ihr das Lied/den Gesang 'setzen' (g̃ $a_{2}$ -

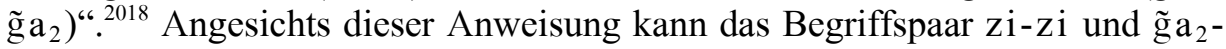
$\widetilde{\mathrm{g}} \mathrm{a}_{2}$ konkret auf die Gestaltung des Liedverlaufs und seiner Melodie bezogen werden.

${ }^{2012}$ DI J 25-36(?); Alster 1985, 220-221, 227.

${ }^{2013}$ S. hier Kapitel 12.3.1.

${ }^{2014}$ Vgl. hier Kapitel 12.3.1.

${ }^{2015}$ DI J 34. gaba ba-da-ab-gu-la gaba ba-da-ab-[tur-ra] gu mu-run ${ }^{7}-\left[\mathrm{na}_{3}-\mathrm{de}_{2}-\mathrm{e}\right.$ ]

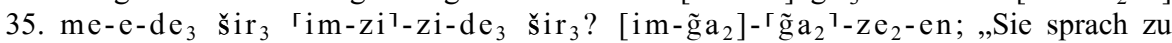
jenen mit großer/starker 'Brust', zu jenen mit kleiner/schwacher 'Brust'; Wenn wir das Lied/den Gesang 'anheben', werdet ihr das Lied/den Gesang 'setzen'“; vgl. Alster 1985, 224:33; anders Jacobsen apud Alster 1985, 228: 33-34(=34-35) ,an irtu lament rendered crescendo is not an irtu lament rendered pianissimo, she said to them. We (that is, she and the women) make the dirge soar, you let the dirge drop down“.

${ }^{2016}$ Volk 1994, 186-187; Jacobsen apud Alster 1985, 228:30.

2017 Als 'Hauptton' möglicherweise mit dem Vadi aus der indischen Musik und dem rāga vergleichbar. Anderer Auffassung ist Sam Mirelman, demzufolge es sich auch um den Verweis auf ein Incipit handeln könnte, das gleichzeitig auch als Memorandum für den Melodienanfang des vorzutragenden Liedes fungiert.

${ }^{2018}$ S. Anm. 2015 
In abgebrochenem Kontext ist der Ausdruck $\tilde{\mathrm{g}} \mathrm{a}_{2}-\tilde{\mathrm{g}} \mathrm{a}_{2}$ auch im bereits behandelten Bauritual AUWE 23 Nr. 122 aus Uruk erhalten. ${ }^{2019}$ Auf den Abschnitt mit der Zusammenstellung des Chores scheinen auch hier genauere Anweisungen zum Verlauf des Liedvortrags gefolgt zu sein. Es sind in diesem Falle die tiefen Stimmen, die es ausführten. ${ }^{2020}$

Ein literarischer Beleg zu zi-zi und $\tilde{\mathrm{g}} \mathrm{a}_{2}-\tilde{\mathrm{g}} \mathrm{a}_{2}$ mit Bezug auf den Liedvortrag findet sich in der Hymne Šulgi E 34. „Dass ich(Šulgi) die Stelle/den Ort kenne zum Anheben und Senken der Tigi und Zamzam-Lieder". ${ }^{2021}$

Beide Termini werden letztenendes inhaltlich wie auch sprachlich mit den Rubriknamen sagida und sag̃ara in Beziehung gesetzt. ${ }^{2022}$ Auch diese beiden Termini verweisen angesichts ihrer wörtlichen Bedeutung auf das ,lang machen“ oder ,ausdehnen“ ( gid $_{2}-\mathrm{da}$ ) einer Saite oder eines Modus (sa), und mit gar(a) auf das ,,(Hin)setzen“ oder 'Absenken'. Beide Rubriken beziehen sich damit auf dieselben Vorgänge im tonalen Verlauf eines Liedes, die auch über zi-zi und g ga $a_{2}-\tilde{g} a_{2}$ bezeichnet werden, das 'Anheben' und das 'Setzen' des Gesangs oder der Stimmung. Die Aussage in der Hymne Šulgi E 34 bezieht sich auf ebendiese Abschnitte von Tigi- und Zamzam-Liedern.

Für zi-zi und g̃ $a_{2}-\tilde{g} a_{2}$ kann damit zusammengefasst werden, dass sie Formen des antiphonalen oder auch responsorialen Gesangs in ihrem tonalen Verlauf organisieren. ${ }^{2023}$ Über sie könnte das Anheben und Absenken des Liedverlaufs nach zwei Abschnitten eingeteilt sein, vielleicht sogar eine Modulation angezeigt werden. Andererseits könnten sie auch ein Wechselspiel von Melodiefloskeln in einem 'Frage-Antwort-Schema' bezeichnen. Da sie in den angegebenen Belegen meist im Zusammenhang mit unterschiedlichen Stimmlagen und Singarten auftreten, könnten sie schließlich auch auf solches zu

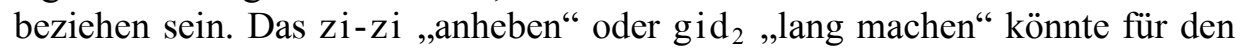
melismatischen und reich verzierten ornamentalen Gesang der im ad-ša versierten hohen Stimmen stehen. Von den tiefen Stimmen wird demgegenüber der 'Ton gesetzt' ( $\tilde{\mathrm{g} a r} / \tilde{\mathrm{g}} \mathrm{a}_{2}-\tilde{\mathrm{g}} \mathrm{a}_{2}$ ), der Gesang, eventuell auch in der Funktion eines Bordun, rezitiert oder psalmodiert $\left(\mathrm{dug}_{4}\right){ }^{2024}$

\footnotetext{
${ }^{2019}$ AUWE 23, 63 Nr. 122 Spalte iii 3'. [ . .KA]L g̃ $a_{2}$ - $\tilde{g} a_{2}$-dam.

${ }^{2020}$ Mit KAL für g̃uruš in Spalte ii $4^{\prime}$ für die tiefen Männerstimmen.

${ }^{2021}$ Hier T 71: Šulgi E 34.

${ }^{2022}$ Kilmer 1992, 105-106; anders Çerný 1994, 25-26; hier Kapitel 14.1.1.

${ }^{2023}$ Kilmer 1992, 106 setzt sie den aus der indischen Musik bekannten Liedabschnitten aläpa und rāga parallel; dazu Çerný 1994, 25-26.

2024 So Çerný 1994, 25-26.
} 


\subsection{2 gennum und zennum}

In mehreren fragmentarisch erhaltenen, altbabylonischen Texten aus Nippur sind die musiktechnischen Termini gennum und zennum enthalten, die sich in erster Linie auf das Spiel eines Saiteninstruments, möglicherweise des ${ }^{\tilde{\text { ó }} \text { ̌s }} \mathrm{Za}_{3}$ $\mathrm{mi}_{2}$ beziehen. ${ }^{2025}$ Beide Ausdrücke sind sonst unbekannt, auch sind die zwei Texte, in denen sie belegt sind, ihrem Aufbau sowie Inhalt nach bisher einzigartig. Da in einem der Texte (N 3354+3355) der Name Lipit-Eštar genannt wird (Kol. ii' 5'), rekonstruiert Kilmer, dass es sich um eine Stimmungsanweisung zum Vortrag der Hymne Lipit-Eštar B handelt, deren erste Zeile mit dem Namen des Königs einsetzt und hier als Titel genannt sei. ${ }^{2026}$ Diese vollständig überlieferte Hymne weist keinerlei Gattungsangaben auf, sie schließt lediglich mit einer $\mathrm{za}_{3}-\mathrm{mi}_{2}$-Formel. ${ }^{2027}$

Angesichts der häufigen Nennung der zwei termini ge-en-nu-um und ze-ennu-um halte ich den Text nicht für eine Stimmungs- oder Modulationsanweisung für die Hymne Lipit-Eštar B, sondern für die Vorgabe einer Sequenz von Intervallen und einzelnen Tönen, die möglicherweise Grundlage der Melodiebildung sind. Die Ausdrücke zennum und gennum werden im Text auf Saitenpaare oder auch einzelne Saiten bezogen. Für ge-en-nu-um vermutet Kilmer eine Entlehnung von sumerisch ge-en, was in seiner reduplizierten Form geen-ge-en auch in Proto- $\mathrm{Lu}_{2}$ bezeugt ist. ${ }^{2028}$ Ihrer Meinung nach ist das Begriffspaar auf Stimmungsvorgänge an einem Musikinstrument $\mathrm{zu}$ beziehen, wobei das Wort ze-en-nu-um eine grobe und ge-en-nu-um wiederum eine feine Stimmung anzeigt, das der genaueren Überprüfung der gestimmten Saitenpaare dient. $^{2029}$

\footnotetext{
${ }^{2025}$ UM 29-15-357+N 3020, N 3354+3355; Kilmer/Civil 1986, 94-98; Kilmer/Tinney 1996, 4956; Kilmer/Tinney 1997, 118.

${ }^{2026}$ Dementsprechend auch in UM 29-15-357 Vs i'1' rekonstruiert; Kilmer/Tinney 1996, 50-52; Kilmer/Civil 1986, 94-97. Lipit-Eštar B (ETCSL 2.5.5.2) 1. ${ }^{\mathrm{d}} 1 \mathrm{i}-\mathrm{pi}_{2}-\mathrm{it}-\mathrm{e} \breve{\mathbf{s}}_{4}-\mathrm{tar}_{2}$ lugal sag̃ il ${ }_{2}$ nun barag-ga „Lipit-Eštar, stolzer König, gekrönter Fürst“; Vanstiphout 1978, 36-37.

${ }^{2027}$ Hierzu kritisch auch Michalowski 2009.

${ }^{2028}$ Hier Kapitel 14.2.

${ }^{2029}$ Kilmer/Tinney 1996, 53-56; Smith/Kilmer 2000, 135-137; Krispijn 2002, 472.
} 
T 109: UM 29-15-357 Kol. ii' (Kilmer/Tinney 1996, 51)

Übersetzung

$1^{\prime} . \quad[U m] k e h\left[r^{?}\right]$

4-1 (Saitenpaar)

gennum zennum

2-4 (Saitenpaar)

5'. Setze fest ${ }^{?} 2-5$ (Saitenpaar) zennum

5-2 (Saitenpaar)

gennum und zennum

4. Saite zennum

10'. 3-6 (Saitenpaar)

gennum
Umschrift

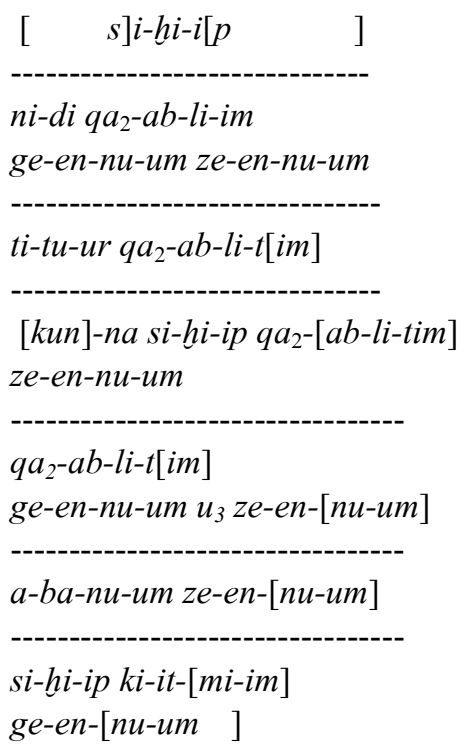

Entsprechend sind die übrigen Abschnitte des Textes aufgebaut, wobei der größte Teil stark zerstört ist. In der angegebenen Übersetzung gehe ich von der Bedeutung „Umkehren; Umwenden“ für sihpum aus, worin ich das Umkehren der eigentlichen Saitenpaarfolge vermute. ${ }^{2030}$ Zusätzlich zu den Saitenpaarnamen, ihrer Umkehrung und den Namen einzelner Saiten fallen vereinzelte Worte auf, die zur Mitte einer jeweiligen Kolumne auftreten: kunna (s .o.) oder

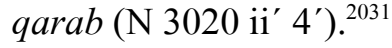

Aus der angegebenen Umschrift wird eine Sequenz von Intervallen deutlich, deren Fortschreiten schrittweise über das Anheben oder Absenken einzelner Töne stattfindet. Die Begriffe zennum und gennum könnten in dieser Weise zu deuten sein, allerdings lässt sich dieses Konzept nicht auf alle Abschnitte des Textes übertragen.

${ }^{2030}$ CAD S 30 sahapu 3. „to turn over(?), upside down(?)“; ähnlich Shaffer 1981, 81-83 als ,inversion of the interval“ allerdings mit Bezug auf einen Stimmvorgang; anders Kilmer 1993-97, 473 mit „flattened/cast down“ entsprechend den plagalen Skalen der Antike und des Mittelalters.

${ }^{2031}$ Dazu auch UM 29-15-357 Rs i' 5' IN DI... und N 3354+3355 Vs ii' 9' [x]-「' $\mathrm{X}^{\top}-z u$ und Rs ii 5' [x]-nam; Kilmer/Tinney 1996, 50-53. 
Auch wenn die genaue Bedeutung der Termini hier nicht erschlossen werden kann, so bleibt zu betonen, dass sich die Anweisungen eher auf die Melodieführung und den Verlauf der Begleitung beziehen und weniger auf ein Umstimmen oder Modulieren.

Abschließend ist festzuhalten, dass mit diesen bisher einzigartigen Texten eine weitere Form der musikpraktischen 'Notation' vorliegt, die die tonale Struktur einer vokalen Komposition und ihre instrumentale Begleitung darzustellen sucht. Ihrer Form nach wäre sie als eine Art Tabulatur anzusehen, also eine 'Griffschrift', die sich auf ein konkretes Instrument, das ${ }^{\tilde{g} i s ̌ s} / \mathrm{zami} /$ bezieht.

\subsubsection{Ein Liebeslied mit Singanweisungen (CT 58, 12)}

Von außerordentlichem Interesse in Hinblick auf vokale Vortragsformen und ihre Darstellungsweise ist ein altbabylonisches, bisher unbearbeitetes sumerisches Dumuzi-Inana-Lied, das neben dem Liedtext bisher nicht in dieser Form bekannte Singanweisungen notiert. Eine erste Darstellung seiner besonderen Problematik wurde von Volk vorgelegt. ${ }^{2032}$ Von der Komposition erhalten sind Anfang und Ende mit je etwa 15-20 Textzeilen. ${ }^{2033}$ Den gesamten Text durchlaufen drei- bis vierzeilige Abschnitte, die jeweils über horizontale Linien voneinander getrennt werden. Insgesamt sind zwölf solcher Abschnitte auf der Tafel enthalten. Inhaltlich ist von einem Treffen der Inana mit ihrem Geliebten Dumuzi die Rede, wobei als Anlass eine 'Herrinnenschaft' angegeben wird. ${ }^{2034}$ Als Vorbereitung schmückt sich die Göttin, um ihrem Gatten (mu-ud-na) anschließend in der Schafhürde zu begegnen. Während auf der Tafelvorderseite die Göttin in der 2. Person besungen wird, spricht sie selbst auf der Rückseite in der 1. Person. Nicht nur der Wechsel der Sprecherperspektive, sondern auch die Inhalte, die Wiederholungen einzelner Verse, sowie das verwendete Emesal entsprechen den Balbale und Kung̃ar. ${ }^{2035} \mathrm{Zu}$ Letzteren weist das Lied im Schriftbild einen erheblichen Unterschied auf, nämlich den Zusatz der vortragstechnischen Anweisungen, die auf jeden Vers des Liedtextes folgen.

Die Angaben bestehen zum einen aus immer wiederkehrenden gleichbleibenden Vokalreihungen $e-(e)-i a-a$ und $a-a(-a)$, die an die Glossen seleukidischer Balag̃-Lieder erinnern. Zum anderen folgt jedem Abschnitt die Angabe mu-lu a-la-lu in-gur „der das alālu anhebt!“. ${ }^{2036}$ Auf jeden der Verse und

\footnotetext{
${ }^{2032}$ Volk 1994, 188-190; s. a. Fritz 2003, 157-158 zu den Textinhalten.

${ }^{2033}$ CT 58 S. 12.

${ }^{2034}$ CT 58, 12 mehrfach auf der Vs; mit Fritz 2003, Anm. 636 nicht als Krönung eines Königs (Dumuzi) zu deuten, wie von CT 58 S. 12 vermutet; es könnten eher Hochzeitsvorbereitungen anstehen.

${ }^{2035}$ Beispw. Balbale DI C, DI F und das Kunga ar DI T.

${ }^{2036}$ Vgl. Volk 1994, 188-190 zu i ${ }_{3}$-gur als Verbalform; CT $58 \mathrm{~S} .12$ korrigiert zu in-du! in Anlehnung an den in CT 58, 15 und 16 mehrfach genannten $l_{u_{2}}$ al-la-lu dug $g_{4}$,der das alalu sagt/spricht".
} 
zugehörigen Gesangsanweisungen folgt außerdem die Rubrik g̃iš-gi $i_{4}-\tilde{g} a l_{2}$. Insgesamt findet sie sich damit 20-mal auf der Tafel verzeichnet und ist möglicherweise an weiteren abgebrochenen Stellen zu rekonstruieren. Im Folgenden sind beispielhaft die besser erhaltenen Abschnitte der Vorder- und Rückseite wiedergegeben:

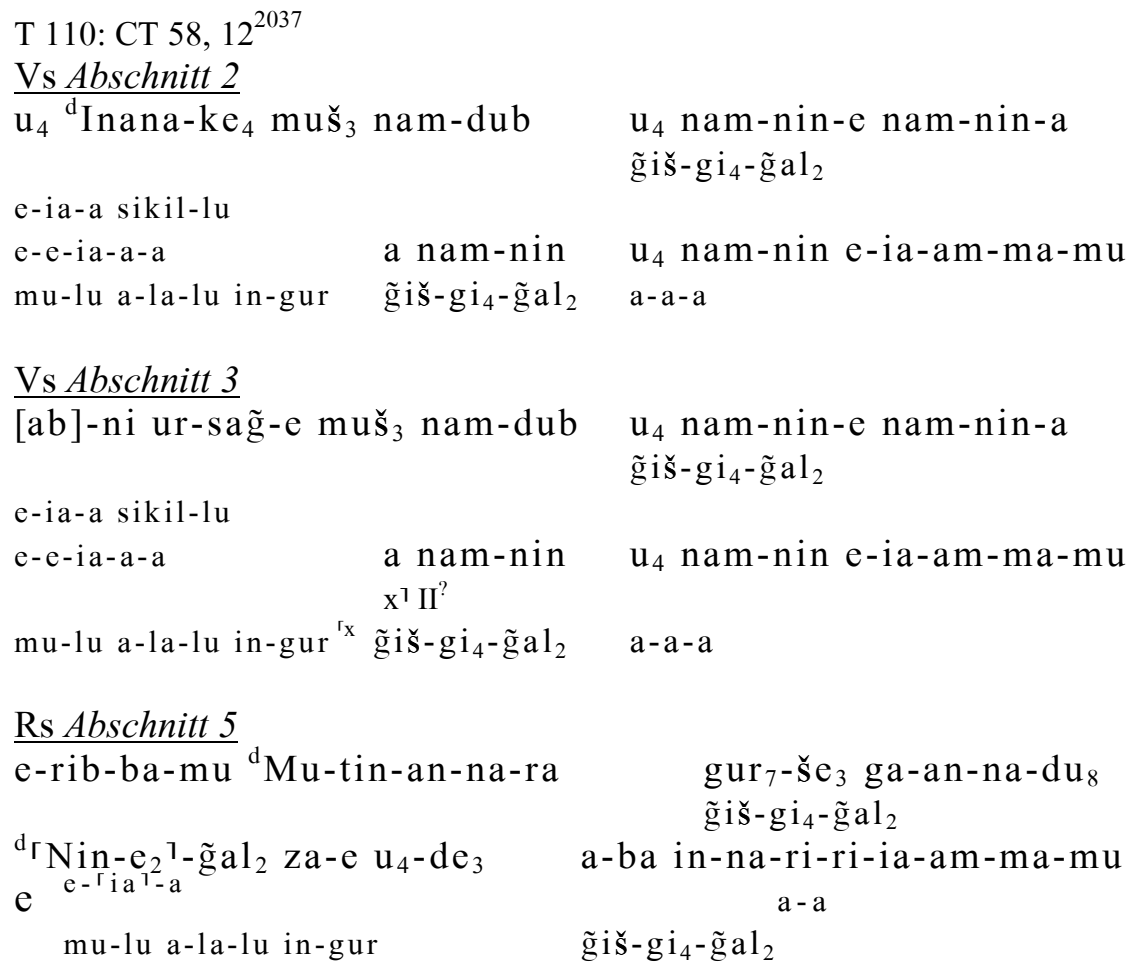

\section{$\underline{\text { Rs Abschnitt } 6}$}

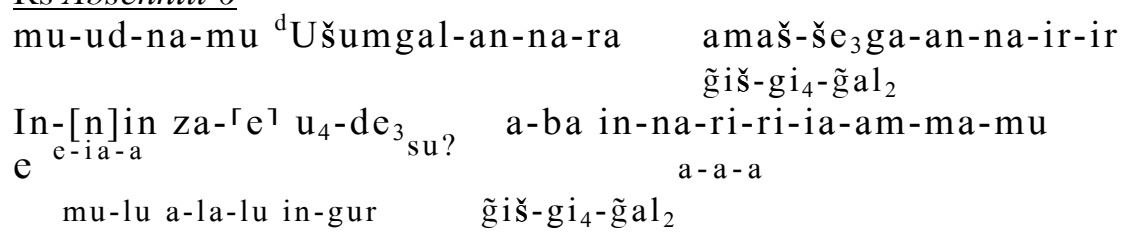

In dieser Form sind alle weiteren Abschnitte des Liedes aufgebaut, wobei auffällt, dass sich die Angaben auf Vorder- und Rückseite unterscheiden. Es zeigt sich außerdem, dass jede Zeile in zwei Vershälften unterteilt wird, von denen jeweils die zweite einen Gegengesang (g̃išgig̃al) bildet. Zweigeteilt

${ }^{2037}$ Vgl. CT 58 S. 12; Volk 1994, 189 Anm. 71 und Fritz 2003, 157-158. 
sind dementsprechend auch die vokalen Anweisungen, den Anfang macht das $e i a$, um dann in ein $a$ - $a$ überzugehen. Das $e-i a$ sikil-lu „reiner eia(-Gesang)“ der Vorderseite gehört nicht zum Liedtext selbst. Ihm gegenüber findet sich eine zweite Vershälfte, die einen Gegengesang bildet. Weitere allerdings unsystematisch erscheinende Glossen sind beispielsweise auf der Vorderseite Abschnitt 3:3-4 oder der Rückseite Abschnitt 6:2-3 enthalten, deren Bedeutung und Bezug allerdings aufgrund ihrer Unlesbarkeit unklar ist. Wesentliche Fragen zu diesem Text betreffen zum einen die 'Leserichtung' zum anderen die Bedeutung der unterschiedlichen Angaben und schließlich ihr Bezug zum Liedtext. $^{2038}$

Der erste Punkt könnte über die Anweisungen der Rückseite zu beantworten sein. Hier 'trennt' sich ein großes vorgeschriebenes $e$ in zwei kleiner geschriebene Zeilen, dem eia und der Angabe 'der das alälu anhebt'. Diese Schreibung könnte neben der üblichen horizontalen auch eine vertikale Leserichtung intendieren, sodass eia und alālu gleichzeitig zu erklingen hatten. Die Anweisungen der Vorderseite scheinen hingegen drei solcher möglichen 'Stimmen' darzustellen. Wobei die erste Vershälfte wohl von einem textlosen 'reinen', vielleicht in übertragenem Sinne 'hohen' Jubelgesang (?) (eia sikil-lu) gebildet wird.

Zumindest für das $a-a(-a)$ der jeweils zweiten Vershälfte kann beobachtet werden, dass es als Angabe zum Liedtext fungiert, da es jeweils einer $a$ haltigen Silbe unterschrieben ist. Da die angegebenen Vokal- und Silbenreihen immer gleich wiederholt werden, scheint jeder Vers auch unabhängig von leichten Textvarianten die gleiche Singart oder Melodie aufzuweisen.

Für die Vortragspraxis kann rekonstruiert werden, dass mehrere auch gleichzeitig erklingende 'Stimmen' beteiligt waren, wobei die erste Vershälfte solistisch, die zweite als Gegengesang wohl chorisch gesungen wurde. Es ergibt sich eine Art Frage-Antwort-Schema, das auch die den einzelnen Vershälften zugeordneten Laute und ihre Qualität berücksichtigt, auf die hellen $e-i$ Vokale folgt abschließend ein Gesang auf dem dunklen $a$-Vokal.

Unbeantwortet bleibt die Frage, ob die Anweisungen auch eine Bedeutung für die Entwicklung der Melodiefolge und ihre Begleitung aufweisen. Volk sieht in ihnen eine Art 'Skelett-Notation', die als Basisangabe für die improvisierte Ausführung von Melodiebögen dienen könnte. ${ }^{2039}$

Auffällig ist die Gegenüberstellung der rein vokalischen Angaben $e$-ia- $a$ und $a$ $a$ zum a-la-lu. In ähnlicher Weise wird im sumerischen Sprichwort SP $3.87 \mathrm{zu}$ den wichtigsten Singfähigkeiten des nar das /ua/ und das /alala/ gezählt. ${ }^{2040}$ Einem rein auf Vokalen ausgeführten Singen wird ein von Konsonanten unter-

\footnotetext{
${ }^{2038}$ Vgl. Volk 1994, 189 Anm. 69.

${ }^{2039}$ Volk 1994, 188.

${ }^{2040}$ Hier Kapitel 11.1.2.
} 
brochener, möglicherweise mehr rhythmisch fixierter Gesang entgegengesetzt. Entfernt könnte hier an melismatische gegenüber psalmodischen Vortrag zu denken sein, wie er für die viel jüngere Gregorianik unterschieden wird. Auch das Lied Dumuzi-Inana $J$ stellt die 'Liedsprecher' $\left(\check{s}^{i} r_{3}-\mathrm{dug}_{4}-\mathrm{dug}_{4}\right)$ den 'Melismen(sängern)' (ad-ša $\left.a_{4}-\breve{s}_{4}\right)$ gegenüber, von denen die einen den Gesang anheben, die anderen ihn senken. ${ }^{2041}$ Eine solche Parallelsetzung mit jüngeren auch rezenten Musikpraktiken kann allerdings lediglich der Analogiebildung dienen und sollte nicht zu verfrühten Deutungen verführen.

Angesichts seiner Inhalte, Sprache und Struktur ordne ich das Lied CT 58, 12 den Balbale zu und schließe daraus, dass über diesen Gattungsnamen ein Bezug zur hier bisher einmalig schriftlich fixierten Singpraxis dieser Lieder vorliegt, für die schnell aufeinanderfolgende Gegengesänge charakteristisch sind. ${ }^{2042}$

${ }^{2041}$ S. hier Kapitel 12.3.1 und T 89: Dumuzi-Inana J 30-32; vgl. in diesem Lied Rs Abschnitt 6 Z. 2 das unterschriebene su? , vielleicht als teb̂u(m) ,,absenken“ übertragen auch ,verdunkeln"?

${ }^{2042}$ Ausführlicher Kapitel 12.4.1. 


\section{Zusammenfassung}

Sumerische und akkadische Lieder der altbabylonischen Zeit enthalten keine konkreten Angaben zu ihrem 'Sitz im Leben' und ihrer möglichen Darbietungsform. Anhand der Bildung von Gattungsnamen, der enthaltenen Rubriken, im Text selbst beschriebene Handlungen sowie Sekundärtexten konnten dennoch beachtenswerte Daten zum möglichen Aufführungsrahmen, den Teilnehmern und der Funktion der Texte zusammengetragen werden. Dass ein Großteil der untersuchten Lieder ursprünglich für den öffentlichen Vortrag bestimmt war, legen die Gattungsnamen sowie die enthaltenen Rubriken und termini technici nahe. Fundkontext und Zustand der Tafeln lassen demgegenüber in Einzelfällen darauf schließen, dass sie in altbabylonischen Schreiberschulen (edubba'a) abgefasst und kopiert wurden. Eine aktive Verwendung im Kult kann vor allem bei Vertretern der sumerischen $\breve{s i r}_{3}$-Gattungen, den Hymnen Tigi und Adab, oder einigen der Balbale, ausgeschlossen werden, die sich auf Könige vergangener Dynastien der Ur III- und Isin-Zeit beziehen. Dennoch waren auch sie ursprünglich für einen kultischen Anlass verfasst worden, was an den Liedinhalten und ihrem Bezug zu Festanlässen aufgezeigt werden konnte. $^{2043}$ In den Hauptzentren der sumerischen Schreibtradition, Ur, Nippur und Isin, ${ }^{2044}$ dienten sie sicher nicht nur den Schreibern als Übungsvorlagen, sondern könnten dort auch von Gelehrten aus archivarischen Beweggründen verwahrt und studiert worden sein. Schließlich werden die untersuchten Lieder selten auf Schülertafeln angetroffen im Gegensatz zu den ohne Gattungsnamen versehenen Selbstlobhymnen sowie narrativen, ob epischen oder mythischen Dichtungen. $^{2045}$ Nur wenige Schriftwerke, die einen besonderen Platz in der sumerischen Überlieferung eingenommen haben, wurden in das erste Jahrtausend tradiert, worunter das Širgida Ninurtas Rückkehr, der Auszug des Ninurta oder auch das hymnische Širnamšub Ninisina $C$ fallen. ${ }^{2046}$ Die Verortung

\footnotetext{
${ }^{2043}$ Vgl. Sallaberger 1993, 141 zu Šulgi R; s. a. hier Kapitel 12.1.2.

${ }^{2044}$ Weitere sichere Herkunftsorte der Texte sind beispw. Kiš (Širna mšub Nisaba B) und Larsa (Širnamšub Ur-Namma EF).

${ }^{2045} \mathrm{Ob}$ auch die einkolumnigen Tafeln (im-gid ${ }_{2}-\mathrm{da}$ ) mit Tinney 1999, 160 grundsätzlich als Lehr- bzw. Übungstafeln zu werten sind, ist m. E. zu bezweifeln; zahlreiche der mit Gattungen versehenen Lieder wurden in solchen Formaten gehalten und könnten eventuell auch einer kurzfristigen Archivierung gedient haben; vgl. den Katalog über amerakütum-Klagen in Kapitel 7.4 und 13.3.

2046 Cooper 1978; van Dijk 1983; mA Kolophone bei Hunger 1968: 30 Nr. 44; vgl. das Tigi Nintu A (ETCSL 4.26.1), das in einer einzigen aB Version aus Nippur überliefert ist und
} 
der singulären akkadischen Lieder hinsichtlich ihres Anwendungsbereichs stellt sich als weitaus schwieriger dar. Hier fällt zudem der jeweilige Zustand der Texte ins Gewicht, das Schriftbild und die Sprache, worüber eine Unterscheidung zwischen Schreibübungen oder ad hoc niedergeschriebenen Texten und hochwertigen Bibliothekstafeln angesetzt werden kann. ${ }^{2047}$ Ganz anders stellt sich wiederum die Situation um die liturgischen Bala g̃ - und $\mathrm{er}_{2}$-Gebete, den Klagen des gala dar. Diese sind bis in das erste Jahrtausend hinein dem Kult verhaftet, komponiert wurden sie daher stets zum Zwecke des öffentlichen Vortrags.

\subsection{Inhalt und Kontext der Lieder}

Für die Aufführung der untersuchten Dichtungen werden grundsätzlich zwei Inhalte angesetzt: der Preis und die Klage. Während der Preis Göttern und ihren Tempeln auch in Bezug auf einen König gilt, ist die Klage mit ihrer Funktion eines Fürbittegebets ausschließlich Göttern gewidmet. ${ }^{2048}$ Reine Königshymnen, wie beispielsweise die Selbstlobhymnen des Šulgi und IšmeDagan, aber auch entsprechende akkadische Dichtungen altbabylonischer Könige sind nie mit Gattungsnamen versehen. Eine eigenständige Gruppe innerhalb der Kategorie des Preises bilden die Inana-Dumuzi-Lieder. Inhaltlich sind sie einem Kultgeschehen um Fruchtbarkeit und Fortpflanzung verpflichtet. ${ }^{2049}$ Mit ihren wechselnden Sprechern unterscheiden sie sich grundsätzlich vom 'Hymnus', der die Gottheit meist in der 2. oder 3. Person adressiert, und weisen somit eine andere Aufführungsgestaltung auf, als eine hymnische oder (be)klagende Gottesansprache.

In der Kategorie des Preises werden Wirkunsgsbereich und Eigenschaften der Gottheit adressiert. Eine direkte Anrede muss im Text nicht enthalten sein, so suchen zahlreiche Dichtungen auch in Erzählpassagen die Erhöhung und Herrschaft der Gottheit darzustellen. Damit können sowohl lyrische wie auch teilweise narrative Texte dem Götterpreis dienen.

dann wieder in mehreren nA Tafeln aus der Assurbanipal-Bibliothek von Ninive; Wilcke 1975, 235-239.

2047 Tafeln mit sauberem Schriftbild, wie der Ištar Hymnus des Ammiditana (RA 22, 170-171), Der leidende Gerechte (Lambert 1987) oder die Papuleg̃ara-Hymnen (Streck/Wasserman 2008) sind wohl dem Kontext von Schreib- oder Musikergelehrten zuzuordnen und waren durchaus auch für den öffentlichen Vortrag bestimmt; vgl. Kapitel 13.1.4.1, 13.1.1.2 und 13.3. Beim Dialog Nanaja und Muati (MIO 12, 52f.), der unvollständig zu sein scheint, oder der Amurrum-Hymne des Rīm-Sîn (OECT 11, 1), mit ungewöhnlichen grammatikalischen bzw. dialektalen Eigenheiten handelt es sich vielmehr um Übungen oder Kompositionsversuche; hier Kapitel 13.1.4 und 13.2.

2048 Lediglich die Uruk und Nippur Klage nennen als ihren Initiator den König Išme-Dagan, womit sie einem historischen Rahmen zugeordnet sind.

${ }^{2049}$ Solche Themen finden sich auch unter Vertretern der ši ir $_{3}$-Gattungen 
Im Bereich der Klage wird der öffentlich-gesellschaftliche vom individuellen Kontext unterschieden, hier stehen sich Zerstörung von Städten, Tempeln und ihre Beweinung durch Götter dem Wehklagen eines Einzelnen gegenüber. Es bleibt allerdings unklar, ob damit unterschiedliche Rahmen für die Darbietung verbunden sind und ein privater von einem öffentlichen Bereich zu trennen ist. ${ }^{2050}$ Insbesondere unter den akkadischsprachigen Kompositionen sind häufiger Klagen vertreten, in denen sich ein unbekanntes Individuum an seine Gottheit mit der Bitte um Erlösung von erfahrenem Leid wendet. Vorbilder aus der sumerischen Literatur sind hier Götterbriefe oder auch das einzige bekannte Eršaneša. Dass es sich hierbei nicht um reine 'Gebrauchsliteratur' handelt, zeigt sich an der versierten poetischen Sprache und Struktur der Texte. Der leidende Gerechte könnte dem Kontext einer Musikerinstitution (титти $(m)$ ) entstammen, ob der Text eine Bedeutung für die Kultpraxis hatte, ist nicht feststellbar.

Unter den Liedgattungen mit Instrumentennamen finden sich Vertreter beider Kontexte, des Preises und der Klage. Für die nach Šulgi B 77 (T 83) wahrscheinlich seit dem dritten Jahrtausend tradierten Gattungen Adab und Tigi kann rekonstruiert werden, dass sie für Festanlässe im Zusammenhang mit dem König verfasst wurden. Sie betrafen etwa eine Götterreise, eine Tempeleinweihung oder die Stiftung eines Votivobjekts, also Handlungen, die meist durch den König veranlasst und begleitet wurden. Dass die meisten Adab- und TigiLieder in nur wenigen Versionen überliefert sind, unterstützt weiter die Annahme, dass sie für singuläre Ereignisse komponiert und vorgetragen wurden. ${ }^{2051}$ Mit Beginn der ersten akkadischsprachigen literarischen Überlieferung in der ersten Hälfte des zweiten Jahrtausends wurden die sumerischsprachigen Hymnen dann durch akkadischsprachige Kompositionen verdrängt. Dies lassen nicht nur die im Liederkatalog KAR 158 genannten akkadischen Adab vermuten ${ }^{2052}$ sondern auch die bekannten Hymnen an die Göttinnen Ištar (RA 22, 170-171) und Nanaja (VS 10, 215) mit Fürbitten an einen König, die sowohl in ihrer strophischen Struktur wie auch in ihrem Inhalt den sumerischen Gattungen Tigi und Adab angelehnt sind. Insgesamt sind für die Könige der LarsaDynastie nur noch sehr wenige dieser Gattungen in sumerischer Sprache bekannt, für die Könige der ersten babylonischen Dynastie sogar gar keine. ${ }^{2053}$

${ }^{2050}$ S. hier insbesondere die Diskussion um die Eršahug g̃a, die Dichtungen Ein Mann und sein Gott (sumerisch) oder Der leidende Gerechte (akkadisch) auch in Bezug zu sumerischen Götterbriefen; hier Kapitel 12.3.2, 12.3.3 und 13.3.

${ }^{2051}$ So auch Vanstiphout 1999, 82.

${ }^{2052}$ Vgl. hier T 96: KAR 158 viii 9-11.

${ }^{2053}$ Die Ad ab-Lieder Gungunum A (ETSCL 2.6.2.1; Sjöberg 1973d, 24-31), Rìm-Sìn H (ETCSL 2.6.9.8; UET 6, 100) und Sin-iqišam A (ETCSL 2.6.7.1; Sjöberg 1973c; Dupret 1974), das trotz fehlender Unterschrift mit seiner abschließenden Fürbitte in Form einer u ru(n)-Rubrik wohl als ein Adab konzipiert ist. 
Die Überlieferung der sumerischen Hymnengattungen bis in mittelbabylonische und -assyrische Zeit ist nur noch über literarische Kataloge attestiert, die weitestgehend den Schreiberschulen zugeordnet werden.

Anders verhält es sich mit der nach einem Instrumentennamen gebildeten Gattung Bala g̃, aber auch mit dem ihr zugeordneten Eršema, das trotz der Kennzeichnung als Klage $\left(\mathrm{er}_{2}\right)$ ebenfalls nach einem Membranophon $\left(\mathrm{s}_{\mathrm{e}} \mathrm{m}_{3 / 5}\right)$ benannt ist. ${ }^{2054}$ Diese Kompositionen existierten unabhängig von den Namen regierender Könige. Hierin liegt auch begründet, weshalb ihre Tradierung als fester Bestandteil der Kultliturgie bis ins erste Jahrtausend hineinreichte. Sie gehörten außerdem zum Repertoire eines Priesterstandes, der in spätaltbabylonischer Zeit zunehmend an Bedeutung gewann. Seine Lieder kamen aus Anlass regelmäßiger 'prophylaktischer' Abwehr drohenden Übels zum Einsatz, oder aber sie begleiteten einmalige Ereignisse, beispielsweise Tempel- oder Kultbildrestaurierungen. Die auch akkadischsprachigen amerakütum oder auch $i n h u$-Lieder könnten den in einer speziellen Sprache (Emesal) vorgetragenen Gebeten des gala zur Seite gestellt worden sein.

Bezeichnenderweise finden sich unter den Gattungsnamen, die nach Instrumenten benannt sind, meist Perkussiva, mit Ausnahme des gi-gid 2 „Langflöte?“. Hierin zeigt sich, dass Saiteninstrumente und die mit ihnen erzeugte Musik nicht gattungsbildend sind. Von größerer Bedeutung für die musikalische Einordnung eines Liedes war offenbar der Klang eines Schlaginstruments, vielleicht auch auf ihm erzeugte Rhythmuspattern. Diese Beobachtung führt zu einem wichtigen Schluss hinsichtlich des Charakters der vornehmlich in Südund Mittelbabylonien ausgeübten religiösen Musik, den Ursprungsregionen der meisten sumerischsprachigen Gattungen, die nach Instrumentennamen gebildet sind. Sie scheint vornehmlich perkussiv gewesen zu sein, Melodie-, vor allem Saiteninstrumente sind anderen Bereichen wie auch späteren Entwicklungen der Musikpraxis vorbehalten.

Über $\breve{s i r}_{3}$-Komposita bezeichnete Lieder sind meist einer oder mehreren Gottheiten gewidmet. Unter ihnen finden sich auch solche, die einen Königspreis oder auch nur eine kurze Fürbitte für ihn enthalten, wobei in der Nennung des Königs kein Kriterium für die Zusammengehörigkeit einer Gruppe besteht. Vertreter der Gattung Širgida können beispielsweise mit und auch ohne Königspreis verfasst sein.

${ }^{2054}$ Zum namensgebenden balag̃ wäre in Erwägung zu ziehen, dass es für den untersuchten Zeitraum nicht auf das Instrument verweist, sondern sich auf die Bala g̃-Gottheiten bezieht, die zu den entsprechenden Stadtumrundungen und Prozessionen ausgeführt wurden; vgl. Gabbay 2007, 61-62; zu den Balag̃-Gottheiten im untersuchten Material s. hier die Kapitel 9.2.4, 9.4.4 und 7.1 mit einem bala g̃ der lukur. 
Zwar konnten für die Vertreter der mit šir ${ }_{3}$ gebildeten Liedgattungen teilweise gemeinsame Inhalte festgestellt werden, ${ }^{2055}$ in ihrer formalen Struktur sind sie aber eher uneinheitlich. Auch die Sprachform dieser Lieder ist häufig sehr unterschiedlich, so können einzelne Vertreter einen hymnisch liedhaften Charakter aufweisen, andere aber wieder längere erzählende Textpassagen enthalten. ${ }^{2056}$ Eine bemerkenswerte Ausnahme stellt das Širnamerima dar, das offenbar grundsätzlich aus einer Reihe von /amuzu/-Gebeten an verschiedene Götter bestand. ${ }^{2057}$

Einheitliche inhaltliche oder formale Kriterien für die Einordnung sind somit für die meisten $\breve{s i r}_{3}$-Gattungen nicht feststellbar. Der jeweilige Gattungsname scheint vielmehr auf ihre Funktion im kultischen Zusammenhang zu verweisen, so etwa das Širnamursag̃ g̃a „Heldenlied“, das Širšahula „Lied der Herzensfreude“, das Širkalkal „Lied des Kostbaren(?)“ und auch das Širnamerima „Feind(schafts)lied“. Dementsprechend könnte auch das Širgida als „Auszugslied“ auf seinen kultischen Sitz und nicht auf die musikalische Form verweisen. Nicht zu beantworten ist die Frage, ob mit den Gattungsnamen auch Darbietungsformen verbunden waren.

Eine Aussage zur Aufführungspraxis ließ sich über die in den Liedern auftretenden Rubriken treffen. Hier war vor allem eine Aufteilung nach kiruguEinheiten zu beobachten, bei Širnamgala, Širnamšub und dem einzigen Širnamursag̃a Iddin-Dagan A, wobei auch dies wieder nicht für alle Vertreter einer Gattung Geltung hat. Das Širnamerima Šulgi $S$ weist zudem eine abschließende kišu-Rubrik auf, die in ihm vollzogene Abtrennung einzelner Passagen über durchgezogene Linien könnte adäquat zur Kenzeichnung von kirugu-Einheiten fungieren. Aufgrund der enthaltenen Rubriken könnte bei diesen Liedern auf eine ähnliche Aufführungspraxis geschlossen werden. ${ }^{2058}$ Dieselbe Praxis haben sie mit den Balag̃-Liedern gemein, die bis ins erste Jahrtausend nach kirugu und kišu unterteilt werden. Beachtenswert ist, dass auch die akkadischsprachige Dichtung Agušaya $A / B$ über dieselben Rubriken verfügt und somit wohl in gleicher Form zur Aufführung kam. Hierin zeigt sich, dass im Zuge der 'Akkadisierung' kultischer Gesänge zwar ein Wechsel der Sprache unternommen, dieselbe Praxis für ihre Aufführung im Kult aber dennoch beibehalten wurde.

${ }^{2055}$ Beim Širnamšub sind jedoch auch die Inhalte sehr unterschiedlich, die meisten sind Hymnen, nur Nisaba B ist eine Klage; hier Kapitel 12.2.4.

${ }^{2056}$ Am deutlichsten sind diese Unterschiede an der Gattung Širgida nachzuvollziehen; hier Kapitel 12.2.6.

${ }^{2057}$ Kapitel 12.2.5.

${ }^{2058} \mathrm{Zu}$ kirugu und kišu auch als mögliches Merkmal des Repertoires des gala s. hier Kapitel 14.1.5. 
Anders als die šir ${ }_{3}$-Lieder sind mit er ${ }_{2}$ „Klage, Träne“ gebildete Gattungsnamen meist einheitlich in ihrer Sprache, ihrem Inhalt und ihrer Struktur. Variationen in der motivischen Darstellung werden in den Eršema angetroffen. Doch auch wenn in ihnen zuweilen ein Preis formuliert oder aber mythologische Themen verarbeitet werden, ${ }^{2059}$ so bleiben sie dennoch dem Topos 'Zerstörung und Verlust' verpflichtet. Beachtenswert ist zudem, dass keine der mit $\mathrm{er}_{2}$ gebildeten Klagegebetsgattungen Rubriken aufweist. ${ }^{2060}$ Mit dem jeweiligen Gattungsnamen sind somit die einheitliche Struktur und Motivik, die Funktion und wahrscheinlich auch eine festgelegte Vortragsform definiert.

Dem Repertoire des gala-Priesters können die Gattungen Širnamgala und Širnamšub zugeordnet werden. Auch wenn sie nicht wie Balag̃ und Eršema als Klagen formuliert sind, so gehörten sie dennoch wohl ursprünglich seinem Wirkungsbereich an. Die Širnamšub wurden ihren Inhalten nach zu Götterreisen, dem Einzug in den Tempel oder auch zu einer kultischen Reinigung gesungen. In den Širnamgala wird hingegen der Erhöhung und Einsetzung des Königs mehr Gewicht beigemessen. Von Bedeutung ist hier die Rolle weiblicher Gottheiten wie Inana oder Ninisina, die den König vor die Götterversammlung führen. Ähnliche Inhalte und Kontexte konnten für die akkadischsprachigen Hymnen an Mami/Aruru (CT 15, 1-2; HS 1884) rekonstruiert werden. ${ }^{2061} \mathrm{Zu}$ all diesen Ereignissen, bei denen eine rituelle 'Grenzüberschreitung' stattfand, war ein besonderer Schutz über die Besänftigung von Gottheiten notwendig, worin der Grund für ihre Zuordnung zum gala vorliegt.

Außer dass auch akkadische hymnische Dichtungen, darunter die šir ${ }_{3} t a-$ na/itti( $(m)$ oder Vertreter der Gattung pāru $(m)$, für den Vortrag bei einem offiziellen Festgeschehen bestimmt waren, lassen sich über die Gattungsnamen selbst fast keine Rückschlüsse zu Anlass und Funktion ziehen. Lediglich das šir $_{3}$ kummi „Lied des Heiligtums“ scheint auf den Vortragsort oder auf den rituellen Anlass der Komposition zu verweisen. Der in der Überschrift dieses Liedes angegebene Terminus inhu ordnet es wiederum dem Kontext der Klage zu. $^{2062}$

Details zur Aufführungspraxis konnten auch über die Liedinhalte erschlossen werden. In den Hymnen an Ištar, Papuleg̃ara und Bēlet-ilī finden sich Angaben zu den Beteiligten, als Vorträger treten Beschwörungspriester (āšipu), gala-Priester und auch größere Frauenchöre auf, die möglicherweise begleitend inhu-Klagen ausführten. ${ }^{2063}$ Neben allgemeinen Beschreibungen von

\footnotetext{
${ }^{2059}$ Vor allem die Eršema an Iškur oder an Ninisina; hier Kapitel 12.3.1.

${ }^{2060}$ Mit Ausnahme des g̃išgi g̃al in einem Textzeugen des Eršaneša; hier Kapitel 12.3.3.

${ }^{2061}$ Vor allem am Anfang der Hymne HS 1884 nachzuvollziehen; hier Kapitel 13.1.5.2.

${ }^{2062}$ S. Kapitel 13.1.3 zu T 95: CT 15, 3-4:1-3.

${ }^{2063}$ In den šir ${ }_{3}$ tana/ittim Ištar Louvre und an Papuleg̃ara (Kapitel 13.1.1), der Hymne HS 1884
} 
Opferhandlungen und Prozessionen werden auch konkrete Anlässe genannt, etwa Bauunternehmen, Objektweihungen oder das eššešsum-Fest.

Unter den Liedgattungen aus dem Themenkomplex Fruchtbarkeit und Sexualität, auch in Bezug auf das Hirtentum, gruppieren sich die auch sprachlich verwandten Balbale und Kung̃ar sowie das nur einmal belegte Uadi, welche vornehmlich dem Götterpaar Dumuzi und Inana gewidmet sind. In zahlreichen Vertretern dieser Lieder wird dennoch auf einen König Bezug genommen, weshalb für sie der Rahmen einer Heiligen Hochzeit oder entsprechende königliche Fruchtbarkeitsriten angesetzt werden. Ihre Anwendung in der offiziellen Kultpraxis legen außerdem die Aussagen der Sekundärquellen nahe, in denen Balbale und Kung̃ar als Königshymnen ausgewiesen werden. An akkadischen Dichtungen sind dieser thematisch-inhaltlichen Gruppe die spätaltbabylonischen $\operatorname{irātu}(m)$ 'Brust(-Gesänge)' zuzuordnen, die ebenfalls die Liebesverbindung der Ištar zu einem König thematisieren.

Eine Anwendung im privaten Rahmen ist für das akkadische pāru(m) an Ištar anzunehmen. Auch für einige Vertreter der Balbale könnte angenommen werden, dass sie zu Hochzeitsfeierlichkeiten privater aber dennoch höher gestellter Persönlichkeiten gesungen wurden. ${ }^{2064}$ Für die Aufführung dieser Lieder kann eine lebendige Darbietung rekonstruiert werden, die von einem schnell aufeinander folgenden Wechsel von solistischem und chorischem Gesang geprägt ist. ${ }^{2065}$ Anders sind die Vortragsformen der kultischen Liebeslyrik vorzustellen, die möglicherweise auch in einer szenischen Form dargeboten wurden. Bei einigen singulären akkadischen Dichtungen bleibt grundsätzlich die Frage, ob sie überhaupt einem religiösen Kontext zuzuordnen sind, oder nicht vielmehr der Unterhaltung dienten. ${ }^{2066}$

\subsection{Singpraxis und Musikperformance}

Anhand der Liedrubriken und ihrer Bedeutung, technischen Termini in Primärund Sekundärtexten sowie glossenartigen Angaben konnten verschiedene Details zur möglichen Vortragspraxis der erörterten Lieder aufgedeckt werden. Es lassen sich unterscheiden: Hinweise zur Zusammenstellung des beteiligten Musikerensembles, zum Ablauf des Liedvortrags oder begleitenden Handlungen, zum tonalen und strukturellen Verlauf der Lieder, sowie zu den Singarten. Es steht außer Frage, dass die hier gebotenen Rekonstruktionen auf wenigen

an Bēlet-ilī (Kapitel 13.1.5.2); in der fragmentarischen Ištar-Hymne VS 10, 213 könnte auch ein Hinweis auf eine instrumentale Begleitung durch tigiātum vorliegen; s. Kapitel 13.1.5.1.

${ }^{2064}$ Cooper 1997 zum Fokus auf 'Frauenthemen' in Balbale-Liedern; hier Kapitel 12.4.1.

${ }^{2065}$ Kapitel 12.4.1 auch in Bezug auf das Liebeslied CT 58, 12 in Kapitel 14.2.3.

${ }^{2066}$ So Groneberg 2002 zum Faithful Lover ('Der Treue Liebhaber'); hier Kapitel 13.2.3. 
und zudem schwer deutbaren Quellendaten beruhen und damit kein endgültiges Bild von der altbabylonischen Vokalpraxis zulassen.

Die Lieder wurden entweder rein vokal oder mit instrumentaler Begleitung vorgetragen. Für die sumerischen Lieder Tigi, Adab sowie Balag̃ und Eršema ist diese wohl vornehmlich perkussiv. Anders verhält es sich mit den akkadischsprachigen irātu $(m)$ oder den bislang unbekannten šitru( $m)$, die nach Ausweis des Liederkatalogs KAR 158 in unterschiedlichen Modi mit einem Saiteninstrument, wahrscheinlich dem ${ }^{\tilde{g} i \mathrm{~s}} / \mathrm{zami} /$ begleitet wurden. Aus dieser Beobachtung zur instrumentalen Begleitung von sumerischen und akkadischen Kompositionen lässt sich für die Spielanweisungen aus Nippur (Kapitel 14.2.2) rückschließen, dass sie wohl eher auf die Aufführung akkadischsprachiger oder zumindest 'akkadisierter' Dichtungen des Lipit-Eštar verweisen. Schließlich wird in ihnen auf ein Saiteninstrument und die auf ihm gespielten Skalen Bezug genommen. Rohrinstrumente sind zur Begleitung von Liedern selten. Sicher ist, dass der Gattungsname gi-gid 2 ,langes Rohr" eine solche anzeigt. Sekundärquellen bringen außerdem den Nachweis, dass auch Klagegesänge zu Bestattungsfeiern mit Blasinstrumenten, vielleicht Schalmeien, begleitet wurden. ${ }^{2067}$

Größe und Zusammenstellung eines Musikerensembles richten sich nach Funktion und Kontext der vorgetragenen Lieder. Für die Klageliedgattungen des gala sind solistischer Vortrag, aber auch chorische Darbietungen nachgewiesen, letztere möglicherweise responsorial. Der Priester begleitete seine Lieder selbst auf einem Rhythmusinstrument, den Membranophonen balag̃, lilis oder dem šem ${ }_{3}$, akkadisch halhallatu $(m)$, das hinsichtlich der Beleglage für das erste Jahrtausend möglicherweise auch als Idiophon zu deuten ist. Für den Vortrag von Preisliedern können größere Vokal- und Instrumentalensembles zusammengestellt sein. Erinnert sei hier an die tigiātu $(m)$, bei denen es sich um eine Gruppe von Rahmentrommelspielerinnen handeln könnte. Die Ausgabenliste YOS 5, 163 (WS 5) aus Ur beschreibt das Zusammenwirken eines einzigen Saiteninstrumentenspielers (nar-sa), einer Gruppe von männlichen Vokalisten (nar-a- $\mathrm{u}_{3}-\mathrm{a}$ ) sowie eines nar-gal.

Den strukturellen und tonalen Verlauf insbesondere der Liedgattungen Tigi und Adab markieren die Rubriken sagida und sag̃ara. Werden diese beiden Rubriken auf die Termini zi-zi und $\tilde{g} a_{2}-\tilde{g} a_{2}$ bzw. šu $u_{2}-\breve{s ̆}_{2}$ bezogen, lässt sich ein musikalischer Verlauf rekonstruieren, der sich über ein 'Anheben' und 'Niederlegen' des Gesangs kennzeichnet. Unglücklicherweise bleibt die konkrete Bedeutung dieser Anweisungen unklar, vor allem da nicht deutlich wird,

${ }^{2067}$ S. Kapitel 12.1.4 und 11.2.2 zu lexikalischen er ${ }_{2}$-Komposita; ob möglicherweise auch das Balbale durch Blasmusik begleitet wurde, bleibt unsicher; s. Kapitel 12.4.1. 
ob sie sich auf die Gestaltung einzelner Verse oder ganzer Liedabschnitte beziehen. Es wurde der Versuch unternommen, sie mit unterschiedlichen Singarten in Zusammenhang zu bringen, sodass über das 'Niederlegen' des Gesangs ein Bordun oder psalmodischer, über das 'Anheben' ein melismatischer Vortrag bezeichnet wäre. Andererseits legt die Bildung der Namen mit sa „Saite“ nahe, die zwei Rubriken - einleitend das sagida, abschließend das sag̃ara - auf den modalen Verlauf zu beziehen und ein Hoch- und Niederstimmen eines Saiteninstruments zu vermuten. Variationen oder Abwandlungen im sagida, ob in seiner melodischen Form oder instrumentalen Begleitung, zeigen weitere Rubriken an, das barsud und das šaba-TUKU.

Das abschließende uru(n) von Adab-Liedern könnte entweder eine kultische Handlung an einem bestimmten Ort oder aber eine Singart anzeigen. ${ }^{2068}$

Auf die Handhabe der begleitenden Instrumente sowie auf kultische Handlungen an verschiedenen Stationen eines Liedvortrags verweisen die Rubriken kirugu, kišu und šaba-TUKU. Letzteres, das ähnlich dem g̃išgigal in gänzlich unterschiedlichen Gattungen vertreten ist, gibt möglicherweise die Position eines Instrumentenensembles und seiner Spieler für die Aufführung an. Andererseits könnte mit ihm auch der Wechsel von Liedpartien zwischen verschiedenen Ensembles, vielleicht auch eine Art instrumentales Zwischenspiel angezeigt sein.

Liturgische Handlungen, die den Umgang mit einem Instrument betreffen können, markieren die für das Repertoire des gala charakteristischen Rubriken kirugu und kišu. Das kirugu teilt die langen liturgischen Lieder in einzelne Gesänge ein, die an unterschiedlichen Stationen eines längeren Festgeschehens vorgetragen wurden. Den Abschluss des gesamten Liedvortrags bildet das kišu, was gleichzeitig das Abdecken des heiligen Instruments anzeigt.

Den Wechsel zwischen Solosänger und Chören, die nach verschiedenen Stimmlagen und Singarten unterschieden werden, zeigt die Rubrik g̃išgigal $/$ mehru $(m)$ an. Am bislang einzigen altbabylonischen Lied CT 58, 12 mit glossenartigen Gesangsanweisungen war zu sehen, dass ein solcher Wechsel innerhalb eines einzigen Liedes weitaus häufiger stattfinden konnte, nämlich nicht nur nach längeren Liedabschnitten, sondern auch zur Mitte einzelner Verse. Die Form der Angaben in diesem Lied lässt neben der responsorialen oder antiphonalen Technik auch eine Mehrstimmigkeit vermuten, die sich möglicherweise nicht nur über die Tonhöhe, sondern auch über die Singart nach psalmodischem $\left(\begin{array}{lll}\check{s i r}_{3} & \mathrm{dug}_{4}\end{array}\right)$ und melodiös-melismatischem $\left(\mathrm{ad}-\breve{s ̆ a}_{4}\right)$ Gesang unterscheidet. ${ }^{2069}$

\footnotetext{
${ }^{2068}$ Vgl. beispw. das aus dem Synagogen-Gottesdienst übernommene Graduale in der römischkatholischen Liturgie, das nach dem Ort, an dem es ausgeführt wurde - gradus „Stufe“ - benannt ist und solistisch vorgetragen wurde.

${ }^{2069}$ S. Kapitel 14.1.4 auch zu T 89: Dumuzi-Inana J 30-32.
} 
Bei den Formen der Mehrstimmigkeit wäre an einen Bordun zu denken oder an eine organale oder auch heterophone Singpraxis. Andererseits könnten sich die verschiedenen 'Chorstimmen' auch abgewechselt haben, beginnend mit einer melismatisch angehobenen 'Frage' (zi-zi), auf die eine rhythmisch und in tieferen Stimmlagen angesetzte schließende 'Antwort' folgte ( $\tilde{\mathrm{g}} \mathrm{a}_{2}-\tilde{\mathrm{g}} \mathrm{a}_{2}$ oder $\left.\breve{s} \mathrm{u}_{2}-\breve{s}_{2}\right)_{2}{ }^{2070}$ Bezeichnend ist, dass den Texten keinerlei Informationen zum Rhythmus zu entnehmen sind, obwohl mehrere Gattungen mit Namen von Perkussionsinstrumenten gebildet sind. Denkbar wäre daher, dass sie nicht nur das begleitende Instrument, sondern zugleich den für ihn charakteristischen Rhythmus angezeigt haben.

Auch wenn verschiedene Formen der schriftlichen Fixierung des musikalischen Verlaufs - der Melodieführung, der Folge von Doppelgriffen oder dem Wechsel von Skalen - nachgewiesen sind, ${ }^{2071}$ so kann von einer 'Notation' in unserem heutigen Sinne noch nirgends die Rede sein. Es zeigt sich allerdings, dass es den Schreibern und Ausführenden ein Bedürfnis war, den aufführungstechnischen Verlauf der Lieder schriftlich festzuhalten. Eine standardisierte Form der Fixierung bestand offensichtlich für die sumerischen Gattungen Tigi, Adab und Zamzam, deren tonaler Verlauf über die Rubriken sagida und sag̃ara angezeigt wurde. Die Entwicklung neuer Formen wie der Glossen oder von Tabulaturen, die den Zweck verfolgten, den Tonhöhenverlauf eines Liedes 'lesbar' zu machen, könnten aus einem verstärkten Bemühen um die korrekte Überlieferung einer aussterbenden Singpraxis resultieren.

Die Musikperformance im Verlaufe eines gesamten Festgeschehens wird vom Wechsel spezialisierter Solisten und Ensembles bestimmt, die als eine rein vokale Gruppe oder auch mit instrumentaler Begleitung auftraten. Solistisch vorgetragene Klagen wurden durch einen Chor, der auch von Frauen und damit hohen Stimmen gebildet wurde, unterstützt. Instrumentalgruppen, die vor allem aus Pekussionisten bestanden, begleiteten lobpreisende Opferhandlungen und Festprozessionen. Der Einsatz von Saiteninstrumenten im öffentlich-kultischen Bereich ist erst für die irātu(m)-Lieder spätaltbabylonischer Könige attestiert. In diesem Zusammenhang sei an die parsu $u(m)$-Rituale von Sippar erinnert, in deren Verlauf auch nar-sa auftraten. ${ }^{2072}$ In keiner anderen Stadt sind ähnlich viele Saiteninstrumentalisten und entsprechende Tempeldienste attestiert.

\footnotetext{
${ }^{2070}$ Kapitel 14.2.1.

${ }^{2071}$ Kapitel 14.2.2 zu gennum und zennum als eine Art Tabulatur für das g̃iš/zami/; Kapitel 14.1.1 zur Angabe von Skalenwechsel über die Rubriken sagida und sa g̃ara.

${ }^{2072}$ Hier Kapitel 9.6.3.1.3; zu sumerischer vs. akkadischer Musiktradition s. a. Michalowski 2009 in Bezug auf die Termini musiktheoretischer Texte.
} 
Auch wenn die neu komponierten akkadischen Lieder den traditionellen im Kult erforderlichen Funktionen und Abläufen angepasst waren, so lässt sich an ihnen dennoch die Einführung einer neuen Musikpraxis nachvollziehen. Dieser Wandel scheint sich schrittweise vollzogen zu haben. So sind zu Zeiten der Larsa-Könige noch sumerische Adab-Lieder bezeugt mit den für sie gängigen Rubriken sagida, sag̃ara und ihren Unterrubriken. Könige der ersten babylonischen Dynastie veranlassen zunehmend die Komposition neuer Liedformen, die in einer anderen Sprache verfasst und einer neuen Musikpraxis verhaftet sind. Vereinzelt wird dennoch auf frühere Strukturen zurückgegriffen und die ursprünglich für das Sumerische konzipierten liturgischen Rubriken beibehalten. Die Aufteilung des Liedes Agušaya nach kirugu-Rubriken könnte als ein singulärer Versuch des Hammurabi zu deuten sein, die überwiegend sumerischsprachige Liturgie durch entsprechende akkadische Dichtungen zu ersetzen. ${ }^{2073}$ Der Vortrag in einer neuen Sprache war sicher auch mit Veränderungen in der Vortragsweise verbunden, der sich möglicherweise über gezielte Studien der Verstruktur und der Stilfiguren ermitteln ließe. Von der jeweiligen Sprache und der zugrunde liegenden Instrumentalpraxis unabhängig ist schließlich der 'Gegengesang' (g̃ išgiğgl), weshalb er seine Bedeutung für alle Bereiche der vokalen Praxis beibehält und auch beispielsweise in den neu komponierten akkadischen $\operatorname{irātu}(m)$-Liedern, die auf Saiteninstrumenten begleitet wurden, über die entsprechende akkadische Angabe mehrum zur Anwendung kommt.

${ }^{2073}$ Schwierig bleibt die Einordnung der sumerischen Hymne Abi'êšuh A an Marduk mit nur einem ersten kirugu; van Dijk 1966-67. 



\section{SCHLUSSBETRACHTUNG UND AUSBLICK}

Die in dieser Arbeit unternommene detaillierte Sicht verschiedener Textarten zu einer bislang in der Forschung nicht in dieser Weise angesetzten Fragestellung stand vor der Schwierigkeit, die unterschiedlichen Quellenaussagen und Detailinformationen zu einem Bild zusammenzuführen, das zum einen den sozialen Hintergrund und die Organisation von Musikern, zum anderen die Inhalte und Aufführungsformen der von ihnen vorgetragenen Lieder darzustellen vermag.

In der Auswertung von Alltagsdokumenten und literarischen Texten zu den Musikerberufen zeigte sich, dass sich die Aussagen einerseits ergänzen, andererseits jedoch disgruent und lückenhaft sind. Vor allem in der Terminologie wurden erhebliche Unterschiede ausgemacht, so sind zahlreiche der Berufsnamen, beispielsweise gala-tur, balag̃-di oder Spezialisierungen des nar, wie nar-a- $\mathrm{u}_{3}-\mathrm{a}$ und nar $\mathrm{um-mi-a}$, auf eine Textgattung beschränkt, wodurch die erhaltenen Informationen bezüglich ihrer Berufsinhalte einseitig ausfallen. Die Anwendung der Terminologie ist somit von der jeweiligen Textgattung und ihrer Funktion abhängig, bezeichnend ist hier beispielsweise auch die Fülle an singulär belegten Termini in lexikalischen Listen, zu denen außer über ihre wörtliche Bedeutung nur selten weitere Details erschließbar sind. ${ }^{2074}$

Wichtig für die Einordnung verschiedener Textgattungen sind vor allem auch Daten zu den Fundumständen, worüber direkte Aussagen zur Zusammenstellung eines Musikerarchivs möglich werden. Dies ist hier nur am Beispiel des zusammenhängenden Ur-Utu-Archivfunds von Sippar oder des UrNininsina von Isin möglich gewesen, zukünftige und gezielt zu diesem Thema gestellte Untersuchungen könnten hier neue Erkenntnisse erbringen. ${ }^{2075}$

In der prosopographischen Auswertung der Alltagsdokumente zeigte sich, dass auch wenn die Hauptmusikerberufe gala und nar in allen Hauptstädten des babylonischen Raums vertreten waren, dennoch große Unterschiede in ihrer Verteilung und Organisation bestanden. Dies betraf zunächst die ranghöheren Ämter gala-mah und nar-gal, was auch auf politische und historische Veränderungen in der altbabylonischen Zeit zurückgeführt werden kann.

Aufgaben und Einfluss des gala-mah-Priesters nahmen von der früh- bis zur spätaltbabylonischen Zeit in den wichtigsten Stadtzentren Sippar und Kiš deutlich zu. Ihm oblag in der Tempelverwaltung die Organisation großer Götterfeste aber auch höher gestellte Privatpersonen betreffende Kultrituale

\footnotetext{
${ }^{2074}$ Vgl. lediglich zum nar $\mathrm{gu}_{3} / \mathrm{inim}-\mathrm{bal}$-bal Kapitel 12.4.1.

${ }^{2075}$ Vgl. in diesem Sinne Löhnert 2008 und Shehata 2009.
} 
$($ parsu $(m)){ }^{2076} \mathrm{Im}$ Vergleich zur literarischen Evidenz, wo Existenz und Wirken des gala eng mit der Göttin Inana verbunden sind, zeigte sich dem entgegen in den Verwaltungstexten, dass er sowohl männlichen wie auch weiblichen Gottheiten dienen konnte. Während in frühaltbabylonischer Zeit ausschließlich ein einziger gala-mah im Dienste der Hauptgottheit einer Stadt amtierte, sind für die spätaltbabylonische Zeit an verschiedenen Tempeln einer Stadt entsprechende Priesterämter attestiert. Diese Beobachtung ist zum Teil auf 'Kultverschiebungen' zurückzuführen und auf die Übernahme ursprünglich in Südbabylonien beheimateter Götter nach Nordbabylonien. Für diese Zeit ist zudem eine verstärkte Tätigkeit von gala-mah im Kult weiblicher Gottheiten $\mathrm{zu}$ beobachten, zu nennen sind für Sippar Annunītum, Șarpanītum und Tašmētum, für Kiš die usprünglich urukäischen Göttinnen Inana und Nanaja, für Dilbat möglicherweise der Kult der Ninegala.

Im Umfeld und unter der Aufsicht des gala-mah befanden sich vielfach Gruppen von Frauen, darunter kezrētu $(m)$, harimātu $(m)$, möglicherweise auch die kulmašiātu $(m)$. Primär waren diese wohl nicht als Musikerinnen tätig, sie könnten dennoch begleitend zu seinen Darbietungen den Chor gestellt haben. Dass der solistische Klageliedvortrag eines solchen Priesters durch größere Gruppen von 'Klageweibern' aber auch von gala begleitet wurde, bestätigen literarische Beschreibungen (z. B. T 27).

Den rituellen Handlungsbereich des gala kennzeichnen 'Grenzübergänge'. In diesem instabilen Zustand oblagen ihm die Kommunikation mit dem Göttlichen und die Abwendung möglichen Übels. Dies erreichte er über die Besänftigung der Gottheit mithilfe seines Gesangs und seiner Perkussiva. In früheren Studien wurde das Wirken dieses Priesters auf den Vortrag von Klagen beschränkt, die zunächst Bestandteil von Bestattungszeremonien waren, schließlich als feste Liturgie (Balag̃, Eršema, Eršahugãa) den regelmäßigen Tempelgottesdienst bildeten. Darüberhinaus lässt sich hinsichtlich der Inhalte der ihm zugeordneten Širnamgala aber auch anhand von Andeutungen in der akkadischen Hymne an Bēlet-ilī (HS 1884) mutmaßen, dass er auch bei der Einführung des Königs vor die Götterversammlung stellvertretend für eine weibliche Gottheit oder als Mittler und Bote fungierte. Hierdurch ließe sich auch die inhaltliche und funktionale Verwandtschaft des gala zu Ninšubur nachvollziehen. ${ }^{2077}$ Die hymnischen Širnamšub thematisieren außerdem freudige Anlässe, wodurch die Beschränkung dieses Priesters auf den Kontext der Klage zumindest für die frühaltbabylonische Zeit zu revidieren wäre. ${ }^{2078}$

\footnotetext{
${ }^{2076}$ Kapitel 9.6.3.1.

2077 Gabbay 2008 und hier Exkurs I 6.3.4.

${ }^{2078}$ Ausführlich auch in Bezug zu den parșu(m) von Sippar hier Kapitel 6.3.5.
} 
Ob sich der gala schließlich durch ein verändertes Geschlecht oder Gender auszeichnete, konnte nicht endgültig bewiesen werden. Zumindest könnte für den Vortrag seiner Klagen sowie für die begleitenden Chöre angesichts der teilnehmenden Gruppen eine hohe Stimmlage vermutet werden.

Für den nar-gal wurden hinsichtlich seiner Stellung in der Administration gegenteilige Beobachtungen gemacht, was wohl größtenteils mit der Herkunft der untersuchten Texte zu begründen ist. Eine hohe Stellung kam ihm nach Texten der frühaltbabylonischen Zeit aus Nippur und Ur zu, die für die spätaltbabylonische Zeit nicht mehr beobachtet werden kann. Dies mag mit der Verlagerung seiner Berufsinhalte zusammenhängen. In frühaltbabylonischer Zeit ist sein Dienst an einer Gottheit auch aus der Titulatur als ,nar-gal des Gottes NN" zu ersehen. ${ }^{2079}$ Unter Rìm-Sîn von Larsa und zunehmend unter Hammurabi kann beobachtet werden, dass individuelle nar-Musiker über die Vergabe von Lehensfeldern eine enge Verbindung zum Königshaus aufweisen (Kapitel 9.2.2.3). Auch der nar-gal scheint zunehmend der Institution des Palastes verpflichtet zu sein, wo er die Aufsicht über die Organisation musikalischer Darbietungen nicht nur für den König, sondern auch bei Götterfesten innehatte. In diesem Institutionswandel für den Beruf des nar-gal könnte möglicherweise der Grund für die dürftige Beleglage im untersuchten spätaltbabylonischen Material sein, das hauptsächlich die Tempeladministration dokumentiert. Ähnlich der von N. Ziegler in Mari beobachteten Aufgaben des obersten Palastmusikers ${ }^{2080}$ kann auch für den babylonischen Raum der spätaltbabylonischen Zeit festgestellt werden, dass dem nar-gal verschiedene künstlerische Berufsgruppen unterstellt waren, darunter die huppî $(m)$, aluzinnu(m) oder auch die $\operatorname{tigiātu}(m)$.

Die neue Verpflichtung des nar-gal am Palast könnte mit politischen Interessen zu begründen sein. Über den Wirkungsbereich des obersten Musikers, der auch die Aufsicht über die musikalischen Darbietungen am Tempel innehatte, konnte der König Einfluss auf die dort vorgetragenen Hymnen und Preislieder nehmen und so womöglich auch im Kult propagandistisch für seine eigenen Interessen agieren.

Gänzlich dem Palast unterstellt und von ihm unterhalten sind schließlich größere Gruppen von weiblichen wie männlichen, aber auch auf bestimmte Instrumente spezialisierte nar-Musiker, die dort eigene Häuser bewohnten, wo sie möglicherweise auch ausgebildet wurden. Dies zeigte sich insbesondere an den Texten des Lederarchivs von Isin (Kapitel 9.4.3.2) sowie an den Musikerinnenlisten aus Larsa (Kapitel 9.2.2.4). Hierin bestätigt sich, dass in den dynastischen Hauptstädten, Isin, Larsa und wohl auch Babylon am Königspalast

${ }^{2079}$ Kapitel 5.2.2, anhand von Belegen aus Larsa und Ur.

${ }^{2080}$ Ziegler 2007, 7-12. 
Musiker versammelt und von ihm unterhalten wurden. Dies sollte nicht nur der Prestigebildung oder der Unterhaltung des Königs dienen. Schließlich traten die dem Palast zugeordneten Instrumentalistinnen tigiātu(m) (Kapitel 5.4.1) auch bei Kultfesten auf. Ihre Auftritte beschränkten sich hier allerdings auf den Kult weiblicher Gottheiten.

Bemerkenswerte lokale Unterschiede sind schließlich für die Spezialisierungen des nar bekannt geworden. Diese könnten mit der Form der Kultfeste, vor allem mit den sie begleitenden Musikdarbietungen zu begründen sein. Der auf Ur beschränkte Terminus nar-a- $\mathrm{u}_{3}-\mathrm{a}$ bezeichnet meines Erachtens einen auf eine bestimmte Singart spezialisierten Vokalisten oder auch Klagesänger, der möglicherweise primär im Kult des Mondgottes Nanna/Sîn auftrat. ${ }^{2081}$ Für Nippur wurde wiederum ein nar um-mi-a, ein „Musikgelehrter“ bekannt. Sein lokales Wirken als Komponist oder auch 'Musikwissenschaftler' ist durch die besondere Stellung der Stadt Nippur zu erklären, welche bereits antik als das Zentrum sumerischer Gelehrsamkeit galt. Für diese Stadt ist insgesamt die Organisation und Einrichtung von Musikerämtern und Pfründen sehr ausgeprägt, auch da sie im Mesopotamien der altbabylonischen Zeit die Position eines bedeutenden religiösen Zentrums einnahm. Aus dieser Stadt ist schließlich auch die größte und wohl sehr einflussreiche nar-Familie des Lu-Ninurta bekannt. Im Gegensatz dazu nahmen in den übrigen Städten nar-Musiker eine eher untergeordnete Stellung ein.

Migration von Musikern ist im altbabylonischen Material mit Ausnahme der im Zusammenhang von Kultverschiebungen auftretenden gala-mah kaum dokumentiert. ${ }^{2082}$ Vereinzelt wurde versucht, die Herkunft einer Person am theophoren Namenselement oder auch an der Familiengottheit nachzuvollziehen. ${ }^{2083}$ Nähere Hintergründe einer Migration oder auch Daten zu reisenden Musikern lässt die Quellenlage für den babylonischen Raum nicht zu, reichhaltiger ist hierzu das Material zu den nar der Ur III-Zeit oder auch zu den altbabylonischen Musikern von Mari. ${ }^{2084}$

\footnotetext{
${ }^{2081}$ Allerdings wird er literarisch auch als Instrumentalist beschrieben; hier Kapitel 5.4.3.

${ }^{2082}$ S. aber den im Brief AbB 14, 50 (=VAB 6, 246) genannten subaräischen gala, der im Hause eines Babyloniers unterkommt; dazu auch Renger 1969, 194 Anm. 899.

${ }^{2083}$ Beispielhaft Kalla 2002, 123-169; s. a. Exkurs II 8.1.1.

${ }^{2084}$ Pruzsinszky 2007; Ziegler 2007; ob sich hinter dem Ausdruck nar $\mathrm{ra}_{2}$-gaba (hier Kapitel 9.2.2.3) ein reisender Musiker verbirgt, lässt sich vorerst nicht klären.
} 
Für die Unterscheidung der zwei Hauptmusiker gala und nar lässt sich zusammenfassen, dass diese nicht wie bisher vielfach angenommen auf inhaltlichen oder funktionalen Kriterien beruht. Eine Abgrenzung über das von ihnen gesungene Repertoire nach Hymnen für den nar und Klagen für den gala oder auch nach der Sprache muss hinsichtlich der hier erbrachten Ergebnisse revidiert werden. ${ }^{2085}$ Belege aus Larsa und Ur ordnen auch nar dem Bereich der Klage zu (nar tassistim; nar-a- $\mathrm{u}_{3}-\mathrm{a}$ ). Daneben gehören dem Repertoire des gala auch Hymnen im Emegir (Širnamgala, Širnamgub) und wohl auch in akkadischer Sprache (Agušaya $A / B)$ an. Ihre Unterscheidung ist weitaus differenzierter und zudem über begriffliche Kriterien anzusetzen. ${ }^{2086}$ Das Wort nar fasst in sich alle künstlerischen und musikalischen Tätigkeitsfelder zusammen und bezeichnet in erster Linie instrumental oder vokal musizierende Personen, die sich auch nur sekundär mit der Ausübung von Musik befassen können. ${ }^{2087}$ Als Bezeichnung eines Berufs oder Amtes wird nar in Alltagsdokumenten gebraucht, Spezialisierungen werden über Komposita angezeigt. Sein musikalisches Wirken ist unabhängig von Inhalt, Kontext und Funktion des Anlasses. Er konnte am Hofe des Königs wie auch im Tempel bei religiösen Festen mit dem Vortrag von Hymnen, Gebeten oder auch Klageliedern auftreten. Das Wort gala bezeichnet dementgegen in erster Linie einen Priester, dessen Wirken auf religiöse Anlässe beschränkt bleibt. Hier nahm er im zweiten Jahrtausend noch unabhängig von den Inhalten oder der Sprache seiner Lieder die Funktion eines Mittlers ein, der zwischen göttlicher und irdischer Welt zu vermitteln hatte. Neben seiner Tätigkeit als Sänger und Perkussionist war er auch für die Darbringung verschiedener Opfer zuständig. In diesem Sinne ist auch die stärkere ökonomische Präsenz des gala-mah an den Tempeln der babylonischen Zentren zu verstehen. Status der jeweiligen Musiker sind von den familiären Hintergründen und den Beziehungen zum regierenden König abhängig. Während die Institution des nar-gal-Amtes dem Palast angegliedert wird, reagieren spätaltbabylonische gala-mah auf das veränderte politischzentralistische Umfeld, indem sie ihre Siegelinschriften einem König und nicht wie zuvor einer Gottheit widmen. ${ }^{2088}$

$\mathrm{Ob}$ eine Unterscheidung verschiedener Musikerberufe auch in der Singpraxis bestand, ist zwar an den seltenen Termini nar tassistum und nar $\mathrm{a}-\mathrm{u}_{3}-\mathrm{a}$ sicher anzunehmen, aber nicht im Detail nachweisbar. Es fällt zumindest auf, dass der nar häufig mit dem Ausdruck ad-ša ${ }_{4}$ in Zusammenhang gebracht wird, der gala dagegen nie. Außerdem werden literarisch wie lexikalisch für den nar

\footnotetext{
${ }^{2085}$ So Jacobsen 1976, 15.

${ }^{2086}$ Beachte, dass einzelne Individuen mit dem Titel beider Berufe im babylonischen Raum nicht belegt sind; s. dementgegen bei Al-Rawi 1992, 180-185.

${ }^{2087}$ So schon Gelb 1975, 60-62.

${ }^{2088}$ S. vor allem die gala-mah von Kiš Nanna-šalasud und Rīš-Marduk; hier Kapitel 9.8.2.
} 
zahlreiche Vortragstechniken unterschieden (Kapitel 5.1 und T 4). Professionelle Sänger waren damit wohl besonderer und vielfältiger Singtechniken fähig, die für die Ausübung des gala-Berufs nicht erforderlich waren. Die Form responsorialen und antiphonalen Gesangs ist wiederum für den Vortrag zahlreicher Lieder nachgewiesen, ganz gleich ob sie dem Preis oder der Klage zugeordnet sind. Hier konnte auch eine Unterscheidung nach Stimmlage und Singart der begleitenden Chöre festgestellt werden, für jene, die den galaVortrag begleiteten, war zudem eine Bevorzugung von hohen Stimmen zu beobachten.

Eine wichtige Unterscheidung beider Berufe ist schließlich über das Instrumentarium möglich. Nur nar sind auch Spieler von Saiteninstrumenten (Kapitel 9.4.3.1), gala beschänken sich hingegen auf das Spiel von Perkussiva, Membranophonen wie Idiophonen (Kapitel 6.3.2.1). Angesichts der Beobachtungen für die instrumentale Begleitung des sumerischen wie akkadischen Liedmaterials (Kapitel 15.1) könnte eine entsprechende Abgrenzung des Repertoires nach diesen Kriterien anzusetzen sein. Akkadische Liedgattungen wie $\operatorname{irātu}(m)$ und šitru(m), in unterschiedlichen tonalen Skalen gespielt, müssen dem Repertoire professionell ausgebildeter Musiker, womöglich den nar-sa zugeordnet weden. Detailliertere Abgrenzungen des Repertoires hinsichtlich der instrumentalen Begleitung sind allerdings nur auf der Basis entsprechender Studien zu führen. Dies soll weiterführenden Untersuchungen im Bereich der mesopotamischen Musikkulturen vorbehalten sein.

Für die Rekonstruktion der Inhalte und Kontexte der vokalen Praxis zeigten sich zwar vornehmlich die in den Liedern und Hymnen selbst enthaltenen Informationen als ergiebig. Merklich fehlen hier jedoch Ritualtexte und Kultkalender, die genaue Abläufe und Anweisungen zu einem Kultgeschehen beschreiben. Nichtdestotrotz konnten aus Verwaltungstexten, vor allem Ausgaben- und Rationenlisten aus Ur (YOS 5, 163), Larsa (Kapitel 9.2.3) und Sippar (Kapitel 9.6.3), wichtige Erkenntnisse zu den Beteiligten und Vorgängen verschiedener Festgeschehen erbracht werden. Zusammen mit den in literarischen Texten gebotenen Beschreibungen zu musikalischen Darbietungen und Kultabläufen, markant sind hier sumerische Hymnen (Iddin-Dagan A, Ein Mann und sein Gott, Dumuzi-Inana J) wie akkadische Lieder (Ištar Louvre, HS 1884), ergab ein sich in vielen Punkten ergänzendes Bild. Zusammenfassend ist von Bedeutung, dass die verschiedenen Kompositionen, seien es Hymnen, Klagen oder Liebeslieder, höchstwahrscheinlich auch aufeinanderfolgend zu größeren Festanlässen vorgetragen wurden. Deutlich nachzuvollziehen ist dies an der Ritualliste von Larsa (CM 33, 158ff.=HUCA 34, 1ff.), wo zu unterschiedlichen Tageszeiten verschiedene Kulthandlungen von nar und gala mit ihren klagenden oder auch hymnischen Gesängen begleitet wurden. Daneben traten auch zahlreiche Frauengruppen auf, tigiātum als Trommlerinnen neben 
kezrētum, vielleicht als Chorsängerinnen. Weitere Akteure sind Ekstatiker $\left(\mathrm{lu}_{2} \text {-gub-ba; assinnu }\right)^{2089}$ und Tänzer $($ hupp $\hat{u}(m))$, letztere stellten mit ihren Darbietungen möglicherweise ein Kampfgeschehen oder die Jagd dar, um damit das Krieger- und Heldentum des adressierten Gottes oder Königs zu lobpreisen, Topoi, die in sumerischen wie akkadischen Preishymnen vielfach vertreten sind. Auch akkadischsprachige Lieder, Ištar Louvre aber auch die Bēlet-ilī-Hymnen, bestätigen von ihrem Inhalt her, dass der Vortrag von hymnischem Preis und fürbittenden Klagen im Kontext längerer Prozessionen neben verschiedenen auch szenisch ausgeführten Spielen in einer wahrscheinlich festgelegten Abfolge stattfand. ${ }^{2090}$ Je nach Anlass der Zeremonie, ob Tempelöffnung, Eintritt einer Gottheit oder eines Königs, rituelle Gastmähler mit begleitenden Opferhandlungen, wurde mit den begleitenden Gesängen der Preis und die Erhöhung oder auch eine Einflussnahme auf die Gottheit verfolgt.

Die in dieser Arbeit untersuchte Fragestellung bestätigte nicht zuletzt auch die auf politischer wie sozial-kultureller Ebene stattfindenden Umwälzungen dieser Zeit. Diese sind zunächst in der Organisation der Priesterämter zur altbabylonischen Zeit hin zu beobachten. So lässt sich der Machtzuwachs der gala-mah, die in dieser Zeit eine eigene, vom Königsnamen unabhängige Liturgie entwickeln und pflegen, auch politisch begründen, auch wenn der Versuch einer Bindung dieser Priester an das Königshaus über die Siegelinschriften zu beobachten war. Die vom Palast aus unternommene Abwendung vom sumerischsprachigen Kult und den ihm zugeordneten Liedern spiegelt sich in den akkadischsprachigen Neudichtungen wider. Zwar lehnen sie sich über die Verwendung ähnlicher Rubriken der 'alten' Kultperformance an, daneben wird jedoch eine neue Musikpraxis und ein entsprechendes Repertoire eingeführt, das eine größere Beteiligung spezialisierter Musiker, den nar-gal, möglicherweise auch nar-sa, erfordert. Es zeigt sich hierin, dass politische, ökonomische und soziale Veränderungen ihren direkten Einfluss auf den Kult, die dargebotenen Lieder und Gebete sowie den Status der hieran beteiligten Musiker haben. Schon aus diesem Grund sind intensivere Studien zur Musikkultur gerechtfetigt und weiterhin wünschenswert, da sie als Spiegel kultureller, historischer wie politischer Neuerungen $\mathrm{zu}$ werten sind. Weiterführend sind hier diachrone Studien zu den einzelnen Musikerberufen zu erhoffen, die den Blick auf andere Epochen und geographische Räume ausweiten. ${ }^{2091}$ Auch zu

${ }^{2089}$ Zum Personal des Larsa-Festes s. hier Kapitel 9.2.3.2 ; ein assinnu wird im Hymnus Ištar Louvre genannt; hier Kapitel 13.1.1.1.

${ }^{2090}$ Einen Wechsel von Preis und Trauer beobachtete Sallaberger 1993, 309 auch für die Abfolge der Ur III-zeitlichen Duku- und Tummal-Feste.

${ }^{2091}$ Eine diachrone Studie zum nar wird von Regine Pruzsinszky (Albert-Ludwigs-Universität Freiburg i.Br.) vorbereitet; interessante Ergebnisse zum gala in der Ur III-Zeit sind für den Abschluss der Dissertation von Fabienne Huber-Vulliet (Ludwigs-Maximilian-Universität München) zu erwarten. 
den sumerischen und akkadischen Dichtungen sind weiterführende Studien vonnöten, die sich Einzelphänomenen in Form und Sprache einzelner Textgruppen zuwenden, auf die in dieser Arbeit aufgrund der Fülle des Materials nicht näher eingegangen werden konnte.

Abschließend ist für die Musiker und ihr vokales Repertoire der altbabylonischen Zeit festzustellen, dass an ihnen eine hoch spezialisierte und organisierte Form der Musikpraxis nachgewiesen werden konnte. Dies drückt sich in der Institutionalisierung von Berufszweigen und Priestergruppen am Tempel oder im Palast aus. Doch auch die beobachtete Vielfältigkeit des Liedrepertoires und die der möglichen musikalischen Aufführungspraktiken lassen auf eine bereits hoch spezialisierte Form der Musikausübung in dieser Zeit schließen. 


\section{ANHÄNGE UND VERZEICHNISSE}

\section{Musikerkatalog}

\begin{tabular}{|c|c|}
\hline $\begin{array}{l}\text { A-ba-an-da-sa }, \text { gala-mah } \\
\text { Zababa S. Be-[ ] }\end{array}$ & Kiš \\
\hline A-ba-Enlil-gin ${ }_{7}$, nam-gala & Nippur \\
\hline $\begin{array}{l}\text { Abum, gala UD.NI'-X? S. } \\
{ }^{\mathrm{d}} \mathrm{EN}-[\text { ] }\end{array}$ & Sippar \\
\hline A-da-lal $l_{3}$, gala & H.u. \\
\hline Ahāssunu, munus-nar & Larsa \\
\hline Ahāti-šeme'at, munus-nar & Larsa \\
\hline $\begin{array}{l}\text { Ali-talīmi, nar-sa S. Nūr- } \\
\text { Adad }\end{array}$ & Sippar \\
\hline Amat-Kūbi, munus-nar & Larsa \\
\hline Amerti-Ištar, munus tigi & Isin \\
\hline
\end{tabular}

Amurrum-tillassu(/tillatī), Larsa
dumu nar

An-dul- ${ }^{\mathrm{S}}$ Sinn, gala

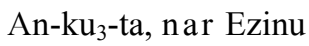

Anu-pī-Ninšubur, nar S. Nūr-Ninšubur
YOS 13, 90 (D.a.) Hauskaufurkunde (Zeuge)

BE 6/2, 42 (Si 13) Erbschaftsübergabe

(Empfänger)

VS 9, 18 (Ha 1) Empfangsquittung des

Sîn-Tempels (Empfänger+Siegel)

AUCT 5, 36:11(RS 58) Silberausgabe für

Eheschließung (Zeuge)

JCS 4, 111 b (Sid 5b) Rationenliste

(Empfängerin)

JCS 4, 111a/b (Sid 5b) Rationenlisten

(Empfängerin)

BE 6/2, 86 (Si 30) Rechtsstreit über

Hausgrundstück (Zeuge)

JCS 4, 111a/b (Sid 5b) Rationenlisten

(Empfängerin)

IB 1304 (o.D.) Gersterationenliste

(Empfängerin)

IB 1293 (o.D.) Gersterationenliste

(Empfängerin)

RA 85, 38 Nr. 2 (RS 49) Schenkung über Felder (Empfänger)

YOS 8, 153 (RS 55) Schenkung über

Felder (Empfänger)

YOS 12, 225 (Si 7) Sklavenkauf (Käufer?)

YOS 12, 307 (Si 8) Quittung über Getreide und Haus (Empfänger?)

Nisaba 19, 296 (D.a.) Kaufvertrag (Zeuge)

Nisaba 19, 296 (D.a.) Kaufvertrag (Zeuge)

Kutalla TSifr 65 (Si 4) Baugeländekauf (Zeuge) 


\begin{tabular}{|c|}
\hline Apil-Amurrum, nar-sa \\
\hline $\begin{array}{l}\text { Apil-ilīšu, nar S. Nūr- } \\
\text { Ninšubur }\end{array}$ \\
\hline Apil-ilī̌su, nar \\
\hline $\begin{array}{l}\text { Apiljatum, eren }{ }_{2} \text { gala S. } \\
\text { Sîn-iqīšam }\end{array}$ \\
\hline Aplum, gala \\
\hline A-ra-šsu'-ta, nar \\
\hline Arrabūtum, munus-nar \\
\hline $\begin{array}{l}\text { Asalluhi-bāni, gala-mah } \\
\text { Šamaš }\end{array}$ \\
\hline Awīl-Amurrum, aluzinnu \\
\hline Awīl-dāri, gala Gula \\
\hline $\begin{array}{l}\text { Awīlija, nam-gala S. } \\
\text { Zarriqum }\end{array}$ \\
\hline Awīl-Sîn, gala \\
\hline $\begin{array}{l}\text { Bal-a-ni-he } e_{2} \text {-in-zalag, gala- } \\
\text { mah }\end{array}$ \\
\hline Bēlānu, nar \\
\hline $\begin{array}{l}\text { Bēlānum, gala-mah An- } \\
\text { nunītum }\end{array}$ \\
\hline
\end{tabular}

Ur

Kutalla

Nippur

Nippur

Nippur

Ur

Larsa

Sippar

Dilbat

Ur

Sippar

Dilbat

Sippar

Sippar

Sippar

Būr-Adad, nar

Būratum, nar-sa

Dabītum, munus-nar

Damiq-ilīšu, nar-sa S.

Lugal-he $_{2}$-g̃al 2

Dig̃ir-ša ${ }_{6}$-ga, gala-mah
$\mathrm{Ur}$

Sippar

Larsa

Nippur

Sippar
YOS 12, 353 (Si 11) Auslösungsvertrag (Zeuge)

TSifr 40/40a (Ha 36) Feldtausch (Zeuge)

TSifr 41/41a (Ha 36) Feldtausch (Zeuge)

PBS 8/1, 81 (Ha 31) Rechtsprotokoll (Zeuge)

PBS 8/1, 94 (o.D.) Arbeiterliste (Arbeiter)

BE 6/2, 57 (Si 22) Adoption und Erbschaftsteilung (Erblasser)

TSifr 4 (RS 6) Feldkaufvertrag (Zeuge)

JCS 4, 111a/b (Sid 5b) Rationenlisten (Empfängerin)

RA 82, 28 (D.a.[Aș]) Erbschaftsvertrag über gala-Pfründe (Zeuge)

YOS 13, 169 (Aṣ 13) Arbeiterliste (Arbeiter)

TSifr 9/9a (RS 10) Hausgrundstückskauf (Zeuge)

Di 1499 (Si 28) Kauf über gala-Pfründe (Käufer)

VS 7, 122 (Aṣ 16) Darlehen über Silber (Zeuge)

AbB 2, 89 Gimil-Marduk an ? (Steuerzahler)

CT 6, 23b (Aṣ 17+e) Erntearbeiterliste (Arbeiter)

AbB 11, 107 ([Aș]) Sohn an den Vater (Tafelübergabe)

Di 2189 (Aṣ 5) Urkunde, s. Janssen 1992, $47-48$

s. a. Ur-Utu, gala-mah Annunītum

UET 5, 453 (D.a.) Empfangsquittung über Wolle (Empfänger)

RA 85, 42 Nr. 13 (Si 9) Hauskaufurkunde (Zeuge)

JCS 4, 111a/b (Sid 5b) Rationenlisten (Empfängerin)

BE 6/2, 48 (Si 18) Heiratsurkunde (Zeuge)

YOS 13, 12 (Ad 15) Auflistung von Feldbesitz (Feldbesitzer) 
Dudu, nar

Dulluqum, nar PN

Dumm[uqtum], munus-nar

Ea-kīma-ilìja, nar

E-an-na-tum, gala-mab Inana Uruk S. Ina-palēšu/ Aplatum

Ur

Šaduppûm

Larsa

Larsa

Kiš

Aplatum

Larsa

Nippur

Nippur

Larsa

H.u.

Larsa

Šaduppûm

Ur

Larsa

Etel-pī-Sîn, nar-sa S. Zarriqum

Gimillum, gala
AbB 10, 1 an šāpir mātim betreff Lehensdienst (babbilūtum) und igisûmAbgabe eines gala (Absender)

UET 5, 550 (AbS 6) Empfangsquittung (Empfänger eines al-g̃ar)

YOS 14, 75 (D.a.) Rationenliste (Empfänger)

JCS 4, 111a (Sid 5b) Rationenliste (Empfängerin)

AbB 4, 14 Hammurabi an Šamaš-ḩāzir (Feldpächter)

AbB 9, 188 Hammurabi an Šamaš-hāzir (Feldpächter)

TJA 48ff. (Ad 21) Abgabenquittung (igisûm, nemettum) (Zeuge)

TJA 55f. (D.a.[Ad 1-10]) Immobilientauschvertrag (Zeuge) 2092

YOS 13, 24 (Ad 35) Silberdarlehen (Vater des Garanten)

YOS 13, 174 (Ad 21) Depositum von Gold und Silber ( $\left.\mathrm{gir}_{3}\right)$

TCL 10, 112 (RS 56) Darlehen über Silber für eine Handelsreise (Zeuge) PBS 8/2, 176 (D.a.) Erbschaftsvertrag (Zeuge)

BE 6/2, 15 (Ha 38) Darlehen (Zeuge)

YOS 8, 13 (RS 23) Sklavensicherheit (Zeuge)

YOS 8, 41 (RS 23) Sklavensicherheit (Zeuge)

YOS 14, 46 (o.D.) Darlehen (Zeuge)

JCS 4, 111a/b (Sid 5b) Rationenlisten (Empfängerin)

YOS 14, 75 (D.a.) Rationenliste (Empfänger)

UET 5, 160 (Sel 6) Grundstückskauf (Zeuge)

TCL 11, 146 (Ha 33) Ausgabe von Pachtfeldern (Empfänger)

Sippar MHET II, 544 (Aṣ 16) Hausmietvertrag (Zeuge)

${ }^{2092}$ Vgl. Pientka 1998, 197+Anm. 109. 


\begin{tabular}{|c|c|c|}
\hline \multirow[b]{2}{*}{ Gimillum, nar } & \multicolumn{2}{|r|}{ chen) } \\
\hline & Kutalla & $\begin{array}{l}\text { TSifr } 99 \text { (RS 25) Ausgleichszahlung für } \\
\text { Baugelände (Zeuge) }\end{array}$ \\
\hline $\begin{array}{l}\text { Gir }_{3}-n i-i_{3}-\mathrm{sa}_{6}, \text { nam-nar S. } \\
\text { Sîn-išmēni }\end{array}$ & Nippur & $\begin{array}{l}\text { ARN } 35 \text { (RS 37) Kauf über nam-nar- } \\
\text { Pfründe (Verkäufer) }\end{array}$ \\
\hline $\begin{array}{l}\text { Hadulu-zērum, nar-sa- } \\
\text { Pfründner S. Ilī-erībam }\end{array}$ & Sippar & $\begin{array}{l}\text { BE 6/2, } 86 \text { (Si 30) Rechtsstreit über } \\
\text { Hausgrundstück (Erbe) }\end{array}$ \\
\hline Halija, nar & Ur & BIN 2, 75 (Si 7) Adoption (Zeuge) \\
\hline $\begin{array}{l}\text { Ha-AŠ/AK/AL-iștum, } \\
\text { munus-nar }\end{array}$ & Larsa & $\begin{array}{l}\mathrm{JCS} 4,111 \mathrm{a} / \mathrm{b}(\mathrm{Sid} 5 \mathrm{~b}) \text { Rationenlisten } \\
\text { (Empfängerin) }\end{array}$ \\
\hline $\begin{array}{l}\text { Huzālum, gala S. Inana- } \\
\text { mansum }\end{array}$ & Sippar & $\begin{array}{l}\text { CT 48, } 45 \text { (Sd 4) parșum-Abrechnung } \\
\quad \text { (Garant) }\end{array}$ \\
\hline Ibbi-ilim, nar V. Ilšu-nāșir & Larsa & $\begin{array}{l}\text { TCL 11, } 174 \text { (Ha 34) Erbschaftsvertrag } \\
\text { (Zeuge) }\end{array}$ \\
\hline & & $\begin{array}{l}\text { TCL 11, } 224 \text { (RS 51) Erbschaftsteilung } \\
\text { (Zeuge) }\end{array}$ \\
\hline Ibni-Ea, nar & Kutalla & $\begin{array}{l}\text { TSifr 12/12a (RS 12) Baugeländekauf } \\
\text { (Zeuge) }\end{array}$ \\
\hline $\begin{array}{l}\text { Ibni-Marduk, gala-mah } \\
\text { Inana }\end{array}$ & Sippar & AbB 6, 29 ([Sd]) Schuldsache \\
\hline $\begin{array}{l}\text { Ibni-Marduk, gala-mah } \\
\text { Šamaš Babylon }\end{array}$ & Sippar & VS 29, 84 (Sd 13) Darlehen (Gläubiger) \\
\hline Iddijatum, nar Amurrum & Larsa & $\begin{array}{l}\text { TCL 11, } 174 \text { (Ha 34) Erbschaftsvertrag } \\
\text { (Zeuge) }\end{array}$ \\
\hline Iddin-Ištar, nar-a- $\mathrm{u}_{3}-\mathrm{a}$ & Ur & UET 5, 95/95a (Ha 33) Adoption (Zeuge) \\
\hline Iddin-Marduk, nar & Sippar & $\begin{array}{l}\text { OLA 21, } 67 \text { (Aṣ 17+a) Bierrationenliste } \\
\text { (Empfänger) }\end{array}$ \\
\hline Iddin-mēšar, nar & Nippur & $\begin{array}{l}\text { ARN } 135 \text { (o.D.) Schadensersatzurkunde } \\
\text { (Empfänger) }\end{array}$ \\
\hline $\begin{array}{l}\text { Igmil-Ištar, gala-mah } \\
\text { Nanaja }\end{array}$ & Kiš & $\begin{array}{l}\text { YOS 13, } 348 \text { (Ad 31) Depositum von } \\
\text { Vieh (Zeuge) }\end{array}$ \\
\hline Ikūn-pī-Ištar, nar & Sippar & $\begin{array}{l}\text { MHET II, } 40 \text { (Sa 5) Grundstücks- und } \\
\text { Hauskauf (Nachbar, Zeuge) }\end{array}$ \\
\hline Ilì-awìlī, nar S. Ka- ${ }^{\mathrm{d}} \mathrm{Dudu}$ & Kutalla & $\begin{array}{l}\text { TSifr 10/10a (RS 11) Geländekauf } \\
\text { (Zeuge) }\end{array}$ \\
\hline $\begin{array}{l}\text { Ilī-erībam nar-sa-Pfründner } \\
\text { S. Mār-erșetim }\end{array}$ & Sippar & $\begin{array}{l}\text { BE 6/2, } 86 \text { (Si 30) Rechtsstreit über } \\
\text { Hausgrundstück (Erblasser) }\end{array}$ \\
\hline Ilī-hāzirī, dumu ugula nar & Larsa & $\begin{array}{l}\text { TCL 10, } 112 \text { (RS 56) Darlehen über } \\
\text { Silber für eine Handelsreise (Zeuge) }\end{array}$ \\
\hline Ilī-iddinam, nar-gal & Larsa & YOS 12, 227 (Si 7) Geländekauf (Zeuge) \\
\hline Ilī-iqīšam, nar $\mathrm{ra}_{2}$-gaba & Larsa & $\begin{array}{l}\text { AbB 4, } 12 \text { Hammurabi an Šamaš-ḩāzir } \\
\text { (Feldbesitzer) }\end{array}$ \\
\hline
\end{tabular}

AbB 7, 153 Bittschrift (Kontext abgebro-

RN 35 (RS 37) Kauf über nam-nar-

Sîn-išmēni

Hadulu-zērum, nar-sa-

Pfründner S. Ilī-erībam

Halija, nar

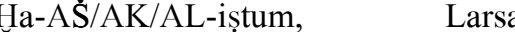

munus-nar

Uuzälum, gala S. Inana- _ Sippar

48, 45 (Sd 4) parșum-Abrechnung (Garant)

L 11, 174 (Ha 34) Erbschaftsvertrag

CL 11, 224 (RS 51) Erbschaftsteilung

Sifr 12/12a (RS 12) Baugeländekauf

(Zeuge)

Ibni-Marduk, gala-mah Sippar

Ibni-Marduk, gala-mah

Šamaš Babylon

Iddijatum, nar Amurrum

Iddin-Ištar, nar-a- $\mathrm{u}_{3}-\mathrm{a}$

Ur

Iddin-Marduk, nar

RN 135 (o.D.) Schadensersatzurkunde

OS 13, 348 (Ad 31) Depositum von

(Zienge)

Hauskauf (Nachbar, Zeuge)

(Zeuge)

BE 6/2, 86 (Si 30) Rechtsstreit über

CL 10, 112 (RS 56) Darlehen über

Silber für eine Handelsreise (Zeuge)

Ilī-iddinam, nar-gal Larsa

AbB 4, 12 Hammurabi an Šamaš-hāzir

(Feldbesitzer) 


\begin{tabular}{|c|c|c|}
\hline Ilūni, gala & $\begin{array}{l}\text { Sippar } \\
\text { T.ed-Dēr }\end{array}$ & $\begin{array}{l}\text { BM } 80371 \text { (Aș 5? ) Personenliste } \\
\text { MHET I/1, } 94 \text { (o.D.) Rechtsurkunde } \\
\text { (Zeuge) }\end{array}$ \\
\hline $\begin{array}{l}\text { Ilšu-[ ], gala-mah Inana } \\
\text { Uruk S. Samsu-i[luna-x ] }\end{array}$ & Kiš & $\begin{array}{l}\text { YOS 13, } 314 \text { (Aș 9) Bürgschaft über } \\
\text { Silber. nébeh kezērim (Siegel) }\end{array}$ \\
\hline Ilum-pī-Ištar, gala & Sippar & BM 81591 (Ad 24) Kaufurkunde (Zeuge) \\
\hline Ilūnim, nar & Nippur & $\begin{array}{l}\text { PBS } 8 / 1,81 \text { (Ha 31) Rechtsprotokoll } \\
\text { (Zeuge) }\end{array}$ \\
\hline Imgur-Sîn, nar & Sippar & $\begin{array}{l}\text { CT 4, 50a (Im/S1 ?) Dattelpalmgartenkauf } \\
\text { (Zeuge) }\end{array}$ \\
\hline $\begin{array}{l}\text { Inana-ma-an-sum, dub-sar, } \\
\text { nam-gala }\end{array}$ & Nippur & $\begin{array}{l}\text { BE 6/2, } 26 \text { (Si 6) Erbschaftsvertrag, } \\
\text { darunter je eine gala- und gudu } 4^{-} \\
\text {Pfründe (Erblasser) }\end{array}$ \\
\hline \multirow[t]{5}{*}{${ }^{\mathrm{d}}$ Inana-ma-an-sum, gala } & \multirow[t]{5}{*}{ T.ed-Dēr } & $\begin{array}{l}\text { MHET I/1, } 53 \text { (Aș 1) Erntearbeiterliste } \\
\text { (Arbeiter) }\end{array}$ \\
\hline & & $\begin{array}{l}\text { MHET I/1, } 44 \text { (D.a.) Rationenliste } \\
\text { (Empfänger) }\end{array}$ \\
\hline & & $\begin{array}{l}\text { MHET I/1, } 51 \text { (o.D.) Rationenliste } \\
\text { (Empfänger) }\end{array}$ \\
\hline & & $\begin{array}{l}\text { MHET I/1, } 56 \text { (o.D.) Erntearbeiterliste } \\
\text { (Arbeiter) }\end{array}$ \\
\hline & & $\begin{array}{l}\text { MHET I/1, } 60 \text { (o.D.) Erntearbeiterliste } \\
\text { (Arbeiter) }\end{array}$ \\
\hline \multirow[t]{6}{*}{$\begin{array}{l}\text { Id Inana-ma-an-sum, } \\
\text { gala/sa g̃ g̃a S. Sîn-rēmēni }\end{array}$} & \multirow[t]{5}{*}{ Sippar } & $\begin{array}{l}\text { CT 48, } 54 \text { (Aș 12) Mietvertrag über } \\
\text { Schafpferch (Mieter) }\end{array}$ \\
\hline & & $\begin{array}{l}\text { MHET II, } 544 \text { (Aș 16) Hausmietvertrag } \\
\text { (Mieter) }\end{array}$ \\
\hline & & $\begin{array}{l}\text { MHET II, } 545 \text { (Aṣ 16) Hausmietvertrag } \\
\text { (Zeuge) }\end{array}$ \\
\hline & & $\begin{array}{l}\text { PBS 8/2, } 218 \text { (Aṣ 16) Hausmietvertrag } \\
\text { (Zeuge) }\end{array}$ \\
\hline & & $\begin{array}{l}\text { PBS 8/2, } 224 \text { (Aṣ 16) Hausmietvertrag } \\
\text { (Zeuge) }\end{array}$ \\
\hline & T.ed-Dēr & $\begin{array}{l}\text { MHET I/1, } 43 \text { (o.D.) Silberausgabe } \\
\text { (Garant }^{\text {(G) }}\end{array}$ \\
\hline \multirow{3}{*}{$\begin{array}{l}\text { dinana-ma-an-sum, gala- } \\
\text { mah Annunitum S. Mar- } \\
\text { duk-nāṣir }\end{array}$} & \multirow[t]{2}{*}{ Sippar } & $\begin{array}{l}\text { Di } 1804 \text { (Aș 5) Urkunde über parșum- } \\
\text { Zahlung (Zahler) }\end{array}$ \\
\hline & & $\begin{array}{l}\text { MHET II, } 626 \text { (o.D.) Feldkaufvertrag } \\
\text { (Käufer) }\end{array}$ \\
\hline & T.ed-Dēr & $\begin{array}{l}\text { MHET I/1, } 13 \text { (Aș 1) biltu-Abgabe über } \\
\text { Getreide (Eintreiber) }\end{array}$ \\
\hline
\end{tabular}

${ }^{2093}$ Harris 1975, 174+Anm. 119 


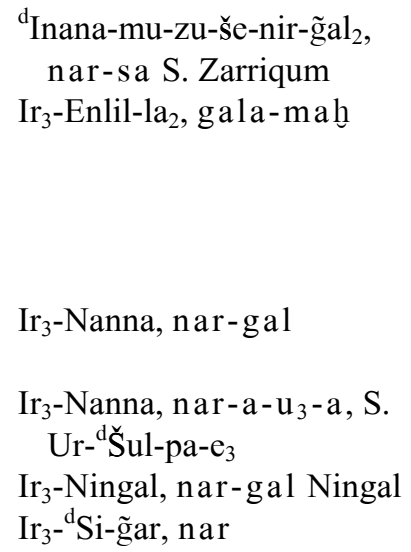

MHET I/1, 5 (Aṣ 3) Feldpachtvertrag (Pächter)

MHET I/1, 42 (Aș 5) Getreiderationenliste (Empfänger)

Larsa TCL 11, 146 (Ha 33) Ausgabe von Pachtfeldern (Empfänger)

Nippur $\quad$ ARN 44 (RS 55) Erbschaftsvertrag (Zeuge)

BE 6/2, 26 (Si 6) Erbschaftsvertrag, darunter g a la - und g u d $\mathrm{u}_{4}$-Pfründe (Zeuge)

Ur TSifr 93 (RS 2) Hausgrundstückskauf (Zeuge)

UET 5, 160 (Sel 6) Grundstückskauf (Zeuge)

Ur UET 5, 363 (RS 34) Darlehen (Zeuge)

T.ed-Dēr MHET I/1, 53 (Aṣ 1) Erntearbeiterliste (Arbeiter)

MHET I/1, 51 (o.D.) Rationenliste (Empfänger)

MHET I/1, 54 (o.D.) Erntearbeiterliste(?) (Arbeiter)

MHET I/1, 56 (o.D.) Erntearbeiterliste (Arbeiter)

MHET I/1, 60 (o.D.) Erntearbeiterliste (Arbeiter)

Isin $\quad$ BIN 9, 334 (IšEr 13/14? ) Ausgabe (ba-zi). Lederhüllen, sabitum und sa-e š ( ğir $\left.{ }_{3}\right)$

H.u. JCS 11, 107 ([Si]) Brief (puršum bìtim).

Uruk $\quad$ BaM 24, 150ff. Nr. 202 (o.D.) Silberausgaben (Empfänger)

Sippar $\quad$ MHET II, 633 (o.D.) Immobilienliste (Hausbesitzer)

Larsa YOS 8, 6 (RS 3) Immobilien Kaufurkunde (Nachbar, Zeuge)

BIN 9, 415 (IšEr 24) Ausgabe (ba-zi). Taschen, Sandalen (Empfänger)

JCS 4, 111a/b (Sid 5b) Rationenlisten (Empfängerin)

JCS 4, $111 \mathrm{a} / \mathrm{b}$ (Sid 5b) Rationenlisten (Empfängerin)

JCS 4, 111a (Sid 5b) Rationenliste (Empfängerin) 


\begin{tabular}{|c|c|c|}
\hline Jašuhatum, munus-nar & Larsa & $\begin{array}{l}\text { JCS } 4,111 \mathrm{a} / \mathrm{b}(\mathrm{Sid} 5 \mathrm{~b}) \text { Rationenlisten } \\
\text { (Empfängerin) }\end{array}$ \\
\hline Kaki, nar PN & Šaduppûm & $\begin{array}{l}\text { YOS 14, } 75 \text { (D.a.) Rationenliste (Emp- } \\
\text { fänger) }\end{array}$ \\
\hline Kalbatum, munus-nar & Larsa & $\begin{array}{l}\text { JCS } 4,111 \mathrm{a} / \mathrm{b} \text { (Sid 5b) Rationenlisten } \\
\text { (Empfängerin) }\end{array}$ \\
\hline $\begin{array}{l}\text { Ka- }{ }^{\mathrm{d}} \text { Inana, gala-mah V. } \\
\text { Idin-Ištar }\end{array}$ & Kiš & RlAA 238 (Si ?) Sklavenkauf (Zeuge) \\
\hline \multirow[t]{3}{*}{$\mathrm{Ka}-{ }^{\mathrm{d}}$ Ninurta, nar-gal } & Nippur & $\begin{array}{l}\text { PBS 8/2, 116/116a (RS 50) Versorgungs- } \\
\text { urkunde (Zeuge) }\end{array}$ \\
\hline & & $\begin{array}{l}\text { ARN } 44 \text { (RS 55) Erbschaftsvertrag } \\
\text { (Zeuge) }\end{array}$ \\
\hline & & $\begin{array}{l}\text { PBS 8/2, } 142 \text { (Si 2) Hausgrundstückskauf } \\
\text { (Zeuge) }\end{array}$ \\
\hline Kulālum, gala-mah & Sippar & BM 82437 (Im) Rechtsurkunde (Zeuge) \\
\hline Lālum, nar & Larsa & $\begin{array}{l}\text { YOS 8, 48/48a (RS 34) Darlehen über } \\
\text { Datteln (Zeuge) }\end{array}$ \\
\hline $\mathrm{L}\left[\mathrm{i}-\mathrm{pi} \mathrm{i}_{2}\right.$-it $]$-Ištar, gala & Kutalla & $\begin{array}{l}\text { TSifr 27/27a (RS 57) Baugeländekauf } \\
\text { (Zeuge) }\end{array}$ \\
\hline \multirow[t]{2}{*}{$\mathrm{Lu}_{2}-{ }^{\mathrm{d}} \mathrm{Ba}-\mathrm{ba}_{6}$, nar } & Isin & $\begin{array}{l}\text { BIN 9, } 353 \text { (IšEr 12) Ausgabe von } \\
\quad \text { /zami/ }\left(\tilde{g} \operatorname{ir}_{3}\right)\end{array}$ \\
\hline & & $\begin{array}{l}\text { BIN 9, } 354 \text { (IšEr 13) Ausgabe von } \\
\left.\quad / \text { zami/ ( } \text { gir }_{3}\right)\end{array}$ \\
\hline \multirow[t]{2}{*}{$\begin{array}{l}\text { Lugal-gaba-ri-nu-tuku, nar- } \\
\text { gal }\end{array}$} & Nippur & $\begin{array}{l}\text { JCS 20, } 45 \text { Nr. } 7 \text { (RS 25) Hausgrund- } \\
\text { stückstausch (Zeuge) }\end{array}$ \\
\hline & & $\begin{array}{l}\text { TIM 4, } 10 \text { (RS 25) Hausgrundstückskauf } \\
\text { (Zeuge) }\end{array}$ \\
\hline \multirow[t]{3}{*}{$\begin{array}{l}\text { Lugal-he }_{2}-\tilde{g a l}_{2}, \text { nar S. } \\
\text { Ubarrum }\end{array}$} & Nippur & $\begin{array}{l}\text { ARN } 41 \text { (RS 53) Schenkungsurkunde } \\
\text { (Zeuge) (Duplikat Ni 1924:8') }\end{array}$ \\
\hline & & $\begin{array}{l}\text { ARN } 113 \text { (D.a.) Kaufurkunde(?) (Zeu- } \\
\text { ge?) }\end{array}$ \\
\hline & & $\begin{array}{l}\text { PBS 8/1, } 81 \text { (Ha 31) Rechtsprotokoll } \\
\text { (Zeuge) }\end{array}$ \\
\hline $\begin{array}{l}\text { Lugal-ibila, nar Ninurta } \\
\text { S. Du-du-kal-la }\end{array}$ & Nippur & ARN 57 (o.D.) Erbschaftsliste (Erbe) \\
\hline $\begin{array}{l}\text { Lugal-me-lam } 2 \text {, nar S. Nig g } 2^{-} \\
\text {DU-DU }\end{array}$ & Nippur & $\begin{array}{l}\text { ARN } 23+\text { PBS 8/2, } 169 \text { (D.a.[Sel 28? }]) \\
\quad \text { Erbschaftsvertrag (Zeuge) }\end{array}$ \\
\hline \multirow[t]{3}{*}{ Lugal-me-lam 2 -g̃ir 3 , nar-gal } & Nippur & $\begin{array}{l}\text { PBS } 8 / 2,116 / 116 a \text { (RS 50) Versorgungs- } \\
\text { urkunde (Zeuge) }\end{array}$ \\
\hline & & $\begin{array}{l}\text { ARN } 44 \text { (RS 55) Erbschaftsvertrag } \\
\text { (Zeuge) }\end{array}$ \\
\hline & & $\begin{array}{l}\text { PBS 8/2, } 142 \text { (Si 2) Hausgrundstückskauf } \\
\text { (Zeuge) }\end{array}$ \\
\hline
\end{tabular}


Lugal-zi-ma-an-sum, gala- Dilbat mah S. Ilī-erībam

$\mathrm{Lu}_{2}$-igi-KU, gala-mah Isin

$\mathrm{Lu}_{2}{ }^{\mathrm{d}}{ }^{\mathrm{Ninlil}}-\mathrm{la}_{2}$, gala

$\mathrm{Lu}_{2}{ }^{\mathrm{d}}$ Ninurta, gala

$\mathrm{Lu}_{2}-{ }^{\mathrm{d}}$ Ninurta, nar

$\mathrm{Lu}_{2}-\mathrm{pa}_{3}-\mathrm{da}$, nar

Marduk-muballiț, gala

Marduk-muballiț, gala-mah

Marduk-muballit, gala-mah

Marduk-muballiț, nar-gal

$\mathrm{Me}-\mathrm{a}\left(/ \mathrm{am}_{3}\right)$-im-ri-a-g̃ $\mathrm{u}_{10}$, unūtim gala-mah Zababa

S. ${ }^{\mathrm{d}}$ Inana-zi-g̃ $\mathrm{u}_{10}$

Isin

H.u.

Dilbat

Sippar

Sippar

Kiš

Nippur

S. Šurbūtum
YOS 13, 289 (Ad 34) Getreidedarlehen (Zeuge+Siegel)

VS 7, 94 (Aṣ 11) Getreidedarlehen (Zeuge+Siegel)

BIN 9, 445 (IšEr 25) Ausgabe (ba-zi) balag̃ der Inana und des Išbi-Erra ( $\left.\tilde{\mathrm{g}} \mathrm{ir}_{3}\right)$

PBS 8/1, 11 (Zam 1) Darlehen (Zeuge)

TJDB 84f., 27:20 (Si 8) Feldmietvertrag (Zeuge)

ARN 4+PBS 8/1, 2 (BS a) Erbschaftsprozess (Erblasser)

ARN 58 ([BS ?]) Tempelämterliste (Erblasser)

JCS 3, 185a (o.D.) Tempelämterliste (Erblasser)

JCS 3, 185b (o.D.) Erbschaftsprozess (Erblasser)

BIN 9, 352 (IšEr 13) Ausgabe (ba-zi). /zami/ für e ${ }_{2}$ nar G̈IŠ.A.A.AB.DU ( $\left.\mathrm{gir}_{3}\right)$

AbB 1, 11 Verhör eines Sklaven (Eidesabnehmer)

VS 7, 57 (Ad 30) Arbeiterliste (Empfänger)

VS 7, 58 (Ad 30) Schuldschein über Arbeiter (Zeuge)

AbB 11, 93 ([Sd]) von Ibni-Šamaš (Bullen für den gala-mah).

CT 48, 45 (Sd 4 ) parșum-Abrechnung (oberste Verwaltungsinstanz)

CT 8, 21c (Aṣ 10) Quittung über igisûm Silber (Zahler)

YOS 13, 33 (Ad 3) Silberdarlehen (Zeuge)

YOS 13, 325 (Ad 5) Mitgiftsurkunde (Zeuge+Siegel)

YOS 13, 94 (Ad 13) Immobilienkauf (Zeuge)

TLB 1, 257 (Ad 14? ) Gerichtsurkunde (?) (Zeuge)

PBS 8/1, 94 (o.D.) Arbeiterliste (Arbeiter) 
Mu-mu-he $e_{2}$-gub, gala

Nabi-Šamaš, gala

Nabīum-mālik, gala

${ }^{\mathrm{d} N a n n a-a-r a}{ }_{2}-\mathrm{mu}-$ un-ge-en, nam-gala S. Inana-maan-sum

${ }^{\mathrm{d}} \mathrm{Nanna-g̃eštu}$-bi, nar

${ }^{\mathrm{d}}$ Nanna-g̃eštug, nar

S. Nūr-Ninšubur

${ }^{\mathrm{d}}$ Nanna-gu ${ }_{2}$-gal, gala-mah

${ }^{\mathrm{d}}$ Nanna-ki-ag̃ 2 , gala-mah

S. Imgur-Sîn

${ }^{\mathrm{d}} \mathrm{Nanna}-\mathrm{s̆a}_{3}-\mathrm{la}_{2}$-sud, gala-mah Zababa

S. Me-a(/am 3$)$-im-ri-a-g̃u $u_{10}$
Nippur

Sippar

Sippar

Nippur

$\mathrm{Ur}$

Kutalla

Nippur

Larsa

Kiš
BE 6/2, 26 (Si 6) Erbschaftsvertrag, darunter g a la - und g u d u ${ }_{4}$-Pfründe (Zeuge)

MHET II, 928 (Si ?) Feldkauf (Nachbar)

AbB 10, 1 Dig̃ir-šaga an šāpir mātim (Zahler einer igisûm-Abgabe)

BE 6/2, 26 (Si 6) Erbschaftsvertrag, darunter gala- und gudu ${ }_{4}$-Pfründe (Erbe)

UET 5, 663 (D.a.) Rationenliste über Getreidekörbe (Empfänger)

TSifr 49/49a (Ha 41) Geländekaufvertrag (Zeuge)

TSifr 50a (Ha 41) Nicht-Anspruch an Dattelhain (Zeuge)

TSifr 51a (Ha 41) Feldkauf (Zeuge)

TSifr 65 (Si 4) Baugeländekauf (Zeuge)

ARN 23+PBS 8/2, 169 (D.a.[Sel 28?])

Erbschaftsvertrag (Zeuge)

ARN 29 (RS 21) Schenkungsurkunde (Feldnachbar)

PBS 8/1, 11 (Zam 1) Darlehen (Gläubiger)

VS 13, 80 (RS 39) Gartenkauf (Zeuge)

YOS 13, 266 (Aș 8) Quittung über Silberzahlung $\left(\mathrm{lu}_{2}-\mathrm{kurun}_{2}-\mathrm{na}\right.$, Eintreiber)

YOS 13, 77 (Aș 9) Bierlieferung

YOS 13, 88 (Aș 9) Bierlieferung

YOS 13, 232 (Aṣ 9) Bierlieferung

YOS 13, 217 (Aṣ 17+b ) Empfangsquittung über Silber (Empfänger)

YOS 13, 268 (Sd 1) Darlehen über Opfervieh (Empfänger+Siegel)

YOS 13, 324 (Sd 1) Pachtvertrag über Flur(?) (Feldbesitzer)

YOS 13, 224 (Sd 4) Bürgschaft über Silber nēbeh parșim (Zahler)

YOS 13, 216 (Sd 5) Quittung über Silberzahlung (Empfänger)

YOS 13, 203 (D.a.) Prozessurkunde (Zeuge+Siegel) 


$\begin{array}{ll}\begin{array}{l}\text { Nannatum, nu-eš } \\ \text { gala }\end{array} & \text { Nippur } \\ \text { Nidin-Ištar, gala-mah } & \text { Sippar } \\ \text { Šamaš } & \\ { }^{\text {dd Ninurta-ma-an-sum, gala }} & \text { Dilbat } \\ \begin{array}{l}\text { Ninurta-mušallim, gala- } \\ \text { mah }\end{array} & \text { Nippur }\end{array}$

Nūr-kabta, nar

Nūr-Šamaš, gala-mah

Nuțtuptum, munus-nar

Pû-ilī, nar

Pušuja, nar

Qurdi-Ištar, gala Inana

Rē'išu-dāmiq, huppûm

Rī̌s-Marduk, gala-mah Inana Uruk S. E-[ ]

Sallatum, munus-nar

Saniq-pī-[GN], gala-mah Inana Zabalam (Sanqum),

S.d. Warad-Zugal

Sîn-abūšu, nam-gala

S. Nanna-lu ${ }_{2}$-ti

Sîn-erībam, gala-mah
Larsa

$\mathrm{Ur}$

Larsa

Lagaba

Larsa

Sippar

Larsa

Kiš

Larsa

Larsa

Nippur

Ur
BE 6/2, 42 (Si 13) Erbschaftsübergabe (Halter des gala-Amts)

TCL 1, 145 (Si 30) Erbschaftsvertrag (Zeuge)

VS 7, 149 (o.D.[Ha]) Rechtsurkunde (Schulddienst)

BE 6/2, 26 (Si 6) Erbschaftsvertrag, darunter je eine g a la - und g udu 4 $^{-}$ Pfründe (Zeuge)

BE 6/2, 42 (Si 13) Erbschaftsübergabe (Zeuge)

YOS 8, 47 (RS 6) Kaufurkunde über (?) (Zeuge)

TSifr 7/7a (RS 8) Kauf einer Hausruine (Zeuge)

UET 5, 248 (RS 16) Erbschaftsprozess (Zeuge)

PBS 8/2, 264 (RS 35) Erbschaftsvertrag (Zeuge)

UET 5, 96 (o.D.[RS]) Adoption und Erbschaftsregelung (Zeuge)

JCS 4, 111a/b (Sid 5b); JCS 4, 112b (Sid 5b) Rationenlisten (Empfängerin)

RA 90, 125 Brief (Feld des Musikers) YOS 8, 20 (RS 8) Häusertausch (Zeuge) OLA 21, 71 (Aṣ 13) Erbteilungsvertrag (Nachbar)

Di 1801 und Di 2231 (Nachbar) s. Janssen/Gasche/Tanret 1994, 114.

AbB 4, 45 Lu-Ninurta an Šamaš-hāzir (Feldbesitzer)

YOS 13, 262 (Sd 2) Tierkauf (Käufer)

YOS 13, 90 (D.a.) Hauskaufurkunde (Zeuge+Siegel)

JCS 4, 111a/b (Sid 5b) Rationenlisten (Empfängerin)

RA 69, 122 Fig. 8 (Si 3) Scheidung (Zeuge+Siegel)

YOS 12, 325 (Si 10) Rechtsstreit (Zeuge)

BE 6/2, 42 (Si 13) Erbschaftsübergabe (Erblasser)

YOS 12, 297 (Si 8) Kauf einer gudu - $^{-}$ Pfründe (Zeuge) 
Sîn-erībam, ugula munus Nippur tigi

Sîn-ēriš, gala

Sîn-ēriš, lu $u_{2}$ nar-gal?

Sîn-iddinam, nar-sa

S. $\mathrm{Lu}_{2}-\breve{S ̆}_{6}$-ga

Sîn-ilī, nar

Sîn-iqī̌sam, huppû

Sîn-išmeanni, gala-mah

Nanaja? S. Ibbi-ilim

Sîn-māgir, nar

Sîn-māgir, nar

B.d. 'Bal-g̃ $u_{10}$-nam-he

Sîn-māgir, nar Awīl

Maškan-šāpir

Sîn-māgir, nar

Sîn-muballiṭ, šāpir nārī

Sîn-mudi, nar

Dilbat

Kiš
Larsa Riftin 20 (RS 30) Feldkauf (Käufer)

Larsa Bab. 7, 46 (RS 3) Rationenliste (Empfänger)

Sippar BE 6/2, 86 (Si 30) Rechtsstreit über Hausgrundstück (Zeuge)

Larsa HUCA 34, 1ff. (RS 2) Opferrationenliste (Empfänger eines Gewands)

YOS 5, 191 (RS 9) Ausgabe (ba-zi) über Gerste (Empfänger)

YBC $6207^{2094}$ (RS 10) Ausgabe von Bronze (Empfänger)

YOS 5, 235 (RS 13) Empfangsquittung über Bronze (Empfänger) VS 7, 127 (A’ 17+a) Getreideausgabe (Empfänger)

YOS 13, 325 (Ad 5) Mitgiftsurkunde (Zeuge+Siegel)

Larsa YOS 14, 348 (SiEr 1) Liste über Silberschenkungen (Empfänger)

Larsa YOS 5, 128 (WS 10) Darlehen über Getreide (Zeuge)

YOS 8, 31 (RS 21) Sklavenkauf (Zeuge)

YOS 8, 36 (RS 22) Sklavenkauf (Zeuge)

Bab. 7, 45 (RS 23) Sklavenkauf (Zeuge)

YOS 8, 25 (RS 23) Sklavensicherheit (Zeuge)

YOS 8, 45 (RS 25) Sklavensicherheit (Zeuge)

YOS 8, 72 (RS 25) Sklavensicherheit (Zeuge)

YOS 8, 19 (RS 31) Sklavensicherheit (Zeuge)

Larsa TCL 10, 39 (RS 14) Ausgabenliste (Empfänger)

Sippar BA 5, 491 Nr. 12 (Si 9) Arbeiterliste (suhār nar Arbeiter)

Šaduppûm YOS 14, 75 (D.a.) Rationenliste (Empfänger)

Nippur $\quad$ PBS 8/1, 81 (Ha 31) Rechtsprotokoll (Zeuge)

${ }^{2094}$ S. Dyckhoff 1999/II, 51. 
Sîn-mušallim, nar-gal

Sîn-mušallim, gala unūtim

Sîn-mušallim, gala-mah

Annunītum

Sîn-nādin-šumi, gala

Sîn-nūrī, munus-nar

Sîn-rē'i, gala

Sîn-rīmēni, nar

Sîn-šemi, dumu gala-mah

Sîn-šemi, nar-sa Enki

V. Sîn-gāmil

Sîn-uballit, gala

Sîn- $u_{2}$-WI-li, gala

Sîn-[ ], nar S. Šumum-libši

Șillī-Adad, nar-igi-lu[gal] Isin

S. Bēlī-ašarēd

Șillī-Ištar, gala

Șillī-Šamaš, gala

Šallūrum, gala

S. $\operatorname{Ir}_{11}{ }^{\mathrm{d}} \mathrm{Da}-\mathrm{mu}$

Šamaš-muballit, gala
Šaduppûm YOS 14, 75 (D.a.) Rationenliste (Empfänger)

H.u. $\quad$ AbB 1, 11 Brief: Verhör eines Sklaven (Eidesabnehmer)

T.ed-Dēr $\quad$ BE 6/1, 119 (o.D. [Ad 4+]) Auflistung von Immobilienkäufen (Zeuge)

AbB 2, 73 ([Ae]) Abi'ēšuh an Marduknāṣir (Rechtsangelegenheit)

T.ed-Dēr MHET I/1, 69 Briefabschrift? : Rechtsstreit betreff nudunnûm (Eidesabnehmer)

Larsa

Sippar

JCS 4, 111a/b (Sid 5b) Rationenlisten (Empfängerin)

MHET II, 633 (o.D.) Immobilienliste (Hausbesitzer)

Sippar $\quad$ MHET II, 595 (o.D.) Mietvertrag (Zeuge)

Sippar TCL 1, 168 (A’13) Getreideabrechnung (Empfänger)

TCL 1, 230 (o.D.[A’ 13]) Getreideabrechnung (Empfänger)

Ur $\quad$ UET 5, 191 (RS 54) Freilassungsurkunde (Zeuge)

Uruk (?) AbB 8, 3 Lu-Ninurta an Šamaš-hāzir (Feldempfänger)

Ur TSifr 25 (RS 35) Eigentumsprozess über Haus und $\mathrm{nam}$ - šit $\mathrm{a}_{4}$-Amt (Zeuge)

BE 6/2, 26 (Si 6) Erbschaftsvertrag, darunter je eine gala- und gudu - $^{-}$ Pfründe (Zeuge)

BIN 7, 69 (D.a. [Di i]) Grundstückskauf (Käufer)

Kutalla TSifr 42 (Ha 36) Besitzverhältnisse an Baugelände (Zeuge)

TSifr 43/43a (Ha 36) Tauschurkunde über Haus und Gelände (Zeuge)

MHET II, 633 (o.D.) Immobilienliste (Hausbesitzer)

BIN 7, 68 (Di A) Kauf eines $x^{?}$-Amtes (Zeuge)

BIN 7, 212 (o.D.) Hausgrundstückskauf (Verkäufer+Siegel ohne Titel)

BIN 7, 65 (Di ?) Kauf eines Braueramtes (Zeuge)

Sippar? AbB 12, 178 
Šamaš-muballit, gala Ninšubur

Šamaš-nīšu, nar-sa

S. Rī̌̌-ilim

Šamšī-libūr, nartu

Šāt-Ištar, munus-nar

Šēp-Sîn, $1 u_{2}$ nar

Šēp-Sîn, nar

Šēp-Sîn, nar

S. Nūr-Ninšubur
$\mathrm{Ur}$

Sippar

Sippar

Larsa

Uruk

Kutalla

Kutalla

Šeš-ki, nar-LA?

S. Ad-da-du ${ }_{10}$-ga

Šibia/â-pīša, munus-nar

Šìmi-[ ], munus-nar

Šu-Amurrum, nar-gal

Šu-ilī̌su, nar S. Șillī-Ištar

Šumum-libši, ugula tigiātim

Šu-Sîn, nar

Tarībum, nar

Ubarrum, gala
Nippur

Larsa

Larsa

Larsa

Kutalla

Sippar

Larsa

Dilbat

Nippur
YOS 12, 78 (Si 3) Rationenliste über Getreide (Empfänger)

YOS 12, 353 (Si 11) Auslösungsvertrag (Zeuge)

BE 6/2, 86 (Si 30) Rechtsstreit über Hausgrundstück (Zeuge)

JCS 2, 109 Nr. 18 (Ae 28) Getreideausgabe (Empfängerin)

JCS 4, 111a (Sid 5b) Rationenliste (Empfängerin)

BaM 23, 136 Nr. 173 (D.a.) Ausgabe von Textilien ( $\left.\mathrm{g}_{\text {i }} \mathrm{r}_{3}\right)$

TSifr 28/28a (RS 37) Baugeländekauf (Zeuge)

TSifr 40/40a (Ha 36) Feldtausch (Zeuge + Siegel)

TSifr 41/41a (Ha 36) Feldtausch (Zeuge)

TSifr 56/56a (Ha 42) Erbteilungsvertrag über Baugelände (Zeuge)

TSifr 65 (Si 4) Baugeländekauf (Zeuge)

TSifr 66/66a (Si 4) Kaufvertrag über Hausruine (Zeuge)

BE 6/2, 44 (Si 14) Erbteilungsvertrag (Zeuge)

JCS 4, 111a/b (Sid 5b) Rationenlisten (Empfängerin)

JCS 4, 111a (Sid 5b) Rationenliste (Empfängerin)

AbB 9, 193 Hammurabi an Šamaš-hāzir, betreff huppū

TSifr 30/30a (RS 47) Kaufvertrag über Hausruine (Zeuge)

CT 8,21c (Aș 10) Empfangsqittung über igisûm -Silber (Eintreiber)

TCL 10, 45 (RS 16) Ausgabe (ba-zi) über Silber (Empfänger)

VS 7, 155 (D.a.[Ad/Aṣ]) Arbeiterrationenliste (Empfänger)

Cornell 18 (Si 8) Hausgrundstückskauf (Nachbar)

Cornell 6 (Si [x]) Erbschaftsvertrag (Vater der Nachbarn)

OECT 8, 4 (Ha 31) Kaufvertrag über Haus und Amt (Zeuge) 
Ubārum/Ubarra, nar

Isin

Ubār-Šamaš, gala-mah

Larsa

Ur-du 6 -ku - -ga, nam-gala

S. Inana-ma-an-sum

Ur- ${ }^{\mathrm{d}} \mathrm{Gu}_{4}{ }^{\text {ud }}$-an-na-ka, gala$\mathrm{mah}$ [GN]

Ur- ${ }^{\mathrm{d}}$ Nin-in-si-na, gala-mah

Ninisina S. Ibni-Amurrum

Ur- ${ }^{\mathrm{d}}$ Pabilsag̃, nam-nar

S. Ubarrum

Ur- ${ }^{\mathrm{d}}$ PAP-nu'-še, nar

Ur- ${ }^{\mathrm{d}}$ Sak-kud, gala-mah

Ur- ${ }^{\text {S̆ }}$ Sul-pa-e 3 -a, nam-gala

S. Inana-ma-an-sum

Ur- ${ }^{\mathrm{d}} \mathrm{Utu}$, gala-mah

Annunītum S. 'Inana-ma-

an-sum

Isin

Ur
BIN 9, 496 (IšEr 14) Ausgabe (ba-zi). /zami/, al-balag̃, marītum, sa-ěs, $\breve{s a}_{3}$-TAR (11. ki nar Ubār)

BIN 10, 82 (D.a.[IšEr]) Quittung. /zami/ und $\check{s}_{3}$-TAR für $\mathrm{e}_{2}$ nar ki $\mathrm{U}_{4}$ !-barra

BIN 10, 104 (IšEr 13) Ausgabe (ba-zi). /zami/ und ša $a_{3}$-TAR für $\mathrm{e}_{2}$ nar munus ki Ubarra

BIN 10, 186 (o.D.) Lieferschein über Tannenholztüren (Empfänger)

HUCA 34, 1 ff. (RS 2) Opferrationenliste (Empfänger)

Nippur BE 6/2,26 (Si 6) Erbschaftsvertrag, darunter je eine gala- und gudu - $^{-}$ Pfründe (Erbe)

Sippar

AbB 6, 61 ([Aș]) Ammișaduqa an EbbiEnlil (Königsverordnung)

Wilcke 1985, 189: IB 1536 (o.D.[Si]) Brief; IB 1538 (o.D.[Si]) Brief über Silberforderung; IB 1539 (D.a.[Si]) Urkunde; IB 1540 (D.a.[Si]) Urkunde; IB 1541 (o.D.[Si]) Brief (Empfänger); IB 1669 (D.a.[Si]) Darlehen.

TIM 5, 26 (Si 15) Landkauf von gudu 4 (Käufer)

Nippur $\quad$ ARN 35 (RS 37) Kauf über nam-narPfründe (Käufer) ${ }^{2095}$

UET 5, 561 (o.D.) Ausgabe von Silberobjekten und -beträgen (Empfänger)

UET 5, 672 (o.D.) Ausgabenquittung über Getreiderohrkörbe und Emmerbier (Empfänger)

Sippar $\quad$ MHET II, 909 (Aṣ 15) Feldmietvertrag (Zeuge)

Nippur

Sippar

BE 6/2, 26 (Si 6) Erbschaftsvertrag, darunter je eine gala- und gudu - $_{4}$ Pfründe (Erbe)

Di 620 Brief von Kubburum, S. Inanamansum (betreff Rinder)

MHET II, 898 (Aṣ 6) Mietvertrag (Mieter)

CT 48, 76 (Aṣ 17) Landkauf (Zeuge)

${ }^{2095}$ Weitere Belege zu dieser Person bei Stone/Owen 1991, 12. 
Usātum, nar

[U]Š?-UR-ni, nar PN

${ }^{\mathrm{d}}$ Utu- ${ }^{\mathrm{d}}$ Enlil-la 2 , nar

${ }^{\mathrm{d}}$ Utu-ma-an-sum, gala

${ }^{\mathrm{d} U t u-m a-a n-s u m, ~ g a l a ~ S . ~}$ $\mathrm{Ur}-{ }^{\mathrm{d}} \mathrm{Utu}$

$U_{2}-t u-m e_{2}-\check{s} a-r a-a m$, nar

${ }^{\mathrm{d}} \mathrm{Utu}-\mathrm{zi}-\tilde{g} \mathrm{u}_{10}$, nar
RA 82, 28 (D.a.[Aș]) Erbschaftsvertrag über gala-Pfründe (Zeuge)

CT 45, 62 (D.a.) Rücktrittseinlösung (Verkäufer)

T.ed-Dēr MHET I/1, 68 Brief: Erbstreit? (Absender?)

MHET I/1, 6 (Aș 5) Gemeinschaftspachtvertrag (Pächter)

MHET I/1, 10 (Aṣ 5) Empfangsquittung über Silber (Zahler)

MHET I/1, 42 (Aș 5) Getreiderationenliste (Empfänger)

MHET I/1, 61 (Aș 8) Kupferausgabe (Empfänger)

MHET I/1, 25-30 (Aṣ 14) Bierlieferung (Empfänger)

MHET I/1, 17-24 (Aṣ 15) Bierlieferung (Empfänger)

Sippar

BA 5, 491 Nr. 12 (Si 9) Arbeiterliste (Arbeiter)

Šaduppûm YOS 14, 75 (D.a.) Rationenliste (Empfänger)

Nippur $\quad$ ARN 35 (RS 37) Kaufvertrag über ein Amt (nam-nar) (Zeuge)

ARN 76/BE 6/2, 23 (Si 4) Erbschaftsvertrag (Nachbar)

T.ed-Dēr $\quad$ MHET I/1, 53 (Aṣ 1) Erntearbeiterliste (Arbeiter)

MHET I/1, 44 (D.a.) Rationenliste (Empfänger)

MHET I/1, 51 (o.D.) Rationenliste (Empfänger)

MHET I/1, 56 (o.D.) Erntearbeiterliste (Arbeiter)

MHET I/1, 60 (o.D.) Erntearbeiterliste (Arbeiter)

CT 45, 15 (Sm 17) Kaufurkunde (Zeuge)

Larsa

AbB 4, 62 Awīl-Ninurta an Šamaš-hāzir (Feldpächter)

Larsa YOS 8, 36 (RS 22) Sklavenkauf (Zeuge) YOS 8, 15 (RS 23) Sklavensicherheit (Zeuge) 
Warad-Bunene, nar-sa S. Sippar

${ }^{\mathrm{d}}$ Utu-za-e-me-en

Warad-Ešurrītum, gala- Dilbat mah S. Na-[ ]

Warad-Ibari, gala

Warad-ilī̌su, gala

Warad-Ištar, gala

Warad-Kūbi, nar

Warad-Nabīum, nar

Warad-Sîn, nar

Zabarddabbû, nar PN

Zarriqum, gala S. Ekibigi Sippar

[PN S. ...]-al, eren 2 gala

[ ]-bubu, eren 2 gala S.

Nanna-mansum

[ ]- ${ }^{\mathrm{d}}$ Bunene, nar-sa

[ ]- ${ }^{\mathrm{d}}$ Nanaja, munus tigi

[ - ${ }^{\mathrm{d}}$ Nin-ur]ta, nar

[ ]-iqiišam, nar

[... S. ...-iqī] šam, eren $_{2}$ gala

$\mathrm{Ur}$
BE 6/2, 86 (Si 30) Rechtsstreit über Hausgrundstück (Zeuge);

s. a. [ ]- ${ }^{\mathrm{d} B u n e n e}$

BBVOT 1, 91 (Ad 34) Auslösevertrag (kiššatum) über Silber (Zeuge)

YOS 13, 37 (Aṣ 17+b) Empfangsquittung über Getreide und Silber (Ausgebender)

YOS 13, 329 (Sd 3) Empfangsquittung über Silber (Empfänger+Siegel)

T.ed-Dēr MHET I/1, 69 Briefabschrift?: Rechtsstreit über nudunnûm (Eidesabnehmer)

Larsa TCL 11, 156 (Ha 36) Ausgabe von Pachtfeldern (Feldpächter)

Nippur BE 6/2,26 (Si 6) Erbschaftsvertrag, darunter je eine gala- und gudu - $^{-}$ Pfründe (Zeuge).

Dilbat TJA 94 (Aș 10) Erntearbeitervertrag (Zeuge)

Kiš YOS 13, 43 (Sd 13) Quittung über Getreide (Empfänger)

Sippar CT 8, 41b (o.D.) Personenliste (Arbeiter)

Šaduppûm YOS 14, 75 (D.a.) Rationenliste (Empfänger)

Di 2015 (Ha 38) Kauf über g a la Pfründe (Käufer)

VS 18, 8a/b (Si 8) Feldkauf (Zeuge)

TCL 1, 130/131 (Si 10) Feldkauf (Zeuge)

Nippur

PBS 8/1, 94 (o.D.) Arbeiterliste (Arbeiter)

Nippur

PBS 8/1, 94 (o.D.) Arbeiterliste (Arbeiter)

Sippar $\quad$ CT 45, 84 (o.D.) Opferrationenliste über parșum (Empfänger);

s. a. Warad-Bunene, nar-sa, S. ${ }^{\mathrm{d}}$ Utu-zae-me-en

Isin IB 1293 (o.D.) Gersterationenliste (Empfängerin)

Kutalla

TSifr 23 (RS 30-25?) Kauf eines [ ]Amts (Zeuge)

TSifr 31 (D.a. [n. RS 13]) Geländekauf (Zeuge)

Nippur $\quad$ PBS 8/1, 94 (o.D.) Arbeiterliste (Arbeiter) 


\section{Literaturverzeichnis}

Ali, F. A.

1964, Sumerian Letters: Two Collections from the Old Babylonian Schools. Michigan.

Al-Rawi, F. N. H.

1992a, A New Hymn to Marduk from Sippar, $R A$ 86, 79-83.

1992b, Two Old Akkadian Letters Concerning the Offices of kala'um and nārum, $Z A$ $82,180-185$.

Al-Rawi, F. N. H. / J. Black

2000, A balbale of Ninurta, God of Fertility, ZA 90, 31-38.

Alster, B.

1972, Dumuzi's Dream. Aspects of Oral Poetry in a Sumerian Myth. Mesopotamia 1.

1978, Sumerian Proverb Collection Seven, RA 72, 97-112.

1982, Emesal in Early Dynastic Sumerian? What is the UD.GAL.NUN-Orthography?, ASJ 4, 1-6.

1985, Geštinanna as Singer and the Chorus of Uruk and Zabalam: UET 6/1 22, JCS 37, 219-228.

1991, Incantation to Utu, ASJ 13, 27-96.

1992, Two Sumerian Short Tales Reconsidered, ZA 82, 186-201.

1993, Marriage and Love in the Sumerian Love Songs, in: M. E. Cohen, D.C. Snell \& D.B. Weisberg (Hrsg.). The Tablet and the Scroll. Near Eastern Studies in Honor of William W. Hallo. Bethesda, 15-27.

1996, Inanna Repenting: The Conclusion of Inanna's Descent, ASJ 18, 1-18.

1997, Proverbs of Ancient Sumer. The World's Earliest Proverb Collection. Bethesda, Md.

2004, Gudam and the Bull of Heaven. With an appendix by Laura Feldt, in: J. G. Dercksen (Hrsg.). Assyria and Beyond: Studies Presented to Morgen Trolle Larsen. Leiden, 21-46.

Alster, B. \& C. B. F. Walker

1989, Some Sumerian Literary Texts in the British Museum, in: H. Behrens, D. Loding \& M. T. Roth (Hrsg.) Dumu-E $E_{2}-D u b-b a-a$. Studies in Honor of Ake W. Sjöberg, Occasional Publications of the Samuel Noah Kramer Fund 11. Philadelphia, 7-19. 
Alster, B. \& U. Jeyes

1990, Two Utu Hymns and a Copy of a Royal Inscription, ASJ 12, 1-14.

Ambos, C.

2004, Mesopotamische Baurituale aus dem 1. Jahrtausend v. Chr. Mit einem Beitrag von Aaron Schmitt. Dresden.

2008, Sänger, Sängerin. A. Philologisch, in: RlA 11, 499-503.

Anbar, M.

1975, Textes de l'époque babylonienne ancienne, $R A$ 69, 109-136.

Anbar, M. \& M. Stol

1991, Textes de l'époque babylonienne ancienne III, $R A$ 85, 13-48.

Armstrong, J. A.

1992, West of Edin: Tell al-Deylam and the Babylonian City of Dilbat, Biblical Archaeologist 55/4, 219-226.

Arnaud, D.

1976, Catalogue des textes et des objets inscrits trouvés au cours de la deuxième campagne, Syria 53, 57-93.

1981, 2. Catalogue des documents inscrits trouvés au cours de la huitème campagne (1978), avec une annexe de textes divers concernant le royaume de Larsa, Syria 58, 41-99.

1989, Altbabylonische Rechts- und Verwaltungsurkunden aus dem Musée du Louvre. BBVOT 1. Berlin.

1994, Texte aus Larsa. Die epigraphischen Funde der 1 Kampagne in Senkereh-Larsa 1933. BBVOT 3. Berlin.

Assante, J.

1998, The kar.kid / harimtu, Prostitute or Single Woman? A Reconsideration of the Evidence, UF 30, 5-96.

Attinger, $\mathrm{P}$.

1984a, Enki et Ninhursag̃a, ZA 74, 1-52.

1984b, Remarques à propos de la «malédiction d'Accad», RA 78, 99-121.

1993, Eléments de linguistique sumérienne : la construction de $d u_{11} / e / d i$ "dire" /. Orbis biblicus et orientalis: Sonderband.

1998, Inanna et Ebih, ZA 88, 164-195.

Batto, B. F.

1974, Studies on Women at Mari. Baltimore, London. 
Beaulieu, P.-A.

1995, Theological and Philological Speculations on the Names of the Goddess Antu, OrNS 64, 187-213.

Benito, C. A.

1970, Enki and Ninmah and Enki and the World Order. Diss. phil. Univ. of Pennsylvania 1969. Ann Arbor.

Bernhardt, I. \& S. N. Kramer

1956-57, Götter-Hymnen und Kult-Gesänge der Sumerer auf zwei Keilschrift„Katalogen“" in der Hilprecht-Sammlung. Wissenschaftliche Zeitschrift der Friedrich-Schiller-Universität Jena. Gesellschafts- und sprachwissenschaftliche Reihe 6, 389-395.

1975, Die Tempel und Götterschreine von Nippur, OrNS 44, 96-102.

Bielitz, M.

1970, Melismen und ungewöhnliche Silbenwiederholung, bzw. Alternanz in sumerischen Kulttexten der Seleukidenzeit, OrNS 39, 152-156.

Biggs, R. D.

1998, Nin-Nibru, RlA 9, 476-477.

Black, J. A.

1983, Babylonian Ballads. A New Genre, JAOS 103, 25-34.

1985, A-še-er Gi 6 -ta, a Balag of Inanna, ASJ 7, 11-87.

1987, Sumerian Balag Compositions, BiOr 44, 32-79.

1989/90, Rez. zu Maul Herzberuhigungsklagen (1988), AfO 36/37, 124-126.

1991, Eme-sal Cult Songs and Prayers, in: P. Michalowski, P. Steinkeller, E. C. Stone \& R. L. Zettler (Hrsg.). Velles Paraules: Ancient Near Eastern Studies in Honor of Miguel Civil on the Occasion of his Sixty-Fifth Birthday. AuOr 9, 23-36.

2002, En-hedu-ana not the composer of the temple hymns, N.A.B.U. 2002, 2-4.

2005, Songs of the Goddess Aruru, in: Y. Sefati \& P. Artzi et al. (Hrsg.). "An Experienced Scribe who Neglects nothing”. Ancient Near Eastern Studies in Honor of Jacob Klein. Publications of the Samuel Noah Kramer Institute of Assyriology and Ancient Near Eastern Studies. Bar Ilan, Bethesda, MD, 39-62.

Black, J. A. \& A. Green

1992, Gods, Demons and Symbols of Ancient Mesopotamia. An Illustrated Dictionary. London.

Blocher, F.

1987, Untersuchungen zum Motiv der nackten Frau in der altbabylonischen Zeit. München. 
Borger, R.

1967, Das dritte 'Haus' der Serie bit rimki (VR 50-51, Schollmeyer HGŠ Nr. 1), JCS 21, 1-17.

1979, Babylonisch-Assyrische Lesestücke. 2., neubearbeitete Auflage. Teil I/II. Analecta Orientalia 54. Rom.

1982, Akkadische Rechtsbücher, in: R. Borger et al. (Hrsg.). Rechts- und Wirtschaftsurkunden. Historisch-chronologische Texte. Rechtsbücher. Texte aus der Umwelt des Alten Testaments 1,1. Gütersloh, 32-95.

2003, Mesopotamisches Zeichenlexikon. AOAT 305, Münster.

Bottéro, J. \& S. N. Kramer

1989, Lorsque les dieux faisaient l'homme. Mythologie Mésopotamienne. Bibliothèque des Histoires. Paris.

Bouzon, E.

1995, Die soziale Bedeutung des șimdat-šarrim-Aktes nach den Kaufverträgen der Rim-Sin-Zeit, in: O. Loretz \& M. Dietrich (Hrsg.). Vom Alten Orient zum Alten Testament. Festschrift für Wolfram Freiherrn von Soden zum 85. Geburtstag am 19. Juni 1993. AOAT 240, 11-30.

Brinkmann, J. A.

1993-95, Meerland (Sealand), in: RlA 8, 6-10.

Brisch, N.

2007, Tradition and the Poetics of Innovation. Sumerian Court Literature of the Larsa Dynasty (c. 2003-1763 BCE. AOAT 339, Münster.

Buccellati, G.

1972, Rez. zu AbB 4, Oriens Antiquus 11, 147-152.

Bruschweiler, F.

1990, La Plainte de Roseau. eršemma de Dumuzi, MAH 16014, RA 84, 119-124.

Castellino, G. R.

1959, Urnammu. Three Religious Texts (continued), ZA 53, 106-132.

1972, Two Šulgi Hymns. Studi Semitici 42. Roma.

Catagnoti, A.

1997, Les listes des húb.(ki) dans les textes administratifs d'ébla et l'onimastique de nagar, MARI 8, 563-596.

1998, Sur le balag Uruamma'irabi et le Rituel de Mari, N.A.B.U. 1998 No. 43. 
Cavigneaux, A. \& F. N. H. Al-Rawi

1993a, Gilgameš et Tureau de Ciel (šul-mè-kam) (Textes de Tell Haddad IV), RA 87, 97-126.

1993b, New Sumerian Literary Texts from Tell Haddad (Ancient Meturan): A First Survey, Iraq 55, 91-105.

2000, Gilgameš et la Mort. Textes de Tell Haddad VI avec un appendice sur les textes funéraires sumériens. Cuneiform Monographs 19. Groningen.

Cavigneaux, A. \& M. Krebernik

1998-2001a, Nin-e'igara, in: RlA 9, 348.

1998-2001b, Nin-hinuna, in: RlA 9, 378.

1998-2001c, Nin-gublaga, in: RlA 9, 374-376.

Çerný, M. K.

1994, Some Musicological Remarks on the Old Mesopotamian Music and its Terminology, ArOr 62, 17-26.

Charpin, D.

1978, Recherches sur la $<$ Dynastie de Mananâ $>$ (I): Essai de localisation et de chronologie, $R A$ 72, 13-40.

1979, Rez. zu YOS 14, BiOr 36, 188-200.

1980, Archives familiales et propriété privée en babylonie ancienne: études des documents de $<$ Tell Sifr $>$. Centre de recherches d'histoire et de philologie de la IVe Section de l'école pratique des Hautes études. II Hautes études orientales 12. Paris.

1981, La Babylonie de Samsu-iluna à la lumière de nouveaux documents, BiOr 38, 517-547.

1984, Nouveaux documents au bureau de l'huile à l'epoque assyriene, MARI 3, 83-126.

1986, Le clergé d'Ur au siècle d'Hammurabi (XIXe-XVIIIe siècles av. J.-C.). Hautes Etudes Orientales 22. Paris.

1988, Sippar: deux villes jumelles, $R A$ 82, 13-32.

1992, Le point sur les deux Sippar, N.A.B.U. 1992 No. 114.

1994/39, Inanna/Eštar, divinité poliade d'Uruk à l'époque paléo-babylonienne, N.A.B.U. 1994 No. 39.

2003, La politique immobilière des marchands de Larsa à la lumière des découvertes épigraphiques de 1987et 1989, in Huot (Hrsg.) 2003.

2004, Histoire politique du Proche-Orient Amorrite (2002-1595), in: P. Attinger, W. Sallaberger \& M. Wäfler (Hrsg.). Mesopotamien. Die altbabylonische Zeit. Annäherungen 4 (=OBO 160/4). Fribourg, Göttingen.

2006 , Les inscriptions royales suméro-akkadiennes d'époque paléo-babyloniennes, $R A$ 100, 131-160.

Civil, M.

1967, Šū-Sîn’s Historical Inscriptions: Collection B, JCS 21, 24-38. 
1976, The Song of the Plowing Oxen, Kramer Anniversary Volume. Cuneiform Studies in Honor of Samuel Noah Kramer. AOAT 25, 83-95.

1983, Enlil and Ninlil: The Marriage of Sud, JAOS 103, 43-66.

1985, On Some Texts Mentioning Ur-Namma, OrNS 54, 27-45.

1987, The Tigidlu Bird and a Musical Instrument, N.A.B.U. 1987 No. 48.

1989, The Statue of Šulgi-ki-ur ${ }_{5}-\mathrm{sag}_{9}$-kalam-ma. Part One: The Inscription, in: $\mathrm{H}$. Behrens, D. Loding \& M. T. Roth (Hrsg.). Dumu-E ${ }_{2}-D u b-b a-a$. Studies in Honor of Ake W. Sjöberg. Occasional Publications of the Samuel Noah Kramer Fund 11. Philadelphia, 49-64.

Clavet, Y.

2003, Bâtiments paléobabyloniens à Larsa, in: Huot (Hrsg.) 2003, 143-297.

Cohen, A. C.

2005, Death Rituals, Ideology, and the Development of Early Mesopotamian Kingship. Toward a New Understanding of Iraq's Royal Cemetery of Ur. Ancient Magic and Divination 7. Leiden, Boston.

Cohen, M. E.

1975, The Incantation Hymn: Incantation or Hymn?, JAOS 95, 592-611.

1975/76, ur.sag.me.šár.ur 5 . A Širnamšubba of Ninurta, $W d O$ 8, 22-36.

1977, Another Utu-Hymn, ZA 67, 1-19.

1981, Sumerian Hymnology: The Eršemma. Hebrew Union College Annnual. Supplements Number 2.

1988, The Canonical Lamentations of Ancient Mesopotamia. Vol. I/II. Potomac, Maryland.

1993, The Cultic Calendars of the Ancient Near East. Bethesda, Maryland.

Conti, G.

1993, Sur la construction de zà-mí, N.A.B.U. 1993 No. 109.

Collaer, P. \& J. Elsner

1983, Musikgeschichte in Bildern. Nordafrika. Band I: Musikethnologie. Lieferung 8.

Cooper, J. S.

1978, The Return of Ninurta to Nippur. an-gim dim-ma. Utilizing Materials prepared by E. Bergmann. Analecta Orientalia 52. Rom.

1983, The Curse of Agade. London.

1997, Gendered Sexuality in Sumerian Love Poetry, in: I. L. Finkel, M. J. Geller (Hrsg.). Sumerian gods and their representations (=CM 7). Groningen, 85-97. 2006a, Prostitution, in: RlA 11, 12-21.

2006b, Genre, Gender, and the Sumerian Lamentation, JCS 58, 39-47. 
Dalley, S.

2005, Old Babylonian Texts in the Ashmolean Museum. Mainly from Larsa, Sippar, Kish, and Lagaba. Oxford Editions of Cuneiform Texts 15.

De Meyer, L.

1982a, Deux prières ikribu de temps d'Ammī-Șaduqa, in: G. van Driel et al. (Hrsg.). Zikir Sumim. Assyriological Studies Presented to F. R. Kraus on the Occasion of his Seventieth Birthday. Nederlands Instituut voor het Nabije Oosten Studia Francisci Scholten Memoriae Dicata. Volomen Quintum. Leiden, 271-278.

1982b, mubabbilūtum dans une lettre paléo-babylonienne tardive, in: J. Quaegebeur (Hrsg.). Studia Paulo Naster Oblata II Orientalia Antiqua. OLA 13. Leuven, 31-36.

1989, Une lettre d'Ur-Utu Galamah à une divinité, in: M. Libeau \& Ph. Talon (Hrsg.). Reflets des deux Fleuves. Volume de Mélanges offerts à André Finet. Akkadica Supplementum VI. Leuven, 41-43.

Dekiere, L.

1994, La généalogie d'Ur-Utu, in: Cinquante-deux reflexions sur le proche-orient ancien. Offertes en hommage à Léon de Meyer. Mesopotamian History and Environment II. Ghent, 125-141.

Delaporte, L.

1911, Tablettes de Dréhem, RA 8, 183-198.

Diakonoff, I. M.

1975, Ancient Writing and Ancient Written Language: Pitfalls and Pecularies in the Study of Sumerian, in: Sumerological Studies in Honor of Thorkild Jacobsen on his Seventieth Birthday June 7. Assyriological Studies 20. Chicago, London, 99-121.

Dombradi, E.

1996, Die Darstellung des Rechtsaustrags in den Altbabylonischen Prozessurkunden. Band I/II. Freiburger Altorientalische Studien 20/1, 2.

Donbaz, V. \& N. Yoffee

1986, Old Babylonian Texts from Kiš Conserved in the Istanbul Archaeological Museums. Bibliotheca Mesopotamica 17. Malibu.

Dunham, S.

1985, The Monkey in the Middle, ZA 75, 234-264. 
Duponchel, D.

1997, Les Comtes d'huile de palais de Mari datés de l'année de Kahat, in: J.-M. Durand \& D. Charpin (Hrsg.). Recueil d'études à la mémoire de Marie-Thérèse Barrelet. FM 3, Mémoires de N.A.B.U. 4, 201-262.

Dupret, M.-A.

1974, Hymne au dieu Numušda avec prière en faveur de Sîniqī̌šam de Larsa, OrNS 43, 327-343.

Durand, J.-M.

1982, Sumerien et Akkadien en pays amorite I. Un document juridique archaïque de Mari, Mari 1, 79-89.

1983, Textes administratifs des salles 134 et 160 du palais de Mari. Transcrit, traduits et commentés. ARM(T) 21. Paris.

1984, Trois études sur Mari, MARI 3, 127-180.

1988, Archives épistolaires de Mari 1/1. ARM(T) 26. Paris.

1990, Documents pour l'histoire du royaume de haute-mesopotamie II, MARI 6, 271301.

2000, Documents épistolaires du Palais de Mari. Tome III. Litterature Ancienne du Proche-Orient 18. Paris.

Durand, J.-M. \& M. Guichard

1997, Les Rituels de Mari, in: J.-M. Durand \& D. Charpin (Hrsg.). Recueil d'études à la mémoire de Marie-Thérèse Barrelet. FM 3. Mémoires de N.A.B.U. 4, 1978.

Dyckhoff, C. B.

1998, Balamunamhe von Larsa - eine altbabylonische Existenz zwischen Ökonomie, Kultus und Wissenschaft, in: J. Prosecký (Hrsg.). Intellectual Life of the Ancient Near East. Papers Presented at the 43. Rencontre Assyriologique Internationale. Prague, July 1-5, 1996. Academy of Sciences of the Czech Republic Oriental Institute, 117-124.

1999, Das Haushaltsbuch des Balamunamhe. Band 1: Darstellung. Band 2: Belegmaterial. Inaugural-Dissertation zur Erlangung des Doktorgrades der Philosophie an der Ludwig-Maximilians-Universität München. München.

2002, Priester und Priesterinnen im altbabylonischen Larsa. Das Amtsarchiv als Grundlage für prosopographische Forschung, in: S. Parpola \& M. Whiting (Hrsg.). Sex and Gender in the Ancient Near East. Proceedings of the 47th Rencontre Assyriologique Internationale. Part I / II. The Neo-Assyrian Text Corpus Project, 132-127.

Ebeling, E.

1938, Ezinu, in: RlA 2, 489-490.

1948, Ein Gebet an einen "verfinsterten Gott" aus neuassyrischer Zeit, Or 17, 416-422. 
1952, Kultische Texte aus Assur, Or 21, 129-148.

Edzard, D. O.

1968, Sumerische Rechtsurkunden des III. Jahrtausends aus der Zeit vor der II. Dynastie von Ur. München.

1970, Altbabylonische Rechts- und Wirtschaftsurkunden aus Tell ed-Der im Iraq Museum, Baghdad. Abhandlungen, Bayerische Akademie der Wissenschaften, Philosophisch-Historische Klasse; N.F. 72.

1997, Gudea and His Dynasty. RIME 3/1.

1998, Name, Namengebung (Onomastik). A. Sumerisch. B. Akkadisch, RlA 9, 94-116.

2000, Nin-Isina, RlA 9, 387-388.

2003, Sumerian Grammar. Handbuch der Orientalistik 71. Leiden, Boston.

Edzard, D. O. \& McG. Gibson

1976-80, Kiš, in: RlA 5, 607-620.

Edzard, D. O. \& W. Röllig

1987-90, Literatur, in: RlA 7, 35-66.

Ellis, M. de Jong

1976, Agriculture and the State in Ancient Mesopotamia. An Introduction to Problems of Land Tenure. Occasional Publications of the Babylonian Fund 1. Philadelphia.

1995, Myth and Narrative: Structure and Meaning in Some Ancient Near Eastern Texts. AOAT 241. Münster.

Falkenstein, A.

1949, Ein sumerisches Kultlied auf Samsu'iluna, ArOr 17/I, 212-226.

1950, Sumerische Religiöse Texte, $Z A 49,80-150$.

1957, Sumerische Religiöse Texte, $Z A$ 52, 58-75.

1957-71, Gebet I, in: RlA 3, 160-170.

1959, Sumerische Götterlieder 1. Abhandlungen der Heidelberger Akademie der Wissenschaften Jahrgang 1959. 1. Abhandlung.

1964, Sumerische Religiöse Texte, ZA 56, 44-129.

Falkenstein, A. \& W. von Soden

1953, Sumerische und Akkadische Hymnen und Gebete (SAHG). Die Bibliothek der Alten Welt. Der Alte Orient. Zürich, Stuttgart.

Farber, G. \& W. Farber

2003, Von einem, der auszog, ein gudu 4 zu werden, in: W. Sallaberger, K. Volk \& A. Zgoll (Hrsg.). Literatur, Politik und Recht in Mesopotamien. Festschrift für Claus Wilcke. Orientalia Biblica et Christiana 14. Wiesbaden, 99-114. 
Farber, W.

1987-90, me (garza, parșu), in: RlA 7, 610-613.

1985, Akkadisch „blind“, ZA 75, 210-233.

1987, Rituale und Beschwörungen in akkadischer Sprache, in: Rituale und Beschwörungen. Texte aus der Umwelt des Alten Testaments Bd.II/2, 212-281.

1989, Schlaf, Kindchen, Schlaf! Mesopotamische Baby-Beschwörungen und -Rituale. Mesopotamian Civilizations 2. Winona Lake.

2003, Singing an eršemma for the Damaged Statue of a God, ZA 93, 208-213.

Farber-Flügge, G.

1973, Der Mythos “Inanna und Enki” unter besonderer Berücksichtigung der Liste der me. Studia Pohl 10. Rom.

Ferrara, A. J.

1973, Nanna-Suen's Journey to Nippur. Studia Pohl: Studies Maior 2. Rom.

Ferwerda, G .T.

1985, A Contribution to the Early Isin Craft Archive (=SLB 5). Leiden.

Fincke, J. C.

2000, Augenleiden nach keilschriftlichen Quellen. Untersuchungen zur altorientalischen Medizin. Würzburger medizinhistorische Forschungen Band 70. Würzburg, Univ.-Diss.

Finet, A.

1981, Les dieux voyageurs en Mésopotamie, Akkadica 21, 1-13.

Finkel, I. L.

1988, A Fragmentary Catalogue of Lovesongs, ASJ 10, 17-18.

Finkelstein, J. J.

1972, Late Old Babylonian Documents and Letters. YOS 13. New Haven, London.

Flückiger-Hawker, E.

1996, Der <Louvre-Katalog> TCL 15, 28 und sumerische $\mathrm{na}-\mathrm{ru}_{2}$-a-Kompositionen, N.A.B.U. 1996 No. 119.

1999, Urnamma of Ur in Sumerian Literary Tradition. Orbis biblicus et orientalis 166.

Foster, B. R.

1974, Humor and Cuneiform Literature, The Journal of the Ancient Near Eastern Society of Columbia University 6, 69-85.

1993, Before the Muses. An Anthology of Akkadian Literature. Vol. I: Archaic, Classical, Mature. Vol. II: Mature, Late. Bethesda, Maryland. 
Frayne, D. R.

1990, Old Babylonian Period. (2003-1595 BC). RIME 4. Toronto, Buffalo, London.

1993, Sargonic and Gutian Periods (2334-2113 BC). RIME 2. Toronto, Buffalo, London.

1997, Ur III Period (2112-2004). RIME 3/2. Toronto, Buffalo, London.

1998, New Light on the Reign of Išme-Dagan, ZA 88, 6-44.

Friedl, C.

2000, Polygynie in Mesopotamien und Israel. Sozialgeschichtliche Analyse polygamer Beziehungen anhand rechtlicher Texte aus dem 2. und 1. Jahrtausend v. Chr. AOAT 277. Münster.

Fritz, M. M.

2003, „.. . .und weinten um Tammuz“. Die Götter Dumuzi-Ama'ušumgal'anna und Damu. AOAT 307. Münster.

Fronzaroli, P.

1989, A proposito del culto dei re defunti a Ebla, N.A.B.U. 1989 No. 2.

1991, Noms de fonction dans les textes rituels d'Ebla, N.A.B.U. 1991 No. 49.

Gabbay, U.

2007, The Sumero-Akkadian Prayer "Eršema”: A Philological and Religious Analysis. Unpublished dissertation. Hebrew University, Jerusalem.

2008, The Akkadian Word for "Third Gender": The kalû (gala) Once Again, in: R. D. Biggs, J. Myers \& M. Roth (Hrsg.). Proceedings of the $51^{\text {st }}$ Rencontre Assyriologique Internationale held at The Oriental Institute of The University of Chicago, July 18-22, 2005. Chicago, Illinois, 47-54.

Gadotti, A.

2006, Gilgameš, Gudam, and the Singer in Sumerian Literature, in: P. Michalowski / N. Veldhuis. Approaches to Sumerian Literature. Studies in Honour of Stip (H. L. J. Vanstiphout). Leiden. Boston, 67-83.

2009, The Nar and Gala in Sumerian Literary Texts, in: R. Pruzsinszky \& D. Shehata (Hrsg.), Musiker und Tradierung. Studien zur Rolle von Musikern bei der Verschriftlichung und Tradierung von literarischen Werken, WOO 7. Wien (im Druck).

Gallery, M. L.

1980, Service Obligations of the kezertu-Women, OrNS 49, 333-338.

Gasche, H.

1989, La Babylonie au 17e Siècle avant notre ère: Approche Archéologique, Problèmes et Perspectives. Mesopotamian History and Environment. Memoirs I. Series II. Ghent. 
Gelb, I. J.

1975, Homo Ludens in Early Mesopotamia, in: Armas I. Salonen, S.Q.A. Studia Orientalis $46,43-74$.

Geller, M. J.

1985, Forerunners to Udug-Hul. Sumerian Exorcistic Incantations. Freiburger Altorientalische Studien 12. Stuttgart.

1992, CT 58, No. 70. A Middle Babylonian Eršahunga, BSOAS 55, 528-532.

1996, Jacobsen's "Harps" and the Keš Temple Hymn, ZA 86, 68-79.

2003, Music Lessons, in: G. J. Selz (Hrsg.), Festschrift für Burkhart Kienast zu seinem 70. Geburtstage dargebracht von Freunden, Schülern und Kollegen, AOAT 274, 109-111.

Genouillac, H. de

1924, Premières recherches archéologiques à Kich. Rapport sur les travaux et inventaires, Facsimilés, Dessins, Photographies et Plans. Tome premier. Fouilles Français d'el-Akhymer. Paris.

1925, Premières recherches archéologiques à Kich. Notes archéologiques et inventaires, Facsimilés, Dessins, Photographies. Tome second. Fouilles Français d'elAkhymer. Paris.

George, A. R.

1993, House Most High. The Temples of Ancient Mesopotamia. Mesopotamian Civilizations 5.

1997, Sumerian t i r u = «eunuch», N.A.B.U. 1997 No. 97.

2003, The Babylonian Gilgamesh Epic. Introduction, Critical Edition and Cuneiform Texts. Vol. I-II. Oxford.

Gesche, P. D.

2000, Schulunterricht in Babylonien im ersten Jahrtausend v. Chr. AOAT 275. Münster.

Gibson, McG.

1972, The City and Area of Kish. Florida.

Goddeeris, A.

2000, The Local Calendar of Sippar, N.A.B.U. 2000 No. 63.

2002, Economy and Society in Northern Babylonia in the Early Old Babylonian Period (ca. 2000-1800 BC). OLA 109. Leuven.

Goetze, A.

1948, Thirty Tablets from the Reign of Abīešuh and Ammī-ditana, JCS 2, 73-112.

1950, Sin-iddinam of Larsa. Two Tablets from his Reign, JCS 4, 83-118. 
1957, Old Babylonian Letters in American Collections. I. Catholic University of America (Washington, D. C.), JCS 11, 106-109.

1965, Date Formula of Iddin-Dagān of Isin, JCS 19, 56-58.

1968, An Old Babylonian Prayer of the Divination Priest, JCS 22, 25-29.

Gordon, E. I.

1959, Sumerian Proverbs. Glimpses of Everyday Life in Ancient Mesopotamia. Museum Monographs. Philadelphia.

Grayson, K.

1987, Assyrian Rulers from the Third and Second Millennia BC (to 1115 BC). The Royal Inscriptions of Mesopotamia, Assyrian Periods I (RIMA). Toronto, Buffalo, London.

Green, M. W.

1978, The Eridu Lament, JCS 30, 127-167.

1984, The Uruk Lament, JAOS 104, 253-279.

Green, M. W. \& H. J. Nissen

1987, Zeichenliste der archaischen Texte aus Uruk. Ausgrabungen der Deutschen Forschungsgemeinschaft in Uruk-Warka 11, Archaische Texte aus Uruk 2. Berlin.

Greengus, S.

1987, The Akkadian Calendar at Sippar, JAOS 107, 209-229.

Groneberg, B.

1980, Die Orts- und Gewässernamen der altbabylonischen Zeit. Répertoire Géographique des Textes Cuneiformes 3. Beihefte zum Tübinger Atlas des Vorderen Orients. Reihe B Nr. 7/3.

1981, Rezension zu M.-J. Seux Hymnes et Prières aux dieux de Babylonie et d'Assyrie. Paris 1976, WdO 12, 178-183.

1986, Die sumerisch-akkadische Inanna/Ištar: „Hermaphroditos?“, WdO 17, 25-46.

1997a, Lob der Ištar. Gebet und Ritual an die altbabylonische Venusgöttin. Tanatti Ištar. Cuneiform Monographs 8. Groningen.

1997b, Namûtu ša Ištar : «Das Transvestiespiel der Ištar », N.A.B.U 1997 No. 68.

1999, 'Brust'(irtum)-Gesänge, in: B. Böck, E. Cancik-Kirschbaum \& Th. Richter (Hrsg.). Munuscula Mesopotamica. Festschrift für Johannes Renger. AOAT 267, 169-195.

2001, Die Liebesbeschwörung $M A D$ V 8 und ihr literarischer Kontext, $R A$ 95, 97-113. 2002, 'The Faithful Lover' Reconsidered: Towards Establishing a New Genre, in: S. Parpola \& R. M. Whiting (Hrsg.). Sex and Gender in the Ancient Near East. Proceedings of the 47. Rencontre Assyriologique Internationale. Part I/II. Helsinki: 2002, 165-183. 
2003, Searching for Akkadian Lyrics: From Old Babylonian to the "Liederkatalog" KAR 158, JCS 55, 55-74.

2007, Liebes- und Hundebeschwörungen im Kontext, in: M. T. Roth et al., Studies Presented to Robert D. Biggs, From the Workshop of the Chicago Assyrian Dictionary Vol. 2. Chicago, 91-107.

Groneberg, B. \& H. Hunger

1978, Rezension zu TIM 9, JAOS 98, 521-523.

Gurney, O. R. \& S. N. Kramer

1976, Sumerian literary texts in the Ashmolean Museum, (=OECT 5). Oxford.

Güterbock, H. G.

1983, A Hurro-Hittite Hymn to Ishtar, JAOS 103, 155-64.

Hall, M. G.

1985, A Study of the Sumerian Moon-God, Nanna/Suen. 2 Parts. Dissertation. Philadelphia.

1986, A Hymn to the Moon God, Nanna, JCS 38, 152-165.

Hallo, W. W.

1963, On the Antiquity of Sumerian Literature, JAOS 83, 167-176.

1966, New Hymns to the Kings of Isin. Rezension zu Römer 1965, BiOr 23, 239-247.

1968, Individual Prayer in Sumerian: The Continuity of a Tradition, JAOS 88, 71-89.

Harris, R.

1975, Ancient Sippar. A Demographic Study of an Old-Babylonian City (1894-1595 B.

$C$.). Uitgaven van het Nederlands Historisch-Archaeologisch Instituut te Istanbul 36, Istanbul.

Hartmann, H.

1960, Die Musik der Sumerischen Kultur. Diss. Phil. Frankfurt am Main.

Haupt, P.

1917/18, Der Litaneidialekt des Sumerischen, ZA 31, 240-147.

Hecker, K.

1989, Akkadische Hymnen und Gebete, in: Lieder und Gebete I. Texte aus der Umwelt des Alten Testaments 2,5. Gütersloh, 718-783.

Heimerdinger, J. W.

1976, An Early Babylonian Offering List from Nippur, in: Kramer Anniversary Volume. Cuneiform Studies in Honor of Samuel Noah Kramer. AOAT 25. Kevelaer, Neukirchen-Vluyn, 225-229. 
Heimpel, W.

1981, The Nanshe Hymn, JCS 33, 65-139.

1993-97, Mythologie (mythology). A.I, in: RlA 8. Berlin, New York, 537-564.

1998, A Circumambulation Rite, ASJ 20, 13-16.

1998-2001a, Ninigizibara I und II, in: RlA 9. Berlin, New York, 382-384.

1998-2001b, Ninsiana, in: RlA 9. Berlin, New York, 487-488.

Held, M.

1961, A Faithful Lover in an Old Babylonian Dialogue, JCS 15, 1-26.

Henshaw, R. A.

1994, Female and Male. The Cultic Personnel. The Bible and the Rest of the Ancient Near East XIII. Princeton Theological Monographs. Princeton.

Horowitz, W.

2000, Astral Tablets in the Hermitage, Saint Petersburg, ZA 90, 149-206.

Horowitz, W. \& N. Wasserman

1996, Another Old Babylonian Prayer to the Gods of the Night, JCS 48, 57-60.

Horsnell, M. J. A.

1999, The Year Names of the First Dynasty of Babylonia. Vol. 1 Chronological Matters: The Year-Name System and the Date Lists. Vol. 2 The Year-Names Reconstructed and Critically Annotated in Light of their Exemplars. Hamilton, Ontario.

Hrouda, B. (Hrsg.)

1977, Isin - Ǐsān Bahrīyāt I. Die Ergebnisse der Ausgrabungen 1973-1974. Bayerische Akademie der Wissenschaften. Philosophisch-Historische Klasse, Abhandlungen, Neue Folge, Heft 79. München.

1981, Isin - Išān Bahrìyāt II. Die Ergebnisse der Ausgrabungen 1975-1978. Bayerische Akademie der Wissenschaften. Philosophisch-Historische Klasse, Abhandlungen, Neue Folge, Heft 87. München.

1987, Isin - Išān Bahrìyāt III. Die Ergebnisse der Ausgrabungen 1983-1984. Bayerische Akademie der Wissenschaften. Philosophisch-Historische Klasse, Abhandlungen, Neue Folge, Heft 94. München.

1992, Isin - Išān Bahrìyāt IV. Die Ergebnisse der Ausgrabungen 1986-1989. Bayerische Akademie der Wissenschaften. Philosophisch-Historische Klasse, Abhandlungen, Neue Folge, Heft 105. München.

Hunger, $\mathrm{H}$.

1968, Babylonische und Assyrische Kolophone. AOAT 2. Butzen, Neukirchen-Vlyn. 
Hurowitz, V. A.

1995, An Old Babylonian Bawdy Ballad, in: Z. Zevit (Hrsg.), Solving Riddles and Untying Knots. Biblical, Epigraphic, and Semitic Studies in honor of Jonas C. Greenfield, Winona Lake, Indiana, 543-558.

Jacobsen, Th.

1953, The Reign of Ibbī-Suen, JCS 7, 36-47.

1976, The Treasures of Darkness. A History of Mesopotamian Religion. New Haven, London.

1987, The Harps that Once..Sumerian Poetry in Translation. New Haven, London.

1997, The Sacred Marriage of Iddin-Dagan and Inanna, in: W. W. Hallo (Hrsg.). The Context of Scripture. Vol. I. Canonical Compositions from the Bible World. Leiden, New York, Köln, 554-559.

Jacobsen, Th. \& S. N. Kramer

1953, The Myth of Inanna and Bilulu, JNES 12, 160-188, pl. lxvi-lxix.

Jacobsen, Th. \& W. L. Moran (Hrsg.)

1970, Toward the Image of Tammuz and other Essays on Mesopotamian History and Culture. Harvard Semitic Series 21. Cambridge.

Jakob, S.

2003, Mittelassyrische Verwaltung und Sozialstruktur. Untersuchungen. Cuneiform Monographs 29. Leiden, Boston.

Janssen, C.

1992, Inanna-mansum et ses fils: Relation d'une succession turbulente dans les archives d'Ur-Utu, $R A$ 86, 19-52.

Janssen, C., H. Gasche \& M. Tanret

1994, Du chantier à la tablette. Ur-Utu et l'histoire de sa maison à Sippar-Amnānum, Offertes en hommage à Léon de Meyer. Mesopotamian History and Environment II. Ghent, 91-123.

Jaques, M.

2006, Le vocabulaire des sentiments dans les textes sumériens. Recherche sur le lexique sumérien et akkadien. AOAT 332. Münster.

Kalla, G.

1999, Die Geschichte der Entdeckung der altbabylonischen Sippar-Archive, ZA 89, 201-226.

2002, Namengebung und verwandtschaftliche Beziehungen in der altbabylonischen Zeit, in: P. Streck \& S. Wenninger (Hrsg.). Altorientalische und semitische Onomastik. AOAT 296. Münster, 123-169. 
Kilmer, A. D.

1960, Two New Key Lists of Mathematical Operations, Or 29, 273-308.

1965, The Strings of Musical Instruments: Their Names, Numbers, and Significance, in: H. G. Güterbock \& Th. Jacobsen (Hrsg.). Studies in Honor of Benno Landsberger on his Seventy-Fifth Birthday, April 21, 1965. Assyriological Studies 16, 261-281.

1971, How was Queen Ereshkigal tricked? A new Interpretation of the Descent of Ishtar, UF 3, 299-309.

1977, Notes on Akkadian uppu, in: M. DeJong Ellis (Hrsg.). Essays on the Ancient Near East in Memory of Jacob Joel Finkelstein. Memoirs of the Connecticut Academy of Arts and Sciences Vol. 19, 129-138.

1980-83a, Laute.A. Philologisch. in: RlA 6, 512-515.

1980-83b, Leier.A. Philologisch. in: RlA 6, 571-576.

1984, A Music Tablet from Sippar(?): BM 65217 + 66616, Iraq 46, 69-80.

1991, An Oration on Babylon, AoF 18, 9-22.

1992, Musical Practice in Nippur, in: M. DeJong Ellis (Hrsg.). Nippur at the Centennial. Papers Read at the 35e Rencontre Assyriologique Internationale. Philadelphia 1988. Occasional Publications of the Samuel Noah Kramer Fund 14, 101-112.

1993-97, Musik. A.I. In Mesopotamien, in: RlA 8, 463-482.

2000, Continuity and Change in the Ancient Mesopotamian Terminology for Music and Musical Instruments, in: E. Hickmann, I. Laufs \& R. Eichmann (Hrsg.). Studien zur Musikarchäologie II. Musikarchäologie früher Metallzeiten. Orient-Archäologie Band 7. Rahden, Westf., 113-119.

2003-05, Pauke und Trommel. A. In Mesopotamien, in: RlA 10, 367-371.

Kilmer, A. D. \& M. Civil

1986, Old Babylonian Musical Instructions Relating to Hymnody, JCS 38, 94-98.

Kilmer, A. D. \& S. Tinney

1996, Old Babylonian Music Instruction Texts, JCS 48, 49-56.

1997, Correction to Kilmer/Tinney 'Old Babylonian Music Instruction Texts' JCS 48 (1996), JCS 49, 118.

Kingsbury, E. C.

1963, A Seven Days Ritual in the Old Babylonian Cult at Larsa. Hebrew Union College Annual 34, 1-34.

Klein, J.

1980, Some Rare Sumerian Words Gleaned from the Royal Hymns of Šulgi, in: G. B. Sarfatti (Hrsg.). Studies in Hebrew and Semitic Languages Dedicated to the Memory of Eduard Yechezkel Kutscher. Ramat-Gan: 1980, ix-xxviii. 
1981, Three Šulgi Hymns. Sumerian Royal Hymns Glorifying King Šulgi of Ur. BarIlan Studies in Near Eastern Languages and Culture. Publications of the BarIlan University Institute of Assyriology. Ramat-Gan, Indien.

1982, 'Personal God' and Individual Prayer in Sumerian Religion, in: Archiv für Orientforschung, Beiheft 19. Wien, 295-306.

1986, On writing monumental inscriptions in Ur III scribal curriculum, $R A$ 80, 1-7.

1990, Šulgi and Išmedagan: Originality and Dependence in Sumerian Royal Hymnology, in: J. Klein \& A. Skaist (Hrsg.). Bar-Ilan Studies in Assyriology Dedicated to Pinhas Artzi. Bar-Ilan Studies in Near Eastern Languages and Culture, 65-136.

1991, The Coronation and Consecration of Šulgi in the Ekur (Šulgi G), in: M. und I. Eph'al, I. (Hrsg.). Ah, Assyria, .. Studies in Assyrian History and Ancient Near eastern Historiography Presented to Hayim Tadmor. Scripta Hierosolymitana 33. Cogan, Jerusalem, 292-313.

1997, Enki and Ninmah, in: W. W. Hallo (Hrsg.). The Context of Scripture. Vol. I. Canonical Compositions from the Bible World, 516-518.

1998, The Sweet Chant of the Churn: A revised Edition of Išmedagan J, in: M. Dietrich \& O. Loretz (Hrsg.). dubsar anta-men. Studien zur Altorientalistik. Festschrift für Willem H. Ph. Römer zur Vollendung seines 70. Lebensjahres mit Beiträgen von Freunden, Schülern und Kollegen. AOAT 253, 205-222.

2003, Man and his God: Wisdom Poem or a Cultic Lament? in: P. Michalowski \& N. Veldhuis (Hrsg.). Approaches to Sumerian Literature. Studies in Honour of Stip (H. L.J. Vanstiphout). Leiden, Boston, 123-143.

Klein, J., M. Stol \& M. P. Streck

1998, Nippur. A, in: RlA 9, 532-546.

Klengel, $\mathrm{H}$.

1976, Untersuchungen zu den sozialen Verhältnissen im altbabylonischen Dilbat, AoF 4, 63-110.

Klengel, H. \& E. Klengel-Brandt

2002, Spät-altbabylonische Tontafeln. Texte und Siegelabrollungen. Vorderasiatische Schriftdenkmäler der Staatlichen Museen zu Berlin Bd. 29 (N.F. 13). Mainz am Rhein.

Kramer, S. N.

1942, The Oldest Literary Catalogue. A Sumerian List of Literary Compositions Compiled about 2000 B.C, BASOR 88, 10-19.

1957, Hymn to Ekur, in: Scritti in onore di Giuseppe Furlani, Parte I-II. Rivista degli Studi Orientali XXXII, Roma, 95-102.

1960, Two Elegies on a Pushkin Museum Tablet: A New Sumerian Literary Genre. Oriental Literature Publishing House. Moscow.

1969, Inanna and Šulgi: a Sumerian fertility song, Iraq 31, 18-23. 
1973, The Jolly Brother: A Sumerian Dumuzi Tale, JANES 5, 243-253.

1974, CT XXXVI: Corrigenda et Addenda, Iraq 36, 93-102.

1980, Inanna and the numun-Plant: A New Sumerian Myth, in: G. Rendsburg et al.

(Hrsg.). The Bible World. Essays in Honor of Cyrus H. Gordon. New York, 87-97.

1981, BM 29616: The Fashioning of the gala, ASJ 3, 1-11.

1982, Three Old Babylonian balag-Catalogues from the British Museum, in: M. A.

Dandamaiev, N. J. Postgate \& M. T. Larsen (Hrsg.). Societies and Languages

of the Ancient Near East. Studies in Honour of I. M. Diakonoff. Warminster, 206-213.

1985a, BM 86535: A Large Extract of a Diversified Balag-Composition, in: J.-M.

Durand \& J.-R. Kupper (Hrsg.). Miscellanea Babylonica. Mélanges offerts à Maurice Birot. Paris, 115-135.

1985b, BM 23631: Bread for Enlil, Sex for Inanna, OrNS 54, 117-132.

1987, By the Rivers of Babylon. A Balag-Liturgy of Inanna, Aula Orientalis 5, 71-90.

1989, BM 100042: A Hymn to Šu-Sin and an Adab of Nergal, in: H. Behrens, D. Loding \& M. T. Roth (Hrsg.). Dumu-E-Dub-ba-a. Studies in Honor of Ake W. Sjöberg. Occasional Publications of the Samuel Noah Kramer Fund 11. Philadelphia, 303-316.

Kramer, S. N. \& J. Maier

1989, Myths of Enki, The Crafty God. New York, Oxford u. a.

Kraus, F. R.

1951, Nippur und Isin nach altbabylonischen Rechtsurkunden, JCS 3, 1-209.

1955, Rez. Figulla/Martin UET 5, OLZ 50, 516-524.

1959, Ungewöhnliche Datierungen aus der Zeit des Königs Rīm-Sin von Larsa, ZA 53, 136-167.

1984, Königliche Verfügungen in altbabylonischer Zeit. Studia et Documenta ad iura orientis antiqui pertinentia 11. Leiden.

1985, Eine altbabylonische Buchhaltung aus einem Amtsarchiv in Nippur, BiOr 42, 526-541.

Krebernik, M.

1987-1990, Lil, in: RlA 7, 19-20.

1992, Die Textfunde der 9. Kampagne (1986), in: B. Hrouda (Hrsg.) 1992, München, 102-144.

2001, Tall Bia/Tuttul II. Die Altorientalischen Schriftfunde. Ausgrabungen in Tall Bia/Tuttul, Band 2. Wissenschaftliche Veröffentlichungen der Deutschen Orient-Gesellschaft 100. Saarbrücken.

2003/04, Altbabylonische Hymnen an die Muttergöttin (HS 1884), AfO 50, 11-20.

2003-2005, Pa(p)-ule-g̃ara, in: RlA 10, 239-230. 
Krecher, S. J.

1966, Sumerische Kultlyrik. Wiesbaden.

Krispijn, T. J. H.

1990, Beiträge zur altorientalischen Musikforschung. 1. Šulgi und die Musik, Akkadica 70, 1-27.

2002, Musik in Keilschrift. Beiträge zur altorientalischen Musikforschung 2, in: E. Hickmann, A. D. Kilmer \& R. Eichmann (Hrsg.). Studien zur Musikarchäologie III. Orient-Archäologie 10, 465-479.

Kubik, G.

1982, Musikgeschichte in Bildern. Ostafrika. Band 1: Musikethnologie, Lfg. 2. Leipzig.

Kutscher, R.

1975, Oh Angry Sea (a-ab-ba hu-luh-ha): The History of a Sumerian Congregational Lament. Yale Near Eastern Researches, 6. New Haven, London.

1987-90, Malgium, in: RlA 7, 300-304.

1990, The Cult of Dumuzi/Tammuz, in: J. Klein \& A. Skaist (Hrsg.). Bar-Ilan Studies in Assyriology dedicated to Pinhas Artzi. Israel, Jerusalem, 29-44.

Kutscher, R. \& C. Wilcke

1978, Eine Ziegelinschrift des Königs Takil-iliśśu von Malgium, gefunden in Isin und Yale, ZA 68, 95-128.

Lambert, W. G

1960, Babylonian Wisdom Literature. London.

1966-67, Divine Love Lyrics from the Reign of Abi-ešuh, MIO 12, 41-56.

1971, The Converse Tablet: A Litany with Musical Instructions, in: H. Goedicke (Hrsg.). Near Eastern Studies in Honor of William Foxwell Albright. Baltimore, London, 335-353.

1974, Dingir.šà.dib.ba Incantations, JNES 33, 267-327.

1975, The Problem of the Love Lyrics, in: H. Goedicke \& J. J. M. Roberts (Hrsg.). Unity and Diversity. Essays in the History, Literature, and Religion of the Ancient Near East. Baltimore, London, 98-135.

1982, The Hymn to the Queen of Nippur, in: G. van Driel et al. (Hrsg.). Zikir Šumim. Assyriological Studies Presented to F. R. Kraus on the Occasion of his Seventieth Birthday. Nederlands Instituut voor het Nabije Oosten Studia Francisci Scholten Memoriae Dicata. Volomen Quintum. Leiden, 173-218.

1987-90, Lugal-kisunna, in: RlA 7, 146-147.

1987, A Further Attempt at the Babylonian 'Man and his God', in: F. Rochberg-Halton (Hrsg.). Language, Literature, and History: Philological and Historical Studies presented to Erica Reiner, American Oriental Series 67, New Haven, Connecticut, 187-202. 
1989, A Babylonian Prayer to Anūna, in: H. Behrens, D. Loding \& M. T. Roth (Hrsg.). Dumu-E ${ }_{2}$-Dub-ba-a. Studies in Honor of Ake W. Sjöberg. Occasional Publications of the Samuel Noah Kramer Fund 11. Philadelphia, 321-336.

1992, Prostitution, in: V. Haas (Hrsg.). Außenseiter und Randgruppen. Beiträge zu einer Sozialgeschichte des Alten Orients. Xenia 32, 127-157.

1999/2000, Rezension zu B. Groneberg 1997, AfO 46-47, 274-277.

Lambert, W. G. \& A. R. Millard.

1969, Atra-hasis. The Babylonian Story of the Flood. With the Sumerian Flood Story by M. Civil. Oxford.

Landsberger, B.

1968, Der Kultische Kalender der Babylonier und Assyrer. Leipziger Semitische Studien 6/1-2. Leipzig.

Lang, B.

1998, Ritual / Ritus, in: H. Cancik (Hrsg.). Handbuch religionswissenschaftlicher Grundbegriffe Band: 4 Kultbild - Rolle. Stuttgart, 442-458.

Langdon, S.

1924, Excavations at Kish. Volume 1. 1923-24. Paris.

1930, Excavations at Kish. Volume 3. 1925-27. Paris.

1934, Excavations at Kish. Volume 4. 1925-1930. Paris.

Lawergren, B. \& O. R. Gurney

1987, Sound Holes and Geometrical Figures: Clues to the Terminology of Ancient Mesopotamian Harps, Iraq 49, 37-52.

Leemans, W. F.

1966, Cuneiform Texts in the Collection of Dr. Ugo Sissa, JCS 20, 34-53.

Liebermann, S. J.

1982, The Years of Damiqilishu, King of Isin, $R A$ 76, 97-117.

Limet, $\mathrm{H}$.

1993, Note sur la place de la musique dans le culte chez les sumériens, in: Expérience religieuse et expérience esthétique: rituel, art et sacré dans les religions. Actes du colloque de Liège et de Louvain-la-Neuve, 21-22 mars 1990. Homo religiosus (HR) 16, 231-237.

1996, Le texte KAR 158, 151-158, in: H. Gasche \& B. Hrouda (Hrsg.). Collectanea Orientalia: Histoire, Arts de l'Espace, et Industrie de la Terre. Etude offertes en hommage à Agnes Spycket. Civilisations du Proche-Orient Série 1, archéologie et environnement 3. Neuchâtel, 151-158. 
2000, Documents sumériens des Musées Royaux d'Art et d'Histoire Bruxelles, Akkadica 117, 1-20.

Litke, R. L.

1998, A Reconstruction of the Assyro-Babylonian God-Lists, AN: ${ }^{d} A-n u-u m$ and AN: Anu šá amēli. W. W. Hallo (Hrsg.). Texts from the Babylonian Collection (TBC) Vol. 3. New Haven.

Livingstone, A.

1989, Court Poetry and Literary Miscellanea. State Archives of Assyria (SAA) III. Helsinki, Finland.

Löhnert, A.

2008, Scribes and Singers of Emesal Lamentations in Ancient Mesopotamia in the Second Millennium BCE, E. Cingano \& L. Milano (Hrsg.). Papers on Ancient Literatures: Greece, Rome and the Near East, Proceedings of the "Advanced Seminar in the Humanities”. Venice International University 2004-2005, Padova, 421-447.

Ludwig, M.-C.

1990, Untersuchungen zu den Hymnen des Išme-Dagan von Isin XVIII 2. SANTAG Arbeiten und Untersuchungen zur Keilschriftkunde 2. Wiesbaden.

Manniche, L.

1991, Music and Musicians in Ancient Egypt. London.

Margueron, J. \& J. L. Huot

1980-83, Larsa, in: RlA 6, 496-506.

Marzahn, J. \& H. Neumann

1995, Eine altsumerische Urkunde aus Girsu über Silberzahlungen, AoF 22, 110-116.

Maul, S. M.

1988, Herzberuhigungsklagen. Die sumerisch-akkadischen Eršahunga-Gebete. Wiesbaden.

1992, kurgarrû und assinnu und ihr Stand in der babylonischen Gesellschaft, in: V. Haas (Hrsg.). Außenseiter und Randgruppen. Beiträge zu einer Sozialgeschichte des Alten Orients. Xenia 32. Konstanz, 159-171.

1999, Gottesdienst im Sonnenheiligtum zu Sippar, in: B. Böck, A. Cancik-Kirschbaum \& T. Richter (Hrsg.). Munuscula Mesopotamica. Festschrift für Johannes Renger. AOAT 267. Münster, 285-316.

2000, Die Frühjahrsfeierlichkeiten in Aššur, In: A. R. George \& I. J. Finkel (Hrsg.). Wisdom, Gods and Literature. Studies in Assyriology in Honour of W. G. Lambert. Winona Lake, Indiana, 389-420. 
Mayer, W. R.

1976, Untersuchungen zur Formensprache der babylonischen "Gebetsbeschwörungen ". Studia Pohl: Series Maior 5. Rom.

2003, Akkadische Lexikographie: CAD R, OrNS 72, 321-242.

Mayer, W. R. \& W. Sallaberger

2003, Opfer.A.I. Nach schriftlichen Quellen. Mesopotamien, in: RlA 10, 93-102.

Meier, G.

1941-44, Die zweite Tafel der Serie bìt mēseri, AfO 14, 139-152.

Menzel, B.

1981, Assyrische Tempel Bd. I/II. Untersuchungen zu Kult, Administration und Personal. Studia Pohl: Series Maior 10/I-II. Rom.

Metzler, K. A.

2002, Tempora in altbabylonischen literarischen Texten. AOAT 279, Münster.

Meyers, C. L.

1991, Of Drums and Damsels: Women's Performance in Ancient Israel. Biblical Archaeologist 54/1, 16-27.

Michalowski, P.

1987, On the Early History of the Eršahunga Prayers, JCS 39, 37-48.

1989, The Lamentation over the Destruction of Sumer and Ur. Mesopotamian Civilisations (MC) 1. Winona Lake, Indiana.

1990, The Shekel and the Vizier, ZA 80, 1-8.

2001, Nisaba. A. Philologisch, in: RlA 9, 575-579.

2006, Love or Death? Observations on the Role of the Gala in Ur III Ceremonial Life, JCS 58, 49-61.

$2007^{2}$, The Lives of the Sumerian Language, in: S. L. Sanders (Hrsg.). Margins of Writing, Origins of Cultures, Chicago, 163-188.

2009, Learning Music: Schooling, Apprenticeship, and Gender in Early Mesopotamia, in: R. Pruzsinszky \& D. Shehata (Hrsg.). Musiker und Tradierung. Studien zur Rolle von Musikern bei der Verschriftlichung und Tradierung von literarischen Werken, WOO 7. Wien, (im Druck).

Mirelman, S.

2009, Performative Indications in Late Babylonian Texts, in: R. Pruzsinszky \& D. Shehata (Hrsg.). Musiker und Tradierung. Studien zur Rolle von Musikern bei der Verschriftlichung und Tradierung von literarischen Werken, WOO 7. Wien (im Druck). 
Mirelman, S. \& Th. J. H. Krispijn

2009, The Old Babylonian Tuning Text UET VI/3 899, Iraq (im Druck).

Mittermayer, C.

2005, Die Entwicklung der Tierkopfzeichen. Eine Studie zur syro-mesopotamischen Keilschriftpaläographie des 3. und frühen 2. Jahrtausends v. Chr. AOAT 319, Münster.

2006, Altbabylonische Zeichenliste der sumerisch-literarischen Texte. Unter Mitarbeit von P. Attinger. Orbis Biblicus et Orientalis. Sonderband. Göttingen, Fribourg.

Oelsner, J.

1993, Rez. zu Stone/Owen Adoption (1991), OLZ 88, 500-504.

Oppenheim, A. L.

1950, Mesopotamian Mythology III, Or 19, 129-158.

1977, Ancient Mesopotamia. Portrait of a Dead Civilization. Revised Edition. Chicago, London.

Pecha, L.

2001, Die igisûm-Abgabe in den altbabylonischen Quellen, ArOr 69, 1-20.

Pettinato, G.

1971, Das altorientalische Menschenbild und die sumerischen und akkadischen Schöpfungsmythen. Abhandlungen der Heidelberger Akademie der Wissenschaften, Jahrgang 1971, 1. Abhandlung. Heidelberg.

Pientka, R.

1998, Die spätaltbabylonische Zeit. Abiešuh bis Samsuditana. Quellen, Jahresdaten, Geschichte. Teil 1/2. IMGULA 2. Münster.

Pinches, G.

1924, Hymns to Pap-due-garra, Journal of the Royal Asiatic Society of Great Britain and Ireland Centenery Supplement, 63-86.

Podella, T.

1989, Sôm-Fasten. Kollektive Trauer um den verborgenen Gott im Alten Testament. AOAT 224, Neukirchen-Vluyn.

Pomponio, F.

1986, géme-kar-kìd The Sumerian Word for "Prostitute", Oikumene 5, 63-66.

Postgate, J. N.

1990, Archaeology and the Texts - Bridging the Gap, ZA 80, 229-240. 
Pruzsinszky, R.

2007, Beobachtungen zu den Ur III-zeitlichen königlichen Sängern und Sängerinnen, in: M. Köhbach et al. (Hrsg.). Festschrift für Hermann Hunger zum 65. Geburtstag gewidmet von seinen Freunden, Kollegen und Schülern. WZKM 97. Wien, 329-352.

Rashid, S. A.

1984, Musikgeschichte in Bildern. Mesopotamien. Band 2. Musik des Altertums, Lfg. 2. Leipzig.

Reisman, D.

1971, Ninurta's Journey to Eridu, JCS 24, 3-10.

1972, Two Neo-Sumerian Royal Hymns. Diss. University of Pennsylvania 1969. Ann Arbor.

1973, Iddin-Dagan's Sacred Marriage Hymn, JCS 25, 185-202

Renger, J.

1967, Untersuchungen zum Priestertum in der altbabylonischen Zeit. 1. Teil, ZA 58, 110-188.

1969, Untersuchungen zum Priestertum der altbabylonischen Zeit. 2. Teil (Schluss), ZA 59, 104-230.

1983, Zu den altbabylonischen Archiven aus Sippar, in: K. R. Veenhof (Hrsg.). Cuneiform Archives and Libraries. Papers Read at the 30. Rencontre Assyriologique Internationale. (RAI 30) (= Uitgaven van het Nederlands Historisch-Archaeologisch Instituut te Istanbul 57. Leiden, 96-105.

Richter, T.

2004, Untersuchungen zu den lokalen Panthea Süd- und Mittelbabyloniens in altbabylonischer Zeit. (2., verbesserte und erweiterte Auflage). AOAT 257, Münster.

Roberts, J. J. M.

1971, Erra-Scorched Earth, JCS 24, 11-16.

Robertson, J. F.

1984, The Internal Political and Economic Structure of Old Babylonian Nippur: The guennakkum and his 'House', JCS 36, 145-190.

1992, The Temple Economy of Old Babylonian Nippur: The Evidence for Centralized Management, in: M. DeJong Ellis (Hrsg.). Nippur at the Centennial. Papers Read at the 35e Rencontre Assyriologique Internationale. Philadelphia 1988. Occasional Publications of the Samuel Noah Kramer Fund 14. Philadelphia, 177-188. 
Römer, W. H. Ph.

1965, Sumerische 'Königshymnen' der Isin-Zeit. Documenta et Monumenta Orientis Antiqui 13. Leiden.

1966, Studien zu altbabylonischen hymnisch-epischen Texten (2). Ein Lied über die Jugendjahre der Götter Sîn und Išum, JAOS 86, 138-147.

1967, Studien zu altbabylonischen hymnisch-epischen Texten. Ein kummu-Lied auf Adad (CT 15, 3-4), in: D. O. Edzard (Hrsg.). Heidelberger Studien zum Alten Orient. Adam Falkenstein zum 17. September 1966. Wiesbaden, 185-199.

1967-68, Studien zu altbabylonischen hymnisch-epischen Texten (3). Ein Lied mit Bezug auf einen Šubartum-Feldzug Hammurapis (CT 15, 1-2)?, WdO 4, 1228.

1969, Einige Beobachtungen zur Göttin Nini(n)sina auf Grund von Quellen der Ur IIIZeit und der altbabylonischen Periode, in: W. Röllig \& M. Dietrich (Hrsg.). Lišān mithurti. Festschrift Wolfram Freiherr von Soden zum 19. 6. 1968 gewidmet. AOAT 1, 275-309.

1974, Der Spassmacher im Alten Zweistromland. Zum ,Sitz im Leben' Altmesopotamischer Texte, Persica 7, 43-68.

1982, Sumerische Hymnen. I. Ein ér-šèm-ma-Lied für den Gott Iškur von Karkara, in: G. van Driel et al. (Hrsg.). Zikir Šumim. Assyriological Studies Presented to F. $R$. Kraus on the Occasion of his Seventieth Birthday. Nederlands Instituut voor het Nabije Oosten Studia Francisci Scholten Memoriae Dicata. Volomen Quintum. Leiden, 298-317.

1983, Sumerische Emesallieder, BiOr 40, 566-592.

1985, Der Mondgott und die Kuh. Ein Lehrstück zur Problematik der Textüberlieferung im Alten Orient, OrNS 54, 260-273.

1988, Sumerische Hymnen II, BiOr 45, 24-60.

1989, Hymnen, Klagelieder und Gebete in sumerischer Sprache, in: Lieder und Gebete I. Texte aus der Umwelt des Alten Testaments 2,5. Gütersloh, 645-717.

1990, > Weisheitstexte $<$ und Texte mit Bezug auf den Schulbetrieb in sumerischer Sprache, in: Weisheitstexte, Mythen und Epen: Weisheitstexte 1. Texte aus der Umwelt des Alten Testaments 3,1. Gütersloh, 17-109.

1991, Miscellanea Sumerologica II, zum Sog. Gudam-Text, BiOr 48, 363-378.

1993, Mythen und Epen in sumerischer Sprache, in: Weisheitstexte, Mythen und Epen: Mythen und Epen 1. Texte aus der Umwelt des Alten Testaments 3,3. Gütersloh, 351-506.

1996, Ein a-da-ab-Lied auf Ningublaga mit Bitten für König Iddindagān von Isin um Hilfe gegen Feinde wie etwa die Mardubeduinen (Sumerische Hymnen III), UF 28, 527-546.

1998, Eine Schicksalsentscheidung Enlils für König Lipiteštar von Isin, in: „Und Mose schrieb dieses Lied auf“. Studien zum Alten Testament und zum Alten Orient. Festschrift für Oswald Loretz zur Vollendung seines 70. Lebensjahres mit Beiträgen von Freunden, Schülern und Kollegen. M. Dietrich \& I. Kottsieper (Hrsg.). AOAT 250. Münster, 669-683. 
1999, Die Sumerologie. Einführung in die Forschung und Bibliographie in Auswahl. Zweite, erweiterte Auflage. AOAT 262. Münster.

2001, Hymnen und Klagelieder in sumerischer Sprache. AOAT 276. Münster.

2004, Die Klage über die Zerstörung von Ur. AOAT 309, Münster.

Roth, M. T.

1983, The Slave Girl and the Scoundrel. CBS 10467, A Sumerian Morality Tale?, JAOS 103, 275-282.

Rubio, G.

2001, Rez. zu V. Haas Babylonischer Liebesgarten: Erotik und Sexualität im Alten Orient. München: 1999, WZKM 91, 408-4011.

2009, Sumerian literature, in: C. A. Ehrlich (Hrsg.). From an Antique Land. An Introduction to Ancient Near Eastern Literature. Lanham, 11-74.

Sallaberger, W.

1993, Der kultische Kalender der Ur III - Zeit. Teil 1/2. Untersuchungen zur Assyriologie und Vorderasiatischen Archäologie 7/1+2.

1994, Rez. zu P. Watson \& E. B. Horowitz, Catalogue of cuneiform tablets in Birmingham City Museum. 2: Neo-Sumerian texts from Umma and other sites. Warminster: 1993, OLZ 89, 538-545.

1997, Nippur als religiöses Zentrum im historischen Wandel, in: G. Wilhelm (Hrsg.). Die Orientalische Stadt: Kontinuität, Wandel, Bruch. 1. Internationales Colloquium der Deutschen Orient-Gesellschaft 9.-10. Mai 1996 in Halle/Saale, Saarbrücken, 147-168.

Sallaberger, W. \& F. Huber Vulliet

2005, Priester. A.I, in: RlA 10, 617-640.

Sanati-Müller, S.

1988, Texte aus dem Sînkāšid-Palast. Erster Teil. Gerstenwerkverträge und Mehllieferungsurkunden, BaM 19, 471-538.

Scheil, V.

1920, Complainte à la déesse Aruru, $R A$ 17, 45-50.

Schlott, A.

1996, Einige Beobachtungen zu Mimik und Gestik von Singenden, Göttinger Miszellen $152,55-70$.

Schmidt-Colinet, C.

1981, Die Musikinstrumente in der Kunst des Alten Orients. Archäologischphilologische Studien. Abhandlungen zur Kunst-, Musik- und Literaturwissenschaft 312. Bonn. 
Schneider, N.

1932, Die Drehem und Djohatexte im Kloster Montserrat (Barcelona). In Autographie und mit systematischen Wörterverzeichnissen. AnOr 7. Rom.

Schretter, M. K.

1990, Emesal-Studien. Sprach- und Literaturgeschichtliche Untersuchungen zur sogenannten Frauensprache des Sumerischen. Insbrucker Beiträge zur Kulturwissenschaft-Sonderheft 69. Innsbruck.

Schuol, M.

2004, Hethitische Kultmusik. Eine Untersuchung der Instrumental- und Volksmusik anhand hethitischer Ritualtexte und von archäologischen Zeugnissen, OrientArchäologie 14. Rahden/Westf.

Schwemer, D.

2001, Die Wettergottgestalten Mesopotamiens und Nordsyriens im Zeitalter der Keilschriftkulturen. Materialien und Studien nach den schriftlichen Quellen. Wiesbaden.

Sefati, Y.

1998, Love Songs in Sumerian Literature. Critical Edition of the Dumuzi-Inanna Songs. Bar-Ilan Studies in Near Eastern Languages and Culture. Jerusalem.

2005, At Dead of Night I will Come (DI X), in: Y. Sefati \& P. Artzi et al. (Hrsg.). “An Experienced Scribe who Neglects nothing”. Ancient Near Eastern Studies in Honor of Jacob Klein. Publications of the Samuel Noah Kramer Institute of Assyriology and Ancient Near Eastern Studies. Bar Ilan/Bethesda, MD, 254286.

Selz, G. J.

1989, Altsumerische Wirtschaftstexte aus Lagaš Teil I. Die Altsumerischen Wirtschaftsurkunden der Eremitage zu Leningrad. Freiburger Altorientalische Studien 15/1. Stuttgart, Wiesbaden.

1995, Untersuchungen zur Götterwelt des altsumerischen Stadtstaates von Lagaš. Occasional Publications of the Samuel Noah Kramer Fund 13. Philadelphia.

1997, 'The Holy Drum, the Spear and the Harp'. Towards an Understanding of the Problems of Deification in Third Millenium Mesopotamia, in: I. L. Finkel \& M. J. Geller (Hg.). Sumerian Gods and their Representations (= Cuneiform Monographs 7). Groningen, 167-213.

Seminara, S.

2002, The Babylonian Science of the Translation and the Ideological Adjustment of the Sumerian Text to the 'Target Culture', in: A. Panaino \& G. Pettinato (Hrsg.). Ideologies as Intercultural Phenomena. Proceedings of the Third Annual 
Symposium of the Assyrian and Babylonian Intellectual Heritage Project Held in Chicago, USA, October 27-31, 2000. Milano, 245-255.

Shaffer, A.

1981, A New Musical Term in Ancient Mesopotamian Music, Iraq 43, 79-83.

1993, From the Bookshelf of a Professional Wailer, in: M. E. Cohen, D. C. Snell \& D. B. Weisberg (Hrsg.). The Tablet and the Scroll. Near Eastern Studies in Honor of William W. Hallo. Bethesda, Maryland, 209-210.

2000, A New Look at Some Old Catalogues, in: A. R. George \& I. L. Finkel (Hrsg.). Wisdom, Gods and Literature. Studies in Assyriology in Honour of W. G. Lambert. Winona Lake, Indiana, 429-436.

Shehata, D.

2002, Contributions to the Music Theory System of Mesopotamia, in: E. Hickmann, A. D. Kilmer \& R. Eichmann (Hrsg.). Studien zur Musikarchäologie III (=OrA 10). Rahden/Westf., 487-496.

2007, Privates Musizieren in Mesopotamien? in: M. Köhbach et al. (Hrsg.). Festschrift für Hermann Hunger zum 65. Geburtstag gewidmet von seinen Freunden, Kollegen und Schülern. WZKM 97. Wien, 521-529.

2008, On the Mythological Background of the Lamentation Priest, in: A Both et al. (Hrsg.). Studien zur Musikarchäologie VI (= OrA 22). Rahden/Westf., 119127.

2009 Klagesänger und ihr Gesangsrepertoire. Überlegungen zu den Überlieferungswegen altbabylonischer Kultliturgie, in: R. Pruzsinszky \& D. Shehata (Hrsg.). Musiker und Tradierung. Studien zur Rolle von Musikern bei der Verschriftlichung und Tradierung von literarischen Werken, WOO 7. Wien, (im Druck).

2010 Sounds from the Devine: Religious Musical Instruments in the Ancient Near East, in: Y. Maurey, E. Seroussi \& J. Goodnick Westenholz, Sounds from the Past: Music in the Ancient Near East and Mediterranean Worlds. Yuval - Studies of the Jewish Music Research Centre, vol. 8, in collaboration with the Bible Lands Museum Jerusalem. Jerusalem, (im Druck).

Sigrist, R. M.

1977a, Offrandes dans le Temple de Nusku, JCS 29, 169-184.

1977b, Nippur entre Isin et Larsa de Sin-iddinam à Rim-Sin, OrNS 46, 363-374.

1984, Les sattukku dans l'Ešumeša durant la période d'Isin et Larsa. Bibliotheca Mesopotamica (BiMes 11). Malibu, California.

1990, Larsa year names. IPAS 3. Berrien Springs, Michigan.

1992, Drehem. Bethesda, MD.

Simmons, S. D.

1960, Early Old Babylonian Tablets from Harmal and elsewhere (Continued), JCS 14, 49-55. 
Sjöberg, A. W.

1960, Der Mondgott Nanna-Suen in der sumerischen Überlieferung. Teil I: Texte. Uppsala.

1961, Ein Selbstpreis des Königs Hammurabi von Babylon, ZA 20, 51-70.

1970, Beiträge zum sumerischen Wörterbuch, Or 39, 75-98.

1970-71, Hymns to Meslamtaea, Lugalgirra and Nanna-Suen in Honour of King Ibbīsuen (Ibbīîin) of Ur, Orientalia Suecana 19-20, 140-178.

1972, Prayers for King Hammurabi of Babylon, in: H. Ringgren, K. Drynjeff \& J. Bergman (Hrsg.). Ex orbe religionum. Studia Geo Widengren oblata. Pars prior. Studies in the History of Religions. (Supplements to Numen) 21. Leiden, 58-71.

1973a, Two Prayers for King Samsuiluna of Babylon, JAOS 93, 544-547.

1973b, Der Vater und sein missratener Sohn, JCS 25, 105-169.

1973c, Hymn to Numušda with a Prayer for King Sîniqišam of Larsa and a Hymn to Ninurta, Orientalia Suecana 22, 107-121.

1973d, Miscellaneous Sumerian Hymns, ZA 63, 1-55.

1974-75, Miscellaneous Sumerian Texts I, Orientalia Suecana 23-24, 159-181.

1975a, The Old Babylonian Eduba, in: Sumerological Studies in Honor of Thorkild Jacobsen on his Seventieth Birthday June 7. Assyriological Studies 20, 159179.

1975b, Der Examenstext A, ZA 64, 137-167.

1975c, in-nin šà-gur ${ }_{4}$-ra: A Hymn to the Goddess Inanna by the en-Priestess Enheduanna, $Z A$ 65, 161-253.

1976a, Hymns to Ninurta with Prayers to Šusîn of Ur and Būrsîn of Isin, in: B. L. Eichler (Hrsg.). Kramer Anniversary Volume. Cuneiform Studies in Honor of Samuel Noah Kramer. AOAT 25. Kevelaer, Neukirchen-Vluyn, 411-426.

1976b, Three Hymns to the God Ningišzida, Studia Orientalia 46, 301-322.

1977a, A Blessing of King Urninurta, in: M. De J. Ellis (Hrsg.). Essays on the Ancient Near East in Memory of Jacob Joel Finkelstein. Memoirs of the Connecticut Academy of Arts and Sciences. Vol. 19. Hamden, 189-195.

1977b, Miscellaneous Sumerian Texts, II, JCS 29, 3-45.

1983, The First Puchkin Museum Elegy and New Texts, JAOS 103, 315-320. 
1998, Sumerian Texts and Fragments in the University of Pennsylvania Museum Related to Rulers of Isin, in: M. Dietrich \& O. Loretz (Hrsg.). dubsar antamen. Studien zur Altorientalistik. Festschrift für Willem H. Ph. Römer zur Vollendung seines 70. Lebensjahres mit Beiträgen von Freunden, Schülern und Kollegen. AOAT 253. Münster, 345-378.

Sjöberg, Å. W., E. Bergmann \& G. B. Gragg

1969, The Collection of the Sumerian Temple Hymns (and The Keš Temple Hymn). Texts from Cuneiform Sources III. Locust Valley, New York.

Sjöberg, A.. W. \& H. Otten

1957-71, Götterreisen, in: RlA 3, 480-483.

Sladek, W. R.

1974, Inanna's descent to the netherworld. Ann Arbor, Michigan, University Microfilms. Baltimore, MD, Johns Hopkins Univ., Diss.

Soden, W. von

1936, Schwer zugängliche russische Veröffentlichungen altbabylonischer Texte, $Z A 43$, 305-308.

1938, Altbabylonische Dialektdichtung, $Z A 44$, 26-44.

1948, Das altbabylonische Briefarchiv von Mari, $W d O$ 1, 187-204.

1950, Ein Zwiegespräch Hammurabis mit einer Frau (Altbabylonische Dialektdichtung Nr. 2), ZA 49, 151-194.

1957-71, Gebet II. in: RlA 3, 160-170.

1958, Akkadische Gebete an Göttinnen, RA 52, 131-136.

1981, $\mathrm{Zu}$ dem altbabylonischen Hymnus Anmartu und Ašratum mit Verheissung an Rìm-Sîn, N.A.B.U. 1981 No. 105.

1989-90, Rezension zu O. R. Gurney, Literary and Miscellaneous Texts in the Ashmolean Museum. IV. Oxford 1989 (=OECT 11), AfO 36-37, 118-120.

Soden, W. von \& J. Oelsner

1991, Ein spät-altbabylonisches pārum-Preislied für Ištar, OrNS 60, 339-343, Taf. CVI.

Sommerfeld, W.

1992, Die Inschriftenfunde der 10. und 11. Kampagne (1988 und 1989), in: B. Hrouda (Hrsg.). Isin 1992. München, 144-164.

Spaey, J.

1990, Some Notes on KÙ.BABBAR/nēbeh kezēr(t)i(m), Akkadica 67, 1-9.

Spycket, A.

1983, Louez-le sur la harpe et la lyre, Anatolian Studies 33, 39-49. 
Stamm, J. J.

1939, Die akkadische Namengebung. Mitteilungen der Vorderasiatisch-Aegyptischen Gesellschaft 44. Leipzig.

Starr, I.

1983, The Rituals of the Diviner. Bibliotheca Mesopotamica 12. Malibu.

Steible, H.

1975, Rìmsîn, mein König. Drei kultische Texte aus Ur mit der Schlußdoxologie ${ }^{d}$ ri-im${ }^{d}$ sin lugal-mu. Freiburger Altorientalische Studien 1. Wiesbaden.

1982, Die Altsumerischen Bau- und Weihinschriften. Teil I-II. Freiburger Altorientalische Studien 5/1-2. Wiesbaden.

1991/1-2, Die Neusumerischen Bau- und Weihinschriften. Teil I Inschriften der II. Dynastie von Lagaš. Teil II Kommentar zu den Gudea-Statuen Inschriften der III. Dynastie von Ur Inschriften der IV. und ' $V$.' Dynastie von Uruk Varia. Freiburger Altorientalische Studien 9/1-2. Wiesbaden.

Steinkeller, P.

1982, Two Sargonic Sale Documents concerning Women, OrNS 51, 355-368.

Steinkeller, P. \& J. N. Postgate

1992, Third Millenium Legal and Administrative Texts in the Iraq Museum, Baghdad. Mesopotamian Civilizations 4. Winona Lake, Indiana.

Stol, M.

1973, Rez. zu Finkelstein YOS 13 (1972), JCS 25, 215-233.

1976, Studies in Old Babylonian History. Istanbul.

1998, Nippur. A. II. Altbabylonisch, in: RlA 9, 532-544.

1999, Nach dem Gewichtsstein des Šamaš, in: B. Böck, E. Cancik-Kirschbaum \& T. Richter (Hrsg.). Munuscula Mesopotamica. Festschrift für Johannes Renger. AOAT 267. Münster, 573-589.

2001, Rez. zu Richter, Untersuchungen zu den lokalen Panthea Süd- und Mittelbabyloniens in altbabylonischer Zeit, AOAT 257 (1999), BiOr 58, 173-176.

2003, Schauspieler und Flechter als Bedienstete, in: G. J. Selz (Hrsg.). Festschrift für Burkhart Kienast zu seinem 70. Geburtstage dargebracht von Freunden, Schülern und Kollegen, AOAT 274. Münster, 639-645.

2004, Wirtschaft und Gesellschaft in Altbabylonischer Zeit, in: P. Attinger, W. Sallaberger \& M. Wäfler (Hrsg.). Mesopotamien. Die altbabylonische Zeit. Annäherungen 4 (= OBO 160/4). Fribourg, Göttingen.

Stone, E. C.

1982, The Social Role of the naditu women in Old Babylonian Nippur, JESHO 25, 5070.

1987, Nippur Neighbourhoods. SAOC 44. Chicago. 
Stone, E. C. \& D. I. Owen

1991, Adoption in Old Babylonian Nippur and the Archive of Mannum-meșu-lișsur.

Mesopotamian Civilizations 3. Winona Lake, Indiana.

Streck, M. P.

2003, Die Klage „Ištar Bagdad“, in: W. Sallaberger et al. (Hrsg.). Literatur, Politik und Recht in Mesopotamien. Festschrift für Claus Wilcke. Orientalia Biblica et Christiana Bd. 14. Wiesbaden, 301-312.

2007, Der Parallelismus Membrorum in den altbabylonischen Hymnen, in: A. Wagner (Hrsg.). Parallelismus membrorum, Orbis Biblicus et Orientalis 224. Göttingen, Fribourg, 167-181.

Streck, M. P. \& N. Wasserman

2008, The Old Babylonian Hymns to Papulegara, OrNS 77, 335-358.

Tallquist, $\mathrm{K}$.

1938, Akkadische Götterepitheta. Studia Orientalia 7. Helsinki.

Tammuz, O.

1996, Two small Archives from Lagaba, $R A$ 90, 121-133.

Tanret, M.

2002, Per aspera ad astra. L'apprentissage du cunéiforme à Sippar-Amnānum pendant la période paléobabylonienne tardive. Mesopotamian History and Environment Series I Texts 2 (MHET I/1). Ghent.

Tanret, M. \& K. Van Lerberghe

1993, Rituals and Profits in the Ur-Utu Archive, in: J. Quaegebeur (Hrsg.). Ritual and Sacrifice in the Ancient Near East. Proceedings of the International Conference organized by the Katholieke Universiteit Leuven from the 17th to the 20th of April 1991. OLA 55. Leuven, 435-449.

Taylor, J.

2001, A New OB Proto-Lu-Izi Combination Tablet, OrNS 70, 209-234.

Thomsen, M. L.

1984, The Sumerian Language. An Introduction to its History and Grammatical Structure. Mesopotamia. Copenhagen Studies in Assyriology. Vol. 10. Copenhagen.

Thureau-Dangin, F.

1921, Rituels Accadiens. Paris.

1925, Un hymne à Ištar de la haute époque babylonienne, $R A$ 22, 169-177. 
Tinney, S.

1995, On the Poetry for King Išme-Dagan, OLZ 90/1, 5-26.

1996, The Nippur Lament. Royal Rhetoric and Divine Legitimation in the Reign of Išme-Dagan of Isin (1953-1935 B.C.). Occasional Publications of the Samuel Noah Kramer Fund 16. Philadelphia.

1999, On the Curricular Setting of Sumerian Literature, Iraq 61, 159-172.

Van Dijk, J.

1953, La Sagesse Suméro-Accadienne. Recherches sur les genres littéraires de textes sapientiaux. Commentationes Orientales. Vol. 1. Leiden.

1960, Sumerische Götterlieder 2. Abhandlungen der Heidelberger Akademie der Wissenschaften Jahrgang 1960. 1. Abhandlung. Heidelberg.

1965, Une insurrection générale au pays de Larša avant l'avènement de Nūr-Adad, JCS $19,1-25$.

1966-67, L'hymne à Marduk avec intercession pour le roi Abiešuh, MIO 12, 57-74.

1983, Lugal ud me-lám-bi NIR-GÁL. Le récit épique et didactique des Travaux de Ninurta, de Déluge et de la Nouvelle Création. Textes, Traduction et Introduction. Tome I/II. Leiden.

1989, Ein spätaltbabylonischer Katalog einer Sammlung sumerischer Briefe, OrNS 58, 441-452.

Van Driel, G.

2003-05, Pfründe, in: RLA 10, 518-524.

Van Gennep, A.

$2005^{3}$, Übergangsriten. 3. erweiterte Auflage. Frankfurt am Main, Paris.

Van Koppen, F.

2004, The Geography of the Slave Trade and Northern Mesopotamia in the Late Old Babylonian Period, in: H. Hunger \& R. Pruzsinszky (Hrsg.). Mesopotamian Dark Age revisited: Proceedings of an International Conference of SCIEM 2000 (Vienna 8th - 9th November 2002). Wien, 9-33.

Van Lerberghe, K.

1982, New Data from the Archives found in the House of Ur-Utu at Tell ed-Der, in: Vorträge gehalten auf der 28. Rencontre Assyriologique Internationale in Wien, 6.-10. Juli 1981. Archiv für Orientforschung. Beiheft 19. Wien, 280283.

1986, Old Babylonian Legal and Administrative Texts from Philadelphia. OLA 21. Leuven.

Van Lerberghe, K. \& G. Voet

1991, Sippar-Amnānum. The Ur-Utu Archive Vol. 1. Mesopotamian History and Environment Series III Texts 1. Ghent. 
1997, A Poor Man of Sippar, AoF 24, 148-157.

Van de Mieroop, M.

1987a, Crafts in the Early Isin Period: A Study of the Isin Craft Archive from the Reign of Išbi-Erra and Š $\bar{u}$-Ilišu. OLA 24. Leuven.

1987b, The Archive of Balmunamhe, AfO 34, 1-29.

1989a, Gifts and Tithes to the Temples in Ur, in: H. Behrens, D. Loding \& M. T. Roth (Hrsg.). Dumu-E ${ }_{2}$-Dub-ba-a. Studies in Honor of Ake W. Sjöberg. Occasional Publications of the Samuel Noah Kramer Fund 11, 397-401.

1989b, Rez. zu Charpin Clergé (1986), JCS 41, 237-252.

1992, Society and Enterprise in Old Babylonian Ur. Berliner Beiträge zum Vorderen Orient 12. Berlin.

1993, The Reign of Rim-sin, $R A$ 87, 47-69.

Vanstiphout, H. L. J.

1978, Lipit-Ištar's Praise in the Edubba, JCS 30, 33-64.

1990, The Mesopotamian Debate Poems. A General Presentation (Part I), ASJ 12, 271 318.

1999, 'I can put everything in its right place'. Generi and Typological Studies as Strategies for the Analysis and Evaluation of Mankind's Oldest Literature, in: B. Roest \& H. Vanstiphout (Hrsg.). Aspects of Genre and Type in Pre-Modern Literary Cultures, COMERS Communication I. Leiden, 79-99.

Veldhuis, N. C.

1997/98, The Sur 9 -Priest, the Instrument ${ }^{\text {giš }}$ Al-gar-sur, ${ }_{9}$, and the Forms and Uses of a rare Sign, AfO 44/45, 115-128.

2004, Religion, Literature and Scholarship: The Sumerian Composition Nanše and the Birds, with a Catalogue of Sumerian Bird Names. Cuneiform Monographs 22. Leiden.

Villard, P.

1989, ARMT XXVI/2 n ${ }^{\circ}$ 268: Une nouvelle attestation de l'alûm à Mari, N.A.B.U. 1989 No. 92.

1992, Parade militaire dans les jardins de Babylone, in: J.-M. Durand (Hrsg.). Recueil d'études en l'honneur de Michel Fleury, FM, Mémoires de N.A.B.U. 1. Paris, 137-152.

Visicato, G.

1995, The Bureaucracy of Šuruppak. Administrative Centres, Central Offices, Intermediate Structures and Hierarchies in the Economic Documentation of Fara. Abhandlungen zur Literatur Alt-Syrien-Palästinas und Mesopotamiens Bd. 10. Münster. 
Vogelzang, M. E. \& H. L. J. Vanstiphout (Hrsg.)

1992, Mesopotamian Epic Literature. Oral or Aural? New York, Ontario.

Volk, K.

1988, Eine bemerkenswerte nach-Fāra-zeitliche Urkunde, OrNS 57, 206-209.

1989, Die Balag-Komposition úru àm-ma ir-ra-bi. Freiburger Altorientalische Studien 18. Wiesbaden.

1994, Improvisierte Musik im alten Mesopotamien?, Improvisation 2, 160-202.

1995, Inanna und Šukaletuda. Zur historisch-politischen Deutung eines sumerischen Literaturwerkes. SANTAG Arbeiten und Untersuchungen zur Keilschriftkunde Band 3. Wiesbaden.

2000, Edubba'a und Edubba'a-Literatur: Rätsel und Lösungen, ZA 90, 1-30.

Walker, C. B. F. \& C. Wilcke

1981, Preliminary Report on the Inscriptions, Autumn 1975, Spring 1977, Autumn 1978, in: B. Hrouda (Hrsg.) Isin (1981). München, 91-102.

Walker, C. B. F. \& Dick, M.

2001, The Induction of the Cult Image in Ancient Mesopotamia. The Mesopotamian Mìs Pî-Ritual. State Archives of Assyria Literary Texts (SAALT) 1, The NeoAssyrian Text Corpus Project. Helsinki.

Wallace, A. F. C.

1966, Religion. An Anthropological View. New York.

Wallenfels, R.

1994, Hellenistic Seal Impressions in the Yale Babylonian Collection. I: Cuneiform Tablets, Ausgrabungen in Uruk/Warka. Endberichte 19, Mainz.

Wasserman, $\mathrm{N}$.

1992, CT 21, 40-42. A Bilingual Report of an Oracle with a Royal Hymn of Hammurabi, $R A 86,1-18$.

2003, Style and form in Old-Babylonian Literary Texts. Cuneiform Monographs 27, Leiden.

2006, BM 29638: A New Ritual to Marduk from the Old Babylonian Period, ZA 96, 200-211.

Wasserman, N. \& U. Gabbay

2005, Literature in Contact: The Balag̃ Úru àm-ma-ir-ra-bi and its Akkadian Translation UET 6/2, 403, JCS 57, 69-84.

Weiershäuser, F.

2008, Die königlichen Frauen der III. Dynastie von Ur, Göttinger Beiträge zum Alten Orient Bd. 1, Göttingen. 
Westenholz, A.

1974/77, Old Akkadian School Texts. Some Goals of Sargonic Scribal Education, AfO 25, 94-110.

Westenholz, J. G.

1987, A Forgotten Love Song, in: F. Rochberg-Halton (Hrsg.). Language, Literature, and History: Philological and Historical Studies presented to Erica Reiner, American Oriental Series 67, New Haven, Connecticut, 415-425.

1989a, Tamar, qedēša a qadištu, and sacred Prostitution in Mesopotamia, Harvard Theological Review 82/3, 245-265.

1989b, Enheduanna, En-Priestess, Hen of Nanna, Spouse of Nanna, in: H. Behrens, D. Loding \& M. T. Roth (Hrsg.). Dumu-E2-Dub-ba-a. Studies in Honor of Ake W. Sjöberg. Occasional Publications of the Samuel Noah Kramer Fund 11. Philadelphia, 539-556.

1992, Metaphorical Language in the Poetry of Love in the Ancient Near East, in: D. Charpin (Hrsg.). La circulation des biens, des personnes et des idées dans le Proche-Orient Ancien, actes de la XXXVIIIème Rencontre Assyriologique Internationale (Paris, 8 - 10 juillet 1991). Editions Recherche sur les Civilisations. Paris, 381-387.

1994, Eight Days in the Temples of Larsa. Celebrations in the Month Shevat in the Time of Abraham. Jerusalem: Bible Lands Museum.

1997, Legends of the Kings of Akkade. The Texts. Mesopotamian Civilizations 7. Winona Lake, Indiana.

Westenholz, J. G. \& A. Westenholz

2006, Cuneiform Inscriptions in the Collection of the Bible Lands Museum Jerusalem. The Old Babylonian Inscriptions. Cuneiform Monographs 33. Leiden, Boston.

Whittaker, G.

2002, Linguistic Anthropology and the Study of Emesal as (a) Women's Language, in: S. Parpola \& R. M. Whiting (Hrsg.). Sex and Gender in the Ancient Near East. Proceedings of the 47. Rencontre Assyriologique Internationale. Part I/II. Helsinki, 633-644.

Wiggermann, F. A. M.

1988, An Unrecognized Synonym of Sumerian sukkal, 'Vizir', ZA 78, 225-240.

1998-2001, Nergal. A. Philologisch, in: RlA 9, 215-223.

Wiggermann, F. A. M. \& C. Uehlinger

1998-2001, Nackte Göttin (Naked Goddess). A. Philologisch/ B. Archäologisch, in: RlA 9, 46-64.

Wilcke, C.

1973, Sumerische literarische Texte in Manchester und Liverpool, AfO 24, 1-18. 
1975, Formale Gesichtspunkte in der sumerischen Literatur, in: Sumerological Studies in Honor of Thorkild Jacobsen on his Seventieth Birthday June 7. Assyriological Studies 20, 205-292.

1977, Die Anfänge der akkadischen Epen, ZA 67, 153-216.

1983, Nachlese zu A. Poebels Babylonian Legal and Business Documents from the Time of the First Dynasty of Babylon Chiefly from Nippur (BE 6/2) Teil 1, ZA $73,48-66$.

1985a, Liebesbeschwörungen aus Isin, $Z A$ 75, 188-209.

1985b, Familiengründung im Alten Orient, in: E. W. Müller et al. (Hrsg.). Geschlechtsreife und Legitimation zur Zeugung. Veröffentlichungen des „Instituts für historische Anthropologie e.V.“, Band 3, 213-317.

1987, Die Inschriftenfunde der 7. und 8. Campagne, in: B. Hrouda (Hrsg.) Isin (1987). München, 83-120.

1994, Personal eines Enlil-bāni-Palastes in Isin, in: P. Callmeyer et al. (Hrsg.). Beiträge zur Altorientalischen Archäologie und Altertumskunde. Festschrift für Barthel Hrouda zum 65. Geburtstag. Wiesbaden, 303-324.

2000, Wer las und schrieb in Babylonien und Assyrien. Überlegungen zur Literalität im Alten Zweistromland, Bayerische Akademie der Wissenschaften. Philosophisch-historische Klasse. Sitzungsberichte, Jg. 2000, Heft 6. München.

2002, Konflikte und ihre Bewältigung in Elternhaus und Schule im Alten Orient, in: R. Lux (Hrsg.) Schau auf die Kleinen...Das Kind in Religion, Kirche und Gesellschaft. Leipzig, 10-31.

2006, Die Hymne auf das Heiligtum Keš. Zu Struktur und "Gattung” einer altsumerischen Dichtung und zu ihrer Literaturtheorie, in: P. Michalowski \& N. Veldhuis (Hrsg.). Approaches to Sumerian Literature. Studies in Honour of Stip (H. L. J. Vanstiphout). Leiden, Boston, 201-237.

Wilson, E. J.

1996, The Cylinders of Gudea. Transliteration, Translation and Index. AOAT 244. Kevelaer, Neukirchen-Vluyn.

Woods, C.

$2007^{2}$, Bilingualism, Scribal Learning, and the Death of Sumerian, in: S. L. Sanders (Hrsg.). Margins of Writing, Origins of Cultures. Chicago, 95-124.

Woolley, L.

1934, The Royal Cemetery. A Report on the Predynastic and Sargonic Graves Excavated between 1926 and 1931. 1. Text/ 2. Plates. Publications of the Joint Expedition of the British Museum and of the Museum of the University of Pennsylvania to Mesopotamia. Ur Excavations 2. London. 
Yoffee, N.

1977, The Economic Role of the Crown in the Old Babylonian Period. Bibliotheca Mesopotamica 5. Malibu.

1998, The Economics of Ritual at Late Old Babylonian Kish, JESHO 41, 312-343.

Zeeb, F.

2001, Die Palastwirtschaft in Altsyrien nach den spätaltbabylonischen Getreidefelderlisten aus Alalah (Schicht VII). AOAT 282. Münster.

Zettler, R. L.

1992, The Ur III Inanna Temple at Nippur. Berliner Beiträge zum Vorderen Orient 11. Berlin.

Ziegler, N.

1996, Ein Bittbrief eines Händlers, in: A. A. Ambros \& M. Köhbach (Hrsg.). Festschrift für Hans Hirsch zum 65. Geburtstag gewidmet von seinen Freunden, Kollegen und Schülern. WZKM 86, 479-488.

1999, La Population féminine des palais d'après les archives royales de Mari. Le Harem de Zimrî-Lîm, FM 4, Mémoires de N.A.B.U. 5. Paris.

2007, Les Musiciens et la musique d'après les archives de Mari. FM 9, Mémoires de N.A.B.U. 10. Paris.

2009, Teachers and Students. Conveying Musical Knowledge in the Kingdom of Mari, in: R. Pruzsinszky \& D. Shehata (Hrsg.). Musiker und Tradierung. WOO 7. Wien, (im Druck).

Zimmern, $\mathrm{H}$.

1916, Ištar und Șaltu ein altakkadisches Lied mit zwei Tafeln. Berichte und Verhandlungen der Königl. Sächsischen Gesellschaft der Wissenschaften zu Leipzig. Philologisch-historische Klasse 68. Band 1. Heft. Leipzig.

1917/18, Das Nergallied Berl. VAT 603 = Philad. CBM $11344=$ Lond. Sm. 526, ZA 31, 111-121.

Zgoll, A.

1997, Der Rechtsfall der En-hnedu-Ana im Lied nin-me-šara, AOAT 246. Münster.

2003, Die Kunst des Betens: Form und Funktion, Theologie und Psychagogik in babylonisch-assyrischen Handerhebungsgebeten zu Ištar, AOAT 308. Münster.

Zólyomi, G.

2001, Another Recension of Išme-Dagan O: BM 114862 (CT 58 25), Iraq 63, 139-147. 2005, A Hymn to Ninšubur, in: Y. Sefati \& P. Artzi et al. "An Experienced Scribe who Neglects nothing”. Ancient Near Eastern Studies in Honor of Jacob Klein. Publications of the Samuel Noah Kramer Institute of Assyriology and Ancient Near Eastern Studies. Bar Ilan/Bethesda, MD, 396-412. 


\section{Abkürzungen}

\subsection{Allgemeine Abkürzungen / Herrschernamen}

$\begin{array}{ll}\text { aAkk. } & \text { altakkadisch } \\ \mathrm{aB} & \text { altbabylonisch } \\ \mathrm{Ab} & \text { Adad-bāni (König in Tuttul) } \\ \mathrm{Abb} . & \text { Abbildung } \\ \mathrm{Ad} & \text { Ammiditana (1683-1647) } \\ \mathrm{Ae} & \text { Abi'ěšuh (1711-1684) } \\ \text { akk. } & \text { akkadisch } \\ \text { Anm. } & \text { Anmerkung } \\ \mathrm{As} & \text { Abi-sarē (1905-1895) } \\ \mathrm{AS} & \text { Amar-Suen (2042-2034) } \\ \mathrm{Aṣ} & \text { Ammișaduqa (1646-1626) } \\ \mathrm{Aw} & \text { Awīlija (König in Tuttul) } \\ \mathrm{Bd.} & \text { Band } \\ \mathrm{B} .(\mathrm{d} .) & \text { Bruder des } \\ \mathrm{BS} & \text { Bur-Sîn (1895-1874) } \\ \mathrm{D} . \text { a. } & \text { Datum abgebrochen } \\ \mathrm{Dail} & \text { Damiq-ilišs (1816-1794) } \\ \text { Enba } & \text { Enlil-bāni (1860-1837) } \\ \mathrm{GN} & \text { Göttername } \\ \mathrm{Ha} & \text { Hammurabi (1792-1750) } \\ \mathrm{H.u.} & \text { Herkunft unbekannt } \\ \mathrm{Ilil} & \text { Ilīma-ilum } \\ \mathrm{Im} & \text { Immerum } \\ \mathrm{IrIm} & \text { Irra-imitti } \\ \text { IšEr } & \text { Išbi-Erra (2017-1985) } \\ \text { Koll. } & \text { Kollation } \\ \text { Kom. } & \text { Kommentar } \\ \text { Lfg. } & \text { Lieferung } \\ \text { LL } & \text { lexikalische Liste(n) } \\ & \end{array}$

$\begin{array}{ll}\text { mA } & \text { mittelassyrisch } \\ \text { MB } & \text { Middle Babylonian } \\ \text { mB } & \text { mittelbabylonisch } \\ \text { nA } & \text { neuassyrisch } \\ \text { nB } & \text { neubabylonisch } \\ \text { OB } & \text { Old Babylonian } \\ \text { o.D. } & \text { ohne Datum } \\ \text { Pl. } & \text { Plural } \\ \text { PN } & \text { Personenname } \\ \text { Rez. } & \text { Rezension } \\ \text { RS } & \text { Rīm-Sîn (1822-1763) } \\ \text { Sa } & \text { Sabium (1844-1831) } \\ \text { Sd } & \text { Samsuditana (1625-1595) } \\ \text { S.(d.) } & \text { Sohn des } \\ \text { Sel } & \text { Sumu-ēl (1894-1866) } \\ \text { Sg. } & \text { Singular } \\ \text { Si } & \text { Samsuiluna (1749-1712) } \\ \text { Sib } & \text { Sîn-erībam (1842-1841) } \\ \text { Sid } & \text { Sîn-iddinam (1849-1843) } \\ \text { Siq } & \text { Sîn-iqī̌sam (1840-1836) } \\ \text { Sl } & \text { Sumula'ēl (1880-1845) } \\ \text { Sm } & \text { Sîn-muballiṭ (1812-1793) } \\ \text { sum. } & \text { sumerisch } \\ \text { ŠS } & \text { Šu-Suen (2033-2025) } \\ \text { T } & \text { Text } \\ \text { T.(d.) } & \text { Tochter des } \\ \text { V.(d.) } & \text { Vater des } \\ \text { WS } & \text { Warad-Sîn (1834-1823) } \\ \text { Zam } & \text { Zambija (1836-1834) } \\ & \end{array}$




\subsection{Bibliographische Abkürzungen}

A.

$\mathrm{AbB}$

AbB 1

AbB 2

$\mathrm{AbB} 4$

$\mathrm{AbB} 5$

AbB 6

$\mathrm{AbB} 7$

$\mathrm{AbB} 8$

AbB 9

AbB 10

AbB 11

$\mathrm{AbB} 12$

$\mathrm{AbB} 14$

AfO

$\mathrm{AHw}$

$\mathrm{An}=$ Anum

AnOr

AOAT

AoF

ARM

ARM 9

ARM 10

$\operatorname{ARM}(\mathrm{T})$

$\operatorname{ARM}(\mathrm{T}) 21$

$\operatorname{ARM}(\mathrm{T}) 23$

$\operatorname{ARM}(\mathrm{T}) 25$

$\operatorname{ARM}(\mathrm{T}) 26 / 2$

ARN

ArOr
Vorläufge Tafelsignatur der Mari-Briefe (Louvre)

Altbabylonische Briefe (Leiden)

F. R. Kraus, Briefe aus dem British Museum. (CT 43 und 44) (Leiden 1964).

R. Frankena, Briefe aus dem British Museum. (LIH und CT 2-33) (Leiden 1966)

F. R. Kraus, Briefe aus dem Archive des Šamaš-Hāzir in Paris und Oxford. (TCL 7 und OECT 3) (Leiden 1968).

F. R. Kraus, Briefe aus dem Istanbuler Museum (Leiden 1971).

R. Frankena, Briefe aus dem Berliner Museum (Leiden 1974).

F. R. Kraus, Briefe aus dem British Museum. (CT 52) (Leiden 1977).

L. Cagni, Briefe aus dem Iraq Museum. (TIM II) (Leiden 1980).

M. Stol, Letters from Yale (Leiden 1981).

F. R. Kraus, Briefe aus kleineren westeuropäischen Sammlungen (Leiden 1985).

M. Stol, Letters from Collections in Philadelphia, Chicago and Berkeley (Leiden 1986).

W. H. van Soldt, Letters in the British Museum (Leiden 1990).

K. R. Veenhof, Letters in the Louvre (Leiden 2005).

Archiv für Orientforschung (Berlin, Graz, Wien 1923ff.).

W. von Soden, Akkadisches Handwörterbuch (Wiesbaden 19591981).

s. Litke 1998

Analecta Orientalia (Rom 1931ff.).

Alter Orient und Altes Testament, Münster.

Altorientalische Forschungen. Schriften zur Geschichte und Kultur des alten Orients (Berlin 1971ff.).

Archives royales de Mari (= TCL 22-31; Paris 1946-67).

M. Birot, Textes administratifs de la salle 5 (Paris 1960).

G. Dossin, La correspondance féminine (Paris 1967).

Archives Royales de Mari. Traductions (Paris).

$=$ Durand 1983

G. Bardet et al., Archives administratifs de Mari 1 (Paris 1984).

H. Limet, Textes administratifs relatifs aux métaux (Paris 1986).

$=$ Durand 1988

M. Çı̆̆, H. Kızılyay \& F. R. Kraus, Altbabylonische Rechtsurkunden aus Nippur (Istanbul 1952).

Archív Orientální. Quarterly Journal of African and Asian Studies (Prag 1929ff.). 
ARRIM Annual Review of the Royal Inscriptions of Mesopotamia Project

ASJ

ASKT

AUCT

AUCT 5

$\mathrm{AuOr}$

AUWE

AUWE 23

BA

Bab.

BaM

BASOR

BBVOT

BBVOT 1

BBVOT 3

$\mathrm{BE}$

BE 6/1

BE $6 / 2$

BiMes

BiMes 11

BIN

BIN 2

BIN 7

BIN 9

BIN 10

BiOr
(Toronto 1983ff.).

Acta Sumerologica. Japan (Hiroshima 1979ff.).

P. Haupt, Akkadische und sumerische Keilschrifttexte nach den Originalen im Britischen Museum copirt (Leipzig 1881/82).

Andrews University Cuneiform Texts (Berrien Springs, Michigan)

M. Sigrist, Old Babylonian account texts in the Horn Archaeology Museum 2 (=IPAS 8; Berrien Springs, Michigan 2003).

Aula Orientalis (Barcelona 1983ff.)

Ausgrabungen in Uruk-Warka. Endberichte (Mainz 1987ff.)

A. Cavigneaux, Uruk: altbabylonische Texte aus dem Planquadrat Pe XVI-4/5, nach Kopien von Adam Falkenstein (Mainz 1996).

Beiträge zur Assyriologie und semitischen Sprachwissenschaft (Leipzig 1889/90ff.).

Babyloniaca, études de philologie assyro-babylonienne (Paris).

Baghdader Mitteilungen (Berlin/Mainz 1960ff.); auch BagM

Bulletin of the American Schools of Oriental Research (New Haven etc. 1921ff.).

Berliner Beiträge zum Vorderen Orient, Texte (Berlin)

D. Arnaud, Altbabylonische Rechts- und Verwaltungsurkunden (Berlin 1989).

D. Arnaud, Texte aus Larsa. Die epigraphischen Funde der 1. Kampagne in Senkereh-Larsa 1933(Berlin 1994).

The Babylonian Expedition of the University of Pennsylvania. Series A: Cuneiform Texts (Philadelphia).

H. Ranke, Babylonian Legal and Business Documents from the Time of the First Dynasty of Babylon Chiefly from Sippar (Philadelphia 1906).

A. Poebel, Babylonian Legal and Business Documents from the Time of the First Dynasty of Babylon Chiefly from Nippur (Philadelphia 1909).

Bibliotheca Mesopotamica (Malibu, California).

$=$ Sigrist 1984

Babylonian Inscriptions in the Collection of James B. Nies, Yale University (New Haven 1917ff.).

C. E. Keiser, Historical Religious and Economic Texts and Antiquities. C. E. Keiser und J. B. Nies (New Haven, London 1920).

J. B. Alexander, Early Babylonian Letters and Economic Texts (New Haven, London 1943).

V. E. Crawford, Sumerian Economic Texts from the First Dynasty of Isin (New Haven, London 1954).

M. van de Mieroop, Sumerian Administrative Documents from the Reigns of Išbi-Erra and Šū-ilišu (New Haven, London 1987).

Bibliotheca Orientalis (Leiden 1943/44ff.). 
BL

BM

BSOAS

CAD

CBS

$\mathrm{CDA}^{2}$

cdli

$\mathrm{CM}$

CM 33

Cornell

CT

CT 4

CT 6

CT 8

CT 15

CT 21

CT 36

CT 42

CT 44

CT 45

CT 46

CT 47

CT 48

CT 58

CTMMA 2

CUA

DI

ePSD

ETCSL
S. Langdon, Babylonian Liturgies (Paris 1913).

Museumssignatur des British Museum

Bulletin of the School of Oriental and African Studies (London 1917ff.).

A. L. Oppenheim, E. Reiner et al. (Hrsg.), The Assyrian Dictionary of the University of Chicago (Chicago 1956ff.).

Museumssignatur der Collection of the Babylonian Section (Philadelphia).

J. Black, A. George \& N. Postgate (Hrsg.), A Concise Dictionary of Akkadian. 2nd (corrected) printing (Wiesbaden, 2000).

http://cdli.ucla.edu

Cuneiform Monographs (Leiden).

$=$ Westenholz/Westenholz 2006

Tafelsignatur der Olin Library (Cornell University).

Cuneiform Texts from Babylonian Tablets in the British Museum (London 1896ff.).

T. G. Pinches, Commercial documents from the period of the first dynasty of Babylon until the Seleucid period, Late Babylonian prayers and incantations (London 1898).

Ders. Documents from the period of the first dynasty of Babylon, list of Babylon, list of year names (Hammurabi dynasty), extispicy-text (London 1898).

Ders. Commercial documents from the period of the first dynasty of Babylon (London 1899).

L. W. King, God-hymns, fables, myths (Anzu, Inanna's descept, Ea and Atrahasis) (London 1902).

Ders., Royal inscriptions (from Sargon to Samsuiluna) (London 1905).

C. J. Gadd, Royal inscriptions, Sumerian hymns (London 1921).

H. H. Figulla, Sumerian and bilingual religious texts (London 1959).

T. G. Pinches, Miscellaneous texts (London 1963).

Ders., Old-Babylonian Business Documents (London 1964).

W. G. Lambert, Babylonian literary texts (London 1965).

H. H. Figulla, Old-Babylonian Naditu records (London 1967).

J. J. Finkelstein, Old-Babylonian legal documents (London 1968).

B. Alster \& M. J. Geller, Sumerian literary texts (London 1990).

I. Spar (Hrsg.), Literary and Scholastic Texts of the First Millennium

B.C., Cuneiform Texts in the Metropolitan Museum of Art, Vol. 2 (New York 2005).

Tafelsignatur der Catholic University of America

Kürzel für Dumuzi-Inana-Lieder

http://psd.museum.upenn.edu/epsd/nepsd-frame.html

J. A. Black, G. Cunningham, J. Ebeling, E. Flückiger-Hawker, E.

Robson, J. Taylor \& G. Zólyomi, The Electronic Text Corpus of 
Sumerian Literature (http://etcsl.orinst.ox.ac. uk/), (Oxford, 19982006).

FM Florileguim marianum (Paris).

HAV

Hilprecht Anniversary Volume: Studies in Assyriology and Archaeology Dedicated to Hermann V. Hilprecht upon the Twenty-Fifth Anniversary of his Doctorate and his Fiftieth Birthday (July 28) by his Colleagues, Friends and Admirers (Leipzig 1909).

HLC G. A. Barton (Hrsg.), Haverford Library Collection of Cuneiform Tablets or Documents from the Temple Archives of Tello, I-III (Philadelphia, London 1905-1914).

HrwG Handbuch religionswissenschaftlicher Grundbegriffe Band I-V; H. Cancik, B. Gladigow \& K.-H. Kohl (Hrsg.) (Stuttgart 1988-2001).

HS Tafelsignatur der Hilprecht-Sammlung (Jena).

HUCA Hebrew Union College Annual (Cincinnati, Ohio 1924ff.).

IB

IPAS

IPAS 3

Siglum der Texte aus Isin

Institute of Archaeology publications: Assyriological series (Berrien Springs, Michigan).

ISET

$=$ Sigrist 1990

M. Çĭg, H. Kızılyay \& S. N. Kramer, İstanbul Arkeologji Müzelerınde bulunan Sumer edebî tablet ve parçaları [Sumerian Literary Tablets and Fragments in theArchaeological Museum of Istanbul] I-II (Istanbul 1969, 1976).

JANES Journal of the Ancient Near Eastern Society (of Columbia University) (New York 1968/69ff.).

JAOS Journal of the American Oriental Society (New Haven etc. 1843/49ff.).

JCS Journal of Cuneiform Studies (New Haven/Boston etc. 1947ff.).

JESHO Journal of the Economic and Social History of the Orient (Leiden 1957/58ff.).

JNES Journal of Near Eastern Studies (Chicago 1942ff.).

JRL

KAR

Tafelsignatur der John Rylands Library (Manchester).

E. Ebeling, Keilschrifttexte aus Assur religiösen Inhalts, I /II (Leipzig 1919; 1920).

KH Kodex Hammurapi

KTT Keilschrifttexte, Tuttul (Tall Bi'a). Signatur der in Krebernik 2001 publizierten Texte.

L. $\quad$ Siglum der Texte aus Larsa

M. Siglum der Texte aus Mari

MAD Materials for the Assyrian Dictionary, I-V (Chicago 1952-1970).

MAH Inventarsignatur des Musée d'art et d'histoire (Genf).

MAOG Mitteilungen der Altorientalischen Gesellschaft (Leipzig).

MAOG 13/2 B. Meissner, Studien zur assyrischen Lexikographie, Bd. 4 (Leipzig 1940).

MCS Manchester Cuneiform Studies (Manchester 1951-1964). 
MDP

MGG

MHET

MHET I

MHET II

MIO

MS

MSL

MSL 4

MSL 6

MSL 7

MSL 8/2

MSL 12

MSL 13

MSL 14

MSL 16 MSL SS I

N.

N.A.B.U.

NATN

NG

$\mathrm{Ni}$

Nik.

Nisaba 19
Mémoires de la Délégation de Perse (Paris 1921-1939).

Die Musik in Geschichte und Gegenwart. Allgemeine Enzyklopädie der Musik, Bde. I-XVII (Kassel 1949-1986, Kassel/New York/Stuttgart 1994-2007).

Mesopotamian History and Environment, Series 3, Texts (Ghent).

K. van Lerberghe \& G. Voet, Sippar-Amnånum. The Ur-Utu Archive. Vol. 1 (Ghent 1991).

L. Dekiere, Old Babylonian Real Estate Documents from Sippar in the British Museum. Part 1-6 (Ghent 1994-1997).

Mitteilungen des Instituts für Orientforschung (Berlin 1953ff.)

Siglum der Texte aus der Schøyen-Collection.

B. Landsberger et al., Materialien zum sumerischen Lexikon/ Materials for the Sumerian Lexikon (Rom 1937ff.).

Introduction. Part 1: Emesal- Vocabulary (Series dimir- dingir- ilum). Part 2: Old Babylonian grammatical texts. Part 3: Neobabylonian grammatical texts. Nachträge zu MSL III, (Rom 1956).

B. Landsberger, The series "HAR - ra = hubullu". Tab. V - VII (Rom 1958).

B. Landsberger, The series "HAR - ra = hubullu". Tab. VIII - XII (Rom 1959).

B. Landsberger er al., The fauna of Ancient Mesopotamia: part 2, "HAR - ra = hubullu" (Rom 1962).

M. Civil et al., The series "lú = sa" and related texts (Rom 1969)

M. Civil et al., Izi $=$ isatu, Ká-gal $=$ abullu and Níg-ga $=$ makkuru (Rom 1971).

M. Civil et al., Ea $\mathrm{A}=$ nâqu, $\mathrm{Aa} \mathrm{A}=$ nâqu, with their forerunners and related texts (Rom 1979).

I. L. Finkel, The series "SIG7.ALAN = Nabnitu" (Rom 1982).

M. Civil et al., The Sag-tablet, lexical texts in the Ashmolean Museum, Middle Babylonian grammatical texts, miscellaneous texts (Rom 1986).

Siglum der Texte aus Nippur

Nouvelles Assyriologique Brèves et Utilitaires (Paris, Rouen 1987ff.).

D. I. Owen, Neo-Sumerian Archival Texts Primarily from Nippur inthe University Museum, the Oriental Institute and the Iraq Museum (Winona Lake 1982).

A. Falkenstein, Die neusumerischen Gerichtsurkunden I-III (München 1956-1957).

Museumssignatur der Texte aus Nippur in Istanbul.

M. V. Nikol'skiy, Dokumenty chozjajstennoj (St. Petersburg 1908).

J. A. Black et al., Texts from Ur kept in the Iraq Museum and in the British Museum (Messina 2008). 
NYPL H. Sauren, Les tablettes cunéiformes de l'époque d'Ur des collections de la New York Public Library (Louvain-La-Neuve 1978).

OBO Orbis Biblicus et Orientalis (Freiburg, Schweiz 1973ff.).

OBTI S. Greengus, Old Babylonian Tablets from Ishchali and Vicinity (=PIHANS 44, 1979).

OBTR 1. R.J. Lau, Old Babylonian Temple Records (= Columbia University Oriental Studies 3, New York 1966).

OECT Oxford Editions of Cuneiform Texts (Oxford 1923ff.).

OECT $5=$ Gurney/Kramer 1976

OECT 6 S. H. Langdon, Babylonian penitential psalms to which are added fragments of the epic of creation from Kish in the Weld collection of the Ashmolean Museum (Paris 1927).

OECT 11 O. R. Gurney, Literary and Miscellaneous Texts in the Ashmolean Museum. IV (Oxford 1989).

OECT 15 S. Dalley, Old Babylonian texts in the Ashmolean Museum : mainly from Larsa, Sippir, Kish, and Lagaba (Oxford 2005).

OLA Orientalia Lovaniensia Analecta (Leuven).

OLA 21 K. van Lerberghe, Old Babylonian legal and administrative texts from Philadelphia (Leuven 1986).

OLZ Orientalistische Literaturzeitung (Berlin/Leipzig 1898ff.).

Ontario 2 M. Sigrist, Neo Sumerian Texts from the Royal Ontario Museum (Ontario) Vol. 2. Administrative Texts Mainly from Umma (Bethesda, MD 1995).

OrA Orient-Archäologie, Rahden/Westph.

OrNS Orientalia Nova Series (Rom 1932ff.).

PBS Publications of the Babylonian Section, University of Pennsylvania (Philadelphia 1911ff.).

PBS 1/1 D. W. Myhrman, Babylonian hymns and prayers (Philadelphia 1911).

PBS 5 A. Poebel, Historical and grammatical texts (Philadelphia 1914).

PBS 8/1 Chiera, E. Legal and Administrative Documents from Nippur. Chiefly from the Dynasties of Isin and Larsa (Philadelphia 1914).

PBS 8/2 Ders., Old Babylonian Contracts (Philadelphia 1922)

PBS 10/2 S. Langdon, Sumerian liturgical texts (Philadelphia 1917).

PBS 13 L. Legrain, Historical Fragments (Philadelphia 1922)

PIHANS Publications de l'Institut historique et archéologique néerlandais de Stamboul (Leiden 1956ff.).

PRAK H. de Genouillac, Premières recherches archéologiques à Kich. Mission d'Henri de Genouillac 1911-1912, I/II (Paris 1924/1925).

PSD The Pennsylvania Sumerian Dictionary (Philadelphia 1984ff.).

RA Revue d'Assyriologie et d'Archéologie Orientale (Paris 1884/85ff.).

RIAA L. Speleers, Recueil des inscriptions de l'Asie antérieure des Musées Royaux du Cinquantenaire à Bruxelles: Textes sumériens, babyloniens et assyriens (Brüssel 1925). 
Riftin A. P. Riftin, Starovavilonskie juridiçeskie i administrativnie dokumenti v sobranijach SSSR (Moskau 1937).

RIME The Royal Inscriptions of Mesopotamia. Early Periods. Toronto, Buffalo, London.

RIME $2=$ Frayne 1993

RIME 3/1 = Edzard 1997

RIME 3/2 = Frayne 1997

RIME $4=$ Frayne 1990

RlA

SAOC Studies in Ancient Oriental Civilization (Chicago 1931ff.).

SAOC $44=$ Stone 1987

SA

SAT

C.-F. Jean, Sumer et Akkad: contribution à l'histoire de la civilisation dans la Basse-Mésopotamie (Paris 1923).

SAT 1 M. Sigrist, Texts from the British Museum (Bethesda, MD. 1993).

SBH

$\mathrm{SC}$

SEAL

SK

SLB

SLTN S.N. Kramer, Sumerian Literary Texts from Nippur in the Museum of the Ancient Orient at Istanbul (New Haven, Connecticut 1944).

$\mathrm{Sm}$

SP

Smith. Museumssignatur des British Museum (London).

SRT

E. Chiera, Sumerian Religious Texts (Upland 1924).

STVC

E. Chiera, Sumerian Texts of Varied Contents (Chicago 1934).

TCL

TCL 1 F. Thureau-Dangin, Lettres et contrats de l'époque de la premiére dynastie babylonienne (Paris 1910).

TCL 3 Ders., Une relation de la huitième campagne de Sargon: (714 av. J.C.) (Paris 1912).

TCL 6 Ders., Tablettes d'Uruk: à l'usage des prêtres du Temple d'Anu au temps des Séleucides (Paris 1922).

TCL 10 Jean, C.-F. Contrats de Larsa. Première série. Planches I à XCXIX (Paris 1926).

TCL 11 Ders. Contrats de Larsa. Seconde série. Planches C à CLVI (Paris: 1926). 
TCL 15 H. de Genouillac, Textes religieux sumériens du Louvre 1 (Paris 1930).

TCL 16 Ders., Textes religieux sumériens du Louvre 2 (Paris 1930).

TIM

Texts in the Iraq Museum (Baghdad/Wiesbaden 1964ff.).

TIM 4 J. van Dijk, Cuneiform texts: Old Babylonian contracts and juridical texts (1967).

TIM 5 Ders., Cuneiform texts: Old Babylonian contracts and related material (1968).

TIM 9 Ders., Cuneiform texts: Texts of varying content (1976).

TJA(UB) E. Szlechter, Tablettes juridiques et administratives de la III e dynastie d'Ur et de la I re Dynastie de Babylone, conservées au Musée de l'Université de Manchester et, à Cambridge, au Musée Fitzwilliam, à l'Institut d'Études Orientales et à l'Institut d'Egyptologie I-II (Paris 1963).

TJDB E. Szlechter, Tablettes juridiques de la 1re Dynastie de Babylone, conservées au Musée d'art et d'histoire de Genève I-II (Paris 1958).

TLB 1 Tabulae Cuneiformes a F.M.Th. de Liagre Böhl Collectae Leidae Conservatae (Leiden 1954-1973).

TMH NF Texte und Materialien der Frau Professor Hilprecht Collection of Babylonian Antiquities im Eigentum der. Neue Folge (Leipzig, Berlin, Wiesbaden 1937ff.).

TMH NF 3 S. N. Kramer \& I. Bernhardt, Sumerische literarische Texte aus Nippur Band 1 Mythen, Epen, Weisheitsliteratur und andere Literaturgattungen; Band 2 Hymnen, Klagelieder, Weisheitstexte und andere Literaturgattungen (Berlin 1961; 1967).

TRU L. Legrain, Le temps des rois d'Ur: recherches sur la société antique d'après des textes nouveaux (Paris 1912).

TSifr C.-F. Jean, Tell Sifr. Textes cunéiformes conservés au British Museum (Paris: 1931).

TUT G. Reisner, Tempelurkunden aus Telloh (Berlin 1901).

UET Ur Excavations: Texts (London 1928ff.).

UET 1 J. Gadd \& L. Legrain, Royal inscriptions (London 1928).

UET 3 L. Legrain, Business documents of the third dynasty of Ur (London 1947).

UET 5 W. J. Martin, Letters and Documents of the Old-Babylonian Period (London 1953).

UET 6/1-3 C. J. Gadd, S. N. Kramer \& A. Shaffer, Literary and religious texts (London 1963, 1966, 2005).

UET 7 O. R. Gurney, Middle Babylonian legal documents and other texts (London 1974).

UF Ugarit-Forschungen (Neukirchen-Vluyn 1969ff.).

UM Tafelsignatur des University Museum (Philadelphia).

UMM University Museum, Manchester. 


$\begin{array}{ll}\text { VAB } & \text { Vorderasiatische Bibliothek (Leipzig 1907ff.). } \\ \text { VAB } 6 & \text { A. Ungnad, Babylonische Briefe aus der Zeit der Hammurapi- } \\ & \text { Dynastie (Hinrichs 1914). } \\ \text { VAT } & \text { Vorderasiatische Abteilung. Tontafeln. Tafelsignatur des VA Muse- } \\ & \text { ums (Berlin). } \\ \text { VS } & \text { Vorderasiatische Schriftdenkmäler der Königlichen Museen zu Berlin } \\ & \text { (Leipzig 1907-1917), NF Vorderasiatische Schriftdenkmäler der } \\ & \text { Staatlichen Museen zu Berlin (Berlin 1971ff.). } \\ \text { VS 2 } & \text { H. Zimmern, Sumerische Kultlieder aus altbabylonischer Zeit. } 1 . \\ & \text { Reihe (Leipzig 1912). } \\ \text { VS 7 } & \text { A. Ungnad, Kontrakte und Listen (Leipzig 1909). } \\ \text { VS 8 } & \text { Ders., Urkunden aus Sippar (Leipzig 1909). } \\ \text { VS 9 } & \text { Ders., Urkunden der Zeit Hammurabis (Leipzig 1909). } \\ \text { VS 10 } & \text { H. Zimmern, Sumerische Kultlieder aus altbabylonischer Zeit. 1. } \\ \text { VS 13 } & \text { Reihe (Leipzig 1913). } \\ \text { VS 17 } & \text { H. H. Figulla, Altbabylonische Verträge (Leipzig 1914). } \\ & \text { J. A. van Dijk, Nicht-kanonische Beschwörungen und sonstige } \\ \text { VS 18 } & \text { literarische Texte (Berlin 1971). } \\ \text { VS 22 } & \text { H. Klengel, Altbabylonische Rechts- und Wirtschaftsurkunden } \\ \text { VS 24 } & \text { (Berlin 1973). } \\ \text { VS 25 } & \text { Ders., Altbabylonische Texte aus Babylon (Berlin 1983). } \\ \text { J. van Dijk, Literarische Texte aus Babylon (Berlin 1987). } \\ \text { J. Marzahn, Altsumerische Verwaltungstexte aus Girsu/Lagas (Berlin } \\ \text { 1991). }\end{array}$

VS 29 H. Klengel \& E. Klengel-Brandt, Spät-altbabylonische Tontafeln. Texte und Siegelabrollungen (Mainz 2002).

$\mathrm{WdO}$

Die Welt des Orients (Wuppertal/Göttingen 1947/52ff.).

WOO

Wiener Offene Orientalistik, herausgegeben von G. Selz (Wien).

WVDOG

WZKM

Wissenschaftliche Veröffentlichungen der Deutschen OrientGesellschaft (Leipzig/Berlin etc. 1900ff.)

Wissenschaftliche Veröffentlichungen der Deutschen OrientGesellschaft (Leipzig/Berlin etc. 1900ff.)

YBC Signatur der Yale Babylonian Collection (Yale University, New Haven).

YOS Yale Oriental Series. Babylonian Texts (New Haven/London/ Oxford).

YOS 5 E. M. Grice, Records from Ur and Larsa Dated in the Larsa Dynasty (1919).

YOS 8 D. E. Faust, Contracts from Larsa, dated in the reign of Rîm-Sin (1941). 
YOS 11 J. van Dijk et al. Early Mesopotamian incantations and rituals (1985).

YOS 12 S. I. Feigin, Legal and administrative texts of the reign of SamsuIluna (1979).

YOS $13=$ Finkelstein 1972

YOS 14 S. D. Simmons, Early old Babylonian documents (1978).

ZA Zeitschrift für Assyriologie und Vorderasiatische Archäologie (Leipzig später Berlin 1939ff.). 


\section{Textverzeichnis}

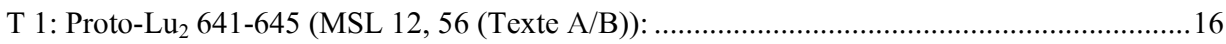

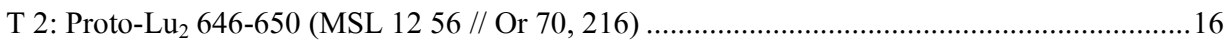

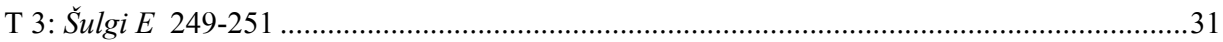

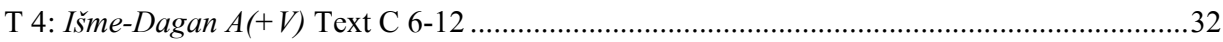

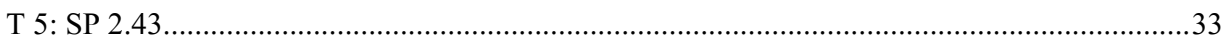

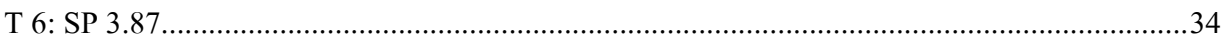

T 7: SP 2.39

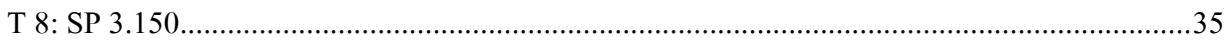

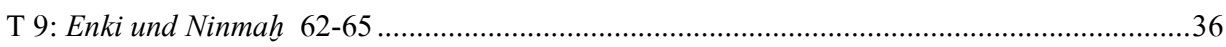

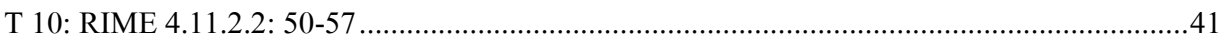

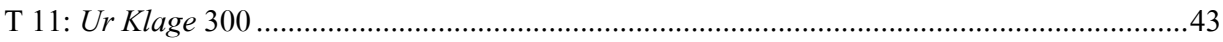

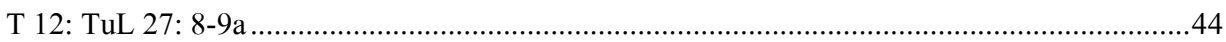

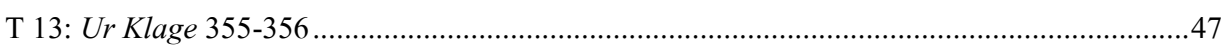

T 14: AbB 9, 193

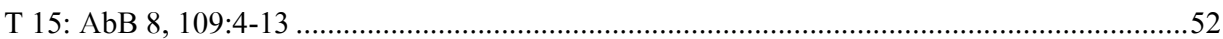

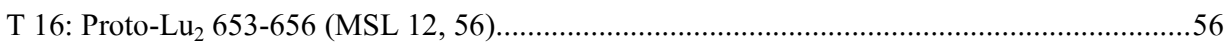

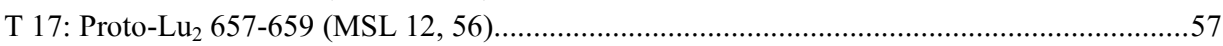

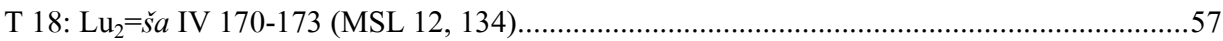

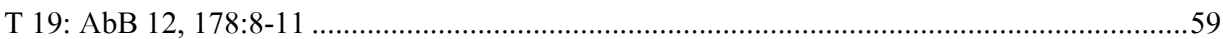

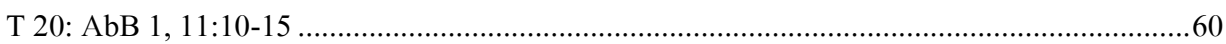

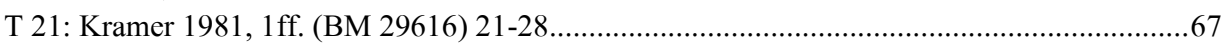

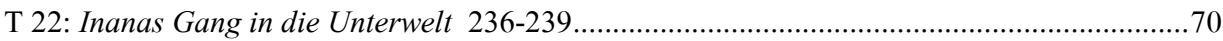

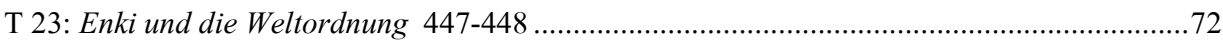

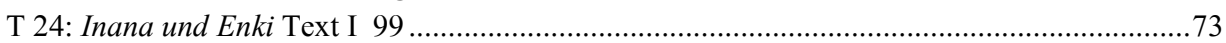

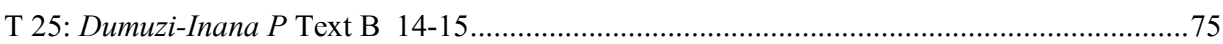

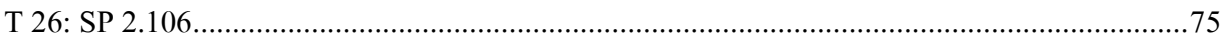

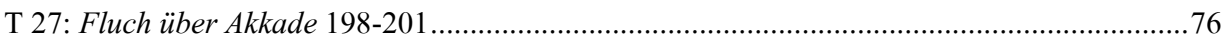

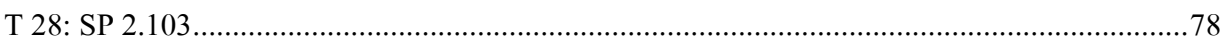

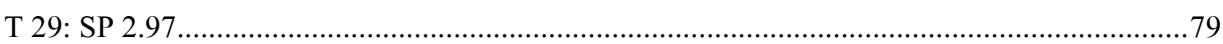

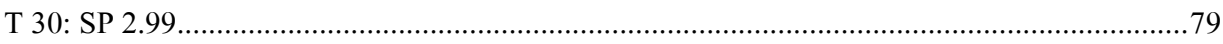

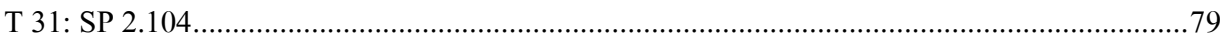

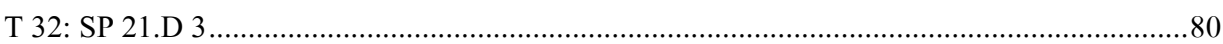

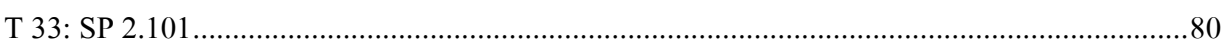

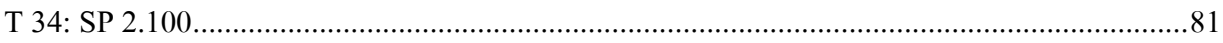

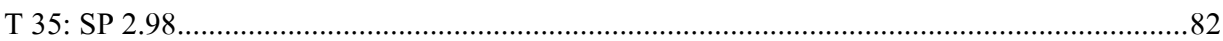

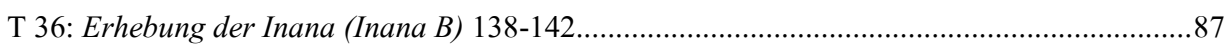

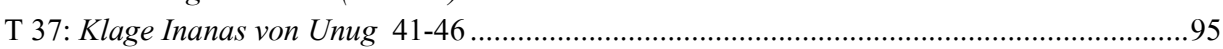

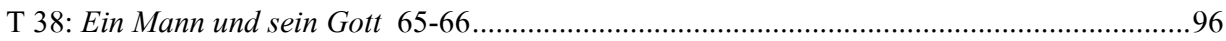

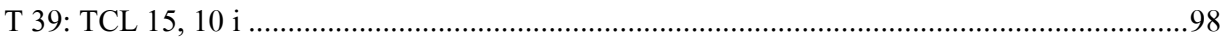

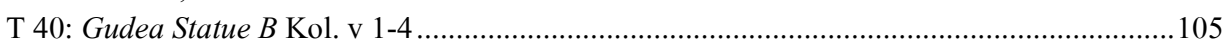




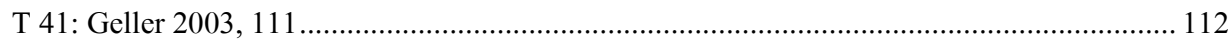

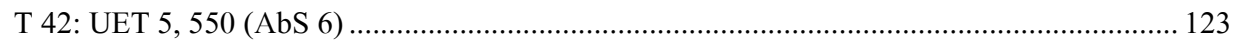

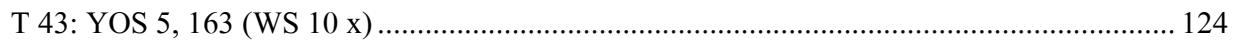

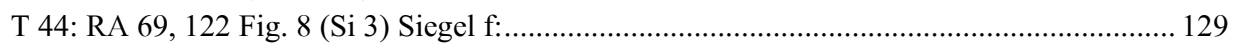

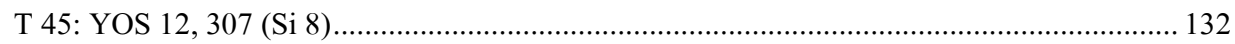

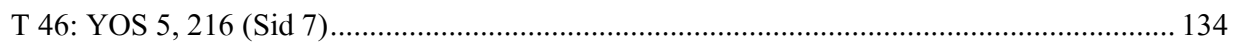

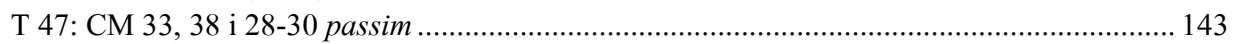

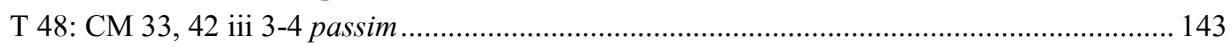

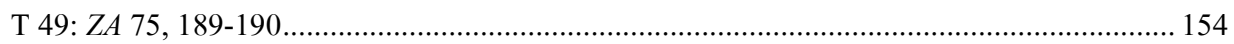

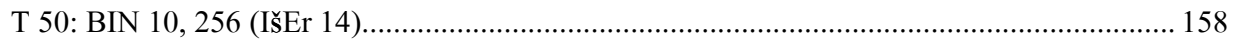

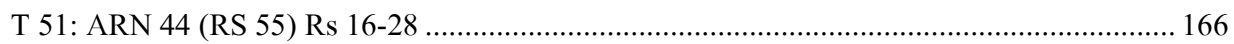

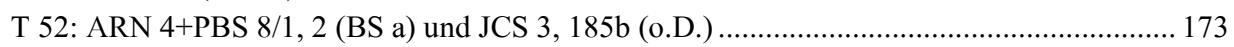

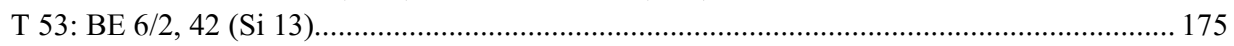

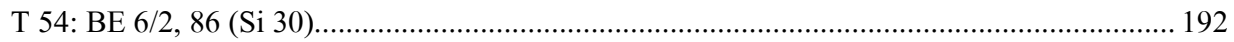

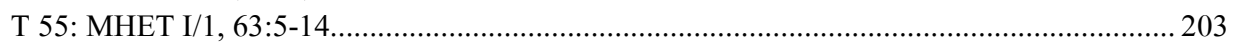

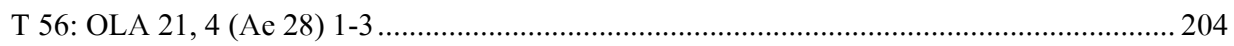

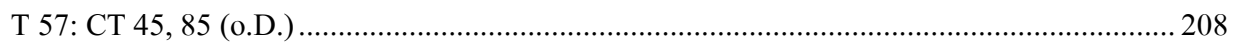

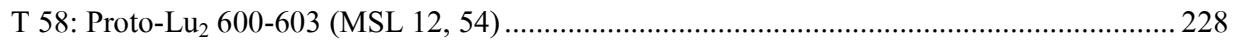

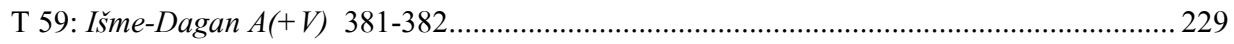

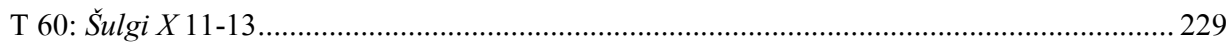

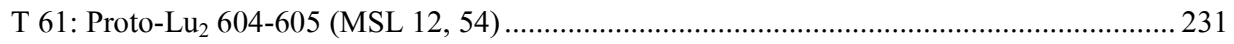

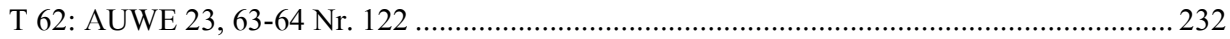

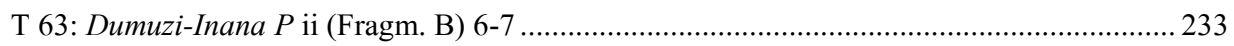

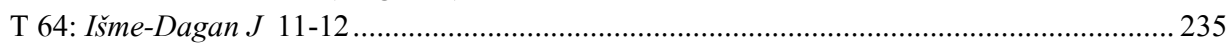

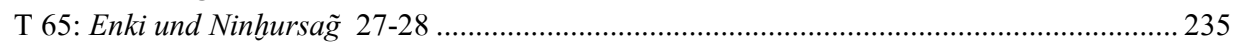

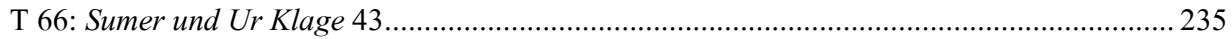

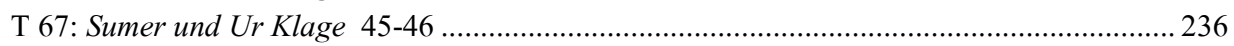

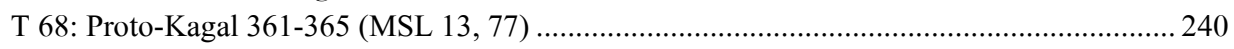

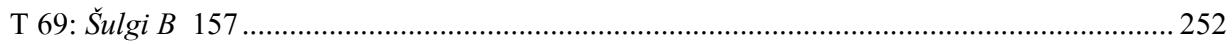

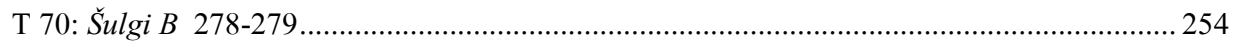

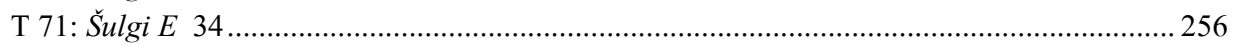

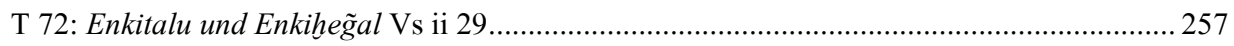

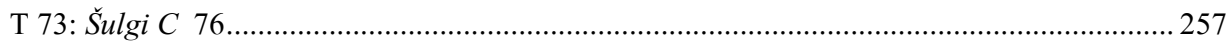

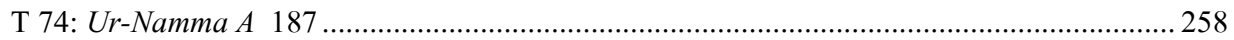

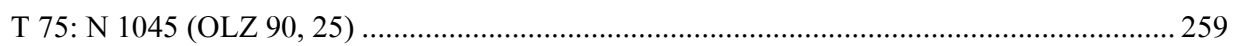

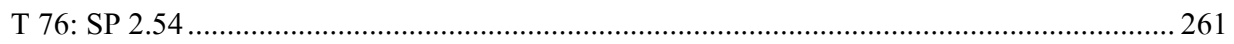

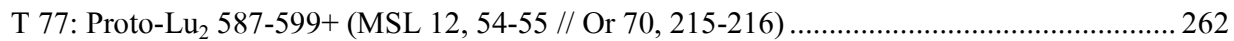

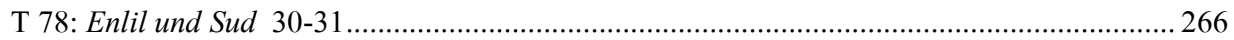

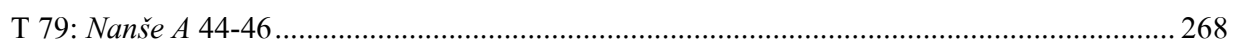

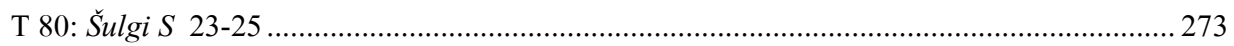

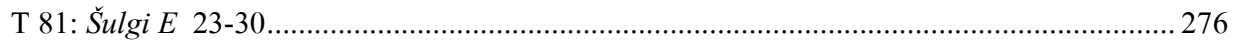

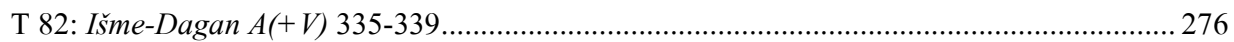

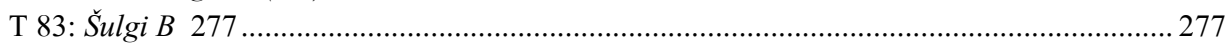

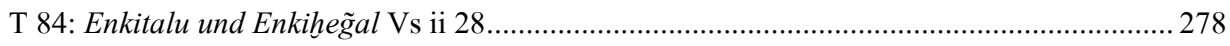




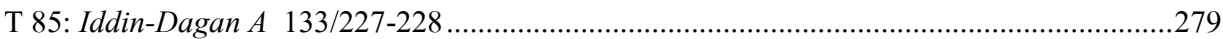

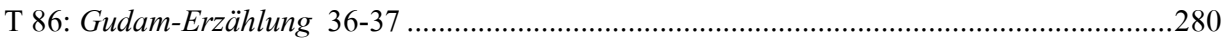

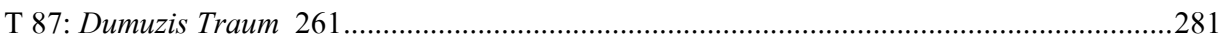

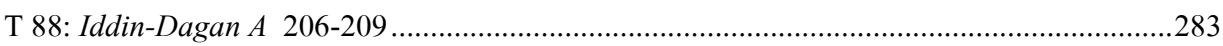

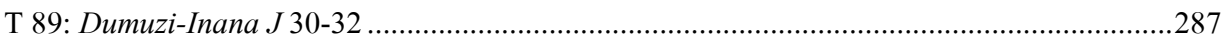

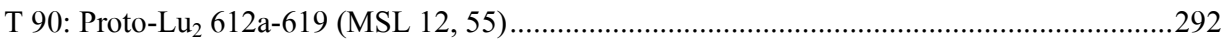

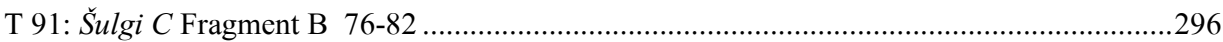

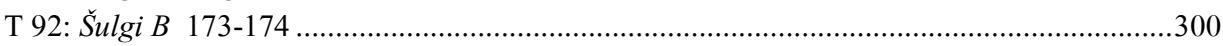

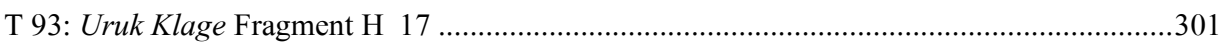

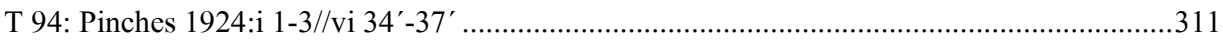

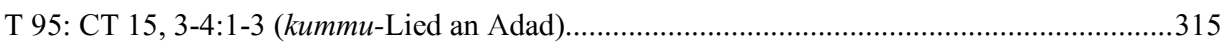

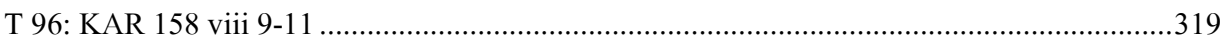

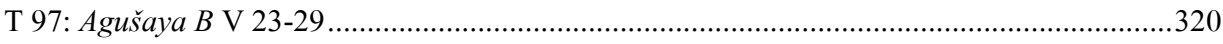

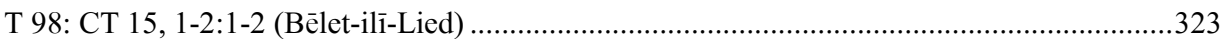

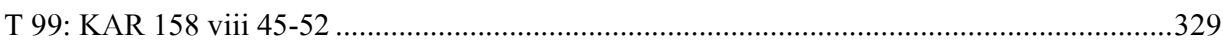

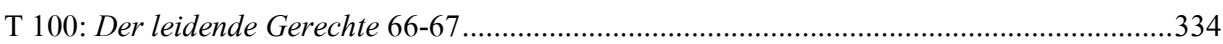

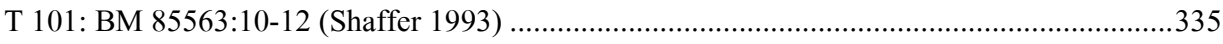

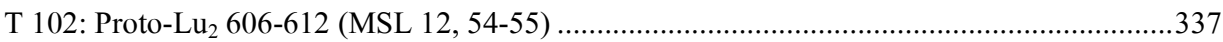

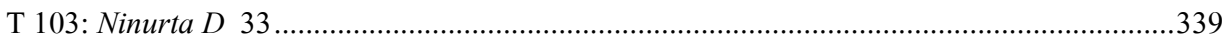

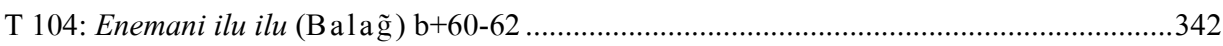

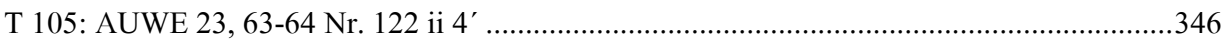

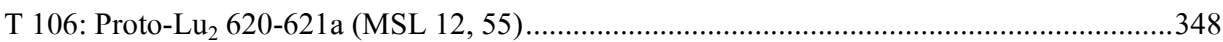

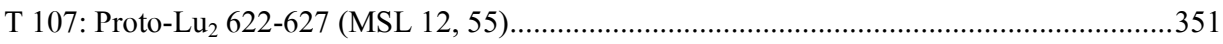

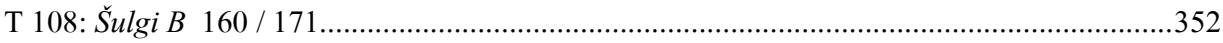

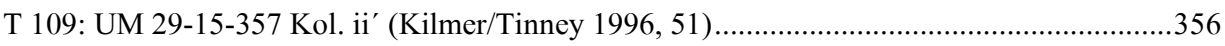

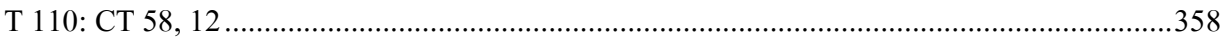

\section{Tabellenverzeichnis}

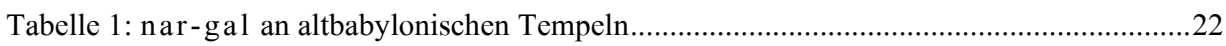

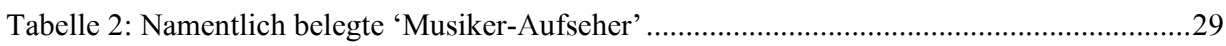

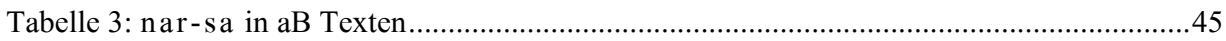

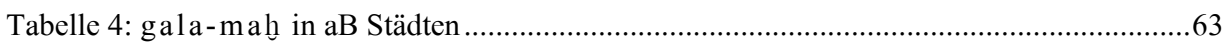

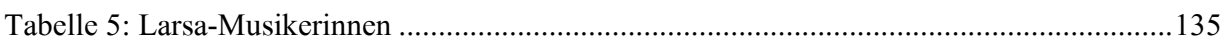

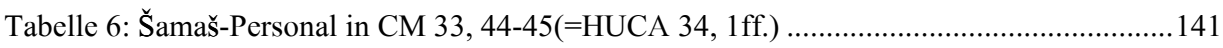

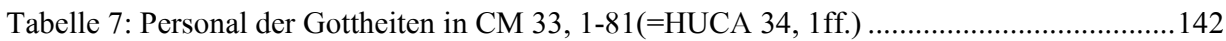

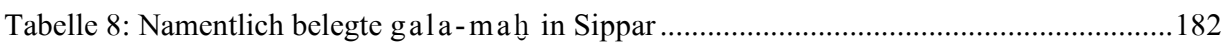

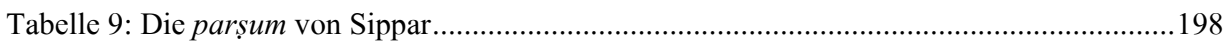

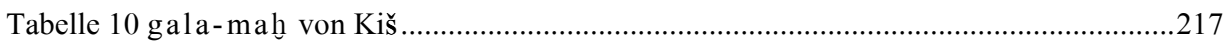

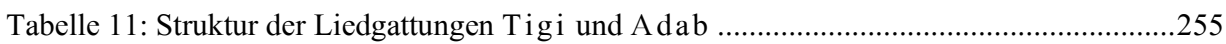




\section{Indices}

\section{Wörter: Sumerisch}

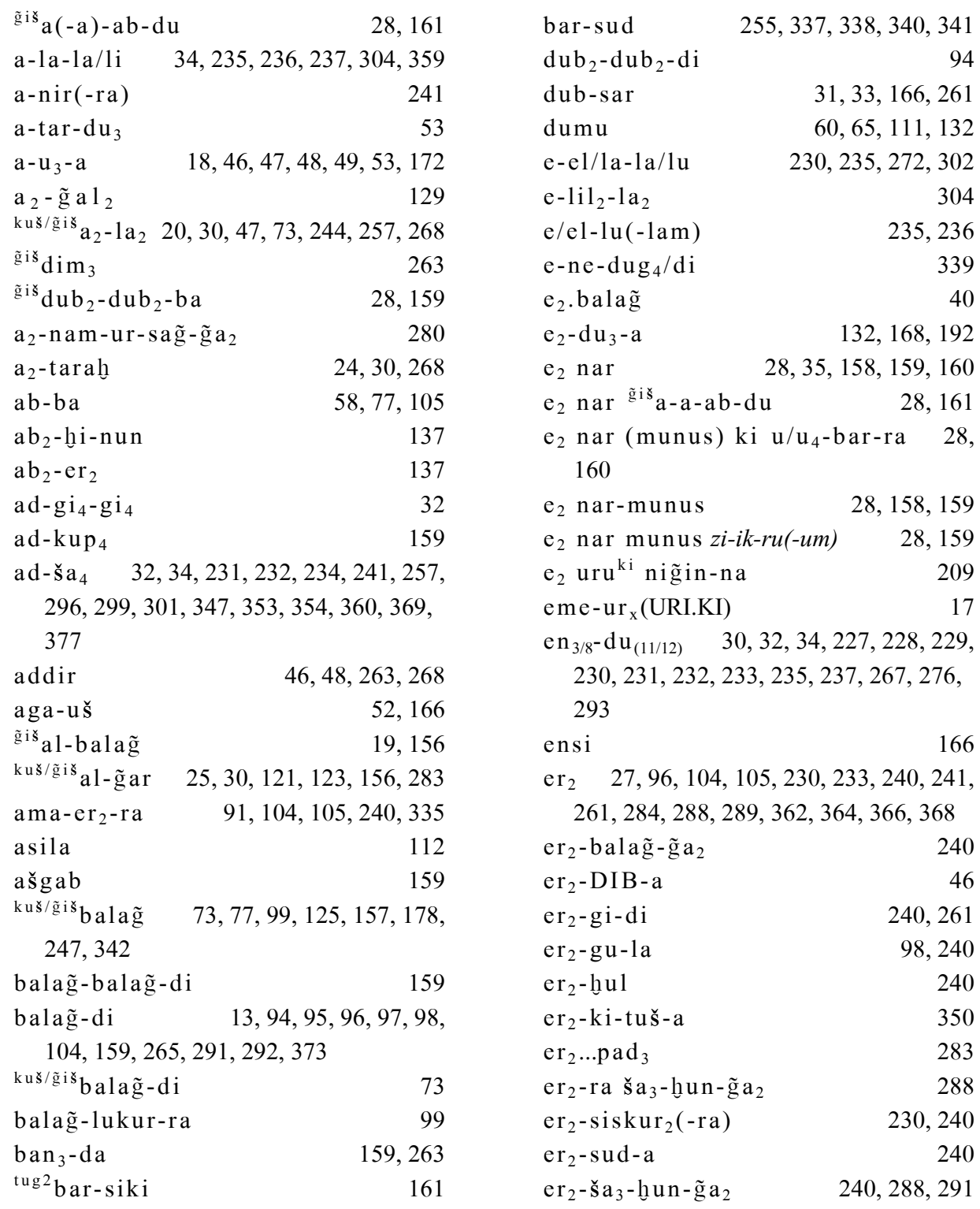




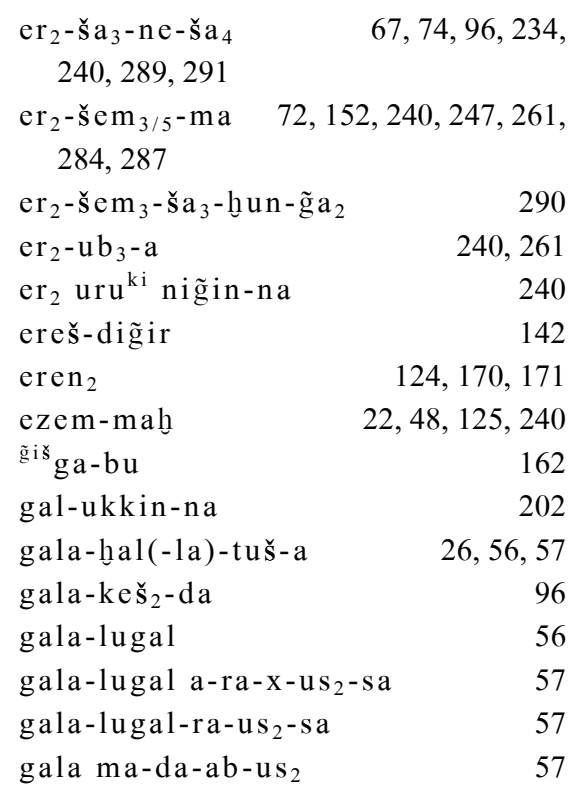

gala-mah $4,45,48,55,56$,

$58,60,61,62,64,65,66,73,76,77,78$,

$87,88,90,91,92,100,101,103,105$,

$107,108,109,110,115,119,120,124$,

$125,127,128,129,137,146,147,153$,

$154,155,157,162,165,166,167,168$,

169, 170, 171, 172, 176, 178, 179, 180,

$181,182,183,184,185,186,187,188$,

189, 195, 196, 197, 199, 201, 202, 203,

204, 205, 206, 208, 209, 212, 213, 214,

$216,217,218,219,220,221,245,272$,

$285,342,373,374,376,377,379$

gala-mah lugal

56

gala- Š $\mathrm{IR}_{3}{ }^{?}-\mathrm{da}$

57

gala-tur(-ra)

$85,92,373$

gala $u_{2}$-nu-tim

60

gala-us $s_{2}-\mathrm{sa}$

57

gala-ze $2-e_{3}$

57

gi-di

260

gi-di(-da) 240, 260, 261, 262, 297, 301

gi-en-gi-en

351,352

gi-er $r_{2}-\mathrm{ra}$ gi-gid $215,231,258,259,260,261$, 262, 295, 297, 330, 364, 368

$\operatorname{gid}_{2}-\mathrm{i}$ 351,352

$\mathrm{gu}_{4}$-bala $\tilde{g}$

147,203

$\mathrm{gu}_{4}$-si-su

303

$\operatorname{gudu}_{4} \quad 14,57,61,81,102,120,123$,

$140,141,142,144,145,153,165,166$,

$167,169,170,172,173,174,175,176$,

192, 194, 204, 208, 209

$\mathrm{gudu}_{4} \mathrm{ke} \check{\mathbf{s}}_{2}-\mathrm{da}$

18

$\tilde{g} a_{2}-d u b-b a$

166

$\tilde{\mathrm{g}} \mathrm{a}_{2}-\mathrm{g} \mathrm{a}_{2}$ 77, 256, 287, 300, 339, 351, 352, $353,354,368,370$

g̃ešbun 263

$\tilde{\mathrm{g}} \mathrm{ili} \mathrm{i}_{3}\left(/ \mathrm{mili}_{2}\right)$

g̃ iš-gi $i_{(4 / 5)}-\tilde{g} a l_{2} \quad 74,77,96,250,252,254$, $255,259,265,269,278,279,280,281$, 291, 294, 295, 296, 303, 311, 317, 318, $319,321,328,331,337,341,343,344$, $345,346,347,349,358,366,371$

g̃iš-h̆ur

68,194

$\tilde{\mathrm{g}} \mathrm{i} \breve{\mathrm{s}}-\mathrm{ki} \tilde{\mathrm{g}}_{2}-\mathrm{ti}$

158,159

$\tilde{g} i \mathrm{~s}-n u_{11}$

ĞIŠGAL-di

304,344

ha-mun

265

i-lu 41, 97, 230, 234, 235, 236, 237, 330

i-lu-bala $\tilde{g}-d i$

234

i-lu-di

234

i-lu-lam-ma

$235,236,303$

i-lu ša $\mathrm{s}_{3}-n e-s ̌ a_{4}$ 234

i-si-iš

$67,241,300,301$

$\mathrm{i}_{3}-\mathrm{du} \mathrm{u}_{8}$

119, 141, 166, 168, 169, 172

$\mathrm{i}_{3}-\tilde{\mathrm{g}} \mathrm{i} \check{\mathrm{s}}$

$20,102,135,141$

igi-nu( $\left(-\mathrm{du}_{8}\right)$

$38,86,195$

im-gid $2-d a$

288,335

inim-bal-bal

$17,296,373$

$\mathrm{ka}_{2}$

41, 182, 208, 209

$\mathrm{kad}_{4}$

96

kal-kal

281,282

$\mathrm{kaš}-\mathrm{de}_{2}-\mathrm{a}$

$102,136,138,139,176$

kes $\check{s}_{2}-d a$

$18,57,173$ 
ki-šu ${ }_{2} \quad 72,76,250,269,270,272,273$, 274, 277, 279, 343, 348, 349, 350, 351, 365,369

$\mathrm{ki}-\mathrm{du} \mathrm{u}_{12}$ 348

ki-gub-ba 287

ki-lukur $163,167,174$

ki-ru-gu $276,146,227,230,233,248$, $250,267,269,270,272,278,279,280$, 281, 283, 284, 320, 321, 338, 343, 345, $348,349,350,351,365,369,371$ (munus) kisal-luh 141, 142, 145, 222 $\mathrm{ku}_{3}$-babbar 59, 113, 132, 208, 209, 218 $\mathrm{kus}_{7} \quad 141,145,149$ la-bar 58 liliz/li-li-is $2 / 3 \quad 67,68,72,73,76,129$, 159, 177, 178, 290, 342, 350, 368

$1 \mathrm{u}_{2}$-bala $\tilde{g}$ 97

$1 u_{2}$-dig̃ir-ra 172

$1 u_{2}$ eme-sal 84

$1 u_{2} \operatorname{er}_{2}-\mathrm{pad}_{3}$ 240

$l u_{2} e_{2}-r a$ 240

$1 u_{2}-g u b-b a$ $50,60,141,145,379$

$1 u_{2}-i-1 u$ 234

$\mathrm{lu}_{2}$ igi-bal 195, 208 $1 \mathrm{u}_{2}-\mathrm{kurun} \mathrm{n}_{2}-\mathrm{na}$ 217,220

$1 \mathrm{u}_{2}$-lunga $124,141,145,152,167$ $1 u_{2}-\check{s ̌ r}_{3}(-r a)$ 32,230 $l u_{2}-\check{s ̆}_{3}-s a \tilde{g}$ 266

lukur $47,61,62,99,163,165$, $166,168,169,172,177,186,364$

${ }^{\text {zid3 }} \mathrm{ma-ad-g̃a} \mathrm{a}_{2}$ 207

maš-gid $2-$ gid $_{2}$ 26 me-ze 2 41, 73, 76, 77, 249, 250, 342, 350 muš-lah ${ }_{4}$ 53,172 munus-nar $\operatorname{murub}_{(2)}$ $22,103,194$ $\mathrm{na}_{4}-\mathrm{gal}{ }^{\mathrm{d}} \mathrm{Utu}$ $198,200,201$ nagar 158,159 nam-nar $1,2,37,112,113$,

$114,173,252,254$ nam-šita 4 124 nam-šub nar- $\mathrm{a}_{2}-\mathrm{na}_{2}$ 16 nar-a-u $u_{3}$-a $18,39,46,47,48,110,121$, $124,125,368,373,376$

nar.bulug 40,112

nar.e $e_{2}$.bala $\tilde{g}$ 40

nar eš $\check{3}_{3}-\mathrm{a}$

nar-gal 15, 16, 20, 21, 22, 23, 24, 26, 28 , $30,31,32,35,45,46,48,49,50,51,52$, 54, 107, 109, 110, 114, 115, 119, 121, $124,125,129,130,141,144,147,166$, $168,169,170,171,174,191,192,220$, $268,368,373,375,377,379$

$\begin{array}{lr}\text { nar } \mathrm{gu}_{3} \mathrm{dug}_{3} \text {-ga } & 16,32 \\ \text { nar } \mathrm{gu}_{3} \text { silim-ma } & 16,32 \\ \text { nar } \mathrm{gu}_{3}{ }^{?} \text { nu-dug } & \text {-ga }\end{array}$ nar hal(-1a)-tuš-a 17, 18, 26 nar igi lugal $16,17,19,21,156$ nar igi suhur-la 16,17 nar inim-bal-bal 16,32 nar-lugal 21 nar-lukur $\quad 145$ nar-munus $\quad 176$ nar pa-ah-tuš(-a) 27 nar pad $_{3}-\mathrm{da}$ 17,18 nar $\mathrm{ra}_{2}$-gaba $18,131,133,376$ nar-sa $16,20,25,39,42,44,45,46,48$, $100,107,108,110,121,122,124,125$, $131,170,172,175,192,193,197,202$, 205, 370, 378, 379

nar ša uppîm 50 nar šir 3 291 nar-tur(-tur) $15,16,18,26,27,44$ nar um-mi-a $171,172,373,376$ nar $\mathrm{ze}_{2}-\mathrm{za}$ 16,17 NE.NE-g̃ar 130,147 $n i \tilde{g}_{2}-a b_{2}$ 137,139 ni $\tilde{g}_{2}-g i_{6}$ 205 ni $\tilde{g}_{2}-\mathrm{gul}$ 200 ni $\tilde{g}_{2}-s u_{3}-a$ 162

ni $\tilde{g}_{2}-s ̌ u$ 49, 101 nin-dig̃ir 61, 172 nu-banda 3 149 


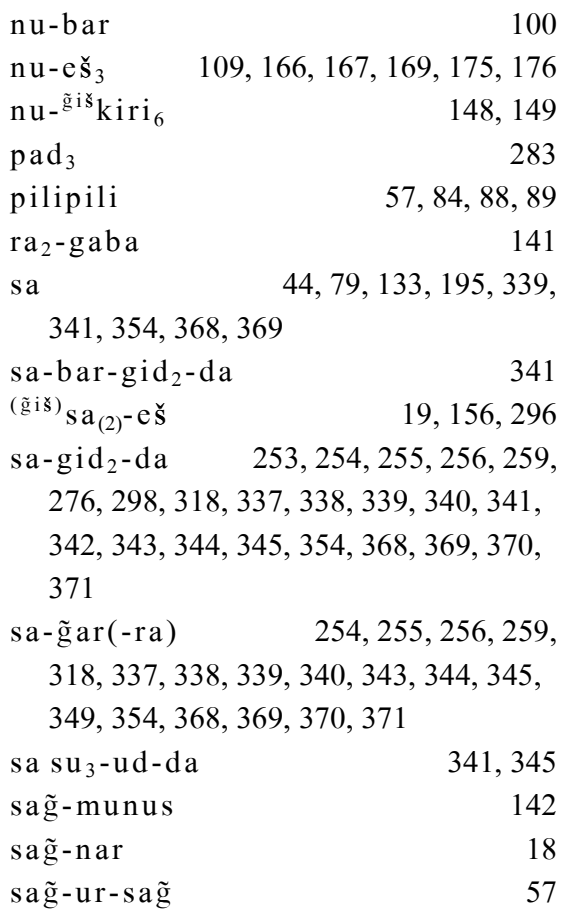

sur $_{9}$

58

ša ${ }_{3}$-ba-TUKU $\quad 11,255,269,270,337$, 338,342

g̃iššs ${ }_{3}$-TAR 19, 25, 28, 156, 160, 161, 263 $\breve{s} \mathrm{a}_{4}$ $96,257,262,276,301$

še $\mathrm{m}_{3-5}$ $27,42,43,47,68,72$, $73,77,85,89,137,240,244,249,250$, $257,268,284,290,364,368$

šid/šid 3

šir $_{3}$

$227,228,229,230,231,232$,

$233,234,235,237,239,252,262,264$,

$265,267,268,277,280,281,282,283$,
287, 292, 307, 311, 315, 338, 353, 360, $361,362,365,366$

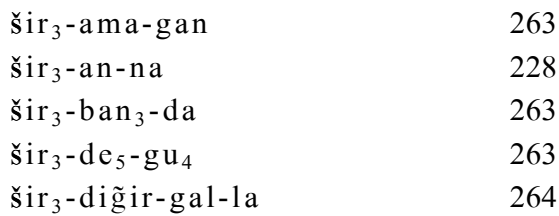

šir $_{3}$ dug $_{4}-$ dug $_{4} \quad 228,347,353$

šir $_{3}$-gal 263

šir $_{3}-$ gid $_{2}$-da $\quad 263,264,274,275,276$

šir $_{3}-$ guruš-dab $b_{5}$-ba $\quad 263$

šir ${ }_{3}$-ha-mun 262,264, 265

šir $_{3}$-i-lu-di 234

šir ${ }_{3}-\mathrm{kad}_{4}(-\mathrm{da}) \quad 96,265$

šir $_{3}$-kal-kal 264

šir $_{3}$-kug 262, 264, 266, 267

šir ${ }_{3}$ kummi $\quad 307,316,366$

šir $_{3}-\mathrm{ma}_{2}-$ gur $_{8}$-re $\quad 263$

šir $_{3}$-mah 263

šir $_{3}(-$ ra) nam-en-na $\quad 75,264$

šir $_{3}$-nam-erim 2 -ma 263,264, 272

šir ${ }_{3}$-nam-gala 262,264, 268

šir ${ }_{3}$-nam-g̃ešbun 263, 265

šir ${ }_{3}$-nam-gi-na 265

šir $_{3}$-nam-keš 2 -da $\quad 263$

šir $_{3}$-nam-nar 262,264,265, 268

šir ${ }_{3}$-nam-sipa-da 264

šir ${ }_{3}$-nam-šub 247, 263, 264, 270

šir ${ }_{3}$-nam-ur-sag̃-g̃a $\quad 264,278,280$

šir $_{3}$-nam-uru-na 264, 343

šir $_{3}$-RI-gu

šir ${ }_{3}$-sa g $\quad 97,98,263,264,265,353$

šir $_{3}$ silim 287

šir $_{3}-$ śa $_{3}-$ hul $_{2}-1 \mathrm{a} \quad 30,263,283$

šir $_{3}-{ }^{\tilde{g} i \mathrm{~s} \breve{s} a_{3}-k a s k a l-1 a} \quad 263$

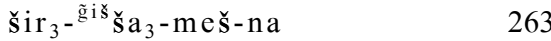

$\check{s ̌ i r}_{3} \operatorname{tana/itti(m)} \quad 307,309,311,312,316$, 366

$\mathrm{sir}_{3}-\mathrm{za}_{3}-\mathrm{mi}_{2}-\mathrm{du} \mathrm{u}_{11}-\mathrm{ga} \quad 230$

šita-eš $\check{S}_{3} \quad 140,141$

šitim 141, 145

šu-i $\quad 121,141,148,149,208$ 


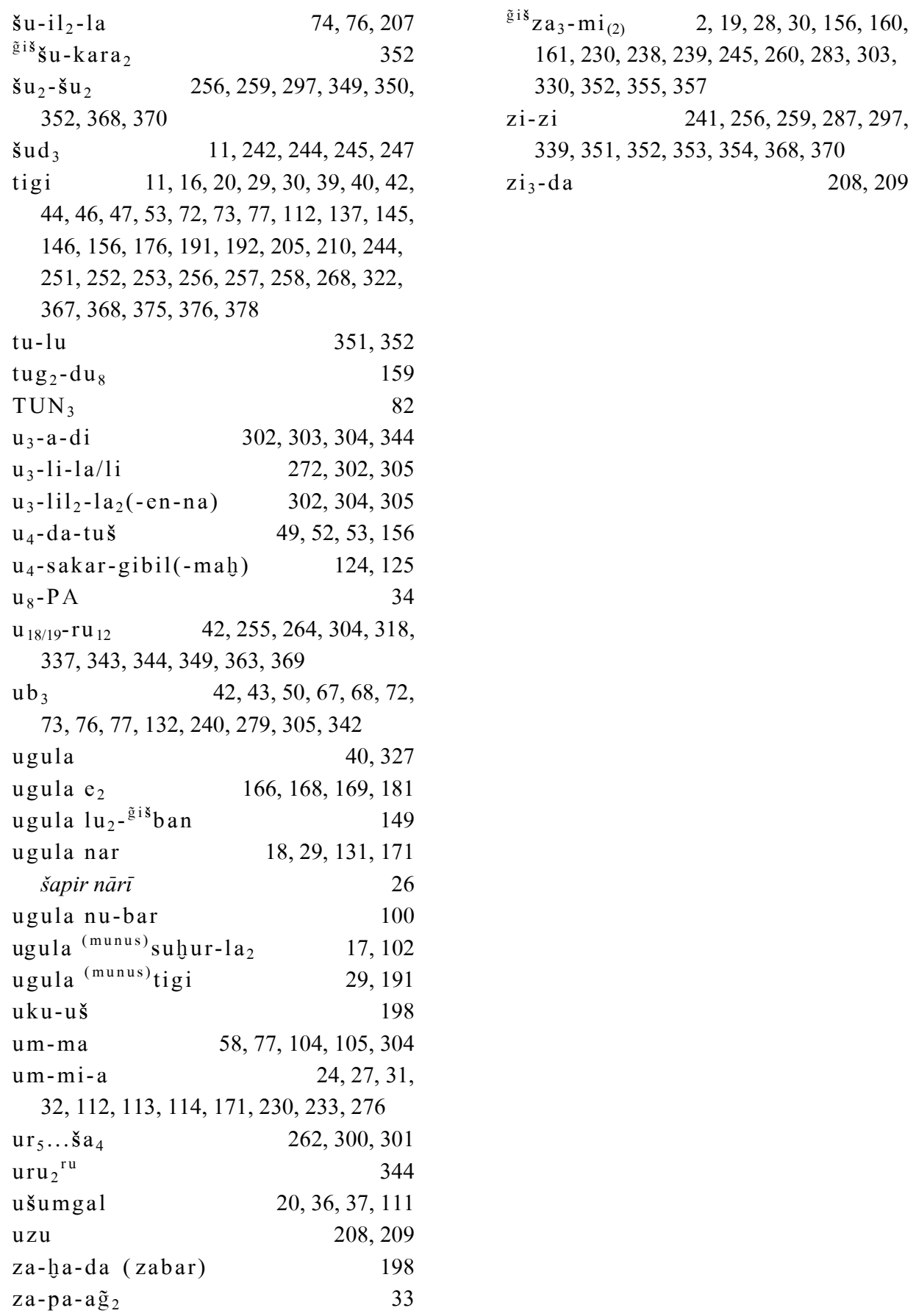




\section{Wörter: Akkadisch}

$a b a b d \hat{u}(m)$

$120,161,204$

$\operatorname{abātu}(m)$

abi șābi(m)

ahulap

ajjābu(m)

alālu

aluzinnu(m)

209, 215, 261, 375

amerakūtum

361,364

arāmu

$\operatorname{assinnu}(m)$

316,379

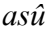

$\bar{a} \underline{s} \hat{u}$

āšipu

a/eštalītu(m)

a/eštalu $(m)$

(h) $a z / s \hat{u}$

babbilūtum

bakû $(m)$

$\operatorname{bakkīu}(m)$

$\operatorname{bikitu(m)}$

$\operatorname{barû}(m)$

$\operatorname{biltu}(m)$

$\operatorname{dimtu}(m)$

em/bbūbu(m)

enû $(m)$

erēbu $(m)$

èrib bìtim

e/iršannišakku

erubbātum

eššěšum

$\operatorname{gag} \hat{u}(m)$

gennum

$\operatorname{gerrānu}(m)$

halālu

halhallatu(m)

hallatušš̂u
56

57

$87,104,106,305,335,336$,

$$
72,159
$$$$
72,159
$$

84, 89, 100, 207, 209, 310,

56

40, 289, 309, 310, 366

27

$13,27,46,53$

17

190, 200

241

104

241,334

$37,189,213,245$

25,188

241,334

$15,260,261,329,330$

267

100, 194, 204

291

139

$299,311,312,367$

$99,177,215$

$354,355,356,370$

137,241

330

$50,77,249,285,368$

26,27 harimūtum

92, 101, 181, 198, 199,

200, 202

$\operatorname{harimtu}(m) \quad 14,91,92,100,101,199$

hassûm

huhupal

71

hupp $\hat{u}(m)$

$14,23,46,49,50,51$,

53, 130, 141, 145, 146, 207, 209, 214 , $324,375,379$

ibru(m)

324

$\operatorname{igis\hat {u}}(m)$

$23,61,108,184$,

190, 191, 218, 220

ikribu(m) 188, 189, 242, 244, 245, 307

ilku(m)

$25,29,52,61$

illatum

214

inhu

$71,92,100,143,307,315$,

316, 334, 364, 366

iptin(n)um

139

irtu(m)

$238,260,307,328$,

$329,330,345,353,378$

isqum

190

išartu(m)

kalûtum

$86,195,268$

$\operatorname{karābu}(m)$

74,244

$\operatorname{kaspu}(m)$

198

kașāru(m)

96,102

$\operatorname{katāmu}(m)$

$72,82,349$

kezertu(m) 14, 16, 17, 91, 101, 102, 103,

141, 145, 146, 198, 199, 200, 221, 222

kinūnu (m)

138

kisurrātu(m)

234

kulmāšum

41

kulmašitu(m)

$14,41,91,100,205$

kulu'u

84,86

kuтmu

315

kunukku(m)

$198,200,201,202$

kurgarrû $(m)$

$57,69,70,71,84,85$,

$88,89,92,100,104,207$

kuššsum

lallār $(t) u(m)$

265,334

lurum

84

mahāru(m)

malīlu(m)

261,330 


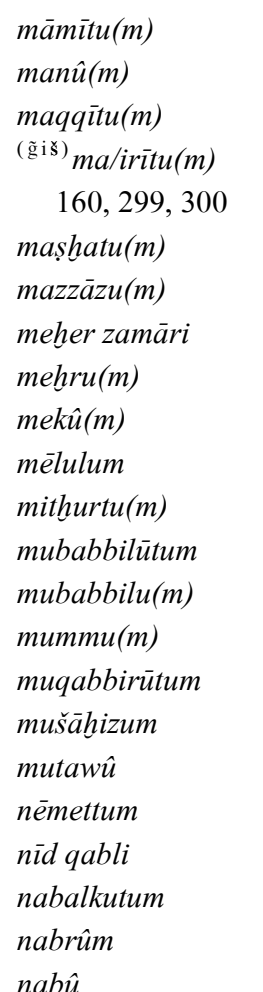

272

267

134

$19,25,28,30,156$,

207

287

345

$328,345,369,371$

304

50,333

265

198,200

50,200

$53,60,76,334,363$

91

$53,103,114$

17

220

330

50

219

18

nadìtu(m)

$14,26,91,99,100,177$,

180, 181, 182, 183, 184, 190, 191, 193,

194

namūtu(m)

$\operatorname{napištu(m)}$

narû

$\operatorname{nas} \bar{a} h u(m)$

nasāsu(m)

nemlû

$n e^{\prime} \hat{u}(m)$

nigûtu(m)

nindabbum

nissatu(m)

$n u b \hat{u}(m)$

пиzzити

pāru(m)

$315,319,366,367$

pìt bābim/bìtim

pìtum
229

352

232

33

352

234

137, 139

232,241

234

304

$307,311,312,314$,

137

330 $\operatorname{parșu(m)} \quad 45,59,91,101,179,181,182$, 183, 184, 187, 188, 189, 192, 193, 195, 196, 197, 198, 199, 200, 201, 202, 204, 220, 221, 370, 374

purìdu 27

puršumu

61

qabû $(m)$

245

qadištu(m)

91, 92, 108, 186, 188, 201

qān gițtu

260

qarāšu $(m)$

207

$\operatorname{qardu}(m)$

314

qebèru $(m)$

199

$q u b b \hat{u}(m)$

234

$q u \operatorname{lm} \hat{u}(m)$

198, 200, 202

qurādu

324

$\operatorname{raggu}(m)$

273

redî $(m)$

198, 199

rēdûtu(m)

$\operatorname{rigmu}(m)$

181, 198, 199, 200, 202

rǐstu(m)

33

112

ru'ūtum

${ }^{(\text {g̃ iš) }} \operatorname{sabitu(m)~}$

198, 200, 202

$156,299,300$

sagarrûm

338

338

sagiddûm

263

sagummargî

43

sapādu

sattukkû

$47,55,121,164,166,167$, 169, 171, 172, 176

sekretum

159,160

sihpum

$349,350,356$

sipittu(m)

27, 287

sirqu

207

$\operatorname{sarāhu}(m)$

227, 265

sirhu

94, 97, 266

șehru(m)

26

suhāru(m)

52, 194

ša em/būbim

13

šagigur(r)ûm

194

šallurānu

236

šaqìtum

193

šas û

143

šassā'u 


\begin{tabular}{|c|c|}
\hline šēru(m) & $227,348,350$ \\
\hline šitru(m) & $41,227,260,329,368,378$ \\
\hline šulpu $(m)$ & 261 \\
\hline $\operatorname{takaltu}(m)$ & 82 \\
\hline $\operatorname{takribtu}(\mathrm{m})$ & $74,91,241$ \\
\hline tānīhu $(m)$ & 241 \\
\hline tanittum & 309 \\
\hline tarāšsim & 207 \\
\hline $\operatorname{târu}(m)$ & 195 \\
\hline tassistum & $137,139,143,205,210,239$ \\
\hline tašrihtum & 16,287 \\
\hline $\operatorname{tazzimtu}(m)$ & 232,304 \\
\hline telītum & 94 \\
\hline tereș qātim & 207 \\
\hline Terītum & 204 \\
\hline tigidlû & $103,112,113,236$ \\
\hline timbuttum & 94 \\
\hline tìru & $206,207,209$ \\
\hline $\operatorname{teb} \hat{u}(m)$ & 360 \\
\hline ugbabtum & 163 \\
\hline unnīnu $(m)$ & 241,290 \\
\hline unūtum & 60 \\
\hline wașûm & 205 \\
\hline zabardabbû $(n$ & 202 \\
\hline $\begin{array}{l}\text { zamāru(m) } \\
286,307,3\end{array}$ & $\begin{array}{l}227,234,237,238, \\
10,327\end{array}$ \\
\hline zamār adapu & 302 \\
\hline zamār alālim & 210 \\
\hline zamār bēlūti & 75,265 \\
\hline zamār šèri & 227,302 \\
\hline zammāru(m) & 13 \\
\hline zammeru(m) & 13 \\
\hline $\operatorname{zappu}(m)$ & 59,198 \\
\hline zarriqum & 17 \\
\hline zennum & $354,355,356,370$ \\
\hline zikrum & 160 \\
\hline
\end{tabular}

\section{Texte: Urkunden und Briefe}

AbB 1, 11

59,60

AbB 1, 72

197

AbB 1, 89

62

AbB 2, 34

$102,145,221$

$\mathrm{AbB} 2,67$

188

AbB 2, 73

$62,179,183$

AbB 2, 89

179,184

AbB 4, 12

AbB 4, 14

$18,20,25,131,133,149$

AbB 4, 45

$20,25,133,149$

AbB 4, 62

50

AbB 5, 135

$20,25,133,149$

AbB 6, 22

$102,145,221$

AbB 6, 29

91

AbB 6, 61

179,183

$$
140,146,159,172,179,184,253,270
$$

AbB 6, 144

$13,15,261$

AbB 6, 174

AbB 7, 17

197

AbB 7, 153

190

AbB 8, 3

61

AbB 8, 109

$23,52,130$

AbB 9, 51

91

AbB 9, 166

56,92

AbB 9, 188

$20,25,133,149$

AbB 9, 193

$23,49,130$

AbB 10, 1 58, 61, 108, 179, 184, 190, 195, 200

AbB 10, 124

56,93

AbB 11, 71

197

AbB 11, 93

$66,91,179,183$

AbB 11, 101

$21,37,47,62,74,126,179$, 237

AbB 11, $107 \quad 19,41,91,155,156,157$, $160,179,187,207$

AbB 11, 167

AbB 12, 141

AbB 12, 178

$59,60,197$

AbB 14, 50

$155,218,376$

AnOr 7, 372 
Anhänge und Verzeichnisse

\begin{tabular}{|c|c|c|c|}
\hline ARM 9, 90 & 138 & BIN 9, 348 & $28,158,159,160$ \\
\hline ARM 9, 175 & 104 & BIN 9, 350 & $28,158,159$ \\
\hline ARM 10,140 & 103 & BIN 9, 352 & $28,156,157,158,161$ \\
\hline $\operatorname{ARM}(\mathrm{T}) 25,1$ & 50 & BIN 9, 353 & 156,157 \\
\hline ARN 4+ & $18,172,173,174$ & BIN 9, 354 & 156,157 \\
\hline ARN 5 & 173 & BIN 9, 412 & 160 \\
\hline ARN 23+ & $29,61,165,167,171$ & BIN 9, 415 & $19,110,157$ \\
\hline ARN 29 & 62,165 & BIN 9, 417 & $28,158,159$ \\
\hline ARN 35 & 170,174 & BIN 9, 433 & 162 \\
\hline ARN 41 & 174 & BIN 9, 441 & $28,158,159$ \\
\hline ARN 44 & $61,107,165,166,168,169$ & BIN 9, 444 & $28,156,160$ \\
\hline ARN 57 & 173 & BIN 9, 445 & $73,157,158,162$ \\
\hline ARN 58 & 173 & BIN 9, 451 & $28,158,159$ \\
\hline ARN 172 & 198 & BIN 9, 458 & 19,156 \\
\hline ARRIM 4 & 131 & BIN 9, 485 & 160 \\
\hline AUCT 5,36 & 59 & BIN 9, 491 & 157 \\
\hline BA 5,491 & 194 & BIN 9, 496 & $19,28,156,157,160,300$ \\
\hline Bab. 7, 45 & 131 & BIN 9, 522 & 158 \\
\hline Bab. 7, 46 & 130,147 & BIN 9, 532 & 29 \\
\hline BaM 23, 136 & 25,144 & BIN 10,75 & 162 \\
\hline $\mathrm{BaM} 24,151$ & 25 & BIN 10, 82 & $28,156,158,160,161$ \\
\hline BBVOT 1,86 & 52 & BIN 10,87 & 156 \\
\hline BBVOT 1,91 & 213 & BIN 10, 104 & $28,156,158,160,161$ \\
\hline BBVOT $3,64 /$ & 128,129 & BIN 10, 186 & 160 \\
\hline BE $6 / 2,26$ & $61,64,109,165,166,167$ & BIN 10, 256 & 28,158 \\
\hline $170,175,17$ & & BM 29638 & 206,209 \\
\hline BE $6 / 2,42$ & $61,109,165,166,167,175$ & BM 80371 & 190 \\
\hline BE $6 / 2,44$ & $109,168,169$ & BM 81591 & 190 \\
\hline BE $6 / 2,48$ & $45,170,175$ & BM $82437 \mathrm{a} / \mathrm{b}$ & 180 \\
\hline $\mathrm{BE} 6 / 2,63$ & 29,171 & \multirow{2}{*}{\multicolumn{2}{|c|}{$\begin{array}{c}\text { CM } 33,158 f f \quad 22,25,42,50,90,125,128, \\
130,131,133,136,141,142,239,378\end{array}$}} \\
\hline BE $6 / 2,86$ & $44,45,192,193$ & & \\
\hline BE $6 / 1,119$ & 61,183 & Cornell 6 & 61 \\
\hline BIN 2, 75 & 120,121 & Cornell 18 & 61 \\
\hline BIN 7, 65 & $59,152,153$ & $\mathrm{CT} 4,8 \mathrm{~b} \quad 44$ & $45,193,196,197,198,200$, \\
\hline BIN 7, 68 & $59,152,153$ & 204 & \\
\hline BIN 7, 69 & $17,19,156$ & CT $4,15 \mathrm{c}$ & $65,101,199$ \\
\hline BIN 7, 212 & 61,152 & CT $4,50 \mathrm{a}$ & 177,193 \\
\hline BIN 9, 185 & 156 & CT $6,23 \mathrm{~b}$ & 25,194 \\
\hline BIN 9, 253 & 156,300 & CT $8,21 \mathrm{c}$ & $23,29,40,191$ \\
\hline BIN 9, 257 & 19,156 & CT $8,41 \mathrm{~b}$ & 194 \\
\hline BIN 9, 328 & 160 & CТ 45,15 & 185,190 \\
\hline BIN 9, 334 & $156,157,300$ & CT 45,62 & 61,183 \\
\hline
\end{tabular}




\begin{tabular}{|c|c|c|c|}
\hline $\mathrm{CT} 45,77$ & 65,206 & IB 1774 & 153 \\
\hline \multirow{2}{*}{\multicolumn{2}{|c|}{$\begin{array}{l}\text { CT } 45,84 \quad 45,59,192,193,195,196 \\
\quad 197,198,200,204,250\end{array}$}} & IB 1829 & 151 \\
\hline & & JAOS 98, 256 & 160 \\
\hline \multirow{2}{*}{$\begin{array}{c}\text { CT } 45,85 \\
351\end{array}$} & \multirow[t]{2}{*}{$65,86,195,206,207,208$} & JCS 2,38 & 206 \\
\hline & & JCS 2, 109 & 26,194 \\
\hline CT 45,89 & 65,206 & JCS 3, 185a & 173,174 \\
\hline CT 47,80 & 52,207 & JCS $3,185 b$ & 18,173 \\
\hline \multirow{2}{*}{\multicolumn{2}{|c|}{$\begin{array}{cc}\text { СТ } 48,45 \quad 66,178 \\
198,199,200,202\end{array}$}} & JCS 4, 111-112 & $131,133,134,135,136$ \\
\hline & & JCS 11,20 & $55,62,65,180$ \\
\hline CT 48,54 & 191 & JCS 11,38 & 65 \\
\hline CT 48,76 & 61,183 & JCS 11,107 & 61 \\
\hline Delaporte 19 & 1 Nr. 14 & JCS 20,45 & 168 \\
\hline Di 113 & 189 & KTT 86 & 55,61 \\
\hline Di 310 & 199 & KTT 130 & 55,61 \\
\hline Di 620 & 184 & MAD 1, 336 & 94 \\
\hline Di 1499 & 186 & MARI 3, 87 & 138 \\
\hline Di 1801 & 189 & MCS 5, 115 Nr. 1 & 156 \\
\hline Di 1804 & $182,197,201$ & MDP 22, 52 & 52 \\
\hline Di 1897 & 186 & MHET I/1, 13 & 188 \\
\hline Di 1996 & 59 & MHET I/1, 42 & 108 \\
\hline Di 2015 & 185 & MHET I/1, 43 & 191 \\
\hline Di 2189 & 187 & MHET I/1, 44 & 191 \\
\hline Di 2231 & 189 & MHET I/1, 51 & $25,191,194$ \\
\hline Ferwerda 198 & 5 (SLB 5) Nr. 24 & MHET I/1, 52 & 108,204 \\
\hline FM 9, 15 & 115 & MHET I/1, 53 & $25,188,191,194$ \\
\hline FM 9, 56 & 53 & MHET I/1, 54 & 25,194 \\
\hline Geller 2003 & s Kienast 111) & MHET I/1, 56 & 25,191 \\
\hline HLC 2 & 56 & MHET I/1, 60 & $25,191,194$ \\
\hline HUCA $34,1 f$ & s. CM 33, 158ff & MHET I/1, 63 & $108,202,203$ \\
\hline IB 1006a & 161 & MHET I/1, 64 & $198,199,200$ \\
\hline IB 1292 & 151 & MHET I/1, 65 & $65,101,181,198,199$ \\
\hline IB 1293 & 156 & 200,202 & \\
\hline IB 1295 & 151 & MHET I/1, 66 & 101,199 \\
\hline IB 1304 & 156 & MHET I/1, 69 & 59,60 \\
\hline IB $1515+$ IB 1 & $112,114,152$ & MHET I/1, 74 & $188,189,200,201$ \\
\hline IB 1536 & 153,154 & MHET I/1, 78 & 101,199 \\
\hline IB 1538 & 153 & MHET I/1, 82 & 179 \\
\hline IB $1539-40$ & 153 & MHET I/1, 92 & 188 \\
\hline IB 1541 & $88,109,115,153,154$ & MHET I/1, 94 & $59,60,190$ \\
\hline IB 1554 & 76,154 & MHET I/1, 95 & 183 \\
\hline IB 1669 & 154 & MHET I/1, 96 & 185 \\
\hline IB 1700 & 151 & MHET I/1, 98 & 197 \\
\hline
\end{tabular}


MHET II, 40

MHET II, 458

MHET II, 536

MHET II, 544

MHET II, 545

MHET II, 595

MHET II, 626

MHET II, 633

MHET II, 895

MHET II, 898

MHET II, 909

MHET II, 928

NATN 853

NG II 110

Nisaba 19, 296

NYPL 47

OBTI 140

OBTI 182

OBTR 92

OLA 21,4 183, 204

OLA 21, 67

OLA 21, 71

Ontario 2, 326

PBS $8 / 1,2$

PBS $8 / 1,11$

PBS $8 / 1,81$

PBS $8 / 1,89$

PBS 8/1, 94

PBS 8/2, 116/116a

PBS 8/2, 142

PBS 8/1, 169

PBS 8/2, 176

PBS 8/2, 195

PBS 8/2, 218

PBS 8/2, 224

PBS 8/2, 264

PBS 13, 61+

RA 8, 129

RA 69, 122

RA 82, 28

RA 85,38
193

193

191

$59,61,190$

59,190

193

183

61,191

204

183

61,184

61,190

$105,240,261$

19

121,122

237

25

28

137

$45,58,61,65,77,100$,

194

$61,66,189$

171

s. ARN 4+

$59,62,165,167$

$170,174,175$

$61,62,165,167$

170,171

107,168

107, 168

s. ARN 23+

59

177

59,190

190

61,119

45,172

s. Delaporte $1911 \mathrm{Nr} .14$

$60,61,111,128,129$

$61,108,182,183,190,195$

131,132
RA 85,42

45, 193

RA 90, 125

25

60,217

RIAA 238

59,130

Riftin 20

171

SAOC 44, 95

SAT 1,118

$29,40,176$

27, 171

Sigrist 1984 Taf. 62

167,171

Sigrist 1984 Taf. 66

167

167

171

171

167

176

167

171

Sigrist 1984 Taf. 415

SLB 5

s. Ferwerda 1984

TCL 1, 130/131

186

TCL 1,145

61,182

65,182

TCL 1,168

TCL 1, 230

TCL 10, 34

TCL 10, 39

TCL 10, 45

TCL 10, 69

TCL 10, 97

TCL 10, 112

TCL 10, 123

TCL 11, 146

TCL 11, 148

TCL 11, 156

TCL 11, 162a

TCL 11, 174

TCL 11, 224

$55,65,182$

60,146

$131,132,146$

25,132

146

133

29, 131

74,91

20, 25, 45, 131, 133

130

61,130

130

133

133

TCL 11, 242

52

TIM 4, 10

168

62,154

TIM 5,26

TJA $55 \mathrm{f}$.

TJA 83f.

TJA 94

TJDB 84f.
$217,219,220$

62,217

221

214

59, 190 
TLB 1, 257

TRU 41

TSifr 4

TSifr $7 / 7 \mathrm{a}$

TSifr 9/9a

TSifr 10/10a

TSifr 12/12a

TSifr 23

TSifr 25

TSifr 27

TSifr 28

TSifr 30

TSifr 31

TSifr 40/40a

TSifr 41/41a

TSifr 42

TSifr 43/43a

TSifr 49/49a

TSifr 50a

TSifr 51a

TSifr 56/56a

TSifr 65

TSifr 66/66a

TSifr 93

TSifr 99

TUT 287

UET 3, 63

UET 3, 282

UET 3, 1113

UET 3, 1702

UET 3, 1745

UET 5, 95

UET 5, 96

UET 5, 160

UET 5, 191

UET 5, 248

UET 5,363

UET 5,440

UET 5, 453

UET 5,550

UET 5,561

UET 5, 592
60,217

125

121

61,119

$59,66,121$

148

148

108, 121

$59,60,121$

59,149

59, 148

148

59,148

107, 108, 148, 149

107,148

$59,60,149$

$59,60,149$

107,148

107,148

107, 148

107,148

107,148

107,148

119,124

59,148

56

27

99

27

161

161

$46,48,121,125$

61,119

$46,47,121,125$

$44,45,121,122,124$

60,119

22, 119

18

121,144

121,123

121

122
UET 5, 663

UET 5, 672

UET 5, 868

UTI 4, 2849

VS 7, 57

VS 7, 58

VS 7, 94

VS 7, 122

VS 7, 127

VS 7, 149

VS 7, 155

VS 7, 185

VS 8, 108/109

VS 9, 18

VS 9, 39

VS 9, 152

VS $13,80 / 80 a$

VS $18,8 \mathrm{a} / \mathrm{b}$

VS 22, 61

VS 22, 62

VS 29, 84

YBC 4936

YBC 6207

YBC 7262

YOS 5, 128

YOS 5, $16322,44,45,46,47,121,124$, $125,368,378$

YOS 5, 172

YOS 5, 191

YOS 5, 216

YOS 5, 235

YOS 8, 6

YOS 8, 13

YOS 8, 15

YOS 8, 19

YOS 8, 20

YOS 8, 25

YOS 8, 31

YOS 8, 36

YOS 8, 41

YOS 8, 45

YOS 8, 47
15,121

121,123

118

99

66, 212

66, 212

212

$59,213,214$

$49,50,214$

214

25, 214

213

29

66,190

$62,65,180$

$56,62,65,180$

65,128

186

60

60

181

52

131

129

131

129

131

$25,131,133,134$

131

25,131

131

131

131

131

131

131

131

131

131

131 
YOS 8, 48/48a

YOS 8,72

YOS 8, 153

YOS 12, 78

YOS 12, 225

YOS 12, 227

YOS 12, 297

YOS 12, 307

YOS 12, 325

YOS 12, 353

YOS 13, 12

YOS 13, 24

YOS 13, 33

YOS 13, 37

YOS 13, 43

YOS 13, 77

YOS 13, 88

YOS 13, 90

YOS 13, 94

YOS 13, 111

YOS 13, 168

YOS 13, 169

YOS 13, 174

YOS 13, 202

YOS 13, 203

YOS 13, 216

YOS 13, 217

YOS 13, 224

YOS 13, 232

YOS 13, 262

YOS 13, 266

YOS 13, 268

YOS 13, 289

YOS 13, 297

YOS 13, 314

YOS 13, 324

YOS 13, 325

YOS 13, 326+236

YOS 13, 329

YOS 13, 338

YOS 13, 348

YOS 13, 375
YOS 13, 388

YOS 13, 390

YOS 13, 401

YOS 13, 435

YOS 13, 471

YOS 14, 46

YOS 14,75

YOS 14, 246

YOS 14, 326

YOS 14, 333

YOS 14, 348

ZA 75, 189f
26

$15,26,28$

221

216

61,218

25

$23,24,25,26,29$

147

153

20, 26

131

154
217

213

220

217,220

217,220

$61,217,218,220$

61,217

221

213

52,215

217

197, 221

$60,217,218,220$

217

217

217

217, 220

217, 219

217,220

$217,218,219,220$

62,212

221

219, 220, 221

217

61, 217, 218

197

189,213

28

217, 219

222 


\section{Texte: Literarisch}

\begin{tabular}{lr} 
A Urume ime & 342 \\
Aabba huluha & 233 \\
Aba Huluhha & 248,249 \\
Abi'éšuh A & $345,348,371$ \\
Abzu Pe'ellam & 230,248 \\
Agušaya 307, 317, 319, 320, 321, 322, \\
\multicolumn{3}{l}{ 348, 349, 351, 365, 371, 377}
\end{tabular}

Ame Amašana

70

Ame Baranara

$228,231,233,266$

Anzû I

237

AoF 18, 9ff.

Asalluhi XA

s. Games Text

230

ASJ 12, $1 \mathrm{ff}$

67

ASKT S. 122 (=) OECT 6 pl. 19

330

Ašergita

216,342

Atramhasis III

237

Auszug des Ninurta

Bür-Sin $A$

Bür-Sin $A-B$

BA 2, 634

BE 31 Nr. 4

BM 47507

BM 86535

CBS 574

CBS 8534

CBS 11344+

262, 361

343,345

253

92

253

327

348

244

338

339

Cohen 1977 (ZA 67, 1ff)

Cohen 1981, Nr. 23

Cohen 1981, Nr. 60

Cohen 1981, Nr. 79

Cohen 1981, Nr. 88

Cohen 1981, Nr. 97

CT $15,1-2$

CT $15,3-4$

CT $15,5-6$

CT 15,18

CT $15,20 \mathrm{f}$

CT 15,22

CT 15, $26 f$.

CT 15,30

$91,201,271$

285

233,260

43

228

71,285

$322,323,366$

315,366

307

260

285

285

248

248
CT 21, 40-42

326,327

CT $36,41-42$

70,262

CT $36,43-44$

340

CT 42,15

250

CT 44,24

288

CT 58, $12 \quad 223,250,296,311,346,357$, $358,360,367,369$

CT 58,23 271

CT 58,70 288

Damgalnuna A 279

De Meyer 1982a (Fs Kraus 271ff) 188, 189, 245

Der 'Treue Liebhaber' 296, 331, 332

Der leidende Gerechte 333, 334, 362, 363

Der Vater und sein missratener Sohn 1

Dingir paea

342

Dumuzi und Enkimdu

293, 294, 296

Dumuzi-Inana A

294, 295

Dumuzi-Inana $A-G$

294

Dumuzi-Inana B1

348

Dumuzi-Inana $C$

$31,295,357$

Dumuzi-Inana E

293, 294, 295

Dumuzi-Inana $F$

294,357

Dumuzi-Inana $F_{l}$

270

Dumuzi-Inana $H$

$252,253,294,338$

Dumuzi-Inana I

298

Dumuzi-Inana J $\quad 18,129,228,230,231$, 233, 266, 286, 287, 340, 347, 353, 360, 370,378
Dumuzi-Inana $M$

Dumuzi-Inana $O$

Dumuzi-Inana $P$ 295

Dumuzi-Inana $R$

338

Dumuzi-Inana $T$

298,357

Dumuzi-Inana $X$

$253,260,297,338$

Dumuzis Traum

233,281

E Turgin Niginam

43

Ebeling 1948 (Or 17, 420) 55, 72, 350, 351

Edubba B

53

Edubba-Brief 3.3.18

114 
Ein Mann und sein Gott 74, 96, 290, 291, 333, 334, 363, 378

Ekur Hymne

338,349

Elegie an Nawirtum

Elum gusun

234, 266

261

268

Emerkar und Aratta

Enemani ilu ilu

249,342

Enki und Ninhursag

Enki und Ninmah

92,235

$20,36,37,39$

Enki und die Weltordnung $\quad 72,236,252$, 257, 267

Enkis Reise 31,77, 230, 267

Enkitalu und Enkiheg̃al 231, 252, 257, 277, 278

Enlil A

Enlil und Sud

266,267

Enzu Samarmar

43

Eridu Klage

$265,267,284,349$

Erra I

237

Eturgin Niginnam

70

Examenstext A 17, 94, 264, 267, 343, 344, 349

Fluch über Akkade $58,71,73,76,77,84$, 105, 249, 258, 259, 287, 342

Fs Kraus $271 \mathrm{ff}$

Fs Sjöberg $321 \mathrm{ff}$

Games Text

s. De Meyer 1982a

s. Lambert 1989

Genf 16056

Gilg. VI

44,333

328

103

Gilgamesch und der Himmelsstier $\quad$ 21, 30

Gottesbrief $H$

291

Gudam-Erzählung

Gudea A

$21,30,280$

253,318

Gudea B

338

Gudea St. B v

Gudea St. B viii

$73,76,104$

229

Gudea St. L

31

Gudea Zyl. A vi/vii

Gudea Zyl. A vii

Gudea Zyl. A xxiv

Gudea $Z y l$. A xxvii

Gudea Zyl. B iv
Gudea Zyl. B x

Gudea Zyl. B xiv

$30,31,36,111$

Gudea Zyl. B xv

280

20,36

Gudea Zyl. B xviii/xix

20

Gungunum $A$

Gungunum B

$253,255,363$

125

229

Hammurabi $A$

Hammurabi $B$

Hammurabi $C$

$128,242,243$

48

242

Hammurabi D

273

HAV pl. 1 Nr. 1

31

Hendursag̃a $A$

HS 1884

$90,323,325,366,374,378$

IB 1537

153

Ibbi-Suen $A$

$230,253,338$

Ibbi-Suen $B$

$268,269,270$

Ibbi-Suen $C$

253,343

Ibbi-Suen $D$

303

Iddin-Dagan A 30, 31, 71, 278, 279, 280, 281, 283, 320, 321, 365, 378

Iddin-Dagan C

$253,255,343$

Iddin-Dagan D

273, 274

Immal Gudede

233

Inana $A$

294

Inana $B$

$87,234,239,267$

Inana $C$

Inana $E$

53, 230, 235, 309, 313

Inana $G$

253, 338

Inana I

270, 271, 272, 293

$270,271,272$

Inana und Bilulu

230, 234, 304

Inana und Ebih

$71,72,88,236$

Inana und Enki

$73,89,284$

27, 229

Inana und Šukaletuda

$56,69,70$,

Inanas Gang in die Unterwelt

$84,85,89,92,260,342$

ISET I 223

288

Išbi-Erra C

$253,255,318,340$

Iškur $A$

253

Išme-Dagan $A(+V) \quad 16,18,21,24,31,32$, 228, 229, 230, 231, 232, 258, 276, 295 , 299, 300, 301, 348

Išme-Dagan B 


$\begin{array}{lr}\text { Išme-Dagan } C & 253,338 \\ \text { Išme-Dagan } E & 294,295 \\ \text { Išme-Dagan F-H } & 253 \\ \text { Išme-Dagan I } & 252,253,254 \\ \text { Išme-Dagan } J & 235,294 \\ \text { Išme-Dagan } K & 338 \\ \text { Išme-Dagan L-N } & 125,253 \\ \text { Išme-Dagan } O & 253 \\ \text { Išme-Dagan } P & 253 \\ \text { Išme-Dagan } Q & 254 \\ \text { Išme-Dagan } U & 253 \\ \text { Išme-Dagan } W & 267 \\ \text { Išme-Dagan } Y & 253 \\ \text { Išme-Dagan } Z & 32,229 \\ \text { Ištar Baghdad } & 333,334 \\ \text { Ištar Louvre 307, 309, 310, 312, 313, 316 } \\ \quad 324,366,378,379 & 69 \\ \text { Ištars Höllenfahrt } & \\ \text { JCS 34, 76 }\end{array}$

JCS 34, 76

295

JCS $39,37-48$

s. Michalowski 1987

JCS 39, 44

288

KAR $115+$

101,103

Keš Tempel-Hymne

30,31

Klage Inanas von Unug

95

Lambert 1982, $173 \mathrm{ff}$

173

Lambert 1989 (Fs Sjöberg 321ff) 333, 334

Letter Collection $B$

35

Lied vom Ochsen

303

Limet 2000

285

Lipit-Eštar B 234,355

Lipit-Eštar $C$

Lipit-Eštar D

$255,341,343$

Lipit-Eštar E $253,254,255,343,345$

Lipit-Eštar $G$

$268,269,270$

Lipit-Eštar H

253

303

LKA 70

Love Lyrics BM 41005

Ludlul

330

71

330

Lugale

275

Lulal-Hymne (HAV 431 No. 5)

Luma A

274

MAD V 8
Martu A 31, 267, 268, 274, 275, 276, 280

Martu B

303

Michalowski 1987 (JCS 39, 37ff) 288

Monkey Letter

35,115

Mugig ana

284

N 3089

243

Nanaja und Muati (MIO 12, 52f.) 331, 362

Nanna A

234

Nanna $B$

Nanna $C$

267,294

Nanna E

125

Nanna F

Nanna $H$

$253,343,345$

Nanna I

253,338

Nanna J

303

Nanna K

$270,271,272$

Nanna L

$125,255,268,269,343$

Nanna/Sîns Reise

Nanna-Hymne N 1542

Nannayas Tod

265

Nanše A $\quad 24,30,31,137,230,265,267$, 268

Nanše B

17,18

Nergal $C$

$230,253,338$

Nergal E

253

Ningublaga $A$

303

Ninisina $A$

274, 275, 276

Ninisina $B$

270,271

Ninisina $C$

$270,271,275,361$

Ninisina $E$

253,343

Ninlil A

253,343

Ninšubur $A$

85,274

Nintu A

$253,338,361$

Ninurta $A$

274

Ninurta $B$

$274,275,280$

Ninurta $D$

$253,338,339$

Ninurta E

253

Ninurta $F$

293

Ninurta $G$

270, 271, 272

Ninurta $J$

274

Ninurta M 
Ninurtas Rückkehr (=Angimdimma) 274, 275, 276, 277, 278, 280, 281, 361

Ningišzida C

230

Nippur Klage

$95,230,362$

Nippur-Klage

234

Nisaba B

Nusku A

$75,270,271,361,365$

Nusku B

274,280

OECT 5,8

$230,274,275$

273

OECT 11,1

OLZ 90, 25

$308,317,362$

259

Or 17, $416 \mathrm{ff}$.

s. Gebet an einen verfinsterten Gott

PBS $1 / 1,11$

PBS 5, 26

27, 287, 326

PBS 10/2, 15

PBS $10 / 2,2$

Pinches 1924

Rìm-Sìn A

Rìm-Sìn $B$

Rìm-Sin $C$

Rìm-Sin $C-G$

Rìm-Sin D

Rìm-Sin E

Rìm-Sìn F

Rìm-Sîn $H$

RA 22, $170 \mathrm{f}$

RA 84, $119 \mathrm{ff}$.

RA 86,81

RIME 3/2.1.4.9

RIME 4.1.4.3-4

RIME 4.2.13.2

RIME 4.11.2.2

Samsuiluna $B$

Samsuiluna $C$

Samsuiluna $E$

Samsuiluna $G$

Samsuiluna $H$

Sargon der Löwe

SBH 1443

SBH 66

SBH 8
30

77,286

266

311,314

242

$230,253,343$

242,243

243

243

243,244

125

$253,255,318,363$

$317,318,362,363$

115

321,322

40

118

122

41

$128,242,243$

242

242,243

326

326

326

250

250

250
Sin-iqüšam A

$42,253,341,345,363$

Sjöberg 1974-75, 161

326

SLTN 65

282

Stadtklage der Mami von Keš 335

Streitgespräch B

Sumer und Ur Klage 230, 235, 236, 267, 345

Šara A

230

Šu-ilī̌̌u A

$253,254,255,341,343$

Šu-ilï̌su $A-C$

253

Šu-ilï̌su $C$

343

Šulgi A 21, 31, 33, 77, 230, 231, 253, 257 , 267

Šulgi $B \quad 21,31,228,229,230,231,233$, 244, 252, 254, 258, 263, 276, 277, 280, 300, 301, 352, 363

Šulgi $C$ 230, 231, 236, 247, 252, 257, 263 , 296, 297, 299, 352

Šulgi $D$

$21,31,40,229,231$

Šulgi E 21, 24, 31, 229, 231, 244, 252, 256, $258,259,276,277,295,299,300,326$, 354

Šulgi $G$

$252,253,343,345$

Šlgi $G-H$

253

Šulgi $L$

253

Šlgi $M$

253

Šulgi $N$

125

Sulgi $Q$

253,345

Šulgi $R$

Šulgi $S$

Šulgi T

Šlgi $U$

Šulgi X

Šulgi $Z$

293, 294

Šu-Sin F

341

Šu-Suen A

295

Š $u$-Suen $A-C$

294

Šu-Suen $B-C$

294

Su-Suen $D$

253, 255, 338

Šu-Suen $E$

$253,255,343$

$\check{S}$-Suen $F$

$253,255,343$

Šu-Suen $H$

293, 294 
Šu-Suen Hymne BM 100042

Šu-Suen-Inschrift $A$

TCL 3, 207

TCL 6, 56

TCL 15,8

TCL 16, 69

Tempel-Hymnen

The Slave and the Scoundrel

TIM 9, 20-26+CT 58, 53

TIM 9, 41

TIM 9, 43

TMH NF 4, 49+88

TMH NF 4, 89

Udam kiamus

UET 1,156

UET 6,84

UET 6, 94

UET 6,104

UET 6, 388-389+

UET 6,403

UET 6,404

UET $6,404+889$ ?

UET 6,521

UET 6, 621f

UET 6,889

Ugaritica V $462 \mathrm{ff}$

UM 29-15-570 (Sjöberg 1977b Nr. 3) 271

Ur Klage 43, 47, 48, 234, 291, 345, 349

Ur-Namma A

Ur-Namma B

$U r$-Namma EF

Ur-Namma $G$

Ur-Ninurta A

Ur-Ninurta B

Ur-Ninurta $C$

Ur-Ninurta $C-D$

Ur-Ninurta D

Ur-Ninurta E

Ur-Ninurta F

Ur-Ninurta $G$

Uruhulake
268, 269

267, 268

301

284

248

249

267

103, 251

307

7, 317

308

274

253, 338

70, 261

326

326

273

243

307

152, 249

322

321,322

273

290

322

329

$95,234,252,258,259$

$252,253,254,338$

270, 271, 361

294

$268,269,345$

253

$255,343,344$

253

$253,318,343$

$253,255,343$

$253,255,343$

253

70,216
Uru-ama 'irabi 56, 71, 73, 88, 96, 152, 248, 249, 286

Uruk Klage $\quad 24,230,233,258,301,362$

Utu A

Utu E

$91,270,271,272,305$

Utu F

271

Utu..Ekura

$73,75,265$

Utugin eta

248, 261

VS 2, 89

307

VS 10,179

288

VS 10, 213

$321,322,367$

VS 10,215

$312,317,318,363$

VS 17,35

288

VS 24, 41

326

Westenholz 1987 (Ki 1063) 331, 332, 343

Winter und Sommer

230, 258

YOS 11, 22

245

YOS 11, 24

128, 308, 331

ZA $67,1 \mathrm{ff}$

s. Cohen 1977

Zimmern 1917/18

339 


\section{Texte: Sonstige}

4R 28

$5 \mathrm{R} 52$

248

248

Aa 757

An $=$ Anum III

AUWE 23 Nr. 122

Bìt mèseri II

BASOR 812 (N2)

BASOR 8, 12 (N12)

BM 23249

BM 23612

BM 50503

BM 59484 (Finkel 1988)

BM 65217+66616

BM 85563

BM 85564

CBS 2241+

CBS 10996

Clark Zylinder

Diri III

Durand/Guichard 1997:2-3 138, 162, 200, 285

Emar VI/1

IB 1318

IB 1514

Izi D

Izi V

KAR 100

KAR 146

KAR 154

KAR 158

KAR 158 i

KAR 158 ii

KAR 158 ii, vii

KAR 158 iii

KAR 158 iii/viii

KAR 158 iv

KAR 158 v/viii

KAR 158 vi

KAR 158 vi/viii
263

227

265

232, 346, 354

137

281

224

248

248

143

328

245

104, 335

248

263

227,260

67,248

263

57, 227, 228

227, 301

305

$94,234,236$

227

196

92

$10,224,237,252,301$

327

293

237

43,253

253

100,275

41

267,316

266, 267
KAR 158 viii $\quad 237,238,256,259,260$, 264, 302, 319, 324, 329, 363

Kilmer/Civil 1986

Kilmer/Tinney $1996 \quad 355$

$\mathrm{Lu}_{2}=\check{s} a$ Excerpt I $\quad 40$

$\mathrm{Lu}_{2}=\check{s} a \mathrm{III} / \mathrm{IV} \quad 17,18,26,40,52,57,96$, 104, 305

$\mathrm{Lu}_{2}$-Azlag A

$26,94,261$

$\mathrm{Lu}_{2}$-Azlag B

17

$\mathrm{Lu}_{2}$-Azlag Fragm. II 53

Menzel 1981, T. $56 \quad 290$

$\mathrm{Mg}$ A II 258

Mg B II 263

N $3020 \quad 356$

Nabnītu 32 iii 159, 230, 234, 262, 263, 280,352

Nabnìtu 32 iv 343, 348, 350

Nabnitu IX 227, 228, 240

Nabnītu Taf. B 296f 304

OrNS 70, 210ff 263

Proto-Izi I 65

Proto-Izi II 279ff 234

Proto-Izi II 424

Proto-Kagal $302 \quad 301$

Proto-Kagal 361ff 240

Proto-Kagal $364 \quad 261$

Proto-Lu $\mathrm{Lu}_{2}$ 278ff., 660ff. 57

Proto- $\mathrm{Lu}_{2} 484 \mathrm{ff} \quad 46$

Proto- $\mathrm{Lu}_{2} 581 \mathrm{ff} \quad 49,262,272$

Proto-Lu $\mathrm{Lu}_{2} 600 \mathrm{ff} \quad 16,27,56,57,228$, 231, 292, 299, 337, 348, 351

Sag̃ A

37

SC 2652/3

21

SP 2.39

33, 34, 231

SP 2.41

33,75

SP 2.43

33

SP 2.54

$15,34,78,261$

SP 2.57

33

SP 2.97

78,79

SP 2.98

82

SP 2.99

79

SP 2.100

,


SP 2.101

SP 2.102

SP 2.103

SP 2.104

SP 2.105

SP 2.106

SP 2.D 15

SP 21.D 3

SP 22

SP 3.150

SP 3.87

SP 5.124

SP 7.77

TCL 15,10

TCL 15, 28 (L) 292

TMH NF 3, 53

TMH NF 3, 54

TuL 27

Udug-hul

UET 6, 123 (U2)

UET 6, 196 (U3)

UET 6,388

UET 6,899

UET 7, 74

Ugu-mu XI

UM 29-15-357

$\mathrm{Ur}_{5}$-ra IX

$\mathrm{Ur}_{5}$-ra VIIB

$\mathrm{Ur}_{5}$-ra XII

$\mathrm{Ur}_{5}$-ra XIV

VS 10, 216 (B1) 272

YBC 3654 (Y1)
72,80

78

78

80

80

$71,75,155,271$

236

78,80

81

$34,35,115$

$33,34,235,236,304,359$

297

236

97, 98

224, 229, 275, 278, 281,

$224,253,264,268$

224, 253

43

267

$224,275,277,281$

224,253

3

329

2, 352

42

356

234

94, 263

74

305

74, 224, 247, 248, 271,

$10,224,231$

\section{Namen: Götter}

d ad-gi $i_{4}-g i_{4}$

265

Adad/Iškur

$76,211,245,253$, $255,270,277,285,311,325,342,366$

Aja

177,182

Ama'ušumgalana

68,298

An

$41,95,140,149,228,242$, $253,255,265,273,282,322,325,341$

Annunìtum $\quad 42,45,63,65,66,100,107$, $108,111,139,177,178,179,181,182$, 183, 184, 185, 186, 187, 188, 189, 190, 201, 202, 203, 204, 205, 219, 220, 221, 245,374

Anūna 333

Anunnāki 322

Aruru $273,322,323,324,335,366$

Asalluhi 137, 139, 142, 144, 173, 174, 322

Baba

$222,231,251,294,295$

${ }^{\mathrm{d}}$ balag $\tilde{g}$-di

98

Bēlet-ālim

59,60

Bēlet-Bābilim

$63,65,181$

Bēlet-ilī

$104,181,305,315,322$,

323, 324, 335, 336, 366, 367, 374, 379

Bēlet-Nippuri

42

Bilulu

285,304

Damgalnuna

$174,243,282,283,284$

Damu

152,171

Deritum

138

Dig̃irmah $\quad 137,139,141,142,166,167$, 311,335

Dumuzi $\quad 63,64,68,83,104,128,129$, $147,230,233,234,248,250,252,260$, 264, 281, 282, 285, 287, 291, 293, 294, 298, 304, 306, 327, 330, 332, 346, 348, $357,362,367$

Enki $1,2,35,36,45,50,51,67,68$, $69,71,72,79,84,113,118,122,128$, $130,131,132,137,139,141,142,144$, $145,146,147,173,174,186,189,195$, $243,253,282,283,288,294,295,314$ 
Enlil $\quad 53,63,70,72,76,77,97,98$, $122,162,163,165,167,168,169,171$, $176,230,233,243,248,249,252,254$, $258,266,267,269,270,273,275,282$, 285, 286, 294, 299, 314, 315, 316, 325, 342

\begin{tabular}{lr} 
Ereškigal & $69,70,89,92,342$ \\
Ešurritum & 213 \\
Ezinu & 122 \\
Gibil & 173 \\
Gudam & $21,30,280$ \\
Gula & $59,66,70,121,150,151,161$, \\
\multicolumn{1}{l}{$162,173,262$} &
\end{tabular}

Gula von Umma 162

$\mathrm{Gu}(\mathrm{a})$ nungia 173

G̃eštinana/Amana $129,147,233,267$, $285,286,287,304,340,347,348,353$

dha-mun

265

Haja 230,343

Hanašar 193

Igigi 317

Igišagšag

173

Inana $\quad 15,22,23,26,30,42,57$, $59,63,64,66,67,68,69,70,71,72,73$, $75,77,78,80,81,84,85,87,88,89,91$, $92,95,102,103,120,126,129,133$, 137, 138, 139, 140, 141, 142, 143, 144, $145,146,147,157,160,161,166,173$, $176,177,181,182,183,186,187,189$, 190, 200, 201, 203, 204, 205, 211, 215, $216,217,222,229,230,233,234,235$, $248,249,250,252,255,260,261,264$, $269,274,278,279,280,281,283,284$, 285, 286, 287, 293, 294, 298, 301, 303, $304,305,306,316,318,320,332,346$, $348,357,362,366,367,374$

Inana Jahrūrum 186 Inana von Uruk $65,211,216$ 217, 218, 219, 220, 221, 222, 298

Inana Zabalam $\quad 64,111,126,129,146$ Irda 173 Ištarān
Išum 173

Kanisurra 216, 219

Lillum 323

Lugalbanda 173,174

Lugalgudua 192, 193

Lugal-irra 269

Lugalkisuna 147,149

Lugal-Marada 218

Lugaltilla

173

Mami 104, 322, 323, 324, 325, 335, 366

Manungal

182

Marduk $40,60,63,64,65,100$, $108,137,163,181,183,186,195,197$, 202, 204, 206, 209, 210, 211, 217, 321, 322,371

Martu/Amurrum $\quad 130,152,170,173$, $174,175,280,317$

Meslamta'ea 269

Muati

331

Nanaja

$42,64,65,102,103,123$, $126,128,137,138,139,140,141,142$, $144,145,146,205,211,216,217,218$, $219,220,222,255,318,321,322,327$, $331,332,333,363,374$

Nanna $\quad 22,35,45,47,48,63,118$, $119,120,121,122,123,124,125,128$, $129,132,169,172,190,203,220,234$, $240,243,253,255,264,268,269,271$, 294, 303, 308, 317, 376

Nanše

24, 31, 86, 294

Nergal 44, 137, 193, 218, 253, $254,255,273$

Ninamaškuga 173

Ninazu 294

Ninegala $42,64,65,137,138,139$, $140,141,142,143,145,146,205,211$, $212,213,214,374$

Nin-e'igara $\quad 120$

Ninezen 147

Ningal 22, 43, 48, 118, 119, 120, 121, 123, $129,243,294$

Ningirgilu 43 
Ningublaga

120,255

Ning̃irsu

Ning̃išzida

Ninhinuna

Ninhursag̃

Ninigizibara

Ninisina $63,100,122,150,151,152,153$, $171,173,233,245,269,270,273,278$, 284, 366

Ninkasi

68,294

Ninlil $165,167,252,253,254,266,273$

Ninmah 20,36

Ninmešara 239,249

Ninnibru $162,173,275$

NinPA 173

Ninsiana 137, 139, 144, 166, 169, 173, 189 , $193,278,284$

Ninsun

$166,174,175$

Ninšubur $41,59,66,68$, $83,85,108,119,120,121,149,374$

Ninurta $18,22,47,63,64,99,162,163$, $164,165,166,167,168,169,173,174$, $211,215,253,254,255,262,273,278$, $280,284,294,303,339$

Nisaba

$31,232,239,275$

Nusku $47,172,230,254,280$

Panig̃ara $139,141,142$

Papuleg̃ara $309,311,312,314,366$

Sud 266

Sugallitum $111,126,129,311$

Șaltu 320

Șarpanìtum $198,202,204,374$

Šamaš $22,49,50,51,59,63,65,91,94$, $108,109,119,121,126,129,130,132$, $137,138,139,140,141,143,144,145$, $146,163,177,180,181,182,184,186$, 187, 190, 192, 193, 201, 211, 215, 220, 245

Šamaš Babylon 182

Šara 99, 294

Šarrat Dilbat
Šarrat Nippuri $\quad 173$

Šulpa'e 173

Šulpa'edara 173

Tašmētum $\quad 45,193,197,202,204,374$

Ulmašitum

$41,203,205,219$

Uraš

$65,66,211,213,259$

Urkītum

211

Usumu

314

Uttu

92

Utu $62,63,73,75,91,109,119,126,137$, $138,141,178,180,187,197,205,305$

Zababa $\quad 64,65,215,216,217,218,219$, 220,222 


\section{Namen: Herrscher}
Abi' ěšuh $\quad 183,205,216,218,331,332$ Ammiditana $183,186,187,198,203$, $212,213,218,219,317,318,319,328$, $330,331,334,362$

Ammișaduqa $\quad 23,29,163,178,182$, $183,185,186,190,198,210,211,212$, 213, 214, 220, 328

Damiq-ilišu $\quad 19,150,152,153$, 156, 170, 175

Enlil-bāni 40, 150, 151, 153, 156, 169, 172

Gilgamesch 21, 30, 84, 101, 111, $166,174,175$

\section{Gudea} $36,42,111,137,229$

Gungunum

$7,126,308,317$

Hammurabi $7,10,20,21,25,48,49$, $107,117,118,126,127,130,133,149$, $150,163,180,190,193,196,211,214$, 216, 221, 229, 308, 312, 317, 320, 321, $323,326,327,332,371,375$

Ibbi-Suen 149,162

Iddin-Dagan $30,273,281,283,284$

Iluma-ilum 163,167 Immerum $56,177,180$

Irra-imitti 171

Išbi-Erra $149,150,157,162$

Išme-Dagan $21,24,31,114,118$, $125,153,225,229,230,276,295,299$, 300, 301, 362

Itēr-pīša 129,153

Kudurmabuk $20,117,119,134$ Lipit-Eštar $270,303,355,368$

Luma 231

Naram-Suen

Nūr-Adad 95,326

Rīm-Sîn $64,126,127,129$ $25,29,117,119,120$, $124,125,126,127,128,131,132,133$, $148,150,164,168,174,242,243,308$, $317,327,331,332,362,375$

Rīm-Sîn II $8,117,126,148,215$
Samsuditana 178, 181, 183, 184, 185, 198, $211,213,215,218$

Samsuiluna $\quad 8,20,25,64,107,117,118$, $119,121,126,127,129,132,148,149$, 150, 152, 154, 163, 166, 168, 174, 176, $177,194,215,216,217,219,220,243$, $313,317,318,319,326,331$

Sargon $118,294,301,326$

Simah-ilān̄̄ 50

Sîn-iddinam 102, 126, 127, 134, 136, 137 , 139, 140, 141, 144, 192, 221

Sîn-iqī̌sam $\quad 51,138,139,167,170,214$

Sumu'ēl 118,126

Sumula'ēl $178,215,216$

Šu-ilišu 151

Šulgi $\quad 21,24,31,56,114,125,225,229$, 233, 256, 276, 277, 287, 293, 299, 300, $301,334,352,354,362$

Šu-Suen

40, 268

Takil-ilissu

41,42

Ur-Namma

$7,153,258$

Ur-Ninurta $42,107,152,172$

Uru-inimgina 105

Warad-Sîn $\quad 117,118,121,122,124,131$, 138, 139, 194

Zimrī-Lîm 27,41 
Namen: Personen

A-la-la-a

Aba-Enlilgin

Abandasa

Abì-simtī

Abum

Abum-țābum

Abum-x

Adad-lamassī

Adda-duga

Aha-nīrši

Ahassunu

Ahāti-šeme'at

Ali-ahī

Ali-talīmi

Amat-Kūbi

Amat-Šamaš

Amerti-Ištar

Ammiṣaduqa-ilūni

Amur-gimil-Šamaš

Amurrum-tillassu

Andul-Sîn

Ane-babdu

Ankuta

Anum-pī-Ninšubur

Apil-Amurrum

Apil-iliš̌u

Apiljatum

Apil-Sîn

Aplatum

Aplum

Arašuta

Arrabūtum

Asalluhii-bāni

Awīl-Amurrum

Awīl-dāri

Awīl-Ea

Awillija

Awìl-Sîn

Awiātum

Bēlānu
237

175

64, 217

295

66

123

190

112

168,169

171

135

135

171

45,192

135

181

41, 156

183

115

$131,132,133$

121,122

153

121,122

148,149

45,121

$148,166,170$

170

166

64, 217

$111,129,170,171$

121

135

63,182

215

66,121

26,28

186,189

212, 213, 214

166

25, 194
Bēlānum

Bēlī-ašarēd

$63,111,182,187$

Bēliātum

156

194

Bēltani

91

Būr-Adad

121,144

Būratum

45,193

Bītum-rabi

140

Balani-he'inzalag

Balg̃unambue

Be-X

Dabītum

Dada

Damiq-ilī̌su

Dan-šu-šu-un

Dig̃ir-šaga

Dig̃ir-addag̃u

Dudu

Dudu-kalla

Dulluqum

Dummuqtum

${ }^{\mathrm{d} X} \mathrm{X}$-iqīšam

Ețirtum

$\mathrm{E}_{2}$ - muballit

Ea-ilī

Ea-kīma-ilīja

Ea-nadinša

Eannatum

Ea-rēșušu

Ea-rabī

Ekigibi

Elmēšum

Enheduana

Enlil-bāni

Enlil-galzu

Enlil-mansum

Ennu-lībur

Erībam-Sîn

Erīb-Sîn-lu-mur!

Erari

Eriš-A.ZU

Erib-Sîn

Etel-Kūbi
$62,63,110,182,184$

$128,129,131,132$

64,217

135

233

45

52

63, 182, 184, 203

285

$25,121,123,174$

170, 174

26

135

170

201

166

195

20,25

195

64, 217, 218, 220

114

195

185

29,131

87, 267, 294

170

170

131

123 


\begin{tabular}{|c|c|c|c|}
\hline Etel-pī-Sîn & $20,25,45,131,133$ & Inana-mansum & $, 88,91,108,109$ \\
\hline $\mathrm{E}-\mathrm{x}$ & 217 & \multicolumn{2}{|c|}{$175,182,183,186,187,188,189,190$} \\
\hline Gimillum & $111,148,190$ & \multicolumn{2}{|c|}{$191,194,197,201,203,205$} \\
\hline $\mathrm{Gir}_{3}-{ }^{\mathrm{d}} \mathrm{Ma}_{3}-\mathrm{a}$ & $\mathrm{al}_{-} \operatorname{sig}_{6}$ & Inana-muzuše-nirg̃al & $20,25,45,131$ \\
\hline G̈irni'isa & 174 & Inana-zig̃u & 64,217 \\
\hline Habiștum & 135 & Ina-palêšu & 64,217 \\
\hline Hablīja & 26 & Inī-Ea & 148 \\
\hline Hadulu-zērum & 192 & Ipiq-Lulu & 157 \\
\hline Halija & 120,121 & Ipqatum & 61 \\
\hline Hebe-Eridu & 112,113 & Ipqu-Arahtum & 25 \\
\hline Huzālum & $110,184,186,187,191,202$ & Ipquša & $25,131,191$ \\
\hline Ibbi-ilim & $64,133,217,218$ & \multicolumn{2}{|l|}{ Ir-Enlila } \\
\hline Ibni-Amurrum & $63,153,204$ & \multicolumn{2}{|l|}{170} \\
\hline Ibni-Marduk & $63,182,183,186,189$ & Ir-Nanna & $, 47,119,121,124$ \\
\hline Iddin-Ištar & $47,121,219$ & Ir-Ningal & 22,119 \\
\hline Iddin-Marduk & 194 & Ir-Sig̃ar & 25,194 \\
\hline Iddin-mēšar & 170 & Išbi-Erra-šâm-balāțim & $19,110,157$ \\
\hline Iddin-Nanaja & 142,145 & Išme-Adad & 186,189 \\
\hline Idijātum & 133 & Iš-ta-[..] & 135 \\
\hline Idin-Eštar & 48 & Ištar-lamassī & 135 \\
\hline Idin-Išum & 166 & Ištar-šarrat & 135 \\
\hline Igmil-Ištar & $64,217,219$ & Jarim-Addu & 50 \\
\hline Ikūn-pī-Ea & 193 & Jašuhatum & 135 \\
\hline Il-ṣìi & 112 & $\mathrm{Ka}-{ }^{\mathrm{d}} \mathrm{Dudu}$ & 148 \\
\hline Ilì-awīlì & 148 & Ka-Inana & $64,217,219$ \\
\hline Ilī-bāni & 18 & Ka-ki & 26 \\
\hline Ilī-erībam & $64,192,212$ & Ka-Nanna & 168 \\
\hline Ilì-ḩāzirī & 29,131 & Ka-Ninurta & $22,107,168,174$ \\
\hline Ilì-iddinam & 22,129 & Kala-Ajja & 153 \\
\hline Ilī-ippalsanni & 112 & Kalbānum & 335 \\
\hline Ilī-iqīšam & $18,20,25,131,133,186,191$ & Kalbatum & 135 \\
\hline Ilša-heg̃alli & $91,197,201$ & Kubātum & 282,295 \\
\hline Ilšu-ibbîšu & $76,103,114$ & Kubburum & 184,186 \\
\hline Ilšu-ibni & 191 & Kulālum & $63,180,182$ \\
\hline Ilšu-nāṣir & 133 & Kunnutum & 166 \\
\hline Ilšu-X & $64,217,219,220,221$ & Kurrûm & 132 \\
\hline Ilūni(m) & $111,170,190$ & Lalûm & 131,180 \\
\hline Iltani & 194 & Lalûtum & 202 \\
\hline Ilum-pī-Ištar & 190 & Lamassāni & 108,186 \\
\hline Imgur-Sîn & $63,65,128,193$ & Lapištum & 213 \\
\hline Imgur-Šamaš & 53 & Lipit-Eštar & 149 \\
\hline & & Lipuš-Jā’um & 95 \\
\hline
\end{tabular}




\begin{tabular}{|c|c|c|c|}
\hline Lu-Baba & 157 & Nanna-zig̃u & 166 \\
\hline $\mathrm{Lu}_{2}$-igi-KU & 63,157 & Nannatum & $109,175,176$ \\
\hline Lu-Ninlila & 165,170 & Narubtum & 132,171 \\
\hline \multirow{2}{*}{\multicolumn{2}{|c|}{$\begin{array}{l}\text { Lu-Ninurta } 23,61,107,110,170,172,173 \\
\quad 174,190,376\end{array}$}} & Nidin-Ištar & 63,182 \\
\hline & & Nig̃ ${ }_{2}$-DU.DU & 170 \\
\hline Lu-pada & 161 & Nig̃g̃a-Nanna & 123 \\
\hline Lu-šaga & 45 & Ninlil-zig̃u & 165 \\
\hline Lušlim & 171 & Ninurta-gāmil & 166 \\
\hline Lugal-abta & 170 & Ninurta-mansum & 214 \\
\hline Lugal-gaba-gal ${ }_{2}$ & 30 & Ninurta-megub & 166 \\
\hline Lugal-gaba-g̃al ${ }_{2}$ & 21,111 & Ninurta-mušallim & $63,64,165,166,168$ \\
\hline Lugal-gaba-g̃ar & 21 & 170 & \\
\hline \multicolumn{2}{|c|}{ Lugal-gabari-nutuku 22, 110, 168, 169, 174} & Nūr-Adad & 45 \\
\hline Lugal-ḩeg̃al & $45,170,175$ & Nūr-kabta & 131 \\
\hline Lugal-ibila & 170,174 & Nūr-Ninšubur & $107,148,149$ \\
\hline Lugal-melam & 170 & Nūr-Šamaš & $63,119,120,124$ \\
\hline \multirow{2}{*}{\multicolumn{2}{|c|}{$\begin{array}{l}\text { Lugal-melam-g̃ir } \quad 22,107,110,168,169, \\
\quad 174\end{array}$}} & Nūratum & 167 \\
\hline & & Nutțuptum & 135 \\
\hline Lugal-zi-mansum & $64,65,212,213,214$ & Pișētum & 145 \\
\hline Lugal-zig̃u & 175 & Pušuja & 131 \\
\hline Mānum & 142 & Pû-ilī & 25 \\
\hline Mār-erșetim & 192 & Qīšti-Erra & 128 \\
\hline \multirow{2}{*}{\multicolumn{2}{|c|}{$\begin{array}{l}\text { Marduk-muballit } \quad 22,63,64,66,91,178, \\
182,183,184,185,187,191,212\end{array}$}} & Qurdi-Ištar & $66,189,190$ \\
\hline & & Rē'išu-damiq & 50 \\
\hline Marduk-nāșir & $63,183,186,187,191$ & Rišija & 114 \\
\hline Mea'imriag̃u & $64,109,217,218$ & Rīš-ilim & 45 \\
\hline Meme-Enlile & 327 & Rīš-Marduk & $218,220,377$ \\
\hline Mi-ta-ku-ma-ta & 26 & Sal-kalla & 171 \\
\hline Mummatum & 111,170 & Sallatum & 135 \\
\hline Mumu-hegub & 170 & Samsuiluna-X & 217,219 \\
\hline Nabi-Šamaš & 190 & Saniq-pī-[GN] & $63,64,111,128,129$ \\
\hline Nabīum-mālik & $61,184,190$ & Sa-pi-ra-tum & 20 \\
\hline Nanna-ara-mungen & 175 & Sîn-abūšu & 175 \\
\hline Nanna-gugal & $63,165,167$ & Sîn-erībam 22,2 & $63,119,120,168,169$ \\
\hline Nanna-g̃eštug & 148 & Sîn-ēriš & 130 \\
\hline Nanna-ibila-mansum & 166 & Sîn-gāmil & $45,121,122,124$ \\
\hline Nanna-ildu ${ }_{2}-\mathrm{mu}$ & 251 & Sîn-iddinam & 45 \\
\hline Nanna-kiag̃ & $63,65,128$ & Sîn-ilī & $131,142,144$ \\
\hline Nanna-luti & 175 & Sîn-imguranni & 204 \\
\hline Nanna-mansum & 170 & Sîn-iqī̌sam & 50 \\
\hline \multirow{2}{*}{\multicolumn{2}{|c|}{$\begin{array}{l}\text { Nanna-šalasud } 64,109,111,185,217,218, \\
\quad 219,220,377\end{array}$}} & Sîn-irībam & 176 \\
\hline & & Sîn-išmeanni & $64,155,217,218$ \\
\hline
\end{tabular}


Anhänge und Verzeichnisse

\begin{tabular}{|c|c|c|c|}
\hline Sîn-išmēni & 120,174 & Šu-Sîn & 25,132 \\
\hline Sîn-māgir & $131,132,194$ & Taqī̌sum & 327 \\
\hline Sîn-muballiț & $26,29,136,193$ & Tarībatum & 190,218 \\
\hline Sîn-mūdi & 170 & Tarību(m) & $25,60,131,171,214$ \\
\hline \multirow{2}{*}{$\begin{array}{c}\text { Sîn-mušallim } \\
186,205\end{array}$} & \multirow[t]{2}{*}{$22,26,60,63,182,183$} & Timgu & 132 \\
\hline & & Țāb-qabâša & 132 \\
\hline Sîn-nādin-šumi & 60 & Ṭābšīrum & 26 \\
\hline Sîn-nāṣir & 191 & U-bar & 157 \\
\hline Sîn-nūr-mātim & 131 & Ubār-Šamaš & $63,64,128,142$ \\
\hline Sîn-nūrī & 135 & Ubarra & 160 \\
\hline Sîn-rē'̄'̄ & 191 & Ubārum & 160 \\
\hline Sîn-rēmēni & $61,188,190,191$ & Ubarrum $28,10^{-}$ & $7,111,157,160,161,170$ \\
\hline Sîn-rīmēni & 193 & 174 & \\
\hline Sîn-šemi & $45,120,121,122,182$ & Udug-ga & 111,285 \\
\hline Sîn- $u_{2}$-WI- $l i$ & 121 & Unnubtum & 132 \\
\hline Sîn-uballiṭ & 61 & Ur-dukuga & 175 \\
\hline Sîn-ușellī & 148 & Ur-Guanaka & $63,182,184$ \\
\hline Sîn-X & 170,313 & Ur-Igizibara & 285 \\
\hline Șillī-Adad & 19,156 & Ur-Inana & $66,108,186,190,191$ \\
\hline Șillī-Ištar & 148,149 & Ur-Nanše & 87 \\
\hline Šallūrum & 152,153 & Ur-Nininsina & $63,88,109,153,154,373$ \\
\hline Šāt-Ištar & 135 & Ur-Pabilsag̃ & $107,170,174,175$ \\
\hline Šamšī-libūr & 194 & Ur- ${ }^{\mathrm{d}}$ PAP-nu'-še & 121 \\
\hline \multirow{2}{*}{$\begin{array}{c}\text { Šamaš-hāzir } \\
133,149\end{array}$} & \multirow[t]{2}{*}{$20,49,61,127,129,130$} & Ur-Sakkud & $63,182,184$ \\
\hline & & Ur-Šulpa'e & $47,121,175$ \\
\hline Šamaš-muballiț & $66,121,288$ & Ur-Utu & $, 63,66,88,107,108,109$ \\
\hline Šamaš-nāșir & 288 & $110,111,178$ & $179,181,182,183,184$ \\
\hline Šamaš-nī̌su & 45,192 & $185,186,187$ & $, 188,189,190,191,194$ \\
\hline Šamaš-tillatī & 132 & $196,202,203$ & 245,373 \\
\hline Šamaš-ummati & 132 & $\mathrm{Ur}^{\mathrm{d}}{ }^{\mathrm{d}}[\ldots$ & 109,154 \\
\hline Šēp-Sîn & $25,144,148,149$ & Urabbâ-ana-Šarri & $\mathrm{im}$ \\
\hline Šeš-ki & 168,169 & Usātum & $190,191,194$ \\
\hline Šeššek-bēlū-rēṣūš & 312 & Ušumgal-kala & $m-m a$ \\
\hline Šibia/â-pīša & 135 & Utu-Enlilla & 170 \\
\hline Šīmi-[..] & 135 & Utu-mansum & $185,190,191,194,202$ \\
\hline Šinunūtum & 38 & Utu-mešaram & 20,25 \\
\hline Šu-Amurrum & $22,49,130$ & Utu-za'emen & 45 \\
\hline Šu-iliı̌su & 148 & Utu-zig̃u & 131 \\
\hline Šulgi-simtī & 205 & Waqar-abūšu & 120 \\
\hline \multirow{2}{*}{$\begin{array}{l}\text { Šumum-libši } \\
313\end{array}$} & \multirow[t]{2}{*}{$29,40,170,171,191,312$, } & Waqartum & 108 \\
\hline & & Warad-Bunene & $45,192,193$ \\
\hline Šurbūtum & 170 & Warad-Damu & 152 \\
\hline
\end{tabular}


Warad-Ešurrītum

Warad-Ibari

Warad-ilī̌su

Warad-Ištar

Warad-kinūni

Warad-Kūbi

Warad-Nabīum

Warad-Sîn

Warad-Zugal

Zabardabbû

Zarriqum $\quad 20,25,45,110,111,131,133$ $185,186,191$

Zikir-ilišu

Zikrum

Zittaša

$\mathrm{x}$-iqišam

$\mathrm{x}$-Nanaja

$\mathrm{x}$-Ninurta

[x U]Š'-UR-ni
20

$64,212,213,214$

60

$61,114,130$

170

181

212,214 220

26

63,129

26

28,160

158,159

148

41,156

121

26

\section{Namen: Toponyme}

Alalah $\quad 52,53$

Amarna 38

Apsû 268, 322

Arba'1̄l 100,159

Assur 43, 237

Babylon 5, 7, 10, 20, 21, 23, 63, 65, 102, $108,117,127,145,150,152,154,163$, $168,181,186,187,193,194,209,210$, 211, 215, 221, 243, 248, 308, 323, 331, 375

Badtibira 63, 64, 129

Boghazköy 26

Dēr $50,177,178,179,180,181,199,201$

Dilbat $7,14,23,25,49,50,52,62,64,65$, $66,99,117,189,210,211,212,213$, 214, 220, 221, 374

Dublamah

120

Eanna

177,298

Ebabbar

Ebla $180,181,184$

Edikuda $49,50,51$

Egalmah

$\mathrm{e}_{2}-\mathrm{gu}-1 \mathrm{a}$ 152

$\mathrm{e}_{2}-\tilde{\mathrm{g}} \mathrm{a}_{2}-\mathrm{gi} \mathrm{i}_{4}-\mathrm{a}$ 167

$\mathrm{e}_{2}$-ka-aš-bar 188

$\mathrm{e}_{2}-{ }^{\mathrm{d}}$ nin-nibru ${ }^{\mathrm{ki}}$ 162,173

Eibbiānum 162 211

Ekallātum

Ekišnugal 22, 48, 118, 119, 120, 121, 122, $124,125,269$

Ekur $\quad 64,76,77,162,163,164,166,167$, $168,169,172,173,176,252,283,299$, $313,326,348$

Elam 20

Emete-ursag̃ 216

Enitendu 48

Eridu 35, 118, 122, 128, 243, 264, 275, 314

Ešumeša $162,168,171,173,174$

Eturkalama 216

E’ulmaš 177,203 


\begin{tabular}{|c|c|}
\hline G̈irsu & $27,56,95,171$ \\
\hline Habbuz & 184 \\
\hline Hana & 204 \\
\hline Hilla & 210 \\
\hline Hindiya & 210 \\
\hline Hursag̃kalama & 215 \\
\hline Ilip & 221 \\
\hline $\begin{array}{r}\text { Isin } \quad 7,9, \\
41,42,51,5 \\
109,110,1 \\
149,150,15 \\
162,163,16 \\
191,193,2 \\
300,326,33\end{array}$ & $\begin{array}{l}1,25,28,29,40 \\
63,76,92,108, \\
117,118,147, \\
156,158,161, \\
171,172,176 \\
244,248,278, \\
373,375\end{array}$ \\
\hline
\end{tabular}

Išçālī

28

Jamutbal

$102,145,221$

Jerusalem

5,308

Karnak

38

Keš $311,312,324$

Kiš 7, 14, 17, 23, 25, 38, 61, 62, 64, 65, 90, 99, 101, 102, 108, 109, 117, 163, 194, 196, 197, 198, 199, 215, 216, 217, 218, 219, 220, 221, 222, 248, 272, 284, 328, 331, 343, 361, 373, 374, 377

Kurdâ 50

Kutalla 14, 62, 66, 107, 117, 147, 148, 149 Kuzaja $22,23,26$

Lagaba 25,93

Lagaš 137,251

Larsa7, 8, 10, 14, 17, 19, 20, 22, 23, 24, 25, $28,29,42,44,45,50,51,52,61,63,64$, $65,66,90,99,102,105,110,111,117$, $118,119,120,125,126,127,128,129$, 130, 131, 133, 134, 135, 136, 137, 139, $140,143,145,146,147,148,150,151$, 152, 163, 164, 167, 168, 180, 204, 205, 207, 210, 211, 215, 221, 222, 224, 239, 242, 248, 249, 284, 288, 297, 308, 310, $317,327,331,361,363,371,375,377$, 378,379

Malgium

41, 299

Marad
Mari $\quad 3,7,11,13,17,19,20,21,22$, $23,27,28,38,41,49,50,51,52,53,55$, $57,60,72,73,76,77,84,87,91,94$, 101, 103, 104, 109, 111, 114, 115, 136, 146, 147, 160, 176, 191, 194, 195, 196, 200, 204, 205, 229, 238, 244, 248, 249, 251, 285, 299, 324, 326, 334, 375, 376

Maškan-šāpir

131,132

Meturān

248, 288

Nagar 49

Nippur $14,16,21,22,23,29,40,42,44$, $45,47,51,53,61,62,63,64,74,77,98$, 99, 103, 105, 107, 108, 109, 110, 114, $117,120,122,144,150,151,162,163$, 164, 165, 166, 167, 168, 169, 170, 171, $172,173,174,175,176,180,198,215$, $227,230,233,240,243,248,252,258$, 273, 275, 278, 281, 282, 283, 284, 290, 292, 299, 303, 312, 313, 326, 334, 338, 340, 354, 361, 368, 375, 376

Razamā 50

Sabium 211,299

Sippar 4, 7, 14, 22, 23, 25, 29, 38, 40, 42, $44,45,52,56,59,61,62,63,65,66,78$, $86,91,99,100,101,105,107,108,109$, $110,117,129,138,147,163,176,177$, $178,179,180,181,182,183,184,185$, 186, 187, 188, 189, 190, 191, 192, 193, 194, 195, 196, 197, 198, 199, 200, 201, 202, 203, 204, 206, 207, 213, 215, 220 , $221,245,247,248,250,272,284,288$, $322,328,332,370,373,374,378$

Sippar Amnānum 23, 65, 88, 100, 107, 108, $110,111,177,178,182,185,186,188$, 189, 191, 198, 203, 221, 245

Sippar Jahrūrum $\quad 65,108,177,179,180$, 181, 182, 184, 186, 190, 198, 199, 200

Sirara 24, 268

Suhûm 212

Susa

52,248

Šaduppûm $22,24,25,26,29$

Šapattānu 221 
T. as-Sulaima

Terqa

Ugarit

Umma

Ur

$2,5,14,16,18,19,21,22,23,24$, $25,27,35,44,45,46,47,51,52,59,61$, $62,63,66,90,99,108,110,117,118$, $119,120,121,122,124,125,130,137$, 138, 149, 150, 151, 158, 159, 162, 166,

171, 173, 180, 187, 197, 203, 204, 205,

55,56

204

329

99,171
209, 219, 224, 231, 233, 237, 240, 241, 243, 244, 248, 249, 250, 275, 277, 281, 282, 290, 291, 292, 294, 302, 303, 304, $326,351,352,361,368,375,376,377$, 378,379

Uruk $7,11,24,25,64,122,129,150,152$, $167,216,217,218,222,232,284,286$, 287, 298, 314, 346, 347, 353, 354

Zabalam 63, 64, 129, 162, 286, 287, 347, 353 
$\mathrm{M}$ usik ist ein wesentlicher Bestandteil geistig-kulturellen Erbes moderner wie antiker Hochkulturen. Die Musik Mesopotamiens und benachbarter Gebiete ist gerade im letzten Jahrzehnt immer mehr in den Fokus wissenschaftlichen Interesses gerückt worden. Es faszinieren in gleicher Weise klanglich-schöpferische Spezifika wie auch inhaltlich-funktionale und strukturelle Hintergründe zur Ausführung von Musik.

Die Tätigkeitsfelder von Musikern, ihr Einflussbereich an Tempel oder Palast aber auch ihr öffentliches Ansehen sind in Hunderten von Briefen, Urkunden sowie literarischen Texten dokumentiert. Zudem ist uns auch der Wortlaut von Liedern und Gesängen erhalten geblieben, die professionelle Sänger zu unterschiedlichen Anlässen zu Gehör brachten. Zum Genuss ihrer hoch spezialisierten Vortragskunst kamen vor allem Götter und Könige, deren Wohlwollen sie mit ihrem süßen Gesang zu sichern wussten.

Die vorliegende Studie setzt den Schwerpunkt in ebendiesem Bereich an, wobei der zeitliche und geographische Rahmen durch das Babylonien des 19. bis 16. Jahrhunderts v.Chr., der altbabylonischen Zeit gebildet wird. Die überwiegend aus schriftlichen Quellen gewonnenen Daten zeichnen ein genaues Bild von der institutionellen wie auch privaten Organisation von Musik. Auch wenn die originalen Musikklänge der Babylonier für immer verklungen sind, so werden doch bedeutende Details zur vokalen Aufführungspraxis bekannt, die eine Annäherung an den Ursprung möglich machen.

$\mathrm{D}$ ie Reihe "Göttinger Beiträge zun Alten Orient" setzt die erfolgreichen "Göttinger Arbeitshefte zur Altorientalischen Literatur" fort. Die Reihe wird vom Seminar für Altorientalistik der Georg-August-Universität Göttingen herausgegeben und behandelt die Erschließung und Deutung der reichhaltigen Schriftdenkmäler in akkadischer oder sumerischer Sprache aus der Zeit von ca. 3100 - 500 v. Chr. 